\title{
Design and Evaluation of a Low NOx Natural Gas-Fired Conical Wire-Mesh Duct Burner for a Micro-Cogeneration Unit
}

\author{
by \\ Omar Barka AB. Ramadan, B.Sc., M.Sc. \\ A thesis submitted to the Faculty of Graduate Studies and Research \\ in partial fulfillment of the requirement for the degree of

\section{Doctor of Philosophy} \\ in Mechanical Engineering \\ Ottawa-Carleton Institute for Mechanical and Aerospace Engineering \\ Department of Mechanical and Aerospace Engineering \\ Carleton University \\ Ottawa, Ontario, Canada
}

(C) Omar Ramadan

May, 2008 


$\begin{array}{ll}\begin{array}{l}\text { Library and } \\ \text { Archives Canada }\end{array} & \begin{array}{l}\text { Bibliothèque et } \\ \text { Archives Canada }\end{array} \\ \begin{array}{l}\text { Published Heritage } \\ \text { Branch }\end{array} & \begin{array}{l}\text { Direction du } \\ \text { Patrimoine de l'édition }\end{array} \\ \begin{array}{l}\text { 395 Wellington Street } \\ \text { Ottawa ON K1A 0N4 } \\ \text { Canada }\end{array} & \begin{array}{l}\text { 395, rue Wellington } \\ \text { Ottawa ON K1A 0N4 } \\ \text { Canada }\end{array}\end{array}$

Your file Votre référence ISBN: 978-0-494-40532-1

Our file Notre référence

ISBN: 978-0-494-40532-1

NOTICE:

The author has granted a nonexclusive license allowing Library and Archives Canada to reproduce, publish, archive, preserve, conserve, communicate to the public by telecommunication or on the Internet, loan, distribute and sell theses worldwide, for commercial or noncommercial purposes, in microform, paper, electronic and/or any other formats.

The author retains copyright ownership and moral rights in this thesis. Neither the thesis nor substantial extracts from it may be printed or otherwise reproduced without the author's permission.
AVIS:

L'auteur a accordé une licence non exclusive permettant à la Bibliothèque et Archives Canada de reproduire, publier, archiver, sauvegarder, conserver, transmettre au public par télécommunication ou par l'Internet, prêter, distribuer et vendre des thèses partout dans le monde, à des fins commerciales ou autres, sur support microforme, papier, électronique et/ou autres formats.

L'auteur conserve la propriété du droit d'auteur et des droits moraux qui protège cette thèse. $\mathrm{Ni}$ la thèse ni des extraits substantiels de celle-ci ne doivent être imprimés ou autrement reproduits sans son autorisation.
In compliance with the Canadian Privacy Act some supporting forms may have been removed from this thesis.

While these forms may be included in the document page count, their removal does not represent any loss of content from the thesis.
Conformément à la loi canadienne sur la protection de la vie privée, quelques formulaires secondaires ont été enlevés de cette thèse.

Bien que ces formulaires aient inclus dans la pagination, il n'y aura aucun contenu manquant.

\section{Canada}




\begin{abstract}
A novel low NOx conical wire-mesh duct burner was designed, built and tested in the present research. This thesis documents the design process and the indepth evaluation of this novel duct burner for the development of a more efficient micro-cogeneration unit. This duct burner provides the thermal energy necessary to raise the microturbine exhaust gases temperature to increase the heat recovery capability. The duct burner implements both lean-premixed and surface combustion techniques to achieve low NOx and CO emissions.

The design of the duct burner was supported by a qualitative flow visualization study for the duct burner premixer to provide insight into the premixer flow field (mixing process). Different premixer geometries were used to control the homogeneity of the fuel-oxidant mixture at the exit of the duct burner premixer. Laser sheet illumination (LSI) technique was used to capture images of the mixing process, for each configuration studied. A quasi-quantitative analysis technique was developed to rank the different premixer geometries in terms of mixing effectiveness. The premixer geometries that provided better mixing were selected and used for the combustion tests.
\end{abstract}

The full-scale gas-fired duct burner was installed in the exhaust duct of a micro-cogeneration unit for the evaluation. Three wire-mesh burners with different pressure drops were used. Each burner has a conical shape made from FeCrAL alloy mat and was designed based on a heat release per unit area of $2500 \mathrm{~kW} / \mathrm{m}^{2}$ and a total heat release of $240 \mathrm{~kW}$ at 100 percent excess air. The local momentum of the gaseous mixture introduced through the wire-mesh was adjusted so that the flame stabilized outside the burner mesh (surface combustion).

Cold flow tests (i.e., the duct burner was off, but the microturbine was running) were conducted to measure the effect of different duct burner geometrical 
parameters on flow split between the combustion zone and the bypass channel, and on pressure drop across the duct burner.

A considerable amount of detailed parametric experimental data was collected to investigate the performance characteristics of the duct burner. The variables studied (firing rate, mass flow ratio, conical burner pressure drop, blockage ratio, conical burner shield length, premixer geometry and inlet conditions) were all found to play an important role on emissions (NOx and $\mathrm{CO}$ ), overall duct burner pressure drop and flame stability. The range of firing rates at which surface combustion was maintained for the duct burner was defined by direct observation of the burner surface and monitoring of the temperature in the combustion zone. Flame images were captured for qualitative assessment.

The combustion tests results presented in this thesis proved that the design procedures that were implemented to design this novel microturbine conical wiremesh duct burner were successful. During the course of the combustion tests, the duct burner displayed stable, low emissions operation throughout the surface firing rate range of $148 \mathrm{~kW}$ to $328 \mathrm{~kW}\left(1574 \mathrm{~kW} / \mathrm{m}^{2}\right.$ to $\left.3489 \mathrm{~kW} / \mathrm{m}^{2}\right)$. Emissions of less than 5 ppm (corrected to 15 percent $\mathrm{O}_{2}$ ) for NOx and $\mathrm{CO}$ emissions were recorded, while the duct burner successfully raised the microturbine exhaust gases temperature from about $227^{\circ} \mathrm{C}$ to as high as $700^{\circ} \mathrm{C}$. The overall duct burner pressure drop throughout was consistently below the design limit of $249 \mathrm{~Pa}$. 


\section{Acknowledgements}

I would like to thank Professor J. E. D. Gauthier, who has served as my thesis advisor during the entire period of this work and has provided expert guidance in all aspects of the thesis.

I am grateful for the help provided by my co-supervisor Patrick M. Hughes, who has been the source of help and encouragement to complete this thesis.

Particular thanks are extended to Richard J. Lacelle and Bryan Holiday for their assistance and cooperation during all the period of my work at CANMET. I would also like to thank Idris A. and Miles for their technical assistance during the course of the experimental work.

Most of all, I would like to thank my family for providing love and support throughout my years of study, and especially my wife, who made the difficult times bearable by providing support and encouragement.

And above all, I thank ALLAH almighty for giving me supreme opportunities and the strength to rise to the challenge of handling demanding tasks in my life. Without the will and help of ALLAH I would not have finished this work. 


\section{Table of Contents}

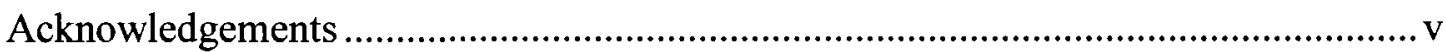

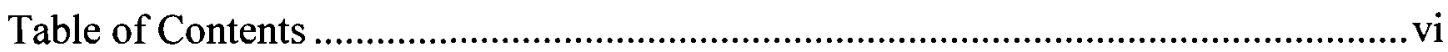

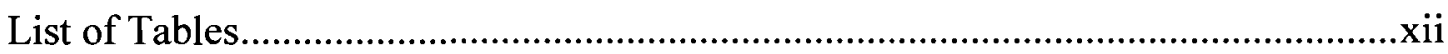

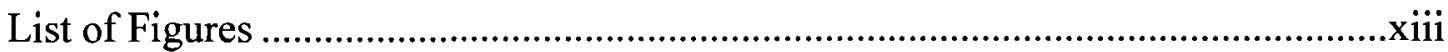

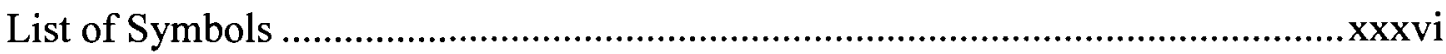

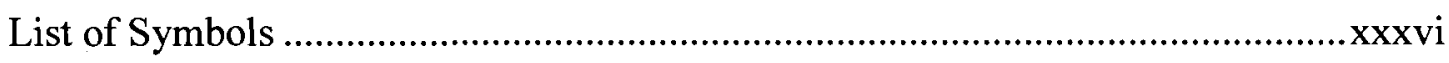

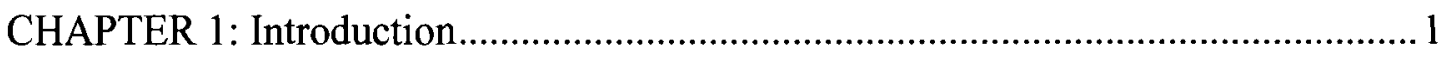

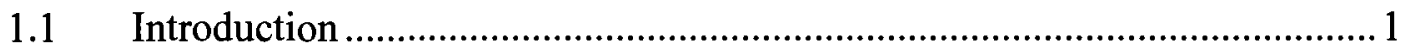

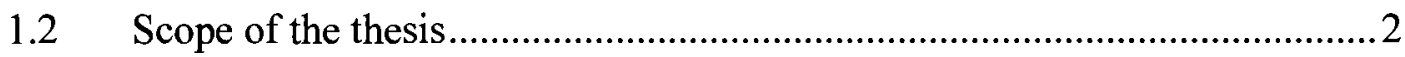

1.3 Thesis outline ............................................................................... 2

CHAPTER 2: Background and literature review ................................................... 4

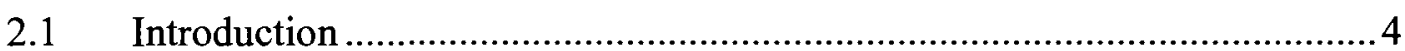

2.2 Distributed generation and micro-cogeneration units ............................... 4

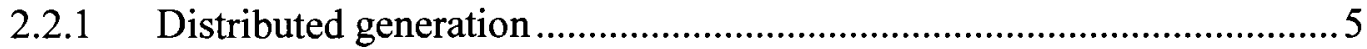

2.2.2 Micro-cogeneration technology ..................................................... 6

2.3 Supplementary firing in cogeneration systems ................................... 14

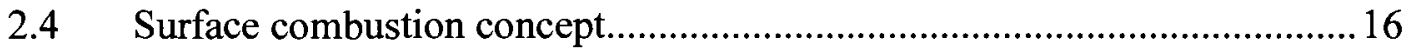

2.5 Lean-premixed combustion and NOx formation .................................2 21

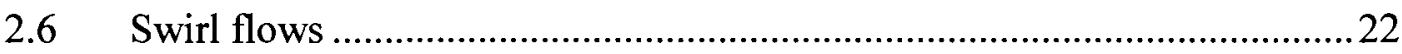

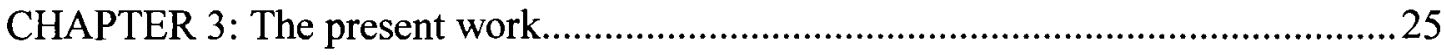

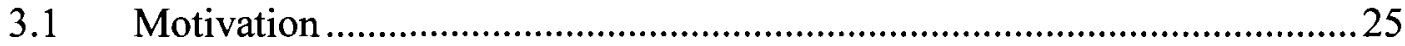

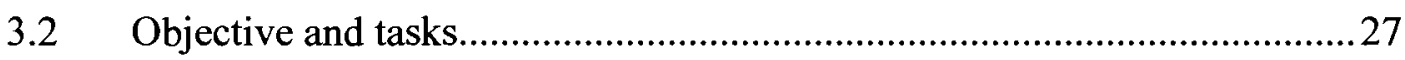

CHAPTER 4: Duct burner design and description .......................................... 30

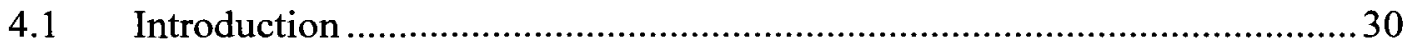

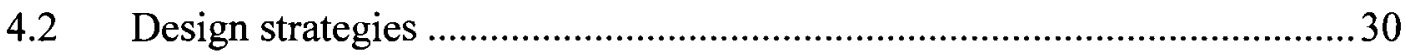

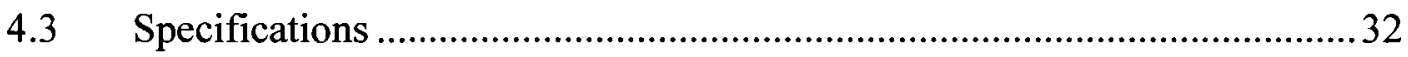

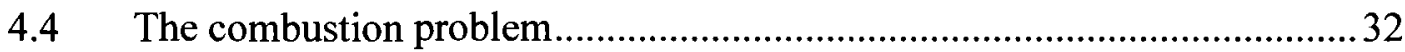


4.4.1 Mass flow rates..................................................................................... 34

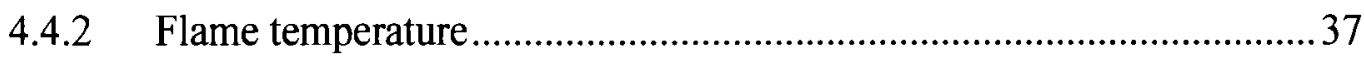

4.4.3 Burner heat release ...............................................................................38

4.4.4 Homogeneous burning velocity .............................................................39

4.4.5 Combustion problem closure …………………...................................39

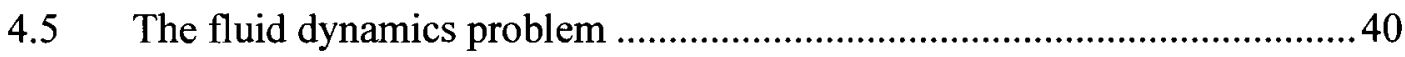

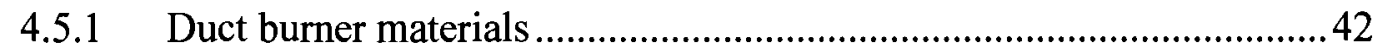

4.5.2 Duct burner reference velocity .............................................................42

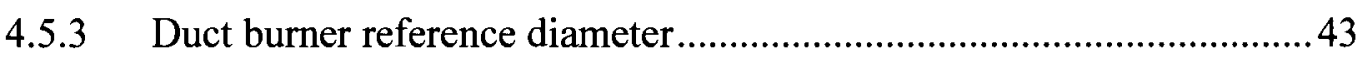

4.5.4 Burner housing ...................................................................................44

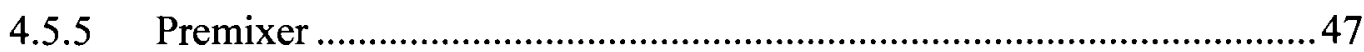

4.5.6 Conical wire-mesh burner design.......................................................59

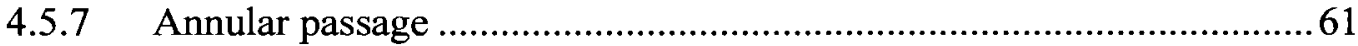

4.5.8 Mesh burner shield (cone liner) .............................................................63

4.5.9 Duct burner pressure drop .................................................................. 65

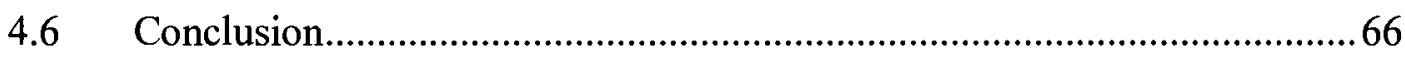

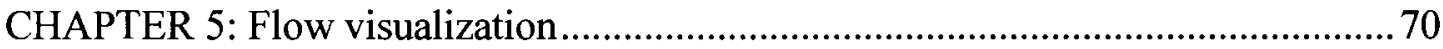

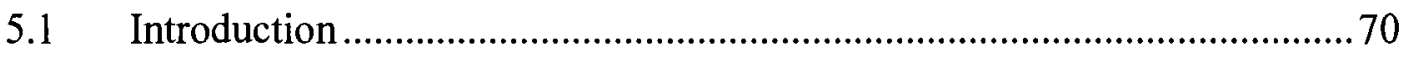

5.2 Objective of the flow visualization study ...............................................

5.3 Laser sheet illumination technique............................................................ 71

5.3.1 The experimental acquisition of images............................................... 72

5.3.2 The computer image processing and analysis ......................................78

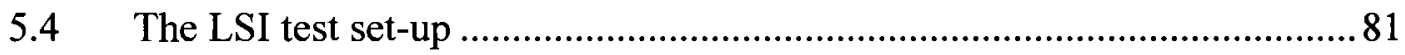

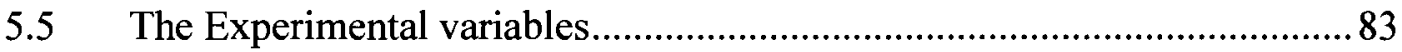

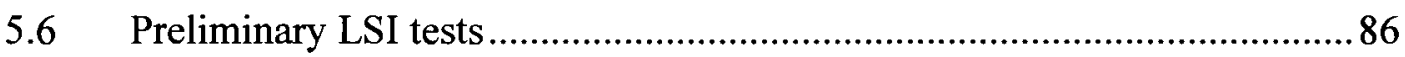

5.7 General procedure for capturing LSI images .............................................. 89

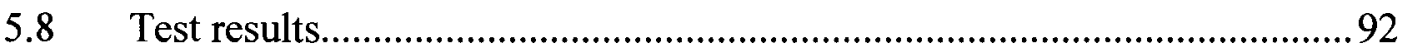

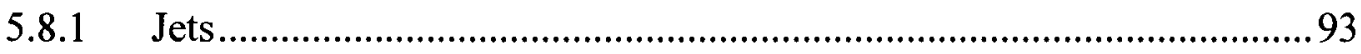

5.8.2 Mixing using round fuel cap ........................................................... 103 
5.8.3 Mixing using flat fuel caps............................................................... 110

5.8.4 Lateral LSI images using flat caps .................................................... 121

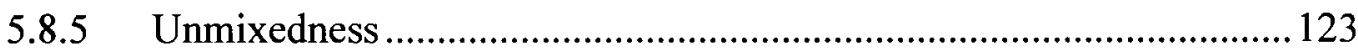

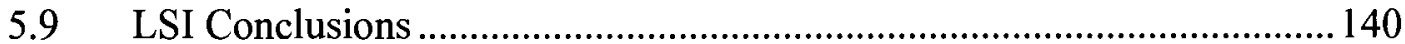

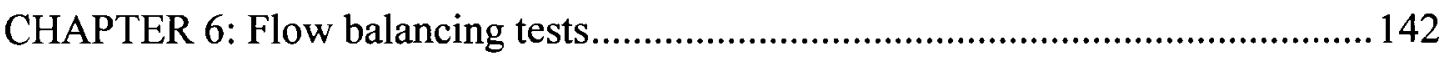

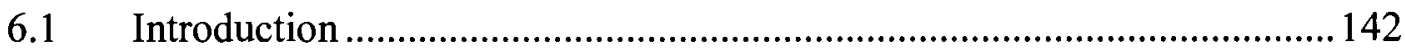

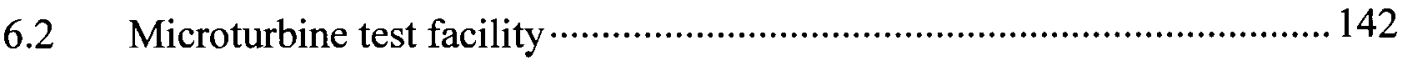

6.2.1 Microturbine start-up procedure........................................................... 142

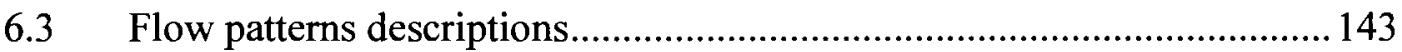

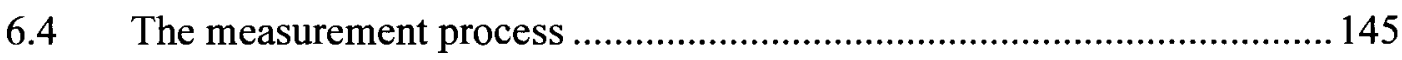

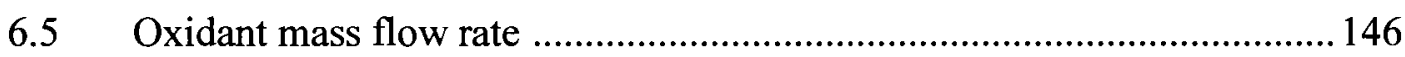

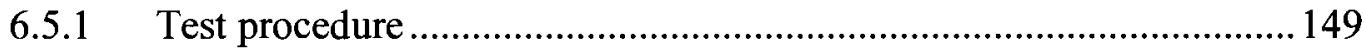

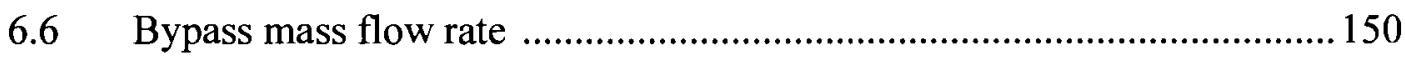

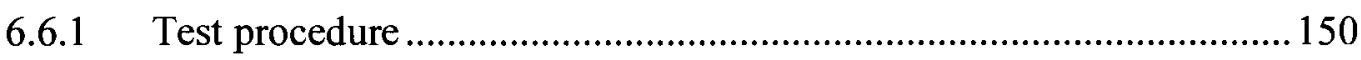

$6.7 \quad$ Test results............................................................................................ 156

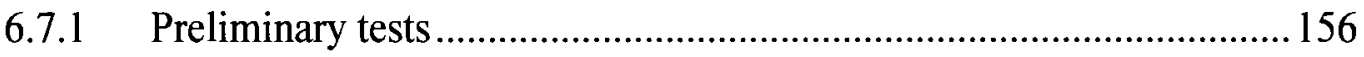

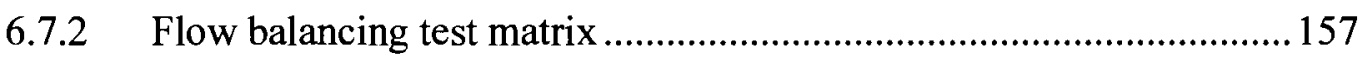

6.7.3 DB inlet velocity profiles ............................................................... 157

6.7.4 DB Annular velocity profiles .............................................................. 160

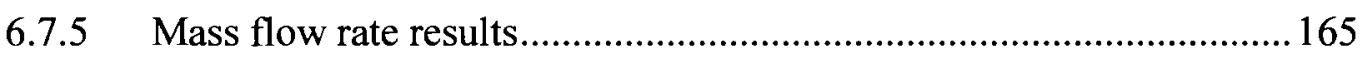

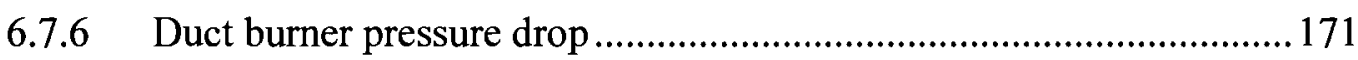

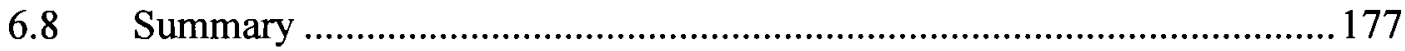

CHAPTER 7: Combustion test procedure and instrumentation.................................. 180

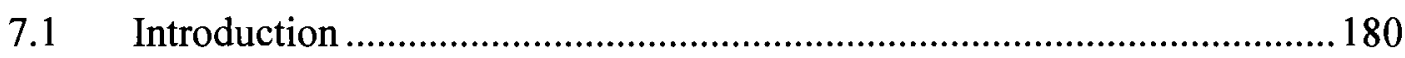

7.2 Duct Burner Management System (BMS) ………................................... 180

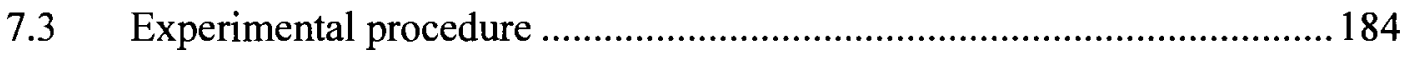

7.3.1 Microturbine start-up procedure......................................................... 184

7.3.2 Duct burner pre-start-up procedures ................................................. 186 
7.3.3 BMS operation and duct burner start-up procedure ............................. 186

7.3.4 Test procedure ................................................................................ 186

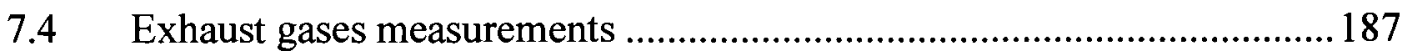

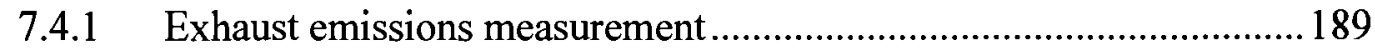

7.4.2 Temperature measurements.............................................................. 192

7.4.3 Duct burner inlet velocity measurement …………………………........ 197

CHAPTER 8: Combustion tests results and discussion ................................................. 198

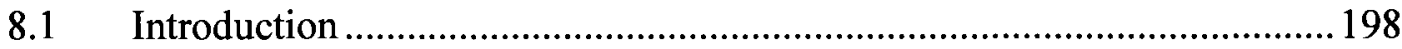

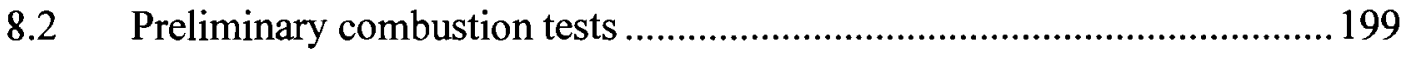

8.3 Combustion test limits............................................................................... 199

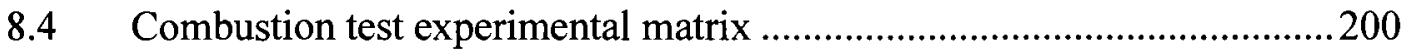

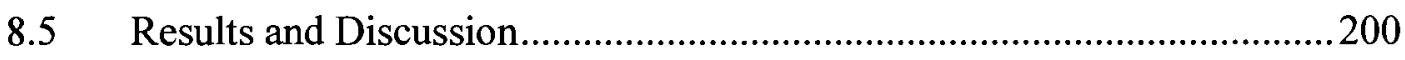

8.5.1 Effect of single-swirl mixer (Mix-1/2) on duct burner performance ..202

8.5.2 Double-swirl mixer results (Mix-2/2) ……………...........................252

8.5.3 Comparisons between the DB parameters and their effect on the

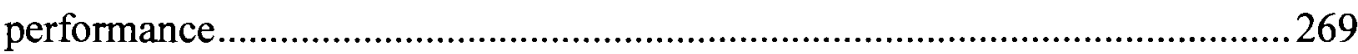

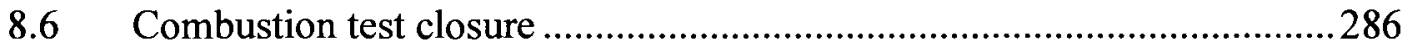

8.6.1 Optimum operating conditions and trade-offs ...................................28

8.6.2 Comparison of experimental results with those of other investigations 289

CHAPTER 9: Conclusions and recommendations..................................................294

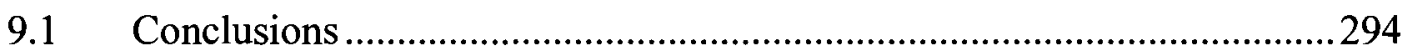

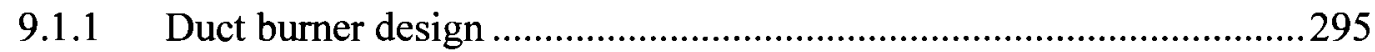

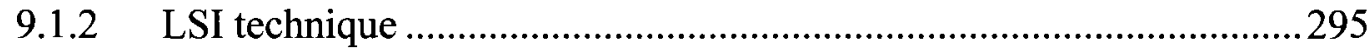

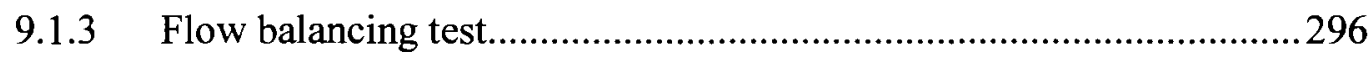

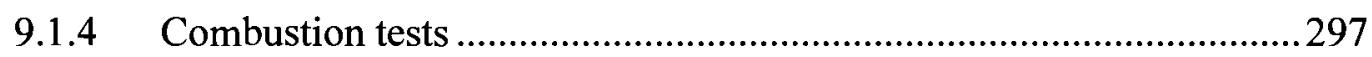

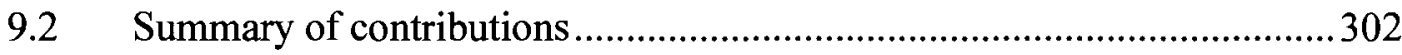

9.3 Recommendations for further work ..........................................................303

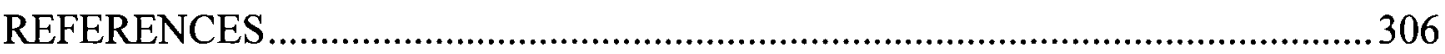


APPENDIX A: General principles of NOx formation.

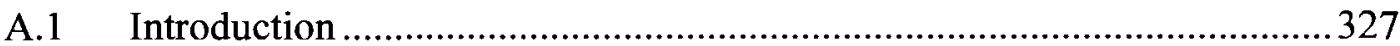

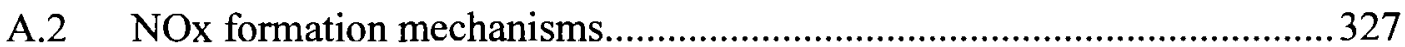

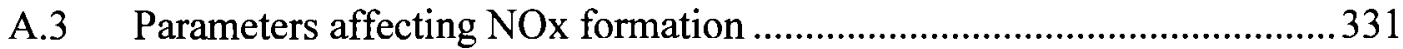

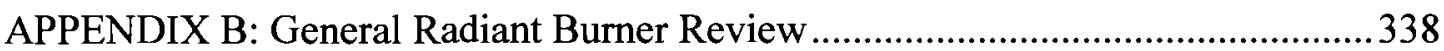

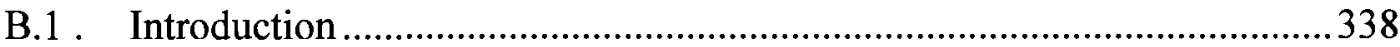

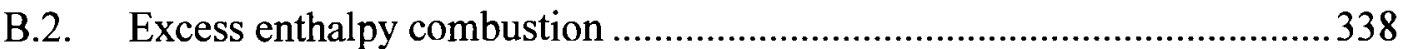

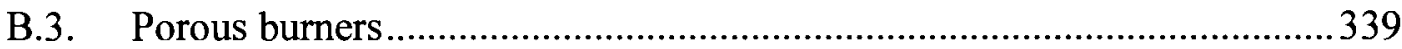

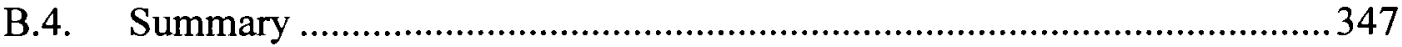

APPENDIX C: Calibration of the fluid flow instrumentation ..............................350

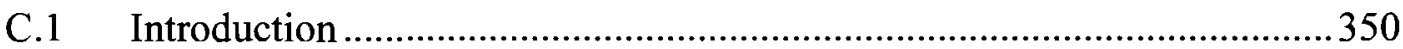

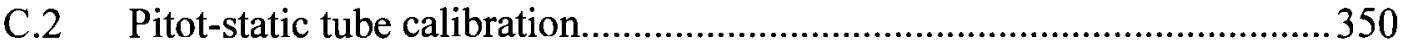

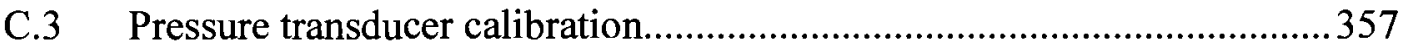

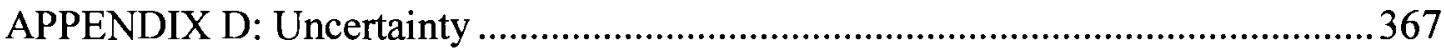

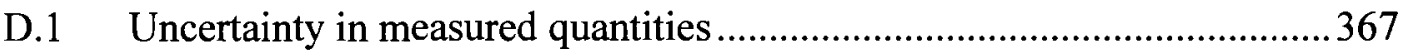

D.2 Estimating uncertainties in calculated quantities using Partial derivatives 369

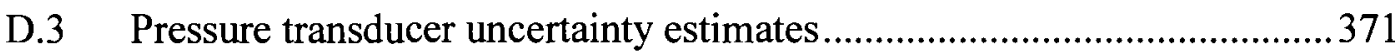

D.4 Examples of uncertainty estimate ................................................. 371

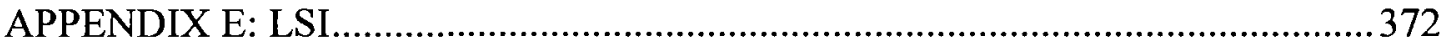

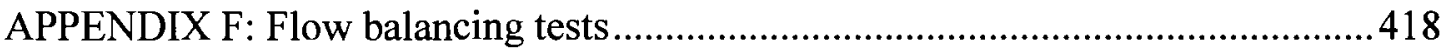

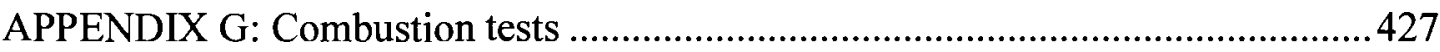

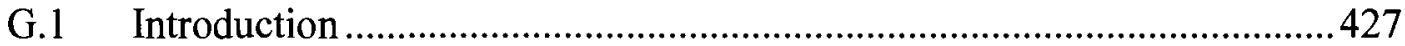

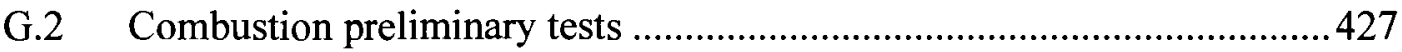

G.3 Additional combustion tests results ..................................................... 431

APPENDIX H: Combustion calculation using exhaust gas analysis.....................450

H.1 Chemical reaction in the duct burner system ....................................450

H.2 Mass flow rate calculations from the exhaust gas analysis ......................453 


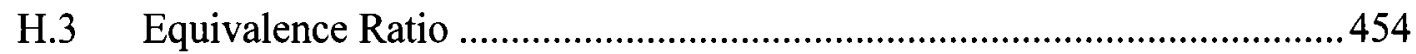

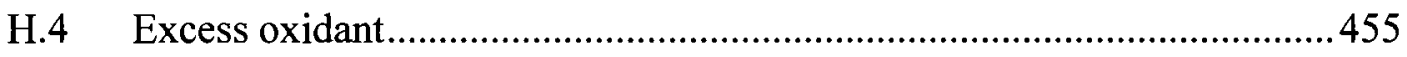

H.5 Comparisons between the mass flow results.............................................456

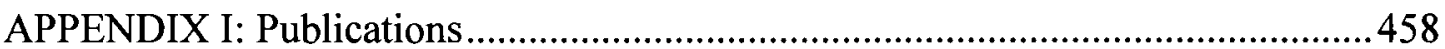

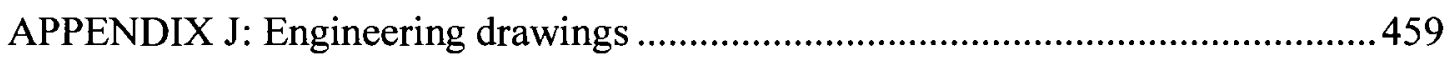




\section{List of Tables}

Table 2.1: Different microturbine technologies ...................................................... 7

Table 4.1: Duct burner design point and specifications:.........................................33

Table 4.2: Exhaust gases (oxidant) flow distribution...........................................40

Table 4.3: Duct burner geometrical parameters .....................................................69

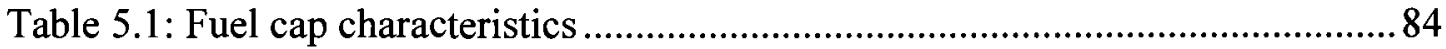

Table 5.2: The experimental matrix used in the LSI phase ......................................85

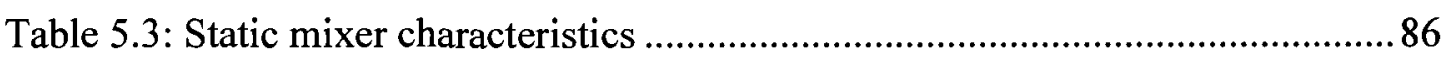

Table 5.4: Operating conditions used for the LSI tests .........................................86

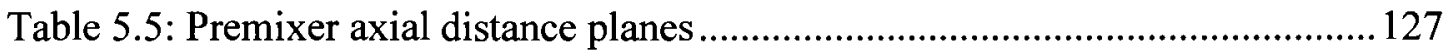

Table 6.1: Ingersoll Rand (IR) microturbine $70 \mathrm{~kW}-\mathrm{CHP}$ unit specifications.......... 144

Table 6.2: Flow balancing test experimental matrix .......................................... 157

Table 6.3: Duct burner flow balancing test results............................................. 170

Table 7.1: HORIBA-PG-250 gas analyzer specifications and calibration gas

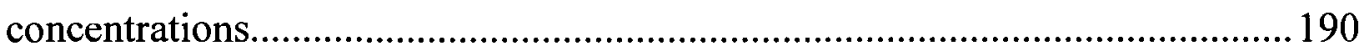

Table 7.2: Characteristics of thermocouples used................................................... 193

Table 7.3: Description of each thermocouple number illustrated in Figure 7.5........ 196

Table 8.1: Experimental matrix used in the combustion tests for Mix-1/2 ............201

Table 8.2: Experimental matrix used in the combustion tests for Mix-2/2 2.............202

Table 8.3: Summary of the combustion tests results, Mix-1/2 _...............................292

Table 8.4: Summary of the combustion tests results, Mix-2/2 ..............................293

Table C.1: Pressure probes used in the flow balancing tests .................................352

Table C.2: Identification data for the pressure transducers...................................358

Table C.3: Temperature effect on transducer sensitivity ......................................359

Table C.4: Uncertainty in the pressure transducer reading .....................................359

Table D.1: Uncertainty estimate for selected parameters. ...................................371

Table E.1: ICCD detector (camera) specification .............................................. 373 


\section{List of Figures}

Figure 2.1: Microturbine power generation cycle ....................................................... 10

Figure 2.2: Micro-CHP system applications and integration with buildings............... 12

Figure 2.3: Porous burners, (a) Surface-stabilized flame. (b) Matrix-stabilized flame

Figure 2.4: Flame images showing two operating conditions (present study) ............20

Figure 2.5: Illustration of reactions responsible for NOx formation under combustion conditions 21

Figure 3.1: General concept of a micro-CHP system with an integrated duct burner28

Figure 4.1: Overall duct burner design strategies flowchart ...........................................31

Figure 4.2: Duct burner schematic (combustion problem) .............................................34

Figure 4.3: Duct burner schematic (fluid dynamics problem) ...................................... 41

Figure 4.4: Overall fluid dynamics problem design flowchart .................................... 42

Figure 4.5: Reference velocity calculations .............................................................. 43

Figure 4.6: Schematic of the duct burner housing components ....................................45

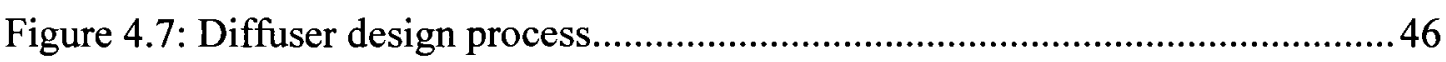

Figure 4.8: Duct burner housing design flowchart....................................................46

Figure 4.9: Schematic of the duct burner premixer components ...................................4 47

Figure 4.10: Geometry of an axial blade swirler........................................................4 49

Figure 4.11: Swirler (static mixer) design flowchart .................................................5

Figure 4.12: Fuel cap design flowchart.................................................................56

Figure 4.13: Duct burner premixer overall component dimensions...............................58

Figure 4.14: Conical wire-mesh burner surface area calculation..................................59

Figure 4.15: Conical wire-mesh burner dimensions ................................................... 61

Figure 4.16: Schematic of the annular passage and the blade operation.......................62

Figure 4.17: Schematic of the different shields used during this investigation ...........65

Figure 4.18: Illustration of the calculation process of the DB overall pressure drop .66

Figure 4.19: Duct burner internal assembly parts ........................................................67 
Figure 4.20: Duct burner overview 68

Figure 5.1: Schematic of the LSI test rig with air, fuel and the seeding systems .......73

Figure 5.2: Schematic of the Plexiglas test section (premixer) and its dimensions .... 74

Figure 5.3: Schematic of the laser sheet generation devices................................... 77

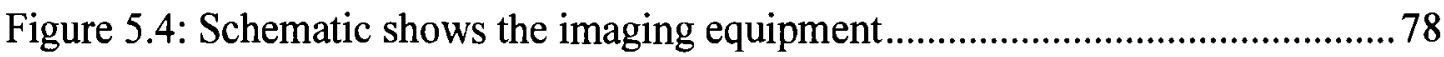

Figure 5.5: Flat-field image optical arrangement with the flat-field box dimensions. 80

Figure 5.6: Schematic of the optical arrangement for vertical image set-up ............8 82

Figure 5.7: Schematic of the optical arrangement for lateral image set-up ...............8 82

Figure 5.8: Schematic of the LSI geometrical variables .....................................83

Figure 5.9: Some of the first trials of the LSI pre-test images .................................87

Figure 5.10: Laser sheet images for the coaxial fuel injection without mixers $\left(\mathrm{MR}_{\mathrm{LSI}}\right.$

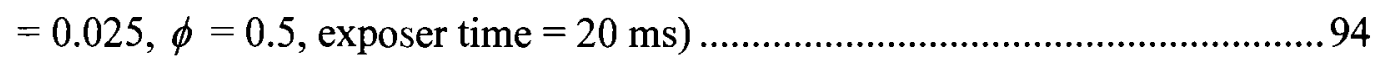

Figure 5.11: Lateral LSI images of the coaxial jets as a function of swirl level (MR $\mathrm{LSI}_{\mathrm{S}}$

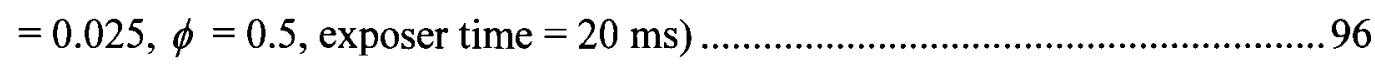

Figure 5.12: Effect streamwise swirls on mixing (Cap-5, $\phi=0.5, \mathrm{MMR}=0.39$

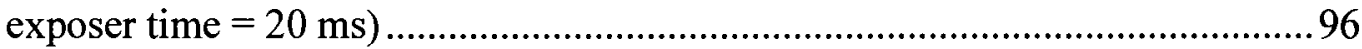

Figure 5.13: Effect Mix-2/3 on mixing $\left(\phi=0.5, \mathrm{MR}_{\mathrm{LSI}}=0.025\right.$, exposer time $=10$ $\mathrm{ms})$ .98

Figure 5.14: Effect of different static mixers on radial fuel jets (Cap-4)...................99 Figure 5.15: Effect of different mixers on penetration ratio (vertical cross-sections for Cap-1) 101

Figure 5.16: Transformation of the fuel jets to swirling jets (Mix-1/2). 102

Figure 5.17: Transformation of the fuel jets to swirling jets (double-swirl mixers). 103

Figure 5.18: LSI images with and without the fuel cap mask and corresponding 3D plots (Mix-2/1 and Cap-5 at $25 \mathrm{~cm}$ ). 105

Figure 5.19: Vertical and lateral cross-sectional LSI images (Mix-1/1 and Cap-5 with $\phi=0.5)$ 105 
Figure 5.20: Vertical and lateral cross-sectional LSI images (Mix-1/2 and Cap-5

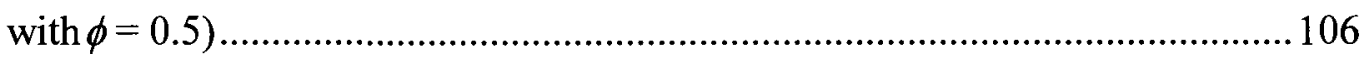

Figure 5.21: Vertical and lateral cross-sectional LSI images (Mix-2/1 and Cap-5 with $\phi=0.5)$ 107

Figure 5.22: Vertical and lateral cross-sectional LSI images (Mix-2/2 and Cap-5 with $\phi=0.5)$ 108

Figure 5. 23: 3D plots for the vertical cross-sectional LSI images for Mix-2/2, Cap-5 and $(\phi=0.5)$ 109

Figure 5.24: Vertical and lateral cross-sectional LSI images (Mix-2/3 and Cap-5 with $\phi=0.5)$ 110

Figure 5.25: Effect of using different mixers on mixing, Cap-5 ( $\phi=0.5)$. 112

Figure 5.26: 3D plots, effect of using different mixers on mixing, Cap-5 $(\phi=0.5) 113$

Figure 5.27: Vertical cross-sectional LSI images for Mix-1/2 and Cap-1 $(\phi=0.5) .114$ Figure 5.28: Vertical cross-sectional LSI images (Mix-2/1 and Cap-1 with $\phi=0.5$ )

Figure 5.29: 3D plots for the vertical cross-sectional LSI images (Mix-2/1, Cap-1 with $\phi=0.5$ ) 116

Figure 5.30: Comparisons between the vertical cross-sectional images (Mix-2/2 with, Cap-2 and Cap-5 and with $\phi=0.5$ ). 116

Figure 5.31: Comparisons between the 3D plots (Mix-2/2 with Cap-2 and Cap-5 and with $\phi=0.5$ ) 117

Figure 5.32: LSI vertical cross-sectional images for all mixers with Cap-4 at $10 \mathrm{~cm}$, $15 \mathrm{~cm}$ and $30 \mathrm{~cm}$ planes $(\phi=0.5)$ 119

Figure 5.33: Vertical cross-sectional LSI images (Mix-2/2 and Cap-2 with $\phi=0.3$ )

Figure 5.34: LSI lateral images showing effect of swirl strength on mixing (Cap-4) 
Figure 5. 35: LSI lateral images showing effect of swirl design and strength on

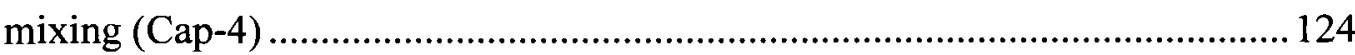

Figure 5.36: LSI lateral images; sample from jet penetration results (Cap-1).......... 125

Figure 5.37: Mixing effectiveness as a function of different fuel caps design (Mix$1 / 1)$ 128

Figure 5.38: Mixing effectiveness as a function of different fuel caps design 129

Figure 5.39: Effect of swirl strength on mixing effectiveness (Mix-1/1, Mix-1/2 and Cap-5)

Figure 5.40: Mixing effectiveness as a function of different fuel caps design (Mix$2 / 2)$

Figure 5.41: Effect of fuel injection angle on mixing effectiveness (Mix-2/2) 131

Figure 5.42: Effect of swirl strength on mixing effectiveness (Mix-1/2, Mix-2/2 and Cap-4) 132

Figure 5.43: Effect of swirl angle sign on mixing effectiveness (Cap-5)

Figure 5.44: Effect of using double-swirl mixers on mixing effectiveness (Cap-2). 134 Figure 5.45: Effect of using double-swirl mixers on mixing effectiveness (Cap-3). 135 Figure 5.46: Effect of equivalence ratio on mixing effectiveness (Mix-1/1 and Cap-2)

Figure 5.47: Effect of equivalence ratio on mixing effectiveness (Mix-1/1 and Cap-2)

Figure 5.48: Effect of swirl strength and design on mixing effectiveness using different caps (at $\mathrm{X}=0.42 \mathrm{D}_{\text {premixer }}$ )

Figure 5.49: Effect of swirl strength and design on mixing effectiveness using different caps (at $\mathrm{X}=1.03 \mathrm{D}_{\text {premixer }} \approx 1 \mathrm{D}_{\text {premixer }}$ )

Figure 5.50: Effect of swirl strength and design on mixing effectiveness using different caps (at $\mathrm{X}=1.94 \mathrm{D}_{\text {premixer }} \approx 2 \mathrm{D}_{\text {premixer }}$ ) ..............................................139

Figure 6.1: Microturbine test facility 143

Figure 6.2: Schematic of the duct burner flow pattern. 145

Figure 6.3: Equal-area method with traverse points indicated for the DB inlet pipe 148 
Figure 6.4: Schematic of the measurement shields used in the flow balancing tests 151 Figure 6.5: Equal-area method with traverse points indicated $(\mathrm{Sh} 5(\mathrm{BR}=0.4)) \ldots \ldots . .153$ Figure 6.6: Equal-area method with traverse points indicated for the annular passage

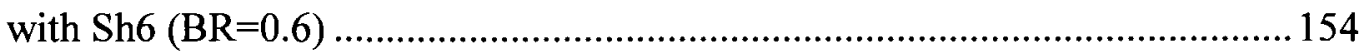

Figure 6.7: Schematic of the pitot-static tube locations in the annular passage for both

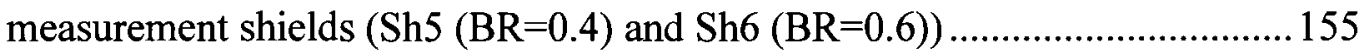

Figure 6.8: Velocity distribution across the DB inlet plane using Port-5 and 6 ....... 158 Figure 6.9: Velocity distribution across the DB inlet plane using Port-6 ………...... 159

Figure 6.10: Effect of the conical burner pressure drop on DB inlet profiles............159

Figure 6.11: Annular region velocity profile repeatability test................................... 161

Figure 6.12: AFCBA effect on annular region velocity profile (Sh5, Port-2) ........... 161

Figure 6.13: Effect of mixer type on the annular region velocity profile (Cone-1, Sh5,

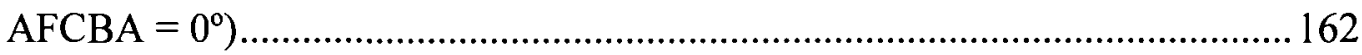

Figure 6.14: Effect of mixers type on the annular region velocity profile (Cone-2, Sh5, $\mathrm{AFCBA}=0^{\circ}$ ) 162

Figure 6.15: Effect of mixers type on the annular region velocity profile (Cone-3,

Sh5, AFCBA $=0^{\circ}$ ) 163

Figure 6.16: Effect of conical burner pressure drop on the annular velocity profile $\left(\mathrm{Mix}-1 / 2, \mathrm{Sh} 6, \mathrm{AFCBA}=0^{\circ}\right)$ 164

Figure 6.17: Effect of mixers type on the annular region velocity profile (Cone-2,

Sh6, AFCBA $=0^{\circ}$ ) 164

Figure 6.18: Effect of the AFCBA on annular region velocity profiles (Mix-2, Cone3 , Sh6) 165

Figure 6.19: Effect of AFCBA on DB mass flow rate split (Mix-1/2, Cone-1 and Sh5) 166

Figure 6.20: Effect of annular blade angle on mass flow rate split (Mix-2/2, Cone-1 and Sh5) 167

Figure 6.21: Effect of mixer design on mass flow ratio (Cone-1, Sh5) ..................... 168

Figure 6.22: Summary of Mix-1/2 results (Sh5, Sh6) ................................................. 169 
Figure 6.23: Summary of Mix-2/2 results (Sh5, Sh6).

Figure 6.24: Effects of conical burner pressure drop and blade angle on DB overall pressure drop (Mix-1/2, Sh5) ...

Figure 6.25: Effects of conical burner pressure drop and blade angle on DB overall pressure drop (Mix-1/2, Sh6) .

Figure 6.26: Effects of conical burner pressure drop and blade angle on DB overall pressure drop (Mix-2/2, Sh5) ...

Figure 6.27: Effects of conical burner pressure drop and blade angle on DB overall pressure drop (Mix-2/2, Sh6) .

Figure 6.28: Effect of mixer design on DB overall pressure drop for different AFCBA

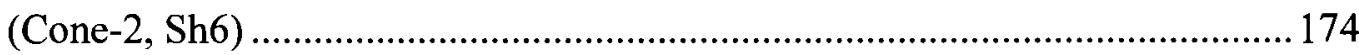

Figure 6.29: Effect of using different shields on $\mathrm{DB} \Delta \mathrm{P}$ (Mix-1/2, Cone-2)............ 176 Figure 6. 30: Effect of using different shields $(\mathrm{BR}=0.4)$ on $\mathrm{DB} \Delta \mathrm{P}(\mathrm{Mix}-1 / 2$, Cone2). 176

Figure 6. 31: Effect of using different shields $(\mathrm{BR}=0.4)$ on $\mathrm{DB} \Delta \mathrm{P}(\mathrm{Mix}-2 / 2$, Cone1). 176

Figure 6.32: Effect of using different shields $(\mathrm{BR}=0.4)$ on $\mathrm{DB} \Delta \mathrm{P}(\mathrm{Mix}-1 / 2$, Cone-1)

Figure 6.33: Effect of using different shields $(B R=0.6)$ on $D B \Delta P($ Mix-1/2, Cone-2) 176

Figure 6.34: Effect of using different shields $(\mathrm{BR}=0.6)$ on $\mathrm{DB} \Delta \mathrm{P}(\mathrm{Mix}-2 / 2 \ldots \ldots . .176$

Figure 7.1: Duct burner and Management system components ................................... 181

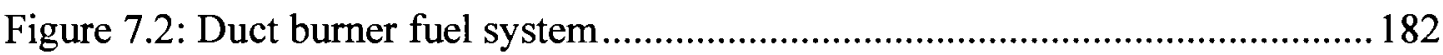

Figure 7.3: Duct burner flame scanner installation ................................................... 183

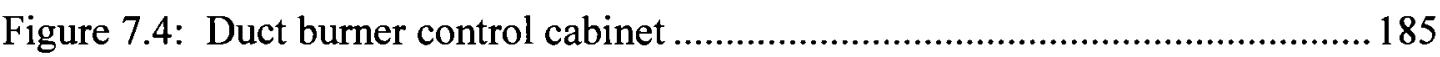

Figure 7.5: Duct burner pressure and temperature measurement points (combustion

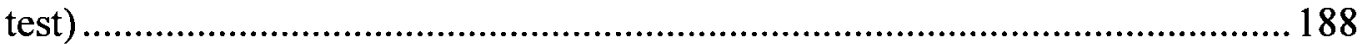

Figure 7.6: Conical burner thermocouple locations .................................................. 194 
Figure 8.1: Effect of firing rate and AFCBA (MR) on DB performance (Mix-1/2, Cap-2 and Cone-1 with Sh2) 205

Figure 8.2: Effect of firing rate and AFCBA on duct burner temperature (Mix-1/2, Cap-2 and Cone-1 with Sh2).. 205

Figure 8.3: The conical burner operating in the blue flame mode (Mix-1/2, Cone-1, Sh2 and Cap-2 at AFCBA $=0^{\circ}$ ). 207

Figure 8.4: Effect of firing rate and AFCBA ( $\left.M R_{C F}\right)$ on NOx emissions (Cone-2) 209

Figure 8.5: Effect of firing rate and AFCBA on CO emissions (Cone-2) 209

Figure 8.6: Effect of FR and AFCBA on combustion zone temperature (Mix-1/2,

Cone-2, Sh2 and Cap-2) 210

Figure 8.7: Exhaust gases temperature distribution at a plane located 1.4 $D_{\text {ref }}$ above the conical burner (Mix-1/2, Cone-2, Sh2 and Cap-2 at AFCBA $\left.=0^{\circ}\right) \ldots \ldots \ldots . . .210$ Figure 8.8: Effect of firing rate and AFCBA on NOx and CO emissions (Mix-1/2, Cone-3, Cap-2 and Sh2) 211

Figure 8.9: Flame images taken for points (i, ii, iii, iv, $v$ and vi) in Figures 8.8 (a) and 8.8 (b), (Mix-1/2, Cone-3, Sh2 and Cap-2) 212

Figure 8.10: Effect of conical burner pressure drop as a function of FR on the duct burner performance (Mix-1/2, Sh2, Cap-2 \& AFCBA $=0^{\circ}$ ) .213

Figure 8.11: Effect of firing rate and conical burner pressure drop on duct burner temperature (Mix-1/2, Cap-2 and Sh2 at AFCBA $=0^{\circ}$ ) 214

Figure 8.12: Effect of firing rate and AFCBA on duct burner performance, for burner configuration; (Mix-1/2, Cap-2 and Cone-2 with Sh1)......................................216

Figure 8.13: Effect of firing rate and AFCBA on duct burner performance, $. . . \ldots . . . . .216$

Figure 8.14: Effect of firing rate and AFCBA on duct burner performance,.............216 Figure 8.15: Flame images taken for points (i), (ii) and (iii) respectively in Figures $8.12,8.13$ and 8.14 . 217

Figure 8.16: Effect of firing rate and AFCBA on duct burner performance,............219

Figure 8.17: Effect of firing rate and AFCBA on duct burner performance, 219 
Figure 8.18: Effect of firing rate and AFCBA on duct burner performance, 219

Figure 8. 19: Effect of firing rate and AFCBA on duct burner performance (Mix-1/2,

Cap-2, Cone-1 and Sh3) 220

Figure 8.20:Effect of combustion intensity on duct burner performance (Mix-1/2,

Cap-2, Cone- 1 and Sh3 at AFCBA $=0^{\circ}$ ) .221

Figure 8.21: Effect of firing rate and ( $L_{\text {eff }} / D_{\text {shield }}$ ) on duct burner NOx emissions

(Mix-1/2, Cap-2 with Sh1, Sh2, Sh3 and Sh4 at AFCBA $=0^{\circ}$ ). 224

Figure 8.22: Effect of firing rate and $\left(L_{e f f} / D_{\text {shield }}\right)$ on duct burner $\mathrm{CO}$ 224

Figure 8.23: Effect of firing rate and $L_{e f f} / D_{\text {shreld }}$ shield ratio on the duct burner temperature (Mix-1/2, Cap-2 and Cap-2 at AFCBA $=0^{\circ}$ ) 225

Figure 8.24: Effect of firing rate and AFCBA on duct burner performance (Mix-1/2,

Cap-4, Cone-1 and Sh1) .228

Figure 8.25: Effect of firing rate and AFCBA on duct burner performance (Mix-1/2,

Cap-4, Cone- 2 and Sh1) .228

Figure 8.26: Effect of firing rate and AFCBA on duct burner performance (Mix-1/2,

Cap-4, Cone-2 and Sh2) .230

Figure 8.27: Effect of firing rate and AFCBA on duct burner performance (Mix-1/2, Cap-4, Cone-3 and Sh2) 230

Figure 8.28: Effect of firing rate and conical burner pressure drop on duct burner performance (Mix-1/2, Cap-4 and Sh1 at AFCBA $=0^{\circ}$ )

Figure 8.29: Effect of firing rate and conical burner pressure drop on duct burner performance (Mix-1/2, Cap-4 and Sh2 at $\mathrm{AFCBA}=0^{\circ}$ ) 232

Figure 8.30: Effect of firing rate and conical burner pressure drop on the duct burner temperature (Mix-1/2, Cap-4 and Sh1 at AFCBA $\left.=0^{\circ}\right)$ .233

Figure 8.31: Effect of firing rate and AFCBA on duct burner performance (Mix-1/2, Cap-4, Cone-1 and Sh2). 235

Figure 8.32: Effect of firing rate and AFCBA on duct burner performance (Mix-1/2, Cap-4, Cone-1 and Sh4) .235 
Figure 8.33: Effect of firing rate and AFCBA on duct burner temperatures at different locations for burner configuration (Mix-1/2, Cap-4 and Cone-1 with Sh2) .....237 Figure 8.34: Effect of firing rate and AFCBA on duct burner performance (Mix-1/2, Cap-4, Cone-2 and Sh3) 239

Figure 8.35: Effect of firing rate and AFCBA on duct burner performance (Mix-1/2, Cap-4, Cone-2 and Sh4) 239

Figure 8.36: Effect of firing rate and AFCBA on duct burner performance (Mix-1/2, Cap-4, Cone-3 and Sh1) 240

Figure 8.37: Effect of firing rate and AFCBA on duct burner performance (Mix-1/2,

Cap-4, Cone-3 and Sh4) 240

Figure 8.38: Flame images taken for points (i) and (ii) in Figure 8.34 (a) 241

Figure 8.39: Flame images taken for points (i) and (ii) in Figure 8.36 (a) 242

Figure 8.40: Summary of $L_{e f f} / D_{\text {shield }}$ ratio effect on the DB performance (Mix-1/2,

Cone-2, Cap-4 at AFCBA $=0^{\circ}$ ) 243

Figure 8.41: Effect of firing rate and $L_{\text {eff }} / D_{\text {shield }}$ on duct burner different locations temperatures (Mix-1/2, Cap-4 and Cone-2 at AFCBA $\left.=0^{\circ}\right)$ 245

Figure 8.42: Effect of firing rate and AFCBA on duct burner performance (Mix-1/2, Cap-4, Cone-3 and Sh7) 247

Figure 8.43: Effect of firing rate and AFCBA on duct burner performance (Mix-1/2, Cap-4, Cone-3 and Sh8) 247

Figure 8.44: Flame images taken for points (i), (ii) and (iii) in Figure 8.42 (a) (Mix1/2, Cone-3, Sh7 and Cap-4) 248

Figure 8.45: Flame images taken for points (i), (ii) and (iii) in Figure 8.43 (a) (Mix$1 / 2$, cone-3, Sh8 and Cap-4 at AFCBA $=0^{\circ}$ ) 249

Figure 8.46: Flame images taken at different test runs (Mix-1/2, Cone-3, Cap-4 with $\mathrm{Sh} 7$ and $\mathrm{Sh} 8$ at $\mathrm{AFCBA}=20^{\circ}$ ). 249

Figure 8.47: Effect of firing rate and BR on NOx and CO emissions (Mix-1/2 and Cone-3 with $\mathrm{AFCBA}=0^{\circ}$ ) 250 
Figure 8.48: Effect of firing rate and BR on overall duct burner pressure drop (Mix$1 / 2$ and Cone- 3 at AFCBA $=0^{\circ}$ )

Figure 8.49: Effect of firing rate and BR on duct burner temperature (Mix-1/2, Cone3 and Cap- 4 at $\mathrm{AFCBA}=0^{\circ}$ ). 252

Figure 8.50: Effect of firing rate and AFCBA on duct burner performance (Mix-2/2,

Cap-2, Cone-2 and Sh3) 254

Figure 8.51: Effect of firing rate and AFCBA on duct burner performance (Mix-2/2,

Cap-2, Cone-3 and Sh3) 254

Figure 8.52: Effect of firing rate and AFCBA on duct burner performance (Mix-2/2,

Cap-2, Cone-1 and Sh2) 256

Figure 8.53: Effect of firing rate and AFCBA on duct burner performance (Mix-2/2,

Cap-2, Cone-1 and Sh2) 256

Figure 8.54: Flame images taken for points (i) and (ii) in Figure 8.50 (a) 257

Figure 8.55: Flame images taken for points (i) and (ii) in Figure 8.53 (a) 258

Figure 8.56: Effect of firing rate and conical burner pressure drop on duct burner performance (Mix-2/2, Cap-2, Sh3 with Cone-1, Cone-2 and Cone-3)............259

Figure 8.57: Effect of firing rate and 259

Figure 8.58: Effect of firing rate and conical burner pressure drop on duct burner temperatures (Mix-2/2, Cap-2 and Sh3 at $\mathrm{AFCBA}=0^{\circ}$ ) 260

Figure 8.59: Effect of firing rate and $L_{e f f} / D_{\text {shield }}$ on duct burner temperatures (Mix$2 / 2$, Cap- 2 and Cone- 2 at AFCBA $=0^{\circ}$ ) 260

Figure 8.60: Effect of firing rate and AFCBA on duct burner performance (Mix-2/2, Cap-4, Cone-1 and Sh2) 263

Figure 8.61: Effect of firing rate and AFCBA on duct burner performance (Mix-2/2, Cap-4, Cone- 3 and Sh2) 263

Figure 8.62: Effect of firing rate and AFCBA on duct burner performance (Mix-2/2, Cap-4, Cone-2 and Sh1) .265 
Figure 8.63: Effect of firing rate and AFCBA on duct burner performance (Mix-2/2, Cap-4, Cone-2 and Sh2) 265

Figure 8.64: Effect of firing rate and conical burner pressure drop on duct burner performance (Mix-2/2, Cap-4, Sh2 with Cone-1, Cone-2 and Cone-3).............266

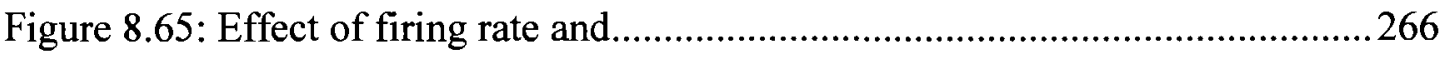

Figure 8.66: Effect of firing rate and conical burner pressure drop on duct burner

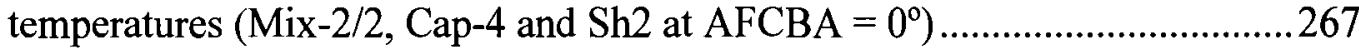

Figure 8.67: Effect of firing rate and $L_{e f f} / D_{\text {shield }}$ on duct burner temperatures (Mix2/2, Cap-4 and Cone- 2 at AFCBA $=0^{\circ}$ ) 267

Figure 8.68: Effect of firing rate and $L_{e f f} / D_{\text {shield }}$ on duct burner performance (Mix2/2, Cap-3, Cone-2 with Sh1, Sh2 and Sh3) 268

Figure 8.69: Flame images taken for different operating points (Mix-2/2, Cone-1, Sh3 and Cap-4) 269

Figure 8.70: Flame images taken for different operating points (Mix-2/2, Cone-2, Sh3 and Cap-4) 269

Figure 8.71: Effect of firing rate, AFCBA and conical burner pressure drop on duct burner NOx emissions and operating range (Mix-1/2, Cap-4 and Sh1) 270

Figure 8.72: Effect of firing rate, AFCBA and $L_{e f f} / D_{\text {shield }}$ ratio on duct burner NOx emissions and operating range (Mix-1/2, Cap-4 and Cone-2) .271

Figure 8.73: Effect of firing rate and DB inlet temperature on duct burner performance (Mix-1/2, Cone-1, Cap-3 and Sh2 at AFCBA $=0^{\circ}$.

Figure 8.74: Effect of firing rate and $\mathrm{DB}$ inlet temperature on duct burner performance (Mix-1/2, Cone-2, Cap-3 and Sh2 at AFCBA $\left.=0^{\circ}\right)$.....................273

Figure 8.75: Flame images taken for points (i) and (ii) in Figure 8.73 (a) ................2. 274 Figure 8.76: Effect of cones on DB exhaust gases temperature (Mix-1/2, Cap-4 and

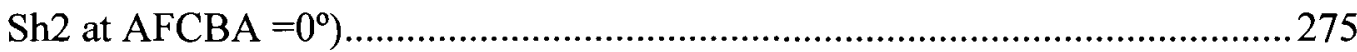

Figure 8.77: Effect of cones on DB exhaust gases temperature (Mix-2/2, Cap-4 and $\mathrm{Sh} 2$ at $\mathrm{AFCBA}=0^{\circ}$. .275 
Figure 8.78: Effect of $\mathrm{L}_{\text {eff }} / \mathrm{D}_{\text {shield }}$ on DB exhaust gases temperature (Mix-1/2, Cone-2

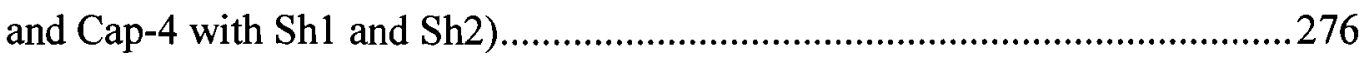

Figure 8.79: Effect of BR on the DB exhaust gases temperature (Mix-1/2, Cone-2 and Cap-4).

Figure 8.80: Effect of FR on DB exhaust gases temperature (Mix-1/2, Cone-3 and Cap-2 with Sh4) 277

Figure 8.81: Effect of AFCBA (MR) on DB exhaust gases temperature (Mix-1/2, Cone-3 and Cap-4 with Sh1). 277

Figure 8.82: Effect of firing rate and fuel caps on duct burner performance, for burner configuration; (Mix-1/2, Cone- 1 and Sh2 at $\mathrm{AFCBA}=0^{\circ}$ ). 279

Figure 8.83: Effect of using different fuel caps as a function of firing rate on the duct burner temperatures, for burner configuration; (Mix-1/2, Sh2, Cone-1 at AFCBA $\left.=0^{\circ}\right)$ 279

Figure 8.84: Effect of using different fuel caps (flame images) 280

Figure 8.85: Effect of firing rate and mixers design on DB performance (Cone-1, Cap-2 and $\mathrm{Sh} 3$ at $\mathrm{AFCBA}=0^{\circ}$ ). 282

Figure 8.86: Effect of firing rate and mixers design on DB temperatures (Cap-4 and Sh2) 282

Figure 8.87: Effect of using different mixers on flame uniformity (flame images)..283 Figure 8.88: Effect of firing rate and fuel injection angle on duct burner performance $\left(\mathrm{Mix}-2 / 2\right.$, Cone-2, Sh3 at AFCBA $\left.=0^{\circ}\right)$ 286

Figure 8.89: Flame images taken for points (i) and (ii) in Figure 8.33 (a) (Mix-2/2, Cone-2, Sh3 and Cap-5 at AFCBA $=0^{\circ}$ ) .287

Figure 8.90: Effect of fuel injection angle on mixture (oxidant/fuel) temperature profiles at the premixer exit plane (Mix-2/2, Cone-2 and Sh3 at AFCBA $=0^{\circ}$ )

\section{Appendices}


Figure A.1: Illustration of reactions responsible for NOx formation under combustion conditions (repeated from Chapter 2).............................................................328

Figure A.2: Effect of temperature on NOx formation [modified from Steele, 1995]334

Figure B.1: Principle of excess enthalpy flame [Weinberg (1971)] ……………........339

Figure C.1: Schematic of the pitot-static tube calibration rig ......................................351

Figure C.2: Calibration curves for pitot-static tube 1 .................................................353

Figure C.3: Calibration curves for pitot-static tube No. 2...........................................353

Figure C. 4: Calibration curves for pitot-static tubes 3 and 4 ....................................354

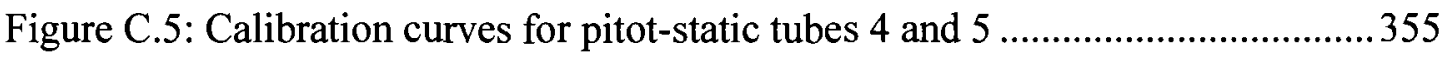

Figure C.6: Calibration curves for pitot-static tube No. 6...........................................355

Figure C.7: Calibration curves for the static prob..................................................356

Figure C. 8: Repeated calibration curves for pitot-static tube No. 3 ..........................356

Figure C.9: Repeated calibration curves for pitot-static tube No.5 .............................357

Figure C.10: Calibration of the different data acquisition transducers channels .......360

Figure C.11: Transducer calibration curves for transducers 16 and 17 ....................361

Figure C.12: Transducer calibration curves for transducers 18 and 19 ....................362

Figure C.13: Transducer calibration curves for transducers 20 and 21 ....................363

Figure C.14: Transducer calibration curve for transducer 22 and 23.........................364

Figure C.15: Pressure transducer calibration (for Tr. 16, 17 and 18) .......................365

Figure C.16: Pressure transducer calibration (for Tr. 19 and 20) .............................366

Figure E.1: Effect of the fuel cap mask on the fuel concentration image and the 3D

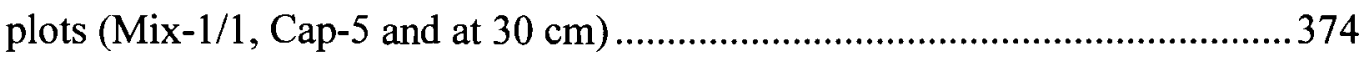

Figure E.2: Effect of the fuel cap mask on the fuel concentration image and the 3D plots (Mix-2/2, Cap-5 and at $15 \mathrm{~cm}$ ) .............................................................374

Figure E.3: Vertical and lateral cross-sectional LSI images (Mix-1/1 and Cap-5 with

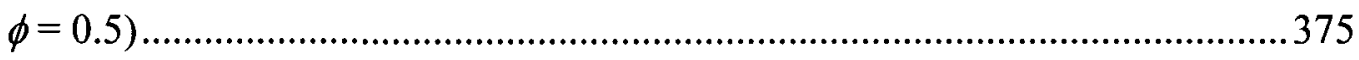

Figure E.4: Vertical and lateral cross-sectional LSI images (Mix-1/2 and Cap-5 with $\phi=0.5$ ) 375 
Figure E.5: Vertical and lateral cross-sectional LSI images (Mix-2/1 and Cap-5 with

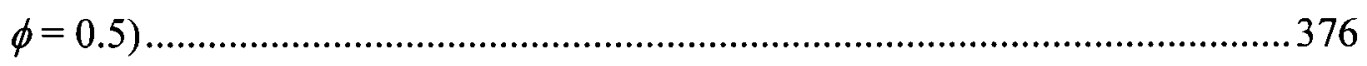

Figure E.6: Vertical and lateral cross-sectional LSI images (Mix-2/2 and Cap-5 with

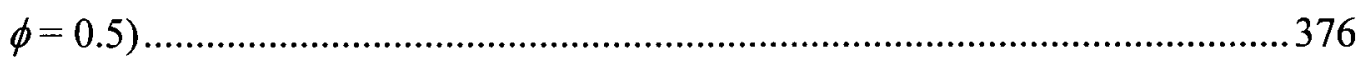

Figure E.7: Vertical and lateral cross-sectional LSI images (Mix-2/3 and Cap-5 with

$$
\phi=0.5)
$$

Figure E. 8: 3D plots for the vertical cross-sectional LSI images (Mix-2/3 and Cap-5 with $\phi=0.5$ )

Figure E.9: 3D plots for the vertical cross-sectional LSI images for Mix-1/1, Cap-5 and $\phi=0.5$

Figure E.10: 3D plots for the vertical cross-sectional LSI images for Mix-1/2, Cap-5 and $\phi=0.5$

Figure E.11: 3D plots for the vertical cross-sectional LSI images for Mix-2/1, Cap-5 and $\phi=0.5$

Figure E.12: 3D plots for the vertical cross-sectional LSI images for Mix-2/2, Cap-5 and $\phi=0.5$

Figure E.13: 3D plots for the vertical cross-sectional LSI images for Mix-2/3, Cap-5 and $\phi=0.5$

Figure E.14: Vertical cross-sectional LSI images (Mix-1/1 and Cap-1 with $\phi=0.5)$

Figure E.15: Vertical cross-sectional LSI images (Mix-1/2 and Cap-1 with $\phi=0.5)$

Figure E.16: Vertical cross-sectional LSI images (Mix-2/1 and Cap-1 with $\phi=0.5)$

Figure E.17: Vertical cross-sectional LSI images (Mix-2/2 and Cap-1 with $\phi=0.5)$ 
Figure E.18: Vertical cross-sectional LSI images (Mix-2/3 and Cap-1 with $\phi=0.5)$

Figure E.19: 3D plots for the vertical cross-sectional LSI images for Mix-1/1, Cap-1 and $\phi=0.5$

Figure E.20: 3D plots for the vertical cross-sectional LSI images for Mix-1/2, Cap-1 and $\phi=0.5$

Figure E.21: 3D plots for the vertical cross-sectional LSI images for Mix-2/2, Cap-1 and $\phi=0.5$

Figure E.22: 3D plots for the vertical cross-sectional LSI images for Mix-2/3, Cap-1 and $\phi=0.5$ 389

Figure E.23: Vertical cross-sectional LSI images (Mix-1/1 and Cap-2 with $\phi=0.5$ )

Figure E.24: Vertical cross-sectional LSI images (Mix-1/2 and Cap-2 with $\phi=0.5)$

Figure E.25: Vertical cross-sectional LSI images (Mix-2/1 and Cap-2 with $\phi=0.5)$

Figure E.26: Vertical cross-sectional LSI images (Mix-2/2 and Cap-2 with $\phi=0.5)$

Figure E.27: Vertical cross-sectional LSI images (Mix-2/3 and Cap-2 with $\phi=0.5$ )

Figure E.28: 3D plots for the vertical cross-sectional LSI images (Mix-1/1, Cap-2 and with $\phi=0.5$ ).

Figure E.29: 3D plots for the vertical cross-sectional LSI images for Mix-1/2, Cap-2 and $\phi=0.5$ 394

Figure E.30: 3D plots for the vertical cross-sectional LSI images for Mix-2/1, Cap-2 and $\phi=0.5$ 
Figure E.31: 3D plots for the vertical cross-sectional LSI images for Mix-2/2, Cap-2 and $\phi=0.5$ 396

Figure E.32: 3D plots for the vertical cross-sectional LSI images for Mix-2/3, Cap-2 and $\phi=0.5$ 397

Figure E.33: Vertical cross-sectional LSI images (Mix-1/1 and Cap-3 with $\phi=0.5$ ) 398

Figure E.34: Vertical cross-sectional LSI images (Mix-1/2 and Cap-3 with $\phi=0.5$ ) 398

Figure E.35: Vertical cross-sectional LSI images (Mix-2/1 and Cap-3 with $\phi=0.5$ ) 399

Figure E.36: Vertical cross-sectional LSI images (Mix-2/2 and Cap-3 with $\phi=0.5$ ) 399

Figure E.37: Vertical cross-sectional LSI images for the Mix-2/3 and Cap-3 $(\phi=0.5)$

Figure E.38: Vertical cross-sectional LSI images for the Mix-1/1 and Cap-4 ( $\phi=0.5)$ 400

Figure E.39: Vertical cross-sectional LSI images (Mix-1/2 and Cap-4 with $\phi=0.5)$ 401

Figure E.40: Vertical cross-sectional LSI images (Mix-2/1 and Cap-4 with $\phi=0.5$ ) 401

Figure E.41: Vertical cross-sectional LSI images (Mix-2/2 and Cap-4 with $\phi=0.5$ ) 402

Figure E.42: Vertical cross-sectional LSI images (Mix-2/3 and Cap-4 with $\phi=0.5$ ) 402

Figure E.43: 3D plots for the vertical cross-sectional LSI images for Mix-1/1, Cap-4 and $\phi=0.5$ 403 
Figure E.44: 3D plots for the vertical cross-sectional LSI images for Mix-1/2, Cap-4 and $\phi=0.5$ 404

Figure E.45: 3D plots for the vertical cross-sectional LSI images for Mix-2/1, Cap-4 and $\phi=0.5$ 405

Figure E.46: 3D plots for the vertical cross-sectional LSI images for Mix-2/2, Cap-4 and $\phi=0.5$ 406

Figure E.47: 3D plots for the vertical cross-sectional LSI (Mix-2/3, Cap-4 and with $\phi$ $=0.5)$ 407

Figure E.48: Vertical cross-sectional LSI images (Mix-1/1 and Cap-2 with $\phi=0.3$ ) 408

Figure E.49: Vertical cross-sectional LSI images (Mix-1/2 and Cap-2 with $\phi=0.3$ ) 408

Figure E.50: Vertical cross-sectional LSI images (Mix-2/2 and Cap-2 with $\phi=0.3$ ) 409

Figure E.51: Vertical cross-sectional LSI images (Mix-2/3 and Cap-2 with $\phi=0.3$ ) 409

Figure E.52: 3D plots for the vertical cross-sectional LSI images for Mix-1/1, Cap-2 and $\phi=0.3$ 410

Figure E.53: 3D plots for the vertical cross-sectional LSI images for Mix-1/2, Cap-2 and $\phi=0.3$

Figure E.54: 3D plots for the vertical cross-sectional LSI images for Mix-2/2, Cap-2 and $\phi=0.3$

Figure E.55: 3D plots for the vertical cross-sectional LSI images for Mix-2/3, Cap-2 and $\phi=0.3$

Figure E.56: Effect of fuel cap design on mixing effectiveness 414

Figure E.57: Effect of fuel injection angle on mixing effectiveness (Cap-2 and Cap-5 comparisons) 
Figure E.58: Effect of mixer design on mixing effectiveness at different premixer axial locations.

Figure E.59: Effect of mixer strength (S) on mixing effectiveness (a) Cap-1 and (b) Cap-2 416

Figure E.60: Effect of $\Phi$ on mixing effectiveness (Cap-2) (a) Mix-1/1, (b) Mix-1/2,

(c) Mix-2/2 and (d) Mix-2/3.

Figure E.61: Effect of fuel cap design on mixing effectiveness using different mixers (at $\mathrm{X}=0.42 \mathrm{D}_{\text {premixer }}$ )

Figure E.62: Effect of fuel cap design on mixing effectiveness using different mixers (at $\mathrm{X} \approx 1 \mathrm{D}_{\text {premixer }}$ ).

Figure E.63: Effect of fuel cap design on mixing effectiveness using different mixers (at $\mathrm{X} \approx 2 \mathrm{D}_{\text {premixer }}$ ). 417

Figure F.1: Repeated velocity profiles across the DB inlet plane using Port-5 419

Figure F.2: Velocity distribution across the DB inlet plane using Port-5, repeatability tests.

Figure F.3: Effect of AFCBA on DB inlet velocity distribution using Port-6 (Mix-1/2, Cone-2 and Sh5)

Figure F.4: Velocity distribution across the DB inlet plane using Port-6, different traverse directions 419

Figure F. 5: Effect of pitot-static tube size on the annular region velocity profile, Port1 (Sh5) 419

Figure F. 6: Effect of pitot-static tube size on the annular region velocity profile, Port3 (Sh5) 420

Figure F.7: Effect of AFCBA on the annular region velocity profile, Port-1 (Sh5) .420 Figure F.8: Effect of pitot-static tube size on the annular region velocity profile (Sh6, Port-2) 420

Figure F.9: Effect of pitot-static tube size on the annular region velocity profile (Sh6, Port-2). 420 
Figure F.10: Effect of AFCBA on the DB mass flow rate split (Mix-1/2, Cone-2 and Sh5) 420

Figure F.11: Effect of AFCBA on the DB mass flow rate split (Mix-1/2, Cone-3 and Sh5) 420

Figure F.12: Effect of AFCBA on mass flow rate split (Mix-1/2, Cone-1 and Sh6) 421 Figure F.13: Effect of AFCBA on mass flow rate split (Mix-1/2, Cone-2 and Sh6) 421 Figure F.14: Effect of AFCBA on mass flow rate split (Mix-1/2, Cone-3 and Sh6) 421 Figure F.15: Effect of AFCBA on mass flow rate split (Mix-2/2, Cone-2 and Sh5) 421 Figure F.16: Effect of AFCBA on mass flow rate split (Mix-2/2, Cone-3 and Sh5) 421 Figure F.17: Effect of AFCBA on mass flow rate split (Mix-2/2, Cone-1 and Sh6) 421 Figure F.18: Effect of AFCBA on mass flow rate split (Mix-2/2, Cone-2 and Sh5) 422 Figure F.19: Effect of mixer design on mass flow ratio (Cone-2 and Sh5) 422

Figure F.20: Effect of mixer design on mass flow ratio (Cone-3 and Sh5) ............... 422

Figure F.21: Effect of BR on mass flow ratio (Mix-1/2, Cone-1) .............................. 422

Figure F.22: Effect of BR on mass flow ratio (Mix-1/2, Cone-2) ..............................422

Figure F.23: Effect of BR on mass flow ratio (Mix-1/2, Cone-3) …..........................422

Figure F.24: Effect of BR on mass flow ratio (Mix-2/2 and Cone-1)....................... 423

Figure F.25: Cone-3 behaviour, effect of different cones on mass ratio (Mix-1/2 and Sh5) 423

Figure F.26: Effect of the AFCBA on annular region velocity profiles (Mix-2, Cone-2 and Sh6) 423

Figure F.27: Effect of conical burner pressure drop on the annular velocity profile $(\mathrm{Mix}-2$ and Sh6 at AFCBA $=0$ ). 423

Figure F.28: Effect of conical burner pressure drop on the annular velocity profile

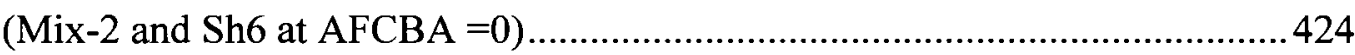

Figure F.29: Effect of BR and $L_{\text {eff }} / D_{\text {shield }}$ on DB $\Delta \mathrm{P}(\mathrm{Mix}-1 / 2$ and Cone-1) ..........424

Figure F.30: Effect of $L_{\text {eff }} / D_{\text {shield }}$ on DB $\Delta \mathrm{P}(\mathrm{Mix}-1 / 2$ and Cone-2) ........................424

Figure F.31: Effect of $L_{\text {eff }} / D_{\text {shield }}$ on DB $\Delta \mathrm{P}(\mathrm{Mix}-1 / 2$ and Cone-3) ......................424 
Figure F.32: Effect of BR and $L_{\text {eff }} / D_{\text {shield }}$ on DB $\Delta \mathrm{P}$ (Mix-2/2 and Cone-2) .........424

Figure F.33: Effect of BR and $L_{e f f} / D_{\text {shield }}$ on DB $\Delta \mathrm{P}($ Mix-2/2 and Cone-1) ..........425

Figure F.34; Effect of BR and $L_{e f f} / D_{\text {shield }}$ on DB $\Delta \mathrm{P}($ Mix-2/2, Cone-3) ................ 425

Figure F.35: Effect of $L_{\text {eff }} / D_{\text {shield }}$ on DB $\Delta \mathrm{P}($ Mix-1/2, Cone-3) .............................425

Figure F.36: Effect of $L_{\text {eff }} / D_{\text {shield }}$ on DB $\Delta \mathrm{P}(\mathrm{Mix}-2 / 2$ and Cone-2) ...................... 425

Figure F.37: Effect of using shield on DB $\Delta \mathrm{P}$ (Mix-1/2 and Cone-1) ......................425

Figure F.38: Effect of using shield on DB $\triangle \mathrm{P}(\mathrm{Mix}-1 / 2$ and Cone-2) .......................425

Figure F.39: Effect of using shield on $\mathrm{DB} \Delta \mathrm{P}$ (Mix-1/2 and Cone-3) .......................426

Figure F.40: Effect of $L_{\text {eff }} / D_{\text {shield }}$ on DB $\Delta \mathrm{P}$ (Mix-2/2 and Cone-2 2.......................426

Figure F.41: Effect of $L_{e f f} / D_{\text {shield }}$ on DB $\Delta \mathrm{P}($ Mix-2/2, Cone-3) ............................. 426

Figure F.42: Effect of BR and $L_{e f f} / D_{\text {shield }}$ on DB $\Delta \mathrm{P}$ (Mix-2/2 and Cone-3) ......... 426

Figure G.1: Combustion preliminary tests emissions results (microturbine + DB).. 429

Figure G.2: Combustion preliminary tests emissions results (Mix-1/2, Cone-3, Cap-4 and $\mathrm{Sh} 4$ at $\mathrm{AFCBA}=0^{\circ}$ )

Figure G.3: Combustion preliminary tests NOx emissions results (repeatability test)

Figure G.4: Combustion preliminary tests $\mathrm{CO}$ emissions results (repeatability test) 430 Figure G.5: Combustion preliminary tests NOx emissions results (effect of fuel caps)

Figure G.6: Effect of firing rate and AFCBA on duct burner performance (Mix-1/2,

Cap-3, Cone-1 and Sh1)

Figure G.7: Effect of Firing rate on duct burner performance, Component contributions (Mix-1/2, Cap-3, Cone-1 and Sh1 at AFCBA $=0^{\circ}$

Figure G.8: Effect of firing rate and.

Figure G.9: Effect of firing rate and AFCBA on duct burner performance (Mix-1/2,

Cap-3, Cone-1 and Sh3) 433 
Figure G.10: Effect of firing rate and AFCBA on duct burner performance (Mix-1/2,

Cap-3, Cone-2 and Sh1

Figure G.11: Effect of firing rate and AFCBA on duct burner performance (Mix-1/2,

Cap-3, Cone-2 and Sh2). 434

Figure G.12: Effect of firing rate and AFCBA on duct burner performance (Mix-1/2,

Cap-3, Cone-2 and Sh3) 435

Figure G.13: Effect of firing rate and AFCBA on duct burner performance (Mix-1/2, Cap-3, Cone-3 and Sh1)

Figure G.14: Effect of firing rate and AFCBA on duct burner performance (Mix-1/2,

Cap-3, Cone-3 and Sh2) 436

Figure G.15: Effect of firing rate and AFCBA on duct burner performance (Mix-1/2,

Cap-3, Cone-3 and Sh3) 436

Figure G.16: Flame images taken for points (i) and (ii) in Figure G.8 (a).

Figure G.17: Flame images taken for points (ii) and (v) in Figure G.9 (a).

Figure G.18: Flame images taken for points (ii) and (v) in Figure G.12 (a)

Figure G.19: Effect of firing rate and conical burner pressure drop on duct burner

NOx emissions (Mix-1/2, Cap-3 with Cone-1, Cone-2 and Cone-3 at AFCBA = $\left.0^{\circ}\right)$ 438

Figure G.20: Effect of firing rate and $\left(L_{\text {eff }} / D_{\text {shiel }}\right)$ on duct burner NOx emissions (Mix1/2, Cap-3 with Sh1, Sh2 and Sh3 at AFCBA $=0^{\circ}$ ) 438

Figure G.21: Effect of firing rate and AFCBA on duct burner performance (Mix-2/2,

Cap-3, Cone-1 and Sh3) 439

Figure G.22: Effect of firing rate and AFCBA on duct burner performance (Mix-2/2,

Cap-3, Cone-2 and Sh3) 439

Figure G.23: Effect of firing rate and AFCBA on duct burner performance (Mix-2/2,

Cap-3, Cone-1 and Sh3) 440

Figure G.24: Effect of firing rate and conical burner pressure drop on duct burner performance (Mix-2/2, Cap-3, 440

Xxxiii 
Figure G.25: Effect of firing rate and AFCBA on duct burner performance (Mix-1/2,

Cap-4, Cone-1 and Sh7)

Figure G.26: Effect of firing rate and AFCBA on duct burner performance (Mix-1/2,

Cap-4, Cone-1 and Sh8).

Figure G.27: Effect of firing rate and AFCBA on duct burner performance (Mix-1/2,

Cap-4, Cone-2 and Sh7)....

Figure G.28: Effect of firing rate and AFCBA on duct burner performance (Mix-1/2,

Cap-4, Cone-2 and Sh8).

Figure G.29: Effect of firing rate and AFCBA on duct burner performance (Mix-1/2,

Cap-4, Cone-3 and Sh3).

Figure G.30: Effect of firing rate and AFCBA on duct burner performance (Mix-2/2,

Cap-2, Cone-2 and Sh1) 443

Figure G.31: Effect of firing rate and AFCBA on duct burner performance (Mix-2/2,

Cap-2, Cone-2 and Sh2). 444

Figure G.32: Effect of firing rate and AFCBA on duct burner performance (Mix-2/2,

Cap-2, Cone-3 and Sh1) 444

Figure G.33: Effect of firing rate and AFCBA on duct burner performance (Mix-2/2,

Cap-2, Cone-3 and Sh2).

Figure G. 34: Effect of firing rate and AFCBA on duct burner performance (Mix-2/2,

Cap-4, Cone-1 and Sh1 445

Figure G.35: Effect of firing rate and AFCBA on duct burner performance (Mix-2/2,

Cap-4, Cone-1 and Sh3). 446

Figure G.36: Effect of firing rate and AFCBA on duct burner performance (Mix-2/2,

Cap-4, Cone-2 and Sh3). 446

Figure G.37: Effect of firing rate and AFCBA on duct burner performance (Mix-2/2,

Cap-4, Cone-3 and Sh1). 447

Figure G.38: Effect of firing rate and AFCBA on duct burner performance (Mix-2/2,

Cap-4, Cone-3 and Sh3) 447 
Figure G.39: Effect of firing rate and AFCBA on duct burner performance (Mix-2/2, Cap-4, Cone-3 and Sh8)

Figure G.40: Effect of firing rate and AFCBA on duct burner performance (Mix-1/2,

Cap-2, Cone-1 and Sh1) 448

Figure G.41: Effect of firing rate and fuel caps on duct burner performance, for burner configuration; (Mix-1/2, Cone-1 and Sh2 at AFCBA $=0^{\circ}$ )

Figure G.42: Effect of firing rate and fuel caps on duct burner performance, for burner configuration; (Mix-1/2, Cone-2 and Sh2 at AFCBA $=0^{\circ}$ )

Figure G.43: Effect of firing rate and fuel caps on duct burner performance, for burner configuration; (Mix-1/2, Cone-3 and Sh2 at $\mathrm{AFCBA}=0^{\circ}$ )

Figure H.1: Comparisons between the mass flow rate results for the burner geometry

(Mix-1/2, Cone-3, ap-4, Sh3 at AFCBA $=40^{\circ}$ )

Figure H.2: Comparisons between the mass flow rate results for the burner geometry

(Mix-1/2, Cone-1, Sh4, Cap-4 at AFCBA $=0^{\circ}$ ). 


\section{List of Symbols}

\section{Nomenclature}

\begin{tabular}{|c|c|}
\hline$A$ & Area \\
\hline$a$ and $a 1$ & Constants used for methane mole fractions (Eq. 4.1 and 4.2) \\
\hline$A_{\text {cone }}$ & Conical burner surface area (Figure 4.15) \\
\hline$A D I$ & Acquired data image (Eq. 5.2) \\
\hline$A I_{F F I}$ & Average light intensity of the flat field image (Eq. 5.2) \\
\hline$A R$ & Area ratio (Figure 4.7) \\
\hline$A R_{\text {diff }}$ & Diffuser area ratio (Figure 4.7) \\
\hline$A s w$ & Swirler area (Eq. 4.22) \\
\hline$b$ & Systematic error \\
\hline$b_{i}$ & Individual systematic error \\
\hline$b 1$ and $b 2$ & Constants used for gaseous mole fractions (Eq. 4.1 and Eq. 4.2) \\
\hline$B G I$ & Background image (Eq. 5.2) \\
\hline$B R$ & Blockage ratio \\
\hline$C$ & Carbon \\
\hline$C 1, C 2, C 3 \& C 4$ & Velocity distribution constants (Eq. 4.15) \\
\hline$c$ and $c 1$ & Constants used for gaseous mole fractions (Eq. 4.1 and Eq. 4.2) \\
\hline$C_{b}$ & Blade length \\
\hline$C d$ & Discharge coefficient \\
\hline$C F M($ actual $)$ & Actual air supplied flow rate $[\mathrm{cfm}]$ (Eq. 5.3) \\
\hline CFM(setting) & Flow control unit operator setting value [cfm] (Eq. 5.3) \\
\hline$C I$ & Corrected image (Eq. 5.2) \\
\hline$C_{P}$ & Specific heat at constant pressure \\
\hline$D$ and $d$ & Diameter \\
\hline
\end{tabular}




$\begin{array}{ll}d 1 \text { and } d 2 & \text { Constants used for gaseous mole fractions (Eq. 4.1 and Eq. 4.2) } \\ D B & \text { Duct burner } \\ D B \Delta P & \text { Overall duct burner pressure drop } \\ D C I & \text { Dark charge frame (Eq. 5.2) } \\ \Delta P & \left.\text { Pressure drop [Pa or in } \mathrm{H}_{2} \mathrm{O}\right] \\ E & \text { Activation energy (Eq. 4.14) } \\ E_{\text {oxid }} & \text { Excess oxidant } \\ f & \text { Constant used for gaseous mole fraction (Eq. 4.1 and Eq. 4.2) } \\ f_{\text {pipe }} & \text { Pipe friction factor (Figure 4.8) } \\ F F I & \text { Flat field image (Eq. 5.2) } \\ F R & \text { Firing rate } \\ H_{p r o d} & \text { Enthalpy of the products (Eq. 4.9) } \\ H_{r e a c t} & \text { Enthalpy of the reactants (Eq. 4.9) } \\ \bar{h} & \text { Enthalpy of the gas at the reaction temperature (Eq. 4.9) } \\ \bar{h}_{f} & \text { Enthalpy of formation (Eq. 4.9) } \\ \bar{h}_{\circ} & \text { Reference enthalpy of the reaction (Eq. 4.9) } \\ H B V & \text { Homogeneous burning velocity (Eq. 4.14) } \\ H H V & \text { Fuel higher heating value } \\ I & \text { Light intensity } \\ J & \text { Momentum flux ratio } \\ K & \text { Constant of proportionality (Eq. 4.14) } \\ k 1 & \text { Pressure drop constant (Eq. 4.18) } \\ k 2 & \text { Dength } \\ L 1 \text { to } L 6 & \text { Duct burner housing components lengths (Figure 4.6) } \\ L_{d i f f} & \end{array}$




\begin{tabular}{|c|c|}
\hline$L H V$ & Fuel lower heating value \\
\hline$m$ & Mean value \\
\hline$m_{\text {act }}\left(m_{\text {soich }}\right)$ & Actual mole fraction of oxidant used in the combustion process \\
\hline$m_{f}$ & Mean of the fuel concentration in 2D plane. \\
\hline$m_{\text {stoich }}$ & Stoichiometric mole fraction of oxidant used in combustion \\
\hline$\dot{m}$ & Mass flow rate \\
\hline$\dot{m}_{\text {cone }}$ & Conical burner mass flow rate (Figure 4.2 ) \\
\hline$\dot{m}_{\text {bypass }}$ & DB annular passage (bypass) mass flow rate (Figure 4.2) \\
\hline$\dot{m}_{\text {exit }}$ & Duct burner exit mass flow rate (Figure 4.2) \\
\hline$\dot{m}_{\text {fuel }}$ & Fuel mass flow rate \\
\hline$\dot{m}_{\text {oxid }}$ & Oxidant mass flow rate $=\dot{m}_{\text {total }}$ total flow rate \\
\hline$\dot{m}_{\text {flow }}$ & Mainstream mass flow rate (air (LSI) or oxidant) \\
\hline$\dot{m}_{\text {jet }}$ & Fuel jet mass flow rate (seeded air, LSI) \\
\hline$M M R$ & Momentum ratio (Eq.5.1) \\
\hline$M R$ & Mass ratio \\
\hline$M R_{C F}$ & Cold flow test mass ratio \\
\hline$M R_{L S I}$ & LSI test mass ratio (Eq. 5.8) \\
\hline$N$ & Number, (number of measurements \\
\hline$N_{b}$ & Number of blades \\
\hline$n_{\text {prod }}$ & Products component mole fractions (Eq. 4.10) \\
\hline$n_{\text {react }}$ & Reactants component mole fractions (Eq. 4.10) \\
\hline$P_{\text {dist }}$ & Penetration distance (Eq. 4.24, Figures 4.13 and 5.16) \\
\hline$P R$ & Penetration ratio (Figure 5.16) \\
\hline
\end{tabular}




$\begin{array}{ll}Q & \text { Heat transfer } \\ \dot{Q}_{\text {int }} & \text { Combustion intensity }\left[\mathrm{kW} / \mathrm{m}^{2}\right] \\ R & \text { Radius } \\ r & \text { Radial position } \\ \mathrm{Re} & \text { Reynolds number (Figure 4.8) } \\ R h & \text { Inner swirl radius or hub radius } \\ R o & \text { Outer swirl radius } \\ R u & \text { Universal gas constant [8.3145 kJ/ kmol K] } \\ S & \text { Swirl number (Eq. 4.16) } \\ S_{b} & \text { Spacing between blades } \\ T & \left.\text { Temperature [ }{ }^{\circ} \mathrm{C}, \mathrm{K}\right] \\ t & \text { Thickness } \\ t_{\varepsilon, P} & \text { T-estimator, statistics (Eq. D.7) } \\ T_{\text {cold }} & \text { Conical burner cold surface temperature (upstream surface) } \\ T_{c z} & \text { Combustion zone temperature } \\ T_{\text {exhaust-1 }} & \text { Exhaust gases temperature point measurement (Location 19, } \\ & \text { Figure 4.17) } \\ T_{\text {exhaust-1-traverse }} & \text { Exhaust gases temperature, traverse measurement (Location } \\ T_{\text {exhaust-2 }} & \text { 19, Figure 4.17) } \\ T_{\text {flame }} & \text { Exhaust gases temperature, point measurement (Location 20, } \\ T_{\text {hot }} & \text { Figure 4.17) } \\ T_{\text {inlet }} & \text { Flame temperature } \\ T_{\text {premixer }} & \text { Conical burner hot surface temperature (downstream surface) } \\ & \end{array}$


$T_{\text {premixer-traverse }}$

$T_{\text {shield }}$

$T_{u m}$

$U_{\text {rand }}$

$U_{\text {total }}$

$U_{s y s}$

$u_{s y s_{i}}$

$u$ calib

$u_{\text {Fit }}$

Uo

$U x$

$V$

$\dot{V}_{\text {ol }}$

$V R$

$W$

$w$

$X$

$X i$

$x 1, x 2, x 3, x 4$ and $x 5$
Premixer exit temperature (mixture, traverse measurement)

Conical burner shield outer surface temperature

Unburned mixture temperature

Random uncertainty

Total uncertainty

Systematic uncertainty

Individual systematic error sources

Manufacturer transducer uncertainty (error)

Uncertainty in using the curve fit equation

Constant value used to normalize the unmixedness (Eq. 5.7)

Unmixedness (Eq. 5.4)

Fluid velocity

Volumetric flow rate

Velocity ratio

Width

Tangential velocity

Horizontal distance

Individual measurement

Constants used for gaseous mole fractions (Eq. 4.1 and Eq. 4.2)

\section{Subscripts}

1

2

$a c t$

an

$a v$
Inlet condition

Exit condition

Actual

Annular

Average 


$\begin{array}{ll}b & \text { Blade } \\ \text { calib } & \text { Calibration } \\ \text { Fit } & \text { Curve fit } \\ B H & \text { Burner housing } \\ C B & \text { Conical burner } \\ C F & \text { Cold flow } \\ \text { cold } & \text { Cold (cold surface of the wire-mesh burner) } \\ \text { cone } & \text { Conical burner } \\ c z & \text { Combustion zone } \\ \text { diff } & \text { Diffuser } \\ \text { diff }- \text { inlet } & \text { Inlet diffuser section (burner housing) } \\ \text { diff }- \text { exit } & \text { Exit diffuser section (burner housing) } \\ \text { dist } & \text { Distance } \\ \text { exit } & \text { DB exit (Figure 4.2) } \\ \text { exhaust }-1 & \text { Exhaust - location 1 } \\ \text { exhaust }-1-\text { traverse } & \text { Exhaust - location 1, traverse measurements } \\ \text { exhaust }-2 & \text { Exhaust - location 2 } \\ f & \text { Fuel } \\ \text { FFI } & \text { Flat field image } \\ \text { flow } & \text { Mainstream flow } \\ \text { fuel.pipe } & \text { Fuel pipe } \\ h & \text { Hub } \\ \text { hole } & \text { Hole (eight holes at each fuel cap) } \\ \text { hot } & \text { Hot (hot side of the conical burner) } \\ \text { inlet } & \text { DB inlet (Figure 4.2) } \\ \text { int } & \text { Intensity } \\ \text { jet } & \text { Fuel jets } \\ \end{array}$




\begin{tabular}{|c|c|}
\hline local & Local (Eq. 4.8) \\
\hline$L S I$ & Laser sheet illumination \\
\hline $\max$ & Maximum \\
\hline mesh & Conical burner wire-mesh \\
\hline $\operatorname{mix}$ & Mixing \\
\hline$M T$ & Microturbine \\
\hline nozzle & Nozzle or orifice \\
\hline$o$ & Outer \\
\hline$O V-a c t u a l$ & Overall actual (Eq. 4.5) \\
\hline oxid & Oxidant \\
\hline pipe & Stainless steel pipes (DB housing and premixer) \\
\hline pipe -2 & Pipe number 2 (burner housing) \\
\hline pipe-5 & Pipe number 5 (burner housing) \\
\hline premixer & Premixer \\
\hline prod & Products of combustion \\
\hline rand & Random \\
\hline react & Reactants \\
\hline ref & Reference \\
\hline shield & Conical burner shield \\
\hline stoich & Stoichiometric \\
\hline$s w$ & Swirler \\
\hline$s w-e f f$ & Effective swirler \\
\hline sys & Systematic \\
\hline() & Mole basis property \\
\hline
\end{tabular}

Greek Symbols

$\alpha$

Diffuser half angle (Figure 4.7) 
Diffuser loss coefficient

Dynamic viscosity $[\mathrm{kg} / \mathrm{m} \mathrm{s}$ ] (Figure 4.8)

$\varepsilon$

Degree of freedom

$v$

Kinematic viscosity $\left[\mathrm{m}^{2} / \mathrm{s}\right]$

$\phi$

Equivalence ratio

$\psi$

Absolute roughness (Figure 4.8)

$\rho$

Fluid density

$\theta$

$\sigma$

Swirler blade angle

Standard deviation ( $\sigma^{2}$ is the variance)

$\sigma_{f}$

$\eta$

$\eta_{m i x}$

Standard deviation of the fuel concentration in $2 \mathrm{D}$ plane

Efficiency and effectiveness

Mixing effectiveness

\section{Abbreviation}

$3 \mathrm{D}$

AFCBA

Bldg

BMS

CCHP

CFD

CHP

CVP

DG

DB

DBHOS

EGT

FR
Three-dimensional

Annular flow control blade angles

Building

Burner Management System

Combined cooling heating and power

Computational fluid dynamics

Combined heat and power (co-generation)

Counter-rotating vortex pair

Distributed generation

Duct burner

Duct burner housing outer surface

Exhaust gases temperature

Firing rate 


$\begin{array}{ll}\text { F. S. } & \text { Full scale } \\ \text { G } & \text { Generator } \\ \text { GB } & \text { Green button } \\ \text { GL } & \text { Green light } \\ \text { HBV } & \text { Homogenous burning velocity } \\ \text { HRS } & \text { Heat recovery system (Figure 2.2) } \\ \text { ICCD } & \text { Intensified charge coupled device } \\ \text { ID } & \text { Inner diameter } \\ \text { IR } & \text { Ingersoll-Rand } \\ \text { Loc } & \text { Location } \\ \text { LP } & \text { Lean-premixed } \\ \text { LSI } & \text { Laser sheet illumination } \\ \text { LSV } & \text { Laser sheet visualization } \\ \text { Max } & \text { Maximum } \\ \text { MGT } & \text { Maximum gas temperature (Figure 2.3) } \\ \text { Min } & \text { Minimum } \\ \text { MMT } & \text { Maximum matrix temperature (Figure 2.3) } \\ \text { MIT } & \text { Mixture inlet temperature (Figure 2.3) } \\ \text { MW } & \text { Molecular weight } \\ \text { N } & \text { Number } \\ \text { N. G. (or NG) } & \text { Natural gas (methane) } \\ \text { NDIA } & \text { Non-dispersive infrared absorption } \\ \text { OD } & \text { Outer diameter } \\ \text { PB } & \text { Pushbutton } \\ \text { PC } & \text { Personal computer } \\ \text { PI } & \text { Princeton instruments } \\ \text { ppm } & \text { Parts per million } \\ \text { RB } & \text { Read button } \\ \text { RL } & \text { Read light } \\ & \end{array}$


SS

$\mathrm{TC}$

$\operatorname{Tr}$

UV

WL
Stainless steel

Thermocouple

Transducer

Ultraviolet

White light 


\section{CHAPTER 1: Introduction}

\subsection{Introduction}

Air pollution and climate change have been identified as global environmental problems. As a result, government regulations worldwide are becoming more stringent. This has led to an urgent need to develop new designs and methods for improving combustion systems to minimize emissions, such as nitrogen oxides (NOx $=\mathrm{NO}+\mathrm{NO}_{2}$ ). Reduction of NOx emissions is necessary to control smog, acid rain, ozone depletion and greenhouse-effect warming [Bowman (1992)]. One of the areas of rapidly growing importance in mechanical engineering is that of the combined production of heat and power (CHP), which is also known as cogeneration. Microcogeneration units which use microturbines as a prime mover are one of the interesting alternatives for CHP. In this thesis, the term micro-CHP is used to mean the same as micro-cogeneration. This type of unit can promote the shift from large, centralized plants to small-scale, environmentally friendly and economical on-site generation plants (using waste heat and adding new capacity without new transmission lines). The advantages of the small-scale CHP units are particularly attractive to building owners, retail establishments, commercial and light industrial facilities, etc. Efficient utilization of waste heat can easily double the overall efficiency of a micro-CHP system [Lagerstrator, et al. (2002), Meherwan, et al. (2002)]. However, micro-cogeneration technology still needs to be developed to increase their unit efficiencies.

The present thesis attempts to assist in the improvement of the technology in this wide area of research. This work focuses on the design and analysis of a natural gas-fired wire-mesh duct burner (DB) which is integrated with a microturbine cogeneration system. The DB allows supplementary firing to increase and control the thermal output of the micro-cogeneration system. While supplementary firing technology is well known for large-scale CHP systems, it has not been applied to 
micro-CHP systems which are currently drawing interest as a modern distributed power generation scheme. The following sections briefly describe the main goal of the study and the thesis outline.

\subsection{Scope of the thesis}

In this study, a micro-cogeneration system based on a recuperated microturbine engine as a prime mover was used. The present work seeks to provide this microturbine system with a practical and simple supplementary firing unit (hereafter referred to a duct burner) designed to provide near perfect premixing and low emissions. A lean-premixed surface combustion technique utilizing a conical wiremesh burner was used to produce low NOx emissions. This novel natural gas-fired burner increases the quantity and quality of the thermal output (exhaust heat) of the micro-CHP system to improve its heat recovery capability. As well, it maintains the low level of NOx (less than $10 \mathrm{ppm}$ ) emissions produced by the microturbine. The duct burner was designed and manufactured for installation in the exhaust gases duct of an existing recuperated microturbine within a micro-cogeneration unit (namely, a MT70 kW Ingersoll Rand (IR) CHP unit). The experimental work consisted of an extensive parametric study of the performance of the wire-mesh duct burner, including the effect of different operation and geometry variables on $\mathrm{NOx}$ and $\mathrm{CO}$ emissions, pressure loss across the DB and flame stability. The effects of variables such as firing rate, excess oxygen, equivalence ratio, static mixers, fuel nozzles, cones and cone shields will be discussed in Chapter 8 .

\subsection{Thesis outline}

This thesis is organized as follows. Chapter 1 provides an overview as well as the outline for the present thesis. Literature which is relevant to the main topic of this thesis is reviewed in Chapter 2. This covers the literature background for CHP technology, microturbine technology, CHP with duct burners, NOx formation and 
different types of burners (including experimental and theoretical studies). The motivations and detailed objectives as well as the different phases of the present thesis are described in Chapter 3. Chapter 4 discusses the first phase of the study (namely, the duct burner design process) and gives a full description of each component of the wire-mesh duct burner (test rig). Chapter 5 describes details of the flow visualization technique used to study the mixing process inside the duct burner premixer (namely, Laser Sheet Illumination (LSI)). This chapter covers the description of the LSI test rig and its components (laser, optics and camera), the premixer geometry, the method developed to evaluate each geometrical combination of premixer and fuel nozzle. The chapter also includes sections for results, discussion and conclusions. Chapter 6 covers the description of the microturbine test facility and the cold flow tests (also referred to as flow balancing tests) performed in the microCHP unit. Cold flow testing is used in this thesis to mean that the microturbine is running, but the DB is not operating. During cold flow testing, the flow control blades were varied and the amount of oxidant flowing through the wire-mesh burner for surface combustion was measured. Chapter 6 also describes the procedure used for the velocity pressure measurements conducted at the duct burner inlet and annular passage region. The overall duct burner pressure drop during cold flow measurements are also presented in this chapter. Chapter 7 covers the description of the microturbine test facility components (e.g. fuel system) and the instrumentation used during the combustion tests. This chapter also describes the test and the operating procedures used. Chapter 8 covers the combustion tests performed in the micro-CHP unit for this investigation. The goal of these experiments was to establish the DB characteristics, including the effects of variables such as firing rate, excess oxidant, equivalence ratio, conical burner pressure drop, and the different geometrical parameters, on flame stability and pollutant emissions. Chapter 8 also provides a comparison between the results obtained from LSI measurements and from the combustion tests, regarding mixing effectiveness of the duct burner premixer. Finally the major conclusions and contributions of this study are provided in Chapter 9. 


\section{CHAPTER 2: Background and literature review}

\subsection{Introduction}

This chapter contains background information and a literature review covering the main points of interest in this thesis. The review is divided into the following sections; (1) Distributed generation, (2) Microturbine technology and applications, (3) Supplementary firing in cogeneration systems, (4) Surface combustion concept, (5) Lean-premixed combustion and NOx formation (an extended review is presented in Appendix A), and finally (6) Swirl flow.

Excess enthalpy combustion, radiant and surface combustion burners are reviewed in Appendix B. However, a number of references that are particularly relevant to the research are discussed in more detail in the presentation of the results within the thesis.

\subsection{Distributed generation and micro-cogeneration units}

Standard power plants generate electricity and emit heat as a byproduct. These power stations convert about one-third of the energy in the fuel into electricity and the remaining two-thirds are lost in the form of exhaust heat. Traditional power plants are inefficient, expensive and emit large amounts of pollutants such as $\mathrm{NOx}, \mathrm{CO}_{2}$ and $\mathrm{SO}_{2}$, into the environment [Munson et al. 1998]. Cogeneration, on the other hand, is a more efficient and clean method of producing electricity. Cogeneration involves the generation of electricity combined with the productive use of the waste heat from the combustion process using the same primary fuel [Meherwan et al. (2002)]. This type of total energy system is built on the basis of the energy cascade utilization principle in which the waste heat created as a byproduct of power generation is used to perform additional heating or cooling tasks. Therefore, the shift from conventional power plants to CHP systems that co-generate power and thermal energy will save energy, thereby reducing energy costs and pollutant emissions. In addition, it is possible to 
improve the traditional CHP cogeneration system by integrating a duct burner to improve and control the system thermal output. These supplementary fired cogeneration systems will be reviewed later in this chapter. Detailed information on different types of power generation and their application in cogeneration systems is available in ASHRAE (1999).

\subsubsection{Distributed generation}

Distributed generation (DG) refers to the method of generating electricity from small-scale generating facilities that are located close to the end-user (also referred to as on-site generation) [Chiradeja et al. (1998), Kreider (2006)]. CHP distributed generation systems consist of four basic elements; (1) a prime mover (small-scale generating devices (engines)), (2) an electrical generator, (3) a heat recovery system and (4) a control system. The prime mover drives the electrical generator and usable heat is recovered. These CHP systems can be classified with respect to the prime movers used. Depending on the site requirements, CHP systems can be powered by both conventional and renewable energy sources. Technologies that use conventional energy sources are gas turbines, microturbines, internal combustion engines and fuel cells. Some of the new technologies that utilize renewable energy sources in distributed generation are wind-turbines, biomass systems and solar systems. The use of small-scale distributed cogeneration plants using a small gas turbines as a prime mover, or what is known as a recuperated microturbine, is one of the applications actively being pursued by the industry [Lin et al. (2004), Sarvanamutto (2001)].

In the literature, there are several definitions used to differentiate between the micro-cogeneration systems and small-scale cogeneration systems. The type of prime mover used is often ignored and the differentiation is based solely on the system capacity. For example, in Simader (2006), the term micro-cogeneration means a 
cogeneration unit or system with a maximum capacity of less than $50 \mathrm{~kW}$ and the term small-scale cogeneration is used for systems with a capacity below $1 \mathrm{MW}$.

For the purposes of this thesis, the term micro-cogeneration or micro-CHP will be used to refer to the small-scale cogeneration units in the range of 30 to 500 $\mathrm{kW}$ which use a microturbine as a prime mover. Therefore the micro-cogeneration system is a unit which has a recuperated microturbine, works as an electricity generator and is equipped with a heat exchanger to recover waste heat. The combined generation of electricity and the use of the waste heat energy reduce energy cost and cuts greenhouse gas emissions. These CHP units can operate in grid-parallel mode or as standalone units. These advantages are more attractive to building owners, retail establishments, and commercial and light industrial facilities.

\subsubsection{Micro-cogeneration technology}

In recent years, microturbines have been developed as one of the best shortterm distributed generation options because of their simplicity, their ability to use a wide variety of fuels (e.g., natural gas, diesel, propane, biogas, flare gas) and their low emissions. Due to global warming, high gasoline prices and the environmental constraints placed on the different types of power plants, the microturbine has become the preferred scheme for power generation in the newer small power stations worldwide [Lin et al. (2004)]. The world would benefit from the availability of these packaged distributed generation units as small traditional cogeneration systems in diverse locations such as hotels, hospitals, universities, commercial and light industrial facilities, farms and government buildins. The typical performance of microturbine-based distributed generation units is 65 to over 95 percent for the overall efficiency (CHP), and 15 to 33 percent for the power generation efficiency [Kreider (2006), Shibata et al. (2001)]. Many projects using micro-CHP units have been successfully introduced to different applications in different countries. Further 
details on these projects in Canada, the USA and England are discussed in the application section in this chapter.

There are many companies around the world currently working on microturbines. To understand the state of the industry, an overview of some of the best known active companies working in the development of the micro-cogeneration systems will be summarized in this section. Table 2.1 lists different microturbine (integrated CHP) technologies available in the market and gives some of their performance characteristics.

Table 2.1: Different microturbine technologies

\begin{tabular}{|c|c|c|c|c|c|c|}
\hline $\begin{array}{c}\text { Company } \\
\text { name }\end{array}$ & Model & {$[\mathrm{kW}]$} & $\begin{array}{c}\begin{array}{c}\text { Electric } \\
\text { efficiency }\end{array} \\
{[\%]}\end{array}$ & {$\left[{ }^{\circ} \mathrm{C}\right]$} & [dB] & $\begin{array}{c}\text { Emission, } \\
\text { NOx and CO } \\
{\left[\begin{array}{ll}15 \% & \mathrm{O}_{2}\end{array}\right]}\end{array}$ \\
\hline \multirow{3}{*}{$\begin{array}{l}\text { Capstone } \\
\text { Turbine } \\
\text { Corporation }\end{array}$} & C30 & 30 & 26 & 275 & $65 @ 1 \mathrm{~m}$ & $<7$ ppmv NOx \\
\hline & C60 & 65 & 29 & 300 & $65 @ 1 \mathrm{~m}$ & $<7$ ppmv NOx \\
\hline & $\mathrm{C} 200$ & 200 & 33.5 & -- & & $<7$ ppmv NOx \\
\hline \multirow[t]{2}{*}{$\begin{array}{l}\text { Ingersoll- } \\
\text { Rand Energy } \\
\text { System }\end{array}$} & MT70 & 70 & 29 & 232 & $\begin{array}{l}78 @ 1 \mathrm{~m} \\
58 @ 10 \mathrm{~m}\end{array}$ & $\begin{array}{l}<5 \text { ppmv NOx } \\
<9 \text { ppmv CO }\end{array}$ \\
\hline & MT250 & 250 & 30 & 242 & $\begin{array}{l}77-85 @ 19 \\
1 \mathrm{~m}\end{array}$ & $\begin{array}{l}<5 \text { ppmv NOx } \\
\& \mathrm{CO}\end{array}$ \\
\hline $\begin{array}{l}\text { Bowman } \\
\text { Power }\end{array}$ & TG -80CG & 80 & 26 & 260 & $70 @ 1 \mathrm{~m}$ & 25 ppmv NOx \\
\hline $\begin{array}{l}\text { Elliott Energy } \\
\text { Systems }\end{array}$ & TA-100 & 100 & 29 & 293 & $\begin{array}{l}62 @ 10 \mathrm{~m} \\
75 @ 1 \mathrm{~m}\end{array}$ & $\begin{array}{l}24 \text { ppmv NOx } \\
25 \text { ppmv CO }\end{array}$ \\
\hline Turbec AB & T100 & 100 & 31 & 270 & $65 @ 10 \mathrm{~m}$ & $\begin{array}{l}<10 \text { ppmv } \\
\text { NOx \& } 15 \\
\text { ppmv CO }\end{array}$ \\
\hline Honeywell & Parallon-75 & 75 & 27.5 & 270 & $65 @ 10 \mathrm{~m}$ & $<9$ ppmv NOx \\
\hline References & \multicolumn{6}{|c|}{$\begin{array}{l}\text { Treece (2002), Capstone (2003), Capstone (2005), Ingersoll-Rand (2004), } \\
\text { Bowman Power (2002) and Elliott Energy (2005) }\end{array}$} \\
\hline
\end{tabular}


Capstone Turbine Corporation is one of the leading manufacturers of microturbine generators in the $30 \mathrm{~kW}$ range and up. Their units attain 80 percent as an overall efficiency when utilized for heating and cooling. The company has a 30 $\mathrm{kW}$ unit ( $85 \mathrm{~kW}$, thermal energy) and a $65 \mathrm{~kW}$ unit (120 kW thermal energy) [Treece (2002), Capstone (2003), Capstone (2005)]. Recently, the company developed a 200 kW unit in conjunction with the USA Department of Energy's Advanced Microturbine System Program [Capstone (2007)].

Ingersoll-Rand Energy Systems (IR) has developed a $70 \mathrm{~kW}$, and more recently, a $250 \mathrm{~kW}$ micro-cogeneration unit. The latter is currently the largest commercially available microturbine in the USA. The IR $250 \mathrm{~kW}$ unit design is "scaled down" from an existing IR 1.7 MW single-shaft engine [Ingersoll-Rand (2003), Ingersoll-Rand (2004)]. Bowman Power has an $80 \mathrm{~kW}$ unit which has a thermal output of $150 \mathrm{~kW}$ [Bowman Power (2002)]. Elliott Energy Systems, Inc. developed a micro-CHP system capable of producing $100 \mathrm{~kW}$ of electrical energy and $172 \mathrm{~kW}$ of thermal output, and an overall thermal efficiency of 75 percent [Elliott Energy (2005)].

To complete the overview of companies, Allison Energy, JPX of France, Honeywell, Northern Research and Engineering (NREC) and some of the Japanese automotive companies are also working on the development of microturbines, but little information has been released.

\subsubsection{Micro-cogeneration technology}

The concept of microturbine technology is not new. Allison Energy and some Japanese companies began the development of microturbines for the automotive industry as early as 1960 . These microturbines were used in a variety of cars, buses and trucks [Scott (1998), Takase et al. (2002)]. Microturbines evolved from automotive and truck turbochargers, and auxiliary power units for airplanes and small jet engines. These are high-speed power plants, typically with a compressor, a turbine 
and a generator connected on a single shaft. Microturbines use a wide variety of fuels, and have a high reliability, long life cycle, little vibration, and low NOx and CO emissions [Borbely et al. (2001)]. A schematic of a typical microturbine powergenerating cycle is shown in Figure 2.1.

Referring to Figure 2.1, filtered air is drawn into the microturbine through the air intake by the compressor. The compressed air enters the recuperator, where it is heated up to about the turbine exhaust gas temperature (the added heat reduces the amount of fuel required to raise the air temperature to that required by the microturbine combustor). The heated compressed air then passes into the combustor and is burnt with the fuel (typically natural gas). The hot exhaust gases are expanded through a turbine, which drives the compressor and electrical generator. The exhaust gases leaving the recuperator at a temperature close to the compressor discharge temperature enter the cogeneration heat exchanger where much of the remaining energy is extracted as the thermal output. Finally, the exhaust gases are vented directly to a stack.

Microturbines without a recuperator (simple cycle) operate at efficiencies of 14 to 16 percent. The addition of a recuperator to the cycle results in an increase in overall electric efficiency to 28 to 33 percent. As a gas turbine, the performance of the microturbine is sensitive to changes in ambient conditions. Also comparing the microturbine to the large-scale gas turbines, the efficiency of a small gas turbine is usually much lower than that of a larger engine because of the limitation on the turbine inlet temperature and the lower component efficiencies [Meherwan et al. (2002)]. Although the cycle efficiency of a microturbine in a micro-CHP system is low, the exhaust gases have heat quality that can be used for different applications. The exhaust gas characteristics at the recuperator exit are shown in Figure 2.1.

Microturbine manufacturers desire significant mass production of standardized packages for decentralized generation technologies. This will lower the cost and enhance competitiveness of these devices in cogeneration applications. The heat produced by a microturbine can be used to produce low-pressure steam or hot 
water, and for some applications, for cooling using absorption chiller technology. Thus, these units are well suited to provide heat and electricity to small commercial applications. Also microturbines can be used for backup power for public utilities and commercial applications, as well as providing options for peak shaving. Microturbines provide a high overall efficiency of up to 95 percent with heat recovery. The disadvantages include relatively low electrical efficiencies of 20 to 33 percent and a performance sensitive to changes in ambient conditions.

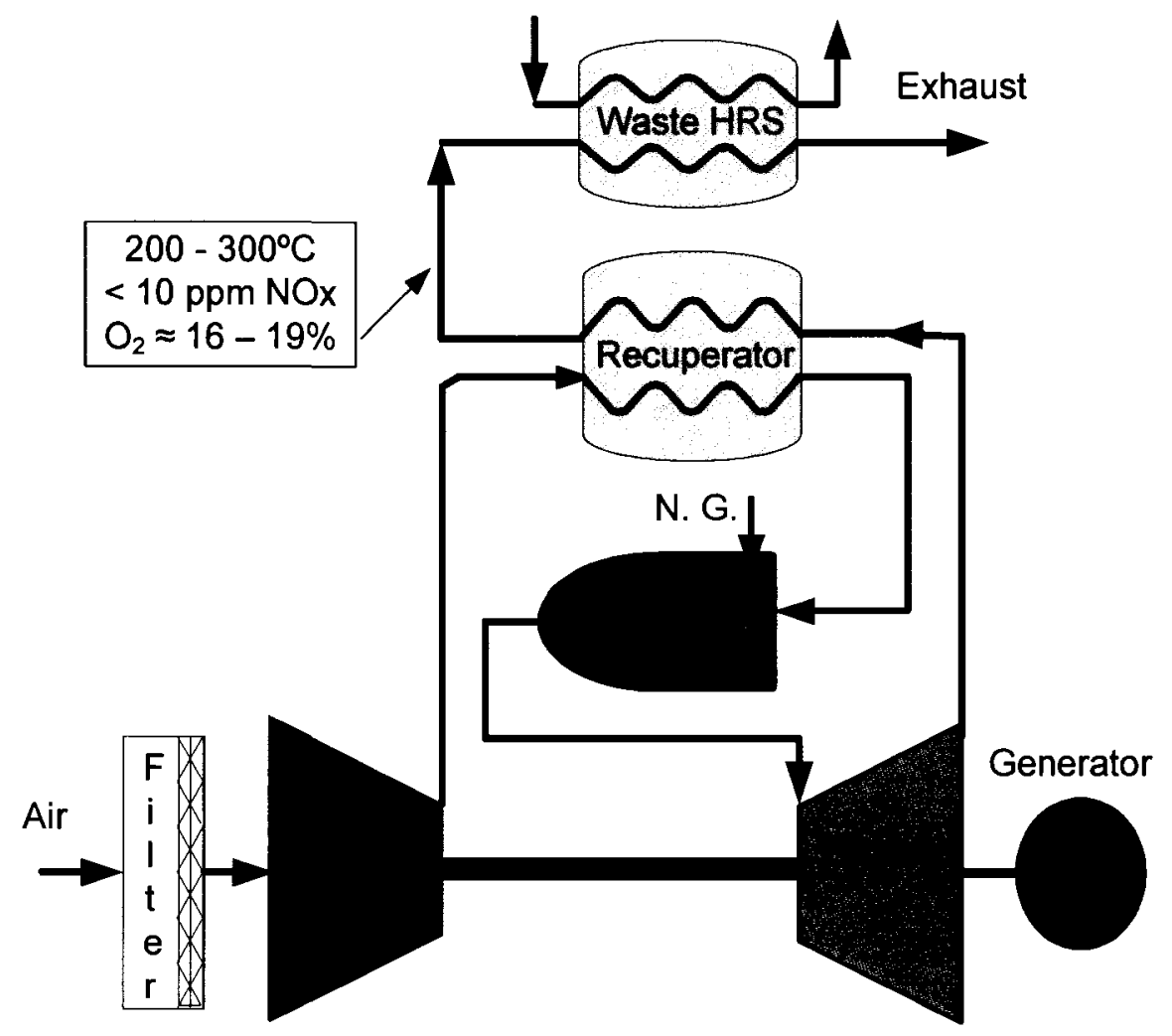

Figure 2.1: Microturbine power generation cycle 


\subsubsection{Application of micro-cogeneration units}

Microturbine cogeneration units are an environmentally friendly, economically sensible way to produce heat and power, and reduce total pollutant emissions. Nearly all of the unused heat from the microturbines goes into the turbine exhaust. This amount of energy available in the exhaust gases can be used as an energy source for other systems. Heat recovery via the combined heat and power installation is the key to improve the overall efficiency of the system. Directing the exhaust gases to a liquid heat exchanger or a small waste-heat boiler allows the best use of the available thermal energy for water heating, space heating and process water heat. The exhaust heat could also be used in a cooling system such as an absorption chiller. Figure 2.2 shows the conceptual representation of the application of microCHP systems. Nowadays, micro-CHP systems are used in many places around the world. Some of the more successful micro-CHP applications will be discussed briefly in this section.

Trends in the micro-CHP applications are towards the development of a complete (also referred to as packaged, integrated or standalone) cogeneration system. This will result in a better recovery of heat and easier integration with different cooling systems. This provides an overall net energy cost saving and a more efficient system.

One of the applications tested in the USA is the combined cooling heating and power (CCHP) package called the Pure-Comfort system at the Ritz-Carlton Hotel [USA Department of Energy (2005)]. In this application four $60 \mathrm{~kW}$ Capstone microturbines exhaust into a common manifold which is directed towards a doubleeffect chiller and produces $240 \mathrm{~kW}$ of electricity. The CCHP system allows the hotel to generate its own electric power and use the rejected heat from the turbine to run an absorption chiller or a heat recovery boiler to handle the possible cooling or heating loads. 
Harbec Plastics (New York, USA) has installed an array of 25 Capstone 30 $\mathrm{kW}$ microturbines to improve the power supply reliability as a standalone system at their plastic manufacturing facility. The array of microturbines was integrated with four Unifin heat exchangers and a 200 Ton Carrier absorption chiller. The system improves its overall efficiency and reliability by utilizing the microturbine exhaust as a thermal source for both facility heating and cooling. The system, as tested, has a total electrical capacity of $750 \mathrm{~kW}$ with an additional heat recovery capability of 1.5 MW [Dugga (2002)].

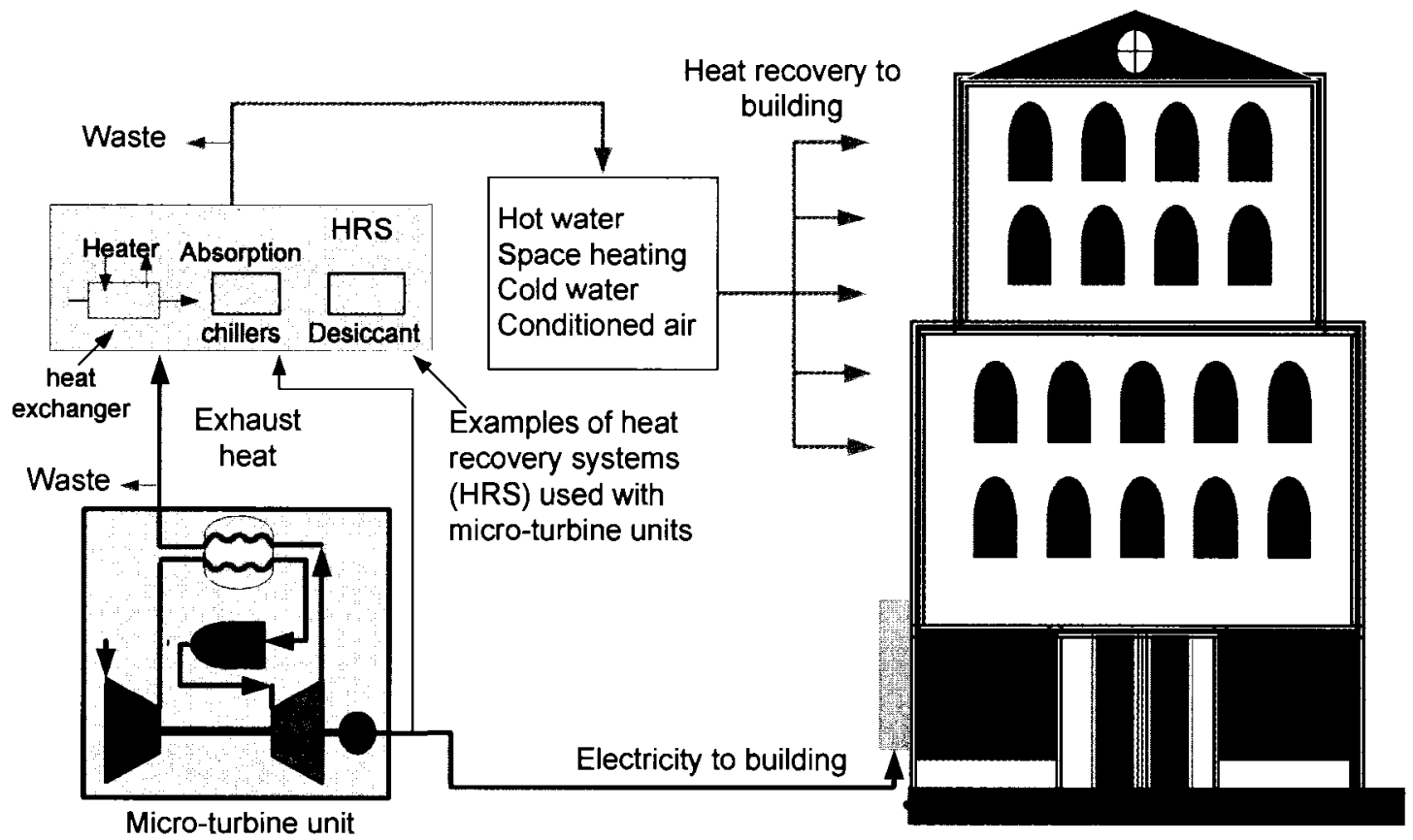

Figure 2.2: Micro-CHP system applications and integration with buildings

As an example from the UK, a TG80CG CHP unit was installed at the Leisure Centre in the London Borough of Enfield. The system was designed to provide 80 $\mathrm{kW}$ of electrical power and $150 \mathrm{~kW}$ of thermal output. The package serves the facilities included in the complex, such as a swimming pool, sports hall, fitness studio and two full-sized synthetic playing fields. The thermal output is also used for heating 
the building and is supplemented by a conventional boiler at times of peak demand [Bowman Power (2002)].

Canada was one of the first countries to adopt microturbines. The CANMET Energy Technology Centre (CETC) started studying micro-CHP applications in 1998. The CETC program concentrated on improving and integrating microturbines with different heat recovery systems to improve the overall efficiency and the heat capability of these units (as a commercial boiler package that produces electricity). Different models of micro-CHP units have been installed and tested in different provinces in Canada [Brandon (2003)]. As an example, a $75 \mathrm{~kW}$ Honeywell microturbine with a Unifin heat exchanger was installed at the Health Canada building in Toronto. Similar devices are used in other buildings in Ottawa and Vancouver. A Capstone $30 \mathrm{~kW}$ microturbine and Mariah CHP were installed and tested at the Tufts Cove power plant in Halifax. As well, there are 25 microturbines in the Calgary oil field operating on flare gas. CETC has also been involved in research and development of thermally activated cooling technologies to use the waste heat from microturbines. CETC is working with commercial suppliers and is also investigating technologies such as jet ejectors, ammonia adsorption chillers and intake air superchargers using evaporative cooling [Brandon et al. (2006)]. Furthermore, many universities around the world are currently studying microturbine applications and testing the reliability of current microturbines. Carleton University is presently working on different projects for the design and development of microturbine technology and its applications. The present thesis is an example of the co-operation between Carleton University and the CANMET Energy Technology Centre to improve the heat recovery capability of micro-CHP units.

In conclusion, microturbines are a new technology. Improvements are continuing to be made in the technology at the same time as more and more applications are being identified for microturbines and integrated micro-CHP 
packages (microturbine and heat recovery system (HRS)). A collection of successful applications, with detailed information, on microturbine cogeneration units all over the world can be found in the following references; [Dugga (2002), Brandon et al. (2006), Brandon (2003), Jennekens (1999), Simader et al. (2001), Anon (2002) and Anon (2004)].

\subsection{Supplementary firing in cogeneration systems}

The gas turbine engine is widely used as the prime mover in large-scale CHP systems. The gas turbine drives a generator, which produces the electricity. The exhaust gases then pass through a recovery heat exchanger which provides heat in the form required by the site (e.g., steam production). Due to the high oxygen content in the exhaust gases of a gas turbine, supplementary combustion of additional fuel to raise the temperature of the exhaust gases can be supported without the addition of extra air. This process is known as supplementary firing. This process can efficiently raise the exhaust gases temperature from around $500^{\circ} \mathrm{C}$ to $1000^{\circ} \mathrm{C}$ or more [Anon (2001)]. Moreover, since the turbine exhaust gas is essentially preheated combustion air, the fuel consumed in supplementary firing is less than that required for a standalone boiler providing the same increment in steam generation, making the supplementary firing highly efficient. Efficiencies of 95 percent or more are typical for supplementary fired systems. NOx emissions in duct burners are relatively low in comparison to ambient air fired burners. This is partially due to lower thermal NOx generation as a result of lower flame temperatures when firing with turbine exhaust gases as an oxidizer. Low NOx duct burners can be used to minimize the $\mathrm{NO}_{x}$ contribution due to supplementary firing.

Several proposals have been made to burn additional fuel, in a proportion of the exhaust gases to improve the heat recovery from CHP systems (large scale). Gjerde (1969) described the use of a duct burner system in which the exhaust gas from a gas turbine is reheated. His duct burner is designed to receive only 40 to 75 percent of the engine exhaust gases flow. Vetterick (1995) addressed the problem of 
high NOx levels that exist in the exhaust of a gas turbine coupled to a heat recovery steam generator with a supplementary duct burner. By bypassing a portion of the gas turbine exhaust to a point downstream of the duct burner in the heat recovery system, and by operating the duct burner in a fuel-rich condition, gas re-burning could be established and NOx from the gas turbine reduced. Many other researchers such as Moreno (1987), Utamura (1998), Weslag (1999) and Vetterick (1999), based their proposals on the oxygen consumption in the turbine combustor and use a duct burner to improve the heat recovery and the efficiency of the system. Froemming (1993), Backlund (1988) and Atallah (2001) presented different applications and the benefits of adding a variety of duct burner designs to an existing gas turbine-based cogeneration plants. These designs include: (1) a waste gas oxidation duct burner, (2) a dual fuel turbine exhaust gases and fresh air, low NOx, duct burner (3) a low pressure coal gas duct burner and (4) a natural gas dual fuel (oil, biogas) duct burner. The application of these burners in gas turbine-based cogeneration plants leads to better control of the system thermal output and a more efficient process (economically improving the steam production).

In summary, supplementary firing directly into the turbine exhaust gases yields important advantages, such as better control of system thermal output, greater process efficiency, ability to burn fuels not suitable for gas turbines, compensation for changing ambient conditions (e.g., inlet air temperature, pressure and humidity), and maintaining a constant level of heat output at lower gas temperatures, reduced lower loads or during gas turbine shut-down [Backlund (1988), Atallah (2001)]. Furthermore, from the above literature reviewed in the CHP cogeneration section and in this section (duct burners), two different problems arise. First, the quantity of exhaust gases available from the turbine is not constant (due to varying ambient and flow conditions), which leads to the need for the use of a duct burner to increase and control the thermal output of the system. Second, when using the duct burner, the fuel added is to be burned under stoichiometric conditions which could increase the production of NOx significantly. 
As micro-cogeneration units use microturbines as a prime mover, they face the same problems as the large-scale CHP units. Micro-CHP exhaust heat is not constant and depends on the ambient conditions and operation mode. This affects the operation of the integrated heat recovery systems and leads to the use of auxiliary systems to overcome this problem (e.g., auxiliary boilers) as a part of the system (increasing capital cost). Micro-CHP technology still needs to be improved to increase the efficiencies of these units. Adding a duct burner to the microturbine CHP system will make the micro-CHP system gain the same benefits as the large-scale fired cogeneration systems. The use of a wire-mesh duct burner as discussed in this thesis responds to the needs for greater efficiency, stable supplementary heat and low NOx performance. This author is not aware of any other examples of the integration of a wire-mesh duct burner with a microturbine cogeneration unit.

From the emissions point of view, as the microturbine cogeneration units are used in sensitive areas (hospitals, hotels, universities, etc.), the added duct burner should use a combustion technology that ensures low NOx and CO emissions. The following section is a review of the combustion technique used in the present thesis: surface combustion technique utilizing a wire-mesh burner.

\subsection{Surface combustion concept}

Surface combustion is a gas-burning technique in which a combustible mixture burns near or within the surface layer of a permeable medium, heating it until it glows and thereby releasing a proportion of the input energy as thermal radiation. Gas-fired radiant burners or what are referred as porous medium burners, are used in a wide range of industrial and commercial boilers and heaters and in other applications (e.g., curing and drying applications). This combustion technique offers special benefits compared to free flame burners (no porous medium). The porous medium burner offers very good flame stability because of the premixed combustion 
process occurs inside or above the surface of the burner. In other words, the porous medium burner is a very good flame holder (see Appendix B for more details).

The flame support layer or porous medium can be made from different materials such as metal wires, metal foils, fibres, ceramic foam, ceramic pebbles and combs. Different materials result in different properties of the porous medium. Material properties of the solid matrix significantly affect its stable operating range [Cerri et al. (2001), Barra (2003)]. Often, the porous medium burner consists of a metal housing, two or more layers of porous material, a plenum chamber, premixer and an ignition system. The porous material layers (diffusion layer) assist in the diffusion of the combustible premixed mixture and as a flame support layer. When the porous medium is made from a fine metal fibre it can be knitted to form a flexible mat, which permits complex burner geometries (cylindrical, conical, etc.).

The wire porous radiant or wire-mesh radiant burners are used in premixed combustion systems. In this type of burner the wire mesh not only acts as support for the flame but acts as a radiating surface. As well, in premixed combustion the different layers of wire mesh also act to prevent flashback. The outer layers are positioned relative to the lower layers such that burning cannot take place behind the outer layers. The outer layers can then be red hot while the inner layers, which serve only to prevent flashback, remain cool. Furthermore, the inner layers in some types of burners are coated so that they reflect back the radiation falling on them.

The flame resulting from the porous medium burner (within or above the fibre mesh) is different from that in free flame combustion because the presence of the solid matrix causes different heat transfer mechanisms (namely, radiative feedback and solid phase conduction). These heat transfer mechanisms create heat recirculation from the combustion products to the reactants (this phenomenon, called excess enthalpy combustion, is reviewed in Appendix B). The advantage of this heat recirculation is that it increases the stable burning rate of a given mixture. Also, it has 
been found that porous medium burners produce lower NOx levels than do free flames [Xiong and Viskanta (1992) and Saracco et al. (1996].

The heat recirculation in these types of burners is a multimode heat transfer effect. The solid, porous material is radiatively active due to the high combustion temperatures, but it also conducts energy. Since the gas is in contact with the medium, there is a convective heat exchange between the solid and the gas. In these burners, depending on the thermo-physical properties of the porous medium (e.g., conductivity, emissivity) and depending on the local momentum of the gaseous mixture introduced through the porous medium, the flame stabilizes within the porous medium (matrix-stabilized), or completely outside and over the burner matrix (surface-stabilized). Figure 2.3 shows the two modes of operation. If the mixture velocity is too low, flashback or flame extinguishments may occur, depending on the operating conditions and the design of the burner [Viskanta et al. (1987)]. If the flame is stabilized within the porous medium then it is said to be in the radiant mode; this regime occurs at low specific power input $\left(\mathrm{kW} / \mathrm{m}^{2}\right)$, low excess air and is characterized by a red-orange glow of the medium. The combustion of the mixture at nearly stoichiometric values occurs completely inside the mesh. As a result, close contact between the combustion gases and the metal fibre maintains the metal at a temperature reaching 800 to $1000^{\circ} \mathrm{C}$ [Saracco et al. (2001)]. Low NOx and high CO emissions are usually expected in this mode of operation. On the other hand, if the flame completely stabilizes outside and over the burner mesh surface (a large part of the combustion process takes place outside the mesh), then it operates in the blue flame mode, this mode occurring at high specific power input and high excess air values is permissible because of the flame stabilizing capacity of the mesh [Saracco et al. (1996), Mohamed (2002)]. In this mode of operation a carpet of blue flames covers the metal matrix, the mesh temperature remains low. Therefore, it produces little radiation and most of the heat released remains in the combustion products. 
Figure 2.4 shows two images from the present investigation. The image on the left-hand side shows an example of the blue flame mode of operation. At higher specific power the flame becomes shorter and combustion zone shifts towards the burner surface and becomes hotter.

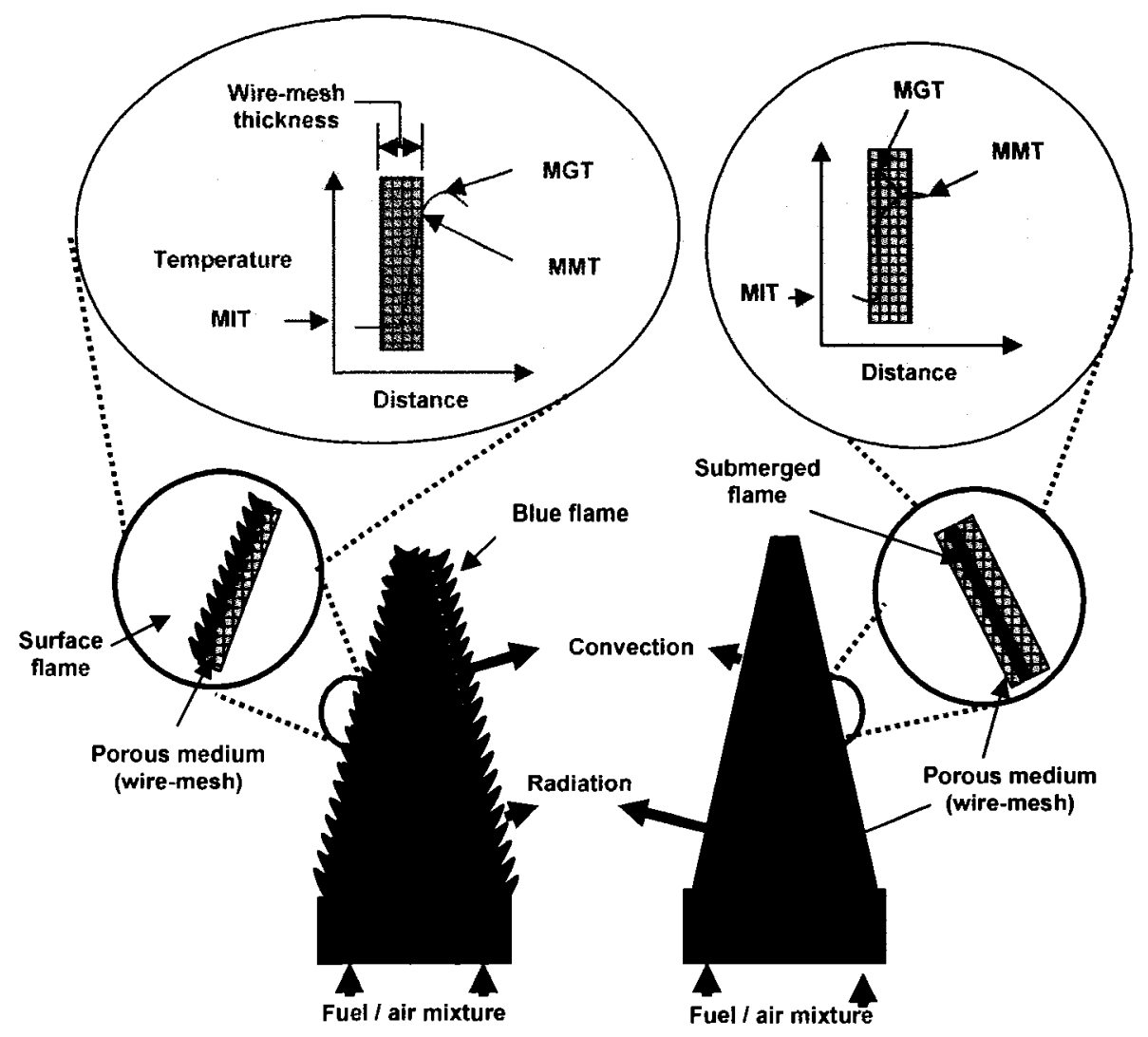

(a) Combustion zone (flame resides just above the burner surface) (Surface stabilized flame)

(b) Combustion zone is trapped completely inside the porous matrix (Matrix stabilized flame)

MGT $=$ Maximum gas temperature

MMT = Maximum matrix temperature

MIT = Mixture inlet temperature

Figure 2.3: Porous burners, (a) Surface-stabilized flame. (b) Matrix-stabilized flame 


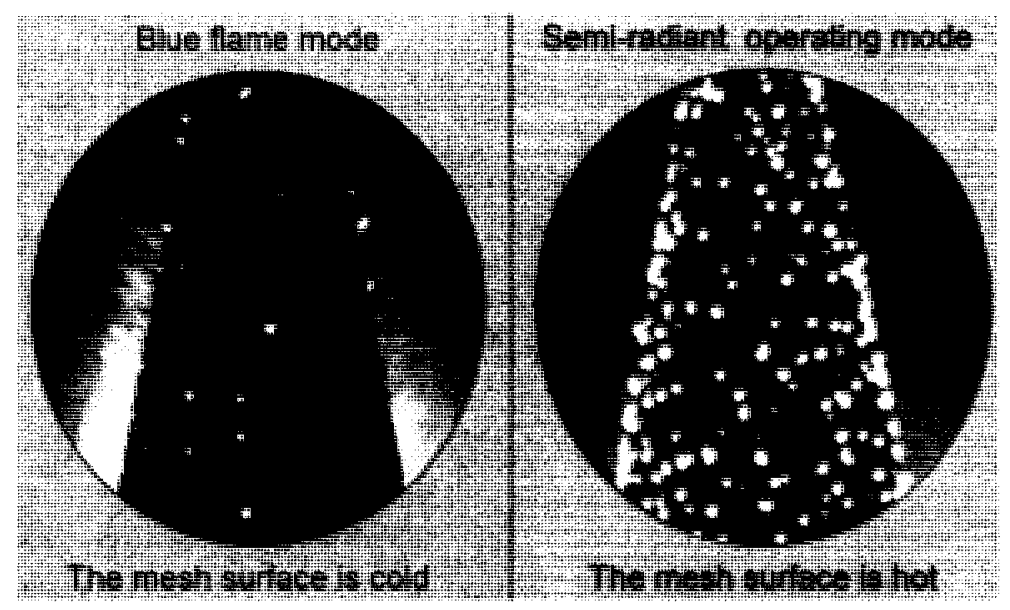

Figure 2.4: Flame images showing two operating conditions (present study)

To achieve low levels of NOx and CO emissions when operating in the blue flame mode, a high firing rate and high excess air (up to 100 percent excess air) is recommended [Saracco et al. (1996), Saracco et al. (1999), Mohamed (2002), Cerri et al. (2000)]. When radiant zones and blue flames simultaneously cover the burner matrix at different locations, this is known as the transition mode [Saracco et al. (1996)].

Almost all mesh burners available in the market today are operating in the radiant mode with low specific input power and low excess air (typically 15 to 25 percent excess air [Cerri et al. (2000)]). From the burner geometry point of view, most of the reviewed work is done (experimentally or numerically) on flat type porous burners. A few numerical simulations are available in the literature, such as the work of Zhdanok, et al. (1998) and of Mohamed (2002) who studied the cylindrical porous burners, in which the fuel-air mixture is forced to flow radially. Greenberg, et al. (2005) reported NOx and CO emissions of surface-stabilized fuel injector of cylindrical shape. To the author's knowledge, there are no experimental data available on porous medium conical burners. 


\subsection{Lean-premixed combustion and NOx formation}

NOx emissions are generated by combustion systems where nitrogen and oxygen are present within a locally high temperature region. The abbreviation NOx is the chemical shorthand for the combined species of $\mathrm{NO}$ and $\mathrm{NO}_{2}$. Much research has been devoted to understanding the mechanisms that affect NOx emissions in laminar and turbulent flames. Miller and Bowman (1989) published a comprehensive review of NOx formation mechanisms. NOx can be formed through many different mechanisms. Appendix A summarizes five main NOx formation mechanisms. Four of the mechanisms are the routes responsible for NOx formation in the combustion of fuels that do not contain nitrogen compounds. Figure 2.5 illustrates the four mechanisms.

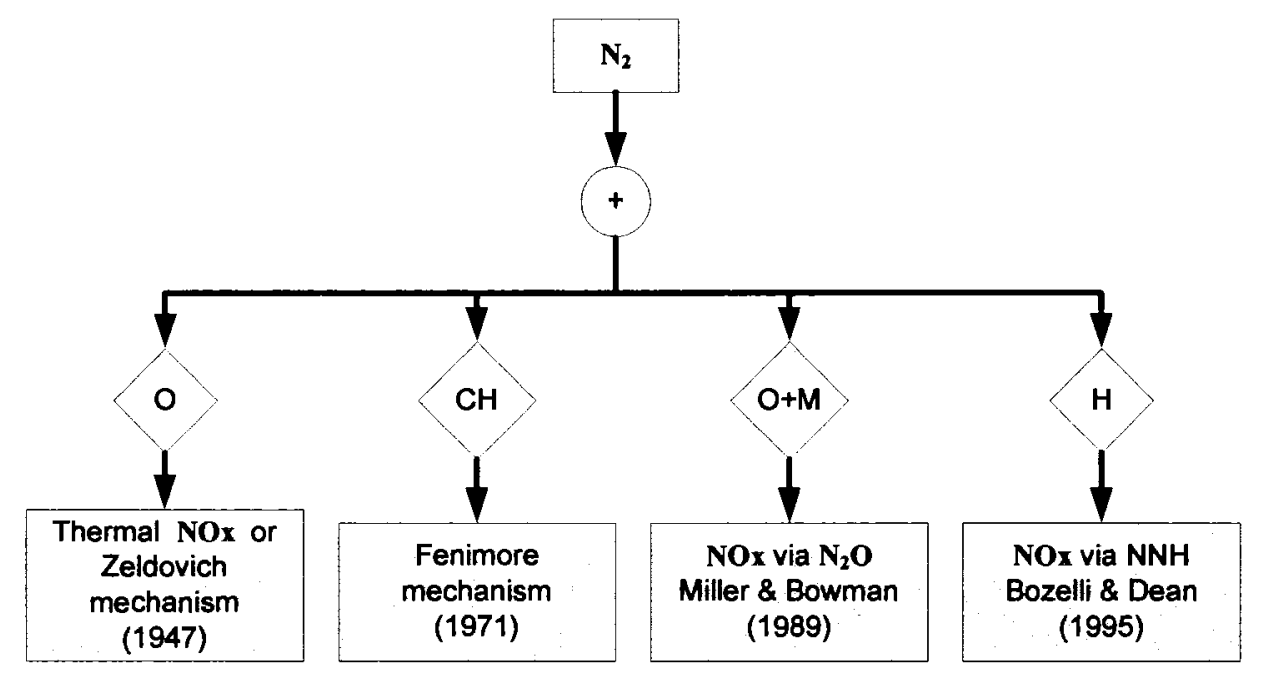

Figure 2.5: Illustration of reactions responsible for NOx formation under combustion conditions

There are many parameters affecting NOx formation. These parameters in general include; fuel type, flame temperature, flame speed, equivalence ratio, residence time, inlet pressure and temperature, the degree of fuel-oxidant premixing, and mixing within the combustion zone [Flanagan et al. (1992)]. A more detailed 
review of the principle of NOx formation with a subsection reviewing the factors affecting NOx formation is presented in Appendix A.

In the present study, natural gas is used as the fuel for the wire-mesh duct burner for the micro-CHP unit. The main mechanism which controls the formation of NOx under lean-premixed combustion of methane is the thermal NOx (Zeldovich) mechanism. The oxides of nitrogen emitted on the lean side of stoichiometry are an increasing function of flame temperature. Therefore, leaning out the fuel-air mixture reduces the flame temperature as well as NOx formation.

There is much work in the literature studying the influence of the degree of premixing between fuel and the oxidizer on NOx formation. Appleton and Heywood (1973), Pompei and Heywood (1972), Lyons (1982), Maughan et al. (1992), Mongia et al. (1996) and Rutar et al. (1997) studied the effects of the initial quality of gaseous fuel-air mixture on NOx production. They concluded that rapid mixing increases mixture homogeneity and shortens the characteristic time for NOx formation. Different techniques are used in the literature to improve the mixing process between fuel and oxidant before introducing the mixture to the combustion region. Swirling flow is one of the techniques widely used in many combustion systems (gas turbine combustors, industrial or commercial burners) to increase fuel-oxidizer mixing and to improve flame stabilization.

\subsection{Swirl flows}

In gas turbine combustors the air enters the combustor with a speed much higher than the flame speed. Therefore, to stabilize the flame in the combustor, a low speed region is needed. This is achieved by creating a recirculation region in the primary zone of the combustor. There are different methods of creating recirculation to stabilize the flame: (1) by the use of an opposed jet; (2) swirl generator, which may be made axial, tangential or combined axial and tangential; (3) combined swirler- 
opposed jet arrangement; (4) placement of a bluff body in the flow of a combustible mixture; (5) a rapid increase in the flow area creating a recirculating, separated flow; and (6) low velocity bypass-ports [Gupta et al. (1984)].

Inserting vane swirlers as a swirl generator upstream of the primary zone of the combustion system is one of the most effective ways of inducing recirculation. In swirling flows when the amount of rotation imported to the flow is high, a torroidal recirculation zone is created and causes flow recirculation in the core region [Mathur and MacCallum (1967)]. For premixed combustion systems, the recirculation zone generates a zone of hot combustion products, which enables the flame to remain at the upstream or the downstream stagnation point [Yegian (1998)]. In general, the recirculation zone generated by a swirler leads to better mixing than is normally obtained by other means (e.g., bluff bodies) due to the strong shear regions produced by swirl components, high turbulence and rapid mixing rates. The advantages of swirling flows include stability control, increased combustion intensity, and control of the size and the shape of the flame region. Swirling flow can also be generated using single-, double- or triple-swirl flow generators (or mixers). Researchers such as Nejad, et al. (1989), Hallett and Ding (1995), Saad A. Ahmed (1998), Schmittel, et al. (2000) and Lee and Moon (2002) used a single-swirl flow generator in their studies. Double-swirl mixers are used to achieve rapid mixing and increase mixture homogeneity. Joshi et al. (1994) and Leonard et al. (1993) performed their studies using double-swirl mixers. Broda et al. (1998) and Pritchard et al. (2002) used tripleswirler mixers in their experimental studies. For more details on swirling flows in combustion systems, the reader is directed to the following references: [Beer and Chigier (1972), Syred and Beer (1974), Lilley (1977) and Gupta et al. (1984)].

Flame stability in radiant burners is achieved by inserting a solid matrix or porous medium in the combustion zone. For this reason, swirlers are not used in radiant burners for stabilizing the flame. Only a few workers used swirlers to improve the mixing process. Moallemi et al. (1999) used a single-swirl mixer generator to induce turbulence in the flow to improve the mixing of fuel and air upstream of their 
porous burner. Later, from the same group of researchers, Dupont et al. (2000) used a single-swirl mixer in the injection system of the fuel and air. In this work the injection system was designed to achieve a high degree of mixedness. Their system made use of two swirlers, one for the air and the other for the fuel. In their experimental results they achieved low emissions.

The swirling flow concept was used to improve the mixing process in the burner premixer of the work reported in this thesis. Different types of static mixers (single- and double-swirl mixers) were investigated in this study to give perfect mixing for the duct burner. Extensive mixing is necessary to achieve the required low emissions. 


\section{CHAPTER 3: The present work}

\subsection{Motivation}

From the previous chapter, the trend in microturbine cogeneration applications is towards the development of a complete packaged (standalone) cogeneration system for improved heat recovery and integration with different cooling systems to provide an overall net energy cost saving and a more efficient system. Micro-CHP units have their limitations and many improvements are yet to be done. Ali et al. (2002) reported some of these limitations.

The exhaust gases leaving the microturbine recuperator in small CHP units contain a substantial amount of heat. The exhaust temperature is not sufficiently high (typically less than $300^{\circ} \mathrm{C}$ ) to be very useful. At these temperatures, these exhaust gases can be used to generate hot water or for space heating and other limited applications (integration with low coefficient of performance (COP) cooling devices). Integration with high quality cooling equipment such as triple-effect absorption chillers (or direct drying, heating processes and cooling applications) requires a higher input temperature (greater than $500^{\circ} \mathrm{C}$ [Shibata (2001)] than is available from the microturbine.

Since the prime mover of the micro-CHP units is a small gas turbine engine, changes in ambient conditions will affect the microturbine performance. This will affect the mass flow rate and the exhaust gas temperature (EGT). As a result, the heat available in the exhaust gases will be dependent on the ambient conditions. The reduction of the quantity of heat available in the exhaust gases may affect the operation of the integrated heat recovery units as well.

When the micro-CHP unit is operated at lower electric or shaft power loads (or even in the case of engine shutdown for standalone systems), this will result in a reduced exhaust gases flow and lower the microturbine exhaust gas temperature. This reduction of EGT will affect the operation and the performance of the integrated heat 
recovery systems. From a heat recovery point of view, many of the applications use an array of microturbines to cover the heat demand of a building and keep a constant source of heat energy to operate the integrated heat recovery devices. In a single-unit application and when the amount of recoverable heat is insufficient (due to the change in ambient conditions or engine load) for operating the CHP integrated system, a stand-by system (e.g., auxiliary boiler) is needed to cover the heat shortage. This will lead to increased complexity and capital cost, which translates into an increase in the energy cost.

From the above discussion, the addition of a high efficiency duct burner is needed to improve the quantity and the quality of heat content of the microturbine exhaust gases. This will increase the heat recovery capability of the small-scale CHP unit and improve the overall micro-CHP package efficiency. Another consideration is that the microturbine exhaust gases typically contain about 16-19 percent oxygen by volume [Thorndyke et al. (2001)], compared to about 21 percent in the intake air. This large proportion of unused oxygen in the exhaust is highly suitable for supporting additional combustion through a duct burner.

According to the literature review, there is no research being published on the integration of a duct burner with a microturbine $\mathrm{CHP}$ unit, and no experiments have been conducted to evaluate this type of burner. To the author's knowledge, there is no literature available (experimental or theoretical) on the use of a conical wire-mesh burner in microturbine cogeneration applications or in radiant burner applications. Very little research has been reported on the use of cylindrical shaped wire-mesh radiant burners. A large proportion of the research reported (experimental or theoretical) deals with radiant flat shaped mesh burners or porous burners. Also, the use of a swirler in these types of burners is not common. In general, most of the radiant burners in the literature use a venturi-mixer to mix the fuel and air to a proper ratio. The premixer of the duct burner in this design uses a swirler to provide mixing between the fuel and the oxidant. The oxidant used in the present investigation was from the exhaust gases leaving the recuperator of a microturbine. 


\subsection{Objective and tasks}

The main objective of the present work was to design, build and evaluate the characteristics of a novel low NOx gas-fired wire-mesh duct burner for the use in exhaust gases duct of an existing, recuperated micro-CHP unit (70 kW IR CHP unit). This duct burner is to burn natural gas efficiently, without generating a significant amount of additional NOx. The duct burner incorporating a conical wire-mesh burner was used to burn a lean combustible mixture above the surface layer of the permeable medium. This combustion technique has the ability to produce low emissions (single digit NOx) and a stable flame. Figure 3.1 presents the general concept of the new supplementary-fired micro-CHP system. This study provides a considerable amount of detailed parametric test data on the performance of this duct burner configuration for microturbine applications. Furthermore, there is no reported literature dealing with the construction and installation of natural gas-fired wire-mesh duct burners for a microturbine. This work will assist in the improvement of the technology in this area of research.

To attain the objectives of this research, the study was separated into four phases:

Phase I: This phase involved the design and construction of the conical wiremesh duct burner. In this phase, the initial design exercise was broken into three parts; (1) a combustion problem, (2) a fluid dynamics problem and (3) the conical mesh burner design.

1) The combustion problem sought to determine the exhaust gases and natural gas flows needed to obtain the desired final temperature.

2) The fluid dynamics problem sought to determine how to actually deliver those flows and to select the mixing system to provide thorough mixing with a relatively low pressure drop.

3) The conical mesh burner design involved the determination of the dimensions of the conical mesh burner and estimation of the pressure drop within the limit allowed for the microturbine operation. 


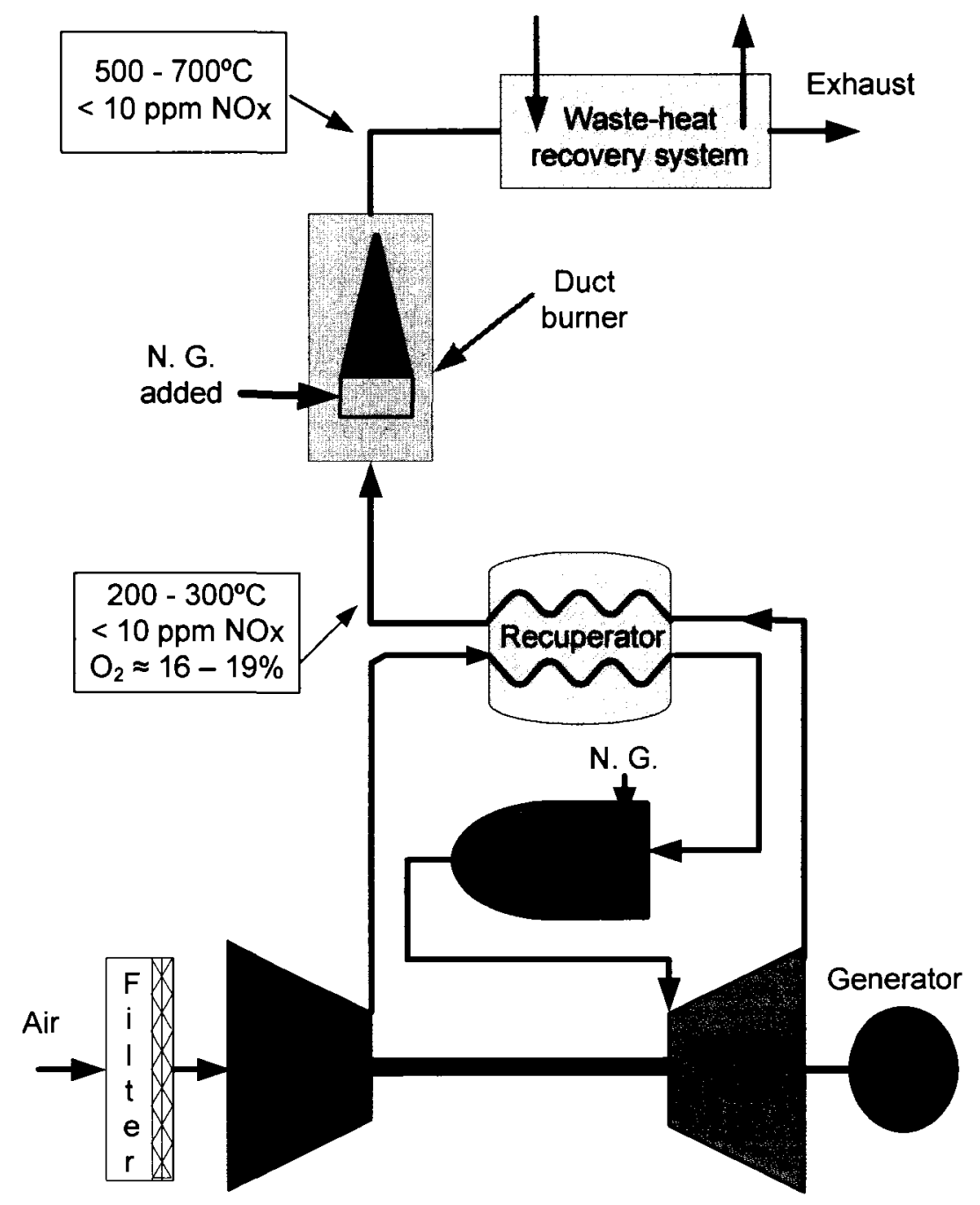

Figure 3.1: General concept of a micro-CHP system with an integrated duct burner

Phase II: In this phase, the design process was supported by a qualitative flow visualization study for the duct burner premixer. The purpose was to achieve two goals:

1) To assist the new design of the burner by introducing an efficient premixer that could be used in this new application. The laser sheet illumination (LSI) technique was used to capture images of the mixing process for different 
configurations analyzed. The term burner configuration in this thesis refers to the combination of mixer, cap, cone and shield, at a particular blade angle. For example, burner configuration; Mix-1/2, Cap-4, Cone- 3 and Sh3 at AFCBA = $0^{0}$ would involve mixer Mix-1/2(single-swirl mixer), fuel nozzle Cap-4 (fuel nozzle injects the fuel at $90^{\circ}$ angle to the mainstream), cone Cone-3 (conical burner with a pressure drop value of $\left(0.9\right.$ in $\left.\mathrm{H}_{2} \mathrm{O}\right)$ and shield $\mathrm{Sh} 3$ (shield covers $75 \%$ of the conical burner length) at a blade angle of zero degrees.

2) To advance the understanding of the mixing process using different premixer geometries. Mixing is the most important parameter for minimum NOx emissions since this has a direct impact on peak flame temperature, which is the main factor in thermal NOx generation.

Phase III: In the third phase of this research program, flow balancing tests (cold flow tests), were performed prior to the reacting flow experimental work. In this phase the following measurements were performed:

1) The correct amount of excess oxidant (mass flow rate split between the different regions) needed to be directed through the mesh burner for blue flame combustion was measured and the angles of the flow control blades were determined for each flow condition.

2) The overall duct burner pressure drop for all the geometries used.

Phase IV: Reacting flow experimental investigations were performed to verify and characterize the novel duct burner. The performance of the duct burner was studied in terms of parameters such as NOx and CO emissions, pressure drop, and temperature of the exhaust gases at the exit pipe of the burner, as a function of variables such as the firing rate employed and the temperature of microturbine exhaust gases. The stable burning operating range for several configurations was determined by direct observation of the burner surface. 


\section{CHAPTER 4: Duct burner design and description}

\subsection{Introduction}

The wire-mesh duct burner for microturbine CHP units is a new concept presented in this thesis. The design procedure was derived from the literature and based on the observation of many previously developed gas turbine combustors and radiant or conventional burners. The challenge was to design a duct burner to provide the thermal energy necessary to raise the microturbine exhaust gases temperature to a specified value without resulting in a significant increase in emissions. The major steps that cover the design and construction of the duct burner are discussed in this chapter. Each major design step is described in a separate section. During the presentation of the design process of the duct burner components, flowcharts summarizing the design principles accompanied with a schematic illustration of each component will be presented.

\subsection{Design strategies}

The overall duct burner design strategy (Figure 4.1) followed in this thesis started by defining and understanding the concept, completing a literature review and selecting the type of the burner. Chapters 1, 2 and 3 cover these parts. The design process, which is the topic of this chapter, involved five main steps:

1) Definition phase: This step consisted of setting the design specifications and requirements which lead to the definition of conceptual design.

2) Preliminary design: In this step the overall dimensions of the duct burner were determined. In the present thesis, the preliminary design consisted of two different steps: the combustion problem and the fluid dynamics problem. This chapter covers in detail these two problems. 
3) Mechanical design: This step consisted of the generation of production drawings (2D drawings) using the PTC ProEngineer design software package. Solid models (3D drawings) were also needed for the detailed design step. The complete engineering drawings are presented in Appendix J.

4) Premixer testing: Here, the performance of the duct burner premixers was verified and validated using LSI. This step will be covered in Chapter 5.

5) Duct burner manufacturing and testing: Experimental testing will be covered in Chapters 6 and 8.

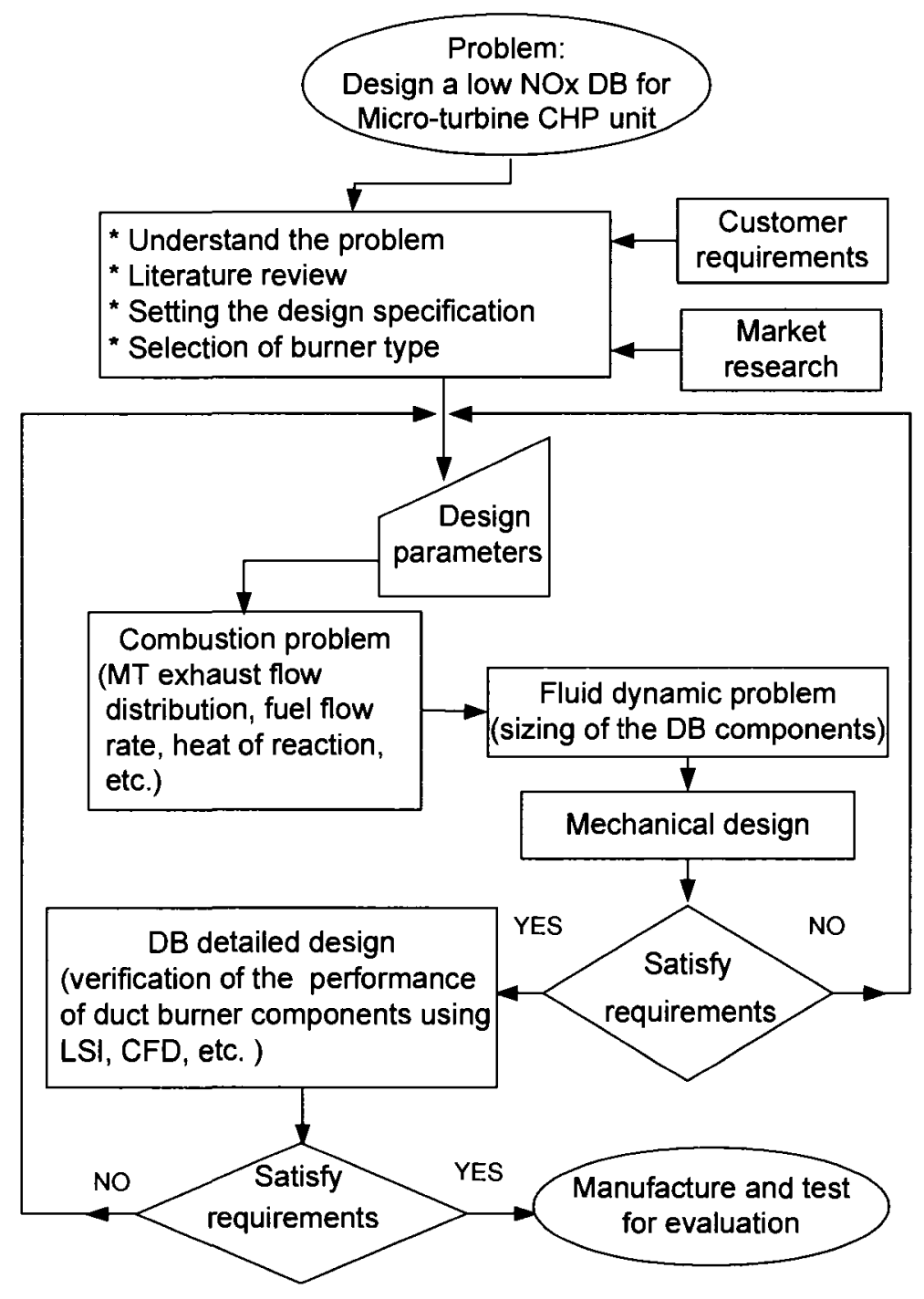

Figure 4.1: Overall duct burner design strategies flowchart 


\subsection{Specifications}

The basic requirements for the duct burner design are:

1. Low manufacturing cost

2. Simple compact design

3. Easy installation and startup

4. Reliable ignition, stable operation and efficient combustion

5. Reliable and safe operation

6. Low burner pressure drop

7. Low gas pressure

8. Operation on natural gas (N. G.)

9. Controlled generation of NOx to meet environmental regulations

10. Good load control

During the preliminary design stage, the duct burner design point was fixed with the inputs and specification listed in Table 4.1.

\subsection{The combustion problem}

The concept was to design a duct burner that can produce a stable flame and ultra-low NOx. To accomplish this, the duct burner was designed to operate in the lean-burn mode and combustion was to be completed over the surface of a conical wire-mesh burner in the blue flame mode. The combustion calculations based on the concept (lean premixed surface combustion) are briefly presented in this section. Figure 4.2 shows the schematic of the duct burner with the quantities to be calculated during the combustion problem. This problem sought to determine the flows of exhaust gases and fuel needed to obtain the desired mode of operation and final temperature. Calculations were based on the $70 \mathrm{~kW}$ microturbine at its design point (Table 4.1). Referring to Figure 4.2, the oxygen contained in the microturbine exhaust gases from the CHP unit recuperator is split into two streams. One stream bypasses the conical burner and the other burns with the added fuel inside the duct burner and 
over the conical burner. The bypass exhaust stream is then mixed with the hot products of combustion, diluting and cooling these. The duct burner fuel was natural gas, but for the design calculations, the fuel was assumed to be methane $\left(\mathrm{CH}_{4}\right)$. Some of the thermodynamic properties of methane are listed in Table 4.1. The result obtained from the combustion calculations were used for sizing the DB components. The sizing of the DB components is referred to in this thesis as the fluid dynamic problem and will be discussed later.

Table 4.1: Duct burner design point and specifications:

\begin{tabular}{|l|l|}
\hline \multicolumn{1}{|c|}{ Parameter } & \multicolumn{1}{c|}{ Design values } \\
\hline Ambient temperature & $25^{\circ} \mathrm{C}(298 \mathrm{~K})$ \\
\hline Operating pressure & Atmospheric \\
\hline Microturbine used & MT70 kW IR CHP unit \\
\hline Microturbine EGT range & $200-250^{\circ} \mathrm{C}$ \\
\hline Microturbine exhaust pipe diameter & $0.254 \mathrm{~m}(10$ inches $)$ \\
\hline $\begin{array}{l}\text { Microturbine exhaust gases composition } \\
\text { (\% volume) }\end{array}$ & $\mathrm{CO}_{2}(1.3 \%), \mathrm{O}_{2}(18 \%)$, \\
$\mathrm{N}_{2}(78.6 \%), \mathrm{H}_{2} \mathrm{O}(2.35 \%)$
\end{tabular}




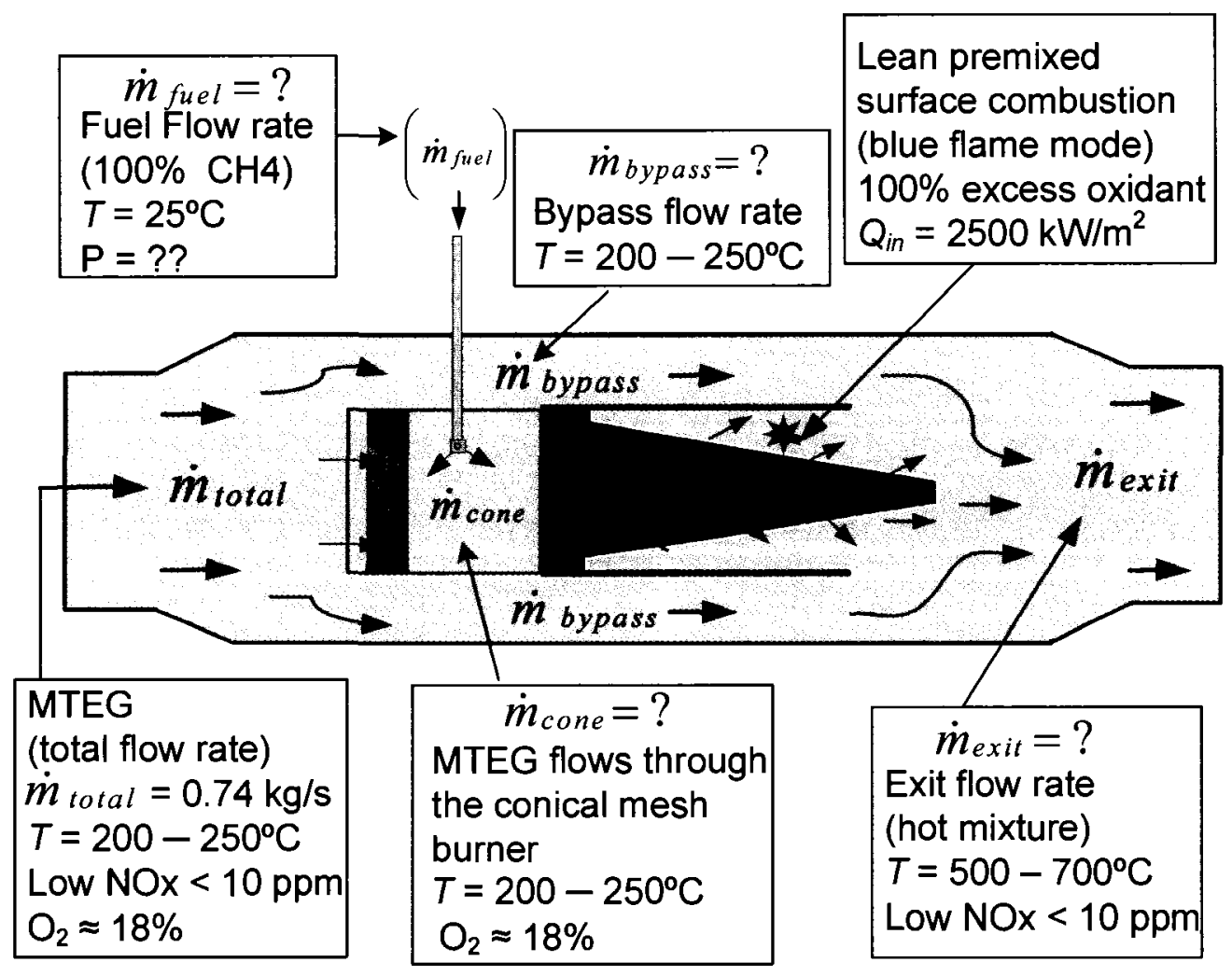

Figure 4.2: Duct burner schematic (combustion problem)

\subsubsection{Mass flow rates}

Calculations were carried out for the fuel-lean combustion reaction using the JANAF Tables [Chase (1998)] for heats of reaction and setting a desired adiabatic flame temperature. The following assumptions were made for these calculations:

- perfect mixing

- complete combustion

- no dissociation

- no heat loss 
During the calculation it was assumed that the only species found in the products of combustion, for the stoichiometric case, are $\mathrm{CO}_{2}, \mathrm{H}_{2} \mathrm{O}$ and $\mathrm{N}_{2}$. For the case of fuel-lean combustion, the species are $\mathrm{CO}_{2}, \mathrm{H}_{2} \mathrm{O}, \mathrm{N}_{2}$ and $\mathrm{O}_{2}$. The microturbine exhaust gases are used as an oxidant in the duct burner combustion process. The combustion equations used are as follows;

For the case of stoichiometric combustion (mole basis): $a \mathrm{CH}_{4}+m_{\text {stoich }}\left(x 1 \mathrm{O}_{2}+x 2 \mathrm{CO}_{2}+x 3 \mathrm{CO}+x 4 \mathrm{H}_{2} \mathrm{O}+x 5 \mathrm{~N}_{2}\right)=b 1 \mathrm{CO}_{2}+c \mathrm{H}_{2} \mathrm{O}+d 1 \mathrm{~N}_{2}$

For a fuel-lean mixture:

$$
a 1 \mathrm{CH}_{4}+m_{a c t}\left(x 1 \mathrm{O}_{2}+x 2 \mathrm{CO}_{2}+x 3 \mathrm{CO}+x 4 \mathrm{H}_{2} \mathrm{O}+x 5 \mathrm{~N}_{2}\right)=b 2 \mathrm{CO}_{2}+c 1 \mathrm{H}_{2} \mathrm{O}+d 2 \mathrm{~N}_{2}+f \mathrm{O}_{2}
$$

where all the constants ( $a, a 1, x 1, x 2, x 3, x 4, x 5, b 1, b 2, c, c 1, d 1, d 2, f)$ are gaseous mole fractions, and $\left(m_{\text {stoich }}\right)$ and $\left(m_{a c t}\right)$ are the stoichiometric and actual mole fraction of oxidant used in the combustion process with $(a)$ and $(a 1)$ moles of methane $\left(\mathrm{CH}_{4}\right)$ respectively.

The atom conservation principle was used to solve the above equations for the values of the relative mole fractions of the stoichiometric and the lean cases. Then the stoichiometric and actual oxidant-to-fuel ratios by mass were computed using the following relations:

$$
\begin{gathered}
(\text { Oxidant / Fuel })_{\text {stoichiometric }}=\left(\frac{\dot{m}_{\text {oxid }}}{\dot{m}_{\text {fuel }}}\right)_{\text {stoichiomeric }}=\left(\frac{m_{\text {stoich }}}{a}\right) \frac{M W_{\text {oxid }}}{M W_{\text {fuel }}} \\
(\text { Oxidant / Fuel })_{\text {actual }}=\left(\frac{\dot{m}_{\text {oxid }}}{\dot{m}_{\text {fuel }}}\right)_{\text {actual }}=\left(\frac{m_{\text {act }}}{a 1}\right) \frac{M W_{\text {oxid }}}{M W_{\text {fuel }}}
\end{gathered}
$$


where $\dot{m}_{\text {oxid }}, \dot{m}_{\text {fuel }}, M W_{\text {oxid }}$ and $M W_{\text {fuel }}$ are the oxidant and fuel mass flow rates and the oxidant and fuel molecular weights respectively.

Knowing the total (overall) mass flow rate of the microturbine exhaust gases, the design equivalence ratio and other design parameters listed in Table 4.1, the fuel flow rate and the amount of oxidant needed for combustion can be computed. What follows are some of the relationships used for the computation.

The overall actual oxidant-to-fuel ratio was estimated using:

$$
(\text { Oxidant } / \text { Fuel })_{O V-a c t u a l}=\frac{L H V-\left(C_{P}\left(T_{a v}\right) \times\left(T_{\text {exit }}\right)\right.}{C_{P}\left(T_{a v}\right) \times\left(T_{\text {exit }}-T_{\text {inlet }}\right)}
$$

where $L H V$ is the lower heating value of the fuel, $C_{P}\left(T_{a v}\right)$ is the constant pressure specific heat of gases at an average temperature, $T_{a v}=0.5\left(T_{\text {exit }}-T_{\text {inlet }}\right)$ is the average temperature, $T_{\text {exit }}$ and $T_{\text {inlet }}$ are the duct burner exit and inlet temperatures.

The equivalence ratio $(\phi)$ is defined as the ratio of the oxidant-to-fuel mass ratio for a stoichiometric process to the actual oxidant-to-fuel mass ratio:

$$
\phi=\frac{(\text { Oxidant } / \text { Fuel })_{\text {stoich }}}{(\text { Oxidant } / \text { Fuel })_{\text {acual }}}
$$

where $\phi<1$ represents the fuel-lean mixture case (excess oxidant), $\phi>1$ the fuel-rich mixture case (excess fuel) and the stoichiometric mixture is represented by $\phi=1$.

The fuel flow rate was calculated using:

$$
\dot{m}_{\text {fuel }}=\frac{\dot{m}_{\text {total }}}{(\text { Oxidant } / \text { Fuel })_{\text {OV-actual }}}
$$

where $\dot{m}_{\text {total }}=\dot{m}_{\text {oxid }}$ is the total mass rate of the microturbine exhaust gases entering the DB. 
The amount of oxidant needed for the combustion process to produce a blue flame over the conical mesh burner surface is estimated using:

$$
\dot{m}_{\text {cone }}=\frac{\dot{m}_{\text {fuel }}}{\left(\phi_{\text {local }} /(\text { Oxidant } / \text { Fuel })_{\text {stoich }}\right)}
$$

Where $\phi_{\text {local }}$ is the equivalence ratio in the combustion zone (over the surface of the conical mesh burner) and $\dot{m}_{\text {cone }}$ is the amount of oxidant flow through the conical mesh burner.

\subsubsection{Flame temperature}

The constant pressure adiabatic flame temperature is the temperature that results when fuel is burned adiabatically during the constant pressure process. Assuming a steady-flow process, no work interaction, the oxidant and the combustion gases are ideal gases and the change in potential and kinetic energy are negligible, the steady flow energy equation leads to:

$$
Q=0=\Delta H=H_{\text {prod }}-H_{\text {react }} \quad \text { or } \quad H_{\text {prod }}=H_{\text {react }}
$$

where $Q, H_{\text {prod }}$ and $H_{\text {react }}$ are the heat transfer, enthalpy of the products and reactants respectively.

Equation (4. 9) can be expressed as:

$$
\sum n_{\text {prod }}\left(\bar{h}_{f}+\bar{h}-\bar{h} \circ\right)_{\text {prod }}=\sum n_{\text {react }}\left(\bar{h}_{f}+\bar{h}-\bar{h} \circ\right)_{\text {react }}
$$

where $n_{\text {prod }}, n_{\text {react }}, \bar{h}_{f}, \bar{h}$, and $\bar{h}$ o are the product and the reactant component mole fractions, the enthalpy of formation, the enthalpy of the gas at the reaction temperature and the reference enthalpy (on a molar basis). These enthalpy values for different species are tabulated for a broad range of temperature in JANAF Tables [Chase (1998)].

The absolute enthalpy in Equation (4. 10) can be written as: 


$$
\left(\bar{h}_{f}+\bar{h}-\bar{h} \circ\right)=\bar{h}_{f}+\int_{T_{\text {ref }}}^{T} \bar{C}_{P_{i}}(T) d T
$$

where $\bar{C}_{P i}(T)$ is the constant pressure specific heat (mole basis) as a function of temperature. The temperatures $T$ and $T_{r e f}$ are the actual and the reference $(298.15 \mathrm{~K})$ temperatures. Expressions for the specific heat in terms of temperature in polynomial forms for different gases are available in many references, such as Kuo (2005) and Turns (2003).

The solution for the adiabatic flame temperature is a trial-and-error solution of Equation (4.9). The iteration continues until the correct flame temperature is determined. The adiabatic flame temperature for non-dissociating products of combustion, such as that shown in Equations (4.1) and (4.2) is usually called the adiabatic frozen-flame temperature [Kuo (2005)].

\subsubsection{Burner heat release}

The heat of reaction is the heat transferred for a certain chemical reaction such as that presented in Equations (4.1) and (4.2), when the reactants and the products are at the same temperature and the pressure kept constant. Then the energy equation, Equation (4.9), will be:

$$
Q=\Delta H=H_{\text {prod }}-H_{\text {react }}
$$

and Equation (4.10) will be:

$$
Q=\sum n_{\text {prod }}\left(\bar{h}_{f}+\bar{h}-\bar{h} \circ\right)_{\text {prod }}-\sum n_{\text {react }}\left(\bar{h}_{f}+\bar{h}-\bar{h} \circ\right)_{\text {react }}
$$

Expanding Equation (4.13) by replacing the sums with the appropriate terms, their values leads to the solution of the heat release equation. 


\subsubsection{Homogeneous burning velocity}

Burning velocity (flame speed) is an important parameter that must be accounted for in the design of the duct burner because it is desirable that the velocity of the oxidant through the mesh burner be equal to the flame speed. If this happens, the flame will be stable on the wire-mesh surface. The Semenov equation (Equation 4.14) and the empirical equations proposed by Gauthier et al. (1996) have been used in the literature to estimate the flame speed in a gas turbine combustor. In the present work the Semenov equation was used for the estimation of the burning velocity in the duct burner design process.

The following equation can be used to calculate the maximum homogeneous burning velocity $(H B V)$ :

$$
H B V=\sqrt{\frac{K T_{u m}{ }^{2} T_{\text {flame }}{ }^{5} \exp \left(\frac{-E}{R_{u} T_{\text {flame }}}\right)}{\left(T_{\text {flame }}-T_{u m}\right)^{3}}}
$$

where $K$ is a constant of proportionality (it can be calculated using a data at a known condition, see Gauthier et al. (1996)), $T_{\text {flame }}$ is flame temperature, $T_{u m}$ is the unburned mixture temperature, $E$ is the activation energy $(E=92 \mathrm{~kJ} / \mathrm{mol})$ and $R_{u}$ is the universal gas constant.

\subsubsection{Combustion problem closure}

Table 4.2 presents the results of the calculation of the distribution of the exhaust gases mass flow around the duct burner. The results show that approximately 75 percent of the turbine exhaust must bypass the burner. The remaining exhaust must mix with the appropriate amount of methane (it was calculated to be 0.00475 $\mathrm{kg} / \mathrm{s}$ ) and burn to give the target exhaust temperature. The combustion products of the duct burner will have a temperature of $1250^{\circ} \mathrm{C}$, with $235 \mathrm{~kW}$ of heat release. These 
combustion products mix with bypass exhaust to give a final temperature of the mixture in the range of $500^{\circ} \mathrm{C} \sim 700^{\circ} \mathrm{C}$.

Table 4.2: Exhaust gases (oxidant) flow distribution

\begin{tabular}{|l|l|l|l|}
\hline Parameters & Symbol & $\begin{array}{l}\text { Mass flow } \\
\text { fraction }\end{array}$ & $\begin{array}{l}\text { Equivalence } \\
\text { ratio }(\phi)\end{array}$ \\
\hline Total (oxidant) mass flow rate & $\dot{m}_{\text {total }}$ or $\dot{m}_{\text {oxid }}$ & 1.0 & \\
\hline $\begin{array}{l}\text { Cone flow rate } \\
\text { (flow through wire-mesh) }\end{array}$ & $\dot{m}_{\text {cone }}$ & 0.25 & 0.5 \\
\hline Bypass flow rate & $\dot{m}_{\text {bypass }}$ & 0.75 & \\
\hline
\end{tabular}

\subsection{The fluid dynamics problem}

This section deals with the selection of the mixing system to provide thorough mixing and minimize pressure drop across the burner. It also describes the design of the fuel system. The amount of oxidant to be burned with the fuel in the combustion zone, the amount of oxidant to bypass the combustion zone and the reference duct burner inlet velocity, are used to determine the geometry of the duct burner and how to deliver these flows to each zone.

A concentric duct-and-conical-burner design was considered, as shown in Figure 4.3. The preliminary geometric parameters to be calculated and the method of mixing to be selected (e.g., fuel and oxidant mixing method) for the fluid dynamic problem are illustrated on the same figure. The dimensions of the duct burner and properties of the mesh are calculated in this section. These include:

- the reference diameter of the duct burner

- the base diameter of the cone burner (the microturbine exhaust gases splits into two streams between the annular passage and the core flow through the conical burner),

- the pressure drop increase caused by the mesh. 
The presence of the metal fibre burner and its support structure in an exhaust gases stream contained within the exhaust gases duct of a microturbine will cause a resistance to the flow and a resulting pressure drop. The total pressure drop due to the duct burner was specified to be no more than $249 \mathrm{~Pa}$ (1.0 inches of water) to maintain the microturbine efficiency.

In general the fluid dynamic calculations aimed to define and size each component of the duct burner. The duct burner was composed of five main components: (1) the burner housing; (2) the premixer; (3) the conical wire-mesh burner; (4) the annular passage; and (5) the conical burner shield. The following subsections provide a short description of the design parameters (geometrical) and design steps used for each component. Figure 4.4 presents the fluid dynamics problem flowchart in which the five components of the duct burner are listed. For each component of the duct burner, a design process flowchart will be presented. The common design parameters such as materials and reference velocity, which will be used for all the duct burner components, will be mentioned before the components design process description.

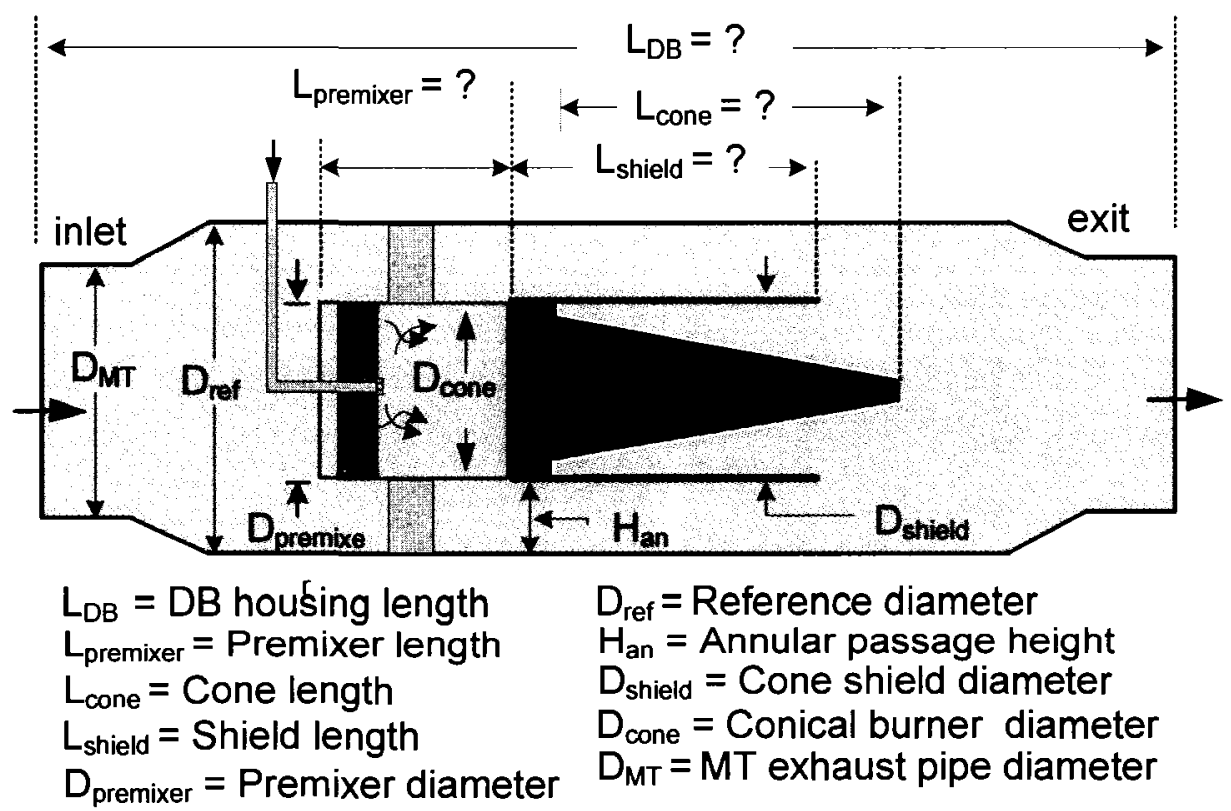

Figure 4.3: Duct burner schematic (fluid dynamics problem) 


\subsubsection{Duct burner materials}

Materials appropriate for a burner or any combustion system design are now available which would give the required life and performance for most applications. In the present thesis, stainless steel grade 304 was selected as the material for the test duct burner. This grade of stainless steel provides acceptable performance and life. Standard size stainless steel pipes, tubes and sheets were used for the manufacture of the duct burner.

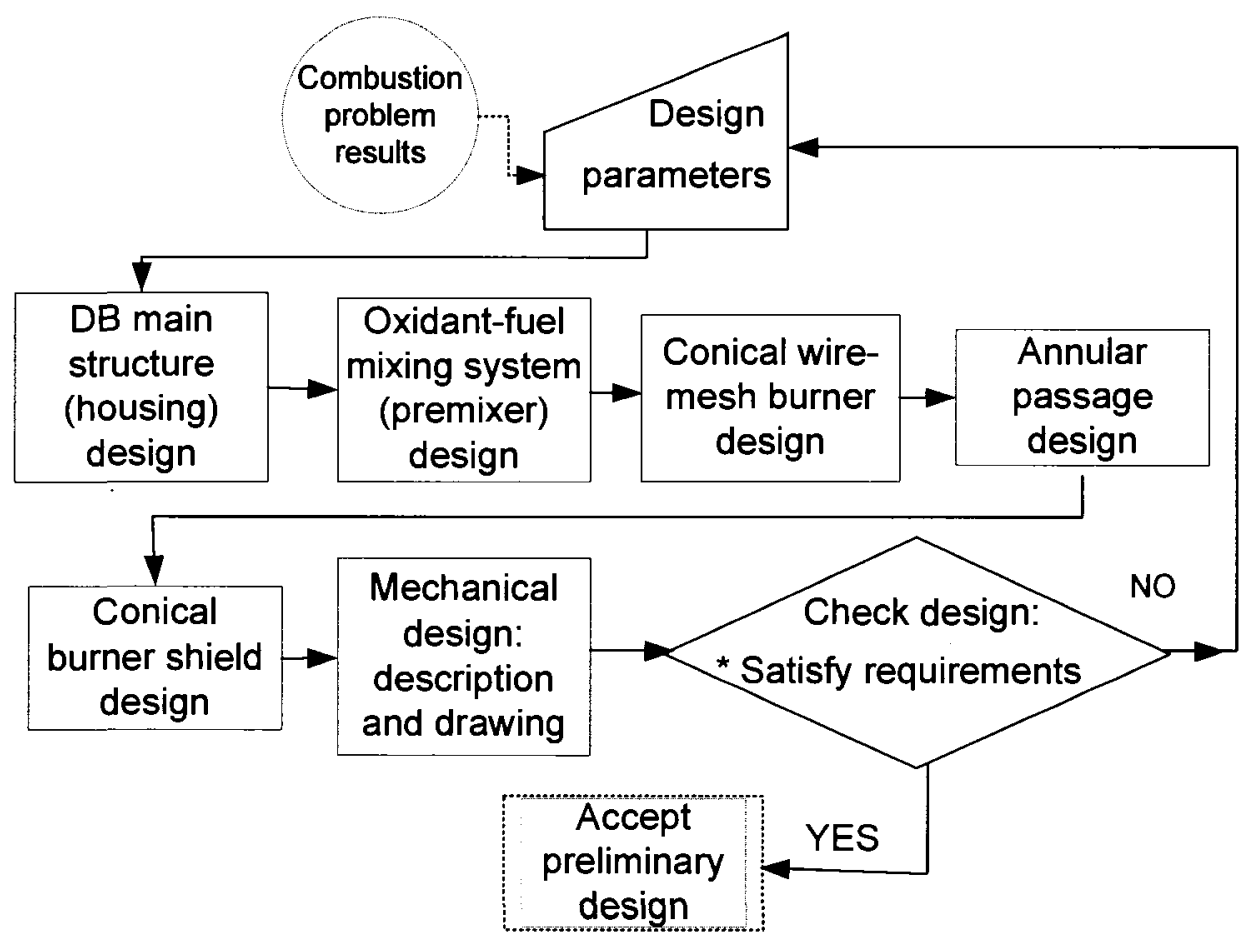

Figure 4.4: Overall fluid dynamics problem design flowchart

\subsubsection{Duct burner reference velocity}

Following guidelines published by Lefebvre (1983), Mellor (1990) and Turns (2003) for gas turbine combustor design, the reference velocity in the present work was defined as the mean velocity across the plane of maximum cross-sectional area of the duct burner housing. The duct burner inlet velocity was measured by traversing a 
pitot-static tube across the microturbine exhaust pipe. The mass-average velocity was measured to be $18 \mathrm{~m} / \mathrm{sec}$. This reference velocity was calculated after the expansion at the maximum cross-sectional area using the continuity equation and it was calculated to be $12 \mathrm{~m} / \mathrm{s}$, see Figure 4.5 .

\subsubsection{Duct burner reference diameter}

Another important design parameter is the burner reference diameter. The duct burner reference diameter is the maximum diameter of the duct burner housing where the reference velocity was defined. The diameter was assigned based on different factors such as duct burner total pressure drop, flame speed, the oxidant mass flow rate, duct burner inlet velocity, the microturbine exhaust pipe diameter and available standard pipe sizes (to minimize cost). A compromise must be made between the mentioned parameters to select the duct burner reference diameter. The duct burner size must be adequate to allow the insertion of probes for measurements without disturbing the flow. At the same time, the duct burner must be small in size to be useful for the microturbine CHP package application. At a microturbine exhaust pipe of $25.4 \mathrm{~cm}$ (10 inches), a duct burner mean inlet velocity of $18 \mathrm{~m} / \mathrm{s}$, a maximum pressure drop of $249 \mathrm{~Pa}$ and with an expected stable flame, the reference diameter was selected to be 12.39 inches. The cross-sectional area based on this diameter is the reference area.

Conservation of mass

$$
\dot{m}_{1}=\dot{m}_{2}
$$

For steady incompressible flow

$$
\begin{gathered}
\rho \times A_{1} \times V_{1}=\rho \times A_{2} \times V_{2} \\
V_{2}=V_{1} \times \frac{A_{1}}{A_{2}} \\
A=\text { area }, \quad V=\text { velocity and } \\
\rho=\text { density } \dot{m}=\text { mass flow rate }
\end{gathered}
$$

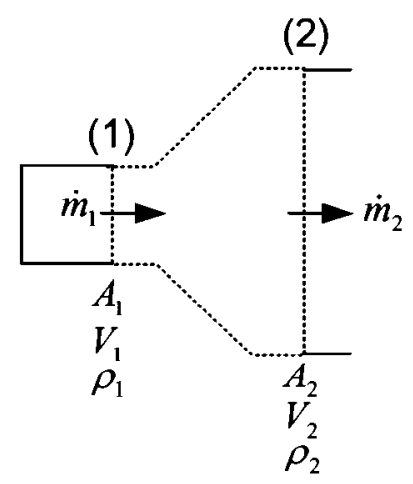

Figure 4.5: Reference velocity calculations 


\subsubsection{Burner housing}

The duct burner housing is composed of different sections. The sizing of these sections affects important performance aspects such as pressure drop, mixing and flow stability. Also, the size must be adequate to allow the introduction of probes for measurements such as thermocouples, pressure probes, and sample probes. In addition, the size of some of the duct burner sections was controlled by the internal pieces located inside these sections. Since many geometrical parameters were studied in the present thesis, the ease of disassembly of the different duct burner components was also considered.

Figure 4.6 shows a schematic of the burner housing components. This figure shows only the main features. For more detail including dimensions and measurement port locations, refer to Appendix J. Stainless steel standard pipe pieces were used for the duct burner housing. The pipe used is a schedule 10S with an inner diameter of $31.5 \mathrm{~cm}$ and $0.457 \mathrm{~cm}$ (12.39 inches and 0.18 inch (standard SS pipe)) wall thickness. The duct burner housing consists of six pieces. Pipe 1: is the duct burner inlet pipe with a diffuser section. This section connects the microturbine exhaust pipe with the duct burner. The microturbine exhaust pipe is a 10 inch standard stainless steel pipe, schedule $40 \mathrm{~S}$, with an inner diameter of $25.4 \mathrm{~cm}$ (10 inches). The expansion to a larger area is used to reduce the velocity for flame stability reasons, to reduce pressure loss and to gain more space for measurement. Figure 4.7 illustrates the design equations used for the diffuser design. Pipe 2: is the premixer inlet pipe; it contains the fuel pipe port. The length of this section provides approximately one reference pipe diameter length to stabilize the flow after the diffuser and to accommodate the fuel pipe. Pipe 3: is the premixer housing pipe. The length of this section was made equal to the premixer length $30 \mathrm{~cm}$ (11.8 inches). The premixer via its supports was mounted inside Pipe 3. The premixer is discussed in a later section. Pipe 4: is the conical wire-mesh burner housing, where the visualization ports are located. This section is $50.8 \mathrm{~cm}$ ( 20 inches) in length. At the end of this section and 
above the conical burner ( $35.6 \mathrm{~cm}$ (14 inches) in length), the hot products mix with the bypass flow. Pipe 3 and Pipe 4 together cover all the duct burner components. Pipe 5: is the exhaust pipe, where the hot products mix with the bypassed cold flow. This section also stabilizes the flow to create a suitable temperature profile and provides the duct burner with more space for measurement. Figure 4.8 presents the design flowchart used for all the straight stainless steel pipe pieces (Pipe 2 to Pipe 5). Pipe 6: is the duct burner exhaust pipe with a contraction section. It is similar to Pipe 1 and connects the duct burner with the main exhaust pipe which leads the exhaust gases out of the building. Flanges were used for each piece to allow ease of assembly. When all the parts of the duct burner are assembled together, they form a $2 \mathrm{~m}$ long test rig. The duct burner test rig was designed with 30 probing ports and 4 sight ports. For full details, the complete engineering drawing is presented in Appendix J.

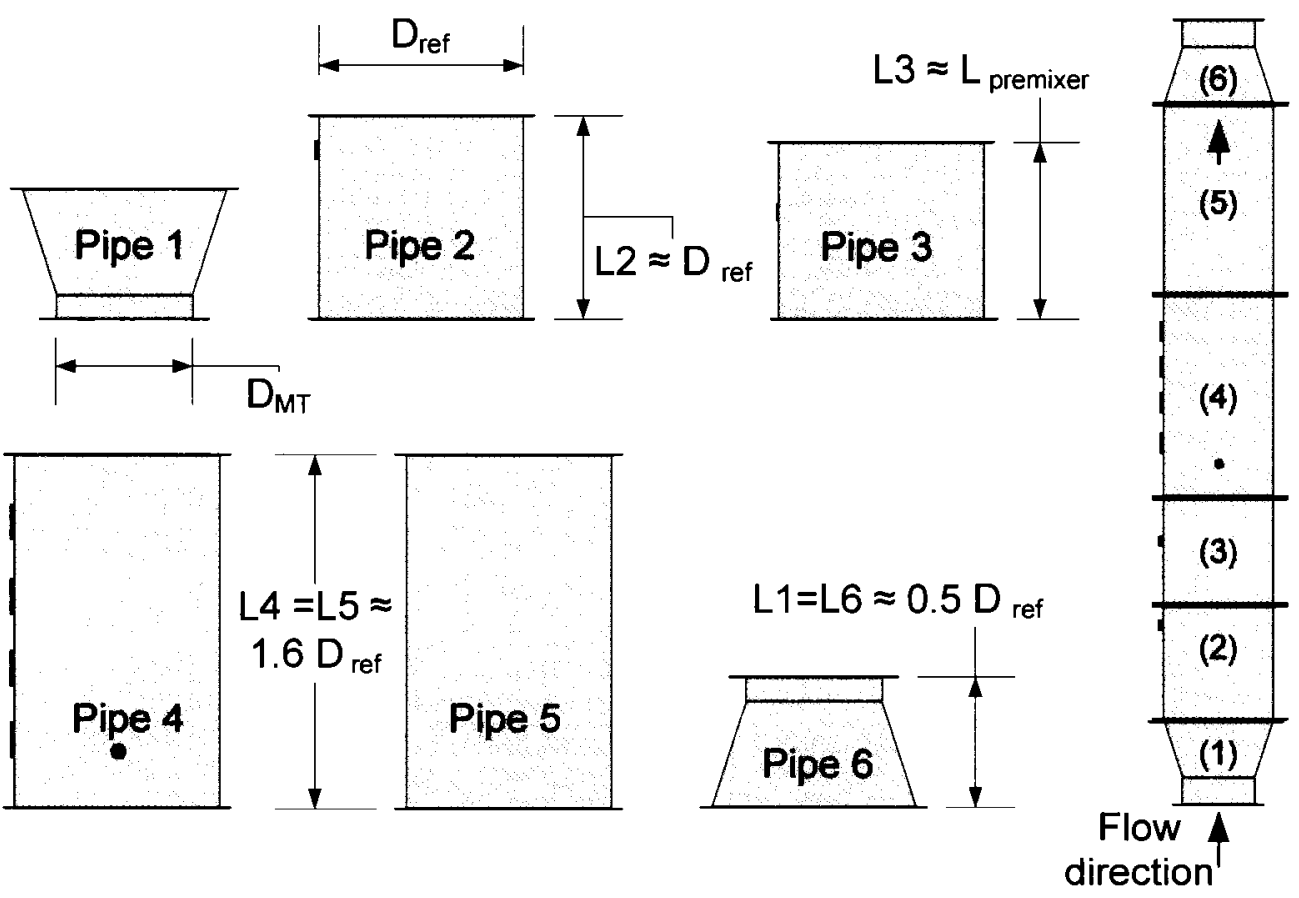

Figure 4.6: Schematic of the duct burner housing components 
Diffuser design:

$$
\begin{array}{ll}
D_{1} & =\text { Inlet diameter } \\
D_{2} & =\text { Exit diameter } \\
L_{d i f f} & =\text { Diffuser length } \\
V_{1} & =\text { diffuser inlet velocity } \\
\rho & =\text { Fluid density } \\
\alpha & =\text { Diffuser half angle }
\end{array}
$$

Diffuser area ratio $\left(A R_{\text {tiff }}\right)$

$$
\begin{aligned}
& A R_{\text {iff }}=\frac{A_{2}}{A_{1}}=\frac{\pi\left(D_{2}\right)^{2}}{\pi\left(D_{1}\right)^{2}} \quad \text { Flow direction } \\
& A R_{\text {diff }}=1+4 \frac{L_{\text {diff }}}{D_{1}}(\tan (\alpha))+\left(\frac{2 L_{\text {diff }}}{D_{1}}(\tan (\alpha))\right)^{2}
\end{aligned}
$$

Diffuser pressure loss:

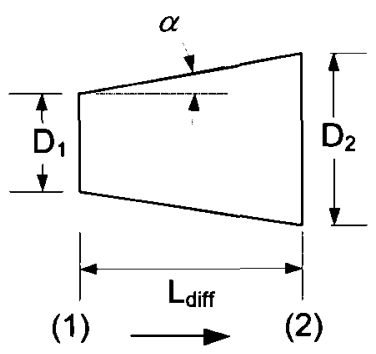

$$
\Delta P_{d i f f}=\lambda .\left(0.5 \rho\left(V_{1}\right)^{2}\right)\left[1-\frac{1}{\left(A R_{\text {diff }}\right)^{2}}\right]
$$

$\lambda=$ Loss coefficient

[Lefebvre (1983)]

\section{Figure 4.7: Diffuser design process}

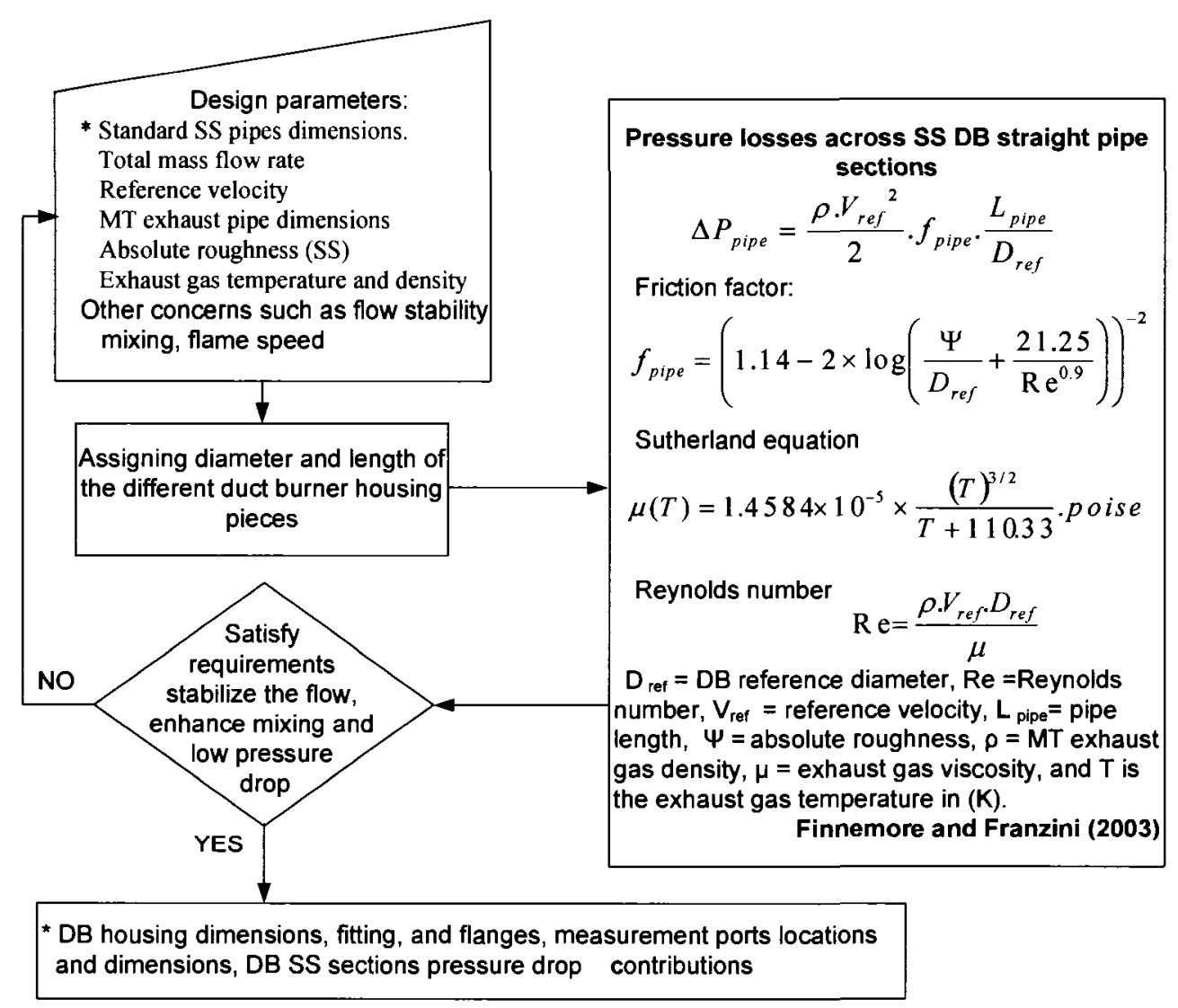

Figure 4.8: Duct burner housing design flowchart 


\subsubsection{Premixer}

As mentioned in Chapter 2, swirling flow is the method used in this work to achieve the best mixing between the fuel and the oxidant. Good mixing provides good combustion and low emissions. Good premixing before the combustion must be achieved with a low pressure drop to maintain the required total pressure drop. The premixer in this duct burner is composed of three main parts: static mixer, fuel caps and the premixer pipe. Figure 4.9 shows the premixer main components.

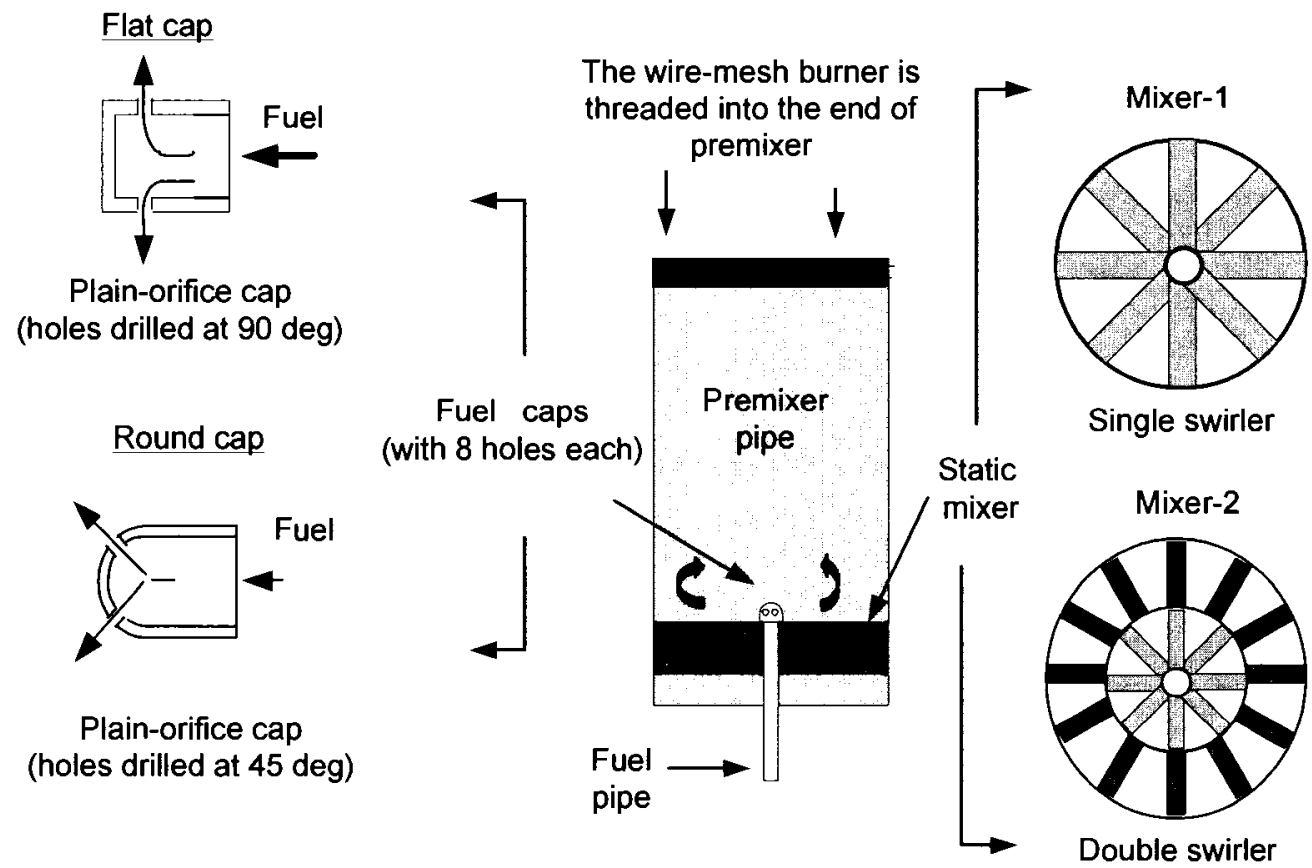

Figure 4.9: Schematic of the duct burner premixer components

\subsubsection{Static mixer (swirlers)}

Swirlers are static mixing devices used to impart swirl (rotation) to the flow. In the present study, the goal of the static mixer design is to give sufficient swirl to the flow to improve the mixing between the oxidant and the fuel in the premixer prior to combustion while minimizing the pressure losses. Swirlers are designed for ease and economy of manufacturing as well as for efficiency of operation. Swirl can be imparted to the flow by different means: drilled holes, slots, curved or straight blades. 
The different types of blade or vane swirl flow generators in practical use include axial, radial and tangential vanes. By combining one or more types of these generators it is possible to get rapid and efficient mixing for the best combustion performance. Hallett (2003) has provided a brief summary of these types of swirlers. Gupta et al. (1984) and Basu et al. (1999) have reviewed existing swirler designs for gas turbine combustors and industrial burners.

\subsection{Swirler design}

The general basic steps used for swirler design following Gupta et al. (1984) are:
a) Select the model for tangential velocity
b) Determine the degree of swirl
c) Develop the swirl geometry

In the first step, the desired tangential velocity profile is determined as a function of radial position. There are four different models of tangential velocity described in the literature: (1) the constant angle, (2) forced vortex, (3) free vortex and (4) the Rankine vortex. These are presented by the following equations respectively as:

$$
w=C 1, w=r C 2, w=\frac{C 3}{r} \text { and } w=\frac{C 4}{r}\left(1-\exp \left(\frac{-r^{2}}{R o^{2}}\right)\right)
$$

where $C 1, C 2, C 3$ and $C 4$ are the velocity distribution constants, $w$ is the tangential velocity, $r$ and $R o$ are the radial position or radius and the outer swirler radius respectively. The axial swirler design of constant angle model was selected for the ease of manufacture for the present work. Figure 4.10 illustrates the axial swirler design parameters.

The second design step listed above is the determination of the degree of swirl which is characterized by the swirl number $(S)$. The swirl number is a nondimensional characteristic of the rotating flow and it is defined by the ratio of the 
axial flux of swirl momentum to the axial flux of axial momentum (axial thrust) times the equivalent nozzle radius (outer radius of swirler) [Chigier and Beer (1964) and Gupta et al. (1984)].

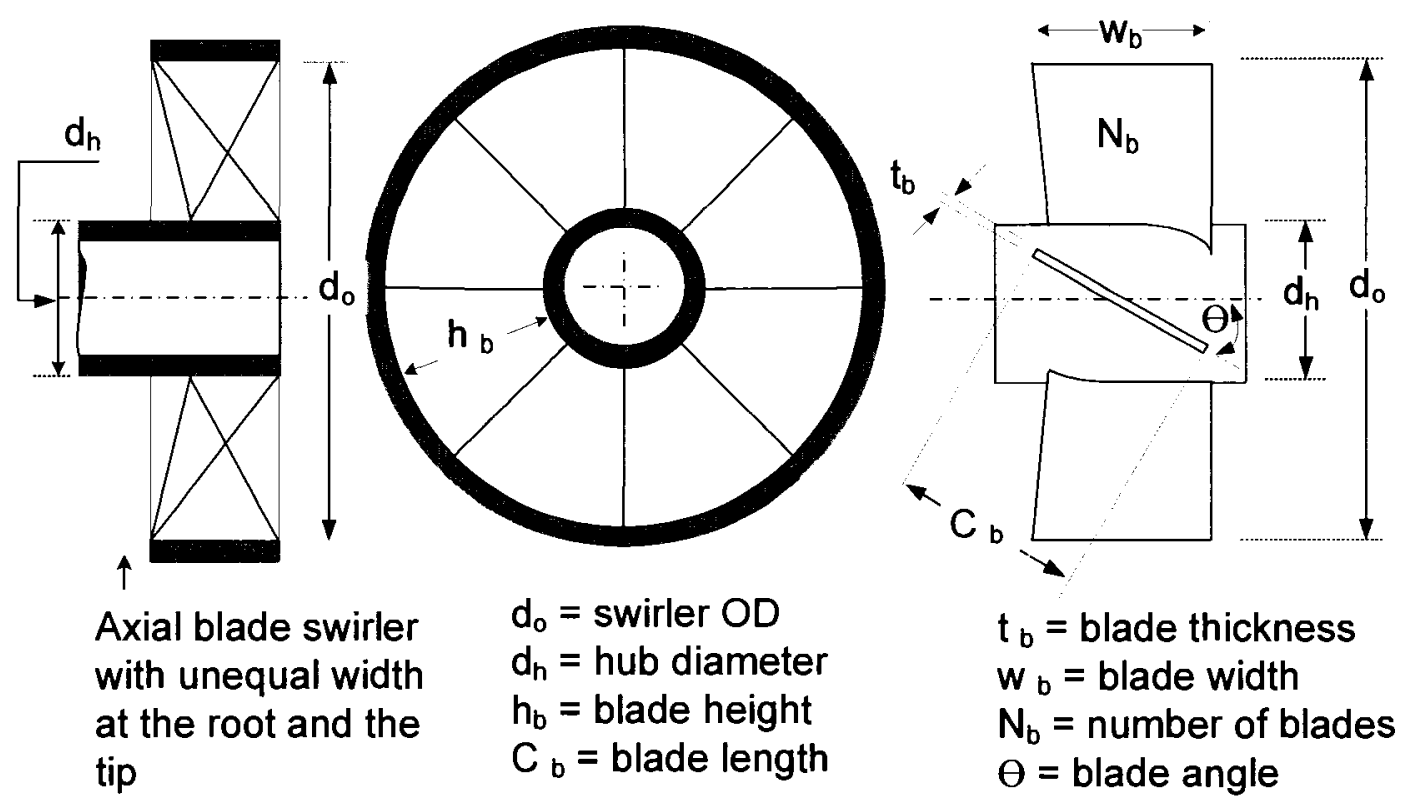

Figure 4.10: Geometry of an axial blade swirler

$$
S=\frac{\int_{R h}^{R o} v w r r^{2} d r}{R o \int_{R h}^{R o} v^{2} r d r}
$$

where $v$ and $w$ are the axial and tangential mean velocities respectively, $r$ is the radial position, $R h$ is the inner swirl radius $\left(d_{h} / 2\right)$ and $R o$ is the outer swirl radius $\left(d_{0} / 2\right)$. See Figure 4.10. If the axial velocity is assumed constant and the constant angle model of tangential velocity is used, Equation (4.16) becomes: 


$$
S=\frac{2}{3} \times\left[\frac{1-\left(\frac{d_{h}}{d_{o}}\right)^{3}}{1-\left(\frac{d_{h}}{d_{o}}\right)^{2}}\right] \times \tan (\theta)
$$

The swirl number determines the criterion for recirculation. Little or no axial recirculation occurs below the critical value of $0.6(\mathrm{~S}<0.6)$, where the adverse pressure gradient is not enough to cause axial recirculation. Above this value $(\mathrm{S} \geq$ 0.6 ), a central recirculation zone forms, due to the presence of strong radial and axial pressure gradients near the swirler exit [Lilley (1977) and Gupta et al. (1984)]. A swirl number of 0.6 will ensure recirculation for a free jet or a flow entering a fairly large expansion, but not necessarly for a flow with constant cross-section as in the present investigation.

The third and the last step in the design process is the development of the swirl vane geometry which is based on experimental or other standard rules. The geometrical design variables (see Figure 4.9) for the swirler used are the hub diameter $\left(d_{h}\right)$, which is needed to provide space for the fuel injector, the outer swirler diameter $\left(d_{o}\right)$, the blade angle $(\theta)$, blade thickness $\left(t_{b}\right)$, the width of the blade $\left(w_{b}\right)$, blade height $\left(h_{b}\right)$, the number of blades $\left(N_{b}\right)$ and the swirler effective area $\left(A_{s w}\right)$. Typical axial swirler designs have blade angles between $30^{\circ}$ and $70^{\circ}$, blade thickness between 0.75 and $1.5 \mathrm{~mm}$, number of swirler blades between 8 and 16 , and blade width between 0.2 to 0.4 times the outer radius [Dodds and Bahr (1990) and Basu et al. (1999)].

\subsection{Swirler pressure drop}

The theoretical analysis of the pressure drop across blade swirlers reported by Mathur and MacCallum (1967) was used in the present work to estimate the pressure drop through the swirler. The fluid flow frictional resistance depends on swirler 
upstream fluid density $(\rho)$ and the velocity of the fluid normal to and upstream of the swirler inlet plane (the reference velocity $V_{\text {ref }}$ ), the surface roughness and wetted surface area. In case of turbulent flow the resistance increases approximately with the velocity squared. The pressure drop across axial blade swirlers $\left(\Delta P_{s w}\right)$ can be found using:

$$
\Delta P_{s w}=\rho \cdot \frac{V_{r e f}^{2}}{2}\left(k 1+k 2 \cdot(\tan (\theta))^{2}\right)
$$

where $k 1$ and $k 2$ are pressure drop constants. For a $30^{\circ}$ blade angle, $k 1$ equals 0.83 and $k 2$ equals 2.9. For values of the pressure drop constants at different blade angles refer to Mathur and MacCallum (1967).

Baukal et al. (2000) presented other empirical formulas for estimating the pressure loss through thin swirl blades as a function of vane angle. Their formulas for thin, flat swirl blades are given as:

and

$$
\begin{array}{cc}
\Delta P_{s w}=\rho \frac{V_{r e f}^{2}}{2}\left(0.02625 \theta^{2}-2.1 \theta+45.5\right) & \text { For } \theta \geq 40^{\circ} \\
\Delta P_{s w}=\rho \frac{V_{r e f}^{2}}{2}(0.0875 \theta) & \text { For } \theta<40^{\circ}
\end{array}
$$

\subsection{Swirler discharge coefficient $\left(C d_{s w}\right)$}

The discharge coefficient is defined by:

$$
\dot{m}_{s w}=\dot{m}_{c o n e}=C d_{s w} \times A_{s w} \times \sqrt{2 \rho \Delta P_{s w}}
$$

where $\dot{m}_{s w}$ is the swirler mass flow rate and $A_{s w}$ is the swirler physical area. The discharge coefficient can be determined by measuring the pressure losses for a certain air flow rate. For radial blades, Alkabie and Andrews (1991) determined the discharge coefficient experimentally for different blade angles $\left(0^{\circ}\right.$ to $\left.70^{\circ}\right)$, by 
measuring the pressure loss for a range of air flow rates. They show that $C d_{s w}$ was independent of the combustor Reynolds number over the range from 30,000 to 70,000 . Some of their findings are: for blade angles $0^{\circ}, 20^{\circ}, 30^{\circ}$ and $45^{\circ}, C d_{s w}$ was $0.92,0.67,0.65$ and 0.61 respectively.

Baukal et al. (2000) showed that $C d_{s w}$ could be assumed to be close to 1.0 in the case of thin axial vanes. If constant area holes or slots are used, then values of 0.75 to 0.8 are typical for $C d_{s w}$ for swirlers with a length/diameter ratio greater than unity swirlers. In the present work, $C d_{s w}$ is assumed to be unity.

\subsection{Swirler physical flow area $\left(A_{s w}\right)$}

The annulus area or the swirler physical area corrected for swirl and flow blockage was calculated by [Mellor 1990]:

$$
A_{s w}=\frac{\pi}{4}\left(d_{o}{ }^{2}-d_{h}{ }^{2}\right) \cos (\theta)-N_{b} t_{b} h_{b}
$$

The effective area for calculation of swirler airflow is given by:

$$
A_{s w-e f f}=C d_{s w} \times A_{s w}
$$

In an axial blade swirler the width of the flow passage at the blade root is smaller than that at the blade tip. When the root-to-tip diameter ratio is small, this leads to a narrower passage, especially at the root of the vanes, resulting in a higher resistance to flow. To reduce the resistance at the root of the vane, the vane root is designed to make the blade side projection wedge-shaped, as shown in Figure 4.10 [Baus et al. 1999]. 


\subsection{Swirler design closure}

Different static mixer configurations were considered for this thesis. An axial swirler with flat blade design was selected for its ease of manufacture. The base mixer design was a single-swirl axial mixer with eight flat blades positioned at an angle of $30^{\circ}$. Other mixers were designed and tested to give a greater understanding of the mixing process. The effect of different static mixer geometries on mixing was investigated using the LSI technique and is discussed in the next chapter.

Five different static mixer configurations consisting of 15 and 30 degree single-swirl mixers, and three double-swirl mixers (concentric with 30 degree blade angle with inner and outer angle directions $+/-,-/+$, and $+/+$ ) were designed for the duct burner premixer. The difference in sign for the angle direction indicates counterrotating swirlers and the same sign represents the co-swirl (rotation at the same angle). All the mixers designed were tested during the LSI phase: only two of them were selected for the combustion test (30 degrees single-swirl mixer and the $(+/-) 30$ degrees double-swirl mixer). The swirler $\left(30^{\circ}\right.$ blade angle $)$ used in this study was selected primarily as a compromise between providing good mixing and pressure drop. The flame stability generated using a swirler is not of concern in this design because the mesh matrix introduced in the combustion zone will act as a flame holder.

Another reason for testing the swirler configuration is that the duct burner will be integrated with a micro-CHP compact unit, which needs a compact duct burner for economy of space. Therefore, mixing in a short distance with minimum pressure drop is a requirement. A double-swirl mixer was included as one of the designs for the duct burner premixer to achieve good mixing [Joshi et al. (1994)]. In the double-swirl mixer, the exhaust gas from the microturbine was divided between the inner swirler (+30 degree swirler angle) and the outer swirler (-30 degree swirler angle) in equal flow areas. The number of blades used for the static mixers was chosen to be 8 for the single-swirl mixer, and 8 inner and 12 outer for the double-swirl mixer [Sawyer 
(1985)] and each blade has a thickness of $1 \mathrm{~mm}$. The swirler effective area was computed following Mellor (1990). The blade root is designed to be shorter than the tip width [Basu et al. (1999)]. The pressure drop calculation across the swirler was initially calculated following Mathur and MacCallum (1967). As the total pressure drop was not to exceed $249 \mathrm{~Pa}$ (1.0 inch of water), the pressure drop across each component of the duct burner was calculated and used as one of the feedback parameters and checked each time during the design process of the duct burner in the design algorithm. Figure 4.11 shows the swirler design process flowchart. Refer to Figure 4.10 for the definitions of the geometrical parameters.

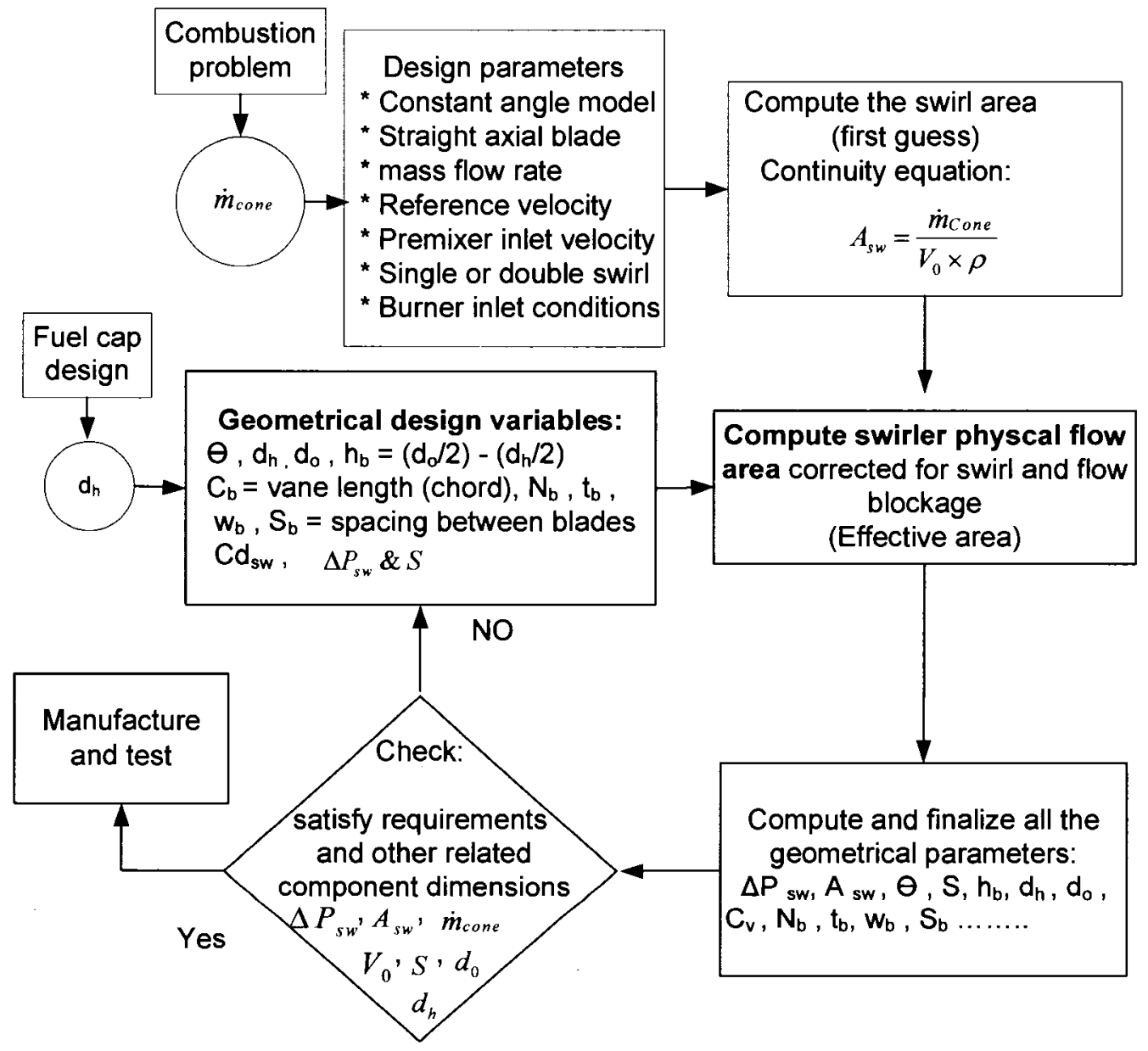

Figure 4.11: Swirler (static mixer) design flowchart 


\subsubsection{Fuel caps}

Different fuel caps (injectors) were designed for the tests. Based on the fuel flow rate considerations (combustion calculation), fuel pressure, fuel temperature and the discharge coefficient, a simple plain orifice fuel injector was designed for the duct burner. In this design, Bernoulli's principle [Blevins (1994)] was used to find the total injector area. To provide a more uniform distribution of the fuel, the total injector area was divided into eight small holes [Sawyer (1985)]. According to those dimensions the fuel pipe diameter was selected. The premixer inner swirler diameter (hub diameter) was chosen to accommodate the fuel pipe. Two types of fuel caps were designed, flat and round caps to accommodate an injection angle of 90 and 45 degrees to the main flow direction respectively. The aim of the present fuel injection technique is to inject the fuel radially from the centre into the swirling turbulent flow region to enhance fuel-oxidant mixing. In addition, different fuel cap holes with diameters of 1.8, 2.3, 2.5 and $3 \mathrm{~mm}$ were designed and built for the testing during the LSI phase. As a result of the LSI studies, the flat caps with 2.3, 2.5, $3 \mathrm{~mm}$ nozzles were used during the combustion tests. Different nozzle sizes were used was to gain an understanding of the effect of the fuel flow rate during the evaluation of the duct burner. Figure 4.12 presents the fuel cap design flowchart and shows the basic design principles used.

The reference cap design was that with eight holes each of $3 \mathrm{~mm}$ diameter and a fuel injection angle of 90 degrees to the main flow. This was designed for a fuel pressure of 2 psig. Using the specifications for the duct burner (fuel pressure range, design fuel flow rate) and the estimated fuel system pressure loss, the additional fuel caps with different hole diameters were designed, manufactured and tested. These additional fuel caps gave greater latitude to the fuel flow rate during the evaluation process of the duct burner. 


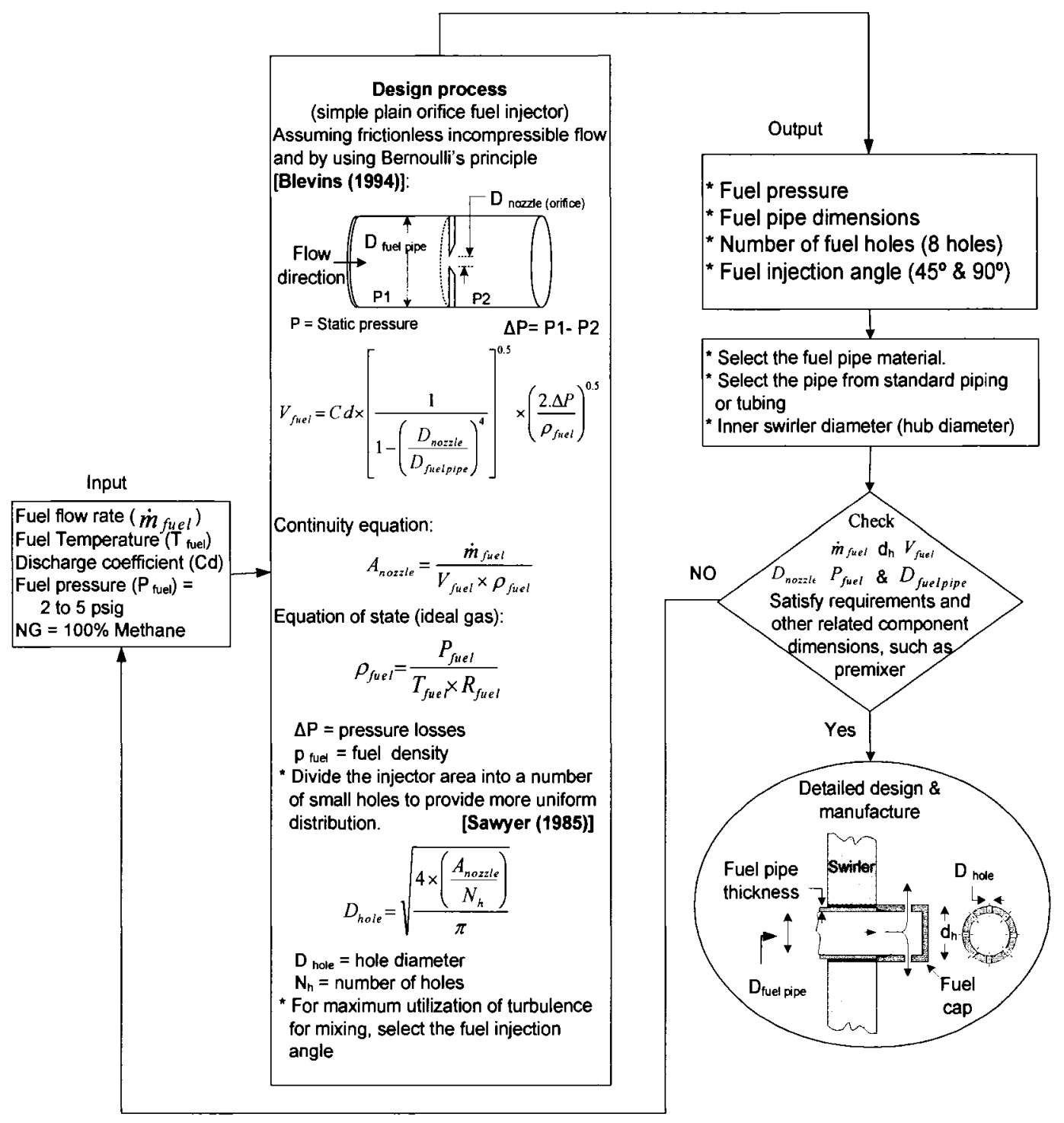

Figure 4.12: Fuel cap design flowchart

\subsection{Fuel jet penetration}

For the purpose of initiating the design the fuel jet penetration inside the premixer was checked. For normal jet penetration, there are different equations available in the literature. Holdeman et al. (1987) provided different jet penetration correlations. Some of those relate to changes in injection angle. In the present 
investigation, the maximum fuel jet penetration distance $\left(\left(P_{\text {dist }}\right)_{\max }\right)$ was estimated using the Lefebvre (1999) formula, which is given by Equation (4. 24):

$$
\left(P_{\text {dist }}\right)_{\max }=1.25 D_{\text {jet }} J^{0.5} \frac{\dot{m}_{\text {flow }}}{\dot{m}_{\text {flow }}+\dot{m}_{\text {jet }}}
$$

where $D_{j e t}, J, \dot{m}_{j e t}$ and $\dot{m}_{\text {flow }}$ are respectively the round jet diameter, the momentum flux ratio, the jet mass flow rate and the main cross-flow mass flow rate.

\subsubsection{Premixer pipe}

The premixer pipe was designed to ensure thorough mixing at all operating conditions. A stainless steel standard pipe of $168.3 \mathrm{~mm}$ (6.625 in pipe Sch-5S) outer diameter was used for the premixer pipe. A similar design procedure was used as that presented in Figure 4.8. The size of the premixer pipe was dictated by two different parameters, the conical wire-mesh burner dimensions and the best mixing length. The diameter of the premixer pipe was fixed as the conical wire-mesh burner base diameter.

For a gas turbine combustor, usually the length of the premixer pipe is based on the length required for evaporation for a liquid fuel-fired combustor and the distance at which auto-ignition occurs. Different correlations are available in the literature for estimating the ignition delay time, such as Mellor (1990) and Liedtke (2002). For a gaseous fuel, the premixer length can be estimated by multiplying the fluid velocity in the pipe by the auto-ignition delay time. Typically, the total residence time in a conventional combustor is 5 to $8 \mathrm{~ms} ; 3$ to $5 \mathrm{~ms}$ is used for fuel vaporization and mixing, and 2 to $3 \mathrm{~ms}$ for mixing of dilution air or oxidant [Dodds and Bahr (1990) and Lefebvre (1983)]. In the present investigation, a correlation from Mellor (1990) and the results presented by Dodds and Bahr (1990) were used to estimate the premixer pipe length. The premixer pipe length was selected to be two premixer diameters (two conical wire-mesh burner base diameter) to give more 
mixing time and space. During the LSI phase, the premixer pipe length was investigated to get the optimum length for mixing.

The premixer is mounted coaxially in the duct burner housing by means of two pairs of four supports. The first pair is the premixer main support, located at 11 $\mathrm{cm}$ from the upstream end of the premixer and 90 degrees apart. The second pair is the premixer hollow supports. The hollow supports were used as ports to make the temperature measurements inside the premixer and as supports to the cone shield. As will be discussed later, this shield protects the flame from the bypass flow to improve flame stability. For full details, the complete engineering drawings are presented in Appendix J. Figure 4.13 shows the overall premixer component dimensions.
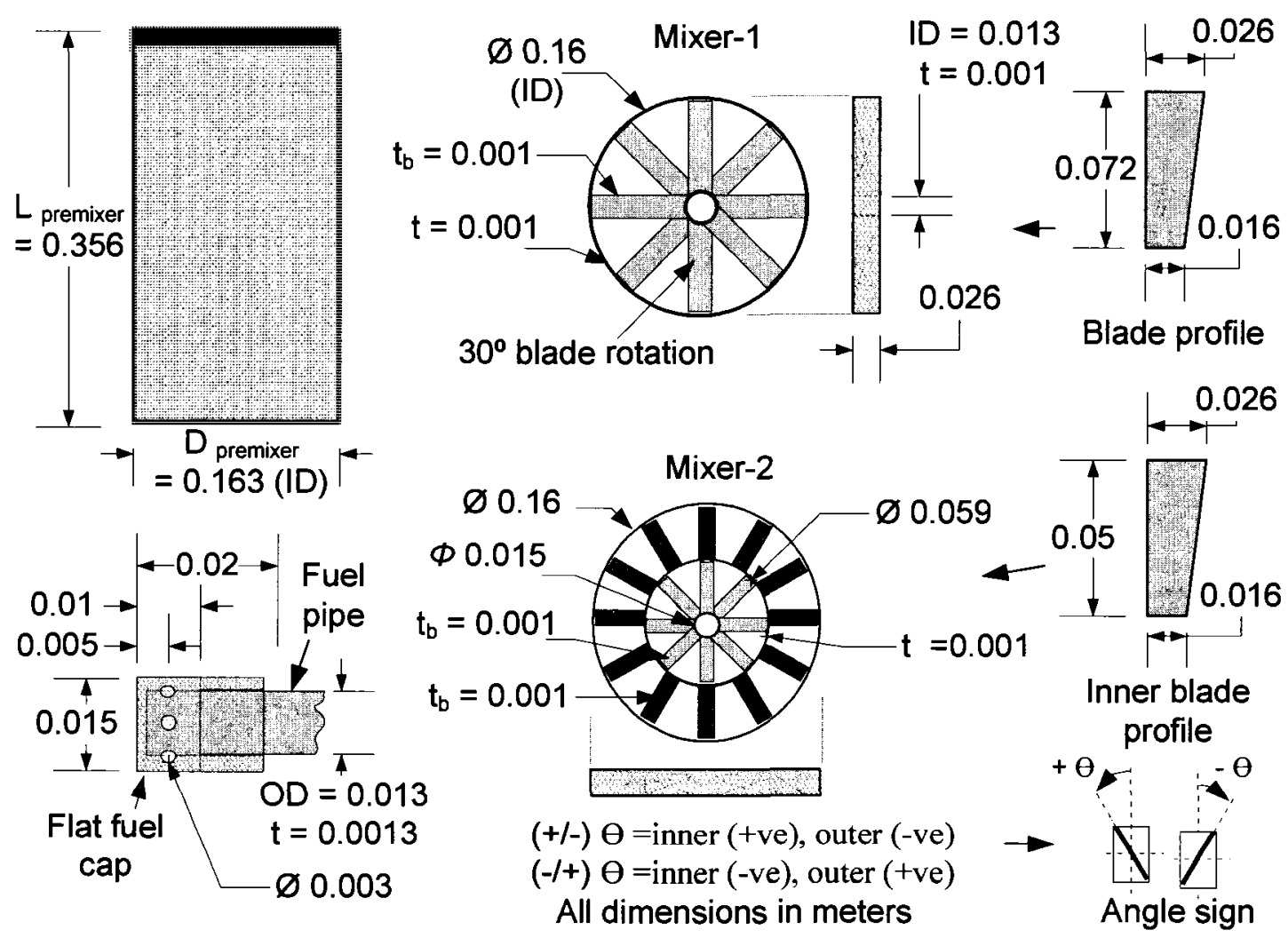

Figure 4.13: Duct burner premixer overall component dimensions 


\subsubsection{Conical wire-mesh burner design}

The considerations for the conical wire-mesh burner design were based on the following parameters: (1) The pressure drop assigned to the conical burner (after estimating the pressure drop in each part of the duct burner, the conical wire-mesh burner pressure drop was calculated); (2) Conical burner diameter; (3) Premixer dimensions; (4) Selection of the method of coupling of the conical burner to the premixer; (5) Heat release per unit area of $2500 \mathrm{~kW} / \mathrm{m}^{2}$ and 100 percent excess air, for low-NOx combustion in the blue flame mode (ACOTECH specification).

The design process was to result in the dimensions of the cone template and the pressure drop estimation for different porosity (open area). A standard pipe coupling was selected for attaching the conical burner with the premixer. The required minimum surface area of the metal fibre burner was found to be $0.094 \mathrm{~m}^{2}$ based on heat release per unit area, see Figure 4.14.

Conical mesh burner

The burner surface area $\left(A_{\text {cone }}\right)$ can be calculated by:

$$
\begin{aligned}
& \begin{array}{c}
\text { Burner surface area }=\frac{\text { Heat released (Equation 4.11) }}{\text { Combustion intensity (Table 4.1) }} \\
A_{\text {cone }}=0.5 \pi D_{\text {cone }} L
\end{array} \\
& H=\sqrt{\left(\frac{A_{\text {cone }}}{0.5 \pi D_{\text {cone }}}\right)^{2}-\left(\frac{D_{\text {cone }}}{2}\right)^{2}}
\end{aligned}
$$

Figure 4.14: Conical wire-mesh burner surface area calculation 
The pressure drop through the mesh burner was only one component of the overall pressure drop of the duct burner. The pressure drop across all the components was first computed as discussed in the sections of this chapter. Then, the value of each pressure drop is subtracted from the overall design pressure drop (199 Pa (0.8 inches of water)). In this way the first pressure drop estimation for the mesh burner was approximately $75 \mathrm{~Pa}(0.3$ inches of water). Correlations from the literature [White (1994), Schetz et al. (1999) and Fuhs et al. (1996)] were used to estimate the functional relationship between the pressure drop and the area ratio (open area / total area). For $75 \mathrm{~Pa}$ pressure drop, the mesh burner must have an area ratio of approximately 95 percent.

Using the performance and physical dimensions discussed above for the conical wire-mesh burner, the company ACOTECH (Advanced Combustion Technology, Bekaert Group and Royal Dutch/Shell Group) manufactured the metal mesh burners for the present investigation. The burner cone template was made of a support cone, with a large open area, covered with the wire-mesh (NIT100S). The NIT100S FeCralloy panel composition is made of $20 \%$ Chromium (Cr), $5 \%$ Aluminium (Al), Yttrium $(\mathrm{Y})>0.1 \%$, 0.3\% Silicon $(\mathrm{Si}), 0.08 \%$ Manganese $(\mathrm{Mn}), 0.03 \%$ Copper $(\mathrm{Cu})$, $0.03 \%$ Carbon and the balance Iron $(\mathrm{Fe})$.

To study the effect of the conical burner pressure drop on the performance of the duct burner, a total of three mesh burners with different nominal pressure drops (75 $\mathrm{Pa}\left(0.3\right.$ in $\left.\mathrm{H}_{2} \mathrm{O}\right), 149 \mathrm{~Pa}\left(0.6\right.$ in $\left.\mathrm{H}_{2} \mathrm{O}\right)$ and $224.2 \mathrm{~Pa}\left(0.9\right.$ in $\left.\mathrm{H}_{2} \mathrm{O}\right)$ were manufactured by ACOTECH and used in the present study. The open area corresponding to each conical burner nominal pressure value was respectively 95 percent, 80 percent and 70 percent. The dimensions of the conical wire-mesh burner are shown in Figure 4.15. The wire-mesh burners were attached to the end of the premixer as one part then the assembly was mounted coaxially with the duct burner outer housing by means of the premixer supports, as mentioned in the previous section. 


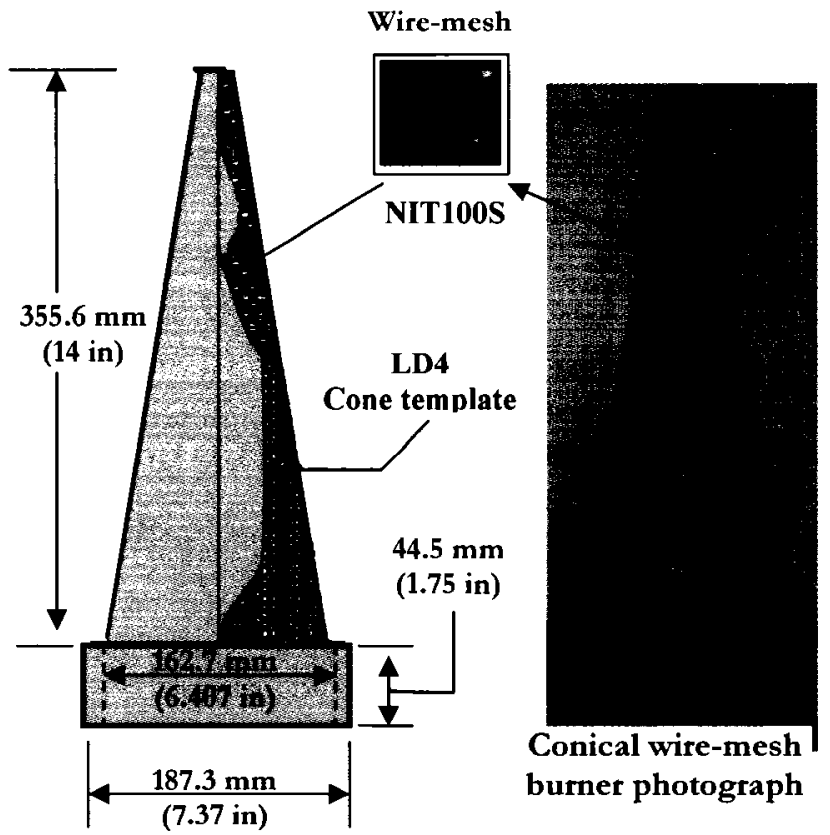

Figure 4.15: Conical wire-mesh burner dimensions

\subsubsection{Annular passage}

The annular passage in the duct burner starts at the leading edge of the premixer and ends at the trailing edge of the cone shield (premixer length (fixed) + cone shield length (variable), to be discussed later). The length of the annular passage depends on the shield length used in a particular test. The width of the annular passage is defined by the distance between the cone shield outer surface and the duct burner housing inner surface. This width depends on the cone shield diameter used for the particular test configuration. The cone shields used will be discussed in the following section.

During the conceptual design process of the duct burner, key assumptions were made in both the combustion and the fluid dynamic calculations. These 
assumptions lead to some uncertainty. For this reason, flat axial movable blades were positioned in the annular passage to provide flexibility and control for stable combustion. Eight flat axial movable blades (annular flow control blades) are located $8 \mathrm{~cm}$ downstream from the leading edge of the annular passage to provide control of the flow through the combustor for stable combustion. The annular flow control blades are adjusted manually by blade handles which move on a scale ranging from 0 to 90 degrees. Figure 4.16 is a schematic of the annular passage section and how the annular flow control blades operate. The blades are used to adjust the microturbine exhaust gas flow split between the conical wire-mesh and the annular passage and to achieve a trade-off between emissions and flame stability.

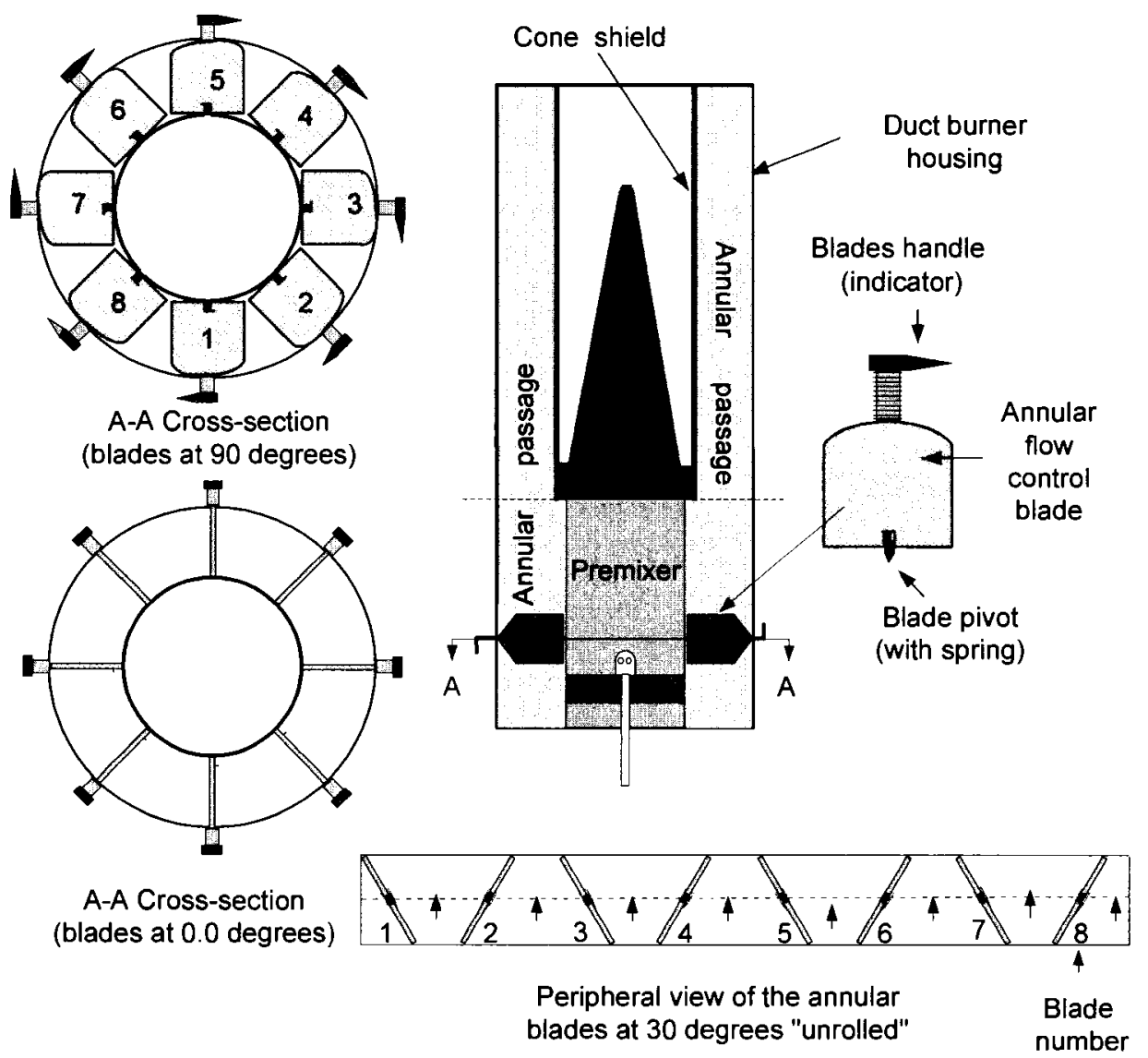

Figure 4.16: Schematic of the annular passage and the blade operation 
Adjusting the blades to zero degrees results in the minimum microturbine exhaust gas introduced into the combustion zone through the mesh burner. The blades set at a 90 degree angle result in the maximum amount of exhaust gas to be introduced through the mesh burner. Figure 4.16 shows a schematic of the annular region of the duct burner and the arrangement of the flow control blades. The figure also shows a cross-section, where the blades are at 30 degrees and the way the blades are adjusted. The blades are operated in such a way that the microturbine exhaust gases flow in convergent-divergent passages to avoid a generation of swirling flow in the annular region. This approach also ensures that the use of a pitot-static tube for flow measurements can be easily done with minimum error.

\subsubsection{Mesh burner shield (cone liner)}

A shield for the cone was introduced to provide a region of stable flow for ignition purposes. In this way, after ignition, the flame can stabilize on the surface of the mesh burner and provides a continuous source of ignition for the incoming mixture flowing through the wire-mesh burner. The cone shield minimizes the interaction of the bypass flow with the mesh burner surface to avoid flame chilling.

The conical burner shield has some of the same functions as the gas turbine combustor liner. In the design of a gas turbine combustor, the liner dimensions are usually estimated as a function of combustor reference dimensions. Sawyer (1985) states that, for a conventional combustor, the liner cross-sectional area should be kept within 60 to 72 percent of the casing (reference) area. Grobman et al. (1957) states that, for a tubular combustor with constant annular cross-section, the ratio of liner area-to-reference area should be in the range of 50 to 60 percent for minimum pressure losses. Because this combustor was to function within a turbine, different design criteria were used. Most of the burner designs available in the literature do not use a liner and their flame is undisturbed from the surrounding flow (i.e. free flame). In the present thesis the ratio of burner shield cross-sectional area to the burner 
reference cross-sectional area is defined as a blockage ratio $\left(B R=D^{2}{ }_{\text {shield }} / D^{2}{ }_{\text {ref }}\right)$ Two different types of shields were used in the design considered here, with blockage ratio values of 0.4 and 0.6 . As the blockage ratio increases, the pressure drop across the duct burner increases, leading to more microturbine exhausts gases entering the combustion zone.

For the duct burner baseline design, a shield with a 0.4 blockage ratio and a length covering 25 percent of the conical mesh burner height (effective length) was used. This shield provides an undisturbed region for the development of combustion on the conical surface. The conical burner shape results in an increase in the distance between the burner surface and the shield inner surface in the downstream direction. This design protects the flame from quenching due to the close shield surface and provides more space for combustion.

To study the effect of shield dimensions on the stability of the flame, different shield designs were tested. Shields covering 50 percent, 75 percent and 100 percent of the conical mesh burner length, with varying blockage ratio were used and their effect on flame stability and emissions (NOx and $\mathrm{CO}$ ) were measured. As will be explained in later sections, two measurement shields were used at the flow balancing test phase. These two shields were used to provide a smooth uniform flow for pitot-static tube measurements. Figure 4.17 shows the schematics of all the shields used in the present investigation with the main shield parameters. The holes on the shields give access to the visualization ports located at the DB outer housing (Pipe 4). One port was used as an igniter port and the semi-circle cut at the bottom was for setting the shield on the premixer hollow supports. 


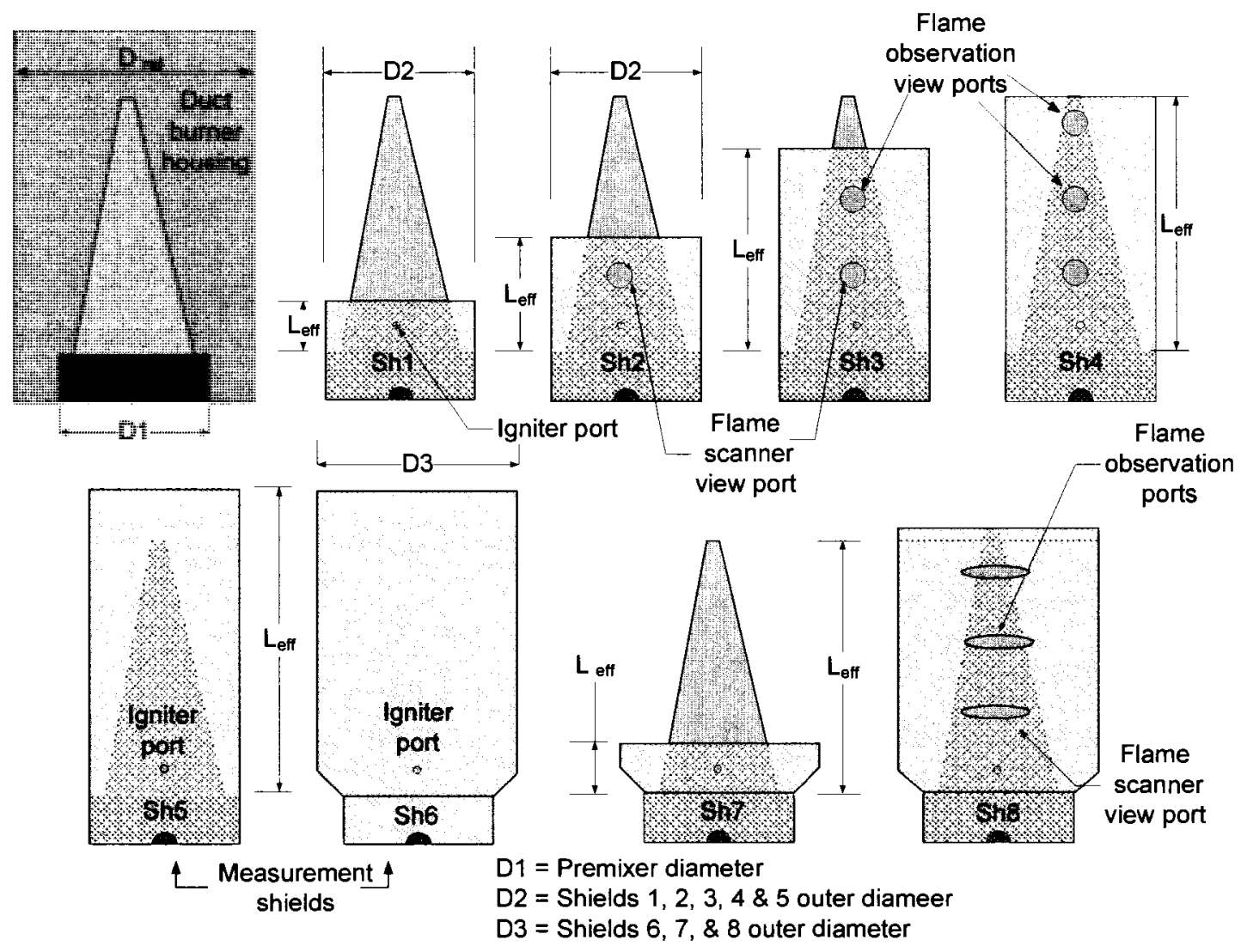

Figure 4.17: Schematic of the different shields used during this investigation

\subsubsection{Duct burner pressure drop}

One of the important parameters used in the design of the duct burner was the overall total pressure drop. Figure 4.18 shows a schematic of the pressure drop calculation process. From the specification, the overall pressure drop limit was set to $249 \mathrm{~Pa}\left(1\right.$ in $\mathrm{H}_{2} \mathrm{O}$ ), see Table 4.1. The value used during the design program was 199 $\mathrm{Pa}\left(0.8\right.$ in $\left.\mathrm{H}_{2} \mathrm{O}\right)$ to account for uncertainties in the correlations used. Operating at a pressure drop higher than $249 \mathrm{~Pa}\left(1\right.$ in $\left.\mathrm{H}_{2} \mathrm{O}\right)$ may have an adverse effect on the turbine performance. The pressure drop across the duct burner was measured during the flow balancing tests (cold flow tests) and during the combustion tests. The pressure drop results will be discussed in later chapters. 


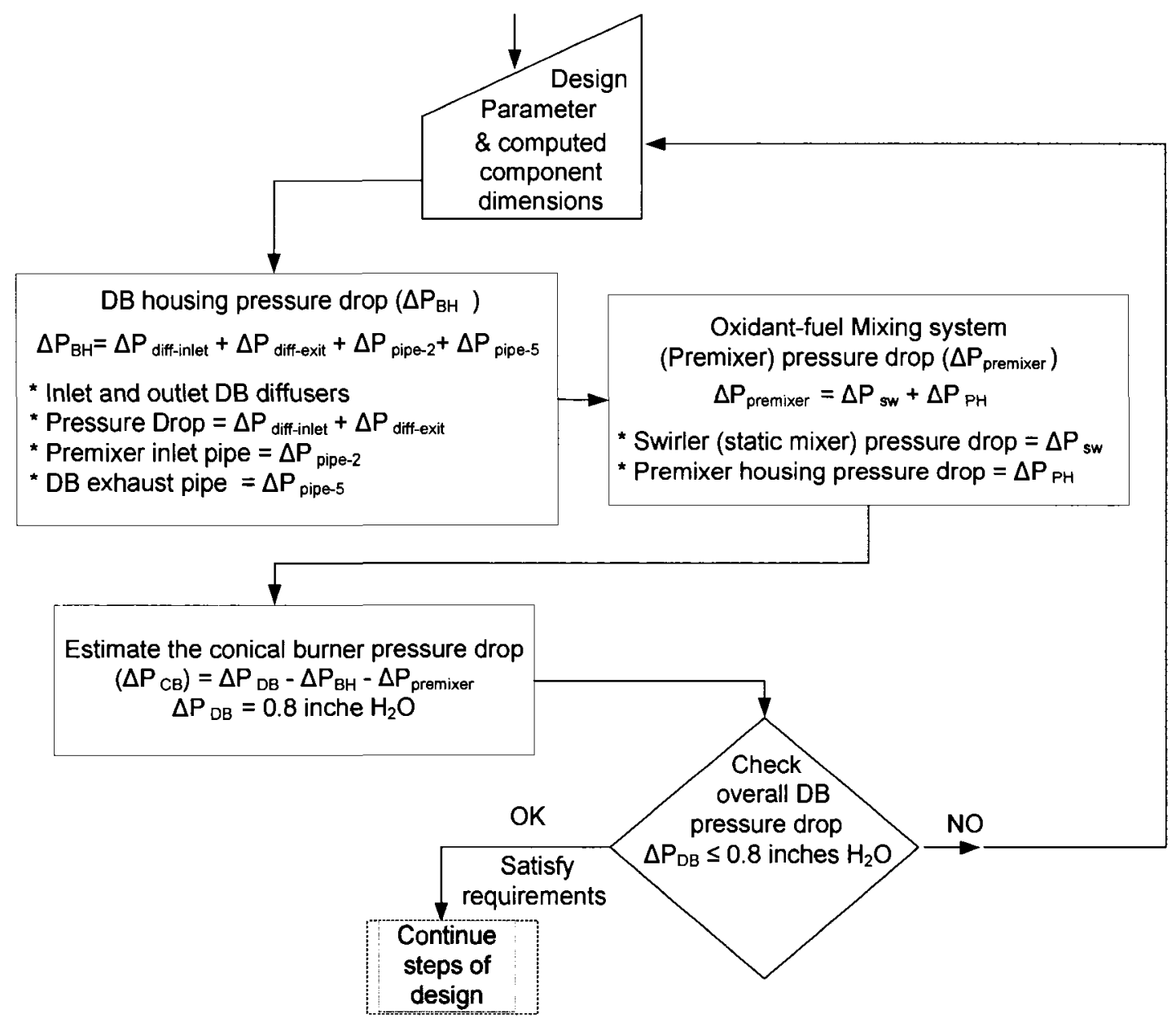

Figure 4.18: Illustration of the calculation process of the DB overall pressure drop

\subsection{Conclusion}

The procedures discussed in this chapter form a methodology for the preliminary design of a conical, wire-mesh duct burner. The complete design processes, including the combustion and the fluid dynamic problems were programmed, using the Mathcad software. This Mathcad code was used during the conceptual design process. 
In this chapter, all the basic design principles and the description of the different components of the duct burner were presented. The effect of annular blade angle settings and the effect of using different cone shields on pressure drop were measured experimentally and will be presented in a later chapter (flow balancing tests). Some of the designed parts were used only during the Laser Sheet Illumination (LSI) tests. LSI technique was used at the design stage to assist the design of the premixer and to select the best combination of static mixers and fuel caps. The objective is to have thorough mixing between the fuel and the oxidizer to minimize NOx formation. Finally, Figure 4.19 presents the duct burner internal assembly and Figure 4.20 shows the overall duct burner schematic. Appendix J gives more details on each component of the duct burner (technical drawings, etc.). Table 4.4 summarizes all the burner geometric parameters used in this work.

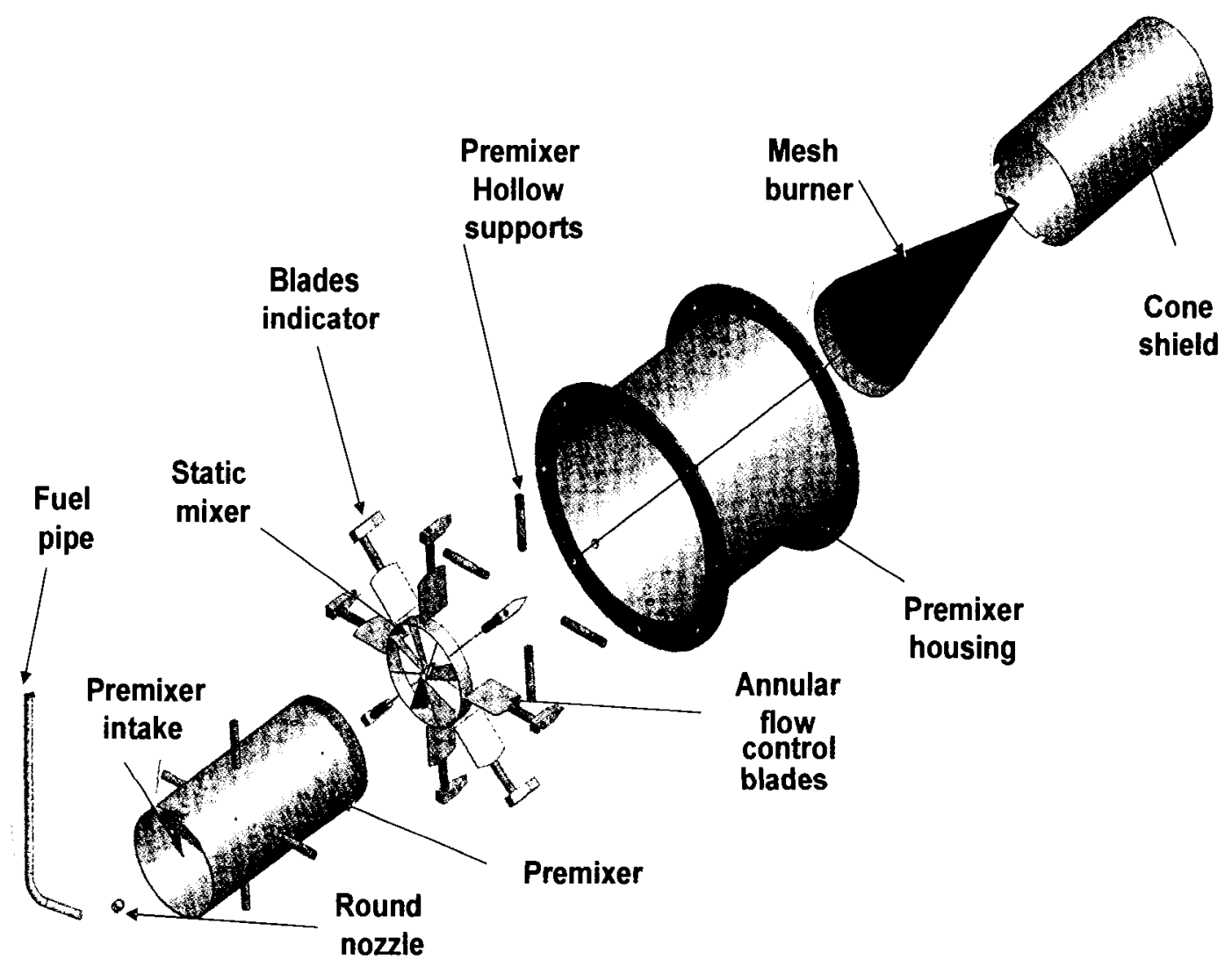

Figure 4.19: Duct burner internal assembly parts 


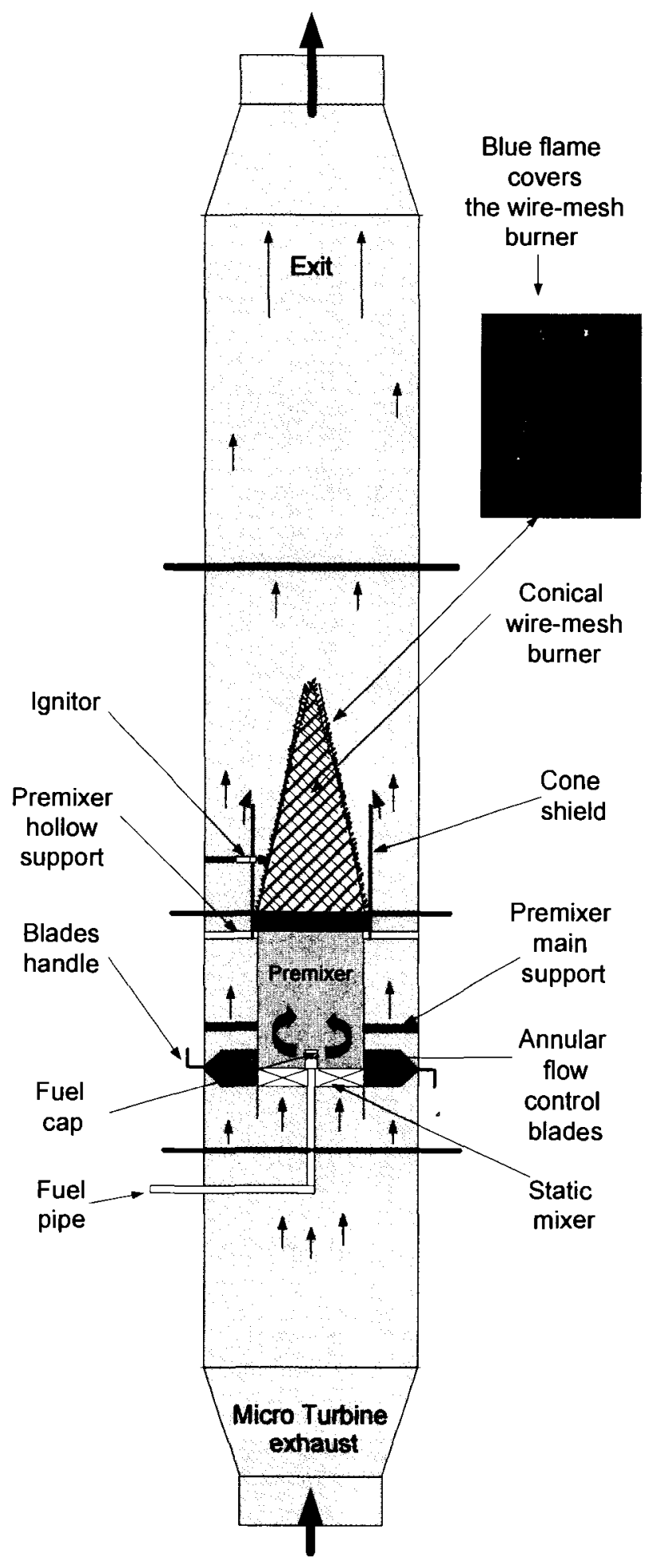

Figure 4.20: Duct burner overview 
Table 4.3: Duct burner geometrical parameters

\begin{tabular}{|c|c|c|c|c|}
\hline \multirow{4}{*}{ Conical wire-mesh } & Cone No. & \multicolumn{3}{|c|}{ Nomical pressure drop, $\mathrm{Pa}\left(\right.$ in $\mathrm{H}_{2} \mathrm{O}$ ) } \\
\hline & Cone-1 & \multicolumn{3}{|c|}{$75(0.3)$} \\
\hline & Cone-2 & \multicolumn{3}{|c|}{$149(0.6)$} \\
\hline & Cone-3 & \multicolumn{3}{|c|}{$224(0.9)$} \\
\hline \multirow{9}{*}{ Shield characteristics } & Shield No. & $L_{e f f} / D_{\text {shield }}$ & BR & $\begin{array}{c}\text { Cone } \\
\text { Covered- } \\
\% \%\end{array}$ \\
\hline & Sh1 & 0.4 & 0.4 & 25 \\
\hline & Sh2 & 0.8 & 0.4 & 50 \\
\hline & Sh3 & 1.5 & 0.4 & 75 \\
\hline & Sh4 & 1.9 & 0.4 & 100 \\
\hline & Sh5 & 4 & 0.4 & 200 \\
\hline & Sh6 & 4 & 0.6 & 200 \\
\hline & Sh7 & 0.3 & 0.6 & 25 \\
\hline & Sh8 & 1.5 & 0.6 & 100 \\
\hline \multirow{4}{*}{ Diameters } & \multicolumn{2}{|c|}{ DB reference diameter $=D_{\text {ref }}$} & \multicolumn{2}{|c|}{$0.315 \mathrm{~m}(12.39 \mathrm{in})$} \\
\hline & \multirow{2}{*}{\multicolumn{2}{|c|}{$\begin{array}{l}\text { Sh1, Sh2, Sh3, Sh4\& Sh5 OD = D2 } \\
\text { Sh6 Sh7 \& Sh8 outer diameter = D3 }\end{array}$}} & \multirow{2}{*}{\multicolumn{2}{|c|}{$0.188 \mathrm{~m}(7.4 \mathrm{in})$}} \\
\hline & & & \multirow{2}{*}{\multicolumn{2}{|c|}{$\begin{array}{l}0.245 \mathrm{~m}(9.63 \mathrm{in}) \\
0.17 \mathrm{~m}(6.625 \mathrm{in})\end{array}$}} \\
\hline & \multicolumn{2}{|c|}{ Premixer outer diameter $=\mathrm{D} 1$} & & \\
\hline \multirow{6}{*}{ Fuel caps } & Cap No & Cap type & \multicolumn{2}{|c|}{ Hole diameter } \\
\hline & Cap-1 & Flat & \multicolumn{2}{|c|}{$1.8 \mathrm{~mm}$} \\
\hline & Cap-2 & Flat & \multicolumn{2}{|c|}{$2.3 \mathrm{~mm}$} \\
\hline & Cap-3 & Flat & \multicolumn{2}{|c|}{$2.5 \mathrm{~mm}$} \\
\hline & Cap-4 & Flat & \multirow{2}{*}{\multicolumn{2}{|c|}{$3.0 \mathrm{~mm}$}} \\
\hline & Cap-5 & Round & & \\
\hline Mixers number & \multicolumn{2}{|c|}{ Type of static mixer } & \multicolumn{2}{|c|}{ Test conditions } \\
\hline Mix-1/1 & \multicolumn{2}{|c|}{ Single-swirl (15 deg.) } & \multicolumn{2}{|c|}{ LSI } \\
\hline Mix-1/2 & \multirow{2}{*}{\multicolumn{2}{|c|}{$\begin{array}{l}\text { Single-swirl }(30 \mathrm{deg} .) \\
\text { Double-swirl }((+/+) 30 \text { deg. }\end{array}$}} & \multirow{2}{*}{\multicolumn{2}{|c|}{$\begin{array}{l}\text { LSI + Combustion } \\
\text { LSI }\end{array}$}} \\
\hline Mix-2/1 & & & & \\
\hline Mix-2/2 & \multicolumn{2}{|c|}{$\begin{array}{l}\text { Double-swirl }((+/+) 30 \text { deg. }) \\
\text { Double-swirl }((+/-) 30 \text { deg. }\end{array}$} & \multicolumn{2}{|c|}{$\frac{\text { LSI }}{\text { LSI + Combustion }}$} \\
\hline Mix-2/3 & \multicolumn{2}{|c|}{ Double-swirl $((-/+) 30 \mathrm{deg})}$. & \multicolumn{2}{|c|}{ LSI } \\
\hline
\end{tabular}




\section{CHAPTER 5: Flow visualization}

\subsection{Introduction}

Flow visualization has played a very important role in the improvement of understanding different fluid flow problems [Tavoularis (2001), Clemens et al. (1990), Goldstein (1996)]. Flow visualization is a technique that can give qualitative information about a flow field. However, using high speed digital cameras, lasers and advanced image analysis, it is possible to derive quantitative information about the flow field. A large variety of flow visualization techniques are available for different flow conditions. For more details on the different techniques used and their principles, refer to Clayton and Massey (1967), Lauterborn (1984), Merzkirch (1987), Eckbreth (1988), Goldstein (1996) and Tavoularis (2005). The Mie scattering technique using a laser sheet is one of the flow visualization techniques used by different researchers [e.g., Durao et al. (1993), Grant et al. (1997), Gal et al. (1999), Solero and Coghe (2000), Harinaldi et al. (2001), Stowe (2001)]. The planar Mie scattering technique is a diagnostic approach that produces images of the flow field and has widely been used for flow visualization in gas phase flows due to its simplicity [Clemens (1991)]. The basic idea of the laser sheet visualization technique is to illuminate a seeded flow by means of a sheet of laser light and to record the scattered light.

The planar Mie scattering technique was adopted in this study to identify the design and operating parameters that will provide rapid and enhanced mixing between the oxidant (microturbine exhaust gases) and the fuel inside the duct burner premixer. 


\subsection{Objective of the flow visualization study}

The mixing of the air and fuel is critical for the reduction of NOx emissions from premixed combustion burners. It is important to achieve near perfect premixing, to avoid regions that can generate locally high flame temperatures leading to high level of NOx emissions [Leonard and Correa (1990), Jeffery and Warren (1995)]. For this reason the mixing process between the fuel and the oxidizer in the burner premixer was studied in detail. The effect of premixer geometry and the flow conditions on mixing of the oxidant and the fuel was first examined by performing qualitative flow visualization tests. In this way the geometrical variables (static mixer type, single- and double-swirl mixer, blade angle, premixer length and fuel injector types) can be optimized for maximum burner performance.

Specifically, the objectives of this phase of the study were to:

- Investigate the burner premixer flow field using the laser sheet flow visualization technique and capture images to be used to compare effectiveness of the mixing processes,

- Identify and characterize the effects of burner premixer geometry as well as the operating parameters on the mixing processes,

- Develop measuring techniques and a data analysis procedure that permits a quantitative evaluation of the mixing effectiveness for the different premixer geometries and operating conditions (predicts quantitative information from the qualitative images obtained),

- Use this technique to assist in the design of the burner by introducing an effective premixer that could be used in this new application.

\subsection{Laser sheet illumination technique}

The laser sheet illumination technique (hereafter referred to as LSI) was used to test the mixing of the oxidant and the fuel. The LSI or LSV (V for visualization) 
technique is a non-intrusive optical diagnostic procedure which is relatively inexpensive and can quickly demonstrate how flow fields interact. In this study, using this technique, a laser sheet illuminates the plane of interest (a two-dimensional crosssection) inside the premixer so that the air and "fuel" jet mixing can be easily recorded as images. The images provided by this technique show the occurrence of regular, periodic structures in the flow field under observation.

The novel aspects of this technique as applied here consist of: (1) the experimental acquisition of images and (2) the computer image processing and analysis. This section includes a description of the various components of the LSI system used in the present study.

\subsubsection{The experimental acquisition of images}

This part can be divided into three components; (1) the experimental set-up (test rig), (2) the laser and optical set-up and (3) the image acquisition equipment. The following subsections describe briefly each part.

\subsubsection{Experimental set-up}

The premixer test facility was designed and set up to study the mixing process. The test rig is made of Plexiglas to permit optical access. A schematic diagram of the LSI premixer test rig is shown in Figure 5.1. The premixer was tested at full scale in this fully transparent test rig. A relatively long premixer tube was used to minimize the effect of flow turning at the premixer exit (Plexiglass Box 2 Figure 5.1). Figure 5.2 shows the Plexiglas premixer (test section) and the relevant dimensions.

During the design of the LSI experiment, to achieve similarity between the real flow field and the flow used in the LSI tests, the two main parameters to be considered are the geometry and Reynolds number. Geometrical similarity was achieved using the full-scale premixer (approximately the same dimensions, see 
Figures 4.14 and 5.1). The Reynolds number for the real flow situation tests is sufficiently high $(\operatorname{Re}>50000)$ and as such the flow is dominated by turbulent mixing. For this reason the Reynolds number is not a parameter that is to be matched for the LSI tests, as long as it is sufficiently high to respect dynamic similarity $(\operatorname{Re}>50000)$. Therefore, the momentum ratio (defined in Eq. 5.1) was the parameter matched between the real model (duct burner) and the physical or cold flow LSI model.

$$
M M R=\frac{\dot{m}_{\text {fuel }} V_{\text {fuel }}}{\dot{m}_{\text {flow }} V_{\text {flow }}}
$$

where $M M R, \dot{m}_{\text {fuel }}, \dot{m}_{\text {flow }}, V_{\text {fuel }}$ and $V_{\text {flow }}$ respectively are the momentum ratio, fuel stream mass flow rate, mainstream mass flow rate, fuel exit velocity and the mainstream inlet velocity.

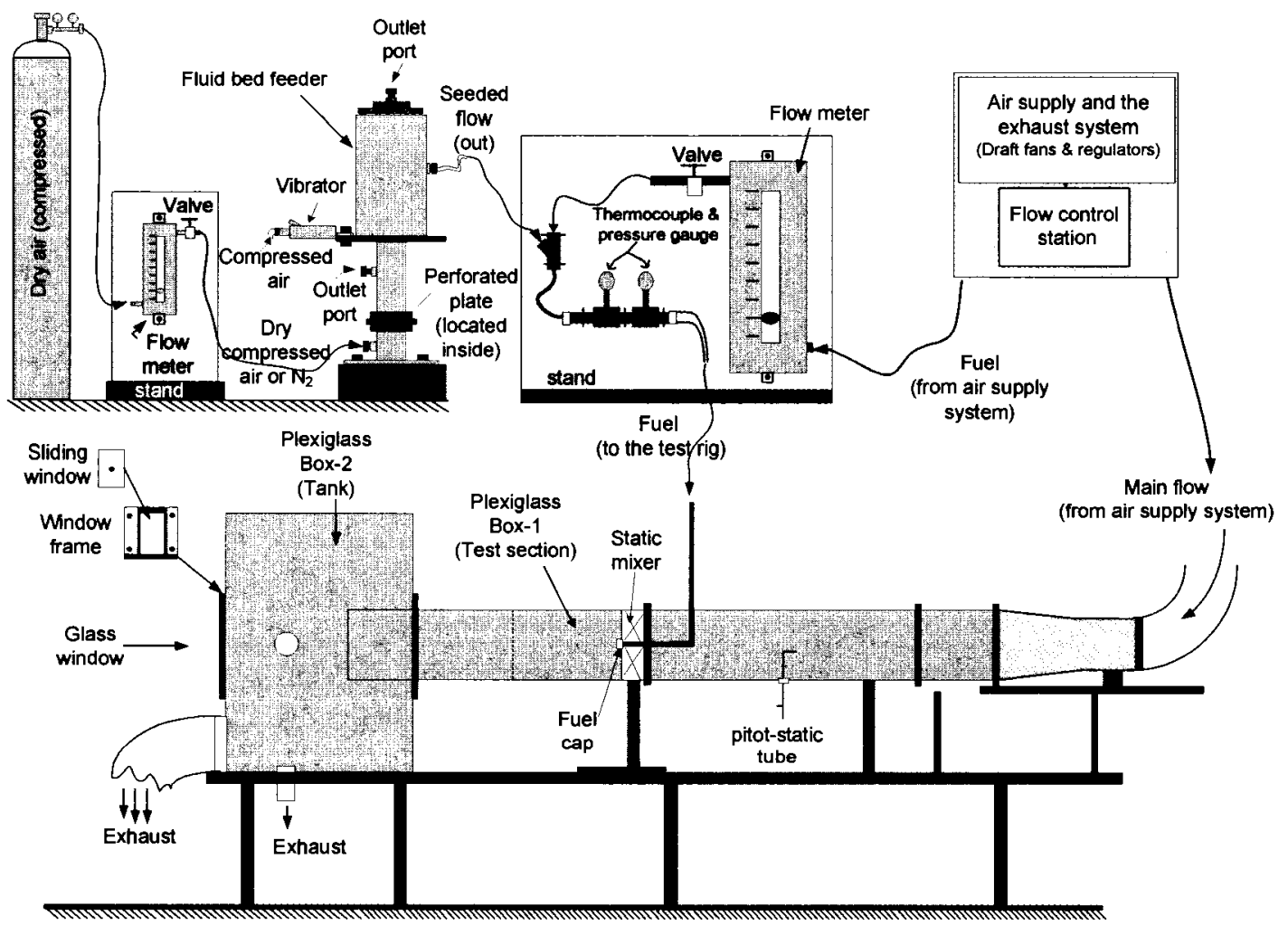

Figure 5.1: Schematic of the LSI test rig with air, fuel and the seeding systems 


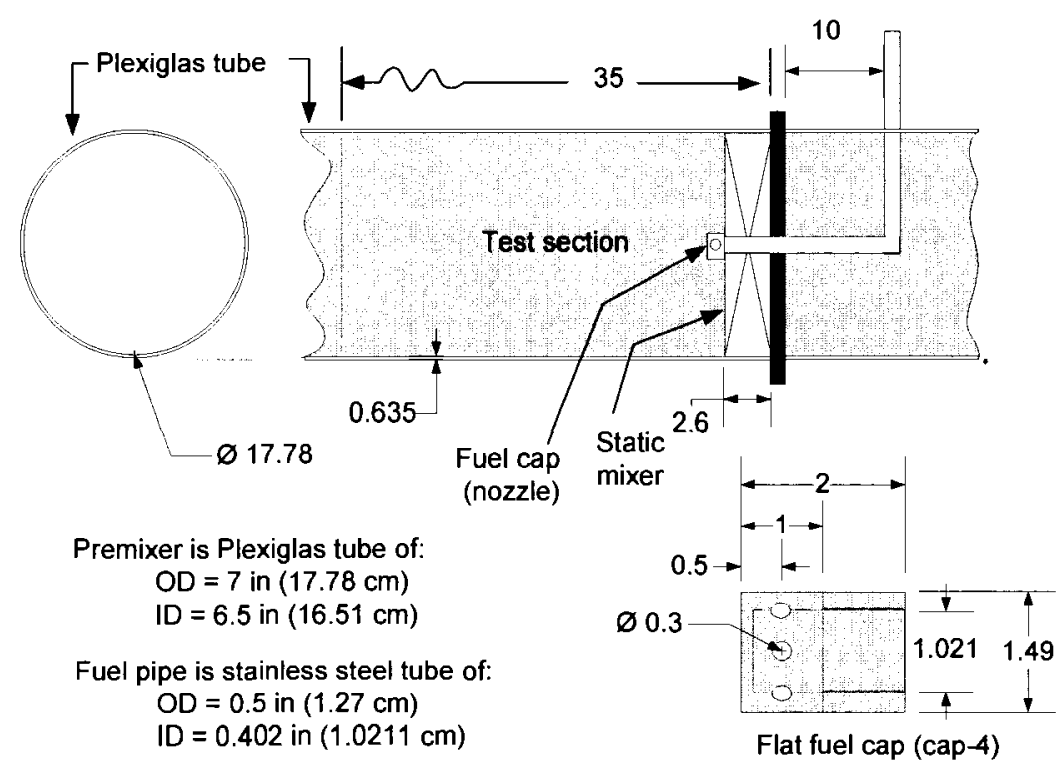

All dimensions in $\mathrm{cm}$

Figure 5.2: Schematic of the Plexiglas test section (premixer) and its dimensions

The description of the premixer and its components was presented in Chapter 4. The premixer has a centrally positioned fuel tube, coaxial with the swirling flow where the swirling flow is introduced through a static mixer of different designs. Two different fuel injection methods were investigated; (1) transverse injection through eight holes (different hole diameters were used), inclined holes (at 90 degrees to the co-flowing air stream) (referred to as flat caps) and (2) transverse injection through the same number of holes at 45 degrees (referred to as round caps). The relevant dimensions of the premixer and its components are presented in Figure 4.14; full details are available in Appendix J.

During the tests, the premixer model was installed in the Plexiglas tank at the adapter and air was supplied to the "fuel" and air inlet of the premixer. In this case, air simulated both the fuel and microturbine exhaust gases flowing through an actual test rig. The air supply system consisted of a forced-draft fan, which supplied the air for the test rig. The flows were regulated and monitored by a CPU-based control 
station. The air supply system could supply the two inlets, gas and air, ranging from 0 to $55 \mathrm{CFM}$ for the gas and 0 to $800 \mathrm{CFM}$ for the air.

\subsection{Seeding particles}

Selecting the proper seeding particles is a difficult task in any flow visualization work. It is important that the seeding particles be very small to faithfully follow the flow under the level of fluctuations and large enough to scatter the required amount of light. The characteristics of seeding particles such as the particle diameter, concentration, refractive index, density of particles, type of the laser, and thickness of the light sheet play a major roll in the accuracy of the system. The light sheet dimensions and the laser characteristics together indicate qualitatively the interaction between the choice of the particle diameter and the scattered light intensity

The choice of the size of the seeding particles is dependent on the measurement objectives. When measuring turbulent flow characteristics such as velocity, small size particles are needed. Using small particles size $(\leq 1 \mu \mathrm{m})$ it is necessary to have higher power laser energy. For larger particles less energy is used [Melling A., (1997)].

Alumina particles are favoured for seeding flames and high temperature flows and also offer the advantage of a high refractive index. Anderson et al. (1996) used alumina as seeding particles in their investigation of the flow around wind turbine rotors using particle image velocimetry (particle diameter of $3 \mu \mathrm{m}$, density $=3970$ $\mathrm{kg} / \mathrm{m} 3$, refractive index $=1.76, \mathrm{Nd}$ : YAG laser of $9 \mathrm{~mJ}$ pulse energy and $6 \mathrm{~ns}$ pulse time).

In the present investigation, the objective of the LSI tests is to study the mixing between the fuel and the air at the macro scale level with the purpose to rank the different swirl geometries. Therefore, the "fuel" flow was seeded uniformly with alumina particles $\left(\mathrm{Al}_{2} \mathrm{O}_{3}\right)$ to distinguish it from the main air flow and to follow the mixing. The particles are classified in the size range 3 to $7 \mu \mathrm{m}$. 


\subsection{Seeding system}

The particle feeder was a small fluid bed feeder fluidized with dry compressed air with controls for the pressure and flow rate. The particle feeder had two ports from which particles could be extracted, depending on the concentration needed. Figure 5.1 shows the schematic of the seeding system used and how it was integrated with the premixer test rig. The seeding system consisted of the fluid bed feeder, compressed dry air cylinder, vibrator, flow meters, thermocouples, pressure gauges and flow control valves. Two flow meters were used, one to measure the simulated fuel flow rate from the main air supply system and the other to measure the seeded air flow part. The figure also shows the main air and the fuel supply systems.

\subsubsection{Laser and optics set-up}

Figure 5.3 shows the laser and the optics (basic devices) used in this laser sheet illumination technique. When a laser beam travels through a cylindrical lens it spreads as a triangular thin sheet of monochromatic coherent light. The standard cross-sectional planes of illumination are vertical (Y-Z plane) and horizontal (X-Y plane). The laser sheet used to illuminate the plane of interest inside the burner premixer for this work was produced by a $2 \mathrm{~W}$ Argon Ion Continuous Wave Laser operating single-line at $514.5 \mathrm{~nm}$ with beam diameter of $1.3 \mathrm{~mm}$. The laser was formed into a vertical sheet by a $6.35 \mathrm{~mm}$ focal length cylindrical lens. The sheet thickness was approximately $2 \mathrm{~mm}$ throughout the test section measurement area. The laser light sheet has a Gaussian intensity profile [Asanuma (1986) and Thiery et al. (1996)]. 


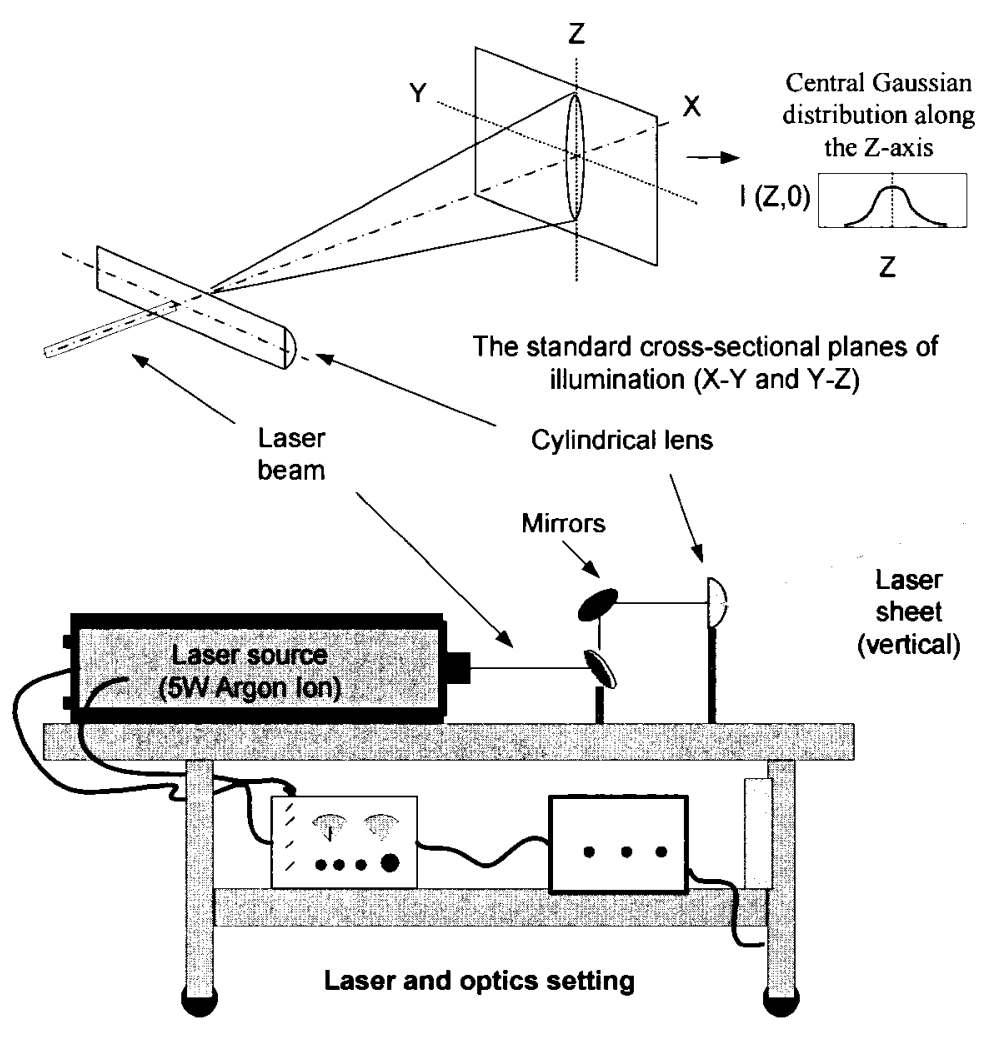

Figure 5.3: Schematic of the laser sheet generation devices

\subsubsection{Imaging equipment}

Figure 5.4 shows the LSI imaging equipment. The equipment used is divided into two parts: (1) the camera and (2) the data acquisition system. The camera used to record the images during this phase of the thesis was a water cooled Princeton Instruments (PI) Intensified Charge Coupled Device camera, model number ICCD576-LDG. The ICCD is a device that amplifies the intensity of the image and can be saturated at $\left(1 / 10^{\text {th }}\right)$ the light level an unintensified CCD. For this reason only a laser power of 1 Watt was used during all the LSI tests. This ICCD camera has a $576 \times 384$ full frame CCD pixel array. The CCD array was cooled by a thermoelectric cooler. Water was used as a coolant to carry away the heat generated by the thermoelectric cooler in the ICCD camera. Nitrogen was used to continuous flushing of the detector 
to avoid condensation on the CCD. The camera specifications are presented in Appendix E.

The data acquisition system connected to the detector consisted of a controller and a pulse generator. The controller (PI, model ST-130) was used to regulate the internal temperature of the camera, to receive the data from the camera and transmit it to the computer, where it could be viewed as an image in "real time" using the WinView software. The pulse generator could be used to control the exposure time of the camera as well as the delay between exposures.

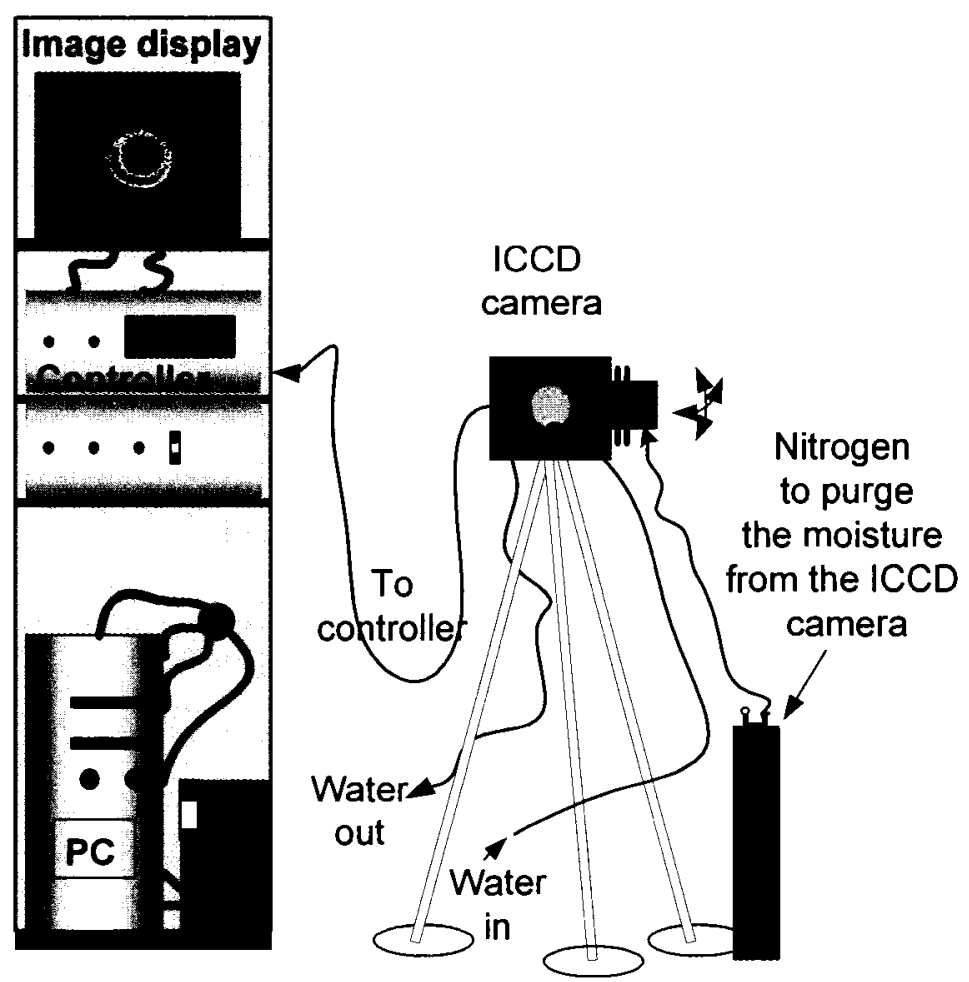

Figure 5.4: Schematic shows the imaging equipment

\subsubsection{The computer image processing and analysis}

The development of a correction procedure for images taken using LSI is essential for an accurate representation of the flow field. To ensure accurate visual representation of the flow field as a digital image, a correction procedure was applied 
to each image. The images were corrected for the intensity variation across the laser sheet (illumination non-uniformities), background (noise) and any variation in the response of the ICCD camera pixels [Eckbreth (1988)].

The illumination non-uniformities in the illuminated region are the result of two different causes; (1) the laser source, due to the Gaussian intensity variation in the profile and (2) the presence of seeding particles in the path of the incident light decreases its intensity in the forward direction (scattering and absorption). Koochesfahani (1984), Ferrier et al. (1993), Su et al. (1998) and Crimaldi et al. (2001) described and used correction algorithms for the laser non-uniformity.

Correction for the non-uniformity of the light distribution across the flow field in this thesis was performed using a LaserSheet 4.0 program written by Belanger et al. (2000). The program computes a theoretical approximation of the amount of light energy that illuminates each effective area seen by each pixel of the CCD array, including the distance factor. The result of these computations is referred to as a Gaussian template for each experimental set-up. The correction was performed by dividing each captured frame by the Gaussian template.

After the acquired images were corrected for the laser non-uniformity, the images were corrected for the variation in response of the CCD camera, pixel by pixel, using the following formula [Crimaldi et al. (2001), Watkins et al. (1993) and Clemens (1991)]:

$$
C I=\frac{(A D I)-(B G I)}{(F F I)}\left(A I_{F F I}\right)
$$

where $C I$ is the corrected image (frame), $A D I$ is the original acquired data image corrected for light non-uniformity, $B G I$ is the background image, $F F I$ is the flat field image (as a normal data file) and $A I_{F F I}$ is the average light intensity of the flat field image corrected from the CCD fixed pattern signals (dark charge or bias frame). A dark charge frame ( $D C I$ ) should be subtracted from all types of collected images, such as the background $(B G I-D C I)$ and the flat field images $(F F I-D C I)$. 
The dark charge frame is the fixed pattern signal that occurs with no light incident on the camera. It is captured with no illumination into the camera or by a completely blocked detector (when the lens cap is on). This frame accounts for pixels which have an offset from zero. The background frame is due to reflections of the laser from walls and windows or particles not of interest and external light sources. The background image was taken with the laser running and without the scattering particles. This background image is also affected by the dark charge of the detector. Therefore, the dark charge image had to be subtracted from the background image. The flat-field or the white-field frame image is due to a non-uniform pixel response. This was done by illuminating a flat, uniform white surface (card) and capturing an image of the surface with the camera. This image also corrected for the dark charge. In the present work, to achieve a uniform light distribution, a flat-field box was used, see Figure 5.5.

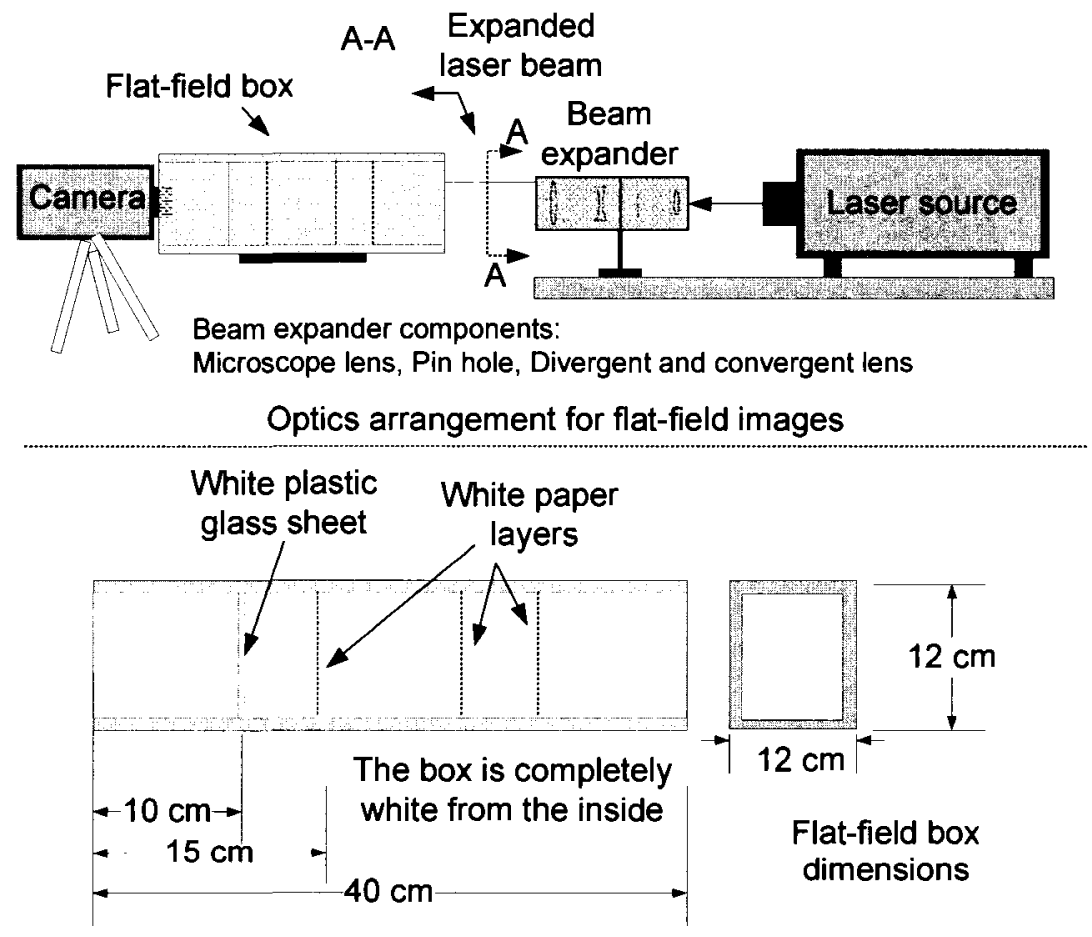

Figure 5.5: Flat-field image optical arrangement with the flat-field box dimensions 
After all the necessary corrections were made, various weighting schemes could be used to improve the visual quality or to emphasize certain aspects of the images. Visualization of the data was performed on a PC using WinView (version V1.6.2.) in real time while running the experiments. ERGOvista (version 4.4.1) is another software package used during the data processing. This latter program is capable of generating two- and three-dimensional plots of the intensity data and extracting other information such as the statistical data used for computing the unmixedness which will be defined in a later section. Another package called MathLab was also used in processing some of the images.

\subsection{The LSI test set-up}

Two different optical arrangements were used for the LSI tests: (1) a vertical cross-section (see Figure 5.6) and (2) a lateral cross-section (see Figure 5.7). In the first set-up, the images produced by the light scattered from the alumina particles were recorded at $90^{\circ}$ by the ICCD camera (Figure 5.6). The camera was placed facing the static mixer from the downstream location. For this set-up, the experimental analysis was performed at eight different axial distances from the exit plane of the static mixer, starting at the fuel cap edge. Figure 5.8 shows a schematic of the Plexiglas premixer and the locations of the imaging planes. The image planes were: fuel cap exit plane, and planes located at $0,5,10,15,20,25$ and $30 \mathrm{~cm}$ measured from the fuel cap edge. The other set-up is illustrated in Figure 5.7. In this arrangement the camera was positioned facing the side view of the test section and the laser was at $90^{\circ}$ to the camera. The lateral images were taken on the centreline plane of the test section assuming symmetry in the flows and geometry. To view the plane of interest in this case, the location of the camera and the optics table were moved from that of the first case. Only one plane was used when capturing the lateral images. 


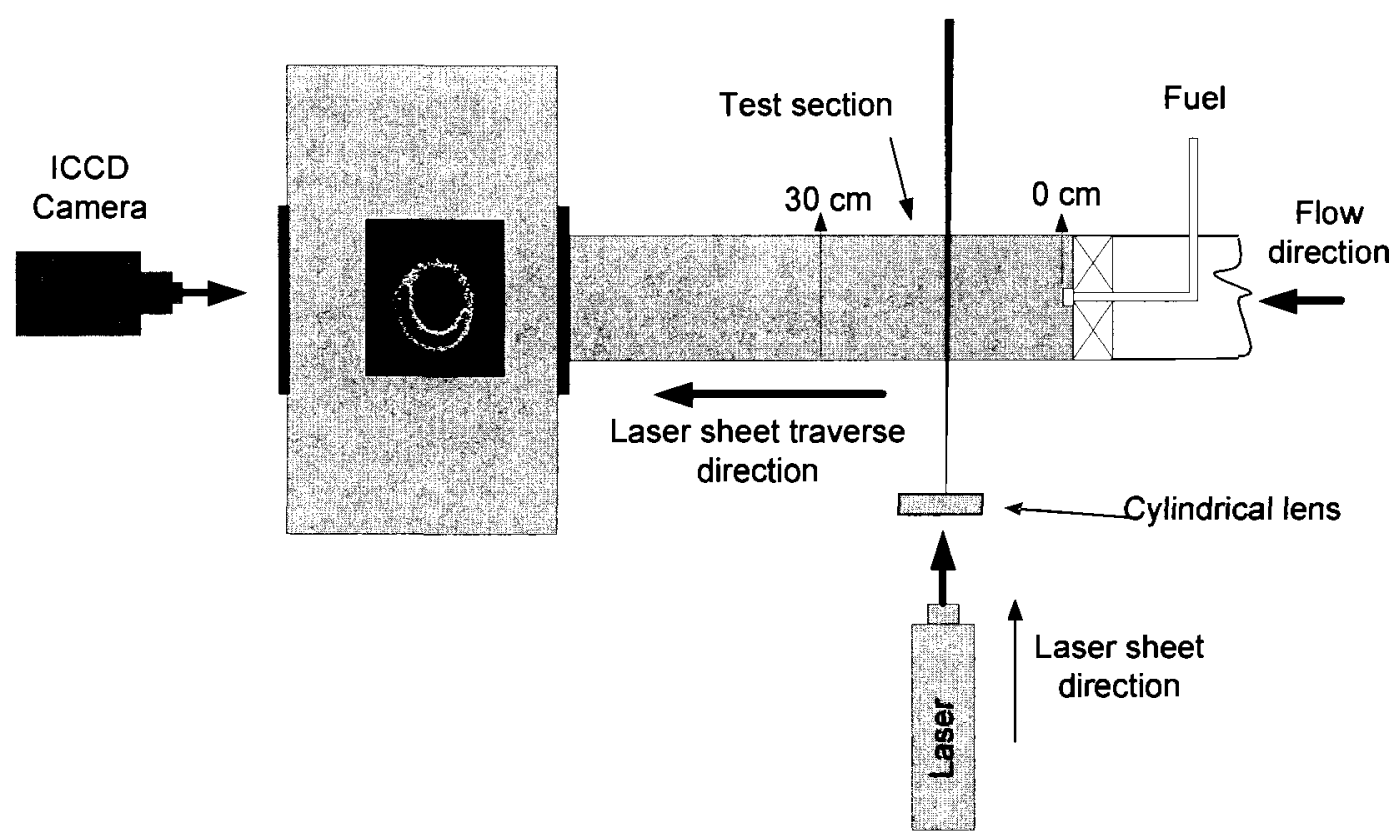

Figure 5.6: Schematic of the optical arrangement for vertical image set-up

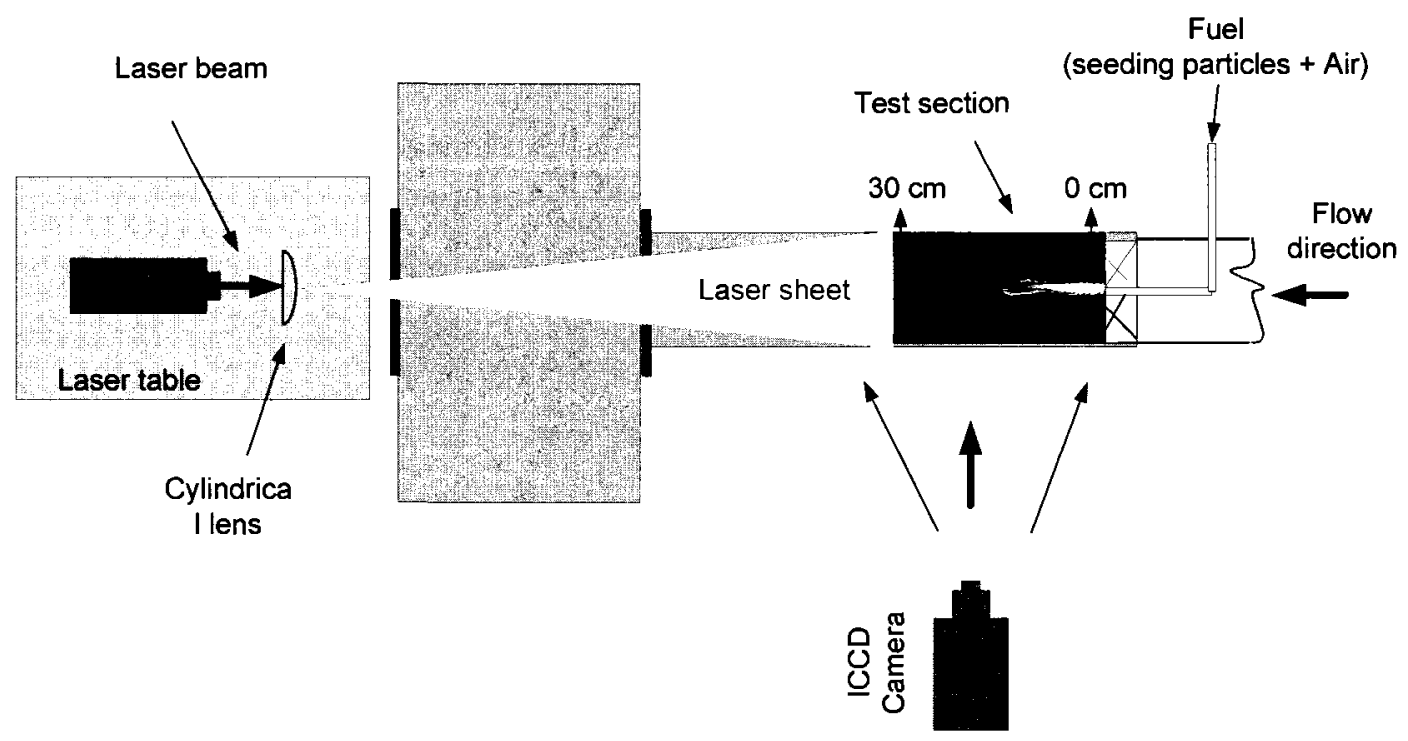

Figure 5.7: Schematic of the optical arrangement for lateral image set-up 

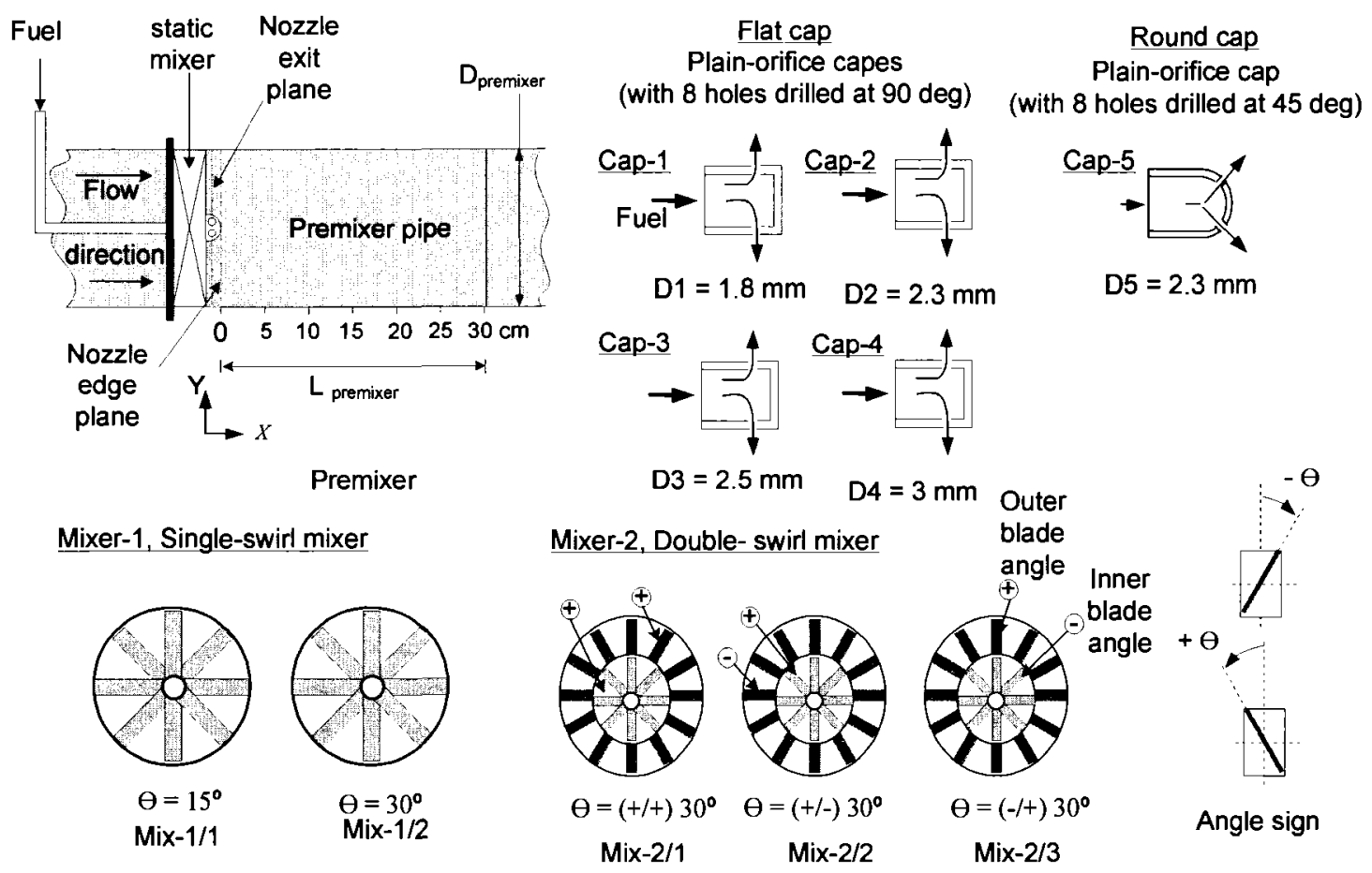

$\underline{\theta=\text { blade angle }} \& \underline{D=\text { nozzle diameter }}$

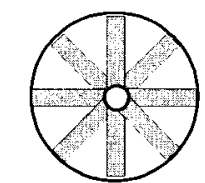

$\theta=15^{\circ}$

Mix-1/1

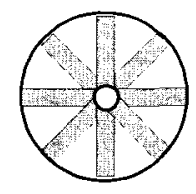

$\theta=30^{\circ}$

$\operatorname{Mix}-1 / 2$
Mixer-2, Double- swirl mixer

Mix-2/1

Mix-2/2

Mix-2/3

Round cap

8 holes drilled at $45 \mathrm{deg}$ )

$\mathrm{D} 5=2.3 \mathrm{~mm}$

Figure 5.8: Schematic of the LSI geometrical variables

\subsection{The Experimental variables}

The key factors governing the turbulent mixing are velocity, density and momentum ratios (fuel-to-air), angle of fuel penetration, mixing path length, geometry of the fuel nozzles, and the inlet velocity profiles of the fuel and the main stream. In this study, the effects of some of the above mentioned parameters on the mixing process inside the duct burner premixer were investigated qualitatively using the LSI technique.

During the LSI tests, the experimental variables were; (1) premixer length (eight planes), (2) flow mixer type (single- and double-swirl mixer type and strength (different angles)), (3) fuel injector caps (injection angle and nozzle diameter), (4) equivalence ratio ( $\phi=0.5$ (design condition) and $\phi=0.3$ ) and (5) the momentum 
ratio $(0.23,0.33,0.39$ and 0.64$)$. Figure 5.8 shows the schematic of the LSI geometrical variables. Table 5.1 presents the different fuel cap characteristics used in the present investigation (shown in Figure 5.8). The experimental matrix used for the LSI phase is presented in Table 5.2. For the vertical cross-sectional image set-up, each experimental run shown in Table 5.2 was performed at different axial distances from the exit plane of the static mixer from $X / D_{\text {premixer }}=0.06$ to 2 (eight locations). The first two planes were at the nozzle exit ( $X=0.06 \mathrm{D}_{\text {premixer }}$ ) and the edge of the fuel cap ( $X=0.12 \mathrm{D}_{\text {premixer }}$ or $0 \mathrm{~cm}$ from the fuel cap edge, see Figure 5.8). Subsequent image planes were at $5 \mathrm{~cm}$ separation intervals up to the plane located at the premixer end $\left(2 D_{\text {premixer }} \approx 30 \mathrm{~cm}\right.$ from fuel cap edge). $X$ represents the axial distance starting from the downstream face of the static mixer and $D_{\text {premixer }}$ represents the premixer pipe inner diameter (see Figure 5.8). For the lateral cross-sectional image set-up, Table 5.2 gives the run numbers for the tests. Table 5.3 summarizes the static mixer characteristics used in the present investigation. . As there is no standard for quantifying the strength of the swirl inside the present investigation premixer (pipe), Equation 4.17 was used with the static mixer dimensions shown in Figure 4.13 to estimate the swirl number for all the tested mixers. In Table 5.3, the combined geometrically determined swirl number is taken as the square root of the sum of the squares of the inner swirl number and outer swirl number [Stacey (2005)]. The standard operating characteristics used are summarized in Table 5.4. The standard operating characteristics used are summarized in Table 5.4.

Table 5.1: Fuel cap characteristics

\begin{tabular}{|c|c|c|c|c|}
\hline $\begin{array}{c}\text { Fuel } \\
\text { cap }\end{array}$ & $\begin{array}{c}\text { Number of } \\
\text { holes in cap }\end{array}$ & $\begin{array}{c}\text { Fuel nozzle } \\
\text { diameter } \\
\text { (mm) }\end{array}$ & $\begin{array}{c}\text { Fuel injection } \\
\text { angle } \\
\text { (o) }\end{array}$ & Cap shape \\
\hline Cap-1 & 8 & 1.8 & 90 & Flat \\
\hline Cap-2 & 8 & 2.3 & 90 & Flat \\
\hline Cap-3 & 8 & 2.5 & 90 & Flat \\
\hline Cap-4 & 8 & 3.0 & 90 & Flat \\
\hline Cap-5 & 8 & 2.3 & 45 & Round \\
\hline
\end{tabular}


Table 5.2: The experimental matrix used in the LSI phase

\begin{tabular}{|c|c|c|c|c|}
\hline Run number & Mixer & Fuel cap & $\begin{array}{l}\text { Momentum ratio } \\
\text { (MMR) }\end{array}$ & $\begin{array}{l}\text { Equivalence ratio } \\
(\phi)\end{array}$ \\
\hline 1 & Mix-1/1 & Cap-1 & 0.64 & 0.5 \\
\hline 2 & Mix-1/1 & Cap-2 & 0.39 & 0.5 \\
\hline 3 & Mix-1/1 & Cap-2 & 0.39 & 0.3 \\
\hline 4 & Mix-1/1 & Cap-3 & 0.33 & 0.5 \\
\hline 5 & Mix-1/1 & Cap-4 & 0.23 & 0.5 \\
\hline 6 & Mix-1/1 & Cap-5 & 0.39 & 0.5 \\
\hline 7 & Mix-1/2 & Cap-1 & 0.64 & 0.5 \\
\hline 8 & Mix-1/2 & Cap-2 & 0.39 & 0.5 \\
\hline 9 & $\mathrm{Mix}-1 / 2$ & Cap-2 & 0.39 & 0.3 \\
\hline 10 & Mix-1/2 & Cap-3 & 0.33 & 0.5 \\
\hline 11 & Mix-1/2 & Cap-4 & 0.23 & 0.5 \\
\hline 12 & Mix-1/2 & Cap-5 & 0.39 & 0.5 \\
\hline 13 & Mix-2/1 & Cap-1 & 0.64 & 0.5 \\
\hline 14 & Mix-2/1 & Cap-2 & 0.39 & 0.5 \\
\hline 15 & Mix-2/1 & Cap-2 & 0.39 & 0.3 \\
\hline 16 & Mix-2/1 & Cap-3 & 0.33 & 0.5 \\
\hline 17 & Mix-2/1 & Cap-4 & 0.23 & 0.5 \\
\hline 18 & Mix-2/1 & Cap-5 & 0.39 & 0.5 \\
\hline 19 & Mix-2/2 & Cap-1 & 0.64 & 0.5 \\
\hline 20 & $\mathrm{Mix}-2 / 2$ & Cap-2 & 0.39 & 0.5 \\
\hline 21 & Mix-2/2 & Cap-2 & 0.39 & 0.3 \\
\hline 22 & Mix-2/2 & Cap-3 & 0.33 & 0.5 \\
\hline 23 & $\mathrm{Mix}-2 / 2$ & Cap-4 & 0.23 & 0.5 \\
\hline 24 & Mix-2/2 & Cap-5 & 0.39 & 0.5 \\
\hline 25 & Mix-2/3 & Cap-1 & 0.64 & 0.5 \\
\hline 26 & Mix-2/3 & Cap-2 & 0.39 & 0.5 \\
\hline 27 & Mix-2/3 & Cap-2 & 0.39 & 0.3 \\
\hline 28 & Mix-2/3 & Cap-3 & 0.33 & 0.5 \\
\hline 29 & Mix-2/3 & Cap-4 & 0.23 & 0.5 \\
\hline 30 & Mix-2/3 & Cap-5 & 0.39 & 0.5 \\
\hline
\end{tabular}


Table 5.3: Static mixer characteristics

\begin{tabular}{|l|l|l|c|c|}
\hline Swirl type and distribution & $\begin{array}{l}\text { Mixer } \\
\text { number }\end{array}$ & $\begin{array}{l}\text { Inner swirler } \\
\text { blade angle } \\
\left(\mathbf{(}^{\mathbf{9}}\right.\end{array}$ & $\begin{array}{l}\text { Outer swirler } \\
\text { blade angle } \\
(\mathbf{})\end{array}$ & $\begin{array}{l}\text { Swirl number } \\
\text { (geometrical) } \\
\text { (Eq. 4.17) }\end{array}$ \\
\hline Single-swirl & Mix-1/1 & 15 & - & 0.18 \\
\hline Single-swirl & Mix-1/2 & 30 & - & 0.4 \\
\hline Double-swirl, co-swirl, (-/-) & Mix-2/1 & 30 & 30 & 0.58 \\
\hline Double-swirl, counter-swirl, (+/-) & Mix-2/2 & 30 & -30 & 0.58 \\
\hline Double-swirl, counter-swirl, (-/+) & Mix-2/3 & -30 & 30 & 0.58 \\
\hline
\end{tabular}

Table 5.4: Operating conditions used for the LSI tests

\begin{tabular}{|l|l|}
\hline Parameter & Design value \\
\hline Fuel flow rate & $0.00475 \mathrm{~kg} / \mathrm{s}$ \\
\hline Fuel pipe inner diameter & $10.21 \mathrm{~mm}$ \\
\hline Methane molecular weight & $0.01604 \mathrm{~kg} / \mathrm{mol}$ \\
\hline Fuel line pressure & $2 \mathrm{psig}$ \\
\hline Fuel line Reynolds number (Re) & 54,000 \\
\hline Fuel injectors Reynolds number (different nozzle diameters) & $23,000-30,000$ \\
\hline Duct burner (DB) total mass flow rate & $0.7 \mathrm{~kg} / \mathrm{s}$ \\
\hline DB cone mass flow rate (25\% of total mass flow rate) & $0.186 \mathrm{~kg} / \mathrm{s}$ \\
\hline Mass ratio (MR LSI $_{\text {fuel flow rate/ cone mass flow rate) }}$ & 0.025 \\
\hline DB premixer pipe inner diameter & $16.3 \mathrm{~cm}(6.407 \mathrm{in})$ \\
\hline Premixer inlet velocity (upstream of the static mixer) & $12 \mathrm{~m} / \mathrm{s}$ \\
\hline Oxidant (microturbine exhaust gases) temperature & $200^{\circ} \mathrm{C}$ \\
\hline Premixer inlet Reynolds number & 57,000 \\
\hline Turbulent intensity & $\approx 10 \%$ \\
\hline DB premixer dimensions & See Figure 4.14 \\
\hline LSI model dimensions & See Figure 5.2 \\
\hline Uncertainty in velocity measurement & $\pm 3 \%$ \\
\hline
\end{tabular}

\subsection{Preliminary LSI tests}

Optimizing the set-up and capturing the appropriate images using the LSI technique required a lot of trial and error. The first phase of the LSI experimental work program consisted of preliminary tests. These tests were performed for the two 
test configurations (vertical and lateral) to ensure consistent and reliable results. These preliminary tests helped to define the following parameters: test procedures, camera settings, laser intensity levels, number of frames, appropriate equipment locations, image correction procedures, seeding conditions, and setting of the air and fuel flow rates.

Figure 5.9 shows the first set of images captured during the preliminary tests. This is an example of the premixer vertical cross-section images. Figure 5.9a shows the high reflection from the fuel cap. This reflection affects the quality of the images and a background subtraction may remove only some of the valuable image information. As a result, all the mixers and the fuel caps used were painted black to reduce this kind of reflection. In addition, during the final LSI tests the region of the nozzles were masked to overcome the high light reflection. Figure $5.9 \mathrm{~b}$ shows an image of the premixer vertical cross-section arrangement without seeding the flow. This image is a background image taken during the selection of the best location of the camera. The reflection in the image is due to the light reflection from the static mixer outer ring.

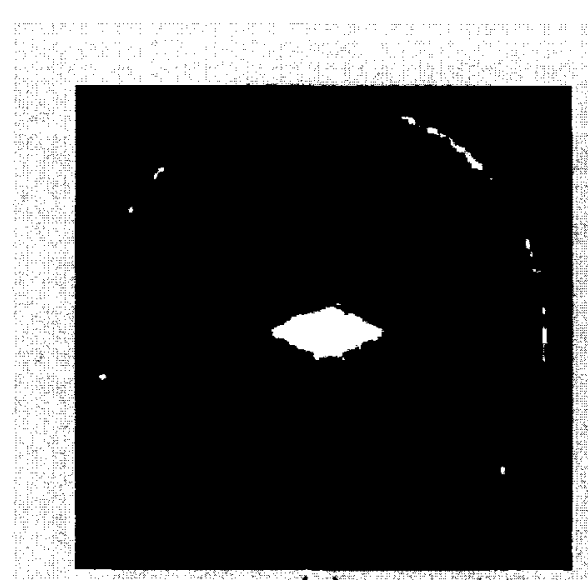

(a)

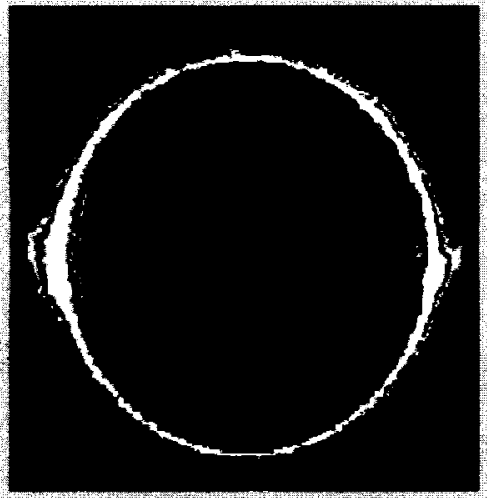

(b)

Figure 5.9: Some of the first trials of the LSI pre-test images 
Great efforts were made to eliminate or minimize all sources of interferences in the capture of images. Another example of sources of interference is the problem of accumulation of the seed powder on the inner surface of the Plexiglas viewing sections. Build-up of alumina particles (seeding) on the inner surface of the imaging window have the effect of lowering and eventually completely blocking the transmission of the scattered light from the flow inside, thereby obstructing and even prohibiting optical access. Efforts were taken to minimize the formation of the seeded particles on the Plexiglas window. For the vertical cross-sectional set-up the back plate of the Plexiglas box was cut at the centre (imaging area) and a window frame was installed allowing the use of a sliding glass window in place of the Plexiglas one. This arrangement gave quick cleaning access to the viewing section without disassembling the test rig. In addition, the window region was purged with clean gas from the inside to reduce deposition and maintain window transparency.

Another useful result of the LSI preliminary tests was the qualitative determination of the jet penetration of the fuel (seeded air) jets into the cross flow. Figure 5.9a shows the poor penetration of the fuel jets for the design flow condition. According to the calculations made during these preliminary tests, the maximum penetration distance was around 60 to 70 percent of the premixer radius using the flow rate indicated by the flow control unit. This result was estimated using Equation (4.24) and the flow rate given by the flow control unit. The poor penetration (less than 30 percent of the premixer radius) measured from the LSI images led to the conclusion that the flow control unit was in error and the decision to calibrate the flow control unit, and the use of a pitot-static tube for all the LSI experiments. Equation (5.3) presents the calibration equation:

$$
C F M(\text { actual })=1.026 . C F M(\text { setting })-21.81
$$

where $C F M$ (setting) is the flow control unit operator setting value in cubic feet per minute and $C F M($ actual) is the actual air supplied flow rate (cubic feet per minute). 
The calibration was performed in the main air supply line only. The fuel line has a separate calibrated flow meter.

These preliminary tests were very useful for the planning of the LSI tests. The lessons learned from the LSI preliminary experiments were applied to improve the quality of the final LSI tests. The procedures followed during the final LSI tests are presented in the following section.

\subsection{General procedure for capturing LSI images}

The general procedure for capturing LSI images consisted of setting up the equipment, aligning the laser and the camera, acquiring the images and correcting them. The following describes all the steps taken during the LSI phase:

1- Select the LSI test arrangement (vertical or lateral) as illustrated in Figures (5.6) and (5.7).

2- Set up the laser and the optical equipment that includes the following:

a. Start the laser system by following the safety operating procedure used at the CANMET laser laboratory.

b. Adjust the laser power (1 Watt).

c. Align the laser sheet to cover the region of interest by adjusting the cylindrical lens.

3- Set up the camera, which included:

a. Starting up the camera.

b. Adjusting the camera water and nitrogen flows and waiting for 30 minutes for the camera to warm-up (camera manual). 
c. Running the WinView software and adjusting the different camera variables such as; exposure time and number of frames.

d. Starting the real-time viewing of the region of interest on the computer monitor. The static mixer and the fuel cap were only visible in the case of the vertical cross-section arrangement.

4- Set up the air supply system, which included:

a. Connecting the LSI test rig with the air supply system. This required connecting the three lines: (1) main air line, (2) fuel air line and (3) the exhaust line.

b. Starting up the air supply system, then setting the main air flow to a certain setting (e.g., 100 CFM). The fuel line controller, at the air supply system, was set to be fully opened. The fuel flow rate was controlled from the particle seeding system. At this point, only the main air flow was allowed to flow through the test section.

5- Set up the seeding system, which included:

a. Connecting the seeding system to the test rig fuel pipe as shown in Figure 5.1.

b. Filling the particle feeder with dry alumina particles taken from the oven.

c. Connecting the vibrator to one of the compressed air ports located in the laboratory.

6- Double check the alignment of the laser and the camera.

7- Check the main air flow speed using the calibrated pitot-static tube placed upstream of the premixer inlet section (see Figure 5.1) and 
connected to a pressure transducer. The supplied air temperature was measured by a K-type thermocouple. All the measured quantities in the main air and the air which represented the fuel were fed to a spreadsheet. The geometrical parameters for the Plexiglas premixer were also inserted into the spreadsheet. Adjustments were made to keep the same momentum ratio, as a similarity variable, between the original premixer design conditions and the Plexiglas LSI premixer. The spreadsheet computed the fuel flow rate needed to be supplied to the LSI test section for that particular set-up.

8- Knowing the fuel flow rate first, adjust the flow meter control valve that is connected to the air supply system to get the larger part of the fuel flow contribution. The rest of the fuel flow rate needed was fed from the fluidized feeder. The flow meter used for the feeder has the range of 0 to 15 liters per minute.

9- Before opening the seed fuel valve, the fluidized bed vibrator should be operating.

10- At this point everything is ready for a particular selected set-up to capture the LSI images needed. Open and adjust the fuel flow control valve to the desired value and acquire the images. All the light sources inside the laboratory, except the laser, should be turned off to reduce the interference signals.

11-A series of visualization images were obtained for each recording event. Each image contains 10 frames, for averging.

12- A number of background files were regularly taken immediately before and after the start of each recording event. These images also provide geometrical scales to the flow images. 
13-A number of dark charge files were captured before starting any new set-up

\subsection{Test results}

Direct LSI images for the premixer flow field were captured to measure qualitatively the effect of different geometries on the mixing process. A number of flow configurations were investigated using different sets of mixers and fuel caps providing different flow conditions. The experimental analysis was performed for the two LSI test set-ups mentioned in Section 5.4. Referring to Table 5.2, 240 runs (30 $\times$ $8=240$ ) were performed for the vertical image set-up and 30 runs were performed for the lateral image set-up.

To reach the momentum ratio of interest listed in Table 5.2, the main air stream (referred to in the thesis as mainstream) flow rate was maintained constant and the fuel flow rate through the seeding system was controlled and varied. The velocity ratio was the characteristic parameter used to attain the momentum ratio and hence controls the penetration of transverse injection into the mainstream air and the mixing of seeded air (fuel) and the mainstream air in the coaxial geometry.[Solero et al. (2000)]

A series of approximately 10,000 images were acquired including the real data, dark charge, flat field and background images. 10 to 20 images were obtained for each recording event. Each image contains 10 to 15 frames, for averaging. The exposure time (refers to how long the camera is allowed to receive light) were varied between 20,40,60 and $80 \mathrm{~ms}$. most of the images used in the processing have the same exposure time $(40 \mathrm{~ms})$. The images were then processed to extract the necessary information needed for the evaluation of the different geometrical combinations studied. The selected approach was to evaluate the mixing process in the burner premixer using the LSI qualitative results (images) and to define an unmixedness 
index which could be evaluated through quantitative analysis of light distribution on the planar images. Under this mode of visualization (direct excitation mode), all the images of the mixing region show the spreading out of fuel (seeded flow) into the mainstream flow by the turbulent motion caused by the different static mixers.

The results of this phase of the thesis will be presented in different subsections, starting with a subsection investigating the effect of different static mixer designs on a simple jet flow using different velocity ratios. The second and the third subsections will cover the vertical and the lateral image set-up results. The last section will study the evaluation of the different geometrical combinations used by referring to the value of unmixedness.

\subsubsection{Jets}

In this subsection, the effect of different static mixer designs are studied and presented. Both set-ups presented in Figures 5.6 and 5.7 were used. The fuel line was seeded with alumina particles which were capable of tracing the gas diffusion into the mainstream. The fuel concentration distribution was measured by LSI in the lateral cross-section parallel to the premixer axis as well as in the vertical cross-sectional planes for particular cases. The particle concentration was assumed proportional to the fuel concentration [Solero et al. (2000)].

\subsubsection{Coaxial Jet}

To show the mixing behaviour of each mixer or each combination used (Table 5.2), LSI images were used. LSI tests were performed in the premixer pipe without using any mixing system components, such as fuel cap or mixer. Only an image of the coaxial jet was captured and analyzed. Vertical and lateral image set-ups were used. Figure 5.10 shows a lateral image with vertical cross-section visualizations located at $5,10,15,25$ and $30 \mathrm{~cm}$ of the jet injection plane. The fuel pipe inner diameter was $1.02 \mathrm{~cm}(0.4 \mathrm{inch})$, see Figure 5.2 . 


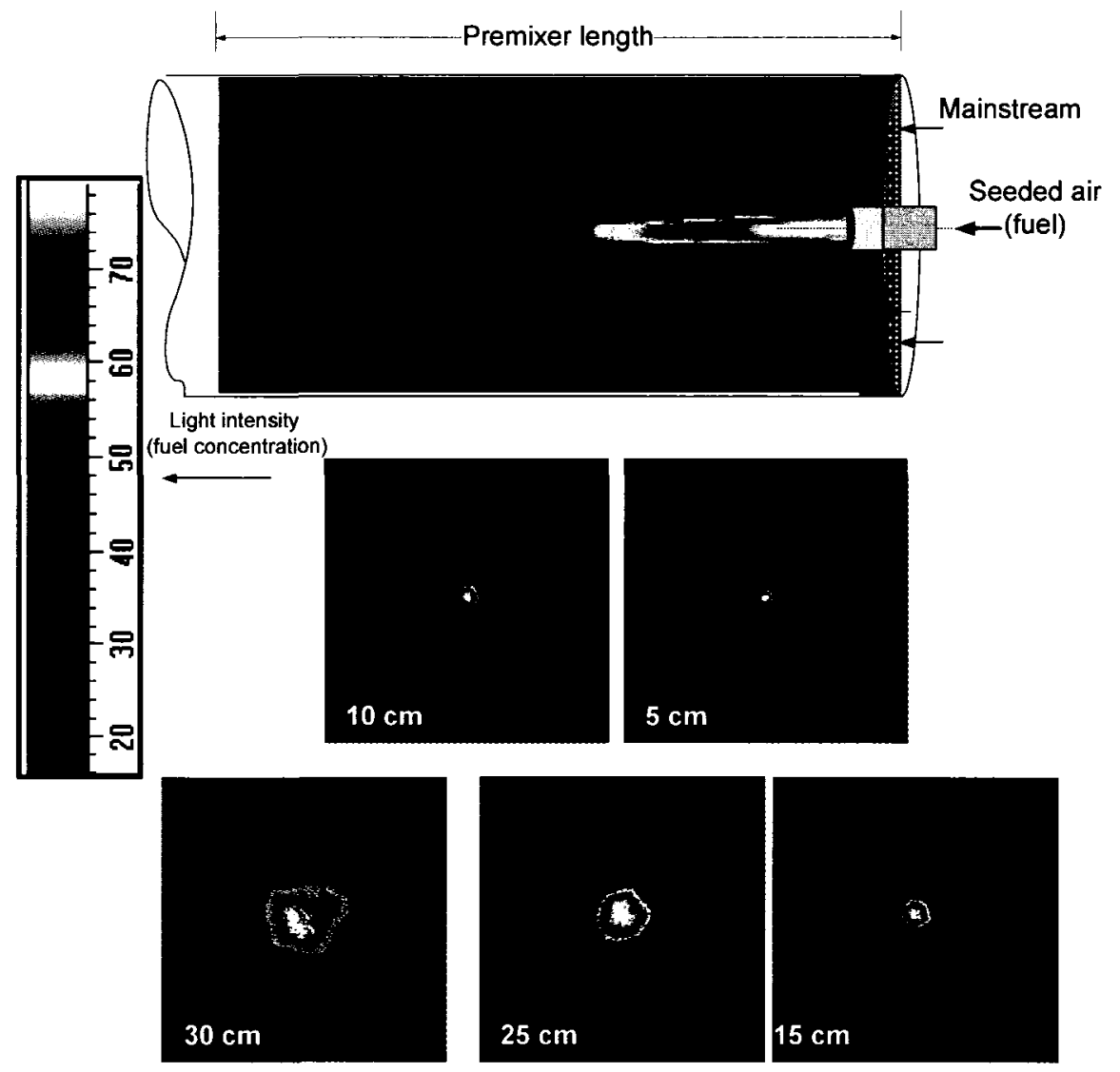

Figure 5.10: Laser sheet images for the coaxial fuel injection without mixers $\left(\mathrm{MR}_{\mathrm{LSI}}=0.025, \phi=0.5\right.$, exposer time $\left.=20 \mathrm{~ms}\right)$

The areas occupied by the seeded stream (fuel) region for the locations 5 and $15 \mathrm{~cm}$ had diameters of 2.6 and $5.1 \mathrm{~cm}$ respectively. At $30 \mathrm{~cm}$ distance $(30$ times the fuel injector diameter) the fuel occupied a circular area with a diameter equal to 8.7 $\mathrm{cm}$ (approximately half of the premixer pipe diameter). Clayton et al. (1968) show that approximately 100 injector diameters are needed to achieve a homogeneous fuelair mixture. The inner unmixed region shown in Figure 5.10 (with high light intensity) a short distance downstream from the fuel cap corresponds to the potential core of the fuel jet and decreases as the flow moves downstream. 


\subsubsection{Coaxial Jet in a swirling flow}

The effect of using a mixing device, such as static mixer, on mixing of the coaxial jet with the mainstream flow was studied. The swirl flow mixers are known as high effectiveness mixing devices, which shortens the mixing length, especially when limited space is available, as in the case of the duct burner under investigation. LSI tests were performed in the premixer pipe without using a fuel cap to produce a coaxial jet with a static mixer installed. Figure 5.11 shows the effect of different swirl strengths and designs on the spread of the coaxial jet. Flows entering the static mixer are forced into swirling vortices by the blades. This swirling action forces the mainstream toward the centre of the duct, shortening the jet potential core and causing mixing to occur. The figure indicates that the area occupied by the injected fuel is greater with the use of the different mixers than in the first case where no mixers are used. The non-swirling case in Figure 5.11 serves as a reference for comparison with the other swirling configurations. The double-swirl mixer accelerates the fuel-air mixing in shorter distances. The swirl flow caused by Mix-2/1 forces the mainstream towards the premixer centreline to mix with the fuel jet in a very short distance downstream of the fuel nozzle compared to other mixers.

\subsubsection{Inclined $\left(45^{\circ}\right)$ jet in a swirling flow}

In this subsection, the effect of using a complete mixing system, such as mixer and fuel cap, is tested. Figure 5.12 shows the effect of using the round fuel cap (Cap5 ) with the different mixers. The fuel is injected at 45 degrees to the mainstream. The figure presents only the lateral images for those cases. In later subsections both the vertical images and the lateral image for a particular case will be presented for all the conditions listed in the LSI experimental matrix. 


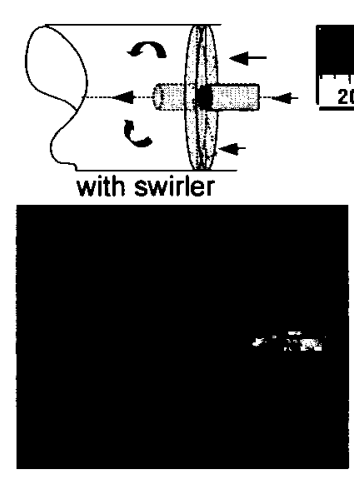

Mix-1/2

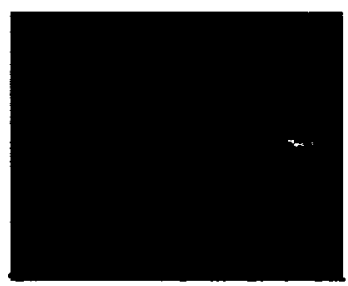

Mix-2/1

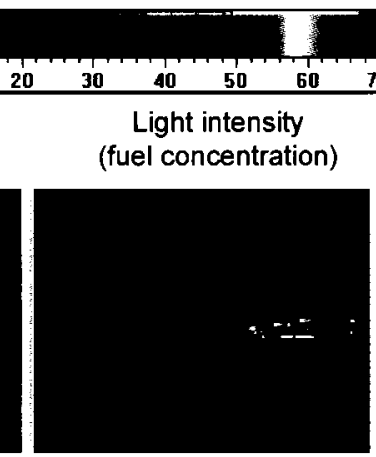

Mix-1/1

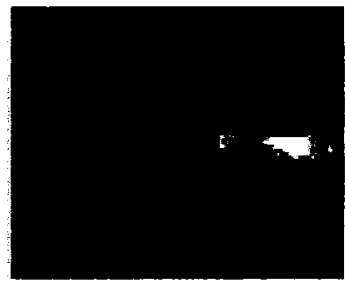

Mix-2/2
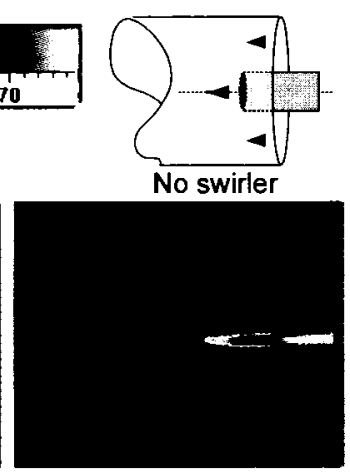

No swirler

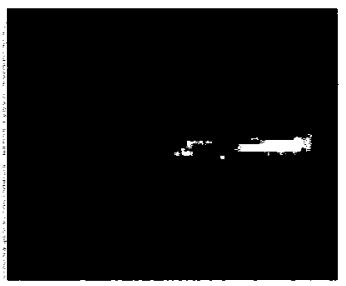

Mix-2/3

Figure 5.11: Lateral LSI images of the coaxial jets as a function of swirl level $\left(\mathrm{MR}_{\mathrm{LSI}}=0.025, \phi=0.5\right.$, exposer time $\left.=20 \mathrm{~ms}\right)$
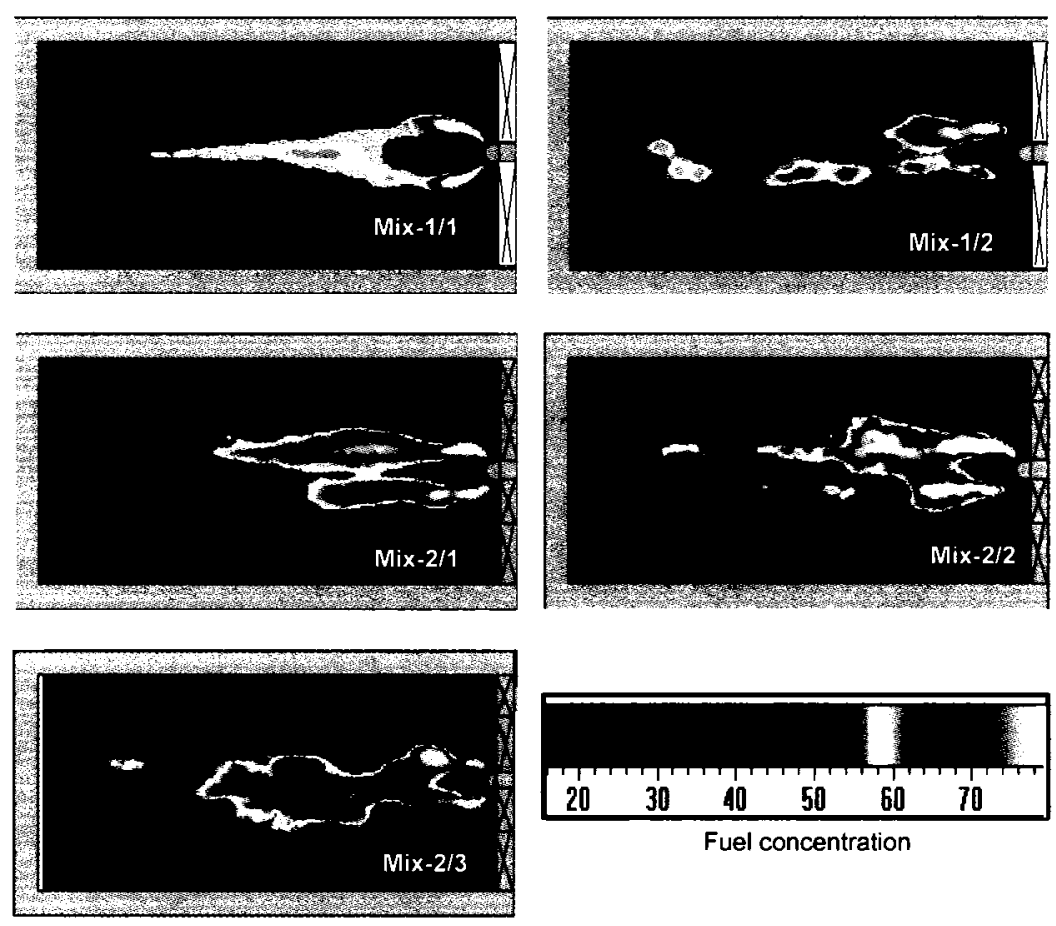

Fuel concentration

Figure 5.12: Effect streamwise swirls on mixing $(\mathrm{Cap}-5, \phi=0.5, \mathrm{MMR}=0.39$ exposer time $=20 \mathrm{~ms}$ ) 
Qualitatively, one can clearly see the effect of different mixer designs, and the improvement of the mixing process using the different fuel caps for fuel injection when compared to the coaxial fuel injection. The fuel in Figure 5.12 was injected at 45 degrees to the mainstream air flow. The lower swirl angle of 15 degrees (Mix-1/1, $\mathrm{S}=0.18$ ) does not improve the mixing when compared to the other mixers. The second mixer with a 30 degree blade angle $(\mathrm{Mix}-1 / 2, \mathrm{~S}=0.4)$ produces better mixing characteristics than the 15-degree angle swirler. At a given length from the nozzle exit, the homogeneity is greater with double-swirl mixers $(\mathrm{S}=0.58)$ than with singleswirl mixers. From the lateral images shown in Figure 5.11, we see that Mix-2/2 and Mix-2/3 provides the best spread of the injected fuel in the mainstream flow. Mix-2/1 provides less spread from the lateral image shown, but provides good mixing characteristics. This mixer bends the fuel jets towards the premixer centre, causing the fuel jet to mix with mainstream air rapidly. This will be clear when the vertical cross-sectional results are presented below. Mix-2/1 in Figure 5.11 shows a strong rotation which may be good for mixing, but may affect the flame stability later in the combustion tests. In Figures 5.11 and 5.12, for the single-swirl mixer, as the swirl number increases, the turbulence increases. This is clear from the fuel spread in the images.

For the double-swirl mixer case, although all the mixers have the same swirl number, the fuel spread shown in the images has different trends, due to the different design. The counter-swirl mixers show more fuel spread compared to the co-swirl one.

Therefore, the streamwise swirl vortices are effective at causing the mainstream to quickly mix with the fuel jets. The implication is that the swirl produced by Mix-1/1 does not have enough strength to quickly drive the mainstream to mix with the fuel jets. An increase in the swirl strength as with the case of Mix-1/2 improves the mixing process. The use of the double-swirl mixers accelerates the mixing process. 
Figure 5.13 compares the previously mentioned two cases (coaxial and with fuel cap) for Mix-2/3. These images were taken under identical flow conditions showing the variation of the images with time. The random nature of the fluid motion is apparent from the differences among the images.

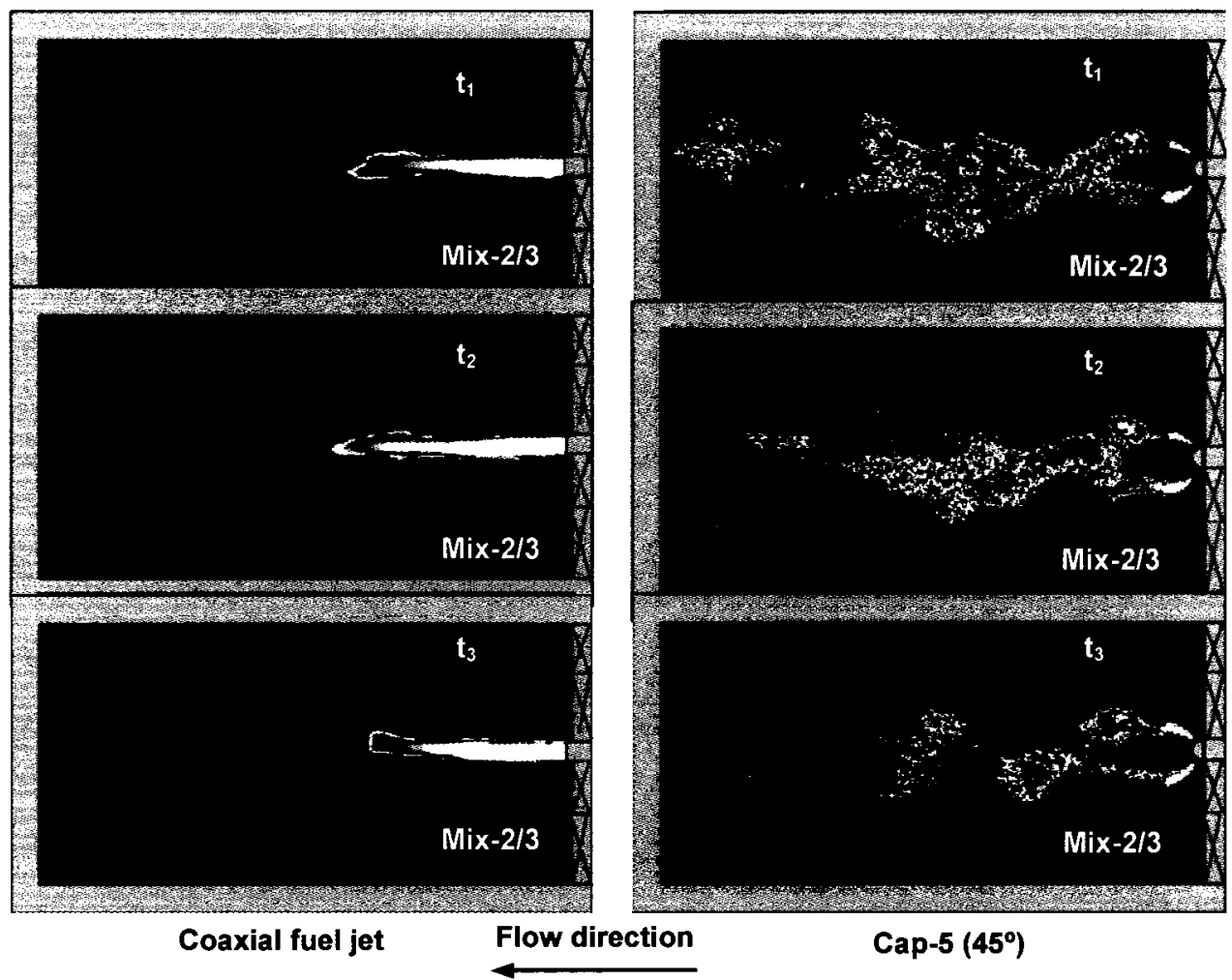

Figure 5.13: Effect Mix-2/3 on mixing $\left(\phi=0.5, M_{\text {LSI }}=0.025\right.$, exposer time $=10$ ms)

\subsubsection{Jet penetration in a swirling flow}

In this subsection the radial fuel jet penetration in the swirling mainstream will be briefly discussed. The fuel jet penetration is defined as the measure of the maximum radial distance the fuel penetrates into the body of the co-flow at a given downstream distance. Images showing the jet penetration of some of the flow conditions and geometrical arrangements are presented in this subsection. The images qualitatively give an idea of how far the radial fuel jet trajectory penetrates. When a 
free jet is injected into a non-swirling cross flow, the jet bends over in the direction of the cross-flow due to pressure difference between the upstream stagnation region and the wake region on the downwind side of the jet, causing the jet to deflect. The crossflow also distorts the cross-section of the jet and causes a counter-rotating vortex pair, CVP, [Smith et al. (1998)] in the wake.

Figure 5.14 shows the effect of using different swirlers on fuel jet penetration. The images are taken from the lateral cross-section images captured for the radial fuel injection Cap-4. The jet trajectories penetrating through a swirling cross-flow are clearly affected by the different swirler designs. The swirling cross-flow also forces the fuel jets to bend due to the existence of pressure differences across the jet. Mix$2 / 1$ shows the stronger effect among other mixers at this condition. It bends the jet sharply over in the direction of the swirling cross flow. Mix-2/2 has the maximum fuel jet penetration through the swirling cross flow.
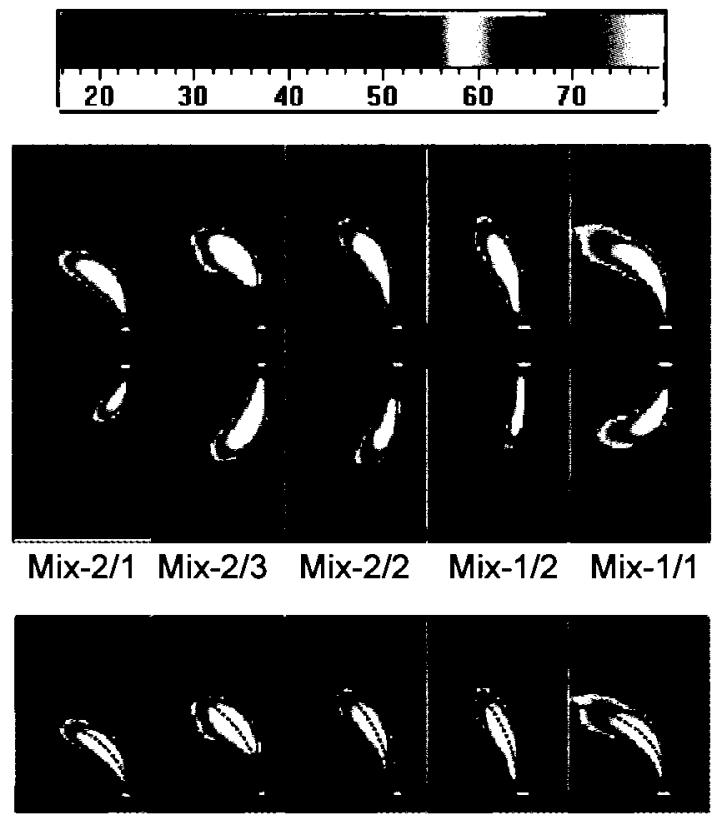

Figure 5.14: Effect of different static mixers on radial fuel jets (Cap-4) 
Figure 5.15 shows the fuel jets (fingers) from the vertical viewing crosssection. A sample from the vertical cross-section images are presented in this figure for the case MMR of 0.64 when using Cap-1 with the five different mixers. The figure clearly shows the eight fuel jets penetrating through the swirling cross flow. These vertical cross-sectional images were taken at the fuel nozzle exit plane. On the image, the penetration ratio (PR) is illustrated for each image. Sawyer (1985) defined the penetration ratio as the ratio of the penetration distance to the combustor liner diameter. In the present work, the premixer pipe diameter was used in place of the combustor liner diameter. Sawyer (1985), states that the optimum PR value for a gas turbine combustor is 0.33. All the flow conditions presented in Figure 5.15 show a good value of PR. This case was for Cap-1 which produces the higher momentum ratio of 0.64. All the cases studied with the LSI technique produced a good penetration ratio in the order of 0.3 . Figure 5.15 shows clearly the direction of rotation of the swirling flow. Single-swirl mixers rotate according to the blade angle direction; Mix-1/1 produces a clockwise rotation according to its positive (+ve) angle, see Figure 5.8 for the angle sign, and Mix-1/2 introduces anticlockwise rotation to the flow stream resulting from its negative (-ve) blade angle. For the three double-swirl mixers the direction of rotation introduced to the mainstream flow depends on the sign of the inner swirl blade angles. Mix-2/1 and Mix-2/3 both show an anticlockwise rotation (both have -ve inner swirl angles), but Mix-2/2 shows a clockwise rotation due to its inner swirl blade angle (+ve). Later coloured images will show the direction of rotation clearly.

Another result observed from Figure 5.15 is the quick distortion of the normal circular jet cross-section at the top of each jet finger to an oval deformed shape. This fact will be clearly shown in later images where the vertical cross-sectional images are taken at the edge of the fuel cap plane for the different mixers at a location of 1 $\mathrm{cm}$ downstream of the nozzle exit. 

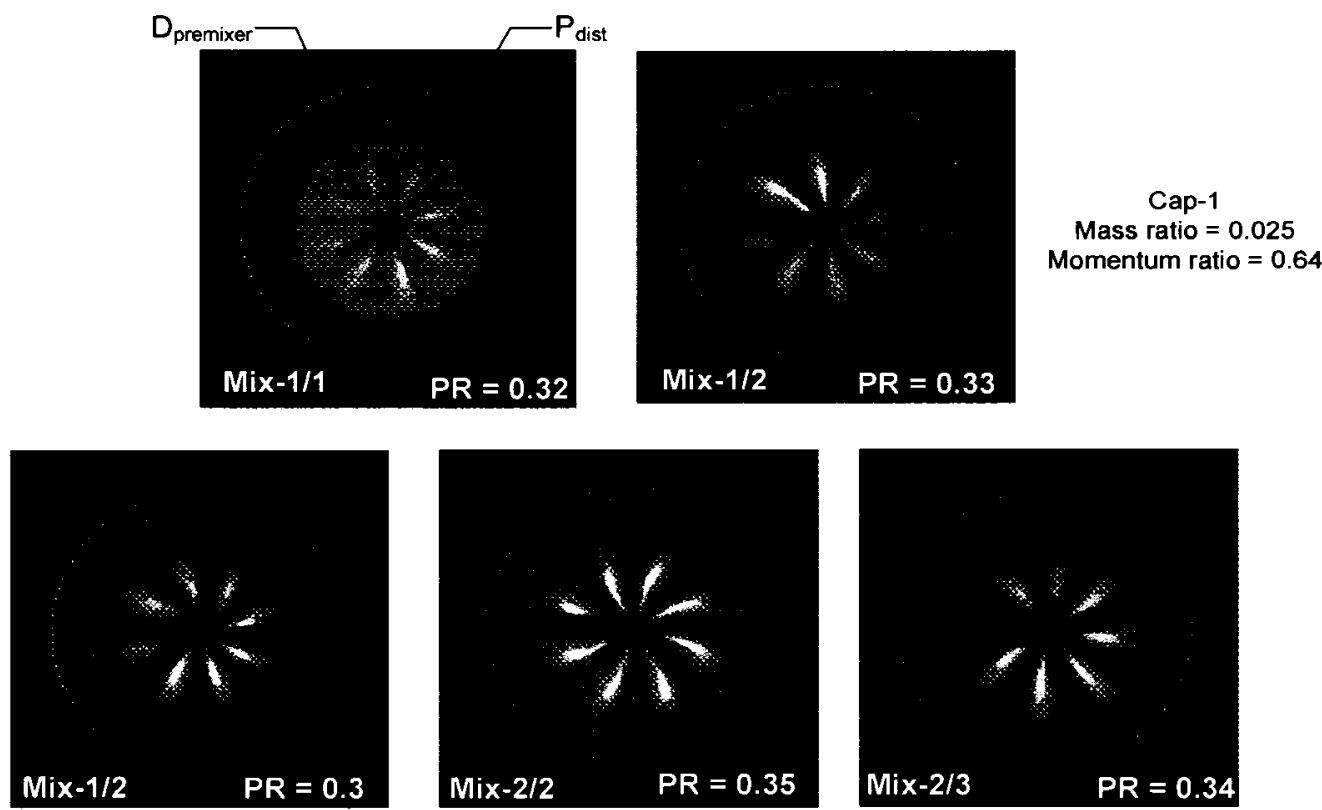

$P_{\text {dist }}=$ Penetration distance (measurement taken from other images captured at the cap edge)
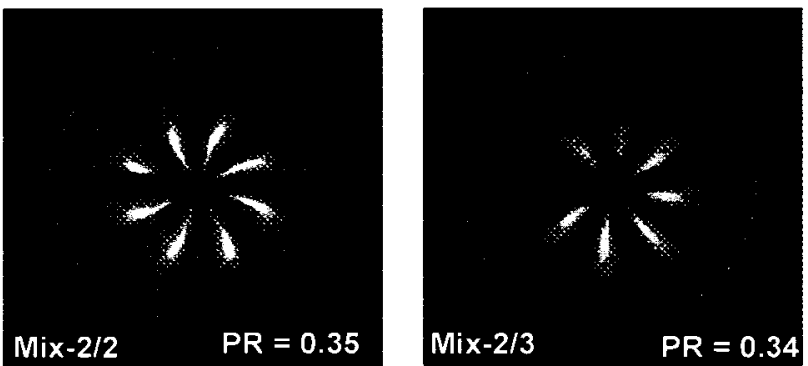

$D_{\text {premixer }}=$ Premixer diameter

Penetration Ratio $=P R=P$ dist $/ D_{\text {premixer }}$

Figure 5.15: Effect of different mixers on penetration ratio (vertical crosssections for Cap-1)

As mentioned previously in LSI preliminary tests (Section 5.6) the cap was masked. The reflection from the cap increases when the images are captured closer to the fuel jets and the cap. For viewing and evaluating the growth of the fuel jets inside the premixer vertical cross-section, scaling images were captured. The scaling images were used for sizing the premixer pipe and the fuel cap boundary in all the vertical cross-section images. In Figure 5.15, the premixer cross-sectional boundary (premixer annulus region) is represented by the red circles (or gray in later coloured images) sketched on the figure. The fuel cap was located approximately at the central ring (image centre).

Figure 5.16 shows the change in fuel concentration or the fuel spread inside the swirling cross-flow at two different locations, for the case using Mix-1/2. The top left image taken at the nozzle exit was used here in this figure, just to show the original rotation of the imported swirling flow. The other three images were captured 
at the same location, which is $1 \mathrm{~cm}$ downstream from the nozzle exit plane $(0.0 \mathrm{~cm})$, using different fuel caps (different momentum ratios). At this time the spread of the fuel inside the premixer and the comparison between the three different caps is not important, but an interesting phenomenon is clearly observed in this figure. If one compares the direction of rotation of the top two images, the fuel jets were distorted and transformed to swirling jets. The tangential movement of these jets is in the opposite direction of the initial movement observed at the nozzle exit plane image (the direction of rotation is shown in the images). Similar observations were reported by Barrue et al. (2001). Other qualitative results can be observed from the bottom left image shown in Figure 5.16. The two fuel jets numbered 1 and 6 assigned on the lower left image demonstrate the CVP reported by Smith et al. (1998) and mentioned earlier for the case where the jet penetrates in a non swirling flow.
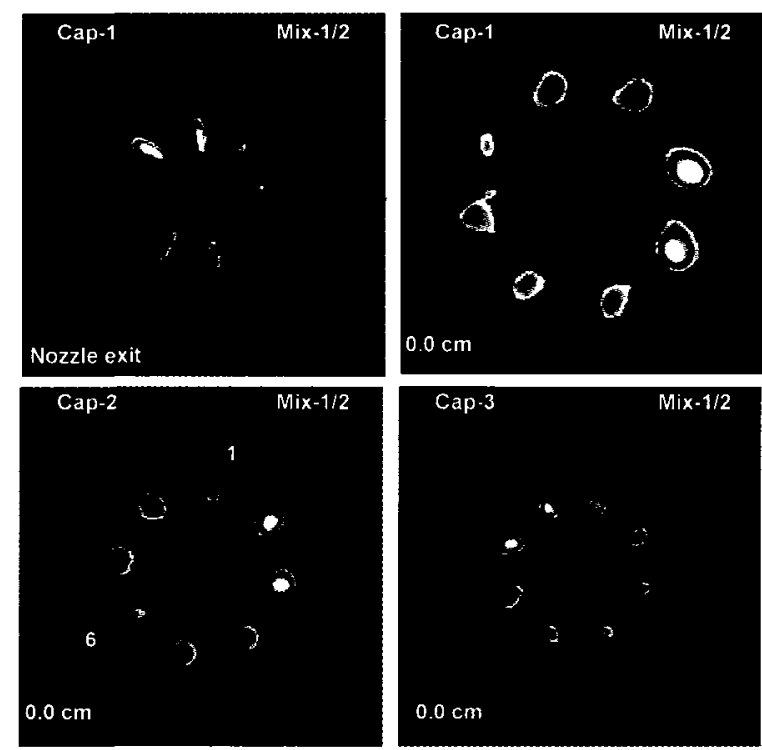

Figure 5.16: Transformation of the fuel jets to swirling jets (Mix-1/2)

Figure 5.17 shows the same observed opposite rotating phenomena for the double-swirl mixers. The LSI experiments were not designed to investigate the above 
mentioned phenomena and the images shown here were chosen to demonstrate the important trends found for the tests. For more observations and comparisons between the images captured for all the geometrical combinations, the reader is referred to Appendix E.
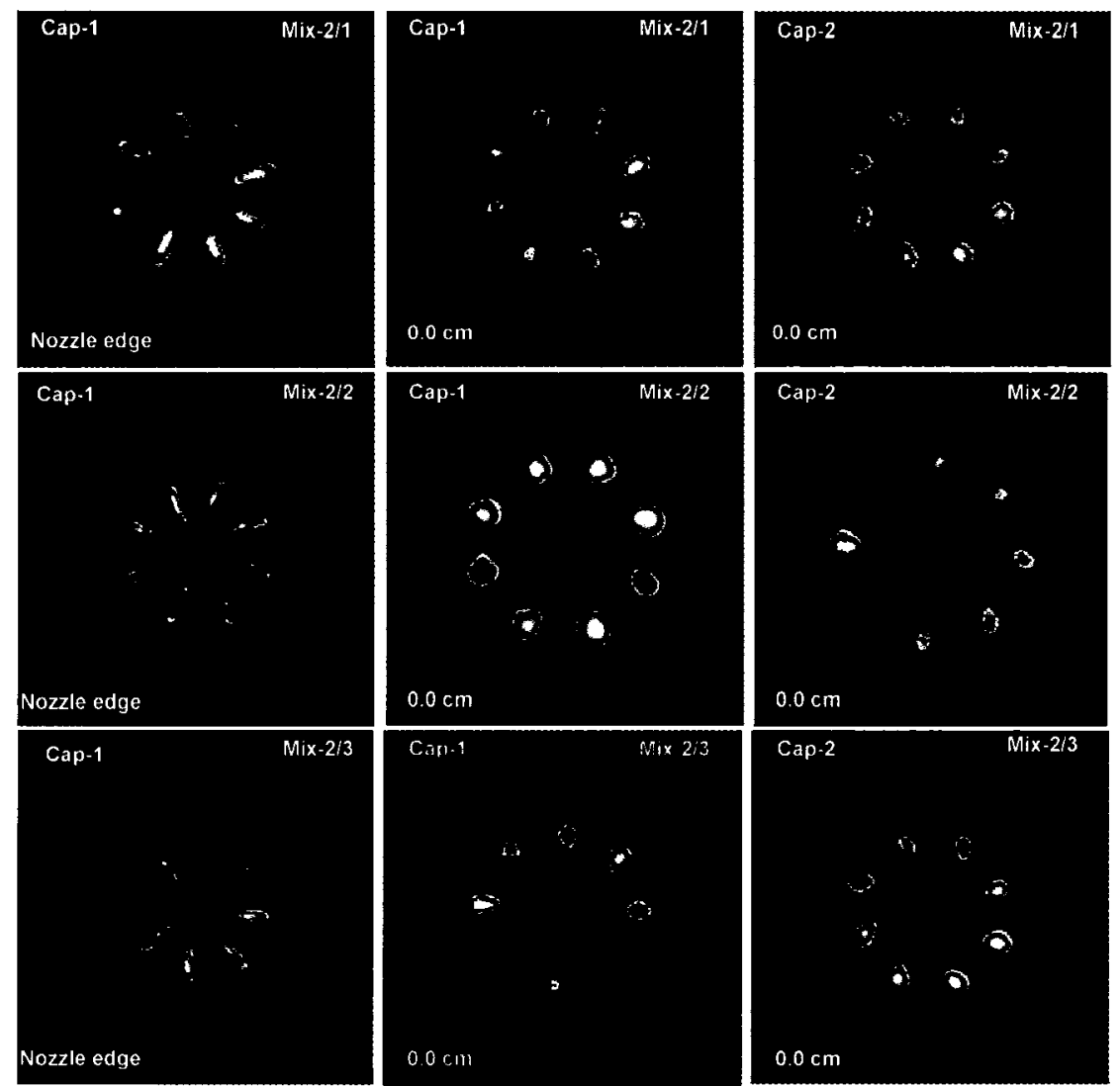

Figure 5.17: Transformation of the fuel jets to swirling jets (double-swirl mixers)

\subsubsection{Mixing using round fuel cap (Cap-5)}

The results (images) of all the conditions tested for the round fuel cap will be presented in Appendix E. In this section, brief qualitative assessments and observations of some of those images will be discussed. The section starts with results showing the effect of using the fuel cap mask. Then, the combined vertical and lateral cross-sectional images for the round fuel cap with the different mixers will be 
presented. Images were captured at all the eight planes, see Figure 5.8, when the flat fuel caps were used and in the case of the round cap images were captured at six planes shown in Fig $5.8(5,10,15,20,25$ and $30 \mathrm{~cm})$ due to the difficulty caused by the round edge of the cap. Only the images captured at the four planes $(5,10,15 \approx$ $1 \mathrm{D}_{\text {premixer, }}$, and $30 \mathrm{~cm} \approx 2 \mathrm{D}_{\text {premixer, }}$, where the distance is measured downstream of the mixer) will be presented in this section. Also the three-dimensional plots of the fuel concentration or fuel flow spread images will be shown for all the six imaging planes. All the cases presented in this section have $\phi=0.5$ and a momentum ratio of 0.39 . As only one camera was used during the LSI phase, the lateral image shown in this section was taken under identical flow conditions as the vertical cross-sections cases, but at a different time. Therefore, due to the random nature of the fluid motion and other uncontrolled flow parameters (atmospheric pressure and temperature), the lateral images presented in this section may not coincide exactly with the vertical cross-sectional images presented at the same figure. The lateral images qualitatively gave an insight into what the flow or the fuel spread looks like in the lateral sections.

As mentioned in Section 5.6, the fuel caps were masked during the LSI imaging due to the higher reflection produced by the fuel caps (caused by the quick powder build-up on the surface of the cap). Figure 5.18 shows that some images were successfully captured without masking the fuel cap when Cap-5 was used. The figure also shows the 3D plots of the image intensity. The images were taken at different time periods. 

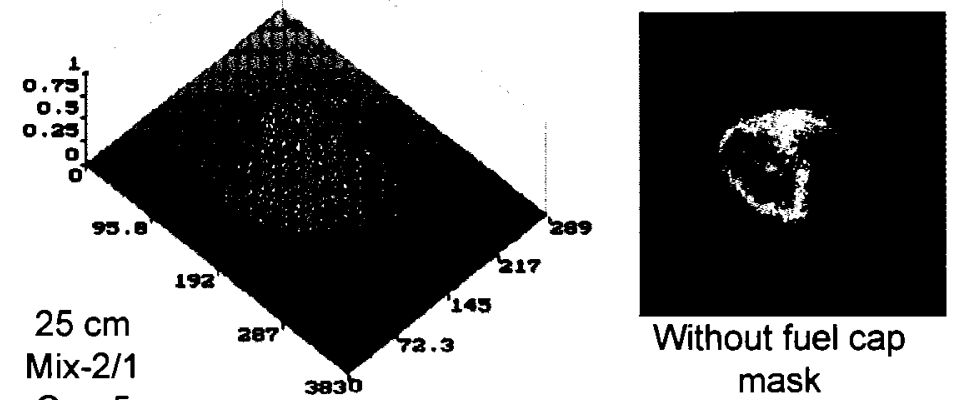

Without fuel cap mask

Cap-5
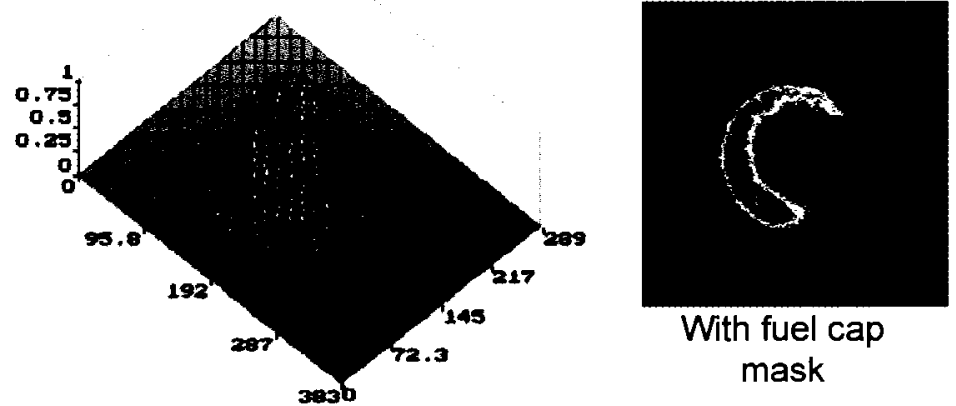

With fuel cap mask

Figure 5.18: LSI images with and without the fuel cap mask and corresponding $3 D$ plots (Mix-2/1 and Cap-5 at $25 \mathrm{~cm}$ )
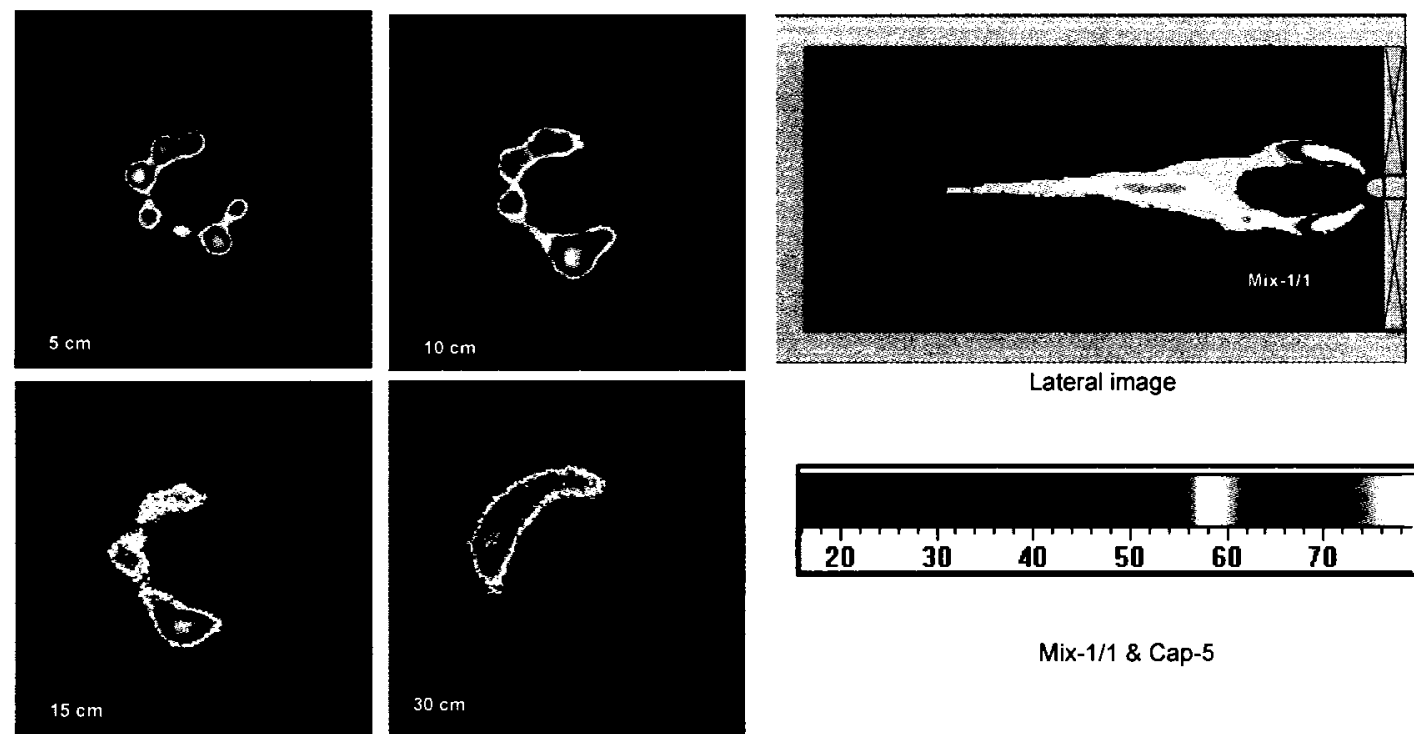

Mix-1/1 \& Cap-5

Figure 5.19: Vertical and lateral cross-sectional LSI images (Mix-1/1 and Cap-5 with $\phi=0.5$ ) 
Figures 5.19 to 5.24 show the effect of using different swirl strength and geometry on fuel-air mixing. Vertical and lateral cross-sectional images are presented. Figure 5.19 shows that at the $5 \mathrm{~cm}$ plane the fuel jets are not completely combined or mixed with each other. High fuel concentration spots distributed around the fuel cap are clearly visible. As the distance increases downstream, the fuel jets mix together and occupy more of the premixer area. The figure clearly shows the rotation of the flow field. The image at the end of the premixer $(30 \mathrm{~cm})$ shows an inhomogeneous spread of the fuel in the premixer cross-section. The mixing is shown to slowly improved from the first station $(5 \mathrm{~cm})$ to the premixer end plane. The fuel spread forms a kidney shape with horseshoe contours around the fuel cap. Figure 5.20 shows the effect of using a stronger swirl number mixer compared to that used in Figure 5.19. As can be seen, more turbulence caused by the stronger swirl improves mixing as the fuel rotates and grows in the radial direction. The ends of the horseshoe grow and combine with each other to form a circle around the fuel cap (doughnut shape). Mix-1/2 shows better mixing behaviour than that of Mix-1/1 due to the higher swirl number for Mix-1/2.
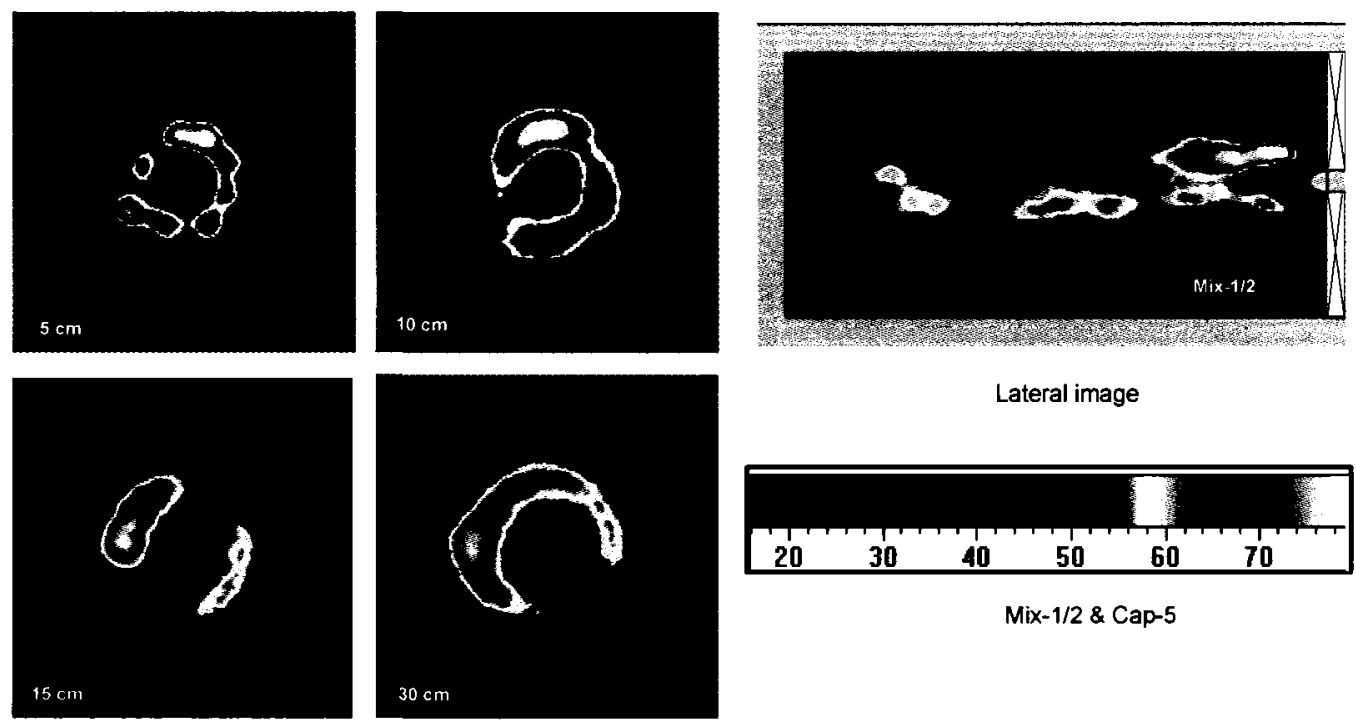

Mix-1/2 \& Cap-5

Figure 5.20: Vertical and lateral cross-sectional LSI images (Mix-1/2 and Cap-5 with $\phi=0.5$ ) 
Figure 5.21 shows the LSI results for the double-swirl mixer, Mix-2/1. At 5 $\mathrm{cm}$, the figure shows a smaller spread of the fuel inside the premixer cross-sectional area compared to the two single-swirl mixers (discussed above). This is due to the strong swirl strength introduced to the flow (co-swirl case). The figure shows the horseshoe contours legs remain uncombined until the last station $(30 \mathrm{~cm})$.
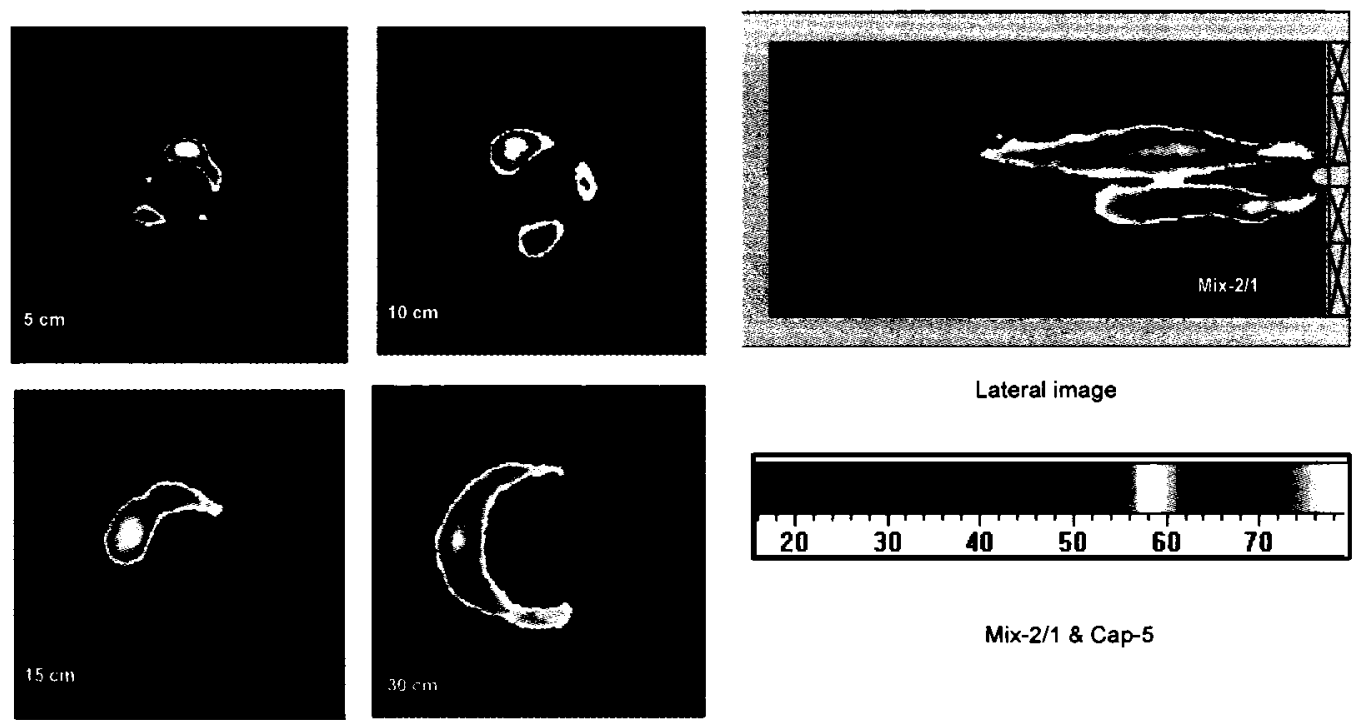

Mix-2/1 \& Cap-5

Figure 5.21: Vertical and lateral cross-sectional LSI images (Mix-2/1 and Cap-5 with $\phi=0.5$ )

Figure 5.22 presents the results for the counter swirl flow mixer, Mix-2/2, which shows the wider fuel spread across the lateral cross-section. The images in Figure 5.22 show that this mixer produces better mixing than the previously mentioned mixers. The fuel spread grows to the doughnut shape at the premixer mid plane $(15 \mathrm{~cm})$. Figure 5.23 shows the 3D plots for the images taken at all the six planes of measurements presented in Figure 5.22. These plots clearly show how the image intensity peaks grow, rotate and combine in proportion to the fuel concentration as the distance increases downstream of the fuel cap. Comparing the vertical cross-sectional images with the $3 \mathrm{D}$ plots gives a clear qualitative idea about how fuel spreads in the swirling main flow. 

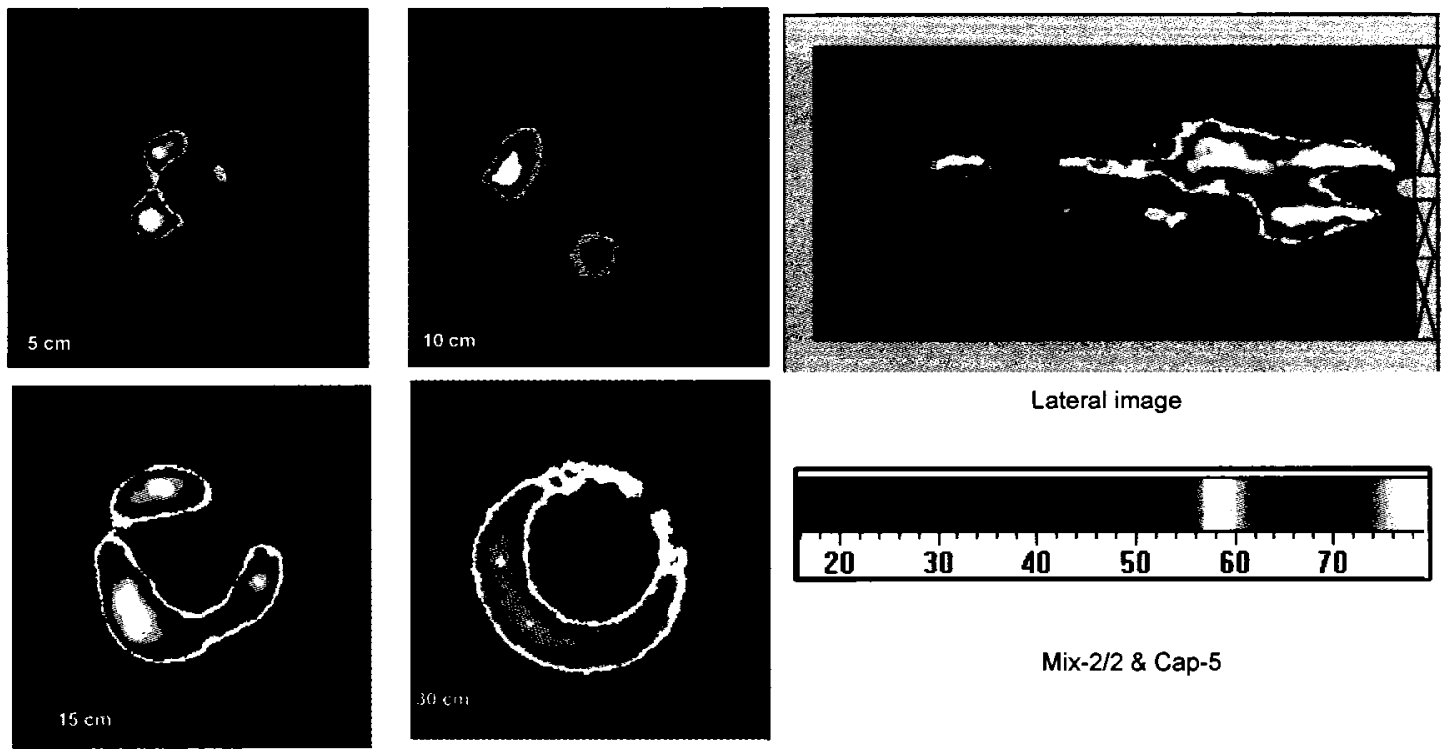

Lateral image

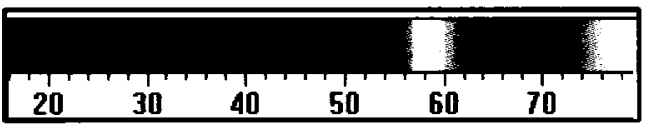

Mix-2/2 \& Cap-5

Figure 5.22: Vertical and lateral cross-sectional LSI images (Mix-2/2 and Cap-5 with $\phi=0.5)$

The LSI images shown in Figure 5.24 present the effect of using the doubleswirl mixer, Mix-2/3, on the mixing process. In this mixer the rotation imparted to the flow is in a different direction than that of the previous case. At the first two stations (5 and $10 \mathrm{~cm}$ ), Mix-2/2 and Mix-2/3 have approximately the same contour shapes, except that the contours in Mix-2/2 occupy more of the cross-sectional area. The images captured at the planes located at $15 \mathrm{~cm}$ and $30 \mathrm{~cm}$ show less fuel growth or spread in the premixer cross-section compared to the Mix-2/2.

Figure 5.25 combines all the LSI vertical images for the cases under investigation to give a qualitative overview of the effect of different mixers on mixing. In addition, Figure 5.26 combines the $3 \mathrm{D}$ plots for all the cases studied in this section. Both figures present the results at $5 \mathrm{~cm}, 15 \mathrm{~cm}\left(1 \mathrm{D}_{\text {premixer }}\right)$ and at $30 \mathrm{~cm}$ $\left(2 \mathrm{D}_{\text {premixer }}\right)$. From both figures one can conclude that the increase in swirler strength increases turbulence and improves mixing. The three double-swirl mixers used have the same strength; however, the effect on mixing is different. Mix-2/2, (+/-) $30^{\circ}$ blade angle, which has (+ve) angles at the inner swirl and (-ve) angle for the outer swirl, 

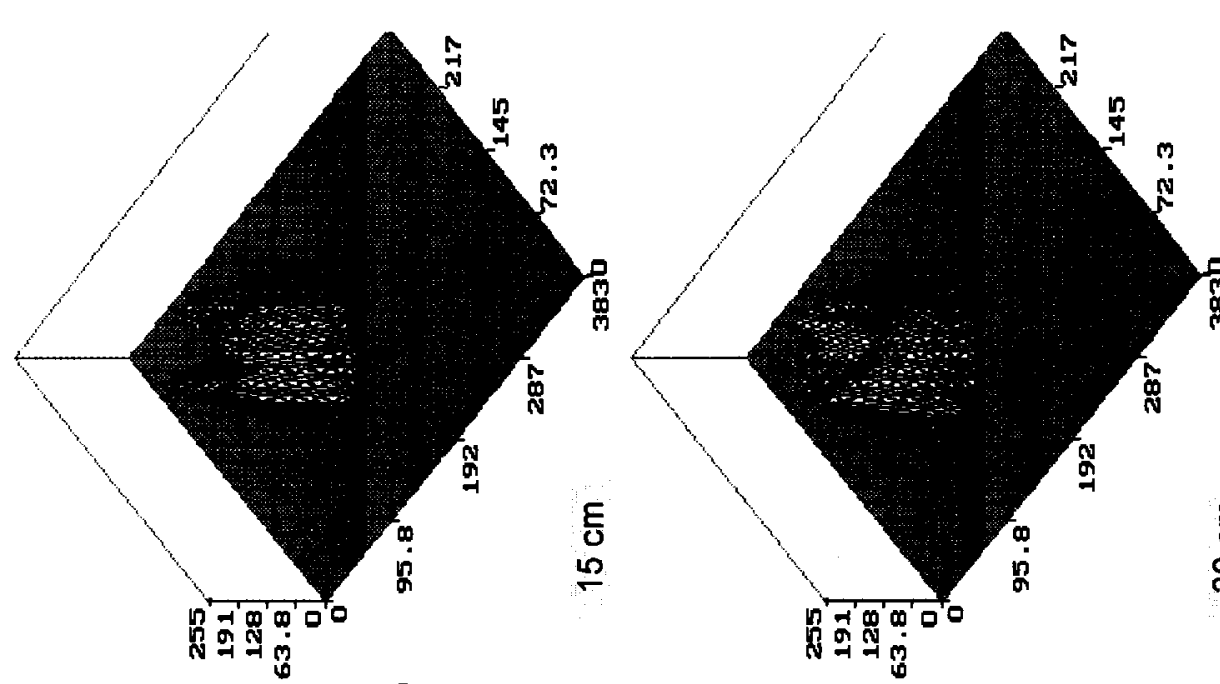

8
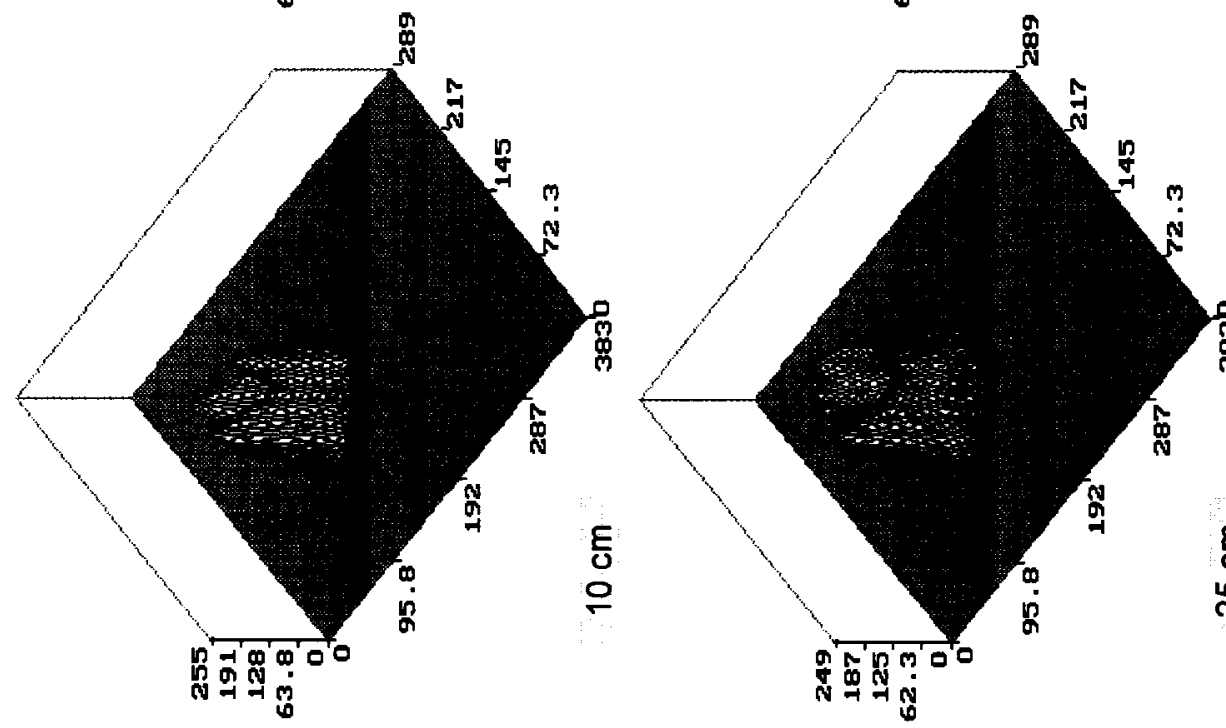

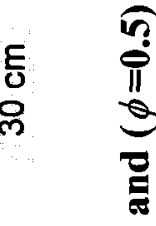
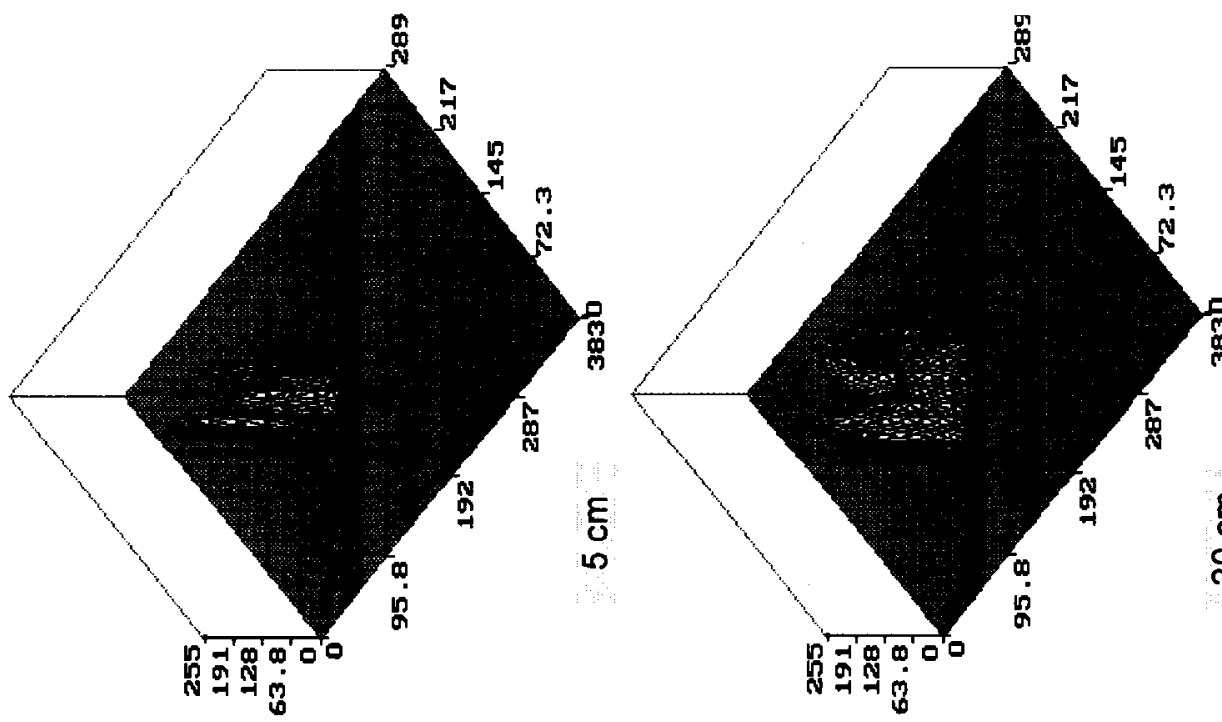

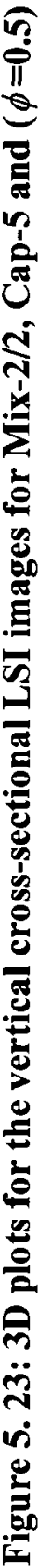


provides the best mixing compared to the other mixers. As well, the 3D figures show that Mix-2/2 has the best increase in intensity peak at the end of the premixer length which is proportional to the fuel concentration. Mix-1/2 compared to the rest of the mixers used, produces good fuel spread through the premixer length. It also shows close qualitative results compared to double-swirl, co-swirl and the counter-swirl mixers with the (-ve) inner swirl blade.
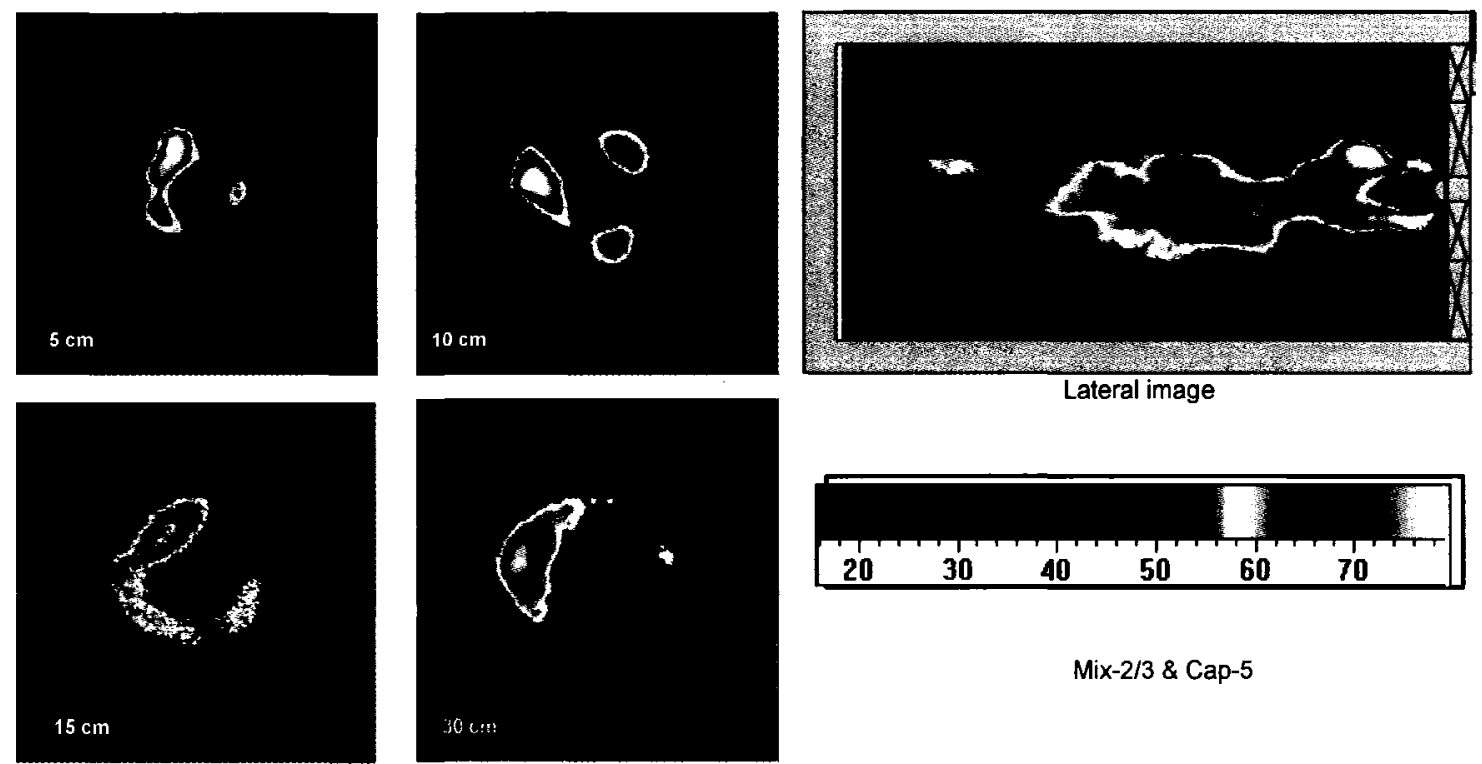

Mix-2/3 \& Cap-5

Figure 5.24: Vertical and lateral cross-sectional LSI images (Mix-2/3 and Cap-5 with $\phi=0.5$ )

In general, this qualitative assessment for the mixing process extracted from Figures 5.26 and 5.27 shows that all the mixers did not provide good mixing with this particular method of fuel injection (using Cap-5 at $45^{\circ}$ to the mainstream flow). The LSI investigation for the fuel caps that injects the fuel at $90^{\circ}$ is the topic of the next section. The 3D plots and the vertical images for all the mentioned cases are presented in Appendix E.

\subsubsection{Mixing using flat fuel caps}

The results (images) of all the conditions tested for the flat fuel cap are presented in Appendix E. Similar to the previous section, qualitative assessments and 
observations for some of these images will be discussed. In this section the LSI vertical cross-sectional images were captured at all the planes shown in Figure 5.8. These planes are the nozzle exit, fuel cap edge $(0.0 \mathrm{~cm}), 5,10,15,20,25$ and $30 \mathrm{~cm}$ planes. Six planes for each case will be presented in the main text. For comparison, only two planes of view are used during the presentation of the results, the $15 \mathrm{~cm}$ plane (located approximately at $1 \mathrm{D}_{\text {premixer }}$ downstream of the static mixer) and the 30 $\mathrm{cm}$ plane (located approximately at $2 \mathrm{D}_{\text {premixer }}$ downstream of the static mixer).

Figure 5.27 shows the effect of using the flat fuel cap, Cap-1, with Mix-1/2, which has a $30^{\circ}$ swirl blade angle, on the spread of the fuel jets throughout the premixer vertical cross-sections. The nozzle exit plane image shows the fuel jet trajectories penetrate into the swirling mainstream. Also, it shows the direction of rotation (anticlockwise) the mixer imparts to the main flow. The opposite rotation (clockwise) at the the fuel cap edge plane compared to that at the the nozzle exit plane as discussed in previous sections (see Figure 5.16) is also shown in Fig. 5.27. At the fuel cap edge plane $(0.0 \mathrm{~cm})$ the image shows the distinct structure of the distorted inlet fuel jets (small swirls) in a ring, with local maximum fuel concentration at roughly the same radius from the premixer centre axis. Also, one can observe that the small swirls are connected to a central disc. The view of the central disc is not completely shown due to the fuel cap mask used to avoid the light reflection. Figure 5.27 also shows that as the distance increases downstream, the spread of the fuel is increased and becomes more homogeneous. By close observation of the last two images in Figure 5.27 (at the $20 \mathrm{~cm}$ and $30 \mathrm{~cm}$ planes) one can observe some similarity. It could be said that the fuel jet spreads slowly in this region. However, compared to the $45^{\circ}$ fuel injection, Cap-5 (e.g., Figure 5.20), the fuel spread (homogeneity) is greater with the radial fuel injection, Cap-1. At $5 \mathrm{~cm}$, the spread of the fuel occupies approximately half of the premixer cross-sectional area in Figure 5.20 while at the same distance in Figure 5.27; the fuel jet covers almost all of the premixer cross-sectional area. 

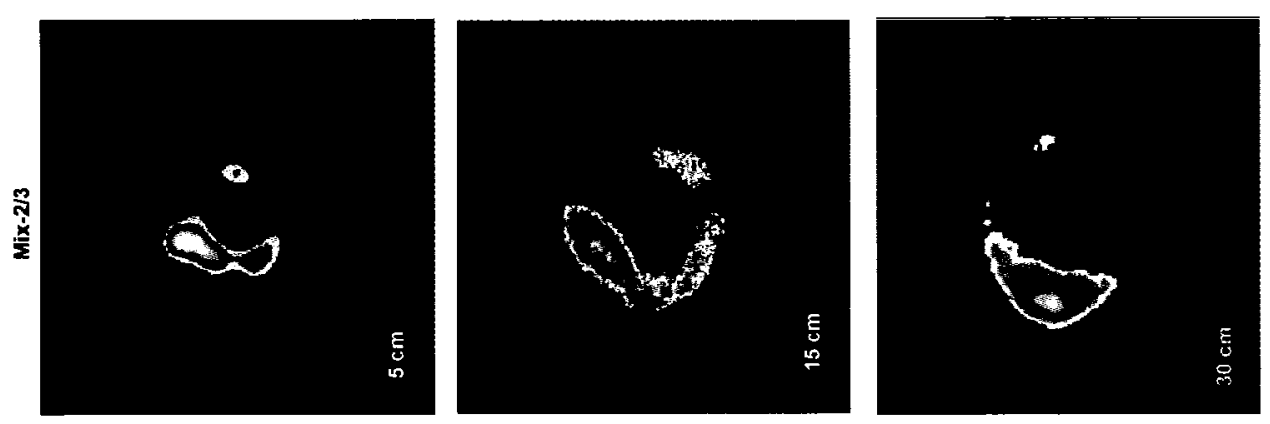

$\stackrel{ }{=}$
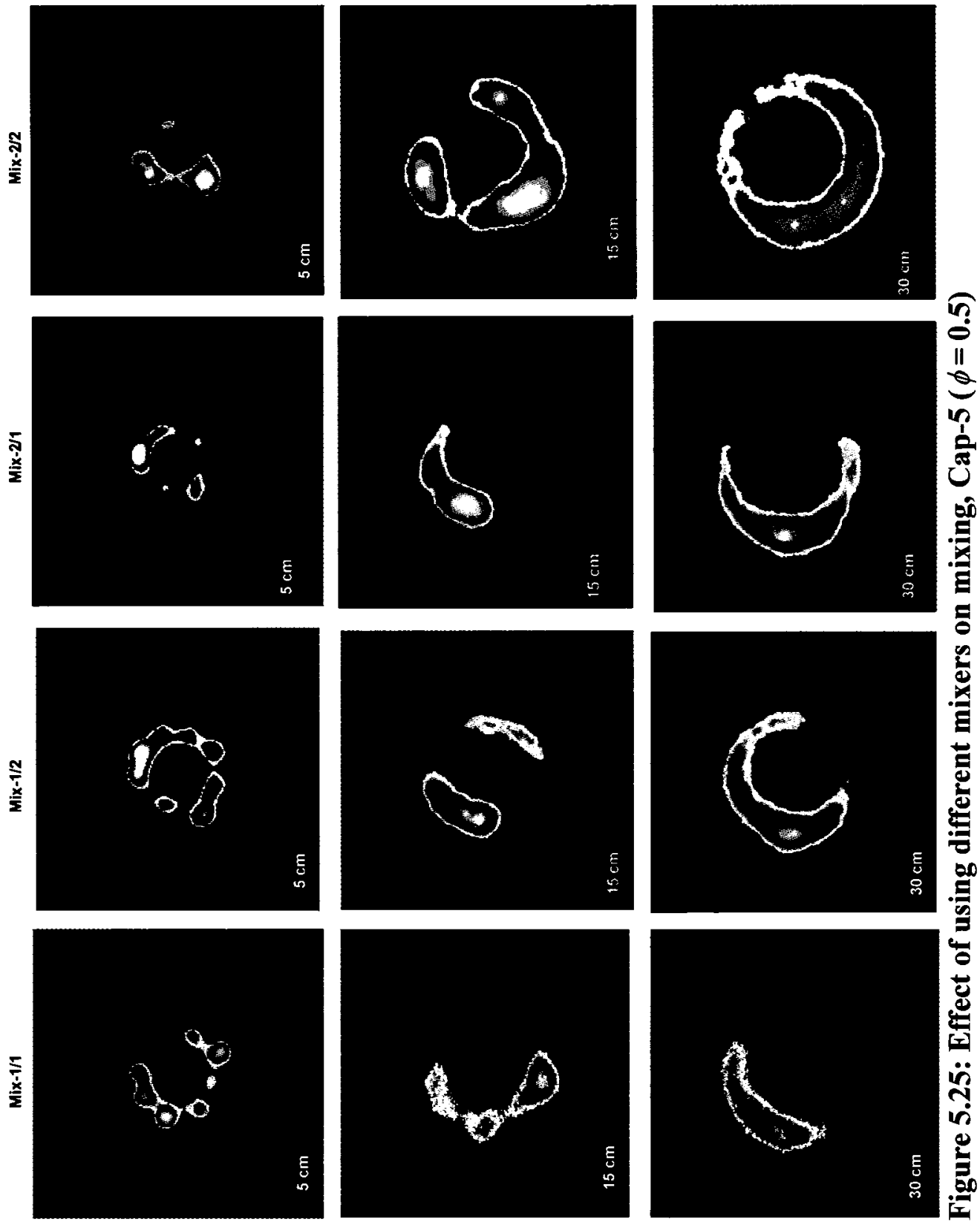

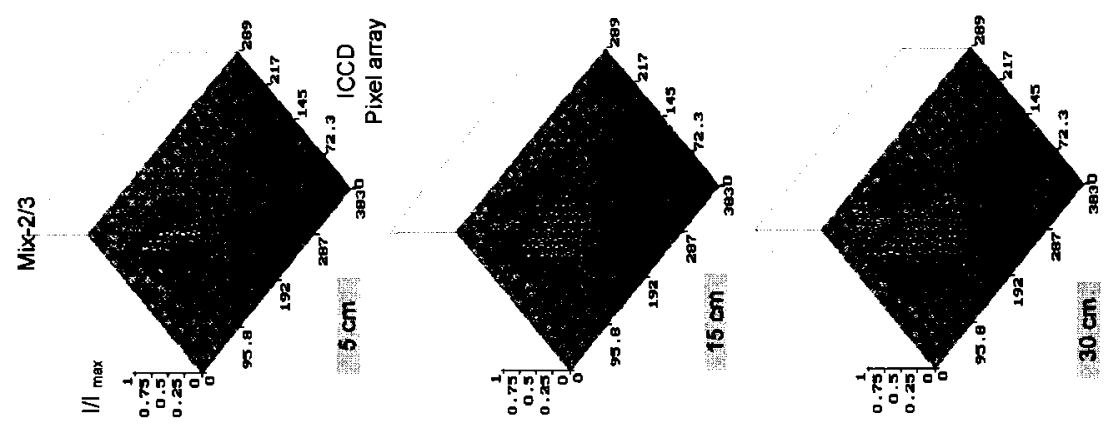

$\stackrel{m}{=}$
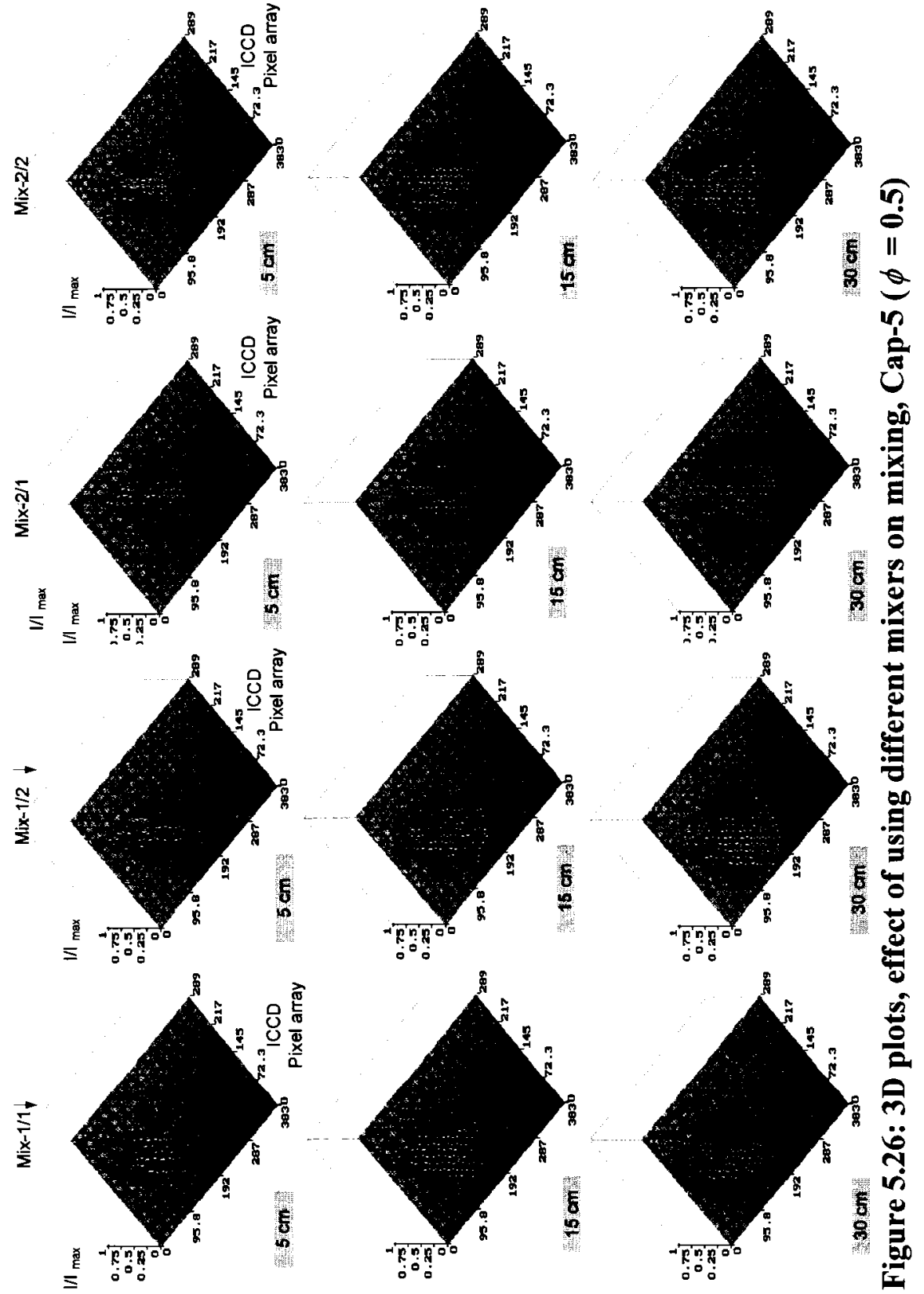
Figure 5.28 shows the LSI images for the double-swirl mixer, Mix-2/1 and fuel cap Cap-1. This co-swirl mixer imparts a strong rotation to the flow which helps to improve the fuel spread (mixing) in the premixer. This figure shows the quick and rapid growth of the fuel jet through the premixer cross-sections. Compared to the previous results (Figure 5.27) obtained when using the round fuel cap, the mixing is greatly improved. Figure 5.28 also shows the same similarity at the last two sections mentioned for Figure 5.27.

Figure 5.29 shows the 3D plots for the vertical cross-sectional LSI images shown in Figure 5.28. The plots are for Mix-2/1, Cap-1 and an equivalence ratio of 0.5 . In Figure 5.29, the 3D plots show the growth in the fuel jets and the initial increase in the height of the intensity profile in proportion to the fuel spread. These 3D images also demonstrate an improvement in the mixing when using the flat cap, Cap-1 (90 degrees), as compared to the rounded cap, Cap-5 (45 degrees, see Figure 5.26).
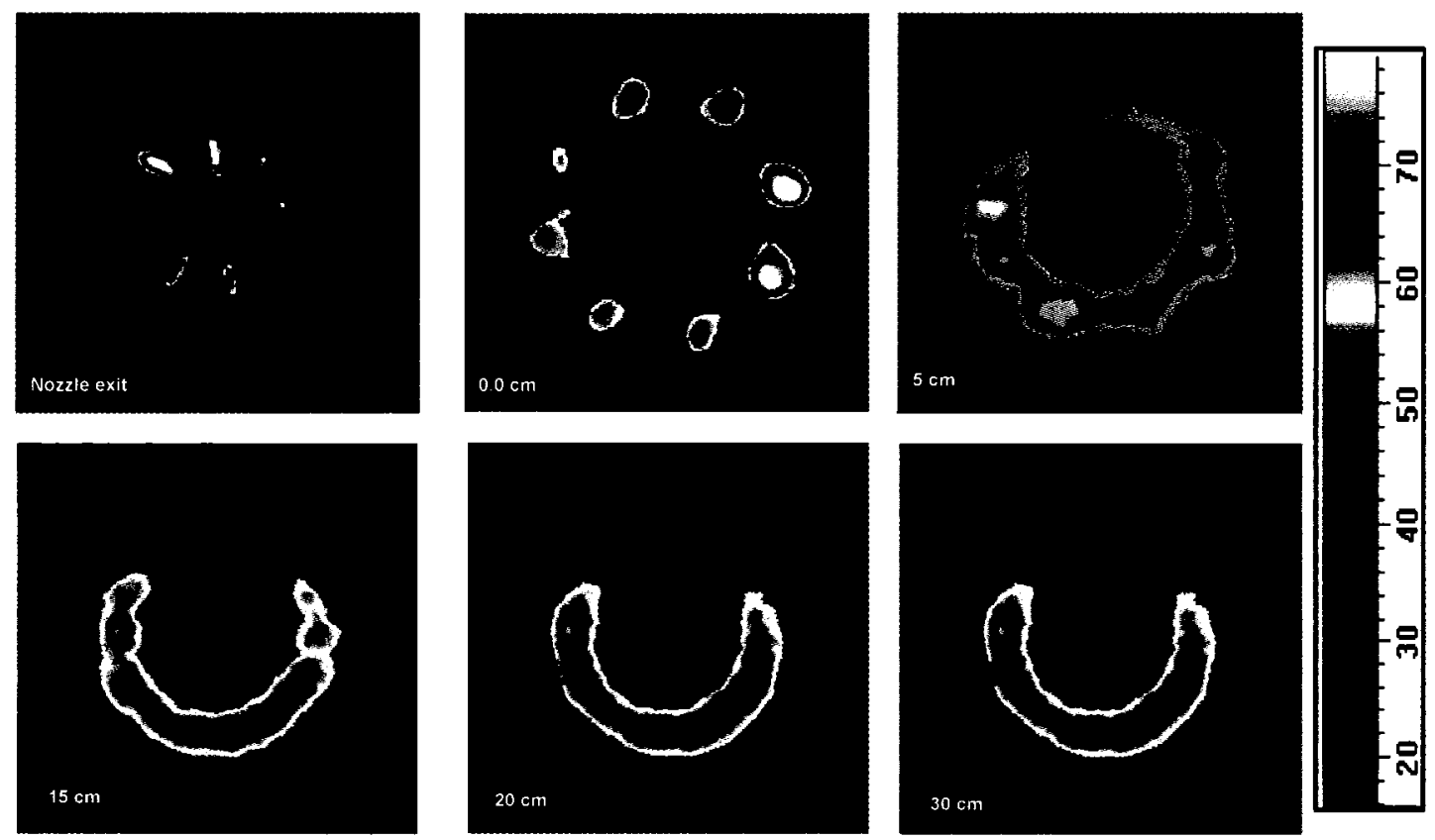

Figure 5.27: Vertical cross-sectional LSI images for Mix-1/2 and Cap-1 ( $\phi=0.5)$ 
Figure 5.30 is a direct comparison of the two fuel injection methods. This figure presents the vertical cross-sectional images for fuel caps, Cap-2 (90 degrees) and Cap-5 (45 degrees). Both caps have the same nozzle diameter and thus, the same momentum ratio and an equivalence ratio of 0.5 . Mix- $2 / 2$ shows good mixing characteristics when compared to other mixers when tested with Cap-5. However, using the radial fuel injection method, Cap-2, it has even better mixing, especially at a very short distance from the fuel cap. At the $5 \mathrm{~cm}$ plane when using Cap-5, the fuel spread occupies around 22 percent of the premixer cross-sectional area, at the same distance with Cap-2, the fuel occupies around 84 percent of the premixer crosssectional area. This is also clear from the 3D plot shown in Figure 5.31, which presents the 3D plots for all the cases illustrated in Figure 5.30.
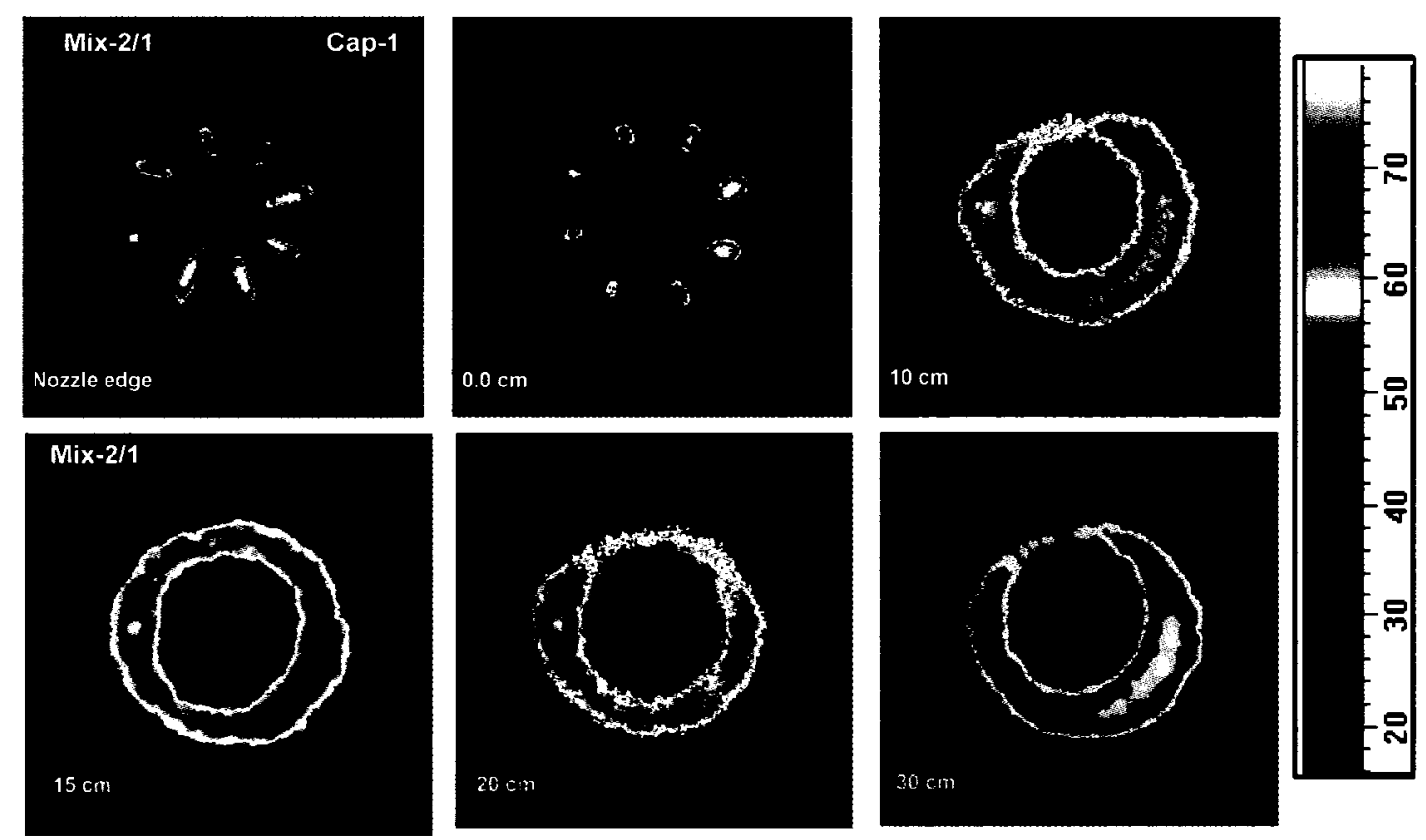

Figure 5.28: Vertical cross-sectional LSI images (Mix-2/1 and Cap-1 with $\phi=$ 0.5) 
Mix-2/1, Cap-1
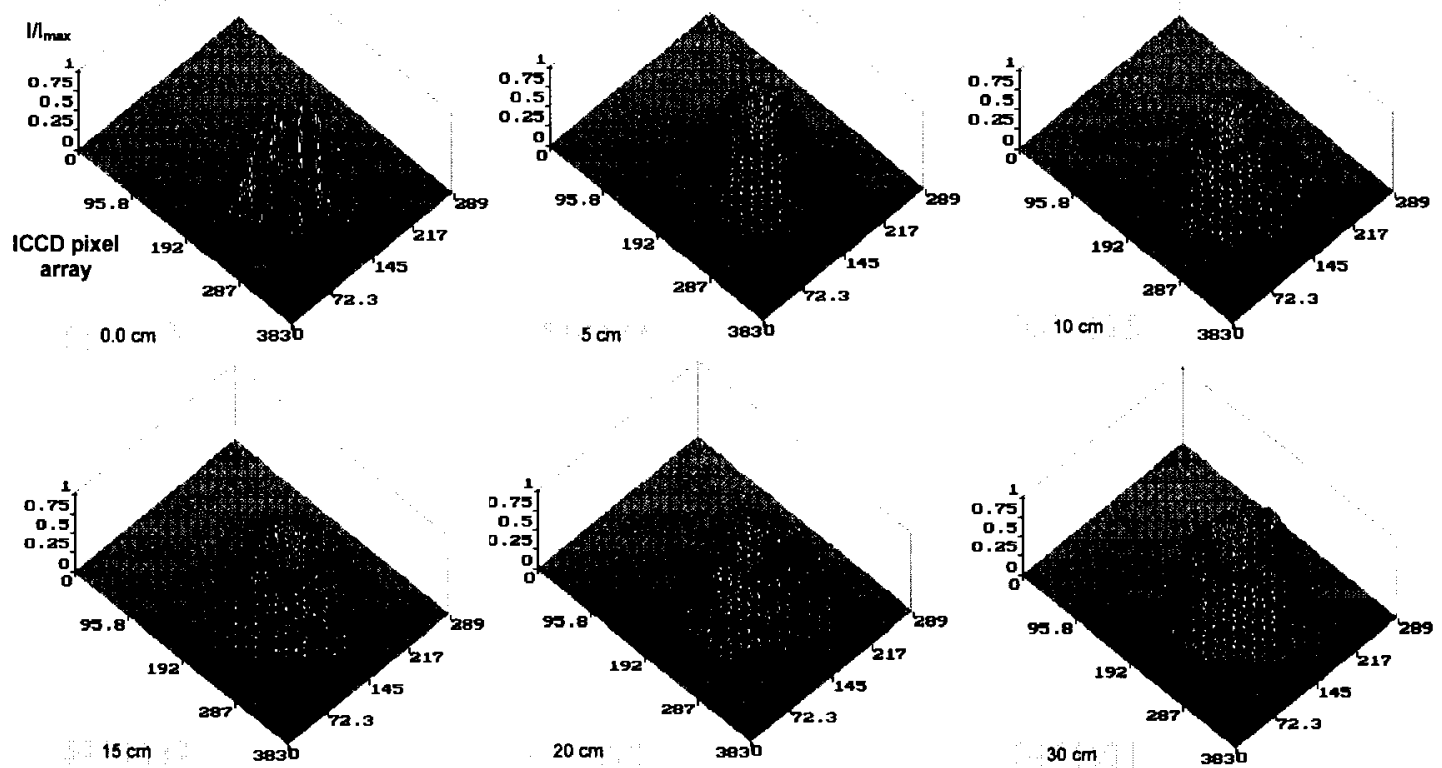

Figure 5.29: 3D plots for the vertical cross-sectional LSI images (Mix-2/1, Cap-1 with $\phi=0.5$ )
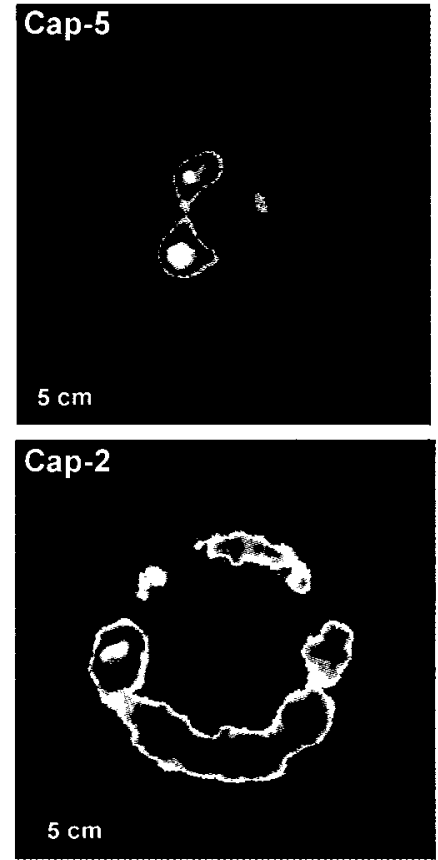
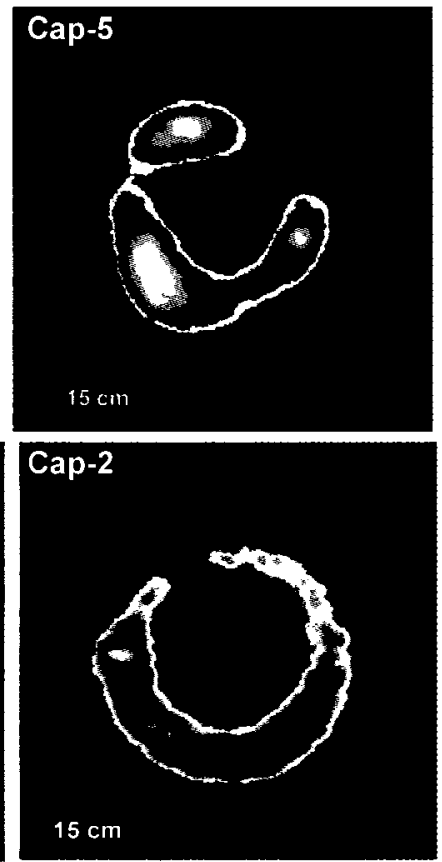

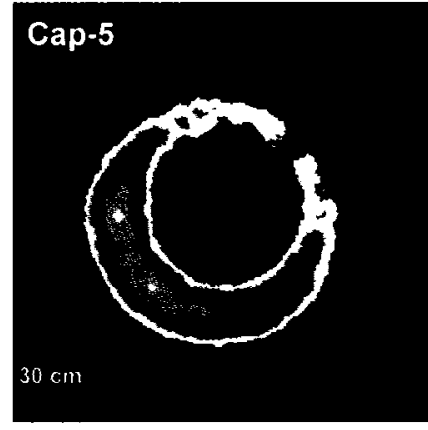

Cap-2

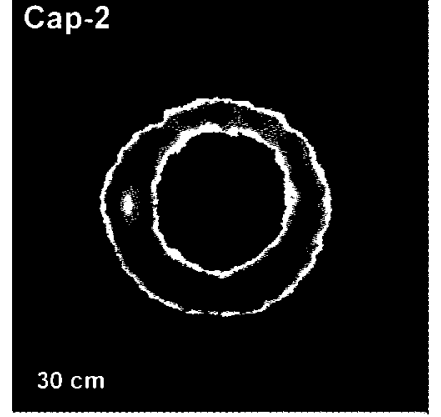

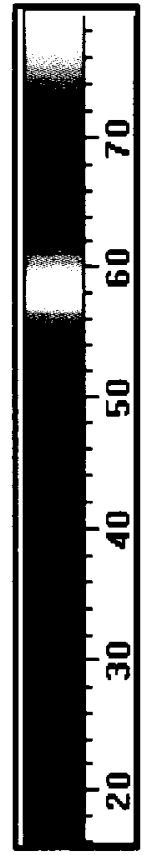

只

Figure 5.30: Comparisons between the vertical cross-sectional images (Mix-2/2 with, Cap-2 and Cap-5 and with $\phi=0.5$ ) 

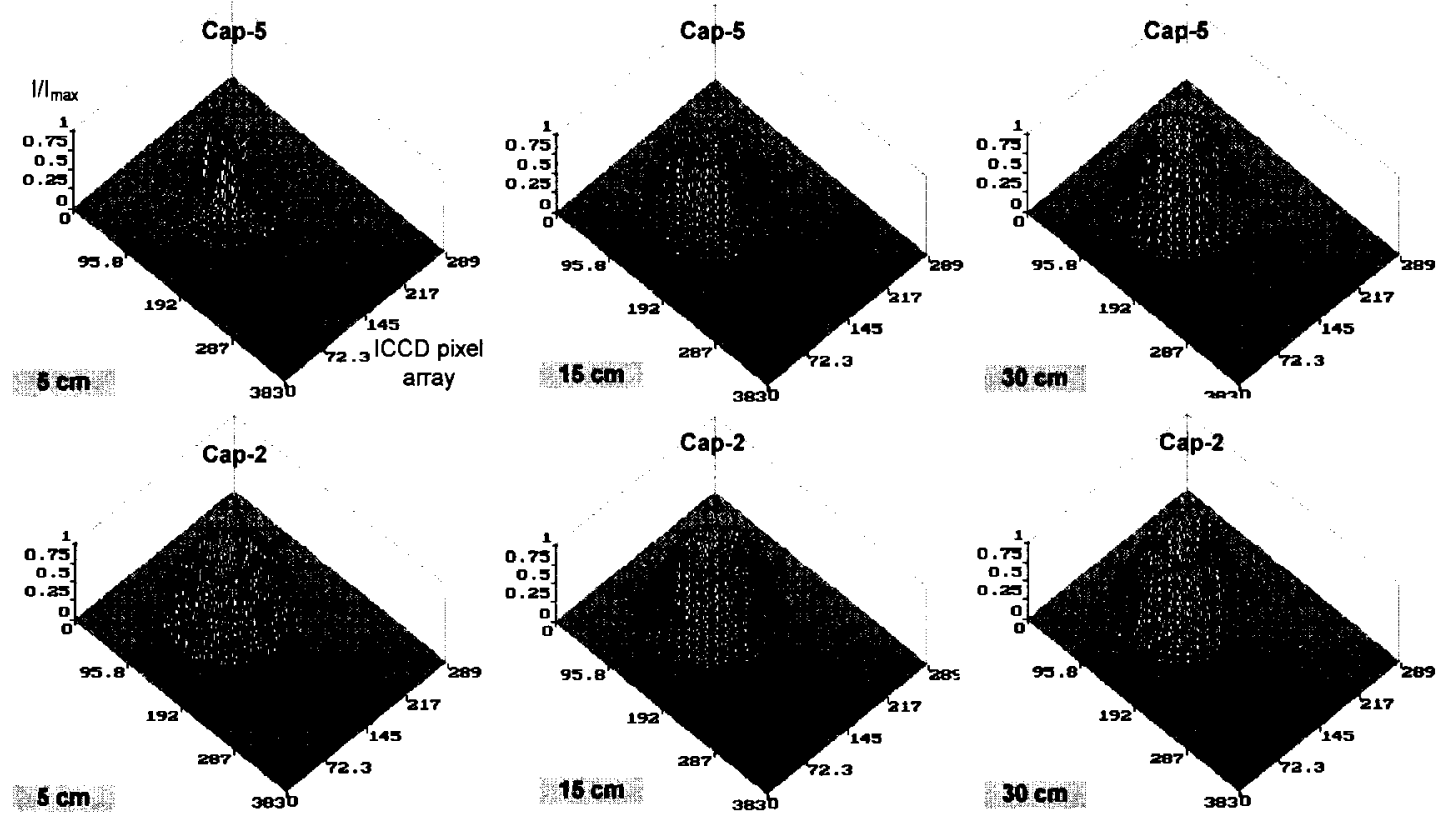

Figure 5.31: Comparisons between the 3D plots (Mix-2/2 with Cap-2 and Cap-5 and with $\phi=0.5$ )

Figure 5.32 shows a direct comparison between the LSI images captured at 10,15 and $30 \mathrm{~cm}$ planes for all the mixers tested with the flat cap (Cap-4) which has a $3 \mathrm{~mm}$ nozzle diameter and the momentum ratio of 0.23 . Mix-1/1 shows that at a 10 $\mathrm{cm}$ distance from the fuel cap edge, the fuel jets grow in diameter and join together to form a large circle. At the $15 \mathrm{~cm}$ plane, the jets join together; however, the initial jet structure can still be seen. The fuel eventually becomes homogeneously distributed in the premixer due to turbulent diffusion by $30 \mathrm{~cm}$. The other mixers, on the other hand, cause the fuel jets to join together and form a large circle rapidly after the fuel cap edge.

As a preparation for the combustion tests where the burner is expected to operate at a nominal lean condition ( $\phi<0.5$ ), LSI tests were performed using all the mixers at $\phi=0.3$ to consider the possibility of operating with conditions as lean as possible. Figure 5.33 shows the vertical cross-sectional images at six planes. The images show the same trend as in the previous results. Approximate similarity 
(maintain fuel spread identity) started from about the $15 \mathrm{~cm}$ plane image and improved slowly to the premixer end plane at $30 \mathrm{~cm}$. The penetration at $\phi=0.3$ cases is less compared to the previous $\phi=0.5$ cases.

The images shown in this section were chosen to demonstrate the important trends found for the tests. For more observations and comparisons between the images captured for all the geometrical combinations used, the reader is referred to Appendix E. On some of the images, there is a high concentration point located at the left-hand side of the image. This is attributed to the reflection of the input laser sheet on the premixer inner wall back into the flow. The image appears more intense on this side because of the extra light scattered on this side of the flow.

The following is a summary of qualitative conclusions from the direct observation of the LSI images:

1- The fuel spread through the premixer is affected by different factors, such as momentum ratio, swirl flow strength, swirl mixer configuration and the fuel injection angle.

2- $\quad$ The observations from LSI images indicate that swirl does have a pronounced effect on mixing. At a given length downstream of the fuel cap, the fuel spread is greater with double-swirl mixers than with single-swirl mixers and more with the use of flat caps (90 degrees) than with the round ones (45 degrees).

3- At approximately 1 premixer diameter $\left(1 \mathrm{D}_{\text {premixer }}\right)$ downstream of the static mixer, when using the flat caps, the images are approximately similar (maintain the same trend), which indicates that good mixing is achieved at a shorter mixing length (< $1 \mathrm{D}_{\text {premixer }}$ ).

4- Qualitatively, Mix-2/2 shows the best mixing compared to the other mixers, at $30 \mathrm{~cm}$ plane, where the best complete doughnut shape was observed. 


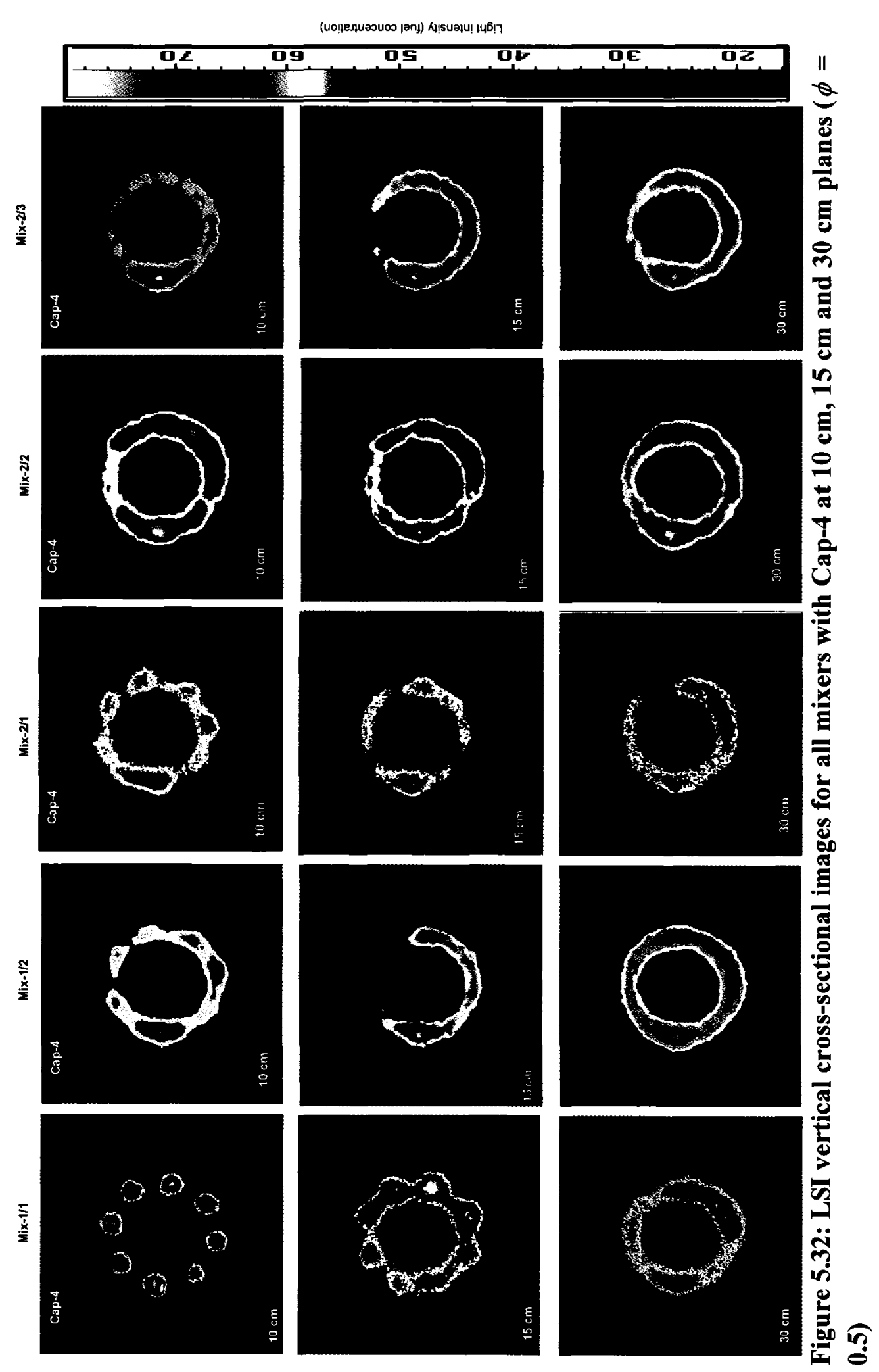

$\stackrel{9}{=}$ 


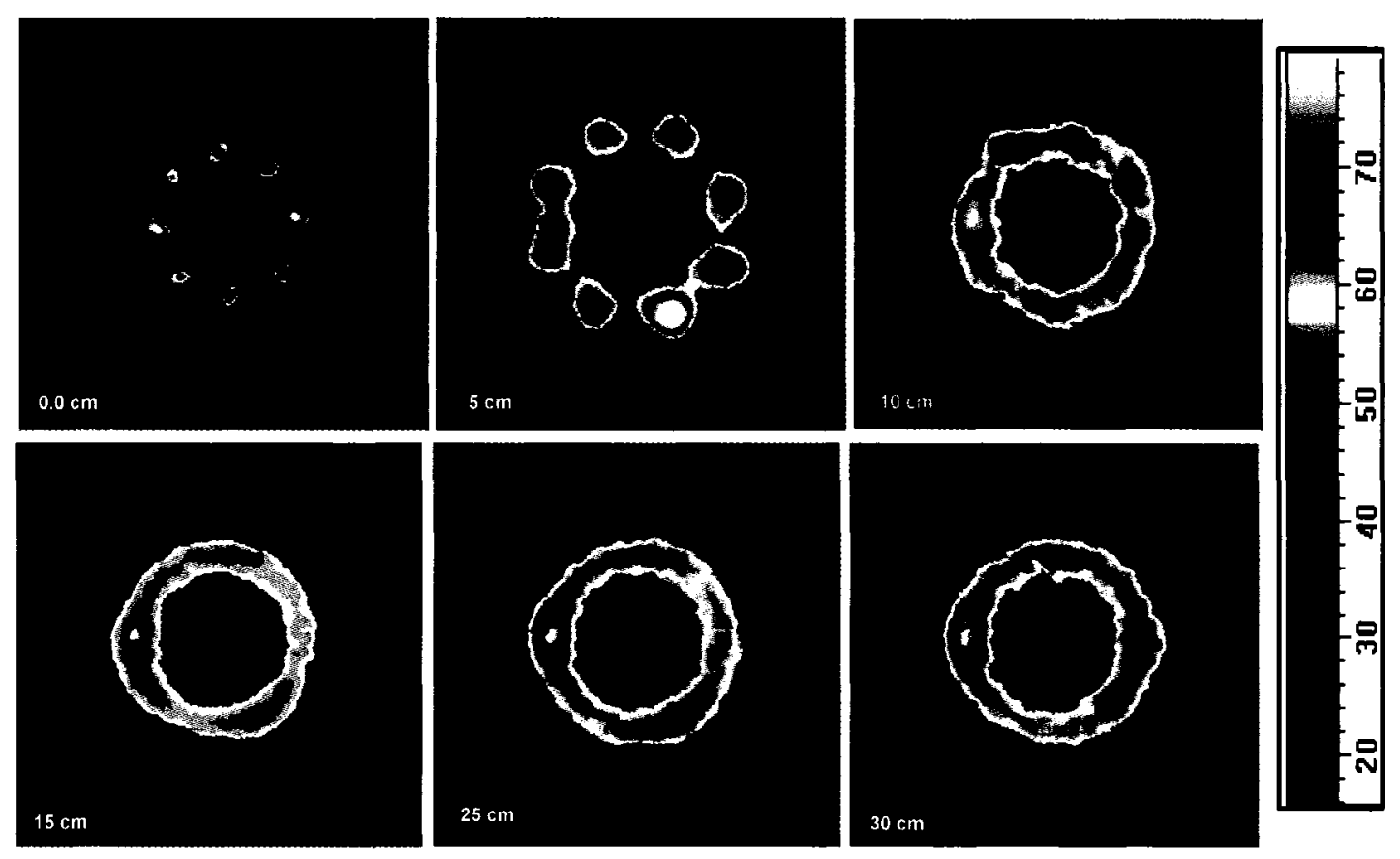

Figure 5.33: Vertical cross-sectional LSI images (Mix-2/2 and Cap-2 with $\phi=$ 0.3)

5- $\quad$ In general, the three double-swirl mixers and the $30^{\circ}$ single-swirl mixers provide good mixing when used with the flat caps.

6- $\quad$ The co-swirl mixer, Mix-2/1, provides good mixing and a strong swirl behaviour. For the case when this mixer is used with Cap-3 (see Appendix E, Figure E.34) the mixer shows less fuel spread (mixing) compared with the other two double-swirl mixers due to the lack of the shear layer between the inner and the outer swirl the other counter-swirl mixers have. Clear strong rotation was observed even at the $30 \mathrm{~cm}$ plane.

7- $\quad$ Cap-1 with all the mixers produces a wider spread of the fuel inside the premixer vertical cross-section. This is due to the high fuel penetration distance provided by this fuel cap. 
8- $\quad 3 \mathrm{D}$ figures help in the qualitative ranking of the different combinations used.

The fuel air mixing is qualitatively characterized by the laser sheet visualization. From the direct observation of the LSI images and the 3D plots, one can generally rank the different geometrical combinations tested with respect to the mixing between the fuel and the mainstream air. To improve the ranking procedure, a quasi-quantitative technique was developed to rank the mixers in terms of mixing effectiveness. This topic will be covered in a subsequent section.

\subsubsection{Lateral LSI images using flat caps}

The optical arrangement used for capturing LSI lateral images (side view) for both types of caps (round and flat) is shown in Figure 5.7. The lateral LSI images for the axial jet and for the round cap (Cap-5) were presented in Subsections 5.8.1 and 5.8.2. Testing the flat caps (injection of the fuel at 90 degrees to the mainstream) had a problem caused by the obstruction of the optical access to the test section. The build-up of alumina particles on the inner surface of the premixer reduced and eventually partially blocked the premixer wall transparency (optical path for LSI image capture). In addition, this formation of the seeded particles made the upper and lower boundary of the premixer a large source of light reflection back into the flow field (in addition to the fuel cap reflection). Efforts were made to minimize the strong interfering signals and improve the optical access. These include reduced test duration, cleaning the walls, using masks for both the fuel cap and the side walls, changing the premixer pipe from a circular cross-section to a rectangular one, and capturing more dirty background images for processing.

In the end, the lateral images were captured for the entire test matrix listed in Table 5.2, regardless of the quality of the images, aiming to use those results qualitatively to assist the ranking of the different premixer geometrical combinations used. Two sets of lateral images were captured. In the first set the fuel caps were 
masked to prevent excessive reflection. The second set of images was captured without masking the fuel caps.

Due to the unsatisfactory image quality of all lateral cross-sectional images, the images were not used for computing the unmixedness in the following section. The lateral images captured in this investigation were used qualitatively to give an overall view of the nature of the mixing field. Some of the lateral images which have good quality at some regions, such as near the fuel caps, were used to discuss the fuel jet penetration, mentioned in previous sections.

Figure 5.34 shows the effect of the swirl strength on the mixing region. This figure shows the increased spread of the mixture (fuel and air) when using Mix-1/2 compared to Mix-1/1. The image at the top of this figure is a reference image, representing the case of no swirling flow. With swirling flow, the eight jets merge quickly with the main flow in a short distance. Without swirl (top image) the eight jets can be observed to be only partially merged with each other at the premixer midsection. The images placed at the left-hand side of the figure show the effect of using a fuel cap mask on the appearance of the lateral images. The reason for masking this reason will be discussed below.

Figure 5.35 shows the effect of using the three different double-swirl mixers. Similar to the results presented in Figure 5.34, the left-hand side images show the effect of using a fuel cap mask on the appearance of the lateral images. One important result was observed for the Mix-2/1 unmasked image. The (right) image shows very clearly the existence of a low intensity zone (low pressure, circulation zone was observed) on axis that is formed after the premixer midsection plane due to the high swirl (co-swirl mixer). This region can not be observed during the capturing of the LSI vertical images due to the fuel cap mask. The Mix-2/1 unmasked lateral image also shows the excessive light reflection produced by the fuel cap. Subtracting a dirty background image, containing the light reflection produced by the fuel cap, leads to an image similar to that of the unmasked lateral image of Mix-2/2. 
Figure 5.36 shows another example of the importance of the use of the lateral images. This figure shows that the fuel jets touched the wall at a downstream location. This result can be used during the evaluation process in the following sections.

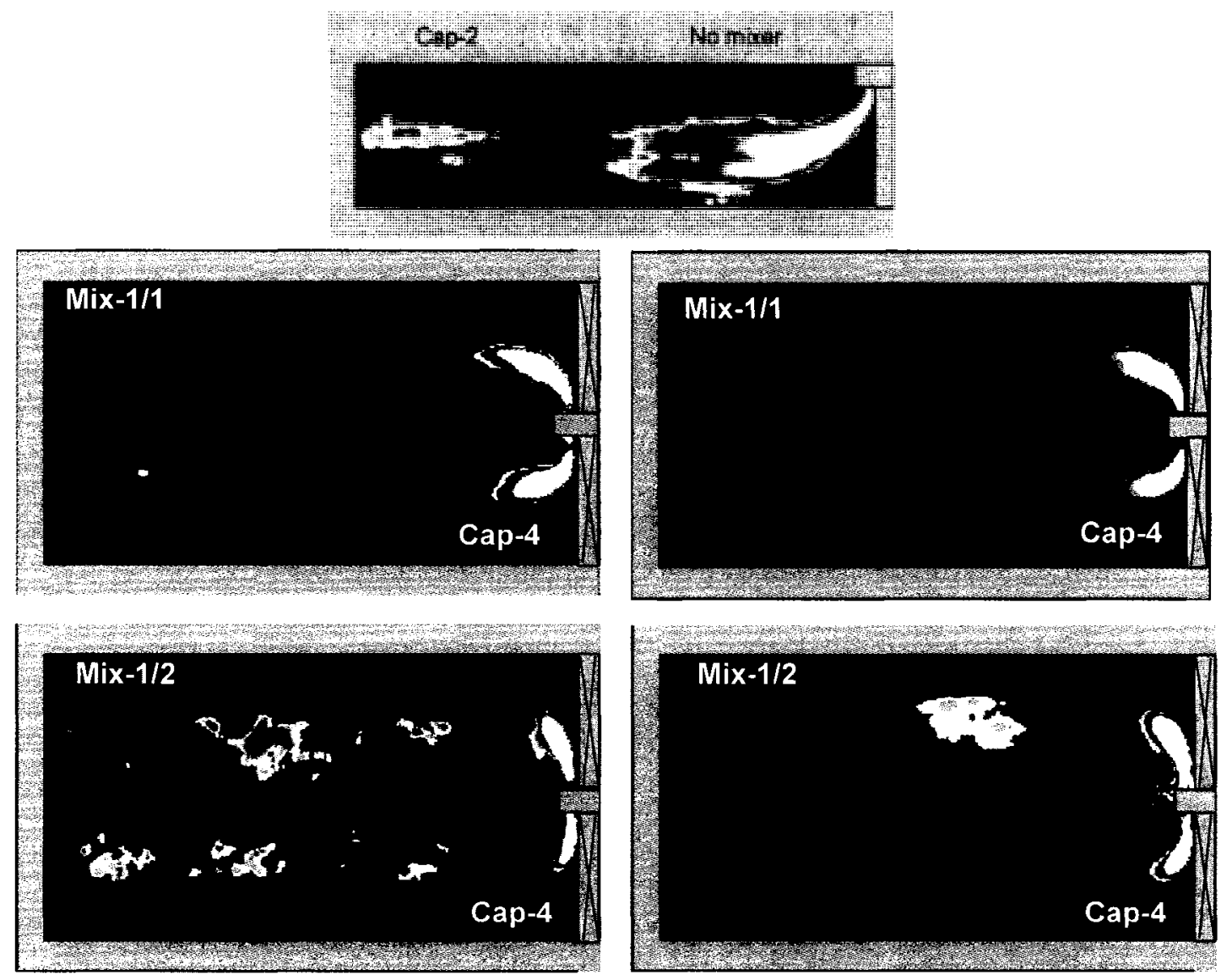

Figure 5.34: LSI lateral images showing effect of swirl strength on mixing (Cap4)

\subsubsection{Unmixedness}

One of the objectives of the LSI phase was to develop a measurement technique and data analysis procedure to evaluate the mixing effectiveness for the different premixer geometries and operating conditions; that is to say, to develop a 
technique which can derive quantitative information from the qualitative images analysed in the previous sections. To this end it is assumed that the scattered light intensity in the captured images is proportional to the number density of the particles in the illuminated cross-section and the particle concentration is assumed to be proportional to the fuel concentration [Solero et al. (2000)].
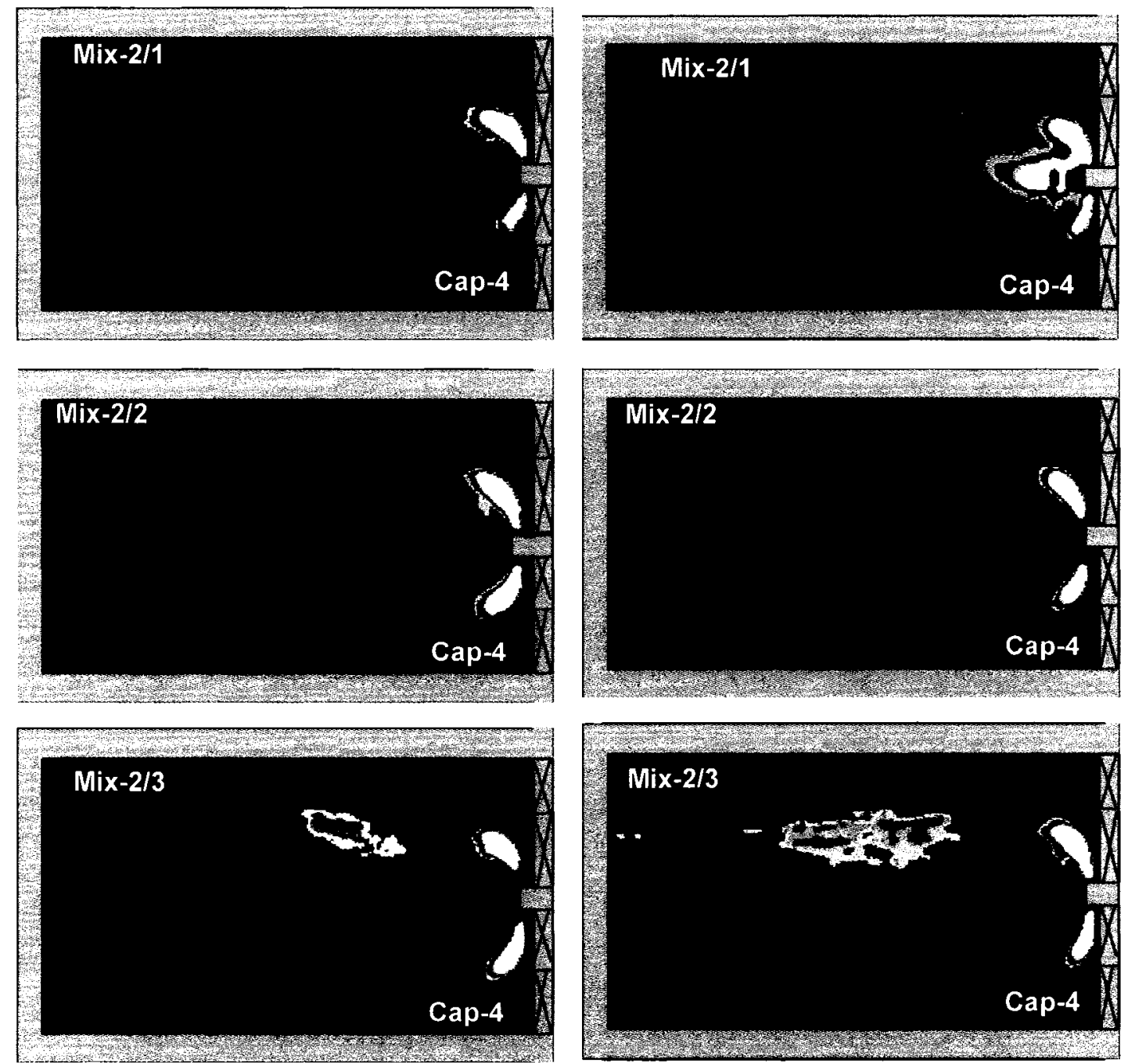

Figure 5. 35: LSI lateral images showing effect of swirl design and strength on mixing (Cap-4) 


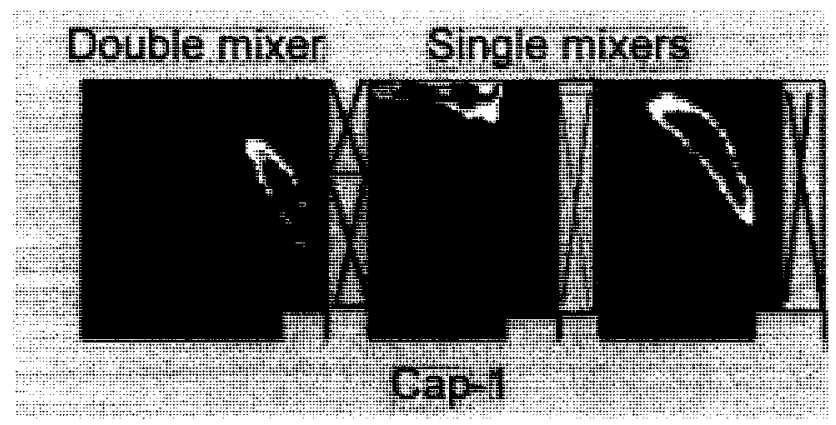

Figure 5.36: LSI lateral images; sample from jet penetration results (Cap-1)

Mixing can be defined as the process in which the unhomogeneous system is made homogeneous or uniform. Unmixedness is the term used in the literature [Turek et al. (2005), Demayo et al. (2004), Yimer et al. (2003), Solero et al. (2000), Bakker et al. (2000), Harding et al. (1998), Vranos et al. (1991)] as a measure of nonhomogeneity. Some researchers used the term coefficient of variation for this same unmixedness definition as a measure of uniformity. The spatial unmixedness, $U x$ (or unmixedness index), used in the present investigation, can be evaluated through quantitative analysis of light distribution (fuel concentration) on the LSI images and can be expressed as [Radhakrishnan et al. (1981), Bakker et al. (2000), Yimer et al. (2003)]:

$$
U x=\frac{\sigma_{f}}{m_{f}}
$$

where $\sigma_{f}$ is the standard deviation of the fuel concentration in a $2 \mathrm{D}$ plane and $m_{f}$ is the mean of the fuel concentration over the same $2 \mathrm{D}$ plane.

$$
\sigma_{f}=\sqrt{\frac{1}{N-1} \sum(x-\bar{x})^{2}}
$$

where $N$ is the number of pixels in the image, $x$ is the individual pixel value and $\bar{x}$ is the average pixel value. 
Yimer et al. (2003) used only the unmixedeness index to evaluate the mixing process. Bakker et al. (2000) used a normalized unmixedness to evaluate the mixing process. The unmixedness (the term coefficient of variation was used in their paper) was normalized by the unmixedness (coefficient of variation) at the nozzle exit where all the jet mass is injected. In the present investigation it was difficult to obtain the unmixedness from the images captured at the plane located at the fuel nozzle exit (the laser sheet passed over the fuel cap) as the fuel cap gave high light reflection. This reflection affects some of the images taken at the exit plane, therefore in the present investigation and for the purpose of ranking the different premixer geometries used, the unmixedness index was normalized by a quantity named $U o$ which is a function of the fuel to mainstream mass flow rate ratio (constant for all the tests).

The mixing effectiveness can then be defined as:

$$
\eta_{m i x}=\frac{U x}{U o}
$$

where $U o$ is defined as:

$$
U o=\sqrt{\frac{1-M R_{L S l}}{M R_{L S l}}}
$$

where $\mathrm{MR}_{\mathrm{LSI}}$ is the fuel jet-to- mainstream (air) mass flow ratio

$$
M R_{L S t}=\frac{\dot{m}_{j e t}}{\dot{m}_{\text {flow }}}
$$

The $\eta_{m i x}$ has values between 0 and 1 , where $\eta_{m i x}=1$ represents a maximum variance and thus corresponds to a totally unmixed mixture, a decreasing $\eta_{\operatorname{mix}}$ corresponds to increasing homogeneity of the premixed mixture, and $\eta_{m i x}=0$ represents the best mixing.

The mixing effectiveness was computed at several cross-sections downstream of the static mixer for the different geometric combinations studied (Table 5.2). The mixing process can therefore be analyzed by comparing these computed results. 
All the computed results $(U x / U o)$ are plotted versus axial distance for all studied cases. For a better presentation of the results, and as stated in Section 5.5, the axial distance was normalized by the premixer diameter. Table 5.5 presents the different plane locations at which the mixing effectiveness computation was performed.

The unmixedness parameter is referred to as the mixing effectiveness in this thesis. Only selected results of the mixing effectiveness as a function of different operating conditions (i.e., momentum ratio (fuel nozzle diameter), swirl strength, equivalence ratio ( $\phi=0.5)$ and fuel injection angle) are presented in this section. The remaining mixing effectiveness results are presented in Appendix E; however, they are used in the final conclusions when ranking the different geometrical combinations.

Table 5.5: Premixer axial distance planes

\begin{tabular}{|c|c|}
\hline $\begin{array}{c}\text { Cross-section or plane location } \\
\text { (From Figure 5.8) }\end{array}$ & $\begin{array}{c}\text { Axial distance / premixer diameter } \\
\left(X / \mathrm{D}_{\text {premixer }}\right)\end{array}$ \\
\hline Static mixer exit plane & 0.0 \\
\hline Nozzle exit & 0.06 \\
\hline Fuel cap edge & 0.22 \\
\hline $5 \mathrm{~cm}$ & 0.42 \\
\hline $10 \mathrm{~cm}$ & 0.73 \\
\hline $15 \mathrm{~cm}$ & 1.03 \\
\hline $20 \mathrm{~cm}$ & 1.33 \\
\hline $25 \mathrm{~cm}$ & 1.64 \\
\hline $30 \mathrm{~cm}$ & 1.94 \\
\hline Premixer exit plane & 2 \\
\hline
\end{tabular}

Figure 5.37 shows the variation of mixing effectiveness with the axial distance along the premixer for different fuel cap designs tested with Mix-1/1. At the 
fuel cap nozzle where all the jet fuel mass is injected, $U x / U o$ reaches its maximum value and then decreases downstream as the jet spreads and mixes with the swirling cross-flow. It is clearly noticeable that Cap-5 has the highest unmixedness values at all the axial locations measured. This is the result of the fuel injection angle $\left(45^{\circ}\right)$, compared to the radial injection caps. This result can also be concluded by direct observation of the LSI images discussed in the previous sections. Figure 5.37 also shows that for Cap-5 the mixing effectiveness improves (decreases) slowly as the axial distance increases and still does not attain the best mixing effectiveness at the end of premixer. On the contrary, for the other flat mixers (radial fuel injection caps) the mixing effectiveness reaches its maximum (lower value) even before the premixer mid plane $\left(X / \mathrm{D}_{\text {premixer }}=1\right)$.

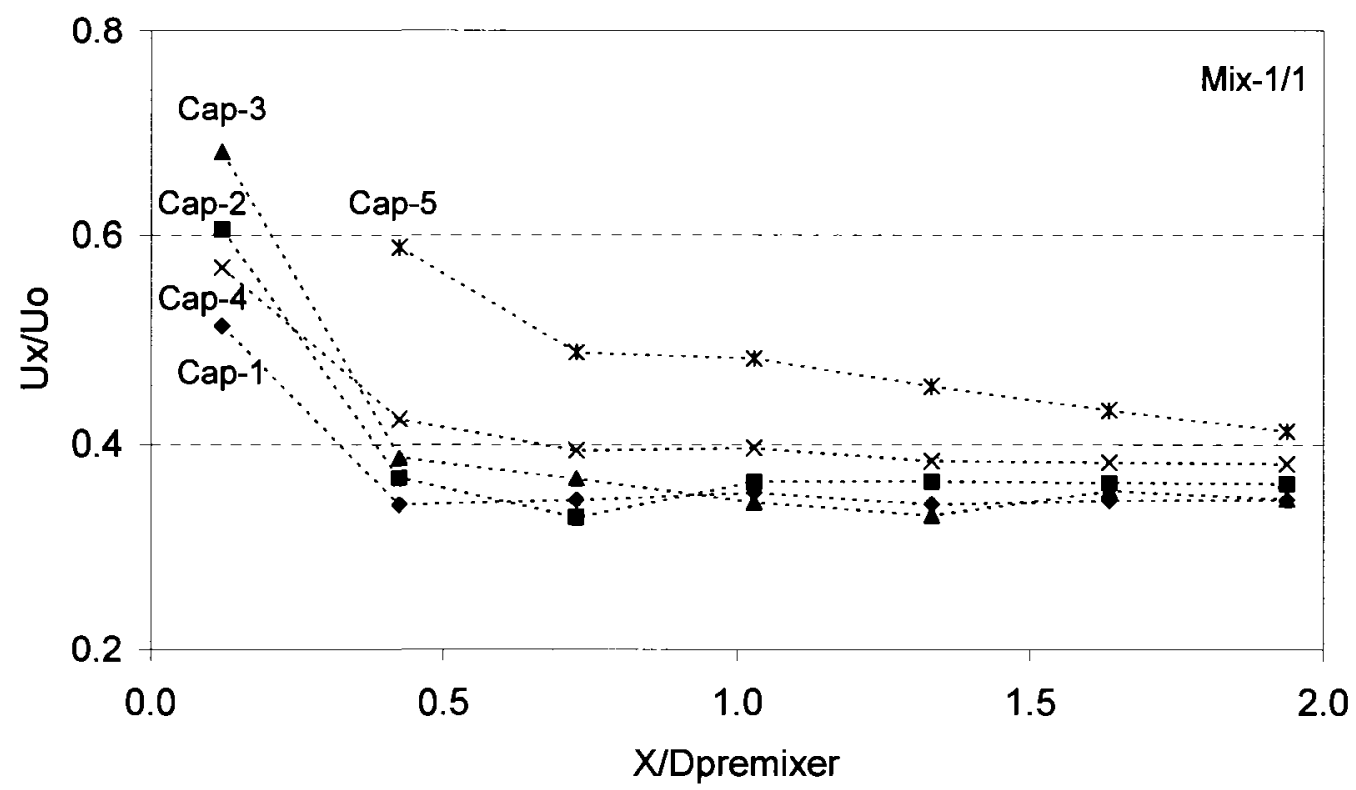

Figure 5.37: Mixing effectiveness as a function of different fuel caps design (Mix1/1)

Figure 5.38 shows the variation of mixing effectiveness with the axial distance along the premixer for different fuel cap designs tested with Mix-1/2. By comparing the results presented in both Figures 5.38 and 5.39, it is clearly noticeable 
that the mixing effectiveness is improved using the higher strength single-swirl mixer, Mix-1/2. In this figure Cap-5 also has the higher unmixedness values at all the axial locations measured. Figure 5.39 shows the effect of swirl strength on mixing effectiveness. The round cap, Cap-5, was used with the two single-swirl mixers, Mix$1 / 1\left(15^{\circ}\right.$ blade angle, $\left.\mathrm{S}=0.18\right)$ and Mix-1/2 $\left(30^{\circ}\right.$ blade angle, $\left.\mathrm{S}=0.4\right)$. The results show that as the swirl strength increases in the main cross-flow the mixing effectiveness improves due to the higher turbulence imparted to the main flow.

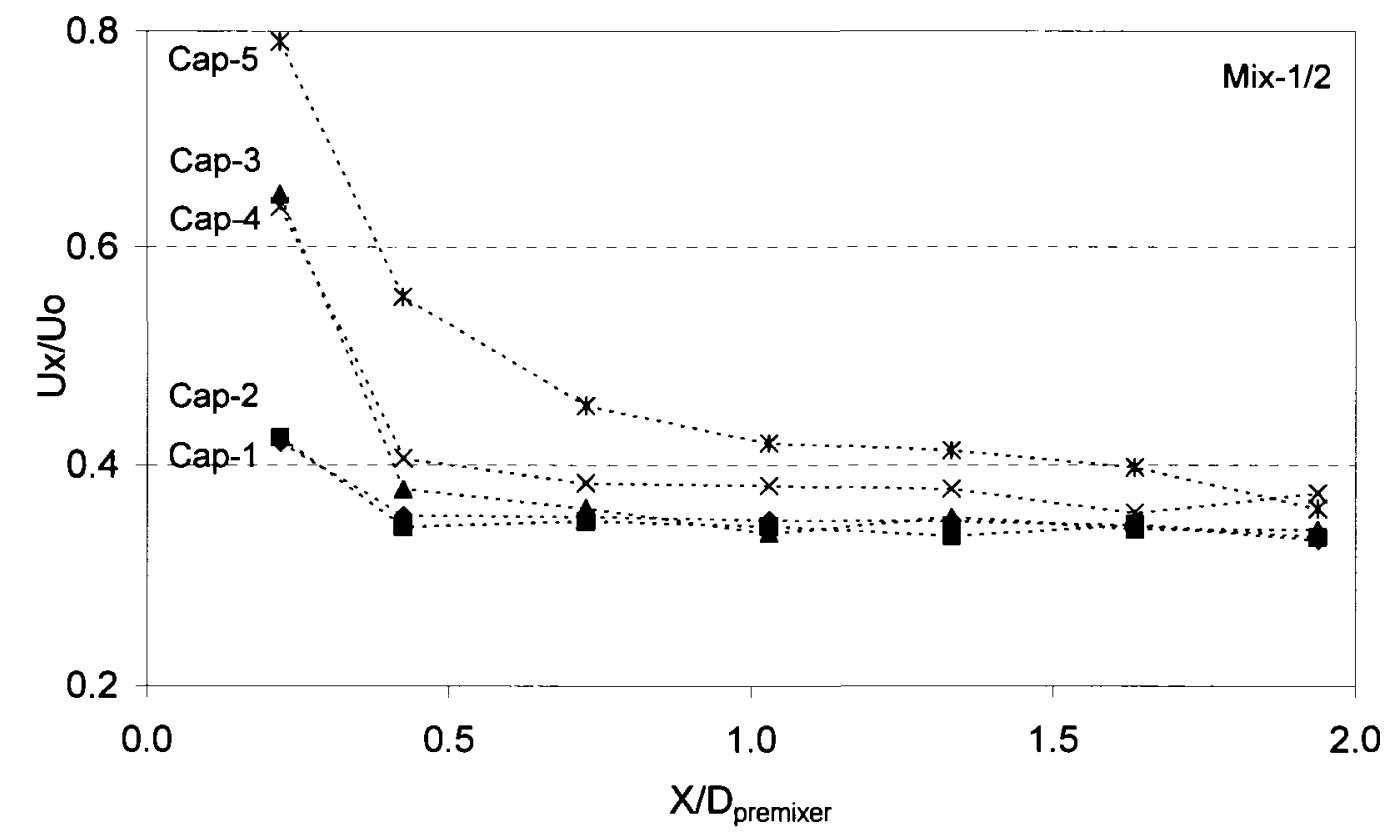

Figure 5.38: Mixing effectiveness as a function of different fuel caps design (Mix-1/2)

As a sample from the mixing effectiveness results of the double-swirl mixers, Figure 5.40 shows the variation of mixing effectiveness with the axial distance along the premixer for different fuel cap designs tested with Mix-2/2. It is clearly noticeable that, Cap-5 shows an improvement in the mixing effectiveness when tested with this mixer comparing with its result with Mix-1/1 and Mix-1/2, see Figures 5.38 and 5.39. In Figure 5.40, Cap-5 attained unmixedness value of less than 0.4 starting at the 
premixer half-length. However it never reached this value, even at the end of the premixer when it was tested with Mix-1/1.

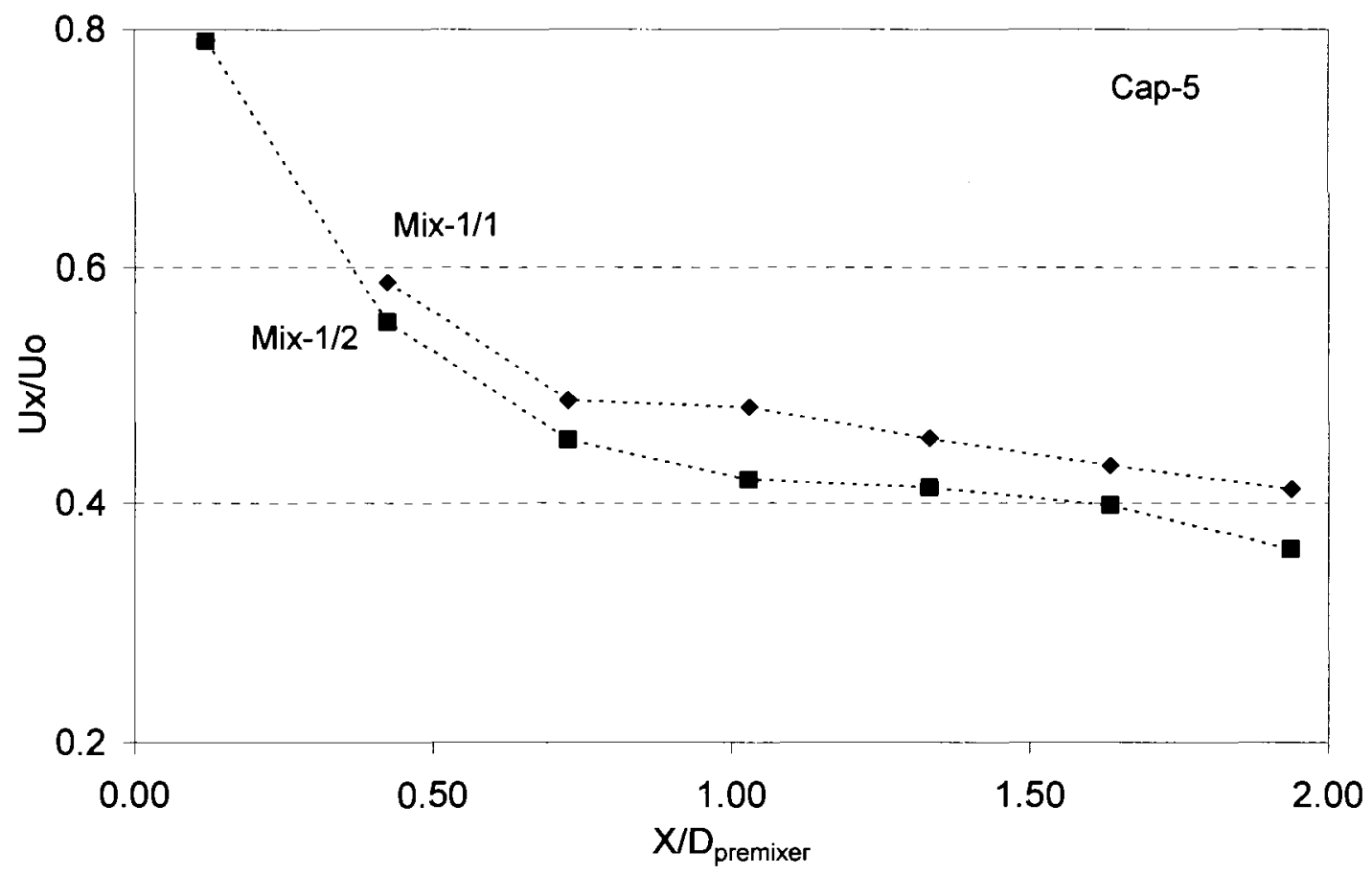

Figure 5.39: Effect of swirl strength on mixing effectiveness (Mix-1/1, Mix-1/2 and Cap-5)

Figure 5.41 shows the effect of fuel injection angle on mixing effectiveness. The double-swirl mixer, Mix-2/2, was used with the two caps, Cap2 and Cap-5, with the same nozzle diameters and so the same momentum ratio $(2.3 \mathrm{~mm}$ and $\mathrm{MMR}=$ 0.39). Cap-2 shows the best mixing effectiveness compared to Cap-5 when both are used with Mix-2/2. The direct observation of the LSI images presented in Figure 5.30 and 3D plots in Figure 5.31 in the previous section show the same results. 


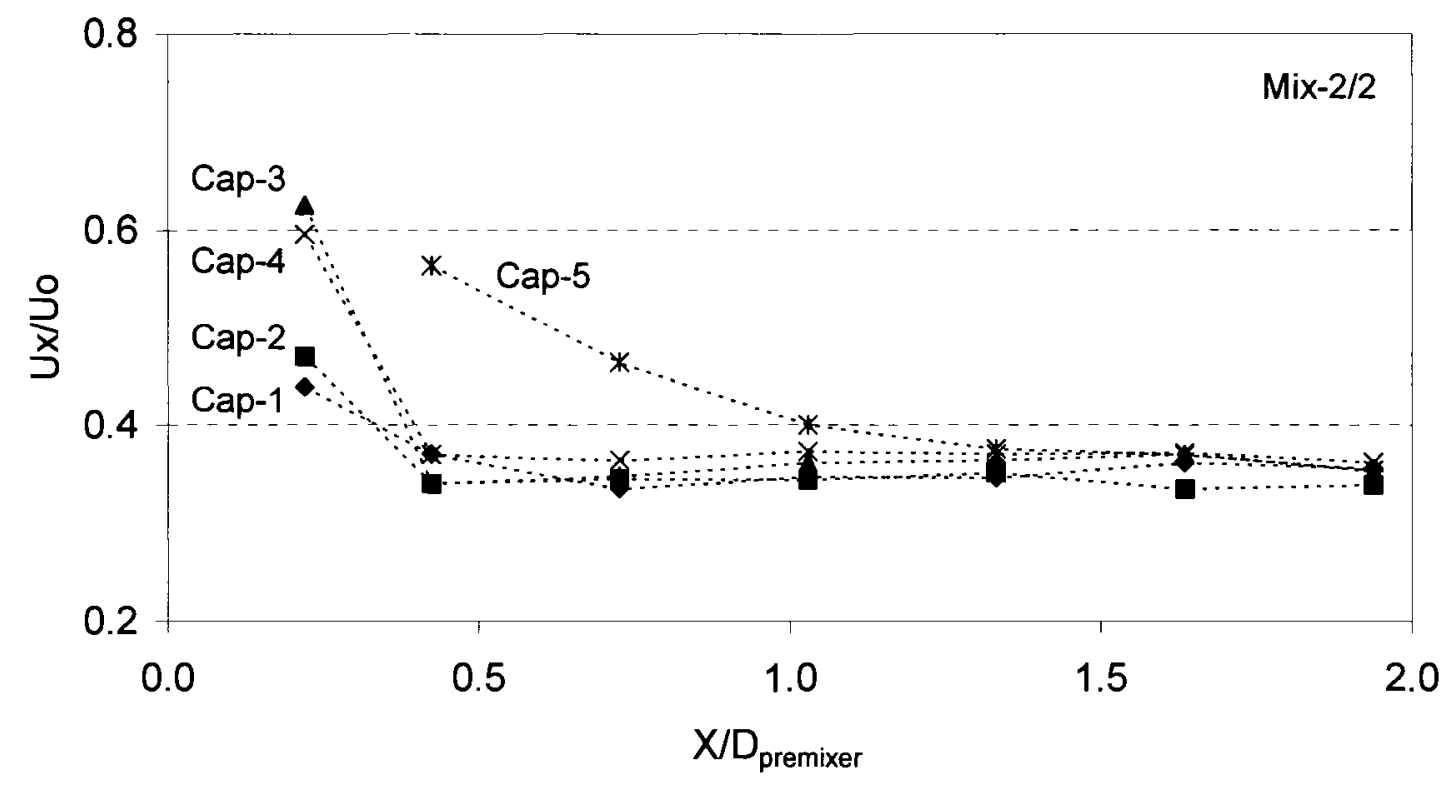

Figure 5.40: Mixing effectiveness as a function of different fuel caps design (Mix2/2)

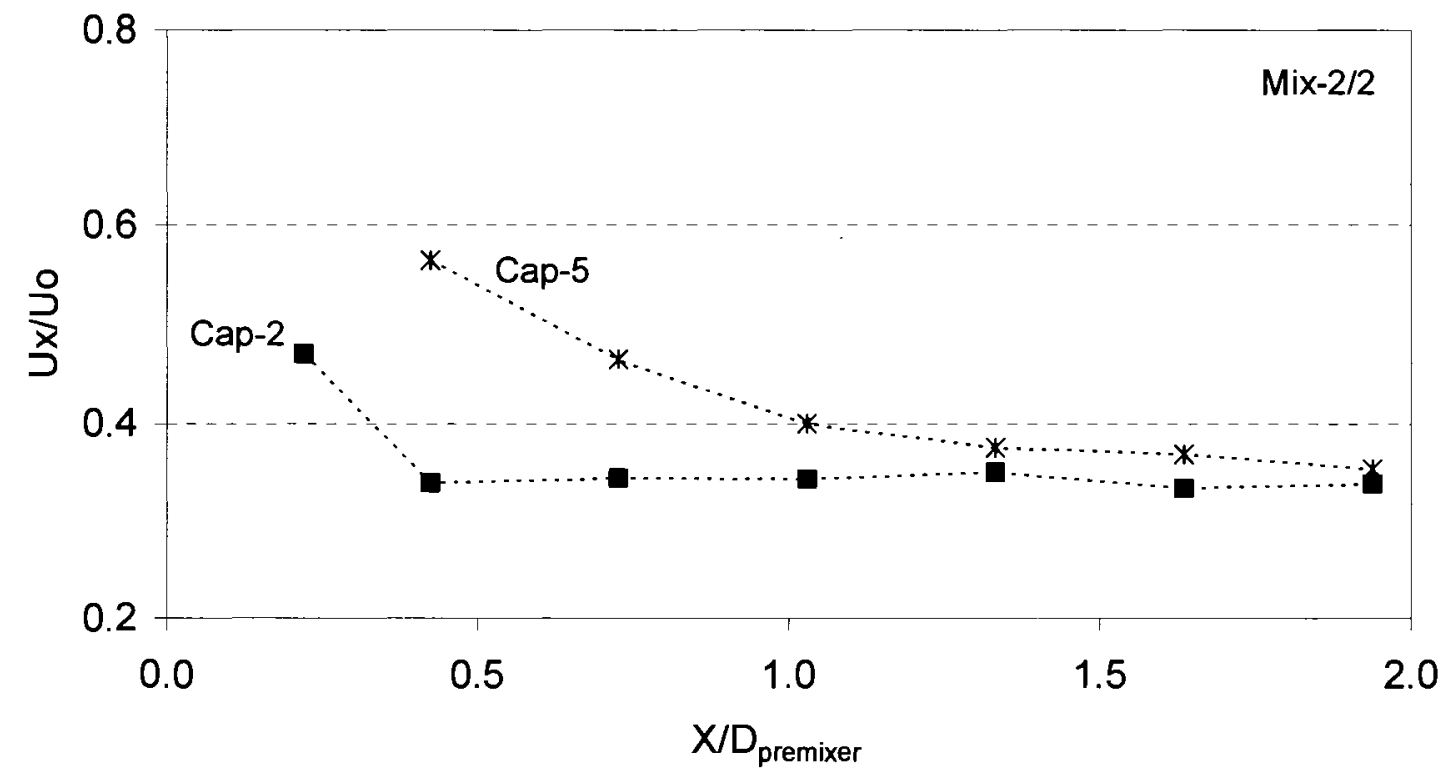

Figure 5.41: Effect of fuel injection angle on mixing effectiveness (Mix-2/2) 
Figure 5.42 shows the effect of swirl strength on mixing effectiveness. In this figure the comparison is between two different design mixers. The single-swirl mixer Mix-1/2 $\left(30^{\circ}\right.$ blade angle, $\left.\mathrm{S}=0.4\right)$ and the double-swirl mixer, Mix- $2 / 2\left(+/-30^{\circ}\right.$ blade angle and $\mathrm{S}=0.58)$, were used in this comparison. The flat cap (Cap-4 (3 mm)), was used with the two mixers. Mix-1/2 $\left(30^{\circ}\right.$ blade angle, $\left.\mathrm{S}=0.4\right)$ and $\mathrm{Mix}-2 / 2$ (counterswirl, (+/-) $30^{\circ}$ blade angle, $\left.\mathrm{S}=0.58\right)$. The results show that as the swirl strength increases in main cross-flow the mixing effectiveness improves. The improvement in mixing was remarkable through the first half of the premixer length, but after that both mixers provided close results. This may be attributed to the effect of the fuel cap mask used.

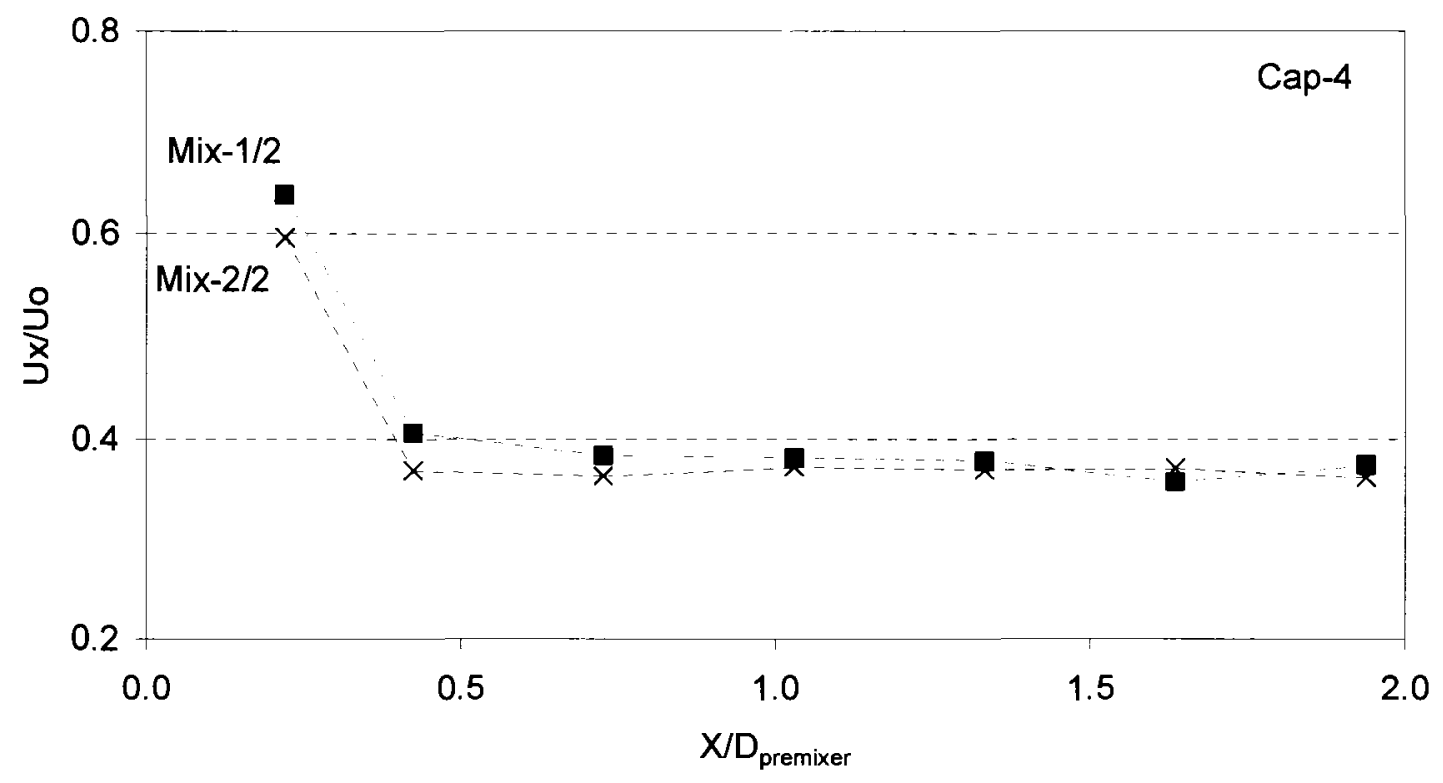

Figure 5.42: Effect of swirl strength on mixing effectiveness (Mix-1/2, Mix-2/2 and Cap-4)

Figure 5.43 shows the effect of variation of the swirl direction of rotation on mixing effectiveness. The round cap (Cap-5) was used with the two double-swirl mixers, Mix-2/2 ((+/-) $30^{\circ}$ blade angle, $\left.\mathrm{S}=0.58\right)$ and Mix- $2 / 3\left((-/+) 30^{\circ}\right.$ blade angle, 
$\mathrm{S}=0.58$ ). The results show that the mixer with the +ve inner swirl mixer (clockwise rotation) and -ve outer swirl mixer (anticlockwise rotation), Mix-2/2, has relatively better mixing effectiveness than Mix-2/3 which has the opposite directions. This result is also observed from the LSI images, see figures 5.13, 5.26, 5.27 (3D plot) and 5.33. Actually Mix-2/2 and Mix-2/3 should give identical results because one is a mirror image of the other and their results are very close. The difference reflects manufacturing defects or measurement uncertainty.

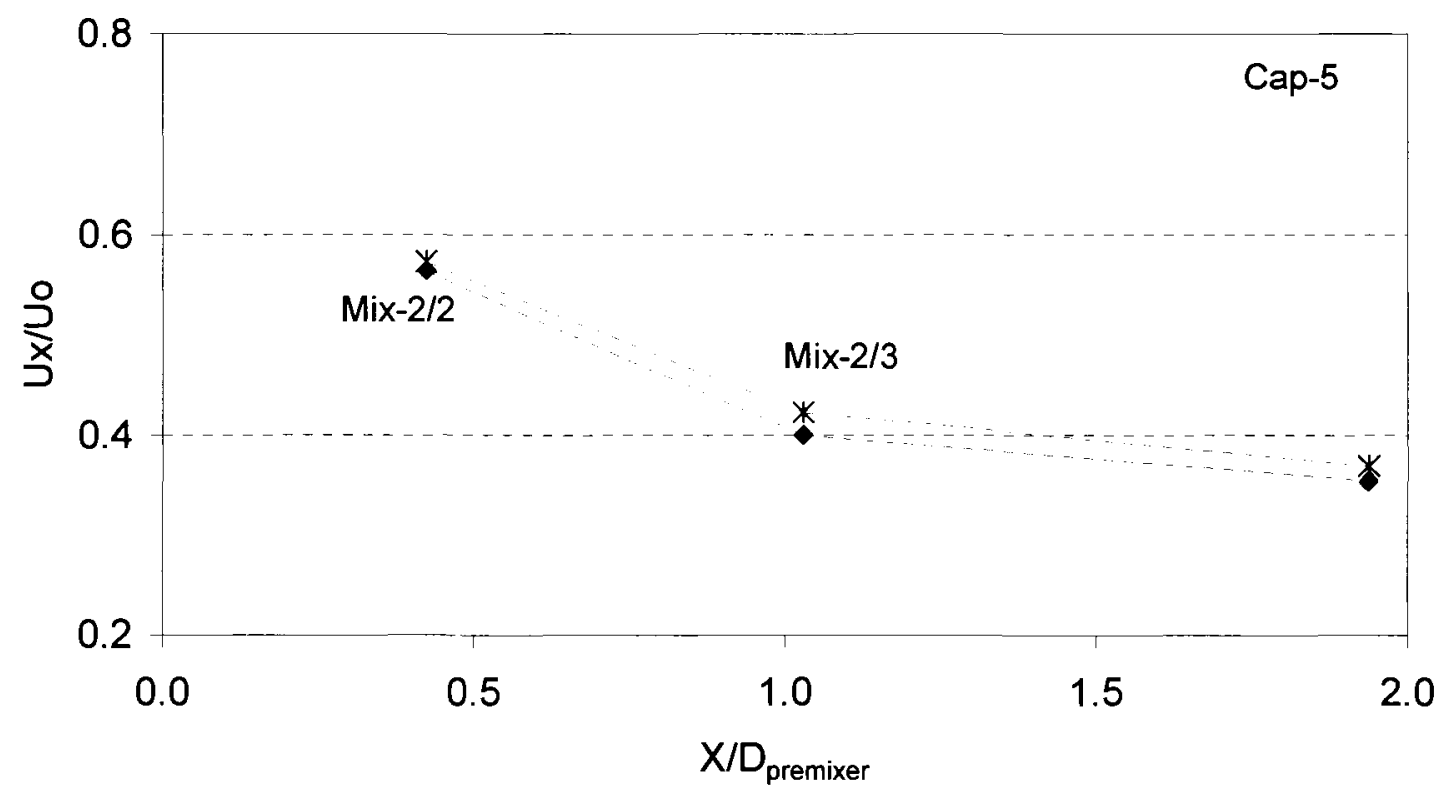

Figure 5.43: Effect of swirl angle sign on mixing effectiveness (Cap-5)

Figure 5.44 shows the effect of using different mixer designs on mixing effectiveness with Cap-2. Only the double-swirl mixer results were used in this plot. The three mixers used have the same geometrical swirl number, but Mix-2/1 gives the better mixing effectiveness (minimum) compared to other two double-swirl mixers. This co-swirl mixer shows stronger swirl strength than the other two double-swirl mixers (Mix-2/2 and Mix-2/3), while they have the same geometrically calculated swirl number. In fact the swirl number calculated using Equation (4.17), is more of an ideal swirl number. The equation does not takes into consideration factors such as 
momentum losses and swirler interaction which can reduce the swirl strength. Archer (2005) experimentally reported that the swirl number calculated using Equation (4.17) under-predicts the swirl number for the co-swirl mixers and over-predicts the swirl number for counter-swirl mixers. Figure 5.44 shows that the mixing effectiveness falls to a minimum near the axial location, $\mathrm{X} / \mathrm{D}_{\text {premixer }}=1$ and remains at this value.

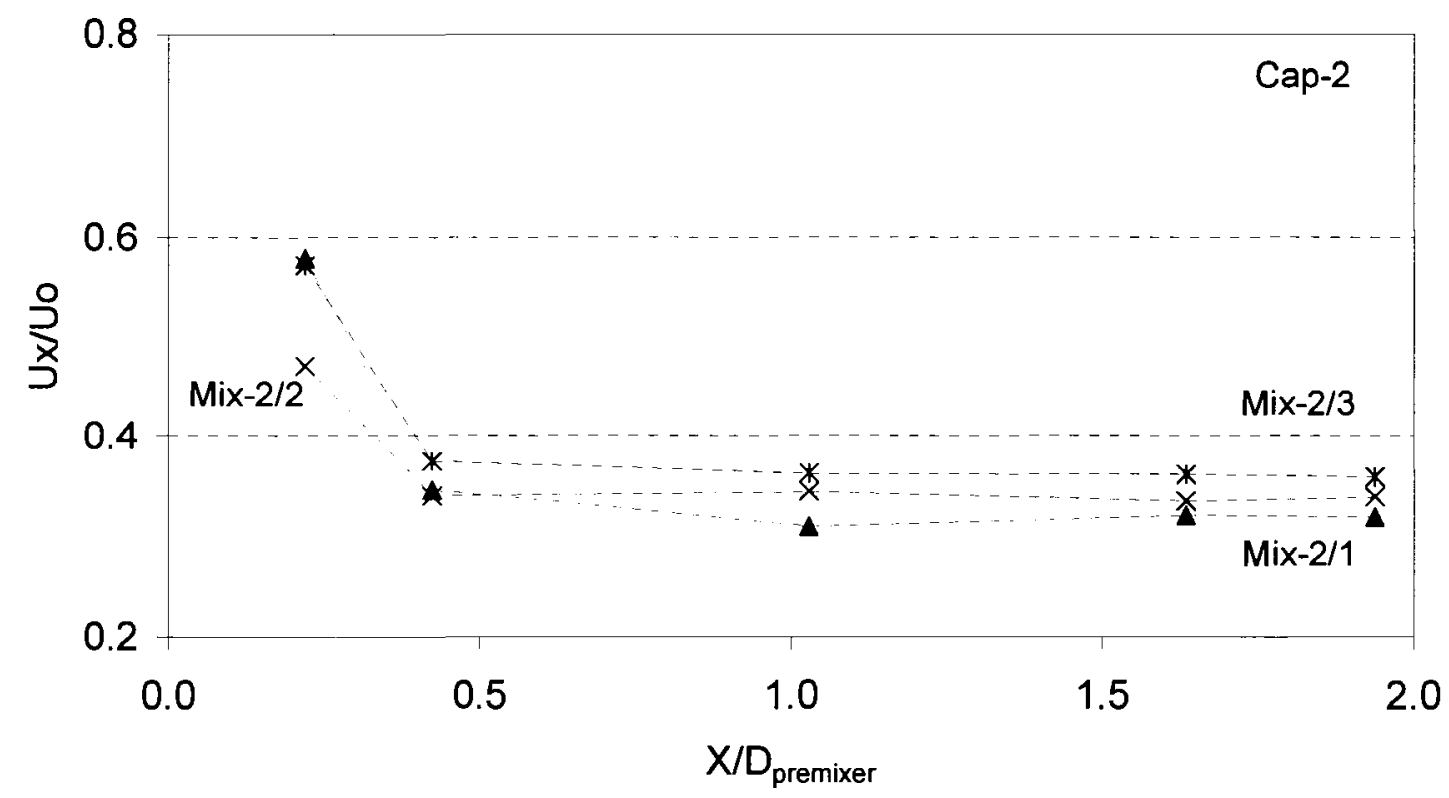

Figure 5.44: Effect of using double-swirl mixers on mixing effectiveness (Cap-2)

Figure 5.45 shows the variation of mixing effectiveness with the premixer axial distance planes. The geometrical parameters used in this figure are the same as that used in Figure 5.44 except that Cap-3 was used. Mix-2/1 in Figure 5.45 is shown to have the worst mixing effectiveness compared to the other mixers. This may be due to the strong rotation that Mix-2/1 produces. The LSI images corresponding to these mixing effectiveness results are presented in Appendix E (Figure E.34). In this figure the mixer shows less fuel spread. Looking at Figure 5.11 (effect of Mix-2/1) and Figure E.34, one can see how the swirl imparted affects the bulk flow. 


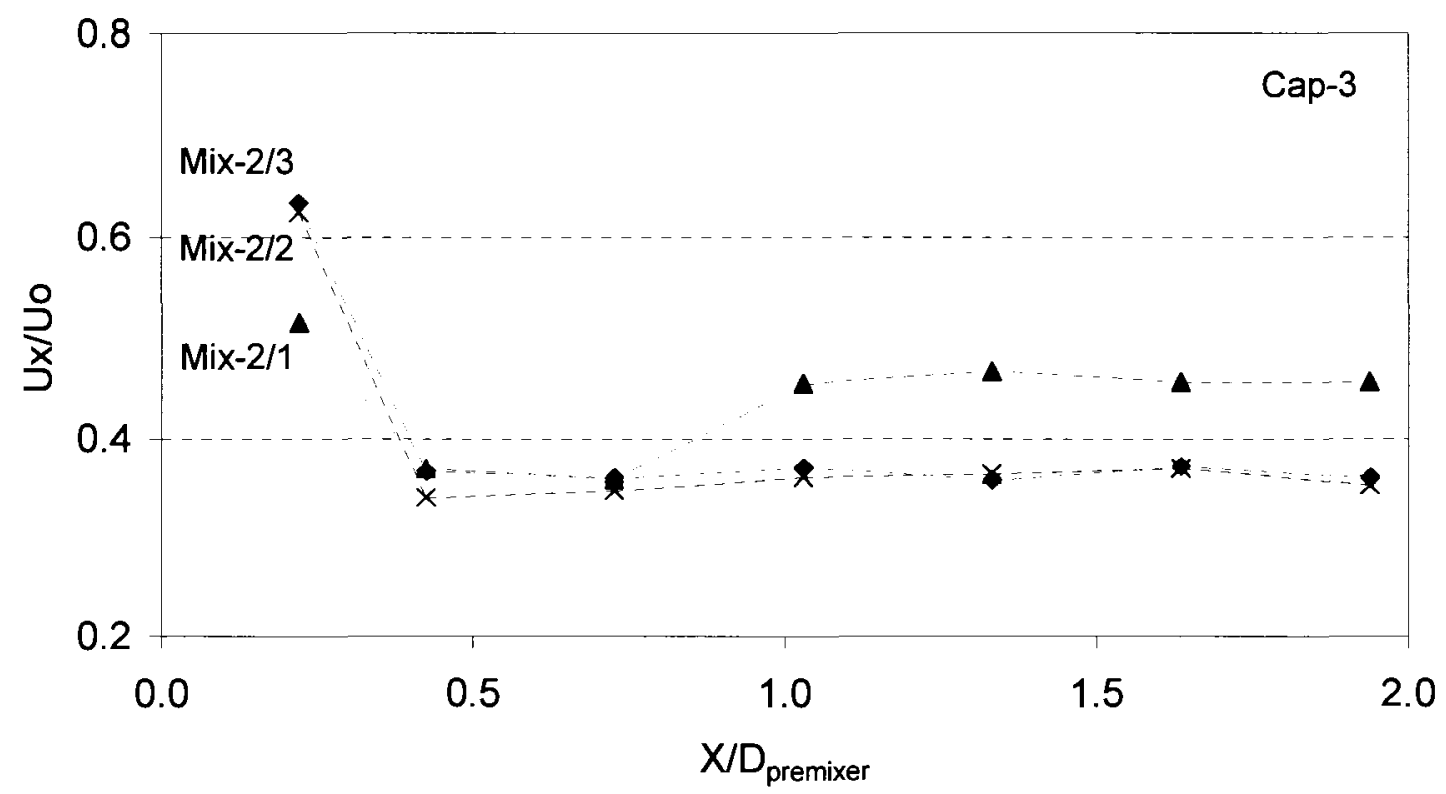

Figure 5.45: Effect of using double-swirl mixers on mixing effectiveness (Cap-3)

To be relevant to the combustion tests, the effect of using different equivalence ratios on mixing effectiveness was also studied and presented in Figures 5.46 and 5.47. Figure 5.46 shows the effect of changing the equivalence ratio on mixing effectiveness. The single-swirl mixer, Mix1/1 with fuel Cap-2 was used in this comparison. The figure shows that with this premixer geometry, the higher the equivalence ratio the higher the mixing effectiveness will be. Figure 5.47 shows a similar comparison with different parameters: Mix-2/2 with Cap-2 was used. The figure shows that the difference between the two mixing effectiveness profiles was very small and the results become closer with the distance. By comparing both Figures 5.46 and 5.47 one can observe that as the swirl strength increases, the mixing effectiveness improves and the equivalence ratio will not have any significant effect on the performance of the premixer. 


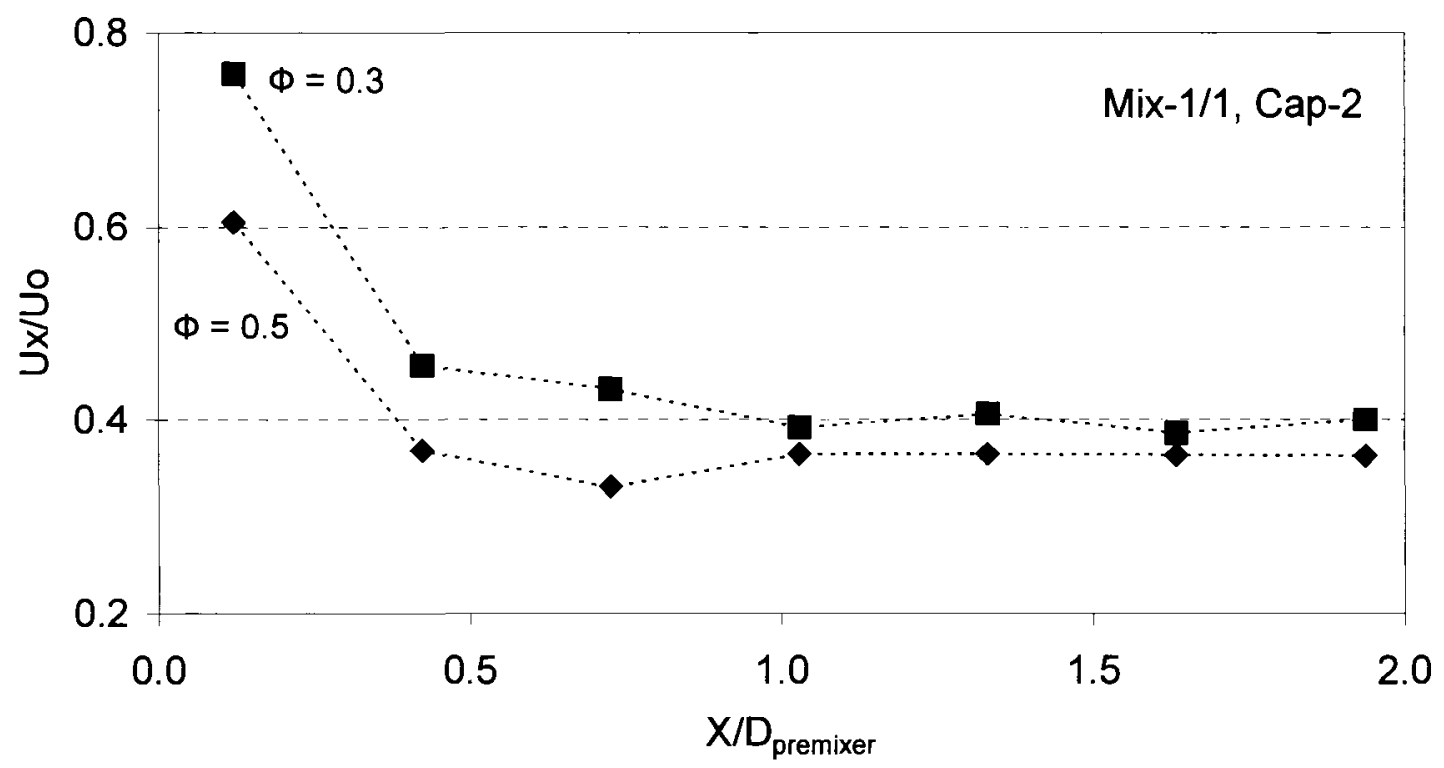

Figure 5.46: Effect of equivalence ratio on mixing effectiveness (Mix-1/1 and Cap-2)

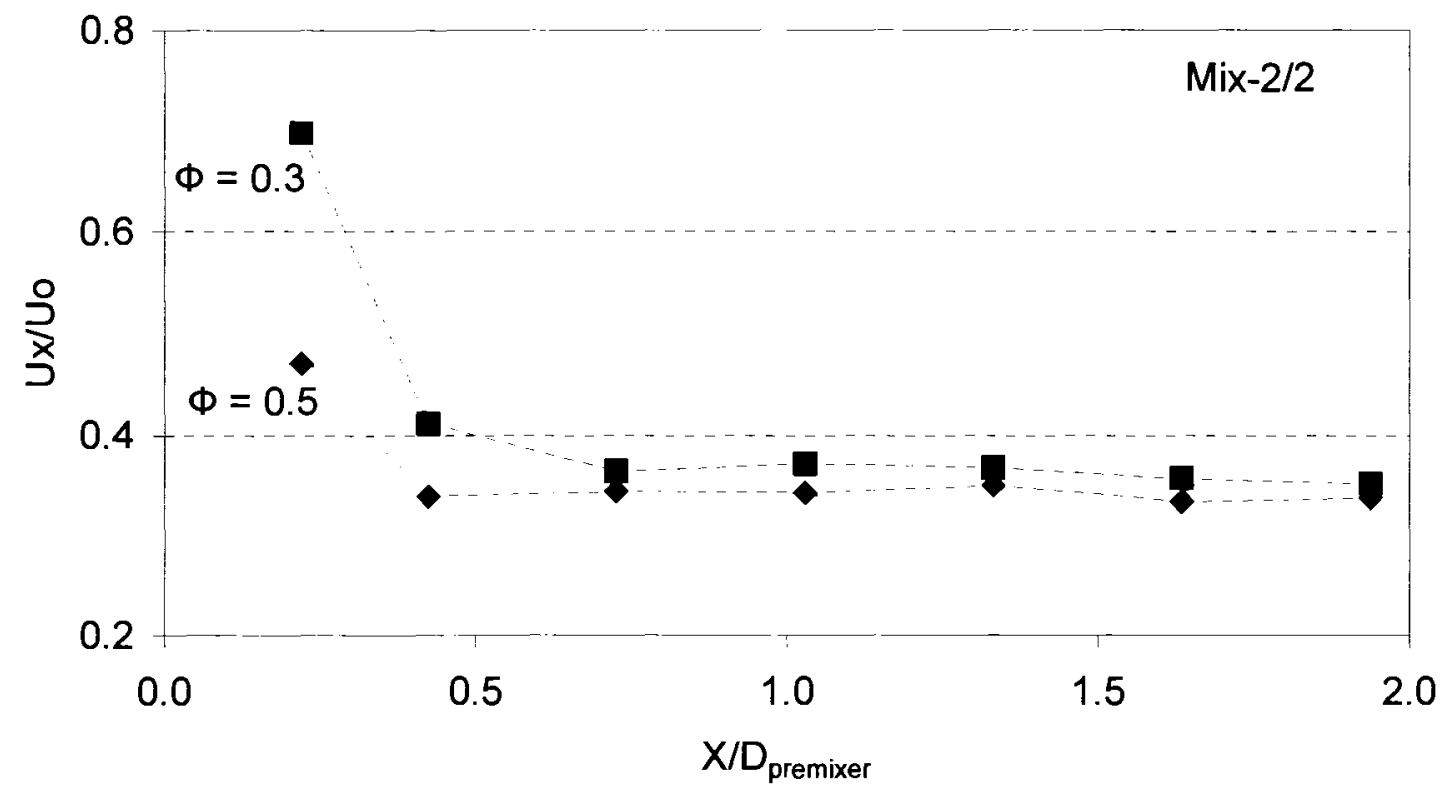

Figure 5.47: Effect of equivalence ratio on mixing effectiveness (Mix-1/1 and Cap-2) 


\subsubsection{Mixers and fuel cap combination ranking}

Based on the mixing effectiveness discussed above, the mixers and the fuel caps were evaluated and ranked. From the previous discussion of the $U x / U o$ results, three axial locations were used for the premixer evaluation: the planes located at 5 $\mathrm{cm}, 15 \mathrm{~cm}$ and $30 \mathrm{~cm}$ downstream from the fuel cap edge (at $X=0.42 \mathrm{D}_{\text {premixer }}, X$ $\approx 1 \mathrm{D}_{\text {premixer }}$ and, $X \approx 2 \mathrm{D}_{\text {premixer }}$ from the mixer downstream edge, see Table 5.5).

Figures 5.48 to 5.50 show the effect of different combinations of mixers and fuel caps used in the present investigation at the three locations mentioned above. In these figures, each set of bars represent one mixer and each bar represents a fuel cap. The ranking of both mixers and fuel caps was based on the quasi-quantitative technique discussed in the previous section. The direct observation results obtained from the LSI vertical images with their 3D plots and LSI lateral images were also used during the evaluation.

A comparison between the five caps leads to ranking them, from best to worst, in the order of Cap-1, Cap-2, Cap-3, Cap-4 and Cap-5. Increasing the momentum of the fuel jets will generate more turbulence and decrease the level of unmixedness. Cap-1 has the highest momentum ratio and therefore produces the maximum penetration into the body of the mainstream which enhances mixing by increasing the exposure of fuel to the mainstream flow. Although Cap-1 gives the best results with almost all the mixers, it was eliminated due to the over-penetration of the fuel jets, which sometimes touched the wall. Figure 5.36 shows this over-penetration. Cap-5 is a round cap injecting the fuel at $45^{\circ}$ to the mainstream. This cap has the highest unmixedness value when compared to the flat caps and with all the mixers. Further points will be discussed during the presentation of the combustion test results.

In almost all cases (different caps and different axial locations) Mix-1/1 gives a poorer mixing effectiveness. This is supported in the vertical and lateral images and the 3D plots discussed above. As a result Mix-1/1 was eliminated and was not used during the combustion tests. Mix-1/2 gives good mixing results compared to Mix-1/1. 
In the case of the double-swirl mixers, the three mixers have the same blade angle $\left(30^{\circ}\right)$. This angle is selected to impart a low swirl level $(\mathrm{S}<0.6)$ to the mainstream entering the premixer. The main reason for this swirling flow as mentioned in the previous chapter is to improve the mixing between the eight fuel jets and the mainstream in a short distance. As the flame stability is not an issue in this design, the flow field inside the premixer pipe should be free from any low pressure zones (i.e., recirculation). The presence of low pressure zones in the premixer pipe during the combustion test could trigger flashback.

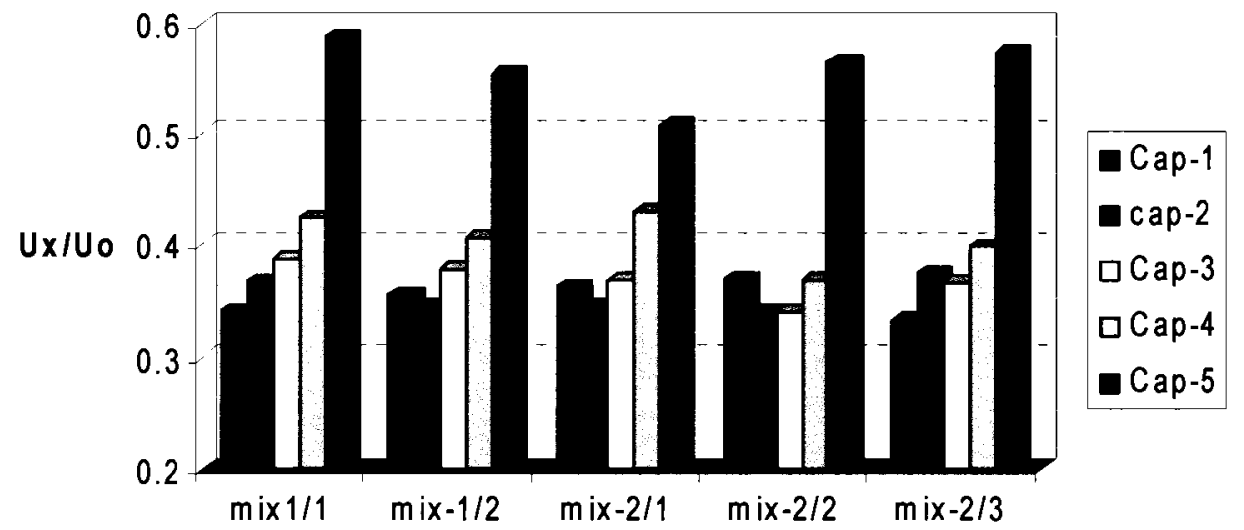

Figure 5.48: Effect of swirl strength and design on mixing effectiveness using different caps (at $X=0.42 D_{\text {premixer }}$ )

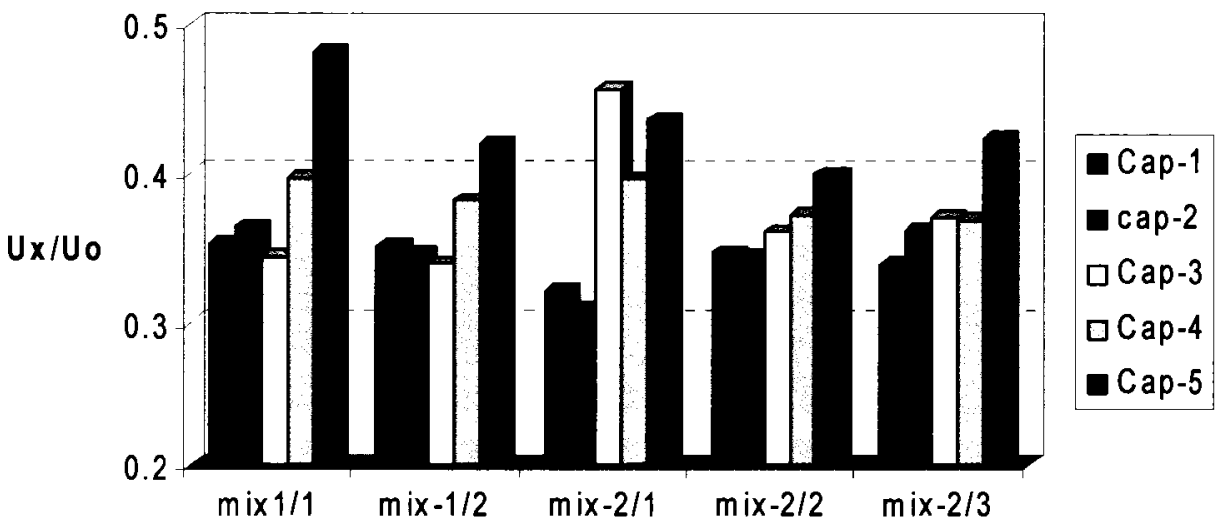

Figure 5.49: Effect of swirl strength and design on mixing effectiveness using different caps (at $X=1.03 D_{\text {premixer }} \approx 1 D_{\text {premixer }}$ ) 


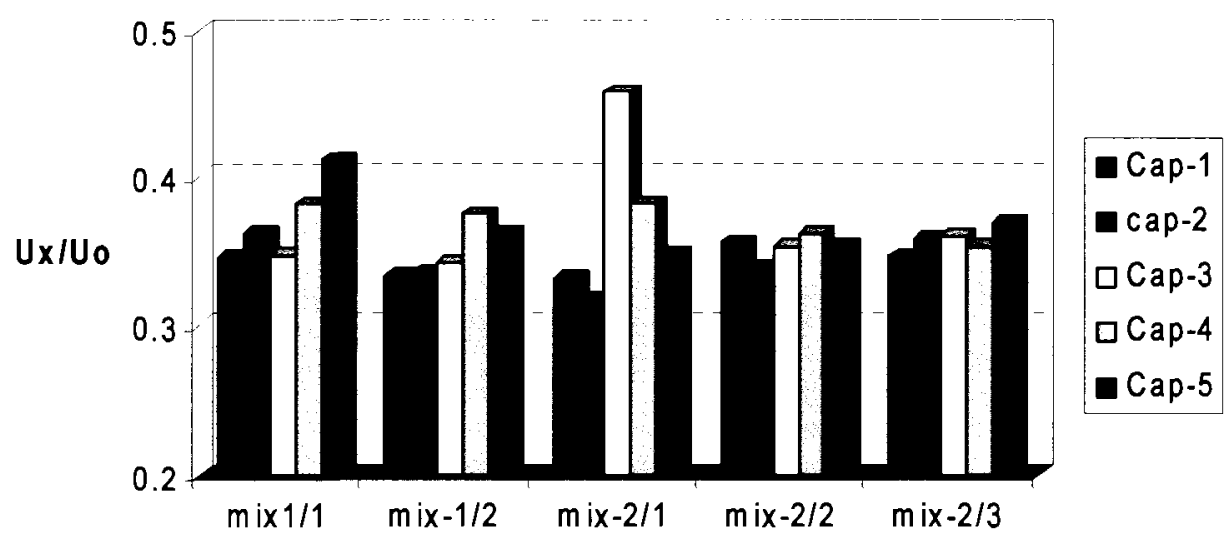

Figure 5.50: Effect of swirl strength and design on mixing effectiveness using different caps (at $X=1.94 D_{\text {premixer }} \approx 2 D_{\text {premixer }}$ )

Mix-2/1 gives good mixing results in a very short distance along the premixer axis. This co-swirl mixer shows stronger swirl strength than the other two doubleswirl mixers (Mix-2/2 and Mix-2/3), while they have the same geometrically calculated swirl number. In fact the swirl number calculated using Equation (4.17), is more of an ideal swirl number. The equation does not takes into consideration factors such as momentum losses and swirler interaction which can reduce the swirl strength. Archer (2005) experimentally reported that the swirl number calculated using Equation (4.17) under-predicts the swirl number for the co-swirl mixers and overpredicts the swirl number for counter-swirl mixers. This is also demonstrated in the LSI results shown here. Mix-2/1 is shown to have a low pressure region at a distance greater than $1 \mathrm{D}_{\text {premixer }}$ downstream of the mixer (see Figure 5.35). This result explains the strong rotational behaviour the mixer produces, which means that the mixer has a higher swirl number than that computed in Table $5.3(\mathrm{~S}>0.6)$ using Equation (4.17). Another reason for the relatively poor mixing Mix-2/1 has compared with mixers Mix-2/2 and Mix-2/3 is the lack of shear between two layers (inner and outer swirl region) that is found in contra-rotating flows. Due to these mentioned results, Mix-2/1 is eliminated and was not be used in the combustion tests.

In the case of Mix-2/2 and Mix-2/3, both are counter-swirl mixers and tend to lower the flow velocity due to the counter-shearing force produced which destroys 
the momentum and velocity. However, Mix- $2 / 2$ shows a relatively better mixing effectiveness with some of the cases compared to Mix-2/3. Because Mix-2/2 is a mirror image of Mix-2/3, they both should give identical results in all respects. This is also supported in some of the vertical images and the $3 \mathrm{D}$ plots discussed in previous sections (see Figure 5.32). The results which show different mixing for these mixers reflect experimental uncertainty and/or manufacturing differences between the two swirlers. Of the mixers used, the double-swirl mixer (Mix-2/2) gives the best observed mixing effectiveness at different locations along the premixer axis.

Finally and according to the above mentioned results, Mix-2/2, from the double-swirl mixers, and Mix-1/2, from the single-swirl mixers, were selected for the second stage of testing: the combustion tests. Cap-2 shows the best results when combined with Mix-2/2. However, during the combustion tests, the three fuel caps (Cap-2 to Cap-4) were used to provide the duct burner evaluation with different fuel flow rates that allows scanning of all the possible stable operating ranges. The fuel flow momentum in a real micro-turbine is dependent on the fuel line pressure available and as such these caps were chosen to cover possible real fuel flow situations. Cap-5 was used for investigating the effect of mixing on flame stability, NOx and $\mathrm{CO}$ emissions.

\subsection{LSI Conclusions}

The mixing process in the premixer of the duct burner was studied qualitatively using the laser sheet illumination (LSI) technique. A quasi-quantitative technique was developed to rank the relative mixing performance of the different types of mixers and fuel cap tested.

The LSI images provided a qualitative picture of the flow conditions analyzed in this work. The direct observation to the LSI vertical and lateral cross-sectional images along with the 3D plots assisted in ranking the different geometrical combinations used. 
LSI can provide invaluable information on the overall flow field structure. Many important observations were discussed such as fuel spread and mixing, swirling fuel jets (transformation of the fuel jets to swirling jets), mainstream rotation direction, fuel jet penetration, over-penetration, strong rotational field and swirl number, variation of swirl distribution and low pressure zone.

The LSI results obtained were helpful to gain a better comprehension of the mixing process in the burner premixer, providing useful information for the optimization of burner design and operating conditions. The resulting burner designs were studied in the combustion tests to arrive at a final design that is expected to achieve high combustion efficiency and reduced NOx and CO emissions. 


\section{CHAPTER 6: Flow balancing tests}

\subsection{Introduction}

Prior to the combustion tests, the duct burner (DB) oxidant (microturbine exhaust gases) flow balancing test was performed. During these tests, the correct amount of excess microturbine exhaust gases that is needed to be directed through the mesh burner for surface combustion was measured. The angles of the flow control blades were assigned for each flow condition. In the present chapter a brief description to the microturbine test facility will be made (only the components related to the flow balancing tests) including the measurement procedures and the instrumentation used in flow balancing tests as well as the results. The results found in this chapter will be used as basic measurements for the combustion tests.

\subsection{Microturbine test facility}

Because the work reported herein was part of collaboration between Carleton University and the CANMET Energy Technology Centre, Natural Resources Canada, all the flow balancing tests (Chapter 6) and the combustion experiments (Chapter 8) were carried out in the indoor CANMET microturbine test facility. The test rig consisted of an Ingersoll-Rand $70 \mathrm{~kW}$ CHP unit, mounted on the first floor of the building, and the tested duct burner installed on the second floor of the building and flanged onto the microturbine exhaust pipe. Figure 6.1 shows a schematic of the experimental setup used in this work and Table 6.1 presents the specification of the IR $70 \mathrm{~kW}$ CHP unit installed. The components of the test facilities related to the combustion test will be described in the following chapter (Chapter 7).

\subsubsection{Microturbine start-up procedure}

During all the cold flow tests performed in this thesis the microturbine CHP heat recovery water system is dry (no heat recovery) and the heat recovery unit is 
disabled (this is ensured on the microturbine display). The test procedure starts by activating the microturbine work station and then the necessary inspection of the microturbine (e. g., oil levels) following the inspection guide-lines prepared by the microturbine operator at the CANMET microturbine facility. Then the main manual gas valves for the microturbine were opened and the line pressure was checked. At this time if every thing is correct the microturbine display panel should show the "READY" sign. Then the START button is pressed. The workstation screen shows the turbine pre-start stage. If this step is successfully completed the microturbine will proceed to ramp up to normal operation conditions. The microturbine is allowed to warm-up for a period not less than 30 minutes before

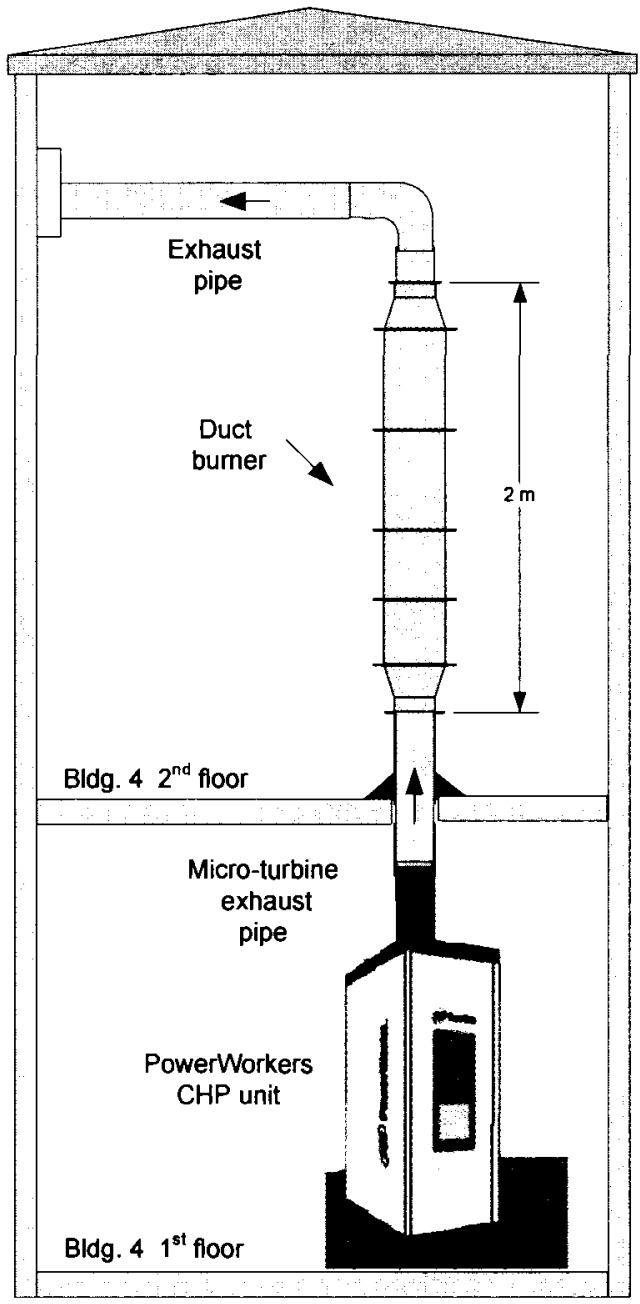
starting the tests.

Figure 6.1: Microturbine test facility

\subsection{Flow patterns descriptions}

Figure 6.2 shows the schematic of the duct burner flow pattern. All of the microturbine exhaust gases (i.e., the oxidant) enter the duct burner. A large amount of the exhaust gases bypasses the conical wire-mesh burner (bypass flow rate). 
Table 6.1: Ingersoll Rand (IR) microturbine $70 \mathrm{~kW}$-CHP unit specifications

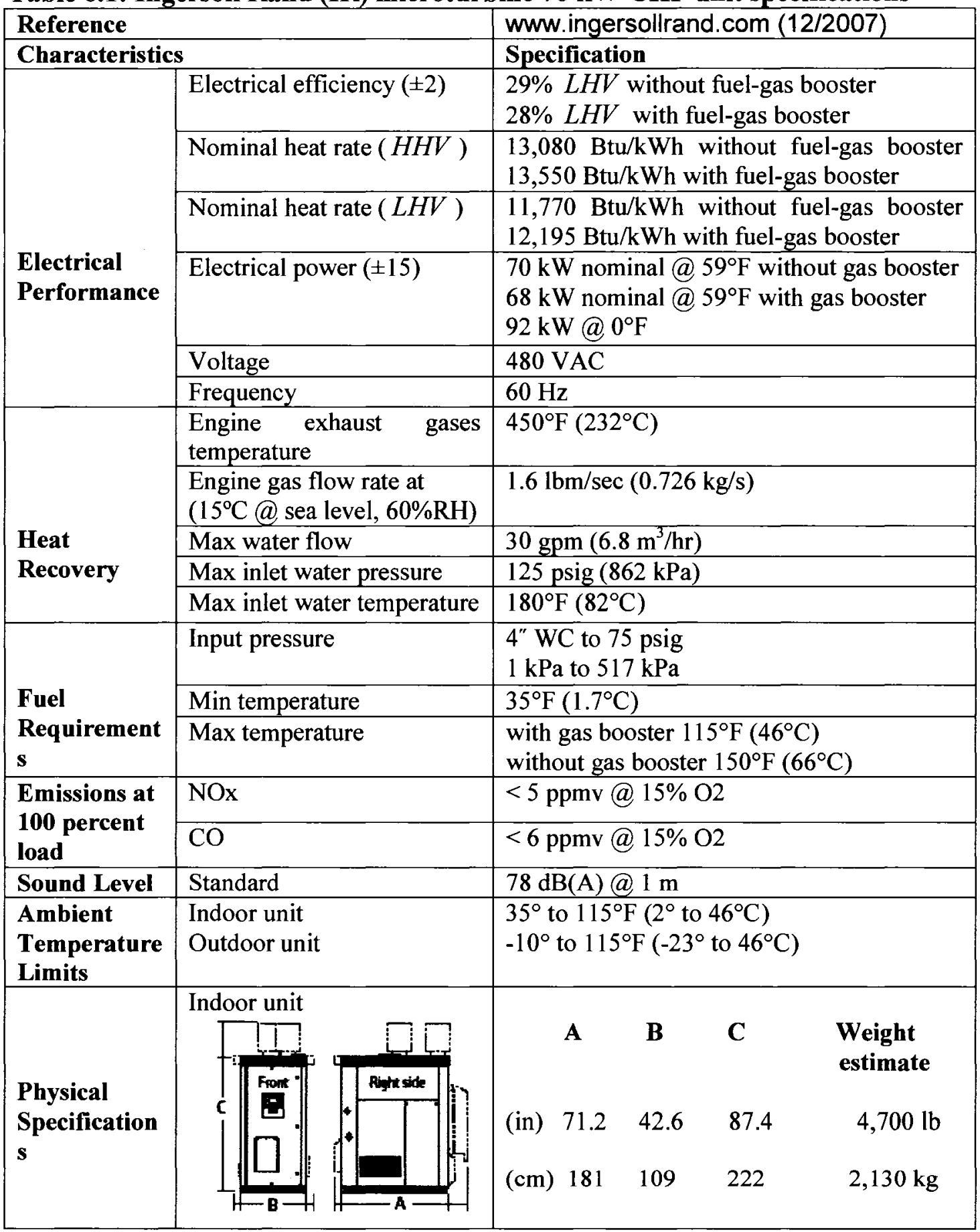


The remaining exhaust gas enters the duct burner premixer (defined as the cone mass flow rate) and mixes with the appropriate amount of fuel (fuel flow rate) injected into the premixer. This mixture burns over the wire-mesh surface, producing a carpet of short blue flames covering the mesh surface (blue flame mode). The bypassed flow cools the cone shield and mixes with the products of combustion at the end of the cone shield. The blades located upstream of the annular passage are constructed and arranged to control the bypass and cone flow rates.

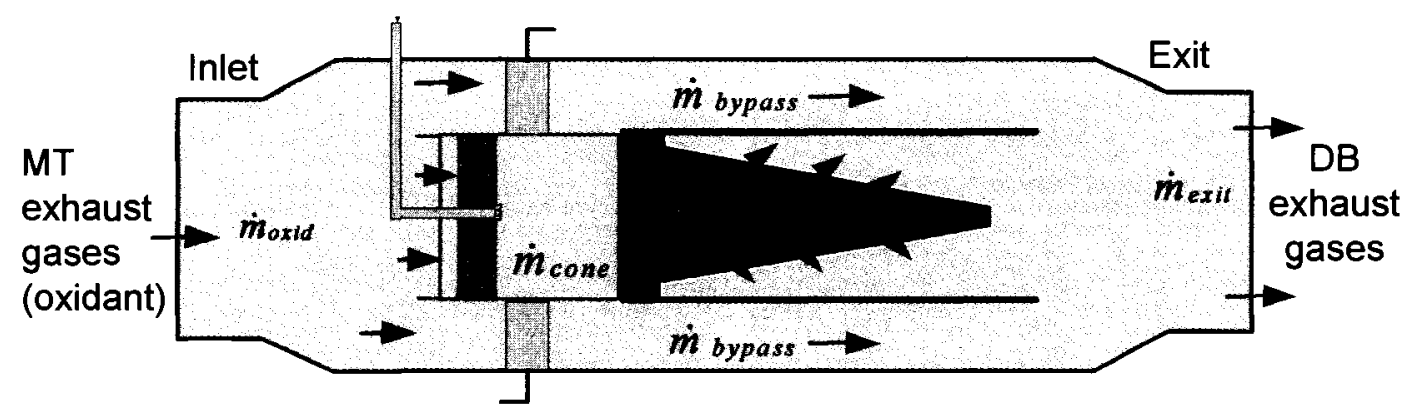

Oxidant flow rate $\left(\dot{m}_{\text {oxid }}\right)=$ Bypass flow rate $\left(\dot{m}_{\text {bypass }}\right)+$ Cone flow rate $\left(\dot{m}_{\text {cone }}\right)$

Exit flow rate $\left(\dot{m}_{\text {exil }}\right)=$ Oxidant flow rate $\left(\dot{m}_{\text {oxid }}\right)+$ Fuel flow rate $\left(\dot{m}_{\text {fuel }}\right)$

Figure 6.2: Schematic of the duct burner flow pattern

\subsection{The measurement process}

The pitot-static tube is a common instrument that measures the local flow velocity from a pressure difference, and is used because of its simplicity and low cost. During the flow balancing test the oxidant mass flow rate and the annular mass flow rate were measured using a pitot-static tube. This is performed by taking velocity measurements at various radial positions across the duct and then, using these values, calculating the mass flow rate through the duct. The process is discussed in the following section. 


\subsection{Oxidant mass flow rate $\left(\dot{m}_{\text {oxd }}\right)$}

The volume flow rate of the oxidant (microturbine exhaust gases) entering the duct burner (assuming incompressible fluid) was determined by multiplying the integrated-average velocity of the oxidant by the flow cross-sectional area of the intake pipe. The mass flow rate was determined by multiplying the volume flow rate by the oxidant density.

The measurement of the integrated average velocity was performed by traversing the cross-sectional flow area with a pitot-static tube. Bernoulli's equation was used with the pitot-static tube measurements (pressure difference) and the velocity of the oxidant was obtained from Equation (6.1).

The equal area method, supported by the Associated Air Balance Council [AABC (1989)], was adopted in all the mass flow measurements to calculate the flow. In this method, the inlet flow area (duct) was divided into five concentric equal areas. Figure 6.3 shows the schematic of the duct burner with a view showing the equal area method. Figure 6.3, also shows the way the pitot-static tube was installed during this experimental work. Brief descriptions of the formulas used in the mass flow calculation are presented below.

The velocity of the fluid (Bernoulli's principle) can be obtained from:

$$
V=\sqrt{\frac{2(\Delta p)}{\rho}}
$$

where $V$ is the velocity of the fluid (oxidant), $\Delta p$ is the pressure difference and $\rho$ is the density of the oxidant.

The volumetric flow rate $\left(\dot{V}_{o l}\right)$ is derived from:

$$
\dot{V}_{o l}=A_{d u c t} \times \frac{1}{n} \sum_{i=1}^{n} V_{i}
$$

And the mass flow rate $(\dot{m})$ from: 


$$
\dot{m}=A_{d u c t} \times \frac{1}{n} \sum_{i=1}^{n} \rho V_{i}=\sum_{i=1}^{n} \rho A_{i} V_{i}
$$

where $A_{d u c t}$ is the duct cross-sectional area, $n$ is the number of traverse points, $V_{i}$ is the indicated velocity at each traverse point, $\rho$ is the density of the gas (oxidant) in the duct and $A_{i}$ is the sub-sectional area (the measuring point located at its centre).

Two perpendicular ports were drilled in the duct for the measurements, ensuring enough hole-clearance to insert the pitot-static tube (Port-5 and Port-6 as shown in Figure 6.3). The measurement axes through the entry ports were perpendicular to each other and intersect at the centre of the test section or the (measuring plane). The measurement traverse points were specified at the centroid of those equal areas so that the integrated-average velocity can be approximated by the average of the measured values for all traverse points. Ten traverse points along two equally spaced diameters were used (20 traverse points) as shown in Figure 6.3.

A stainless steel pitot-static tube with an outer diameter of $3.175 \mathrm{~mm}$ (1/8 in) and an inner diameter of $1.65 \mathrm{~mm}$ (1/16 in), from United Sensor Inc., were used. Table C. 1 in Appendix C presents the different types of pressure probes used in the investigation. The Reynolds number based on the inner and the outer tube diameter, at all the measurement points, exceeds the range given by Macmillan (1954) (200 and 400 for the inner and outer, respectively). Therefore, during the current experimental work the influence of Reynolds number on the measured total pressure is small and not included. The duct burner inlet pipe diameter $(25.4 \mathrm{~cm}$ (10 inches)) is large compared to the probe diameter such that blockage effects can be neglected as well. As the measurements were taken at approximately 3 to 5 pitot tube (impact) diameters from the wall, the measurements were not corrected for wall interference effect [ASHRAE (1988), Hus and Bennen (2002)].

The pitot-static tube was connected to pressure transducers using Teflon tubing. OMEGA differential pressure transducers, model PX277, were used with a typical range of $\pm 1 \%$ FS ( 0 to 5 in $\mathrm{H}_{2} \mathrm{O}$ ). An MKS Baratron pressure sensor, model 
627B13TAC1B was used for absolute pressure measurements. To reduce uncertainty in the different pressure measurements, the output pressure signals from the data acquisition system were post-processed with measured transducer calibration coefficients.

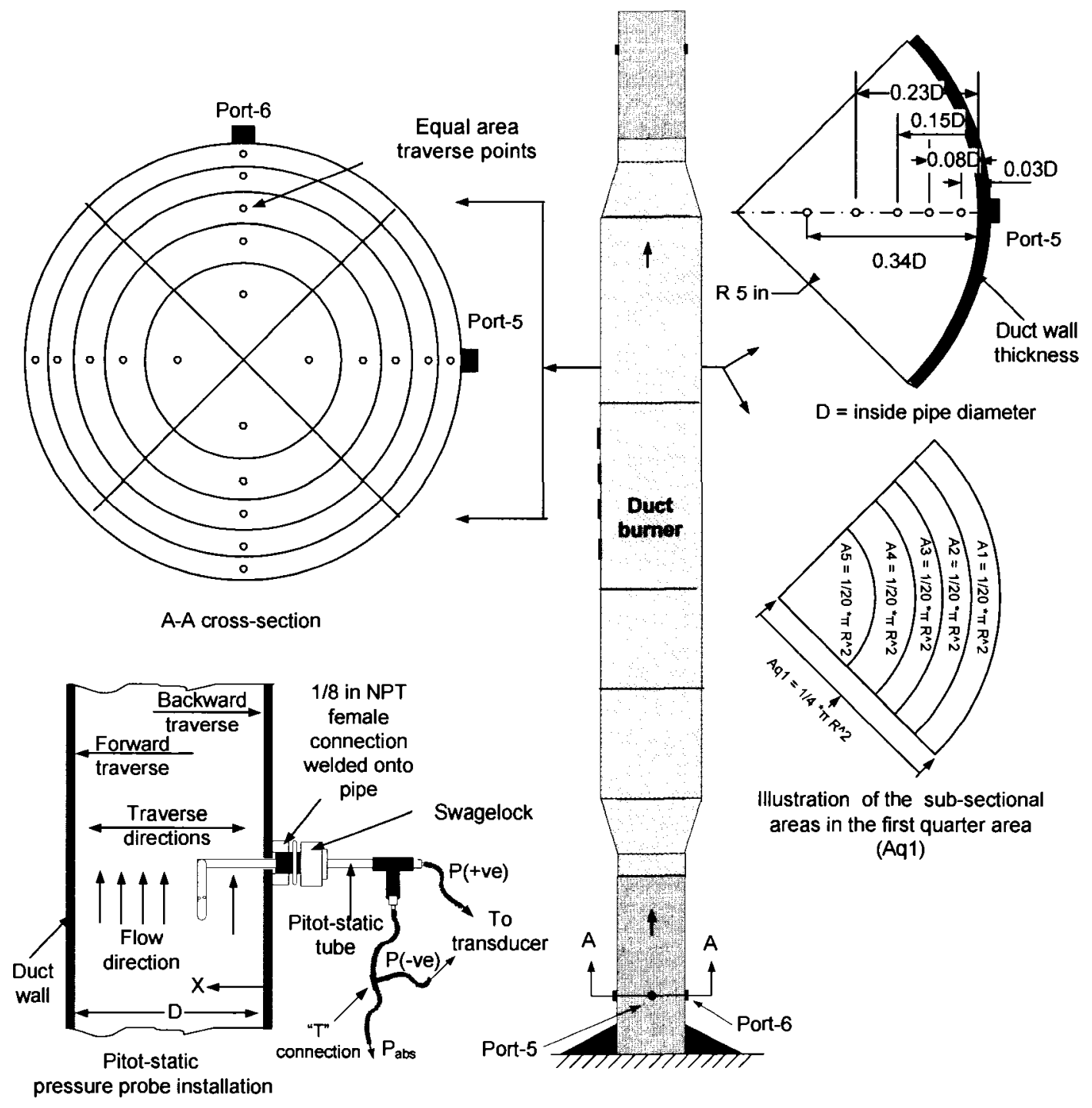

Figure 6.3: Equal-area method with traverse points indicated for the DB inlet pipe 
All the pitot-static tubes used in this investigation were calibrated using a suitably designed test rig (the existing Mechanical engineering department test rig located in room 2268ME). The test rig was used by different researchers in the department [Mahallati (2003) and Benner (2003)]. See Appendix C (Figure C.1) for the schematic and description of the calibration rig. The pressure transducers were calibrated using a $\mathrm{PX}^{2 \mathrm{i}}$ Digital calibrator from CRYSTAL Engineering Corporation with a pneumatic low pressure pump, from Ralston Instruments, model DP0V. Overall system calibrations were performed by comparing input pressure values to those of the transducers with their measured results taken from the data acquisition system. The calibration data and the uncertainty estimated values for the pitot-static tubes and the transducers are presented in Appendix C.

\subsubsection{Test procedure}

Before inserting the pitot-static tube into the duct, the traverse point positions were marked on each probe for each port, taking into account the dimensions of each probe fitting. Then the pitot-static tube was carefully inserted into the duct and positioned at the first grid point, as shown in Figure 6.3. Care was taken to ensure that at each traverse location the pitot-static tube is aligned using the alignment guide on the tube and a line marked at the top plane of the pitot-static tube. When the pitotstatic tube is correctly aligned, the velocity pressure indicator will read the correct flow velocity. The pitot-static tube was left in this position for a period of time until a stabilized reading was reached (steady state condition). After reaching steady state, the sampling period was from 3-5 minutes. After the velocity pressure at a point was recorded, the pitot-static tube was moved to the next grid point. At each point the port area was tightly sealed (Teflon-ferrules was used to make the traversing easier). These steps were repeated until the traverse was completed. The absolute pressure was measured simultaneously with the differential pressure measured by the pitotstatic tube. A "T" tubing barb was used to connect the static port of the pitot-static 
tube to the negative pressure port of the differential pressure transducer as well as the absolute pressure transducer, see Figure 6.3.

\subsection{Bypass mass flow rate $\left(\dot{m}_{\text {bypass }}\right)$}

A procedure similar to that used during the measuring of the oxidant mass flow rate mentioned in the previous section was used to measure the bypass mass flow rate. The volume flow rate of the oxidant entering the annular passage (bypass flow) was determined by multiplying the integrated-average velocity of the oxidant by the flow cross-sectional area of the annular passage. The measurement of the integrated average velocity was performed by traversing the cross-sectional annular flow area with a pitot-static tube. Two stainless steel pitot-static tubes with outer diameters of 0.065 in (inner diameter $=0.028$ in) and 0.095 in (inner diameter $=$ $0.042 \mathrm{in}$ ) were used for the annular flow measurements. For more information on the probes used, see Table C.1, Appendix C. Equation (6.3) was used to calculate the bypass mass flow rate.

\subsubsection{Test procedure}

As mentioned in Chapter 4 (Section 4.5.7), the annular passage in the duct burner starts at the leading edge of the premixer and ends at the trailing edge of the cone shield. The dimensions of the annular passage depend on the shield length and diameter used in a particular test. The different types of cone burner shields used in this investigation are described in Chapter 4, Figure 4.17 and summarized in Table 4.3. During the flow balancing test, two measurement shields, Sh5 and Sh6, with two different blockage ratios were used. Figure 6.4 shows the schematic of the two measurement shields. Each shield, when installed in the duct burner, results in different annular areas. Therefore, applying the equal area method will lead to 
different traverse locations for each case. Both measurement shields are made without any ports to provide uniformity to the flow upstream of the pitot-static tube. For both shields, the annular passage of the duct burner was divided into four equal quadrants. For Sh5 $(\mathrm{BR}=0.4)$ the annular area region was divided into five equal concentric areas to scan the maximum number of points in the annular region. Figure 6.5 shows a schematic illustration of the equal area method. Each quadrant in the annular region was divided into twenty equal sub-areas.

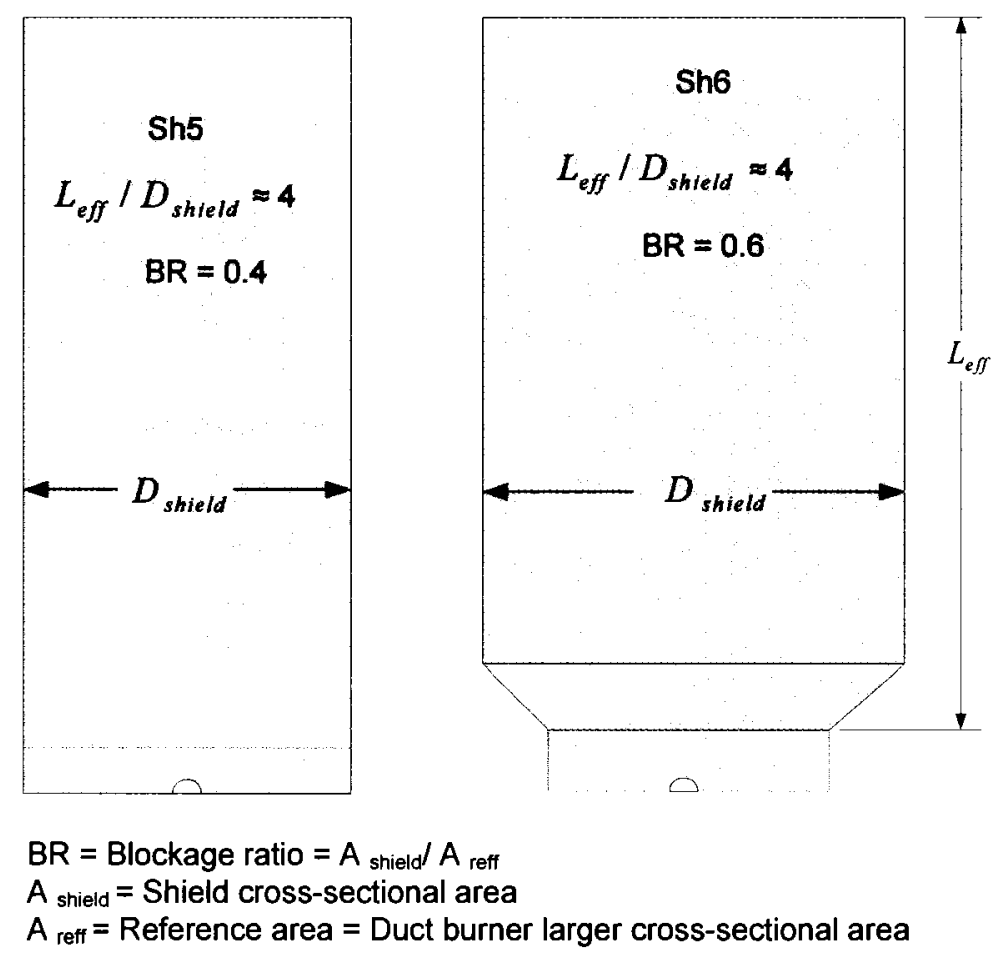

Figure 6.4: Schematic of the measurement shields used in the flow balancing tests

Due to the axisymmetry of the annular region surrounding the shield, the flow conditions were assumed to be the same at all similar points (e.g., station 1 in the first quadrant is similar to station 1 in the $2^{\text {nd }}, 3^{\text {rd }} \& 4^{\text {th }}$ quadrant). So if one of the quadrants was measured by the pitot-static tube, the results found could be used to 
find the average velocity in a similar annular region of the other quadrants. The locations of the four ports at the first quadrant are shown in Figure 6.5, step 2. The measurement locations are distributed at 22.5 degrees from each other. Due to the small dimensions of the annular passage and to avoid interference between the pitotstatic tubes and complexity of welding the ports in one quadrant, the actual measurement ports were distributed through the different quadrants as shown in Figure 6.5, Step 3. Finally, the measurements of the velocity pressure were taken along four different radial locations through four different circumferential locations (Step 3). In addition to the illustration of the sub-sectional areas used in the equal area method, Figure 6.5 shows the traverse point locations used for Sh5.

When using Sh6 the annular region was divided into two equal concentric areas. Then each quadrant in the annular region was divided to eight equal sub-areas. Similar assumptions and procedures were used to locate the traverse points similar to that used with Sh5. The measurements of the velocity pressure were taken along four radial locations through the same four ports used in the first case.

Figure 6.6 shows a schematic illustration of the sub-sectional areas used in the equal area method with the traverse point locations used for Sh6. To make the measurement procedure more clear, other schematic illustrations are presented in Figure 6.7. The figure presents the pitot-static tube locations in the annular passage for both shields (Sh5 and Sh6). Figure 6.7 also shows an open cross section view to show the relationship between the pitot-static tube measurement locations and the positions of the annular flow control blades. Regarding uncertainty in the different measured values and the setting the blade angle or positioning the pitot-static tube refer to Table D.4 in Appendix D. 

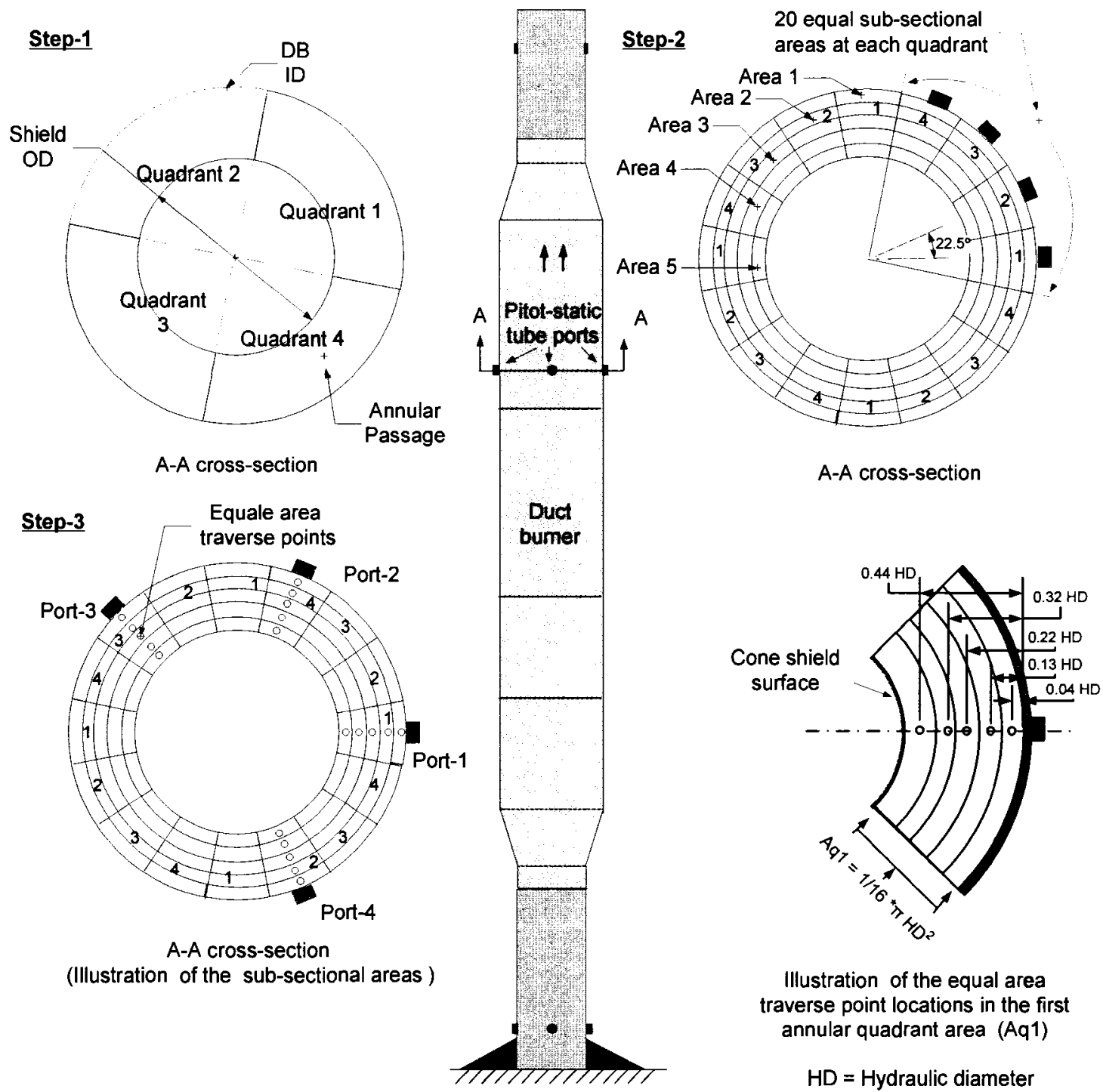
Illustration of the equal area traverse point locations in the first annular quadrant area (Aq1)
$\mathrm{HD}=$ Hydraulic diameter $A=$ Area

Figure 6.5: Equal-area method with traverse points indicated (Sh5 $(B R=0.4))$ 


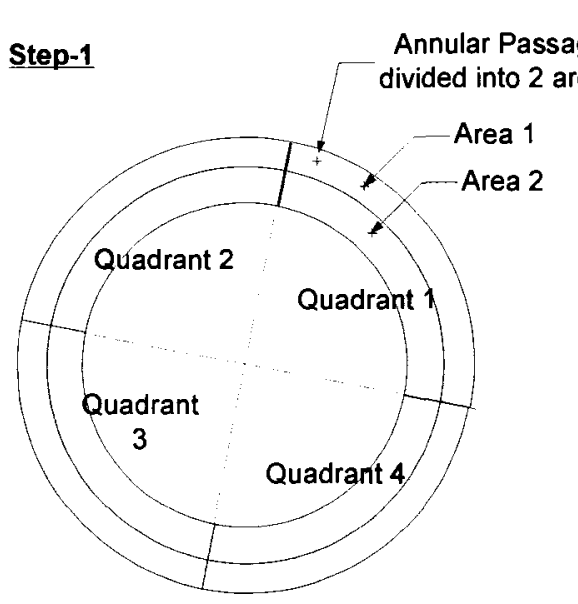

A-A cross-section

Step-3

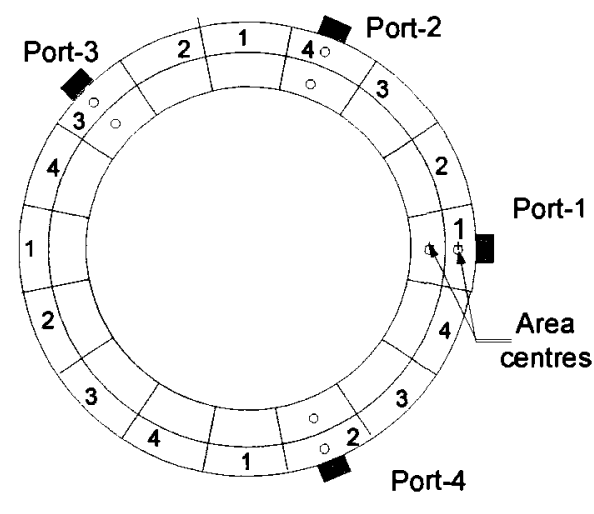

A-A cross-section

(Illustration of the sub-sectional areas and the 4 ports used )

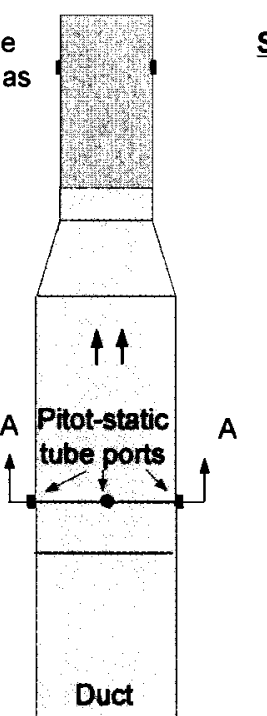

8 equal sub-sectiona areas at each quadrant
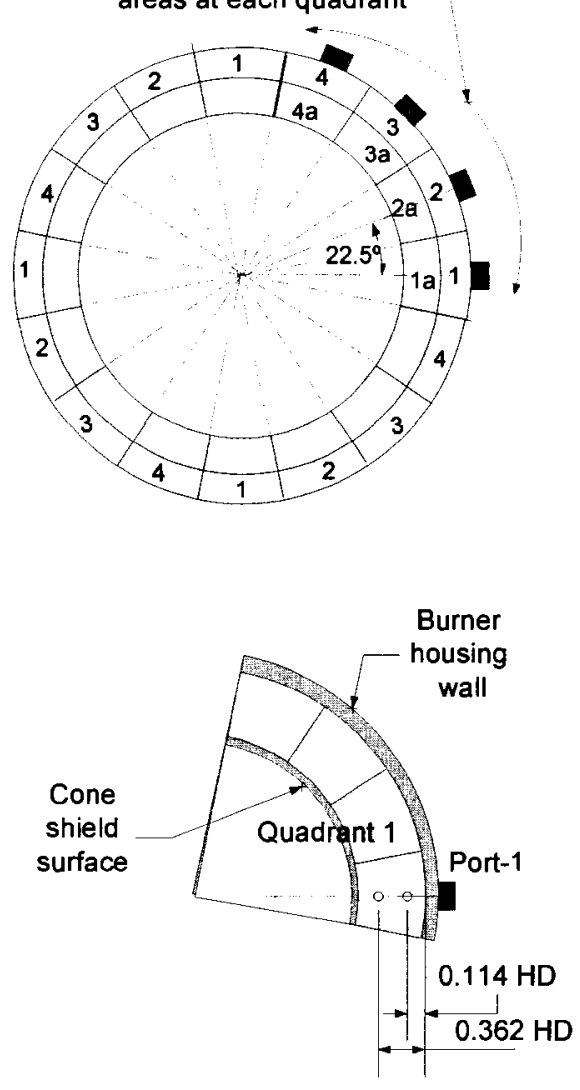

Illustration of the equal area traverse point locations in the first annular quadrant

$\mathrm{HD}=$ Hydraulic diameter

Figure 6.6: Equal-area method with traverse points indicated for the annular passage with Sh6 (BR=0.6) 


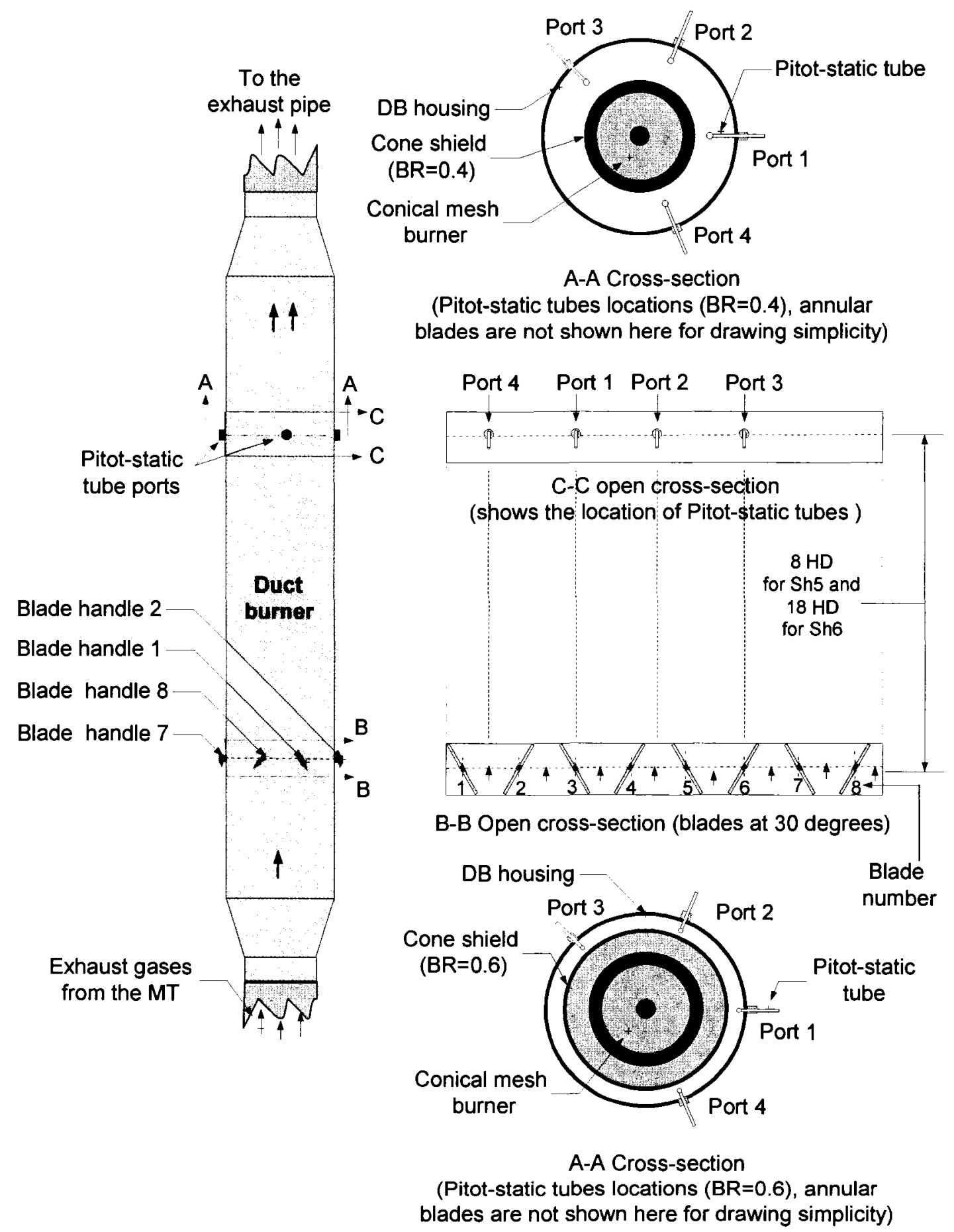

Figure 6.7: Schematic of the pitot-static tube locations in the annular passage for both measurement shields (Sh5 $(B R=0.4)$ and Sh6 $(B R=0.6))$ 


\subsection{Test results}

During this phase, the following measurements and calculations were performed: velocity pressure, absolute pressure, duct burner overall pressure drop, temperature measurements, flow velocity for each flow pattern using Equation (6.1), the oxidant mass flow rate at the burner inlet and the annular mass flow rate (bypassed) using Equation (6.3). The results presentation in this section will cover briefly the effect of the different cones on the burner pressure drop, annular flow control blade angles, mixer design and the blockage ratio (using Sh5 and Sh6) on the duct burner inlet velocity profiles, the annular passage velocity profiles and the overall duct burner pressure drop. Prior to the presentation of these results, a brief discussion will be presented of some preliminary tests which were conducted prior to the main flow balancing tests.

\subsubsection{Preliminary tests}

In a similar fashion to the LSI tests some preliminary tests were conducted to develop a reliable experimental technique. These tests were performed for a selected geometrical set-up prior to the main flow balancing test phase to ensure consistent and reliable measurements with a reasonable level of confidence. The preliminary testing allowed the definition of the following parameters; the test planes, traversing procedure, appropriate sampling period, pitot-static tube size, repeatability of measurement and an estimate of the uncertainty. During these preliminary tests all the measurements (e.g. velocity pressure, absolute pressure, overall duct burner pressure drop and temperature) for the selected burner geometry, were taken for annular blade angles ranging from 0.0 to 90 degrees with an interval of 10 degrees. Only some of the preliminary results demonstrating the repeatability of the measurements will be presented during the results presentation in the following section. Appendix $F$ presents in a graphical form some of the preliminary test measurement practices conducted during this phase of investigation. 


\subsubsection{Flow balancing test matrix}

The experimental matrix used for the flow balancing test phase is presented in Table 6.2 for Mix-1/1 and Mix-2/2 with both measurement shields Sh5 and Sh6. During the preliminary testing the measurements were taken for annular blade angles ranging from 0.0 to 90 degrees with an interval of 10 degrees. Using a small blade angle interval was found to be time consuming and the change in the mass flow rate was small when compared to a larger step interval. During the flow balancing tests, measurements were performed for the annular flow control blade angles of $0,20,40$, 60 and 80 degrees. A total of 60 experimental settings were tested during the flow balancing tests in addition to the tests performed in the preliminary test stage.

Table 6.2: Flow balancing test experimental matrix

\begin{tabular}{|c|c|c|c|c|c|c|c|c|c|c|c|c|}
\hline \multirow{2}{*}{$\begin{array}{l}\text { Mixer } \\
\text { type }\end{array}$} & \multirow{2}{*}{$\begin{array}{c}\text { Cone } \\
\text { numbe } \\
\mathbf{r}\end{array}$} & \multicolumn{5}{|c|}{ Sh5 } & \multirow{2}{*}{$\begin{array}{c}\text { Cone } \\
\text { number }\end{array}$} & \multicolumn{5}{|c|}{ Sh6 } \\
\hline & & \multicolumn{5}{|c|}{ Blade angle [degrees] } & & \multicolumn{5}{|c|}{ Blade angle [degrees] } \\
\hline \multirow{3}{*}{$\begin{array}{c}\text { Mix-1/2 } \\
\text { Single- } \\
\text { swirl } \\
\text { mixer }\end{array}$} & Cone-1 & 0 & 20 & 40 & 60 & 80 & Cone-1 & 0 & 20 & 40 & 60 & 80 \\
\hline & Cone-2 & 0 & 20 & 40 & 60 & 80 & Cone-2 & 0 & 20 & 40 & 60 & 80 \\
\hline & Cone-3 & 0 & 20 & 40 & 60 & 80 & Cone-3 & 0 & 20 & 40 & 60 & 80 \\
\hline \multirow{3}{*}{$\begin{array}{c}\text { Mix-2/2 } \\
\text { Double- } \\
\text { swirl } \\
\text { mixer }\end{array}$} & Cone-1 & 0 & 20 & 40 & 60 & 80 & Cone-1 & 0 & 20 & 40 & 60 & 80 \\
\hline & Cone-2 & 0 & 20 & 40 & 60 & 80 & Cone-2 & 0 & 20 & 40 & 60 & 80 \\
\hline & Cone-3 & 0 & 20 & 40 & 60 & 80 & Cone-3 & 0 & 20 & 40 & 60 & 80 \\
\hline
\end{tabular}

\subsubsection{DB inlet velocity profiles}

Selected samples from the pitot-static tube measurements are presented in this section. Figure 6.8 shows the velocity distribution measured along the duct burner inlet plane (plane A-A, Figure 6.3) using Ports 5 and 6. The x-coordinates is the distance, $x$, from the inner wall (along the duct burner inlet plane) normalized by the duct burner inlet diameter. To ensure repeatability of the data, several runs were 
repeated at different periods of time for different burner configurations (i.e., combinations of mixer, cap, mixer, cone and shield, at a particular blade angle).

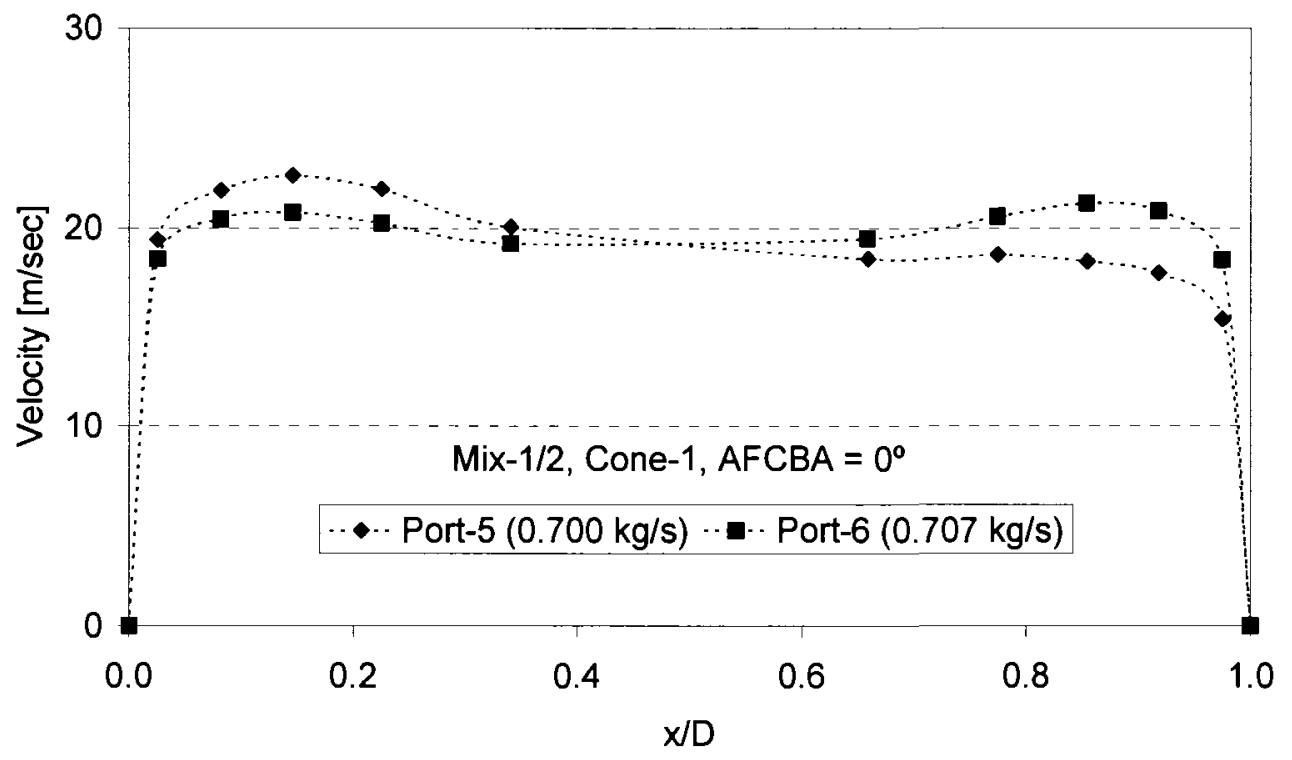

Figure 6.8: Velocity distribution across the DB inlet plane using Port-5 and 6

Figure 6.9 shows the velocity profiles of three tests performed through Port- 6 . The geometrical parameters used in this figure are the same parameters used in Figure 6.8. Good repeatability was observed when comparing the three curves. The results in Figure 6.9 were for a forward and backward traverse performed on one day and another forward traverse performed on a different day. See Figure 6.3 for the port location and the traverse plane and directions. The forward and backward measurements were used to estimate the uncertainty. See Appendix F, for more results showing the repeat trends for the measured velocity profiles.

The effect of using different conical burners on the pressure drop of the duct burner and the inlet velocity profiles is presented in Figure 6.10. The figure presents the velocity profile at the duct burner inlet using port 5 . The three cones used were; Cone-1, Cone-2 and Cone-3, with nominal pressure drops of $75 \mathrm{~Pa}\left(0.3\right.$ in $\left.\mathrm{H}_{2} \mathrm{O}\right), 149$ $\mathrm{Pa}\left(0.6\right.$ in $\left.\mathrm{H}_{2} \mathrm{O}\right)$ and $224 \mathrm{~Pa}\left(0.9\right.$ in $\left.\mathrm{H}_{2} \mathrm{O}\right)$, respectively. The results in Figure 6.10 
show that the change in the conical burner pressure drop did not significantly affect the total inlet velocity profiles. The difference is mostly due to the change in the inlet conditions of the microturbine engine. The measurements of the three profiles plotted in Figure 6.10 were conducted at different times (one day separation between each test).

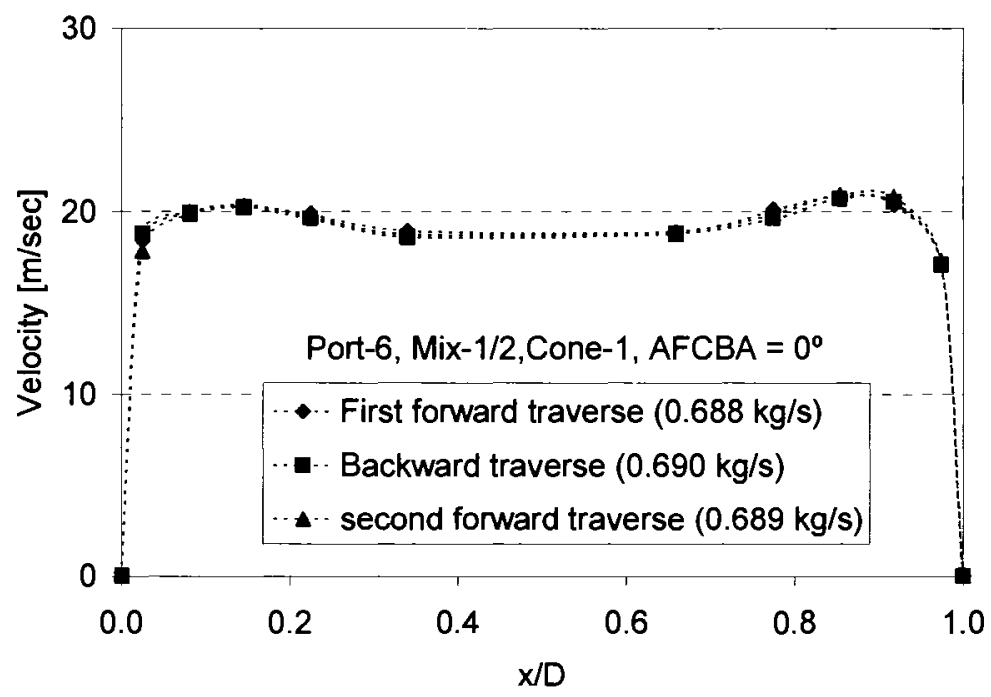

Figure 6.9: Velocity distribution across the DB inlet plane using Port-6

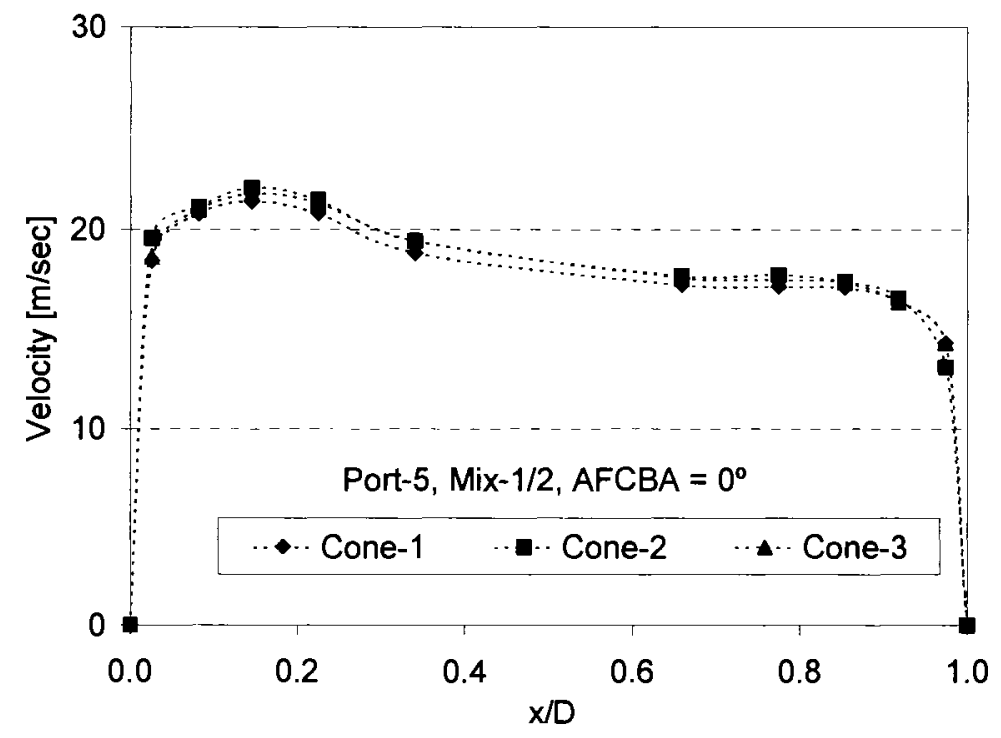

Figure 6.10: Effect of the conical burner pressure drop on DB inlet profiles 


\subsubsection{DB Annular velocity profiles}

Similar procedures or tests were performed when measuring the pressure velocity in the annular region. The annular region velocity profiles were affected by the size of the annular region. Two different sets of results are presented, one set for shield Sh5 and the other set for shield Sh6. As discussed earlier, the annular passage was wider in the case of Sh5 than for Sh6. Five traverse points along each traverse radius for Sh5 and two traverse points for Sh6 were used.

In these tests and during the flow balancing preliminary testing stage, the effect of the pitot-static tube size (percentage of the blockage) on the velocity profile measured inside the annular passage was studied. The three pitot-static tube sizes $(0.165,0.241$ and $0.317 \mathrm{~cm}, \mathrm{OD})$ were used for taking the measurement in the annular passage region through the four ports. The results show no remarkable differences. It was decided to use the two smaller pitot-static tube diameters (Pitot-1 and Pitot-2) in the annular mass flow rate measurements due to their lower percentage of blockage. The results of using different pitot-static tube sizes are presented in Appendix F.

\subsubsection{Sh5 results $(B R=0.4)$}

As was done in Section 6.6.3, some of the repeatability test results conducted in the annular passage will be presented in this section. Figure 6.11 shows typical results of a repeatability test. The tests plotted in this figure were performed on different days using the same geometrical parameters and approximately the same operating conditions. Good repeated results and trends are observed. The figure is presented in a way that one can observe the change in the velocity profiles through the four ports in the same graph.

Figure 6.12 shows the effect of changing the annular blade angle on the annular region velocity profiles at one of the ports (see Appendix $\mathrm{F}$ for more results 
for other ports). As the value of the annular blade angle increases, the velocity at the annular passage reduces, as does the mass flow rate.

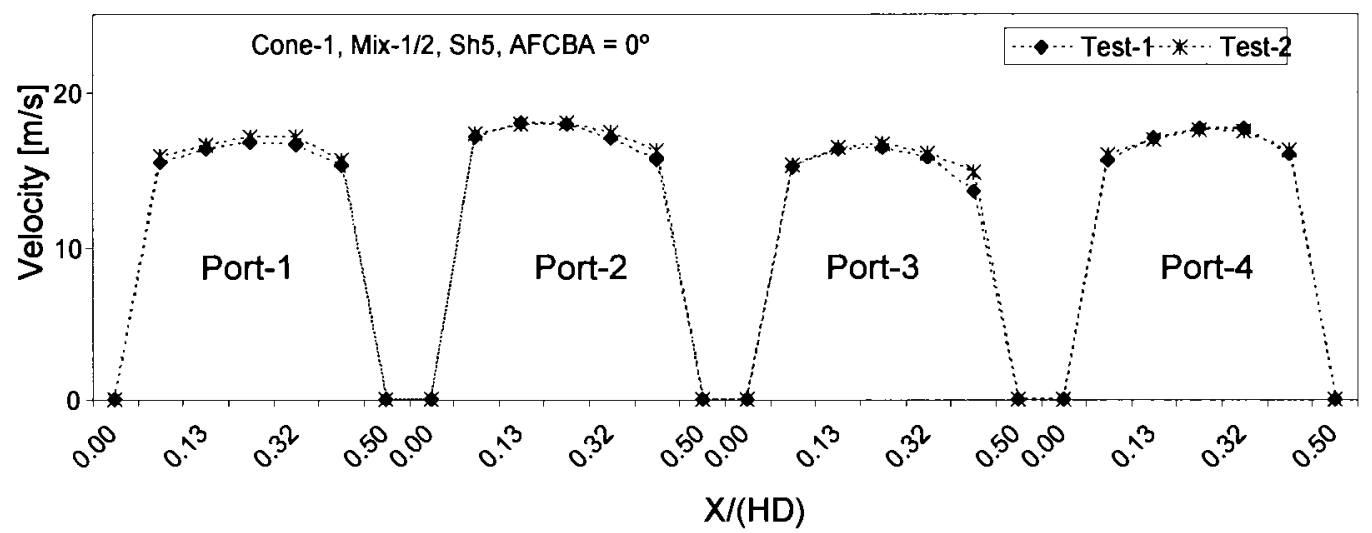

Figure 6.11: Annular region velocity profile repeatability test

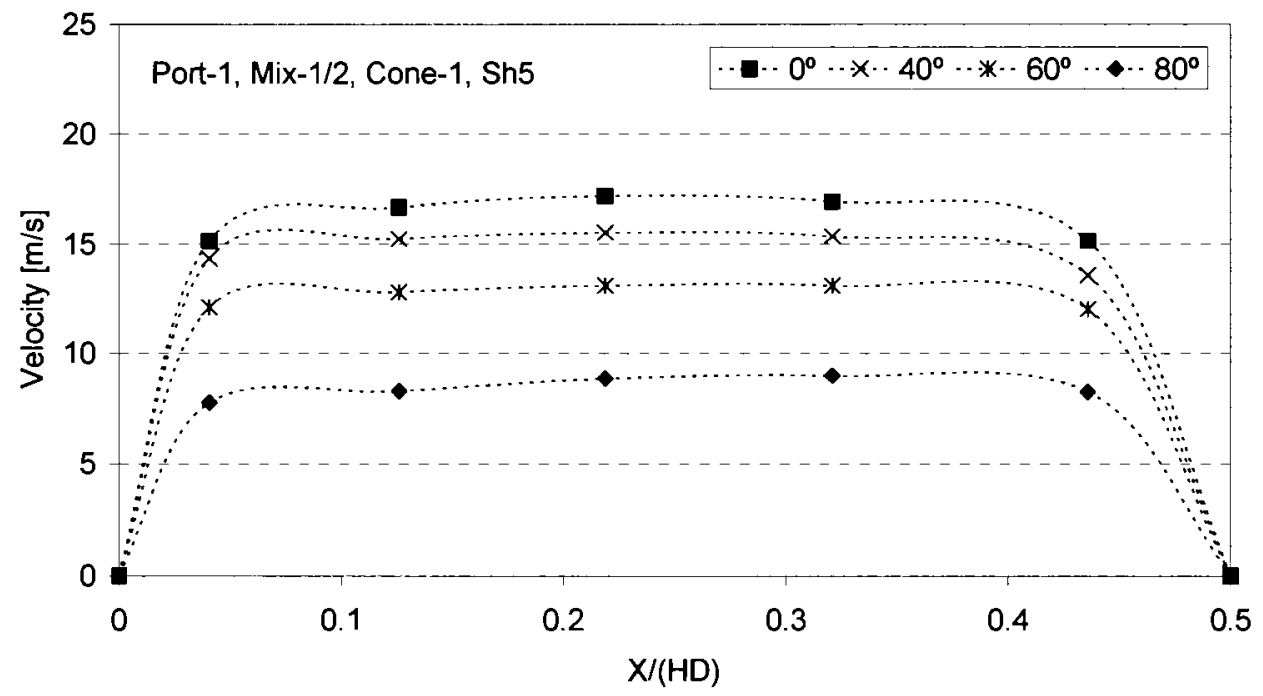

Figure 6.12: AFCBA effect on annular region velocity profile (Sh5, Port-2)

Figures $6.13,6.14$ and 6.15 show the effect of using the different types of mixers with the various cones on the velocity profile at the annular region. When 
using the double-swirl mixer (Mix-2/2) more microturbine exhaust gases were forced to flow through the annular passage than the case using the single-swirl mixer (Mix1/2) due to the blockage Mix-2/2 introduces at the premixer inlet.

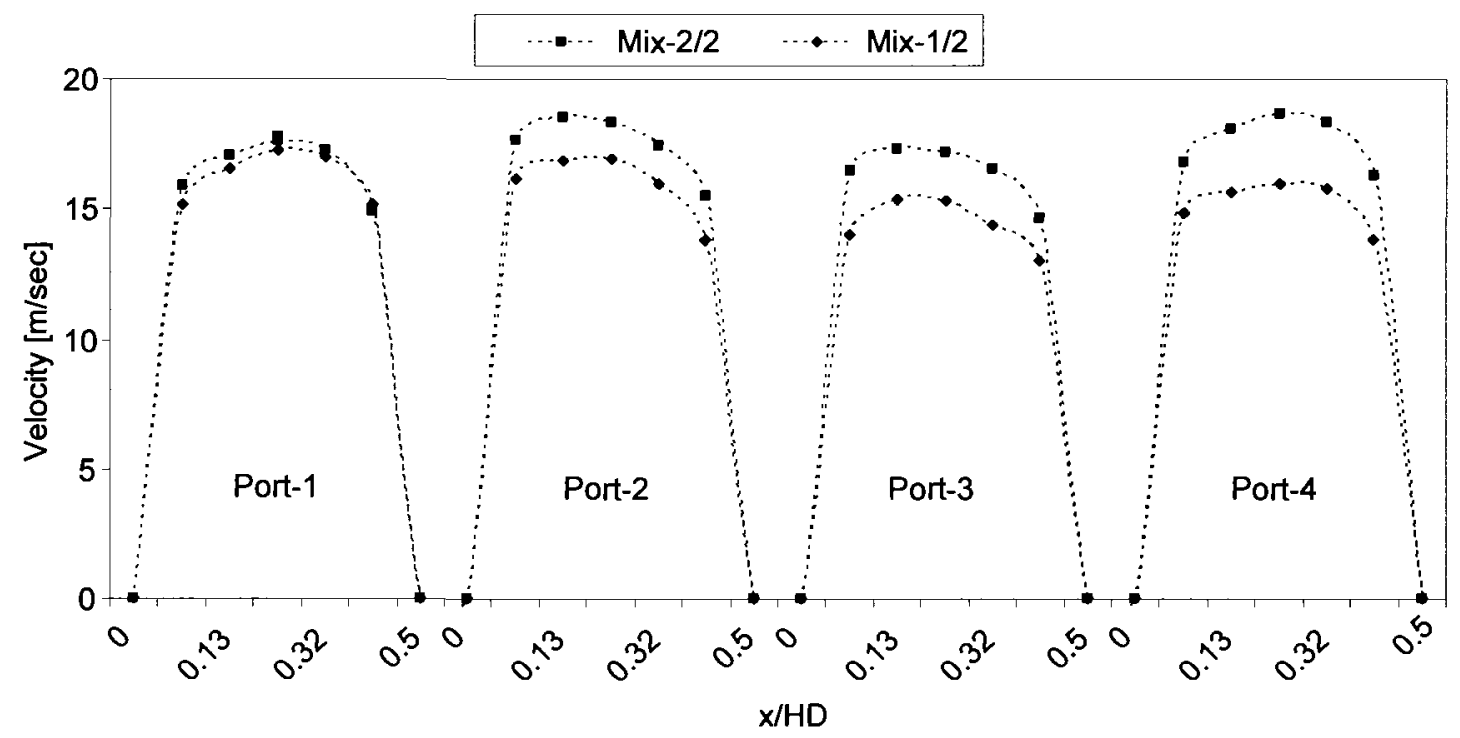

Figure 6.13: Effect of mixer type on the annular region velocity profile (Cone-1, Sh5, AFCBA $=0^{\circ}$ )

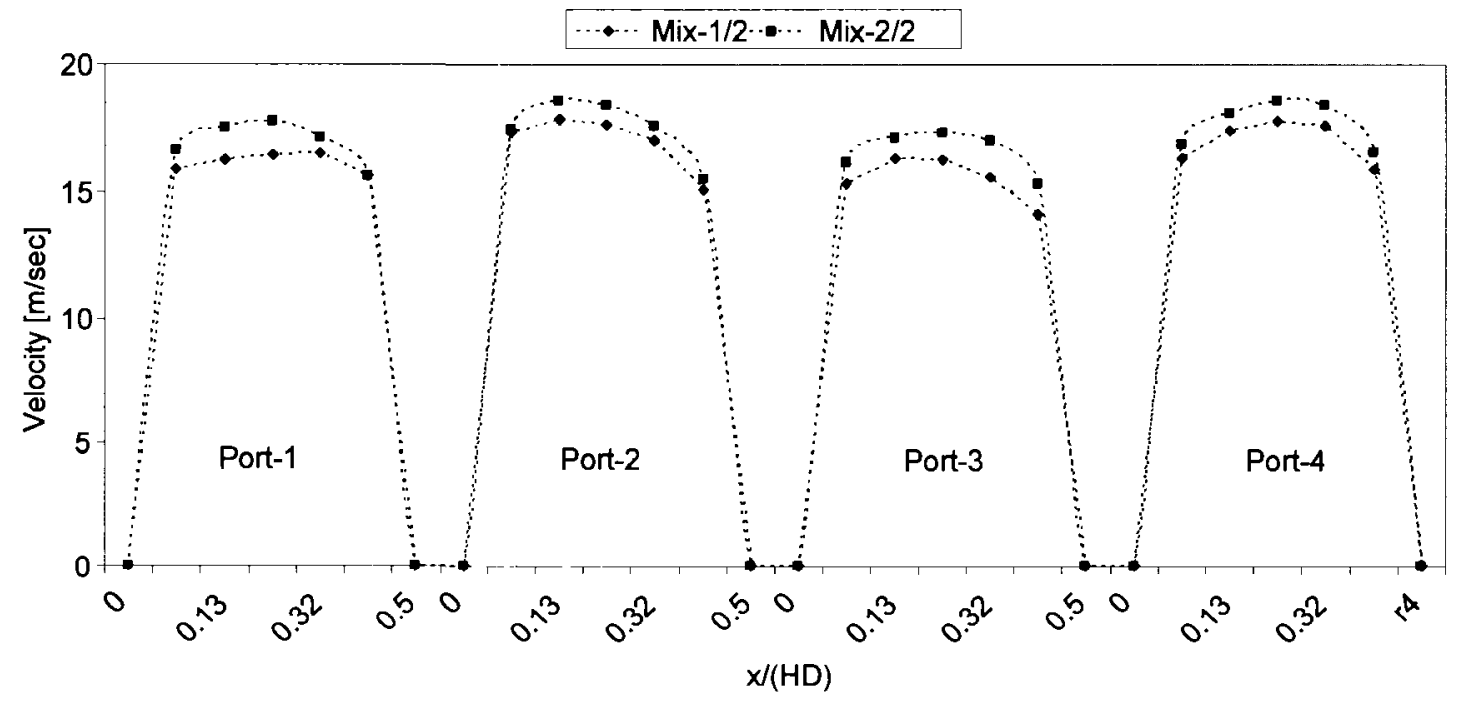

Figure 6.14: Effect of mixers type on the annular region velocity profile (Cone-2, Sh5, AFCBA $=0^{\circ}$ ) 


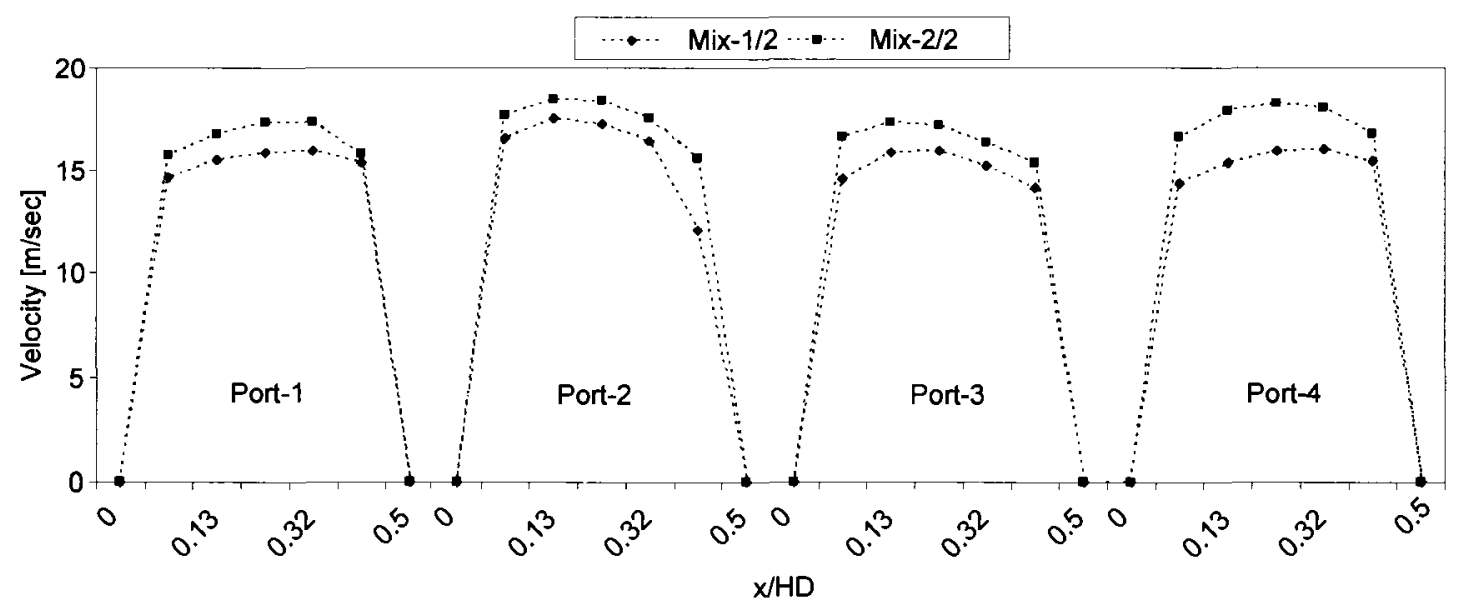

Figure 6.15: Effect of mixers type on the annular region velocity profile (Cone-3, Sh5, $\operatorname{AFCBA}=0^{\circ}$ )

\subsubsection{Sh6 results $(B R=0.6)$}

As discussed earlier, the annular passage width decreases when using Sh6. Only two traverse points along each port were used for the measurement of the velocity pressure. The pitot-static tube size effects on the velocity pressure measurements in this small annular passage are also studied during the preliminary testing. Very similar results were obtained when Pitot-1 and Pitot-2 were used. In this small passage Pitot-1 was used due to its lower percentage of blockage. See Appendix $F$ for the test results of the pitot-static tube size effect.

Figure 6.16 shows the variation in velocity profiles in the annular passage due to the change in the conical burner pressure drop. As the conical burner pressure drop increases the blockage increases and relatively more microturbine exhaust gases will be forced towards the annular passage. Cone-3 results showed a different behaviour compared to the other cones (this behaviour was also observed during the duct burner pressure drop measurements) and will be presented in a later section. These results indicated that the nominal conical burner pressure drop of $149 \mathrm{~Pa}\left(0.6\right.$ in $\left.\mathrm{H}_{2} \mathrm{O}\right)$ is an optimal value for the duct burner (see Figure F.25) 
Figure 6.17 shows the effect of using different mixer types on the velocity measured. When using Mix-2/2 more flow through the annular passage was observed. The results are for the geometrical parameters using Cone- 2 and AFCBA $=0^{\circ}$. When the annular flow control blades angle is set at zero degrees, as described in Chapter 4, the maximum amount of microturbine exhaust gases is bypassed through the annular passage. The effect of the AFCBA on annular region velocity profiles for configuration; Mix-2/2, Cone-3 and Sh6 is presented in Figure 6.18. As the AFCBA increases, more of the oxidant flows through the conical burner.

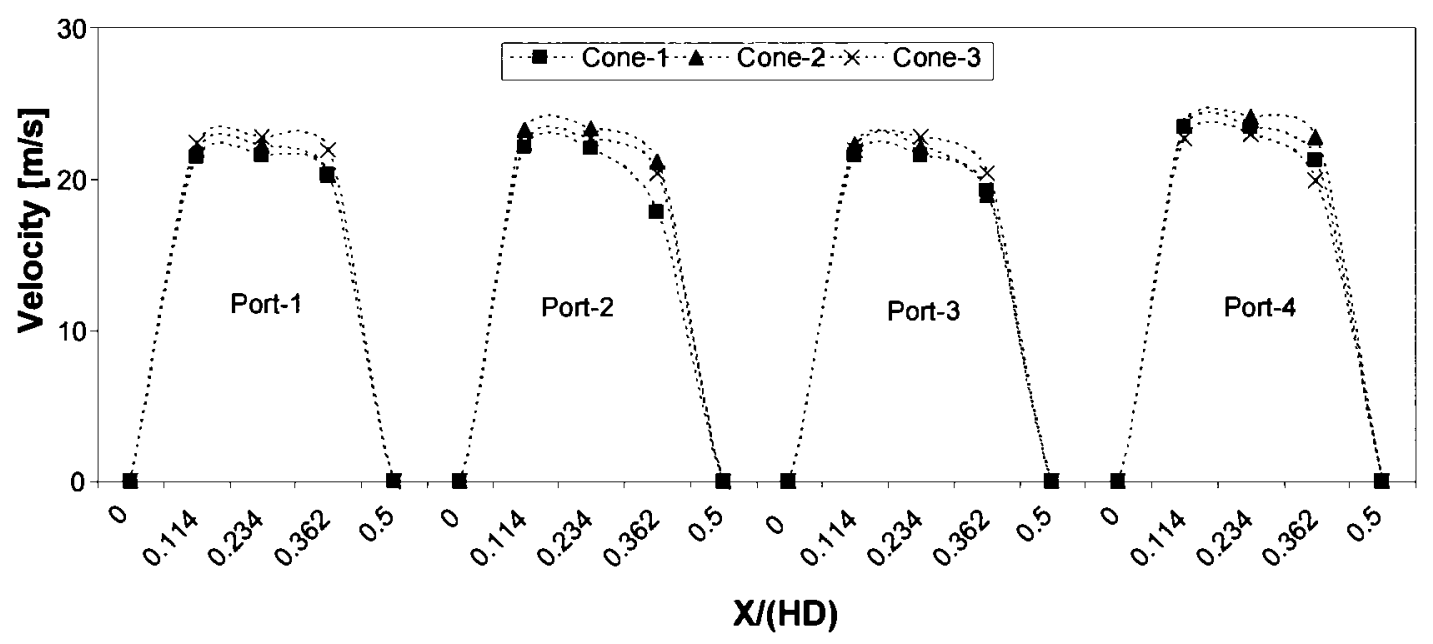

Figure 6.16: Effect of conical burner pressure drop on the annular velocity profile (Mix$1 / 2$, Sh6, AFCBA $=0^{\circ}$ )

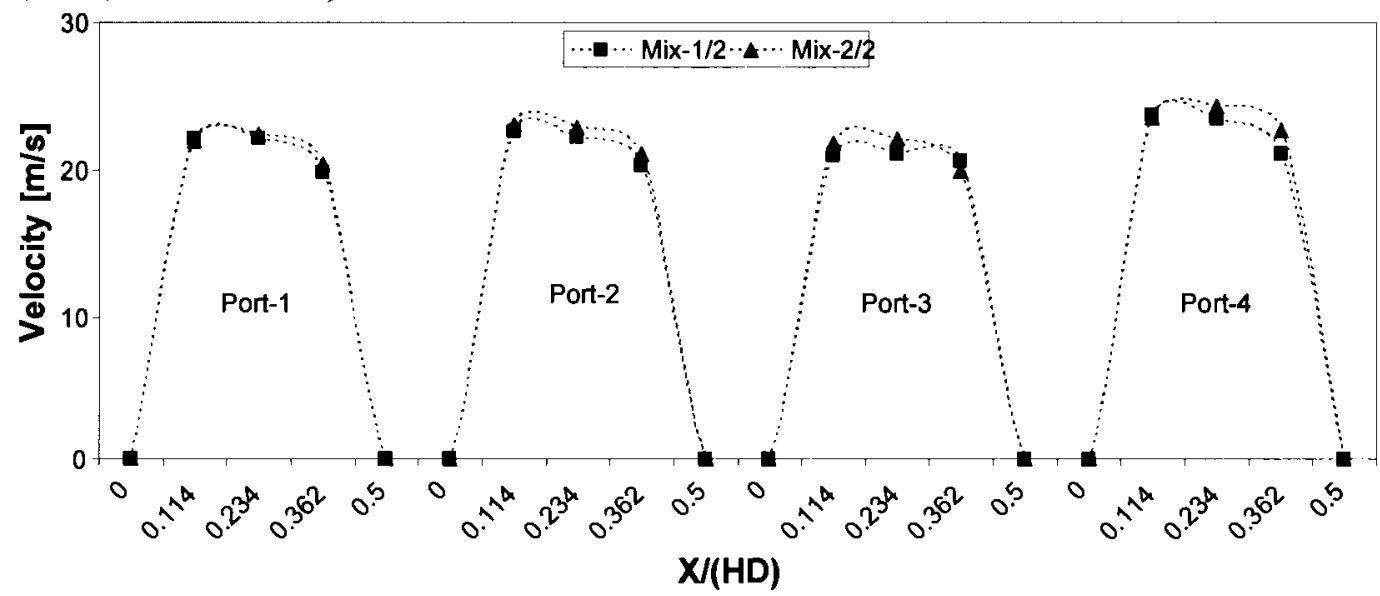

Figure 6.17: Effect of mixers type on the annular region velocity profile (Cone-2, Sh6, AFCBA $=0^{\circ}$ ) 


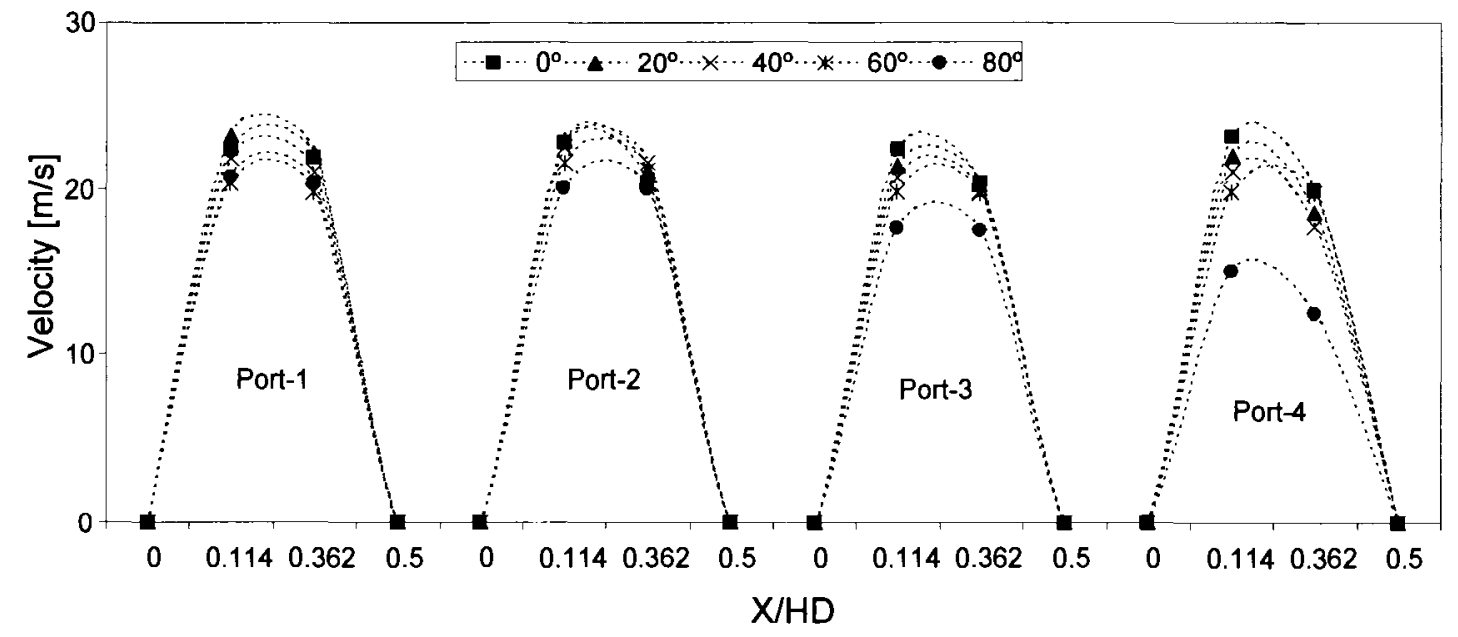

Figure 6.18: Effect of the AFCBA on annular region velocity profiles (Mix-2, Cone-3, Sh6)

\subsubsection{Mass flow rate results}

The velocity pressure measurements were conducted for each experimental setting presented in Table 6.2. Results from selected runs are presented in the previous two sections. From those measurements the velocity was calculated using Equation (6.1) and both the total oxidant mass flow rate $\left(\dot{m}_{\text {oxid }}\right)$ and the annular passage mass flow rate ( $\dot{m}_{\text {bypass }}$ ) were calculated using Equation (6.3). The cone mass flow rate was calculated from the difference between the two calculated quantities:

$$
\dot{m}_{\text {Cone }}=\dot{m}_{\text {oxid }}-\dot{m}_{\text {bypass }}
$$

A sample of the test results is presented in this section. The results are presented graphically; each plot shows the effect of the annular flow control blade angles (AFCBA) on the split of the duct burner mass flow rate between the different regions.

Figure 6.19 shows the flow balancing test results of the first test run for the fixed burner parameters Mix-1/2 (single-swirl mixer), Cone-1 (conical burner with a 
pressure drop of $75 \mathrm{~Pa})$ and cone burner shield, Sh5 $(\mathrm{BR}=0.4)$. The figure shows that as the AFCBA increases, the amount from the oxidant (microturbine exhaust gases) flow directed through the conical burner (combustion zone) increases.

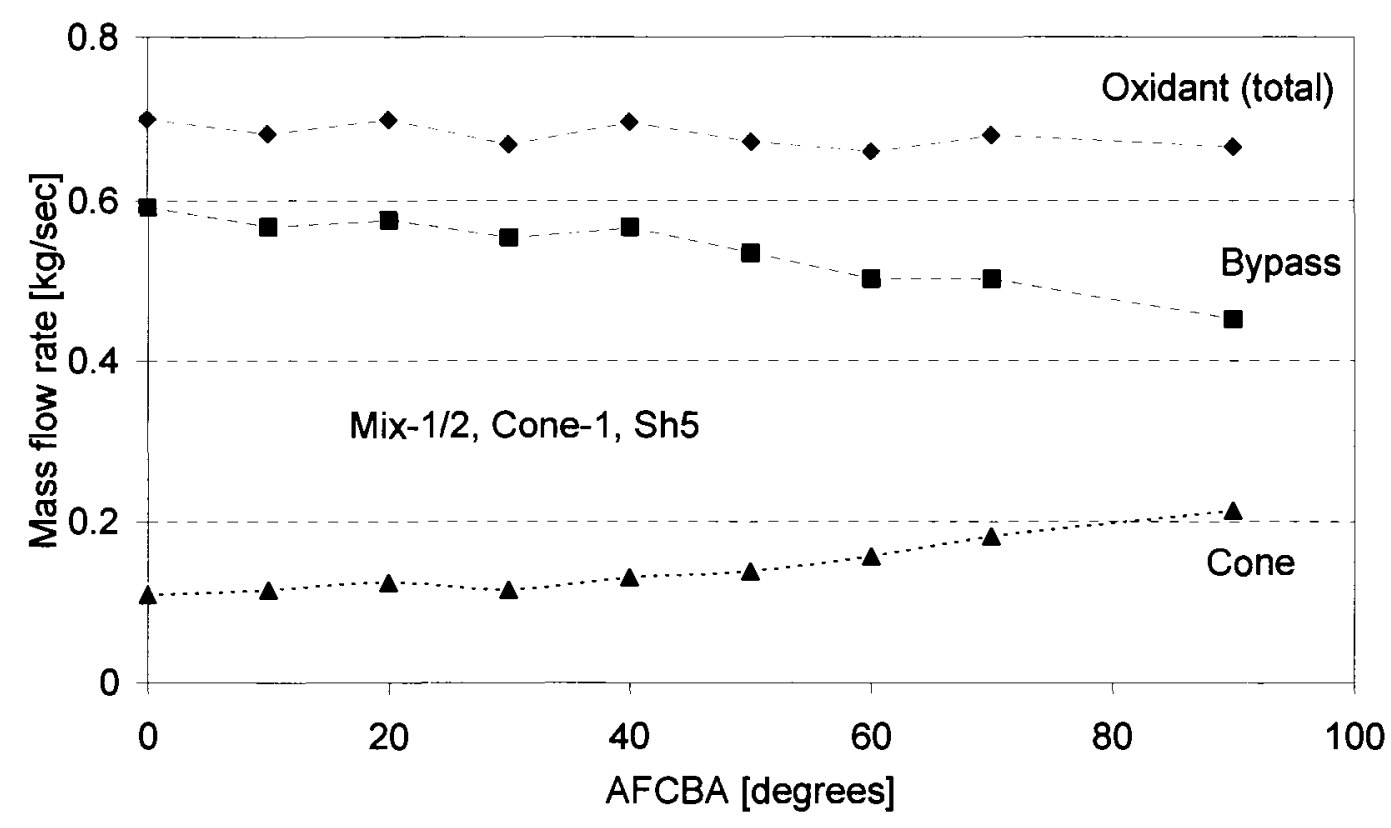

Figure 6.19: Effect of AFCBA on DB mass flow rate split (Mix-1/2, Cone-1 and Sh5)

Figure 6.20 shows the effect of the annular flow control blade angles on duct burner mass flow rate split. In this test the double-swirl mixer, Mix-2/2, was tested with Cone-1 and Sh5. The results show a similar trend as that presented in Figure 6.19 .

Because of the similar trend of the results, the effect of the AFCBA on duct burner mass flow split for the other geometrical parameters such as; Cone-2, Cone-3 and Sh6 are presented in Appendix F.

With these duct burner mass flow measurements it is possible to calculate the cone mass flow rate-to-oxidant mass flow rate ratio (also called, cold flow mass ratio, $M R_{C F}$ ) (Equation 6.5) using the previous results: 


$$
M R_{C F}=\frac{\dot{m}_{\text {cone }}}{\dot{m}_{\text {oxid }}}
$$

In the following results, the $\mathrm{x}$-coordinate of the graphs is the AFCBA in degrees (as in previous figures) and the y-coordinates is the calculated mass flow ratio (Equation 6.5).

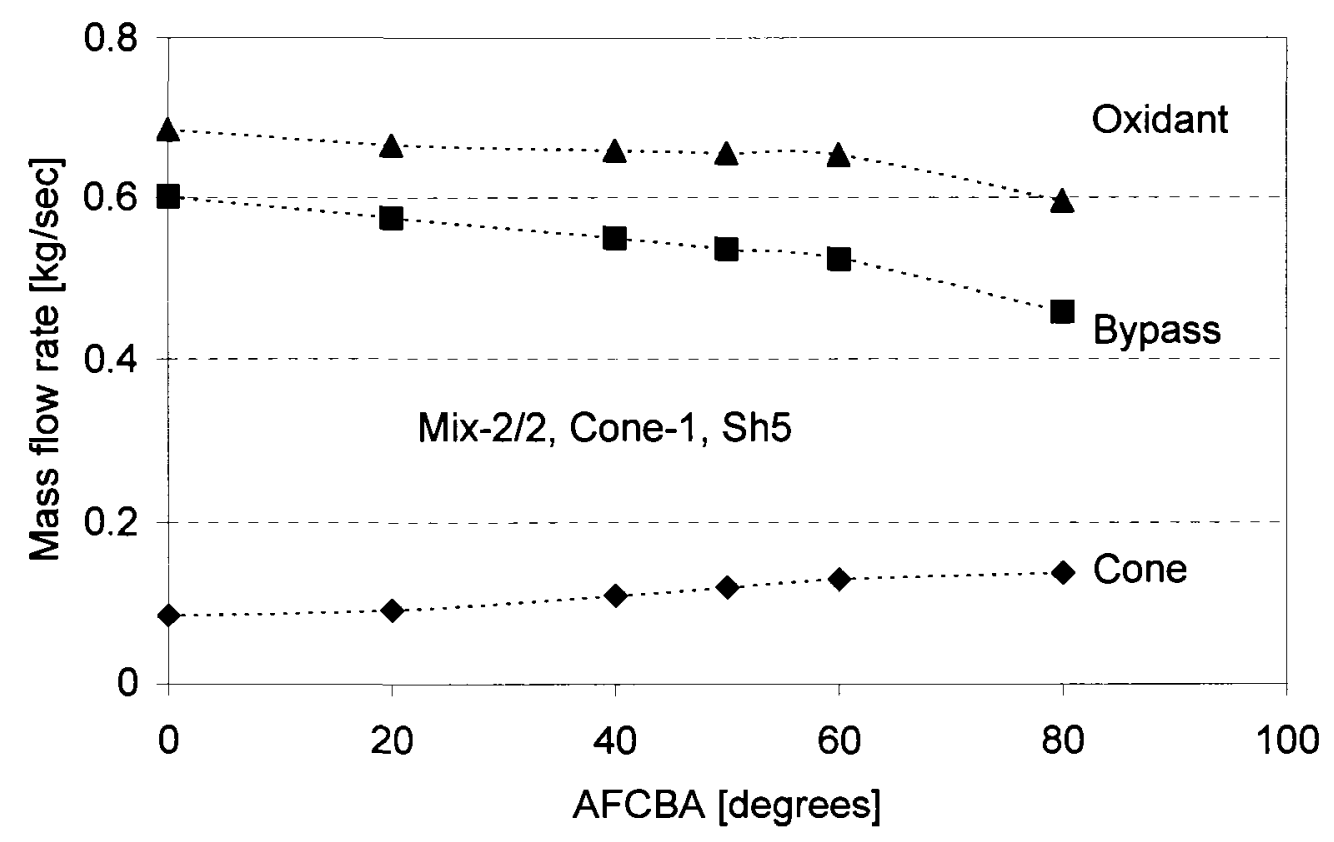

Figure 6.20: Effect of annular blade angle on mass flow rate split (Mix-2/2, Cone-1 and Sh5)

Figure 6.21 shows the effect of mixer design on mass flow ratio, as a function of AFCBA. The figure summarizes the two previous results presented in Figures 6.19 and 6.20. The figure shows that the mass flow ratio is reduced when the double-swirl mixer is used due to its greater flow blockage compared to the single-swirl mixer.

All the tests conducted in this section on the effect of the different geometrical parameters as a function of AFCBA on duct burner mass flow rate split (in form of mass ratio) are summarized in Figures 6.22 and 6.23

Figure 6.22 shows comparisons between the results of Sh5 and Sh6 when tested with Mix-1/2. This figure shows the effect of the pressure drop of the different 
conical burners and the effect of blockage ratio (BR) on mass flow ratio. At AFCBA $=0^{\circ}$ the effect of changing Sh5 to Sh6 caused an increase in the mass flow ratio of approximately $\mathbf{7 8 \%}$ for all the cones. The difference in the mass flow ratio between the two shields decreases by increasing the AFCBA. At a $60^{\circ}$ blade angle, the increase in mass flow ratio (from Sh5 to Sh6) was approximately $40 \%$ for both cones, Cone- 1 and Cone-2. Cone- 3 compared to the other cones shows different trends than expected (lower mass flow ratio compared to the other two cones at all AFCBA angles, see discussion below).

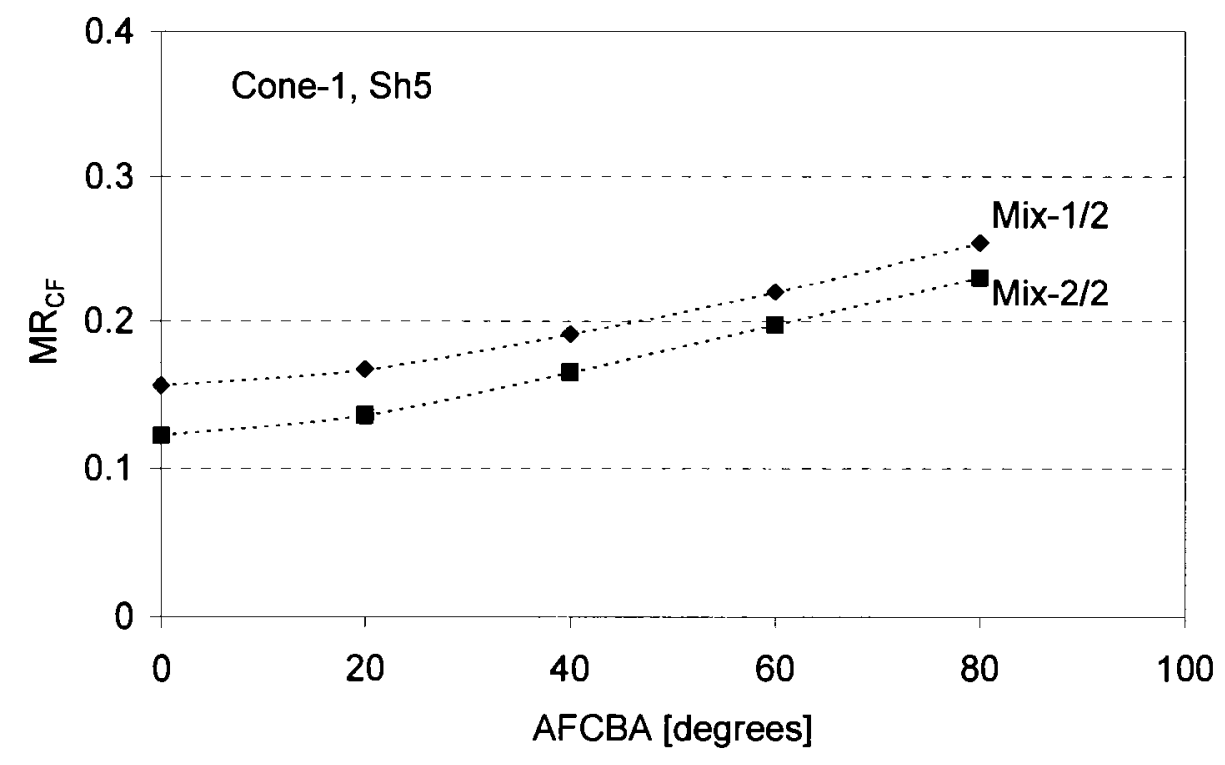

Figure 6.21: Effect of mixer design on mass flow ratio (Cone-1, Sh5)

Figure 6.23 shows a similar comparison as that presented in Figure 6.22 for the double-swirl mixer, Mix-2/2. This figure shows the effect of BR, conical burner pressure drop as a function of AFCBA on mass flow ratio. The results show that using Sh6, the mass ratio almost doubles at AFCBA equal to zero degrees for all the cones. At a 60 degree AFCBA angle, using Sh6, causes an increase in the mass flow ratio by approximately $50 \%$ for Cone- 1 and Cone- 2 . Cone- 3 shows similar results (trend) as that shown in Figure 6.22 (when tested with Mix-1/2). 


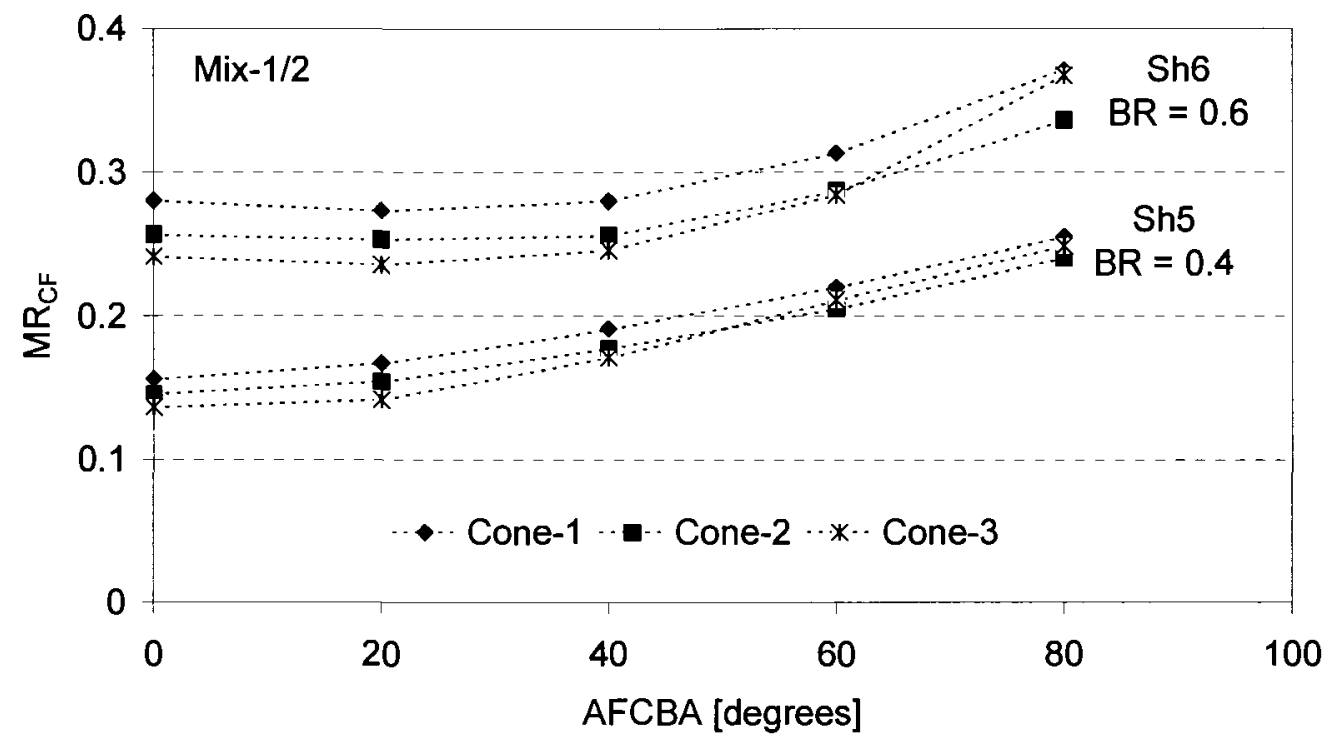

Figure 6.22: Summary of Mix-1/2 results (Sh5, Sh6)

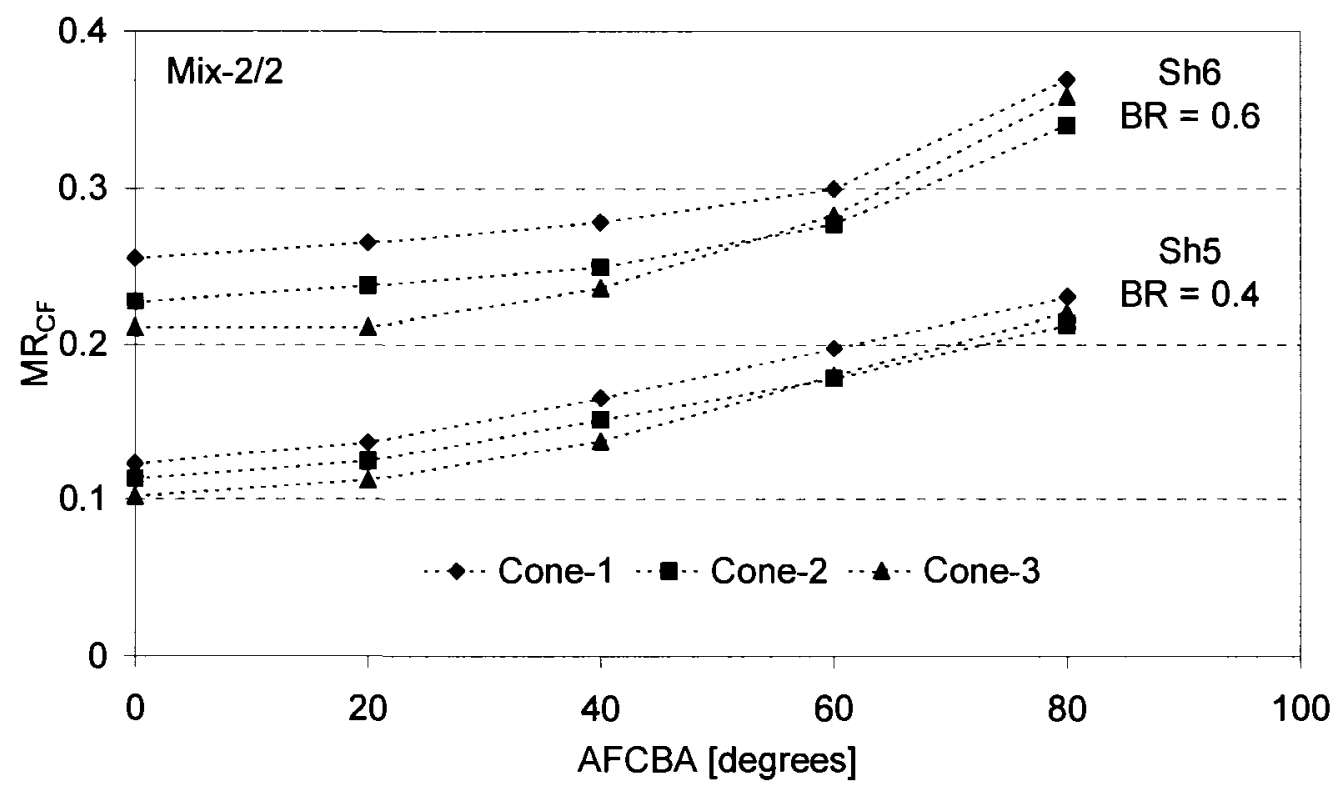

Figure 6.23: Summary of Mix-2/2 results (Sh5, Sh6)

Cone- 3 shows different trends regarding the mass flow ratio compared to the other cones. The expected results from this conical burner, which has a nominal pressure drop of $224 \mathrm{~Pa}$ (compared to $75 \mathrm{~Pa}$ and $149 \mathrm{~Pa}$ for Cones 1 and 2 
respectively), was a mass flow ratio lower than that produced with the other two cones. As can be seen in the above tests, the Cone-3 mass flow ratio results lie between the results of the two cones (Cone-1 and Cone-2) for most of the AFCBA tested. In other tests, the results show the expected (lower mass ratio) trend at lower AFCBA and a higher mass ratio than the other cones at the higher angles. This behaviour was also shown in repeat tests conducted with Cone-3 and their average values were used in the presentation Cone-3 results (Figures 6.21 and 6.22). This point will be discussed later in the chapter.

From the calculated $\left(M R_{C F}\right)$ ratio, correlations (best curve fit) were found to estimate the mass flow ratio as a function of annular blade angle for each of the tests conducted. The results of these correlations are presented in a Table 6.3 showing a summary of the results of the flow balancing tests.

Table 6.3: Duct burner flow balancing test results

\begin{tabular}{|c|c|c|c|c|c|c|}
\hline \multirow{4}{*}{$\begin{array}{l} \\
\text { Annular blade } \\
\text { angle [degrees] }\end{array}$} & \multicolumn{3}{|c|}{ Mixer-1 } & \multicolumn{3}{|c|}{ Mixer-2 } \\
\hline & \multicolumn{3}{|c|}{ For shield $5[\mathbf{S h 5}, \mathrm{BR}=0.4]$} & \multicolumn{3}{|c|}{ For shield $5[\mathbf{S h 5}, \mathrm{BR}=0.4]$} \\
\hline & Cone-1 & Cone-2 & Cone-3 & Cone-1 & Cone-2 & Cone-3 \\
\hline & $M R_{C F}$ & $M R_{C F}$ & $M R_{C F}$ & $M R_{C F}$ & $M R_{C F}$ & $M R_{C F}$ \\
\hline 0 & 0.155 & 0.144 & 0.132 & 0.121 & 0.111 & 0.100 \\
\hline 10 & 0.161 & 0.149 & 0.137 & 0.130 & 0.119 & 0.105 \\
\hline 20 & 0.169 & 0.156 & 0.144 & 0.140 & 0.128 & 0.112 \\
\hline 30 & 0.178 & 0.165 & 0.153 & 0.152 & 0.138 & 0.127 \\
\hline 40 & 0.189 & 0.176 & 0.164 & 0.164 & 0.150 & 0.133 \\
\hline 50 & 0.203 & 0.189 & 0.177 & 0.183 & 0.163 & 0.150 \\
\hline Blade angle & \multicolumn{3}{|c|}{ For shield $6[\mathrm{Sh} 6, \mathrm{BR}=0.6]$} & \multicolumn{3}{|c|}{ For shield $6[$ Sh6, BR $=0.6]$} \\
\hline 0 & 0.282 & 0.258 & 0.244 & 0.259 & 0.230 & 0.211 \\
\hline 10 & 0.296 & 0.269 & 0.262 & 0.266 & 0.240 & 0.220 \\
\hline 20 & 0.316 & 0.284 & 0.287 & 0.277 & 0.250 & 0.235 \\
\hline 30 & 0.342 & 0.303 & 0.320 & 0.290 & 0.260 & 0.256 \\
\hline 40 & 0.373 & 0.326 & 0.361 & 0.310 & 0.280 & 0.283 \\
\hline 50 & 0.411 & 0.353 & 0.414 & 0.330 & 0.300 & 0.316 \\
\hline
\end{tabular}


As a preparation for the combustion tests (Chapter 8), this table shows the amount from the total mass flow (microturbine exhaust gas) which is directed through the conical mesh burner for each blade angle.

\subsubsection{Duct burner pressure drop}

The overall duct burner pressure drop measurements were performed by averaging the static pressure from the sidewall pressure taps located upstream and downstream from the duct burner. A static pressure probe was also used for the downstream location. In this section, first the effect of the different conical burners (Cone-1, Cone-2 and Cone-3) and the measurement shields (Sh5 and Sh6) as a function of AFCBA on the overall duct burner pressure drop will be presented. Then, the effect of the different shields which will be used in the combustion tests (Sh1, Sh2, Sh3, Sh4, Sh7 and Sh8, see Figure 4.18) as a function of AFCBA on the overall duct burner pressure drop will be presented.

\subsubsection{Effect of conical burner pressure drop and BR on the DB $\Delta P$}

Figure 6.24 shows the effect of conical burner pressure drop (different cones) as a function of annular flow control blade angles on DB overall pressure drop for the geometrical configuration using Mix-1/2 and Sh5. As expected, the overall pressure drop increases by increasing the AFCBA. Also, the figure shows that as the conical burner pressure drop increases the DB overall pressure drop increases. At lower AFCBA the difference between the measured pressure drop values between the cones is small compared to the same values at higher AFCBA.

Figure 6.25 presents the effect of the conical burner pressure drop as a function of AFCBA on DB overall pressure drop for the burner parameters Mix-1/2 with Sh6 (Sh6 has a higher BR than Sh5). By comparing Figure 6.24 and 6.25, one 
can observe that for $\mathrm{AFCBA}=0^{\circ}$, the overall duct burner pressure drop increased by a factor larger than 2 when the BR increased from 0.4 (Sh5) to 0.6 (Sh6).

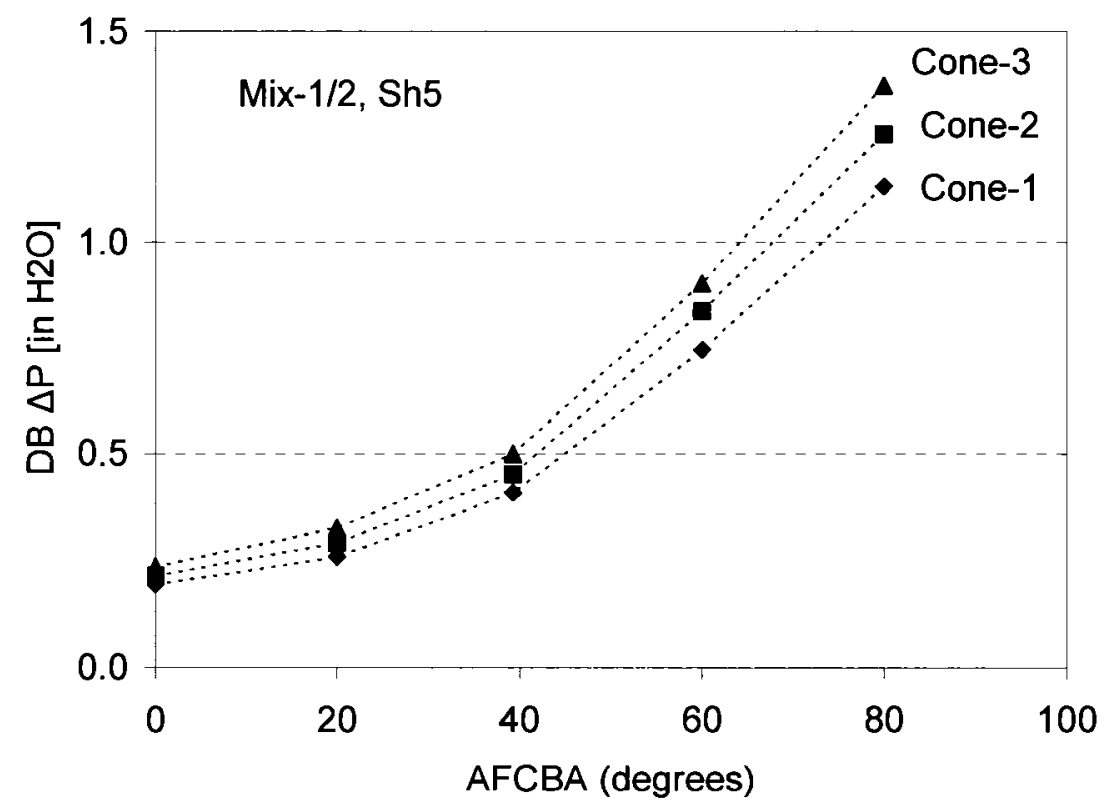

Figure 6.24: Effects of conical burner pressure drop and blade angle on DB overall pressure drop (Mix-1/2, Sh5)

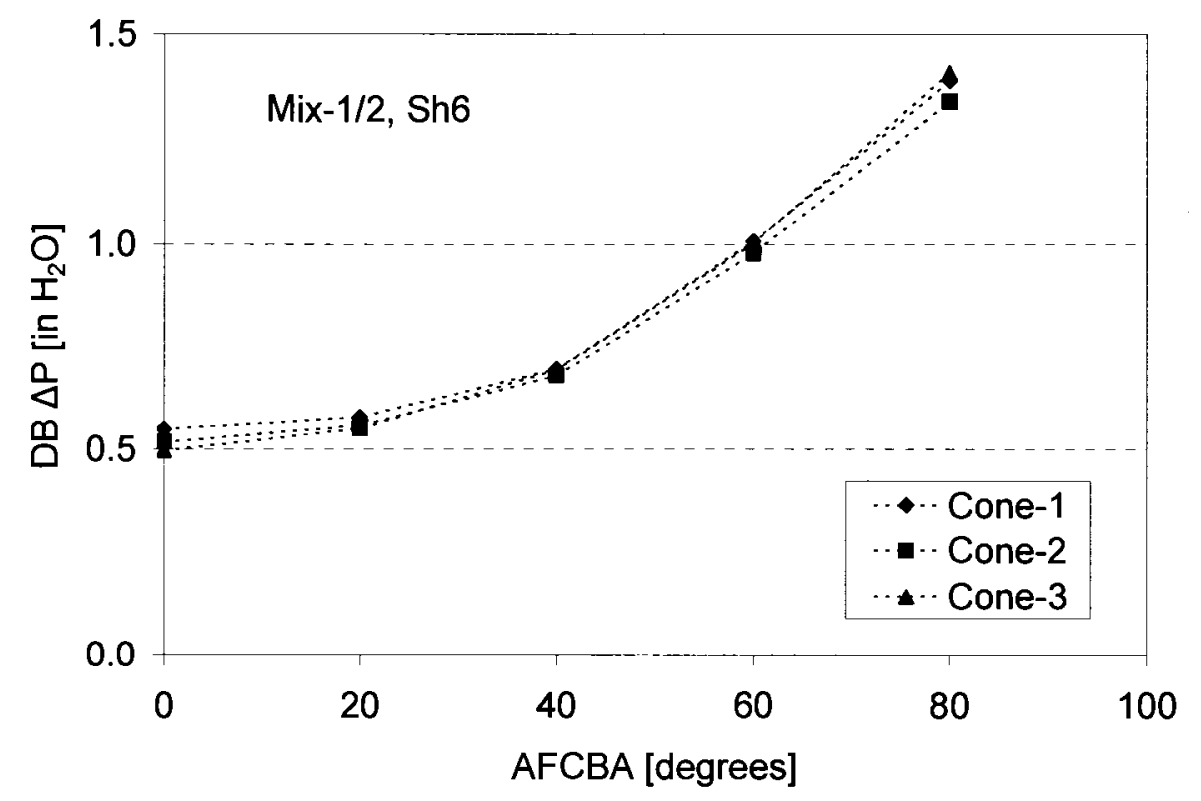

Figure 6.25: Effects of conical burner pressure drop and blade angle on DB overall pressure drop (Mix-1/2, Sh6) 
Figures 6.26 and 6.27 show the effect of using the three tested cones as a function of AFCBA on DB overall pressure drop. The burner parameters in these two tests were Mix-2/2 with Sh5 (Figure 6.26) and Sh6 (Figure 6.27). Similar observations are shown as in the previous results with Mix-1/2; the larger the BR of the shield the higher the pressure drop value. At lower AFCBA, all cones show relatively similar results; as the angle increases the pressure drop difference increases.

Figure 6.28 shows the effect of mixer design on duct burner overall pressure drop. For these test results the burner parameters were Cone-2 and Sh6. The results show an increase in the pressure drop when the double-swirl mixer is used. The difference in the pressure drop was very small at $\mathrm{AFCBA}=0^{\circ}$ and increased with an increase in the AFCBA. For more comparisons between the different burner parameters see Appendix F.

In general, the DB overall pressure drop was found to be less than $249 \mathrm{~Pa}$ $\left(1.0\right.$ in $\mathrm{H}_{2} \mathrm{O}$ ) for all the cases tested with an AFCBA $<60^{\circ}$.

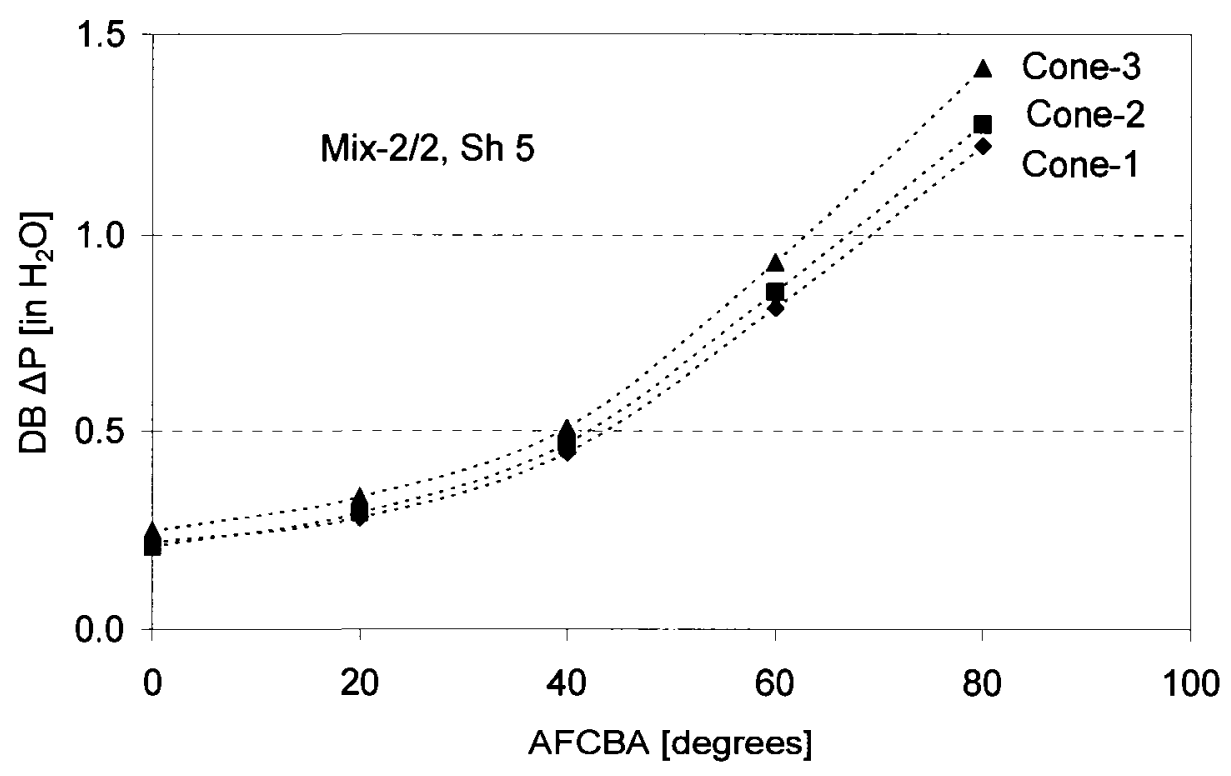

Figure 6.26: Effects of conical burner pressure drop and blade angle on DB overall pressure drop (Mix-2/2, Sh5) 


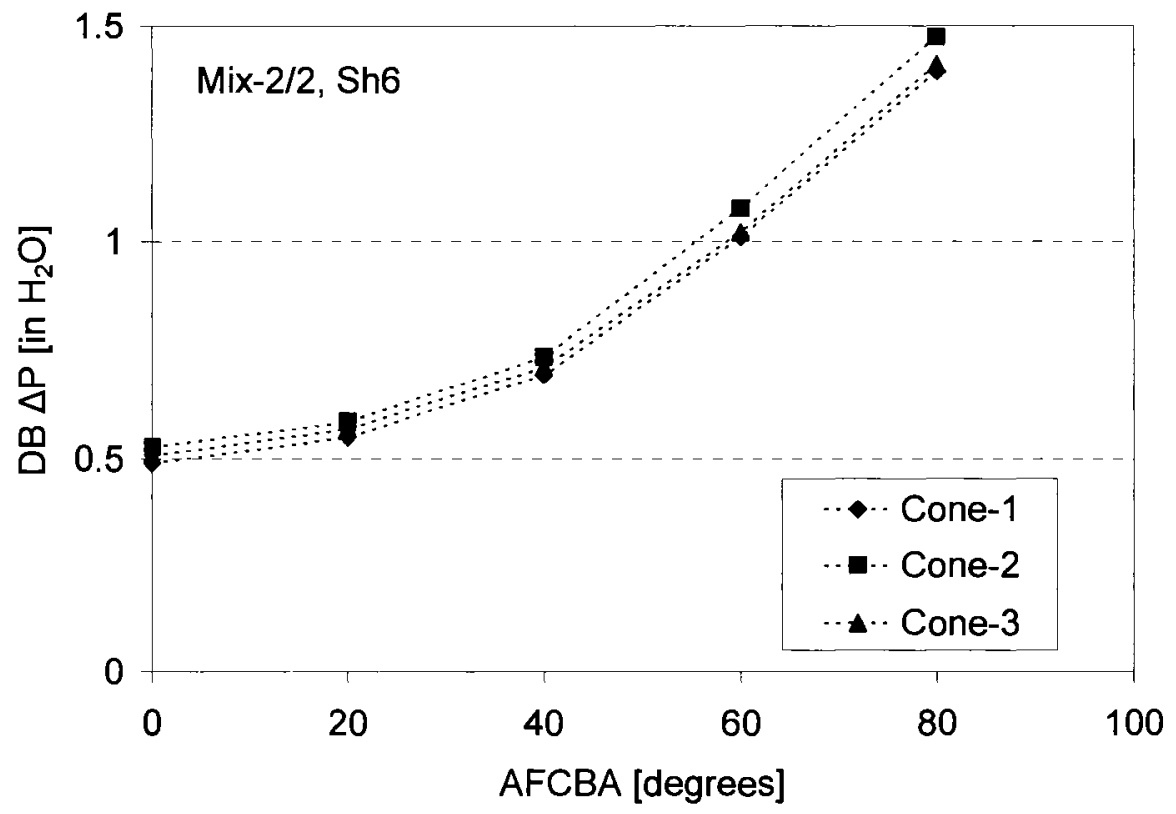

Figure 6.27: Effects of conical burner pressure drop and blade angle on DB overall pressure drop (Mix-2/2, Sh6)

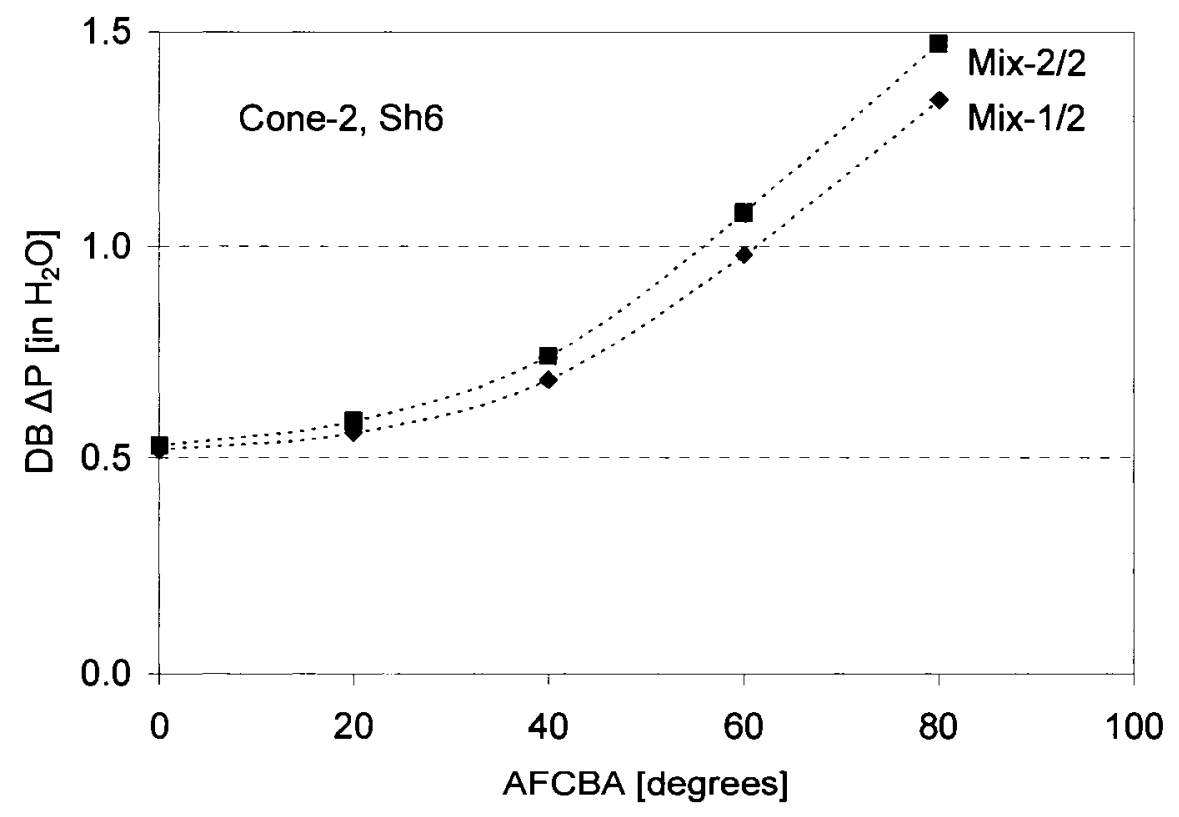

Figure 6.28: Effect of mixer design on DB overall pressure drop for different AFCBA (Cone-2, Sh6) 


\subsubsection{Effect of different conical burner shields on the DB $\Delta P$}

As previously mentioned, the measurement shields were designed to be used only in the flow balancing tests and not in the combustion tests (view ports missing from these shields). The shields that will be used in the combustion tests must give access to the combustion zone for measurements and flame observation and to ensure the protection of the flames from the bypass flow. Different shields were designed in this investigation to allow the study of different parameters and their effect on the duct burner performance. Figure 4.18 illustrates all the shields which will be used in the combustion tests. The effect of these different shields (Sh1, Sh2, Sh3, Sh4, Sh7 and Sh8) as a function of AFCBA on overall duct burner pressure drop was measured and will be presented in this section.

Figure 6.29 shows a comparison between two test results; in one test, the burner was using the shortest shield, Sh1 $(B R=0.4)$ and in the other test, no shield was used. As mentioned in Chapter 4, Sh1 covers only 25 percent of the conical burner length. The results indicated that integrating this shield with the duct burner reduces the overall pressure drop of the duct burner (improves the flow uniformity around the conical burner base). The pressure drop increases as the AFCBA increases.

Figures 6.30 and 6.31 show the effect of using all the shields that have a BR $=$ 0.4 on duct burner overall pressure drop. Figure 6.30 is for the duct burner parameters Mix-1/2 and Cone-1 and Figure 6.31 is for Cone-2. The results show that the measurement shield (Sh5) showed a higher pressure drop compared to the other shields. However, at lower values of AFCBA, the pressure drop results are very close to each other.

Figure 6.32 shows the effect of using the higher BR shields (0.6) when tested with Mix-1/2. The measurement shield (Sh6) shows a slight increase in the overall pressure drop compared to the other shields (Sh7 and Sh8). 


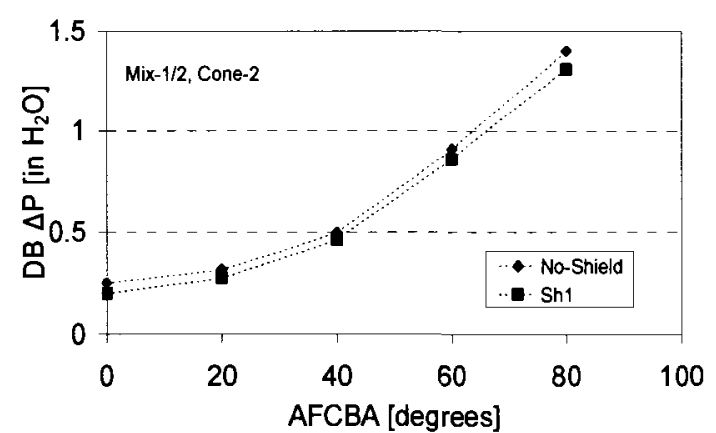

Figure 6.29: Effect of using different shields on DB $\Delta \mathrm{P}$ (Mix-1/2, Cone-2)

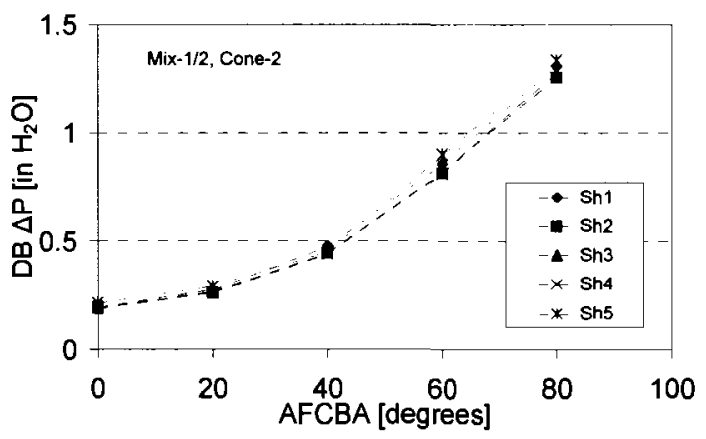

Figure 6. 30: Effect of using different shields $(B R=0.4)$ on $D B \Delta P(M i x-1 / 2$, Cone-2)

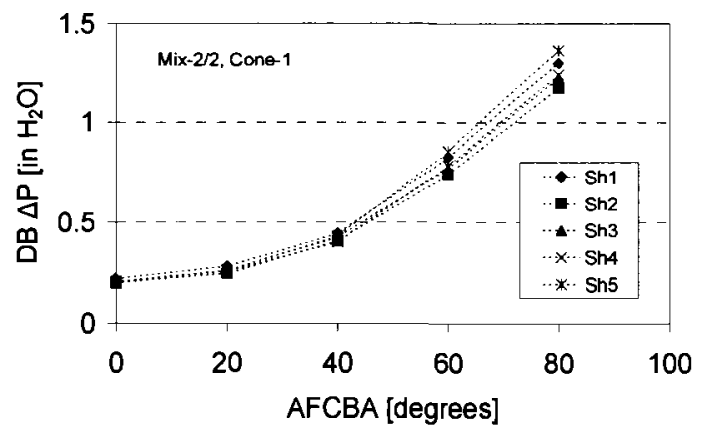

Figure 6. 31: Effect of using different shields $(B R=0.4)$ on DB $\Delta \mathrm{P}(\mathrm{Mix}-2 / 2$, Cone-1)

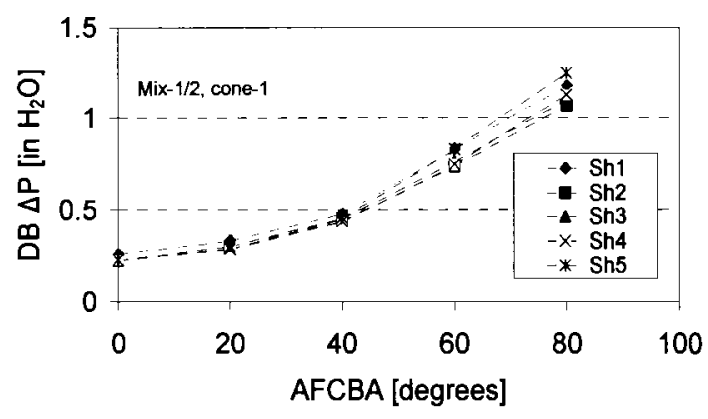

Figure 6.32: Effect of using different shields $(B R=0.4)$ on DB $\Delta$ P (Mix1/2, Cone-1)

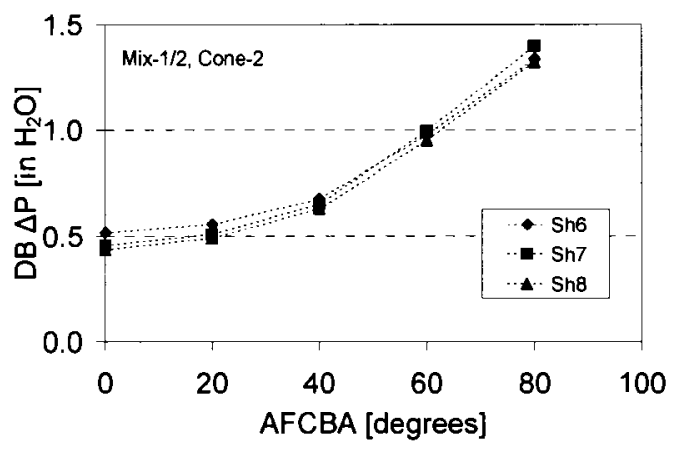

Figure 6.33: Effect of using different shields $(B R=0.6)$ on DB $\Delta P(M i x-1 / 2$, Cone-2)

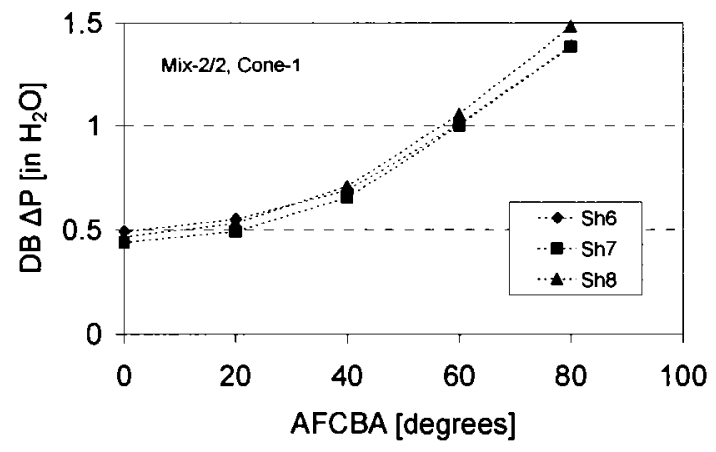

Figure 6.34: Effect of using different shields $(B R=0.6)$ on DB $\Delta P(M i x-2 / 2$ , Cone-1) 
Figures 6.33 and 6.34 show respectively the effect using the low BR (0.4) shields and the higher BR (0.6) shields at different AFCBA on the overall duct burner pressure drop when Mix-2/2 was used. Similar trends were observed for Mix-1/2.

Refer to Appendix $\mathrm{F}$ for more results regarding the effect of the different shields on duct burner overall pressure drop.

\subsection{Summary}

The DB oxidant flow balancing test was performed. During this extensive testing, the correct amount of excess microturbine exhaust gases needed to be directed through the mesh burner for surface combustion was measured and the angles of the flow control blades were determined for each flow condition.

Bernoulli's equation was used for pitot-static tube measurements. The integrated average velocity for both the DB inlet region and the annular passage was measured by traversing the cross-sectional flow area with the pitot-static tubes. The equal area method was used in all the mass flow measurements. The oxidant (total) mass flow rate entering the duct burner was calculated using the measurements performed from the two ports, Port- 5 and Port- 6 . The locations of the maximum velocity are not located at the centre of the inlet duct as shown in Section 2.6.2, due to the nature of the flow at the exit of the microturbine.

The velocity profile drawn from the measurement results through Port-6 is more symmetrical than that measured from Port-5. This may be due to the small inclination of the flexible pipe connecting the micro turbine exit pipe to the stainless steel pipe which is connected to the DB inlet pipe. There are approximately 4 pipe diameters between this connection and the measurement locations. The results show also that there is no significant effect of the conical mesh burner pressure drop on total mass flow rate. The difference is mostly due to the change in the inlet conditions of the microturbine engine. As the annular blade angle increases from zero the DB 
pressure drop increases and the total mass flow rate decreases by a small amount. The measurements for the annular passage mass flow rate were performed using four ports (Port-1 to Port-4). The annular region velocity profiles were affected by the size of the annular region. Two different sets of results are presented, one for Sh5 with a blockage ratio of 0.4 and another for Sh6 with a blockage ratio of 0.6. The smaller the blockage ratio the more asymmetric the flow was and the position of the maximum velocity is skewed toward the inner wall (shield wall) in most of the cases presented. This tendency was also pointed out in the numerical investigation done by Chung et al. (2002). As the annular blade angle increases, the annular or the bypass flow rate decreases. A zero blade angle yields the maximum bypass flow rate and the minimum cone mass flow rate. A blade angle of 90 degrees yields the minimum bypass flow rate and the maximum cone mass flow rate. As the pressure drop across the conical mesh burner increases the mass flow rate through the cone decreases and hence the bypass flow increases. The single-swirl mixer (Mix-1/2) produces less blockage than the double-swirl mixer (Mix-2/2). For this reason, Mix-1/2 allows more oxidant to flow through the cone than Mix-2/2. When the single-swirler mixer was used with Sh6, the mass flow ratio increased by approximately $78 \%$ at an AFCBA $=0^{\circ}$. This difference reduces to $40 \%$ at an $\mathrm{AFCBA}=60^{\circ}$ compared to the cases where $\mathrm{Sh} 5$ was used. In the case of the double-swirl mixer using Sh6, the mass flow ratio almost doubles at an AFCBA $=0^{\circ}$ and gives an increase of $50 \%$ at an AFCBA $=60^{\circ}$.

After plotting all the mass flow ratio results for all the cases, the best curve fit for all the test runs were found and the results of the correlations that related the mass flow rate ratio $\left(M R_{C F}\right)$ with the annular blade angle were calculated and are presented in Table 6.3.

The pressure drop across the duct burner was also measured and is presented in this chapter. For the shield with a BR of 0.4 the effect of the conical burner pressure drop and the blade angle variation was clearly observed. As the conical burner pressure drop and the blade angle increases the overall $\mathrm{DB}$ pressure drop 
increases exponentially. When Sh6 was used, the effect of the BR was the most significant factor affecting the overall pressure drop (compared to the effect of the conical burner pressure drop). The overall duct burner pressure drop increased by a factor larger than 2 at $\mathrm{AFCBA}=0^{\circ}$ when the BR increases from $0.4(\mathrm{Sh} 5)$ to 0.6 (Sh6). Low pressure drop values of less than $249 \mathrm{~Pa}\left(1.0\right.$ in $\left.\mathrm{H}_{2} \mathrm{O}\right)$ were recorded for all the cases tested with an AFCBA $<60^{\circ}$

In addition to the effect of the shields on the duct burner overall pressure drop, the effect of the shields that will be used in the combustion tests were tested to measure their effect on the overall pressure drop as well. The results indicate that Sh1, Sh2, Sh3 and Sh4 in general show similar pressure drop results compared to $\mathrm{Sh} 5$. Shields that have a $\mathrm{BR}=0.6(\mathrm{Sh} 7$ and $\mathrm{Sh} 8)$ show results that are similar to those measured for shield Sh6. Due to this, it is assumed that the use of the different shields during the combustion tests will not significantly alter the mass flow split between the different regions inside the duct burner.

Other point should be mentioned before closing Chapter 6 is that during the cold flow tests Cone-3 (higher pressure drop cone) shows normal result trend when tested at an annular flow blade control angles less than $50^{\circ}$ for both measurement shields (see Figures 6.22 and 6.23) Above $50^{\circ}$ the trend was different. In some cases during the cold flow test, Cone-3 shows unexpected results also at lower annular flow control blades (see Appendix F, Figure F.26). The behaviour of Cone-3 may be attributed to the aerodynamics of the flow field through the mesh burner or due to a manufacturer error regarding porosity (open area/total conical area). More disccusion will cover this part in Chapter 8.

The results obtained in this chapter were used to help setup the operating conditions for the combustion tests. 


\section{CHAPTER 7: Combustion test procedure and instrumentation}

\subsection{Introduction}

This chapter describes briefly the microturbine test facility components related to the combustion tests such as the burner management system and the fuel system. Also in this Chapter the start-up procedure for the duct burner, as well as the test procedure and the main instrumentation used during the combustion tests will be briefly presented

\subsection{Duct Burner Management System (BMS)}

The microturbine duct burner test facility was configured with a safety system called the Burner Management System (BMS). This system was designed (Federal Industrial Boiler Program, FIBP, CANMET, Ottawa, Canada) to provide a safe startup operation and shut down of the DB fuel system and associated equipment. The BMS is comprised of several subsystems and components, the fuel system, the combustion monitoring system and the operating cabinet. Figure 7.1 illustrates the different components of the BMS.

\subsubsection{Fuel delivery system (gas train)}

This system includes all the natural gas system components necessary to ensure safe delivery of fuel to the duct burner. Figure 7.2 shows the schematic of the duct burner fuel system. The system includes manual shut-off valves, pressure regulating valve, pressure switches (high and low) and two motorized shut-off valves. As part of the preliminary testing, the fuel system was tested for leakage. In addition, testing the joint with a leak-detecting solution after applying the gas pressure was performed whenever the duct burner was disassembled to change any test parameters. 


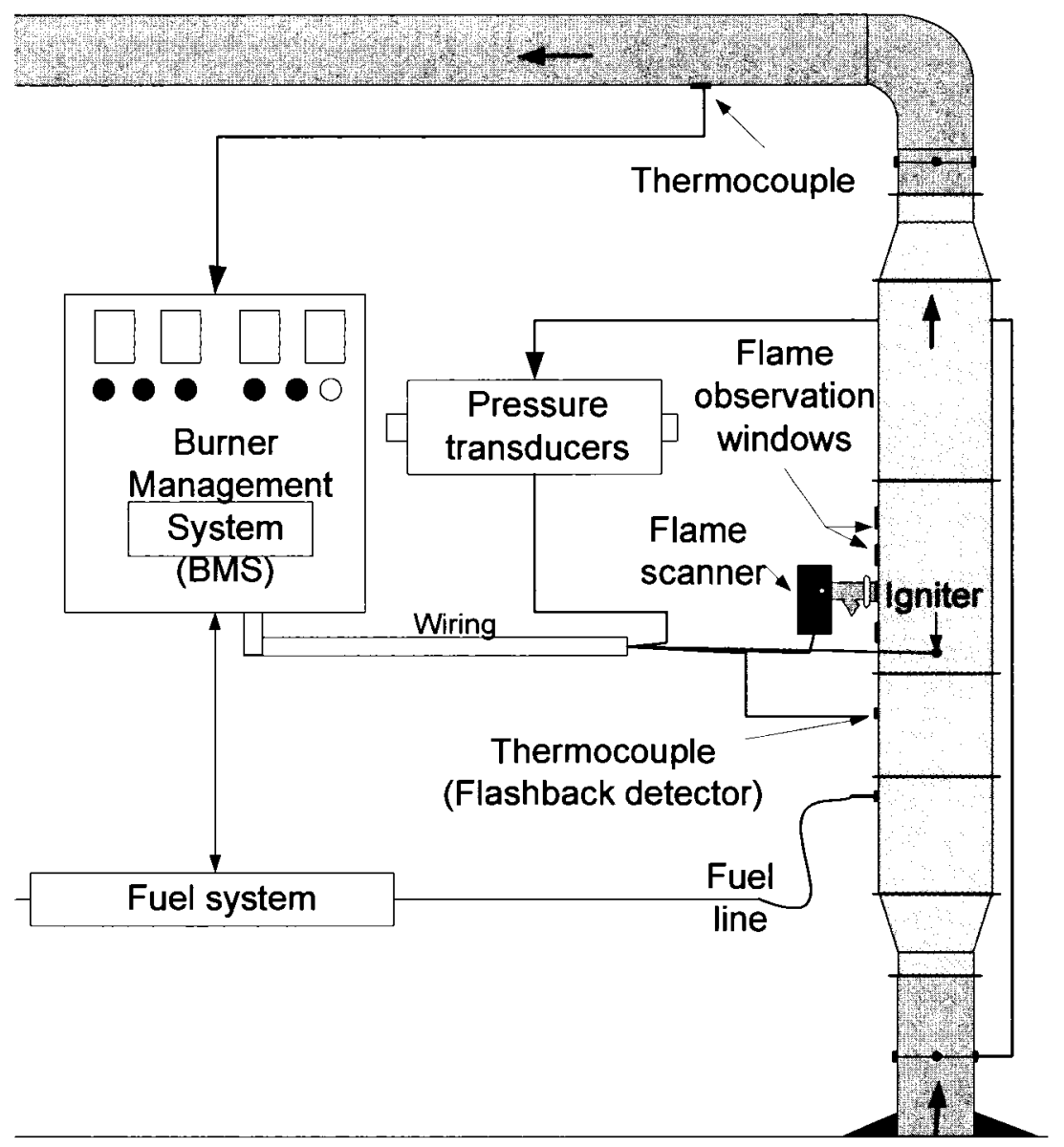

Figure 7.1: Duct burner and Management system components

\subsubsection{Combustion zone monitoring system}

This system ensures that safe conditions exist in the combustion region only over the conical wire-mesh burner at all times. The system includes the following components: a microturbine exhaust gases flow switch, a DB exit temperature sensor, a flame scanner, ignition transformer and spark plug. A pressure transducer was used to sense and ensure that the microturbine was running and that the airflow is proven. A K-type thermocouple was used for sensing the exhaust gases temperature 


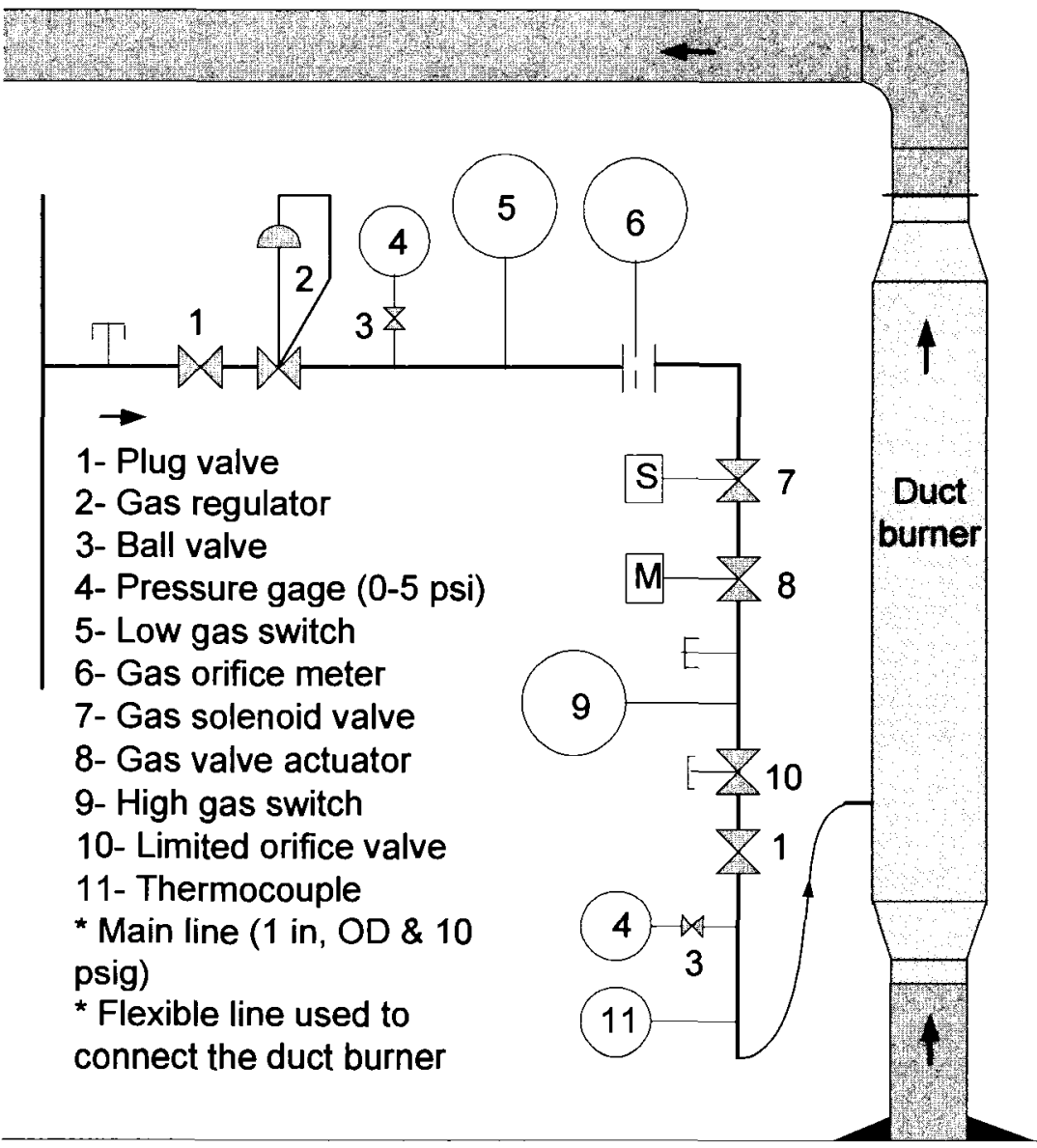

Figure 7.2: Duct burner fuel system

\subsubsection{Ignition}

The fuel was ignited using a standard spark plug which had shown satisfactory performance in another laboratory-scale burner. The spark plug was placed perpendicular to the duct burner longitudinal axis and the spark gap was located inside the conical burner shield and away from the wire-mesh surface to avoid direct spark on the wire-mesh. The spark was powered by a high voltage electric transformer (10,000 volts). 


\subsubsection{Flame scanner}

A Fireye model 65UV5-1000, flame scanner was used for the duct burner management system. The scanner uses an ultraviolet (UV) eye detector. The eye detects the UV emissions (radiation) from the natural gas (methane) flame. For conventional burners, usually the scanner is installed at an angle to the burner centre for the best flame scanner sighting results. In the present investigation, due to the use of the conical wire-mesh burner, the scanner is mounted perpendicular to the duct burner vertical axis so that the scanner line of sight intersects with the blue flame centreline at a slight angle to get the best results. The scanner was mounted on one of the flame viewing windows as shown in Figure 7.1 and Figure 7.3. To keep the scanner temperature in the operating range $\left(-40^{\circ} \mathrm{C}\right.$ to $\left.+65^{\circ} \mathrm{C}\right)$ an air flow of approximately $110 \mathrm{~L} / \mathrm{min}$ was connected to the scanner for purge and cooling.

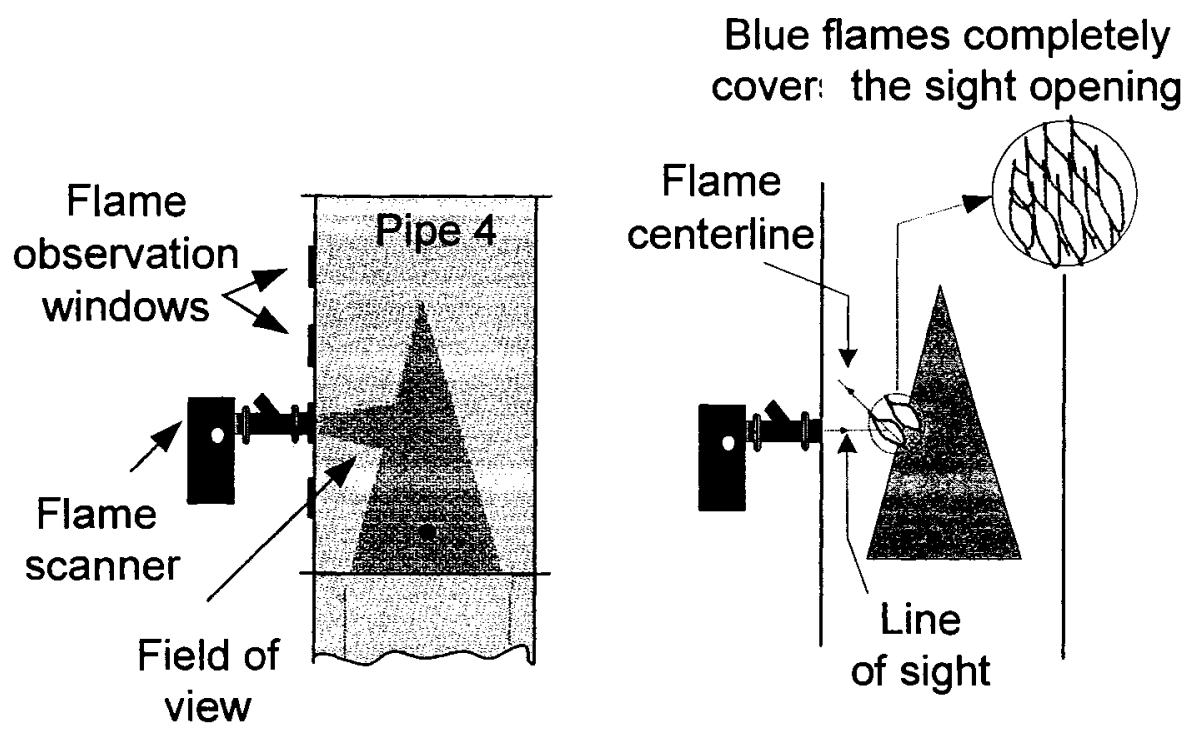

Figure 7.3: Duct burner flame scanner installation 


\subsubsection{Control cabinet}

The duct burner monitoring and control devices, which comprise the fuel delivery and combustion zone monitoring systems described above, are wired to the BMS controller housed in the control cabinet. In addition, the cabinet houses various electric devices such as relays, timers and circuit breakers. Various BMS indicator lights and pushbuttons are mounted in the control cabinet front panel. The BMS controller display is visible through the transparent control cabinet front cover. This display provides more detailed information, where required, for certain BMS operating conditions, such as indicating the specific cause of a Duct Burner trip. Figure 7.4 shows an image of the control cabinet front panel combined with the definition of each control button.

\subsection{Experimental procedure}

This section briefly describes the test procedure followed during the present investigation. The test procedure is discussed in four subsections, the microturbine start-up procedure, the duct burner pre-start-up procedure, BMS operation and duct burner start-up procedure and the combustion test procedure.

\subsubsection{Microturbine start-up procedure}

During all the combustion tests performed in this thesis the microturbine CHP heat recovery water system is dry (no heat recovery) and the heat recovery unit is disabled (this is ensured on the microturbine display). The test procedure starts by activating the microturbine work station and then the necessary inspection of the microturbine (e. g., oil levels) following the inspection guide-lines prepared by the microturbine operator at the CANMET microturbine facility. Then the main manual gas valves for both the microturbine and the duct burner were opened and the line pressure was checked. At this time if every thing is correct the microturbine display panel should show the "READY" sign. Then the START button is pressed. The 
workstation screen shows the turbine pre-start stage. If this step is successfully completed the microturbine will proceed to ramp up to normal operation conditions. The microturbine is allowed to warm-up for a period not less than 30 minutes before starting the duct burner.

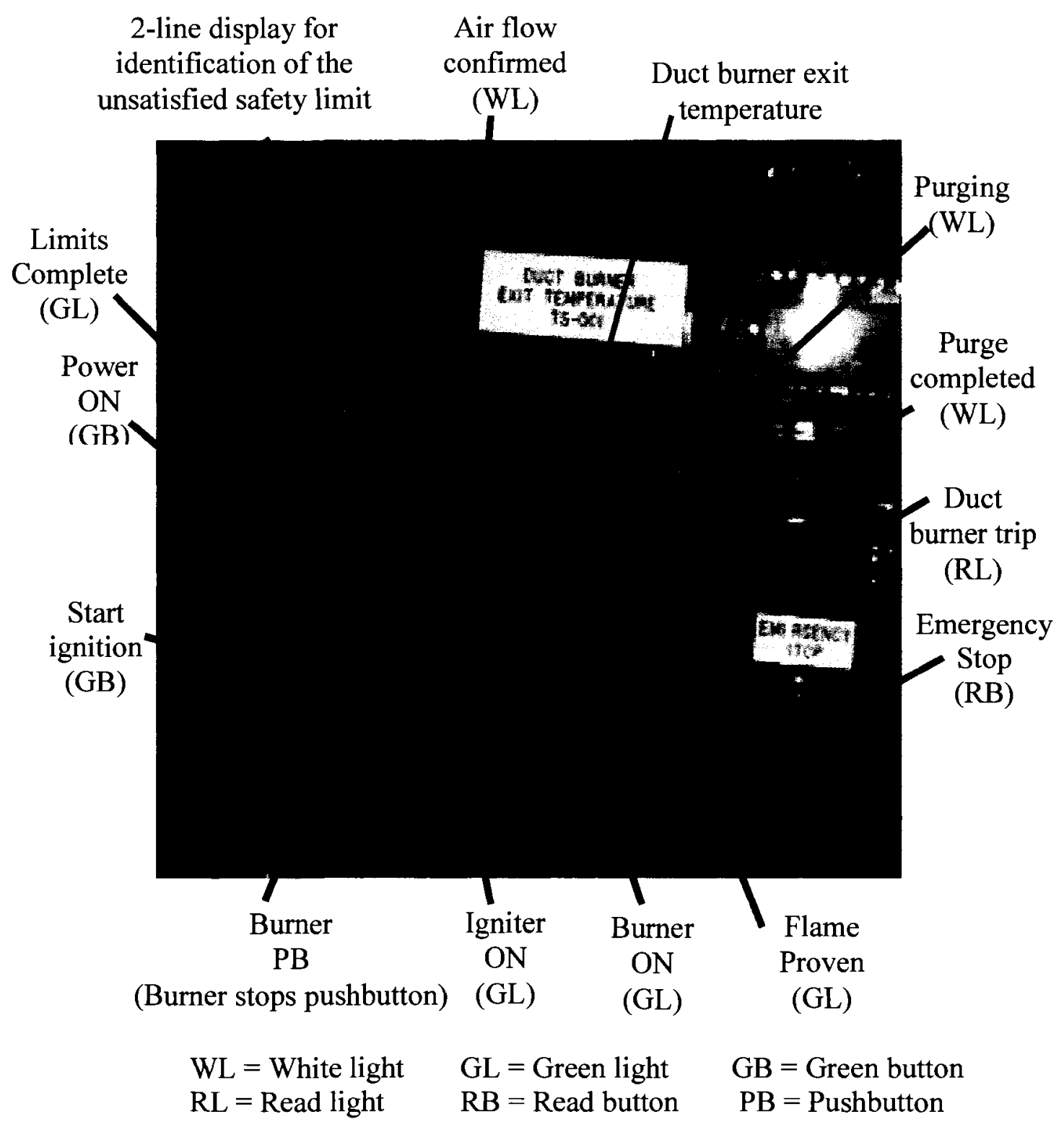

Figure 7.4: Duct burner control cabinet 


\subsubsection{Duct burner pre-start-up procedures}

In the present investigation, a period of 1 hour (from the microturbine start up) was allowed before starting a duct burner combustion test. During this hour the calibration of the combustion analyzer was performed. Also, during this time and before starting the duct burner, a general inspection of the duct burner components and instrumentation was performed. The inspection includes setting the annular blade angle (starting at 0.0 degrees), the instrumentation (i.e., thermocouples, pressure transducers, pitot-static tube all are connected and aligned), sampling probes (connected and aligned) and the scanner purge flow line should be connected. All is ready for the duct burner combustion test. The two secondary manual duct burner gas valves located before and after the gas train are opened and the fuel pressure is adjusted to the operating burner pressure for a fuel-rich mixture $(\sim 3.0 \mathrm{psig})$.

\subsubsection{BMS operation and duct burner start-up procedure}

At this point, it is necessary that the BMS is powered and the green power on the indicator light is illuminated. The green Start Ignition button is pushed. The white Purging indicator light illuminates. After a purge time period of 90 seconds, the white Purge Complete indicator light illuminates. Then the ignition transformer and the Gas Safety Shutoff valves are energized. The ignition transformer remains energized for a period of 10 seconds, with the igniter sparking and the burner fuel valves opened. At the end of the 10 -second ignition period, the flame scanner must successfully detected a flame If this is so, the green Flame Proven and Burner On indicator lights will be illuminated. Once the Duct Burner has been successfully started the test plan can proceed (see Figure 7.4)

\subsubsection{Test procedure}

After the duct burner $\mathbf{O N}$ indicator light was illuminated the duct burner test procedure was started. The flame was observed on the conical wire-mesh burner 
surface via the quartz windows located on the duct burner and the fuel flow rate $( \pm$ $1.7 \%)$ was adjusted (to increase or decrease the firing rate $\left.\left(F R=\dot{m}_{\text {fuel }} \cdot L H V\right)\right)$ to find the stability limits of the burner. The exhaust gas temperature was also monitored and recorded to coincide with the stability of the flame. After the flame was stabilized on the mesh, the emission measurement system was started. After finishing a particular set of conditions the next set of conditions were established by adjusting the exhaust gases flow rate (blade angles) for the test conditions (i.e., 10 degrees) and the same procedure was repeated until the flame could not be stabilized on the mesh surface. At that point, the test conditions were changed (i.e., change the cone, mixer, shield or fuel cap). The general experimental variable parameters used in the present investigation were air-to-fuel ratio, firing rate, inlet temperature, different pressure drop conical wire-mesh burners, different static mixer designs, different conical wire-mesh burner shields and different fuel caps. When changing one of these test configurations the duct burner and the microturbine were shut down and a new test procedure started again.

\subsection{Exhaust gases measurements}

The duct burner was equipped with diagnostic instrumentation to measure the gas composition at the exit of the burner using an extraction probe and analyzer, exhaust gas and duct burner surface temperatures using thermocouples and the duct burner inlet velocity using a pressure probe. The following subsections will describe briefly the instrumentation used for concentration, temperature and velocity measurements. Figure 7.5 shows the different duct burner measurement points used in the combustion tests. 


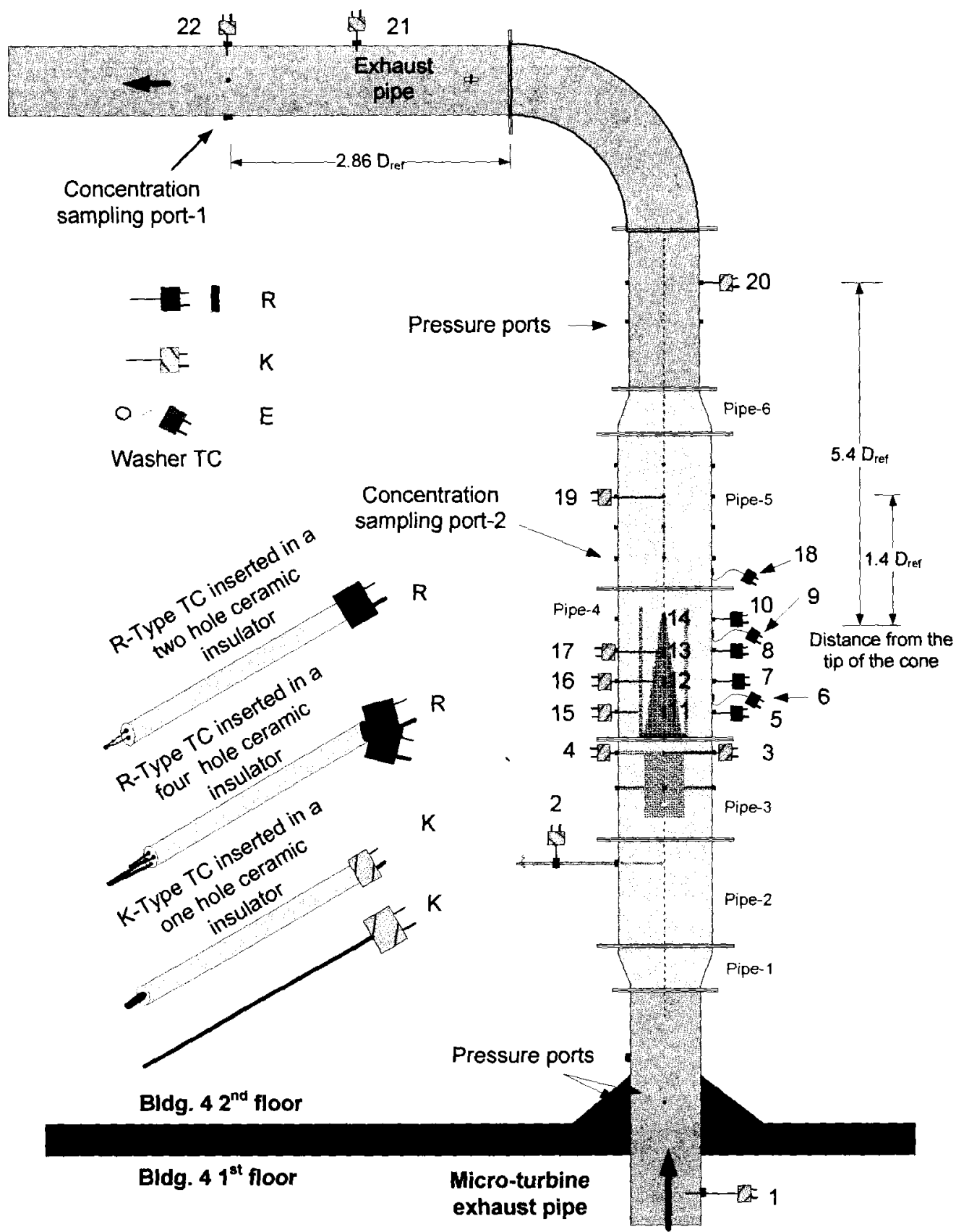

TC-1: DB inlet

TC-3: Premixer exit

TC-15: Outer shield

TC-2: Fuel line

TC-4: Cold matrix surface

TC-16 and 17: Hot matrix

TC-6, 9 and 18: DB surface TC-19, 20, 21 and 22: DB burner exhaust

TC-5, 7, 8, 10, 11, 12, 13 and 14: Combustion zone

"Pressure ports (static pressure taps at the inlet and the exit of the DB)

Figure 7.5: Duct burner pressure and temperature measurement points (combustion test) 


\subsubsection{Exhaust emissions measurement}

NOx and $\mathrm{CO}$ emissions from the duct burner exhaust gases were measured at various operating conditions. A HORIBA model PG-250 portable gas analyzer system was used for the combustion gas analyses. This system simultaneously measures the exhaust gases concentrations of $\mathrm{CO}, \mathrm{CO}_{2}, \mathrm{O}_{2}, \mathrm{NOx}$ and $\mathrm{SO}_{2}$ and uses different analysis principles for measurements (such as the Chemiluminesence method used for NOx measurements). The analyzer has a built-in sample conditioning system with sample pump (4 liters per minute), filters and a thermoelectric cooler. Table 7.1 shows the detailed specifications of the PG-250 analyzer. In this analyzer the hot gas was extracted from the exhaust duct by the sampling probe and transported via the sample line to the portable gas conditioning and sampling system (M\&C, model PSS-5) for treatment prior to introduction into the analyzer. The treatment includes removal of particulate matter and water vapour from the sample in addition to cooling it to the instrument temperature. The Horiba analyzer was connected to a data acquisition system that recorded the emissions data (it can be connected directly to a laptop via the RS-232C port).

To maintain the accuracy of the concentration measurements in the present work, the analyzer was calibrated at the start and at the end of each test setting. Two forms of drift calibrations were performed, the zero and the span drift. Zero drift is defined as the change of the zero reading of the analyzer due to a change in ambient condition, while span drift adjust for the change in the sensitivity of the analyzer with a change in ambient conditions. To carry out zero calibration a zero gas (Nitrogen, $\mathrm{N}_{2}$ ) was fed into the analyzer and readings for $\mathrm{NOx}, \mathrm{SO}_{2}, \mathrm{CO}, \mathrm{CO}_{2}$ and $\mathrm{O}_{2}$ were set to zero. For the span calibration, a bottle containing a gas a mixture of $\mathrm{NOx}, \mathrm{SO}_{2}, \mathrm{CO}$, $\mathrm{CO}_{2}$ and $\mathrm{O}_{2}$ was used. Table 7.1 shows the span gas concentration used. 
Table 7.1: HORIBA-PG-250 gas analyzer specifications and calibration gas concentrations

\begin{tabular}{|c|c|c|c|c|c|c|}
\hline \multicolumn{2}{|c|}{ Component measured } & \multicolumn{5}{|c|}{5 components, $\mathrm{NOx}, \mathrm{SO}_{2}, \mathrm{CO}, \mathrm{CO}_{2}$ and $\mathrm{O}_{2}$} \\
\hline \multirow{3}{*}{\multicolumn{2}{|c|}{ Analysis principle }} & \multicolumn{5}{|c|}{ NOx: Chemiluminescence (CLD) } \\
\hline & & \multicolumn{5}{|c|}{$\mathrm{SO}_{2}, \mathrm{CO}$ and $\mathrm{CO}_{2}:(\mathrm{NDIR})$} \\
\hline & & \multicolumn{5}{|c|}{$\mathrm{O}_{2}:$ Galanic cell } \\
\hline \multirow{5}{*}{ Range } & $\mathrm{CO}_{2}$ & \multicolumn{3}{|c|}{$0-5 / 10 / 20$ vol\% } & \multicolumn{2}{|l|}{ (3 ranges) } \\
\hline & $\mathrm{O}_{2}$ & \multicolumn{3}{|c|}{$0-5 / 10 / 25$ vol\% } & \multicolumn{2}{|l|}{ (3 ranges) } \\
\hline & $\mathrm{SO}_{2}$ & \multicolumn{3}{|c|}{$0-200 / 500 / 1000 / 3000 \mathrm{ppm}$} & \multicolumn{2}{|l|}{ (4 ranges) } \\
\hline & $\mathrm{NOx}$ & \multicolumn{3}{|c|}{$0-25 / 50 / 100 / 250 / 500 / 1000 / 2500 \mathrm{ppm}$} & \multicolumn{2}{|l|}{ (7 ranges) } \\
\hline & $\mathrm{CO}$ & \multicolumn{3}{|c|}{$0-200 / 500 / 1000 / 2000 / 5000 \mathrm{ppm}$} & \multicolumn{2}{|l|}{ (5 ranges) } \\
\hline \multicolumn{2}{|l|}{ Drift } & \multicolumn{5}{|c|}{ $\pm 1.0 \%$ of F.S./Day, $\left(\mathrm{SO}_{2}: \pm 2.0 \%\right.$ of F.S./Day) } \\
\hline \multicolumn{2}{|c|}{ Linearity } & \multicolumn{5}{|c|}{ $\pm 2 \%$ of F.S. } \\
\hline \multicolumn{2}{|c|}{ Repeatability } & \multicolumn{5}{|c|}{$\begin{array}{l} \pm 0.5 \% \text { of } \mathrm{F} . \mathrm{S} . \text { ( } \mathrm{NOx} \leq 100 \mathrm{ppm} \text { range, } \mathrm{CO} \leq 1000 \mathrm{ppm} \text { range) } \\
1.0 \% \text { of F.S. }\end{array}$} \\
\hline \multicolumn{2}{|c|}{ Response time } & \multicolumn{5}{|c|}{$45 \mathrm{sec}$ or less $\left(\mathrm{SO}_{2}\right.$ only : $240 \mathrm{sec}$ or less) } \\
\hline \multicolumn{2}{|c|}{ Sample gas flow rate } & \multicolumn{5}{|c|}{ Approx $0.4 \mathrm{~L} / \mathrm{min}$} \\
\hline \multicolumn{2}{|c|}{ Sample gas condition } & \multicolumn{5}{|c|}{ Temperature: less than $40^{\circ} \mathrm{C}$} \\
\hline \multicolumn{7}{|c|}{ Calibration gas concentration } \\
\hline \multicolumn{2}{|c|}{ Calibration Gas } & NOx [ppm] & $\mathrm{SO}_{2}[\mathrm{ppm}]$ & $\mathrm{CO}[\mathrm{ppm}]$ & $\mathrm{CO}_{2}[\%]$ & $\mathrm{O}_{2}[\%]$ \\
\hline \multicolumn{2}{|c|}{ Concentration } & 22.6 & 197 & 27.8 & 9.99 & 20.9 \\
\hline \multicolumn{2}{|c|}{ Analyzer Uncertainty } & $\pm 5 \%$ & $\pm 3 \%$ & $\pm 2 \%$ & $\pm 2 \%$ & \\
\hline
\end{tabular}

Emissions limits are generally expressed in parts per million, corrected to a specific $\mathrm{O}_{2}$ level to remove the effects of dilution so that a true comparison of emissions can be performed [Turns (2000)]. A typical standard would require that emissions be reported in parts per million, on a dry basis, corrected to a 15 percent $\mathrm{O}_{2}$ value to which the concentration is corrected as defined by regulation. All reported concentrations (NOx and $\mathrm{CO}$ emissions) in this thesis are corrected to a 15 percent $\mathrm{O}_{2}$ (oxygen) and expressed on a dry basis. The following formula was used for the correction [Ganapathy (2003), Jahnke (2000), Yegian et al. (1998) Santoni et al. (2002)]:

$$
\text { Corrected }[\mathrm{ppm}]=\text { Measured }[\mathrm{ppm}] \times \frac{20.9-\mathrm{O}_{2}(\text { reference })}{20.9-\mathrm{O}_{2}(\text { measured })}
$$


where $\mathrm{O}_{2}$ (reference) is the oxygen reference level (15 percent $\mathrm{O}_{2}$ in the present work), Corrected [ppm] is the corrected gas concentration in ppm (e.g., to 15 percent $\mathrm{O}_{2}$ ) and Measured [ppm] is the measured gas concentration in ppm

The exhaust gases were sampled using a $6 \mathrm{~mm}(0.25 \mathrm{inch})$ diameter stainless steel sampling tube through the concentration sampling port number 1 shown in Figure 7.5. The flow was drawn through an approximately 1 meter long, $6 \mathrm{~mm}(0.25$ inch) diameter Teflon tube into the conditioning system and then to the analyzer using Teflon tube.

Before finalizing the sampling plane location, the exhaust gas concentration measurements were performed by traversing the sampling probe on a line that passes through the centroid of the exhaust duct. This measurement was performed to avoid any bias due to sampling probe location and stratification in gas concentration [Jahnke (2000)].

The following two subsections describe briefly the two main pollutants measured in this investigation.

\subsubsection{Carbon Monoxide (CO)}

Carbon monoxide is a very toxic odourless and colorless gas. It blocks the supply of oxygen to the body tissue, which could lead to suffocation. Carbon monoxide is generated when combustion occurs under oxygen-deficient conditions. Thus, $\mathrm{CO}$ is mainly generated when fuel rich mixtures are burned. However, even under lean conditions, $\mathrm{CO}$ occurs because of incomplete combustion. The effect of the different duct burner parameters on $\mathrm{CO}$ emissions will be presented in Chapter 8 . The emission levels of $\mathrm{CO}$ should be within acceptable limits at all operating conditions (less than $10 \mathrm{ppm}$ at 15 percent $\mathrm{O}_{2}$ ) 


\subsubsection{Nitrogen Oxides}

Nitrogen Oxides mainly occur in the form of nitric oxide (NO) and nitrogen dioxide $\left(\mathrm{NO}_{2}\right)$. Nitrogen dioxide is reddish-brown with a pungent smell and toxic, damaging the lung tissue. Nitric oxide is odourless and colorless and relatively harmless, as compared to $\mathrm{NO}_{2}$. Both nitrogen oxides $\left(\mathrm{NOx}=\mathrm{NO}+\mathrm{NO}_{2}\right)$, play an important role in the formation of acid rain, photochemical smog and the depletion of the ozone layer. See Appendix A for more details. Similar to CO, the effect of the different duct burner parameters on duct burner NOx emissions will be presented and discussed in Chapter 8. The emission level of NOx should be within acceptable limits at all operating conditions (less than $10 \mathrm{ppm}$ at 15 percent $\mathrm{O}_{2}$ ).

\subsubsection{Temperature measurements}

Temperature is one of the key quantities in combustion research. The knowledge of the accurate temperature and the distribution of the temperature within the combustion system are of great interest. In the present work, gas temperature profiles at the exit section of the burner are made to confirm the required exhaust gases temperature in the range 500 to $700^{\circ} \mathrm{C}$. As well, monitoring the temperature in the combustion zone is needed to achieve single digit NOx emissions (flame temperature must be less than $1800 \mathrm{~K}$ to reduce thermal NOx).

Of the variety of methods available for temperature measurement, the most common electric-based sensors are thermocouples (point measurement device). A thermocouple is a thermoelectric sensor made of standardized materials and is identified by a type letter rather than by proprietary names (E, J, K, R, etc.). Thermocouples have been used in a great number of published papers to measure the gas temperature in the combustion zones of porous burners [e.g., Hus et al. (1993a), Speyer et al. (1996), Rumminger and Dibble (1996), Kataoka (1998), JugJai et al. (2002) and Greenberg et al. (2005)]. Among the rare metal thermocouples used, the R-type, platinum versus platinum 13 per cent rhodium (Pt-Pt/13\% Rh) is the most 
common and accurate thermocouple combination for applications up to about $1800^{\circ} \mathrm{C}$ [Gupta and Lilley, (1985)].

Thermocouples were used to measure and monitor the temperature during duct burner combustion tests. Three types of thermocouples were used in this study; (1) R-type, (2) K-type and (3) E-type. Table 7.2 presents some of the general properties of these thermocouple types. Figure 7.5 schematically illustrates the different temperature measurement points and different types of thermocouples used in this study. In addition, Figure 7.6 shows in greater details, the thermocouple locations around the conical mesh burner.

Table 7.2: Characteristics of thermocouples used

\begin{tabular}{|c|l|c|c|}
\hline $\begin{array}{l}\text { Thermocouple } \\
\text { Type }\end{array}$ & Materials & $\begin{array}{l}\text { Temperature } \\
\text { Range }(\mathrm{K})\end{array}$ & Limits of error \\
\hline $\mathrm{E}$ & Chromel/Constantan & $3-1150$ & $\begin{array}{c} \pm 1.7^{\circ} \mathrm{C} \\
( \pm 0.5 \%)\end{array}$ \\
\hline $\mathrm{K}$ & Chromel/Alumel & $3-1530$ & $\begin{array}{c} \pm 2.2^{\circ} \mathrm{C} \\
( \pm 0.75 \%)\end{array}$ \\
\hline R & Platinum-13\% Rhodium/Platinum & $223-1800$ & $\begin{array}{c} \pm 1.5^{\circ} \mathrm{C} \\
( \pm 0.25 \%)\end{array}$ \\
\hline $\begin{array}{l}\text { Chromel = Nickel-Chromium alloy Constantan = Copper-Nickel alloy } \\
\text { Alumel = Nickel-Aluminium alloy } \\
\text { This information was taken from the thermocouple supplier web site (www.omega.ca) }\end{array}$ \\
\hline
\end{tabular}

Fine bead thermocouples (0.25 and $0.38 \mathrm{~mm}$ diameter type $\mathrm{R}(\mathrm{Pt}-\mathrm{Pt} / 13 \% \mathrm{Rh})$ ) were used to measure the exhaust gas temperature in the combustion zone. These fine thermocouples were protected by ceramic sleeves (see Figure 7.5). The thermocouple measurement ports are placed at four levels, separated by $10 \mathrm{~cm}$ and arranged in 3 columns, separated by 90 degrees. At each level two different bead diameters were used. Assuming the duct burner has an axi-symmetric geometry, the two temperature measurements at the same point can be used to estimate the radiation correction for the measurements [Zhuang et al. (1998) and Rumminger et al. (1996)]. 


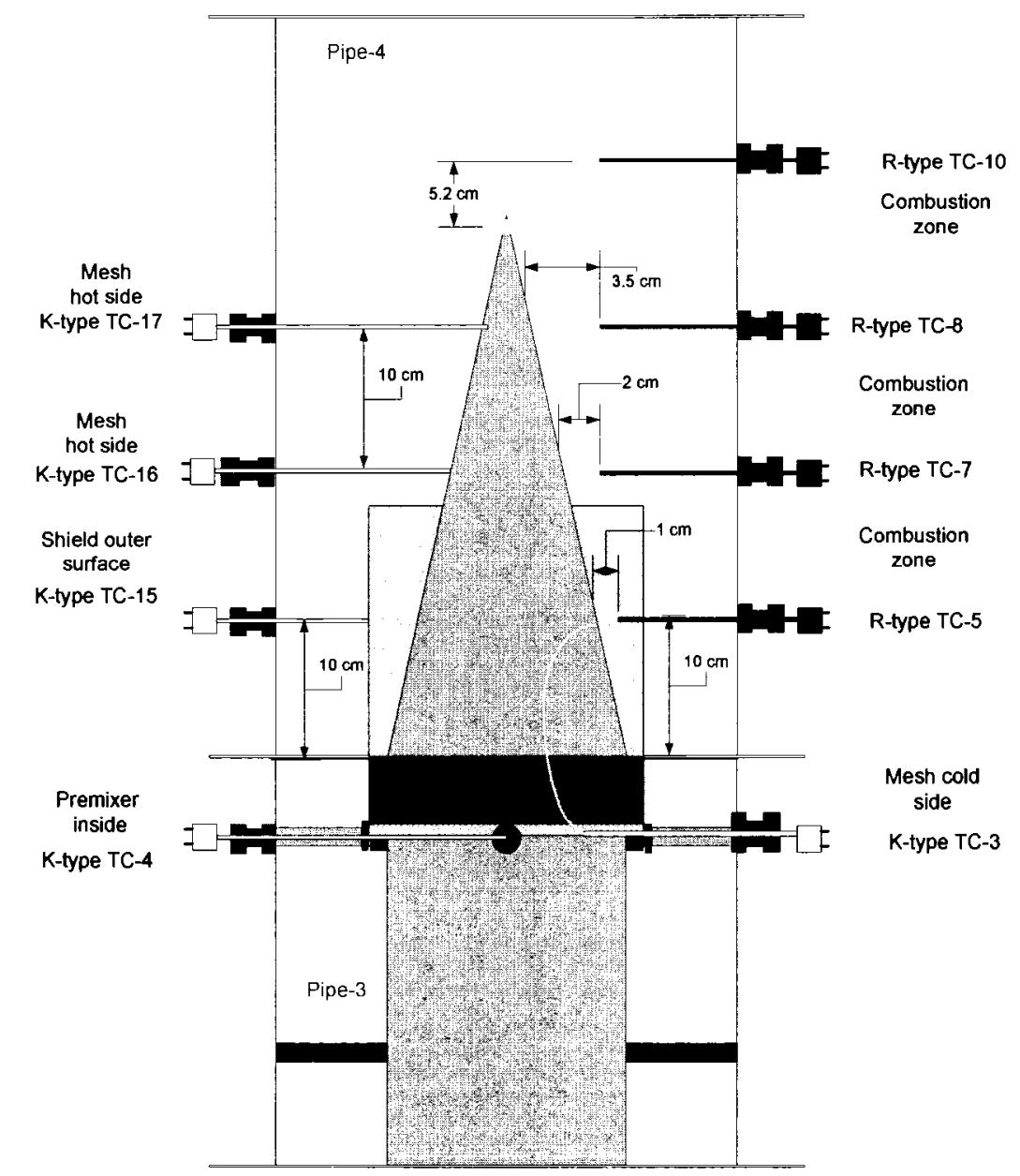

Figure 7.6: Conical burner thermocouple locations

This thermocouple arrangement was used on two pipes of the duct burner housing: Pipe 4 and Pipe 5. K-type thermocouples were used to measure the duct burner inlet and exit temperatures, the fuel temperature, the premixer exit temperature and the conical burner surface temperature. The thermocouple used to measure the hot side of the conical wire-mesh burner was K-type. It measures the mesh surface temperature by simply touching the surface. The remaining part of this thermocouple was insulated within a single bore ceramic cylinder, which in turn was housed within a stainless steel protective tube. The thermocouple used to measure the premixer exit 
temperature was also used to detect the occurrence of flashback. E -Type washer thermocouples were used to measure the duct burner housing surface temperatures at two locations on Pipe 4 (conical burner housing) and one location on Pipe 5. All the thermocouples used were manufactured by OMEGA. Following Al-Shemmeri et al. (1992) and Al-Shemmeri et al. (1985), a basic calibration procedure was performed prior to starting combustion tests in which each thermocouple was tested in an ice bath at $0{ }^{\circ} \mathrm{C}$. Then the span was tested in boiling water, $100{ }^{\circ} \mathrm{C}$, as a hot reference. This procedure was used as a system calibration (thermocouples and data acquisition).

The different temperature terms which will be used during the discussion in Chapter 8 are defined in Table 7.3. The table also describes the function of each thermocouple number illustrated in Figure 7.5. The number of the thermocouples will be used during the discussion of the combustion results. The following is a description of the method of the measurement technique.

For the duct burner inlet temperature measurement, the tip of the thermocouple TC-1 was located at the duct centre. The temperature of the unburned mixture (oxidant and the fuel) was measured at the exit of the premixer where the TC was located at the centre of mixing duct. The conical wire-mesh burner inside surface temperature was measured via TC-4, which was placed touching the inner surface at a point located approximately $10 \mathrm{~cm}$ above the conical burner base.

The conical wire-mesh burner downstream surface temperature (hot surface or combustion zone side temperature) was measured using TC-17. This TC was made to touch the outer surface at a point located $30 \mathrm{~cm}$ above the cone base (see Figure 7.6). In Chapter 8 the combustion zone temperature was used to indicate the presence of the flame and it was measured using three pairs of TCs as stated in Table 7.3 and shown in Figure 7.6. Two different bead sizes (R-type (Pt/Pt-13\%Rh) are used in each pair. The temperature beads were located in the flame and approximately $1.0 \mathrm{~cm}$ above the mesh surface for the pair TC-5 and $11,2.0 \mathrm{~cm}$ for TC-7 and 12 and $3.5 \mathrm{~cm}$ for TC-8 and 13. The two different readings were used to extrapolate to zero bead 
size to correct for losses [Zhuang et al. (1998) and Rumminger et al. (1996)]. The duct burner exhaust gas temperature was measured at different locations as shown in Figure 7.5. Only two measurement locations, TC-19 and TC-20, are used in the discussion in Chapter 8. TC-19 was placed at the centre of the duct at a plane located $1.4 \mathrm{D}_{\text {ref }}$ above the conical wire-mesh burner. The tip of TC-20 was located at the exhaust duct centre. TC-15 was used to measure the conical burner shield outer surface temperature (bypass flow side). The tip of TC-15 was made to touch the shield surface at a point located approximately $10 \mathrm{~cm}$ above the conical burner base (see Figure 7.6).

Table 7.3: Description of each thermocouple number illustrated in Figure 7.5

\begin{tabular}{|l|l|l|l|l|}
\hline $\begin{array}{l}\text { Thermocouple } \\
\text { No. }\end{array}$ & $\begin{array}{l}\text { Symbol used } \\
\text { in Chapter } 8\end{array}$ & $\begin{array}{l}\text { Temperature } \\
\text { Measured }\end{array}$ & $\begin{array}{l}\text { Measur- } \\
\text { ement type }\end{array}$ & $\begin{array}{l}\text { TC } \\
\text { type }\end{array}$ \\
\hline TC-1 & $T_{\text {inlet }}$ & duct burner inlet & Point & K-type \\
\hline TC-2 & $T_{\text {fuel }}$ & Fuel line & Point & K-type \\
\hline TC-3 & $T_{\text {premixer }}$ & $\begin{array}{l}\text { (Oxidant-fuel) mixture } \\
\text { at the premixer exit plane }\end{array}$ & Point & K-type \\
\hline TC-3 & $T_{\text {premixer-traverse }}$ & $\begin{array}{l}\text { (Oxidant-fuel) mixture } \\
\text { at the premixer exit plane }\end{array}$ & Traverse & K-type \\
\hline TC-4 & $T_{\text {cold }}$ & $\begin{array}{l}\text { Conical burner inner surface } \\
\text { (upstream) }\end{array}$ & Point & K-type \\
\hline TC-15 & $T_{\text {shield }}$ & $\begin{array}{l}\text { Conical burner shield outer } \\
\text { surface (facing the bypass flow) }\end{array}$ & Point & K-type \\
\hline $\begin{array}{l}\text { TC-16 } \\
\text { TC-17 }\end{array}$ & $\begin{array}{l}\text { Conical burner outer surface } \\
\text { (downstream, the hot side) }\end{array}$ & Point & K-type \\
\hline $\begin{array}{l}\text { TC-(5, 11) } \\
\text { TC-(7, 12) } \\
\text { TC-(8, 13) }\end{array}$ & $T_{c z}$ & $\begin{array}{l}\text { Combustion zone (level-1) } \\
\text { Combustion zone (level-2) } \\
\text { Combustion zone (level-3) }\end{array}$ & $\begin{array}{l}\text { Point } \\
\text { Point } \\
\text { point }\end{array}$ & $\begin{array}{l}\text { R-type } \\
\text { R-type } \\
\text { R-type }\end{array}$ \\
\hline TC-19 & $\begin{array}{l}T_{\text {exhaust-1 }} \\
T_{\text {exhaust-1-traverse }}\end{array}$ & $\begin{array}{l}\text { DB exhaust gases } \\
\text { DB exhaust gases }\end{array}$ & $\begin{array}{l}\text { Point } \\
\text { Traverse }\end{array}$ & K-type \\
\hline TC- 20 & $T_{\text {exhaust-2 }}$ & DB exhaust gases & point & K-type \\
\hline TC-6, 9 and 18 & $T_{\text {DBHOS }}$ & DB housing outer surface & point & E-type \\
\hline $\begin{array}{l}\text { Temperature measurements are not used in the discussion of chapter 8: TC-(7, 12), TC-(8, } \\
\text { 13), TC-16 and TC-6, 9 and 18 }\end{array}$ &
\end{tabular}


Traverse temperature measurements were conducted at two specific locations for certain test conditions during the combustion tests. One was made at a plane located 1.4 $\mathrm{D}_{\text {ref }}$ above the conical wire-mesh burner (TC-19, $T_{\text {exhaust-1-traverse }}$ ) to investigate the level and the uniformity of the temperature at that specific plane. The second traverse location was at the premixer exit plane (TC-3, $T_{\text {premixer-traverse }}$ ) to measure the fuel-oxidant mixture temperature. This was also used to investigate the level of mixing between the fuel jets and the swirling oxidant flow. Both traverse measurements were conducted using a K-type thermocouple. In addition to these two locations, the exhaust gas temperature at the gas sampling plane was also traversed to investigate the temperature distribution (uniformity) at that plane.

\subsubsection{Duct burner inlet velocity measurement}

The same pressure probe (pitot-static tube) used during the flow balancing test, was used to measure the duct burner inlet velocity during the combustion tests. In this test the pressure probe was not traversed across the duct burner inlet cross section but kept at the same point which was selected to give representative flow results. One velocity traverse was made at the concentration measurement location plane to investigate flow stratification. 


\section{CHAPTER 8: Combustion tests results and discussion}

\subsection{Introduction}

The goal of the combustion tests was to establish the operating characteristics

of the duct burner, namely (1) the range of firing rates $\left(F R=\dot{m}_{\text {fuel }} \cdot L H V\right)$ over which stable surface combustion occurs and produces low NOx and CO emissions; and (2) NOx and CO emissions as well as overall pressure drop over a wide range of operating conditions. The results presented in this chapter are part of a larger data package collected throughout this research project. The complete set of measured data is available in the appendices, but to reduce the length of this chapter, only the cases needed to complete the analysis and draw conclusions are included here. In these extensive parametric tests, the effect of the variation of the different configurations and operating conditions (e.g., shield length, mixer, fuel cap, blade angle and pressure drop) on NOx and $\mathrm{CO}$ emissions, and flame stability were determined. In this investigation, duct burner performance includes NOx and $\mathrm{CO}$ emissions, overall duct burner pressure drop, DB exhaust gas temperature and the stable operating range.

During the test period, the heat recovery unit in the CHP unit was disabled, except when the effect of varying the duct burner inlet temperature was investigated. The exhaust gases from the microturbine had the following measured characteristics (duct burner inlet conditions); 226 to $230^{\circ} \mathrm{C}$ exit temperature (depending on the microturbine inlet conditions), oxygen-rich concentration (18 to 19 percent by volume), low NOx emissions (1 to $1.4 \mathrm{ppm}$ ), low CO emissions ( 3.5 to $5 \mathrm{ppm}$ ), and, depending on the geometric setting used, the exhaust gases entered the duct burner with a velocity of 16 to $19 \mathrm{~m} / \mathrm{s}$. All NOx and CO emissions values presented in this thesis were corrected to 15 percent oxygen on a dry basis. These values are for the 
duct burner only (i.e., incremental to the microturbine emissions), unless otherwise stated.

\subsection{Preliminary combustion tests}

Similar to the LSI and flow balancing tests (Chapter 5 and Chapter 6), the first phase of the combustion tests consisted of preliminary tests. These tests were performed for a selected geometrical setting to verify the functionality of the different parts of the burner system. These tests also served to verify the data acquisition system and to determine the confidence in the data collected during the main combustion tests. These preliminary tests helped to define the following steps: the test procedures, gas analyzer calibration and sampling procedures and uncertainty, and DB operational limitations. Appendix $G$ describes some of the preliminary combustion tests and measurement practices conducted during this investigation.

\subsection{Combustion test limits}

One of the results of the preliminary combustion tests (Appendix G) was the determination of the combustion test limits. There were three limits of interests during this study. The blow-off limit is the minimum firing rate for each configuration providing stable operation. Below this limit, the flame cannot be stabilized and blow-off occurs. Second, the upper emissions limit for NOx must be less than $10 \mathrm{ppm}$ as set in the design requirements for the DB. Third, the overall duct burner pressure drop throughout the entire test period was limited to a value of less than $249 \mathrm{~Pa}\left(1.0\right.$ in $\left.\mathrm{H}_{2} \mathrm{O}\right)$. Finally, the last limitation was dictated by the fuel pressure available at the test location (specifically, $4.3 \mathrm{psig}$ ). The fuel line pressure and the fuel cap size limit the amount of fuel flow. 


\subsection{Combustion test experimental matrix}

The experimental matrix used for the combustion tests is presented in Table 8.1 for Mix-1/1 and Table 8.2 for Mix-2/2. Each experimental run listed in these tables was performed at different annular flow control blade angles (AFCBA). Unlike the flow balancing test presented in Chapter 6, the combustion tests were performed at AFCBA of $0^{\circ}, 10^{\circ}, 20^{\circ}, 30^{\circ}, 40^{\circ}$ and $50^{\circ}$. Depending on the case tested, the maximum AFCBA value was varied between 30, 40 and 50 degrees. For each case, above a certain maximum AFCBA value, the flame never stabilized on the conical wire-mesh burner. Furthermore, the DB overall pressure drop increased with the presence of combustion and exceeded the limit value (249 $\mathrm{Pa}$ or 1.0 in $\mathrm{H}_{2} \mathrm{O}$ ) at angles higher than 50 degrees. In some of the runs, the combustion tests were difficult to perform due to unstable combustion. This happened with a few cases where Sh1, Sh7 and Sh8 were used. Sh1 is the shortest shield and had a BR value of 0.4 , while both Sh7 and Sh8 had a BR value of 0.6. These cases will be discussed during the presentation of the results. In addition to the number of runs listed in Table 8.1 and Table 8.2, additional runs were performed to check the repeatability of the test results. A number of runs were also conducted to study the effect of the duct burner inlet temperature on its performance.

\subsection{Results and Discussion}

During this phase, great efforts were made to facilitate the variation of operating parameters to determine their effect on the performance of the duct burner. Combustion tests were conducted in which the effect of the variation of the different duct burner geometrical and physical parameters on NOx and $\mathrm{CO}$ emissions, overall duct burner pressure drop and flame stability were determined. The presentation of the results will be divided in two main parts, each part covering the results for one mixer. The results of each mixer will be divided into two main subsections in which fuel caps Cap-2 and Cap-4 will be covered. The results of the selected fuel caps will 
be presented in this chapter to cover the stable operating range the duct burner achieved during this evaluation. Cap-3 was used to study the difference in duct burner performance when the duct burner inlet temperature was reduced (heat recovery system enabled). Cap-3 results were used in the summary section for some of the comparisons, but the complete results for Cap-3 are presented in Appendix G. All the results presented in this chapter in graphic form are accompanied by flame images for qualitative assessment. As mentioned in Chapter 7, during the tests, the temperature of the duct burner was measured at different locations for monitoring and analysis purposes. Selected temperature profiles for some of the cases will be presented in this section to assist in the understanding of the different results during this investigation. For the different temperature symbols used in this chapter and the locations of the related temperature measurements refer to Figure 7.5 and Table 7.3.

Table 8.1: Experimental matrix used in the combustion tests for Mix-1/2

\begin{tabular}{|l|l|l|l|l|l|l|l|l|l|}
\hline Run & Mixer & $\begin{array}{l}\text { Fuel } \\
\text { cap }\end{array}$ & Cone & $\begin{array}{l}\text { Cone } \\
\text { shield }\end{array}$ & $\begin{array}{l}\text { R. } \\
\text { no }\end{array}$ & Mixer & $\begin{array}{l}\text { Fuel } \\
\text { cap }\end{array}$ & Cone & $\begin{array}{l}\text { Cone } \\
\text { shield }\end{array}$ \\
\hline $\mathbf{1}$ & Mix-1/2 & Cap-2 & Cone-1 & Sh1 & $\mathbf{1 9}$ & Mix-1/2 & Cap-4 & Cone-1 & Sh1 \\
\hline $\mathbf{2}$ & Mix-1/2 & Cap-2 & Cone-1 & Sh2 & $\mathbf{2 0}$ & Mix-1/2 & Cap-4 & Cone-1 & Sh2 \\
\hline $\mathbf{3}$ & Mix-1/2 & Cap-2 & Cone-1 & Sh3 & $\mathbf{2 1}$ & Mix-1/2 & Cap-4 & Cone-1 & Sh3 \\
\hline $\mathbf{4}$ & Mix-1/2 & Cap-2 & Cone-2 & Sh1 & $\mathbf{2 2}$ & Mix-1/2 & Cap-4 & Cone-1 & Sh4 \\
\hline $\mathbf{5}$ & Mix-1/2 & Cap-2 & Cone-2 & Sh2 & $\mathbf{2 3}$ & Mix-1/2 & Cap-4 & Cone-1 & Sh7 \\
\hline $\mathbf{6}$ & Mix-1/2 & Cap-2 & Cone-2 & Sh3 & $\mathbf{2 4}$ & Mix-1/2 & Cap-4 & Cone-1 & Sh8 \\
\hline $\mathbf{7}$ & Mix-1/2 & Cap-2 & Cone-3 & Sh1 & $\mathbf{2 5}$ & Mix-1/2 & Cap-4 & Cone-2 & Sh1 \\
\hline $\mathbf{8}$ & Mix-1/2 & Cap-2 & Cone-3 & Sh2 & $\mathbf{2 6}$ & Mix-1/2 & Cap-4 & Cone-2 & Sh2 \\
\hline $\mathbf{9}$ & Mix-1/2 & Cap-2 & Cone-3 & Sh3 & $\mathbf{2 7}$ & Mix-1/2 & Cap-4 & Cone-2 & Sh3 \\
\hline $\mathbf{1 0}$ & Mix-1/2 & Cap-3 & Cone-1 & Sh1 & $\mathbf{2 8}$ & Mix-1/2 & Cap-4 & Cone-2 & Sh4 \\
\hline $\mathbf{1 1}$ & Mix-1/2 & Cap-3 & Cone-1 & Sh2 & $\mathbf{2 9}$ & Mix-1/2 & Cap-4 & Cone-2 & Sh7 \\
\hline $\mathbf{1 2}$ & Mix-1/2 & Cap-3 & Cone-1 & Sh3 & $\mathbf{3 0}$ & Mix-1/2 & Cap-4 & Cone-2 & Sh8 \\
\hline $\mathbf{1 3}$ & Mix-1/2 & Cap-3 & Cone-2 & Sh1 & $\mathbf{3 1}$ & Mix-1/2 & Cap-4 & Cone-3 & Sh1 \\
\hline $\mathbf{1 4}$ & Mix-1/2 & Cap-3 & Cone-2 & Sh2 & $\mathbf{3 2}$ & Mix-1/2 & Cap-4 & Cone-3 & Sh2 \\
\hline $\mathbf{1 5}$ & Mix-1/2 & Cap-3 & Cone-2 & Sh3 & $\mathbf{3 3}$ & Mix-1/2 & Cap-4 & Cone-3 & Sh3 \\
\hline $\mathbf{1 6}$ & Mix-1/2 & Cap-3 & Cone-3 & Sh1 & $\mathbf{3 4}$ & Mix-1/2 & Cap-4 & Cone-3 & Sh4 \\
\hline $\mathbf{1 7}$ & Mix-1/2 & Cap-3 & Cone-3 & Sh2 & $\mathbf{3 5}$ & Mix-1/2 & Cap-4 & Cone-3 & Sh7 \\
\hline $\mathbf{1 8}$ & Mix-1/2 & Cap-3 & Cone-3 & Sh3 & $\mathbf{3 6}$ & Mix-1/2 & Cap-4 & Cone-3 & Sh8 \\
\hline
\end{tabular}


Table 8.2: Experimental matrix used in the combustion tests for Mix-2/2

\begin{tabular}{|c|c|c|c|c|c|c|c|c|c|}
\hline $\begin{array}{l}\text { R. } \\
\text { n. }\end{array}$ & Mixer & Cap & Cone & Shield & $\begin{array}{l}\text { R. } \\
\text { n. }\end{array}$ & Mixer & Cap & Cone & Shield \\
\hline 1 & Mix-2/2 & Cap-2 & Cone-1 & Sh1 & 22 & Mix- $2 / 2$ & Cap-4 & Cone-1 & Sh1 \\
\hline 2 & Mix-2/2 & Cap-2 & Cone-1 & Sh2 & 23 & $\mathrm{Mix}-2 / 2$ & Cap-4 & Cone-1 & Sh2 \\
\hline 3 & Mix-2/2 & Cap-2 & Cone-1 & Sh3 & 24 & Mix-2/2 & Cap-4 & Cone-1 & Sh3 \\
\hline 4 & Mix-2/2 & Cap-2 & Cone-1 & Sh4 & 25 & Mix-2/2 & Cap-4 & Cone-1 & Sh4 \\
\hline 5 & Mix-2/2 & Cap-2 & Cone-1 & Sh7 & 26 & $\mathrm{Mix}-2 / 2$ & Cap-4 & Cone-1 & Sh7 \\
\hline 6 & $\mathrm{Mix}-2 / 2$ & Cap-2 & Cone-1 & Sh8 & 27 & $\mathrm{Mix}-2 / 2$ & Cap-4 & Cone-1 & Sh8 \\
\hline 7 & $\mathrm{Mix}-2 / 2$ & Cap-2 & Cone-2 & Sh1 & 28 & $\mathrm{Mix}-2 / 2$ & Cap-4 & Cone-2 & Sh1 \\
\hline 8 & $\mathrm{Mix}-2 / 2$ & Cap-2 & Cone-2 & $\mathrm{Sh} 2$ & 29 & Mix-2/2 & Cap-4 & Cone-2 & Sh2 \\
\hline 9 & $\mathrm{Mix}-2 / 2$ & Cap-2 & Cone-2 & Sh3 & 30 & $\operatorname{Mix}-2 / 2$ & Cap-4 & Cone-2 & Sh3 \\
\hline 10 & $\mathrm{Mix}-2 / 2$ & Cap-2 & Cone-2 & Sh4 & 31 & Mix-2/2 & Cap-4 & Cone-2 & Sh4 \\
\hline 11 & $\mathrm{Mix}-2 / 2$ & Cap-2 & Cone-2 & Sh7 & 32 & $\mathrm{Mix}-2 / 2$ & Cap-4 & Cone-2 & Sh7 \\
\hline 12 & Mix-2/2 & Cap-2 & Cone-2 & Sh8 & 33 & Mix-2/2 & Cap-4 & Cone-2 & Sh8 \\
\hline 13 & $\mathrm{Mix}-2 / 2$ & Cap-2 & Cone-3 & Sh1 & 34 & $\mathrm{Mix}-2 / 2$ & Cap-4 & Cone-3 & Sh1 \\
\hline 14 & $\operatorname{Mix}-2 / 2$ & Cap-2 & Cone-3 & Sh2 & 35 & $\mathrm{Mix}-2 / 2$ & Cap-4 & Cone-3 & Sh2 \\
\hline 15 & Mix-2/2 & Cap-2 & Cone-3 & Sh3 & 36 & $\mathrm{Mix}-2 / 2$ & Cap-4 & Cone-3 & Sh3 \\
\hline 16 & Mix-2/2 & Cap-2 & Cone-3 & Sh4 & 37 & $\mathrm{Mix}-2 / 2$ & Cap-4 & Cone-3 & Sh4 \\
\hline 17 & Mix-2/2 & Cap-2 & Cone-3 & Sh7 & 38 & Mix-2/2 & Cap-4 & Cone-3 & Sh7 \\
\hline 18 & Mix-2/2 & Cap-2 & Cone-3 & Sh8 & 39 & $\mathrm{Mix}-2 / 2$ & Cap-4 & Cone-3 & Sh8 \\
\hline 19 & $\mathrm{Mix}-2 / 2$ & Cap-3 & Cone-1 & Sh3 & & & & & \\
\hline 20 & Mix-2/2 & Cap-3 & Cone-2 & Sh3 & & & & & \\
\hline 21 & $\mathrm{Mix}-2 / 2$ & Cap-3 & Cone-3 & Sh3 & & & & & \\
\hline
\end{tabular}

\subsubsection{Effect of single-swirl mixer (Mix-1/2) on duct burner performance}

This section presents the combustion results of the single-swirl mixer. This mixer has eight straight blades at $30^{\circ}$ angle resulting in a swirl number of 0.4 . The presentation of the results will be divided into two parts where each part covers one fuel cap. Some of the cases will be selected for the discussion of the effect of the firing rate, combustion intensity, equivalence ratio, conical burner pressure drop, shield length and blockage ratio on the performance of the duct burner. The discussion of the results will be assisted with the presentation of some of the temperatures measured during the combustion tests such as the conical wire-mesh burner inner (cold face) and outer (hot face), combustion zone and the exhaust gas temperature. Each subsection will be followed by a short summary. 


\subsubsection{Effect of Mix-1/2 and Cap-2 combinations on DB performance}

Cap-2 is a flat nozzle with eight holes, each of $2.3 \mathrm{~mm}$ in diameter. The fuel is injected at a $90^{\circ}$ angle to the main flow inside the premixer. In this section, the effect of using different conical burners (giving different pressure drops) and different conical burner shields (with different $L_{e f f} / D_{\text {shield }}$ and $\mathrm{BR}$ ) on NOx and CO emissions will be discussed, and a stable operating region will be determined. The duct burner pressure drop measurements during the combustion process for most of the cases will be presented and discussed. During the discussion of the combustion results in this chapter, if the term $L_{e f f} / D_{\text {shield }}$ (or shield length) is used alone, it means implicitly that the comparison is between the shields with equal blockage ratio.

\subsection{Effect of conical mesh burner pressure drop}

To study the influence of the conical burner pressure drop on the duct burner performance, the results of selected runs will be discussed. In these runs, the only variable is the burner pressure drop (due to different cones). The duct burner configurations selected for this discussion were Mix-1/2, Sh2 $\left(L_{\text {eff }} / D_{\text {shield }}=0.8\right.$ and BR $=0.4)$, and Cap-2 with the three different cones. The three cones were; Cone-1, Cone-2 and Cone-3.

Figure 8.1 (a) shows NOx emissions as a function of firing rate at different annular blade angles when using Mix-1/2, Cone-1, Sh2 and Cap2. The $M R_{C F}$ value increases as the blade angle increases. As the $M R_{C F}$ increases for a fixed firing rate, NOx emissions decrease until the blow-off limit is reached. The profiles for all angles shown in the figure have a similar trend; however, NOx emissions values and the lower stable range change with the firing rate. At higher AFCBA $\left(30^{\circ}\right)$, the duct burner operates at a higher firing rate with lower NOx emissions ranging from 1.2 ppm (at $192 \mathrm{~kW}$ ) to $3.2 \mathrm{ppm}$ (at $212 \mathrm{~kW}$ ). This is attributed to the surface combustion mechanism. From direct observation of the flame, as the firing rate decreased, the 
blue flames became longer until the blow-off limit was reached. NOx emissions increased with an increase in the firing rate. This trend was caused by the effect of nitrogen oxidation due to the rise in the flame temperature. However, maximum NOx emissions were less than 7.5 ppm. Labels (i), (ii), (iii) and (iv) shown in Figure 8.1 (a) will be explained in a later figure in this section. Figure 8.1 (b) shows $\mathrm{CO}$ emissions for the same cases shown in Figure 8.1 (a). The plots show that $\mathrm{CO}$ emissions become excessive at very low firing rate. This is attributed to incomplete combustion near the blow-off limit. Past the minimum CO emissions, increasing the firing rate led to higher $\mathrm{CO}$ emissions, which is attributed to higher dissociation levels. The upper AFCBA value used in Figures 8.1 (a), (b) and (c) was 30 degrees. Above this value the flame was no longer stable and blow-off occurred.

The effect of firing rate as a function of annular flow blade angle on duct burner pressure drop is illustrated in Figure 8.1 (c). The first (left side) lower point on each curve represents the pressure drop produced by the duct burner without combustion. As combustion was started inside the duct burner, the temperature increased, which led to a decrease in density, resulting in an increase in stream velocity and momentum. The result of combustion was an increase in the duct burner pressure drop. This figure shows that even with combustion, the pressure drop, with a value less than $149 \mathrm{~Pa}$, is still within the specified limit. The results show that combustion almost doubled the value of the overall duct burner pressure drop. A similar observation regarding the effect of surface combustion on pressure drop was made by Greenberg et al. (2005).

Figure 8.2 shows a sample of the temperature measurements, showing the effect of firing rate and the AFCBA on conical burner inner surface temperature, $T_{\text {cold }}$ (Figure 8.2 (a)), combustion zone temperature, $T_{c z}$ (Figure 8.2 (b)) and the duct burner exhaust gases temperature, $T_{\text {exhaust-2 }}$ (Figure 8.2 (c). Figure 8.2 (a) shows that the highest inner surface temperature occurs at a higher firing rate, or in other words 
increases with richer mixtures. The increase of the temperature of the inner side of the conical burner is due to the heat transfer mechanisms related to surface combustion. Heat is transferred from the reaction zone to the burner wire-mesh and is conducted
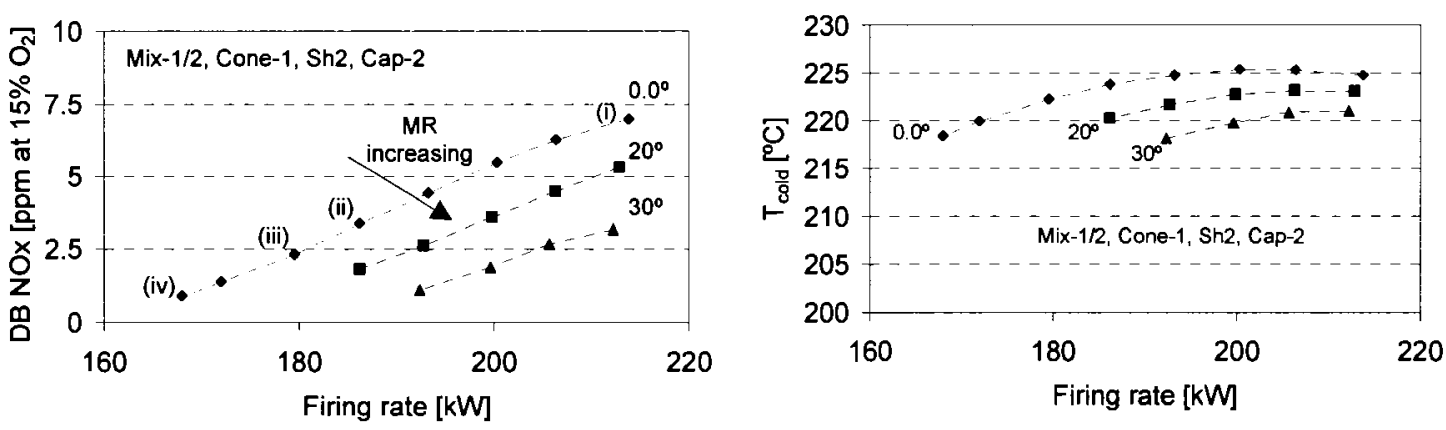

(a) NOx emission

(a) Mesh cold surface temperature

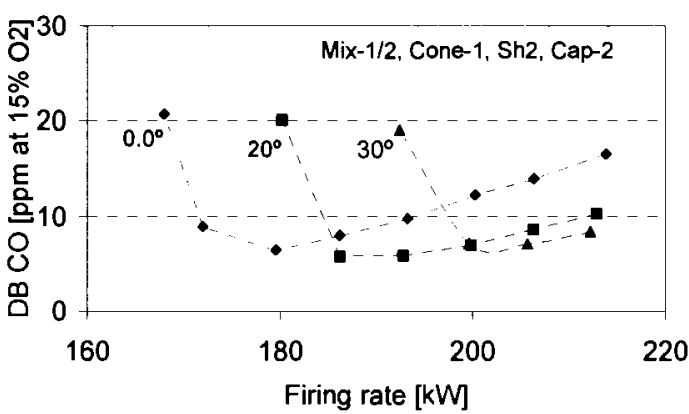

(b) $\mathrm{CO}$ emission

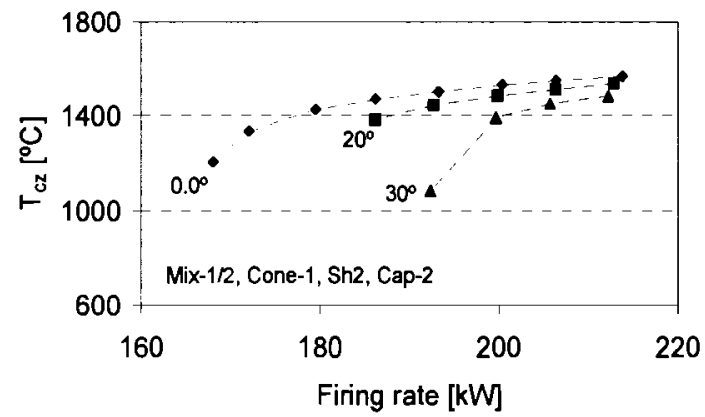

(b) Combustion zone temperature

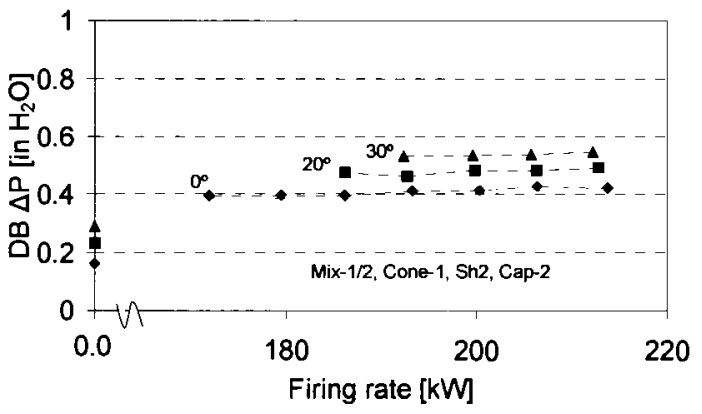

(c) Overall duct burner pressure drop

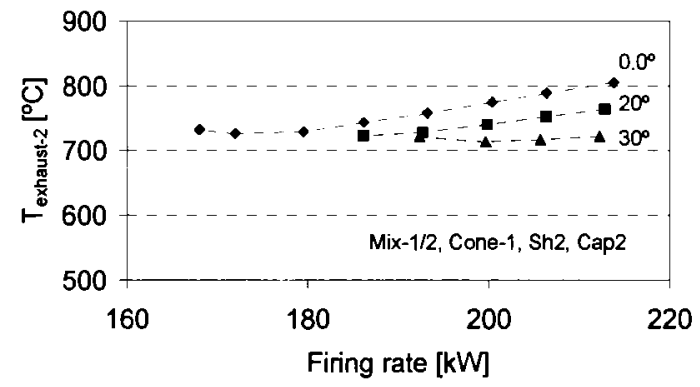

(c) Duct burner exhaust temperature.

Figure 8.1: Effect of firing rate and AFCBA (MR) on DB performance (Mix-1/2, Cap-2 and Cone-1 with Sh2)

Figure 8.2: Effect of firing rate and AFCBA on duct burner temperature (Mix-1/2, Cap-2 and Cone-1 with Sh2) 
to the lower surface. This results in additional preheating of the unburned oxidant fuel mixture. Preheating the reactants increases the combustion zone temperature (Figure 8.2 (b)) and improves flame stability, or shifts the lower operating range to a lower firing rate, which in turn results in NOx emissions reduction. Increasing the AFCBA resulted in more oxidant flow through the conical burner, decreasing the combustion temperature and NOx emissions. In this case, the combustion zone shifted to a higher firing rate region and the stable flame appeared to be longer. The effect of firing rate and the AFCBA on the exhaust gases temperature profiles are shown in Figure 8.2 (c). The results present the improvement in the microturbine exhaust gases temperature caused by the duct burner. This result and all the previously presented results are for burner configuration Mix-1/2, Cone-1, Sh2 and Cap-2.

Due to the brightness of the flame and the rapidly changing flames over the mesh surface, direct observation with the naked eye was difficult. A digital camera was used to capture the flame images over the conical mesh burner. Figure 8.3 shows the conical burner operating in the blue flame mode. These flame images are for the points labelled (i, ii, iii and iv) in Figure 8.1 (a). The images (i), (ii) and (iii) show stable stretched laminar flames covering the entire conical burner wire-mesh surface. The images show that, as the firing rate decreases, the length of the flame increases. The difference in the flame length over the burner surface for the single image is due to the local mass flux gradients resulting from variations in the density of the perforated regions of the wire-mesh matrix. Therefore, for this type of burner, the wire-mesh structure of the conical burner controls the size and the shape of the blue flames. The image labelled (iv) shows a stability limit point, below which blow-off occurred. For this case local extinction occurred at the lower half of the cone, and the position and the shape of the flames were no longer constant (long blue flames were observed at the upper half of the cone). Therefore, in general as the firing rate decreases, the temperature in the combustion zone decreases until at some point this decrease in flame temperature leads to a rapid decrease in the flame speed, followed by flame instability and blow-off. In addition, the images show the decrease in the 
flame length as the firing rate increases. It is observed that operating at higher firing rates shifts the operating mode from the blue flame mode towards the radiant mode of operation (image (i) in Fig. 8.3).

Figures 8.4 and 8.5 show the effect of the firing rate, as a function of annular flow control blade angle, on NOx and CO emissions respectively with a different test configuration. The difference between the case discussed above and this one is the use of Cone-2 which has a higher pressure drop. This conical burner has a nominal pressure drop of $149 \mathrm{~Pa}$. Both figures show that there are no significant changes in the results when using 0 and 10 degrees blade angles. Above 10 degrees, this small increment in the angle had a greater effect on emissions. In these tests, NOx and CO emissions were mostly under $10 \mathrm{ppm}$.

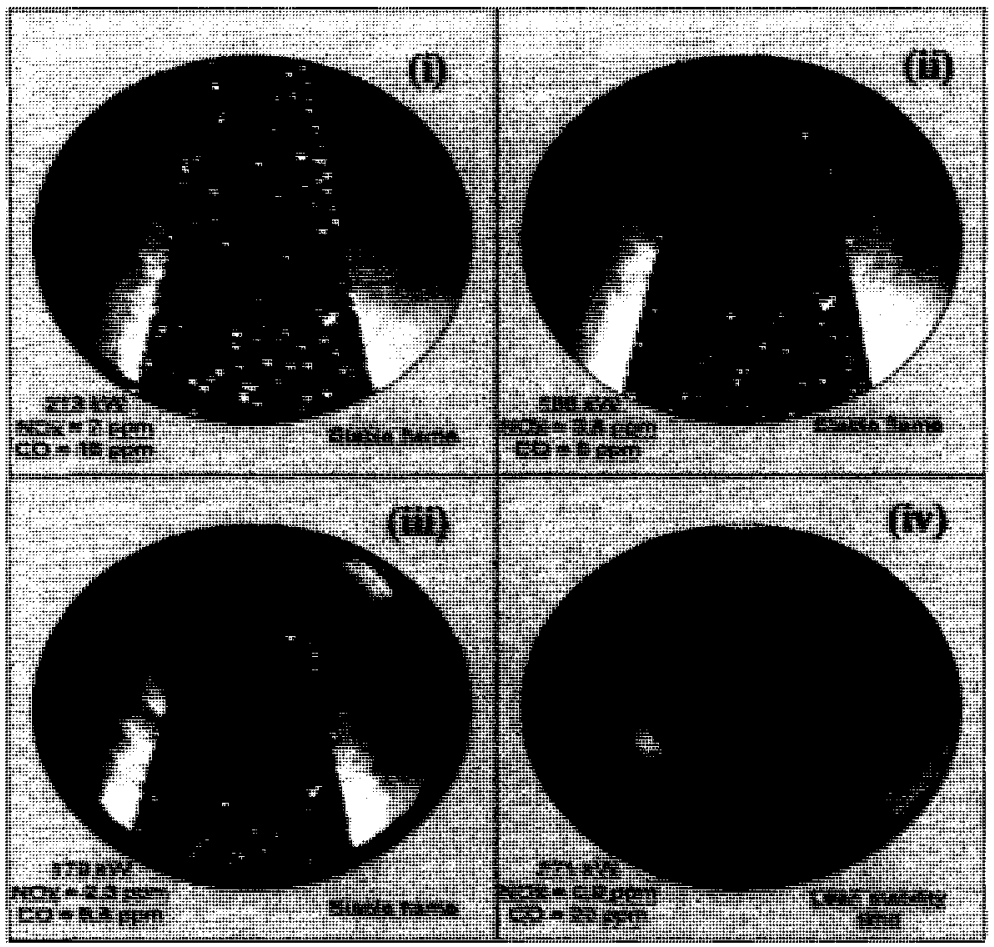

Figure 8.3: The conical burner operating in the blue flame mode (Mix-1/2, Cone1, Sh2 and Cap-2 at AFCBA $=0^{\circ}$ ) 
The combustion zone temperature and the duct burner exhaust gas temperature for the cases are presented in Figures 8.6 and 8.7. Figure 8.6 shows the effect of firing rate and the AFCBA on combustion zone temperature. This figure shows that the higher temperature in the combustion zone at $\mathrm{AFCBA}=0^{\circ}$ leads to the higher NOx emission values shown in Figure 8.4 compared to measurements at $\operatorname{AFCBA}=30^{\circ}$.

Figure 8.7 shows the results of the exhaust gases temperature traverse for burner configuration; Mix-1/2, Cone-2, Sh2 and Cap-2 at zero degrees blade angle. The temperature measurements show a top-hat profile with a maximum value of $950^{\circ} \mathrm{C}$. The results show the improvement in the heat content introduced by the duct burner.

Figure 8.8 (a) shows NOx emissions as a function of firing rate and AFCBA for burner configuration Mix-1/2, Cap-2, Cone-3 and Sh2. These were the same parameters used with Cone-1 (Figure 8.1) and Cone-2 (Figure 8.4) and the only variable is the conical burner pressure drop (i.e. using Cone 3 for these tests). An improvement of the operating range was observed with the increase in the conical burner pressure drop. Figure 8.8 (a) shows the lines of constant equivalence ratio. The equivalence ratio values used in the presentation of the combustion test results was calculated from the concentration analysis of the exhaust gases Eq. (H.29), Appendix H. In Figure 8.8 (a), as the equivalence ratio decreases (moving left on Fig. 8.8 (a)), NOx emissions decrease. At the same AFCBA, NOx emissions decreased until the lower stability limit was reached (blow-off limit). Therefore, the operating zone became wider and the flame stabilized at leaner equivalence ratios. Figure 8.8 (b) shows similar $\mathrm{CO}$ emissions trends as observed in Figure 8.5. CO emissions results for $50^{\circ}$ blade angles are very high, indicating poor combustion. 


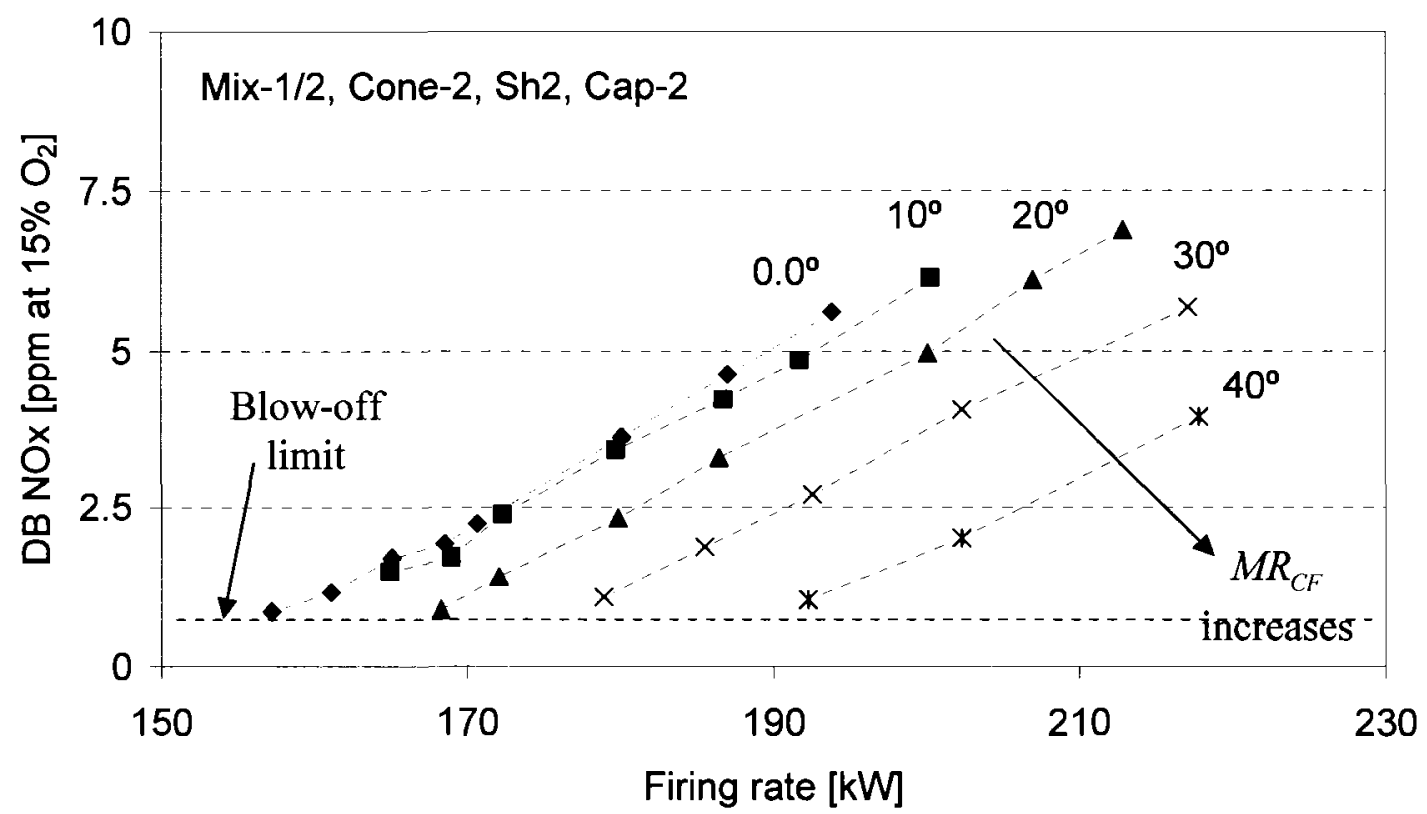

Figure 8.4: Effect of firing rate and AFCBA $\left(M R_{C F}\right)$ on NOx emissions (Cone-2)

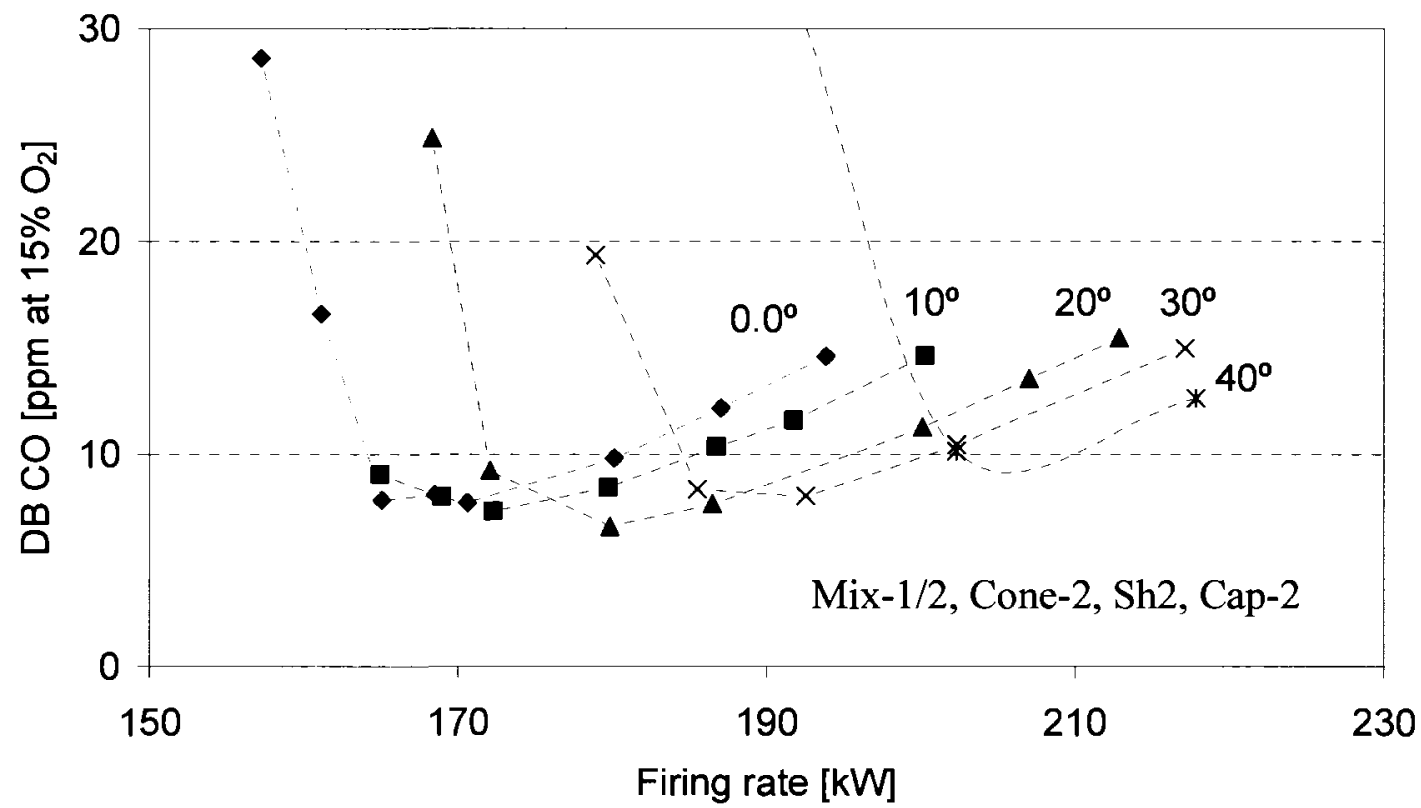

Figure 8.5: Effect of firing rate and AFCBA on CO emissions (Cone-2) 


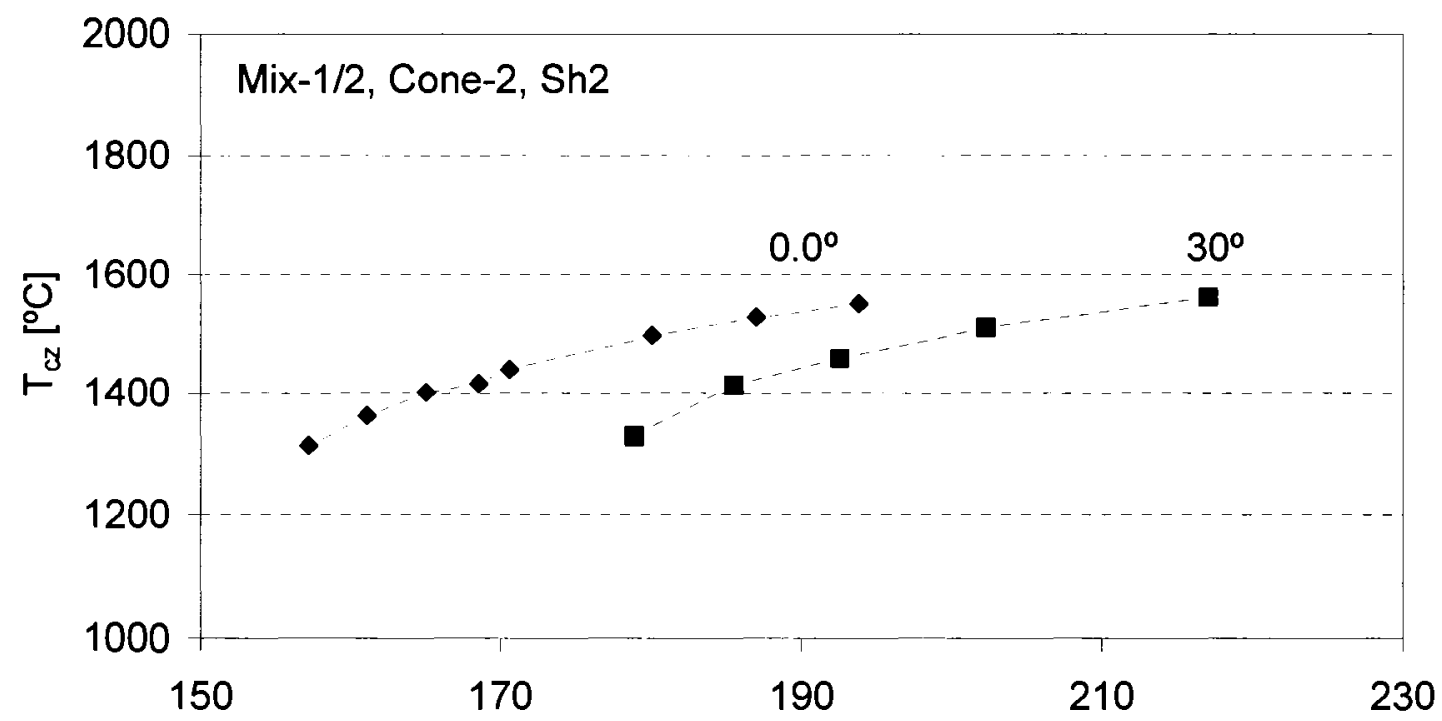

Firing rate $[\mathrm{kW}]$

Figure 8.6: Effect of FR and AFCBA on combustion zone temperature (Mix-1/2, Cone-2, Sh2 and Cap-2)

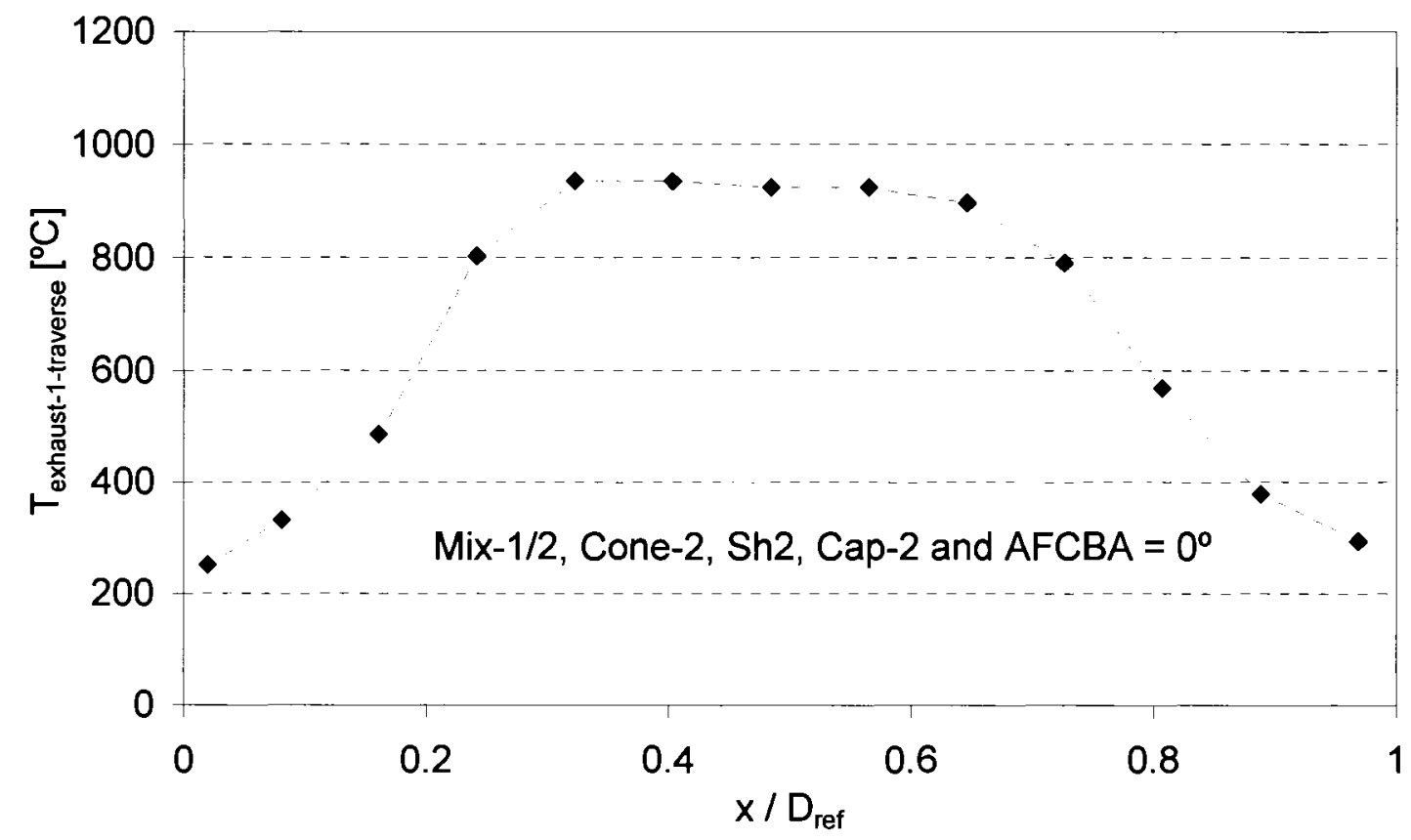

Figure 8.7: Exhaust gases temperature distribution at a plane located $1.4 D_{\text {ref }}$ above the conical burner (Mix-1/2, Cone-2, Sh2 and Cap-2 at AFCBA $=0^{\circ}$ ) 


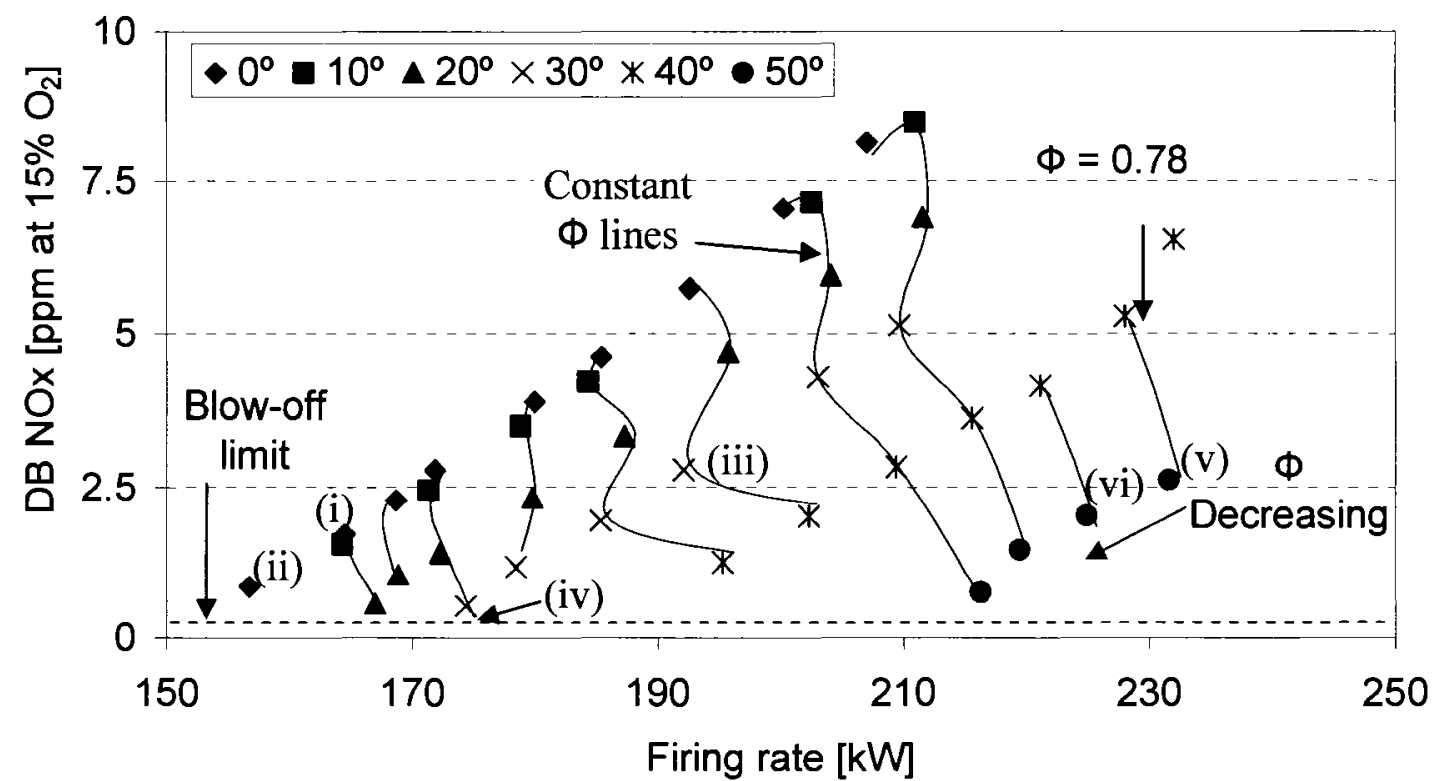

(a) NOx emissions

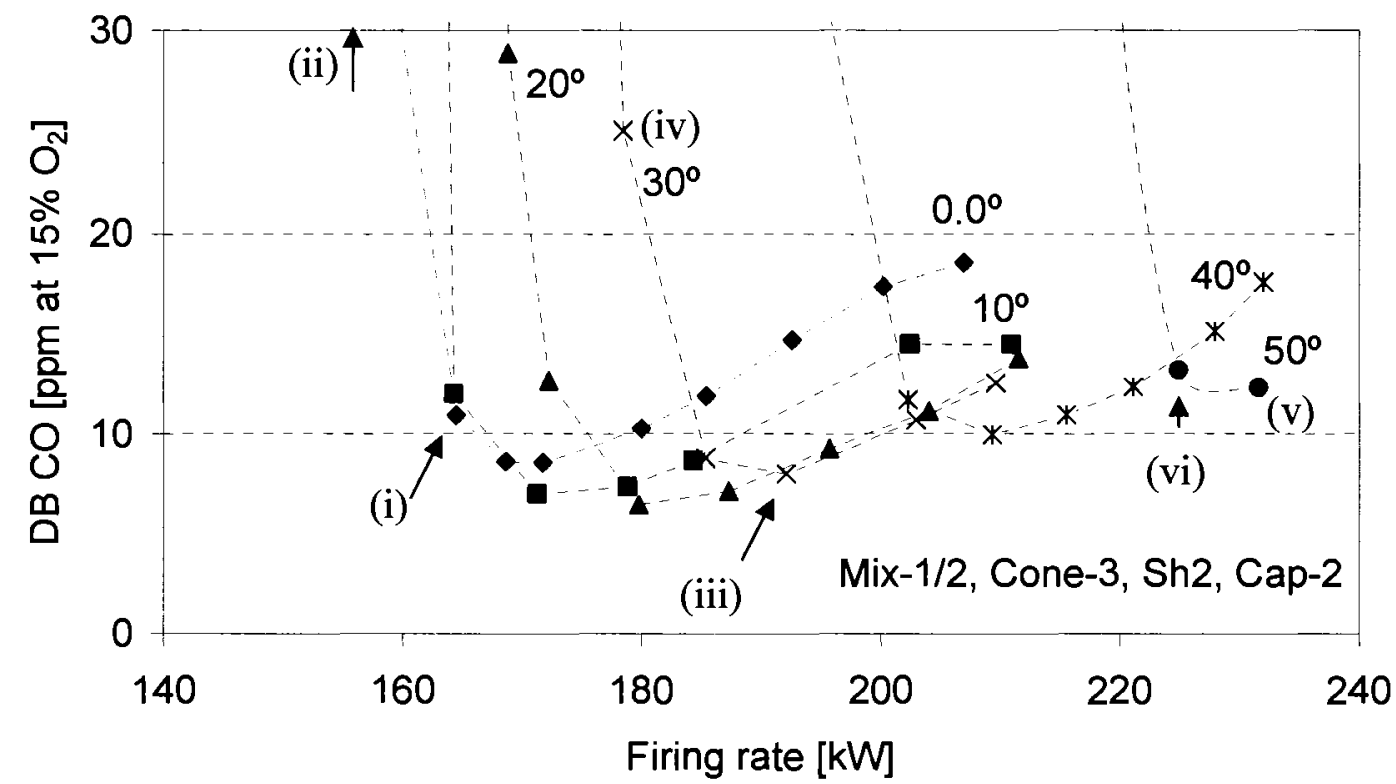

(b) $\mathrm{CO}$ emissions

Figure 8.8: Effect of firing rate and AFCBA on NOx and CO emissions (Mix-1/2, Cone-3, Cap-2 and Sh2) 
Figure 8.9 shows the flame images taken at different firing rate and different mass ratio $\left(M R_{C F}\right)$ for burner configuration; Mix-1/2, Cone-3, Sh2 and Cap-2. These images represent the six operating points labelled ((i, ii), (iii, iv) and (v, vi)) in Figures 8.8 (a) and 8.8 (b). Each pair located at a constant annular flow control angle line. The images (ii), (iv) and (vi) show stability limit points below which, blow-off occurs. Also the images show the increase of the flame length with decreasing firing rate.

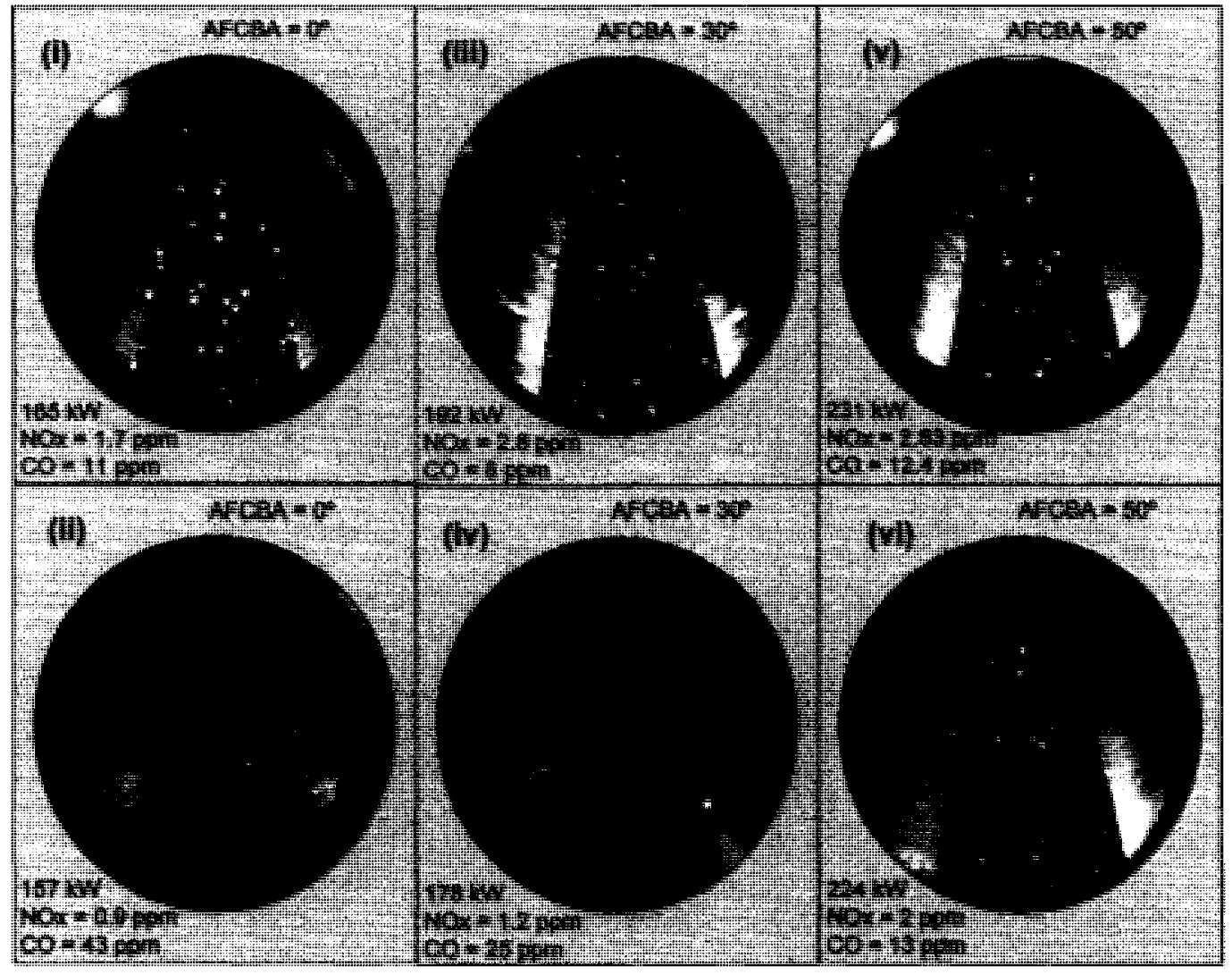

Figure 8.9: Flame images taken for points (i, ii, iii, iv, v and vi) in Figures 8.8 (a) and 8.8 (b), (Mix-1/2, Cone-3, Sh2 and Cap-2)

Samples from NOx and $\mathrm{CO}$ emissions measurements for each are plotted together in Figure 8.10 (a) and Figure 8.10 (b). The figures summarize the effect of the pressure drop provided by the different cones as a function of firing rate on NOx 
and $\mathrm{CO}$ emissions respectively. The results presented are for the case where AFCBA $=0^{\circ}$. At a constant firing rate, as the pressure drop increases (Cone 1 to Cone 2 to Cone 3), NOx and CO emissions increase. To obtain the required low emissions, operation of the burner must move towards a lower firing rate. The increase in local exhaust gas momentum (by choosing a Cone with a higher pressure drop) causes the extension of the stable region towards the lower firing rate value. For the same cone (same pressure drop), as the firing rate decreases, NOx emissions decrease until the blow-off limit is reached. Figure 8.10 (b) shows that as the pressure drop decreases (higher porosity), $\mathrm{CO}$ emissions decrease (more complete combustion). Several phenomena may be responsible for this trend. Greater porosity leads to lower mixture speed through the cone surface, more residence time (more open area causes the reactant to move slower through the combustion zone compared with other cases) and a longer flame. Both of these assist the oxidation reactions to reduce $\mathrm{CO}$ emissions. Figure 8.10 also shows that Cone-3, which has a nominal pressure drop of $224 \mathrm{~Pa}$, produces results similar to those of Cone- 2 with a little improvement in the broadening of the stability range. The duct burner temperature results accompanied with Figure 8.10 will explain some of these behaviours.

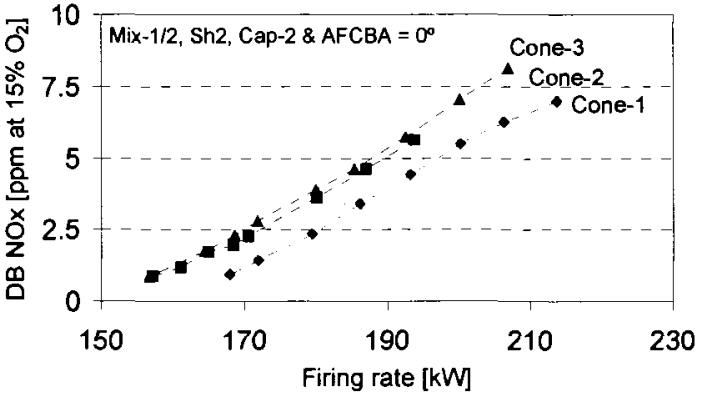

(a) NOx emissions

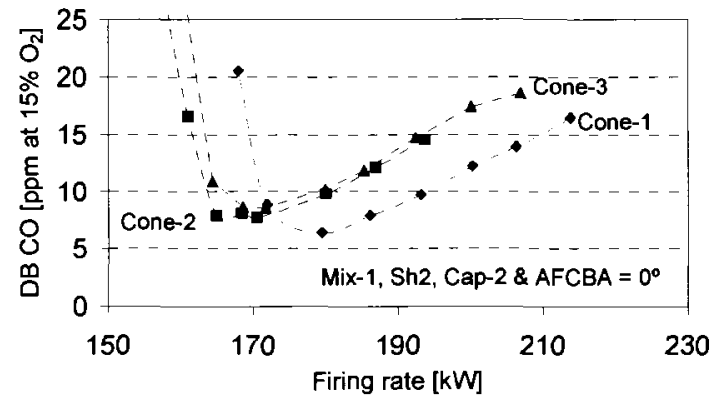

(b) $\mathrm{CO}$ emissions

Figure 8.10: Effect of conical burner pressure drop as a function of FR on the duct burner performance (Mix-1/2, Sh2, Cap-2 \& AFCBA $=0^{\circ}$ ) 
Figure $8.11(a),(b)$ and (c) respectively show the effect of the conical burner pressure drop as a function of firing rate on conical burner inner upstream surface temperature, combustion zone temperature and duct burner exhaust gas temperature. Figure 8.11 (a) clearly shows that Cone-1, which has the lower pressure drop (the larger burner porosity), resulted in the highest cold surface temperature compared to the cones that have higher pressure drops (lower burner porosity). This increase in temperature is due to the increase in energy transfer, such as radiation from the flame zone, between the mesh burner and the combustion zone due to the larger open area of Cone-1. This increase in the temperature enhances preheating of the incoming reactants. However, more open area (higher porosity) leads to more excess oxygen, which decreases the combustion zone temperature and NOx formation.

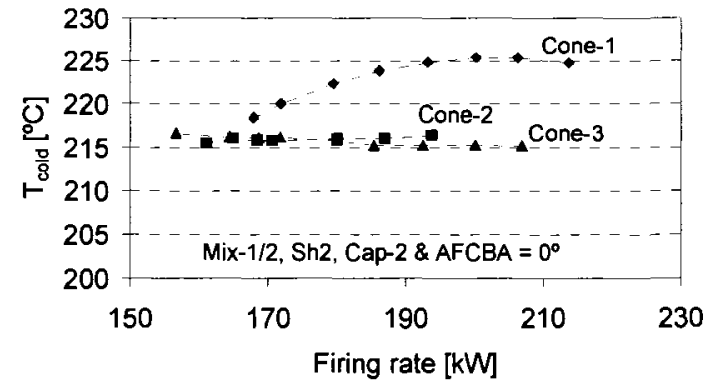

(a): Conical burner cold surface temperature

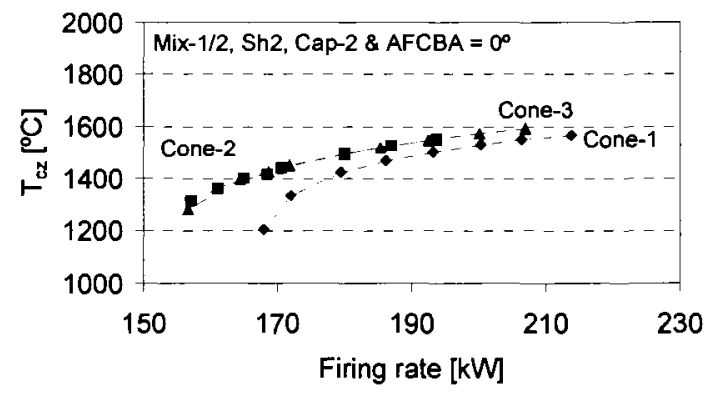

(b): Combustion zone temperature

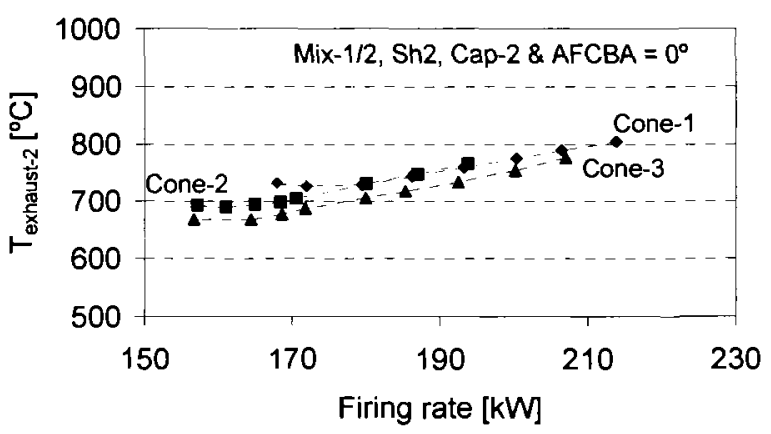

Figure 8.11: Effect of firing rate and conical burner pressure drop on duct burner temperature (Mix-1/2, Cap-2 and Sh2 at AFCBA $=0^{\circ}$ ) 
Figure 8.11 (b) proves this observation and explains the results presented in Figure 8.10 (a). The cone with the higher pressure drop has a higher combustion temperature, therefore higher NOx emissions. Figure 8.11 (c) presents the duct burner exhaust gas temperature measured at the centre of the exhaust duct (TC-20, Figure 7.5). This figure shows that the temperature ranged from 700 to $800^{\circ} \mathrm{C}$ for Cone- 1 and Cone-2. Cone-3 shows a different behaviour than expected that is to say, the operating range extended to a lower firing rate than for Cone-2.

\subsection{Effect of conical burner ( $\left.L_{e f f} / D_{\text {shield }}\right)$ shield ratio}

The burner configuration for the discussion in this subsection is Mix-1/2, Cone-2, Cap-2 with the conical burner shields Sh1 $\left(L_{e f f} / D_{\text {shield }}=0.4\right.$ and BR $=0.4$ ), $\operatorname{Sh} 2\left(L_{e f f} / D_{\text {shield }}=0.8\right.$ and $\left.\mathrm{BR}=0.4\right)$ and $\mathrm{Sh} 3\left(L_{\text {eff }} / D_{\text {shield }}=1.5\right.$ and $\left.\mathrm{BR}=0.4\right)$. Figures 8.12 ( $a$ and $b$ ), 8.13 ( $a$ and $b$ ) and 8.14 ( $a$ and $b$ ) show NOx and CO emissions as a function of firing rate at different annular blade angles, for three different cone shields, Sh1, Sh2 and Sh3 respectively. As the $L_{\text {eff }} / D_{\text {shield }}$ ratio increases, the blowoff limit decreased and the stable operating zone became wider. The flame stabilized at leaner fuel/oxidant mixture ratios with the longer shields. The entire stable operating zone moved towards the lower firing rate direction. Longer shields provide more protection to the flame from the bypassed flow. Selected images of the flames are presented on the same page to help visualize the shift of the operating zone towards the leaner side. Figures 8.4 and 8.5 are repeated here as Figure 8.13 ((a) and (b)) for the sake of comparison only. The figures on the left-hand side (Figures 8.12 (a), 8.13 (a) and 8.14 (a)) show the effect of using different shields and of firing rate on NOx emissions. The figures labelled (b) present the same effect on $\mathrm{CO}$ emissions. A close look at Figures 8.11,8.12 and 8.13 shows that when using Sh1, the firing rate operating range was $171 \mathrm{~kW}$ to $223 \mathrm{~kW}$, when using Sh2 the lower firing rate shifted to $157 \mathrm{~kW}$, then to $148 \mathrm{~kW}$ with Sh3. Operating below those limits, flame blow-off occurred. 


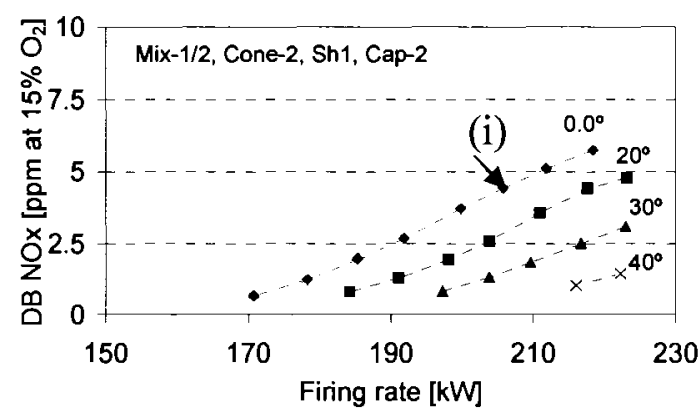

(a) NOx emissions

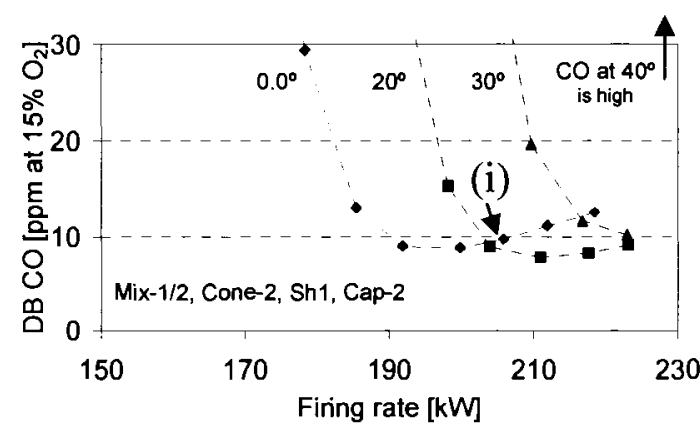

(b) $\mathrm{CO}$ emissions

Figure 8.12: Effect of firing rate and AFCBA on duct burner performance, for burner configuration; (Mix-1/2, Cap-2 and Cone-2 with Sh1)

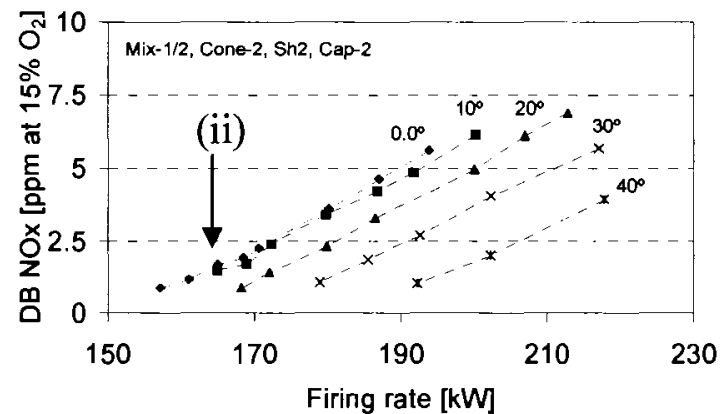

(a) NOx emissions

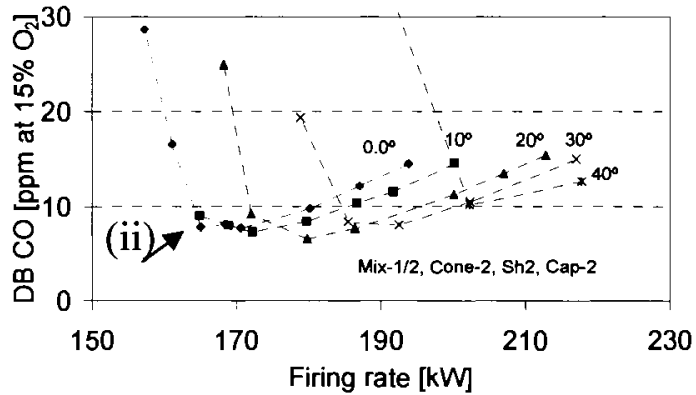

(b) $\mathrm{CO}$ emissions

Figure 8.13: Effect of firing rate and AFCBA on duct burner performance, for burner configuration; (Mix-1/2, Cap-2 and Cone-2 with Sh2)

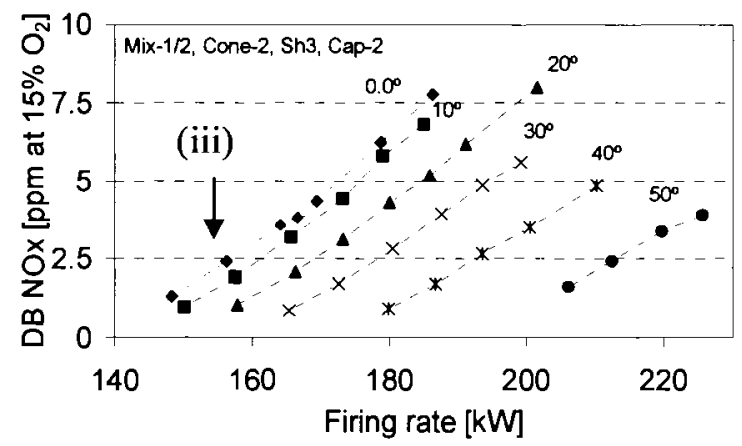

(a) NOx emissions

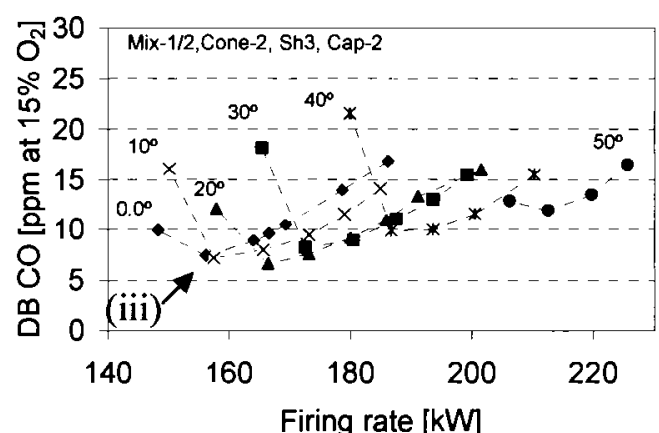

(b) $\mathrm{CO}$ emissions

Figure 8.14: Effect of firing rate and AFCBA on duct burner performance, for burner configuration; (Mix-1/2, Cap-2 and Cone-2 with Sh3) 
Figure 8.15 shows flame images for the duct burner at different operating conditions. The flame images were taken for the points labelled (i), (ii) and (iii) respectively in Figures 8.12, 8.13 and 8.14. The figures show the effect of using different shields ( $L_{\text {eff }} / D_{\text {shield }}$ ratio). The FR, $\phi$, AFCBA, and NOx and CO emissions for those specific operating points are indicated on each image.

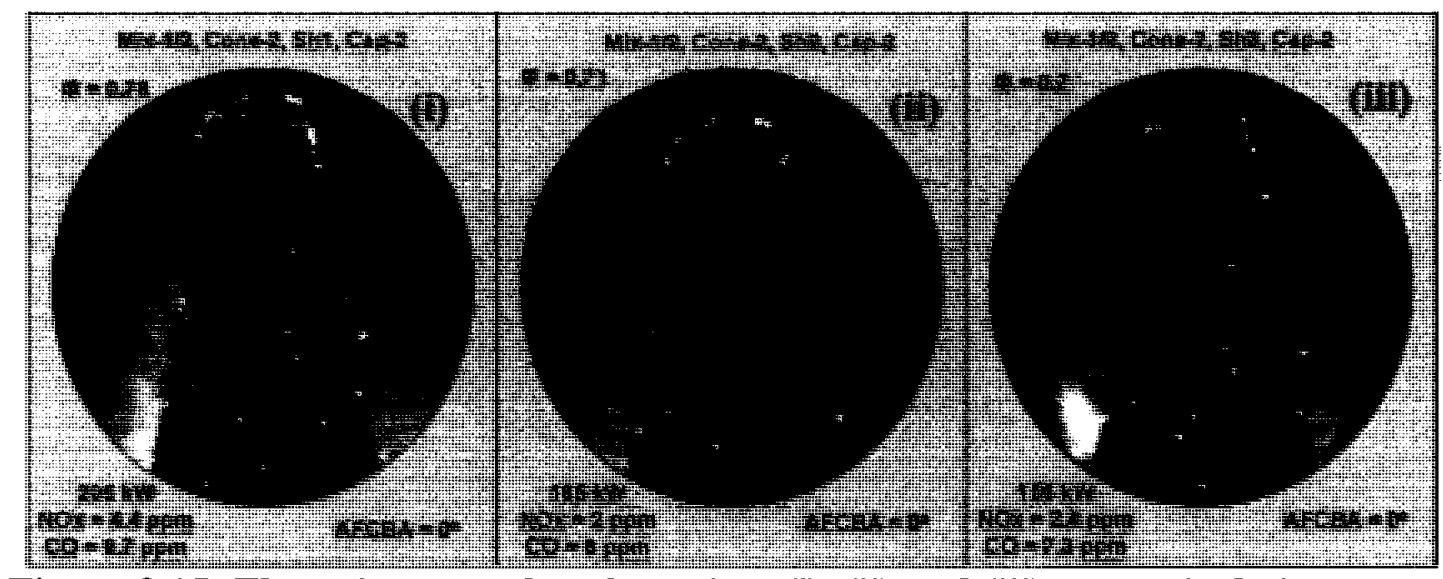

Figure 8.15: Flame images taken for points (i), (ii) and (iii) respectively in Figures 8.12, 8.13 and 8.14.

Figure 8.15 also shows that with $\mathrm{Sh} 3$ the operating range extended to a lower equivalence ratio, and stable longer blue flames (compared to other shields results) were observed. In these tests, with Sh1, the range of operating equivalence ratio was from $\phi=0.78$ to $\phi=0.72$. For Sh2, the range was from 0.78 to 0.69 and for Sh3 the lower limit reduced to an equivalence ratio of 0.65 .

Figures $8.16(a$ and $b), 8.17(a$ and $b)$ and $8.18(a$ and $b$ ) show the effect of firing rate and AFCBA on duct burner performance, for the burner configurations Mix-1/2, Cap-2 and Cone-3 with shields Sh1, Sh2 and Sh4 ( $L_{e f f} / D_{\text {shield }}=1.7$ and BR $=0.4$ ). The figures labelled (a) show NOx emissions results and those labelled (b) show $\mathrm{CO}$ emissions results. The difference between this set of figures and the previous set is the use of Cone-3. A similar trend can be seen: as the shield length 
increases the entire stable range moves towards the lower firing rate region and stable combustion can be sustained at a leaner limit. The firing rate range using Sh1 was $202 \mathrm{~kW}$ to $228 \mathrm{~kW}$ (Figure 8.16) which is less than that recorded with Cone-2 (Figure 8.12). When Sh2 was used with Cone-3 (Figure 8.17), the lower operating limit was $156 \mathrm{~kW}$. With Sh4, which has a $L_{\text {eff }} / D_{\text {shield }}=1.7$ and $\mathrm{BR}=0.4$, the range of operation was between $151 \mathrm{~kW}$ and $196 \mathrm{~kW}$, see Figure 8.18. The results show that when using Cone-3, even with a longer burner shield, the range of operation (FR range) is less than that recorded with Cone-2. Relatively when Sh2 was used both cones recorded closer results. Figures 8.8 ((a) and (b)) are repeated here as Figure 8.17 (a and b) to make the comparison easier.

The burner configuration in Figure 8.16 produced very low NOx emissions (less than $2.5 \mathrm{ppm}$ ) but produced high $\mathrm{CO}$ emissions. This case had a rather narrow range of stable firing rates. The combustion was stable, and had low NOx and CO emissions only at two operating points. The first was at $222 \mathrm{~kW}$ (AFCBA $=0$ degrees) with $\mathrm{CO}$ emissions of $11 \mathrm{ppm}$ and the NOx emissions of $1 \mathrm{ppm}$. The second point was at $228 \mathrm{~kW}$ (AFCBA $=10$ degrees) with CO emissions of $11 \mathrm{ppm}$ and NOx emissions of $1 \mathrm{ppm}$. By increasing the length of the shield, the operating range became wider and lower emissions were recorded. In Figure 8.17 where Sh2 was used, the operating range was from $156 \mathrm{~kW}$ to $232 \mathrm{~kW}$ with NOx emissions of 1.4 ppm and CO emissions 6.4 ppm. The effect of using Sh4, presented in Figure 8.18, shows that the burner had NOx emissions of $1.7 \mathrm{ppm}$ and $\mathrm{CO}$ emissions of $5 \mathrm{ppm}$ at $\mathrm{AFCBA}=10$ degrees. At AFCBA $=20$ degrees, NOx emissions were $2.0 \mathrm{ppm}$ and CO emissions 5 ppm CO. 


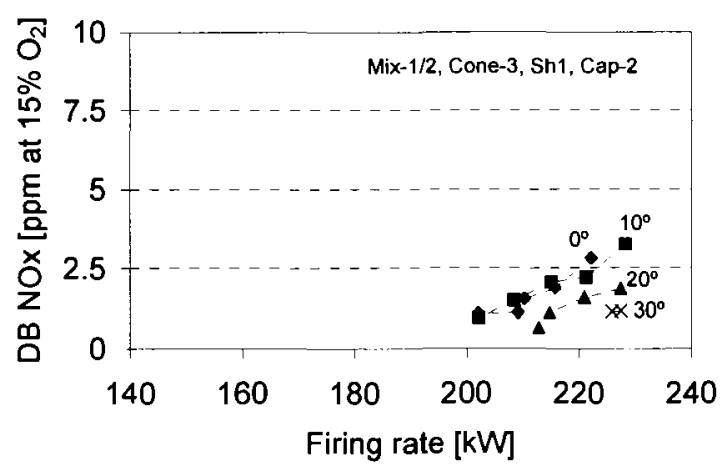

(a) DB NOx emissions

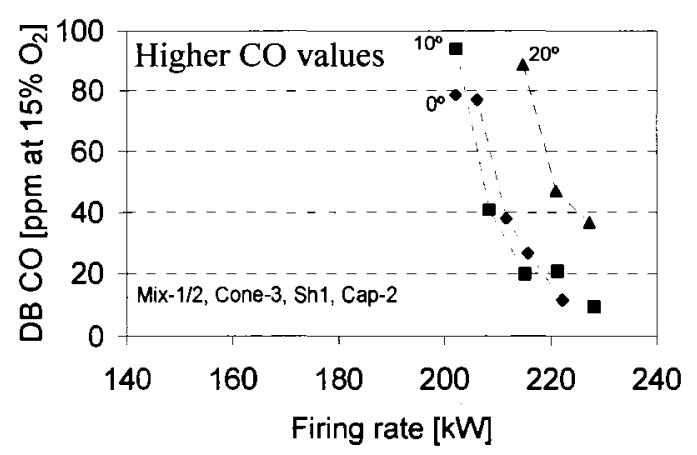

(b) DB CO emissions

Figure 8.16: Effect of firing rate and $A F C B A$ on duct burner performance, for burner configuration (Mix-1/2, Cap-2 and Cone-3 with Sh1)

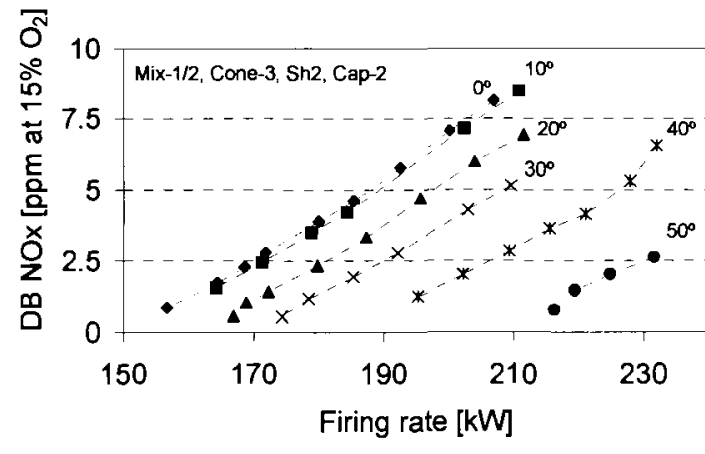

(a) DB NOx emissions

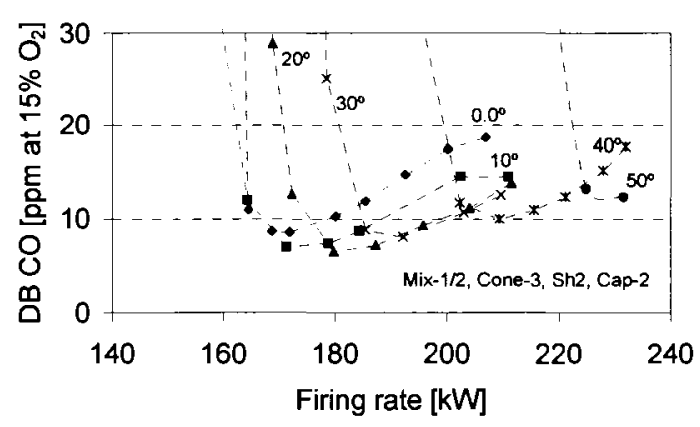

(b) DB CO emissions

Figure 8.17: Effect of firing rate and AFCBA on duct burner performance, for burner configuration (Mix-1/2, Cap-2 and Cone-3 with Sh2)

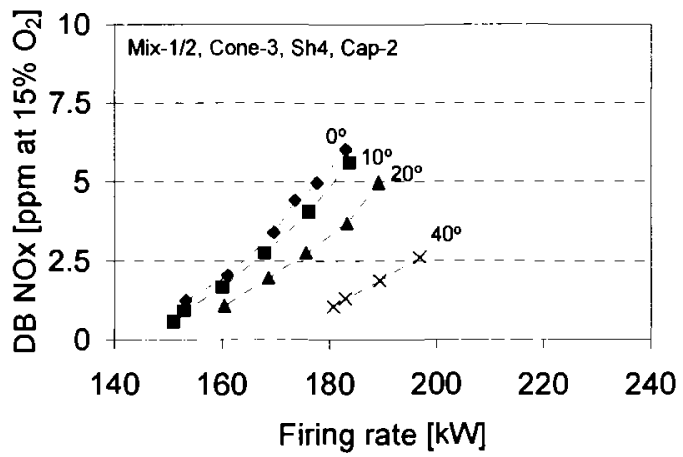

(a) DB NOx emissions

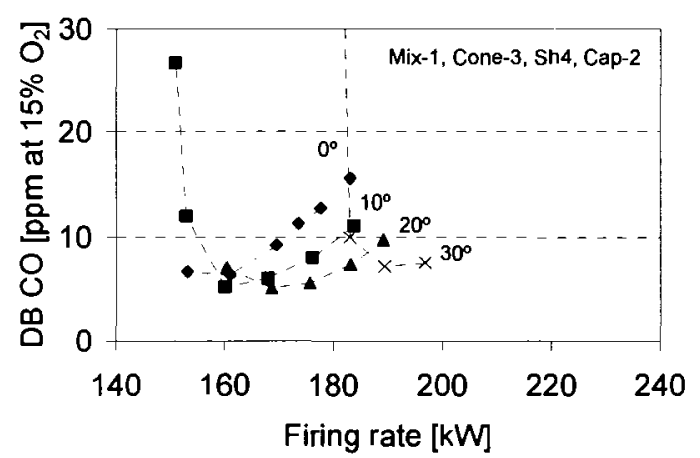

(b) DB CO emissions

Figure 8.18: Effect of firing rate and $A F C B A$ on duct burner performance, for burner configuration (Mix-1/2, Cap-2 and Cone-3 with Sh4)

As mentioned in the section dealing with combustion test limits, the upper firing rate limit is not our concern in the present investigation. It is observed from the 
above results that the upper limit varies from test to test due to the different operating conditions. During the experimental work, when NOx emissions were higher than 10 ppm (the design limit for the complete system) the firing rate was recorded as the limiting firing rate value. In some cases, the total duct burner pressure drop was the limiting value and in other cases the limitation was the fuel flow rate. In some cases, even with low NOx and $\mathrm{CO}$ emissions, the test was terminated due to the shift of the operating range from the blue flame mode to the radiant mode where the wire-mesh becomes red and hot.

To show the microturbine contribution to NOx and $\mathrm{CO}$ emissions and the effect of the surface combustion on duct burner overall pressure drop, one test run will be presented and the contribution of each component will be shown. These results are plotted in Figures 8.19 and 8.20.

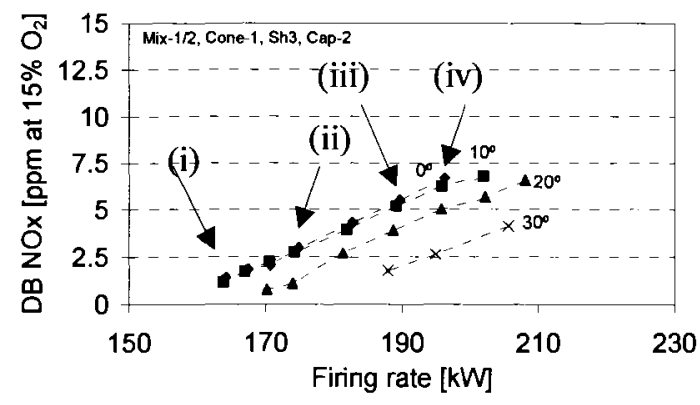

a) DB NOx emissions

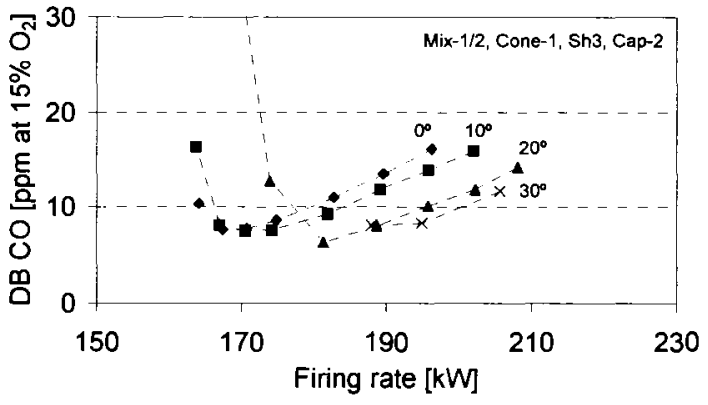

(b) DB CO emissions

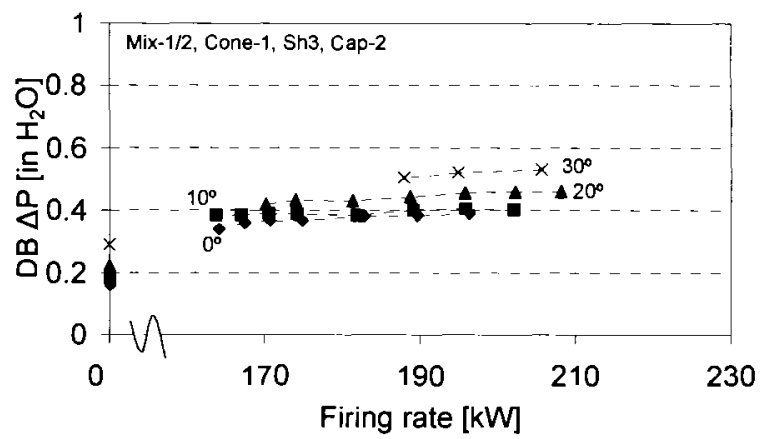

(c) DB pressure drop

Figure 8. 19: Effect of firing rate and AFCBA on duct burner performance (Mix-1/2, Cap-2, Cone-1 and Sh3) 
NOx emissions for the duct burner as a function of firing rate for different annular blade angles are presented in Figure 8.19 (a) for burner configuration Mix-1/2, Cone-1, Sh3 and Cap-2. The figure shows low values of NOx emissions between 1.7 and 7 ppm for the firing rate ranging from 164 to $208 \mathrm{~kW}$ respectively. Figure 8.19 (b) shows CO emissions for the same case shown in Figure 8.19 (a). The figures show that $\mathrm{CO}$ emissions become excessive at very low firing rates near the blow-off limit. CO emissions of single digit were reported in this case. Figure 8.19 (c) presents the overall duct burner pressure drop during the combustion process for this case. The surface combustion approximately doubles the overall pressure drop. However,

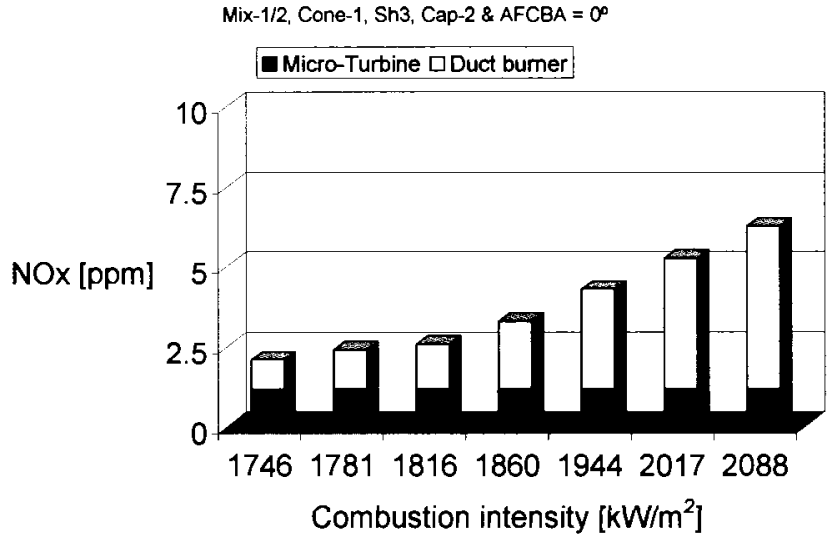

(a) Component contribution to $\mathrm{NOx}$

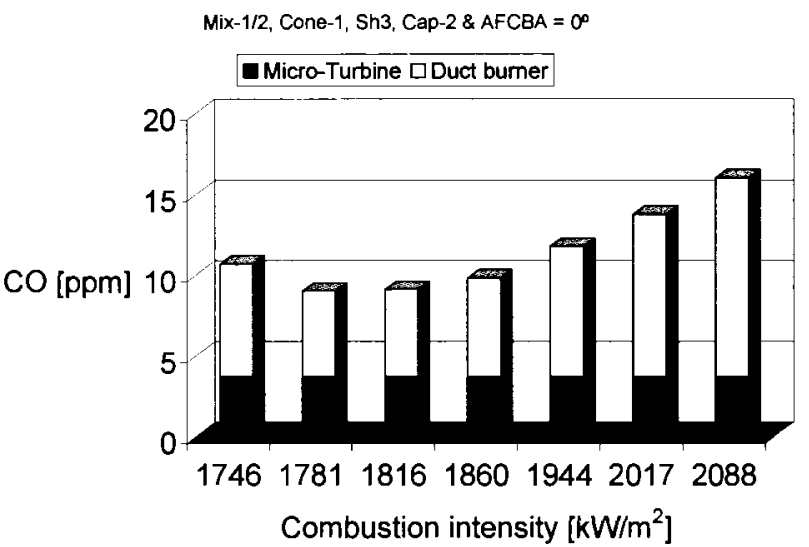

(b) Component contribution to $\mathrm{CO}$

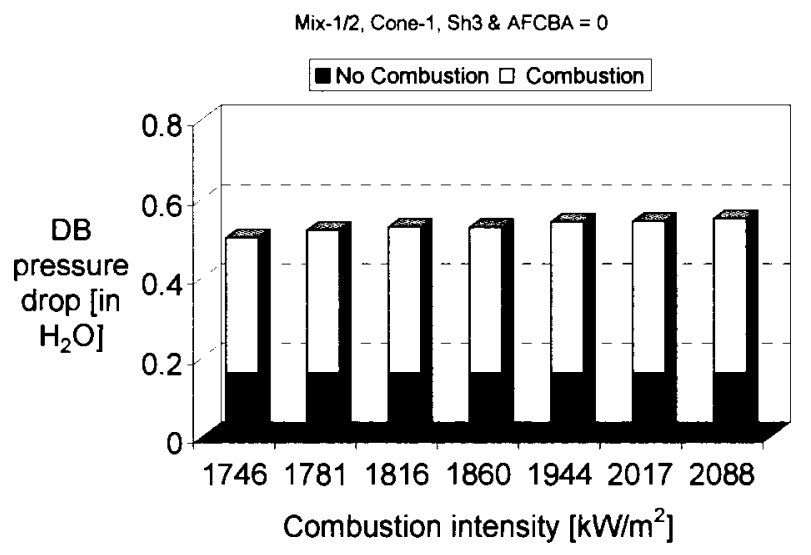

(c) Pressure drop

Figure 8.20:Effect of combustion intensity on duct burner performance (Mix-1/2, Cap-2, Cone-1 and Sh3 at AFCBA $=0^{\circ}$ ) 
the recorded pressure drop values of less than $149 \mathrm{~Pa}$, even at the highest AFCBA, were less than the limit value of $249 \mathrm{~Pa}$.

Figure 8.20 presents the emissions contribution of each component of the system (microturbine and duct burner) as a function of firing rate at zero degree blade angles for the cases presented in Figure 8.19 (Mix-1/2, Cap-2, Cone-1 and Sh3 at AFCBA $=0^{\circ}$ ). The figure labelled (a) shows the component contribution to NOx emissions (b) shows the component contribution to $\mathrm{CO}$ emissions and (c) presents the duct burner pressure drop during the combustion process. It should be noted that the $\mathrm{x}$-axis in Figure 8.20 uses the combustion intensity $\left(\dot{Q}_{\mathrm{int}}=\right.$ firing rate/conical mesh area). The points labelled (i, ii, iii, iv) in Figure 8.19 (a) are the points with the same labels in Figures 8.20 ( $a$ and $b)$ ). As expected, the contribution from the gas turbine is nearly constant and the contribution from the $\mathrm{DB}$ increases with increasing firing rate. During all these tests, the microturbine NOx emissions contribution was between 0.94 and $1.4 \mathrm{ppm}$, and $\mathrm{CO}$ emissions ranged from 3 to $5 \mathrm{ppm}$. As a complete system (DB + microturbine), Figure 8.20 shows that less than 5 ppm NOx emissions and less than 10 ppm CO emissions were measured.

One of the observations during the above tests (with Mix-1/2 and Cap-2) is that the blow-off occurred gradually. It started with an increase in the flame length, then instabilities of the flame at the lower part of the cone could be observed, and then complete flame blow-off occurred. Only in few cases when Sh1 was used, the blow-off was accompanied by a small vibration of the duct burner.

Figures 8.21 and 8.22 summarize Section 8.5.1.1.2, showing the effect of $L_{\text {eff }} / D_{\text {shield }}$ ratio and firing rate on NOx and CO emissions. The figures summarize some of the results of the shields tested with burner configurations Mix-1/2, Cap-2 with Cone-1, Cone-2 and Cone-3. The results presented here are for AFCBA equal to zero degrees and for the shields that have a blockage ratio of 0.4 (Sh1, Sh2, Sh3 and Sh4). The shields that have a BR of 0.6 were tested with Cap-2, but no stable combustion was achieved due to the higher amount of oxidant introduced through the 
conical mesh burner compared to shields that have a 0.4 blockage ratio. The amount of fuel introduced into the combustion zone using Cap-2 could not sustain and support stable combustion over the mesh surface when tested with shields of $\mathrm{BR}=$ 0.6. It is clearly observed from Figure 8.21 that the stable operating zone is extended when using the longer shield. When using shorter shields the burner operates at a high firing rate with low emissions over a limited range. Figure 8.21 also shows the effect of using different conical burner pressure drops by comparing the figures labelled (a), (b) and (c) (discussed in the previous section). Figure 8.22 presents the effect of using different $L_{\text {eff }} / D_{\text {shield }}$ ratios on CO emissions. This figure compares CO emissions for the different shields tested with three cones, Cone-1 (Figure 8.22 (a)), Cone-2 (Figure 8.22 (b)) and Cone-3 (Figure 8.22 (c)). From both Figures 8.21 and 8.22, one can conclude that Cone- 2 provides a good stable operating range with all the shields tested. The results of Sh1 with the different cones (Figures 8.21 and 8.22) show that $\mathrm{CO}$ emissions were very high with Cone-1, and an unstable flame was observed. With Cone-2 the stable operating range became wider and had lower $\mathrm{CO}$ emissions compared to both Cone-1 and Cone-3. When Sh1 is used with Cone-3, the stable operating range became rather narrow and high $\mathrm{CO}$ emissions were measured.

To assist the discussion regarding both Figures 8.21 and 8.22 , the DB combustion zone temperatures $\left(T_{c z}\right)$, for the cases presented in Figures 8.21 (b) and 8.22 (b) are presented in Figure 8.23 (a). The plotted results show that the shorter shield produced lower $T_{c z}$ and lower NOx emissions. As the shield length increased, $T_{c z}$ increases due to the protection of the combustion zone from the bypass flow. 


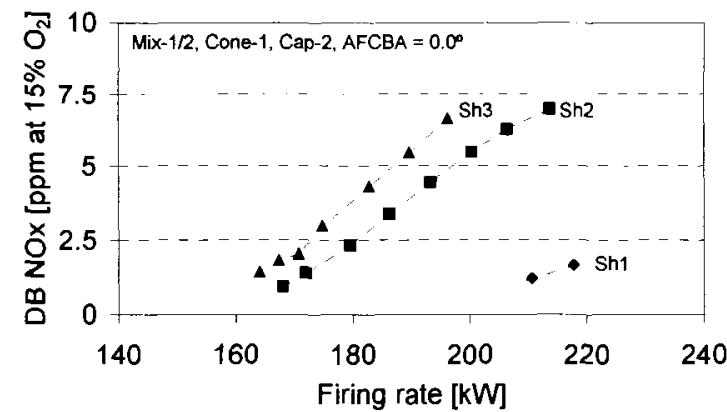

(a) Cone-1

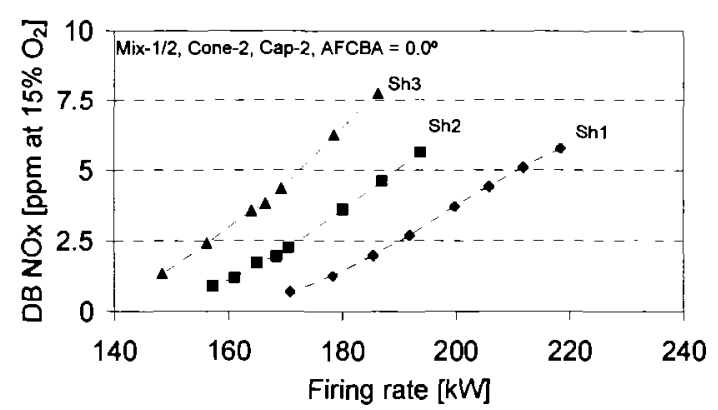

(b) Cone-2

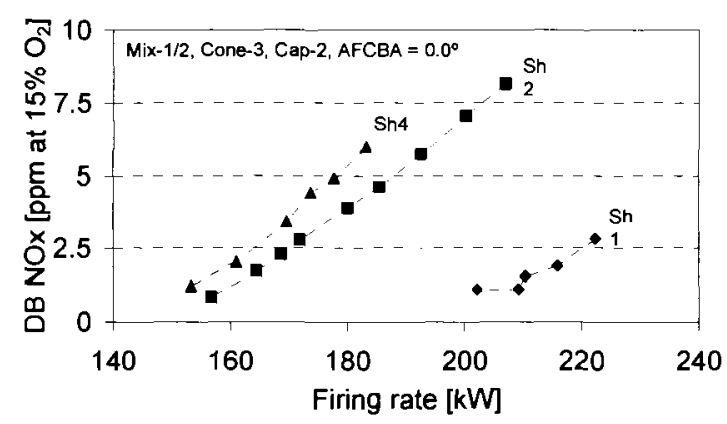

(c) Cone-3

Figure 8.21: Effect of firing rate and $\left(L_{e f f} / D_{\text {shield }}\right)$ on duct burner NOx emissions (Mix-1/2, Cap-2 with Sh1, Sh2, Sh3 and Sh4 at AFCBA $=0^{\circ}$ )

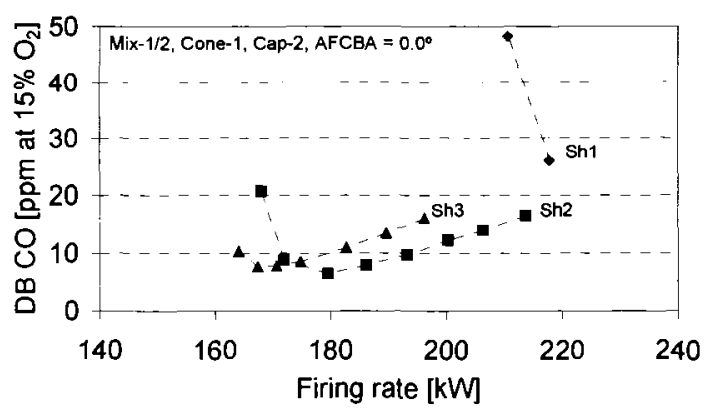

(a) Cone-1

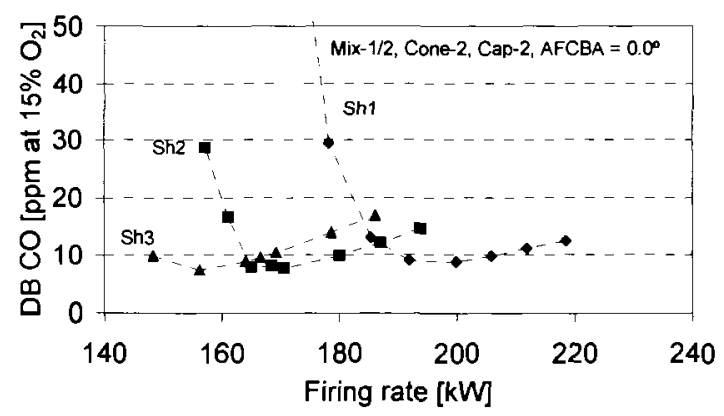

(b) Cone-2

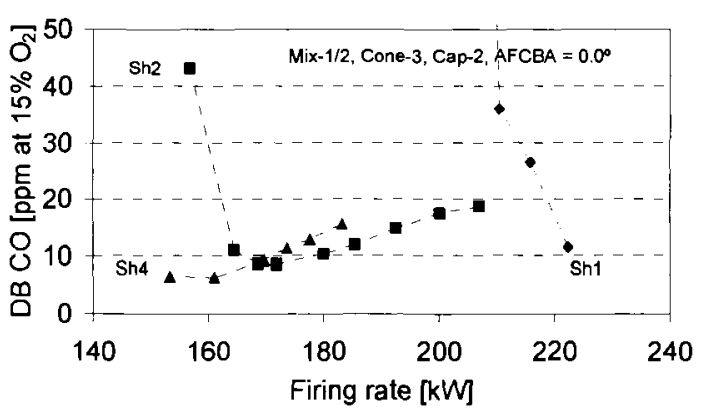

(c) Cone-3

Figure 8.22: Effect of firing rate and ( $\left.L_{\text {eff }} / D_{\text {shield }}\right)$ on duct burner CO emissions (Mix-1/2, Cap-2 with Sh1, Sh2, Sh3 and Sh4 at AFCBA $=0^{\circ}$ ) 


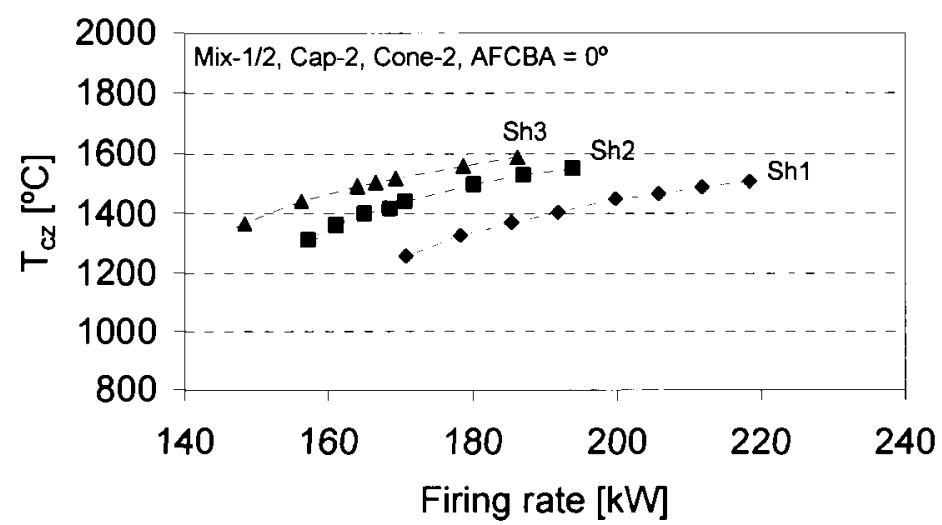

(a) Combustion zone temperature

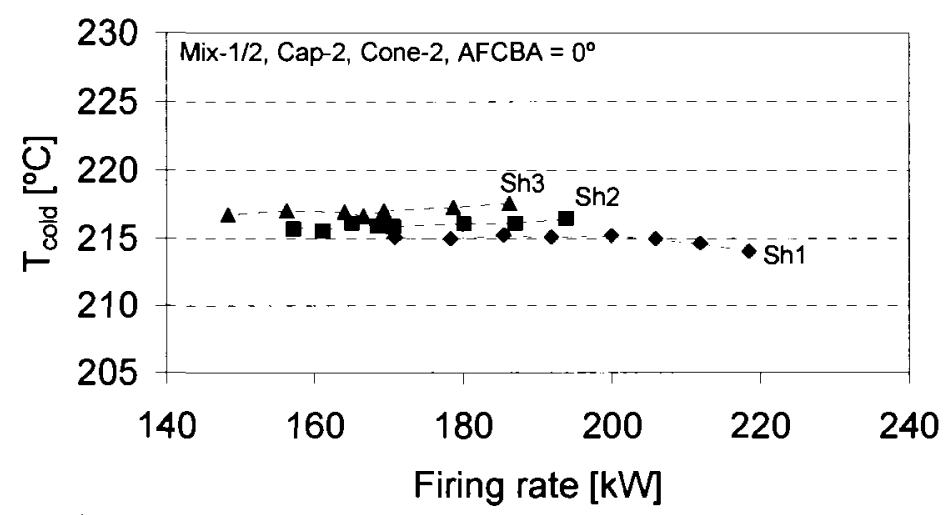

(b) Conical burner inner surface temperature

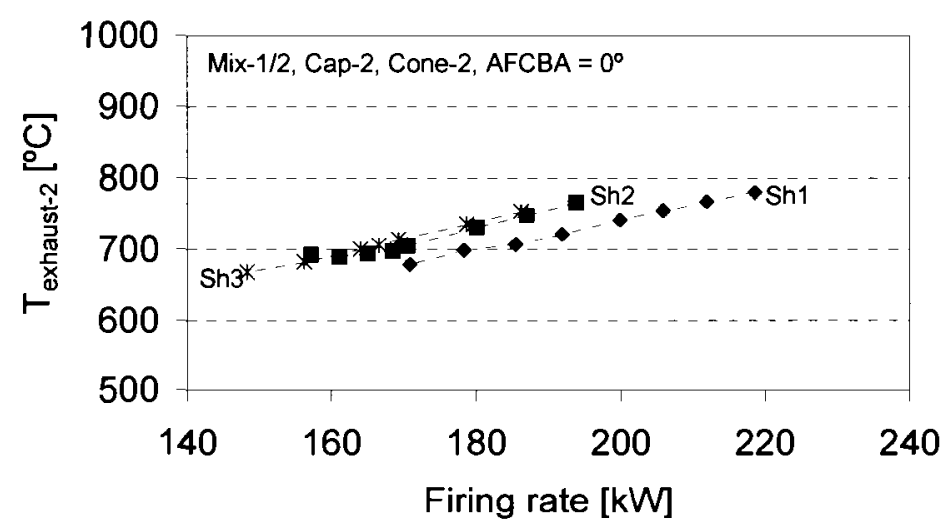

(c) Duct burner exhaust temperature

Figure 8.23: Effect of firing rate and $L_{\text {eff }} / D_{\text {shield }}$ shield ratio on the duct burner temperature (Mix-1/2, Cap-2 and Cap-2 at AFCBA $=0^{\circ}$ ) 
One explanation may be that the longer shield prevents early dilution of the flame region caused by the interaction with the unburned microturbine exhaust gases. This increases the flame temperature and NOx formation. Another reason responsible for the increase in combustion zone temperature may be the energy feedback from the shield, such as the heat transfer by radiation from the flame to the shield and back to the flue gases. Figure 8.23 (b) shows the increase in the conical inner surface temperature due to the heat transfer mechanisms from the flame on the surface. Figure 8.23 (c) presents the duct burner exhaust gas temperature. The figure does not show a remarkable increase of the exhaust gas temperature with the shield length and the range in general was between $700^{\circ} \mathrm{C}$ and $800^{\circ} \mathrm{C}$.

\subsubsection{Mix-1/2 and Cap- 4 combinations}

Cap-4 is a flat nozzle with eight holes, each of $3 \mathrm{~mm}$ in diameter. The fuel is injected at $90^{\circ}$ angle to the main flow stream inside the premixer. Cap-4 provides the duct burner with more fuel flow rate compared to Cap-2 (at the same fuel line pressure). Therefore, it increases the duct burner range of operation. The effect of conical burner pressure drop, $L_{e f f} / D_{\text {shield }}$ ratios (shield lengths) and blockage ratio (BR) on the performance of the duct burner will be presented in this section. The presentation of the results in this section will be similar to the way that Cap-2 results are presented. Each subsection will cover the effect of one of the three mentioned parameters. Selected duct burner temperature profiles and flame images will be presented for this case too, and a short summary in a graphical form will follow each subsection. 


\subsection{Effect of conical mesh burner pressure drop}

Figures 8.24, 8.25, 8.26 and 8.27 show the duct burner NOx and $\mathrm{CO}$ emissions and duct burner pressure drop ((a), (b) and (c)), as a function of firing rate at different annular blade angles, respectively for the duct burner configurations, (Mix-1/2, Cone-1, Sh1 and Cap4), (Mix-1/2, Cone-2, Sh1 and Cap4), (Mix-1/2, Cone-2, Sh2 and Cap4), and (Mix-1/2, Cone-3, Sh2 and Cap4). Each pair of figures is presented on one page, to help visualize the effect of using different conical pressure drops (cones). For example, Figures 8.24 and 8.25 use the same burner configuration and the only variable was the conical burner pressure drop. Cone-1 (74.7 Pa) was used in Figure 8.24 and Cone-2 (149 Pa) was used in Figure 8.25. As observed from the previously presented results (for Cap-2), for any configuration which included Sh1, the duct burner could be operated at a higher firing rate. The same result was observed with Cap-4. Figure 8.24 shows the duct burner operated stably in the range from $260 \mathrm{~kW}$ to $313 \mathrm{~kW}$. This is a broader stable operating range when compared to those results obtained with Cap-2, for the same case. The crossover point, where NOx and $\mathrm{CO}$ emissions are equal, generally occurred around 4 ppm for the AFCBA $=30^{\circ}$, corresponding to a FR of $289 \mathrm{~kW}$. CO emissions were less than $5 \mathrm{ppm}$ for all the settings tested in Figure 8.24 (b). For example, at a $10^{\circ}$ angle and $\mathrm{FR}=268 \mathrm{~kW}$, NOx emissions were $4 \mathrm{ppm}$ and $\mathrm{CO}$ emissions were 3.5 ppm. Figure 8.24 (c) shows the overall duct burner pressure drop results for these conditions. The points located on the y-axis represent the values of the measured pressure drop without combustion (DB is not running). Combustion approximately doubles the value of the duct burner overall pressure drop.

With the higher pressure drop cone, Cone-2, Figure 8.25 shows the shift of the lower stable limit from $260 \mathrm{~kW}$ to $199 \mathrm{~kW}$. In Figure 8.25 (b), the results show an increase in $\mathrm{CO}$ emissions with the increase of the conical burner pressure drop (4 $\mathrm{ppm}<\mathrm{CO}<10 \mathrm{ppm}$ ). For this case, the lowest NOx emissions value with stable combustion was 2 ppm. Figure 8.25 (c) shows the pressure drop for this case. This 
figure shows pressure drop peak values; these values were measured when the duct burner was operated near the blow-off limit. The pressure drop value exceeds the limit at an AFCBA of $40^{\circ}$.

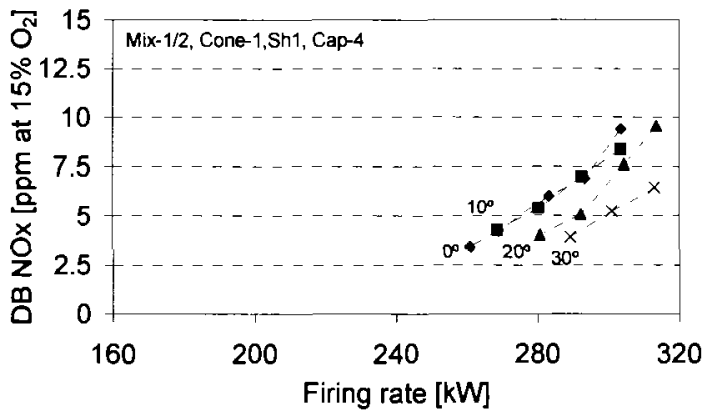

(a) DB NOx emissions

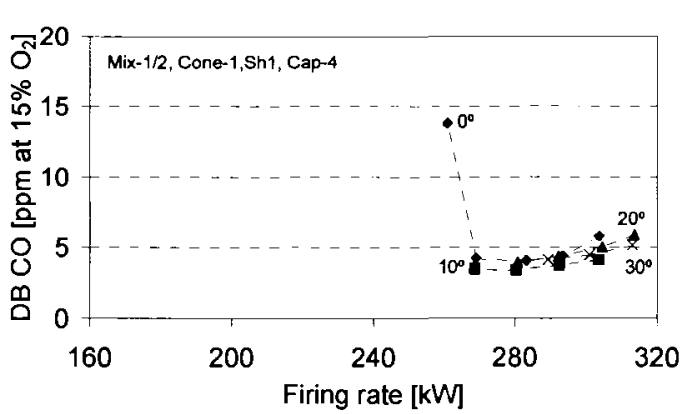

(b) DB CO emissions

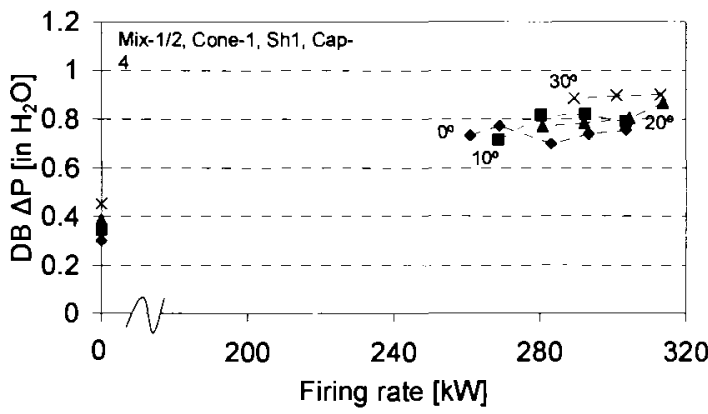

(c) DB pressure drop

Figure 8.24: Effect of firing rate and AFCBA on duct burner performance (Mix-1/2, Cap-4, Cone-1 and Sh1)

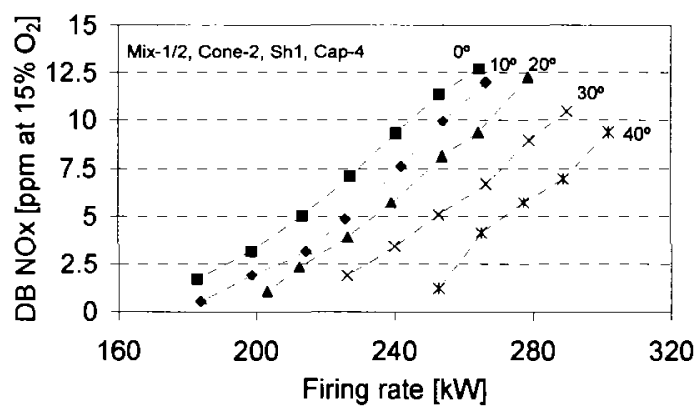

(a) DB NOx emissions

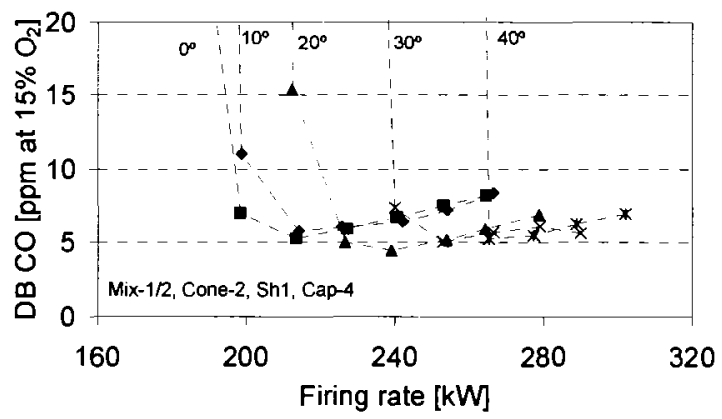

(b) DB CO emissions

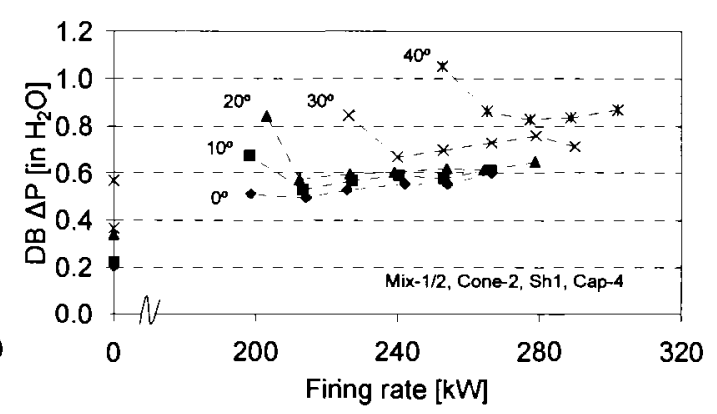

(c) DB pressure drop

Figure 8.25: Effect of firing rate and AFCBA on duct burner performance (Mix-1/2, Cap-4, Cone-2 and Sh1) 
Figures 8.26 and 8.27 are similar to Figures 8.24 and 8.25 , except they are for Cone-2 (149 Pa) and Cone-3 (224 Pa) to show the effect of cone pressure drop. Figure 8.26 shows the operation of the duct burner in the range of $176 \mathrm{~kW}$ to $311 \mathrm{~kW}$. NOx emissions were between 1.83 and $12.5 \mathrm{ppm}$ (Figure 8.26 (a)) and $\mathrm{CO}$ emissions were between 3.54 and 10 ppm (Figure 8.26 (b)). Figure 8.26 (c) represents the duct burner pressure drop results for this case (Mix-1/2, Cap-4, Cone-2 and Sh2).

As the conical burner pressure drop increases (Cone-3 was used), an improvement in the operating range was observed, Figure 8.27, and the operating range was shifted to between $184 \mathrm{~kW}$ to $293 \mathrm{~kW}$. Lower NOx emissions were also found for this case $(1.32 \mathrm{ppm}$, Figure 8.27 (a)). During this test, CO emissions were between 6.6 and $15 \mathrm{ppm}$ (Figure 8.27 (b)). The overall duct burner pressure drop is presented in Figure 8.27 (c). The maximum pressure value reached during this test was around $224 \mathrm{~Pa}$.

In most cases, when the duct burner was tested with Cap-4, the flame blow-off occurred when the blue flame became too long. Flame instability started at the lower part of the conical burner and local extinction was observed. Very long blue flames were also observed at the upper part of the cone. Usually this process was followed by flame blow-off. In some cases, even with no flame at the lower half of the cone, combustion continued with long cone-tip flames. This was accompanied by high $\mathrm{CO}$ emissions, due to poor combustion. At the second lowest firing rate setting, blow-off occurs. When tested, the duct burner with burner configurations Cone-3 with Sh1, Sh7 and Sh8 and Cone-1 with Sh1, the flame blow-off was accompanied by a vibration of the complete duct burner. All the observations of the flame were made through the viewing ports located on the duct burner. The indication of the blow-off limit also can be seen for some cases in the duct burner pressure drop results (see the peak points on the duct burner pressure drop graphs (figures labelled (c)). 


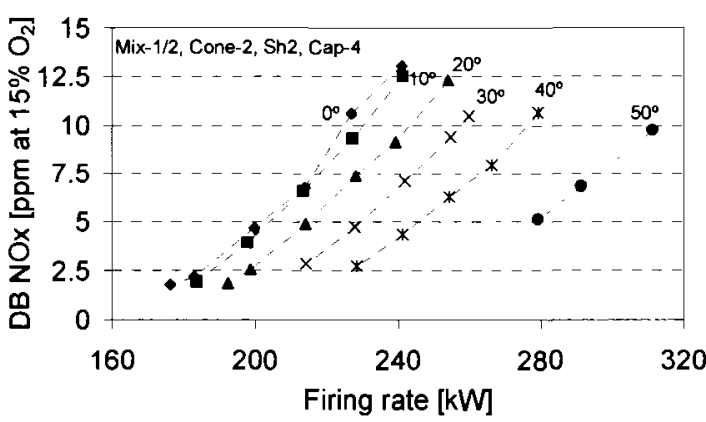

(a) DB NOx emissions

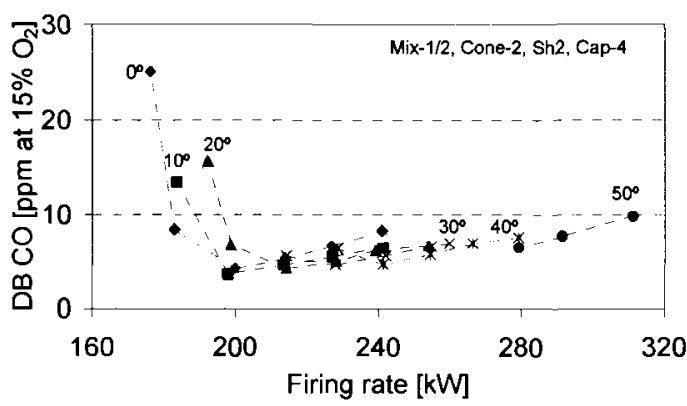

(b) DB CO emissions

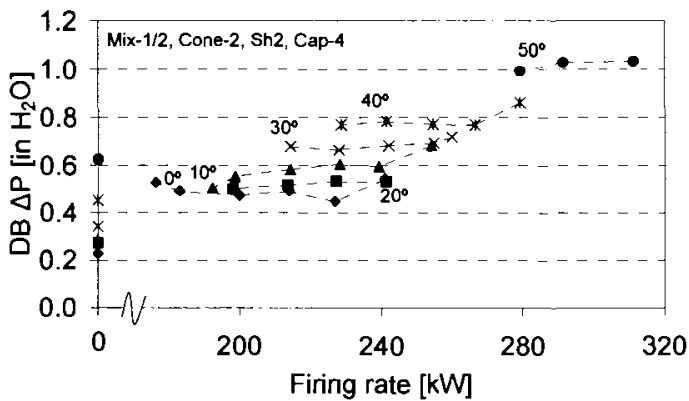

(c) Duct burner pressure drop

Figure 8.26: Effect of firing rate and AFCBA on duct burner performance (Mix-1/2, Cap-4, Cone-2 and Sh2)

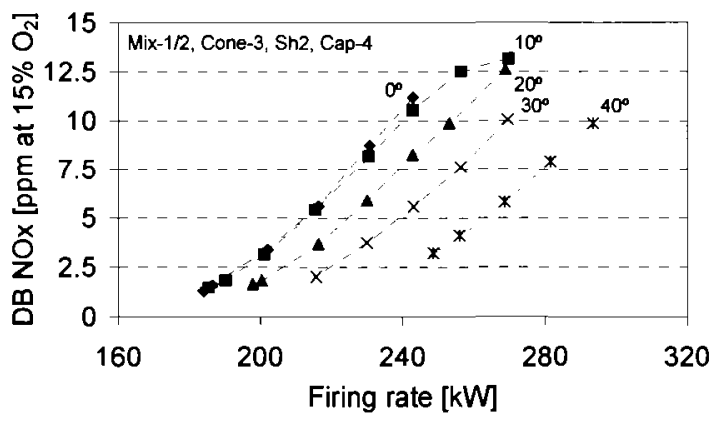

(a) DB NOx emissions

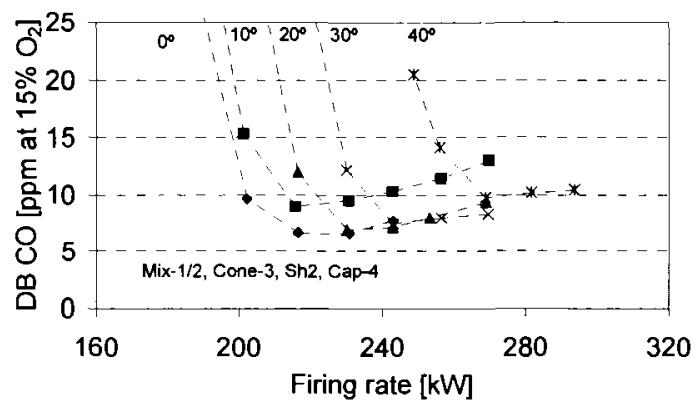

(b) DB CO emissions

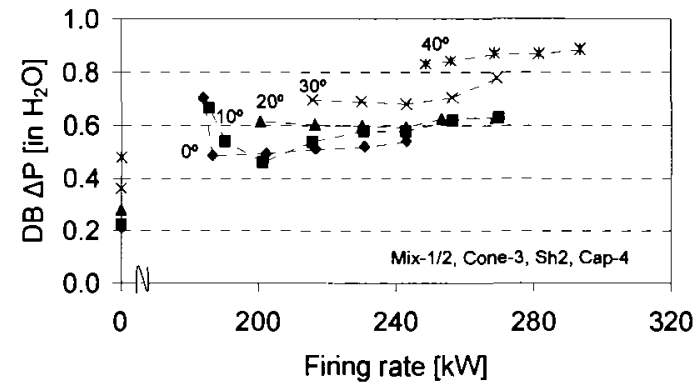

(c) Duct burner pressure drop

Figure 8.27: Effect of firing rate and AFCBA on duct burner performance (Mix-1/2, Cap-4, Cone-3 and Sh2) 
Figures 8.28 and 8.29 summarize the effect of using different pressure drop cones on the performance of the duct burner. Both figures contain the results of NOx and $\mathrm{CO}$ emissions and the overall duct burner pressure drop plots. Lowering of the conical pressure drop values decreases $\mathrm{NOx}$ and $\mathrm{CO}$ emissions and the stable operating range shifts to lower firing rate values. This is due to the higher temperature and the increase in the local gas flow momentum. Again, Cone-3 shows results lying between the two other cones (Cone-1 and Cone-2). In the discussion of the tests with Cap-2 and Cone-3, some of the burner configurations show results similar to those of Cone- 1 and in others the results were similar to those with Cone-2. Figures 8.28 and 8.29 respectively used $\mathrm{Sh} 1$ and $\mathrm{Sh} 2$ as the variable parameter in the test results. The plots labelled (c) in both figures, presents the duct burner pressure drop results. The Cone-3 results show a peak value near the blow-off limit. The effect of the different shield lengths on the performance of the duct burner are presented in the following subsection.

Figure 8.30 (a), (b), (c), (d) and (e) respectively show the effect of the conical burner pressure drop as a function of firing rate on incoming reactants temperature, mesh burner inner surface temperature, mesh burner outer surface temperature (hot side), combustion zone and duct burner exhaust gas temperature, for the case presented in Figure 8.28 (Mix-1/2, Cap-4 and Sh1 at AFCBA $=0^{\circ}$ ). Figures 8.30 (a) and (b) clearly show that Cone-1, which has the lower pressure drop (higher porosity), had the highest temperature compared to the other cones (lower porosity). This is attributed to preheat of the reactants. Preheating gives additional enthalpy to the unburned mixture without dilution by combustion products. Figure 8.30 (c) and (d) confirms this explanation and shows the lowest mesh surface (hot side) and combustion zone temperatures which leads to lower NOx emissions with Cone-1. The exhaust gas temperature profiles are presented in Figure 8.30 (e). The measured range was between 700 and $900^{\circ} \mathrm{C}$ 


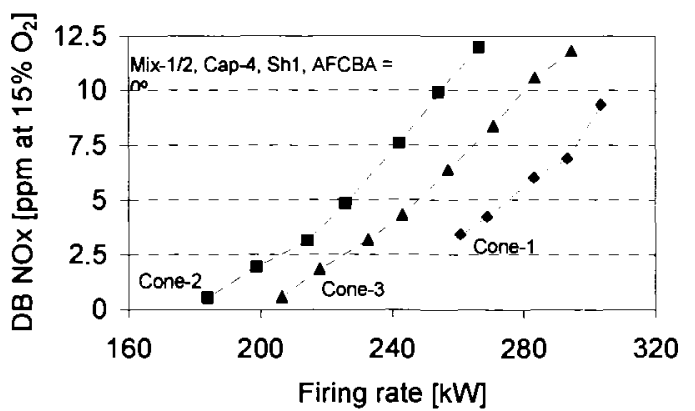

(a) DB NOx emissions

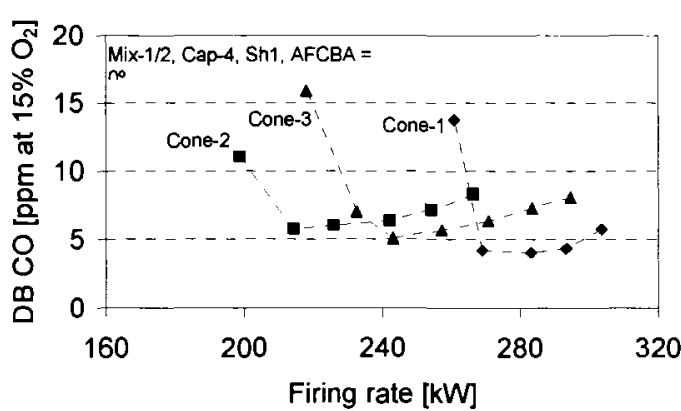

(b) DB CO emissions

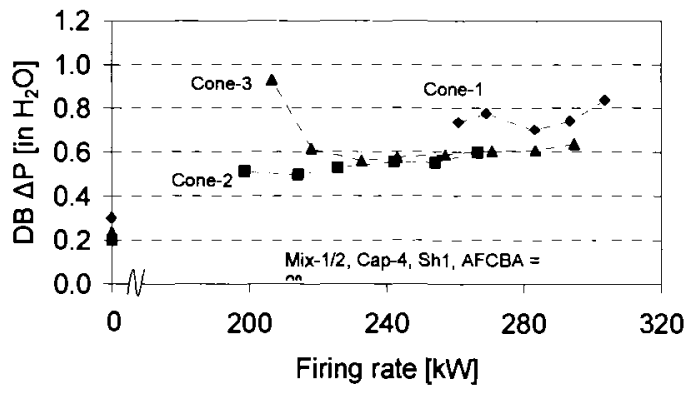

(c) DB pressure drop

Figure 8.28: Effect of firing rate and conical burner pressure drop on duct burner performance (Mix-1/2, Cap-4 and Sh1 at $\mathrm{AFCBA}=0^{\circ}$ )

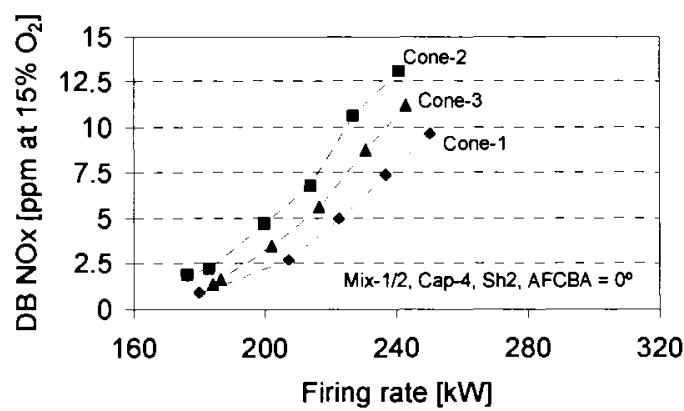

(a) DB NOx emissions

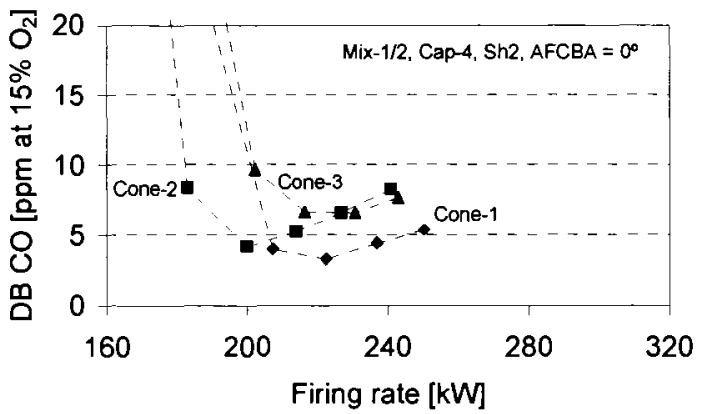

(b) DB CO emissions

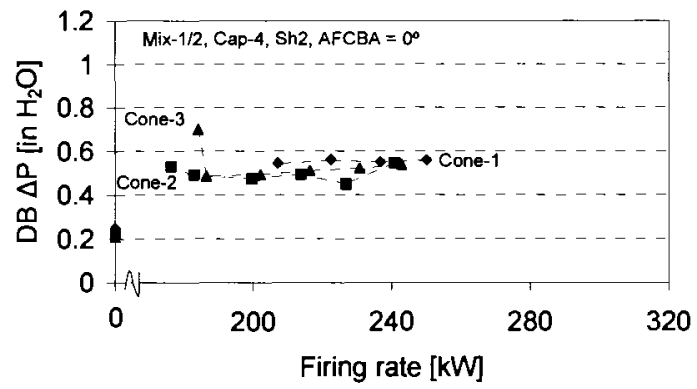

(c) DB pressure drop

Figure 8.29: Effect of firing rate and conical burner pressure drop on duct burner performance (Mix-1/2, Cap-4 and Sh2 at AFCBA $=0^{\circ}$ ) 


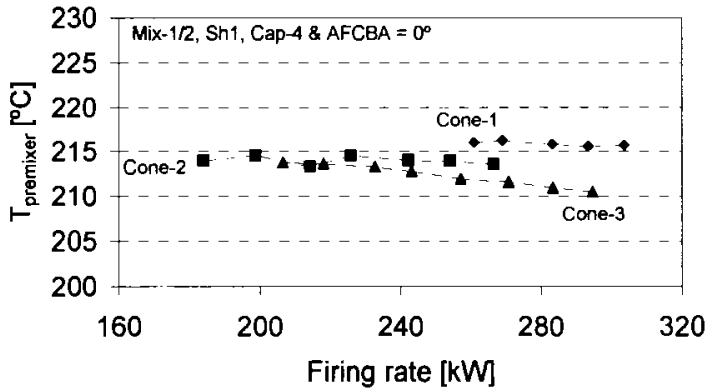

(a) Premixer exit temperature

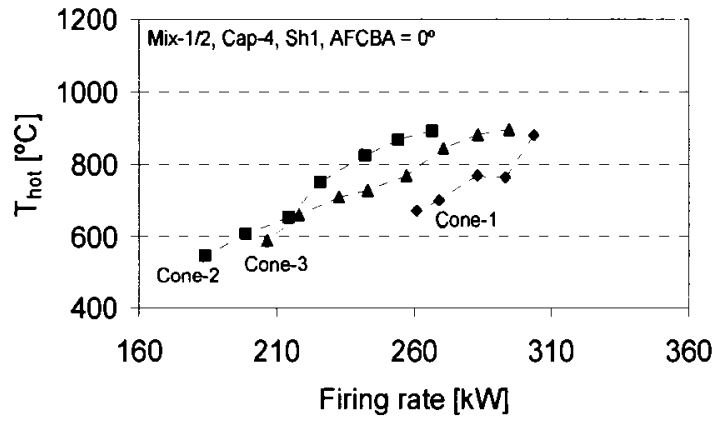

(c) Conical burner hot surface temperature

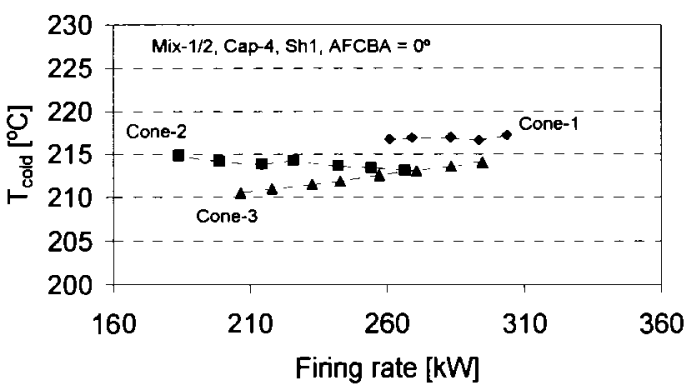

(b) Conical burner cold surface temperature

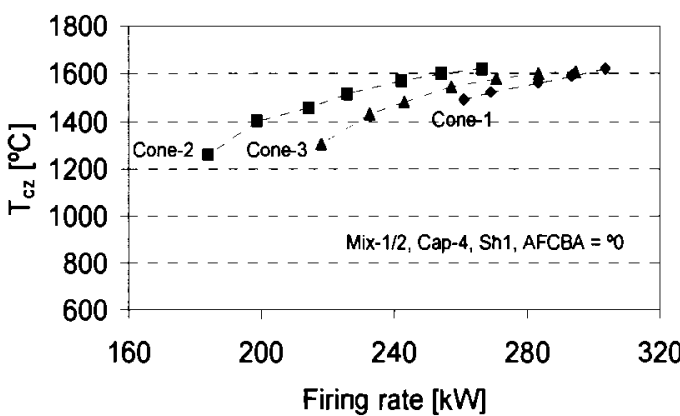

(d) Combustion zone temperature

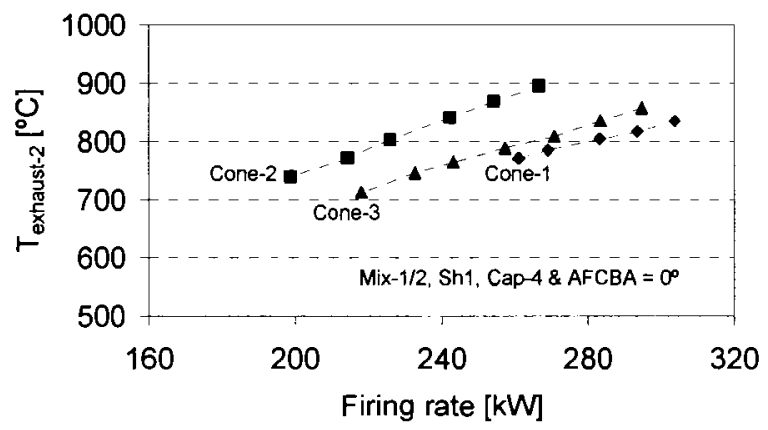

(e) Duct burner exhaust temperature

Figure 8.30: Effect of firing rate and conical burner pressure drop on the duct burner temperature (Mix-1/2, Cap-4 and Sh1 at AFCBA $=0^{\circ}$ )

As Figures 8.28 and 8.29 , Figure 8.30 shows the anomalous behaviour of Cone 3 comparing with the other cones (does not follow the Cone 1 to Cone 2 to Cone 3 pattern). This behaviour occurs especially when Cone-3 is tested with the short shields (Sh1 and Sh2 and Sh7).Other observation recorded with that geometry was the higher pressure peak value attained very close to the blow-off limit. This behaviour of Cone-3 may 
be attributed to the interaction between the aerodynamics of the flow field and the heat transfer mechanism. The lower porosity Cone-3 affects the local momentum through the wire-mesh and moves the combustion zone towards the surface of the mesh and that affects the burner heat transfer mechanism.

\subsection{Effect of conical burner shield $\left(L_{e f f} / D_{\text {shield }}\right)$ ratio}

Different configurations were used to investigate the effect of the shield length or $L_{e f f} / D_{\text {shield }}$ on duct burner performance with Cap- 4 . The presentation of the results in this subsection is divided in to three pairs of plots, each pair presents the results of one cone with the use of two different $L_{e f f} / D_{\text {shield }}$ ratio shields. Figures 8.31 and 8.32 are for Cone-1 with $\mathrm{Sh} 2\left(\mathrm{BR}=0.4\right.$ and $\left.L_{\text {eff }} / D_{\text {shield }}=0.8\right)$ and $\mathrm{Sh} 4(\mathrm{BR}$ $=0.4$ and $\left.L_{\text {eff }} / D_{\text {shield }}=1.7\right)$ respectively. Both figures contain 3 different plots labelled (a), (b) and (c). They show NOx and CO emissions and the duct burner pressure drop respectively. The stable operating range, with Sh2 (Figure 8.31), was between $207 \mathrm{~kW}$ and $307 \mathrm{~kW}$. At this range, the lowest emissions recorded were 2.7 ppm for NOx (Figure 8.31 (a)) and 4 ppm CO (Figure 8.31 (b)) at $207 \mathrm{~kW}$ with stable combustion. Using Sh4 (Figure 8.32) the range shifted to between $182 \mathrm{~kW}$ and 293 $\mathrm{kW}$ and the lowest emissions were $2.9 \mathrm{ppm}$ for NOx (Figure 8.32 (a)) and $3 \mathrm{ppm}$ for $\mathrm{CO}$ emissions (Figure 8.32 (b)). Using a longer shield, the duct burner could provide a stable combustion range at a higher AFCBA (up to $50^{\circ}$ ) and higher firing rate values. The trade-off in this case was the high overall duct burner pressure drop which exceeded the maximum limit value $249 \mathrm{~Pa}$, see Figures 8.31 (c) and 8.32 (c). 


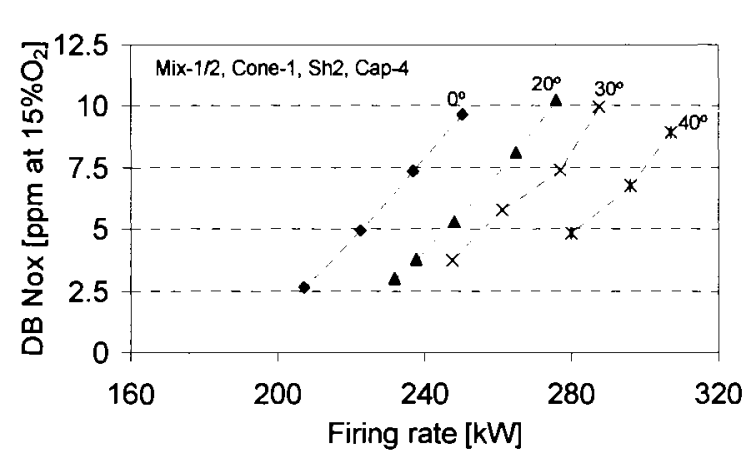

(a) DB NOx emissions

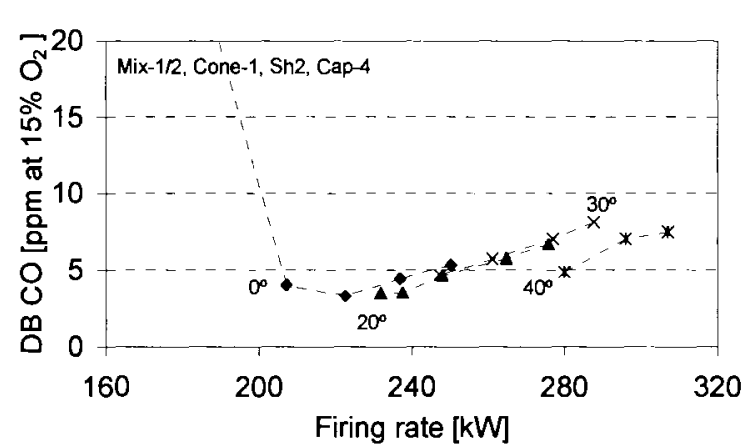

(b) DB CO emissions

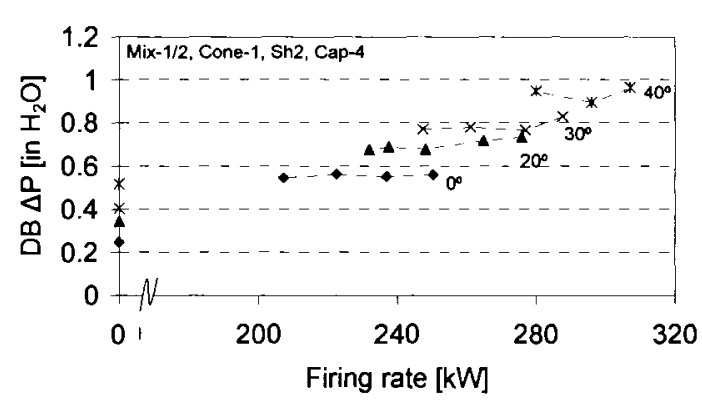

(c) DB pressure drop

Figure 8.31: Effect of firing rate and AFCBA on duct burner performance (Mix-1/2, Cap-4, Cone1 and Sh2)

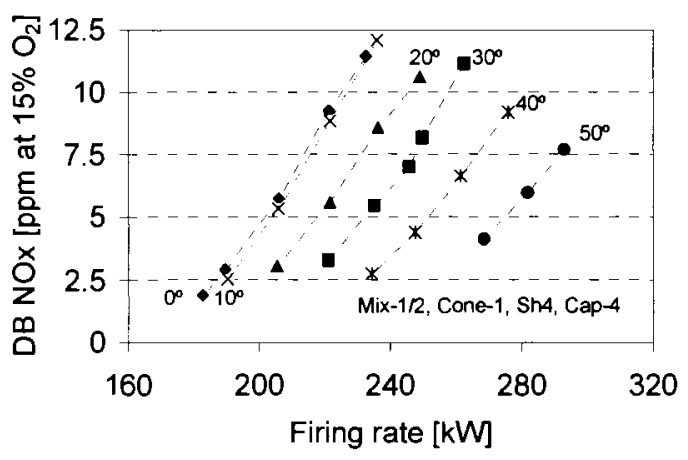

(a) DB NOx emissions

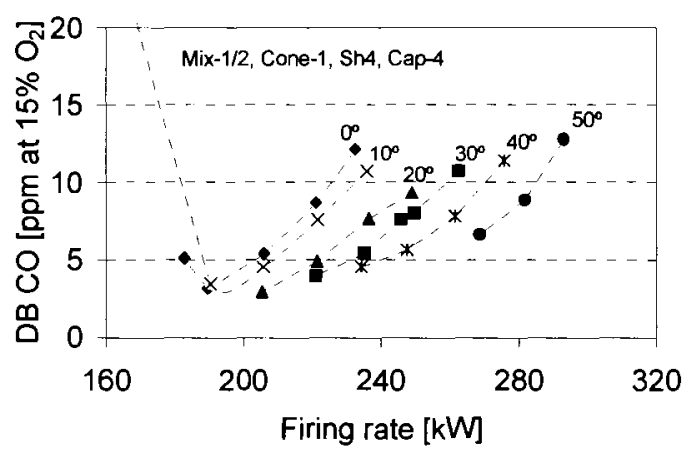

(b) DB CO emissions

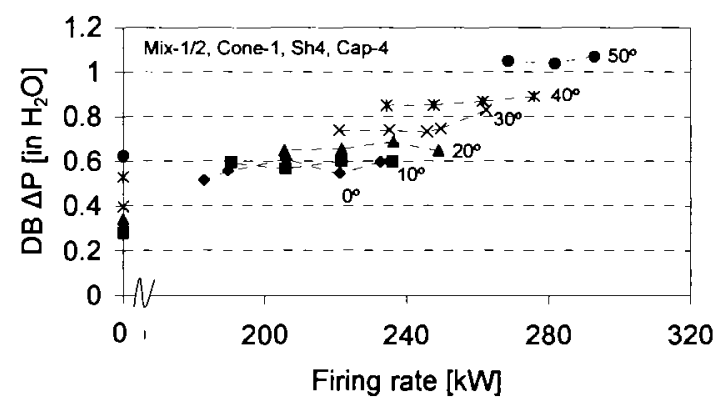

(c) DB pressure drop

Figure 8.32: Effect of firing rate and AFCBA on duct burner performance (Mix-1/2, Cap-4, Cone-1 and Sh4) 
As before, the temperatures measured during these tests are presented to help understand the burner performance. Figure 8.33 shows the various temperature measurements for the same conditions as those for Figure 8.31. This figure contains six different plots, each one showing the effect of firing rate and AFCBA on the specific temperature. Figure 8.33 (a) illustrates the temperature profiles of the unburned mixture (oxidant and fuel) measured using K-type thermocouples located at the centre of the premixer exit plane and upstream of the conical burner base. An average of $215^{\circ} \mathrm{C}$ was measured. Figures 8.33 (b), 8.33 (c) and 8.33 (d) respectively represent the surface temperature measurements at the conical burner inner (cold face), the conical burner outer surface (hot side) and the conical burner shield outer surface temperature. The cold surface temperature shows an average of $220^{\circ} \mathrm{C}$. The effect of different AFCBA settings is small. As the AFCBA is reduced, less oxidant is forced in the combustion zone and the cold side surface temperature increases. The increase in this temperature results from the increase in the combustion zone temperature (Figure 8.33 (d)). Conductive heat transfer brings more heat to the cold side surface. Increasing the firing rate increases the combustion zone temperature and the hot surface temperature of the matrix as well. Figure 8.33 (d) shows the conical burner shield outer surface temperature profiles for the same case. The maximum temperature recorded on this figure was $362^{\circ} \mathrm{C}$. Figure 8.33 (e) shows the combustion zone temperature profiles for different $\mathrm{AFCBA}$ and at different firing rates. The improvements of the level of the duct burner exhaust gas temperature are presented in Figure 8.33 (f). A range from $750^{\circ} \mathrm{C}$ to $850^{\circ} \mathrm{C}$ was recorded during these tests.

Figures 8.34 and 8.35 (OMAR: Try to make the figures to be closer to the discussion.) present the duct burner emissions and overall pressure drop. Cone-2 was used in these plots with both Sh3 $\left(\mathrm{BR}=0.4\right.$ and $\left.L_{\text {eff }} / D_{\text {shield }}=1.5\right)$ and Sh4 $(\mathrm{BR}=$ 0.4 and $\left.L_{e f f} / D_{\text {shield }}=1.7\right)$. The stable combustion range as shown in Figure 8.34 was from $171 \mathrm{~kW}$ to $268 \mathrm{~kW}$. CO emissions were less than $5 \mathrm{ppm}$. The range of NOx emissions was from $2 \mathrm{ppm}$ to $7.5 \mathrm{ppm}$. When Sh4 was used, as in Figure 8.35, the 
stable combustion range was from $162 \mathrm{~kW}$ to $281 \mathrm{~kW}$. For this case, CO emissions increased with increase in the $L_{\text {eff }} / D_{\text {shield }}$ ratio. In this case, test points covering a wide range of operating conditions produced NOx emissions below 5 ppm.

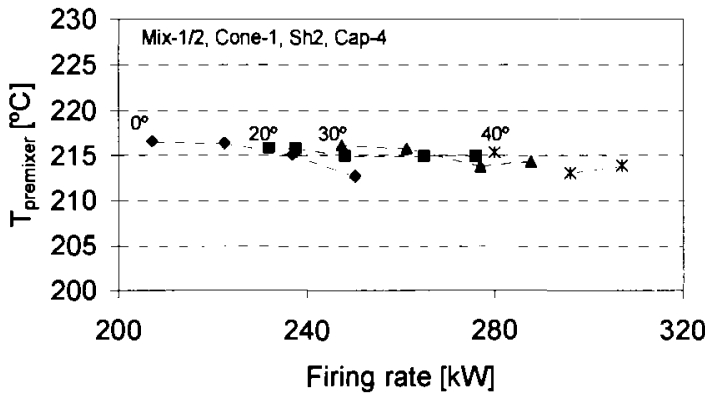

(a) Premixer exit temperature

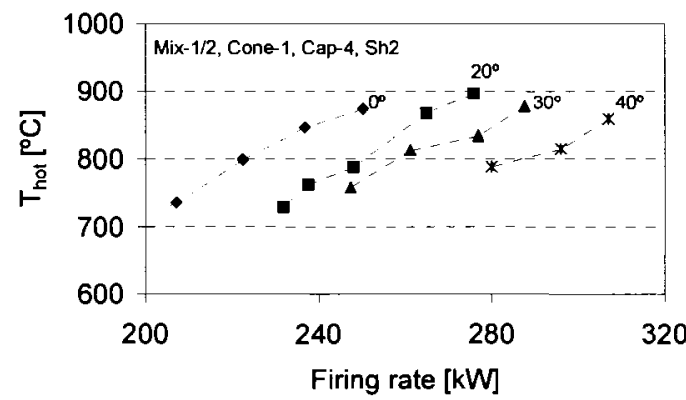

(c) Conical burner hot surface temperature

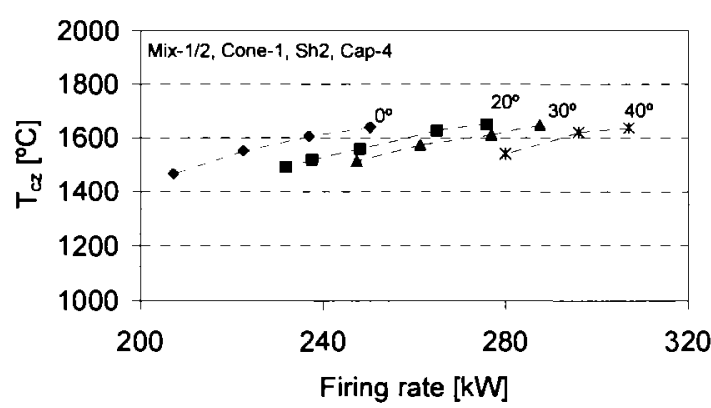

(e) Combustion zone temperature

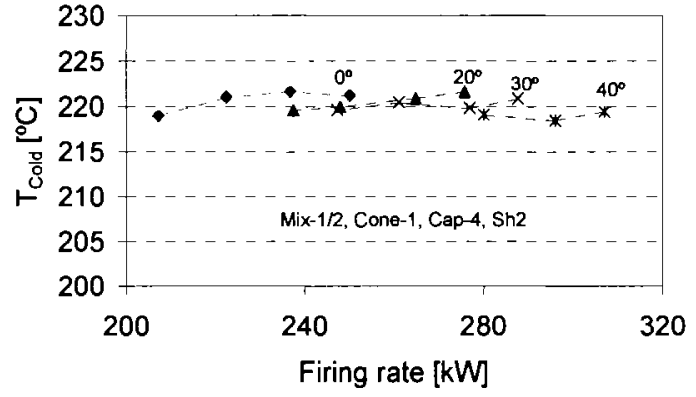

(b) Conical burner cold surface temperature

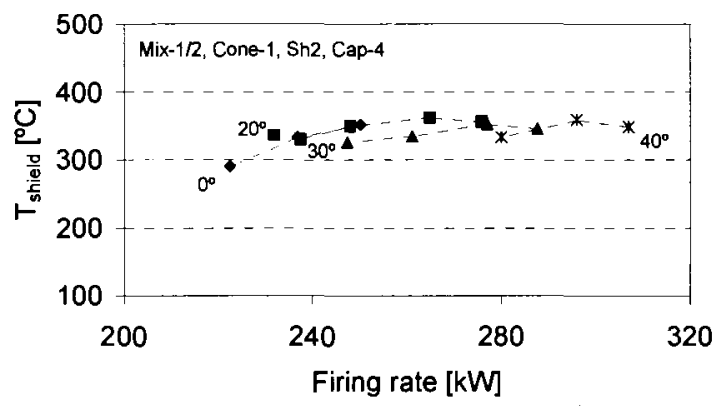

(d) Shield outer surface temperature

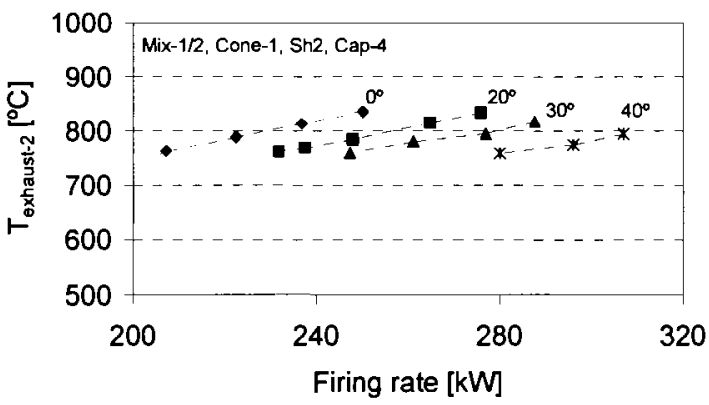

(f) DB exhaust gases temperature

Figure 8.33: Effect of firing rate and AFCBA on duct burner temperatures at different locations for burner configuration (Mix-1/2, Cap-4 and Cone-1 with Sh2) 
Cone-3 (224 Pa) was used in the last set of figures, Figure 8.36 and 8.37. In this case, Shl and Sh4 were used for the comparison. When Shl was used in Figure 8.36, the stable operating range was from $203 \mathrm{~kW}$ to $305 \mathrm{~kW}$. With Sh4 (Figure 8.37) the range was shifted to a lower firing rate $(168 \mathrm{~kW}$ to $280 \mathrm{~kW})$. From Figure 8.37 , at $184 \mathrm{~kW}$, NOx emissions were $2.4 \mathrm{ppm}$ and $\mathrm{CO}$ emissions were $3.6 \mathrm{ppm}$. A low value of NOx emissions equal to $1 \mathrm{ppm}$ was measured in this test run.

A close look at $\mathrm{CO}$ emissions in Figures 8.36 (b) and 8.37 (b), starting at the low firing rate (the blow-off limit) shows that in general by increasing firing rate, $\mathrm{CO}$ emissions decreased rapidly and almost levelled out at a single digit value to give a good operating range. The increase in $\mathrm{CO}$ emissions in this stable zone as the firing rate increased was very small and remained below $10 \mathrm{ppm}$. After that zone, $\mathrm{CO}$ emissions increased gradually, which is attributed to higher dissociation levels. The overall duct burner pressure drop results for the above mentioned cases are presented in Figures 8.36 (c) and 8.37 (c). The figures show an increase in the duct burner total pressure drop with the combustion process. Also, it is clear from the figure that as the flame stabilizes on the mesh. The pressure drop readings remained almost constant with the different firing rates. At AFCBA of 50 degrees (Figures 8.36 (c) and 8.37 (c)), the pressure drop had a value below $249 \mathrm{~Pa}$, which is one of the duct burner operating limits. Some of the pressure drop results, such as Figure 8.36 (c), show an increase in the pressure drop when operating near the lower stability limit (flame blow-off). Of the shields that have a blockage ratio of 0.4 presented in this subsection, Sh1 was the only one showing this peak in the pressure drop value, especially when it was combined with Cone-3. The reason may be attributed to the interaction between the bypass flow and the combustion products. 


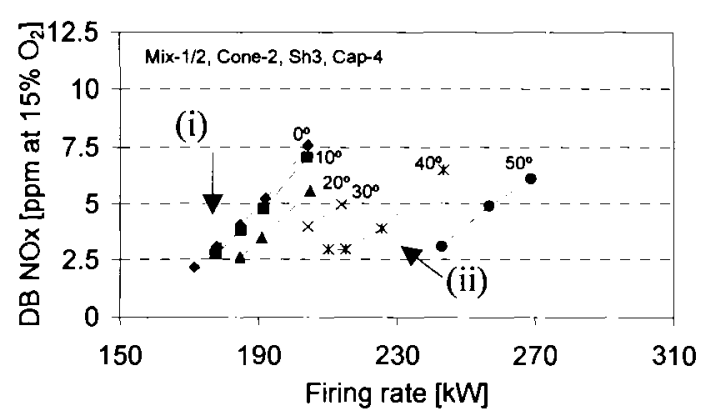

(a) DB NOx emissions

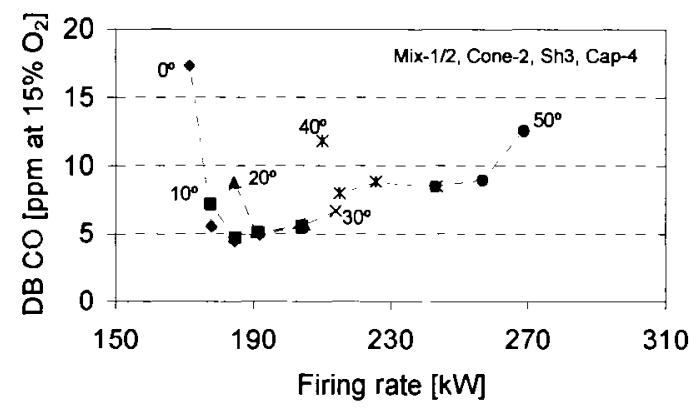

(b) DB CO emissions

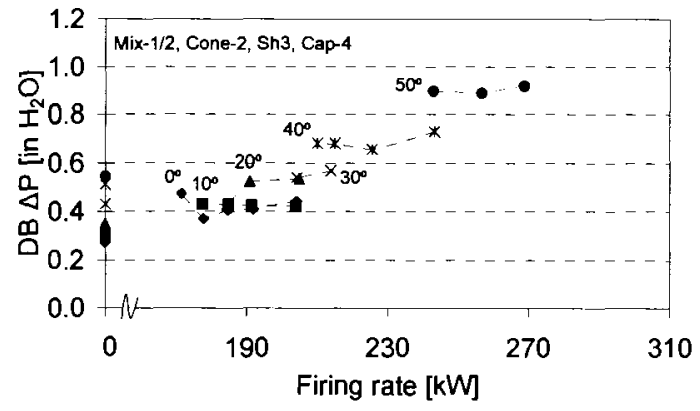

(c) $\mathrm{DB}$ pressure drop

Figure 8.34: Effect of firing rate and AFCBA on duct burner performance (Mix-1/2, Cap-4, Cone-2 and Sh3)

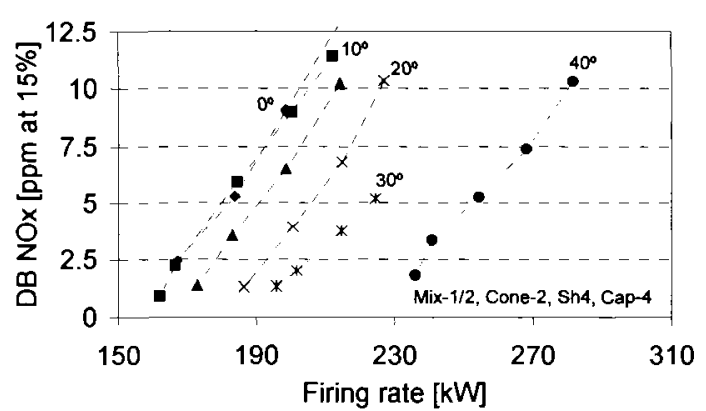

(a) DB NOx emissions

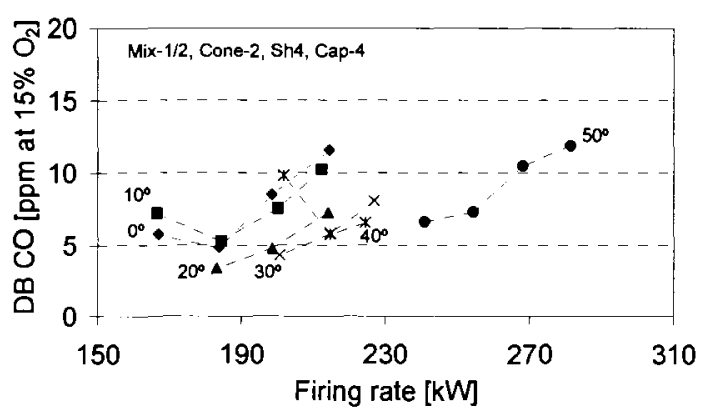

(b) DB CO emissions

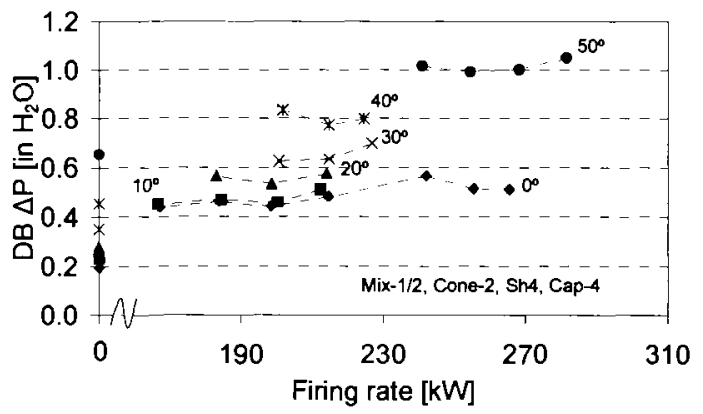

(c) DB pressure drop

Figure 8.35: Effect of firing rate and AFCBA on duct burner performance (Mix-1/2, Cap-4, Cone-2 and Sh4) 


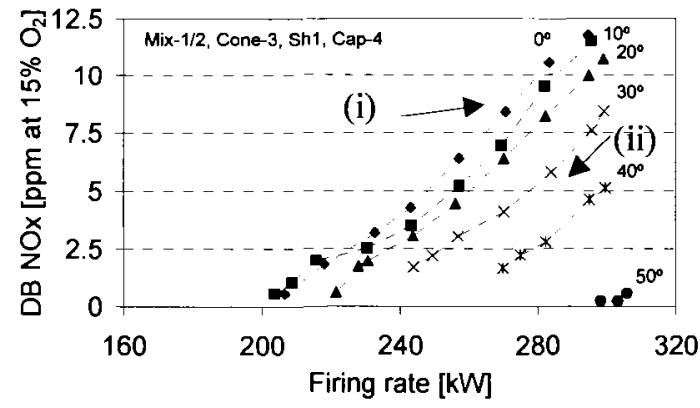

(a) DB NOx emissions

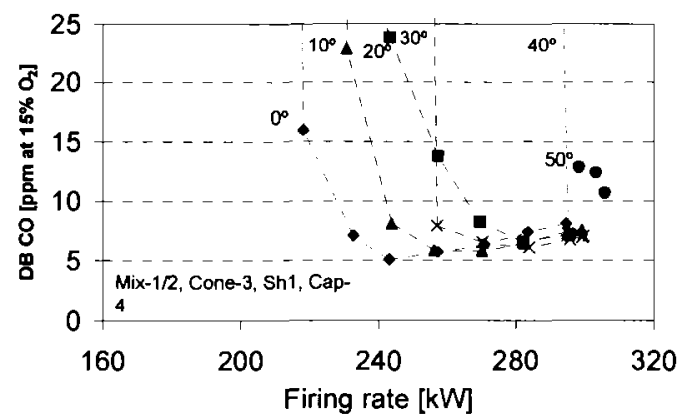

(b) DB CO emissions

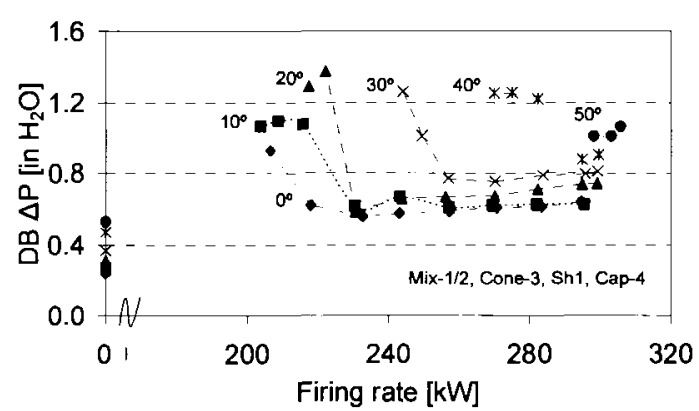

(c) DB pressure drop

Figure 8.36: Effect of firing rate and AFCBA on duct burner performance (Mix-1/2, Cap-4, Cone-3 and Sh1)

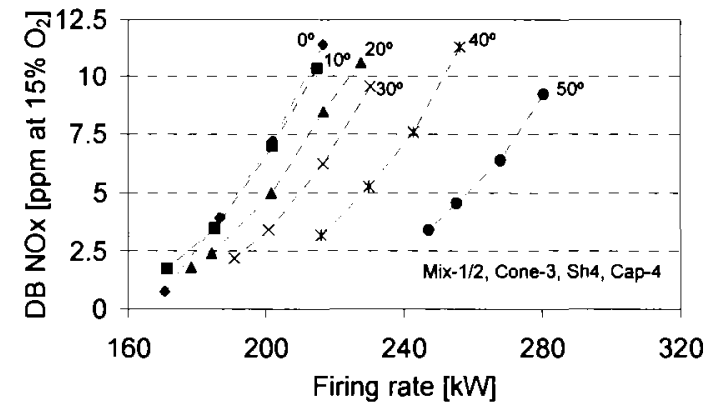

(a) DB NOx emissions

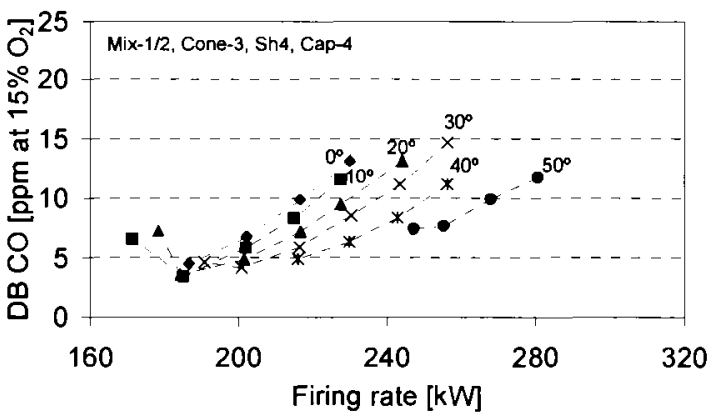

(b) DB CO emissions

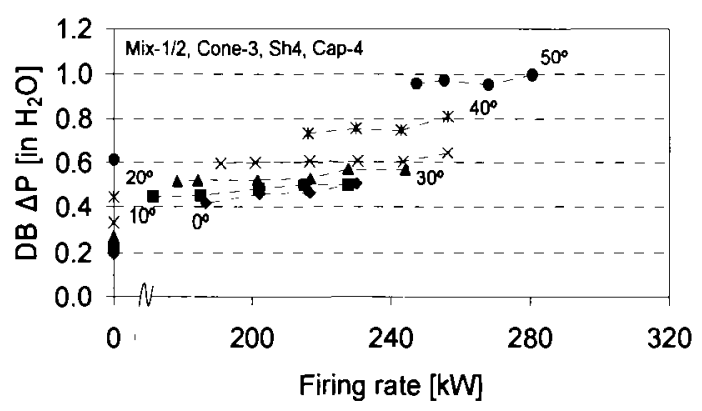

(c) DB pressure drop

Figure 8.37: Effect of firing rate and AFCBA on duct burner performance (Mix-1/2, Cap-4, Cone-3 and Sh4) 
Figures 8.38 and 8.39 show different stable flame images for selected operating points discussed in this section. Each figure contains two images labelled (i) and (ii). The same labels are used on the original results to show the conditions for the presented image. On each image, the firing rate value, NOx and $\mathrm{CO}$ emissions, equivalence ratio, blade angle and the burner parameters are indicated. Figure 8.38 (image ii) shows the burner operating in a blue flame mode; in this case more oxidant is forced to flow through the conical burner (higher AFCBA and so higher $M R_{C F}$ ) compared with image (i), where the $\mathrm{AFCBA}=0^{\circ}$. By comparing the flame images presented in Figure 8.39 and those presented in Figure 8.38 or the previously presented images, the image 8.39 (i) shows that the duct burner is operating with a hotter wire-mesh burner temperature than the other cases. As mentioned before, when operating at higher equivalence ratio, the mode of operation moves towards the radiant mode of operation. At the radiant mode of operation, the surface combustion flame will stabilize within the wire-mesh or just very close to the surface, which makes the surface hotter and glowing red, resulting in a reduction of the overall heat extraction (from the exhaust gases to the HRS).

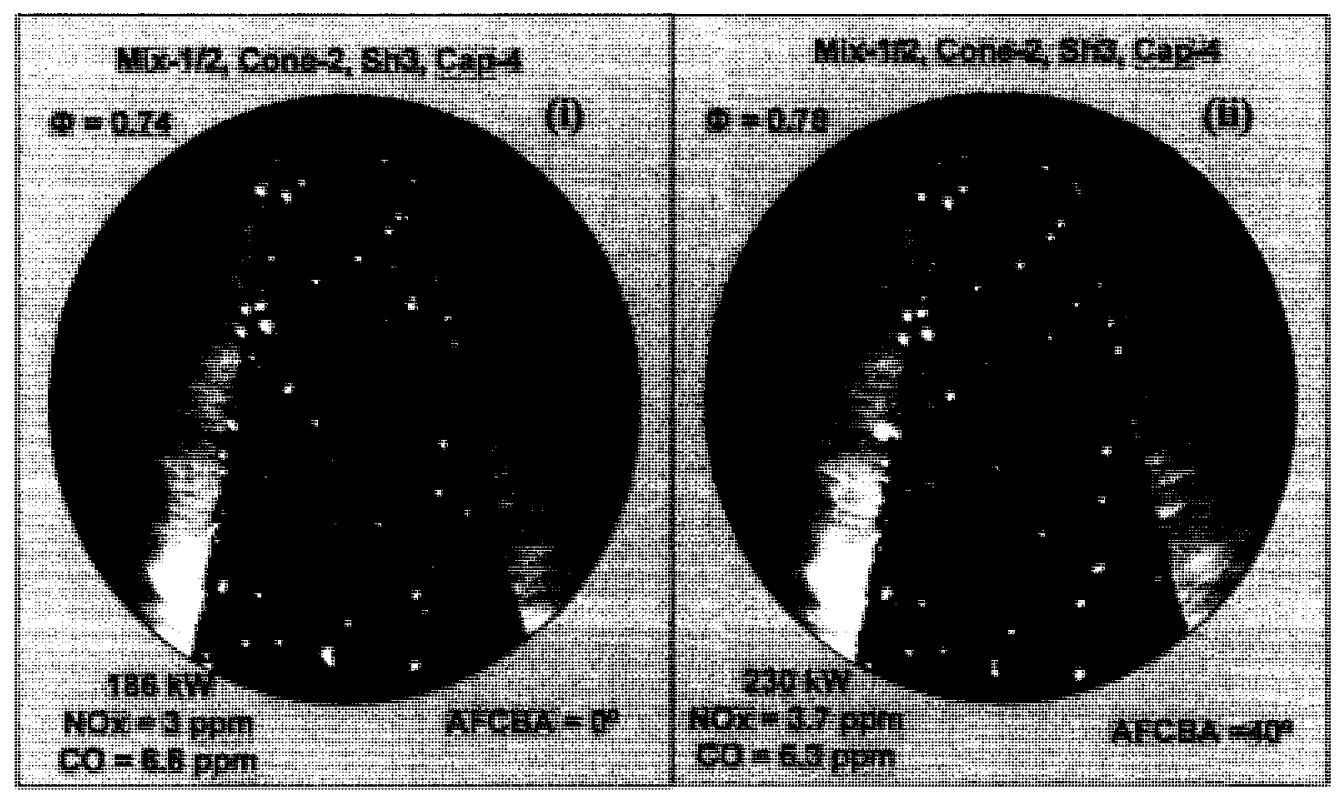

Figure 8.38: Flame images taken for points (i) and (ii) in Figure 8.34 (a) 


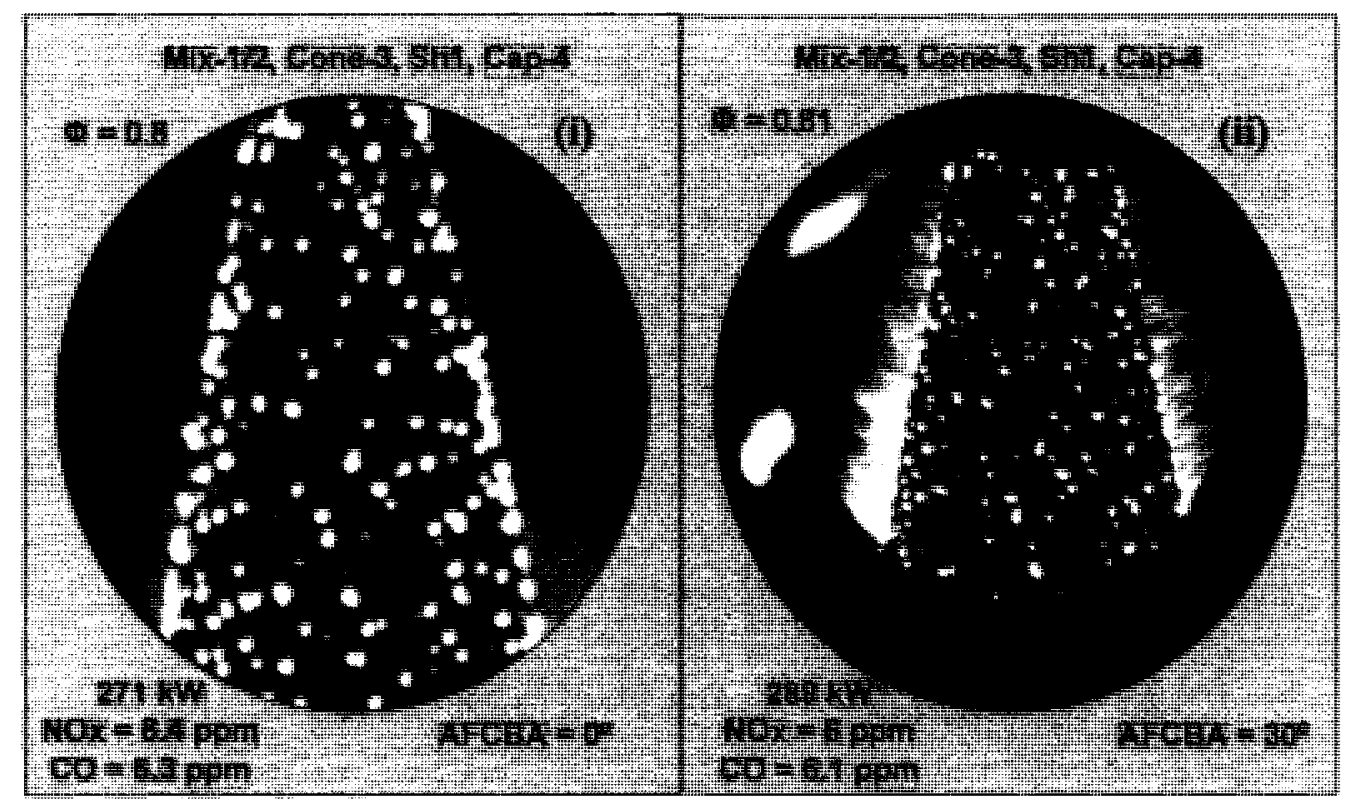

Figure 8.39: Flame images taken for points (i) and (ii) in Figure 8.36 (a)

One case was selected to summarize the effect of shield length and firing rate on NOx and CO emissions. Figure 8.40 (a) shows NOx emissions for all the shields used in the present investigation tested with burner configuration Mix-1/2, Cone-2 and Cap- 4 with AFCBA $=0^{\circ}$. For the shields with $\mathrm{BR}=0.4$, as the length of the shield increased, the lower blow-off limit decreased and the stable operating zone became wider. The entire stable operating zone moved towards lower firing rates. Longer shields provide more protection to the flame from the bypassed flow. Also, the longer shields work as a radiation shield (less heat loss), which leads to an increase in the combustion zone temperature and that tends to keep the flame stable at leaner mixtures. Shields with blockage ratio of 0.6 will be discussed in the following section, but only for general comparisons. The results of Sh7 and Sh8 $(B R=0.6)$ are presented in Figure 8.40. When using shields with $\mathrm{BR}=0.6$, the burner operated at high firing rate with low emissions and with a limited operating range. Figure 8.40 (b) shows that for a fixed firing rate, as the length of the shield increases $(B R=0.4)$, $\mathrm{CO}$ emissions increase. But for shields with $\mathrm{BR}=0.6$ the opposite is true. This can be attributed to several causes. 


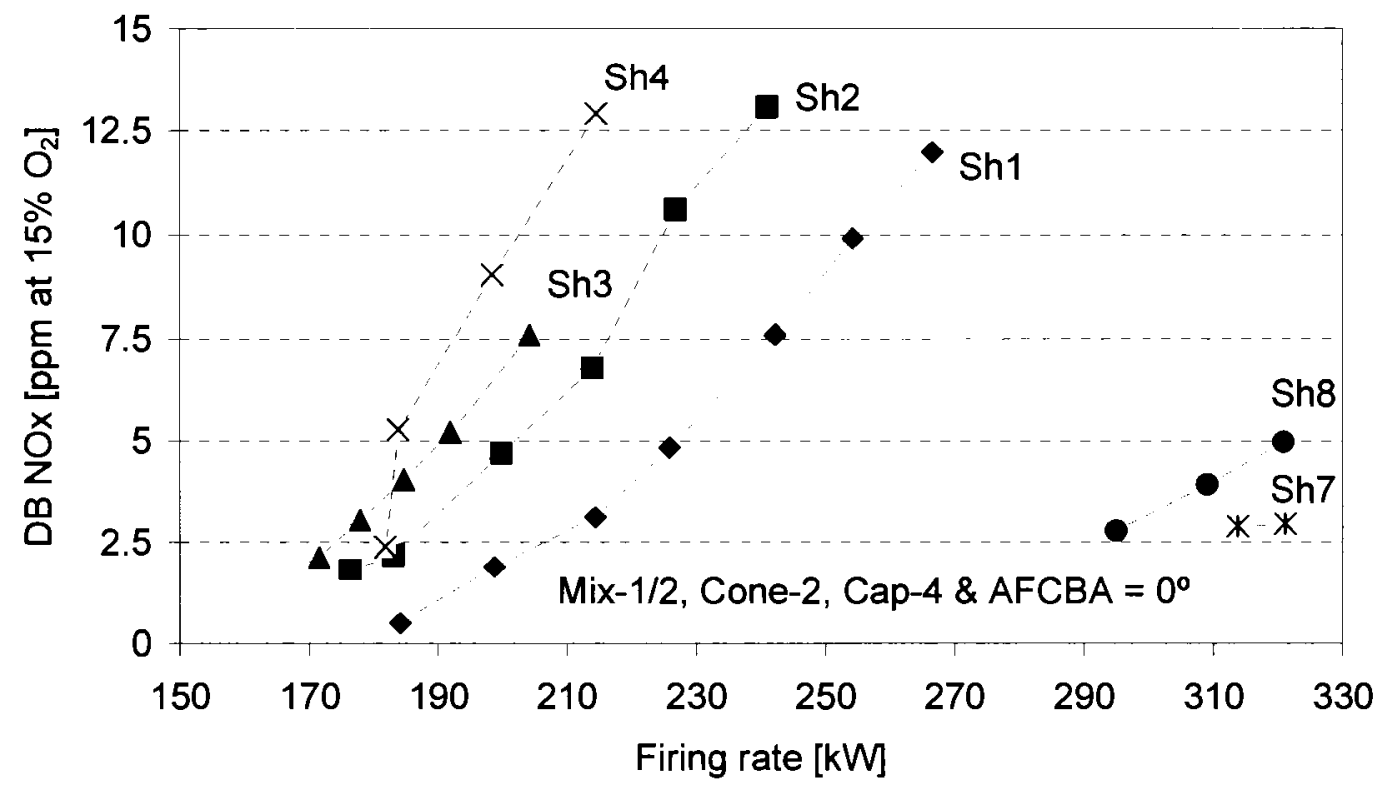

(a) BD NOx emissions

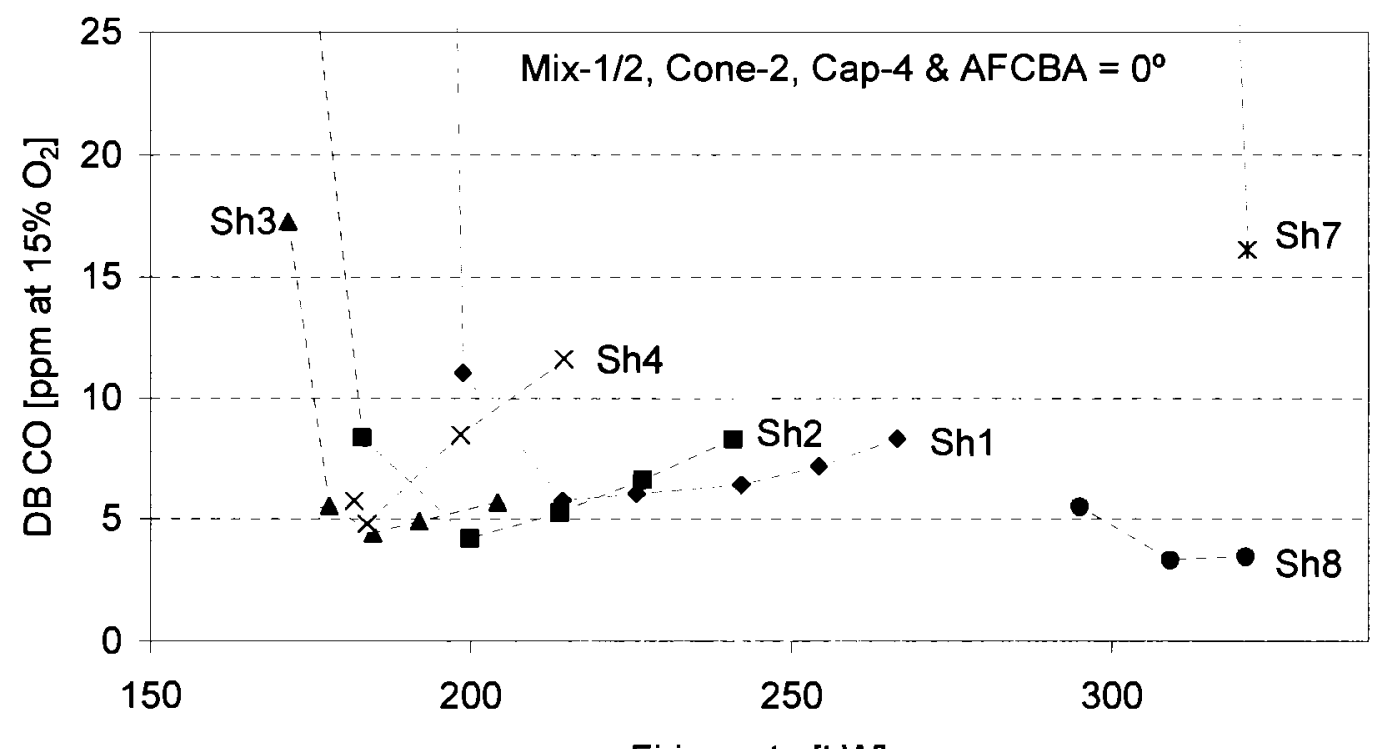

(b) DB CO emissions

Figure 8.40: Summary of $L_{\text {eff }} / D_{\text {shield }}$ ratio effect on the DB performance (Mix$1 / 2$, Cone-2, Cap-4 at AFCBA $=0^{\circ}$ ) 
Sh8 provides more protection to the flame from the surrounding bypass flow, whereas Sh7 covers only a small portion of the cone to provide an ignition protection zone and thus may allow the bypass flow to interfere with the flame above the cone. Another reason may be the higher duct burner pressure drop with Sh7 compared to Sh8, leading to higher mass flow rate to flow through the cone.

In a similar fashion to the previous subsection, the temperature profiles at different locations are presented in Figure 8.41. This figure shows the effect of shield length and firing rate on the duct burner temperatures for two shields (Sh1 and Sh2) as a sample from those presented in Figure 8.40. Both shields have a BR of 0.4 and were tested with the same burner configuration; Mix-1/2, Cap-4 and Cone-2 at AFCBA $=0^{\circ}$.

Figures 8.41 (a) and 8.41 (b) respectively present the conical burner inner (cold) and the outer (hot) surface temperature as a function of firing rate. One can clearly observe that longer shields (Sh2 is longer than Sh1) increased both the cold and the hot surface temperatures. The increase in the cold face temperature was relatively small between the two shields $\left(3^{\circ} \mathrm{C}\right)$. However, the increase in the hot surface temperature between the two shields was about $75^{\circ} \mathrm{C}$ on average. The temperature was reduced by about 70 percent from the hot side surface to the cold one. This demonstrates the benefit of the conical mesh burner design (namely, the wire-mesh material and the arrangement of the different layers) to prevent flashback. During all the tests conducted, even with the burner parameters that had the highest combustion zone temperature, the cold side surface temperature never exceeded $230^{\circ} \mathrm{C}$. Figure 8.41 (c) shows the combustion zone temperature profiles at different firing rates for Sh1 and Sh2. As discussed before, the increase in shield length for the shields with $\mathrm{BR}=0.4$ increased the combustion zone temperature and allowed stable operation with leaner mixtures. The difference between the combustion zone temperature and the hot surface of the conical burner was $700^{\circ} \mathrm{C}$ (on average). 


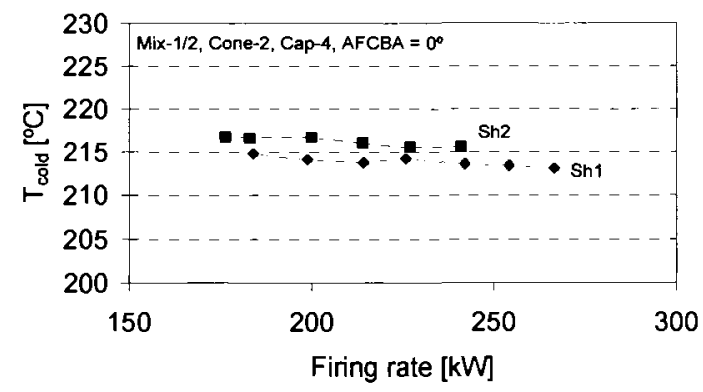

(a) Conical burner cold surface temperature

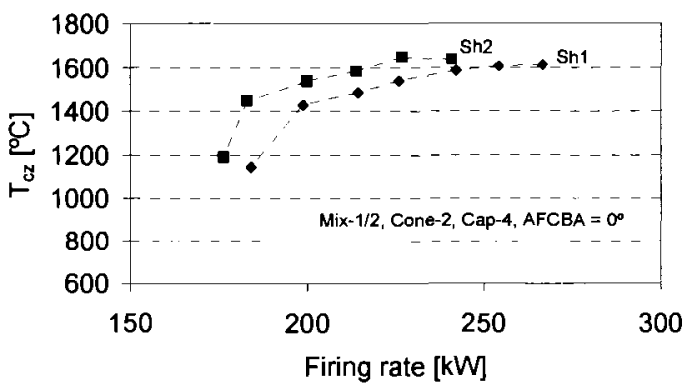

(c) Combustion zone temperature

(e) DB Traversed exhaust gases temperature

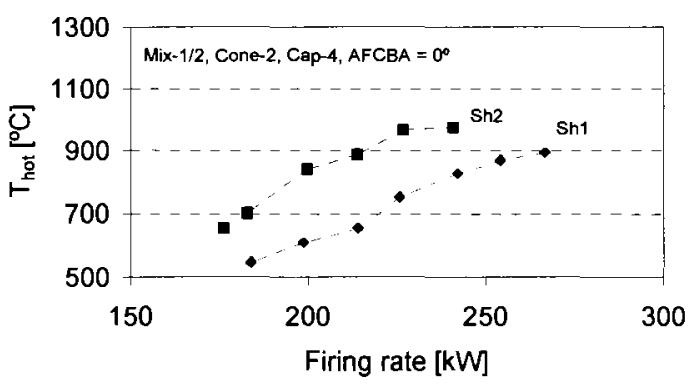

(b) Hot surface temperature

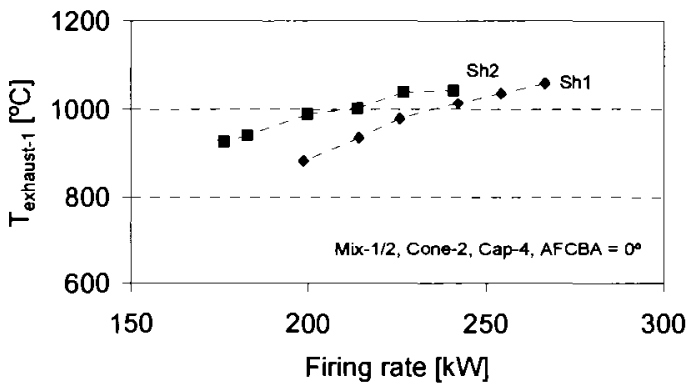

(d) DB exhaust gases temperature

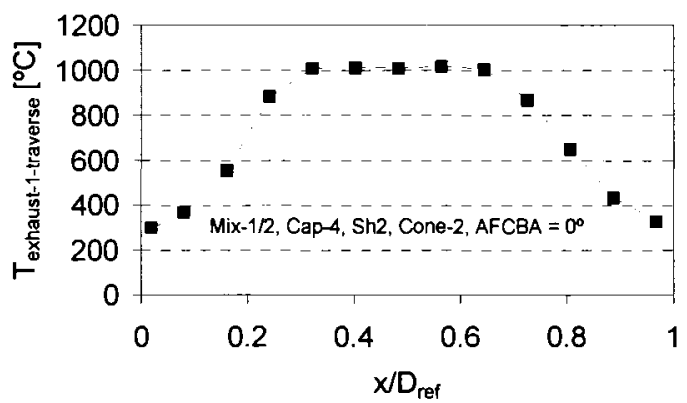

Figure 8.41: Effect of firing rate and $L_{\text {eff }} / D_{\text {shield }}$ on duct burner different locations temperatures (Mix-1/2, Cap-4 and Cone-2 at $\mathrm{AFCBA}=0^{\circ}$ )

The high combustion zone temperatures shown in Figure 8.41 (c) illustrate the reason for the increase in NOx emissions as the shield length increases (see Figure 8.40 (a)). Figure 8.41 (d) shows the duct burner exhaust gas temperature measured at location 19 on the exhaust pipe of the duct burner, see Figure 7.5. A range of 880 to $1060^{\circ} \mathrm{C}$ for the peak temperatures was measured for the firing ranges of $175 \mathrm{~kW}$ to 
$276 \mathrm{~kW}$. Figure 8.41 (e) shows the traverse measurements conducted on the duct burner across a plane located about $1.4 \mathrm{D}_{\text {ref }}$ downstream of the conical burner (location 19 in Figure 7.5). The results presented in Figure 8.41 (e) are for the configuration Mix-1/2, Cone-2, Cap-4 and Sh2 and were conducted at the following condition: $\mathrm{FR}=214 \mathrm{~kW}, T_{\text {inlet }}=228^{\circ} \mathrm{C}, T_{\text {cold }}=216^{\circ} \mathrm{C}, T_{\text {premixer }}=213^{\circ} \mathrm{C}, T_{\text {hot }}=887^{\circ} \mathrm{C}$ and $T_{c z}=1584.5^{\circ} \mathrm{C}$, and at AFCBA $=0^{\circ}$. The figure shows a top-hat profile with a maximum of $1000^{\circ} \mathrm{C}$.

\subsection{Effect of blockage ratio (BR)}

In this subsection, the effect of blockage ratio on the duct burner performance is discussed. All the duct burner results discussed in the previous sections (Figures 8.1 to 8.39) were for shields that have a blockage ratio of 0.4 . Two cases will be presented and due to the similarity of trends only one case will be discussed. Figures 8.42 and 8.43 show the effect of the firing rate and AFCBA on: (a) NOx emissions; (b) $\mathrm{CO}$ emissions; and (c) duct burner pressure drop. The configuration for Figure 8.42 was Mix-1/2, Cap-4 and Cone-3 with Sh7 $\left(\mathrm{BR}=0.6\right.$ and $\left.L_{\text {eff }} / D_{\text {shield }}=0.4\right)$. In

Figure $8.43, \operatorname{Sh} 8\left(\mathrm{BR}=0.6\right.$ and $\left.L_{\text {eff }} / D_{\text {shield }}=1.7\right)$ was used with the same duct burner configuration. In both cases, more microturbine exhaust gases were forced into the combustion zone (more excess oxidant). A stable combustion was achieved over the conical mesh burner at a range of firing rate of $313 \mathrm{~kW}$ to $321 \mathrm{~kW}$ with Sh7 and a range of $295 \mathrm{~kW}$ to $320 \mathrm{~kW}$ with Sh8. NOx and CO emissions below $5 \mathrm{ppm} \mathrm{NOx}$ were measured for both cases. The stable operating zone was rather narrow compared to the cases where shields with $\mathrm{BR}=0.4$ were used. According to the duct burner test limitations discussed at the beginning of this chapter, emissions were very low for these cases and the range of operation could be extended by testing at a higher firing rate. The fuel flow rate that could be supplied by the fuel system was not sufficient to allow tests to be carried out at a higher flow rate (fuel pressure limitations). Figures 8.42 (c) and 8.43 (c) show the effect of using shields with $\mathrm{BR}=0.6$ on pressure drop. 


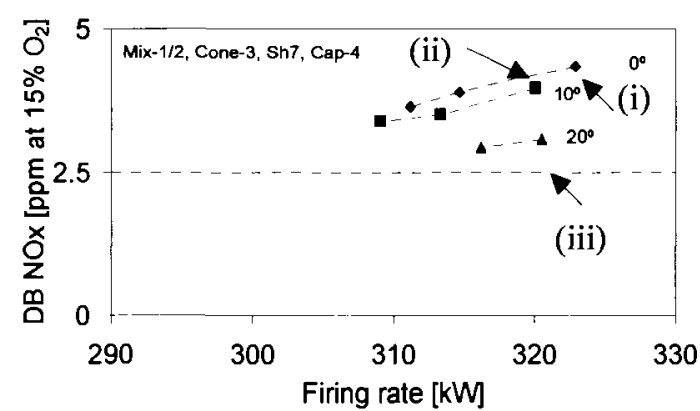

(a) DB NOx emissions

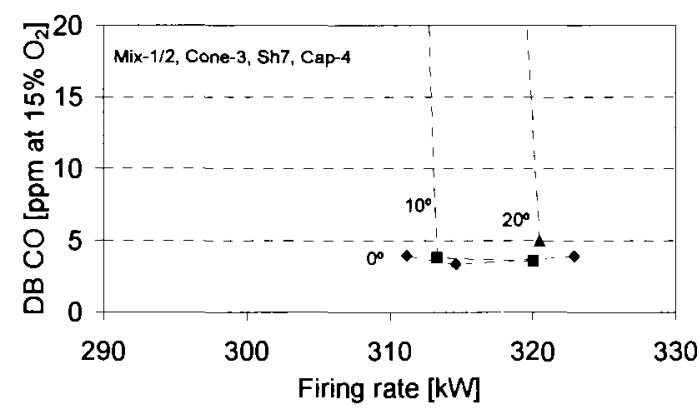

(b) DB CO emissions

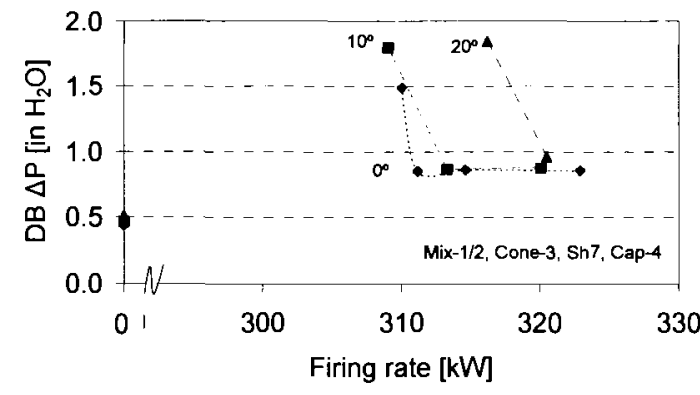

(c) DB pressure drop

Figure 8.42: Effect of firing rate and AFCBA on duct burner performance (Mix-1/2, Cap-4, Cone-3 and Sh7)

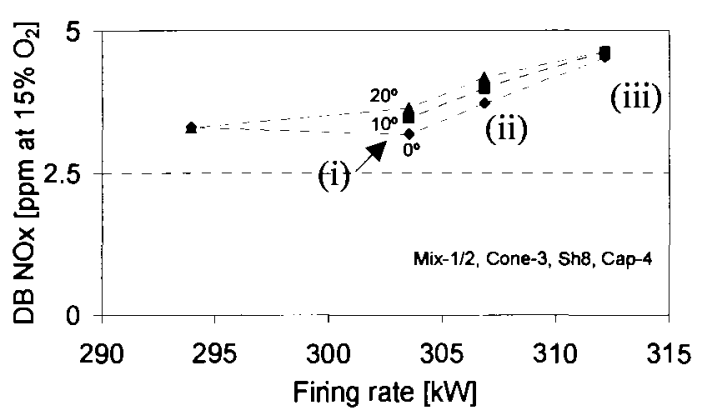

(a) DB NOx emissions

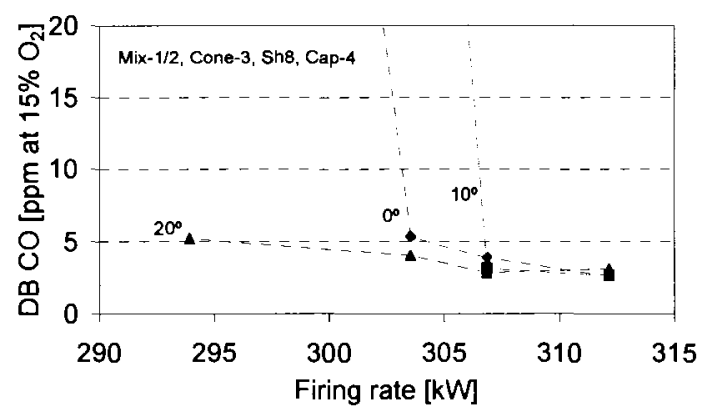

(b) DB CO emissions

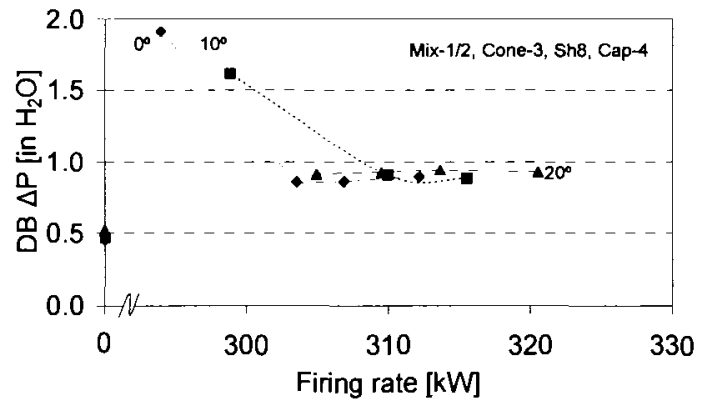

(c) DB pressure drop

Figure 8.43: Effect of firing rate and AFCBA on duct burner performance (Mix-1/2, Cap-4, Cone-3 and Sh8)

The improvement in $\mathrm{CO}$ emissions comes at the expense of a higher pressure drop compared to the cases with $\mathrm{BR}=0.4$. Similar to $\mathrm{Sh} 1$ in the previous sections, Sh7 and Sh8 experience a peak in the pressure drop value when the burner operates 
very close to the lower stability limit. An unstable flame accompanied with the vibration of the duct burner was clearly observed prior to blow-off. The peak in pressure drop occurred when the AFCBA was at 0 and $10^{\circ}$ with Sh8 and in all the cases with Sh7.

Figure 8.44 shows stable flame images for three points at different AFCBA, $\left(0^{\circ}, 10^{\circ}, 20^{\circ}\right)$. The duct burner configuration was; Mix-1/2, Cone-3 and Cap-4 with Sh7. The images represent the points labelled (i), (ii) and (iii) in Figure 8.42. The images show that the duct burner can operate at a higher firing rate. NOx and $\mathrm{CO}$ emissions, and the exhaust gases temperature at the concentration sampling plane $\left(T_{\text {exit }}\right)$ are illustrated on each image.

Figure 8.45 shows stable flame images for three points labelled (i), (ii) and (iii) in Figure 8.43 (a). The images show that the duct burner can operate at a higher firing rate with this configuration as well. NOx and $\mathrm{CO}$ emissions are illustrated on each image. Comparing Figure 8.45 with previous figures, the mesh burner looks hotter and the shield looks hot and red.

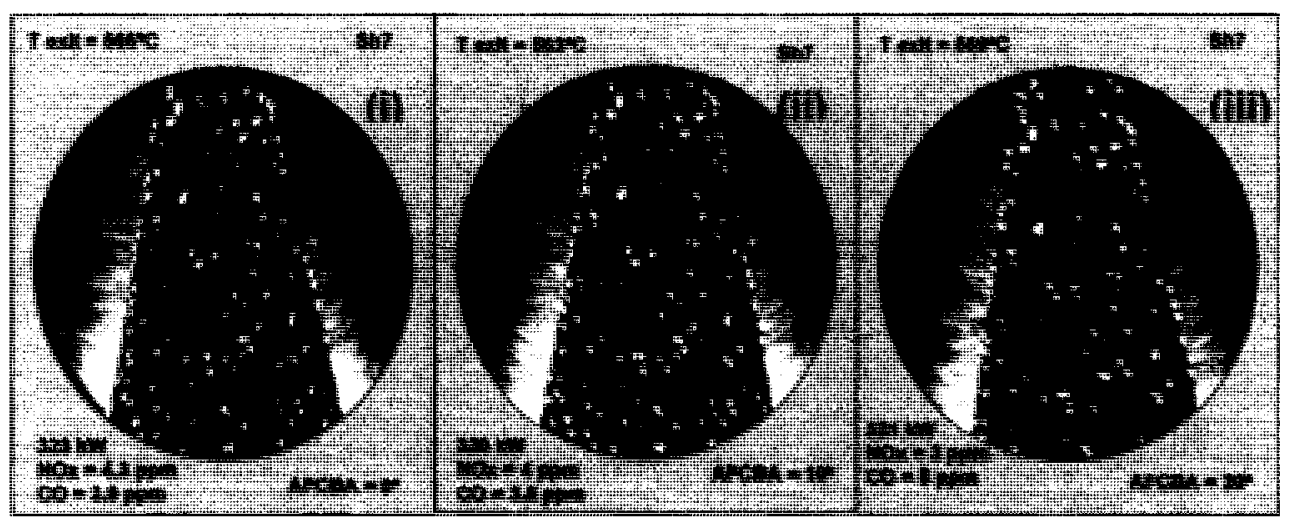

Figure 8.44: Flame images taken for points (i), (ii) and (iii) in Figure 8.42 (a) (Mix-1/2, Cone-3, Sh7 and Cap-4) 


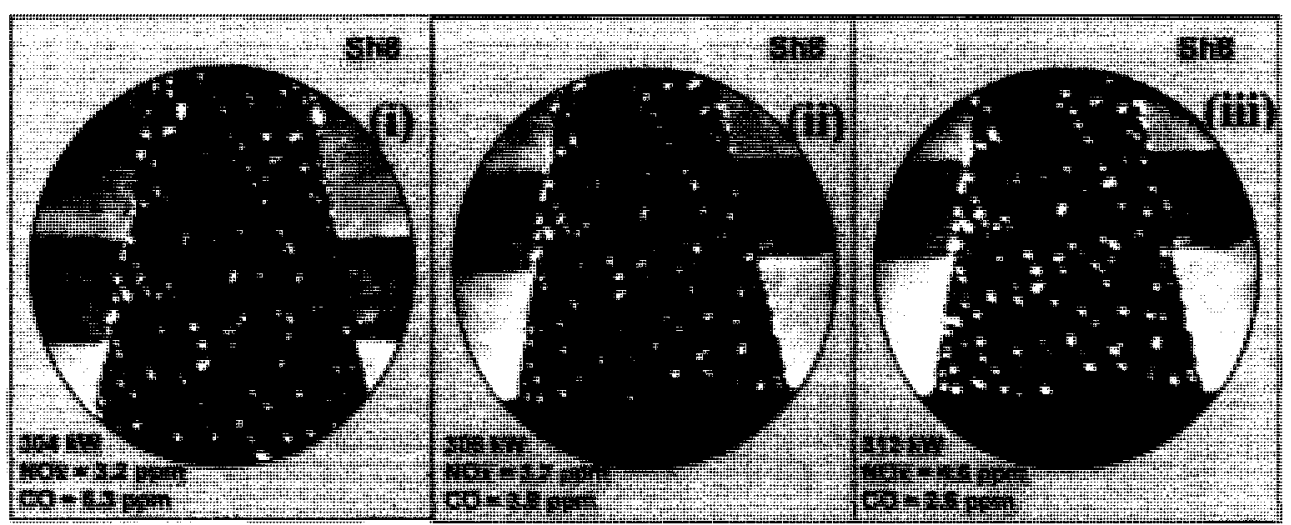

Figure 8.45: Flame images taken for points (i), (ii) and (iii) in Figure 8.43 (a) (Mix-1/2, cone-3, Sh8 and Cap-4 at $\mathrm{AFCBA}=0^{\circ}$ )

As mentioned before, only two conical burner shields have a blockage ratio of 0.6 (Sh7 and Sh8). Sh8 covers all the cone length, but Sh7 covers only 25 percent of the conical mesh burner length. Figure 8.46 shows duct burner stable flame images of two test runs where both Sh7 and Sh8 were used. On each image some of the performance parameters are indicated, such as; NOx and CO emissions, FR, the AFCBA and the exhaust gases temperature $\left(T_{\text {exit }}\right)$ at the concentration sampling plane.

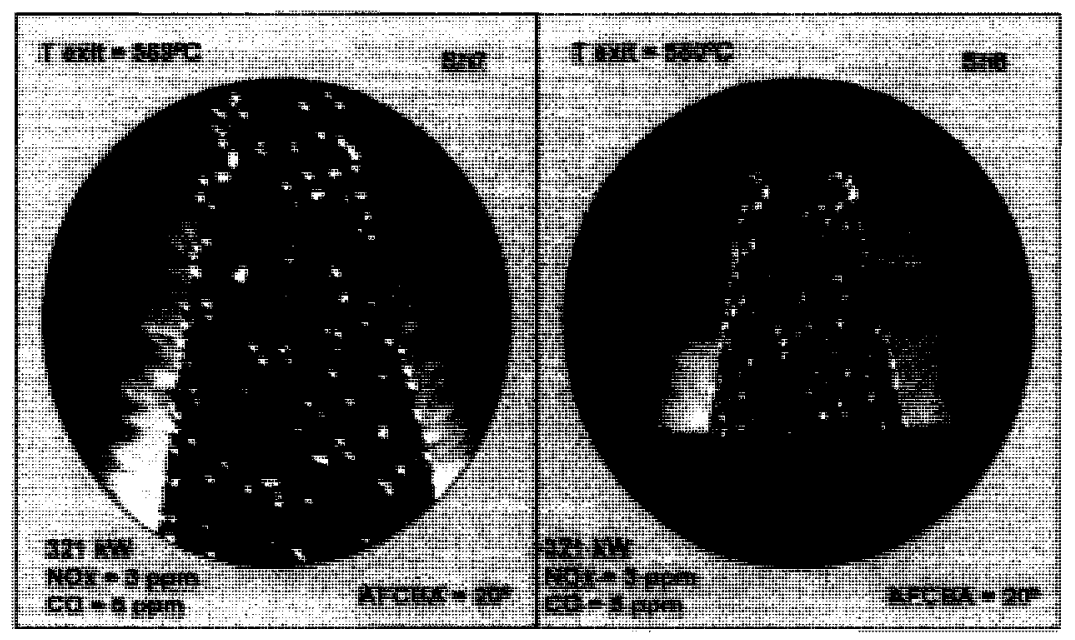

Figure 8.46: Flame images taken at different test runs (Mix-1/2, Cone-3, Cap-4 with Sh7 and Sh8 at AFCBA $=20^{\circ}$ ) 
As a summary to this subsection, NOx and $\mathrm{CO}$ emissions as a function of firing rate for different BR are presented in Figure 8.47. The burner configuration was Mix-1/2, Cone-3, Cap-4 and AFCBA $=0^{\circ}$ with Sh1 and Sh7. The figure shows that as the $\mathrm{BR}$ increased to $0.6(\mathrm{Sh} 7)$, lower emissions were obtained at higher firing rates. At $315 \mathrm{~kW}\left(\mathrm{AFCBA}=0^{\circ}\right) \mathrm{NOx}$ emissions of $4 \mathrm{ppm}$ and $\mathrm{CO}$ emissions of $3.3 \mathrm{ppm}$ were measured. All $\mathrm{CO}$ emissions with $\mathrm{Sh} 7$ were less than $5 \mathrm{ppm}$. When Sh7 was used as mentioned before, the operating range was from 206 to $283 \mathrm{~kW}$ and NOx emissions were in the range from 0.5 to $10 \mathrm{ppm}$. All $\mathrm{CO}$ emissions measurements with Sh7, through all the stable operating range, were less than $8 \mathrm{ppm}$. The test results also show that the operating zone becomes wider with the use of the lower BR shields compared to the higher BR shields. In addition, Figure 8.47 shows that $\mathrm{CO}$ emissions become excessive at very low firing rates due to incomplete combustion near the blow-off limit. NOx and CO emissions below 5 ppm were recorded at FR in the range of 250 to $330 \mathrm{~kW}$.

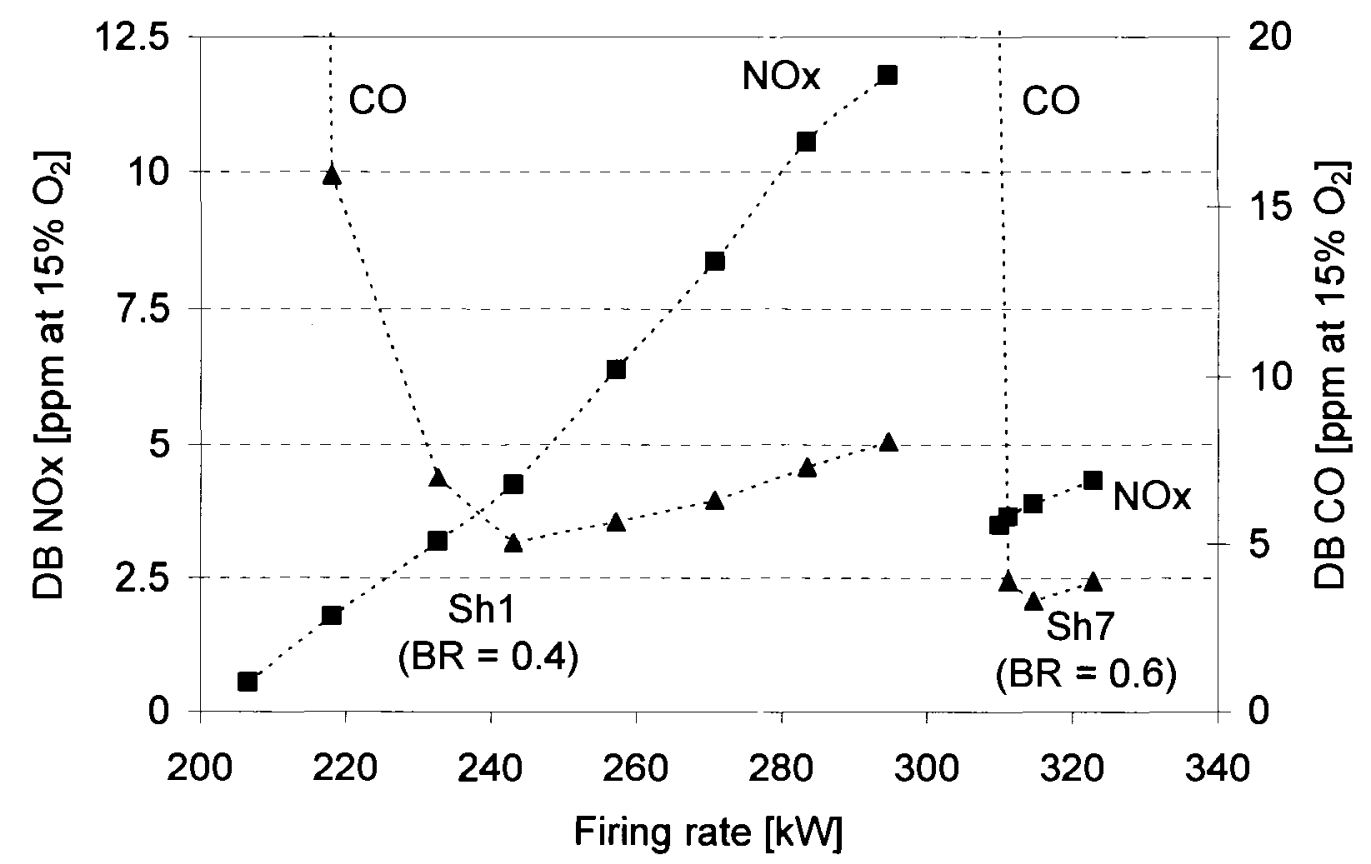

Figure 8.47: Effect of firing rate and $\mathrm{BR}$ on NOx and $\mathrm{CO}$ emissions (Mix-1/2 and Cone-3 with $\mathrm{AFCBA}=0^{\circ}$ ) 
Figure 8.48 shows the effect of $\mathrm{BR}$ as a function of firing rate on overall duct burner pressure drop for the same case shown in Figure 8.47. The figure shows that as the BR increases, the overall duct burner pressure drop increases to a higher value of $199 \mathrm{~Pa}\left(0.8\right.$ in. $\mathrm{H}_{2} \mathrm{O}$ ) which is still less than the design limit. This figure also shows the effect of the surface combustion on pressure drop. As mentioned before, the surface combustion doubles the pressure drop value measured before the combustion process starts on the conical mesh burner.

Figure 8.49 shows the effect of $\mathrm{BR}$ as a function of firing rate on duct burner combustion zone temperature and conical burner hot surface temperature. The hot surface temperatures for the higher BR gave lower values compared to the lower BR tests. As the BR increases, more of the oxidant (microturbine exhaust gases) is forced through the conical wire-mesh burner. The maximum hot surface temperature for Sh7 in this test was $560^{\circ} \mathrm{C}$ and for $\mathrm{Shl}(\mathrm{BR}=0.4)$ was $890^{\circ} \mathrm{C}$. The difference in the temperatures between the combustion zone and the hot surface temperatures was $900^{\circ} \mathrm{C}$ for Sh7 and $770^{\circ} \mathrm{C}$ for Sh1. The reduction in BR from 0.6 to 0.4 reduces the combustion zone temperature by 10 percent.

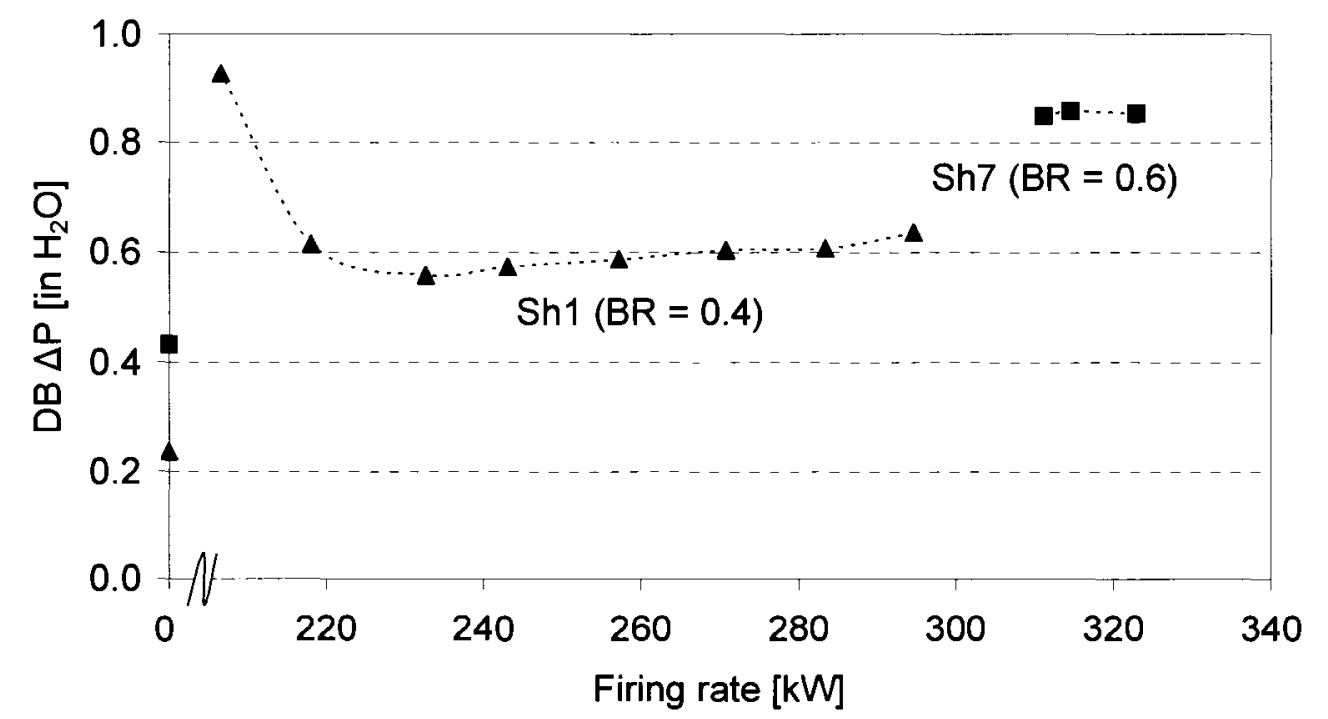

Figure 8.48: Effect of firing rate and $B R$ on overall duct burner pressure drop (Mix-1/2 and Cone-3 at AFCBA $=0^{\circ}$ ) 


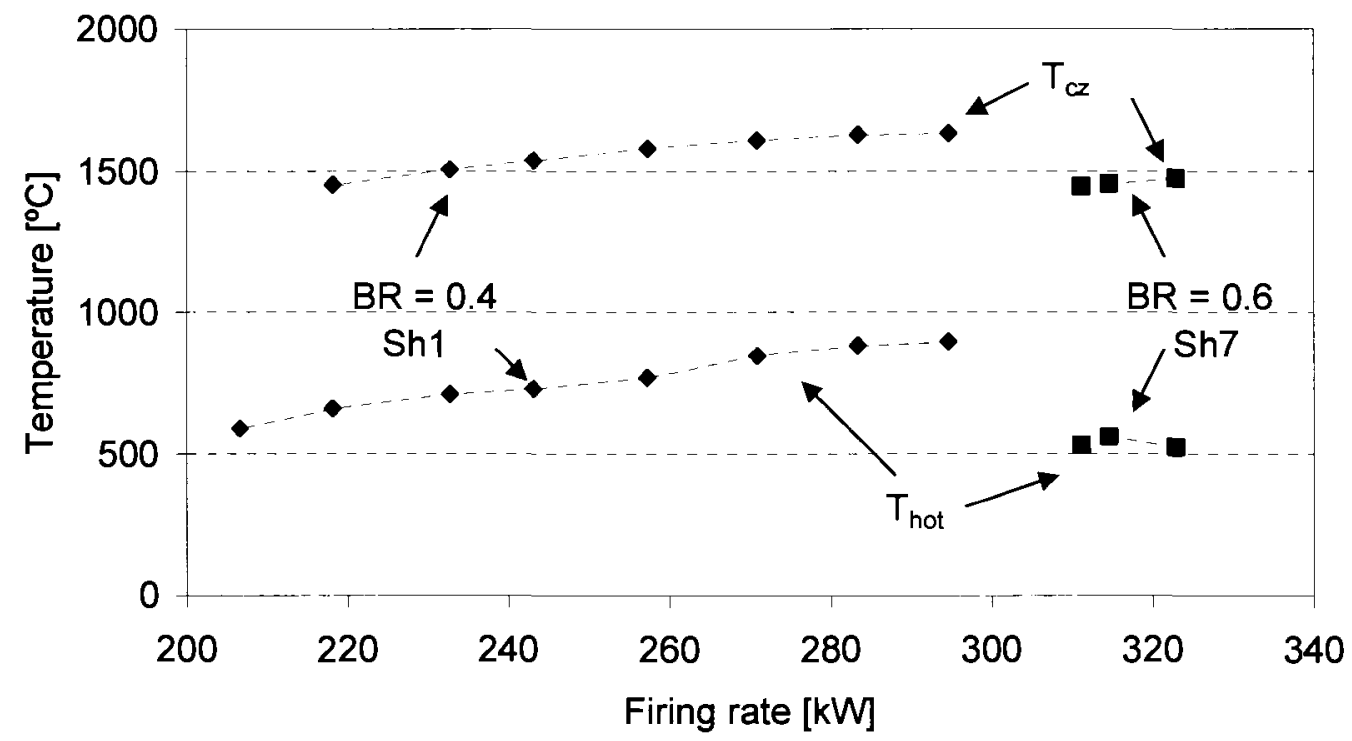

Figure 8.49: Effect of firing rate and $B R$ on duct burner temperature (Mix-1/2, Cone-3 and Cap-4 at AFCBA $=0^{\circ}$ )

\subsubsection{Double-swirl mixer results (Mix-2/2)}

In this section, the combustion results of the double-swirl mixer (counter-swirl $(+/-) 30^{\circ}$ ) will be presented. The mixer has eight straight blades at $30^{\circ}$ in the inner swirler and 12 straight blades at $-30^{\circ}$ angle in the outer swirler. The swirl number of this mixer was 0.58 . To cover the maximum number of results conducted during this investigation related to this section, different duct burner geometric combinations will be used to investigate the effect of conical pressure drop, shield length and blockage ratio (BR) on duct burner performance. In this section a brief summary covering the operating ranges and the emissions values will be presented. In a similar fashion to the Mix-1/2 section, the results presentation will be divided in two subsections, each one will covering the combinations of Mix-2/2 with one of the fuel caps. In each subsection, two pairs of results will be discussed; each pair is plotted on the same page, so comparison is easier. As summary of each subsection, one case (AFCBA = $0^{\circ}$ ) from each test will be plotted on the same graph for comparison. 


\subsubsection{Mix-2/2 and Cap-2 combinations}

Stable surface combustion of this combination with some of the duct burner parameters were not achieved, such as with $\mathrm{Sh} 7$ and $\mathrm{Sh} 8(\mathrm{BR}=0.6)$. Also the flame was unstable with the duct burner parameters Mix-2/2, Cap-2 and Cone-1 with Sh1 $(B R=0.4)$. During these trials, the fuel flow rate was altered to try to achieve a flammable mixture and stable conditions, but these attempts were not successful. In the case of the single-swirl mixer, when tested with Shl the flame was stabilized on the surface of the mesh. However, as stated in the previous section, the range was narrow compared to other cases.

\subsection{Effect of conical mesh burner pressure drop}

Figures 8.50 and 8.51 show the effect of the conical pressure drop on NOx formation (figures labelled (a)), duct burner CO emissions (figures labelled (b)) and the overall duct burner pressure drop (figures labelled (c)). Figure 8.50 shows the combustion results for the duct burner configuration Mix-2/2, Cone-2 and Sh3. Stable blue flames were achieved in the operating range from $157 \mathrm{~kW}$ to $200 \mathrm{~kW}$. NOx emissions were less than $5 \mathrm{ppm}$ for almost the entire range of operation and $\mathrm{CO}$ emissions were less than $10 \mathrm{ppm}$ for most of the operating range. Figure 8.51 shows the duct burner performance for configuration Mix-2/2, Cone-3, Sh3 and Cap2. The stable range achieved at this case was from $154 \mathrm{~kW}$ to $197 \mathrm{~kW}$. Only a very small shift to the stable operating range was measured. From these results, one can clearly see that the stable flame was achieved at a higher AFCBA (higher conical mass flow rate).. During these tests, at each AFCBA the flame blow-off occurs smoothly and with out any vibration. The overall duct burner pressure drop was measured and plotted in figures labelled (c) on each Figure. Higher pressure peak values were not observed during these runs. 


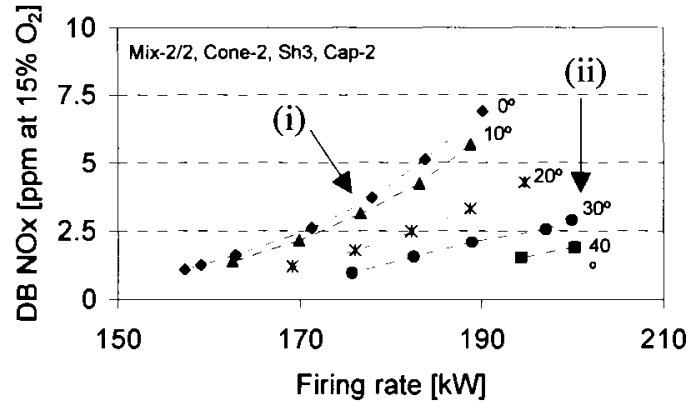

(a) DB NOx emissions

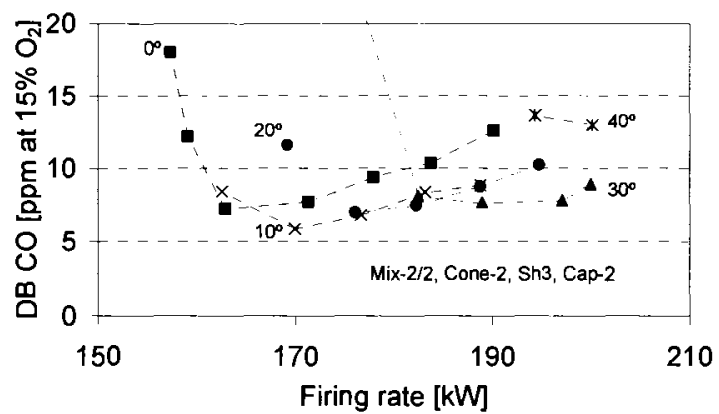

(b) DB CO emissions

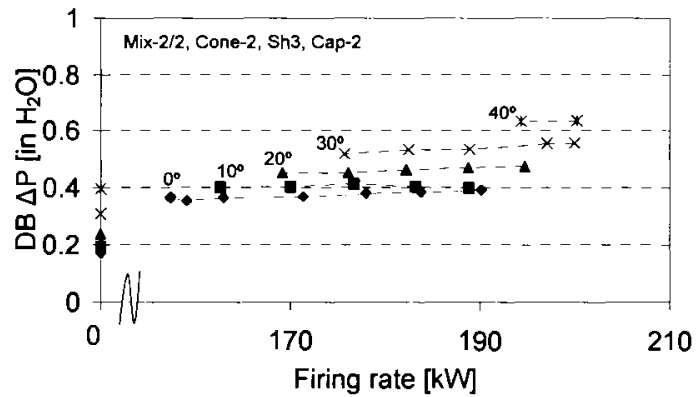

(c) DB pressure drop

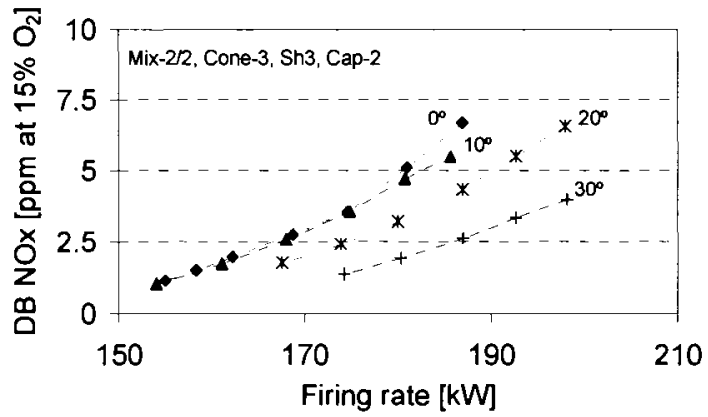

(a) DB NOx emissions

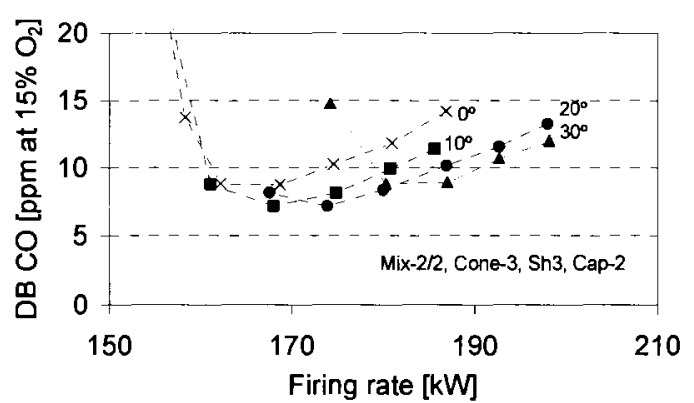

(b) DB CO emissions

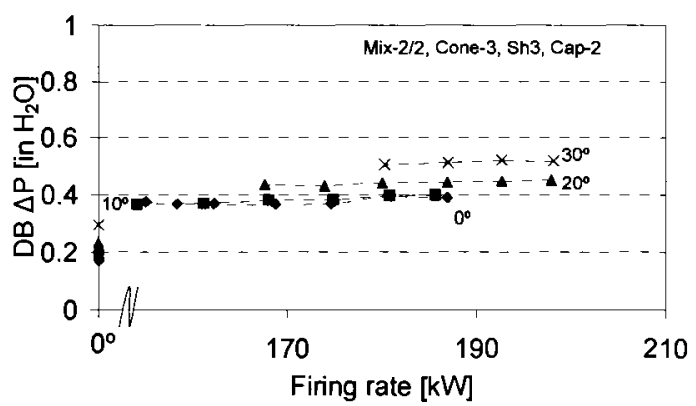

(c) DB pressure drop

Figure 8.50: Effect of firing rate and AFCBA on duct burner performance (Mix2/2, Cap-2, Cone-2 and Sh3)

Figure 8.51: Effect of firing rate and AFCBA on duct burner performance (Mix2/2, Cap-2, Cone-3 and Sh3)

\subsection{Effect of conical mesh shield ( $\left.L_{\text {eff }} / D_{\text {shield }}\right)$ ratio}

Figures 8.52 and 8.53 present the effect of shield length on duct burner performance. The burner configuration in Figure 8.52 was; Mix2/2, Cap-2, Cone-1 
and Sh2 $\left(L_{e f f} / D_{\text {shield }}=0.8\right)$. Figure 8.53 uses the same burner parameters except a shield of $L_{\text {eff }} / D_{\text {shield }}=1.5(\mathrm{Sh} 3)$ was used. The input firing rate range in Figure 8.52 was $196 \mathrm{~kW}$ to $208 \mathrm{~kW}$. A narrow range with very low emissions was achieved. At $208 \mathrm{~kW}$ (at $10^{\circ}$ blade angle), NOx emissions of about $2.5 \mathrm{ppm}$ and $\mathrm{CO}$ emissions of $3.6 \mathrm{ppm}$ were measured. With Sh3, the stable combustion zone was extended and became wider, and the lower firing rate limit was shifted to $178 \mathrm{~kW}$ (see Figure 8.52). NOx emissions were less than 5 ppm throughout the full range. $\mathrm{CO}$ emissions measurements were less than $10 \mathrm{ppm}$. In Figure 8.52 (c), the overall duct burner pressure drop results show the peak value recorded at the blow-off limit when the AFCBA $=0^{\circ}$. Values of less than $149 \mathrm{~Pa}$ were measured in both cases.

Figure 8.54 shows stable flame images for two points labelled (i) and (ii) in Figure 8.50 (a). The images show the duct burner operated at (i) with $177 \mathrm{~kW}$ and (ii) with $197 \mathrm{~kW}$. NOx and CO emissions, and equivalence ratio are presented on each image. Single digit emissions were measured at these two points. Both points were for the burner parameters Mix-2/2, Cone-2, Cap-2 and Sh3.

Figure 8.55 also shows flame images for other stable operating points labelled (i) and (ii) in Figure 8.53 (a). Mix-2/2, Cone-1, Cap-2 and Sh3 were the burner parameters used. NOx and $\mathrm{CO}$ emissions and the equivalence ratio are illustrated on each image.

Figures 8.56 and 8.57 summarize the effect of the two parameters discussed above (Figures 8.50 to 8.53). The results are for cases where AFCBA $=0^{\circ}$ was used. Figure 8.56 shows how the conical pressure drop value affected the burner performance. For a fixed firing rate, the conical burner with the lower pressure drop value (Cone-1) has the lower NOx emissions due to the same reasons discussed in the Mix-1/2 section. Larger pores in the cone burner produced longer blue coloured flames (see Figures 8.54 (ii) and 8.55 (ii)) and the measurements indicated a cooler 
temperature in the combustion zone (Figure 8.58 (b)) and so lower NOx emissions (see Figure $8.56(\mathrm{a})$ ).

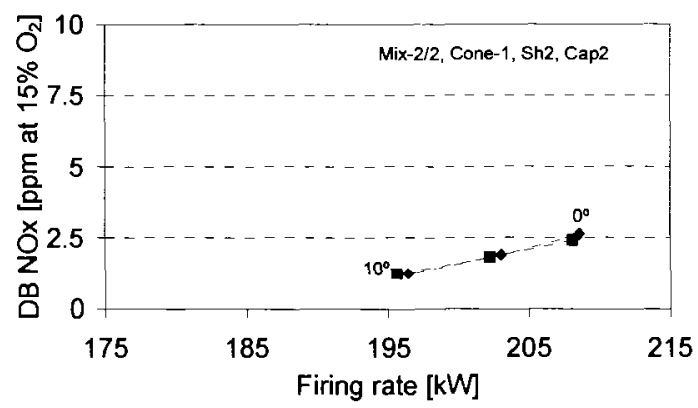

(a) DB NOx emissions

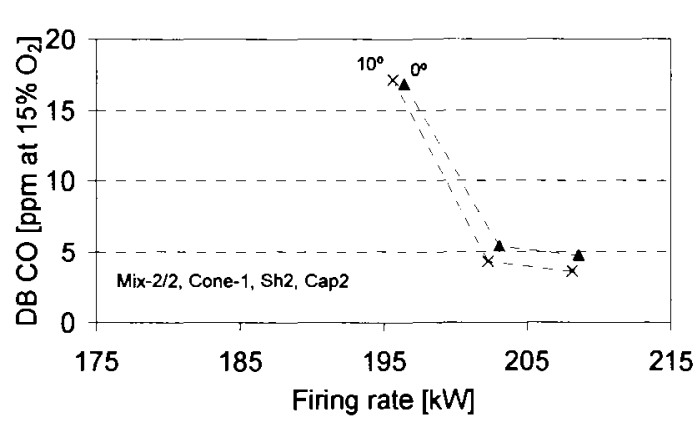

(b) DB CO emissions

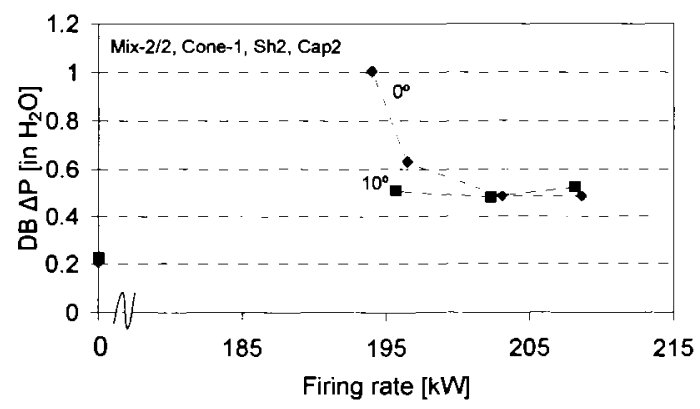

(c) DB pressure drop

Figure 8.52: Effect of firing rate and AFCBA on duct burner performance (Mix-2/2, Cap-2, Cone1 and Sh2)

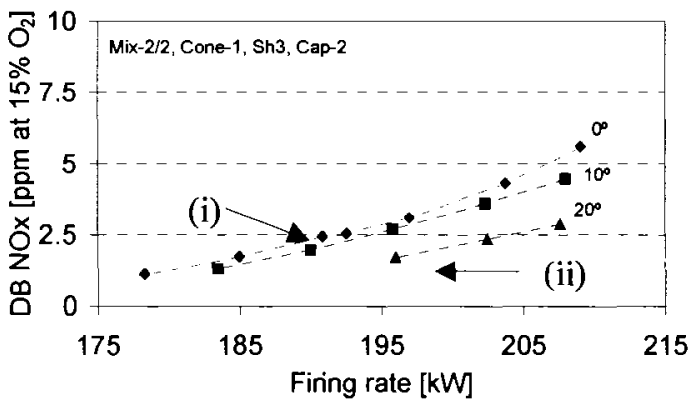

(a) DB NOx emissions

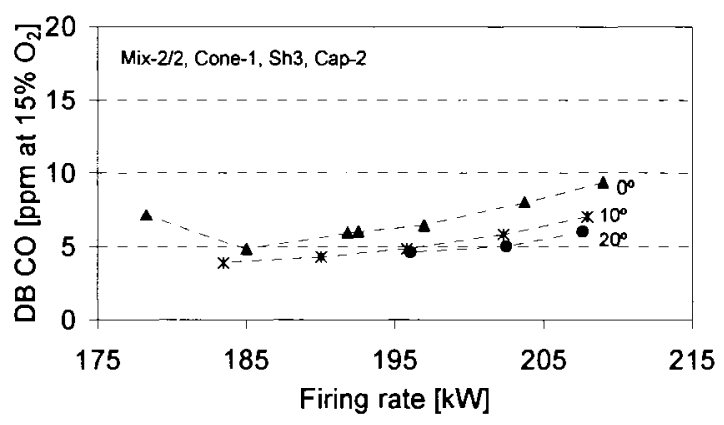

(b) DB CO emissions

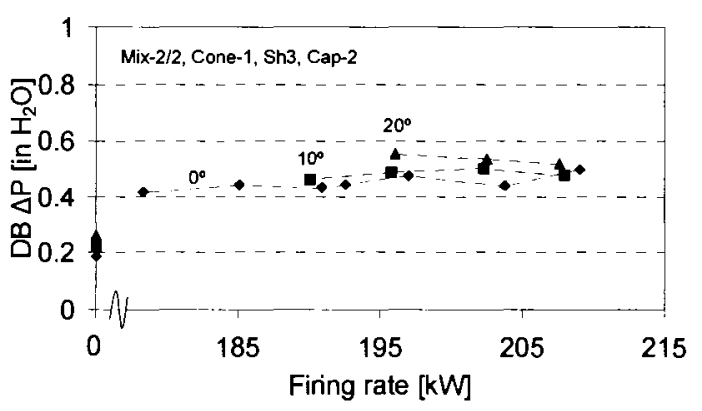

(c) DB pressure drop

Figure 8.53: Effect of firing rate and AFCBA on duct burner performance (Mix-2/2, Cap-2, Cone1 and Sh2) 
At constant conical burner pressure drop, as the firing rate decreases, NOx emissions decrease until the lower stability limit is reached and then flame blow-off occurs. For this case, NOx emissions were less than 7.5 ppm over the entire range of operating points. As expected, NOx emissions increase with an increase in firing rate value (higher flame temperature). As one can observe from Figure 8.56 (a), Cone-3 results were very close to Cone- 2 results. The larger pore mesh burner also produces longer residence times than for the other burners, which helps reduce $\mathrm{CO}$ emissions (see Figure 8.56 (b)). Figure 8.56 (c) presents the overall duct burner pressure drop results for the same burner parameters used in Figure 8.56 (a) and (b), Mix-2/2, Cap-2 and Sh3 with Cone-1, Cone-2 and Cone-3. All the three cones show lower pressure drop measurements of less than of less than $149 \mathrm{~Pa}$. The DB pressure drop had higher values with Cone- 1 compared to other cones, which is not the case as in the cold flow tests (Chapter 6).

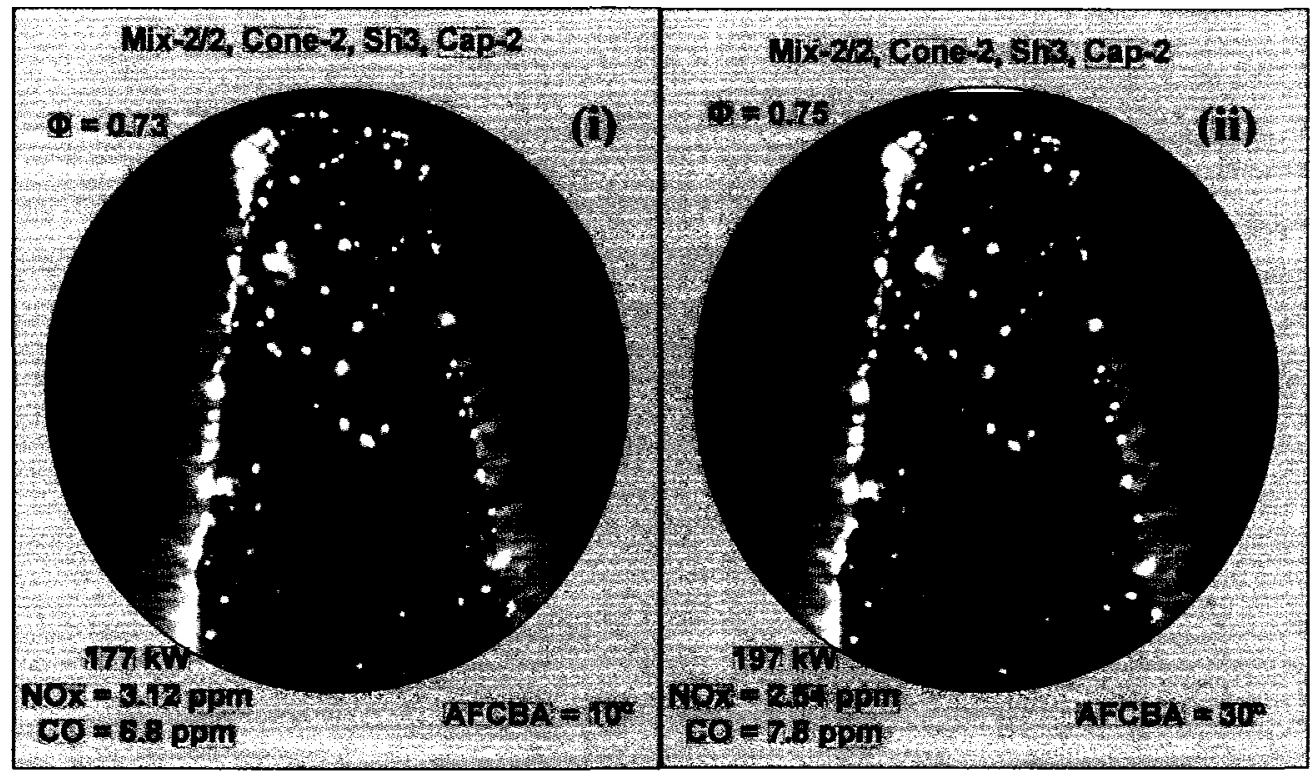

Figure 8.54: Flame images taken for points (i) and (ii) in Figure 8.50 (a) 


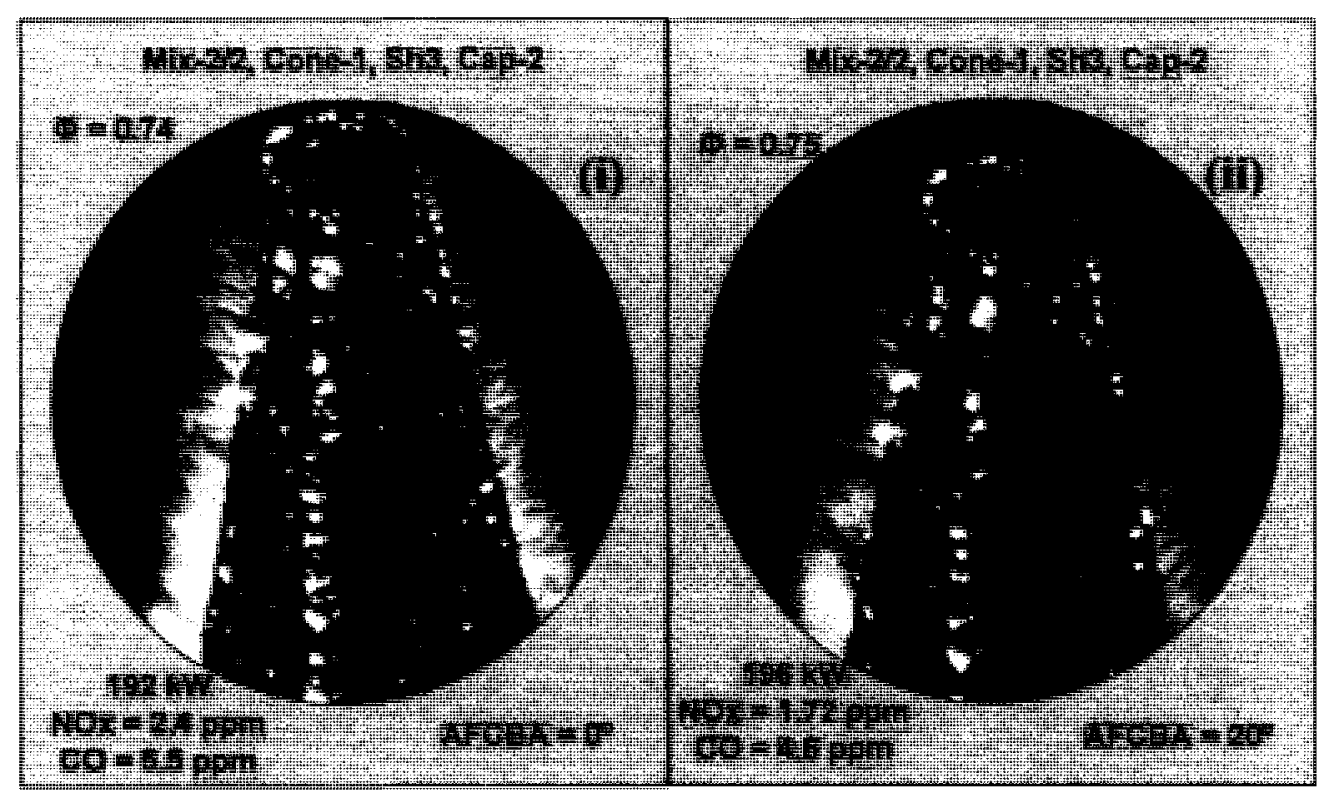

Figure 8.55: Flame images taken for points (i) and (ii) in Figure 8.53 (a)

Figure 8.57 shows the effect of the different shields tested (Sh1, Sh2 and Sh3) with the duct burner configuration (Mix-2/2, Cap-2, with Cone-2) on NOx emissions (Figure 8.57 (a)), $\mathrm{CO}$ emissions (Figure 8.57 (b)) and overall duct burner pressure drop (Figure 8.57 (c)). The DB operated at a higher firing rate whenever the shortest shield was used and very low NOx emissions were measured accompanied by high CO emissions $(>20 \mathrm{ppm})$. As the $L_{\text {eff }} / D_{\text {shield }}$ ratio increases the operating range gets larger and shifts towards the lower firing rate. The shorter the shield, the higher the overall duct burner pressure drop (these results are only for shields that have BR = $0.4)$. As an additional explanation to the duct burner behaviour regarding the emissions, shown in Figures 8.56 and 8.57, Figures 8.58 and 8.59 are presented. These figures summarized respectively the effect of conical burner pressure drop and $L_{e f f} / D_{\text {shield }}$ shield ratio as a function of firing rate on conical burner cold surface temperature $\left(T_{\text {cold }}\right)$, the duct burner combustion zone temperature $\left(T_{c z}\right)$ and duct burner exhaust temperature $\left(T_{\text {exhoust }-2}\right)$. 


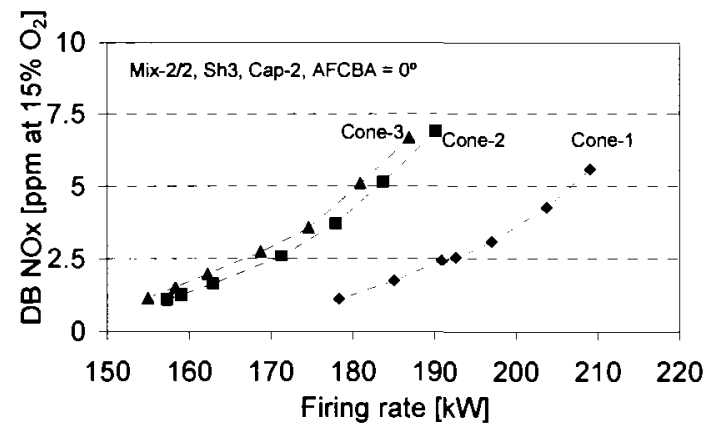

(a) DB NOx emissions

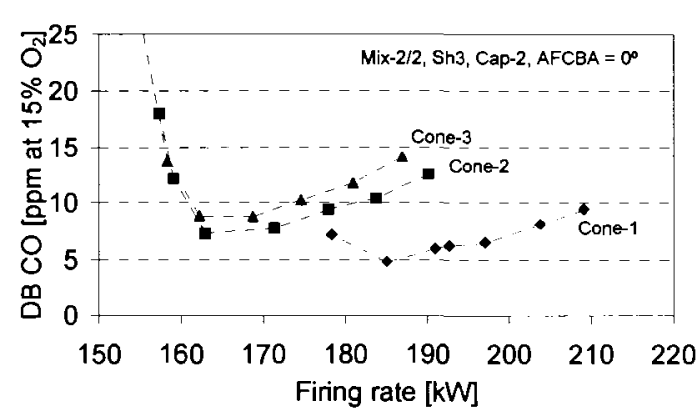

(b) DB CO emissions

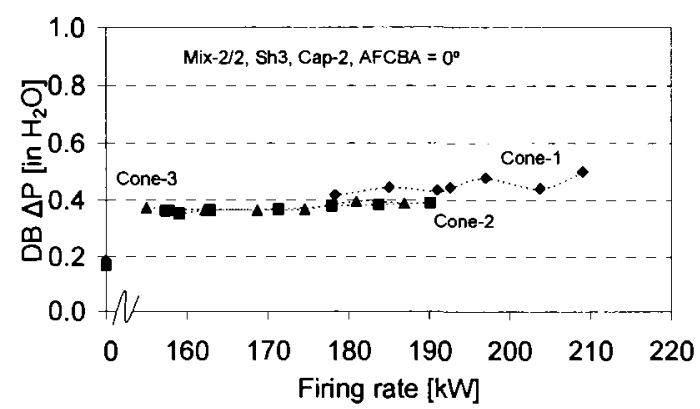

(c) DB pressure drop

Figure 8.56: Effect of firing rate and conical burner pressure drop on duct burner performance (Mix-2/2, Cap-2, Sh3 with Cone-1, Cone-2 and Cone-3)

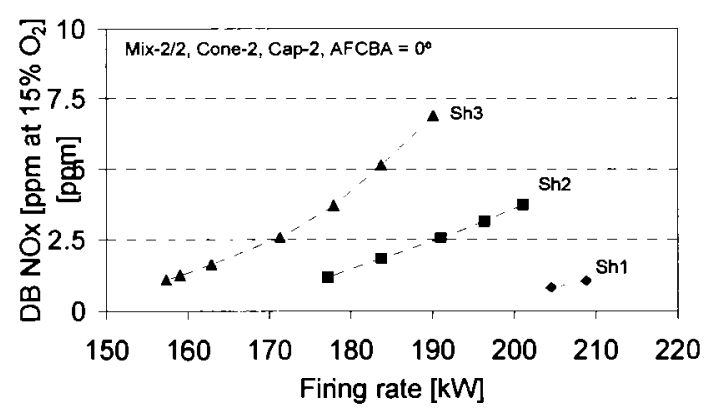

(a) DB NOx emissions

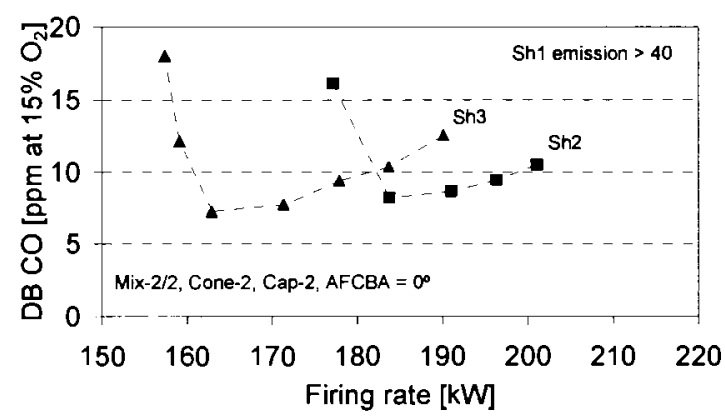

(b) DB CO emissions

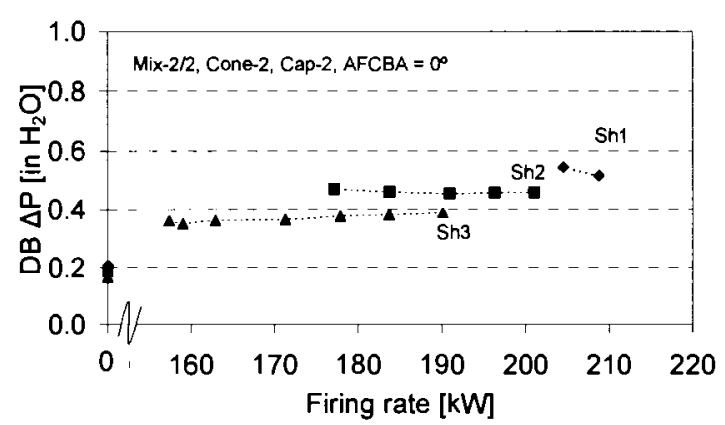

(c) DB pressure drop

Figure 8.57: Effect of firing rate and $L_{\text {eff }} / D_{\text {shield }}$ on duct burner performance (Mix-2/2, Cap-2, Cone-2 with Sh1, Sh2 


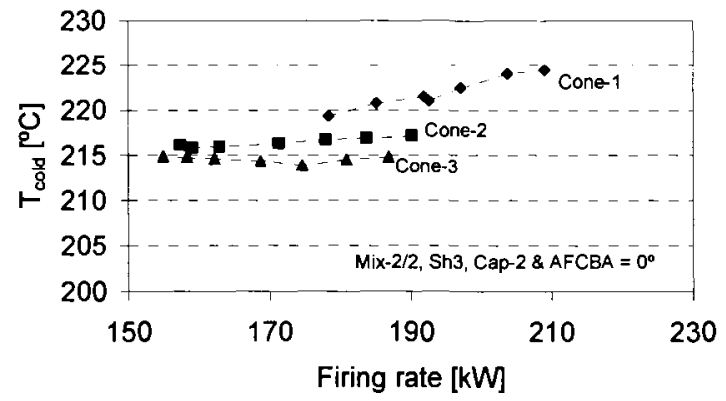

(a) Conical burner cold surface temperature

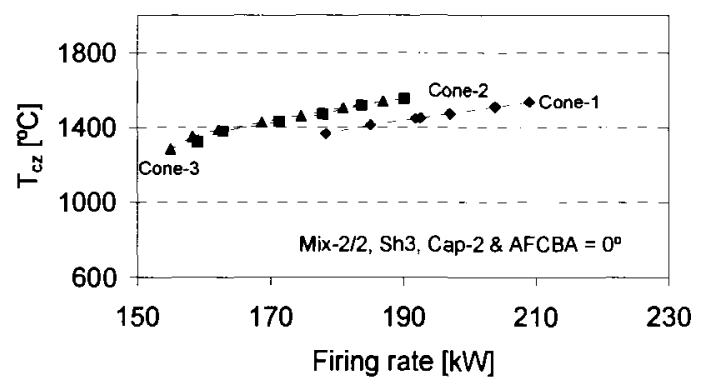

(b) Combustion zone temperature

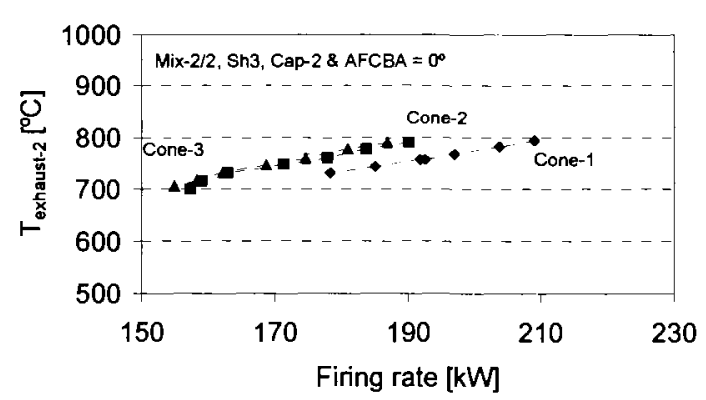

(c) DB exhaust gas temperature

Figure 8.58: Effect of firing rate and conical burner pressure drop on duct burner temperatures (Mix-2/2, Cap-2 and $\mathrm{Sh} 3$ at $\mathrm{AFCBA}=0^{\circ}$ )

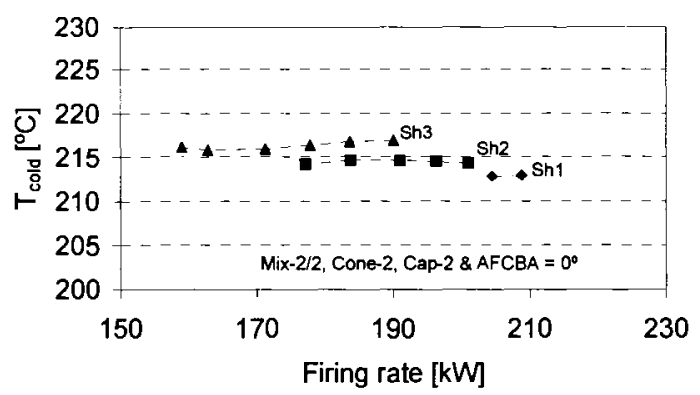

(a) Cold surface temperature

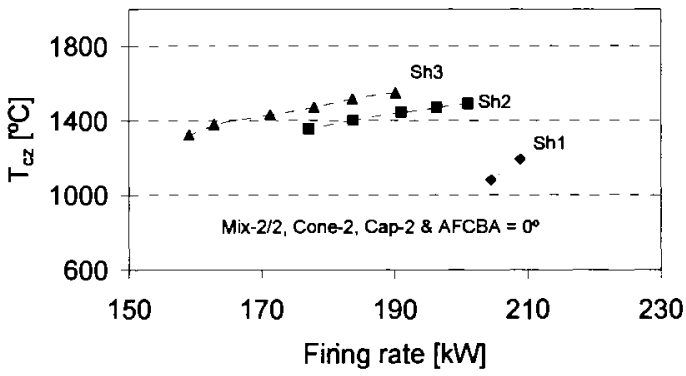

(b) Combustion zone temperature

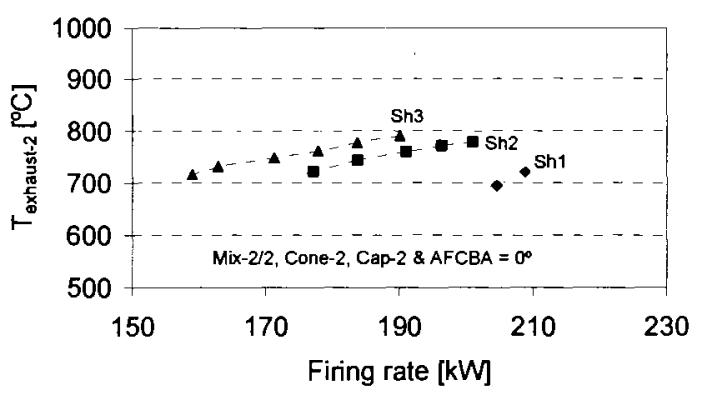

(c) DB exhaust gas temperature

Figure 8.59: Effect of firing rate and $L_{\text {eff }} / D_{\text {shield }}$ on duct burner temperatures (Mix-2/2, Cap-2 and Cone- 2 at $\mathrm{AFCBA}=0^{\circ}$ ) 
The highest $T_{\text {cold }}$ was recorded when the lower pressure drop cone (Cone 1) was used as shown in Figure 8.58 (a). For Cone-1, as the firing rate increases the cold surface temperature increases. For the other two cones, the cold surface temperature experiences very little change with the increase in firing rate. Figure 8.58 (b) clearly shows that increasing the combustion zone temperature increases NOx formation (see Figure 8.56 (a). Figure 8.58 (c) shows the duct burner exhaust temperature as a function of firing rate and the conical burner pressure drop. The range in this figure is from 700 to $800^{\circ} \mathrm{C}$.

Figure 8.59 (a) shows that the cold surface temperature increases by increasing the shield length. For a constant shield length, the cold surface temperature was almost constant with the increase in firing rate. With reference to Figure 8.57 (a), Figure 8.59 (b) clearly shows that increasing the combustion zone temperature increases NOx emissions. In both figures representing the combustion zone temperature (8.58 (b) and 8.59 (b)), the temperature was below the $1800 \mathrm{~K}$ limit for thermal NOx formation indicating that the Prompt NOx mechanism may be involved in NOx formation. Figure 8.59 (c) shows the range of the duct burner exhaust gas temperature for the different shields tested (Sh1, Sh2 and Sh3) is between 700 and $800^{\circ} \mathrm{C}$.

\subsubsection{Mix-2/2 and Cap-4 combinations}

Cap-4 is a flat nozzle with eight holes, each $3 \mathrm{~mm}$ in diameter. The fuel is injected at $90^{\circ}$ angle to the mainstream inside the premixer. Similar to the previous sections, two selected pairs of results will be presented one to show the effect of conical pressure drop on duct burner performance, and the other pair to show the effect of the shield length. Each pair of figures will be presented on the same page for ease of comparison. Selected flame images will be presented for this case too and a short summary in a graphical form will be accompanied by the duct burner temperature profiles for the same cases used in the summary figures. As mentioned before, in general the trends in the profiles are qualitatively similar to the previous 
results. However, each individual case has different stable operating ranges and different NOx and CO emissions.

\subsection{Effect of conical mesh burner pressure drop}

During these tests, the behaviour of NOx and CO emissions, and the overall duct burner pressure drop were measured. Figures 8.60 and 8.61 show the effect of the conical burner pressure drop on the performance of the duct burner. Figure 8.60 uses Cone-1 with Mix-2/2 and Sh2. Figure 8.61 uses Cone-3 with the same parameters as in Figure 8.60. The stable operating range became wider and shifted towards the lower firing rate values when the nominal conical burner pressure drop was increased from 75 to $224 \mathrm{~Pa}$ (i.e Cone 1 or Cone 3). In Figure 8.60 (Cone-1) the range was $199 \mathrm{~kW}$ to $291 \mathrm{~kW}$, and for Figure 8.61 (Cone-3) the lower limit was reduced to $186 \mathrm{~kW}$. CO emissions increased by using higher pressure drop conical burners. The surface combustion was maintained at higher values for AFCBA with the use of larger pressure drop conical burners. This improvement in the range of the AFCBA comes at the expense of increasing the overall duct burner pressure drop to the required limit value of $249 \mathrm{~Pa}$ (see Figure 8.61 (c)).

\subsection{Effect of conical mesh shield ( $\left.L_{\text {eff }} / D_{\text {shield }}\right)$ ratio}

During this part of the experimental work, the duct burner performance was investigated only with the use of the conical burner shields that have a blockage ratio of $\mathrm{BR}=0.4$. A stable flame was not maintained during the test trials with shields that have $\mathrm{BR}=0.6(\mathrm{Sh} 7$ and $\mathrm{Sh} 8)$.

Figures 8.62 and 8.63 illustrate the effect of shield length on duct burner performance. In both figures, Cone-2 was used. In Figure 8.62, where Sh1 $\left(L_{\text {eff }} / D_{\text {shield }}=0.4\right)$ was used, the operating range was from $205 \mathrm{~kW}$ to $295 \mathrm{~kW}$. At $231 \mathrm{~kW}$ (and $10^{\circ}$ angle) emissions were $3.5 \mathrm{ppm}$ for NOx and $4 \mathrm{ppm}$ for CO. In 
Figure 8.63, Sh2 $\left(L_{e f f} / D_{\text {shield }}=0.8\right)$ was used and the operating range was from 185 $\mathrm{kW}$ to $296 \mathrm{~kW}$. At $192 \mathrm{~kW}$ (and with a $0^{\circ}$ angle), NOx emissions of $2 \mathrm{ppm}$ and CO emissions of $3.5 \mathrm{ppm}$ were measured.

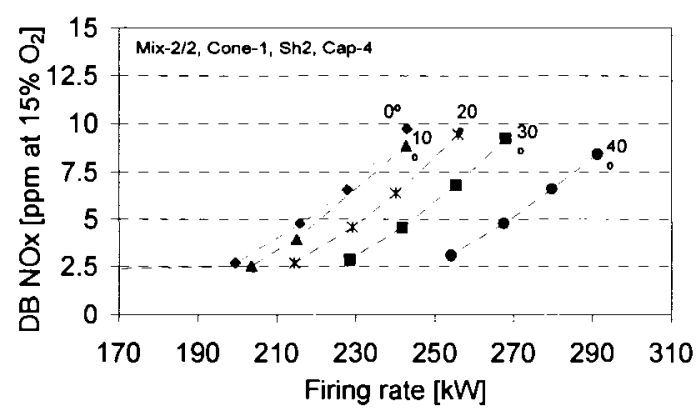

(a) DB NOx emissions

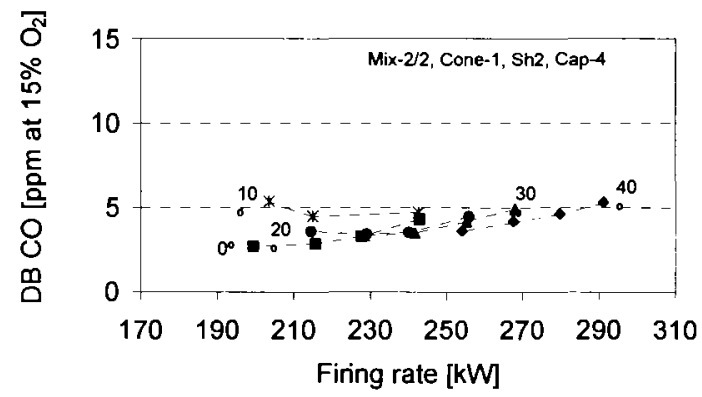

(b) DB CO emissions

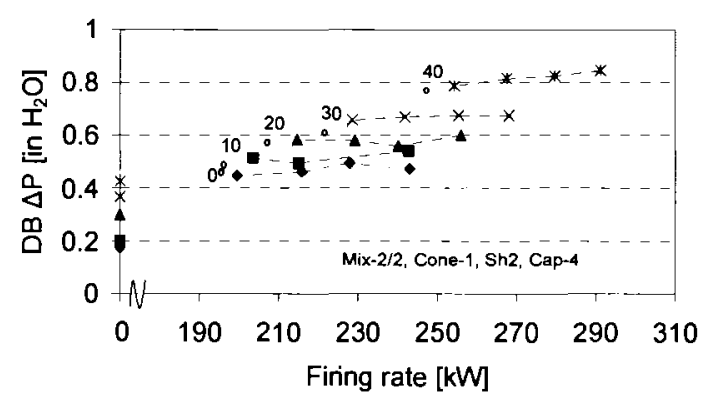

(c) DB pressure drop

Figure 8.60: Effect of firing rate and AFCBA on duct burner performance (Mix-2/2, Cap-4, Cone-1 and Sh2)

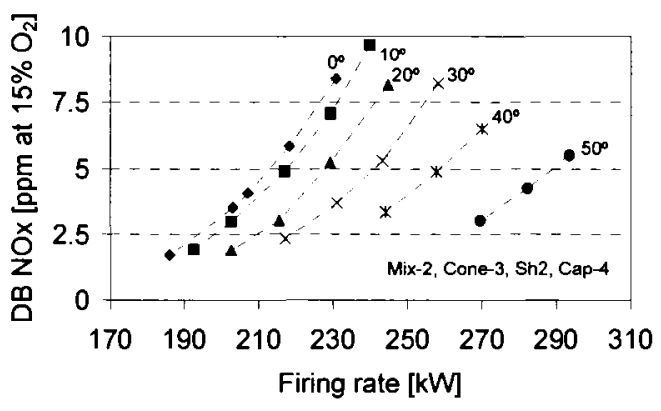

(a) DB NOx emissions

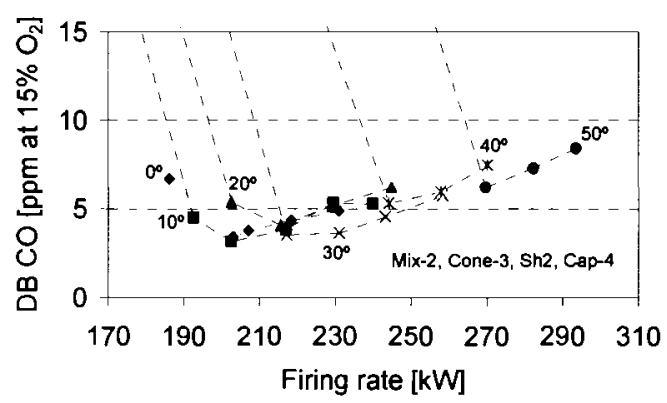

(b) DB CO emissions

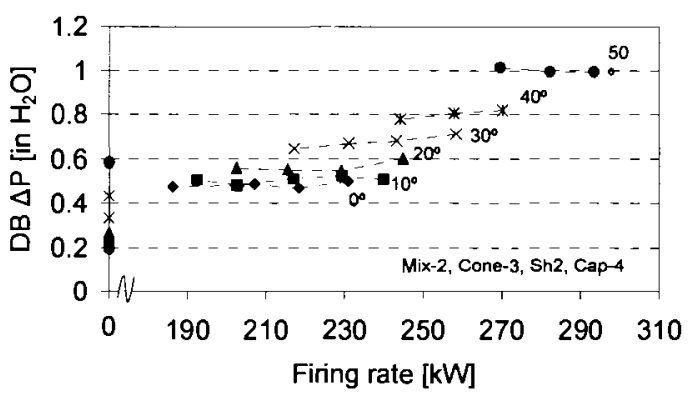

(c) DB pressure drop

Figure 8.61: Effect of firing rate and AFCBA on duct burner performance (Mix-2/2, Cap-4, Cone-3 and Sh2) 
As a summary for these two pairs of results, Figures 8.64 and 8.65 show respectively the effect of conical pressure drop and shield length on duct burner performance. Only one case $\left(\mathrm{AFCBA}=0^{\circ}\right.$ ) was selected and plotted here. Figure 8.64 shows small differences between the plotted results for this case (Mix-2/2 and Sh2 with all the tested cones). Figure 8.65 shows the combustion results for the burner combination Mix-2/2 and Cone-2 with the tested shields, Sh1, Sh2 and Sh3. The effect of using different shields was clearer in this case compared to the effect of cones. Similar to the previous sections, the duct burner temperature profiles for the same case presented in both Figures 8.64 and 8.65 are presented in Figures 8.66 and 8.67. The figures respectively show the effect of conical burner pressure drop and shield length as a function of a firing rate at $\mathrm{AFCBA}=0^{\circ}$ on duct burner temperature. The plots labelled (a) in these figures present the cold surface temperature. The plots labelled (b) present the combustion zone temperature. The plots labelled (c) present the duct burner exhaust gas temperature (point measurement TC-20, see Figure 7.5). Similar trends as in the previous cases were observed here, except that the actual values of NOx, and $\mathrm{CO}$ emissions measurements and the stable operating range values are different.

The results presented in Figure 8.65 were for the shields with a $B R=0.4$. To show the effect of blockage ratio on burner performance, the results of Sh8 (BR = 0.6 ) is presented with other shields for a comparison in Figure 8.68. The results show that as the BR increases (Sh8), the operating range of the duct burner shifts to the higher firing rate range. Although, the duct burner has a rather narrow range of stable operation, emissions were less than $5 \mathrm{ppm}$ values for NOx and CO. At $310 \mathrm{~kW}$ (and $0^{\circ}$ degrees), emissions of NOx emissions of $3 \mathrm{ppm}$ and $\mathrm{CO}$ emissions of $4 \mathrm{ppm}$ were measured. The overall duct burner pressure drop results (Figure 8.68 (c)) shows similar pressure peak values as was observed with Mix-2/2, Cone-3, Sh1 at AFCBA $=0^{\circ}$. 


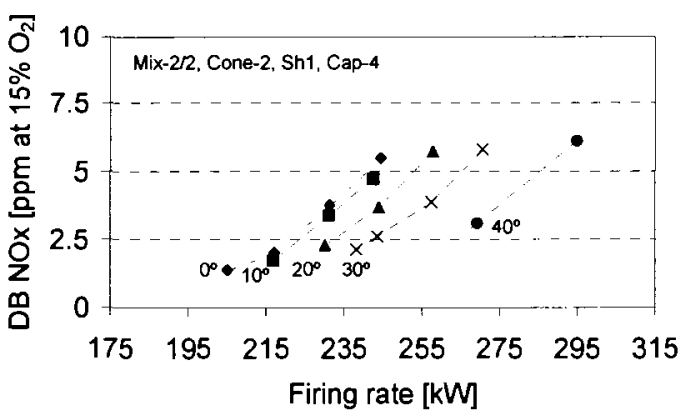

(a) DB NOx emissions

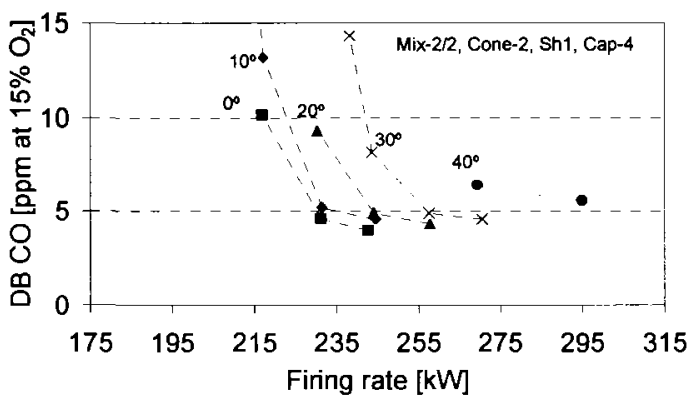

(b) DB CO emissions

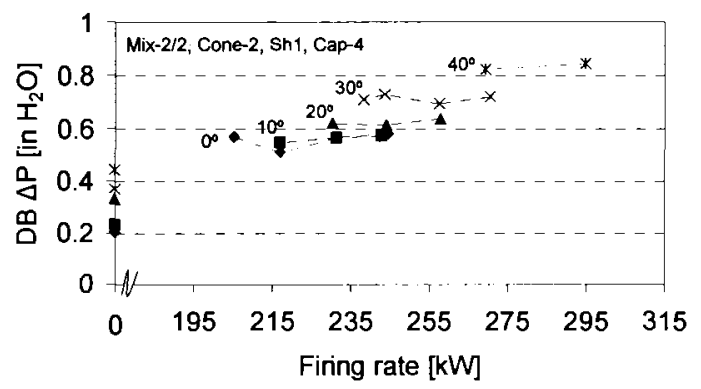

(c) DB pressure drop

Figure 8.62: Effect of firing rate and AFCBA on duct burner performance (Mix-2/2, Cap-4, Cone-2 and Sh1)

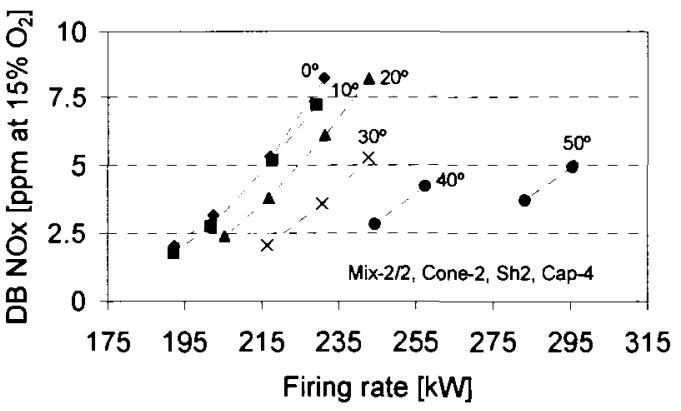

(a) DB NOx emissions

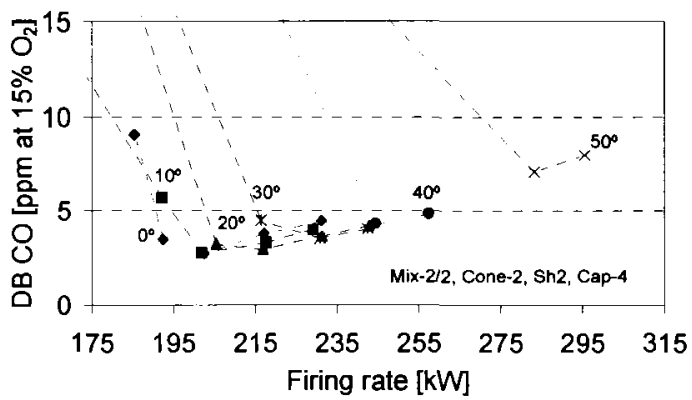

(b) DB CO emissions

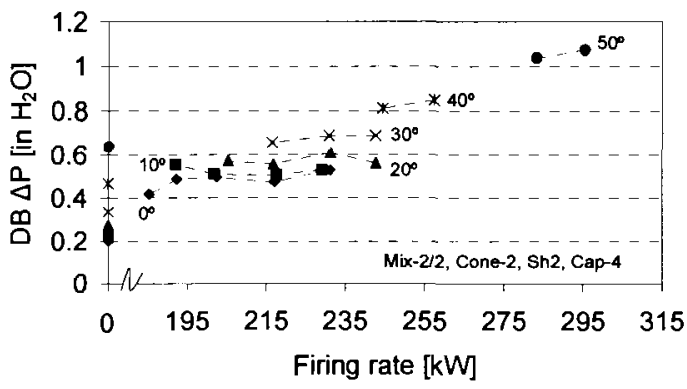

(c) DB pressure drop

Figure 8.63: Effect of firing rate and AFCBA on duct burner performance (Mix-2/2, Cap-4, Cone-2 and Sh2) 


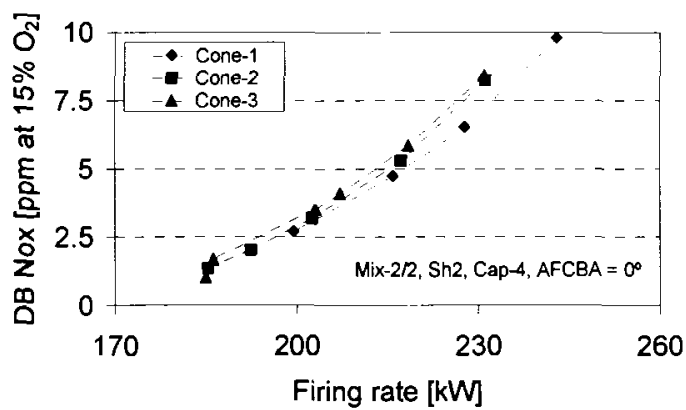

(a) DB NOx emissions

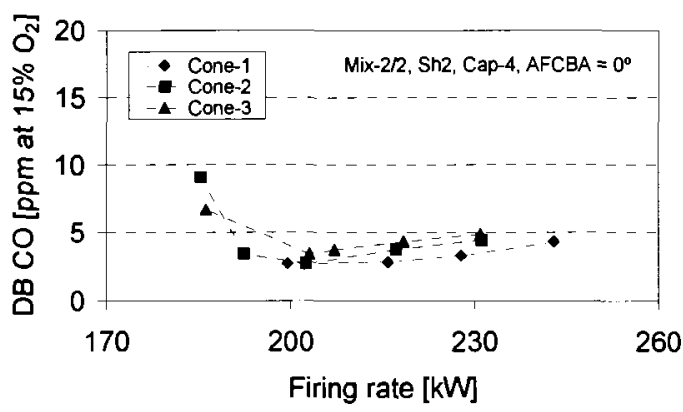

(b) DB CO emissions

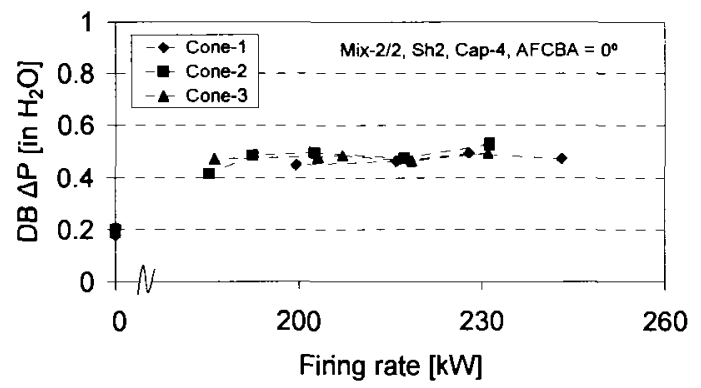

(c) DB pressure drop

Figure 8.64: Effect of firing rate and conical burner pressure drop on duct burner performance (Mix-2/2, Cap-4, Sh2 with Cone-1, Cone-2 and Cone-3)

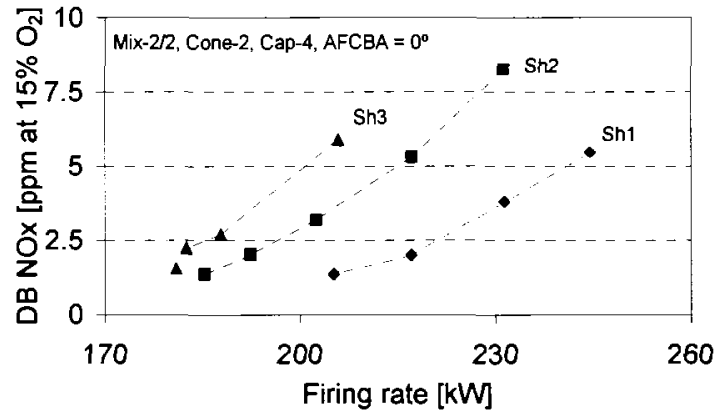

(a) DB NOx emissions

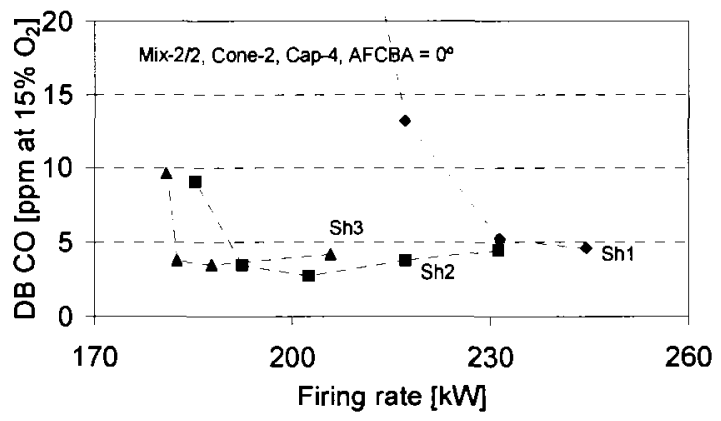

(b) DB CO emissions

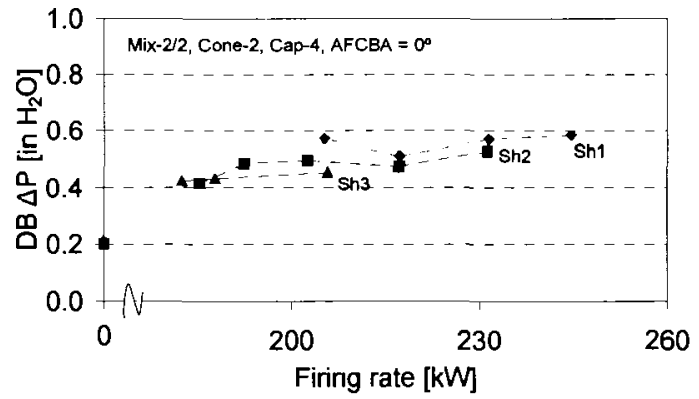

(c) DB pressure drop

Figure 8.65: Effect of firing rate and $L_{\text {eff }} / D_{\text {shield }}$ on duct burner performance (Mix-2/2, Cap-3, Cone-2 with Sh1, Sh2 and Sh3) 


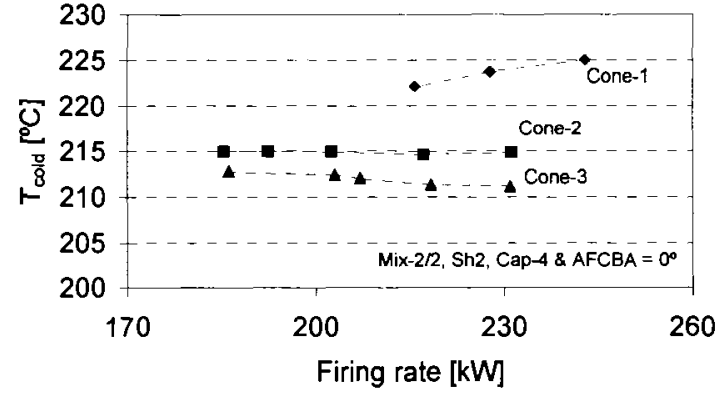

(a) Conical burner cold surface temperature

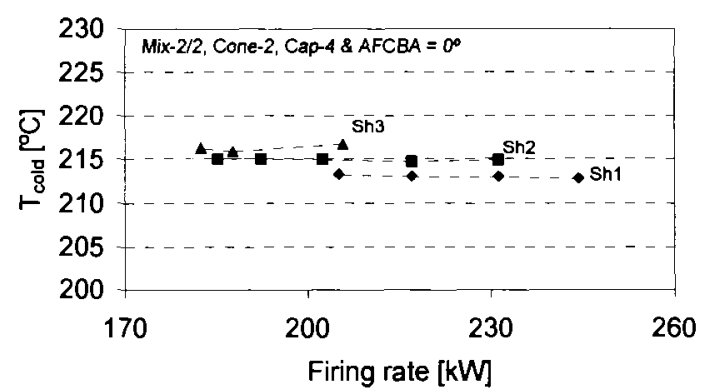

(a) Cold surface temperature

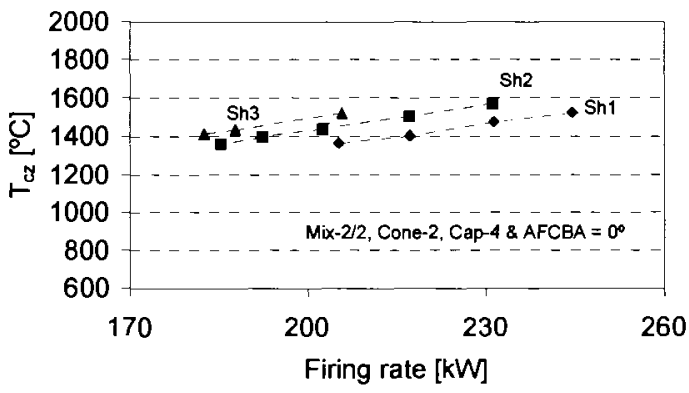

b) Combustion zone temperature

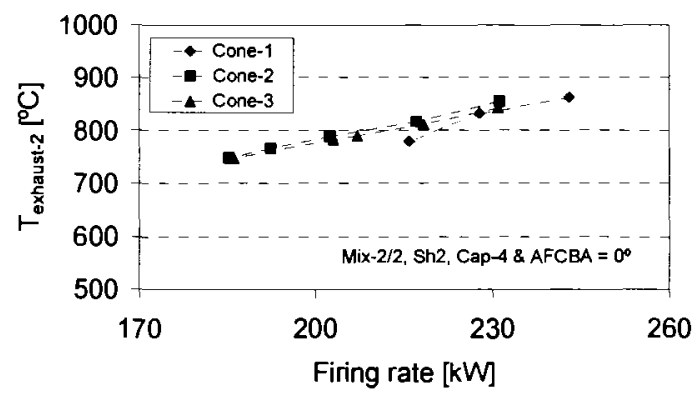

(c) DB exhaust gas temperature

Figure 8.67: Effect of firing rate and $L_{\text {eff }} / D_{\text {shield }}$ on duct burner temperatures (Mix-2/2, Cap-4 and Cone-2 at $\mathrm{AFCBA}=0^{\circ}$ ) 
As in previous sections, stable flame images for selected operating points are presented in Figures 8.69 and 8.70. All the information describing each image is included with the images

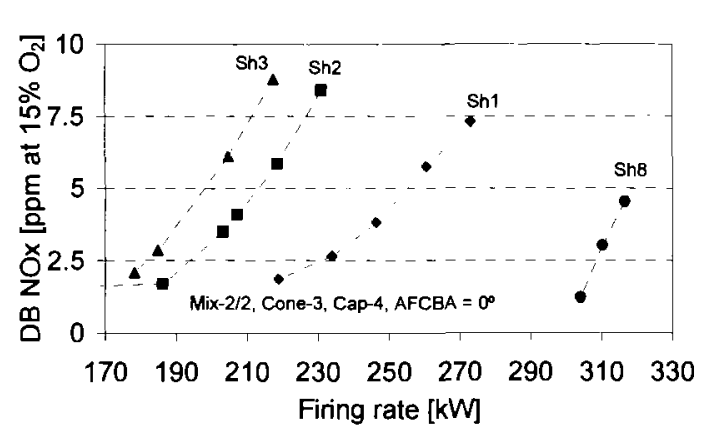

(a) DB NOx emissions

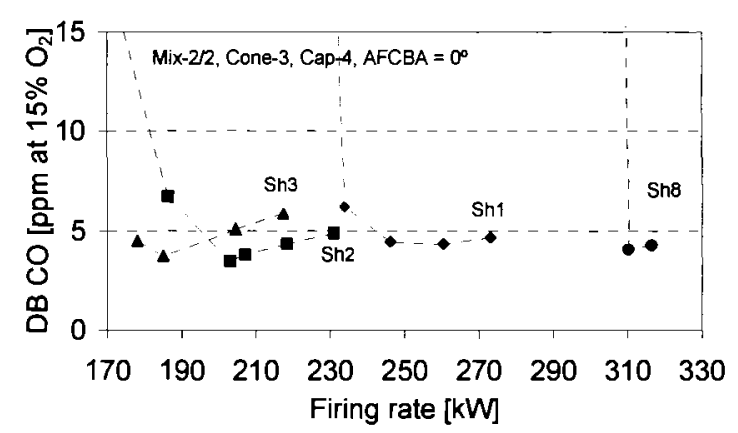

(b) DB CO emissions

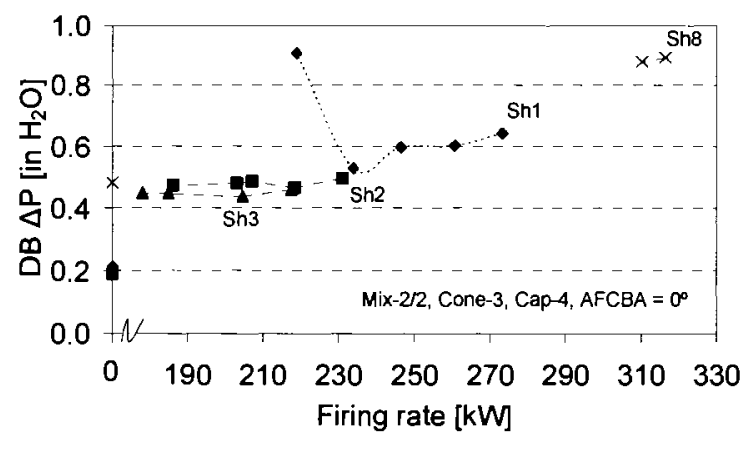

(c) DB pressure drop

Figure 8.68: Effect of firing rate and $L_{e f f} / D_{\text {shield }}$ on duct burner performance (Mix-2/2, Cap-3, Cone-2 with Sh1, Sh2 and Sh3) 


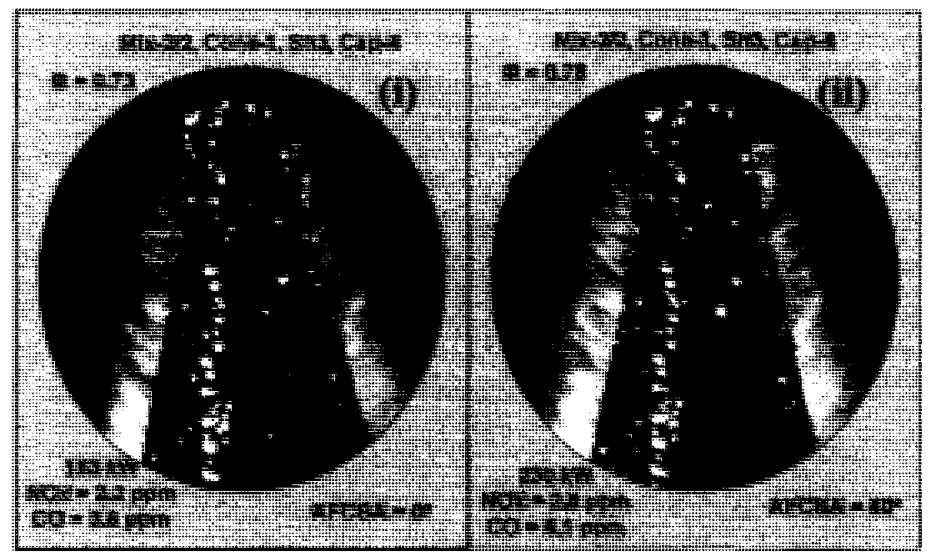

Figure 8.69: Flame images taken for different operating points (Mix-2/2, Cone-1, Sh3 and Cap-4)

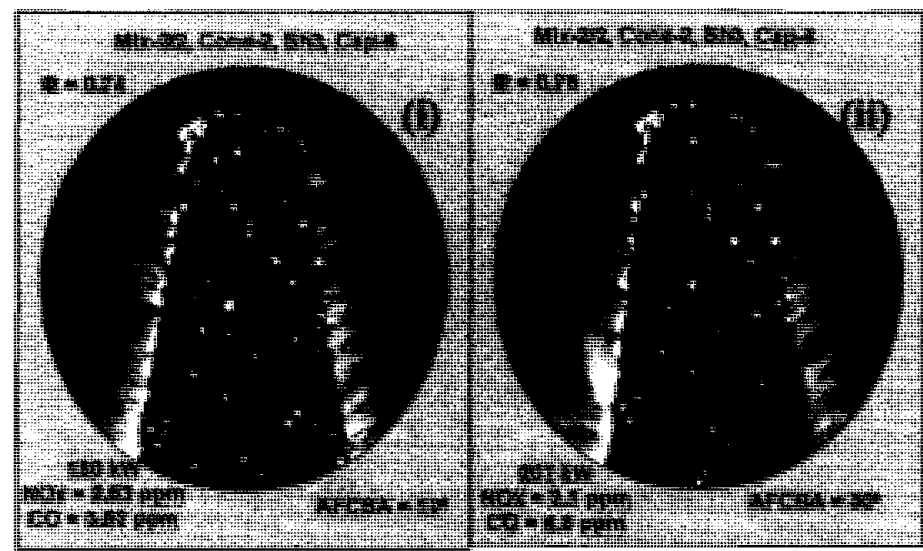

Figure 8.70: Flame images taken for different operating points (Mix-2/2, Cone-2, Sh3 and Cap-4)

\subsubsection{Comparisons between the DB parameters and their effect on the performance}

Based on the above discussion, this section summarizes and compares the effects of changing the burner configuration, on the performance of the duct burner. The effect of firing rate, conical burner pressure drop, shield length, BR and AFCBA on duct burner performance is discussed extensively in both Sections 8.6.1 and 8.6.2, as well as in Appendix F (where Cap-3 was used). However, only one case will be 
plotted in this section to summarize these two sections. This section will also present in graphical form; the effect of the duct burner inlet temperature on performance, how the exhaust gas temperature is affected by different parameters and the effect of fuel caps and mixers on duct burner performance.

\subsubsection{Effect of burner parameters on operating range}

Figure 8.71 summarizes the effect of using different pressure drop conical burners, firing rate (FR) and the AFCBA, on NOx emissions and the stable operating range of the duct burner. The figure shows the improvement in the stable operating range as the pressure drop across the conical burner increases. The higher the conical burner pressure drop, the wide the operating range becomes. The increase in pressure drop due to the lower porosity increases the local gas flow momentum which could be responsible for the shift in the stable zone towards the leaner limit. With increasing the conical burner pressure drop from 75 to $224 \mathrm{~Pa}$, the stable operating range becomes wider until a maximum is reached at a pressure drop of $149 \mathrm{~Pa}$. Thus, 149 $\mathrm{Pa}$ is considered an optimal conical pressure drop for the duct burner. Along with this improvement in the operating range with the use of high conical pressure drop comes an increase in the overall duct burner pressure drop. The increase in the conical pressure drop was slightly affected by the overall duct burner pressure drop but still within the design limit.

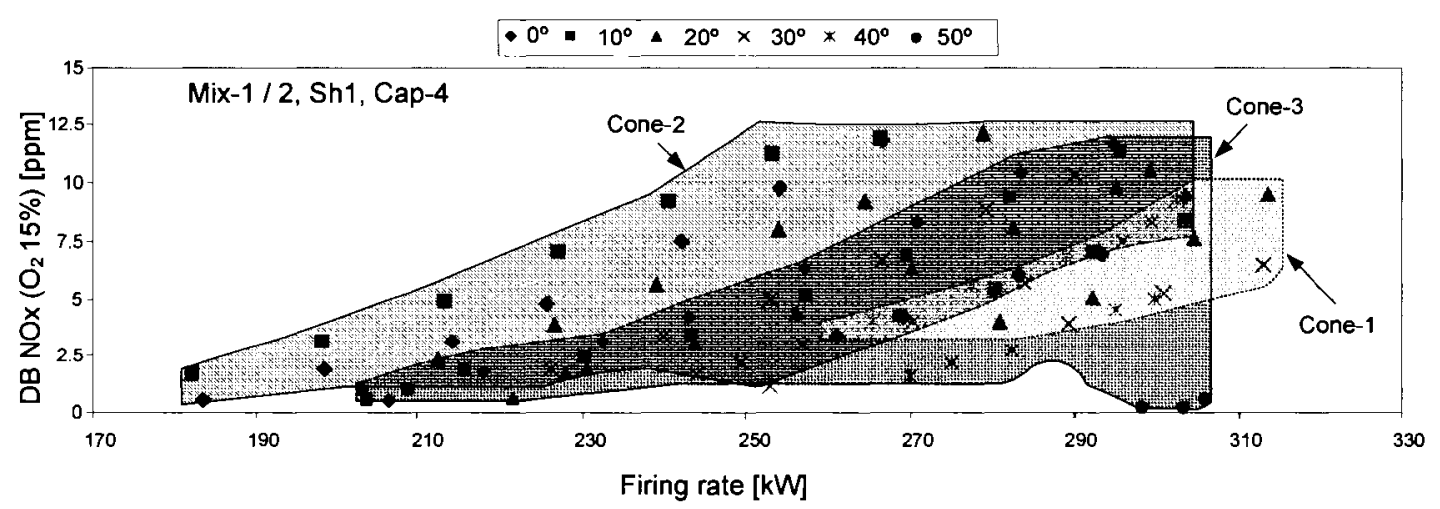

Figure 8.71: Effect of firing rate, AFCBA and conical burner pressure drop on duct burner NOx emissions and operating range (Mix-1/2, Cap-4 and Sh1) 


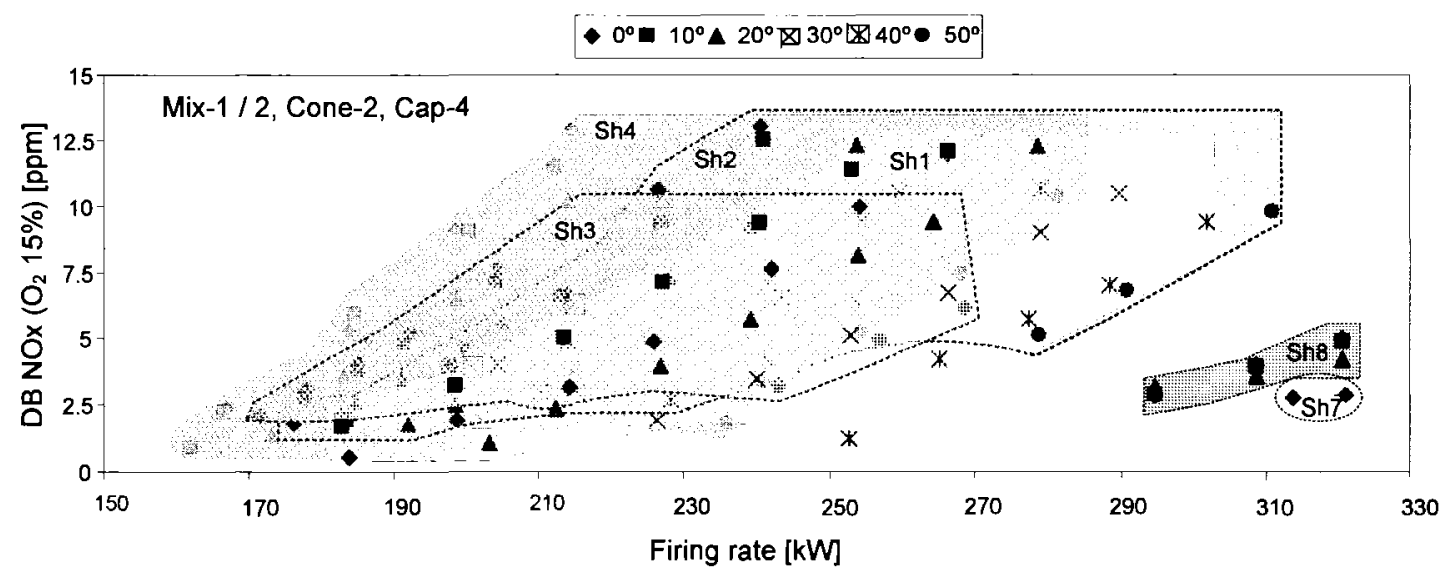

Figure 8.72: Effect of firing rate, AFCBA and $L_{e f f} / D_{\text {shield }}$ ratio on duct burner NOx emissions and operating range (Mix-1/2, Cap-4 and Cone-2)

Figure 8.72 shows NOx emissions as a function of firing rate at different annular blade angles, for the six tested conical burner shields (Sh1, Sh2, Sh3, Sh4, Sh7 and Sh8). The results presented in Figure 8.72 are for burner configuration; Mix$1 / 2$, Cap-4 and Cone-2. The figure shows two groups of results, the upper left side group which demonstrates the results of the shields that have a BR $=0.4$. These shields have different lengths but the same blockage ratio (BR). The lower right side group, however, represents the results of the conical burner shields that have a BR = 0.6. For both groups $(\mathrm{BR}=0.4$ and $\mathrm{BR}=0.6)$, as the shield length increases, the lower blow-off limit decreases (the flame stabilizes at leaner fuel/oxidant mixture ratios) and the stable operating zone becomes wider. For shields with BR of 0.6 the burner is operates at a higher firing rate with a narrow operating range compared to shields that have $\mathrm{BR}=0.4$. Longer shields provide more protection to the flame from the bypassed flow and provide an energy feedback to the combustion zone, which increases the combustion zone temperature and gives the duct burner the ability to operate at a leaner equivalence ratio. 


\subsubsection{Effect of duct burner inlet temperature $\left(T_{\text {inlet }}\right)$}

The overall duct burner pressure drop values measured for all the combustion tests were almost all less than the limit value of $249 \mathrm{~Pa}$. According to the operating manual of the microturbine CHP unit, the pressure drop limit is the value for the device that affects the microturbine performance. It was decided to study the influence of varying the duct burner inlet temperature. A convenient way to change the duct burner inlet temperature was to enable the heat recovery system. A complete set of results in which the duct burner was tested with a reduced inlet temperature are presented in Appendix F. In this section, selected results for certain cases will be used to show the effect of the duct burner inlet temperature on its performance.

Figures 8.73 and 8.74 show the effect of firing rate and the duct burner inlet temperature on duct burner performance respectively for the burner configuration Mix-1/2, Cap-3, Cone-1 and Sh2, and burner configuration Mix-1/2, Cap-3, Cone-2 and Sh2, both at AFCBA $=0^{\circ}$. Figures labelled (a) show NOx emissions, (b) CO emissions and (c) the overall duct burner pressure drop. Preheating the unburned mixture gives additional enthalpy to the reactants, saves energy and increases the combustion zone temperature. This results in broadening the stability range and shifts the blow-off limit towards the lower firing rate value. Both figures show that increasing the duct burner inlet gas temperature increases the operating range limits. However, increasing the combustion zone temperature increases NOx formation. $\mathrm{CO}$ emissions decrease with the increase in the duct burner inlet temperature. The inlet temperature does not show any effect on the overall duct burner pressure drop. The pressure drop remained at an almost constant value. The lower inlet temperature shows less stability close to the blow-off limit.

Figure 8.75 shows flame images for two selected operating points. The images are for the points labelled (i) and (ii) in Figure 8.73 (a). All the information describing each image is illustrated on the figure. 


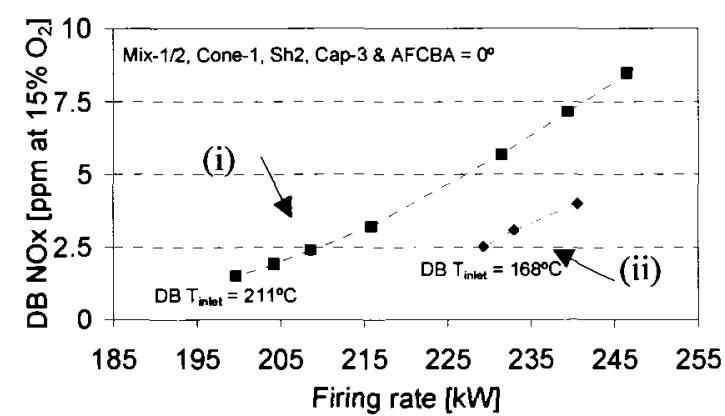

(a) DB NOx emissions

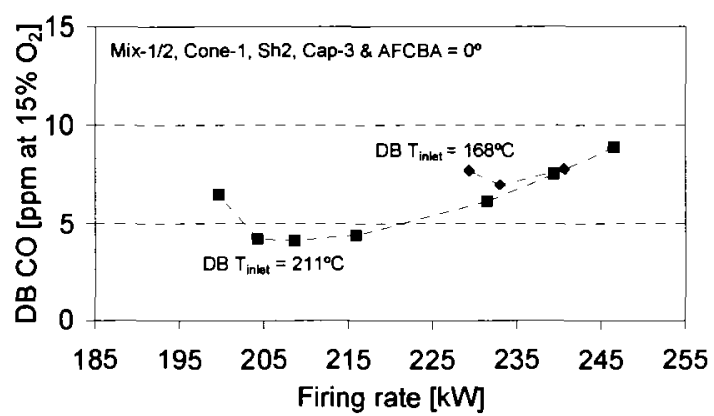

(b) DB CO emissions

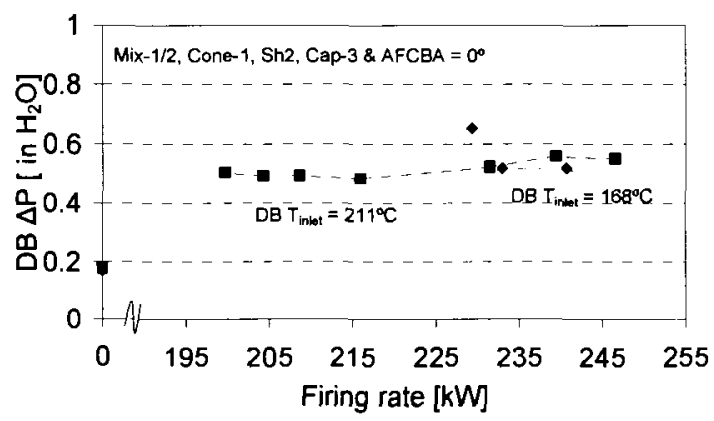

(c) DB pressure drop

Figure 8.73: Effect of firing rate and DB inlet temperature on duct burner performance (Mix-1/2, Cone1 , Cap-3 and $\mathrm{Sh} 2$ at $\mathrm{AFCBA}=0^{\circ}$ )

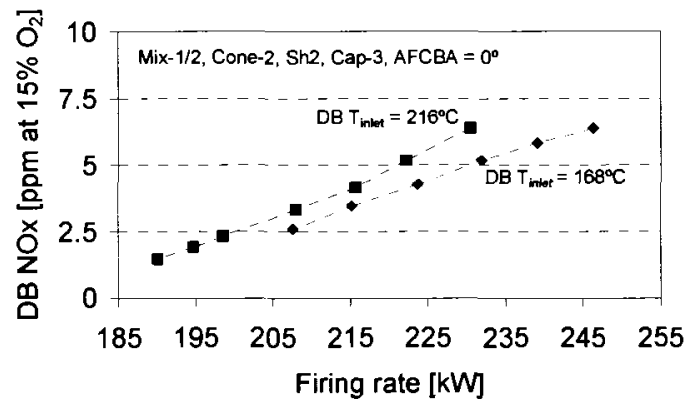

(a) DB NOx emissions

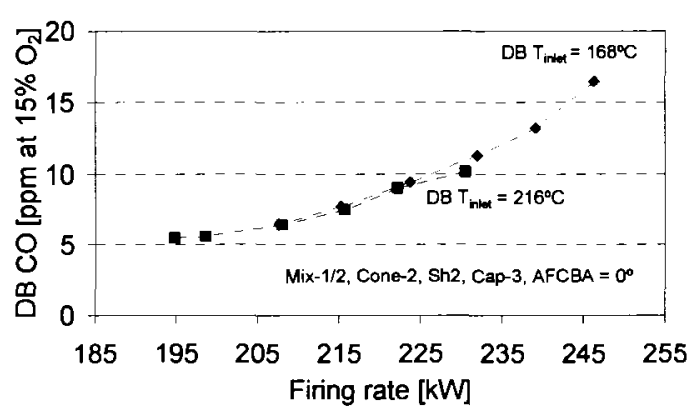

(b) DB CO emissions

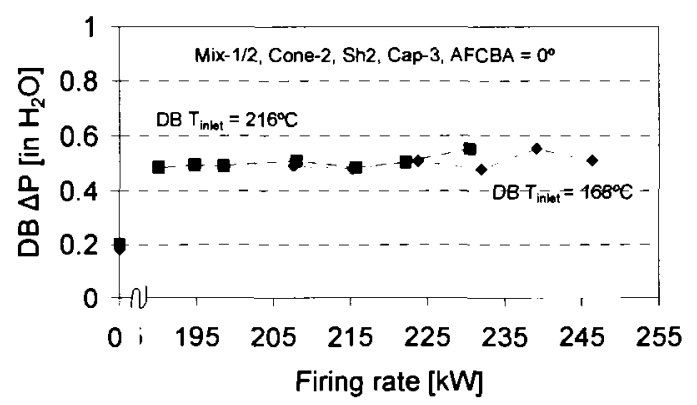

(c) DB pressure drop

Figure 8.74: Effect of firing rate and DB inlet temperature on duct burner performance (Mix-1/2, Cone2, $\mathrm{Cap}-3$ and $\mathrm{Sh} 2$ at $\mathrm{AFCBA}=0^{\circ}$ ) 


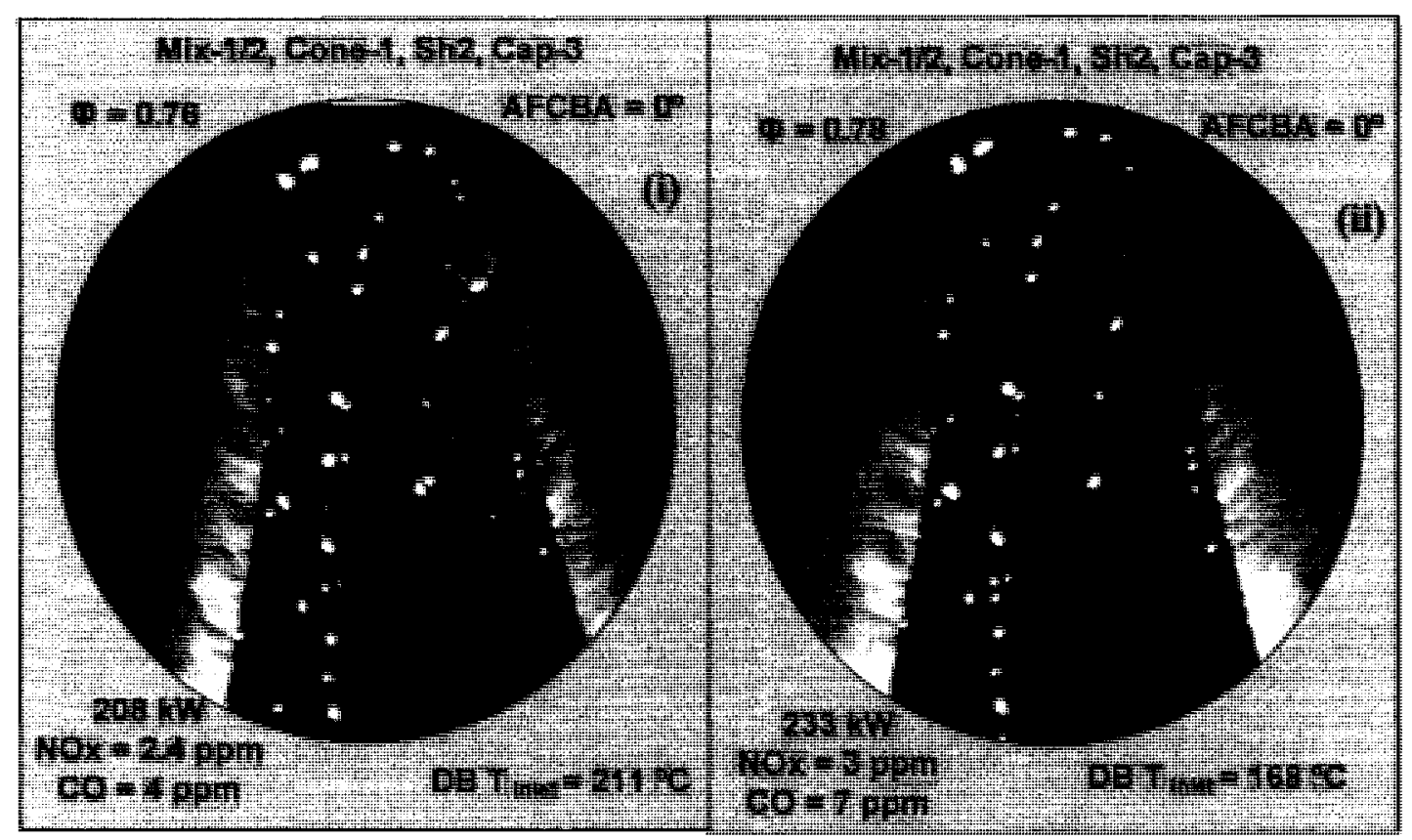

Figure 8.75: Flame images taken for points (i) and (ii) in Figure 8.73 (a)

\subsubsection{Effect of burner parameters on the DB exhaust gas temperature}

In this section, the effect of the burner parameters on duct burner traverse temperature ( $T_{\text {exhaust-1-traverse }}$, location 19, Figure 7.5 ) will be summarized. Figures 8.76 and 8.77 show the effect of using different conical burners with different pressure drop values on the exhaust gas temperature. These figures show how the differences in the temperature distribution across the duct burner reference diameter for the three tested cones are small when tested with the single-swirl mixer. All the cones produce top-hat distributions and their maximum value was around $1000^{\circ} \mathrm{C}$. This improvement in the quality of the exhaust gases (from $227^{\circ} \mathrm{C}$ to $1000^{\circ} \mathrm{C}$ ) was accompanied by single digit emissions for both NOx and CO. For some cases, as presented in Sections 8.6.1 and 8.6.2, emissions were less than $5 \mathrm{ppm}$ for both pollutants. Figure 8.77 shows similar results to those in Figure 8.76 for other burner 
parameters. Additional results are illustrated on both figures, such as FR and equivalence ratio.

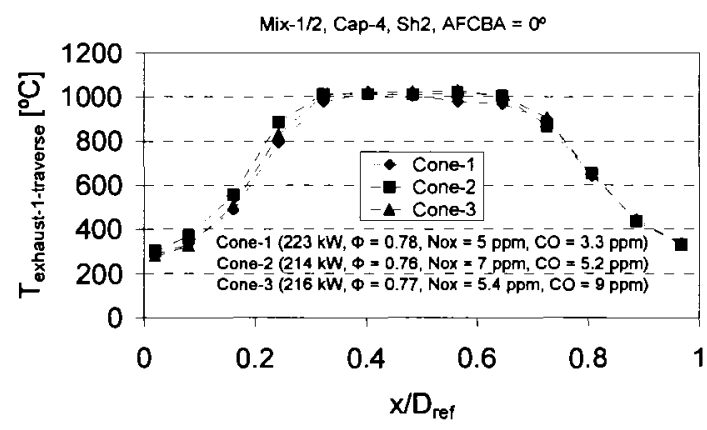

Figure 8.76: Effect of cones on DB exhaust gases temperature (Mix-1/2, Cap4 and Sh2 at AFCBA $=0^{\circ}$ )

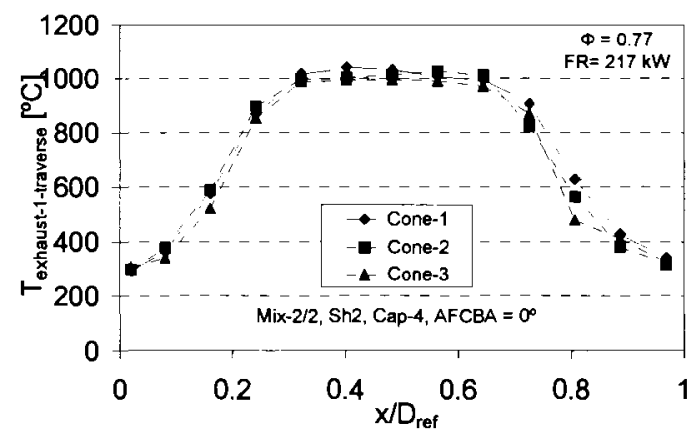

Figure 8.77: Effect of cones on DB exhaust gases temperature (Mix-2/2, Cap4 and Sh2 at $\mathrm{AFCBA}=0^{\circ}$ )

Figure 8.78 shows the effect of shield length on exhaust gas temperature for burner configuration Mix-1/2, Cone-2, Cap-4 at zero degrees blade angle. Shields Sh1 $(B R=0.4)$ and $\operatorname{Sh} 2(B R=0.4)$ were used in this comparison. Similar temperature profiles were obtained as those presented in the previous section. The results show a slight increase of the temperature at the centre region (top-hat) with Sh2. This is due to an increase in the shield length. Increasing the shield length delays the interactions (dilution) between the bypassed microturbine exhaust gases and the duct burner combustion gases. As expected, this observation is also recorded when longer shields were used.

Figure 8.79 shows the effect of BR on exhaust gas temperature. This figure shows the comparison between the two temperature profiles for the duct burner configurations Mix-1/2, Cone- 2 and Cap-4 at AFCBA $=0^{\circ}$ with shields, Sh1 (BR = $0.4)$ and $\operatorname{Sh} 8(B R=0.6)$. The results show that, even using a higher blockage ratio shield $(\mathrm{BR}=0.6)$ the maximum temperature level is almost the same as in the previously mentioned results $\left(\approx 1000^{\circ} \mathrm{C}\right)$. With $\mathrm{Sh} 1$, a maximum of $950^{\circ} \mathrm{C}$ was recorded. Because of the increase in shield diameter, the Sh8 results show a wider 
temperature range across the duct burner reference diameter. Lastly, Sh8 is a longer shield compared to $\mathrm{Shl}$, but the difference between the two peak temperatures is $50^{\circ} \mathrm{C}$. The reason for that is believed to be the different design of Sh8 (Sh8 has different design regarding the viewing ports shape and size, see Figure 4.17).

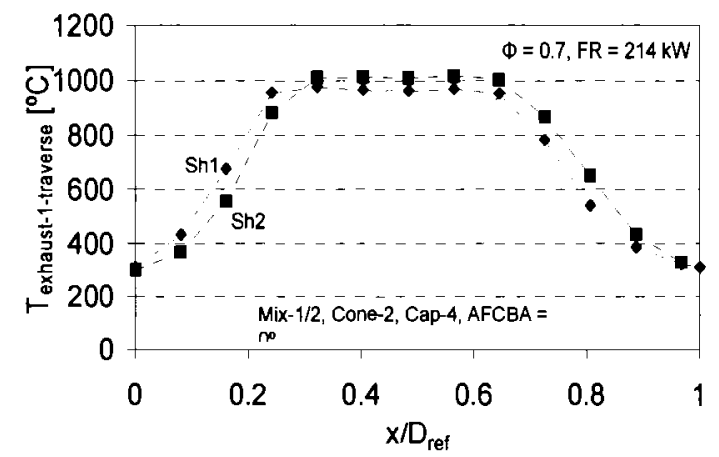

Figure 8.78: Effect of $L_{\text {eff }} / D_{\text {shield }}$ on DB exhaust gases temperature (Mix-1/2, Cone-2 and Cap-4 with Sh1 and Sh2)

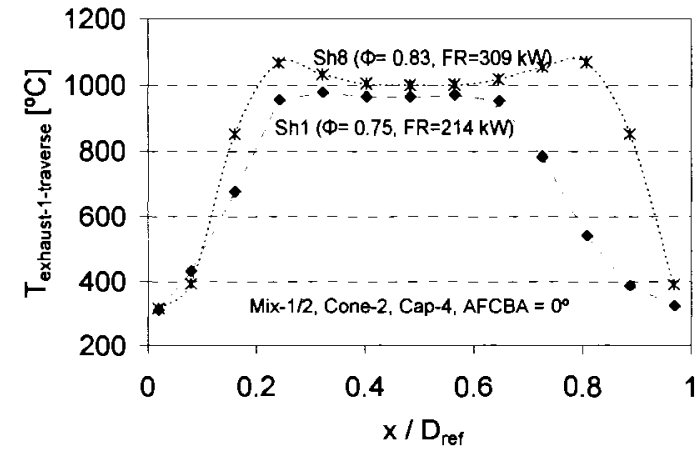

Figure 8.79: Effect of $B R$ on the DB exhaust gases temperature (Mix-1/2, Cone-2 and Cap-4)

Figure 8.80 shows the comparison between the two temperature profiles at different firing rate values $(153 \mathrm{~kW}$ and $174 \mathrm{~kW})$ for duct burner configuration: Mix$1 / 2$, Cone- 3 and Cap-2 at AFCBA $=0^{\circ}$. The results shown in Figure 8.80 indicate that the maximum temperature value increases as the firing rate increases, due to the increase in the temperature at the combustion zone (increase in enthalpy input).

Figure 8.81 shows the effect of changing the AFCBA on exhaust temperature profile. Increasing the AFCBA to a higher value means increasing the mass flow ratio $\left(M R_{C F}\right)$ which means an increase in blockage in the duct burner annular passage, which, in turn, forces more microturbine exhaust gases through the conical burner. For the same test conditions, increasing AFCBA leads to more excess oxidant through the combustion zone, which leads to a reduction in the temperature at the combustion zone and downstream of the conical burner. This observation is shown in Figure 8.79. This figure shows a slight reduction in the temperature profile at a $10^{\circ}$ 
angle compared to that at $0^{\circ}$. The test results presented in Figure 8.79 were for burner configuration Mix-1/2, Cone-3, Cap-4 and Shl. Also, as Shl was used in this case, the temperature profile shows lower values at the burner central region due to the early mixing between the duct burner bypass flow and the combustion gases.

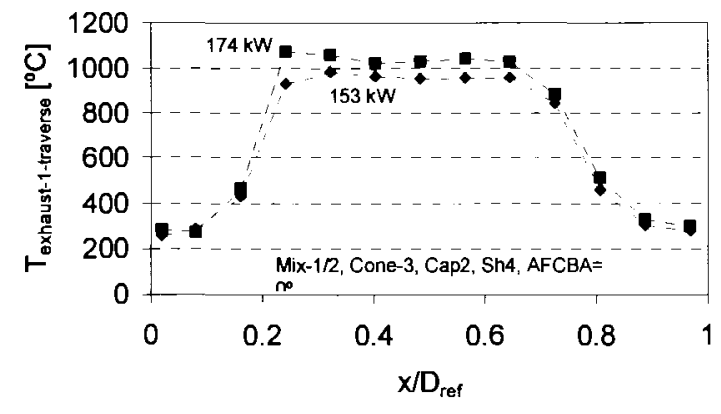

Figure 8.80: Effect of FR on DB exhaust gases temperature (Mix-1/2, Cone-3 and Cap-2 with Sh4)

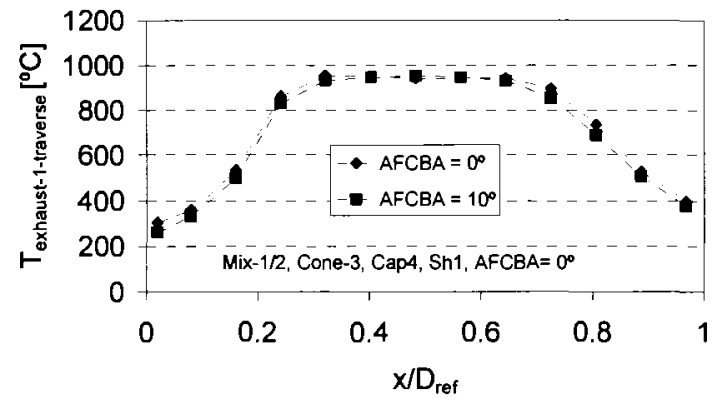

Figure 8.81: Effect of AFCBA (MR) on DB exhaust gases temperature (Mix-1/2, Cone-3 and Cap-4 with Sh1)

\subsubsection{Effect of different fuel caps on DB performance}

Fuel caps Cap-2 and Cap- 4 were used to provide the duct burner with a different range of fuel flow rates. These tests were conducted to determine the effect of differing gas supply pressure on the duct burner performance. This subsection combines selected results from the previous sections, when both fuel caps were used, to show and discuss the differences between their effects on the duct burner performance.

Figure 8.82 shows the experimental test results of NOx emissions (figures labelled (a)) and $\mathrm{CO}$ emissions (figures labelled (b)) as a function of firing rate and fuel cap type. The results are for burner configuration Mix-1/2, Cone-1 and Sh2 at $\mathrm{AFCBA}=0^{\circ}$.

Figure 8.82 shows that NOx and CO emissions were reduced when Cap-4 was used. Cap-2 results show the shift of the lower operating limit towards the leaner combustion side due to the higher flame temperature (see below). The operating range 
with Cap-4 was $194 \mathrm{~kW}$ to $250 \mathrm{~kW}$ With Cap-2 the range shifted to between $168 \mathrm{~kW}$ and $214 \mathrm{~kW}$. For the same operating conditions, Cap-4 provides the duct burner with a higher fuel flow rate, which increases the total reactant mass flow rate (microturbine exhaust gases forced through the conical burner (oxidant) + fuel (natural gas)). The increase in the fuel flow rate reduces the temperature of the incoming oxidant fuel mixture. With Cap-2, the reactant mixture is at a higher temperature than with Cap-4 because Cap- 4 allows more room temperature fuel into the mixer. The additional enthalpy in the Cap-2 mixture increases its flame temperature, causing higher NOx emissions compared to those with Cap-4. Figure 8.83 shows the effect of using different fuel flow rates on duct burner temperatures. Figure 8.83 (a) and (b) show the premixer exit temperature (mixture temperature) and the conical burner cold surface temperature, illustrating the lower mixture temperature for Cap-4. Figure 8.83 (c) shows the combustion zone temperature. This figure shows that the Cap-2 combustion zone temperature is higher. From the heat transfer point of view, when Cap-4 is used, there is an increase in the equivalence ratio (compared to that of Cap-2). This causes the combustion zone to move closer to the conical burner wire-mesh surface (shorter and more compact flames, see Figure 8.84 (a) and (b)). In turn, this causes an increase in the surface temperature (hot side) which will reduce the flame temperature. The flames produced with Cap-2 were much longer blue flames than those with Cap-4 (Figure 8.84 (a) and (b)). Also, the images show that, for Cap-2 as the AFCBA increases the flame becomes longer and stabilized at higher firing rate. In case of Cap-4 as the AFCBA increases the flame stabilized at a higher equivalence ratio and from the image one can say that the hot surface temperature increased compared with the case where $\mathrm{AFCBA}=0^{\circ}$ to the Cap- 4 case, which resulted in a higher combustion zone temperature (Figure 8.83 (c)). This led to more heat remaining in the combustion gases (Figure 8.83 (d)). CO emissions decreased with Cap-4. The slower mixture speed and longer residence time resulted in lower CO emissions (more complete combustion). 


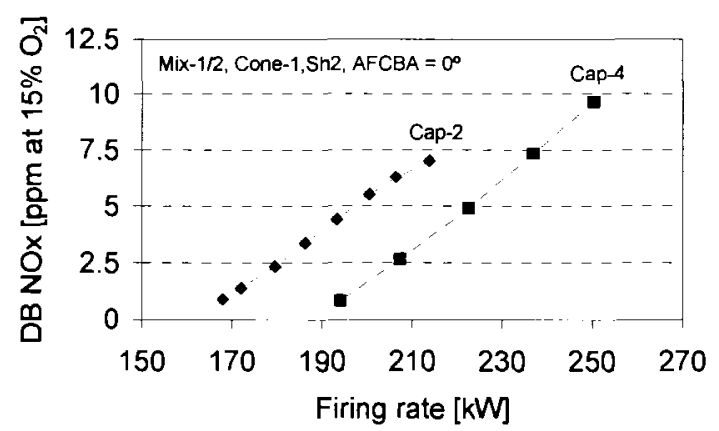

(a) NOx emissions

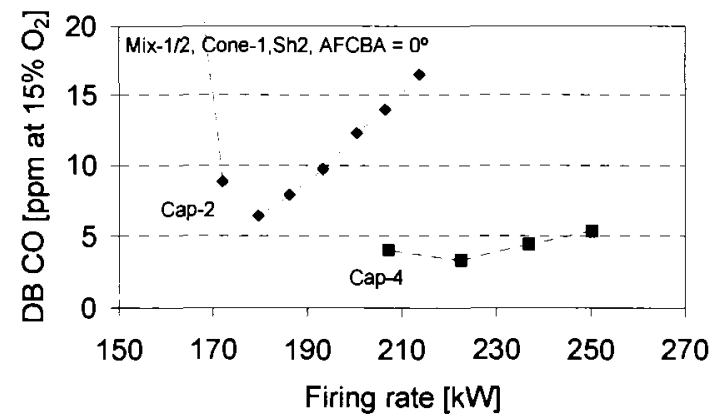

(b) $\mathrm{CO}$ emissions

Figure 8.82: Effect of firing rate and fuel caps on duct burner performance, for burner configuration; (Mix-1/2, Cone-1 and Sh2 at AFCBA $=0^{\circ}$ )

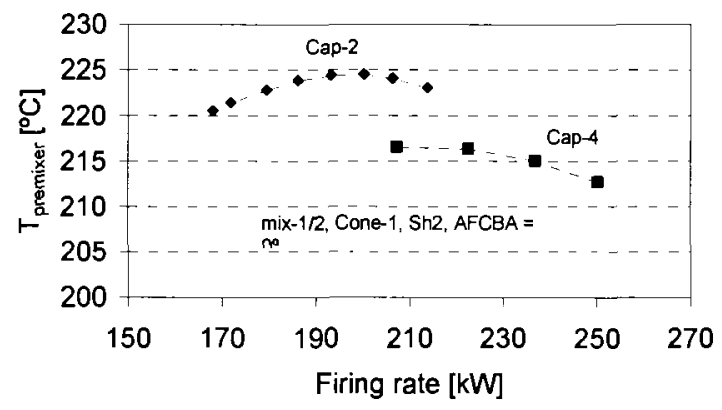

(a) Premixer (mixture) temperature

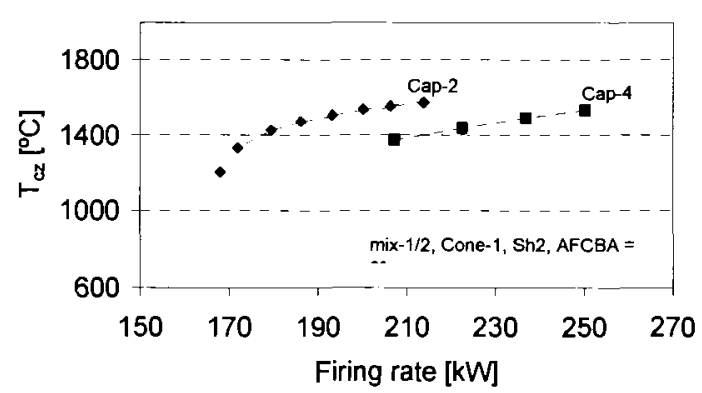

(c) Combustion zone temperature

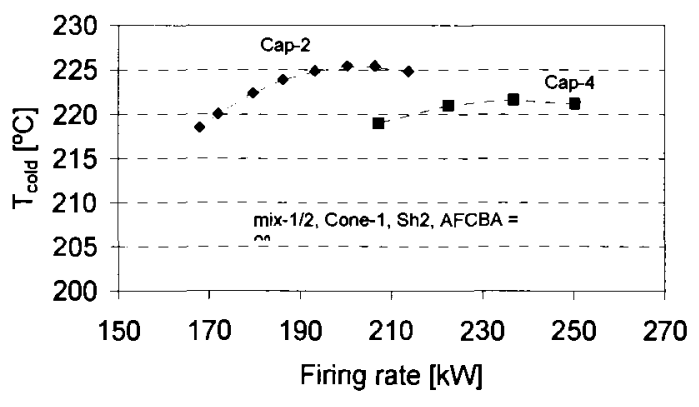

(b) Cold surface temperature

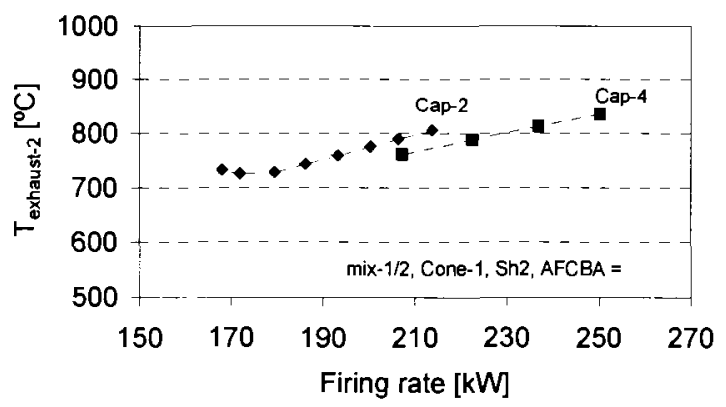

(d) DB exhaust gases temperature

Figure 8.83: Effect of using different fuel caps as a function of firing rate on the duct burner temperatures, for burner configuration; (Mix-1/2, Sh2, Cone-1 at $\operatorname{AFCBA}=0^{\circ}$ ) 


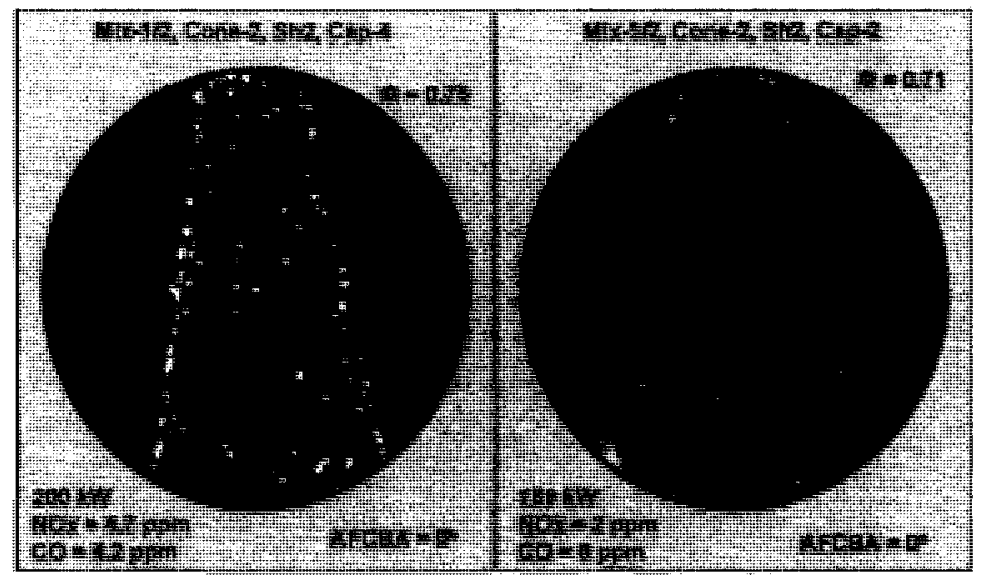

(a) $\mathrm{Mix}-1 / 2, \mathrm{Sh} 2$, Cone- 1 at $\mathrm{AFCBA}=0^{\circ}$

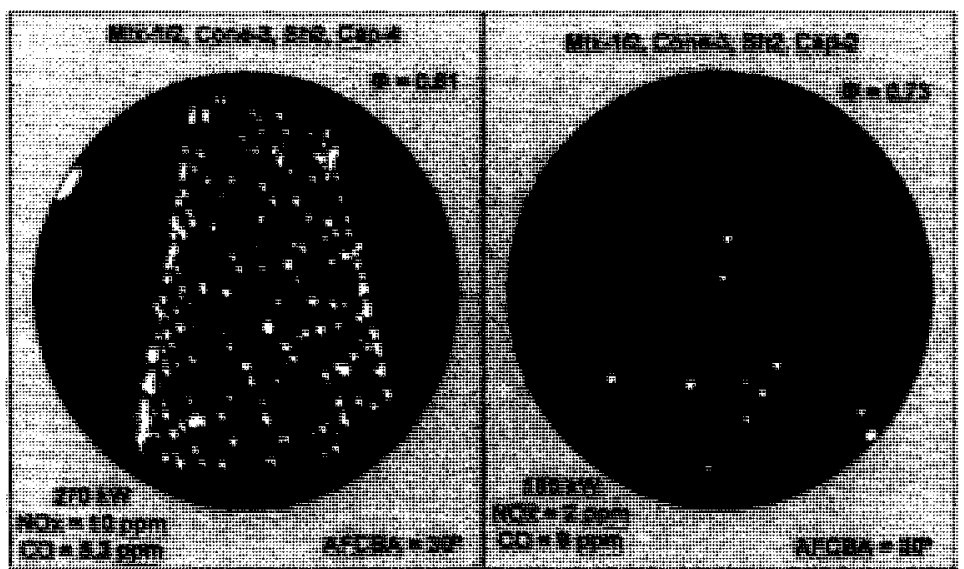

(b) $\mathrm{Mix}-1 / 2, \mathrm{Sh} 2, \mathrm{Cone}-3$ at $\mathrm{AFCBA}=30^{\circ}$

Figure 8.84: Effect of using different fuel caps (flame images)

\subsubsection{Effect of mixer design on the DB performance (mixing)}

To evaluate the effect of using different mixers design (Mix-1/2 swirl number $=0.4$ and Mix $-2 / 2$ swirl number $=0.58$ ) on duct burner performance, two mixers were tested during the combustion tests. Both mixers (Mix-1/2 and Mix-2/2) were tested during the LSI phase of the present investigation and it was proven, from the qualitative and the quasi-quantitative assessments (during the mixer ranking, see Chapter 5) that, Mix-2/2 has the best mixing characteristics compared to the other mixers tested including Mix-1/2. The combustion test results of both mixers when 
combined with other burner parameters were presented in Sections 8.6.1 and 8.6.2 (see Appendix G, for the results of both mixers tested with Cap-3 at a lower DB inlet temperature). In this section and for the purpose of comparison, sample results were taken from the previously presented results conducted at the same operating conditions, and plotted together and presented in this section.

Figure 8.85 shows the effect of firing rate and mixer design on DB performance for burner configuration Cone-1, Cap-2 and Sh3. All the curves shown are for the case where AFCBA $=0^{\circ}$. The figure labelled (a) presents NOx emissions, (b) $\mathrm{CO}$ emissions and (c) overall duct burner pressure drop results. The double-swirl mixer, Mix-2/2, which has a higher swirl strength, shows lower NOx and CO emissions. This is attributed to better mixing induced by the double-swirl mixer. For the single-swirl mixer, the stable operating range shifts and extends towards the lower firing rate values. The decrease of the stable operating range for the double-swirl mixer was due to the increase in the swirl strength. As expected, the overall duct burner pressure drop is slightly increased using the double-swirl mixer, Mix-2/2, (see Figures $8.85(\mathrm{c}))$.

Figure 8.86 shows the effect of firing rate and mixer design on duct burner temperatures for duct burner configuration Cone-1, Cap-2 and Sh3. Figure 86 (a) shows the effect of using the different mixers on oxidant/fuel mixture temperature at the premixer exit. The figure clearly shows the difference in both temperature profiles due to the improvement in mixing. The reactants with the higher inlet temperature are expected to produce higher flame temperatures and higher NOx. Figure 8.86 (b) presents the combustion zone temperature which indicates the relative intensity of the flame. Figure 8.86 (c) shows the traverse exhaust gases temperature profiles downstream of the conical burner (location 19, Figure 7.5). The configuration in this figure was different than the one used in Figure 8.86 (a) and (b). This plot is for burner configuration Cone-1, Cap-4 and Sh2. It shows relatively small differences between the two profiles. Both mixers produced a top-hat profile with a maximum 
value of $1000^{\circ} \mathrm{C}$. The mixers had a stronger effect on the emissions, as compared to the exhaust gas temperature.

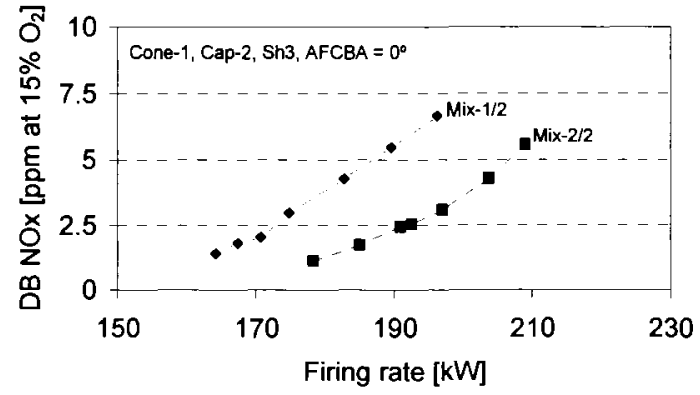

(a) DB NOx emissions

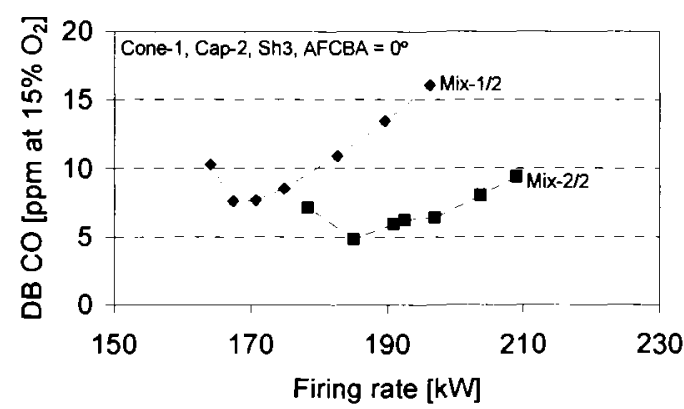

(b) DB CO emissions

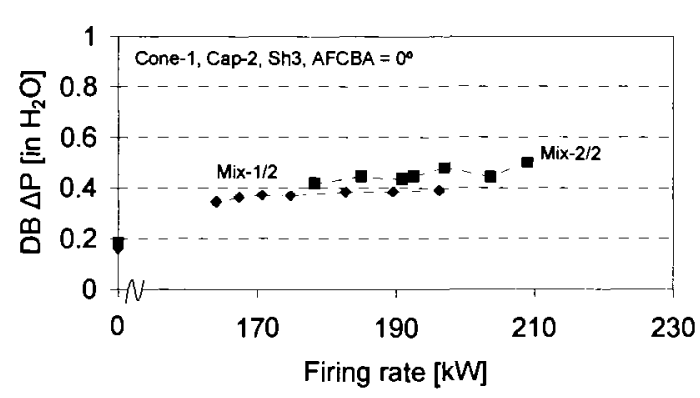

(c) DB pressure drop

Figure 8.85: Effect of firing rate and mixers design on DB performance (Cone-1, Cap-2 and Sh3 at AFCBA = $\left.\mathbf{0}^{\circ}\right)$

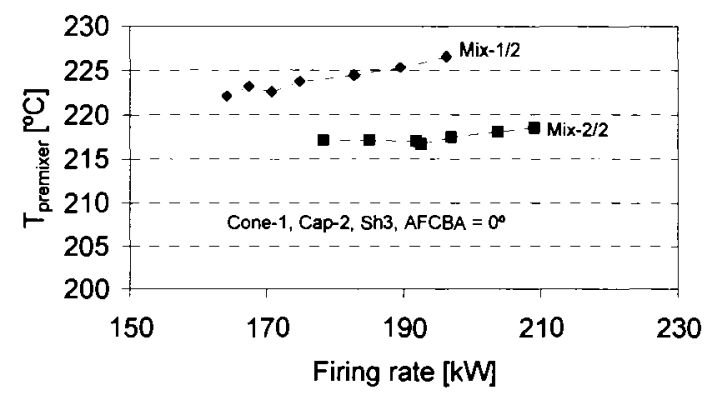

(a) Premixer (mixture) temperature

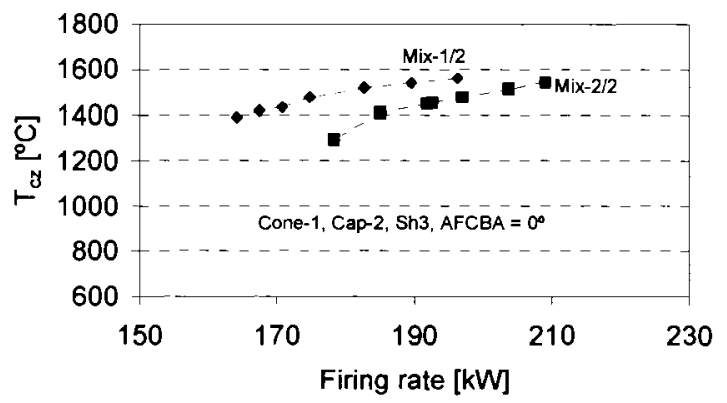

(b) Combustion zone temperature

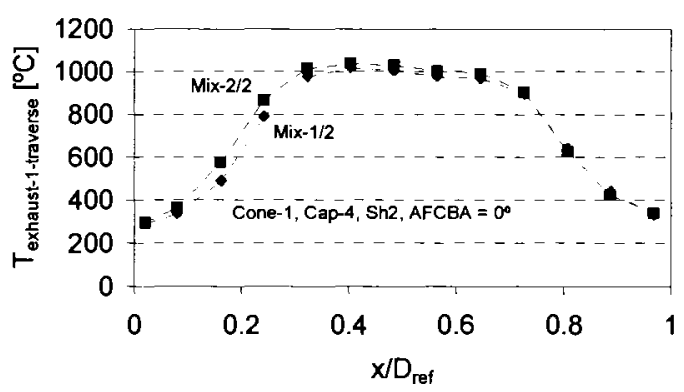

(c) DB exhaust traverse gas temperature

Figure 8.86: Effect of firing rate and mixers design on DB temperatures (Cap-4 and Sh2) 
Figure 8.87 shows stable flame images that demonstrate the effect of using different mixers on the flame structure. The figure shows that the double-swirl mixer, Mix-2/2, provides a better overall flame height uniformity compared to the singleswirl mixer, Mix-1/2.

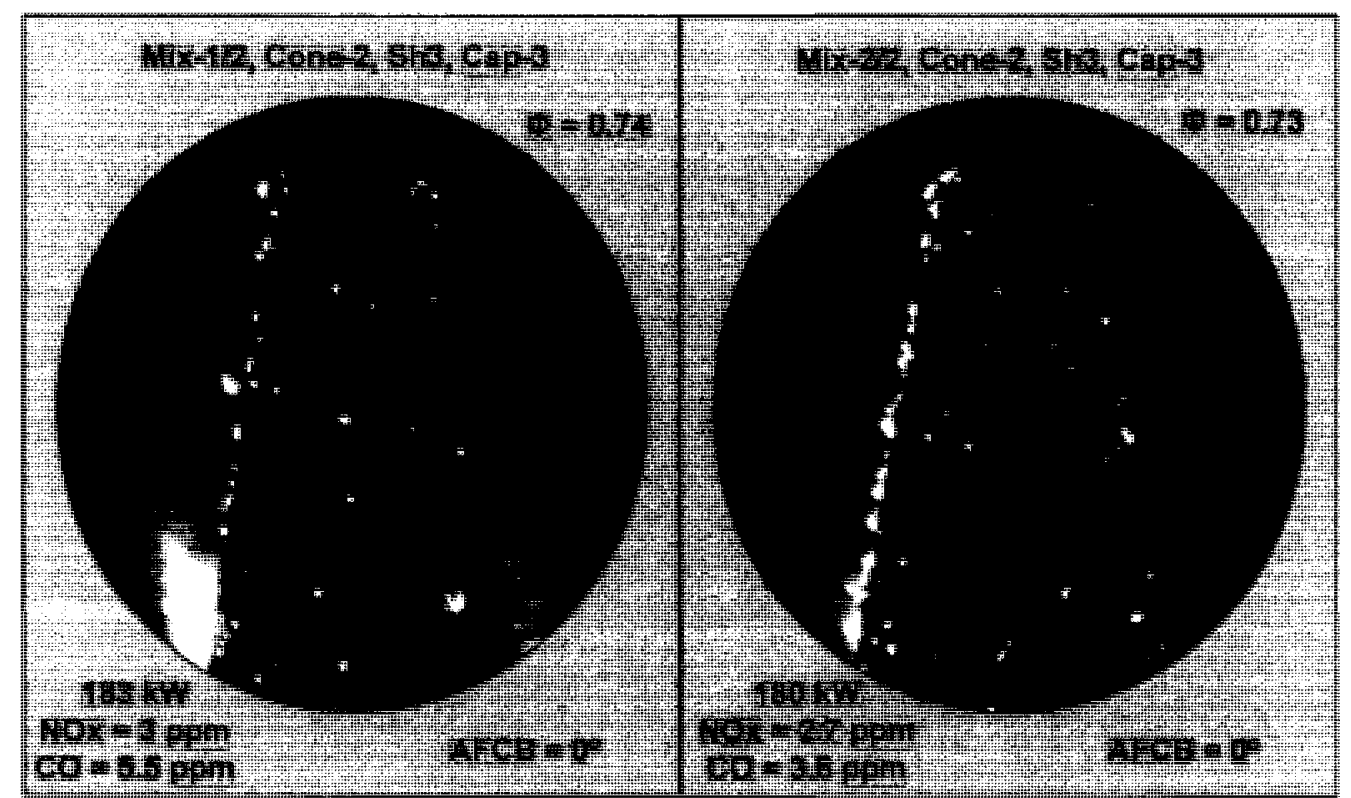

Figure 8.87: Effect of using different mixers on flame uniformity (flame images)

The results from the three last figures (Figure 8.85 to 8.87 ) from a mixing point of view are consistent with the findings from the LSI phase. During the LSI tests (Chapter 5), both mixers (Mix-1/2 and Mix-2/2) provided a good mixing behaviour compared to the other mixers tested. However, the double-swirl mixer, Mix-2/2, compared to the single-swirl mixer, Mix-1/2, was the best with respect to mixing (e.g., when Cap-2 was used with both mixers, the LSI results show that at the exit plane of the premixer Mix-1/2, has unmixedness value of 0.36 and Mix-2/2 has unmixedeness value of 0.3 ). During the combustion tests, both mixers performed well, producing low NOx and $\mathrm{CO}$ emissions and having a low overall duct burner pressure drop. What was observed in the LSI tests has been confirmed in the 
combustion tests: that is, Mix-2/2 is best among the two mixers in terms of mixing and duct burner performance.

\subsubsection{Combustion and LSI tests comparisons (mixing)}

This subsection also covers some of the combustion tests conducted to prove the results obtained from the LSI technique, developed for this investigation. During the design phase, the LSI technique was used to validate and verify the duct burner premixer design and its components. The premixer is one of the important components for the performance of the duct burner by providing the mixing. The better the mixing, the more complete the combustion will be, and hence the lower the emissions. The selected premixer components that were used in the combustion test and their encouraging results regarding the single digit emissions, proves the effectiveness of the LSI technique used in Chapter 5. In the previous subsection the comparison was between the two mixers which, in general, provided good mixing behaviour in the LSI phase tests. To support the results obtained from the LSI tests, it was decided to perform the combustion tests with premixer parameters that provide completely different mixing behaviours (good and poor mixing). Fuel injection angle is the parameter selected for this discussion. Cap-2 $\left(90^{\circ}\right)$ and Cap-5 $\left(45^{\circ}\right)$ have similar designs (number and diameter of fuel injecting holes), but with different injection angles. From the observation of the LSI results, Cap- 5 shows poor mixing results compared to Cap-2. The mixing comparisons between the two caps when the LSI technique was used were presented in Figures 5.31, 5.32 and 5.42. In this subsection, the effect of fuel injection angle on the performance of the duct burner and the mixing process inside the premixer will be presented and discussed.

Figure 8.88 shows the effect of fuel injection angles as a function of a firing rate on duct performance. The duct burner configuration was Mix-2/2 (which provides the best LSI and combustion results), Cone-2 (which provides the wider operating range during the combustion tests) and Sh3 (moderate length shield) at $\mathrm{AFCBA}=0^{\circ}$. NOx emissions are shown in Figure 8.88 (a). Figure 8.88 (b) shows CO 
emissions and Figure 8.88 (c) presents the pressure drop measurements. Cap-2 showed a stable operating range from 157 to $190 \mathrm{~kW}$ with NOx emissions ranging from 1 to $7 \mathrm{ppm}$. $\mathrm{CO}$ emissions ranged from 7.2 to $18 \mathrm{ppm}$. During the combustion tests of Cap-5, the fuel flow rate supplied to the duct burner was not sufficient to allow tests to be carried out at the same fuel flow rate as that used with Cap-2. The flame obtained during these trials was not stable and quickly blew off. The only reason for that was the bad mixing provided by Cap-5 as the temperature profiles below will show. Good mixing improves the ability of the fuel to burn. At this point the fuel flow rate was increased to achieve a flammable mixture and stable conditions. The attempts were successful and continuous combustion over the mesh surface was achieved. Stretched blue flames were observed and high $\mathrm{CO}$ emissions were recorded. The high $\mathrm{CO}$ emissions values were due to the incomplete combustion caused by poor mixing. Local flame instability was observed on the lower part of the conical burner especially at lower firing rates with Cap-5. From Figure 8.88, NOx emissions with Cap-5 were from 3 to $6 \mathrm{ppm}$ and $\mathrm{CO}$ emissions were from 27 to $96 \mathrm{ppm}$. Figure 8.88 (c) shows the effect of different caps on overall pressure drop. A slight increase in the pressure drop was measured when with Cap-5. Figure 8.89 shows two flame images for two operating point labelled (ii) in Figure 8.88 (a). The left-hand side image shows the condition of flame instability. The local extinction at the lower side of the conical burner and the change in the flame length and the position can be observed clearly from this image (i). This case shows the behaviour of the flame between the instability limit and the blow-off limit. The right-hand side image shows a blue flame with low NOx emissions, but very high $\mathrm{CO}$ emissions.

Concerning the mixing process inside the premixer, temperature measurements were conducted by traversing a K-type thermocouple across the premixer exit plane. The thermocouple was inserted through the premixer hollow supports (locations 3 and 4 in Figure 7.5) and the traverses were conducted. The uniformity of these temperature profiles indicates good mixing behaviour between the 
oxidant and the fuel supplied to the burner. Figure 8.90 shows the effect of the fuel injection angle on the traversed temperature profile for the same case presented in Figures 8.88 ( $a, b$ and $c$ ). Cap-2 shows very good temperature profile uniformity (fairly constant over all the premixer cross-section) compared to the results with Cap5. This result again proves the effectiveness of the LSI technique used in this investigation for identifying mixing uniformity.

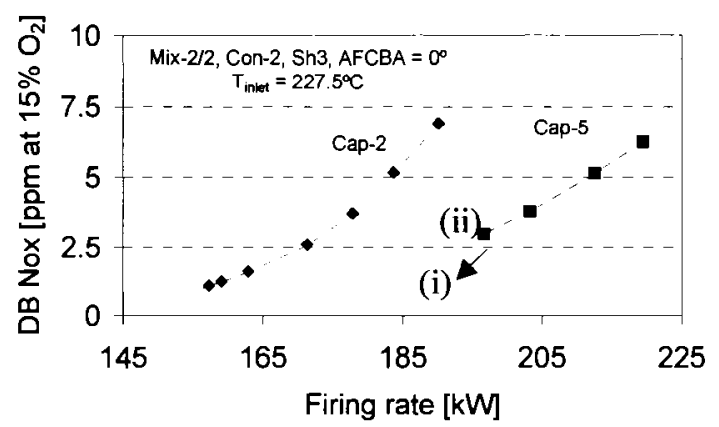

(a) DB NOx emissions

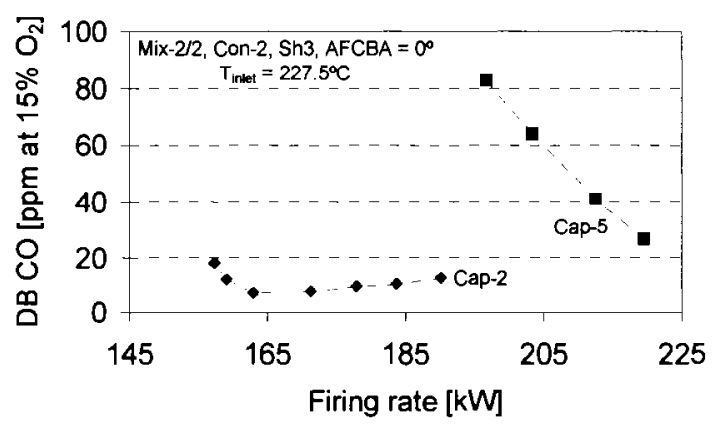

(b) DB CO emissions

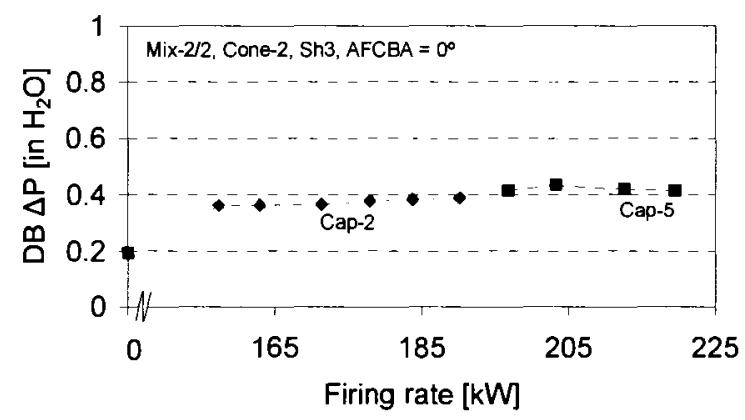

(c) DB overall pressure drop

Figure 8.88: Effect of firing rate and fuel injection angle on duct burner performance (Mix-2/2, Cone-2, Sh3 at AFCBA $=0^{\circ}$ )

\subsection{Combustion test closure}

Section 8.6.3 summarized all the combustion tests results conducted during this investigation. A more fundamental insight of the different parametric combination governing the performance of the duct burner was gained throughout this 
extensive parametric investigation. Based on the presented results, it can be concluded that the development of the duct burner with the conical wire-mesh burner for the use with the microturbine cogeneration units was a success. This design is a step forward towards the practical and real integration of this technology with microturbine cogeneration units to improve their heating capability with a minimum level of emissions.

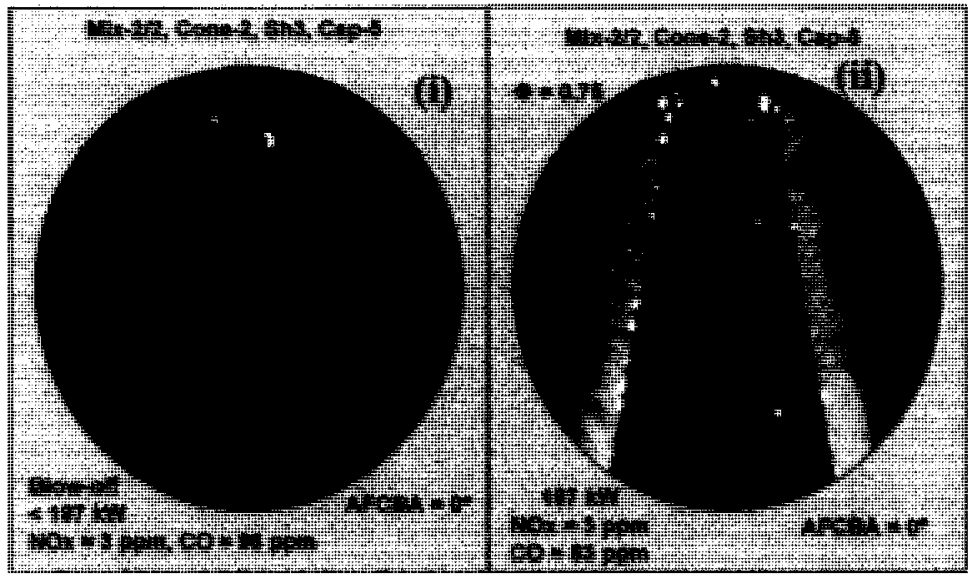

Figure 8.89: Flame images taken for points (i) and (ii) in Figure 8.33 (a) (Mix2/2, Cone-2, Sh3 and Cap-5 at AFCBA $=0^{\circ}$ )

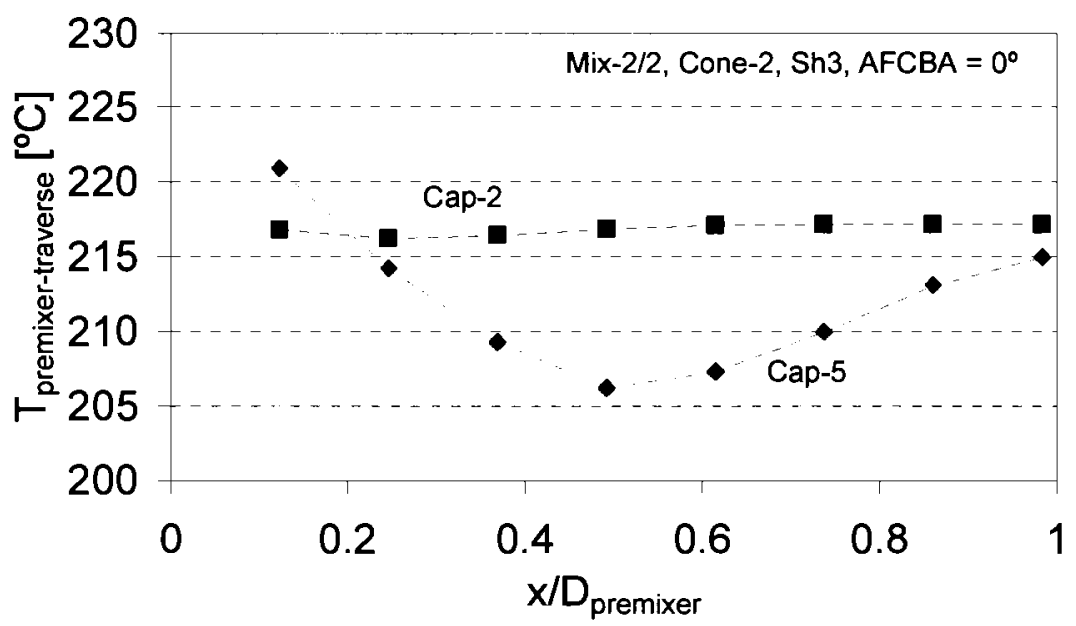

Figure 8.90: Effect of fuel injection angle on mixture (oxidant/fuel) temperature profiles at the premixer exit plane (Mix-2/2, Cone-2 and Sh3 at AFCBA $=0^{\circ}$ ) 
During the course of the tests, the DB displayed stable, low emissions operation throughout the surface firing rate range of $148 \mathrm{~kW}$ to $328 \mathrm{~kW}\left(1574 \mathrm{~kW} / \mathrm{m}^{2}\right.$ to $3489 \mathrm{~kW} / \mathrm{m}^{2}$ ). Emissions of less than $5 \mathrm{ppm}$ for both NOx and CO were recorded, while the DB successfully raised the microturbine exhaust gases temperature from about $230^{\circ} \mathrm{C}$ to as high as $700^{\circ} \mathrm{C}$. The DB overall pressure drop throughout all the conducted tests was below the design point of 249 Pa. Tables 8.3 and 8.4 summarize the firing rate range along with $\mathrm{NOx}$ and $\mathrm{CO}$ emissions for all the cases tested.

\subsubsection{Optimum operating conditions and trade-offs}

Based on the above discussions (Section 8.6.3) of the effect of the different burner parameters, the operating conditions for optimum performance of the duct burner under investigation may be summarized as follows:

1) Cone-2 (pressured drop $=249 \mathrm{~Pa}$ ) was an optimal cone for the duct burner. The duct burner performed well with Cone- 2 over a wide operating range. Cone- 1 could be used if the operator wants to run the duct burner at a higher firing rate $(>300 \mathrm{~kW})$.

2) A lower shield length led to lower NOx emissions. Among the different shields used, Sh2 showed a good operating range with all the duct burner parameters tested.

3) For a moderate operating range and lower fuel line pressure (e. g., 2 psig), the longer shield (Sh4) performed well (lower emissions and wide operating range). The consequent trade-off in this case is that the shield must operate at a higher temperature.

4) Cap-4 provided the duct burner with the amount of fuel which is necessary to cover the entire operating range with lower emissions.

5) The higher the blockage ratio, the lower the emissions were recorded. Sh7 and Sh8 were the shields with the higher blockage ratio $(B R=0.6)$. They produced very low emissions at higher firing rates (up to $328 \mathrm{~kW}$ ). Sh8 was 
the best shield compared to Sh7 due to its relatively wider range of operation. The consequent trade-offs in this case were the higher pressure drop and the narrow operating range compared to the shields that have $\mathrm{BR}=0.4$.

6) Concerning the AFCBA, as the blade angle increased more the oxidant was forced through the conical burner, leading to the lower the emissions. The trade-offs here are similar to those mentioned for the BR, the higher pressure drop and the narrower the operating range compared to the smaller angles. A blade angle of zero degrees showed the widest operating range.

7) Due to the good mixing between the oxidant and the fuel, Mix- $2 / 2$ showed the best performance concerning emissions and the uniformity of the flame compared to Mix-1/2. The consequent trade-offs of using Mix- $2 / 2$ are the reduction in the stable operating zone and the higher pressure drop compared to the other mixer.

\subsubsection{Comparison of experimental results with those of other investigations}

It was mentioned in Chapter 2 and Appendix B that almost all the mesh burners available in the literature are operating in the radiant mode and most of the experimental work was conducted on flat type porous burners (circular, rectangular or square shaped geometry). There is some work available in the literature on the cylindrical porous burners, in which the fuel-air mixture is forced to flow radially. Greenberg et al. (2005) recently reported emissions (NOx and CO emissions as a function of calculated adiabatic flame temperatures) for tests with a surface-stabilized fuel injector that with a cylindrical perforated porous metal surface. Due to the novel application of the conical wire-mesh duct burner investigated here and the lack of the experimental results available on similar shapes, comparisons between some of the common parameters used in the literature for porous burners with the present investigation will be performed. 
In the present investigation, the pressure drop measurements conducted showed that the surface combustion technique doubled the overall duct burner pressure drop (compared to that in cold flow). This observation is similar to the previous observation made by Weakley et al. (2002). Marbach et al. (2005) performed in an experimental study of surface and interior combustion using a square shaped, silicon carbide coated carbon-carbon composite porous inert media. They reported that the surface combustion slightly increases the pressure drop, but the interior combustion increases the pressure drop by more than a factor of two. The difference between results of the present investigation and the one reported by Marbach et al. (2005) are believed to be due to the different material and the structure of the porous media used.

Concerning the different cones pressure drop used in this investigation, as the conical burner pressure drop decreased (higher porosity), the preheating of reactants by the radiation from the flame zone decreased. The temperature profiles presented in Figures 8.15 (a), 8.39 (a and b), 8.66 (a) and 8.74 (a) confirm this observation. Marbach et al. (2005) used their interpretation of the effect of preheating to support their finding regarding NOx emissions without conducting any temperature measurements in their experimental work. They reported that NOx emissions were weakly dependent upon the pore size of the porous burner. In the present investigation the results show a strong trend of higher porosity resulting in lower NOx emissions at a given firing rate. This is consistent with the finding of reported by Jugjai et al. (2002). The preheating effect was not the main factor affecting the combustion zone temperature in this investigation when the effect of porosity (cone pressure drop) on duct burner performance was investigated. It was observed that even if the incoming reactant has a higher temperature in case of higher porous cones, as mentioned above, the combustion zone temperature was the lowest. Figures 8.15 (b), 8.39 (d), 8.66 (b) and 8.74 (b) confirms this result. The lower the combustion zone temperature, the lower the NOx formation was. The factor which may be responsible for this 
behaviour is that the higher the cone porosity (lower pressure drop) is, the more is excess oxidant introduced to the combustion zone. Also, the lower the pressure drop the longer the flame (it was confirmed by different flame images), the more the interaction (dilution effect) between the combustion gases and the bypass flow will be. In addition, shields with different lengths play an important role regarding the dilution effect and how it reduces the combustion zone temperature to decrease NOx emissions. Regarding the effect of the different conical pressure drop cones on $\mathrm{CO}$ emissions, the present investigation confirmed the finding of Marbach et al. (2005). The lower the conical burner pressure drop (higher porosity cones), the lower the $\mathrm{CO}$ emissions. As mentioned in a previous discussion, the lower the pressure drop of the cone used, the longer the flame and the residence time, which will lead to more complete combustion.

The results of the temperature profiles (combustion zone temperature) presented in this investigation agree in terms of their trends with those presented in Saracco et al. (1996). In Saracco et al. (1996) the measurement was conducted above a circular FeCrlloy burner. They plotted the combustion zone temperature as a function of firing rate for different excess air values. Furthermore, the conical burner hot surface temperature profiles presented in the present investigation (e.g., Figure 8.50 (b)) have a similar trend as the burner plate surface temperature profiles presented in Kataoka (1998) and Bizzi et al. (2003). The latter authors presented both experimental and model calculations, both profiles have similar shapes to the one presented in this work.

The structure of the conical wire-mesh burner controls the size and the shape of the flames. The stretched laminar flames established on the surface of the conical wire-mesh burner (see the flame images) tested in this investigation were similar to those flames established on the cylindrical surface stabilized fuel injectors tested in Greenberg et al. (2005). 
Table 8.3: Summary of the combustion tests results, Mix-1/2

\begin{tabular}{|c|c|c|c|c|c|c|c|c|}
\hline $\begin{array}{l}\text { R. } \\
\text { n. }\end{array}$ & Mixer & $\begin{array}{l}\text { Fuel } \\
\text { cap }\end{array}$ & Cone & $\begin{array}{l}\text { Cone } \\
\text { shield }\end{array}$ & $\begin{array}{c}\text { FR } \\
\text { Range } \\
{[\mathbf{k W ]}}\end{array}$ & $\begin{array}{c}\text { NOx } \\
\text { emissions } \\
{[\mathrm{ppm}]}\end{array}$ & $\begin{array}{c}\text { CO } \\
\text { emissions } \\
\text { [ppm] }\end{array}$ & $\begin{array}{l}\text { Comments } \\
\text { (see the last } \\
\text { row) }\end{array}$ \\
\hline 1 & Mix-1/2 & Cap-2 & Cone-1 & Sh1 & $210-218$ & $0.90-1.70$ & $>20.00$ & H. CO \\
\hline 2 & Mix-1/2 & Cap-2 & Cone-1 & Sh2 & $168-214$ & $1.40-7.00$ & $5.70-20.5$ & \\
\hline 3 & Mix-1/2 & Cap-2 & Cone-1 & Sh3 & 164208 & $0.76-6.80$ & $6.40-16.0$ & \\
\hline 4 & Mix-1/2 & Cap-2 & Cone-2 & Sh1 & $171-223$ & $0.67-5.70$ & $7.80-15.3$ & \\
\hline 5 & Mix-1/2 & Cap-2 & Cone-2 & $\mathrm{Sh} 2$ & $157-217$ & $0.86-6.90$ & $6.60-15.0$ & \\
\hline 6 & Mix-1/2 & Cap-2 & Cone-2 & $\operatorname{Sh} 3$ & $\overline{148-225}$ & $1.00-7.50$ & $6.50-18.0$ & \\
\hline 7 & Mix-1/2 & Cap-2 & Cone-3 & Sh1 & $202-228$ & $0.66-3.24$ & $11.0-20.0$ & H. CO \\
\hline 8 & Mix-1/2 & Cap-2 & Cone-3 & Sh2 & $156-232$ & $0.56-8.50$ & $6.40-19.0$ & \\
\hline 9 & Mix-1/2 & Cap-2 & Cone-3 & Sh4 & $151-196$ & $0.55-6.00$ & $5.10-16.0$ & $\mathrm{CO}<10$ \\
\hline 10 & Mix-1/2 & Cap-3 & Cone-1 & Sh1 & $223-247$ & $0.40-3.10$ & $2.50-5.50$ & N. R,H.CO \\
\hline 11 & Mix-1/2 & Cap-3 & Cone-1 & Sh2 & 199-247 & $1.50-8.50$ & $3.90-8.80$ & \\
\hline 12 & Mix-1/2 & Cap-3 & Cone-1 & Sh3 & $191-244$ & $1.90-10.0$ & $4 . \overline{70-10.0}$ & \\
\hline 13 & Mix-1/2 & Cap-3 & Cone-2 & Sh1 & $202-246$ & $1.40-4.70$ & $6.00-12.0$ & \\
\hline 14 & Mix-1/2 & Cap-3 & Cone-2 & Sh2 & $190-243$ & $1.40-7.30$ & $5.30-13.0$ & \\
\hline 15 & Mix-1/2 & Cap-3 & Cone-2 & Sh3 & $178-235$ & $2.00-7.00$ & $5.00-10.0$ & \\
\hline 16 & Mix-1/2 & Cap-3 & Cone-3 & Sh1 & $226-247$ & $2.00-3.30$ & $7.20-11.3$ & \\
\hline 17 & Mix-1/2 & Cap-3 & Cone-3 & $\mathrm{Sh} 2$ & $206-245$ & $1.80-7.40$ & $5.00-11.0$ & \\
\hline 18 & Mix-1/2 & Cap-3 & Cone-3 & Sh3 & $178-208$ & $2.20-7.50$ & $5.20-8.60$ & \\
\hline 19 & Mix-1/2 & Cap-4 & Cone-1 & Sh1 & $260-313$ & $3.40-9.50$ & $3.40-5.90$ & \\
\hline 20 & Mix-1/2 & Cap-4 & Cone-1 & $\mathrm{Sh} 2$ & $207-307$ & $2.65-10.0$ & $3.30-8.10$ & \\
\hline 21 & Mix-1/2 & Cap-4 & Cone-1 & Sh4 & $182-293$ & $1.87-11.0$ & $2.90-13.0$ & \\
\hline 22 & Mix-1/2 & Cap-4 & Cone-1 & Sh7 & $320-321$ & $3.40-4.50$ & $2.10-3.00$ & N. R. \\
\hline 23 & Mix-1/2 & Cap-4 & Cone-1 & Sh8 & $317-328$ & $2.83-3.30$ & $3.35-5.20$ & N. R. \\
\hline 24 & Mix-1/2 & Cap-4 & Cone-2 & Sh1 & 199-302 & $0.50-12.25$ & $4.40-8.30$ & \\
\hline 25 & Mix-1/2 & Cap-4 & Cone-2 & $\mathrm{Sh} 2$ & $176-311$ & $1.83-12.50$ & $3.54-10.0$ & \\
\hline 26 & $\mathrm{Mix}-1 / 2$ & Cap-4 & Cone-2 & Sh3 & $171-268$ & $2.12-7.50$ & $4.40-13.0$ & \\
\hline 27 & Mix-1/2 & Cap-4 & Cone-2 & Sh4 & $162-281$ & $1.00-11.4$ & $3.30-12.0$ & \\
\hline 28 & Mix-1/2 & Cap-4 & Cone-2 & Sh7 & $313-321$ & $2.80-3.00$ & $16.50-66.0$ & H. CO \\
\hline 29 & Mix-1/2 & Cap-4 & Cone-2 & Sh8 & $295-320$ & $2.80-5.00$ & $3.20-5.50$ & \\
\hline 30 & Mix-1/2 & Cap-4 & Cone-3 & Sh1 & $203-305$ & $0.22-12.0$ & $5.00-15.0$ & \\
\hline 31 & Mix-1/2 & Cap-4 & Cone-3 & Sh2 & $184-293$ & $1.32-12.5$ & $6.60-15.0$ & \\
\hline 32 & Mix-1/2 & Cap-4 & Cone-3 & Sh3 & $179-269$ & $1.60-8.00$ & $5.00-10.0$ & \\
\hline 33 & Mix-1/2 & Cap-4 & Cone-3 & Sh4 & $168-280$ & $1.73-11.3$ & $3.40-15.0$ & \\
\hline 34 & Mix-1/2 & Cap-4 & Cone-3 & Sh7 & $309-323$ & $2.90-4.30$ & $3.30-5.00$ & \\
\hline 35 & Mix-1/2 & Cap-4 & Cone-3 & Sh8 & $294-312$ & $3.20-4.60$ & $2.64-5.20$ & \\
\hline 36 & Mix-1/2 & Cap-3 & Cone-2 & Sh2 & $198-213$ & $3.30-6.10$ & $7.40-8.40$ & $T_{\text {inlet }}=216^{\circ} \mathrm{C}$ \\
\hline 37 & Mix-1/2 & Cap-3 & Cone-2 & Sh2 & $208-246$ & $2.50-6.40$ & $6.50-16.4$ & $T_{\text {inlet }}=168^{\circ} \mathrm{C}$ \\
\hline
\end{tabular}


The combinations (Mix-1/2, Cap-2 (and Cap-3), Cone-1, with Sh7 and Sh8), (Mix-1/2, Cap-2 (and Cap3), Cone-2, with Sh7 and Sh8) and (Mix-1/2, Cap-2 (and Cap-3), Cone-3, with Sh7 and Sh8) produces unstable combustion.

N.R. $=$ narrow operating range, $\mathbf{H} . \mathbf{C O}=$ High $\mathrm{CO}$ emissions

Table 8.4: Summary of the combustion tests results, Mix-2/2

\begin{tabular}{|c|c|c|c|c|c|c|c|c|}
\hline $\begin{array}{c}\text { Ru- } \\
\text { n }\end{array}$ & Mixer & $\begin{array}{l}\text { Fuel } \\
\text { cap }\end{array}$ & Cone & $\begin{array}{l}\text { Cone } \\
\text { shield }\end{array}$ & $\begin{array}{c}\text { FR } \\
\text { Range } \\
{[\mathbf{k W}]}\end{array}$ & $\begin{array}{c}\text { NOx } \\
\text { emissions } \\
{[p p m]}\end{array}$ & $\begin{array}{c}\text { CO } \\
\text { emissions } \\
{[\mathrm{ppm}]}\end{array}$ & $\begin{array}{c}\text { Comments } \\
\text { (see the last } \\
\text { row ) }\end{array}$ \\
\hline 1 & Mix-2/2 & Cap-2 & Cone-1 & Sh1 & unstable & unstable & unstable & unstable \\
\hline 2 & Mix-2/2 & Cap-2 & Cone-1 & Sh2 & $196-208$ & $1.24-2.60$ & $3.60-17.0$ & \\
\hline 3 & Mix-2/2 & Cap-2 & Cone-1 & Sh3 & $178-209$ & $1.10-5.60$ & $3.90-9.40$ & \\
\hline 4 & $\mathrm{Mix}-2 / 2$ & Cap-2 & Cone-1 & Sh7 & Unstable & Unstable & Unstable & Unstable \\
\hline 5 & Mix-2/2 & Cap-2 & Cone-1 & Sh8 & Unstable & Unstable & Unstable & Unstable \\
\hline 6 & Mix-2/2 & Cap-2 & Cone-2 & Sh 1 & $181-205$ & $1.00-1.20$ & $>20.00$ & H. CO, NR \\
\hline 7 & $\mathrm{Mix}-2 / 2$ & Cap-2 & Cone-2 & Sh2 & $161-200$ & $1.20-3.70$ & $6.90-16.0$ & \\
\hline 8 & Mix-2/2 & Cap-2 & Cone-2 & Sh3 & $157-200$ & $1.10-6.90$ & $5.80-14.0$ & \\
\hline 9 & $\mathrm{Mix}-2 / 2$ & Cap-2 & Cone-2 & Sh7 & Unstable & Unstable & Unstable & Unstable \\
\hline 10 & Mix-2/2 & Cap-2 & Cone-2 & Sh8 & Unstable & Unstable & Unstable & Unstable \\
\hline 11 & Mix-2/2 & Cap-2 & Cone-3 & Sh1 & $181-205$ & $0.60-2.50$ & $12.0->50$ & $\mathrm{H} . \mathrm{CO}$ \\
\hline 12 & Mix-2/2 & Cap-2 & Cone-3 & Sh2 & $161-200$ & $1.20-6.90$ & $6.70-15.0$ & \\
\hline 13 & Mix-2/2 & Cap-2 & Cone-3 & Sh3 & $154-197$ & $1.02-6.55$ & $7.20-15.0$ & \\
\hline 14 & Mix-2/2 & Cap-2 & Cone-3 & Sh7 & Unstable & Unstable & Unstable & Unstable \\
\hline 15 & Mix-2/2 & Cap-2 & Cone-3 & Sh8 & Unstable & Unstable & Unstable & Unstable \\
\hline 16 & Mix-2/2 & Cap-3 & Cone-1 & Sh3 & $191-241$ & $2.50-8.90$ & $2.80-8.40$ & \\
\hline 17 & $\mathrm{Mix}-2 / 2$ & Cap-3 & Cone-2 & Sh3 & $170-242$ & $1.30-6.20$ & $2.50-8.70$ & \\
\hline 18 & Mix-2/2 & Cap-3 & Cone-3 & Sh3 & $180-240$ & $3.40-8.20$ & $3.70-8.20$ & \\
\hline 19 & Mix-2/2 & Cap-4 & Cone-1 & Shl & $229-293$ & $2.10-12.9$ & $2.50-5.00$ & \\
\hline 20 & Mix-2/2 & Cap-4 & Cone-1 & Sh2 & $199-291$ & $2.50-10.0$ & $2.70-5.00$ & \\
\hline 21 & Mix-2/2 & Cap-4 & Cone-1 & Sh3 & $175-293$ & $1.75-10.6$ & $3.30-7.90$ & \\
\hline 22 & Mix-2/2 & Cap-4 & Cone-2 & Sh1 & $205-295$ & $1.40-6.10$ & $3.90-130$ & \\
\hline 23 & Mix-2/2 & Cap-4 & Cone-2 & Sh2 & $185-296$ & $1.40-8.20$ & $2.74-9.10$ & \\
\hline 24 & Mix-2/2 & Cap-4 & Cone-2 & Sh3 & $181-251$ & $1.24-8.60$ & $3.50-9.60$ & \\
\hline 25 & Mix-2/2 & Cap-4 & Cone-3 & Sh1 & $219-273$ & $1.60-7.30$ & $4.10-6.80$ & \\
\hline 26 & Mix-2/2 & Cap-4 & Cone-3 & Sh2 & $186-293$ & $1.70-10.0$ & $3.20-8.40$ & \\
\hline 27 & Mix-2/2 & Cap-4 & Cone-3 & Sh3 & $178-270$ & $1.90-8.80$ & $3.70-9.50$ & \\
\hline 28 & Mix-2/2 & Cap-4 & Cone-3 & Sh8 & $304-316$ & $1.20-4.60$ & $4.00-4.30$ & N. R. \\
\hline 29 & Mix-2/2 & Cap-5 & Cone-2 & Sh3 & $197-220$ & $3.00-6.24$ & $27.0-83.0$ & H. CO \\
\hline 30 & Mix-2/2 & Cap-3 & Cone-1 & Sh7 & Unstable & Unstable & Unstable & Unstable \\
\hline 31 & Mix-2/2 & Cap-3 & Cone-2 & Sh7 & Unstable & Unstable & Unstable & Unstable \\
\hline 32 & Mix-2/2 & Cap-3 & Cone-3 & Sh7 & Unstable & Unstable & Unstable & Unstable \\
\hline 33 & Mix-2/2 & Cap-2 & Cone-1 & Sh8 & Unstable & Unstable & Unstable & Unstable \\
\hline 34 & Mix-2/2 & Cap-3 & Cone-2 & Sh8 & Unstable & Unstable & Unstable & Unstable \\
\hline 35 & Mix-2/2 & Cap-3 & Cone-3 & Sh8 & Unstable & Unstable & Unstable & Unstable \\
\hline
\end{tabular}




\section{CHAPTER 9: Conclusions and recommendations}

\subsection{Conclusions}

To increase the thermal output of a microturbine powered CHP system, a low NOx natural gas-fired, wire-mesh duct burner was designed, built and evaluated during the different phases of this thesis. This investigation is the first to design and evaluate a duct burner using the lean-premixed surface combustion technique for micro-CHP units. The duct burner preliminary design procedures are presented in this thesis. Before fabrication of the duct burner, the design procedures were verified for one of the important components in the duct burner (the premixer) before manufacturing using a Laser sheet illumination (LSI) technique. After the evaluation using the LSI technique the most promising designs for the duct burner components were built and tested. The duct burner was evaluated by integrating the duct burner with the Ingersol-Rand $70 \mathrm{~kW}$ microturbine. The performance characteristics of the duct burner were investigated and a considerable amount of detailed parametric experimental data was acquired. The parameters studied were all found to play an important role in ensuring the achievement of the required performance of the duct burner, including low emissions (NOx and $\mathrm{CO}$ ), a high exhaust gas temperature and low overall pressure drop. The combustion tests results proved that the procedures that were used to design this novel, microturbine, conical, wire-mesh, duct burner were successful. During the course of the evaluation tests, the DB displayed stable, low emissions operation throughout the firing rate range of $148 \mathrm{~kW}$ to $328 \mathrm{~kW}$ (1574 $\mathrm{kW} / \mathrm{m}^{2}$ to $3489 \mathrm{~kW} / \mathrm{m}^{2}$, mesh surface area) and an equivalence ratio range between 0.65 and 0.90 . Emissions of less than $5 \mathrm{ppm}$ (corrected to 15 percent $\mathrm{O}_{2}$ ) for both $\mathrm{NOx}$ and $\mathrm{CO}$ emissions were recorded, while the duct burner successfully raised the microturbine exhaust gas temperature from about $227^{\circ} \mathrm{C}$ to as high as $1000^{\circ} \mathrm{C}$. The overall duct burner pressure drop throughout all the tests conducted was below the design point of $249 \mathrm{~Pa}$. 
In the following sections, summaries of the different phases of this investigation will be presented.

\subsubsection{Duct burner design}

The design procedures discussed in this thesis form a methodology for the preliminary design of a conical wire-mesh duct burner. The preliminary design procedures were verified and validated for key components, such as the duct burner premixer, using LSI. The designed duct burner was verified to operate in the blue flame mode stably with low concentration of pollutants.

\subsubsection{LSI technique}

The design process of the duct burner was supported by a qualitative flow visualization study of the duct burner premixer to provide insight into the premixer flow field (mixing processes). The laser sheet illumination technique was used for this propose. This method proved to be an excellent method to qualitatively visualize the mixing process and provided invaluable information and helped gain a better comprehension of the mixing processes in the burner premixer. The technique provided useful information for the optimization of burner design and operating conditions, aiming to improve combustion efficiency of the duct burner and reduce NOx and CO emissions. Many of the phenomena observed in these tests were discussed such as; fuel spread and mixing, swirling fuel jets, mainstream rotation directions, fuel jet penetration, over-penetration, strong rotation field and swirl number, variation of swirl distribution and the low pressure region. Different premixer geometries were used to control the homogeneity of the fuel-to-oxidant mixture at the exit of the duct burner premixer. Images of the mixing processes, for each configuration studied, were captured and analyzed. A unique, quasi-quantitative technique was developed to rank the different combinations of mixers and fuel caps in terms of mixing effectiveness. Using this technique, Mix-2/2 demonstrated the best 
mixing behaviour compared to other mixers with nearly all the combinations tested and that is due to the present of the shear between the two layers. Mix-1/2 ranked the better of the two single-swirl mixers tested. Both of these mixers were selected for the combustion tests. With respect to the fuel caps tested, Cap-5 (injecting the fuel at $45^{\circ}$ ) shows the worst performance among the other fuel caps tested with the LSI and the combustion tests. In general, the fuel caps that injected the fuel at $90^{\circ}$ to the main flow show good mixing behaviour. This fuel cap provides a higher momentum ratio (fuel-to-air), a greater penetration and better mixing.

\subsubsection{Flow balancing test}

A set of non-reacting tests (microturbine running, and the DB not operated) were performed to shakedown the test rig, measure the different mass flow rates and measures the overall pressure drop of the duct burner. This phase was named the duct burner oxidant flow balancing test. During this testing the effect of the AFCBA, conical burner pressure drop, mixer design and the shield blockage ratio (BR) on the split of the microturbine exhaust gas (between the conical burner and the annular passage (cooling and dilution)) and the overall duct burner pressure drop were performed. The correct amount of excess microturbine exhaust gas needed to be directed through the mesh burner for surface combustion was measured and the angles of the flow control blades were assigned for each flow condition.

The measurements conducted in the annular passage showed that the smaller the blockage ratio the more asymmetric the flow was and the position of the maximum velocity was skewed toward the inner wall of the annular passage. The single-swirl mixer (Mix-1/2) produces a lower pressure drop compared to the double-swirl mixer (Mix-2/2). Therefore, Mix-1/2 allows more oxidant to flow through the conical burner. The pressure drop measurements across the duct burner were conducted (DB not operating) and presented. As the conical pressure drop (Cones 1, 2 and 3) and the AFCBA increased the overall duct burner pressure drop increases exponentially. The 
AFCBA and the BR were the most significant factors affecting the total pressure drop compared with the conical burner pressure drop. The pressure drop measurements conducted during this phase were found to be under $249 \mathrm{~Pa}$ for all the tested duct burner parameters at an AFCBA $<60^{\circ}$. Increasing the conical burner pressure drop from $75 \mathrm{~Pa}$ to $224 \mathrm{~Pa}$, the overall duct burner pressure drop increases until a maximum is reached at a pressure drop equal to $149 \mathrm{~Pa}$. Above this value (e.g., Cone3) the pressure drop results (also the mass flow calculation results) show unexpected trends (compared with the other cones used, Cone-1 and Cone-2) and varied with the different geometrical parameters tested. The results found in this phase were used as basic measurements for the combustion tests.

\subsubsection{Combustion tests}

The stable surface combustion operating ranges of the duct burner were identified during this phase of the present investigation. A larger data set to study the performance of a novel conical wire-mesh duct burner tested with microturbine CHP unit was presented in this thesis. In the extensive parametric tests, the effect of the variation of the different burner parameters such as: AFCBA (varied from $0^{\circ}$ to $50^{\circ}$ ) or mass flow ratio $\left(M R_{C F}\right)$, conical burner pressure drop (varied from 75 to $224 \mathrm{~Pa}$ ), conical burner shield ratio $L_{\text {eff }} / D_{\text {shield }}$ (varied from 0.4 to 1.9 ), blockage ratio, BR (0.4 and 0.6), swirling flow mixers (Mix-1/2 (S=0.4) and Mix-2/2 (S=0.58)), fuel cap design (fuel injection angle and fuel flow rate, Cap-2, 3, 4 and 5), firing rate (148 to $328 \mathrm{~kW})$ and duct burner inlet temperature $\left(168,216\right.$ and $\left.228^{\circ} \mathrm{C}\right)$ on duct burner

performance were measured and reported. Such a comprehensive data set is not available in the literature. The main performance points that have been covered were NOx and CO emissions, the overall duct burner pressure drop and the duct burner temperatures. The following is a brief overview of the main conclusions discussed during the combustion tests. 


\subsubsection{Effect of AFCBA}

The $M R_{C F}$ increases as the blade angle increases. As the AFCBA increases for a fixed firing rate, NOx emission decreased until the blow-off limit was reached; the lower the AFCBA, the wider the operating range. At higher values of the AFCBA, the duct burner could operate at a higher firing rate, and lower NOx and CO emissions were measured.

\subsubsection{Effect of conical burner pressure drop}

The higher the conical burner pressure drop, the wider the operating range becomes. The lower the conical burner pressure drop, the lower the NOx and CO emissions. Increasing the conical burner pressure drop from $75 \mathrm{~Pa}$ to $224 \mathrm{~Pa}$, the stable operating range becomes wider until a maximum is reached at pressure drop equals to $149 \mathrm{~Pa}$. Thus, $149 \mathrm{~Pa}$ is considered an optimal cone pressure drop for the duct burner. The increase in the cone pressure drop had a small effect on the duct burner overall pressure drop.

\subsubsection{Effect of $L_{\text {eff }} / D_{\text {shield }}$ and BR}

As the $L_{e f f} / D_{\text {shield }}$ ratio increased, the combustion zone temperature increased, allowing the duct burner to operate towards the leaner equivalence ratio and achieve a wider stable operating range. Longer shields provided more protection to the flame from the bypassed flow and provided an energy feed back to the combustion zone. At a constant firing rate, as the $L_{\text {eff }} / D_{\text {shield }}$ ratio increased, NOx emissions increased. As the $L_{e f f} / D_{\text {shield }}$ ratio was reduced, $\mathrm{CO}$ emissions increased (the addition of cool and diluting oxidant to the combustion zone caused high $\mathrm{CO}$ emissions). When the duct burner used the shields with $\mathrm{BR}=0.6$, it operated at a higher firing rate with a narrow operating range compared to shields with $\mathrm{BR}=0.4$. 
Shields with $\mathrm{BR}=0.6$ produced very low $\mathrm{NOx}$ and $\mathrm{CO}$ emissions at a higher firing rate compared to those shields with $\mathrm{BR}=0.4$. NOx and $\mathrm{CO}$ emissions from the duct burner with shields with $\mathrm{BR}=0.6$, showed similar trends as with shields with $\mathrm{BR}=$ 0.4 ; NOx emissions increased and $\mathrm{CO}$ emissions decreased by increasing the shield length.

\subsubsection{Effect of fuel cap design}

The flat design fuel caps (Cap-2, 3 and 4) were used during the combustion tests to provide the duct burner with different fuel flow rates to cover a wide range of firing rates. For the same operating conditions, Cap-4 provides the duct burner with higher fuel flow rate than Cap-2. This increases the total reactant mass flow rate and reduces the temperature of the incoming oxidant fuel mixture. From the observations, Cap-4 produces shorter and compact flames compared to Cap-2. The latter fuel cap when tested with the duct burner shifts the lower operating limit towards the leaner combustion side due to the higher flame temperature. Measurements showed that, for the same firing rate, NOx and CO emissions increased when Cap-2 was used.

\subsubsection{Effect of mixer design on the DB performance (mixing)}

The amount of swirl imparted to the premixer has a very significant effect on emission levels and the stable operating range. The double-swirl mixer, Mix-2/2, shows good results with respect to NOx and $\mathrm{CO}$ emissions. This is attributed to better mixing. The range of operation for the double-swirl mixer was from $154 \mathrm{~kW}$ to 316 $\mathrm{kW}$. However, the single-swirl mixer, Mix-1/2, also performed reasonably well, especially in terms of extending the stability rang to a lower firing rate (148 $\mathrm{kW}$ to $328 \mathrm{~kW}$ ). Reducing the oxidant swirl in the premixer extended the operating range towards a leaner mixture. 


\subsubsection{Effect of burner parameters on the DB exhaust gas temperature}

The effect of the different burner parameters on exhaust gas temperature was investigated and reported in the present thesis. The duct burner exhaust gas temperature was measured at two locations downstream of the conical burner. At one of the locations a traverse measurement was conducted across the duct burner. The effect of the different burner parameters on traverse exhaust gas temperature was presented. All the parameters tested produced top-hat exhaust gas temperature distributions and their maximum value has an average of $1000^{\circ} \mathrm{C}$. The only difference observed was the wider exhaust temperature profiles with the shields with a $\mathrm{BR}=0.6$. This was due to the difference in the shield diameter. This wider profile had the same maximum temperature as in the other cases.

\subsubsection{Effect of duct burner inlet temperature}

Preheating the unburned mixture gives additional enthalpy to the reactants, saves energy and increases the combustion zone temperature. This results in broadening the stability range and shifts the blow-off limit towards the lower firing rate value. However, increasing the combustion zone temperature increases NOx formation. $\mathrm{CO}$ emissions decrease with the increase in the duct burner inlet temperature. The inlet temperature does not show any effect on the overall duct burner pressure drop.

\subsubsection{Combustion and LSI tests comparisons}

A quasi-quantitative technique was developed to rank the different combinations of burner parameters and provided invaluable information concerning the mixing processes. To check and prove the strength of this quasiquantitative LSI technique a comparison between the combustion tests results and the LSI results was conducted. The traverse temperature measurements at the premixer exit plane were used for this. Two sets of comparisons were performed 
the first one between the two mixers and the second was between two fuel caps with different fuel injection angles. The better the mixing, the more uniform the temperature profile at the premixer exit plane, and the more complete the combustion, and hence the lower the emissions. The results show that the LSI technique can be used to evaluate the mixing in the duct burner.

\subsubsection{Duct burner overall pressure drop}

The pressure drop across the duct burner is an essential parameter in determining the oxidant flow split between the conical mesh burner (combustion zone) and the duct burner annular passage. Therefore, the duct burner overall pressure measurements were conducted during the flow balancing test phase and also during the combustion tests. During these tests, the AFCBA and the blockage ratio (BR) were found to have the greater influence on the overall duct burner pressure drop compared to the other parameters investigated. The pressure drop measurements conducted during the combustion tests show that with surface combustion, the overall pressure drop of the duct burner doubles (compared to that in cold flow, i.e. the DB turned off).

\subsubsection{Flame images}

Flame images were presented to show the blue flame mode of the conical burner. Different qualitative observations were made from the flame images captured during this investigation: 1) The wire-mesh structure of the conical burner controls the size and the shape of the flames. 2) Flames with different lengths were observed over the burner surface due to the local mass flux gradients resulting from the perforated regions of the wire-mesh matrix. 3) The length of the flame increased as the firing rate decreases towards the leaner equivalence ratio. 4) Very long blue flames were observed when the burner operated very close to the lower stability limit. 
5) Between the instability and the blow-off condition, local extinction of the flame was observed on the lower half of the conical burner and the position and the shape of the flames were no longer constant. And 6) Operating at higher equivalence ratios (rich conditions) the conical burner surface combustion changed from blue flame mode to radiant mode.

\subsection{Summary of contributions}

The contributions of this work are summarized as follows:

1) A novel low NOx conical wire-mesh duct burner for the development of a more efficient micro-cogeneration unit has been developed (designed, built and tested). This burner provides the thermal energy necessary to raise the microturbine exhaust gas temperature for the purpose of increasing the heat recovery capability of the unit while maintaining the low NOx and $\mathrm{CO}$ emission. The duct burner implements both lean-premixed and surface combustion techniques to achieve low $\mathrm{NOx}$ and $\mathrm{CO}$ emissions.

2) A preliminary design methodology for a conical wire-mesh $D B$ was developed. The combustion results proved that the design procedures that were used to design this novel MT wire-mesh DB were successful.

3) An LSI test rig suitable for studying the flow field in the duct burner premixer has been developed and an investigation of the mixing processes in a wide range of premixer configurations using the LSI technique was performed. A unique, quasi-quantitative technique was developed to rank the different premixer configurations in terms of mixing effectiveness.

4) The duct burner was integrated with Ingersol-Rand $70 \mathrm{~kW}$ microturbine successfully and tested. Detailed cold flow (microturbine on and DB off) measurements of pressure drop and DB inlet velocity and annular passage 
velocity have been obtained for the different geometrical parameters, such as AFCBA, cones and BR.

5) Combustion tests were performed and detailed measurements of pressure drop across the burner, DB inlet velocity, exhaust gas temperature, combustion zone temperature, conical wire-mesh surface temperature (cold and hot sides), conical burner shield outer surface temperature, premixer (oxidant and fuel mixture) outlet temperature, emission levels (NOx and $\mathrm{CO}$ ), operating range and blow-off conditions have been obtained. These measured values have been used to develop an understanding of the interaction of these variables which influence the overall performance of the duct burner.

6) Through the variation of the different duct burner operating parameters during the combustion tests performed, the optimum range of parameters have been determined and reported.

7) The extensive experimental work performed in this investigation starts from the LSI, flow balancing and the combustion tests results provided an improvement to the data-base of information so that theoretical models and computer codes can be validated.

8) The family of curves obtained during the combustion test that describes the DB performance could be used to develop design criteria for a wire-mesh DB with an optimum operational performance

9) This work has been presented and defended in several scientific events. A list of those events and the publications are listed in Appendix I.

\subsection{Recommendations for further work}

From the measurement conducted here, many ideas for future work can be developed 
1) More accurate measurement of the flame temperature or mapping the entire combustion zone around the conical burner and at different heights will improve our understanding to the surface combustion technique used and give a clearer view for the interpretations and the discussion of the results.

2) Using or applying more effective diagnostic techniques such as; direct flame digital photography and particle image velocimetry (PIV) to collect more detailed information on the effect of the different parameters on flame structure.

3) Double-swirl mixers are expected to have a better rapid mixing behaviour than the single-swirl mixers. To obtain the best result from the doubleswirl mixers, the fuel should be injected upstream of the mixers or injected into the shear layer between the two swirling flows. Tests to evaluate this should be undertaken.

4) One of the conclusions from the combustion tests was that the stronger swirl mixer produces better DB performance from the emission point of view due to the improved mixing, but produces a narrower stability range compared to the weaker swirl mixer (similar to the case of open flame (no mesh)). Further work should focus on this aspect in which a comparison of several counter swirl distributions with different blade angles (or even single-swirl mixers with a higher swirl number value) on the duct mesh burner performance.

5) The LSI work has to be further extended to experiment with a greater variety of swirl vane angles and designs (see 4 above) accompanied with LDV measurements to confirm and support the different findings.

6) Other factors which influence surface combustion such as; temperature and burning velocity and wire-mesh materials which may enhance this combustion technique should be investigated. 
7) The conical burner shield used in the present investigation has a very simple design and it performed well during the combustion tests. The purpose of the shield was mainly to protect the surface combustion on the conical burner from the bypass flow. The shield was cooled by convective heat transfer from the backside surface. A new design of the conical burner shield utilizing one of the cooling schemes similar to those used in gas turbine combustor liners is recommended. The new design should maintain the shield wall temperature below material limits to avoid overall shield failure. The improvement in the shield design will improve the performance of the duct burner (emissions and the exhaust gas temperature uniformity).

8) CFD modeling of the complete duct burner, using the measured flow field data, will develop a clear understanding to the different duct burner flow patterns. For example modeling of the duct burner premixer will develop a better understanding of the effect of different premixer geometries on the mixing process.

9) A theoretical model of the combustion over the surface of the conical wire-mesh burner is needed to improve the understanding of the different combustion characteristics and the interactions between the different heat transfer mechanisms in this burner. The experimental results presented in the present investigation on the full scale duct burner could be used to validate such a theoretical model

10) Using what stated in points 1 and 2 (accurate measurement with more effective diagnostic techniques) to study the anomalous behaviour of Cone 3 and investigate whether it is an aerodynamic or a heat transfer problem

11) Study the possibility of employing an induced draft fan and changeover the operation of the duct burner from using the microturbine exhaust gases to fresh air firing which will be useful in case of a gas turbine trip or shutdown. 


\section{REFERENCES}

AABC, (1989), "National Standards, 5th ed., Volume Measurements", Associated Air Balance Council, Washington, D.C.

Ali, A. J-A., Slayzak, S. J., and Ryan, J. P., (2002), "Evaluation of Cooling, Heating, and Power (CHP) for Office Buildings", ASHRAE Transactions, Vol.108, Pt.1. (AC-02-18-3).

Alkabi, H. S., and Andrews, G. E., (1991), "Reduced NOx Emission Using Low Radial Swirler Vane Angles", ASME 91-GT-363, June 3-6, Orlando, Florida, USA.

Al-Shemmeri, T. T., and Wright, C. C., (1985), "A Strategy for Calibration of Thermocouples", J. Measurement and Control, Vol. 18, June.

Al-Shemmeri, T. T., and Mutul, I., (1992), "Numerical Estimation of the Uncertainty of the Predicted Temperature for K-Type Thermocouples", Engineering System Design and Analysis, PD-Vol. 47-1, ASME

Anderson, D.J., Greated C.A., Jones J.D.C., Nimmo G. and Wiseall S., (1996), "Fiber optic PIV studies in an industrial combustor", Proc. $8^{\text {th }}$ Int. Symp. On Applications of laser Techniques to Fluid Mechanics, Lisbon, Paper18.4

Anderson, F. (1992) "Heat Transfer Model for Fiber Burners." Progress in Energy and Combustion Science 18 (1), pp. 1-12.

Anon, (2001), The European Association for the Promotion of Cogeneration, a Guide to Cogeneration, June 2001 available at: \{http://www.cogen.org/publications/reports_and_studies.htm\}.

Anon, (2002), "Micro Map - Mini and Micro-CHP - Market Assessment and Development Plan", Study Supported by the European Commission. London FaberMaunsell Ltd, COGEN Europe, EA Technology, ESTIA Consulting, Energy for Sustainable Development, GERG, SIGMA Elektroteknisk AG.

Anon, (2004), "Directive 2004/8/EC on the Promotion of Cogeneration Based on a Useful Heat Demand in the Internal Energy Market and Amending Directive 92/42/EEC", Final Report (11 February 2004). 
Appleton, J.P. and Heywood, J.B., (1973), "The Effects of Imperfect Fuel-Air Mixing/in a Burner on NO Formation from Nitrogen in the Air and the Fuel," Proceedings of the 4th Symposium (International) on Combustion, pp. 777786, The Combustion Institute.

Archer Sean Stacey, (2005), "Morphology of Unconfined and Confined Swirling Flow under Non-reacting and Combustion Conditions" PhD. Thesis, University of Maryland, College Park, USA.

Asanuma, T., (1986), "Handbook of Flow Visualization." pp. 78-79, 158-164, Asakura Shoten, Tokyo, Japan.

ASHRAE Handbook-HVAC Systems and Equipment, (1999), Chapter 7. Atlanta: American Society of Heating, Refrigerating and Air-Conditioning Engineers, Inc.

ASME Test Code, (1998), the American Society of Mechanical Engineers, "Performance Test Codes, PTC 19.1-1998, Test Uncertainty".

Atallah, E. Batshon and Backlund J. C., (2001), "Alternate Fuels for Supplementary Firing Add Value and Flexibility to Combined Cycle and Cogeneration Plants", Presented at Power-Gen International, Las Vegas, NV, December 1113.

Backlund, J. C., and Fiorenza, E. E., (1988), "Experience with Supplementary Combustion System to Maximize Steam Production in Gas turbine Cogeneration", Paper presented at the Gas Turbine and Aeroengine Congress, Amsterdam, The Netherlands, June.

Bakker, A., LaRoche, R. D., and Marshall, E. M., (2000), "Laminar Flow in Static Mixers with Helical Elements." The online CFM Book, http://www. Bakker.org/cfm.

Barra, A. J., and Ellzey, J. L., (2004), "Heat Recirculation and Heat Transfer in Porous Burners", Combustion and Flame, Vol. 137, pp. 230-241.

Barrue, H., Karoui, A., Sauze, N. Le., Costes, J, Illy, F., (2001), "Comparison of Aerodynamics and Mixing Mechanisms of Three Mixers: Oxynator Gas-Gas Mixer, KMA and SMI Static Mixers", Chemical Engineering Journal, 84, pp.343-354, Elsevier. 
Bartz, D. F., Moreno F. E., and Barone P., (1992), "High VOC Destruction with Low NOx in Adiabatic Radiant Combustion", $11^{\text {th }}$ International Conference on Incineration, University of California, Irvine, CA, USA.

Basu, P., Kefa, C., and Jestin, L. (1999), "Boilers and Burners-Design and Theory", New York: Springer.

Baukal, C. E., JR., (2000), "Heat Transfer in Industrial Combustion", By CRC Press LLC.

Becker, B., Berenbrink, P. and Brandner, H. (1986). "Premixing Gas and Air to Reduce NOx emissions with Existing Proven Gas Turbine Combustion Chamber." ASME, International Gas Turbine Conference and Exhibit, $31^{\text {st }}$, Duesseldorf, Germany; United States; 8-12 June, Paper 86-GT-157.

Beer, J. M., and Chigier, N. A. (1972), "Combustion Aerodynamics", London, Applied Science Publishers Ltd.

Belanger, G., Hughes, P. M. and Parameswaran, T., (2000), "Laser Sheet Illumination and the burner test facility", Internal Report, CANMET Energy Technology Centre, Advanced Combustion Technologies, Measurement and Combustion Kinetics Group, August.

Benner, M. W. (2003), "The Effect of Leading Edge Geometry on Profile and Secondary Losses in Turbine Cascade", Ph.D. Thesis, Carleton University, Ottawa, Canada.

Bizzi, M., Saracco, G., Specchia, V., (2003), "Improving the Flashback Resistance of Catalytic and Non-catalytic Metal Fiber Burners", Chemical Engineering Journal 95 (2003) 123-136, Elsevier.

Blevins, (1994), “Applied Fluid Dynamics Handbook”, Krieger Pub. Company.

Borbely, A., and Kreider, J. F., (2001), "Distributed Generation-The Power Paradigm for the New Millennium", CRC Press.

Bowman, C. T., (1992), "Control of Combustion-Generated Nitrogen Oxide Emissions, Technology Driven by Regulation", $24^{\text {th }}$ Symposium on Combustion, Pittsburgh, PA, The Combustion Institute.

Bowman Power, (2002), "TG80CG", Bowman Power Systems www.energysolutionscenter.org/DistGen/AppGuide/DataFiles/BowmanBroc. 
Bozelli, J. W., and Dean, A. M., (1995), "O+NNH-A Possible New Route for NOx Formation in Flames", Journal Chem. Kinet., Vol. 27, pp. 1097-1109.

Brandon, R., CETC, (2003), "CETC's CHP Programme" \{http://www.nrcan.gc.ca/es/etb/cetc/cetc01/downloads/presentation_200/3 pdfs $\}$

Brandon, R., Halliday, B., and Ramadan, O., (2006), "Inlet Air Supercharging and Low NOx Duct Burners", Presented at the $6^{\text {th }}$ Annual Microturbine Applications Workshop, January 17-19, San Francisco, \{www.ms.ornl.gov/maw06/default.html\}.

Brenner, G., K. Pickenaacker, O. Pickenacker, D. Trimis, K. Wawrzinek, and T. Weber, (2000) "Numerical and Experimental Investigation of MatrixStabilized Methane Air Combustion in Porous Inert Media", Combustion and Flame, Vol. 123, pp. 201-213.

Broda, J. C., Seo, S., Santoro, R. J., Shirhattikar, G., and Yong, V., (1998), "An Experimental Study of Combustion Dynamics of a Premixed Swirl Injector", Symposium (International) on Combustion, Vol. 27, Issue 2, pp. 1849-1856.

Capstone, (2003), "Capstone C30", July, Capstone Turbine Corporation, \{http://www.microturbine.com/documents/C30/ infosheet.pdf\}.

Capstone, (2005), "CR65 Renewable Energy System", Capstone Turbine Corporation. \{http://www.microturbine.com/documents/CR65infosheet.pdf\}.

Capstone, (2007), "Capstone C200", Capstone Turbine Corporation. \{www.microturbine.com/whatsnew/pressrelease.asp?article $=294$ \}.

Cerri, I., Saracco, G., and Specchia, V., (2000), "Methane Combustion Over LowEmission Catalytic From Burners" Catalysis Today, 60, pp. 21-32.

Cerri, I., Saracco, G., Specchia, V., and Trimis D, (2001), "Improved-Performance Knitted Fibre Mats as Supports for Pre-mixed Natural Gas Catalytic Combustion", Chemical Engineering Journal, 82, pp. 73-85.

Chase, M.W., (1998), "JANAF Thermochemical Tables", 3rd ed., Part I and Part II. American Chemical Society, American Institute of Physics and National Bureau of Standards, 14. 
Cheng, T. S., Chao, Y. C., Wu, D. C., Hsu, H. W., and Yuan, T., (2001), "Effects of Partial Premixing on Pollutant Emissions in Swirling Methane Jet Flames", Combustion and Flame, Vol. 125, pp. 865-878.

Chigier, N. A., and Beer, J. M., (1964), "Velocity and Static Pressure Distributions in Swirling Air Jets Issuing from Annular and Divergent Nozzles", Journal of Basic Engineering, Vol. 86, pp. 788-796.

Chiradeja, P., and Ramakumar, R., (1998), "A Review of Distribution Generation and Storage," The $31^{\text {st }}$ Annual Frontiers of Power Conference, Stillwater, Oklahoma, PP. VIII-1 to VIII-11, October.

Cho, K. W., Han, K., Lee, Y. K., Noh, D., Yoon, H. M., Riu, K., and Lee, K., (2001), "Premixed Combustion of Coke Oven Gas in a Metalic Fiber Mat", Journal of Fuel, Vol. 80, (7), pp. 1033-1036, ScienceDirect.

Choi, G-M., and Katsuki, M., (2000), "New Approach to Low Emission of Nitric Oxides From Furnaces Using Highly Pre-Heated Air Combustion." Journal of the Institute of Energy, 73, pp. 18-24.

Chung, S. Y., Rhee, G. H., and Sung, H. J., (2002), "Direct Numerical Simulation of Turbulent Concentric Annular Pipe Flow Part:1 Flow Field", International Journal of Heat and Fluid Flow, Vol. 23, (4), pp. 426-440.

Clayton, B. R. and Massey, B. S., (1968) "Flow Visualization in Water: A Review of Techniques.” Journal of .Sci. Instrum., Vol. 44.

Clemens, N. T., (1991), "An Experimental Investigation of Scalar Mixing in Supersonic Turbulent Shear Layers, $\mathrm{PhD}$ thesis, Stanford University.

Correa, S. M. (1992) "Review of NOx Formation under Gas-Turbine Combustion Conditions.” Comb. Sci. Tech. (87).

Crimaldi, J. P., Kosff, J. R., (2001), "High-Resolution Measurements of Spatial and Temporal Scalar Structure of a Turbulent Plume", Experiments in Fluids, 31, pp. 90-102, Springer-Verlag.

Dalla Betta, R. A., Schlatter, J. C., Yee, D. K., Lottler, D. G., and Shoji, T., (1995), "Catalytic Combustion Technology to Achieve Ultra Low NOx Emissions: Catalyst Design and Performance Characteristics", Catalysis Today, Vol. 26, (3), December-95, pp. 329-335. 
David F. Bartz, Moreno, F. E., and Duggan, P. D., (1992), "Ultra-Low, NOx UltraHigh VOC Destruction with Adiabatic Radiant Combustors", PD-Vol. 39, Fossil Fuels Combustion ASME.

Demayo, T. N., (2004), "Assessing Jet-Induced Spatial Mixing in a Rich, Reacting Crossflow", NACA/CR-2004-212886, USA.

Dodds, W. J., and Bahr, D. W., (1990), “Combustion System Design”, New York, Academic Press.

Drake, M. C. and Blint, R. J. (1991) "Calculations of NOx Formation Pathways in Propagating Laminar, High Pressure Premixed $\mathrm{CH}_{4} /$ Air Flames." Combustion Science and Technology (75).

Dugga, K., (2002), "Microturbine Applications and Issues", Presented at the MidAtlantic Distributed Energy Resources Capstone Turbine Corporation, USA, February 21.

Dupont, V., F. Moallemi, A. Williams and Zhang S. H., (2000), "Combustion of Methane in Catalytic Honeycomb Monolith Burners", International Journal of Energy Research, Vol. 24, pp. 1181-1201.

Durao, D. F. G., Heitor, M. V., and Moreira, A. L. N., (1993), "Flow Measurements in a Model Burner-Part 2." Journal of Fluid Engineering, Vol. 115, pp. 309316.

Eckbreth, A. C., (1988), "Laser Diagnostics for Combustion Temperature and Species." Abacus Press.

Elliott Energy, (2005), “TA-100CHP”, Elliott Energy Systems, www.elliottmicroturbines.com.

Fenimore, C. P., (1971) "Formation of Nitric Oxide in Premixed Hydrocarbon Flames." Proceedings of the $13^{\text {th }}$ Symposium (International) on Combustion Pittsburg, PA, The Combustion Institute.

Ferrara, G., Luca, I., Giacomo, M., Bruno, F., and Anthony, J. (2000). "Heat Transfer Analysis in Modern DLN Combustor", Proceedings of ASME Turbo Expo, Paper No. (2000-GT-0254).

Ferrier, A., Funk, D., and Roberts, P., (1993), "Application of Optical Techniques to the Study of Plumes in Stratified Fluids." DynAtoms Oceans, 20, pp. 155-183. 
Finnemore, E. J., and Franzini, J. B., (2002), "Fluid Mechanics (with Engineering Applications)", McGraw-Hill.

Flanagan, P., Gretsinger, K., Abbasi, H. A., and Cygan, D., (1992), "Factors Influencing Low Emission Combustion" PD-Vol. 39, Fossil Fuels Combustion, ASME.

Forzatti, P. and Groppi, G., (1998), "Combustion Catalysis for the production of Heat and Energy" Second World Congress on Environmental Catalysis, American Institute of Chemical Engineers, Miami Beach. FL.

Froemming, J., Hjalmarson, L., and Houshmand, M., (1993), "Ensure Cogen. Steam Supply with Fresh-Air-Fired HRSG's”, Power, August.

Fuhs, A.E., and Schetz, J.A., (1996), "Handbook of Fluid Dynamics and Fluid Machinery", 3 Volumes set, Wiley-Interscience.

Gal, P. Le, Farrugi, N., Greenhalgh, D.A., (1999), "Laser Sheet Drop Sizing of Dense Sprays." Optics and Laser Technology, Vol. 31, pp. 75-83.

Gauthier, J.E.D., Bardon, M.F., and Rao, V.K., (1996), "General Flame-Propagation Model for Fuel Droplet, Particle and Vapour Mixtures in Air", J. of Institute of Energy, June, Vol. 69, pp. 59-67.

Gauthier, J.E.D., (2003) "Gas Turbines", Carleton University, Ottawa, Canada, Lecture Notes for MECH 5402.

Gjerde, E.G., (1969),”Supplementary Firing System”, United State Patent 3,457,902, July.

Glarborg, P., Miller, J. A., and Kee, R. J., (1986), "Kinetic Modeling and Sensitivity Analysis of Nitrogen Oxide Formation in Well-Stirred Reactors", Combustion and Flame (65).

Glassman, Irvin, (1977). "Combustion” Third Edition, Academic Press, New York.

Goldstein, R. J., (1996), "Fluid Mechanics Measurements." Second Edition, Taylor and Francis.

Golombok, M., Prothero, A., Shirvill, L. C., and Small, L. M., (1991) "Surface Combustion in Metal Fiber Burners." Combust. Sci. and Tech., Vol 77, pp 203-223. 
Grant, I. Parkin, and Wang, X., (1997), "Optical Vortex Tracking Studies of a Horizontal axis wind turbine in yaw using Laser-Sheet, flow Visualization." Experiments in Fluids, Vol. 23, pp. 513- 519.

Greenberg, S. J., McDougald, N. K., Weakley, C. K., Kendall, R. M.,and Arellano, L. O., (2005), "Surface-Stabilized Fuel Injectors With Sub-Three PPM NOx Emissions for a 5.5 MW Gas Turbine Engine", Transactions of the ASME, Vol. 127, pp. 276-285, April.

Grobman, J. S., R. T. Dittrich, and C. C. Graves, 1957, "Pressure drop and Air Flow Distribution in Gas Turbine Combustors", Trans. of ASME, p. 1601.

Gupta, A. K., Lilley, D. G. and Syred, N., 1984. "Swirl Flows", London: Abacus Press.

Hackert, C. L., Ellzey, J. L., and Ezekoye, O. A., (1999). "Combustion and Heat Transfer in Model Two-Dimensional Porous Burners." Combustion and Flame Vol. 116 (1-2), pp. 177- 191.

Hallett, W. L. H., and Ding, C. -Y., (1995), "A Momentum Integral Model for Central Recirculation in Swirling Flow in a Sudden Expansion", The Canadian Journal of Chemical Engineering, Vol. 73, pp. 284-291.

Hallett, W. L. H., (2003), "Combustion in Diffusion Systems", University of Ottawa, Ottawa, Canada, Lecture Notes for MCG 5192.

Hardesty, D. R., and Weinberg, F. J., (1974), "Burners Producing Large Excess Enthalpies", Combustion Science and Technology, Vol. 8 (5-6), pp. 201-214.

Harding, S. C., Greenhalgh D. A., (1998), "Fuel-Air Mixing and Combustion in an Optical, Lean, Premixed, Prevaporised Gas Turbine Combustor", ASME-GT553, Presented at the International Gas Turbine and Aeroengine Congress and Exhibition, Stockholm, Sweden, June 2-5.

Harinaldi, T. U. and Mizomoto, M., (2001), "Laser Sheet Imaging of Recirculation Zone of Backward-Facing Step Flow with Gas Injection." Journal of Chemical Engineering of Japan, Vol. 34, No. 3, pp. 351-359.

Hayashi, S. (1983). "Effects of Heterogeneity of Mixtures on Gaseous Emissions in Premixed/Prevaporized Combustion" pp.245-251.

Heywood, J. B., (1988), "Internal Combustion Engine Fundamentals", McGraw-Hill, Inc. 
Holdeman, J. D., Srinivasan, R., Coleman, E. B., Meyers, G. D., and White, C. D., (1987), "Effect of Multiple Rows and Noncircular Orifice on Dilution Jet Mixing", Journal of Propulsion and Power, Vol. 3, May-June, pp.219-226.

Holman, J. P., (1971), "Experimental Methods for Engineers," McGraw-Hill Book Company, Second Edition.

Howell, J. R., Hall, M. J., and Ellzey, J. L., (1996) "Combustion of Hydrocarbon Fuels Within Porous Inert Media.” Prog. Energy Combust. Sci., Vol. 22, pp. 121-145.

Hsu, P.-F., William, D. E., and Howell, J. R., (1993a), "Experimental and Numerical Study of premixed Combustion within Non-homogeneous Porous Ceramics", Combust. Sci. and Tech., Vol. 90, pp. 149-172.

Hus, P. -F., and Matthews, R. D., (1993) "The Necessity of Using Detailed Kinetics in Models for Premixed Combustion Within Porous Media." Combustion and Flame, 93, pp. 457-466.

Hus, P. -F., Howell, J. R., Matthews, R. D., (1993b), “A Numerical Investigation of Premixed Combustion Within Porous Inert Media." Journal of Heat Transfer, Transaction of the ASME, Vol. 115.

Hus, Y. and Brennen, C. E., (2002), "Effect of Swirl on Rotordynamic Forces Caused by Front Shroud Pump Leakage", Journal of Fluid Engineering, ASME, Vol. 124, pp. 1005-1010, Dec.

Ingersoll-Rand, (2003), "Ingersoll-Rand $\quad$ MT70 kW", \{http://www.irenergysystems.com/IS/product.asp/id/70L_series_micro.pdf\}.

Ingersoll-Rand, (2004), "Ingersoll-Rand MT250, $250 \mathrm{~kW}$ Continuous Onsite Electrical Power with Integrated Heat Recovery", \{http://energy.ingersollrand.com/downloads/pdfs/250_Spec_026LTA.pdf\}.

Jahnke, J. A., (2000), "Continuous Emission Monitoring", Second Edition, John Wiley and Sons, Inc., New York.

Jeffery, A. L., and Warren, J. M., (1995). "Development of a Swirl and Bluff-Body Stabilized Burner for Low-NOx, Lean-Premixed Combustion." ASME, (95GT-166). 
Jennekens, M., (1999),'Learning from Experiences with Small-Scale Cogeneration", CADDET Analyses Series No.1.

Jones, R. E., (1978) "Gas Turbine Emissions-Problems, Progress and Future." Prog. Energy Combust. Sci. (4) 25.

Joshi, N. D., Michael, J. E., Durlak, S., Marakovits, S and Sabla, P. E., (1994). "Development of a Fuel Air Premixer for Aero Derivative Dry Low Emission Combustor" ASME, 94-GT-253.

Jugjai, S., and Somjetlertcharoen, A., (1999). "Multimode Heat Transfer in Cyclic Flow Reversal Combustion in Porous Medium.” Int. J. Energy Res. 23, pp. 183-206.

Kataoka, Akihiro, (1998), "New Type of High Temperature Surface Combustion Burner." Proceedings of the International Gas Research Conference, pp. 115123.

Khanna, V. R. Goel, and Ellzey, J. L., (1994). "Measurements of Emissions and Radiation for Methane Combustion within a Porous Medium Burner." Combust. Sci. and Tech., Vol. 99, pp. 133-142.

Kirkup Les, (1994) "Experimental Methods: An Introduction to the Analysis and Presentation of Data", Jacaranda Willy Ltd., Sydney.

Koochesfahani M., and Dimotakis, P., (1985), "Laser-Induced Fluorescence Measurements of Mixed Fluid Concentration in a Liquid Plane Shear Layer", AIAA J, 23, pp. 1700-1707.

Kotani, Y. and Takeno, T., (1982), "An Experimental Study on Stability and Combustion Characteristics of an Excess Enthalpy Flame," Nineteenth Symposium (Int.) on Combustion, the Combustion Institute, Pittsburgh, pp. 1503-1509.

Kreider, J. F., (2006), "Distributed Electrical Generation -A Scan of the Industry Today", Presented at the CRES (Colorado Renewable Energy Society) Monthly Meeting, April, 26, Colorado, USA.

Krill, W. and Kesselring, J., (1985). "Field evaluation of the Fiber Burner in Fire tube Boilers." GasWarme International, Band 34, Heft 4.

Kuo Kenneth K., (2005), "Principles of Combustion”, Second Edition, John Wiley and Sons, Inc. 
Lagerstrator, G. and Xie, M., (2002), "High Performance \& Cost Effective Recuperator for Micro-Gas Turbines", Proceeding of ASME TURBO EXPO 2002, 3-6 June Amsterdam, Netherlands, GT-2002-30402.

Lauterborn, W. and Vogel, A, (1984), "Modern Optical Techniques in Fluid Mechanics." Annu Rev of Fluid Mech. 16, pp. 223-244.

Lee, C. W., and Moon, S. Y., (2002), "An Experimental Investigation of the Effect of Turbulence Generators Attached to an Axial Swirler Nozzle on Mixing and Combustion”, Aerospace Science and Technology, Vol. 6, No. 7, 11.

Lefebvre, A. H., (1983), "Gas Turbine Combustion", London: Taylor and Francis.

Lefebvre, A. H., (1999), "Gas Turbine Combustion", Second Edition, London, Taylor and Francis.

Leonard, G. and Correa, S., (1990), "NOx Formation in Premixed High-Pressure Lean Methane Flames", Second ASME Fossil Fuel Combustion Symposium, New Orleans, Louisiana, ASME/PD Vol. 30, pp. 69-74.

Leonard, G. and Stegmaier, J. (1993). "Development of an Aeroderivative Gas Turbine Dry Low Emissions Combustion System.” ASME (93-GT)288.

Leonardi, S. A., Viskanata, R., and Gore, J. P., (2002), "Radiation and Thermal Performance Measurements of a Metal Fiber Burner." Journal of Quantitative Spectroscopy and Radiative Transfer 73, pp. 491-501.

Liedtke, O., Schulz, A., and Wittig, S., (2002). "Design Study of A Lean Premixed Prevaporized Counter Flow Combustor For A Micro Gas Turbine" Proceedings of ASME TURBO EXPO, Amsterdam, the Netherlands, (GT2002-3074).

Lilley, D. G., (1974), "Turbulent swirling flame predictions", AIAA Journal, Vol. 12, No. 2, pp. 219.

Lilley, D. G., (1977), "Swirl Flows in Combustion: A Review", AIAA Journal, 15 (8), pp. 1063-1078.

Lin Y., and Gross, G., (2004), "Production Cost Analysis of Dispersed Generation Options in a Transmission-Constrained Load Pocket of an Interconnected System", IEEE Transaction on Energy Conversion, Vol. 19, No. 1, March. 
Lockwood, F. C., EL-Mahallawy, F. A., and Spalding, D. B., (1974), "An Experimental and Theoretical Investigation of Turbulent Mixing in a Cylindrical Furnace", Combustion and Flame, Vol. 23, No. 3, pp. 283.

Luan Yongwei, (2003), Computational and Experimental Investigation of Premixed Combustion in Porous Ceramic Infrared Heaters", PhD. Thesis, Cleveland State University, OH, USA.

Lyons, V. J. (1982). "Fuel/Air Nonuniformity-Effect on Nitric Oxide Emissions." AIAA Journal, (20) 5.

MacMillan, F. A., (1954), "Viscous Effect on Flattened Pitot Tubes at Low Speeds", Journal of Roy. Aeronaut. Soc., Tech. Notes, Vol. 58, (528), pp.837-839.

Mahallati, A., (2003), "Aerodynamics of A Low-Pressure Turbine Aerofoil Under Steady and Periodically Unsteady Conditions", PhD. Thesis, Department of Mechanical and Aerospace Engineering, Carleton University, Ottawa, Canada.

Marbach, T. L. and Agrawal, A. K., (2005) "Experimental study of surface and interior combustion using composite porous inert media", Journal of engineering for Gas Turbine and Power, April, 2005, Vol. 127, ASME.

Marshall, B. N., Pam, R. L., Tidball, R. K. and Ruiz, R., (1991), "Reduction of NOx and CO Emissions in Gas Fired Hot Air Systems Through the use of Adiabatic Radiant Burner Technology.” Fossil Fuel Combustion, Vol. 33, pp. 83-86, ASME.

Mathur, M. L., and Maccallum, N. R. L. (1967), "Swirling Air Jets Issuing from Vane Swirlers", Part 2: Enclosed Jets", Journal of the Institute of Fuel, June, 238245.

Maughan, J. R., Warren, R. E. J., Tolpadi, A. K. and Roloff, T. P. (1992) "Effect of Initial Fuel Distribution and Subsequent Mixing on Emission from Lean Premixed Flames." ASME (92-GT) 121.

Meherwan, P., Boyce P. E., (2002), "Handbook for Cogeneration and Combined Cycle Power Plants." New York, ASME Press.

Melling, A., (1997), "Tracer particles and seeding for particle image velocimetry", Meas. Sci. Technol., Vol. 8, pp. 1406-1416, PII: S0957-0233(97)84480-3, UK. 
Mello, J.P., Mellor A. M., Steele R. C., and Smith K., (1997) "A Study of the Factors Affecting NOx Emissions in Lean Premixed Turbine Combustors". Published by the American Institute of Aeronautics and Astronautics.

Mellor, A. M. (1990), "Design of Modern Turbine Combustor", New York: Academic Press.

Merzkirch, W., (1987), "Flow Visualization, Academic Press, New York.

Miller, J. A. and Bowman C. T., (1989). "Mechanism and Modeling of Nitrogen Chemistry in Combustion.” Prog. Energy Combust. Sci. Vol. 15, pp. 287-338.

Min, D. K. and Shin, H. D. (1991), "Laminar Premixed Flame Stabilized Inside a Honeycomb Ceramic", Journal of Heat Mass Transfer, Vol. 34, pp. 341-355.

Moallemi, F., Batley G., Dupont V., Foster T. J., Pourkashanian M., and Williams A., (1999) "Chemical modeling and measurements of the Catalytic Combustion of CH4/air Mixtures on Platinum and Palladium Catalysts." Catalysis Today 47, pp. 235-244.

Mohamad, A. A. (2002) "Numerical Simulation of Combustion in A Cylindrical Porous Medium." Proceeding of ETCE, ASME Engineering Technology Conference on Energy, Houston, TX, (ETCE2002/CAE-29017).

Mongia, R. K., Tomita, E., Hsu, F. K., Talbot, L., and Dibbie, R. W., (1996), "Use of an Optical Probe for Time-Resolved In-Situ Measurement of Local Air-toFuel Ratio and Extent of Fuel Mixing with Application to Low NOx Emissions in Premixed Gas Turbines", Twenty-Sixth Symposium (International) on Combustion, The Combustion Institute, pp. 2749-2757.

Moreno, F. E., Altos, L., and Hartman, C. D., (1987) "Turbine Exhaust Fed Low NOx Staged Combustor for Teor Power and Steam Generation with Turbine Exhaust Bypass to the Convection Stage", USA Patent 4,706,612.

Munson, R. and Kaarsberg, T., (1998), "Unleasing Innovation in Electricity Generation", Issues in Science and Technology, National Academy of Sciences, spring-98, Washington D.C.

Nejad, A. S., Vanka, S. P., Favaloro, S. C., Samimy, M., and Langenfield, C., (1989), "Application of Laser Velocimetry for Characterization of Confined Swirling Flow", Journal of Engineering for Gas Turbine and Power, Vol. 111, pp. 3645. 
Nicol, D., Malte, P. C., Jenkin, L. Marinov, N. M., Pratt, D. T. and Corr, R. A., (1992), "NOx Sensitivities for Gas Turbine Engines Operation on LeanPremixed Combustion and Conventional Diffusion Flames." ASME (92-GT) 115.

Pillier, A. E., Mercier, X. R., Pauwels, J. F., and Desgroux, P., (2005), "Influence of C-2 and C-3 Compounds of Natural Gas on NO Formation: An Experimental Study Based on LIF/CRDS Coupling", $30^{\text {th }}$ Symposium (Intrnational) Combustion, Vol. 30, pp. 1183-1191.

Pompei, F. and Heywood, J.B., "The Role of Mixing in Burner Generated Carbon Monoxide and Nitric Oxide," M.I.T. Fluid Mech. Lab. Publ. No. 72-2, 1972, Combustion and Flame, 19, pp. 407-418, 1972.

Pompei, F. and Heywood, J. B. (1972). "The Role of Mixing in Burner-Generated Carbon Monoxide and Nritic Oxide." Comb. Flame (19).

Pritchard, B. A., Danis, A. M., Foust, M. J., Durbin, M. D., and Mongia, H. C., (2002), "Multiple Annular Combustion Chamber Swirler Having Atomizing Pilot", European Patent EP 1193448A2.

Qiu, K., and Hayden, A.C.S., (2005), "Premixed Gas Combustion Stabilized in Fiber Felt And its Application to a Novel Radiant Burner,", Fuel, Vol. 85, Issues 78, pp. 1094- 1100.

Radhakrishnan, K. and Heywood, J. B., (1981) "Effects of Combustor Inlet Conditions on Flame Stability", Combustion Science and Technology, Vol. 24 , pp. $165-178$

Razdan, M. K., McLeroy, J. T. and Weaver, W. E. (1994). "Retrofittable Dry Low Emission Combustor for 501-K Industrial Gas Turbine Engines." ASME-94GT-439.

Recktenwald, G., (2004), "Pressure Transducer Calibration for M.E. Thermal Laboratory", Class Notes, Portland State University, Portland, OR, (gerry@me.pdx.edu).

Ricco, G., Adami, P., Martelli, F., and Cecchini, D., Carrai, L., (2002) "Improvement of Gas Turbine Injection Systems By Combined Experimental/Numerical Approach." Proceedings of ASME TURBO EXPO, Amsterdam, the Netherlands, (GT-2002-30101). 
Ruminger, M. D., and Dibble, R. W., (1996), "Gas Temperature above a Porous Radiant Burner: Comparison of Measurements and Model Predictions." Twenty Sixth Symposium (International) on Combustion, the Combustion Institute, pp. 1755-1762.

Rutar, T., Martin, S. M., Nicol, D. G., Malte, P. C., and Pratt, D. T., (1997), "Effect of incomplete premixing on NOx formation at temperature and pressure conditions of LP combustion turbines," ASME paper no. 97-GT-335, ASME, New, York, NY.

Saad A. Ahmed, (1998), "Velocity measurements and turbulence statistics of confined isothermal swirling flow", Experimental Thermal and Fluid Science, Vol. 17, pp. 256-264, Elsevier.

Saracco, C. G., Isotta, Cerri, Vito Specchia, and Accornero, R., (1999), "Catalytic Premixed Fiber Burners.” Chemical Engineering Science, Vol. 54, pp. 35993608 .

Saracco, C. G., Specchia, V., and D. Trimis, (2001) "Improved-Performance Knitted Fiber Mats as Supports for Pre-Mixed Natural Gas Catalytic Combustion", Chemical Engineering Journal, Vol. 82, Issues 1-3,pp. 73-85.

Saracco, G., Sicardi, S., Specchia, V., Accornero, R., Guiducci, M., and Tartaglion, M., (1996), "On the Potential of Fiber Burners to Domestic Burners Applications- an Experimental Study", GasWarme, Vol. 45, Heft 1. pp. 24-31.

Saravanamuttoo, H., Rogers, GFC and Cohen, H., (2001), "Gas Turbine Theory." $5^{\text {th }}$ Edition, Pearson Education Ltd.

Sathe, S. B., Peck, R. E., and Tong, T. W., (1990b), “A Numerical Analysis of Heat Transfer and Combustion in Porous Radiant Burners." Int. J. Heat Mass Transfer, Vol. 33, No. 6, pp. 1331-1338.

Sathe, S. B., Peck, R. E. and Tong, T. W., (1990a), "Flame Stabilization and Multimode Heat Transfer in Inert Porous Media: A Numerical Study." Combust. Sci. and Tech., Vol.70, pp. 93-109.

Sattelmayer, Th., and Wittig, S., (1990), "Performance Characteristics of Prefilming Airblast Atomizers in Comparison with other Airblast Nozzles", Encyclopedia of Fluid Mechanics, Vol. 8, Golf Publishing Company. 
Sawyer, J. W., (1985), “Sawyer's Gas Turbine Engineering Handbook", third Edition, Nor-walk, CT: Turbomachinery International Publications.

Schetz, J. A., and Fuhs, A. E., (1999), "Fundamentals of Fluid Mechanics, John Willey and Sons, Inc.

Schmittel, P., Gunther, B., Leucel, W., and Bockhorn, H., (2000), "Turbulent Swirling Flames Experimental investigation of the flow field and Formation of Nitrogen Oxide", Proceeding of the Combustion Institute, Vol. 28, pp. 303309.

Scott, W. G.,(1998), "Micro-Turbine Generators for Distribution System", IEEE, Industry Application Magazine, PP. 57-62, May/June 1998.

Seo, Y. -S., Kang, S. -K., Han, M. -H., and Baek, Y. -S., (1995), "Development of a Catalytic Burner With Pd/NiO Catalysts.", Catalysts Today 47 (1-4), 421 427.Stabilized Burner for Low-NOx, Lean-Premixed Combustion." ASME, (95-GT-166).

Shibata, S., Inoue, U., Abe, H., Tanaka, T., (2001), "Development and Operation of Microturbine Combined Package of Steam Generator with Supplemental Firing", Japan Tappi Journal, Vol. 55, no. 5, May, p 30-33.

Shoffstal, D. R., (1977), "Burner design criteria for NOx control from low Btu gas combustion, Vol. 1, ambient fuel temperature", Report NO.EPA-600/7-77094a, Institute of gas technology, Chicago.

Simader, G. R., (2001), "Analysis of the market potential for micro-gas turbines in Austria", Study for ATEL company, Vienna.

Simader, G. R., Krawinkler, R. and Trnka, G., (2006), "Micro CHP Systems: state-ofthe art", Final Report, Green Lodges Project (EIE/04/252/S07.38608), Austrian Energy Agency, Vienna, March 2006.

Smith, S. H., and Mungal, M. G., (1998), "Mixing, Structure and Scaling of the Jet in Crossflow", J. Fluid Mechanics, Vol. 357, pp. 83-122, Cambridge University Press.

Smith, K. O., Angello, L. C. and Kurzynske, F. R. (1986). "Design and Testing of an Ultra-Low NOx Gas Turbine Combustor." ASME (86-GT)263. 
Snyder, J. D., and Subramaniam, B., (1994), "Flow Reversal Operation of Backedbed Reactors: Application to Endothermicreactions", Chem. Engng Sci., Vol. 49, pp. 5585-5601.

Solero, G., and Coghe, A., (2000), "Effect of Injection Typology on Turbulent Homogeneous Mixing in a Natural Gas Swirl Burner", Experimental Thermal and Fluid Science, Vol. 21, Issues 1-3, Pages 162-170.

Specchia, S., Civera, A., Saracco, G., and Specchia, V., (2006) "Palladium/perovskite/zirconia Catalytic Premixed Fiber Burners for Efficient and Clean Natural Gas Combustion", Catalysis Today, Vol. 117, pp. 427-432.

Speyer, R. F., Lin, W., and Agrwal, G., (1996), "Radiant Efficiencies and Performance Consideration of Commercially Manufactured Gas Radiant Burners", Experimental Heat Transfer, Vol. 9, (3), pp. 213-245.

Stacey, A. S., (2005), "Morphology of Unconfined and Confined Swirling Flow under Non-reacting and Combustion Conditions" $\mathrm{PhD}$. Thesis, University of Maryland, College Park, USA.

Steele, R. C., Malte, P. C., Nicol, D. G., and Karmlich, J. C., (1995), "NOx and $\mathrm{N}_{2} \mathrm{O}$ in Lean Premixed Jet-Stirred Flames", Combustion Flame, Vol. 100 (3), pp. 440-449.

Steele, R. C., Tonouchi, J. H., Horning, D. G., Malte, P. C., and Pratt, D. T., (1998), "Characterization of NOx, $\mathrm{N}_{2} \mathrm{O}$ and $\mathrm{CO}$ for Lean-Premixed Combustion in a High Pressure Jet-Stirred Reactor", ASME J. Eng. Gas Turbines Power, Vol. 120, pp. 303-310.

Steinbach, C., Ruck, T., Lloyd, J., Jansohn, P., Dobbeling, K., and Sattelmayer, T., (1998), “ABB's Advanced EV Burner- A Dual Fuel Dry Low NOx Burner for Stationary Gas Turbines.” ASME (98-GT)519.

Stowe, R. A., (2001), "Performance Prediction of a Ducted Rocket Combustor." Ph.D. Thesis, Laval University, Quebec, Canada.

Su, K., and C. Q. Zhou, (2000), "Parametric Studies of Gas Turbine Combustion NOx Emissions Using KIVA with A Reduced Mechanism". FACT-Vol. 23/HTDVol. 367, Combustion, Fire, and Computational Modeling of Industrial Combustion Systems ASME. 
Su, L. K., and Clemens, N. T., (1999), "Planar Measurements of the Three Dimensional Scalar Dissipation Rate in Gas Phase Turbulent Flows", Experiments in . Fluids, Vol. 27, pp. 507-521.

Su, L. K., and Clemens, N. T., (1998), "The Structure of the Three-Dimensional Scalar Gradient in Gas-Phase Planar Turbulent Jets ", $36^{\text {th }}$ Aerospace Sciences Meeting and Exhibit, January 12-15, AIAA 98-0429, Reno, NV.

Sullivan, J. D. and McDougald, (2001), "Low NOx Gas Turbine Combustors for Distributed Power Generation", Final report prepared by Alzeta Corporation for The California Energy Commission, Available on the web at http://eisg.sdsu.edu/Far/99-13\%20Final\%20Report.pdf.

Sumrerng, J., and Somjetlertcharoen, A., (1999), "Multimode Heat Transfer in Cyclic Flow Reversal Combustion in a Porous Medium", International Journal Energy Research, Vol. 23, (3), March.

Syred, N., and Beer, J. M., (1974), "Combustion in Swirling Flows: A Review", Combustion and Flame, Vol. 23, pp. 143-201.

Takase, K., Furukawa, H. and Nakano, K., (2002), "A preliminary Study of an InterCooled and Recuperative Micro-gas-turbine Below $300 \mathrm{kW",} \mathrm{ASME} \mathrm{Turbo}$ Expo 2002, GT-2002-30403, June 3-6, Amsterdam, The Netherlands.

Takeno, T. and Sato, K., (1979), "An Excess Enthalpy Flame Theory," Combustion Science Technology, Vol. 20, pp. 73-84.

Tavoularis, S., (2001), "Measurement in Fluid Mechanics", Class Notes, Mech. Eng. Dept., University of Ottawa, Ontario, Canada.

Tavoularis, S., (2005), "Measurement in Fluid Mechanics", First Edition, Cambridge University Press.

Thiery, L., J. Prenel, R. Porcar, (1996), "Theoretical and experimental intensity analysis of Laser Light Sheets for Flow Visualization." Optics Communications, Vol. 123, pp 801-809.

Thorndyke, S. and Rybchuk, R. (2001): "Combustion Gas Analysis at Honeywell Microturbine", Canadian ORTECH Environment Inc., Report \# 20296, Mississauga, Canada. 
Tong, T. W. and Sathe, S. B., (1991) "Heat Transfer Characteristics of Porous Radiant Burners." Journal of Heat Transfer, Transactions of the ASME 113 (2), pp. 423-428.

Treece, B., Vessa, P., Mckeirnan, R., 2002, "Micro-Turbine Recuperator Manufacturing and Operating Experience", ASME Turbo Expo 2002, GT2002-30404, June 3-6, Amsterdam, The Netherlands.

Tseng, Chung-Jen and Chia-Hsin Li, (2001) "Thermally-Enhanced Combustion in a Porous Medium Burner." Journal of the Chinese Society of Mechanical Engineers, Vol. 22, No.3, pp. 217-224.

Tseng Chung-Jen and Howell, J. R., (1996). "Combustion of Liquid Fuels in Porous Radiant Burner." Combust. Sci. and Tech., Vol. 112, pp. 141-161.

Turek, L. J., Chaos, M., Dawson, R. W., Chen, R. H., (2005), "An Investigation of the Effect of Swirl Vane Angle on Fuel Concentration and Velocity Fields Gas Turbine Mixers", GT2005-68152, ASME Turbo Expo: Power for Land, Sea and Air, Reno-Tahoe, Nevada, USA.

Turns, S. R. (2000). "An Introduction to combustion: Concepts and Applications", Second Edition, New York: McGraw- Hill.

USA Dept. of Energy, (2005), Project profiles, pacific region, Application Center, US Department of Energy. $\{$ http://www.chpcenterpr.org/PRACL:brary/ProjectProfiles/index.aspx/\}.

Utamura Motoaki Kirikami, (1998). "Combined-Cycle Power Generation Plant, Including a Gas Turbine, an Annual Exhaust Gas Channel Having Swirl Suppression Vanes and a Heat Recovery Boiler", USA Patent 5,791,136.

Vetterick, R. C., (1995) "HRSG Boiler Design With Air Staging and Gas Reburn", United State Patent 5,461,853.

Vetterick, R. C., John V. Koslosky, Bekhart K. (1999) "Distributive Integral gas Burner", USA Patent 5,961,321.

Viskanta, R. and Menguc, M. P., (1987) "Radiation Heat Transfer in Combustion Systems." Prog. Energy Combust. Sci. Vol.13. pp. 97-160.

Vranos, A, D.S. Liscinsky, B. True And Holdeman, J. D., (1991), "Experimental Study of Cross-Stream Mixing in a Cylindrical Duct", AIAA-91-2459. 
Watkins, C., Sadun, A., Marenka, S., (1993), "Modern Image Processing: Warping, Morphing, and Classical Techniques", Academic Press Professional, UK.

Weinberg, F. J. (1971). “Combustion Temperatures: The Future?” Nature, Vol. 233, pp. 239-241.

Weinberg, F. J. (1986), "Combustion in Heat-Recirculating Burners." Int. Fluid J. Weinberg (Ed.), Advanced Combustion Methods: pp. 183-236, Academic Press.

Weslag, B. P., Miller, Paul F. (1999), "Method and Apparatus for Improving Gas Flow In Heat Recovery System Generators" USA Patent 5,946,901.

White, F. M., (1994), "Fluid Mechanics", $3^{\text {rd }}$ edition, McGraw-Hill, Inc., New York.

Williams, A., Pourkashanian, M., Jones, J. M., and Rowlands L., (1994), "A Review of NOx Formation and Reduction Mechanisms in Combustion Systems with Particular Reference to Coal." Published by the Institute of Energy, Elsevier Science Ltd.

William, B., (1996), "Fundamentals of Gas Turbines", Second Edition, John Wiley and Sons, Inc, New York.

Willis, J. D. Toon, I. J. Schweiger, T. and Owen, D. A. (1993). "Industerial RB211 Dry Low Emission Combustion." ASME (93-GT) 391.

Xiong, T. Y., Viskanta, R., (1992), "Basic Study of a Porous-Matrix CombustorHeater", PD-Vol. 39, Fossil Fuels Combustion ASME.

Yegian, D. T., and Cheng, R. K., (1998), "Development of a Lean Premixed Low Swirl Burner for Low NOx Practical Applications", Combustion Science and Technology, 139, pp. 207-227.

Yimer, I., and Campbell, I., (2002). "Parametric Study to Optimize Air/Fuel Mixing for Lean, Premix Combustion system." Proceedings of the International Joint Power Generation Conference. ASME, Phoenix, Arizona, USA, (IJPGC200226086).

Zeldovich, Y. B., Sadovnikov, P. Y. and Frank-Kamenetskii, Y. A. (1947) "Oxidation of Nitrogen in Combustion." translated by M. Shelef, Academy of Science of the USSR. Moscow. 
Zhdanok, S. A., Dobrego, K. V., Futko, S. I., (1998) "Flame Localization inside AxisSymmetric Cylindrical and Spherical Porous Media Burners." International Journal of Heat and Mass Transfer, 41, pp.3647-3655.

Zhou, X. Y. and Pereira, J. C. F., (1997), "Numerical Study of Combustion and PollutantsFormation in Inert Non-Homogeneous Porous Media." Combust. Sci. and Tech. 130 (1-6), 335-364.

Zhou, X. Y., and Pereira, J. C. F., (1998). "Comparison of Four Combustion Models for Simulating the Premixed Combustion in Inert Porous Media." Fire and Materials, 22, pp.187-197.

Zhuang, J., and Leuckel, W., (1998), "A Modified Two-sensor-method for the Measurement of High Gas Temperature Facing Surroundings with Different Surface Temperatures", Combustion Science and Technology, Vol. 139, pp. 229-247. 


\section{APPENDIX A: General principles of NOx formation}

\section{A.1 Introduction}

Because of increasingly strong emissions control regulations, one major focus in combustion technology is the formation of nitrogen oxides or NOx in combustion processes. An important issue for all combustion systems is the development of efficient systems capable of minimal production of toxic emissions. In particular, reductions in the oxides of nitrogen are necessary to control smog, acid rain, ozone depletion, and greenhouse effect warming [Jones (1978) and Bowman (1992)]. NOx

emissions are generated by combustion systems where nitrogen and oxygen are present within a locally high temperature region. The abbreviation NOx is chemical shorthand for the combined species of $\mathrm{NO}$ and $\mathrm{NO}_{2}$. Many researches have been devoted to understanding the mechanisms that affect NOx emissions in laminar and turbulent flames. Miller and Bowman (1989) have provided a comprehensive review of NOx formation mechanisms.

\section{A.2 NOx formation mechanisms}

NOx can be formed through five different mechanisms. Four of the mechanisms are the routes responsible for NOx formation in the combustion of fuels that do not contain nitrogen compounds (thermal NOx, Prompt NOx, mechanism of $\mathrm{NOx}$ via $\mathrm{N}_{2} \mathrm{O}$ and mechanism of $\mathrm{NOx}$ via $\mathrm{NNH}$ route). The four mechanisms are illustrated in Figure A.1. The fifth NOx formation mechanism is the chemical or fuel NOx. For more details on this topic refer to Kuo Kenneth (2005). 


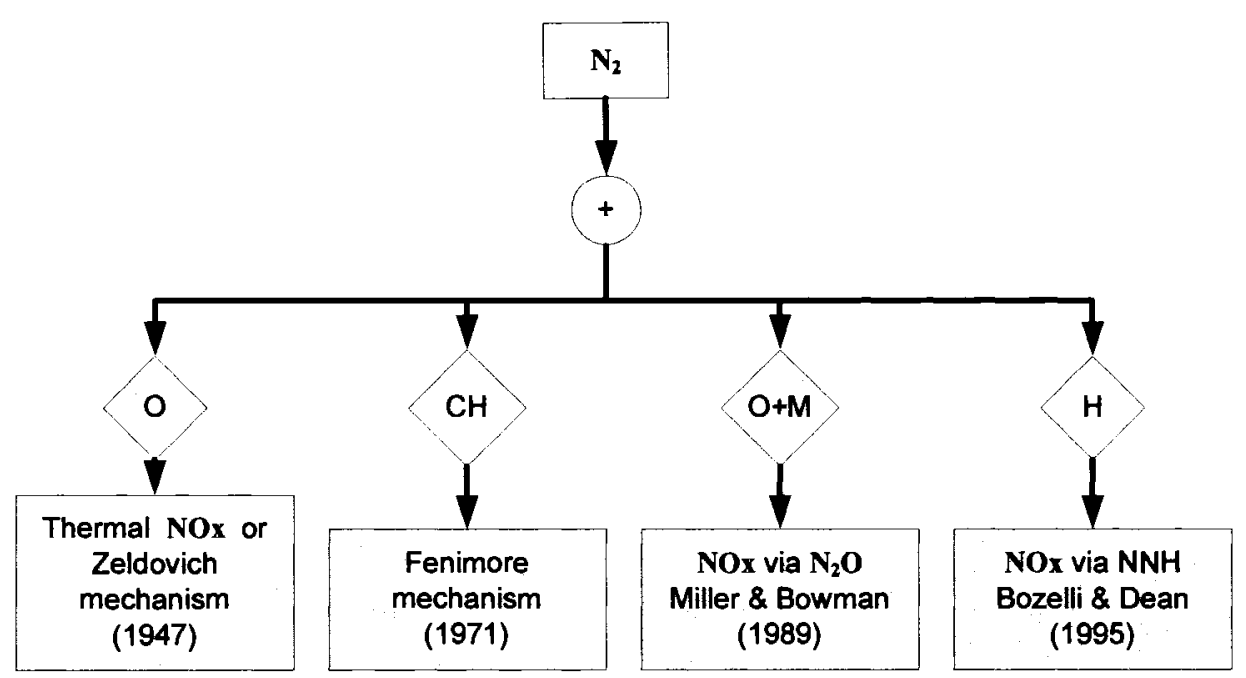

Figure A.1: Illustration of reactions responsible for NOx formation under combustion conditions (repeated from Chapter 2)

\section{A.2.1 Thermal NOx}

Thermal NOx is produced by the high-temperature reaction of the oxygen and nitrogen presents in air. Zeldovich et al. (1947) originally introduced a mechanism for modeling the thermal NOx and the mechanism is presented by the two following principle reactions:

$$
\begin{aligned}
& \mathrm{O}+\mathrm{N}_{2} \Leftrightarrow \mathrm{NO}+\mathrm{N} \\
& \mathrm{N}+\mathrm{O}_{2} \Leftrightarrow \mathrm{NO}+\mathrm{O}
\end{aligned}
$$

Usually the following reaction was added to the Zeldovich mechanism to make it an extended Zeldovich mechanism [Turns (2000), Glassman (1977)].

$$
N+O H \Leftrightarrow N O+H
$$

Equation (A.1) represents the rate-determining step of the extended Zeldovich mechanism and the activation energy associated with this reaction $(319,050 \mathrm{~kJ} / \mathrm{kmol})$ prohibits significant production of NOx at temperature below approximately $1800 \mathrm{~K}$ [Turns 2000]. Above this temperature, the Zeldovich mechanism produces NOx in a manner that exponentially increases with temperature. Thermal NOx production is 
dependent primarily on three variables within the combustion process, local temperature, local oxygen concentration and residence time. The reduction of the flame temperature can be performed in different ways, such as; flue gas recirculation, the dilution with "inert" gas such as; nitrogen or water, divide one large flame into several smaller flames, premixed, radiant surface combustion or lean-premixed combustion [Prabir et al. (1999)]

\section{A.2.2 Prompt mechanism}

Fenimore (1971) first who discovered the prompt mechanism to explain the fast formation of NOx within the flame zone of laminar premixed flames and is believed to be an exclusive characteristic of hydrocarbon combustion. This type of NOx formation occurs in fuel rich (equivalence ratio greater than roughly 1.2) environments and is associated with short flame residence times. The maximum Fenimore NOx concentration is observed near equivalence ratio of 1.4 [Pillier et al. (2005)]. By this mechanism, various hydrocarbon radicals resulting from fuel fragmentation [Drake and Blint (1991)] react with atmospheric nitrogen to form cyano species $(\mathrm{CN}$ and $\mathrm{HCN})$ and monatomic nitrogen. The Fenimore mechanism is shown below [Turns (2000)]:

$$
\begin{aligned}
\mathrm{CH}+\mathrm{N}_{2} & \Leftrightarrow H C N+N \\
\mathrm{C}+\mathrm{N}_{2} & \Leftrightarrow \mathrm{CN}+\mathrm{N}
\end{aligned}
$$

For equivalence ratio less than 1.2, Turns (2000) states the sequence of conversion of hydrogen cyanide, $\mathrm{HCN}$, to form NOx by the following reactions:

$$
\begin{aligned}
H C N+O & \Leftrightarrow N C O+H \\
N C O+H & \Leftrightarrow N H+C O \\
N H+H & \Leftrightarrow N+H_{2} \\
N+O H & \Leftrightarrow N O+H
\end{aligned}
$$

For richer mixture the chemistry becomes much more complex [Glarborg et al. (1986), Miller and Bowman (1989) and Nicol et al. (1992)]. 


\section{A.2.3 $\quad \mathrm{N}_{2} \mathrm{O}$ mechanism}

$\mathrm{N}_{2} \mathrm{O}$ mechanism involves formation of $\mathrm{N}_{2} \mathrm{O}$ and its conversion to NO. This mechanism usually presents in fuel-lean, low temperature and elevated pressures conditions. The 3 steps of this mechanism are:

$$
\begin{gathered}
N_{2}+O+M \Leftrightarrow N_{2} O+M \\
N_{2} O+H \Leftrightarrow N O+N H \\
N_{2} O+O \Leftrightarrow N O+N O
\end{gathered}
$$

The contribution of this mechanism, usually negligible in comparison with those from the Zeldovich and Fenimore routes [Miller and Bowman (1989)].

\section{A.2.4 NNH mechanism}

The fourth route responsible for NOx formation in the combustion process of a non-nitrogen compounds fuel is the $\mathrm{NNH}$ mechanism. The $\mathrm{N}_{2} \mathrm{H}(\mathrm{NNH})$ mechanism is proposed by Bozelli and Dean (1995), in which NOx is formed from the oxidation of NNH radicals. The following reactions present the mechanism:

$$
\begin{gathered}
N_{2}+H \Leftrightarrow N N H \\
N N H+O \Leftrightarrow N O+N H
\end{gathered}
$$

This mechanism was suggested to be the dominant source of NOx production in low temperature fuel-rich premixed hydrogen air flames, where the contribution from Zeldovich is suppressed [Bozelli and Dean (1995) and Steele et al. (1998)].

\section{A.2.5 Fuel-bound mechanism}

The fuel-bound NOx mechanism produced as a result of fuel-bound atomic nitrogen (N) species in the so-called dirty fuels [Flanagan et al. (1992)]. Coal is an 
example of fuel that contains nitrogen in its molecular structure. The nitrogen atoms bound to the fuel molecules can decompose during combustion to form intermediate products, which can react to form NOx as following [Glassman (1977)]

$$
\begin{gathered}
\mathrm{CN}+\mathrm{O} \Leftrightarrow \mathrm{C}+\mathrm{NO} \\
\mathrm{NH}+\mathrm{O}_{2} \Leftrightarrow \mathrm{NO}+\mathrm{OH}
\end{gathered}
$$

As the nitrogen content of the fuel increases, the amount of NOx produced also raises. Stoichiometry and flame temperature are the most important factors relating the fractional conversion of fuel-nitrogen to NOx, although of course the temperature dependence is significantly reduced in case of fuel-lean combustion [Williams et al. 1994]. Production of NOx from fuel-bound nitrogen mechanism can be greatly limited by the proper choice of fuel. In case of methane fuel, this mechanism is completely eliminated.

\section{A.3 Parameters affecting NOx formation}

In this section, the factors affecting NOx formation is presented with a short literature review covering those factors. To achieve NOx emissions standards, a good understanding to the effects of all parameters affecting the production of NOx is needed. These parameters in general include fuel type, flame temperature, equivalence ratio, residence time, inlet pressure and temperature, the degree of fueloxidant premixing and mixing within the combustion [Flanagan et al. (1992)].

The effect of fuel type, flame temperature and equivalence ratio on NOx has been mentioned in the previous section. Fuel type is one of the factors affecting NOx formation in any combustion system. As stated in the previous section, the fuel which contains no bound nitrogen in its molecular structure, such as natural gas (NG), will produce less NOx than that which has bound nitrogen in its molecular structure. Comparing N.G with other fuels, it has lower pollutant emissions, satisfactory supply source and burns homogeneously. During the combustion process in the NG combustion systems the fuel and air are premixed before entering the combustor so 
the combustion occurs at local fuel-lean and lower temperature which leads to a reduction in NOx. Gas turbines and low NOx burners nowadays operate leanpremixed because leaning out the fuel-air mixture at a uniform ratio reduces the flame temperature, therefore NOx formation. Heywood (1988) studied the effect of fuel-air equivalence ratio on NOx emissions. The major drawback for operating a fuel-lean is the combustion instability, which results in flame blow-off, increased flame oscillation and noise.

The effect of combustion residence time depends on the overall operating equivalence ratio. In gas turbine near stoichiometric combustion, NOx is easily produced in the post-flame gases where the influence of combustor residence time is very significant [Drake and Blint (1991)]. Jones (1978) studied experimentally the effect of residence time on the production of NOx in a premixed propane-air gas turbine combustor, for different equivalence ratios $(0.4,0.5$ and 0.6). Under fuel-lean conditions, NOx is produced by relatively fast reaction in the flame zone. So, achieving lower NOx in this condition needs long residence times and in case of rich combustion needs shorter reactor times.

The impact of inlet temperature on NOx formation results from the effect on combustion temperature, and therefore depends upon the operating equivalence ratio. The NOx production mechanisms, which dominate in the flame zone in case of lean combustion, are less sensitive to the inlet temperature changes. It is not the case for near stoichiometric combustion, where the extended Zeldovich mechanism is dominant in the flame zone, resulting in significant sensitivity to inlet temperature changes (due to the non linear temperature influence of the mechanism). Figure A.2 (modified from Steele et al. (1995) shows the effect of combustion temperature on NOx formation for different published lean-premixed NG experimental combustors. Regardless of the differences, for any test results presented in Figure A.2), increasing temperature always causes an exponential increase in NOx formation 
Correa (1992) presented the effect of inlet pressure on NOx emissions, the results show that for stoichiometric combustion an increase in pressure will lead to a significant increase in flame temperature, and as the thermal NOx varies exponentially with temperature, NOx emissions will increase. As the equivalence ratios decreased from stoichiometric, the influence of pressure on NOx production is diminished. In another study by Leonard and Correa (1990), NOx emissions are found to be independent of the inlet pressure at specified equivalence ratio ranges. The results were performed from the measurements in a perforated plate burner. Figure A.2 also shows the effect of combustion pressure on NOx formation for some tested NG fired combustors performed by different researchers. Mongia et al. (1996) and Rutar et al. (1997) studied pressure trends versus unmixedness in the inlet fuel and air. They gave some explanation to the differing trends Figure A.2 shows regarding the effect of pressure. They reported that for perfectly premixed cases, NOx formation is independent of pressure, and NOx becomes positively dependent on pressure with increasing unmixedness (less mixing).

Su and Zhou (2000) presented a numerical study of effects of flow conditions parameters, including inlet temperature and pressure on NOx emissions in gas turbine combustion. In the study, the inlet pressure varied from 0.1 to $2 \mathrm{MPa}$ and the inlet temperature from 400 to $900 \mathrm{~K}$. NOx emissions showed a trend of monotone increase with respect to the inlet temperature, and as the inlet pressure increase, the emissions increase at the beginning and decrease after the maximum condition is reached. The overall fuel-air ratio range used in the study is 0.012 to 0.08 .

Many research efforts have been done to investigate the influence of incomplete fuel-air mixing (degree of premixing) on NOx formation. Appleton and Heywood (1973), Pompei and Heywood (1972) and Lyons (1982) showed that NOx emissions depend significantly on the homogeneity of unburned mixtures and on the characteristic of burned gas pockets in the combustion region. Maughan et al. (1992) studied the effects of the initial quality of gaseous fuel-air mixture on NOx 
production. A clear trend of reduced NOx with improved fuel distribution was recorded at lean equivalence ratios below 0.7. Also Mongia et al. (1996) and Rutar et al. (1997) as mentioned in the previous paragraph studied the effect of unmixedness on NOx formation. Therefore, rapid mixing increases mixture homogeneity and shortens the characteristic time for NOx formation. It is generally recognized that premixed combustion of lean homogeneous mixtures has the ability to achieve low levels of NOx emissions, even at high air temperatures [Hayashi (1983)]. However if the fuel and air enter the combustion zone partially premixed, richer and leaner pockets of reactants are formed and since NOx formation is an exponential function of temperature, the fuel rich pockets forms more NOx than the fuel-lean pockets which results in an overall lean flame with higher NOx values [Rutar et al. (1997)]

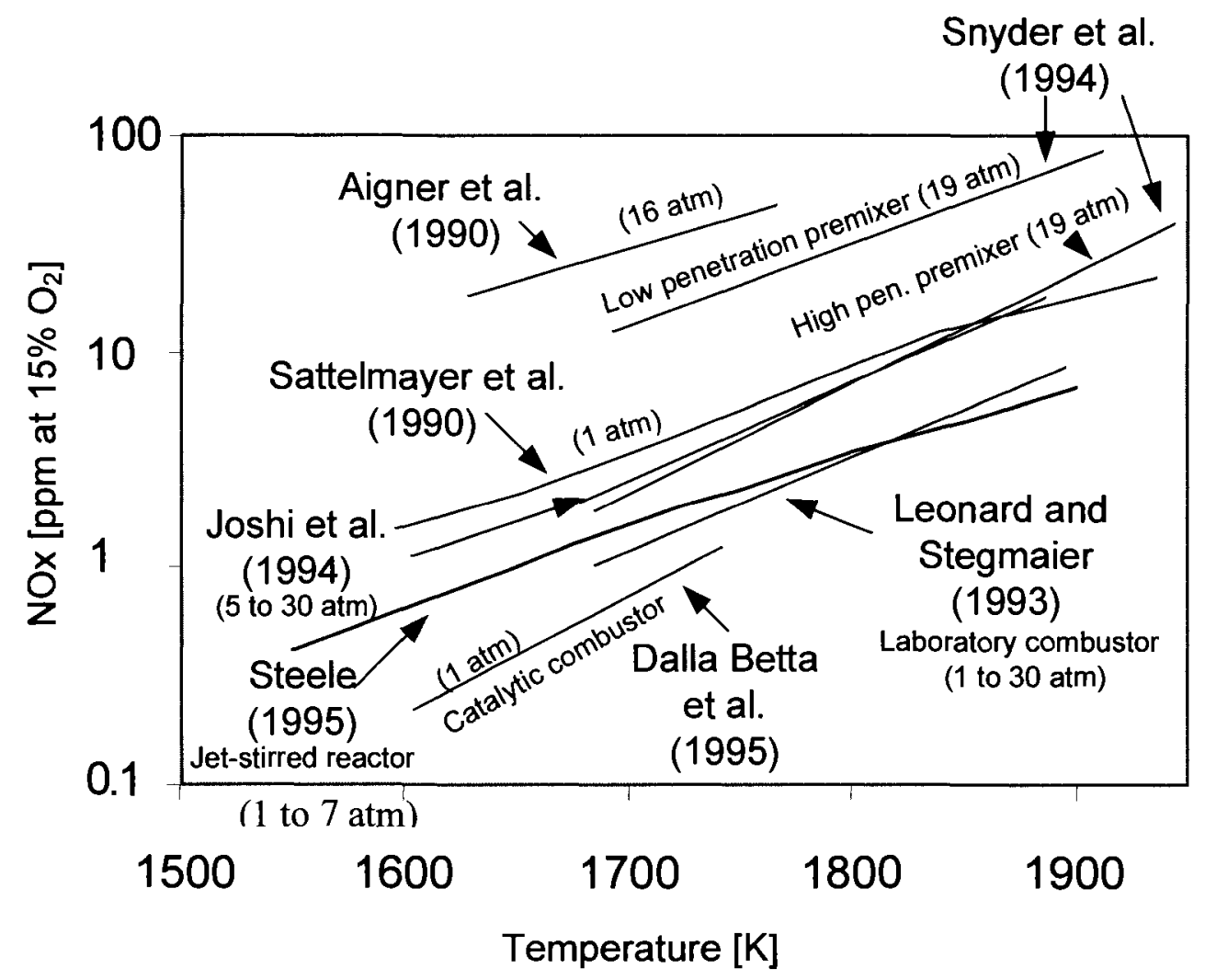

Figure A.2: Effect of temperature on NOx formation [modified from Steele, 1995] 
Different technique were used in the literature to improve the mixing process between fuel and air before introduce the mixture to the combustion region. Swirling flows have been widely used in many combustion systems (gas-turbine combustors, industrial or commercial burners) to increase fuel-air mixing and to improve flame stabilization. It has been shown that swirl can increase mixture homogeneity and reduces the characteristic time for NOx formation, leading to lower NOx emissions [Turns (1996)]. Alkabie and Andrews (1991) determined the influence of swirler design (vane angle, swirl number, for radial swirler) on flame stability, combustion efficiency and NOx emissions. Later Jeffery et al. (1995) studied the effect of swirl flow on NOx emissions. In their study they developed a burner configuration utilizing both swirl and bluff-body stabilization for dry low NOx combustion of natural fuel. They studied the effect of using swirler and its location with respect to the fuel injector, on the fuel-air mixing, flame stability, and NOx and CO emissions.

The strategy to reduce NOx emissions strictly depends on the type of burner used. In general, for gaseous fuels, low NOx production is primarily achieved through reducing the temperature and oxygen availability in the high-temperature regions. For example, when using the nozzle mix combustion technique, flue-gas recirculation, excess air and air or fuel staging are the primary techniques used. Choi and Katsuki (2000) provided a method to lower the emissions of nitric oxide from a regenerative furnace operated with highly preheated combustion air using the coupled effect of the high rate of exhaust gases recycling and combustion in low concentration of oxygen produces low-temperature flames in spite of high pre-heating of combustion air.

From different view point, in case of fully premixed burners, the attention is being concentrated on using fibre burners in which combustion take place close to the burner surface. The heat in this combustion technique is readily removed by means of either radiative or convective heat transfer, thus achieving a very lean flame, which means the combustion can occur at a lower temperatures resulting in low NOx emissions. 
Krill et al. (1985) used a fibre burner in fire-tube boiler (low pressure steam boiler used as a heating element for process heater in the petroleum industry). The work demonstrated the fibre burner benefits of increasing boiler efficiency and reducing NOx and $\mathrm{CO}$ emissions. They reported that NOx emissions were reduced by 80 percent with $\mathrm{CO}$ and $\mathrm{CH}$ emissions of the same levels as those from the conventional burners used in the same applications. Traditional porous surface radiant burners in the beginning of the nineties, operate in the (10 to 20 percent) excess air range produces emissions below $20 \mathrm{ppm}$ (air free) NOx and CO. Marshall et al. (1991) reported that NOx and CO emissions can be significantly reduced for a direct fired heating system using high excess air gas-fired radiant burner. They build a hot air system based on the inward-fired Pyrocore burner operating near 100 percent excess air, which results in NOx and $\mathrm{CO}$ emissions below $1 \mathrm{ppm}$ in the vitiated air stream (unlike conventional flame burners, NOx emissions from radiant burners decreases with increasing excess air).

Saracco et al. (1996) studied the performance of a metal (FeCralloy) and a ceramic $(\mathrm{SiC})$ premixed fibre burner and they reported in their study the effect of excess air and the specific thermal load (Q) on NOx, CO and HC emissions. The study covers the range of operation of the burners from the radiant mode to the blue flame mode. NOx emissions in the radiant mode are lower than those of the blue flame mode at low excess air. As concluded from the study, to get lower NOx emissions from the metal burner when operating in the blue flame mode, the burner should operates at a high firing rate and high excess air.

The drive to lower NOx, CO and UHC emissions in the radiant burners leads to increasing research in other areas like catalytic combustion. Catalytic combustion of natural gas is an alternative to conventional gas-phase combustion, which produces hot gases at a lower temperature and therefore lower (or near zero) pollutant emissions of NOx, CO and UHC [Moallemi et al. (1999), Dupont et al. (2000) and Cerri et al. (2000)]. In addition to the catalytic combustion concept, Moallemi et al. 
(1999) used a swirler located downstream of the fuel injector to create turbulence in the flow to improve fuel-air mixing before entering the catalyst matrix. Also Dupont et al. (2000) used specially designed fuel and air injection system using of two swirlers (one for the air, the other for the fuel), radial fuel injectors in addition to twoflow straightners, to achieve a high degree of mixedness and uniformity of the gas velocity over the whole catalyst cross-section.

In the present work, the mesh burner under investigation was fuelled with methane; therefore thermal NOx is our major concern. The effective method to reduce the thermal NOx is to lower the flame temperature in the combustion region. Aiming to achieve very low NOx emissions a surface combustion technique by means of conical mesh burner was utilized in the presented study. The burner was operated in the blue flame which leads to increase the heat content of the exhaust gases. Also the burner utilized the lean-premixed combustion concept. Swirling flow concept was used to improve the mixing process in the premixer burner of this work. Different types of static mixers were investigated in this study aiming to get a perfect mixing for the duct burner used. 


\section{APPENDIX B: General Radiant Burner Review}

\section{B.1 . Introduction}

Because the surface combustion technique adopted in the present work by means of the wire-mesh burner, which generally belongs to the radiant porous burners, a literature review, which covers those types of burners will be presented. The Appendix starts with a section covers the principles of excess enthalpy combustion then all the key references regarding experimental work on gas porous radiant burners (specially the wire-mesh type of burners) are cited and summarized. Most of the studies were accompanied with analytical or numerical modeling. Only few analytical studies that cover different geometries other than flat burner will be mentioned in this review. Catalytic combustion burners were not reviewed in the present work. Only few papers were reviewed because they use the non-catalytic wire-mesh burners for comparisons.

\section{B.2. Excess enthalpy combustion}

Weinberg (1971) first introduced the idea of re-circulating heat energy from hot products to cold reactants by heat exchange without any direct mixing. The recirculating heat was used to increase temperature in the reaction zone above that of the normal flame temperature that a particular mixture can produce. This fact was proven experimentally using a fused silica burner that presents heat exchanger between the products of combustion and reactants gases. This combustion concept is named excess enthalpy combustion. Figure B.1 (taken from Weinberg (1971)) shows how the excess enthalpy may be re-circulated in a burner system. Hardesty and Weinberg (1974 and 1976) showed theoretically using simple first and second law analyses that this process has the advantages of extending the lean flammability limit and can achieve high reaction rates, leading to higher flame speed than that for open 
flames of similar composition, increase the combustion efficiency and reduce NOx and $\mathrm{CO}$ emissions. All those advantages are due to the internal feedback of heat energy. There are many techniques, which use different heat transfer mechanisms to re-circulate the product enthalpy to the preheat zone. A detailed review of the excess enthalpy combustion and different transport schemes can be found in Weinberg (1986).
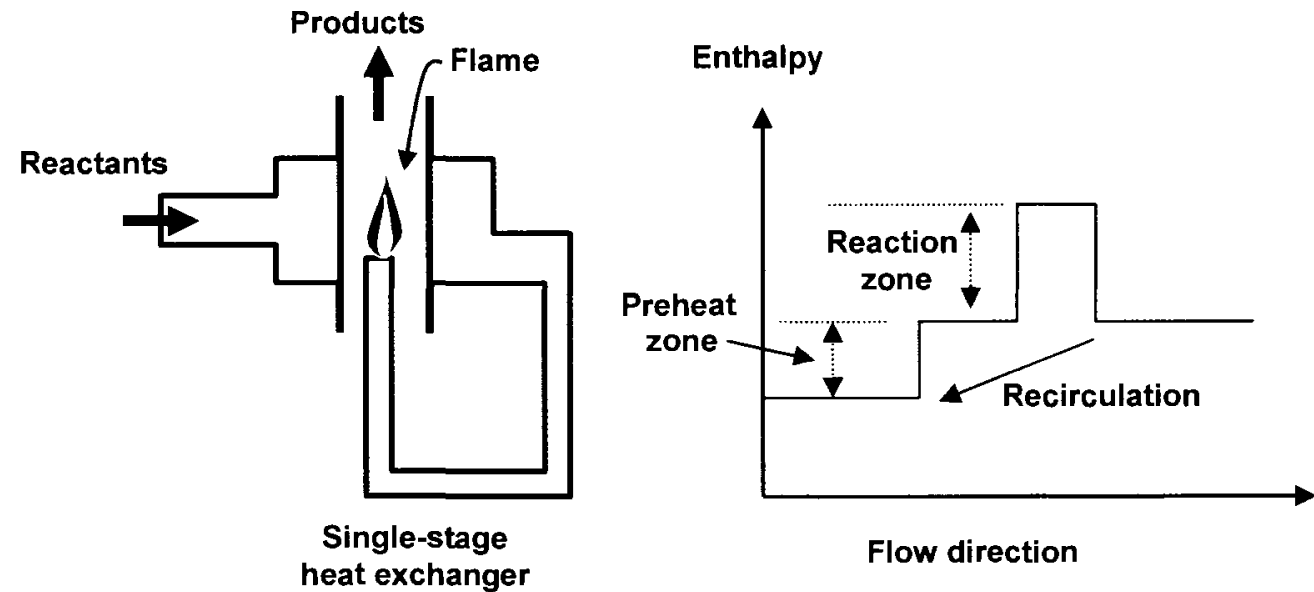

Figure B.1: Principle of excess enthalpy flame [Weinberg (1971)]

\section{B.3. Porous burners}

Takeno and Sato (1979) first proposed inserting a porous, highly conductive solid into the flame to re-circulate the heat energy and aid in preheating the incoming fresh mixture. In porous medium the recirculation of the excess enthalpy occurs through both conduction and radiation. The solid matrix (porous inert media) introduced upstream of the reaction zone is heated by the radiation emitted from the matrix in the reaction zone and post reaction zone and by conduction through the solid matrix. As the fresh mixture pass through this region and before entering the reaction zone, heat is transferred from the radiatively heated solid matrix to the fresh 
mixture through convection. Due to the relatively small emissivity of the gas, only a small amount of radiative heat transferred to the gas Therefore, the convective heat transfer mechanism is dominant. The idea of excess enthalpy combustion or burning associated with heat exchangers has diverse applications in the industry. Kotani and Takeno (1982) experimentally investigated the stability of combustion using excess enthalpy combustion technique. Their experimental apparatus contained a bundle of ceramic tubes sandwiched between ceramic plates containing holes. They reported that the flame could actually be stabilized in three zones, upstream and downstream of the tube bundle, while only over a narrow equivalence ratio range (0.35-0.4) a stable combustion within the tube were achieved. NOx and CO emissions of were reduced clearly when the flame was stabilized inside the tubes. Also they reported about the large increase in the flame speed due to heat recirculation process. The peak flame temperature reported was more than twice the adiabatic flame temperature at equivalence ratios around 0.18 using city gas, which is also due to the circulation of heat. In the mentioned study the authors did not include the radiative heat transfer in their model, the solid matrix was assumed to have infinite thermal conductivity and the way that chemical reaction rates were modeled made their analyses used only for qualitative trends.

Min and Shin (1991) studied experimentally (and theoretically) the leanpremixed flame inside a honeycomb ceramic of 75 percent porosity. The excess enthalpy flames were reported and the results showed extension in the ranges of flammability and flame stability compared to the corresponding free flame. Golombok et al. (1991) used Fecralloy metal fibre of porosity of 80 percent in their study where they obtained stable surface flames with firing rate in the range 100$700 \mathrm{~kW} / \mathrm{m}^{2}$. Xiong and Viskanta (1992) performed an experimental and numerical study to investigate the convective-radiative heat transfer and its interaction with the combustion process in a porous medium. Experimentally they reported high combustion intensity, $310 \mathrm{~kW} / \mathrm{m}^{2}$ heat transfer rate, high density of energy conversion, in addition to the ultra-low emissions (NOx and $\mathrm{CO}$ ) have been achieved. They 
showed the effect of excess air, firing rate on thermal efficiency, and NOx and CO emissions. Also they investigated the pressure drop through the burner, combustion stability and flame location for a range of operating parameters.

Bartz et al. (1992) described a design and an operating characteristic of an inward-fired radiant burner that uses ceramic as solid matrix. In their paper they present the preliminary laboratory results and field tests. The effects of excess air and surface firing rate on NOx emissions were reported. Ultra-low emissions of NOx emissions (5 to $10 \mathrm{ppm}$ ) and $\mathrm{CO}$ emissions (less than $30 \mathrm{ppm}$ ) were achieved. Another experimental and numerical study of the performance of pours media burners were carried out by Hus et al. (1993a). The lean limits for three different pore size burners were determined. The burners tested over the range of lean limit $(0.41<\phi \leq$ $0.68)$, but for the numerical simulation the range is $(0.43<\phi \leq 1.0)$. Their results demonstrated that porous ceramic burners provide a range of stable burning rates at a constant equivalence ratio Also the maximum flame speed inside the burners was much higher compared to the free flame speed and the lean limits were reported lower than that in free flame combustion.

Khanna et al. (1994) experimentally investigated the emissions and radiation output for methane-air combustion within a porous medium burner for various equivalence ratios $(0.6,0.65,0.7,0.75,0.8$ and 0.85$)$ and flow rates. The burner used was similar to the one used in the above-mentioned study by Hus et al. (1993a). The burner was insulated to minimize radial heat losses. They reported that NOx and CO emissions increased with increasing equivalence ratio, the actual and theoretical radiant (theoretical value was obtained by assuming that all thermal losses were due to radiation at exit plane of the burner) output increases with the flame speed and the radiant thermal efficiency of the burner decrease with increasing the flame speed.

Tseng and Howell (1996) performed an experimental and numerical investigation of the combustion of a liquid fuel within porous inert medium. Effects of various parameters on the burner performance are studied. In their experiment they 
used a pressurized atomizing nozzle that aspirated liquid fuel in to the high pressure flow stream, and then mixed the resulting spray with a secondary air flow to control equivalence ratio. The authors concluded that the burning rate were much higher than the free burning flame due to the excess enthalpy recirculated to the preheat region. The mechanism also caused a peak flame temperature higher than the adiabatic free flame temperature for equivalence ratio $\leq 0.76$. For heptane fuel the flame in their burner can sustain combustion as lean as equivalence ratio $=0.3$. The introduction of a liquid spray causes the gas stream temperature about $10 \mathrm{~K}$ and the flame speed to decrease about 2 to $4 \mathrm{~cm} / \mathrm{s}$. CO emissions from the burner were very low $(<10 \mathrm{ppm})$ and NOx emissions are approximately $20 \mathrm{ppm}$. As a result of the increased exit solid temperature, the radiant energy output increases with equivalence ratio.

Saracco et al. (1996) tested two different fibre burners in view of their application in domestic boilers (metallic (FeCralloy) and a ceramic (SiC)). The performance of those burners was discussed and compared. The transition from flameless combustion to the blue flame combustion was analyzed. The effect of firing rate and the percentage of excess air on flue gas temperature and emissions (NOx, CO and UHC) were reported. They concluded that, NOx emissions when the burners operated in the radiant mode are lower than those of the blue flame mode at lower firing rates, the surface area required for the $\mathrm{SiC}$ burner is 35 to 45 percent higher than that needed for the metal (FeCralloy) to operate in radiant mode, When operating at low firing rates the metal burner has comparatively high $\mathrm{CO}$ and $\mathrm{HC}$ emissions, and the pressure drop across the $\mathrm{SiC}$ is acceptable at all the operating conditions while for the metallic burner is too high.

Sumrerng and Somjetlertcharoen (1999) presented results of an experimental and numerical study of the combustion in a porous medium, with and without a cyclic flow reversal of a mixture through a porous medium. This study offers a new method for burning extremely low calorific gaseous fuels. The experiments were conducted to obtain preliminary experimental data and to further physical understanding of the 
combustion regime. They also performed a theoretical analysis to investigate the effect of various operating parameters of the cyclic flow reversal combustion. It was shown that, for maximizing the flame temperature and the net radiative heat flux feedback, the flame should stabilized near the centre of the porous medium with a cycle flow reversal, the period of which should be as small as possible. Self-sustained combustion was reported at the minimum equivalence ratio of $\phi=0.25$ for a typical liquefied petroleum gas fuel.

Saracco et al. (1999) studied the performances of three different premixed fibre burners made of the same FeCrAlloy porous support (one non-catalytic burner and two catalytically active). The three burners were tested in a pilot plant of maximum total power $(30 \mathrm{~kW})$, and the flue gas temperature, NOx, CO, UHC flue gas concentration and emissions intensity of the panel surface were measured as a function of excess air and specific heat power. Besides the operating regimes (radiant, transition and blue flame) were identified by direct observation of the burner surface. As compared to the non-catalytic burner, the two catalytic ones enabled, with nearly unchanged NOx production, up to about 5 times lower $\mathrm{CO}$ and $\mathrm{HC}$ emissions, particularly in the radiant combustion regime. The radiant regime for both the catalytic burners establishes, for excess air less than 30 percent at firing rate values $\left(600-900 \mathrm{~kW} / \mathrm{m}^{2}\right)$ lower than those for the non-catalytic one $\left(600-1500 \mathrm{~kW} / \mathrm{m}^{2}\right)$.

Moallemi et al. (1999) performed an experimental and numerical study carried out on palladium- and platinum-based catalytic monoliths used as methane combustors for heating purposes. Their paper studied the effects of operating conditions on combustion, heat transfer efficiency and pollutant formation. The range of equivalence ratios used (0.3-0.6). A swirler is used in their design to improve mixing of the fuel and air upstream of monolith.

Brenner et al. (2000) conducted an experimental and numerical investigation to study the combustion process within porous medium. The study aimed to evaluate the performance of a numerical model. The experimental and computational results 
show the model to be capable of predicting overall trends, including the effects of equivalence ratio, power variation and material properties.

Sullivan and McDougald (2001) presented Alzeta Corporation Gas Turbine Semi-radiant Burner (GTSB). This product was designed for microturbine applications. They reported that they manufactured and tested the first prototype of the GTSB. They obtained simultaneous low NOx and CO emissions (less than 5 ppm for NOx and less than $10 \mathrm{ppm}$ for $\mathrm{CO}$, at 15 percent $\mathrm{O}_{2}$ ) at every tested pressure from 1 to 12 atmospheres. Less than $1 \mathrm{ppm}$ for both NOx and $\mathrm{CO}$ were reported at various times through their testing. Their burner has a cylindrical configuration (outwardfired) which composed from a layer (1 to $4 \mathrm{~mm}$ thick) of compressed and sintered metal fibres with 80 to 90 percent porosity. In their report they stated that the porous medium used has demonstrated remarkable capability as a flame holder minimizing the occurrence of burner flashback.

Cho, et al. (2001) investigated experimentally the effect of fuel on the variation of surface combustion performance. It has been found that the flame speed of the fuel affects the surface loads showing the upper limit of the radiant mode and the peak temperature of the mat. Different gases fuels can be used with metallic fibre burners but the optimal operating conditions varied from fuel to fuel. In their study the different modes of operation were defended by direct observation of the flame.

Tseng C. et al. (2001) investigated experimentally the stability limits of a small-scale porous medium burner made of stacked stainless steel 304 wire mesh having 86 percent porosity. Flame speed, flame temperature, heat release and emissions are reported. They found that at an equivalence ratio of 0.6 the flame speed of methane in the burner is approximately 1.4 to 4.2 times the flame speed in free combustion and the flammability limits extended to equivalence ratio of 0.4 which is less than the normal lean limit (0.54). NOx emissions were very low (1 to $2 \mathrm{ppm}$ ) due to the low temperature, but $\mathrm{CO}$ emissions are very high. They attributed that to the 
oxidization of the stainless steel wire mesh (which contains about 0.08 percent carbon) at high temperature.

Cerri et al. (2001) compared the performance of two catalytic burners $\left(\mathrm{LaMnO}_{3}+17 \mathrm{MgO}\right.$ and $\left.\mathrm{LaMnO}_{3}\right)$ with a non-catalytic burner as a fucntion of specific power input and an excess air. The non-catalytic burner is made from FeCrAl alloy (NIT 100s by ACOTECH) flat panel made from a fine metal fibre $\left(10 \times 20 \mathrm{~mm}^{2}\right.$ and 2 $\mathrm{mm}$ thick). The surface area of the flat burner used was $160 \mathrm{~mm}$ wide and $250 \mathrm{~mm}$ long. The mat porosity of about 85 percent was used. An extremely low pressure drop was measured across the wire-mesh mat used (from 0.02 in $\mathrm{H}_{2} \mathrm{O}$ at $500 \mathrm{~kW} / \mathrm{m}^{2}$ to 0.12 in $\mathrm{H}_{2} \mathrm{O}$ at $5000 \mathrm{~kW} / \mathrm{m}^{2}$ ). For the three burners tested at a constant excess air value, the blue flame mode rules at higher specific power values while the radiant one at low specific power values. At all the range of operating conditions used, NOx emissions are not affected by the presence of the catalysts. At specific power less than $380 \mathrm{~kW} / \mathrm{m}^{2}$ and excess air less than 15 percent (low specific power and low excess air) $\mathrm{CO}$ emissions reduced by the presence of the catalyst. They reported that the noncatalytic burner produces very high $\mathrm{CO}$ emissions (more than $100 \mathrm{ppmv}$ ).

Leonardi et al. (2002) performed an experimental study on a metal fibre burner with two flame support pad layers (single and double). The experimental data covered a range of firing rates from 170 to $340 \mathrm{~kW} / \mathrm{m}^{2}$ and three equivalence ratios $(0.9,1.0$ and 1.1). The variation of the burner surface temperature, radiation efficiency and the combined (radiation and convection) or total efficiency as a fucntion of firing rates at the different equivalence ratios were reported. Their results show that the surface temperature of the burner increases as the firing rate increases, the same result reported for the exhaust gases temperature. The burner with double layer flame support pad showed higher temperatures than the single layer pad in both temperature measurements (gas and solid). The efficiencies showed independency on the firing rate at higher values (more than $225 \mathrm{~kW} / \mathrm{m}^{2}$ ), also the radiation and the total 
efficiencies for the double layer pad were about 5 percent higher than in the single layer flame support pad.

Mohamed (2002) introduced a mathematical model and simulation results for axial and radial flow burners (cylindrical shape). Preliminary results of the comparison between the thermal performances between the mentioned burners are discussed. The results showed that the cylindrical burner has a wide range stability limits. For the same flow rate and heat release, the peak temperature for axial flow burners is higher than that of radial flow burner and that will lead the radial flow burner to produce less NOx emissions.

Luan Yongwei, (2003) investigated the performance of a radiant heater burner utilizing both experimental tests and Computational Fluid Dynamics modeling. The porous medium of the burner used in this work was made from Silica and Alumina. This porous medium is $275.8 \mathrm{~mm}$ wide, $132.1 \mathrm{~mm}$ long and $11.8 \mathrm{~mm}$ thick. During their experimental work, burner surface temperature, pollutant level and over all efficiency data were measured. Flame stability and the lean limit at different firing rates $\left(20-120 \mathrm{~kW} / \mathrm{m}^{2}\right.$, for surface combustion mode and $240-800 \mathrm{kw} / \mathrm{m}^{2}$, for matrix-stabilized flame) and equivalence ratio were determined. For the lean limit the author reported that for surface combustion a lower limit of 0.2 , while for the matrix stabilize mode the lean limit was 0.6. The transition between the two flame modes occurred at firing rate of 120 and $160 \mathrm{~kW} / \mathrm{m}^{2}$. The author reported that at the transition mode the flame and the surface temperatures do not increase accordingly when firing rate is increased. When comparing the two modes of operation (matrix and surface stabilize flame) the author reported that the surface combustion mode demonstrates a wider firing range and lower lean limit which leads to less NOx production.

Barra and Ellzey (2003) conducted an experimental study in which they studied the dominant heat transfer processes responsible for heat recirculation. For different equivalence ratios they determined the effective flame speed and total heat 
release rate. In addition, the importance of various heat transfer mechanisms was discussed. During the study they used burners of different lengths

Qiu and Hayden (2005) investigated the stability of premixed gas combustion in ceramic fibre felt. They designed and constructed a new recuperative radiant burner for use as a gas-fired light source. The burner has a circular cross-section with porous emitter of $110 \mathrm{~mm}$ in diameter, $16 \mathrm{~mm}$ thick and approximately $0.28 \mathrm{~kg} / \mathrm{m}^{2}$ density. The authors investigated the combustion performance (flame structure, stability and combustion modes) of the burner at various operating conditions and the effect of heat recuperation.

They reported that a very stable flame was attained within or near the exit of the porous medium over a wide range of firing rates $\left(16\right.$ to $\left.54.5 \mathrm{~W} / \mathrm{cm}^{2}\right)$ and excess air (10 to 50 percent). The authors also investigated the effect of varying the fibre diameter and the porosity on surface temperature. They reported that, the surface temperature remains unchanged with the variation of the fibre diameter but increasing porosity results in extensive increment of the surface temperature.

Specchia et al. (2006) performed a study in which comparisons were made between the performances of two different materials-based catalytic burners $\left(\mathrm{LaMnO}_{3} \cdot 2 \mathrm{ZrO} \mathrm{Z}_{2}\right.$ and $\left.\mathrm{Pd} / \mathrm{LaMnO}_{3} \cdot 2 \mathrm{ZrO}_{2}\right)$ with a non catalytic (wire-mesh) one. The authors performed similar study as Cerri et al. (2001) but with different catalytic burners aiming to develop a novel generation of catalytic premixed fibre burners for low-environmental-impact natural gas combustion. They recorded lower NOx and CO emissions over a wide field of operating conditions.

\section{B.4. Summary}

In conclusion, the combustion process in a porous medium is quite different from that which occurs in conventional free flame technology. In general the properties, which made the fully premixed fibre burners particularly attractive, compared to the conventional diffusive burners are: (1) lower combustion temperature 
and NOx emissions. (2) More compact design. (3) Flexibility in seting the burner inside the appliance since the flame is momentum-rather buoyancy-controlled (i.e. the burner can be fired upwards, downwards and sideways). (4) Lower air excess levels are tolerated, which allows higher thermal efficiency. (5) Capability of being shaped so it can fit any required geometry. (6) Uniform heat generation can be achieved over wide burner surfaces [Saracco et al. (1999)].

In the premixed burners the fuel mixed prior to combustion and then fed to the solid matrix. Depending on the porous medium properties and on operating conditions (specific input power and excess air), three different modes of operation can be established. If the flame stabilizes within the solid matrix, it is called radiant mode. If the flame completely stabilized over the solid matrix, the mode is called blue flame mode. The third mode called transition mod, where blue flames and radiant regions at different locations simultaneously cover the burner-mat. To achieve low $\mathrm{NOx}$ and $\mathrm{CO}$ emissions when operating in the blue flame mode, high firing rate and high excess air is recommended [Saracco et al. (1996), Mohamed (2002), Saracco et al. (1999), Isotta Cerri et al. (2000)]. Almost all the burners reviewed operated at a radiant mode, low firing rate and low excess air. The current premixed modulating burners usually work in restricted excess air range (15-25 percent) [Cerri et al. (2000)]. Introducing a swirler to the burner fuel-air mixing system was used (following the gas turbine combustor technology) in the recent burners only to improve the mixing process [Moallemi et al. (1999), Dupont et al. (2000)]. Most of the work is done (experimentally or numerically) on flat type porous burner, where the axial flow of gaseous fuel-air mixture forces through a layer of porous medium. From all the work reviewed only few papers, such as; Mohamed (2002) and Zhdanok et al. (1997) studied the cylindrical porous burners, in which the fuel-air mixture is forced to flow radially. Both studies presented numerical simulation results. As far as author's knowledge concerns, there is no analyze or experimental data is available on 
the conical mesh burner or even on the cylindrical burners, except those mentioned, in the open literature [e.g., Sullivan and McDougald (2001)]

In the present work, the conical mesh burner would be used in a duct burner integrated with the micro-cogeneration, CHP compact package, operating in the blue flame mode (the design based on high specific input power $2500 \mathrm{~kW} / \mathrm{m}^{2}$ and 100 percent excess air) and utilizing the lean premixed along with surface combustion concepts to achieve low NOx, $\mathrm{CO}$ and $\mathrm{UHC}$ emissions. 


\section{APPENDIX C: Calibration of the fluid flow instrumentation}

\section{C.1 Introduction}

Calibration is the process of comparing the response of an instrument to a standard instrument over some measurement range to eliminate large, known systematic errors and thus reduce the measurement uncertainty to some level. An overall system calibration was performed for all the components of the measuring system. The pitot-static tubes were the only devices calibrated separately using the existing Mechanical engineering department test rig located in room $2268 \mathrm{ME}$. $\mathrm{PX}^{2 \mathrm{i}}$ Digital calibrator from CRYSTAL Engineering Corporation with a pneumatic low pressure pump, from Ralston Instruments, model DP0V, were used for all the transducers calibration used in this study. Typical calibration curves for the pitotstatic tubes and the different pressure transducers used in this study are presented in this appendix.

\section{C.2 Pitot-static tube calibration}

The pitot-static tubes used in the present investigation were calibrated using a Mechanical Engineering department in-house rig used by different researchers in the department (Mahallati (2003) and Benner (2003)). Figure C.1 shows an approximate schematic view of the calibration rig. The apparatus consists of a radial vacuum blower, settling chamber, circular nozzle of $5.5 \mathrm{~cm}$ diameter, a bell-mouth and an air filter panels surrounds the air inlet section. The calibration apparatus was calibrated by Mahallati (2003) and Benner (2003). They presented detailed flow field measurements to characterize the jet flow in the calibration rig. The measurements show the present of large inviscid core of approximately $20 \mathrm{~mm}$ in diameter and good uniformity over the axial range of measurements. Also they stated that, the variation 
in total and static pressures within the inviscid core were $\pm 0.1 \%$ of the centreline dynamic pressure and the turbulence intensity was all most constant at $0.4 \pm 0.1 \%$ over the range of jet velocity from 1 to $45 \mathrm{~m} / \mathrm{sec}$. Based on the measurements they performed the pressure probes used in the present investigation, when calibrated, were placed within the jet core at approximately one nozzle diameter downstream of the nozzle exit plane. The pitot-static probes were calibrated over a range of jet velocity from 4 to $38 \mathrm{~m} / \mathrm{sec}$.

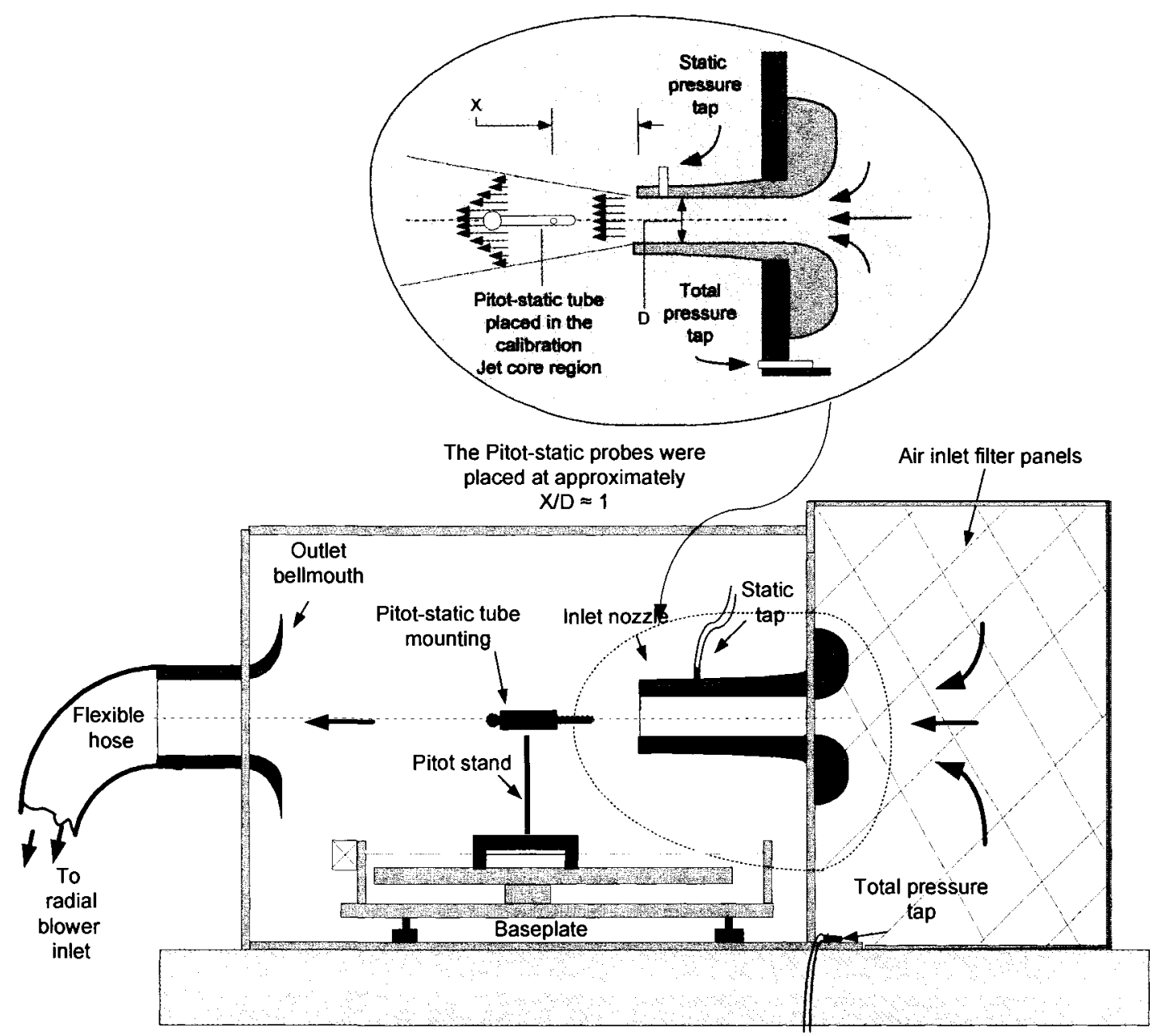

Figure C.1: Schematic of the pitot-static tube calibration rig 
Table C.1 presents the different types of pressure probes used in the present investigation. The table shows the main dimensions of the pressure probes with their calibration uncertainty. Typical calibration curves for the different pressure probes were presented in the figures starting from Figures C.2 to C.5. The numbers on the calibration curves which located above the trend-line present the increasing applied pressure and the numbers located below the trend-line present the decreasing applied pressure.

Table C.1: Pressure probes used in the flow balancing tests

\begin{tabular}{|c|c|c|c|c|c|}
\hline $\begin{array}{c}\text { Pitot- } \\
\text { static tube }\end{array}$ & $\begin{array}{c}\text { Type and } \\
\text { model }\end{array}$ & \multicolumn{2}{|c|}{$\begin{array}{c}\text { Probe diameter } \\
\text { cm (Inches) }\end{array}$} & $\begin{array}{c}\text { Probe } \\
\text { length } \\
\text { cm (Inches) }\end{array}$ & $\begin{array}{c}\text { Uncertainty } \\
\text { in using the } \\
\text { curve fit }\end{array}$ \\
\cline { 3 - 6 } & & OD & ID & $10.12(4)$ & $\pm 1.1 \%$ \\
\hline 1 & PCA-4-KL & $0.156(0.065)$ & $0.071(0.028)$ & $\pm 0.6 \%$ \\
\hline 2 & PCB-6-KL & $0.241(0.095)$ & $0.107(0.042)$ & $15.24(6)$ & $\pm 0.6 \%$ \\
\hline 3 & PCC-12-KL & $0.317(0.125)$ & $0.165(0.065)$ & $30.48(12)$ & $\pm 0.6 \%$ \\
\hline 4 & PCC-18-KL & $0.317(0.125)$ & $0.165(0.065)$ & $45.72(18)$ & $\pm 0.5 \%$ \\
\hline 5 & PCC-12-KL & $0.317(0.125)$ & $0.165(0.065)$ & $30.48(12)$ & $\pm 0.5 \%$ \\
\hline 6 & PCC-18-KL & $0.317(0.125)$ & $0.165(0.065)$ & $45.72(18)$ & $\pm 1 \%$ \\
\hline static tube & PSCA-8 & $0.317(0.125)$ & 0.165 & $20.32(8)$ & \\
\hline Material & & \multicolumn{3}{|c|}{ Stainless steel pressure probes } \\
\hline
\end{tabular}

Due to the hot environment where the pitot-static probes located, the calibration of some of the pressure probes was performed many times to correct for any change in the offset or the sensitivity of the pressure probes. The Least squares fit lines for two different calibrations are shown in Figures C.6. 


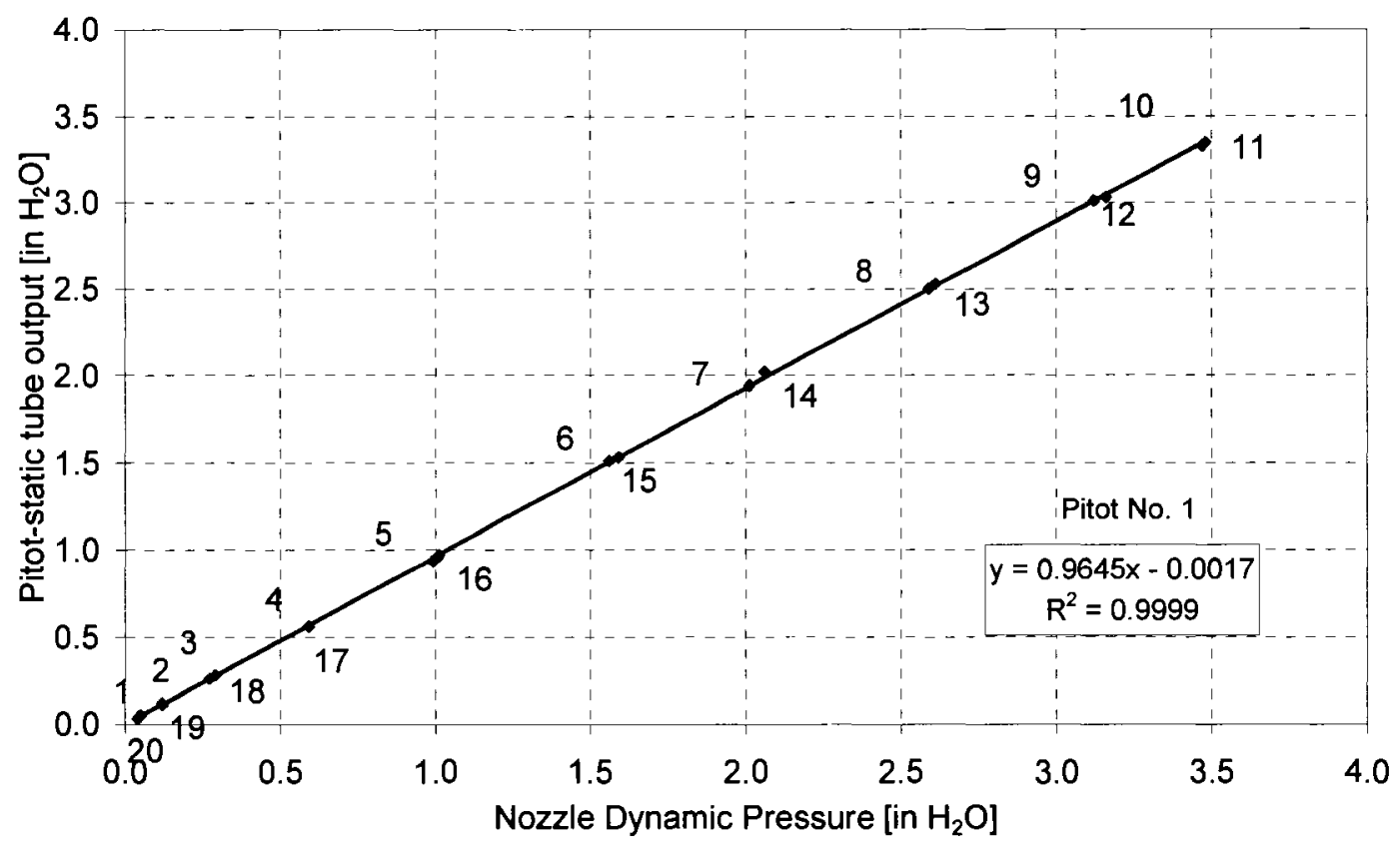

Figure C.2: Calibration curves for pitot-static tube 1

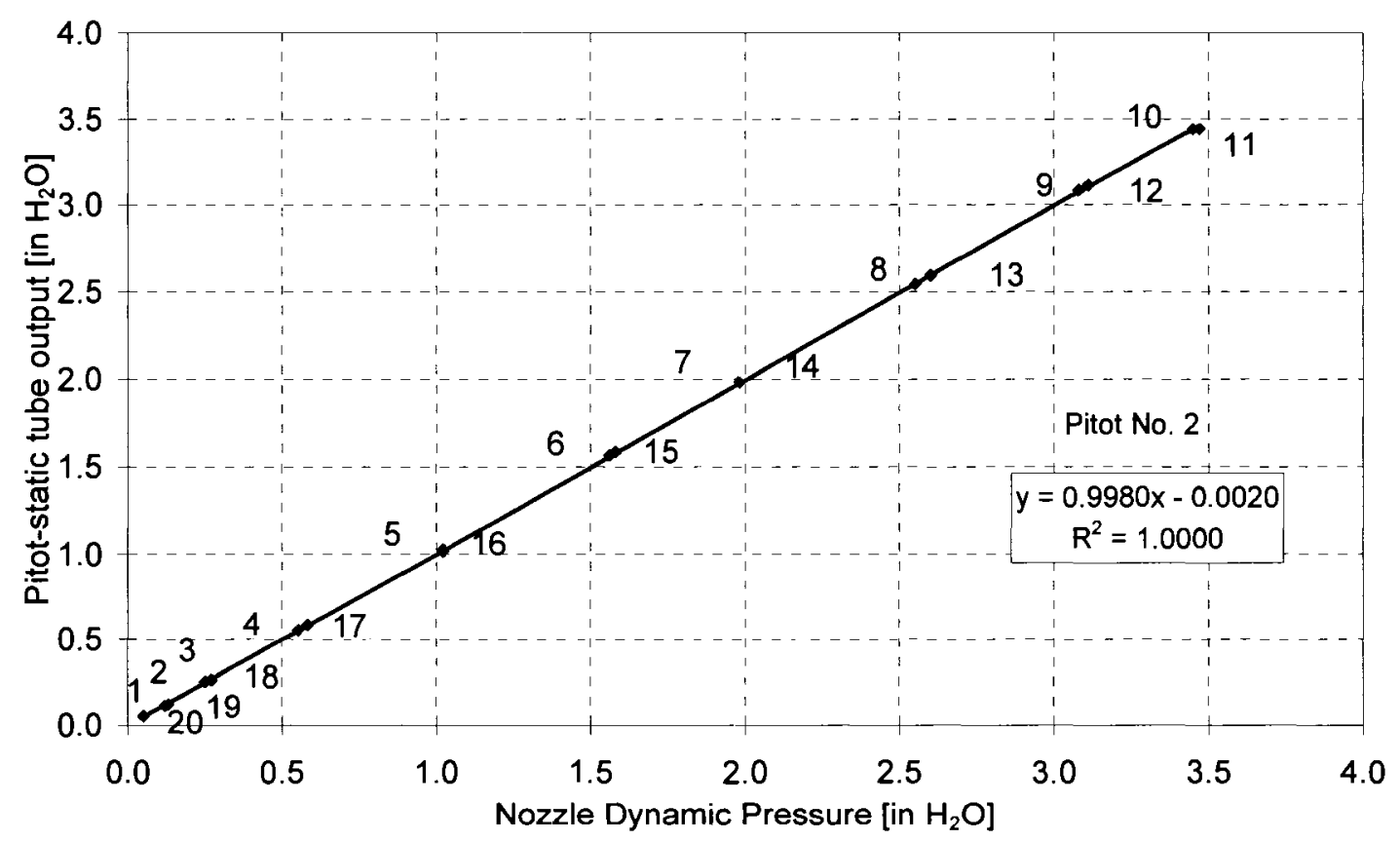

Figure C.3: Calibration curves for pitot-static tube No. 2 

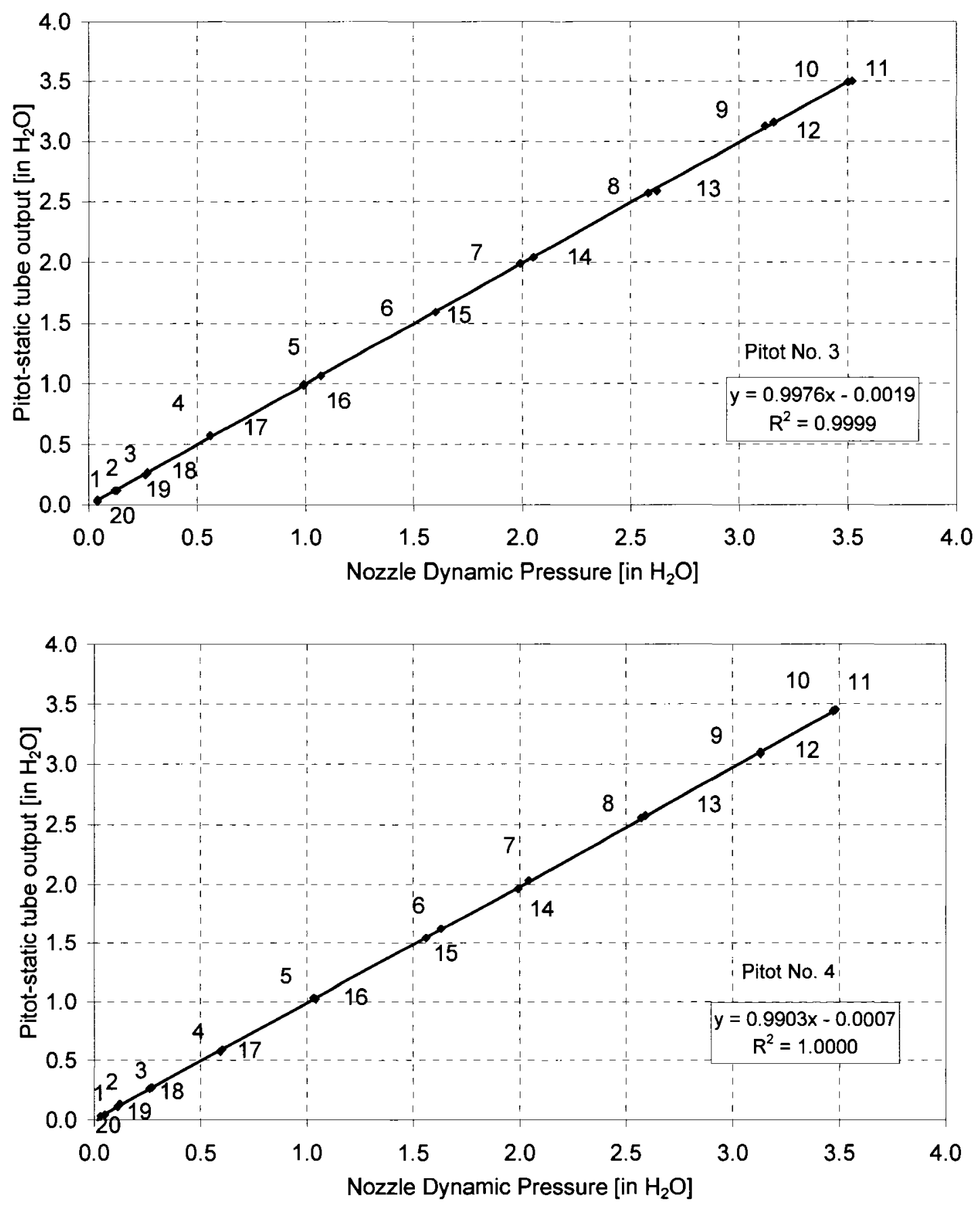

Figure C. 4: Calibration curves for pitot-static tubes 3 and 4 


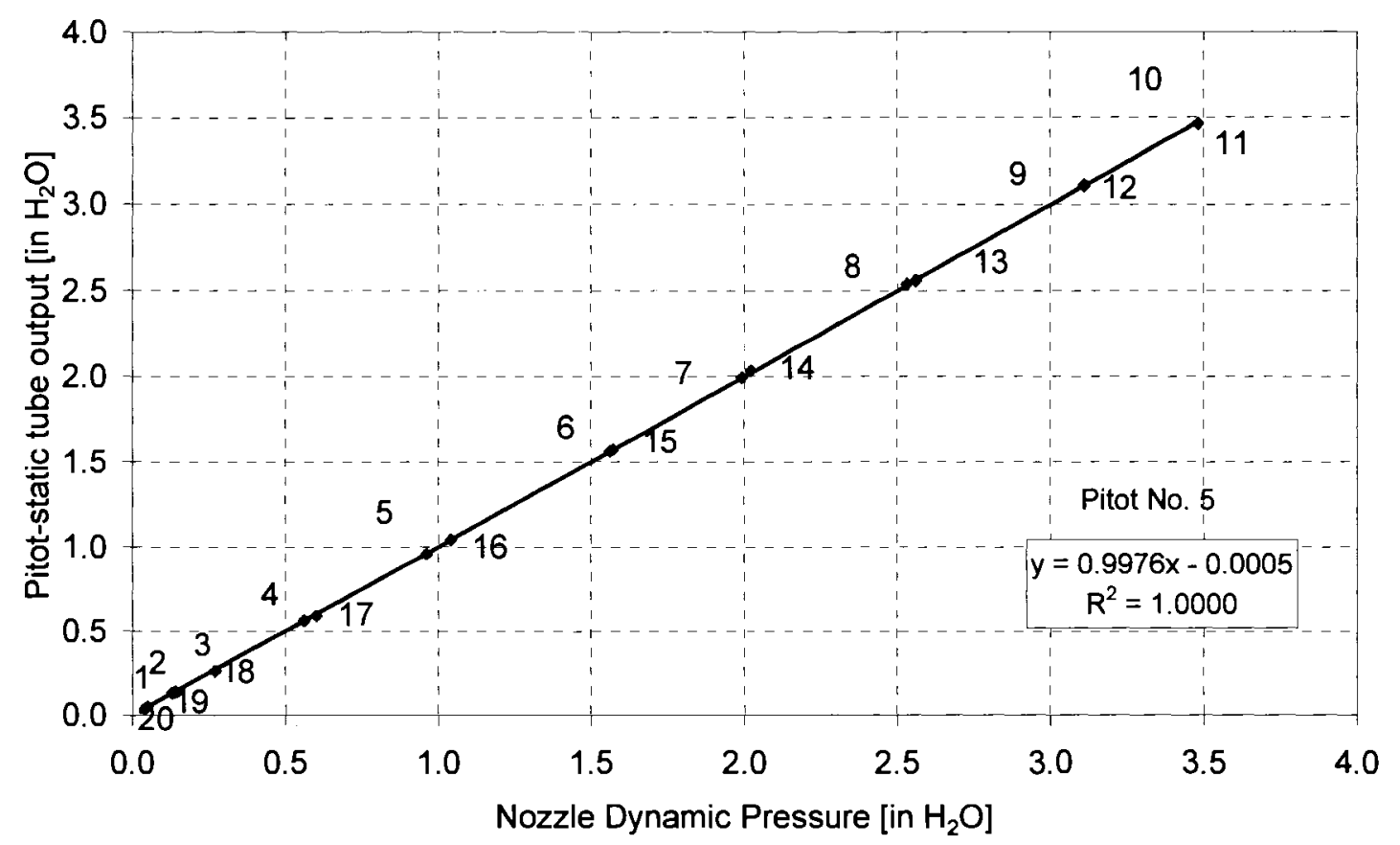

Figure C.5: Calibration curves for pitot-static tubes 4 and 5

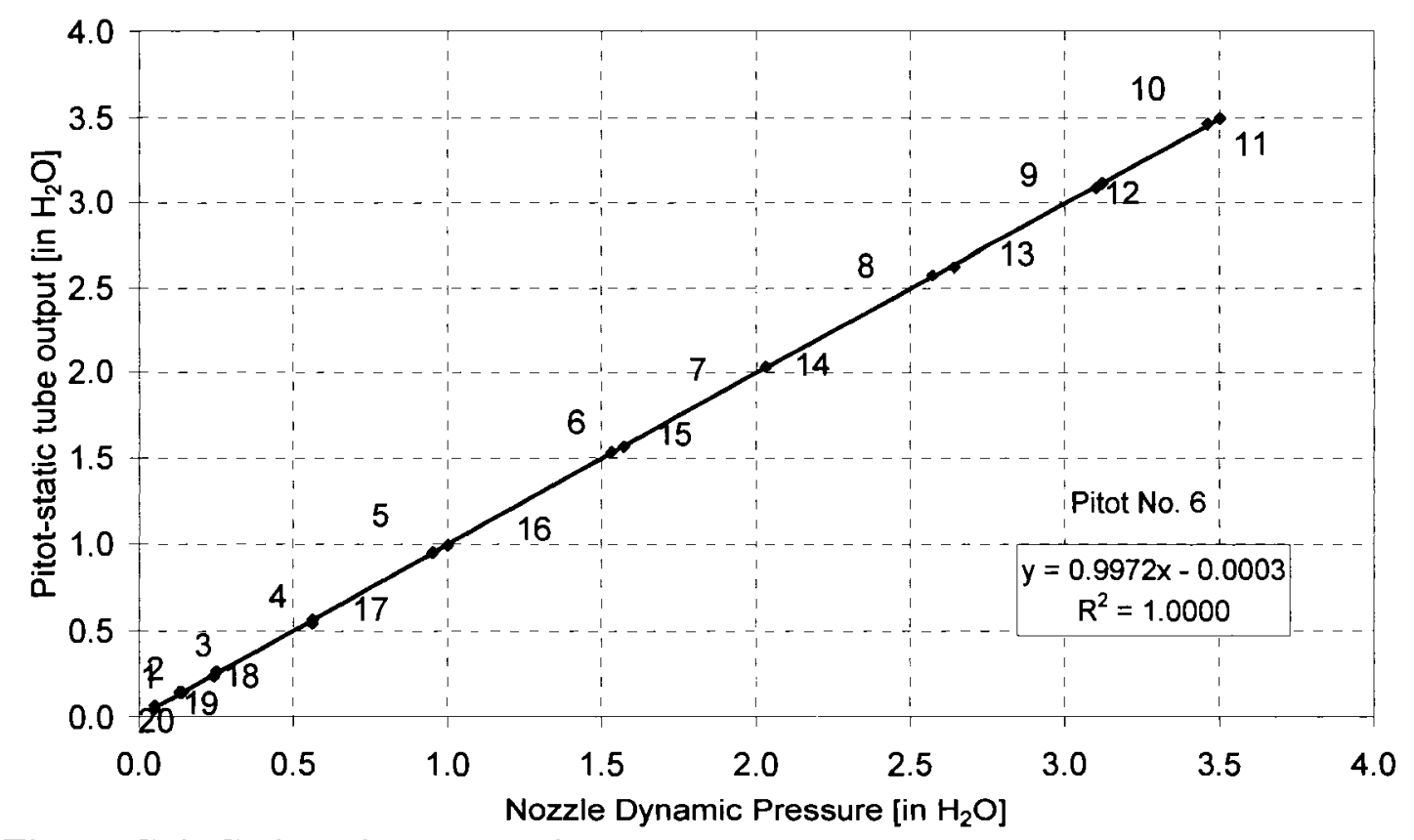

Figure C.6: Calibration curves for pitot-static tube No. 6. 


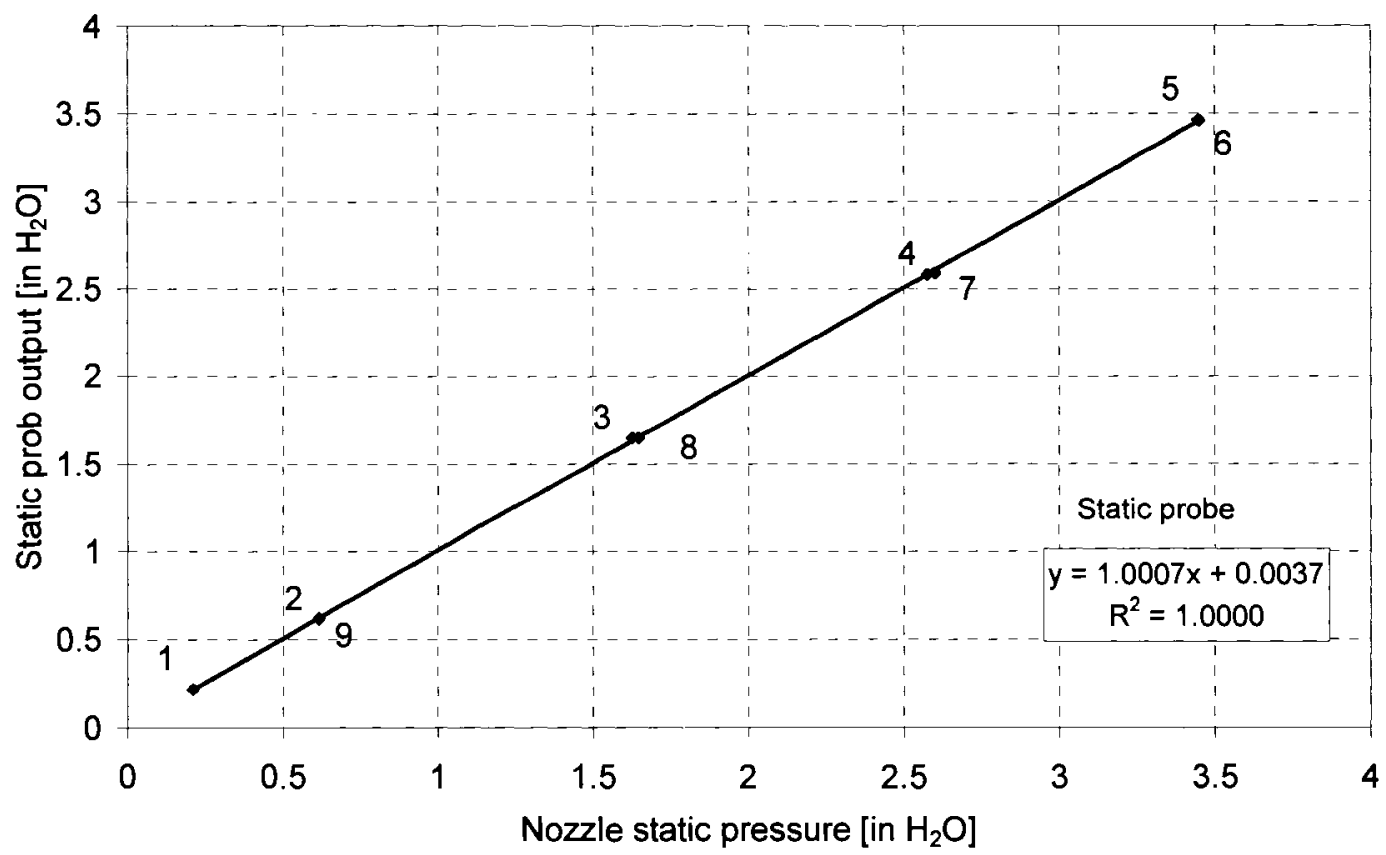

Figure C.7: Calibration curves for the static prob

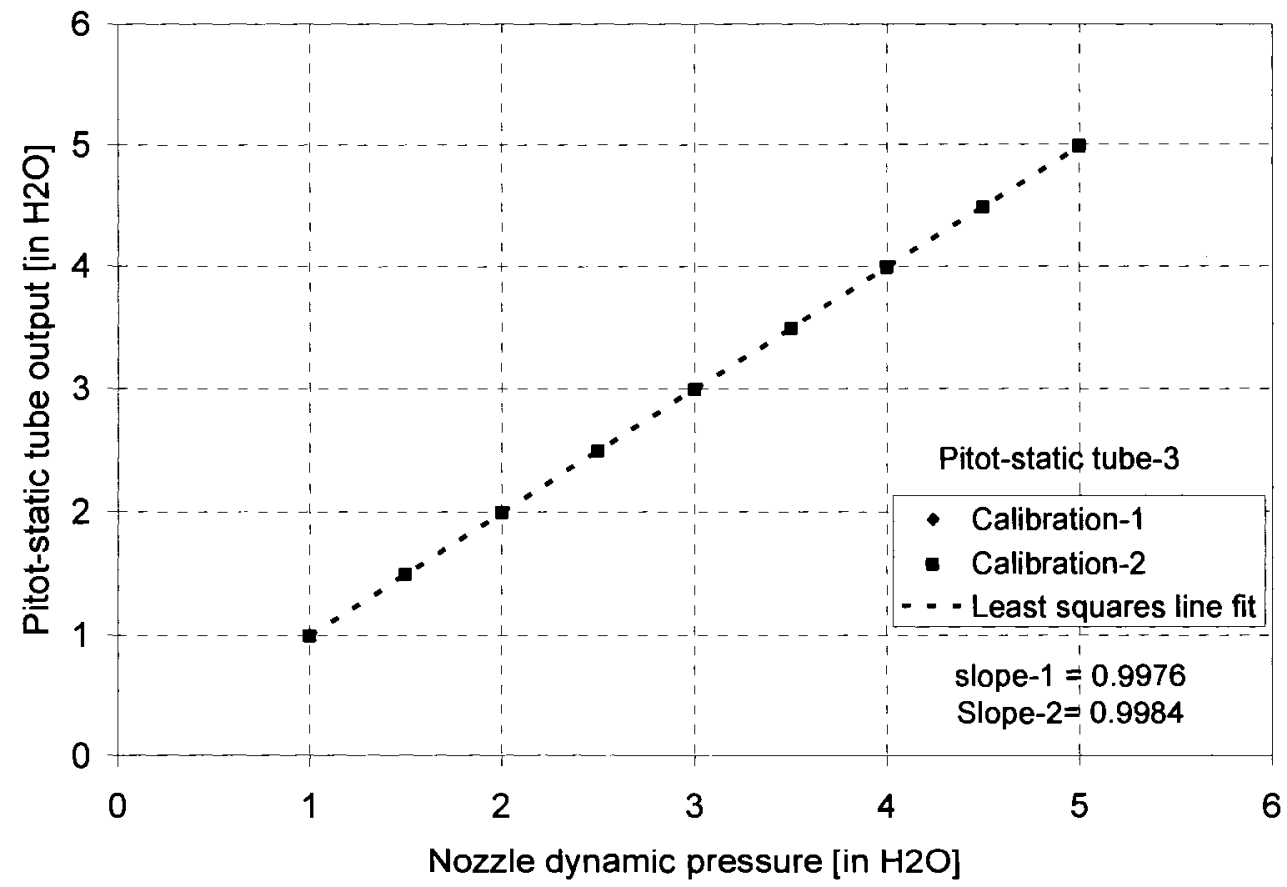

Figure C. 8: Repeated calibration curves for pitot-static tube No. 3 


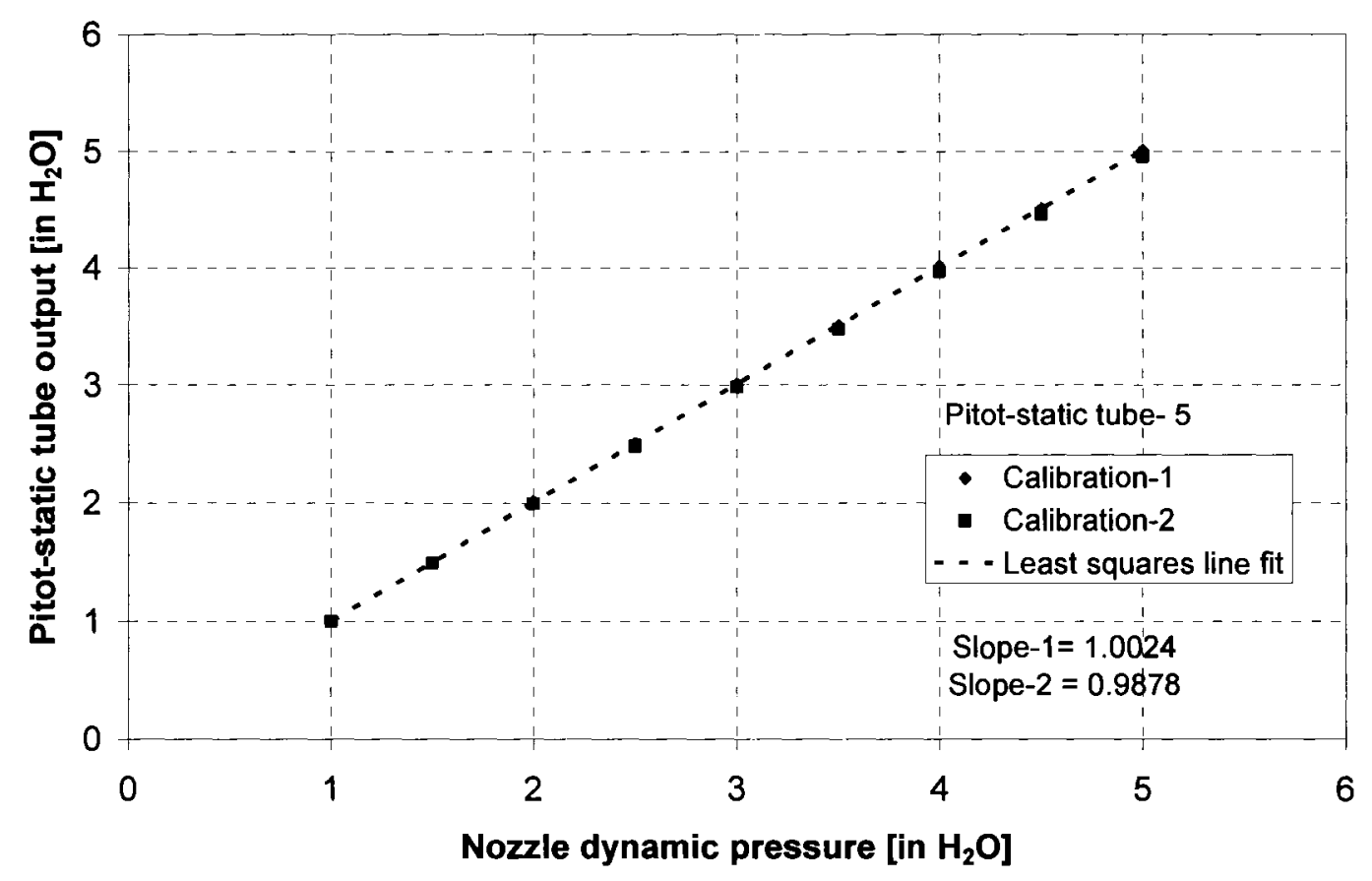

Figure C.9: Repeated calibration curves for pitot-static tube No.5

\section{C.3 Pressure transducer calibration}

The calibration curves for the pressure transducers used in the present investigation combined with the data acquisition system are presented in this section. The transducers were calibrated using a $\mathrm{PX}^{2 \mathrm{i}}$ Digital calibrator from CRYSTAL Engineering Corporation. The calibrations were performed before the experiments started, during and after the experimental period. Two pressures were applied to each transducer, a typical operating pressure and atmospheric pressure using the $\mathrm{PX}^{2 \mathrm{i}}$ digital calibrator (as pressure calibration reference). The pressure transducer readings were acquired through the data acquisition system. Overall system calibrations were performed by comparing input pressure values to the transducers with their measured results taken from the data acquisition system. All the calibration curves are shown in Figures C.7 to C.11.

The calibration was performed in a way that the ability of the transducer to give the same output when the same increasing and then decreasing pressures are 
applied consecutively was checked. The numbers on the calibration curves which located above the trend-line present the increasing applied pressure and the numbers located below the trend-line present the decreasing applied pressure. In all the figures presented in this appendix the following notation were used:

Measured pressure $=$ Combined pressure transducer and data acquisition Applied pressure $=$ standard pressure using the $\mathrm{PX}^{2 \mathrm{i}}$ calibrator .

General information about the transducers used in this study is listed in Table C.2. Due to the hot environment where the pressure transducers located, the calibration of the different transducers was performed many times to correct for any change in the offset or the sensitivity of the pressure transducers. The Least squares fit lines for three different calibrations represents each transducer is shown in Figures C.12 and C.13. Table C. 3 show the slopes of each transducer calibration curve. Table C. 4 presents the different types of pressure probes used in the present investigation along with their estimated uncertainty calculated by the procedure mentioned in Appendix D.

Table C.2: Identification data for the pressure transducers

\begin{tabular}{|c|c|c|c|}
\hline Transducer No. & Type and model & Range & Serial number \\
\hline 16 & Omega-PX277 & 0 to 5 in $\mathrm{H}_{2} \mathrm{O}$ & 71008 \\
\hline 17 & Omega-PX277 & 0 to 5 in $\mathrm{H}_{2} \mathrm{O}$ & 255439 \\
\hline 18 & Omega-PX277 & 0 to 5 in $\mathrm{H}_{2} \mathrm{O}$ & 71008 \\
\hline 19 & Omega-PX277 & 0 to 5 in $\mathrm{H}_{2} \mathrm{O}$ & 255136 \\
\hline 20 & Omega-PX277 & 0 to 5 in $\mathrm{H}_{2} \mathrm{O}$ & 71008 \\
\hline 21 & MKS-627B13TAC1B & 0 to 1000 Torr & 000874386 \\
\hline 22 & $\begin{array}{c}\text { MKS-220CD- } \\
\text { 00100A2B }\end{array}$ & 0 to 100 Torr & $92225203 \mathrm{~A}$ \\
\hline & $\begin{array}{c}\text { SITRANS P, Series } \\
\text { DSIII }\end{array}$ & 0 to 10 in $\mathrm{H}_{2} \mathrm{O}$ & N1-NO17-9350321 \\
& Model 7MF4433 & & \\
\hline
\end{tabular}


Table C.3: Temperature effect on transducer sensitivity

\begin{tabular}{|c|c|c|}
\hline Transducer number & Calibration number & Slope of the best fit line \\
\hline \multirow{4}{*}{ Tr-16 } & Cal-1 & 1.0109 \\
\cline { 2 - 3 } & Cal-2(2 months from first) & 1.0144 \\
\cline { 2 - 3 } & Cal-2(4 months from first) & 1.0115 \\
\hline \multirow{4}{*}{$\operatorname{Tr}-17$} & Cal-1 & 1.0118 \\
\cline { 2 - 3 } & Cal-2 & 1.0116 \\
\cline { 2 - 3 } & Cal-3 & 1.0134 \\
\hline \multirow{4}{*}{ Tr-18 } & Cal-1 & 1.0162 \\
\cline { 2 - 3 } & Cal-2 & 1.0169 \\
\cline { 2 - 3 } & Cal-3 & 1.0145 \\
\hline \multirow{4}{*}{ Tr-19 } & Cal-1 & 1.0069 \\
\cline { 2 - 3 } & Cal-2 & 1.0144 \\
\cline { 2 - 3 } & Cal-3 & 1.0024 \\
\hline \multirow{3}{*}{$\operatorname{Tr}-20$} & Cal-1 & 1.0139 \\
\cline { 2 - 3 } & Cal-2 & 1.0132 \\
\cline { 2 - 3 } & Cal-3 & 1.0092 \\
\hline
\end{tabular}

Table C.4: Uncertainty in the pressure transducer reading

\begin{tabular}{|c|c|c|}
\hline Transducer No. & $\begin{array}{c}\text { Accuracy } \\
\text { (manufacturer) }\end{array}$ & $\begin{array}{c}\text { Uncertainty } \\
\text { (Eq. D.18) }\end{array}$ \\
\hline 16 & $\pm 1 \%$ of Full scale & $\pm 1.1 \%$ \\
\hline 17 & $\pm 1 \%$ of Full scale & $\pm 1.6 \%$ \\
\hline 18 & $\pm 1 \%$ of Full scale & $\pm 1.3 \%$ \\
\hline 19 & $\pm 1 \%$ of Full scale & $\pm 1.3 \%$ \\
\hline 20 & $\pm 1 \%$ of Full scale & $\pm 1.6 \%$ \\
\hline 21 & $0.12 \%$ of the reading & $\pm 0.13 \%$ \\
\hline 22 & $0.15 \%$ of the reading & $\pm 0.18 \%$ \\
\hline 23 & $\geq 0.1 \%$ & $\pm 0.5 \%$ \\
\hline PX & & $\pm 0.02 \%$ \\
calibrator & & \\
\hline
\end{tabular}



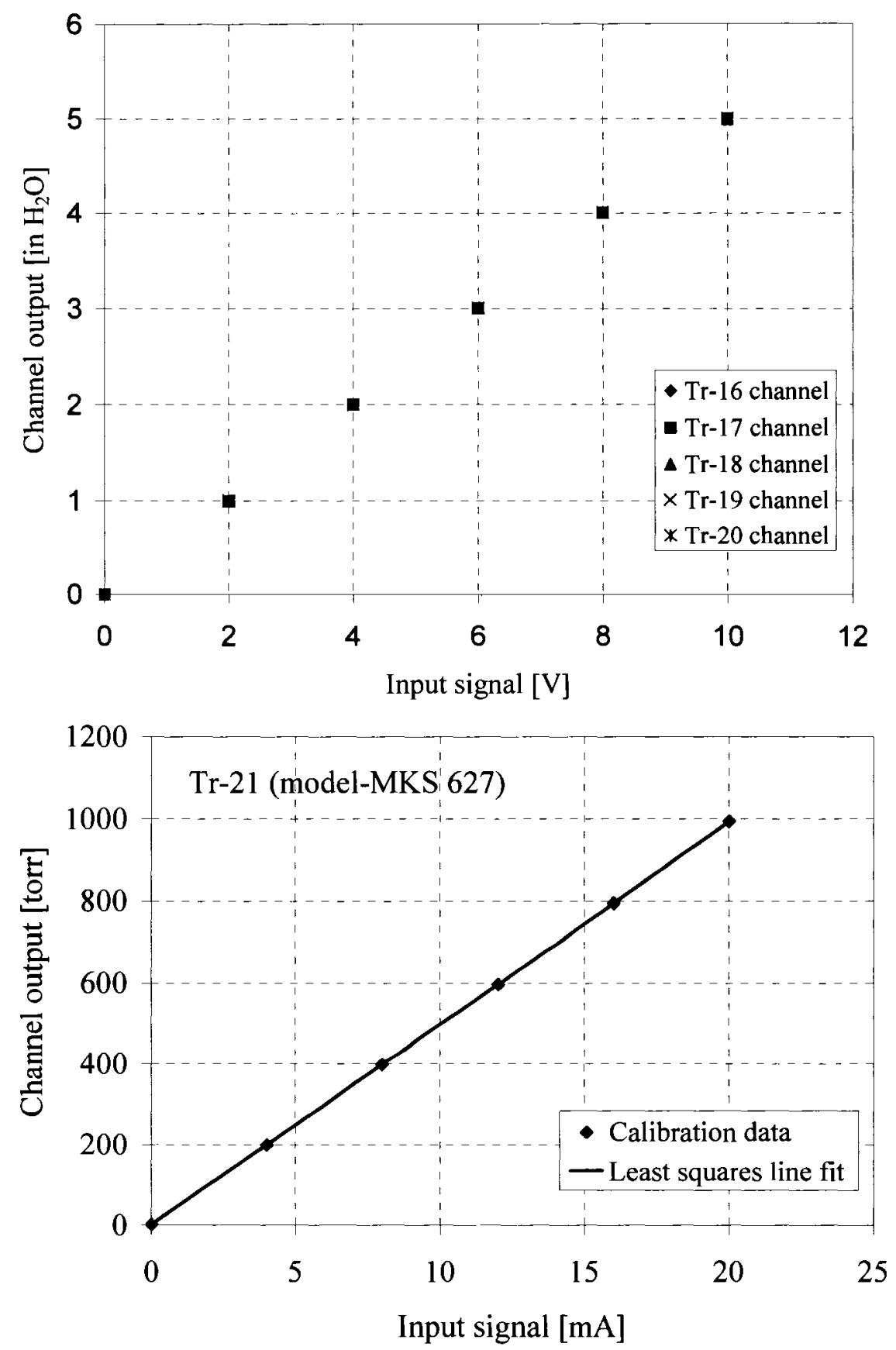

Figure C.10: Calibration of the different data acquisition transducers channels 

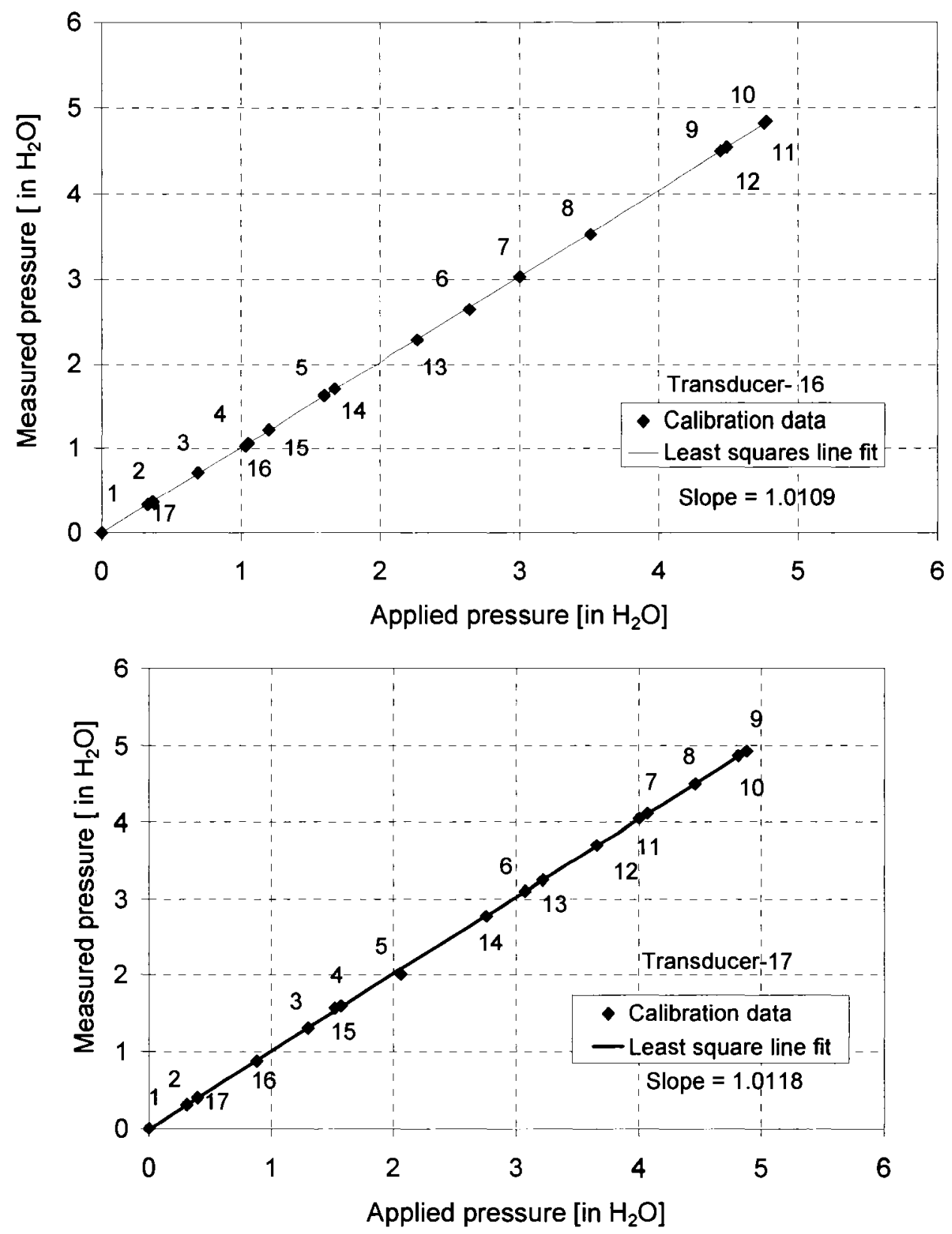

Figure C.11: Transducer calibration curves for transducers 16 and 17 

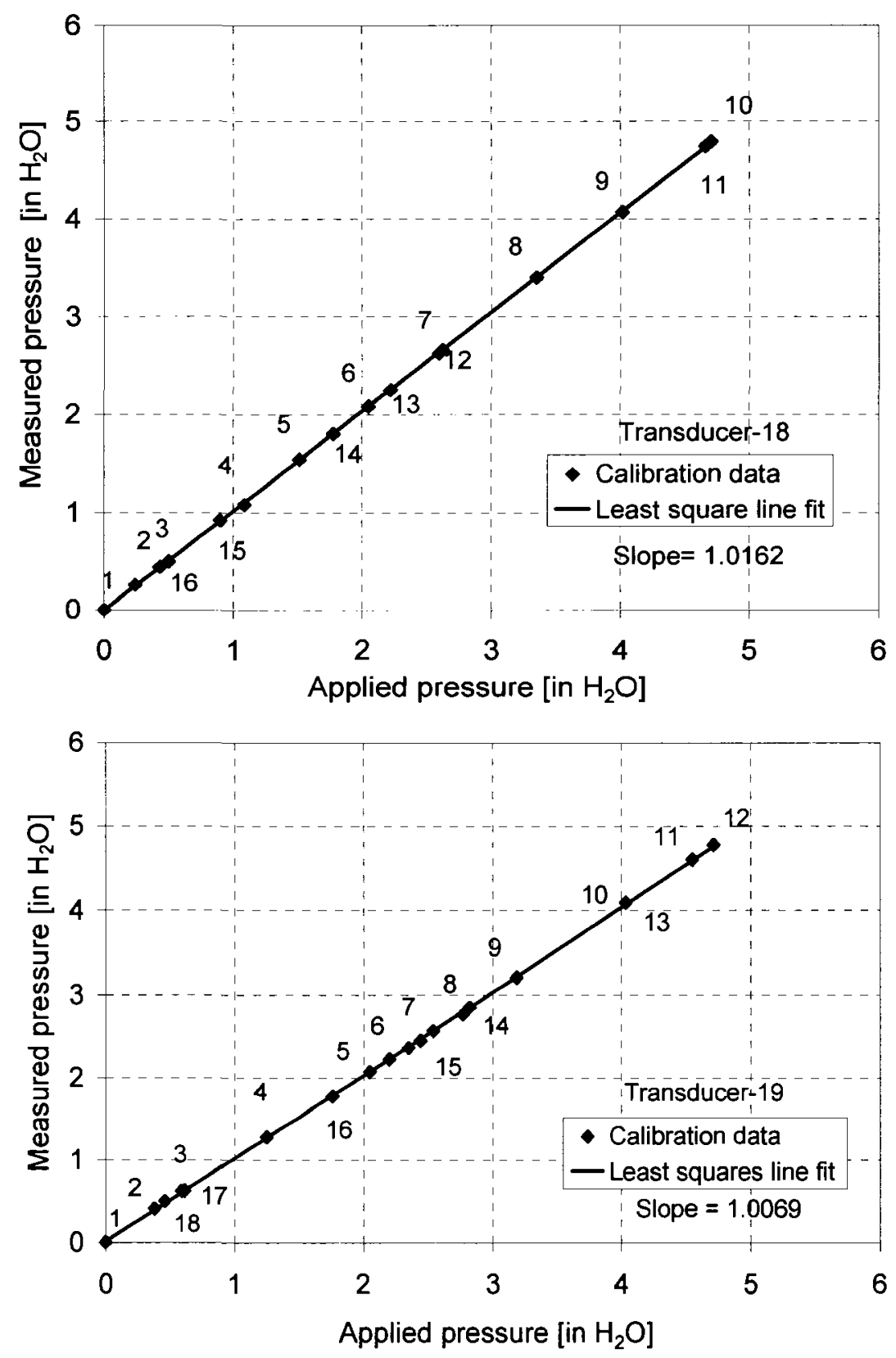

Figure C.12: Transducer calibration curves for transducers 18 and 19 

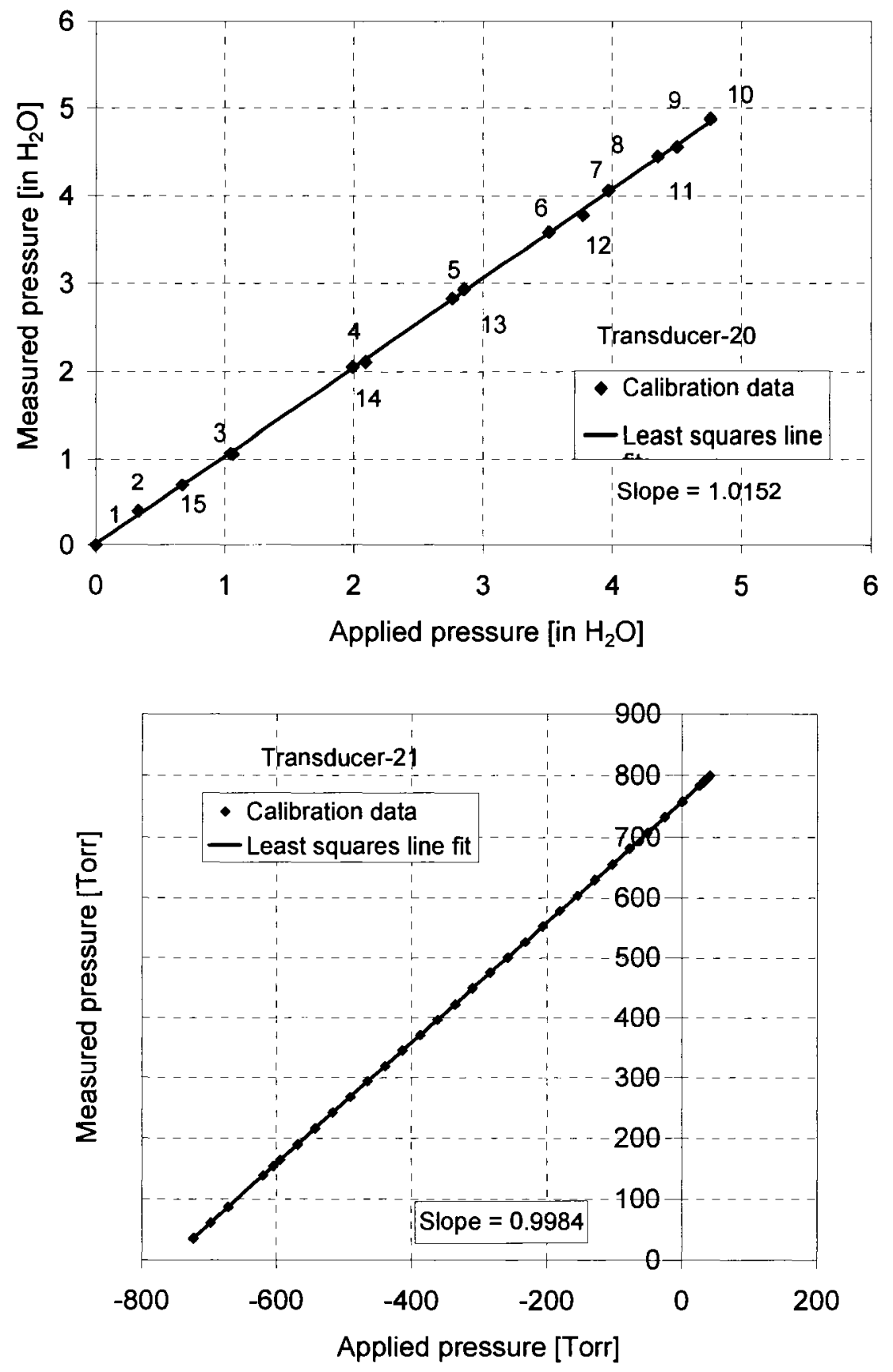

Figure C.13: Transducer calibration curves for transducers 20 and 21 

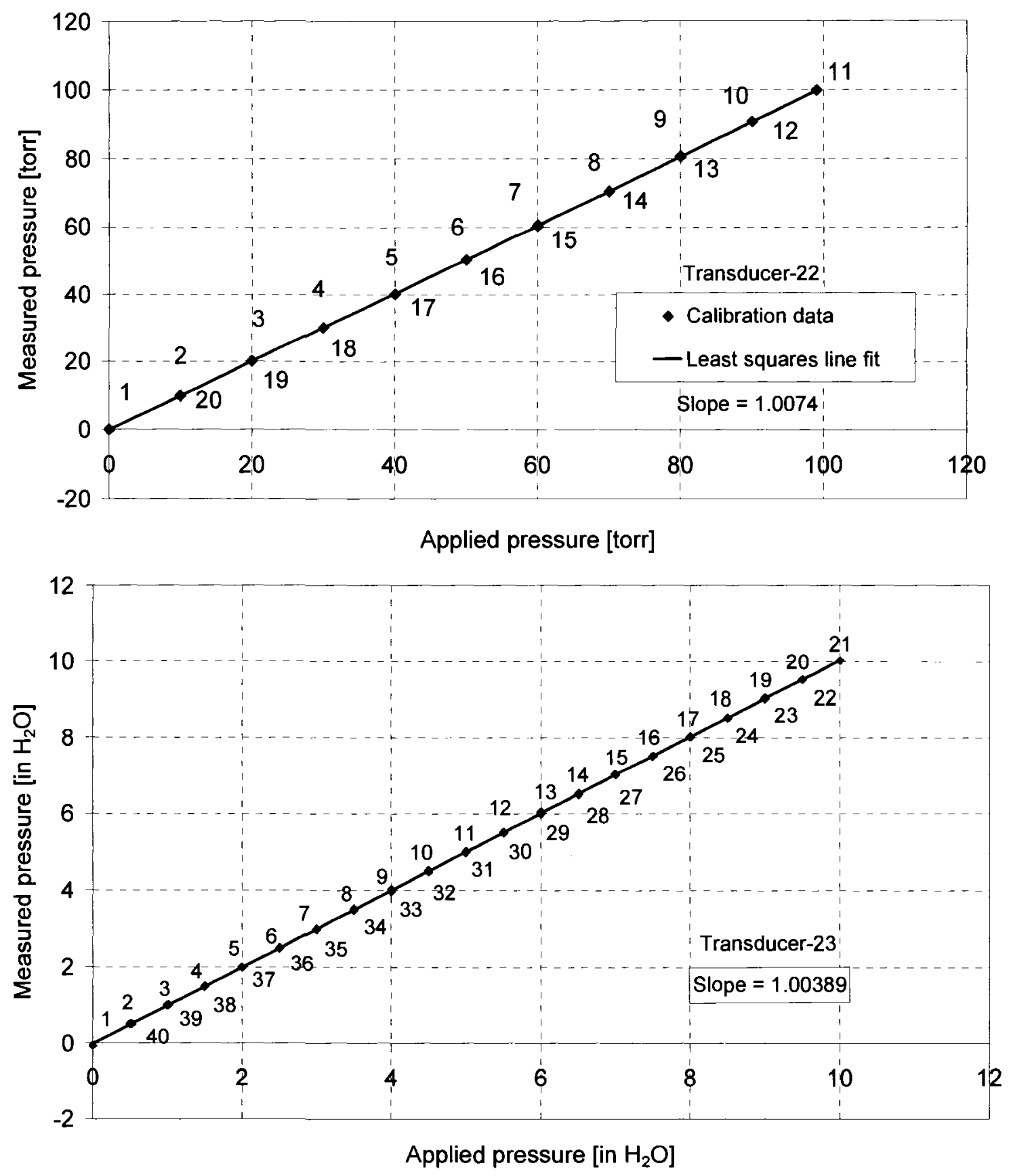

Figure C.14: Transducer calibration curve for transducer 22 and 23 

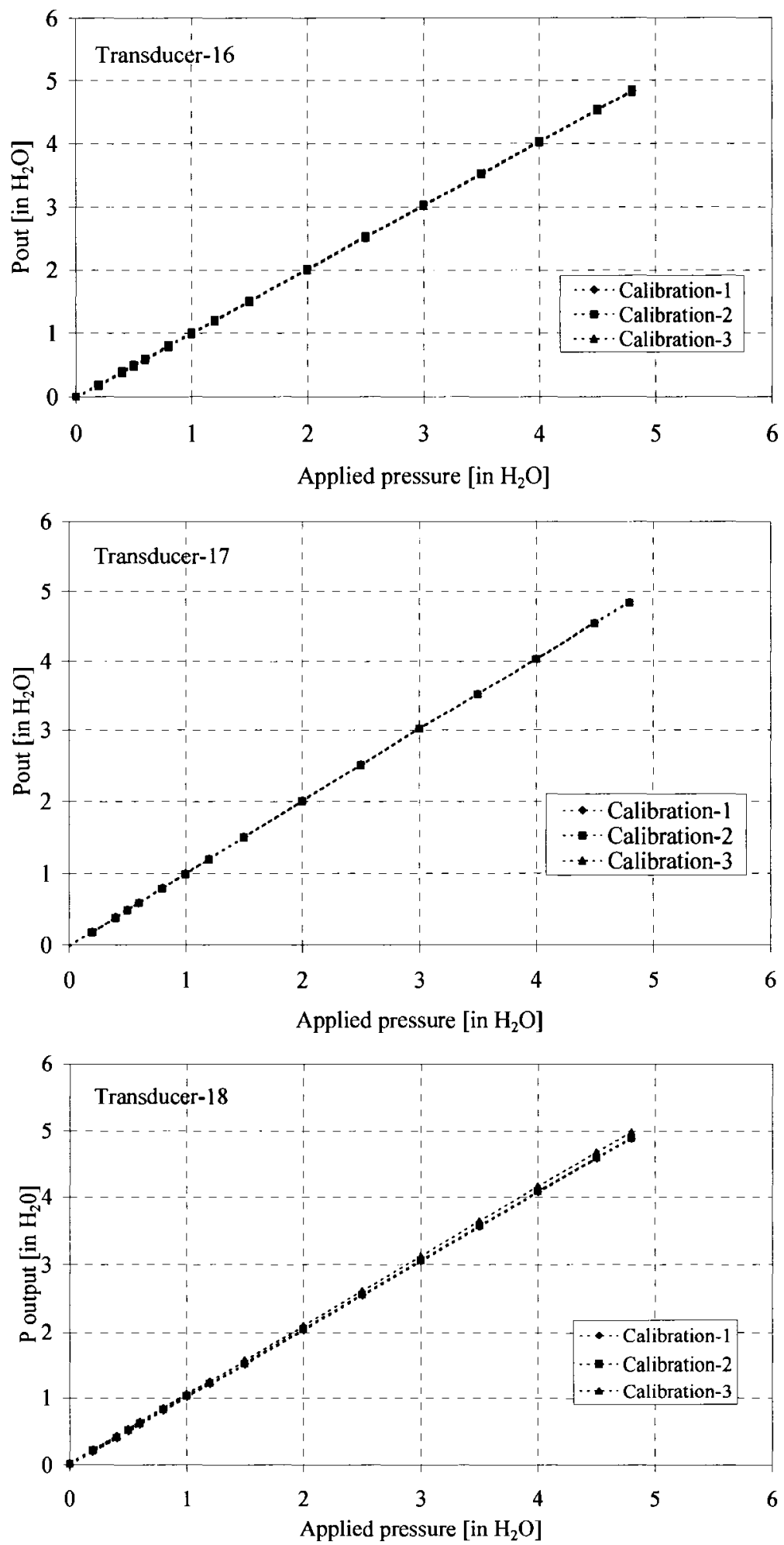

Figure C.15: Pressure transducer calibration (for Tr. 16, 17 and 18) 

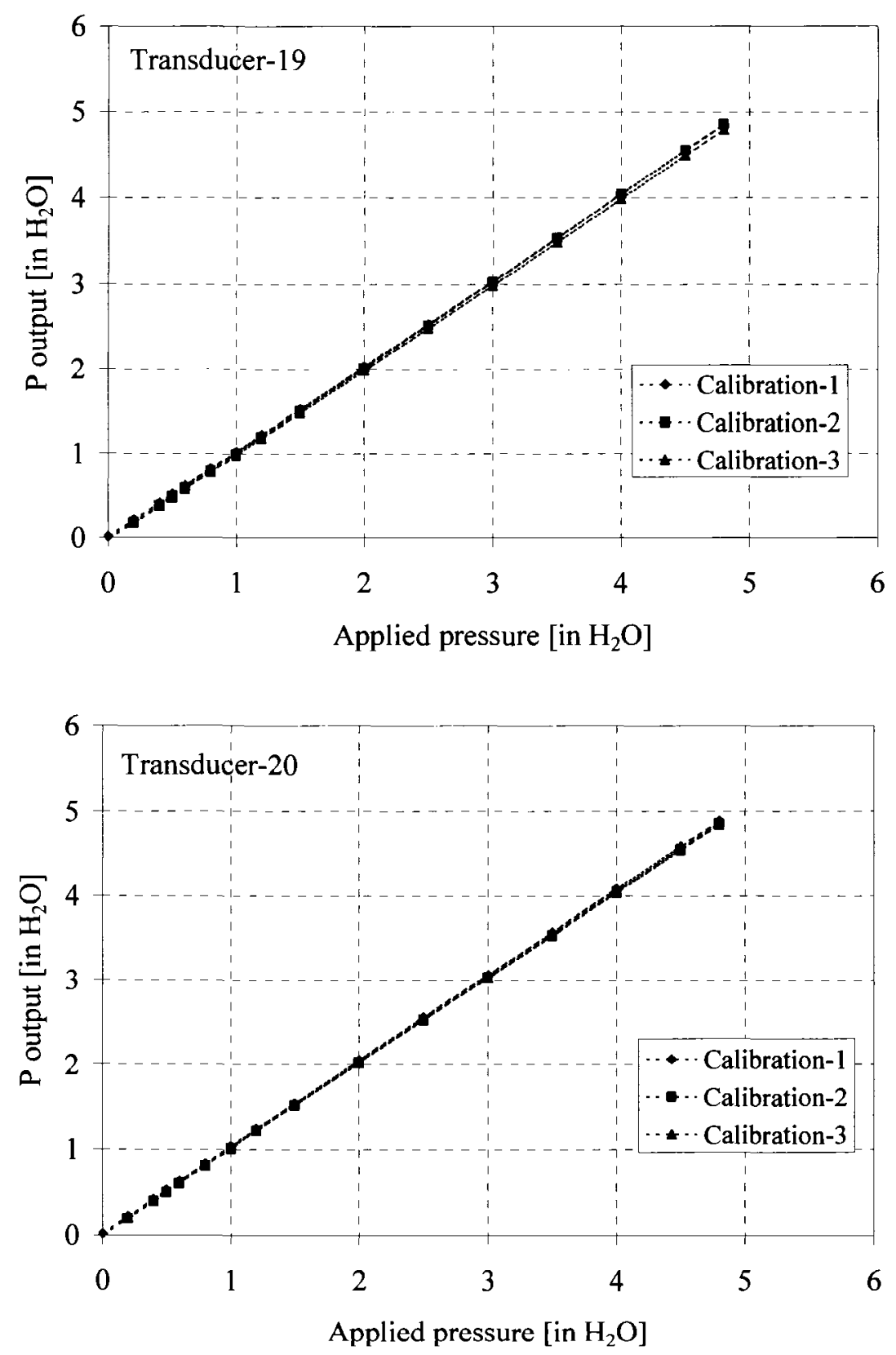

Figure C.16: Pressure transducer calibration (for Tr. 19 and 20) 


\section{APPENDIX D: Uncertainty}

\section{D.1 Uncertainty in measured quantities}

Uncertainty is an estimate of the error in a measurement, which represents the range within which the true value of a measurement lies with a particular confidence level. During the experimental work process, efforts have been made to ensure that all the measured quantities as accurate as possible.

Total uncertainty in a measurement is the combination of uncertainty due to systematic error and uncertainty due to random error. If uncertainty source does not cause a scatter in the results, it is systematic uncertainty caused by systematic errors, if not, it is random uncertainty caused by random errors. Systematic error sources includes for example; calibration of instrument, environmental conditions different from calibration and techniques used (e.g., not at steady state). On the other hand, random error sources may include factors such as; estimate errors, judgement errors, fluctuating conditions and disturbances (e.g., mechanical or electrical). [Holman (1971), ASME test Code (1998)].

The total systematic uncertainty of the measurement (also known as bias limit) is determined as:

$$
U_{s y s}=\sqrt{\sum_{i=1}^{K} u_{s y s_{i}}^{2}}
$$

Where $\mathrm{K}$ is the total number of systematic error sources and $u_{s y s_{i}}$ is the individual systematic error. The random limit can be calculated as [Tavoularis (2001)]:

$$
U_{\text {rand }}=2 \sigma
$$

Where $\sigma$ is the standard deviation of $\mathrm{N}$ repeated measurements.

The total uncertainty of a measurement is then calculated by root-sumsquaring the systematic and random contributions as: 


$$
U_{\text {total }}=\sqrt{U_{\text {sys }}^{2}+\bar{U}^{2} \text { rand }}
$$

To eliminate systematic uncertainties introduced by any measuring instrument used in this study calibration was performed, see Appendix C.

Statistical techniques were used to give the best estimate of the random uncertainty. Also, the best estimate of the probable uncertainties allowed us to calculate the effect of combining uncertainties (propagation of uncertainties). Some statistic definitions used to estimate the different types of errors are summarized in this appendix.

The average mean of the sample given by:

$$
\bar{X}=\frac{1}{N} \sum_{i=1}^{N} X i
$$

Where $\mathrm{N}$ is the number of measurements made or sample point and $X i$ is the individual measurement.

The standard deviation $\left(\sigma_{x}\right)$ is a measure of the spread of the data sample and can be determined by:

$$
\left.\sigma_{x}=\sqrt{\frac{1}{N-1} \sum_{i=1}^{N}(X i}-\bar{X}\right)^{2}
$$

The standard deviation of the sample mean (standard error) is defined as:

$$
\sigma_{\bar{X}}=\frac{\sigma_{x}}{\sqrt{N}}
$$

Confidence limits for true value of quantity $=\left(\bar{X} \pm t_{\varepsilon, P} \sigma_{\bar{X}}\right)$

Where $t_{\varepsilon, P}$ (t-estimator) is a number which depend on the number of data points (degree of freedom, $\varepsilon=\mathrm{N}-1$ ) and the degree of confidence required (probability, P).

A confidence level of 95 percent was used throughout this work when reporting uncertainty. So, Equation D.4 can be rewritten as: 
Confidence limits for true value of quantity $=\bar{X} \pm t_{\varepsilon, 95 \%} \sigma_{\bar{X}}$

And let the uncertainty be equal to:

$$
u_{\bar{X}}=t_{\varepsilon, 95 \%} \sigma_{\bar{X}}
$$

\section{D.2 Estimating uncertainties in calculated quantities using Partial derivatives}

To obtain the uncertainty of calculated quantities, such as; velocity, mass flow rate, based on a series of measured parameters, such as pressure temperature, this section will present a description of the prouder used in the present study.

Assume the calculated quantity is of the form:

$$
V=f\left(y_{1}, y_{2}, y_{3}, \ldots . ., y_{K}\right)
$$

Where, the subscript $K$ represents the total number of parameters that used in the calculated quantity. The calculated quantity $V$ in Equation (D.9) was expressed in terms of the average values of the independent parameters.

The partial derivative of the quantity $V$ will be:

$$
\delta V=\frac{\partial V}{\partial y_{1}} \delta y_{1}+\frac{\partial V}{\partial y_{2}} \delta y_{2}+\frac{\partial V}{\partial y_{3}} \delta y_{3}+\ldots \ldots+\frac{\partial V}{\partial y_{N}} \delta y_{N}
$$

To use Equation (D.10) in error propagation, we replace the quantities $\delta y_{1}, \delta y_{2}, \ldots$ by the uncertainties $u_{-}, u_{y_{1}} \ldots$ so that the equation could be rewritten as [Kirkup (1994)]:

$$
\delta V=\left|\frac{\partial V}{\partial y_{1}}\right| \boldsymbol{u}_{y_{1}}+\left|\frac{\partial V}{\partial y_{2}}\right| \boldsymbol{u}_{y_{2}}+\left|\frac{\partial V}{\partial y_{3}}\right| u_{y_{3}}+\ldots . .+\left|\frac{\partial V}{\partial y_{N}}\right| \boldsymbol{u}_{y_{N}}
$$

We partially differentiate the function with respect to each quantity that possesses uncertainty. Quantities with no uncertainty are regarded as constants. The 
partial derivatives $\left(\frac{\partial V}{\partial y_{i}}\right)$ are known as sensitivity coefficients of the different parameters.

The standard error in the quantity $V$ could be written as:

$$
\begin{gathered}
U_{\bar{v}}^{2}=\left(\frac{\partial V}{\partial y_{1}}\right)^{2} u_{y_{1}}^{2}+\left(\frac{\partial V}{\partial y_{2}}\right)^{2} u_{y_{2}}^{2}+\ldots \ldots . .+\left(\frac{\partial V}{\partial y_{M}}\right)^{2} u_{y_{M}}^{2-} \\
U_{\bar{V}}=\sqrt{\left(\frac{\partial V}{\partial y_{1}}\right)^{2} u_{y_{1}}^{2-}+\left(\frac{\partial V}{\partial y_{2}}\right)^{2} u_{y_{2}}^{2-}+\ldots \ldots .+\left(\frac{\partial V}{\partial y_{M}}\right)^{2} u_{y_{M}}^{2-}} \\
U_{\bar{V}}=\sqrt{\sum_{i=1}^{M}\left(\frac{\partial V}{\partial y_{i}}\right)^{2} u_{y_{i}}^{2}}
\end{gathered}
$$

In the present work, the above mentioned method was used for estimating uncertainty in all the calculated quantities used. As an example, when the pitot-tube was used for the measurement of the average velocity at the entrance of the duct burner (constant cross-sectional area), the uncertainty in the calculated velocity was calculated as following.

Bernoulli's equation is used in this study to describe the flow (friction less incompressible flow), Therefore, the velocity can calculated by the following equation:

$$
V=\sqrt{\frac{2(\Delta p)}{\rho}}=\sqrt{\frac{2(\Delta p) R T}{P}}
$$

Then using Equation (D.14) we get:

$$
U_{\bar{V}}=\sqrt{\frac{1}{2} \frac{R T}{(\Delta p) P} u_{\Delta \bar{p}}^{2}+\frac{1}{2} \frac{(\Delta p) R T}{P^{3}} u^{2} \bar{p}+\frac{1}{2} \frac{(\Delta p) R}{T P} u_{\bar{T}}}
$$

Where the quantities $\Delta p, P$ and $T$ are the pressure velocity measured, absolute pressure and temperature respectively and $u_{\Delta p}, u_{\bar{P}}$ and $u_{\bar{T}}$ are the uncertainty in each quantity with a 95 percent confidence level. 


\section{D.3 Pressure transducer uncertainty estimates}

Pressure transducers, which used in the present work, were calibrated and a least squares line fit was obtained throughout the calibration data for each transducer see Appendix $\mathrm{C}$. The uncertainty in using the calibration equation is due to the transducer accuracy and the ability of the curve fit to represent the calibration data. Therefore, the total uncertainty in the pressure value obtained with the transducer assuming that the two quantities are uncorrelated [Recktenwald (2004)], so that they can combine using the root-sum-squared method as:

$$
U_{\text {total }}=\sqrt{u_{\text {calib }}^{2}+u_{\text {Fit }}^{2}}
$$

Where $\left(u_{\text {calib }}\right)$ manufacturer transducer error and ( $\left.u_{\text {Fit }}\right)$ represents the error in using the conversion equation to predict the calibration data.

In the present work, the uncertainty in all pressure transducers was estimated using Equation (D.18).

\section{D.4 Examples of uncertainty estimate}

The following are examples of the confidence limits for the true value of different quantities used in the present investigation (Eq. D.8):

Where $\Delta P v$ is the velocity pressure at different ports (in $\mathrm{H}_{2} \mathrm{O}$ ), $\mathrm{Pa}$ is the absolute pressure (torr) and Tinlet is the inlet temperature $\left({ }^{\circ} \mathrm{C}\right)$. For uncertainity in NOx and $\mathrm{CO}$ (ppm), see Table 7.1 .

Example: velocity pressure

$$
\begin{array}{|l|l|}
\hline \text { mean }=0.4878 & \begin{array}{l}
\text { Tinlet }=229.42 \pm 0.0198 \\
\sigma O x=1.28 \pm 0.0043 \\
C O=0.018
\end{array} \\
N=54 & \\
\Delta P v=0.4878 \pm 0.0052 & \\
\hline
\end{array}
$$

$$
\begin{aligned}
& \Delta P v=0.566 \pm 0.0074 \\
& \Delta P v=0.5636 \pm 0.011 \\
& \Delta P v=0.3336 \pm 0.0057 \\
& P a=756.26 \pm 0.0228 \\
& \text { Tinlet }=229.42 \pm 0.0198
\end{aligned}
$$

Table D.1: Uncertainty estimate for selected parameters.

\begin{tabular}{|l|l|}
\hline Value & Uncertainty estimate \\
\hline Velocity at the DB inlet (pitot) & $\pm \mathbf{4 \%}$ \\
\hline Velocity at the annular region (pitot) & $\pm \mathbf{2 . 5 \%}$ \\
\hline Fuel flow rate & $( \pm \mathbf{1 . 7 \%})$ \\
\hline Blade angle & $\pm 2^{\mathbf{0}}$ \\
\hline Pitot-static location & $\pm \mathbf{2} \mathbf{~ m m}$ \\
\hline
\end{tabular}




\section{APPENDIX E: LSI}

This appendix contains the ICCD camera specifications and the LSI results (images) obtained during the LSI phase of the present thesis. Images for different imaging locations and for different conditions were selected and used during the results discussions at Chapter 5. The appendix arranged in the following order:

a) Round cap, Cap-5 ( $\phi=0.5)$

i. Effect of fuel cap mask on the images

ii. Vertical and lateral cross-sectional images combined, for all the five mixers.

iii. 3D plots for the cases presented in (ii)

b) Flat caps $(\phi=0.5)$

i. Cap-1 with all the mixers (vertical cross-sectional images)

ii. 3D plots for the cases presented in (i)

iii. Cap-2 with all the mixers (vertical cross-sectional images)

iv. 3D plots for the cases presented in (iii)

v. Cap-3 with all the mixers (vertical cross-sectional images)

vi. Cap-4 with all the mixers (vertical cross-sectional images)

vii. $3 \mathrm{D}$ plots for the cases presented in (vi)

c) Flat cap $(\phi=0.3)$

i. Cap-2 with all the mixers (vertical cross-sectional images)

ii. 3D plots for the cases presented in (i)

d) Unmixedness results

i. Results of each mixer with all the caps

ii. Results of each mixer with Cap-2 and Cap-5

iii. Results of each mixer with Cap-2, at $\phi=0.3$ and $\phi=0.5$

iv. Results of each cap with the single-swirl mixers and the double-swirl mixers

v. Ranking results for all the combinations used (bar graphs) 
Table E.1: ICCD detector (camera) specification

\begin{tabular}{|c|c|}
\hline CCD Array & EEV $576 \times 384$ full frame \\
\hline Image Intensifier & $18 \mathrm{~mm}$ or ( $25 \mathrm{~mm}$ (LD models) \\
\hline Method of coupling & 1:1 fibre optics \\
\hline Spatial Resolution & $85 \mu \mathrm{m}$ spot size FWHM on CCD \\
\hline Geometric distortion & $<1$ pixel \\
\hline Sensitivity & $\begin{array}{l}\text { Variable gain adjustment allows } \\
\text { sensitivities from } 1-70 \text { counts per } \\
\text { photoelectron }\end{array}$ \\
\hline Gating speed & $\begin{array}{l}\text { Fast gate intensifier, 2-7 nsec FWHM } \\
\text { Slow gate intensifier, } 50-70 \mathrm{nsec} \text { FWHM }\end{array}$ \\
\hline Gating ON/OFF ratio & $5 \times 10^{6}: 1$ \\
\hline Response linearity & $\begin{array}{l}\text { Better than } 1 \text { percent for the upper } 95 \\
\text { percent of range shutter mode }\end{array}$ \\
\hline Photocathode dark charge & $\begin{array}{l}\text { Red-blue enhanced, }<5 \text { counts/pixel- } \\
\text { second; Red-enhanced, < } 15 \\
\text { counts/pixel-second; The exact dark } \\
\text { charge in counts is a function of the gain } \\
\text { of the ICCD }\end{array}$ \\
\hline Phosphor Decay & $\begin{array}{l}2 \text { msec standard, } 300 \mathrm{nsec} \text { phosphor is } \\
\text { optional }\end{array}$ \\
\hline Spectral range & $\begin{array}{l}\text { Red-blue enhanced, } 180-800 \mathrm{~nm} \text {; Red } \\
\text { enhanced, } 360-920 \mathrm{~nm}\end{array}$ \\
\hline Nonuniformity & $\begin{array}{llllll}\begin{array}{l}\text { Typically } \\
\text { intensifiers, } 12\end{array} & \text { percent } & \text { for } & 18 & \mathrm{~mm} \\
\text { intensifiers }\end{array}$ \\
\hline CCD cooling & $\begin{array}{l}\text { Down to }-35^{\circ} \mathrm{C} \text { with tap water, down to - } \\
45^{\circ} \mathrm{C} \text { with } 0^{\circ} \mathrm{C} \text { coolant using the ST- } 138 \\
\text { Controller }\end{array}$ \\
\hline Photocathode cooling & $\begin{array}{l}\text { About } 12^{\circ} \mathrm{C} \text { below ambient temperature } \\
\text { due to nitrogen flow }\end{array}$ \\
\hline Readout noise & $1-1.5$ counts in gate mode \\
\hline Operating environment & $\begin{array}{l}\text { Storage temperature: }<55^{\circ} \mathrm{C} \\
\text { Lab. Temperature: } 30^{\circ} \mathrm{C}>\mathrm{T}>-45^{\circ} \mathrm{C}\end{array}$ \\
\hline Water flow & $\begin{array}{l}1-3 \text { liters per minute for maximum } \\
\text { cooling }\end{array}$ \\
\hline Nitrogen Gas & $\begin{array}{l}1-2 \text { liters per minute initially, } 750-1000 \\
\text { ml per minute during experiment }\end{array}$ \\
\hline Lab Humidity & $<50$ percent \\
\hline
\end{tabular}

Reference: ICCD detector manual, Model NO.: ICCD576LDG/EM, Serial No.:F029403, Version 3, July 9, 1999, downloaded at (www.roperscientific.com) 


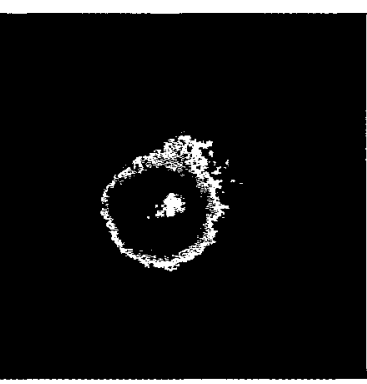

Without fuel cap

$$
\text { mask }
$$
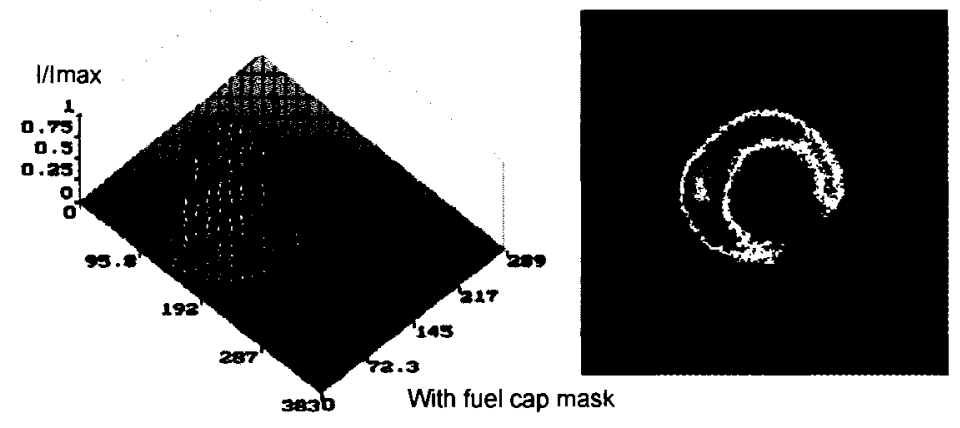

Figure E.1: Effect of the fuel cap mask on the fuel concentration image and the $3 D$ plots (Mix-1/1, Cap-5 and at $30 \mathrm{~cm}$ )
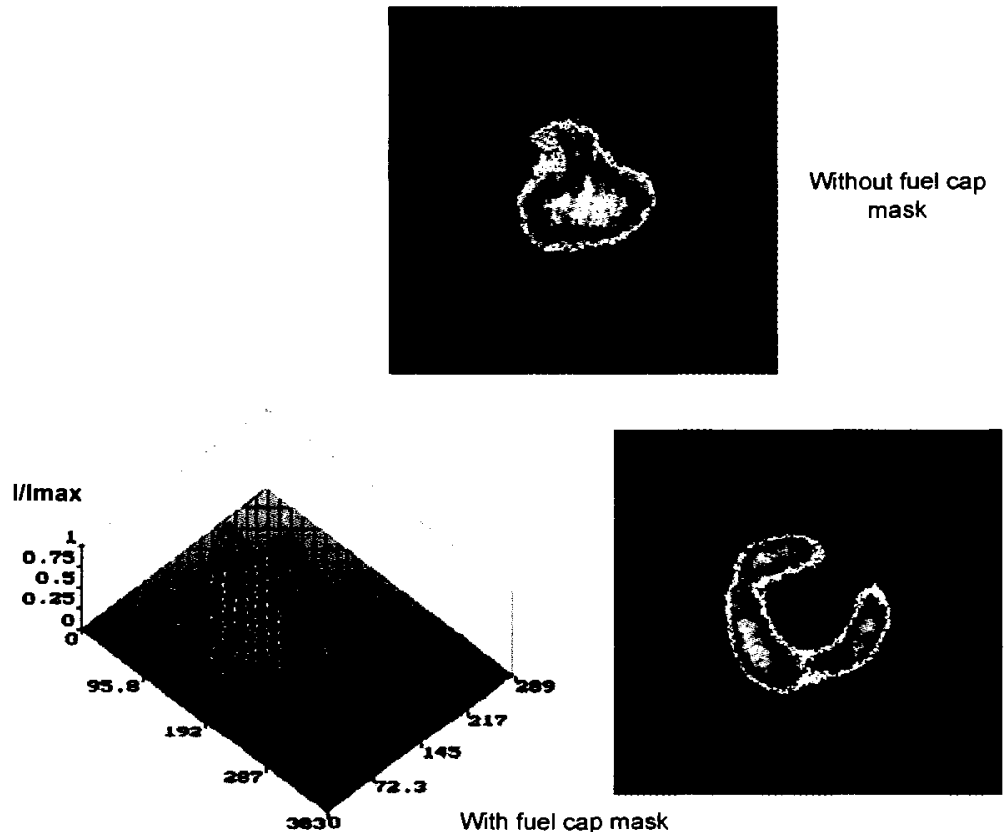

Figure E.2: Effect of the fuel cap mask on the fuel concentration image and the $3 D$ plots (Mix-2/2, Cap-5 and at $15 \mathrm{~cm}$ ) 

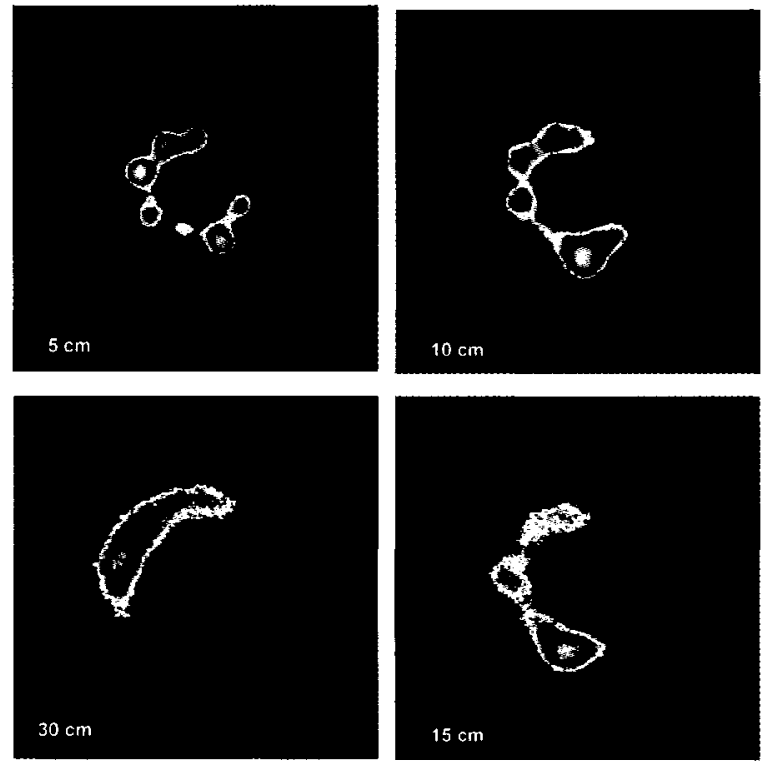

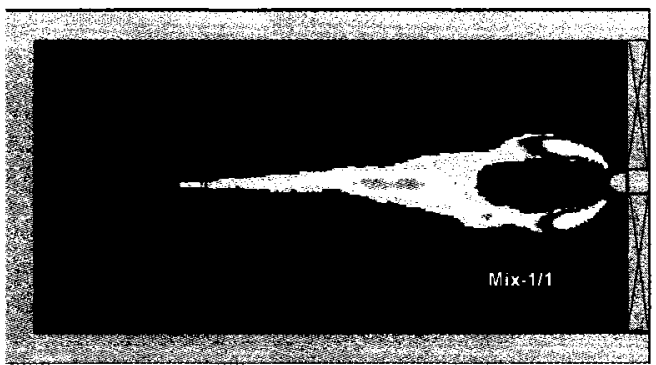

Lateral image

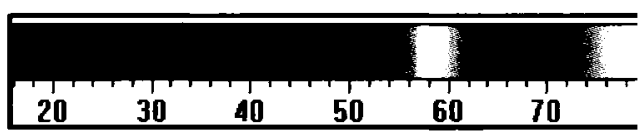

Mix-1/1 \& Cap-5

Figure E.3: Vertical and lateral cross-sectional LSI images (Mix-1/1 and Cap-5 with $\phi=0.5$ )
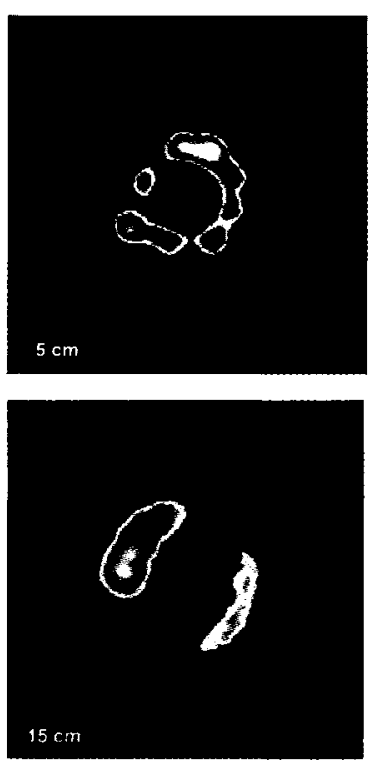
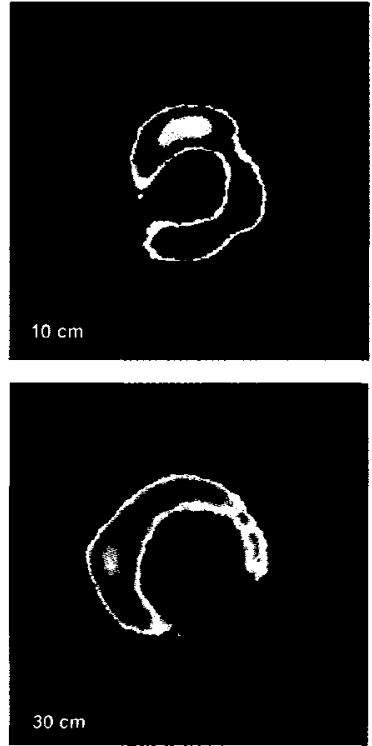

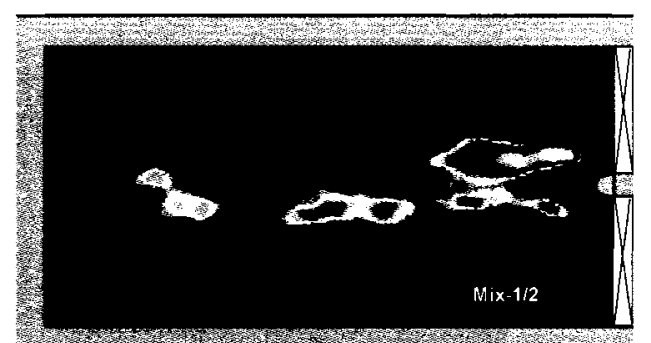

Wrow

Lateral image

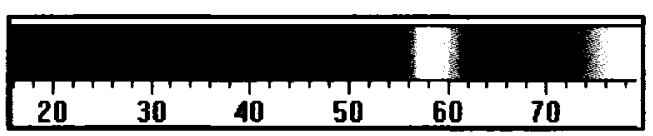

Mix-1/2 \& Cap-5

Figure E.4: Vertical and lateral cross-sectional LSI images (Mix-1/2 and Cap-5 with $\phi=0.5$ ) 

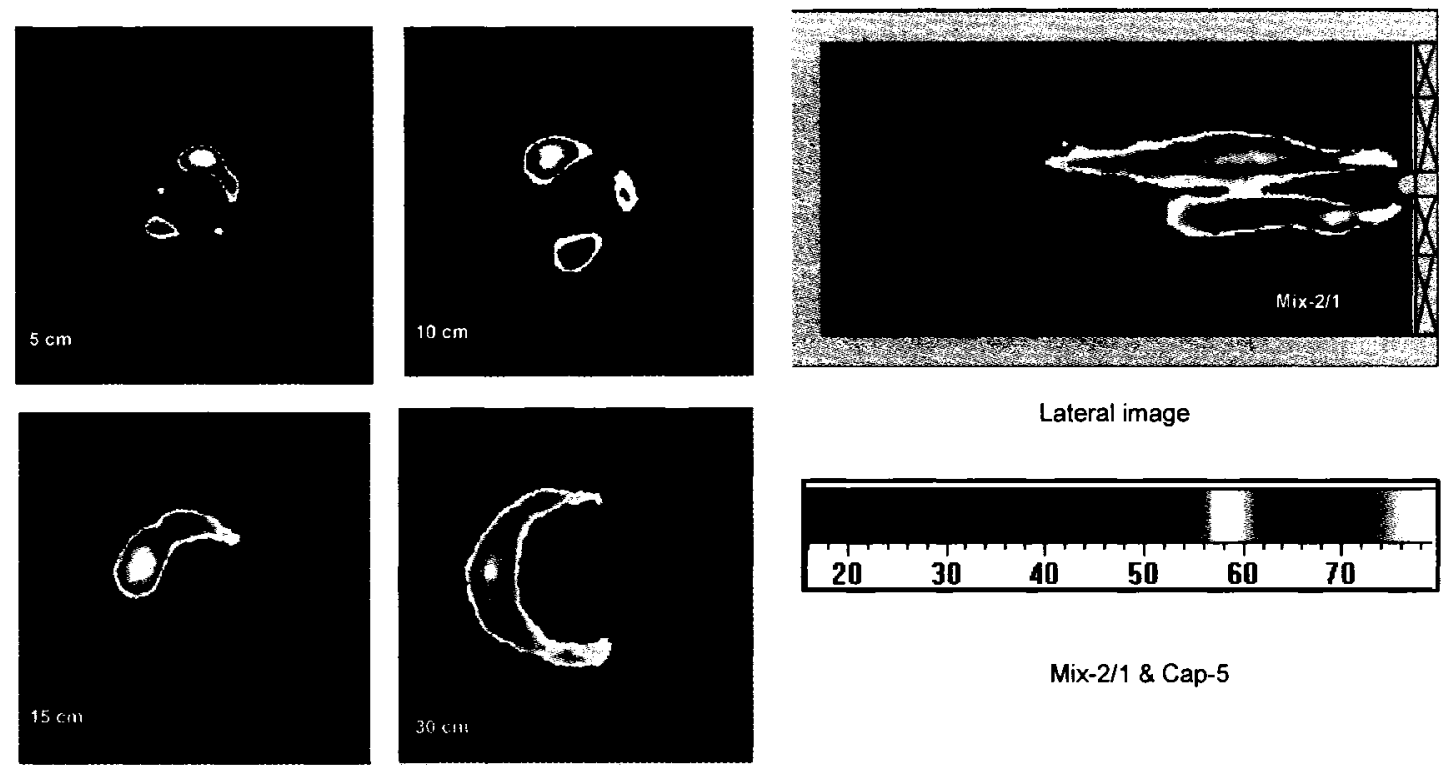

\section{Lateral image}

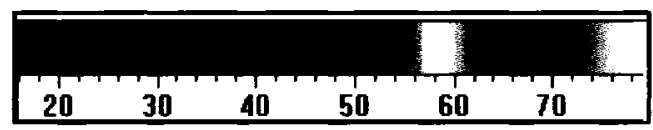

Mix-2/1 \& Cap-5

Figure E.5: Vertical and lateral cross-sectional LSI images (Mix-2/1 and Cap-5 with $\phi=0.5$ )
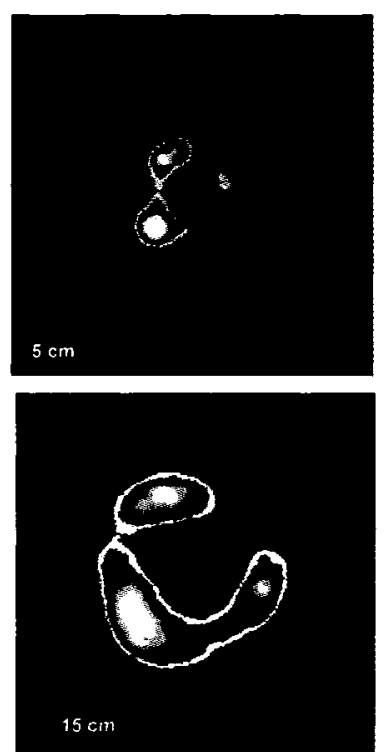
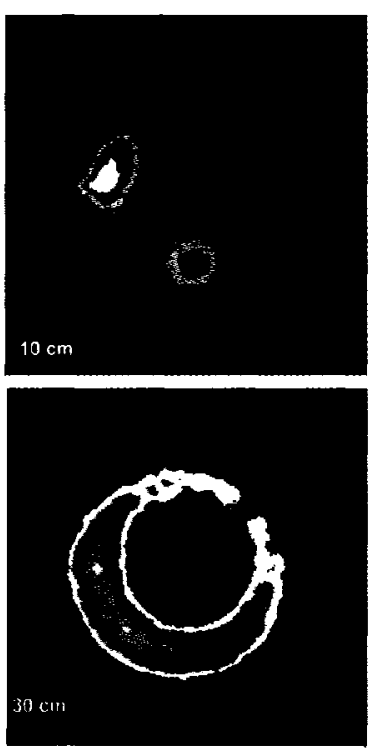

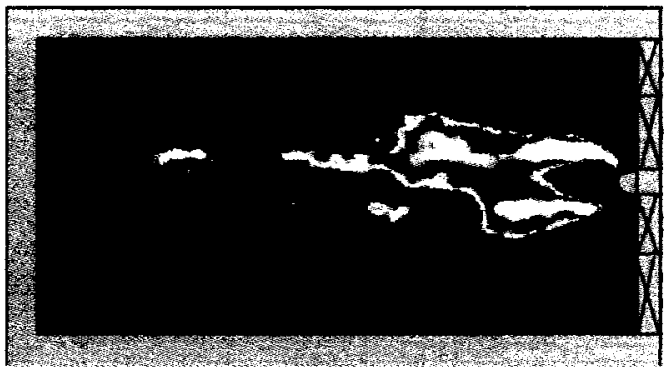

Lateral image

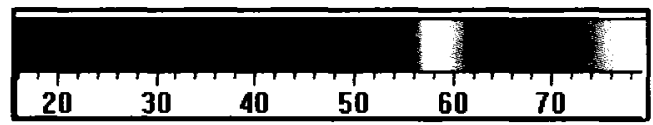

Mix-2/2 \& Cap-5

Figure E.6: Vertical and lateral cross-sectional LSI images (Mix-2/2 and Cap-5 with $\phi=0.5$ ) 

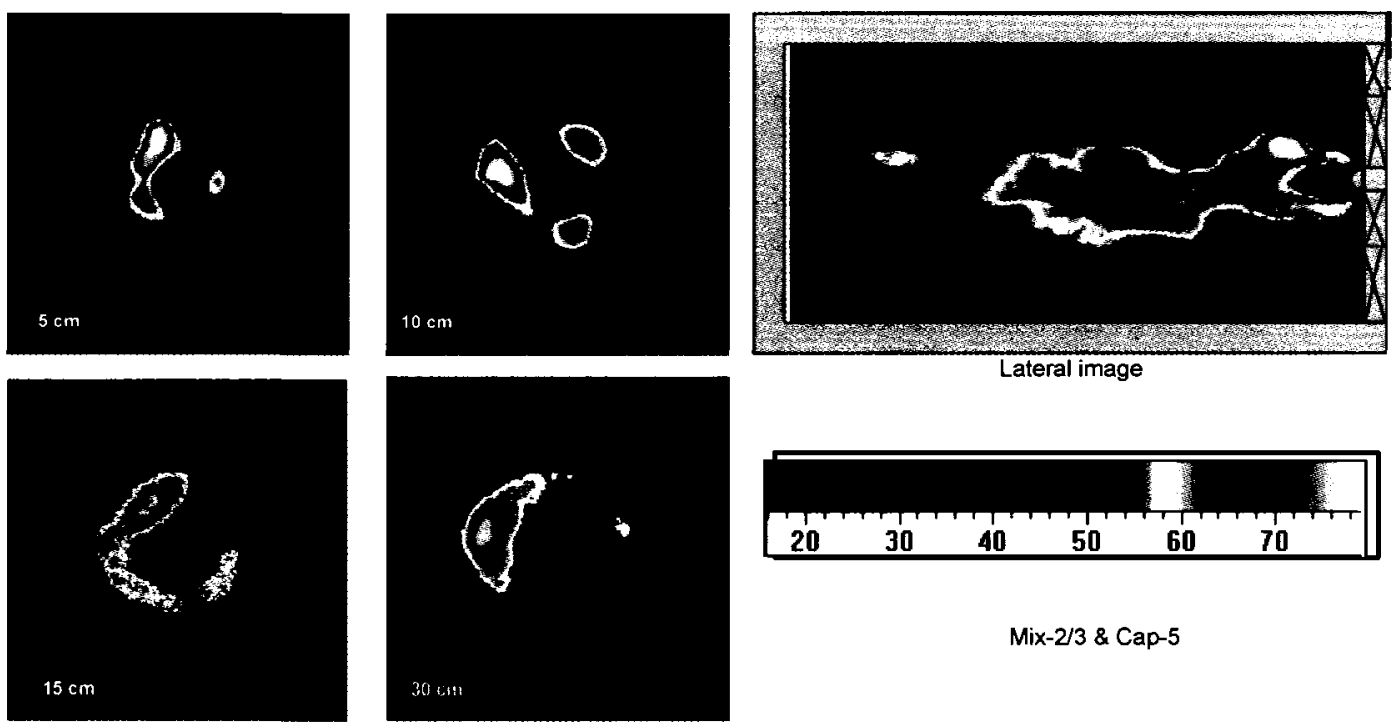

Mix-2/3 \& Cap-5

Figure E.7: Vertical and lateral cross-sectional LSI images (Mix-2/3 and Cap-5 with $\phi=0.5$ )
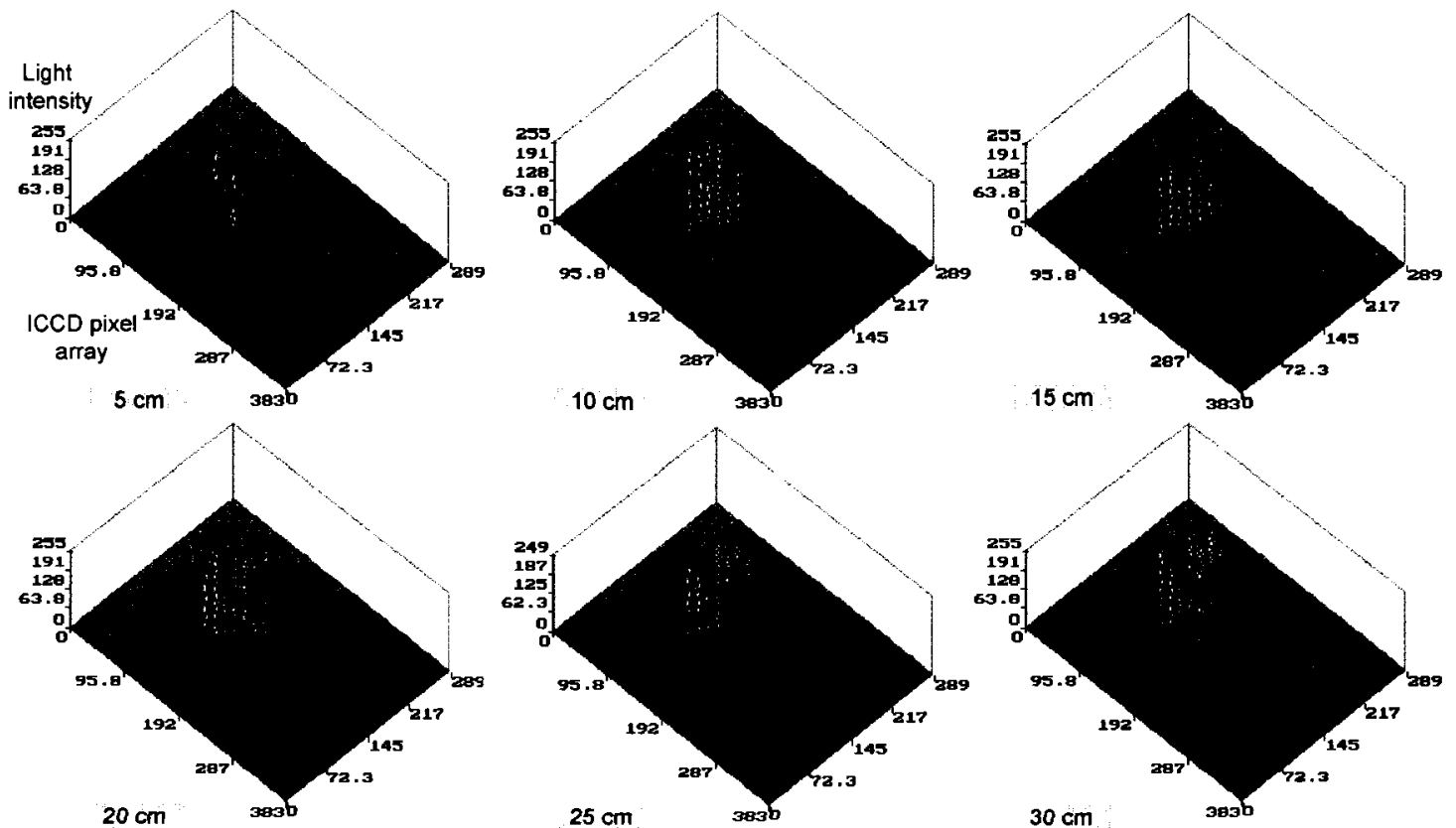

Figure E. 8: 3D plots for the vertical cross-sectional LSI images (Mix-2/3 and Cap-5 with $\phi=0.5$ ) 

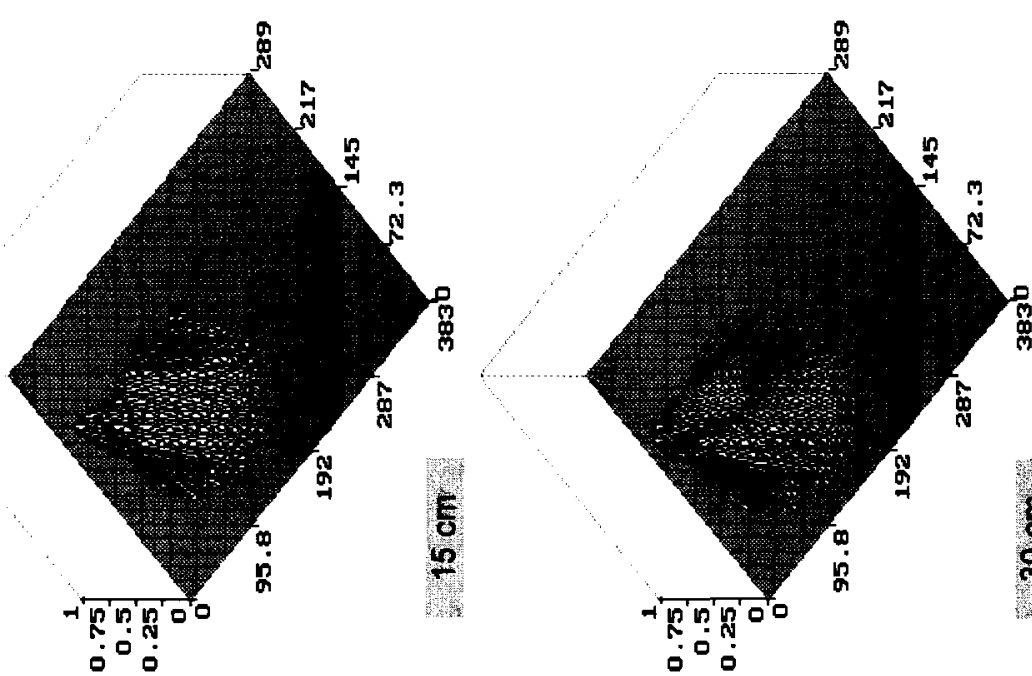

$\stackrel{\infty}{m}$
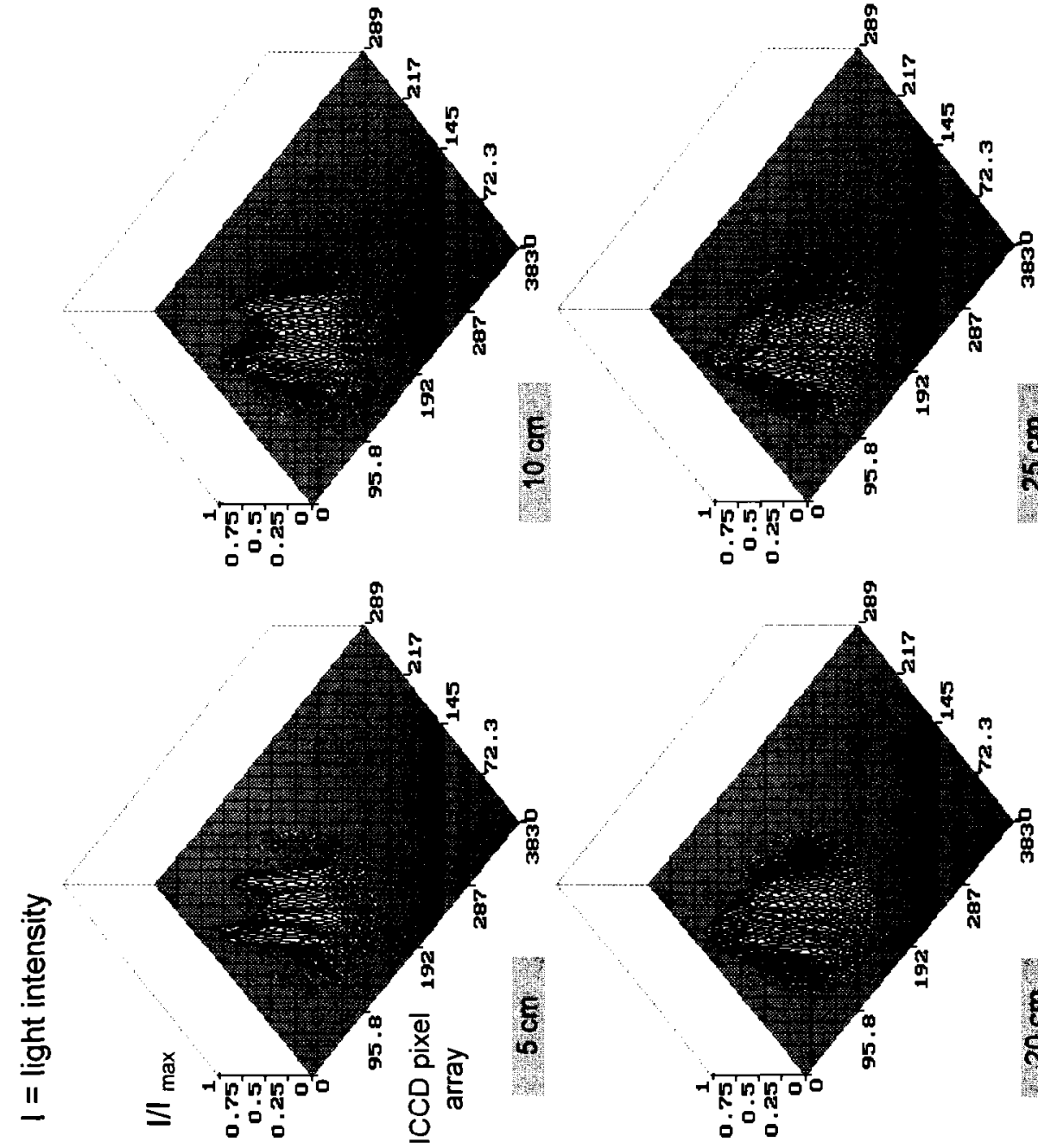

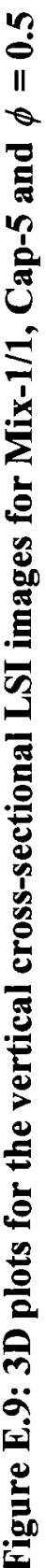



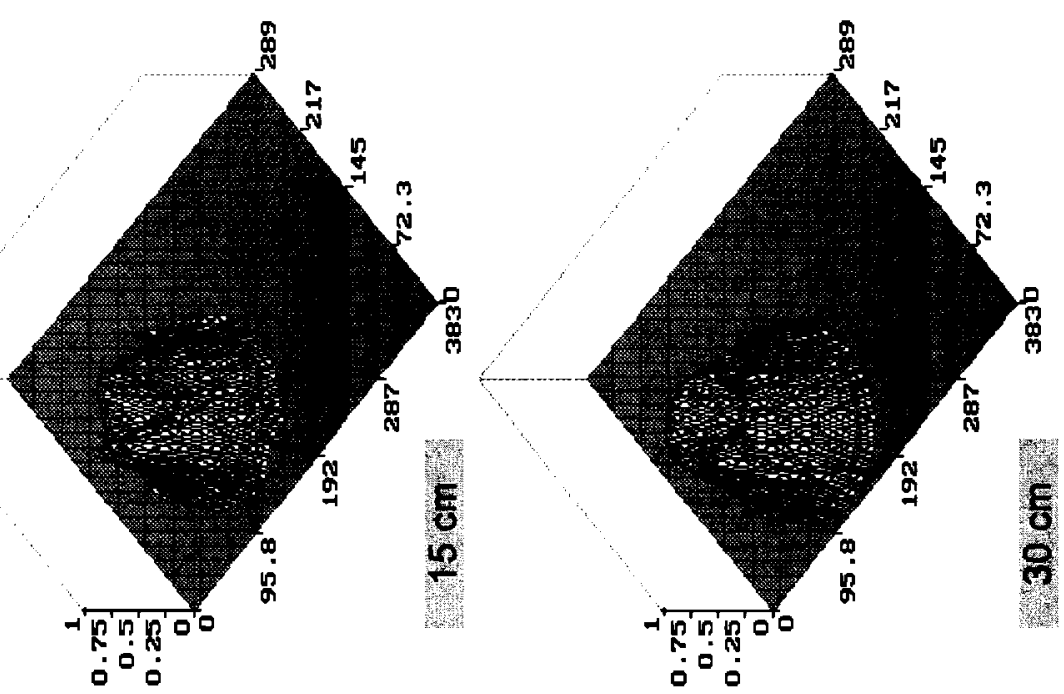

$\frac{9}{n}$
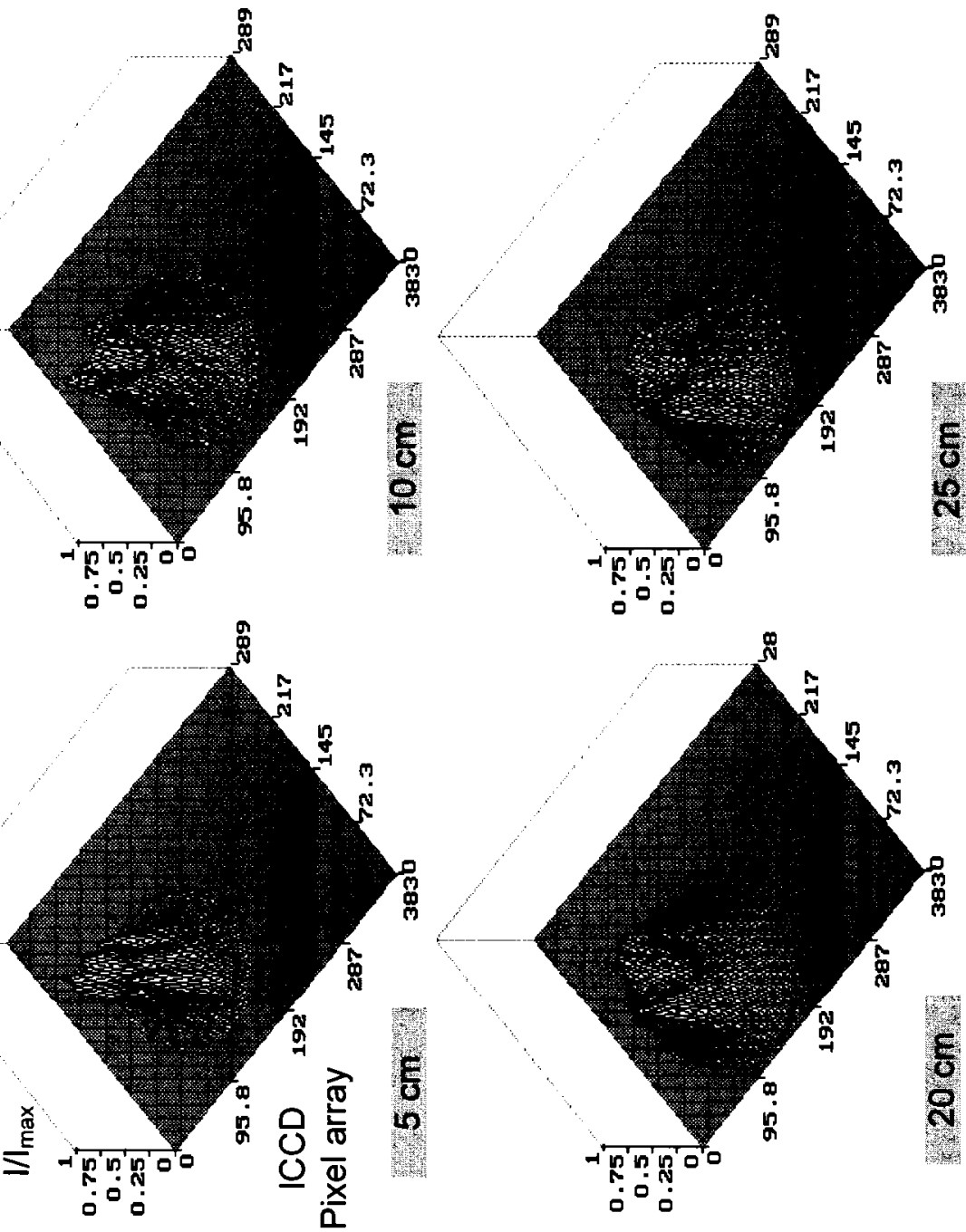

年 

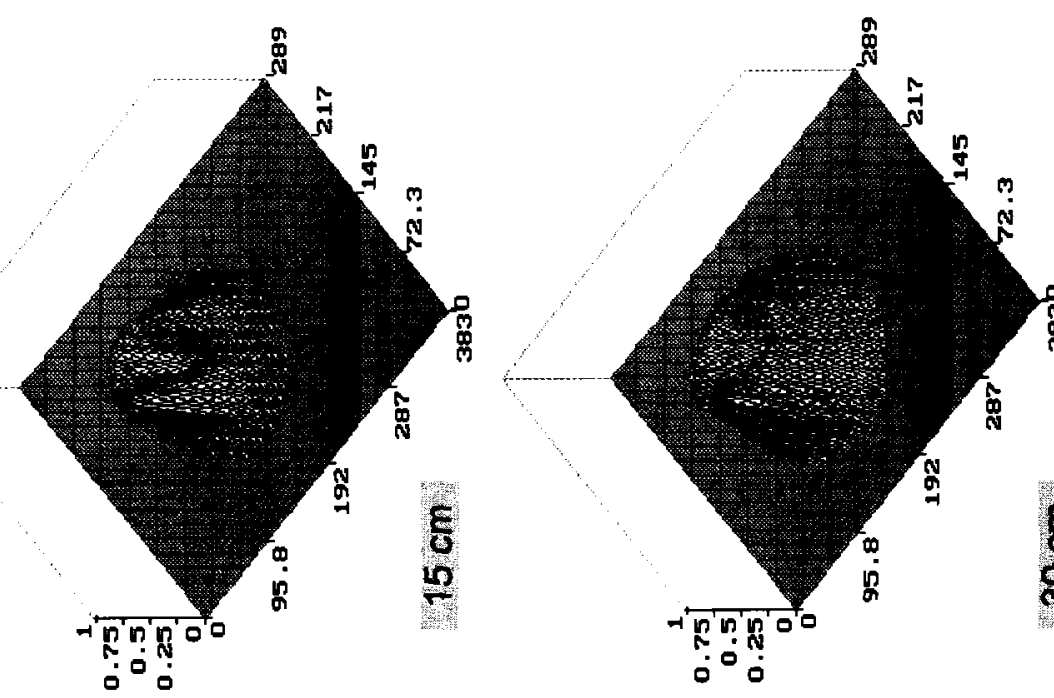

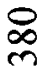
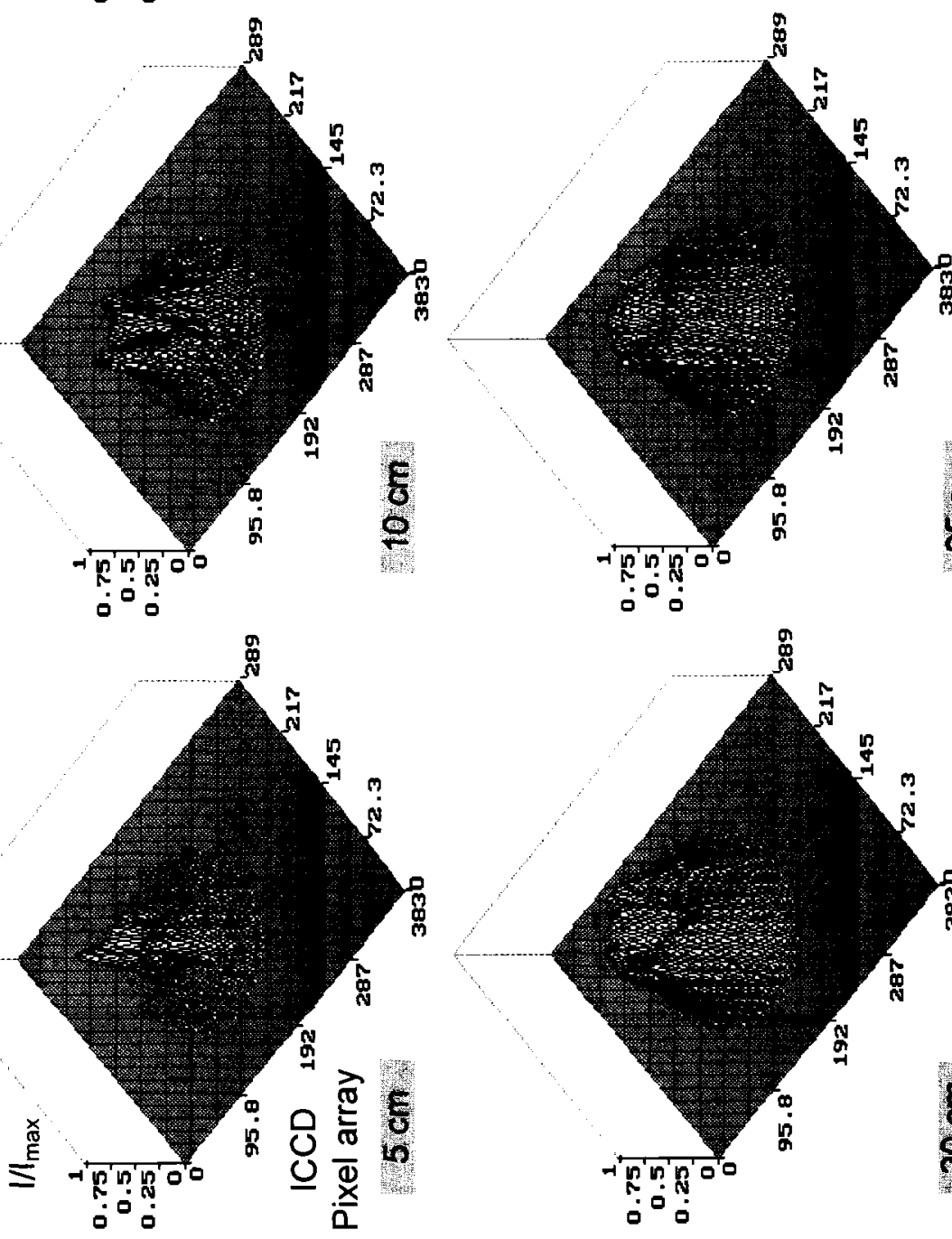

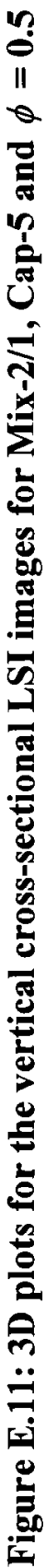



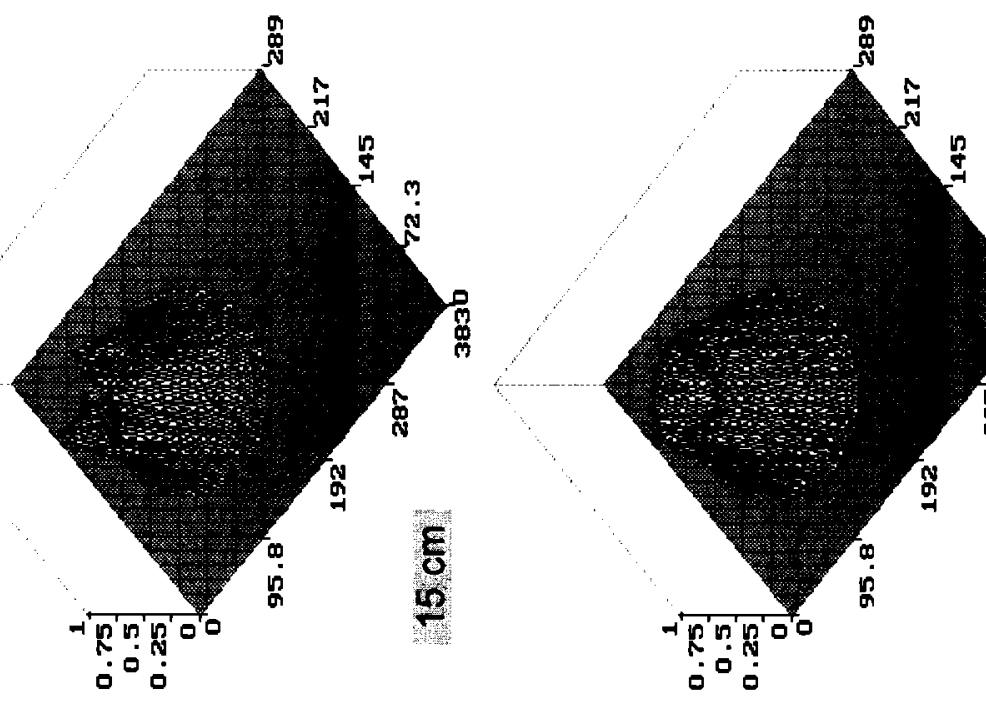

$\underset{m}{\infty}$
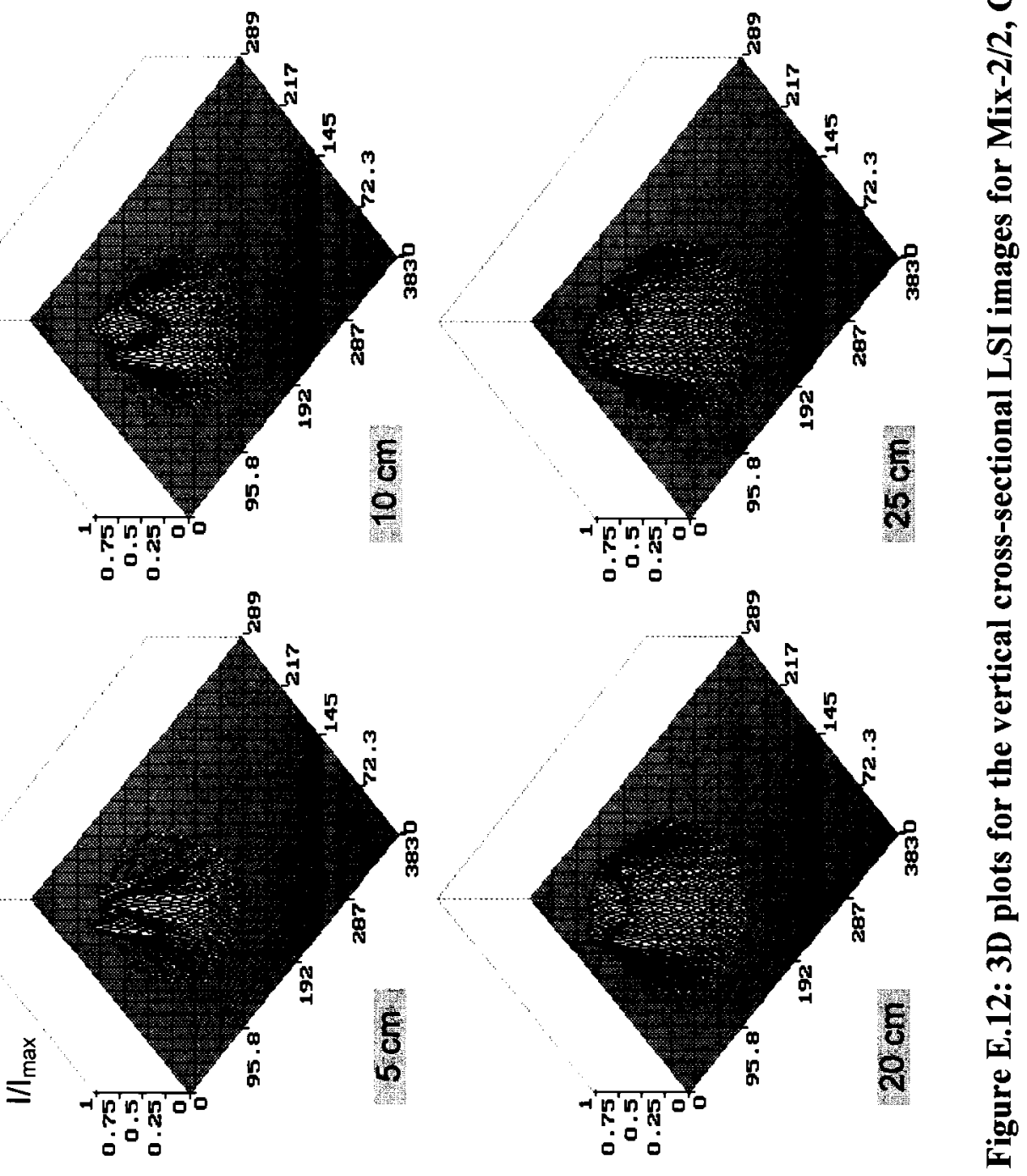

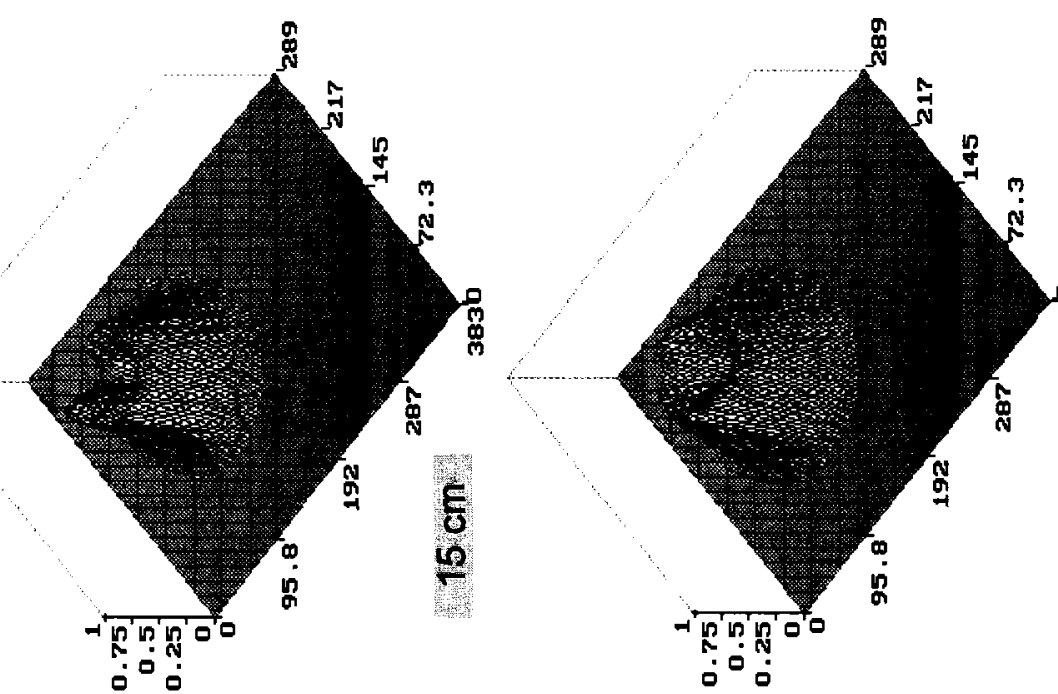

$\underset{\infty}{\infty}$
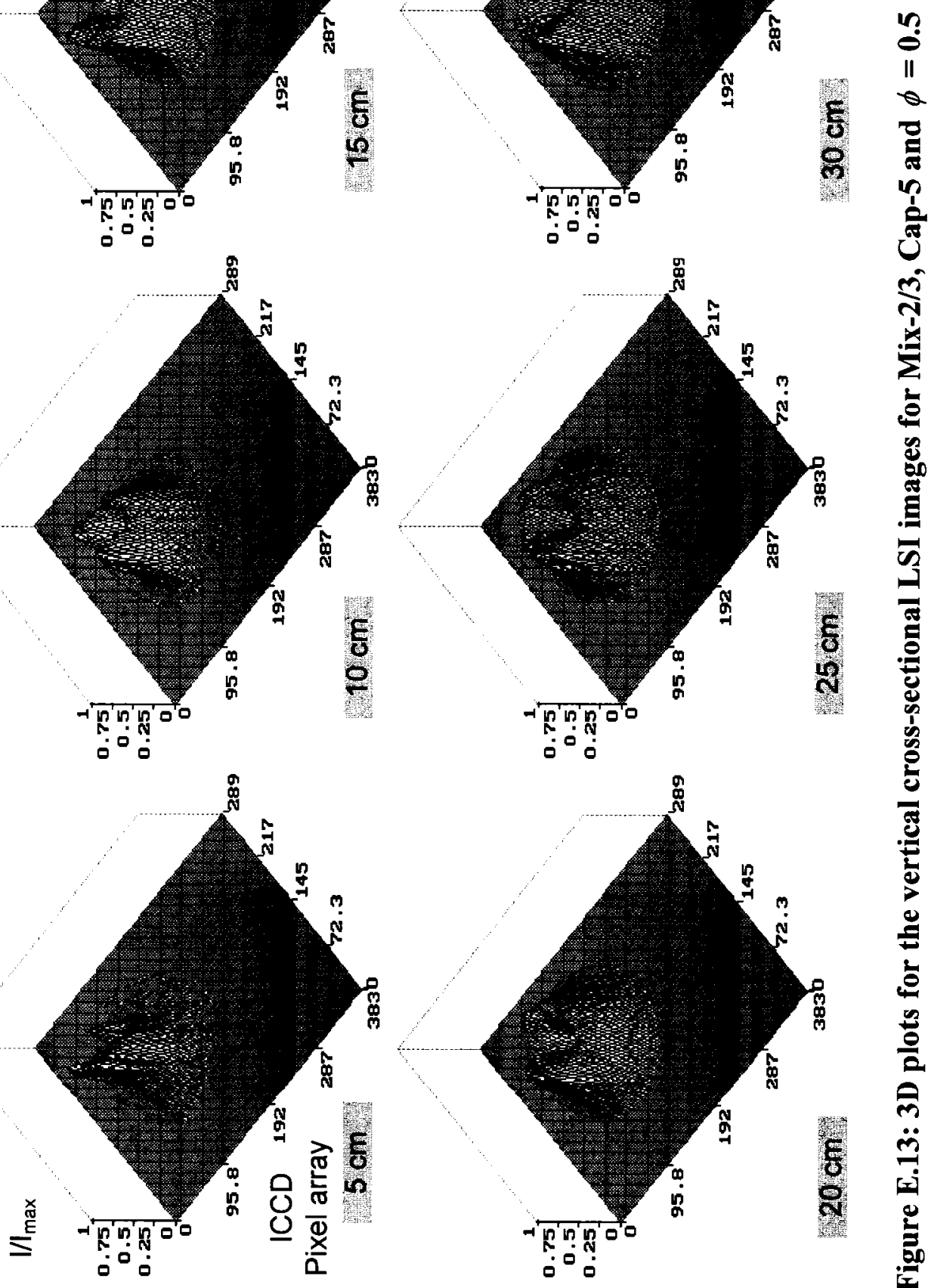

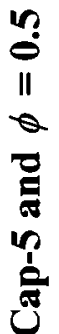

ֻ

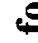

总

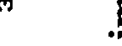




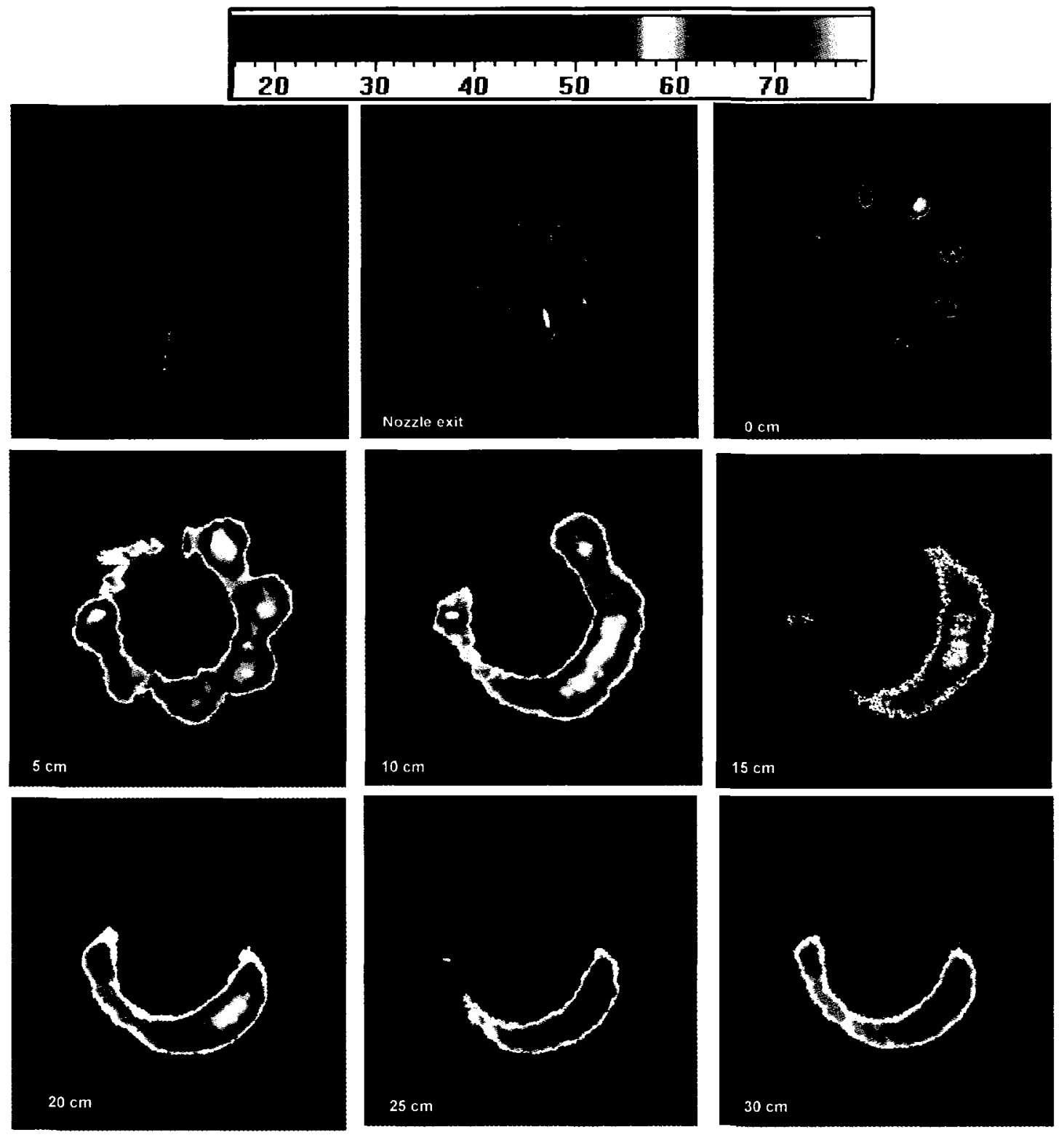

Figure E.14: Vertical cross-sectional LSI images (Mix-1/1 and Cap-1 with $\phi=$ 0.5) 

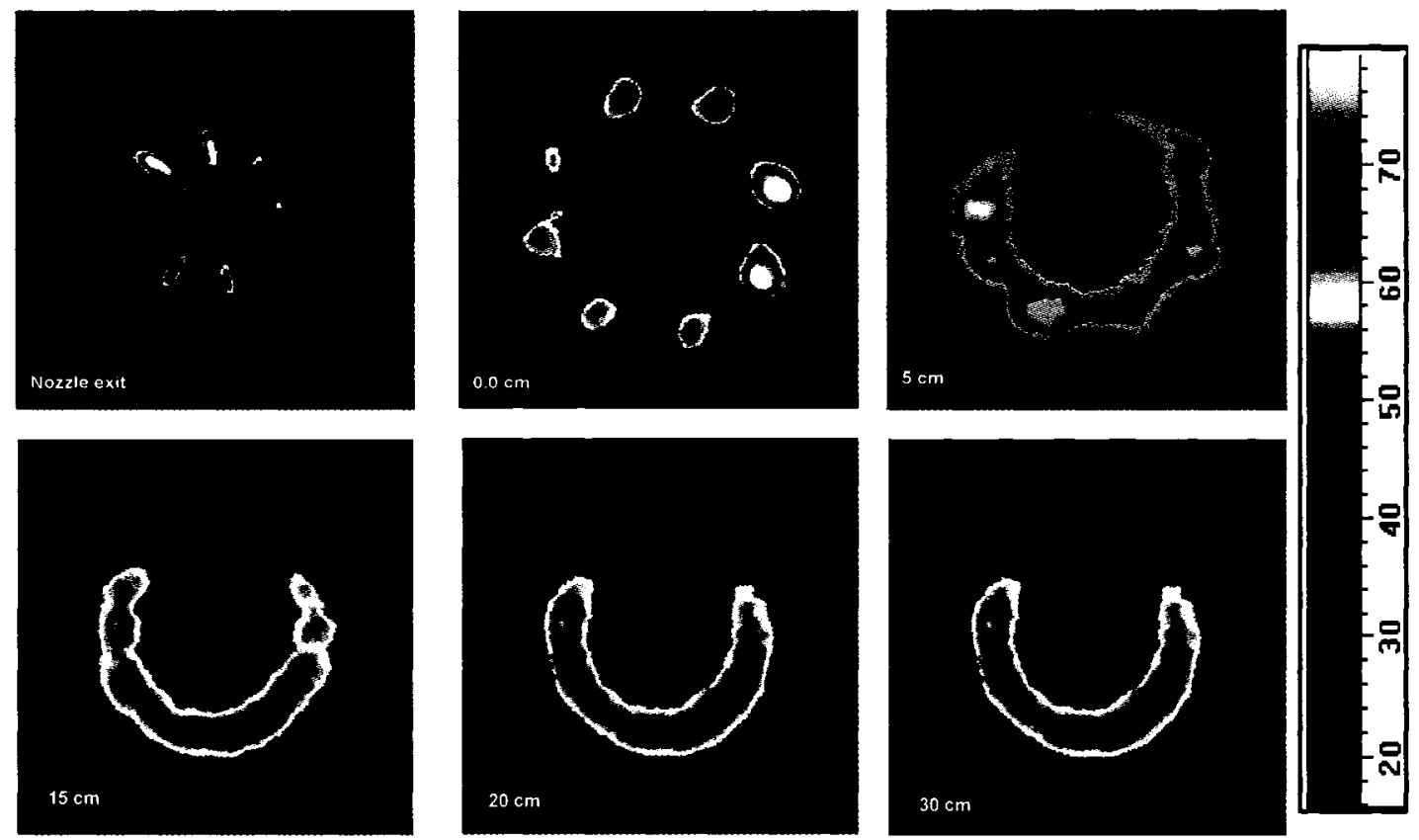

Figure E.15: Vertical cross-sectional LSI images (Mix-1/2 and Cap-1 with $\phi=$ 0.5)
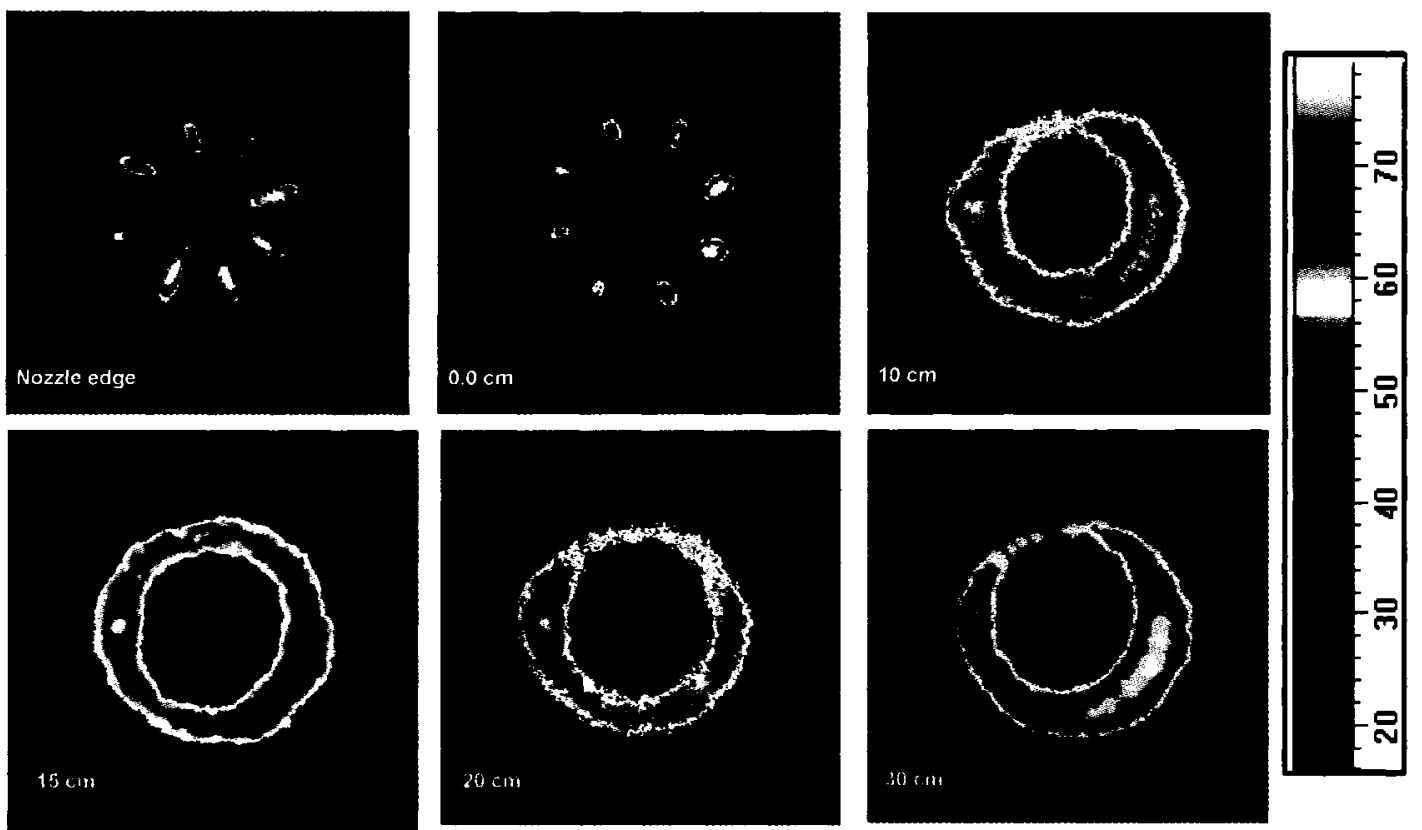

Figure E.16: Vertical cross-sectional LSI images (Mix-2/1 and Cap-1 with $\phi=$ 0.5) 

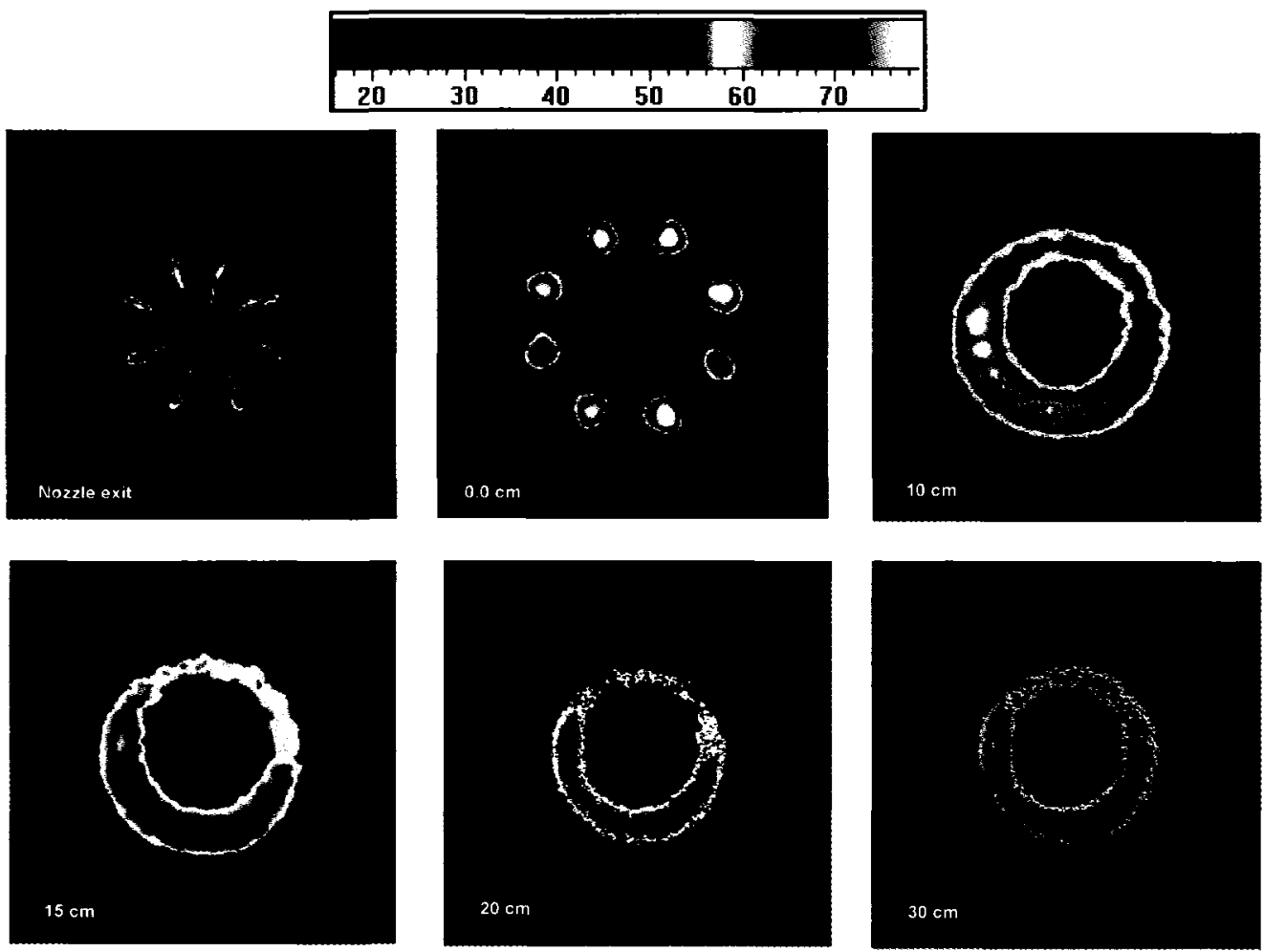

Figure E.17: Vertical cross-sectional LSI images (Mix-2/2 and Cap-1 with $\phi=$ 0.5)
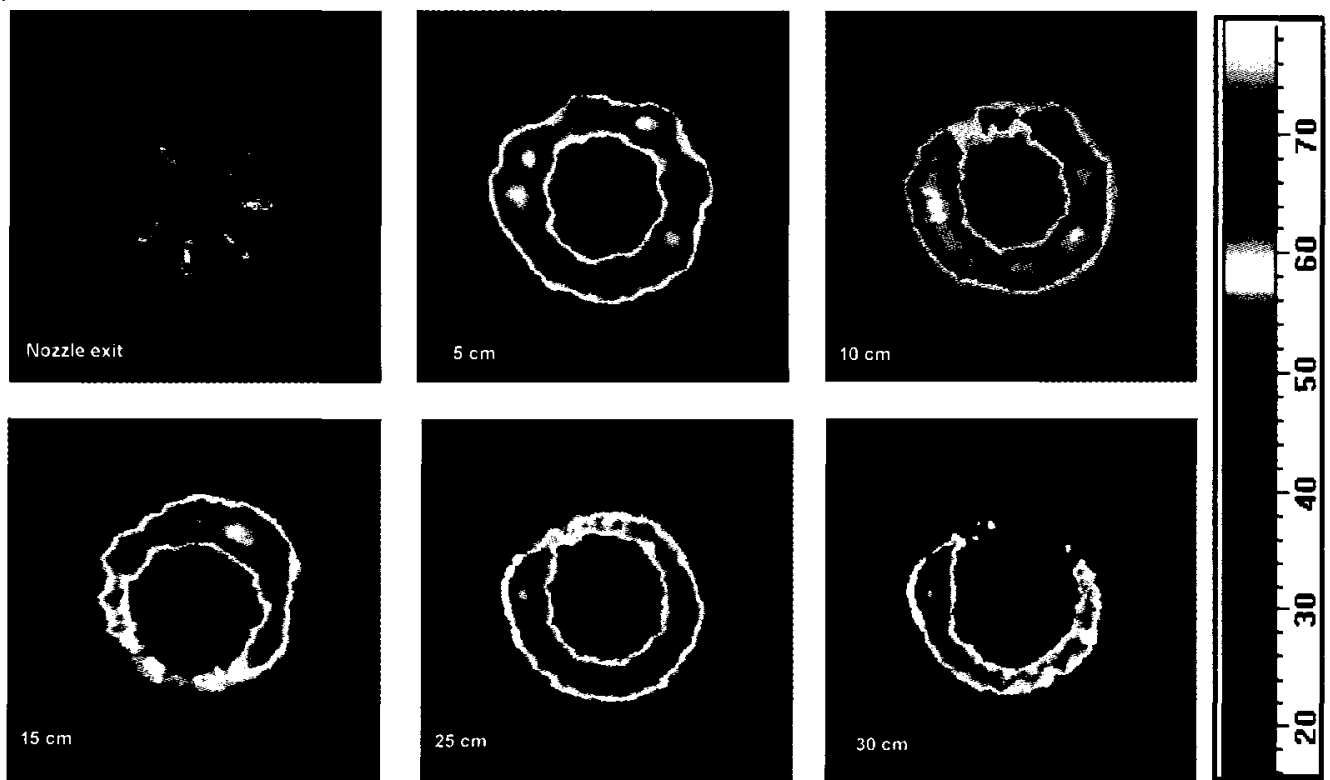

Figure E.18: Vertical cross-sectional LSI images (Mix-2/3 and Cap-1 with $\phi=$ 0.5) 


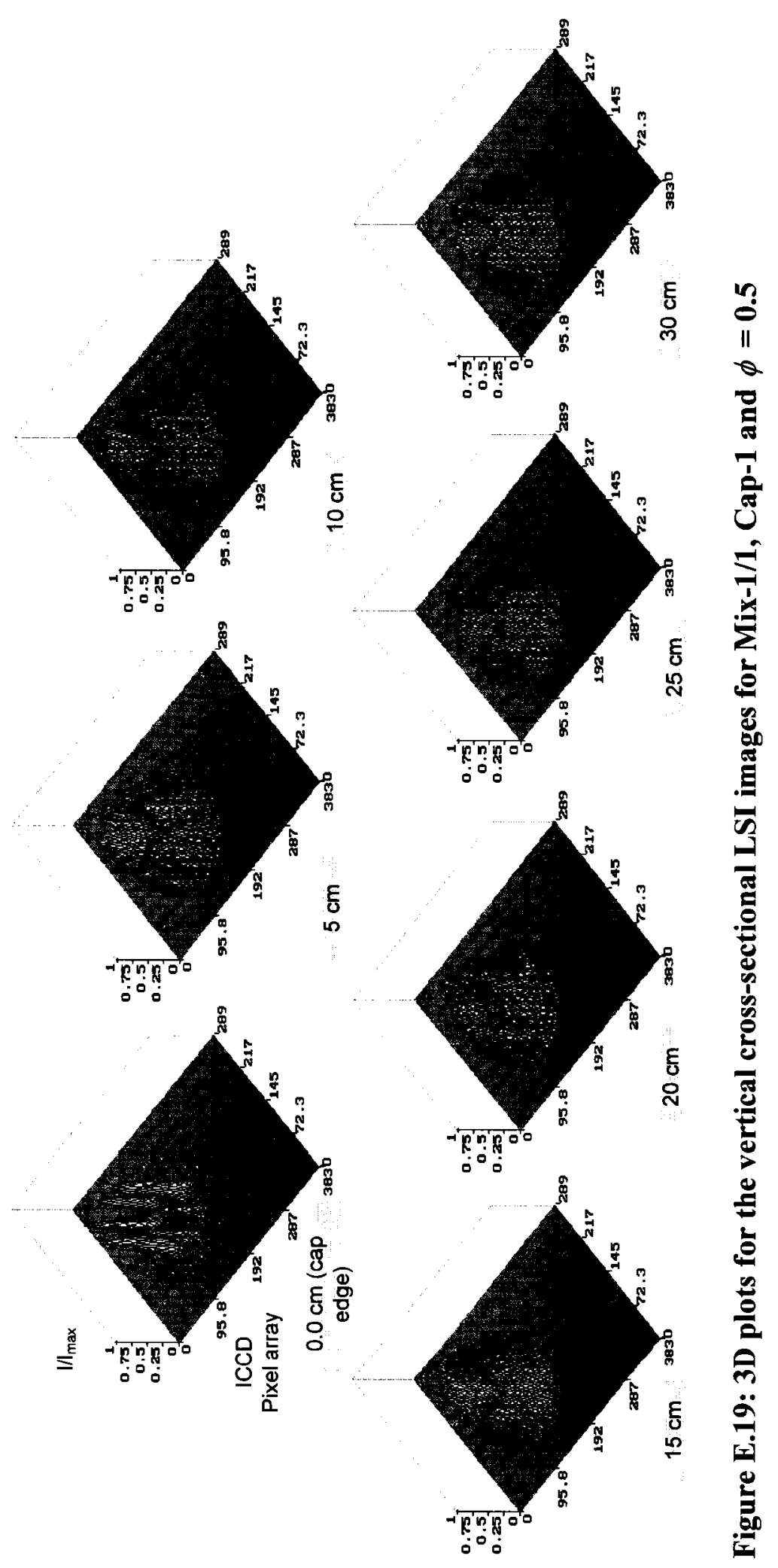

$\underset{\infty}{\infty}$ 

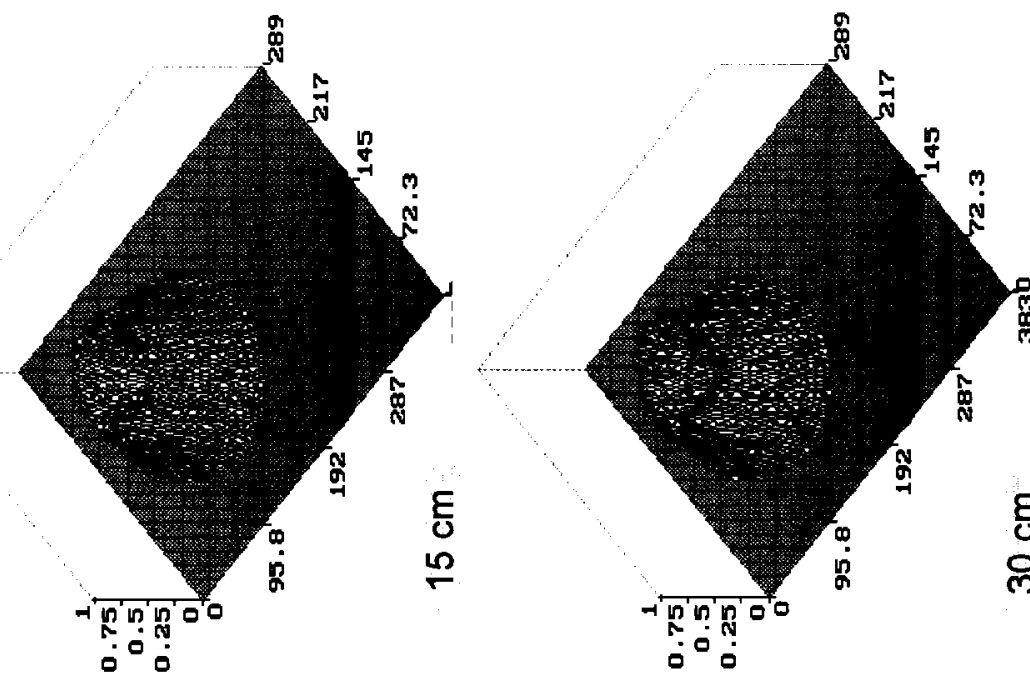

$\infty$
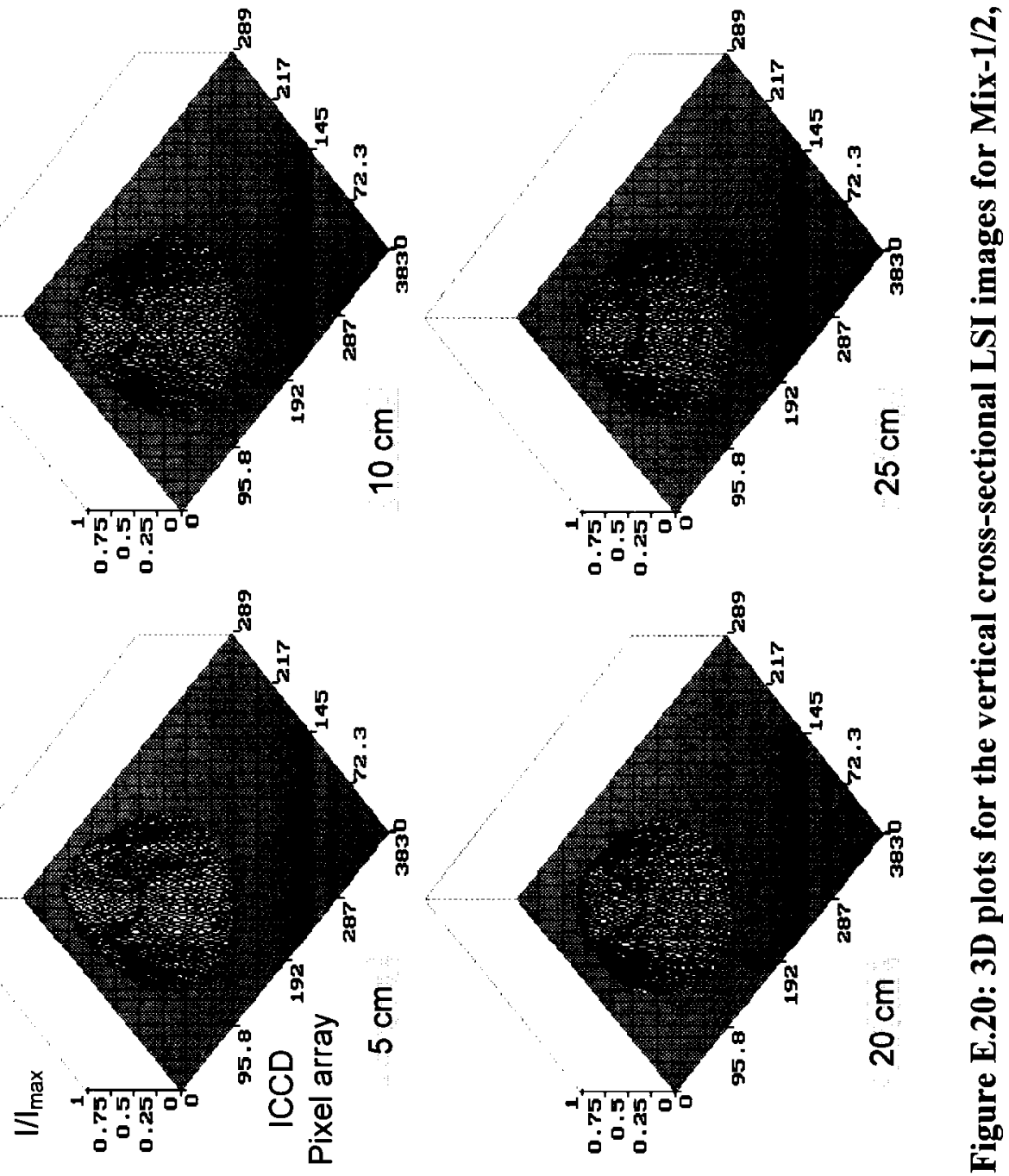


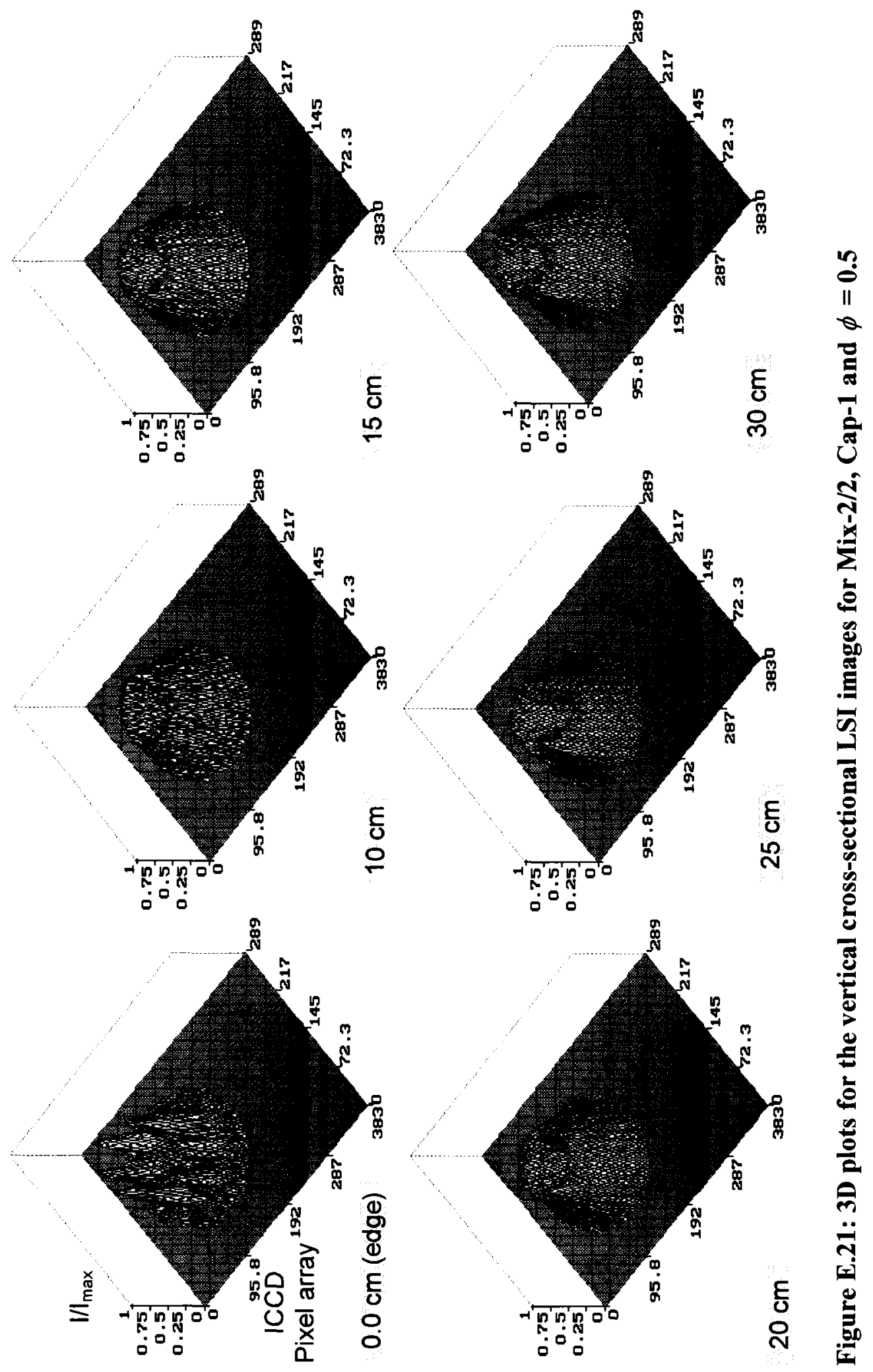

$\infty$ 

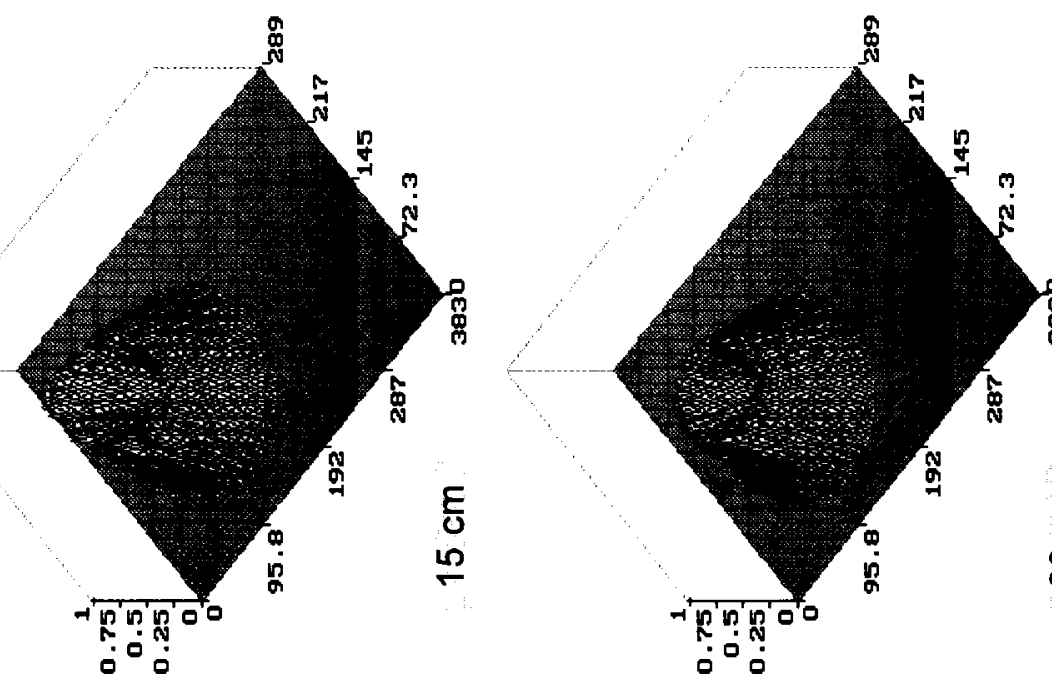

$\stackrel{\infty}{\infty}$
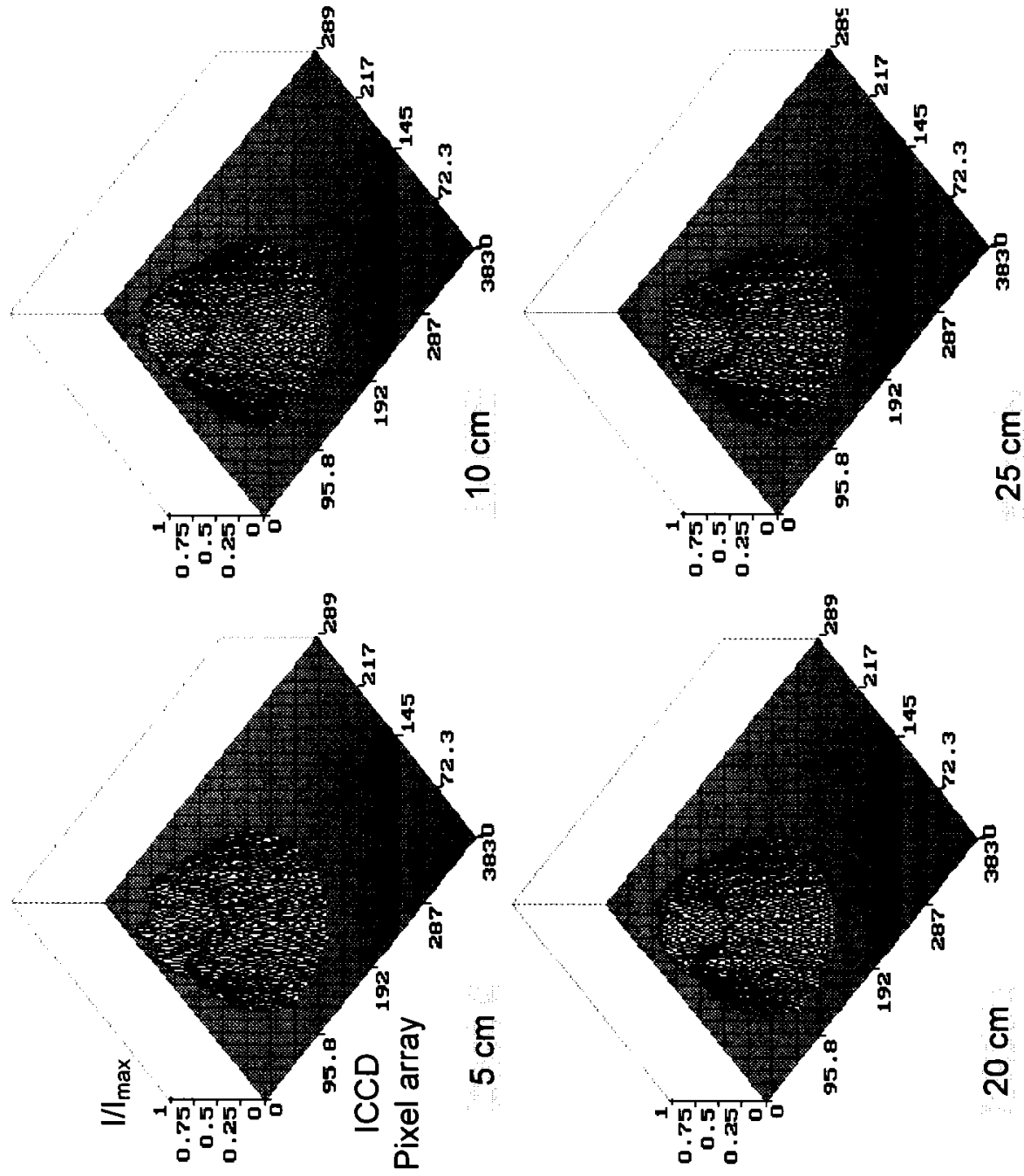

옹 


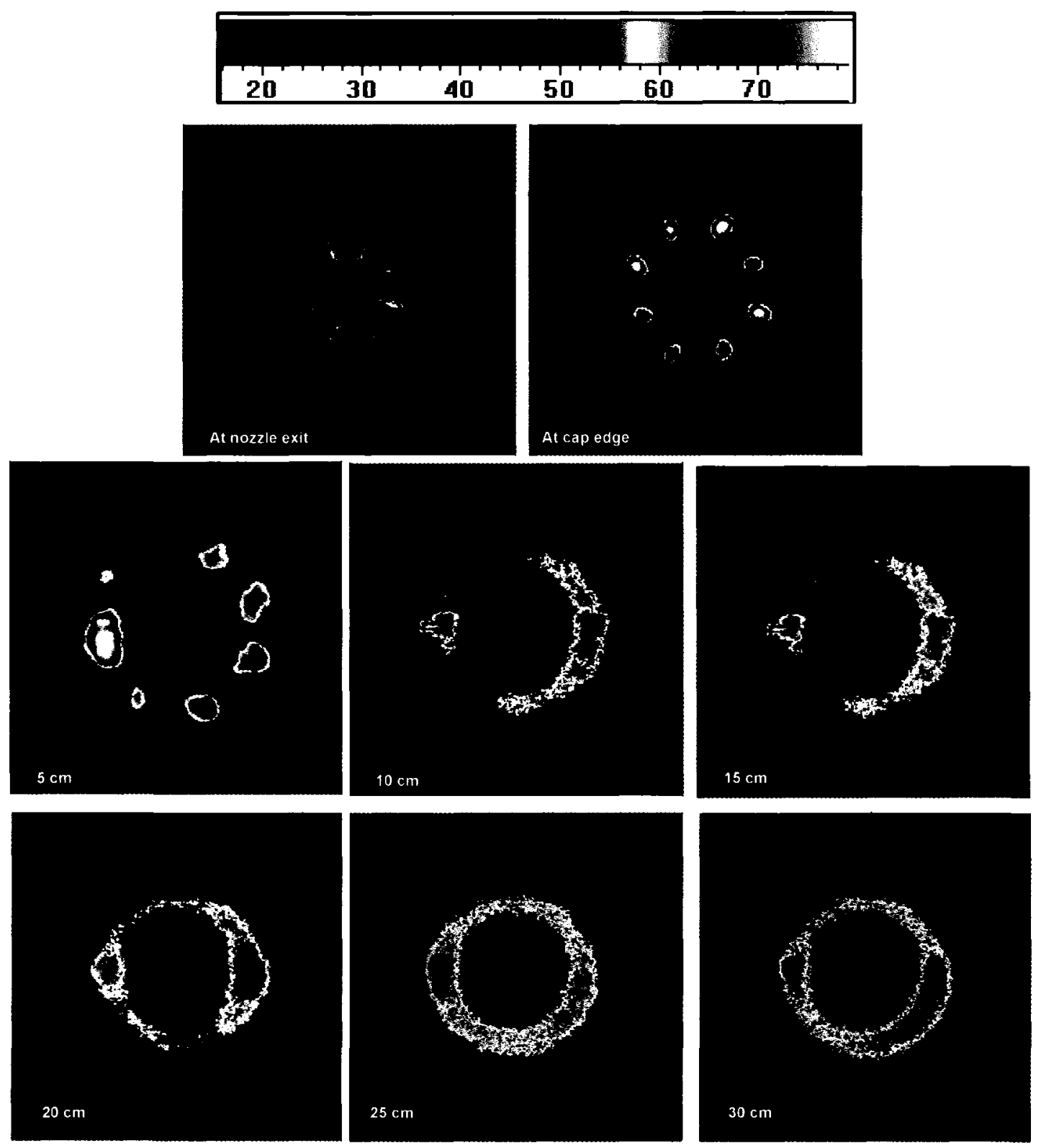

Figure E.23: Vertical cross-sectional LSI images (Mix-1/1 and Cap-2 with $\phi=$ 0.5) 


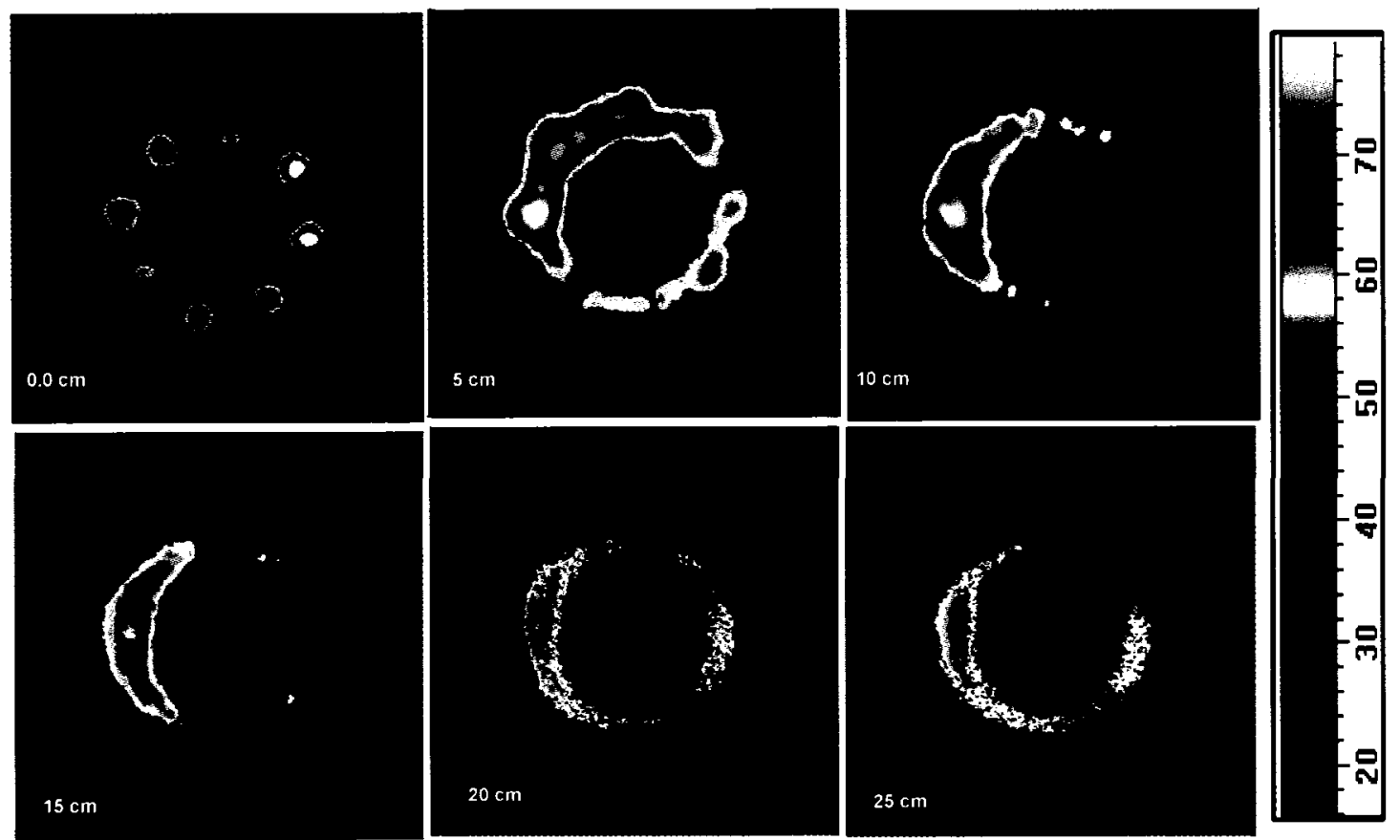

Figure E.24: Vertical cross-sectional LSI images (Mix-1/2 and Cap-2 with $\phi=$ 0.5)
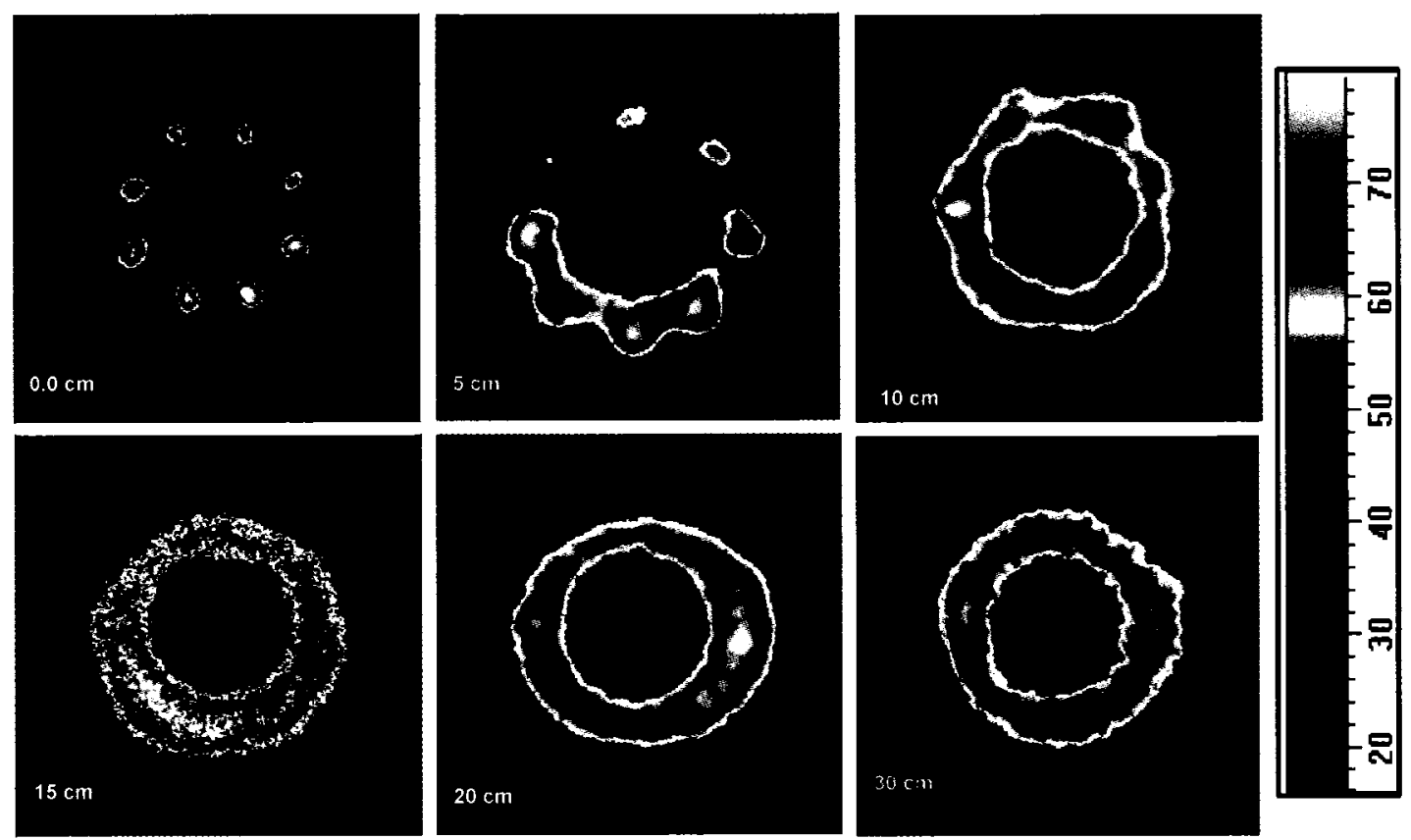

Figure E.25: Vertical cross-sectional LSI images (Mix-2/1 and Cap-2 with $\phi=$ 0.5) 


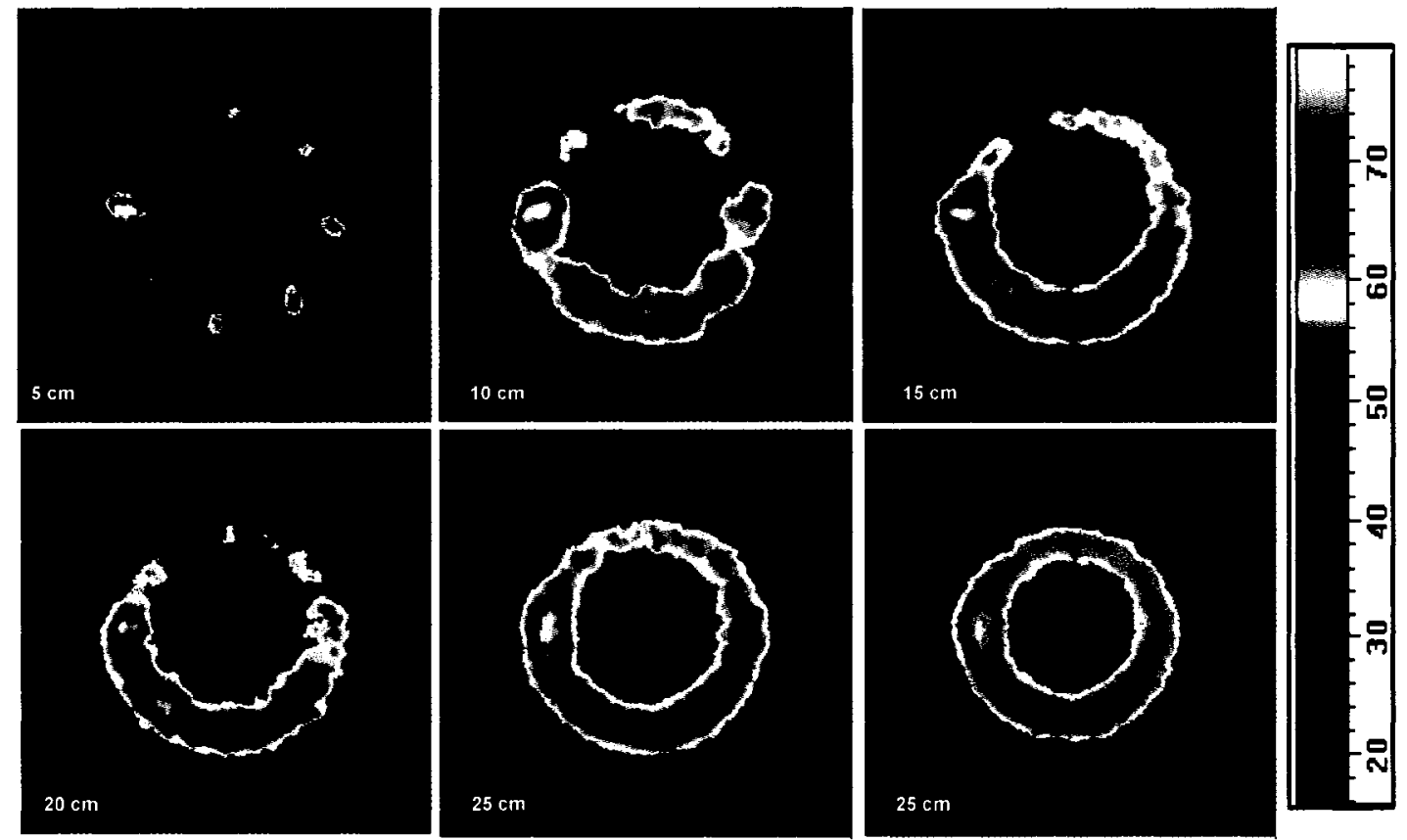

Figure E.26: Vertical cross-sectional LSI images (Mix-2/2 and Cap-2 with $\phi=$ 0.5)

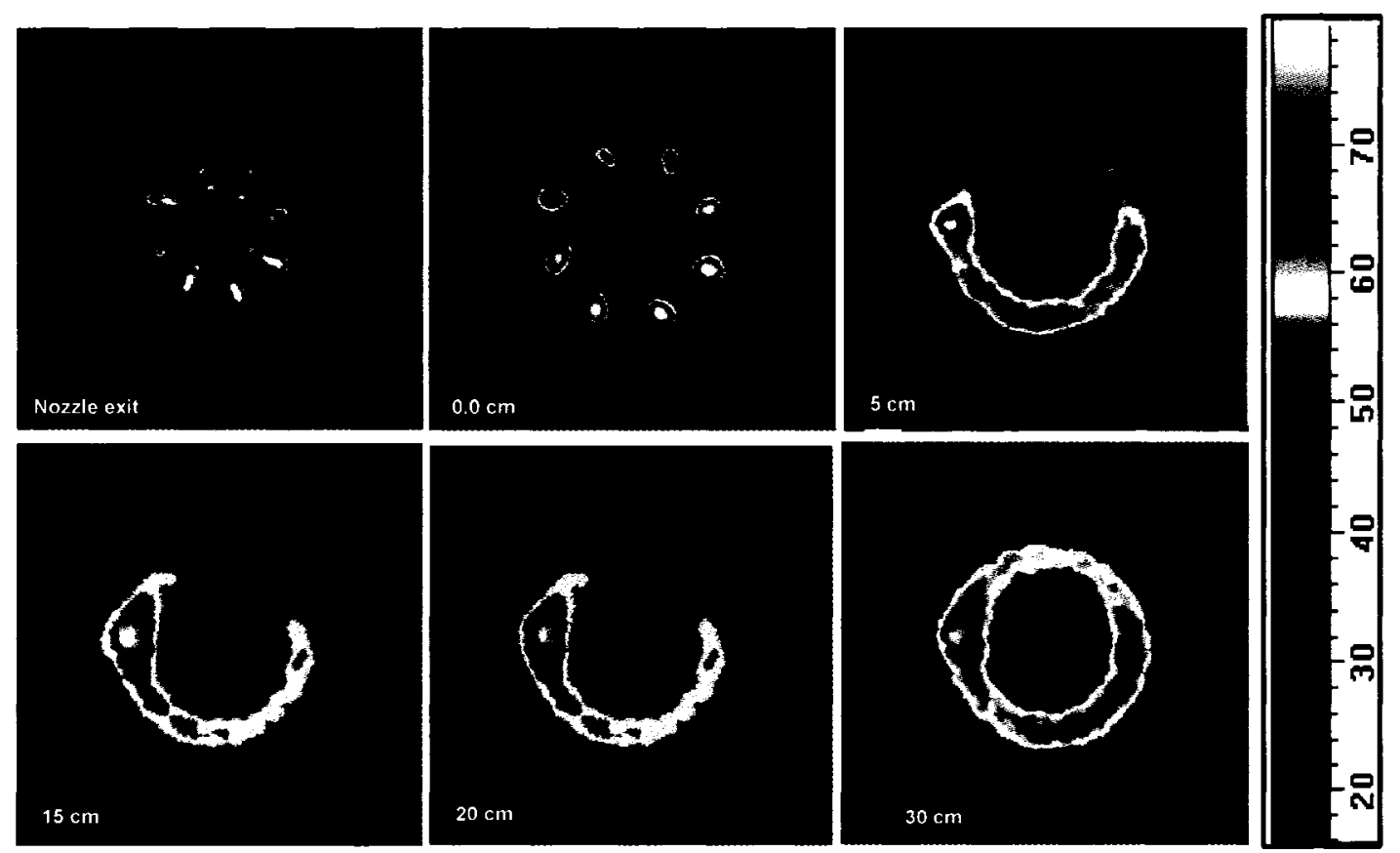

Figure E.27: Vertical cross-sectional LSI images (Mix-2/3 and Cap-2 with $\phi=$ 0.5) 

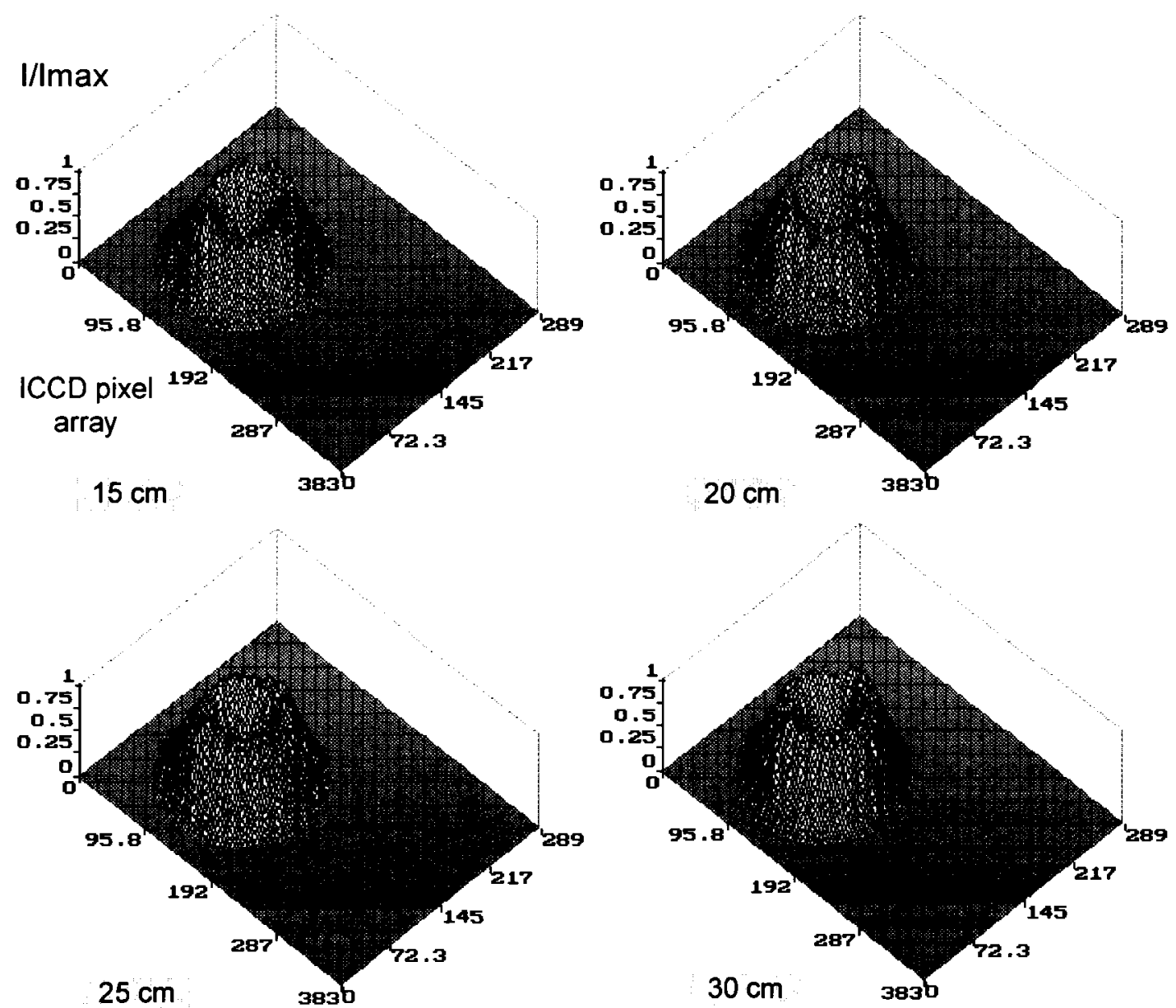

Figure E.28: 3D plots for the vertical cross-sectional LSI images (Mix-1/1, Cap-2 and with $\phi=0.5$ ) 

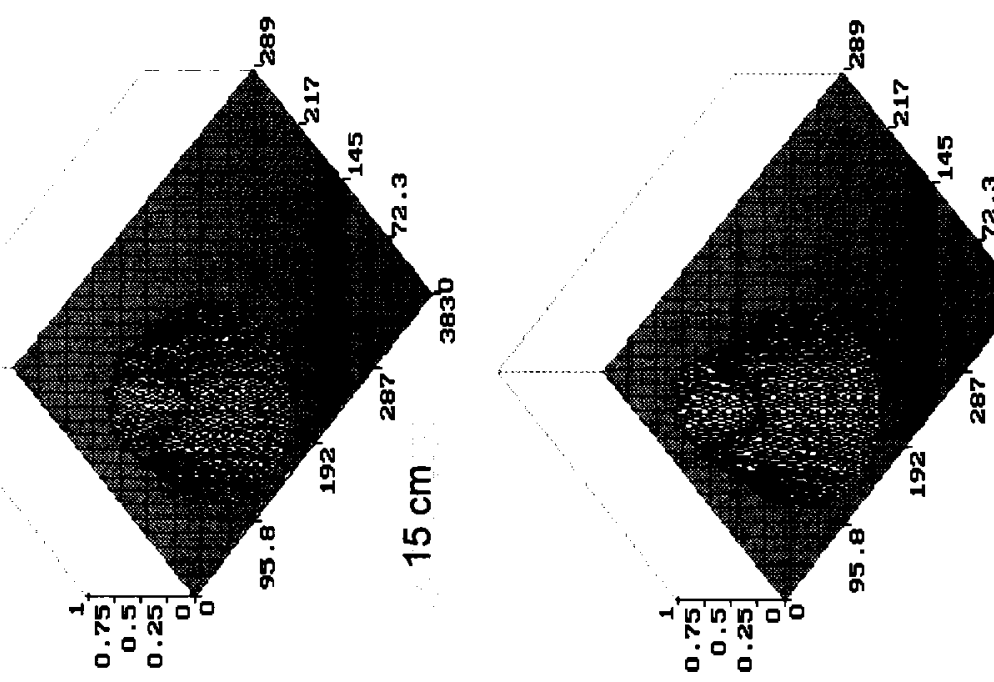

ฐ
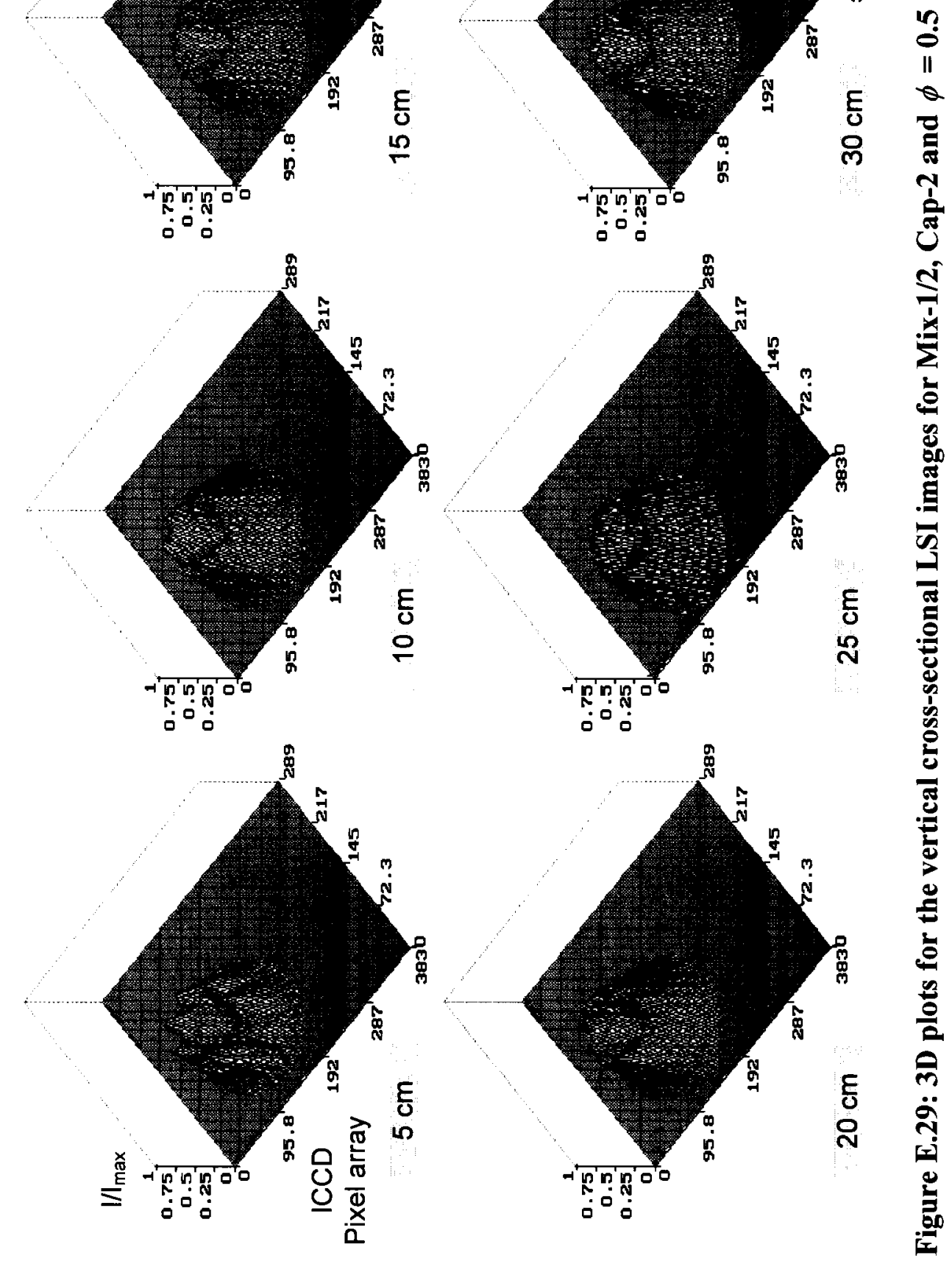

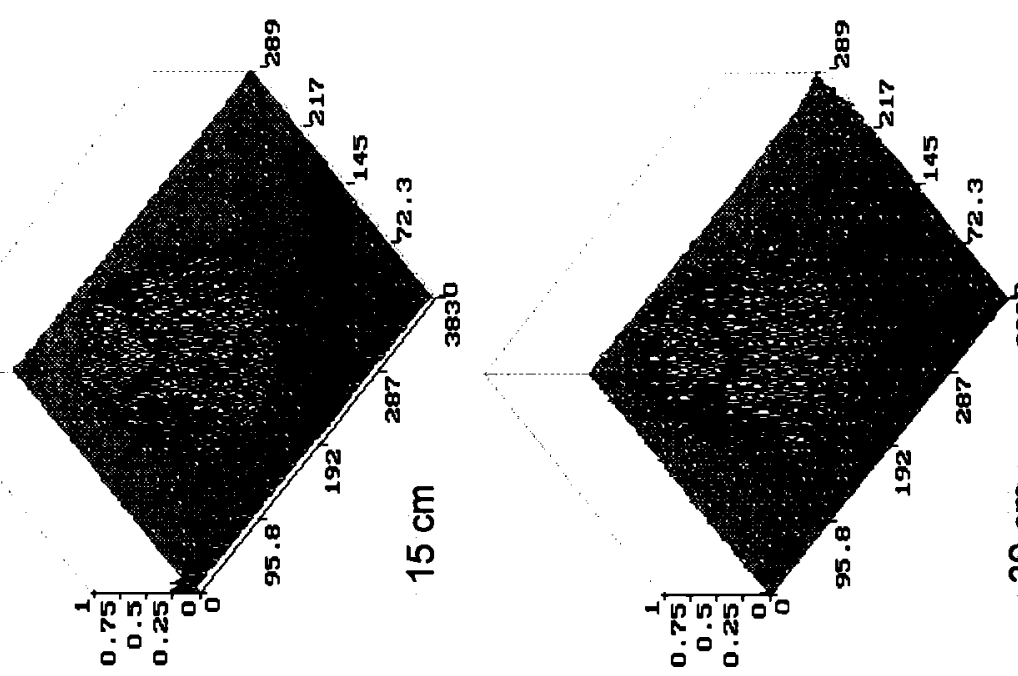

$\stackrel{\circ}{\circ}$
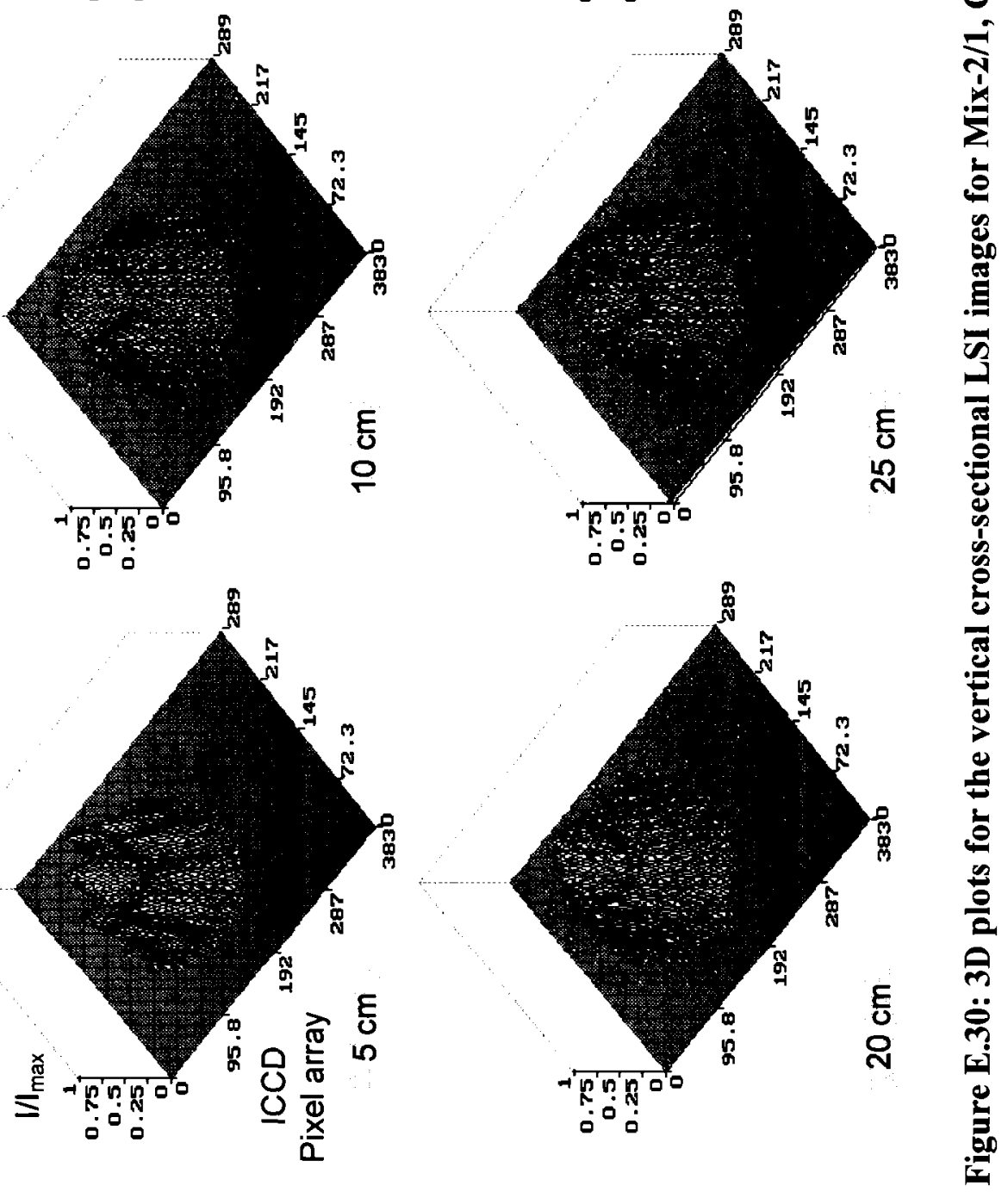

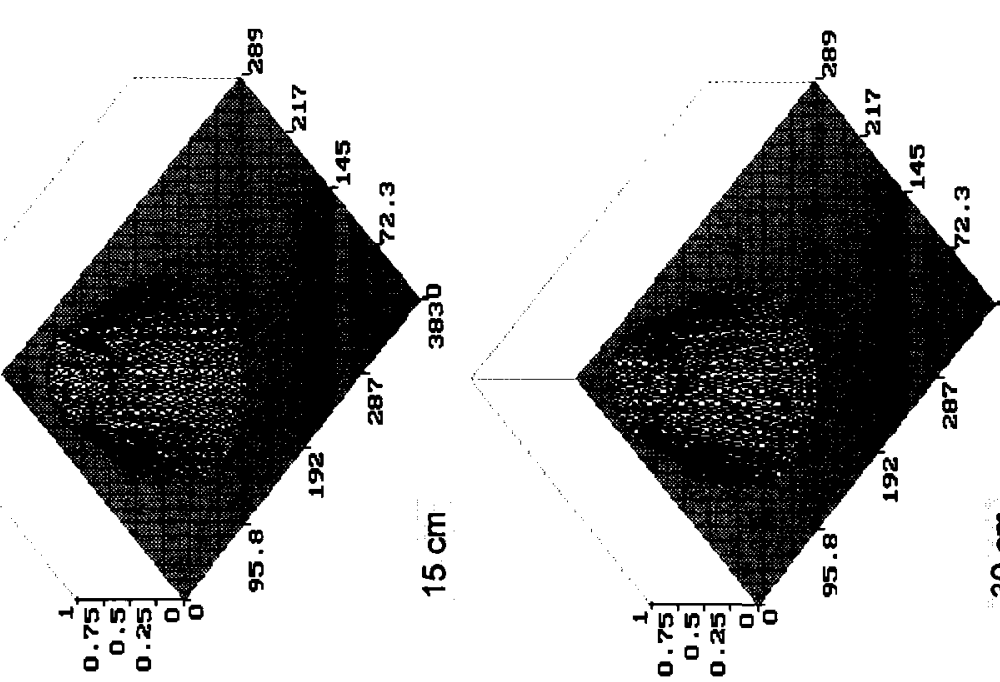

กั
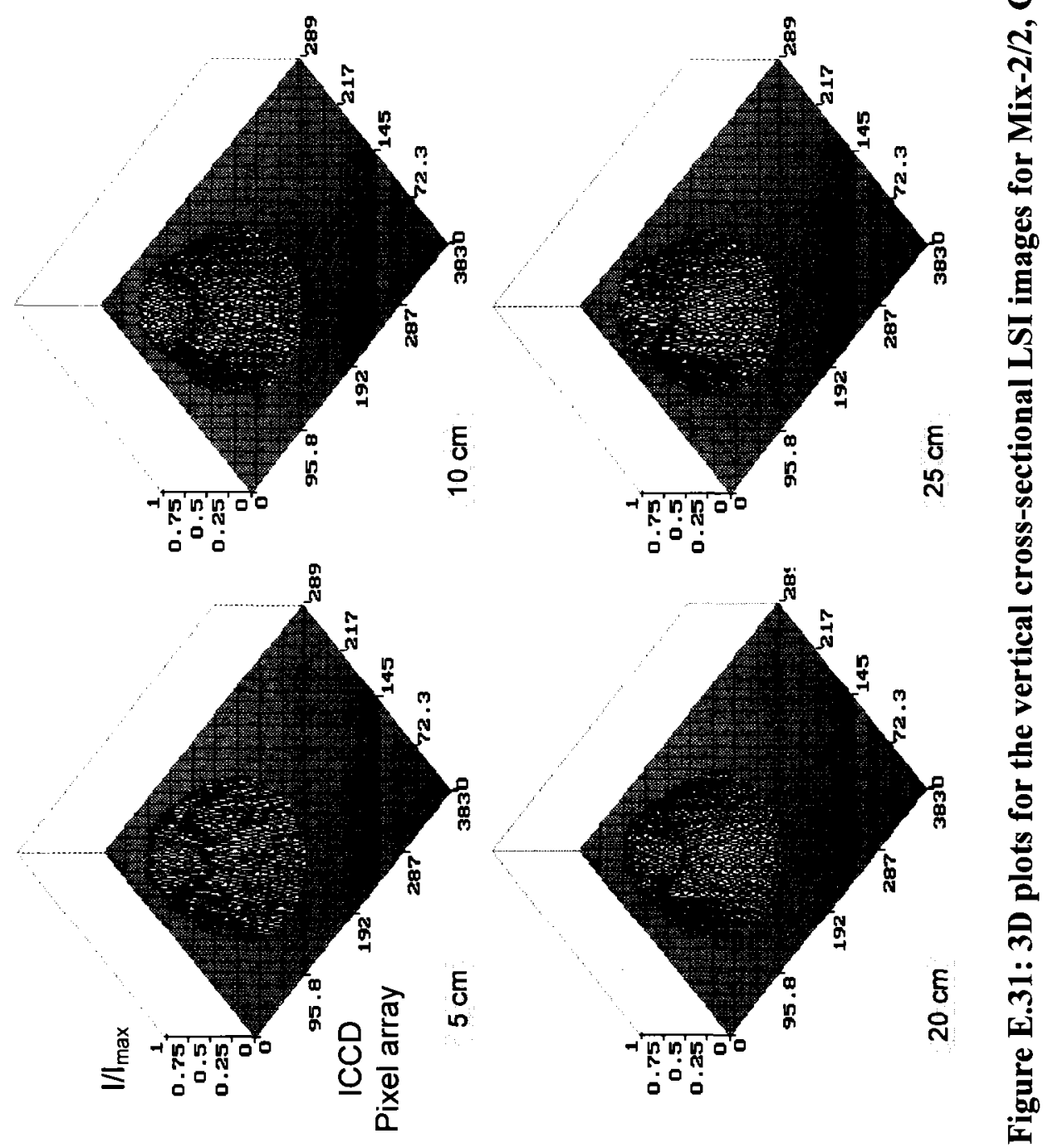

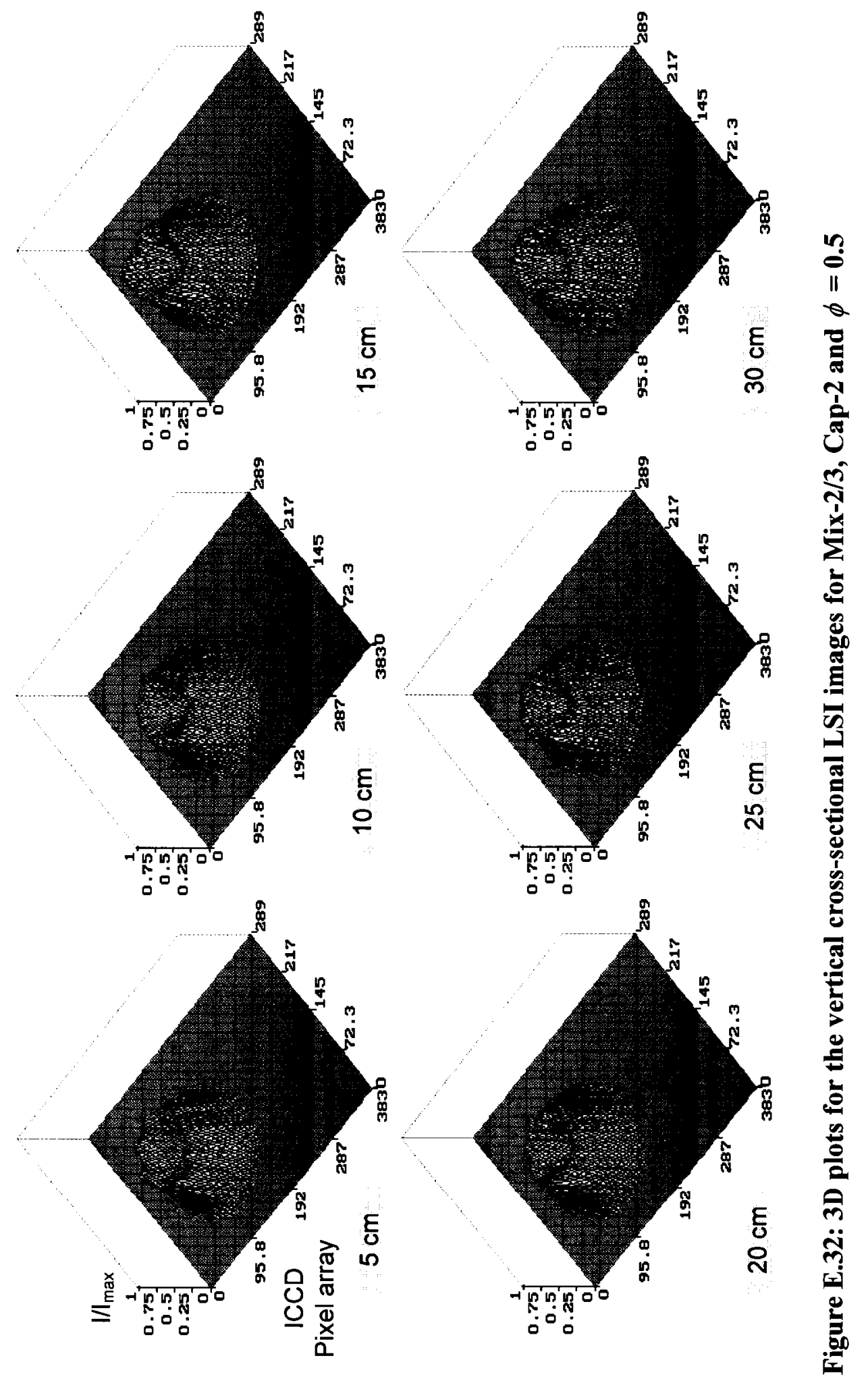

a 

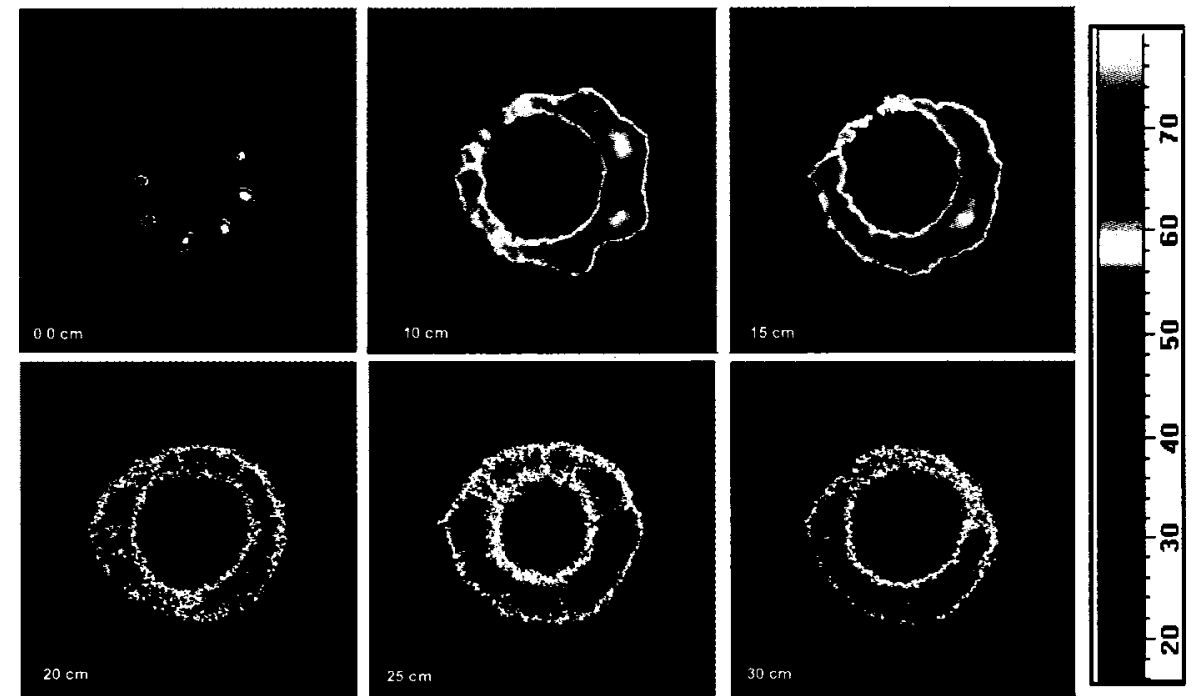

Figure E.33: Vertical cross-sectional LSI images (Mix-1/1 and Cap-3 with $\phi=$ 0.5)
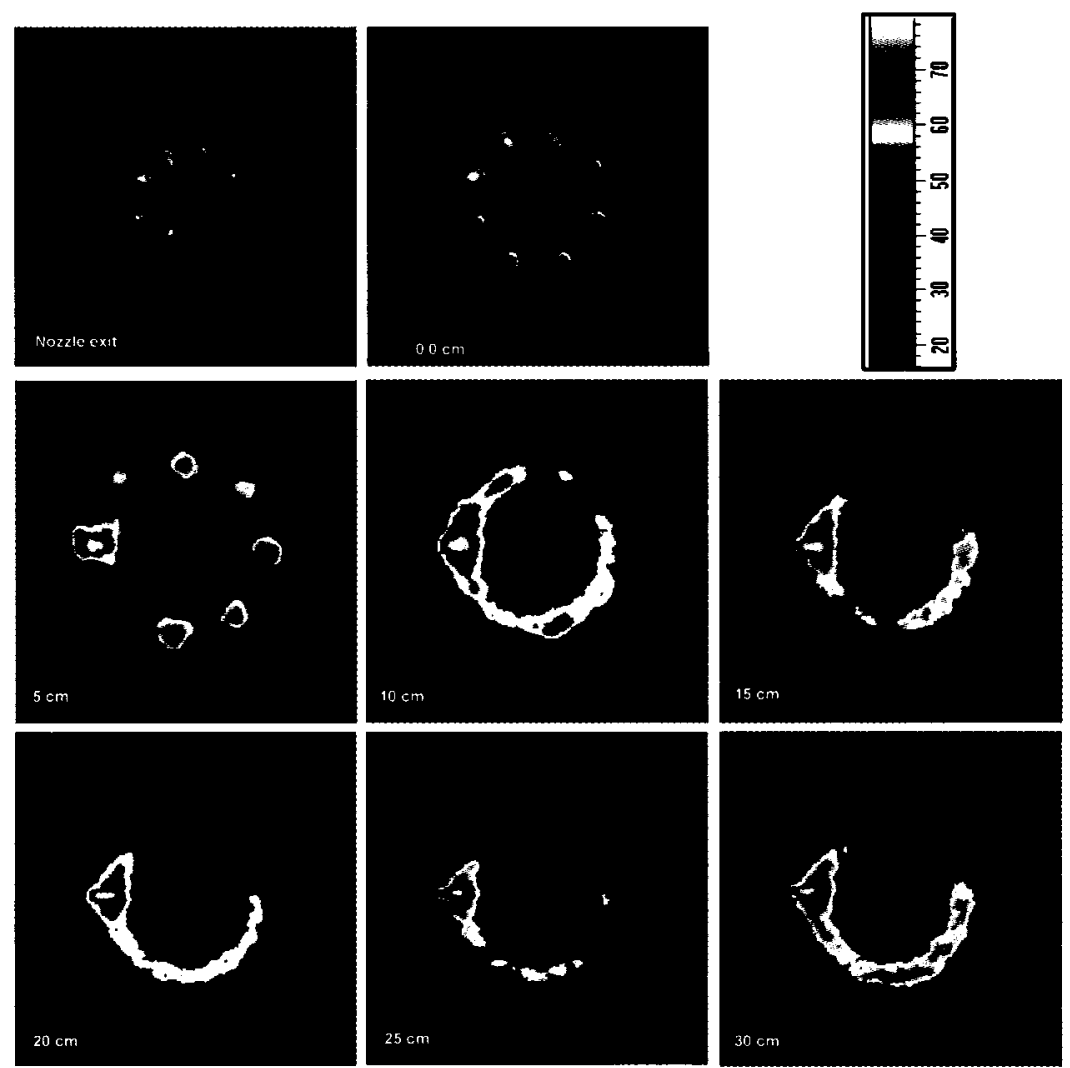

Figure E.34: Vertical cross-sectional LSI images (Mix-1/2 and Cap-3 with $\phi=$ 0.5) 
Figure E.34: Vertical cross-sectional LSI images (Mix-1/2 and Cap-3 with $\phi=$ 0.5)

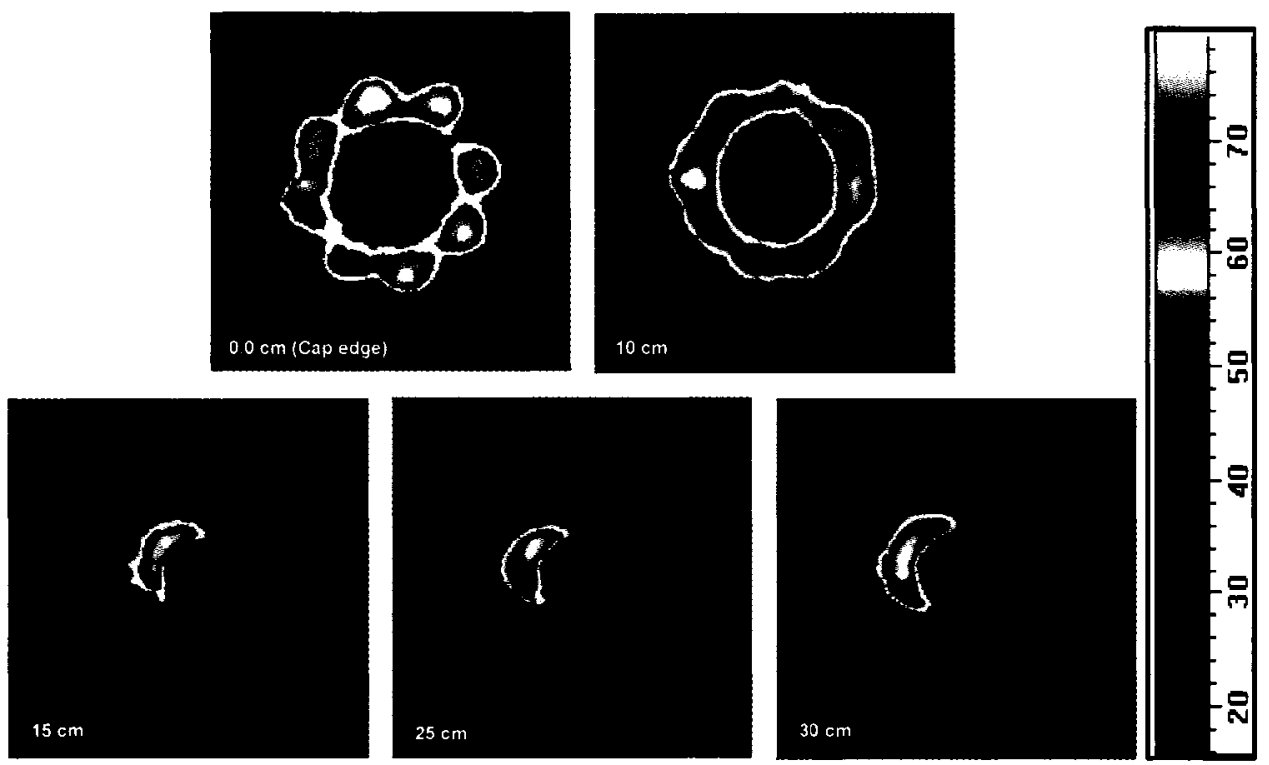

Figure E.35: Vertical cross-sectional LSI images (Mix-2/1 and Cap-3 with $\phi=$ 0.5)
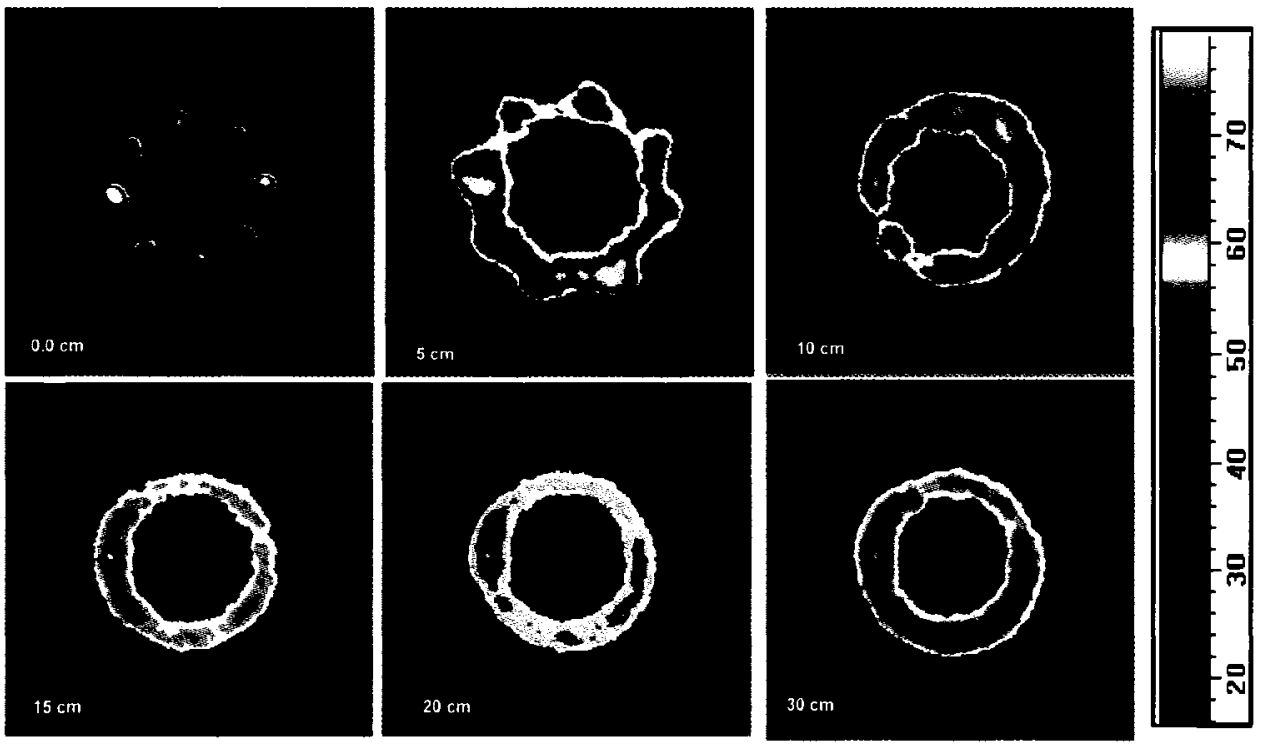

Figure E.36: Vertical cross-sectional LSI images (Mix-2/2 and Cap-3 with $\phi=$ 0.5) 

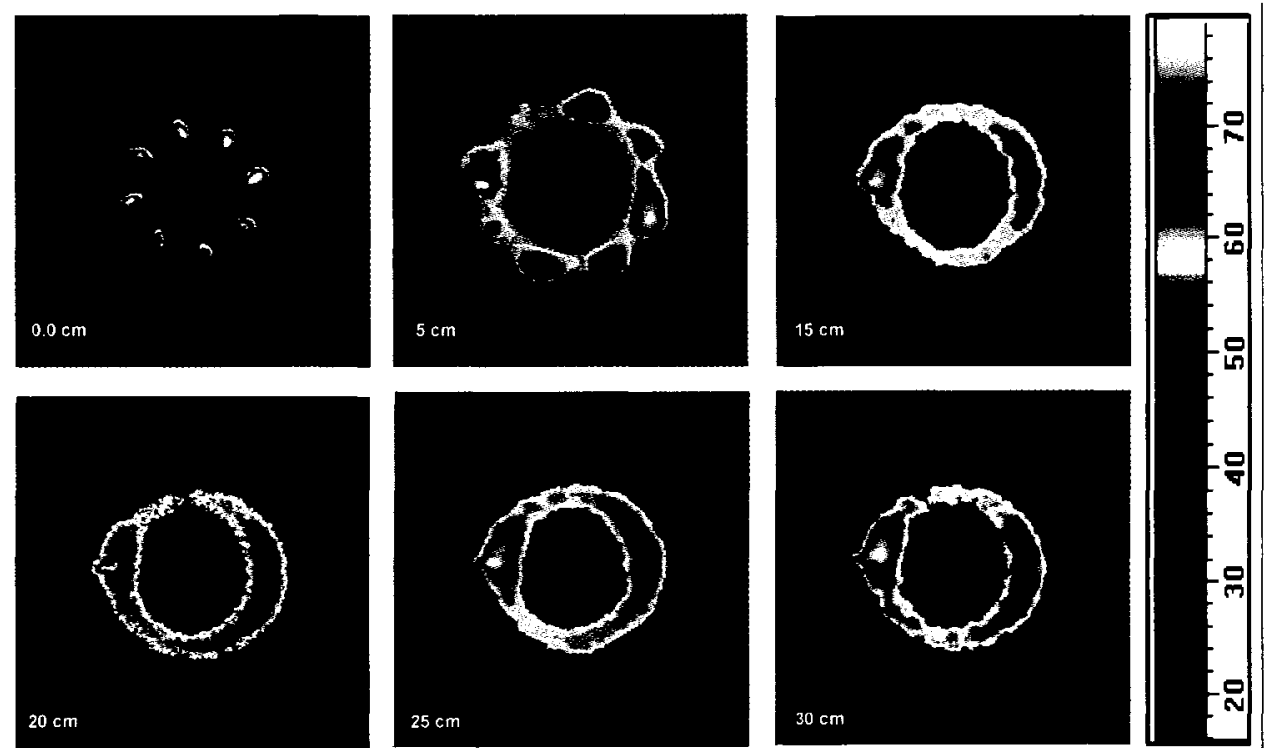

Figure E.37: Vertical cross-sectional LSI images for the Mix-2/3 and Cap-3 ( $\phi=$ 0.5)
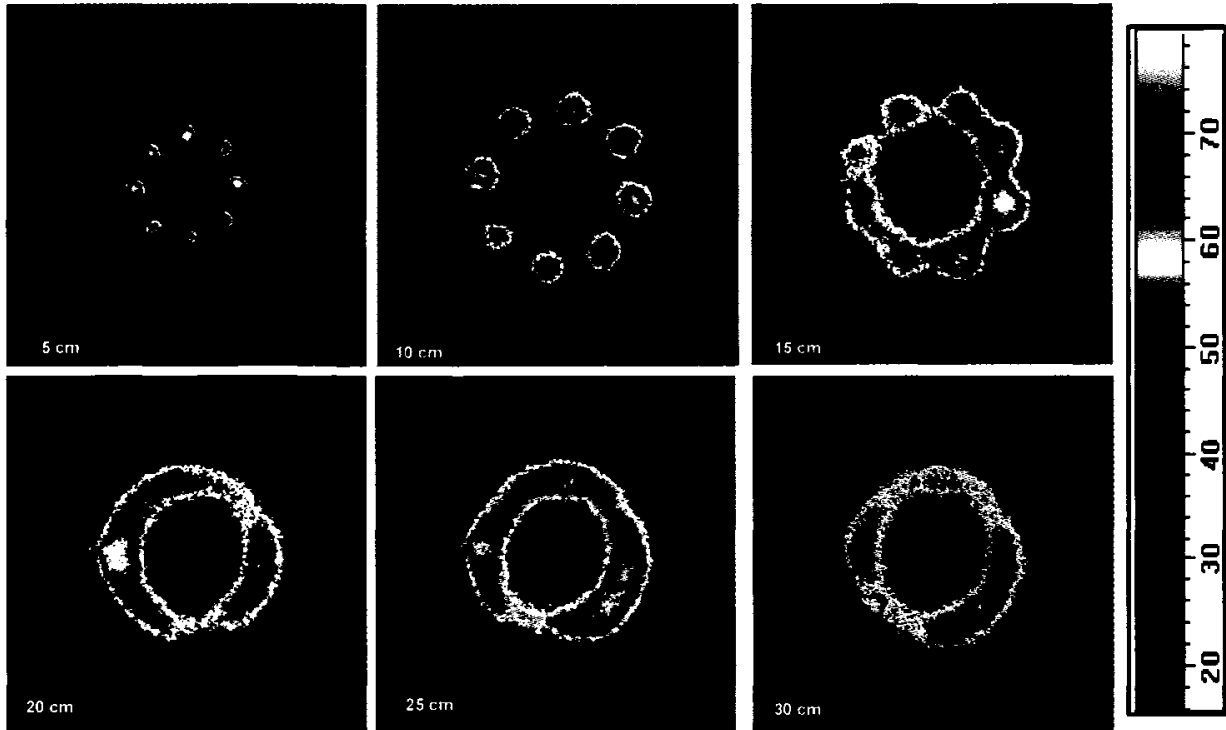

Figure E.38: Vertical cross-sectional LSI images for the Mix-1/1 and Cap-4 ( $\phi=$ 0.5) 


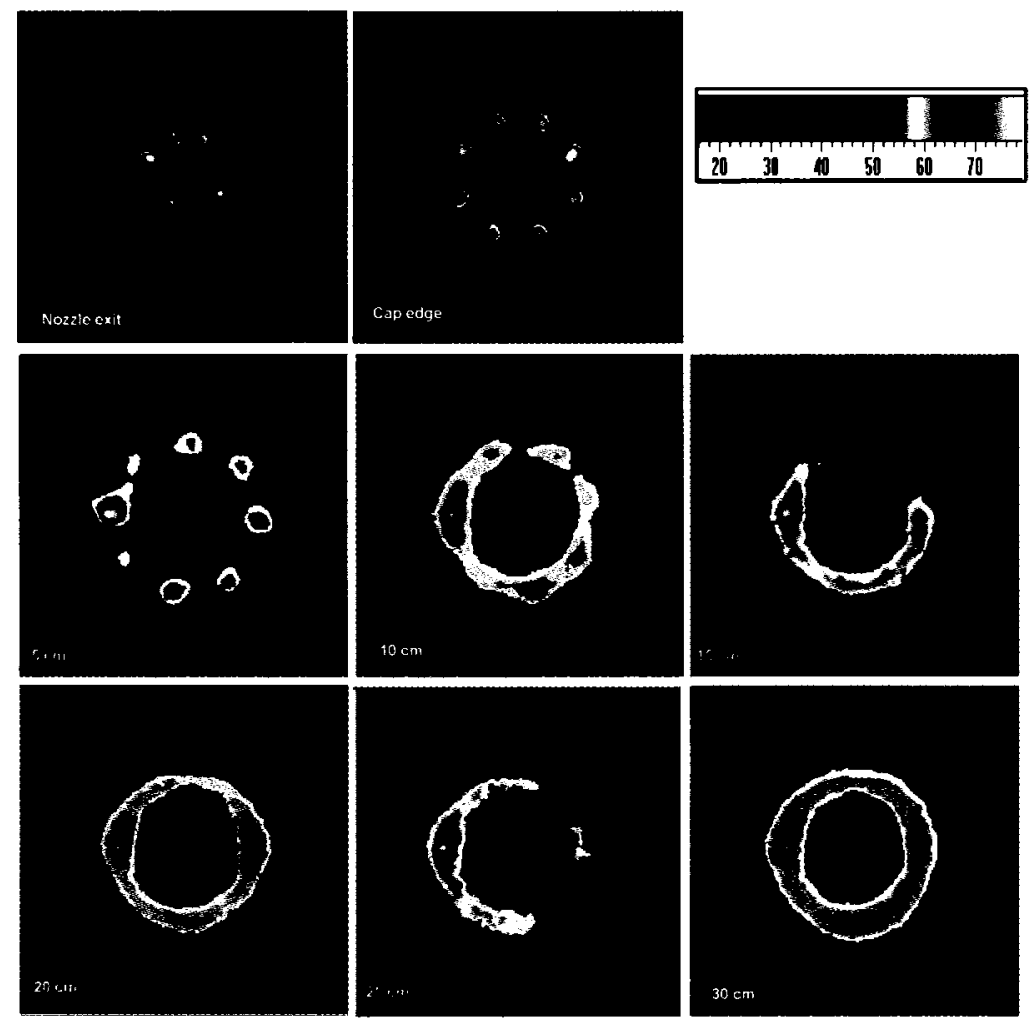

Figure E.39: Vertical cross-sectional LSI images (Mix-1/2 and Cap-4 with $\phi=$ 0.5)
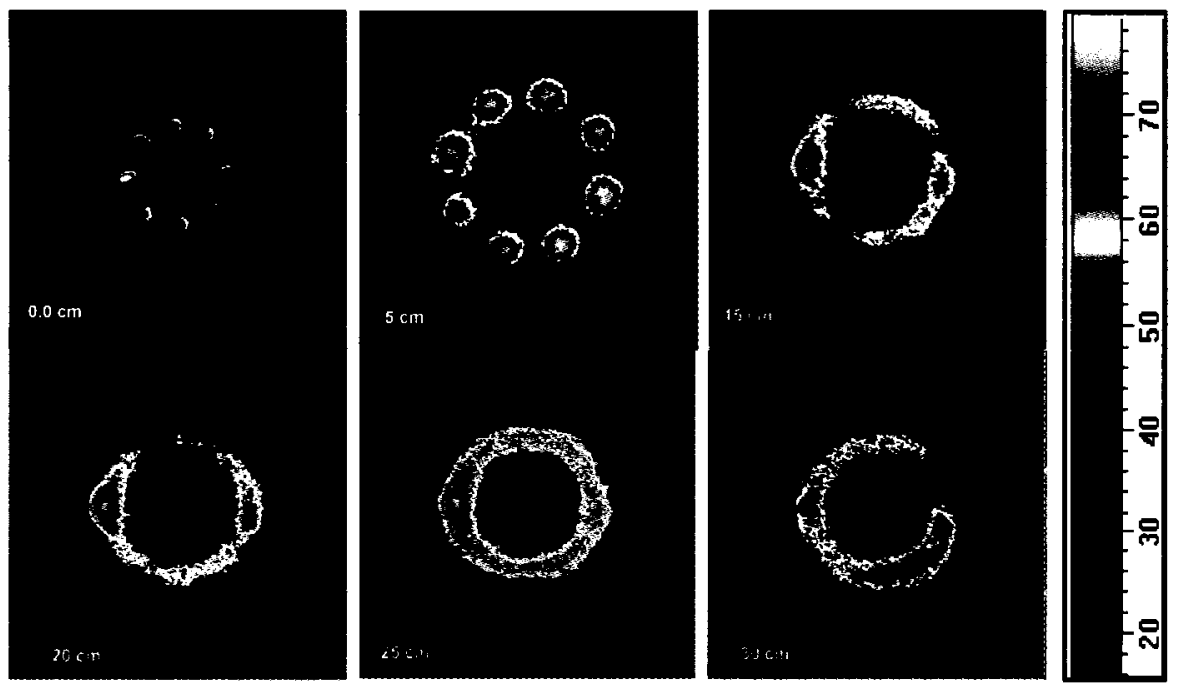

Figure E.40: Vertical cross-sectional LSI images (Mix-2/1 and Cap-4 with $\phi=$ 0.5) 

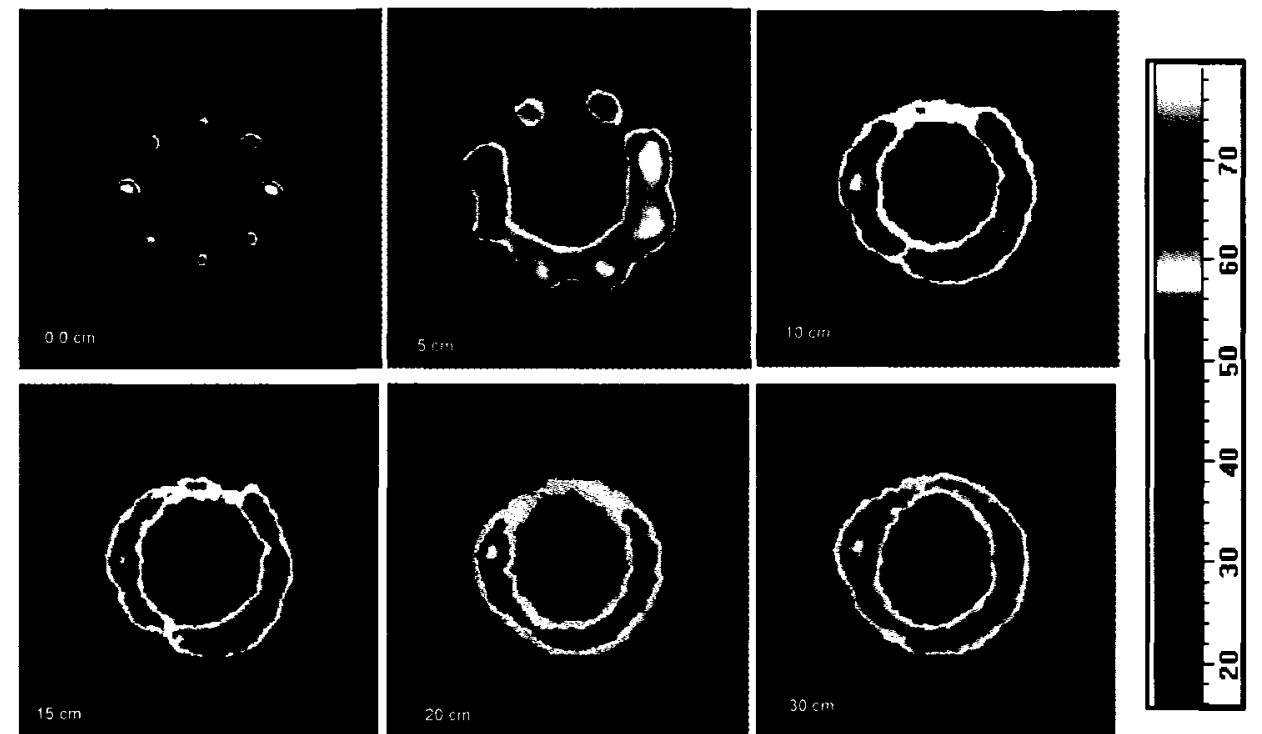

Figure E.41: Vertical cross-sectional LSI images (Mix-2/2 and Cap-4 with $\phi=$ 0.5)
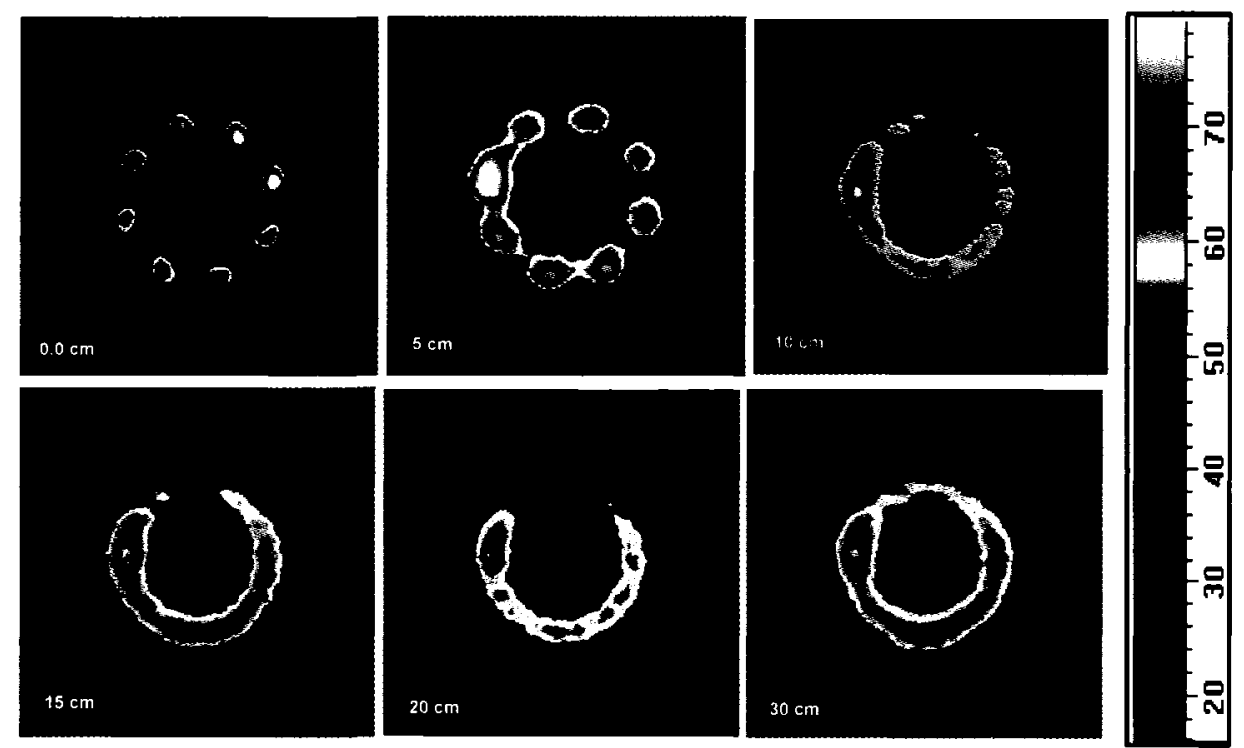

Figure E.42: Vertical cross-sectional LSI images (Mix-2/3 and Cap-4 with $\phi=$ 0.5) 

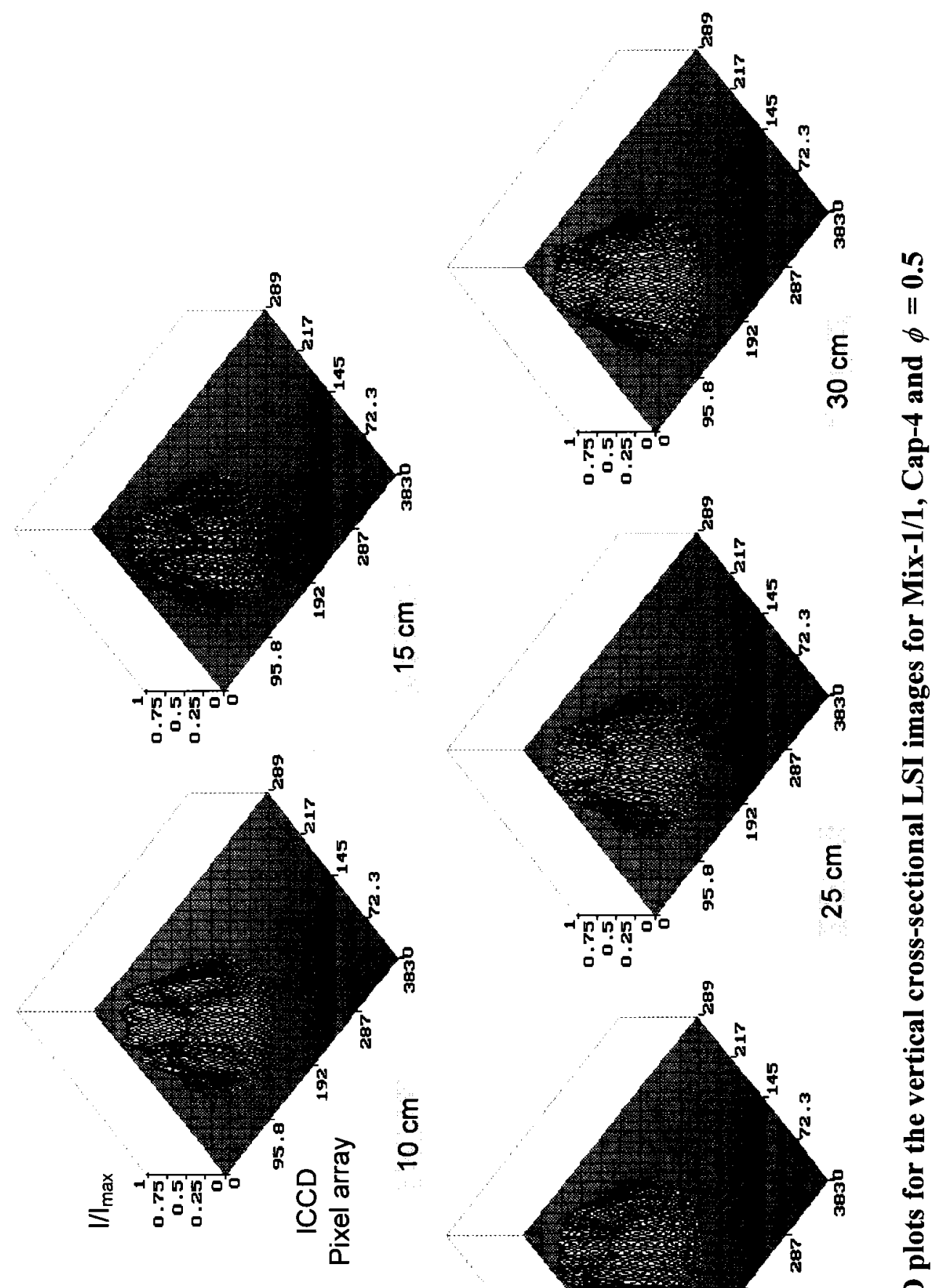

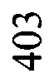

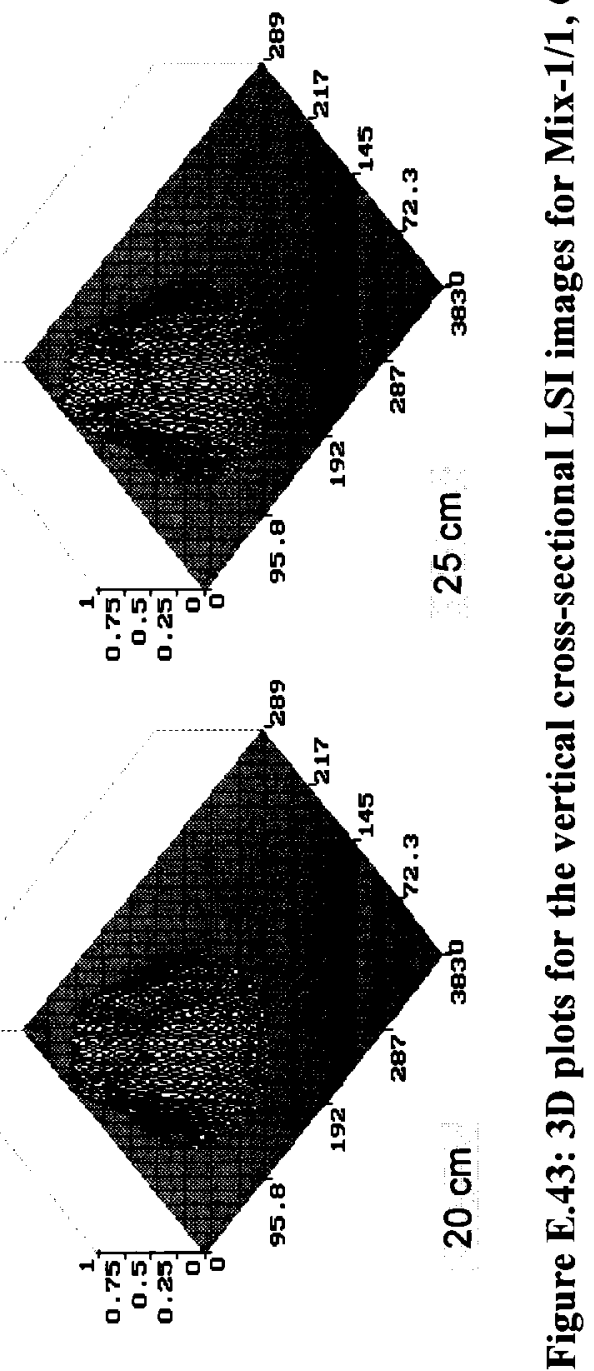



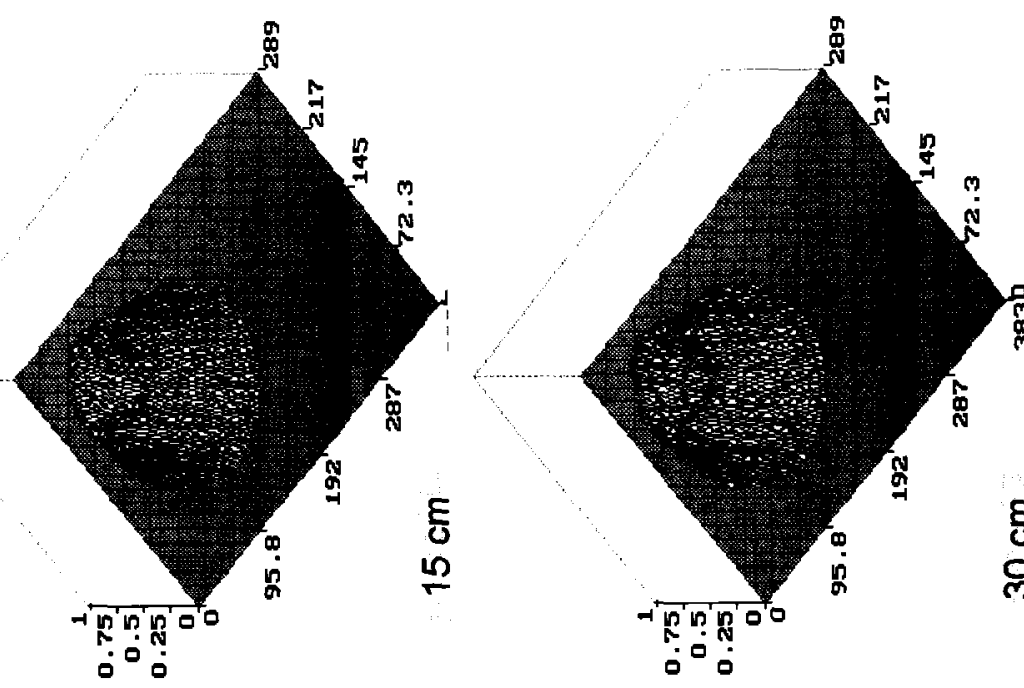

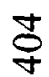
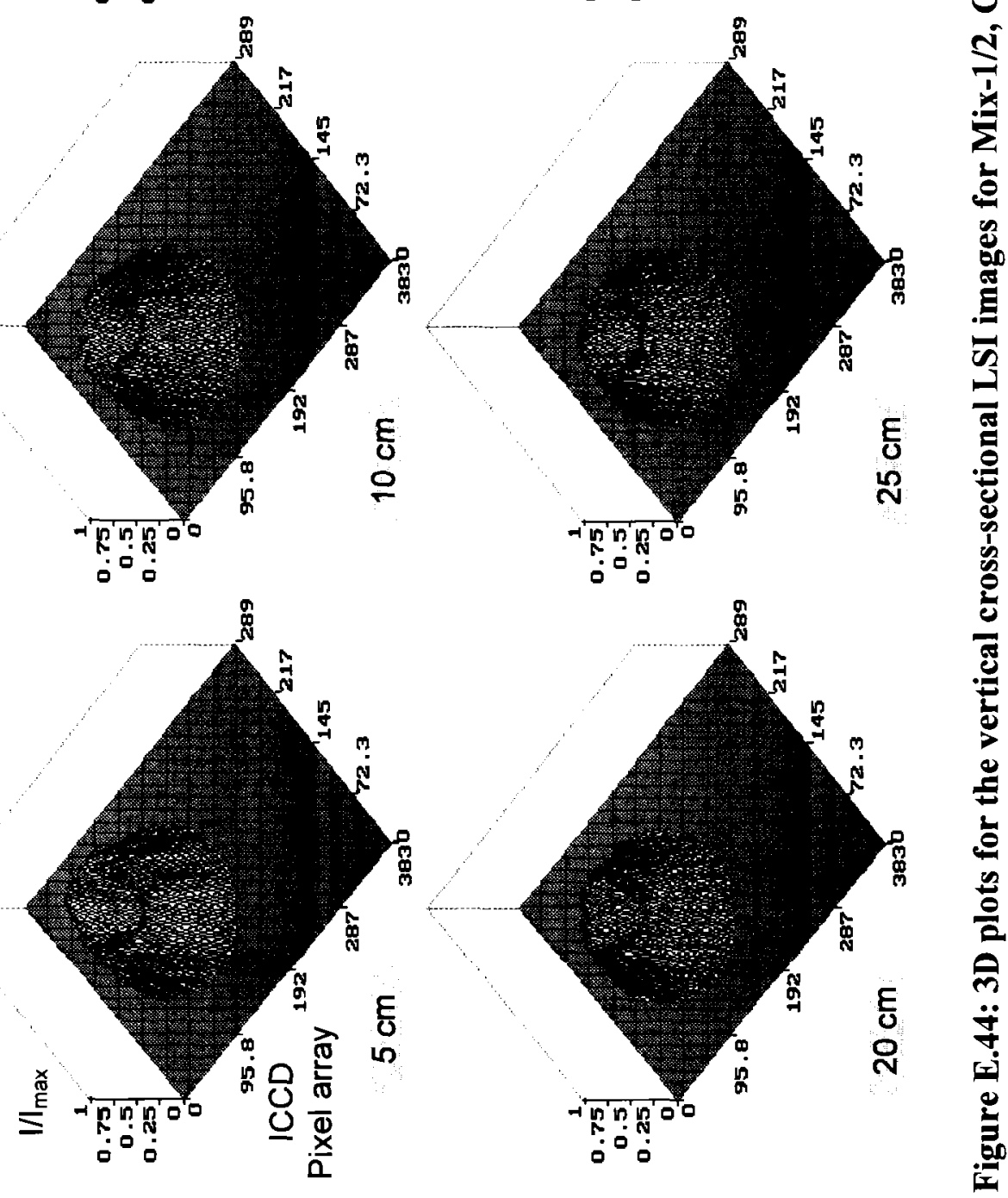

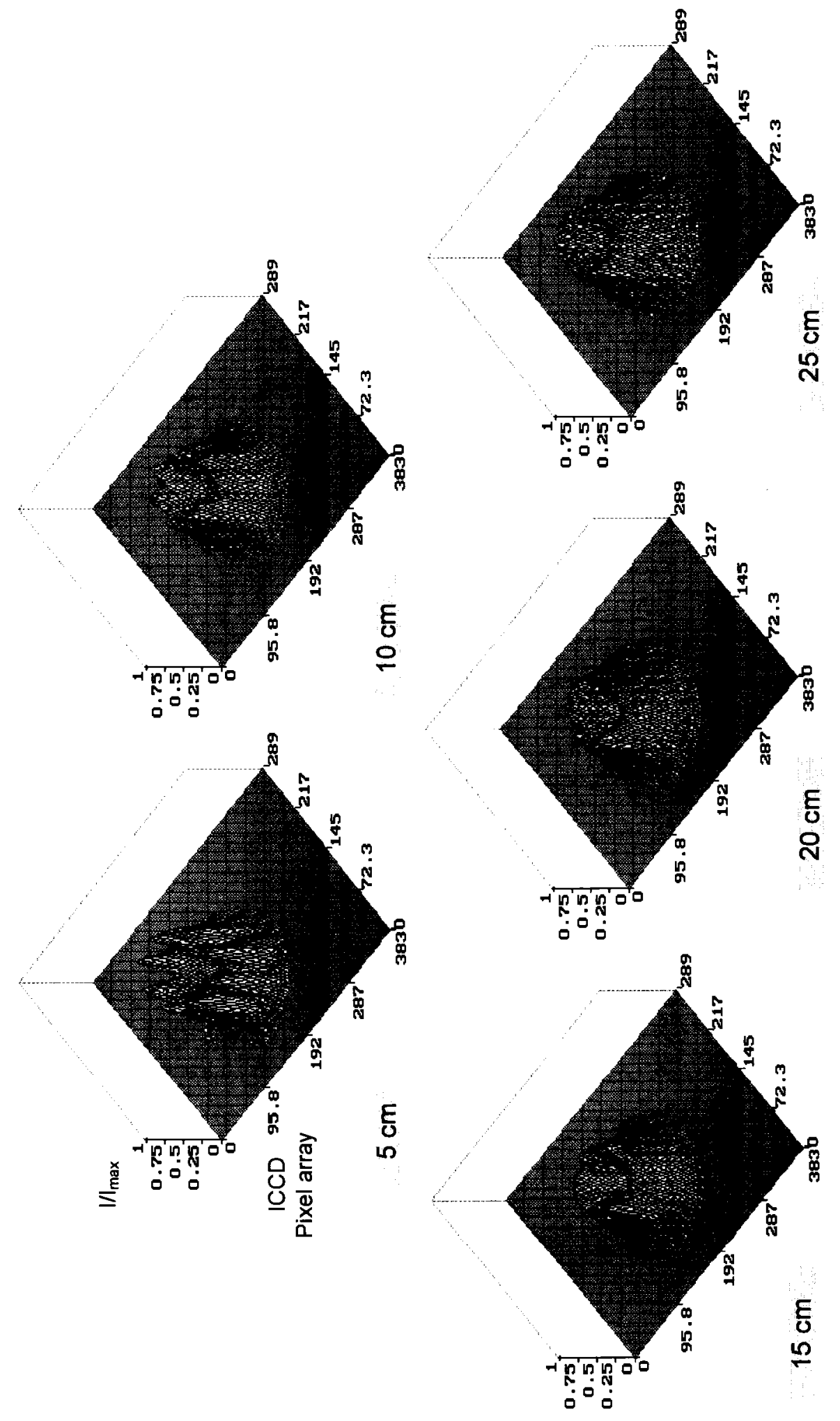

8

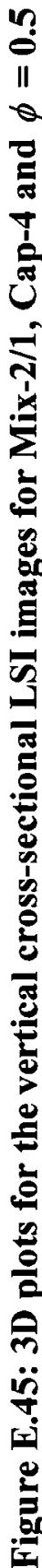



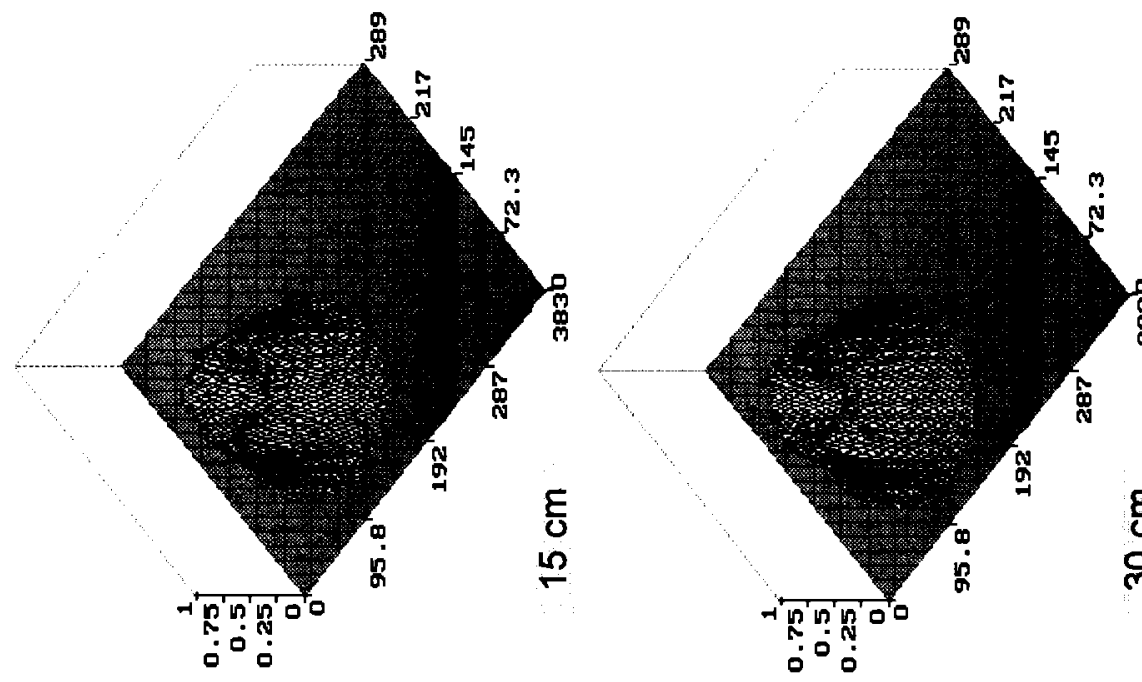

8
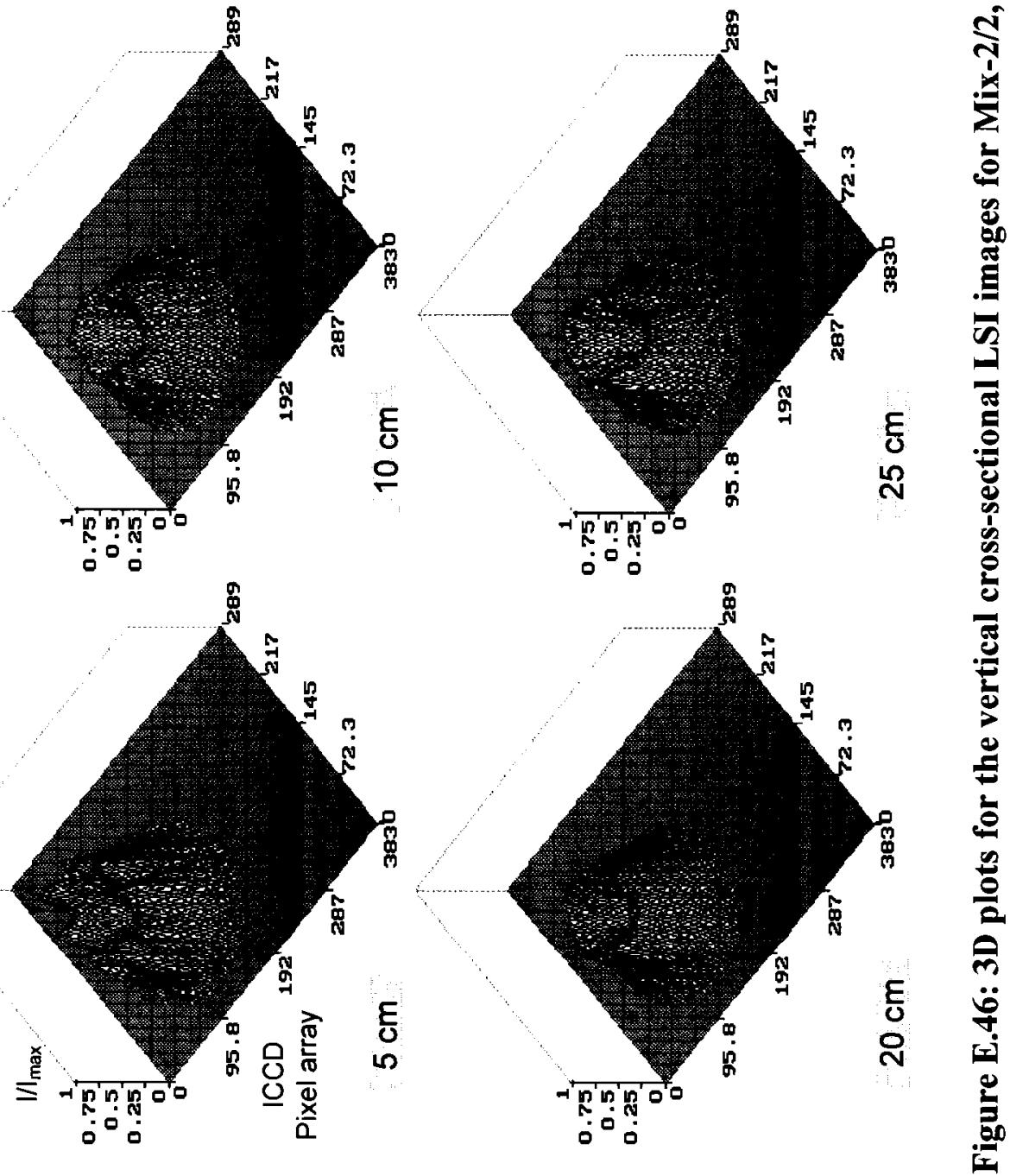
5

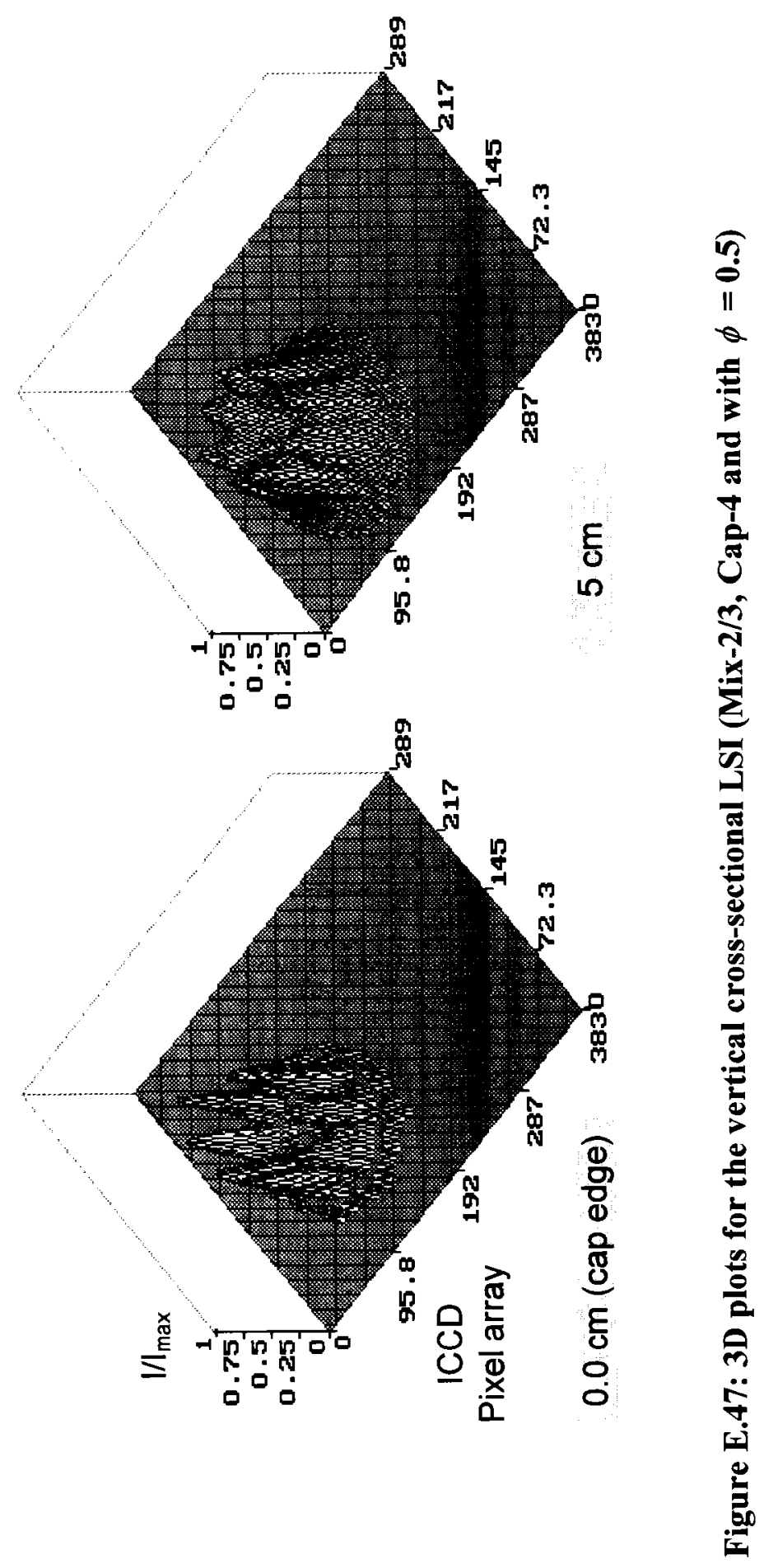



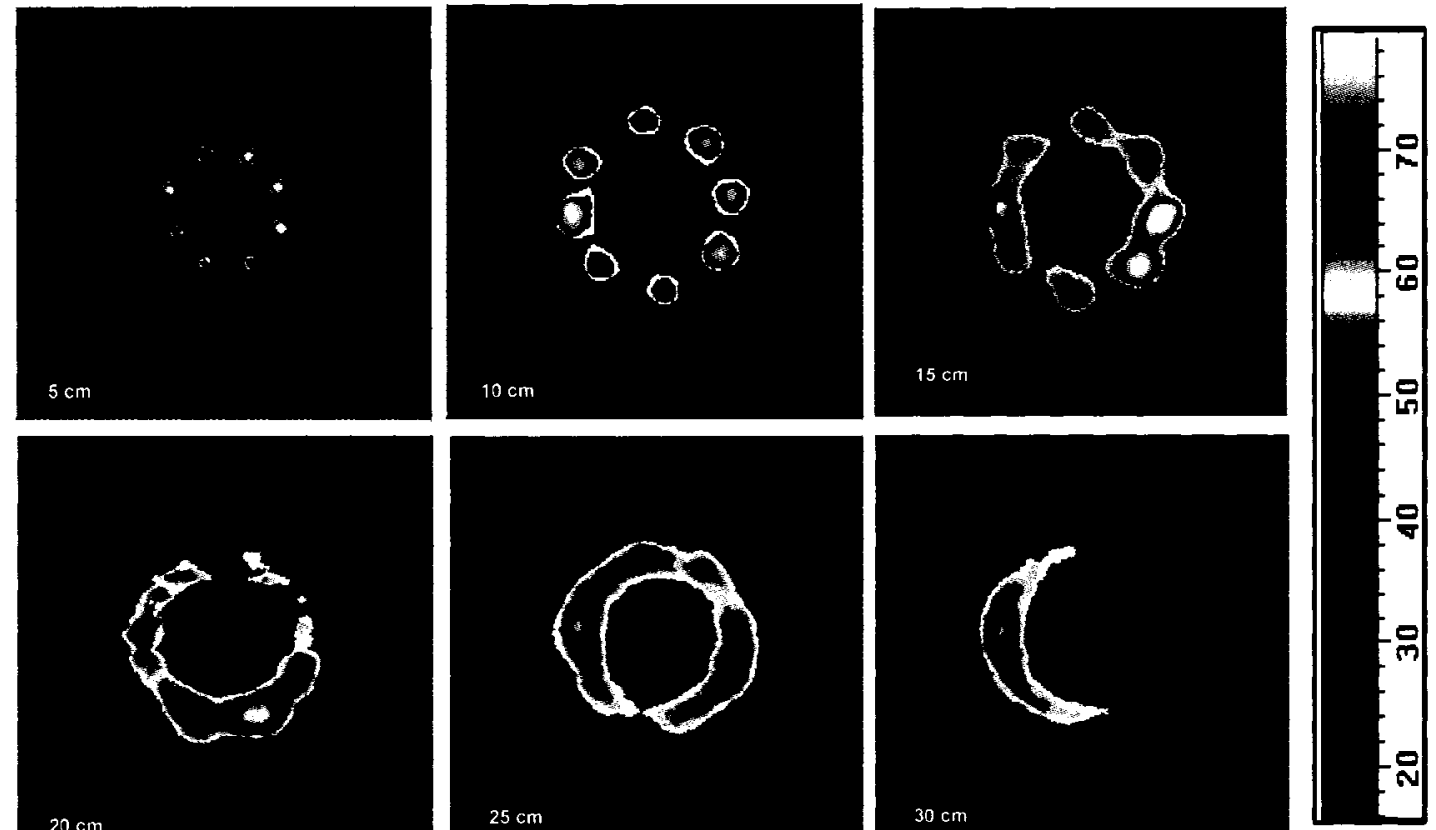

$20 \mathrm{~cm}$
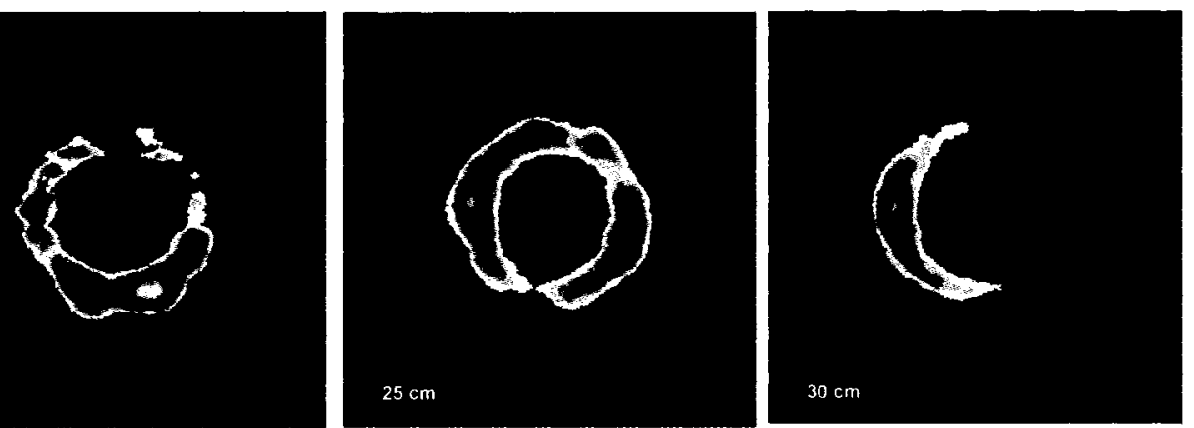

Figure E.48: Vertical cross-sectional LSI images (Mix-1/1 and Cap-2 with $\phi=$ 0.3)
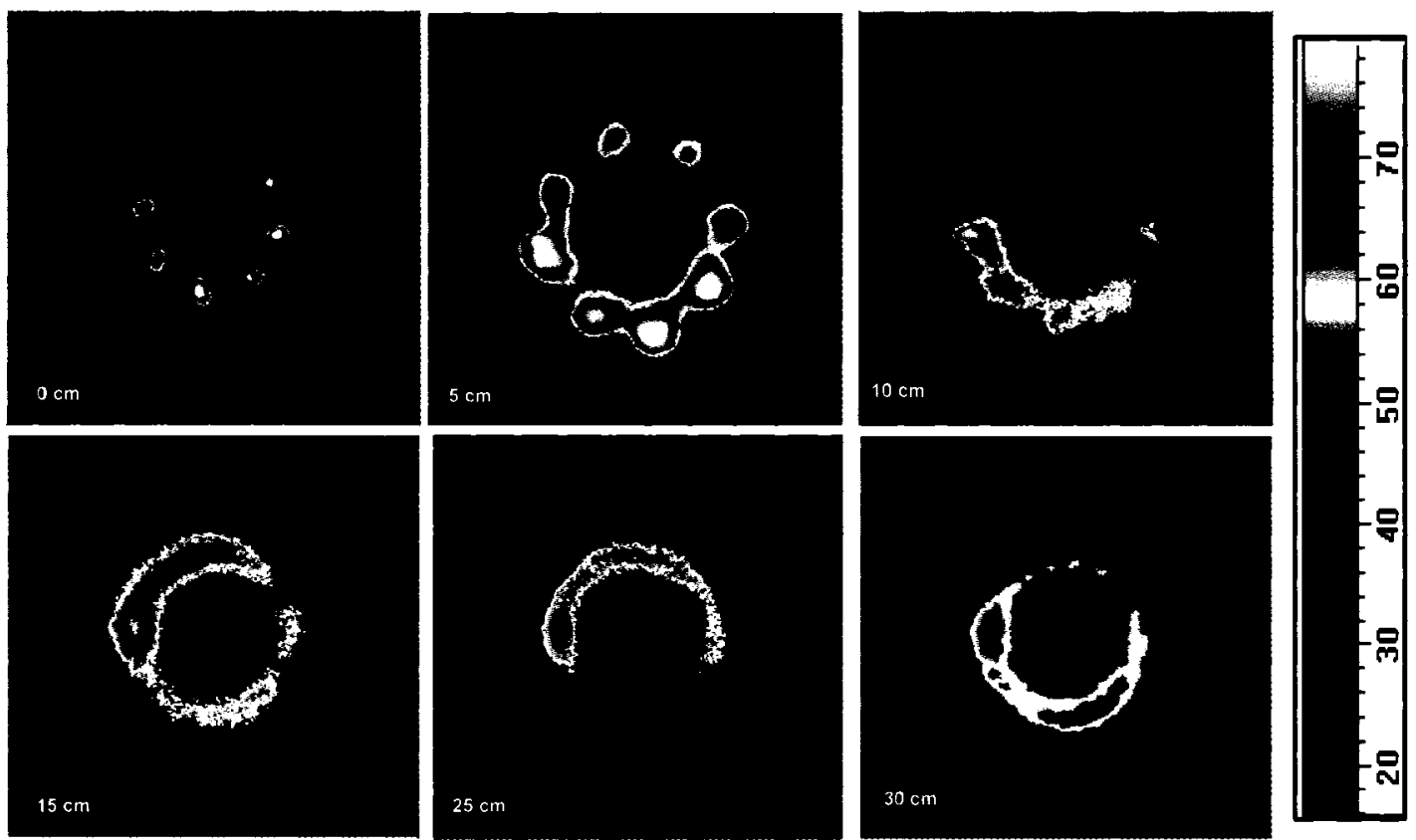

Figure E.49: Vertical cross-sectional LSI images (Mix-1/2 and Cap-2 with $\phi=$ 0.3) 

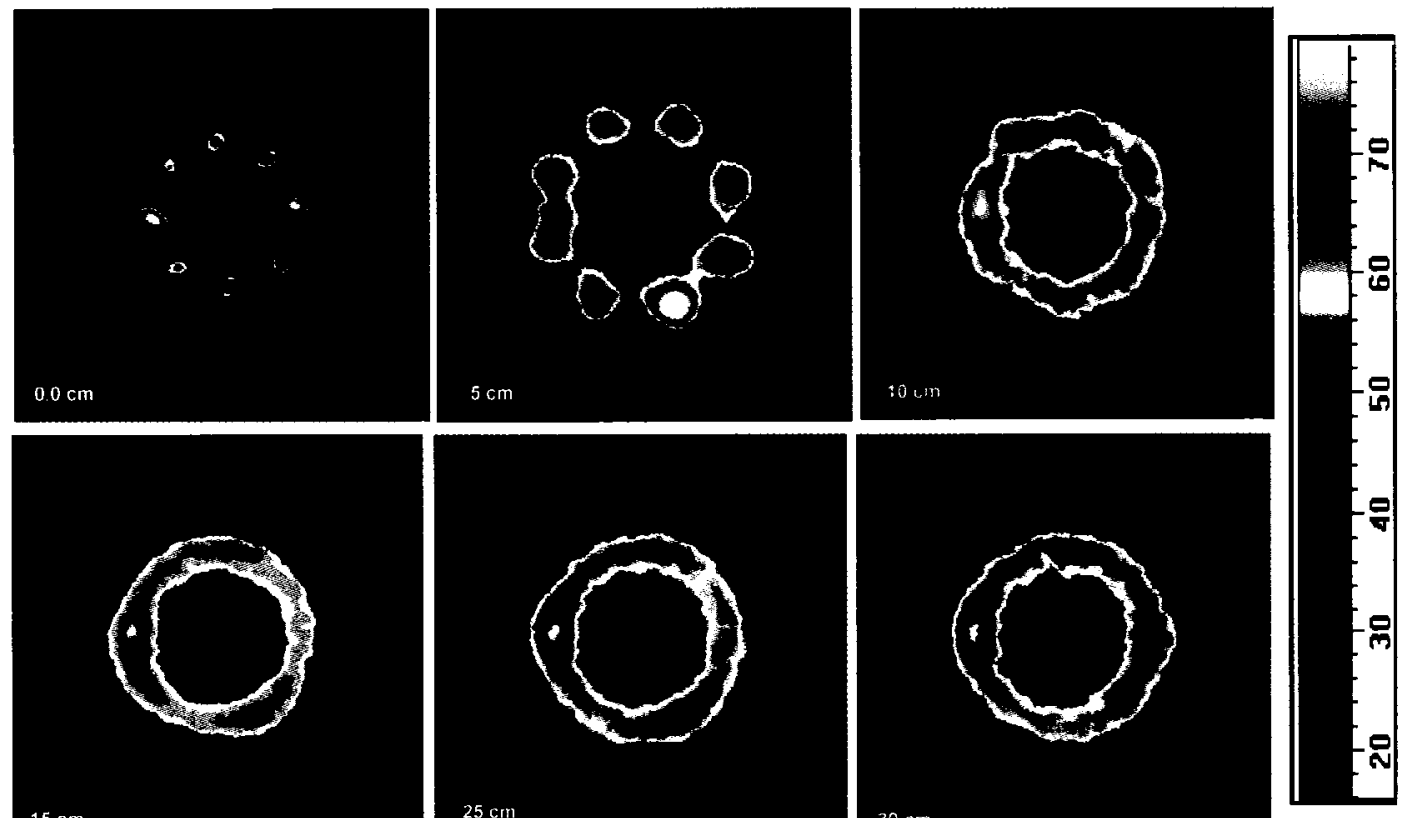

$15 \mathrm{~cm}$
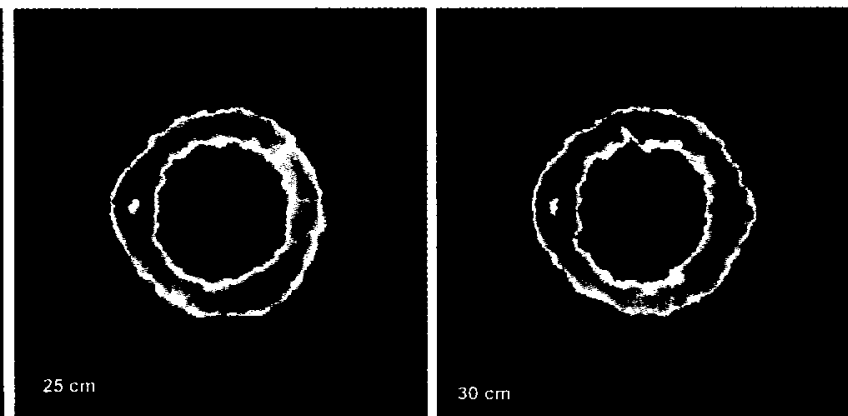

Figure E.50: Vertical cross-sectional LSI images (Mix-2/2 and Cap-2 with $\phi=$ 0.3)
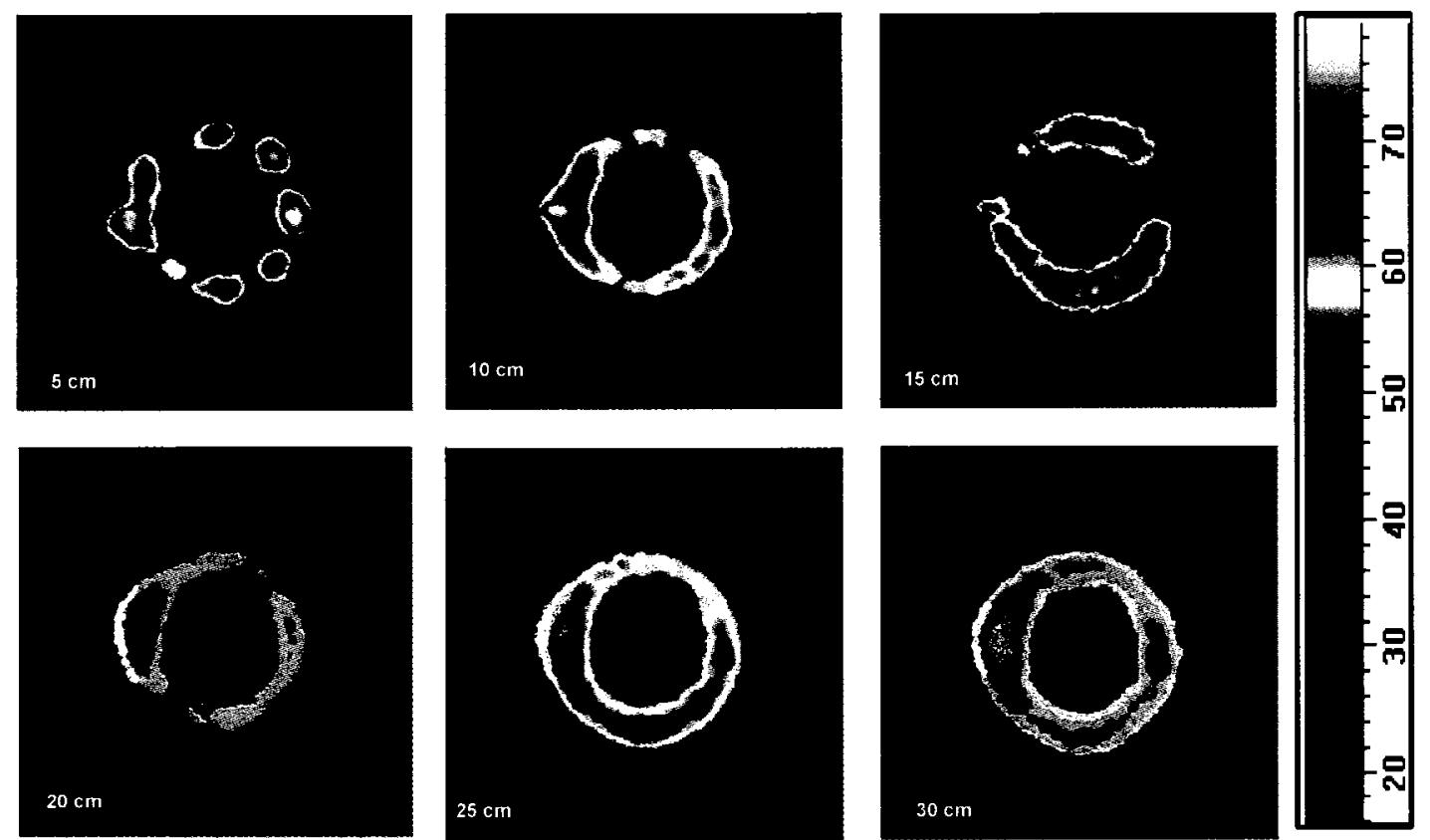

Figure E.51: Vertical cross-sectional LSI images (Mix-2/3 and Cap-2 with $\phi=$ 0.3) 

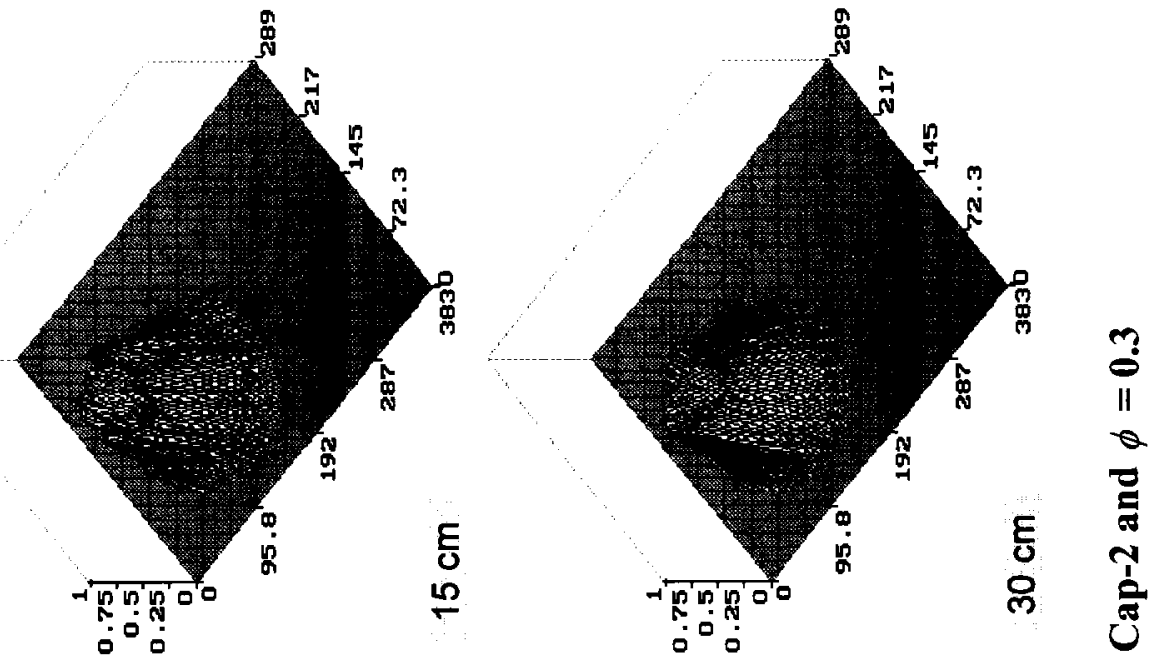

$\frac{0}{7}$

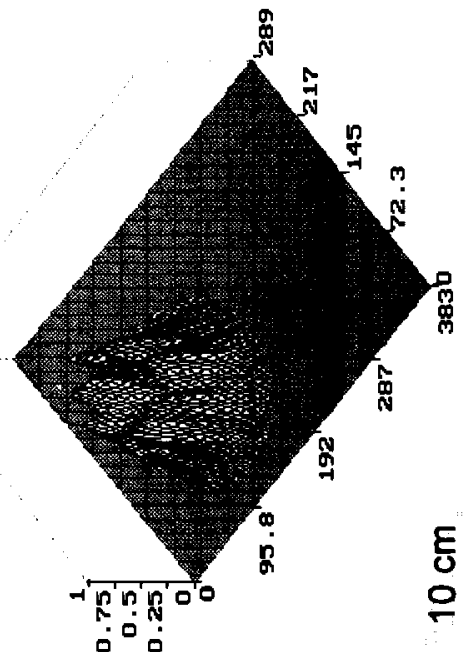

통
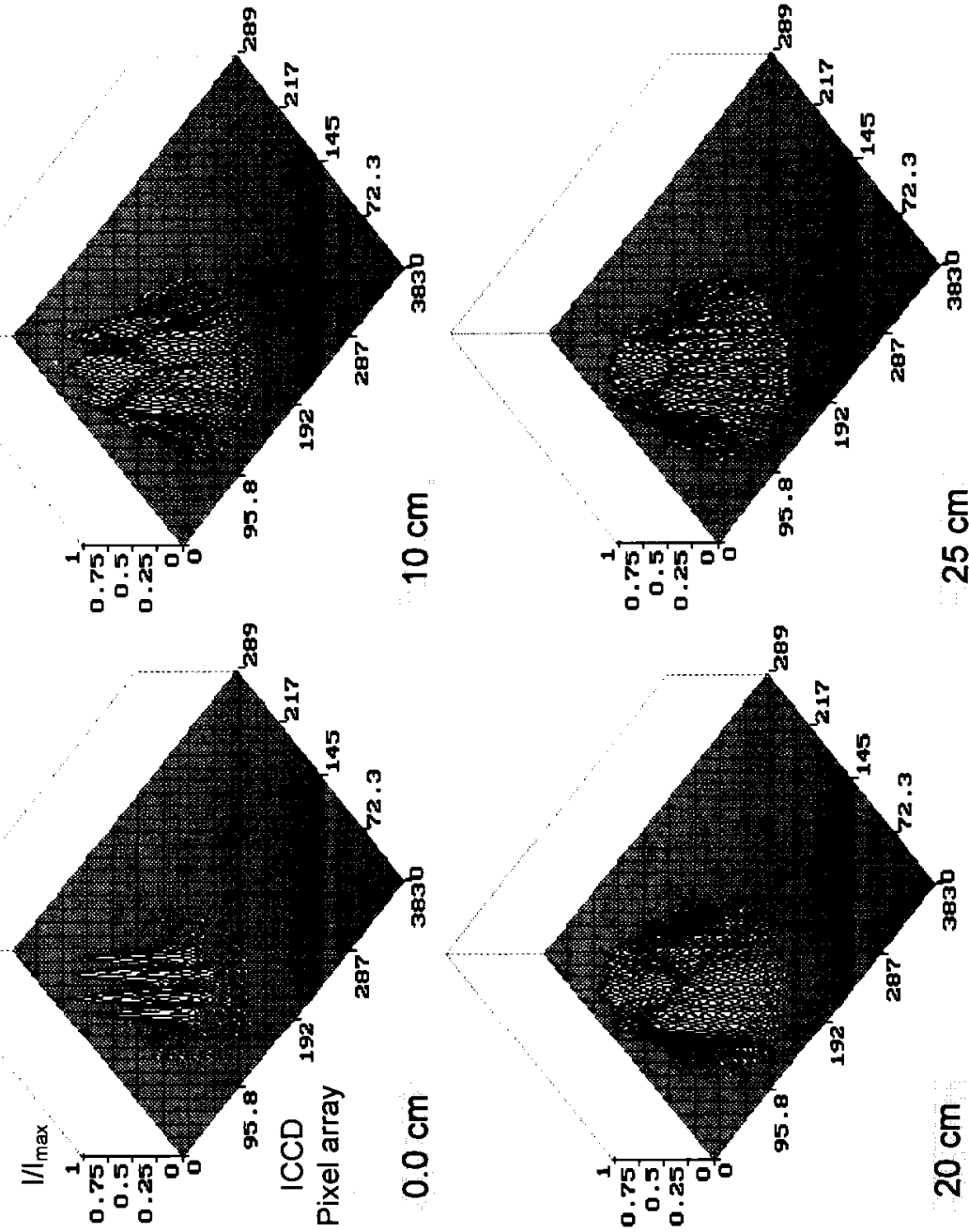

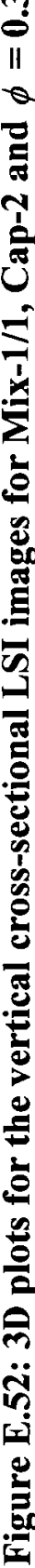



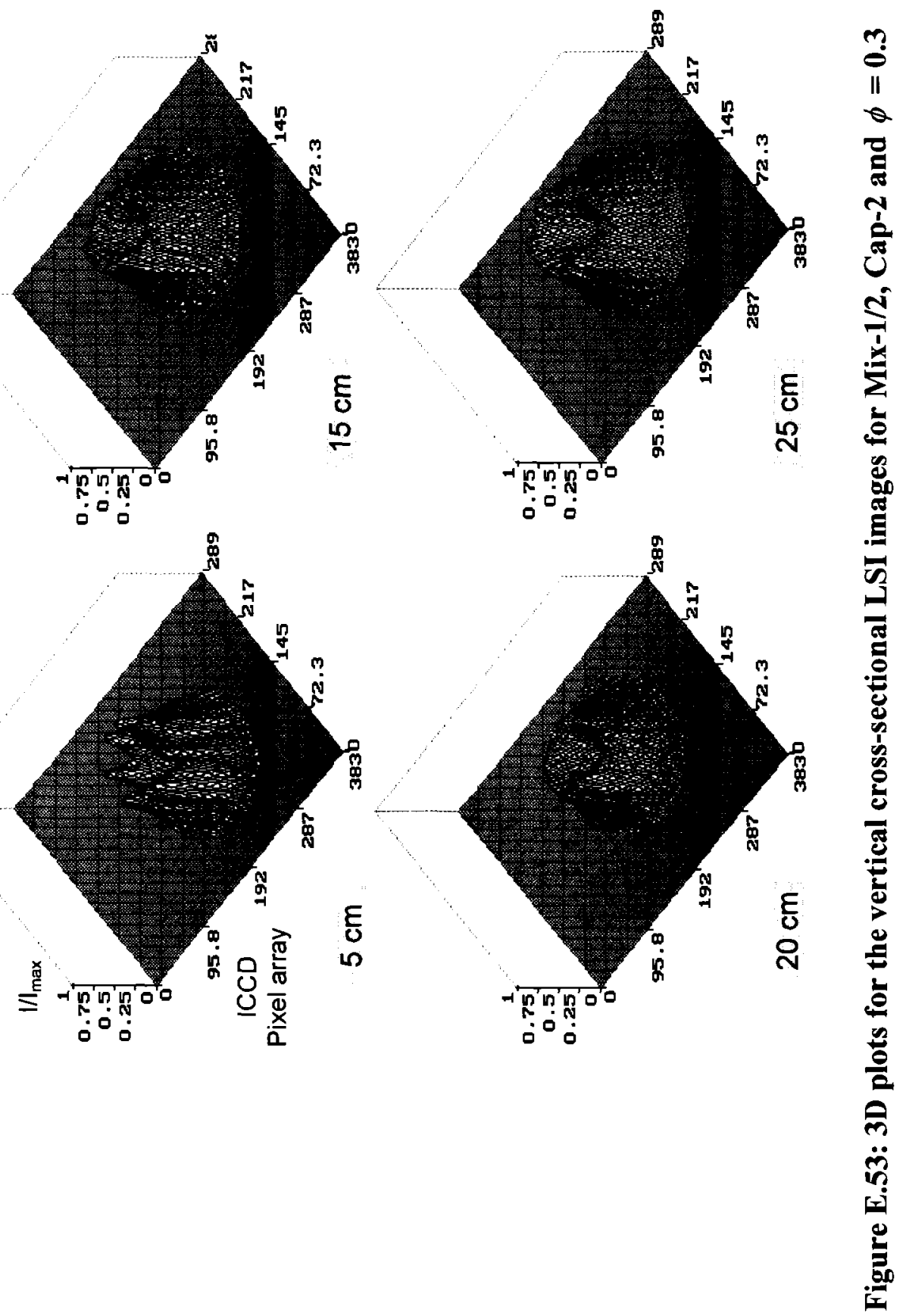

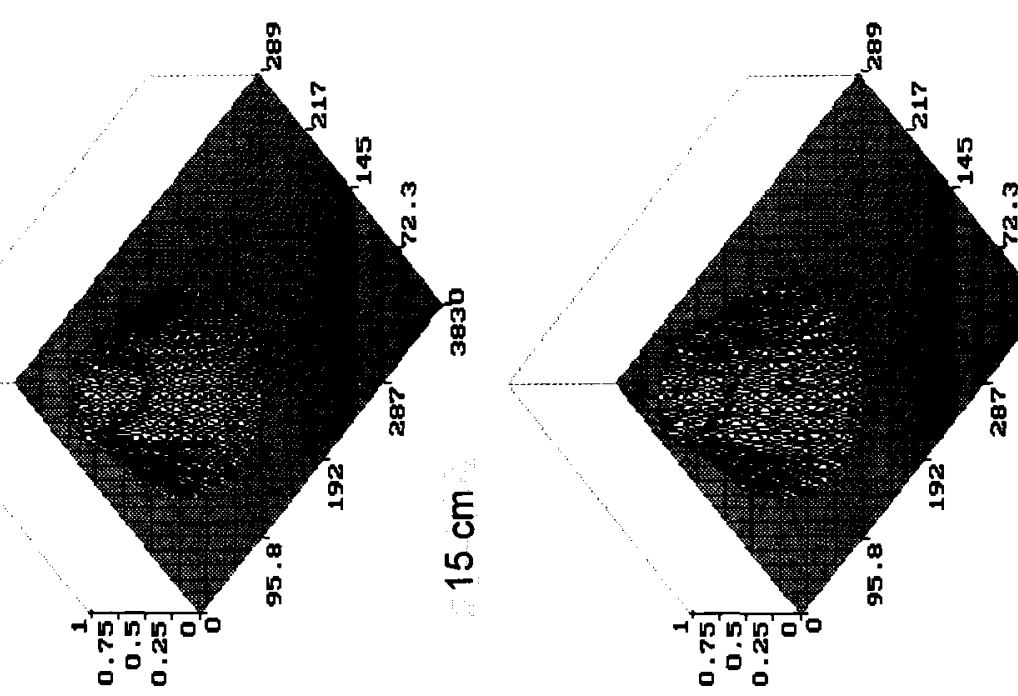

$\frac{N}{7}$
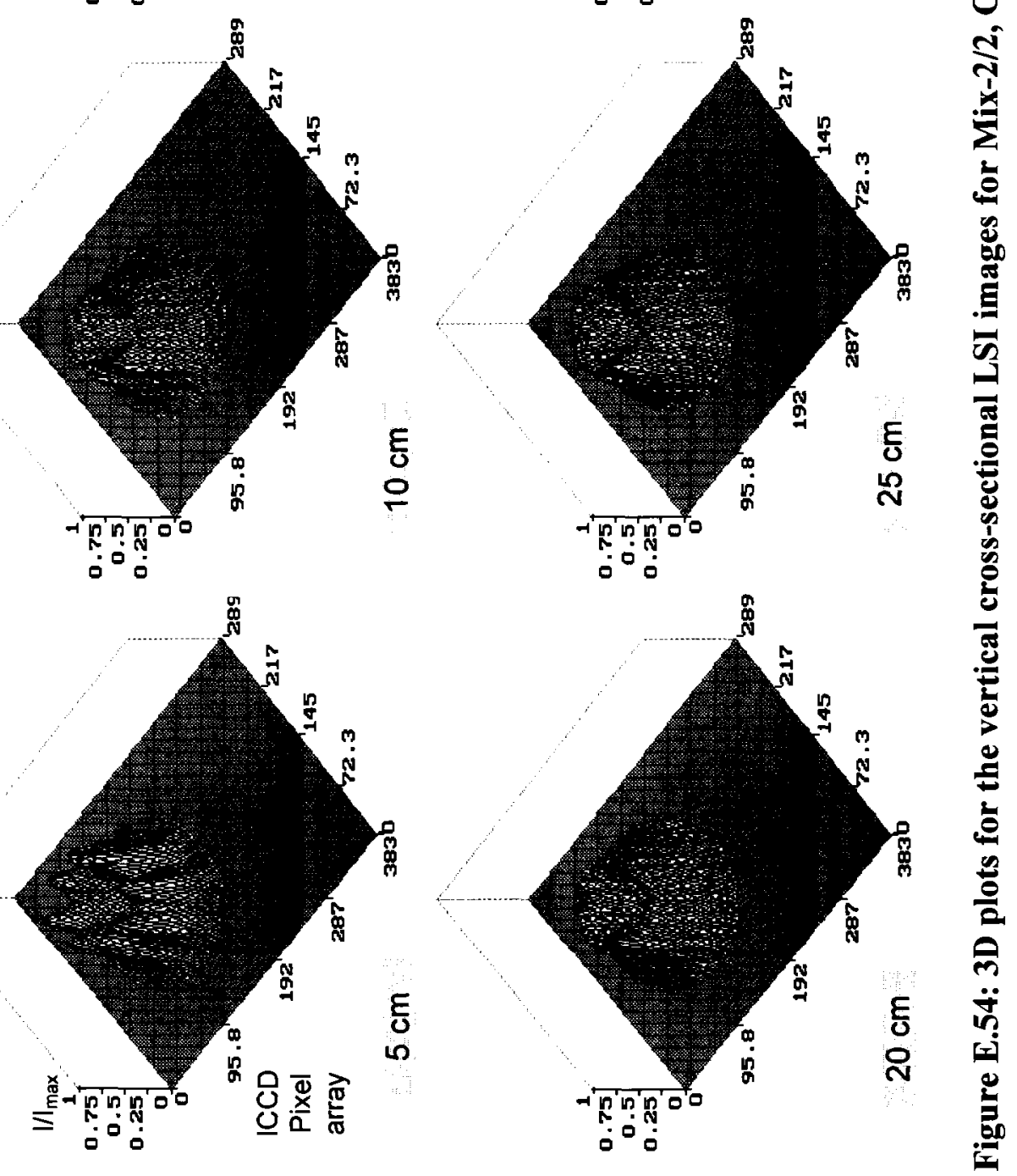

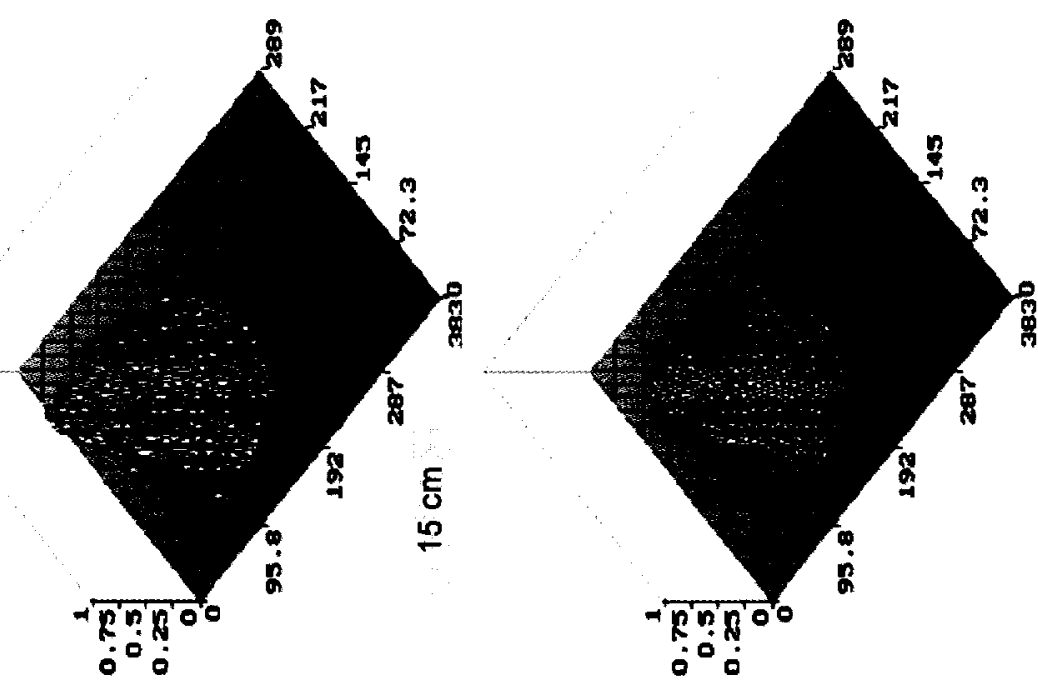

$\frac{n}{7}$
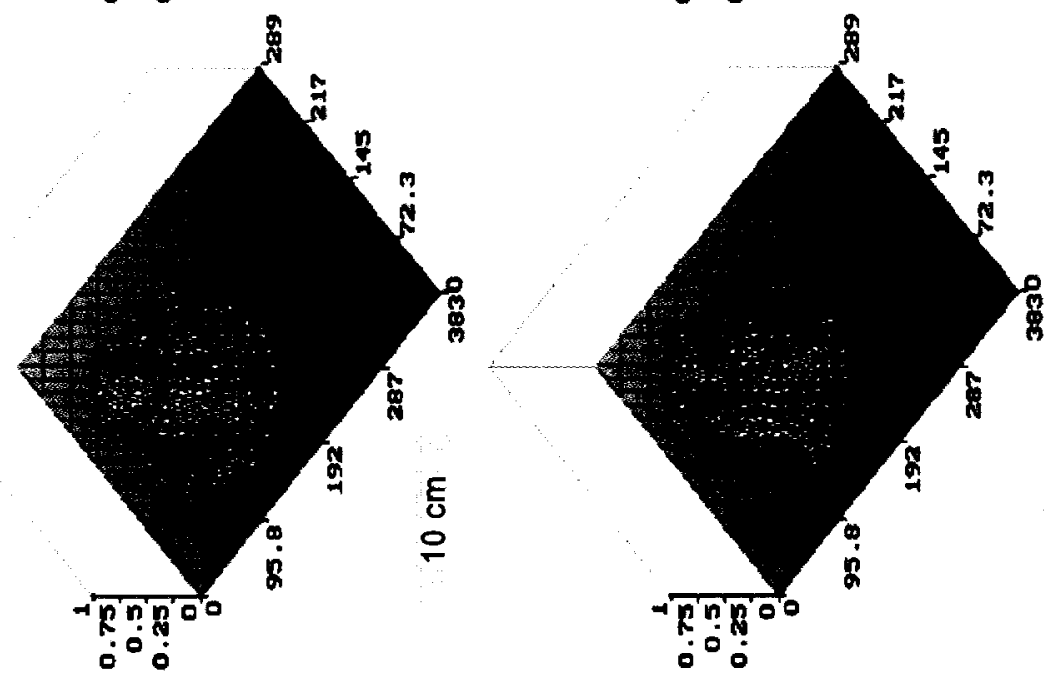

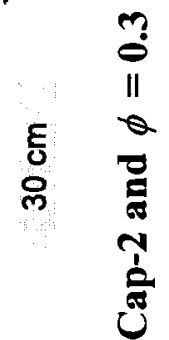
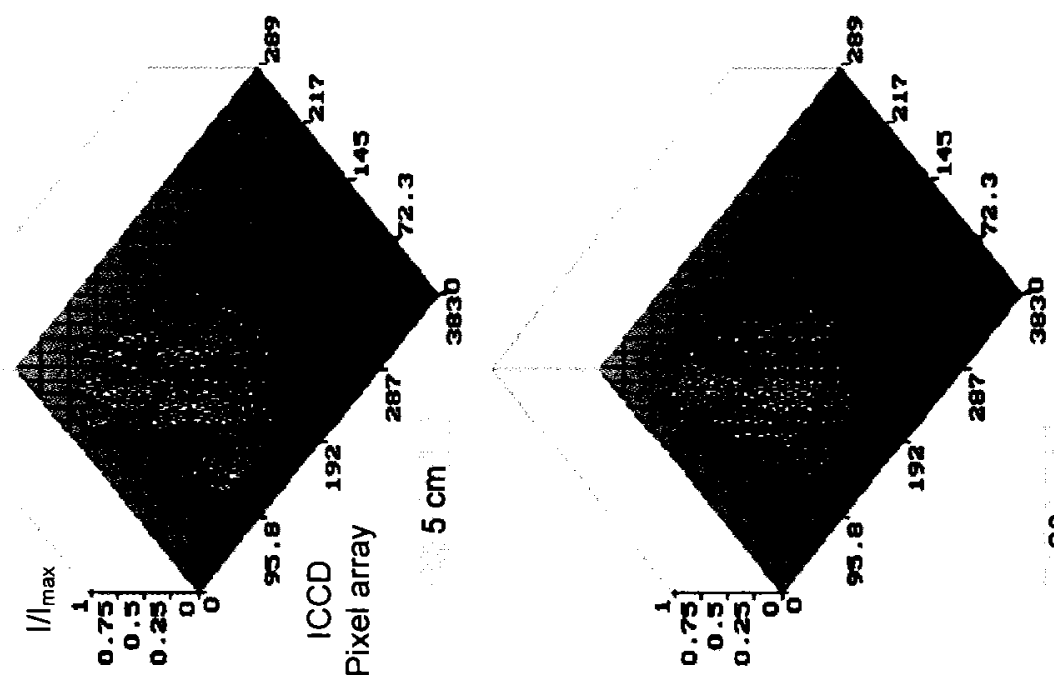

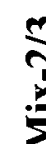



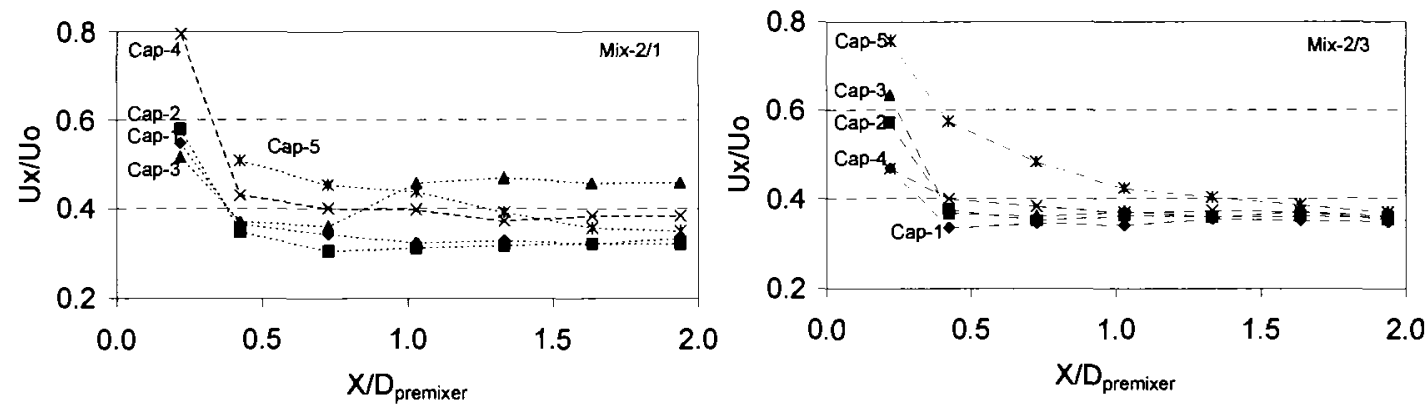

(a) $\operatorname{Mix}-2 / 1$

(b) $\operatorname{Mix}-2 / 3$

Figure E.56: Effect of fuel cap design on mixing effectiveness
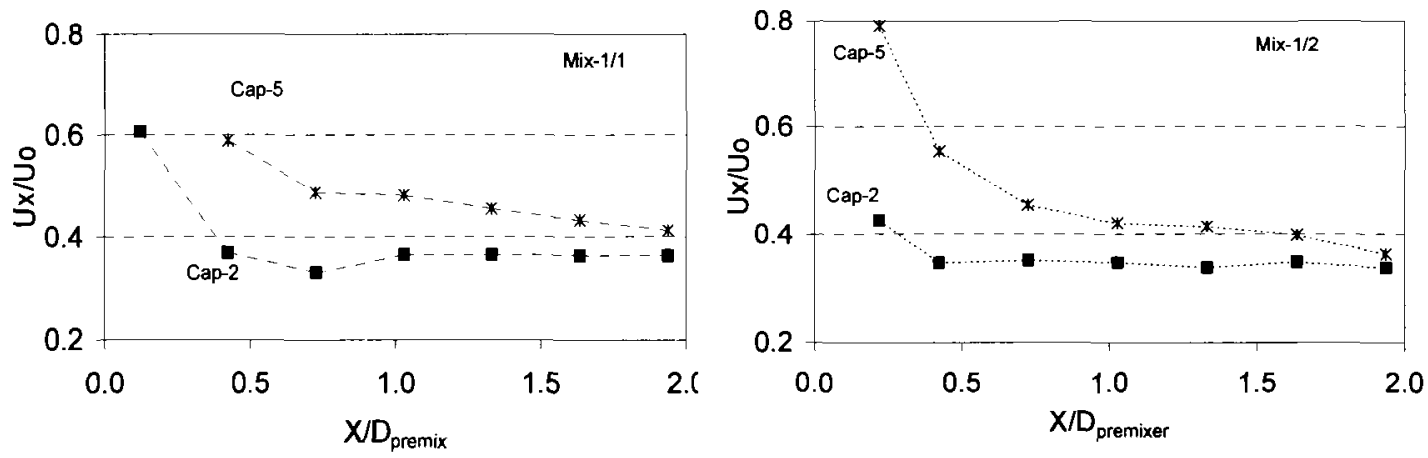

(a) $\mathrm{Mix}-1 / 1$

(b) $\mathrm{Mix}-1 / 2$
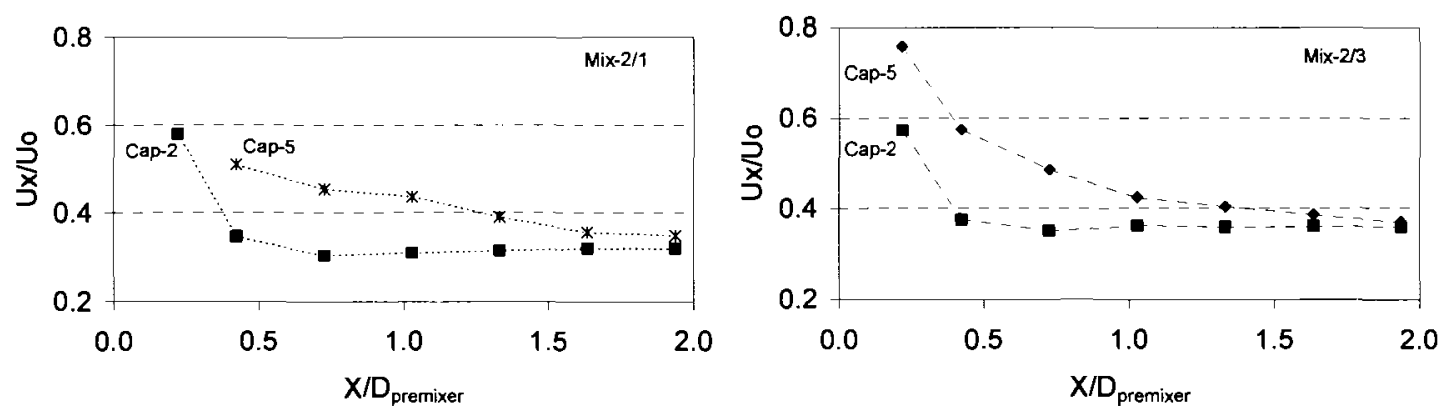

(c) $\mathrm{Mix}-2 / 1$

(d) Mix-2/3

Figure E.57: Effect of fuel injection angle on mixing effectiveness (Cap-2 and Cap-5 comparisons) 

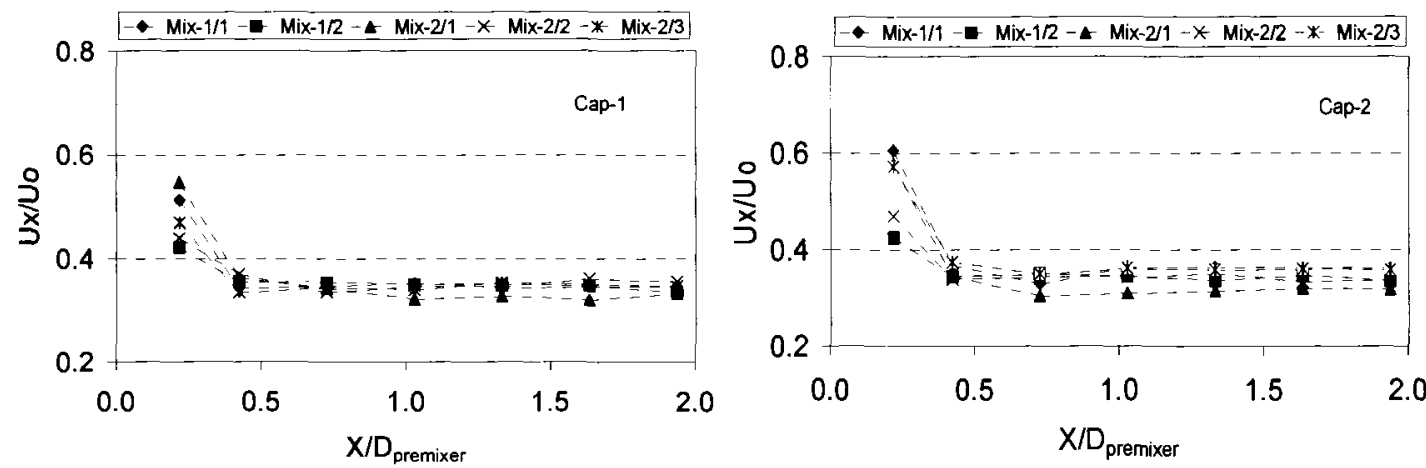

(a) Cap-1

(b) Cap-2
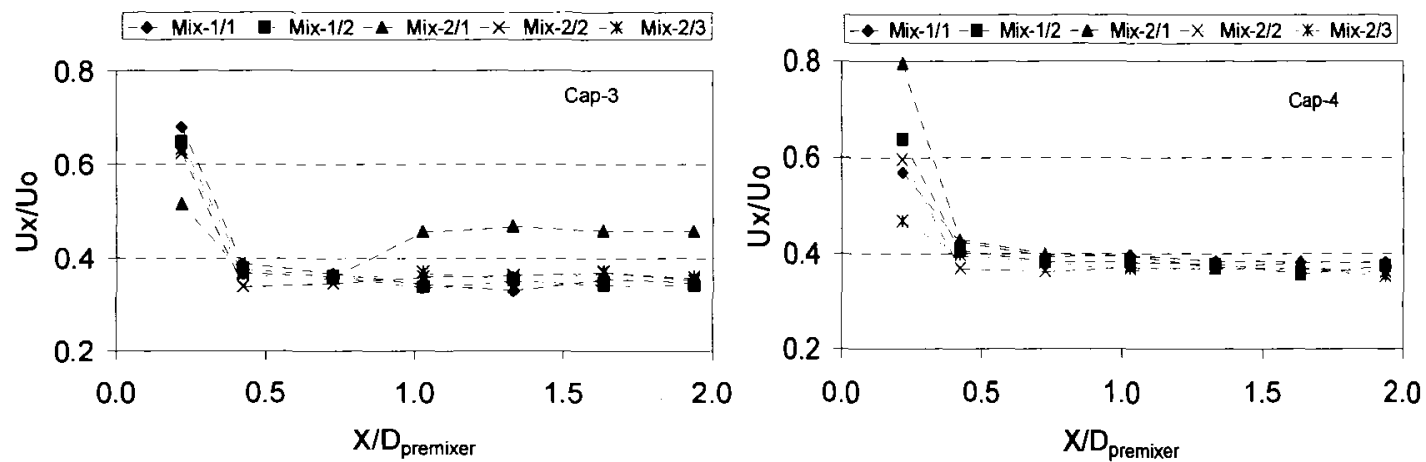

(c) Cap-3

(d) Cap-4

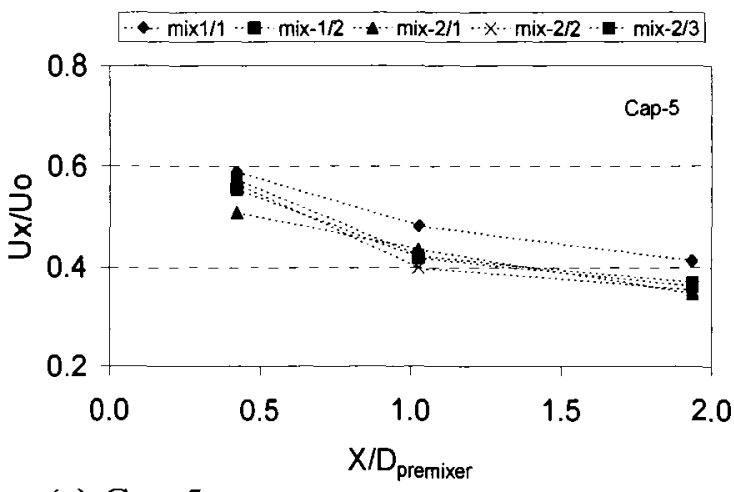

(e) Cap-5

Figure E.58: Effect of mixer design on mixing effectiveness at different premixer axial locations 


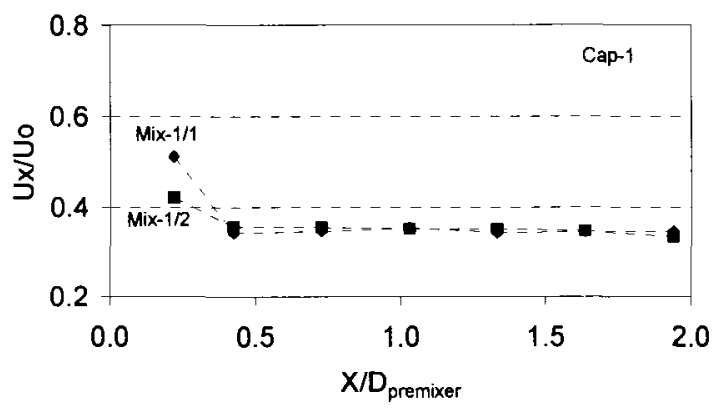

(a) Cap-1

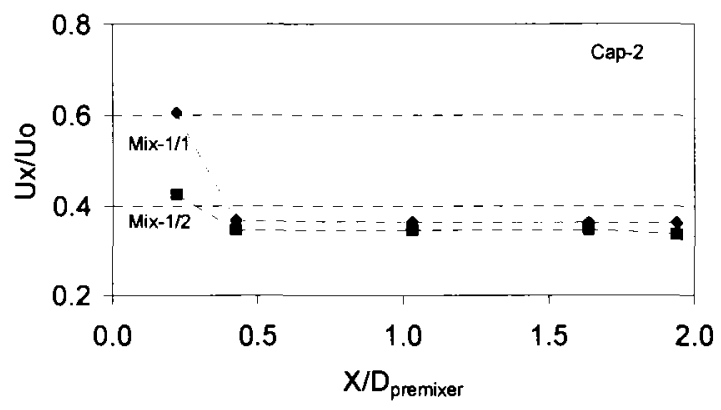

(b) Cap-2

Figure E.59: Effect of mixer strength (S) on mixing effectiveness (a) Cap-1 and (b) Cap-2

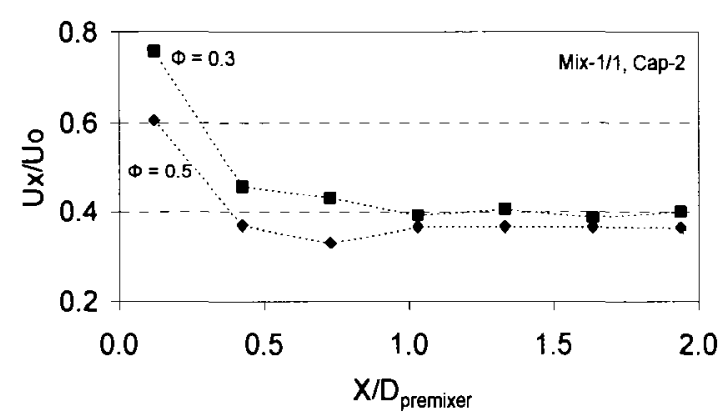

(a) $\mathrm{Mix}-1 / 1$

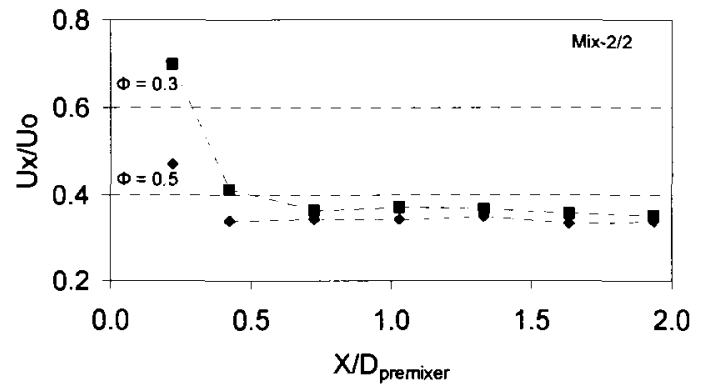

(c) $\mathrm{Mix}-2 / 2$

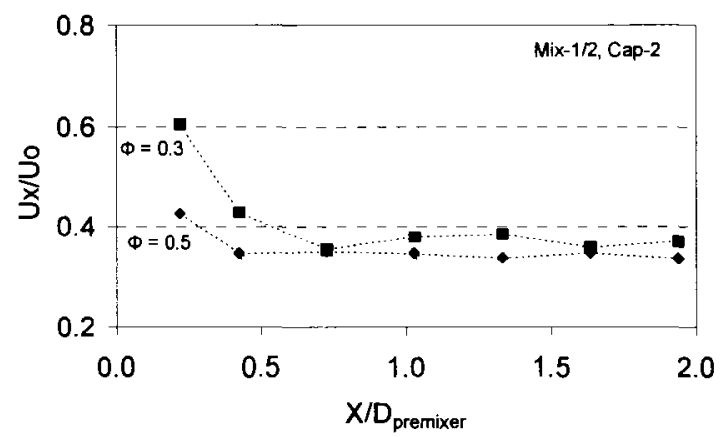

(b) $\mathrm{Mix}-1 / 2$

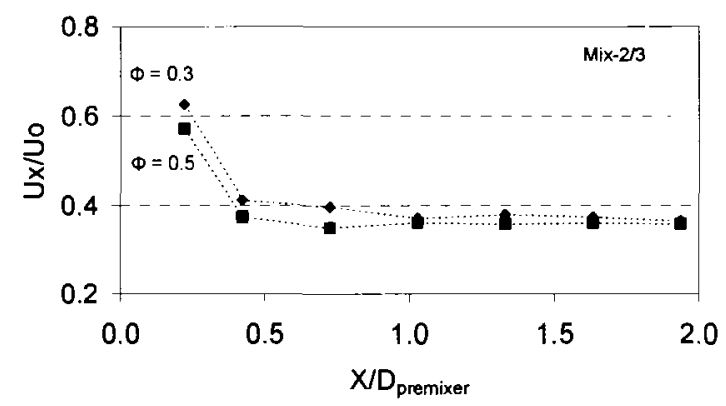

(d) $\mathrm{Mix}-2 / 3$

Figure E.60: Effect of $\Phi$ on mixing effectiveness (Cap-2) (a) Mix-1/1, (b) Mix1/2, (c) Mix-2/2 and (d) Mix-2/3 


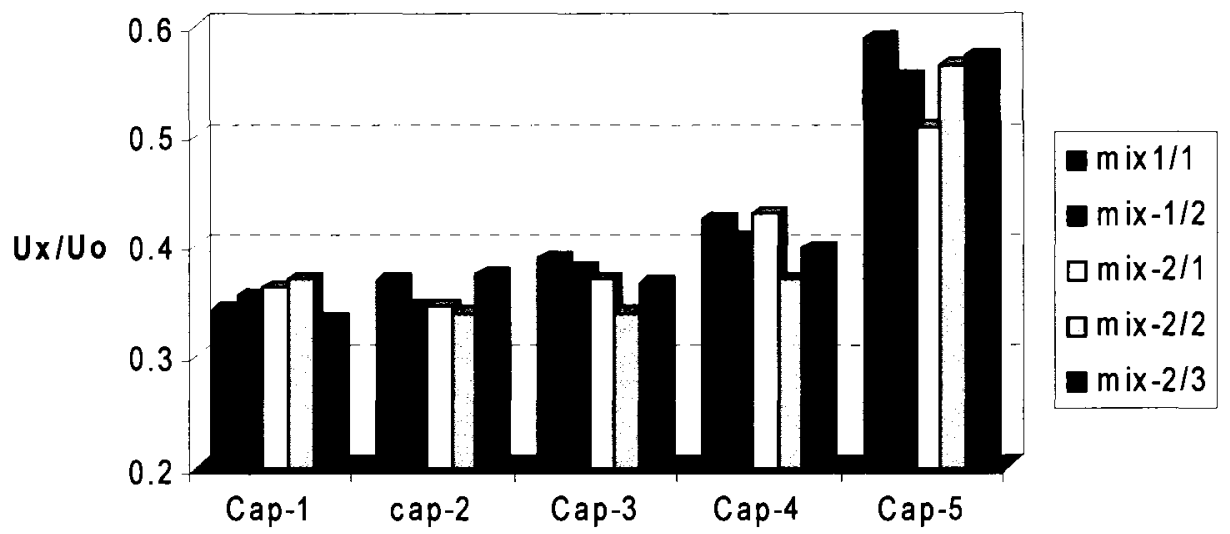

Figure E.61: Effect of fuel cap design on mixing effectiveness using different mixers (at $X=0.42 D_{\text {premixer }}$ )

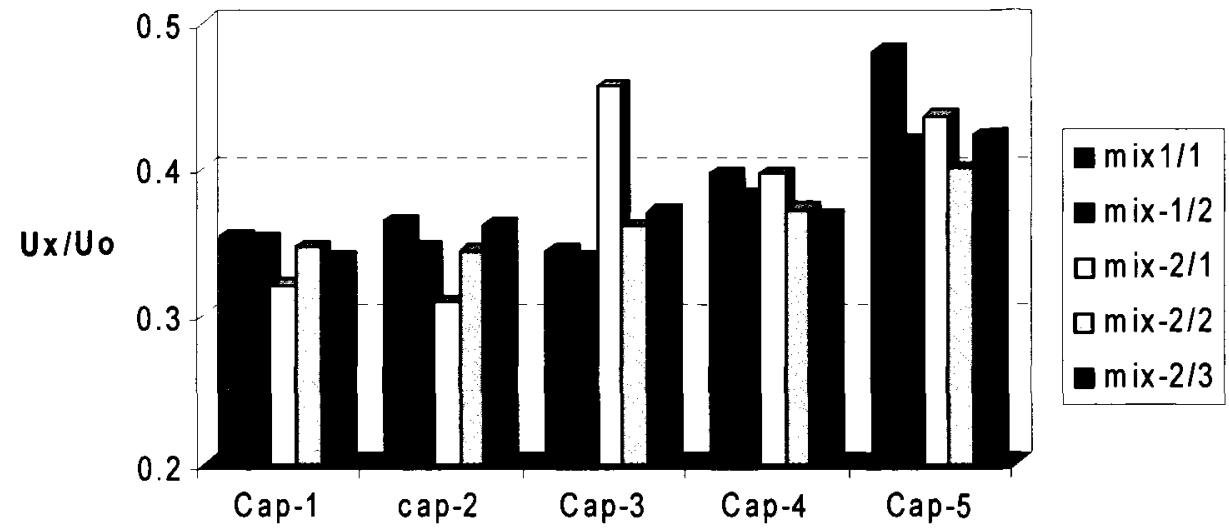

Figure E.62: Effect of fuel cap design on mixing effectiveness using different mixers (at $X \approx 1 D_{\text {premixer }}$ )

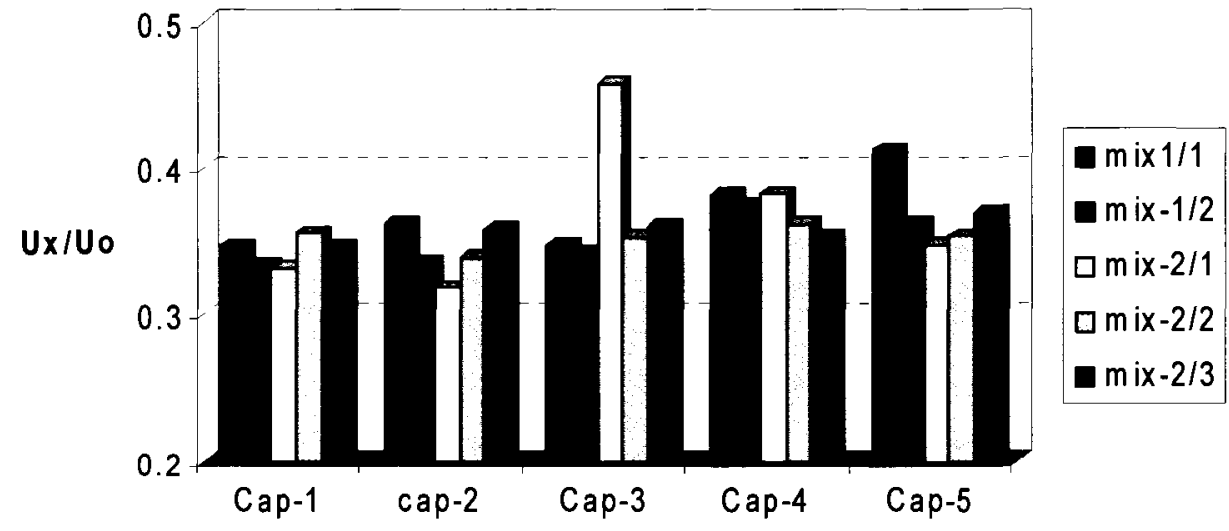

Figure E.63: Effect of fuel cap design on mixing effectiveness using different mixers (at $X \approx 2 D_{\text {premixer }}$ ) 


\section{APPENDIX F: Flow balancing tests}

This appendix contains the some of the flow balancing results (plots) which are not presented in the main text of Chapter6, however the results was used in the general summary of the chapter.

The appendix only contains the result plots and it is arranged as follows.

e) Figures F.1 to F.5 present the duct burner inlet velocity profiles. With a repeatability tests.

f) Figures F.6 to 6.10 present some of the duct burner annular passage velocity profiles (repeatability and different pitot static tube sizes).

g) Figures F.11 to F.19 present the effect of AFCBA on mass flow rate split for different burner geometries.

h) Figures F.20 to F.21 present the effect of mixers design on mass flow ratio for different burner geometries.

i) Figures F.22 to F.25 presents the effect of using the measurement shields (Sh5 and Sh6) on mass flow ratio for different burner geometries.

j) Figure F.26 presents the effect of different cones one the mass flow ratio. Cone- 3 at this figure shows unexpected trend.

k) Figures F.27 to F.29 present some of the duct burner annular passage velocity profiles (effect of AFCBA and effect of mixers design)

1) Figures F.30 to F.43 show the effect of $L_{e f f} / D_{\text {shield }}$ and BR on the overall duct burner pressure drop for different geometrical parameters. 


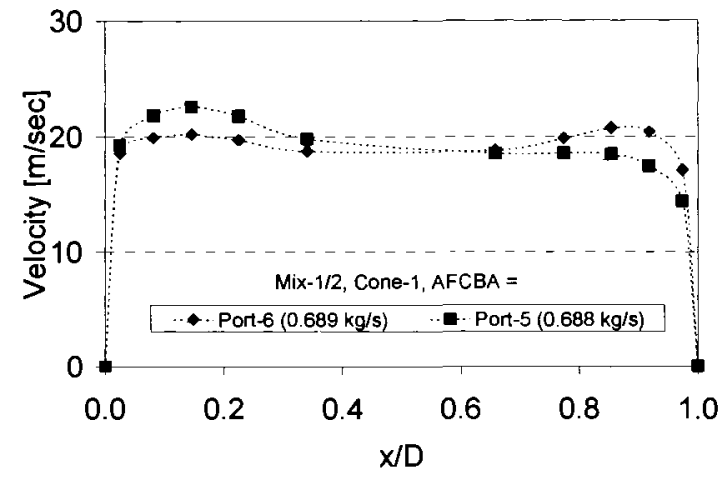

(a) Cone-1

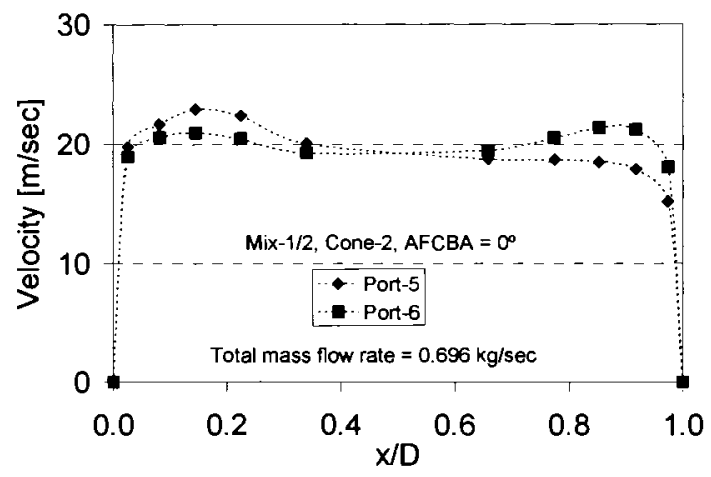

(b) Cone-2

Figure F.1: Repeated velocity profiles across the DB inlet plane using Port-5 and 6 (Mix-1/2 with Cone-1 and Cone-2)

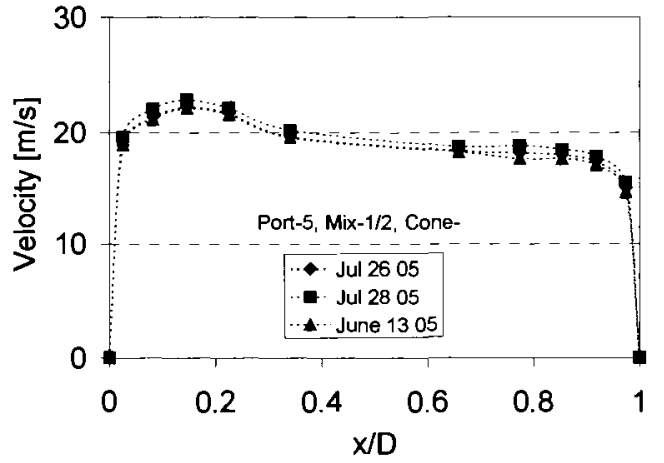

Figure F.2: Velocity distribution across the DB inlet plane using Port-5, repeatability tests

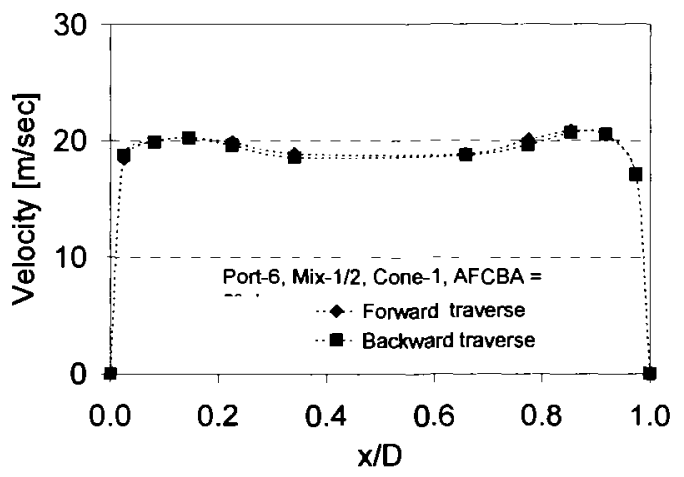

Figure F.4: Velocity distribution across the DB inlet plane using Port-6, different traverse directions

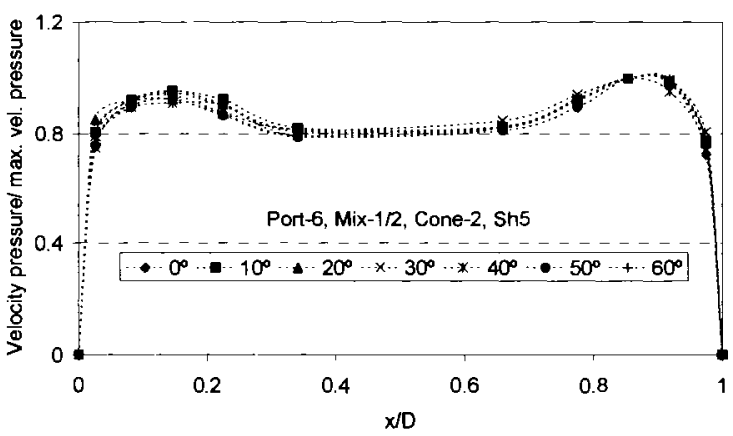

Figure F.3: Effect of AFCBA on DB inlet velocity distribution using Port-6 (Mix-1/2, Cone-2 and Sh5)

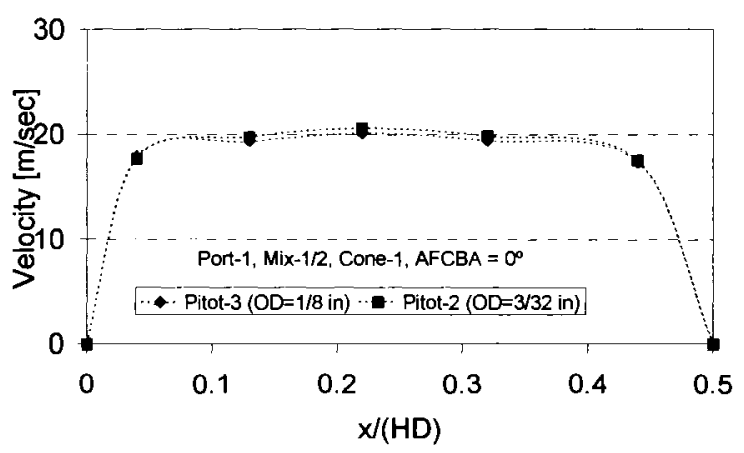

Figure F. 5: Effect of pitot-static tube size on the annular region velocity profile, Port-1 (Sh5) 


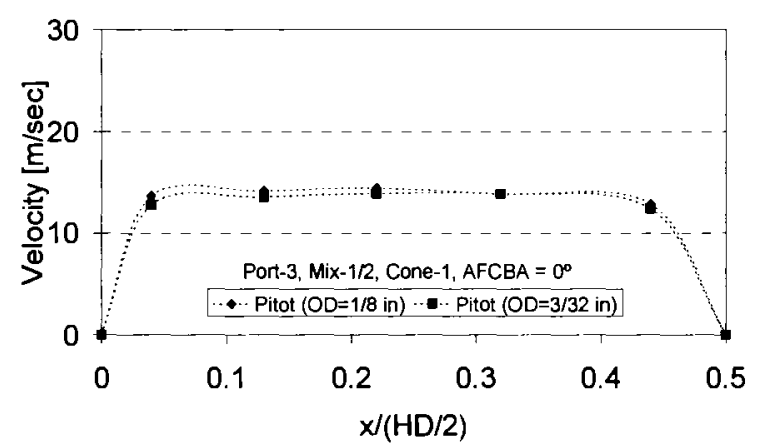

Figure F. 6: Effect of pitot-static tube size on the annular region velocity profile, Port-3 (Sh5)

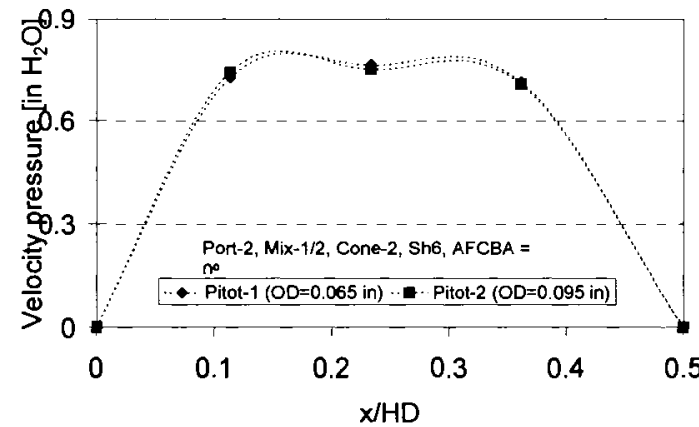

Figure F.8: Effect of pitot-static tube size on the annular region velocity profile (Sh6, Port-2)

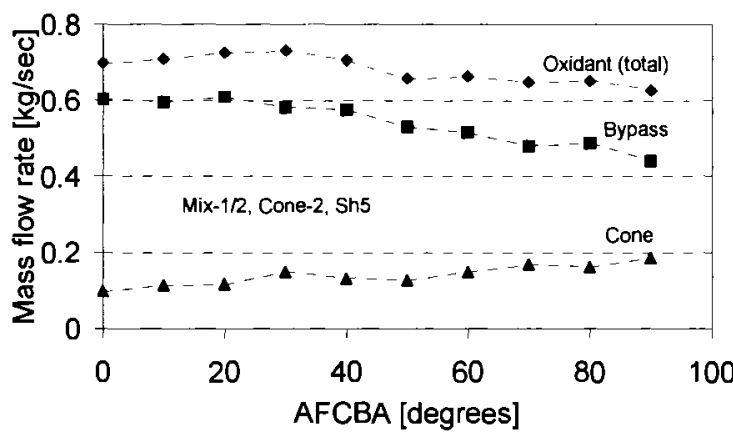

Figure F.10: Effect of AFCBA on the DB mass flow rate split (Mix-1/2, Cone-2 and Sh5)

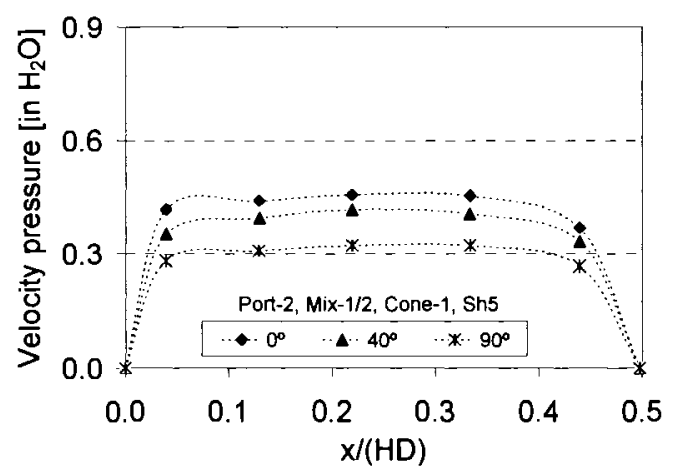

Figure F.7: Effect of AFCBA on the annular region velocity profile, Port-1 (Sh5)

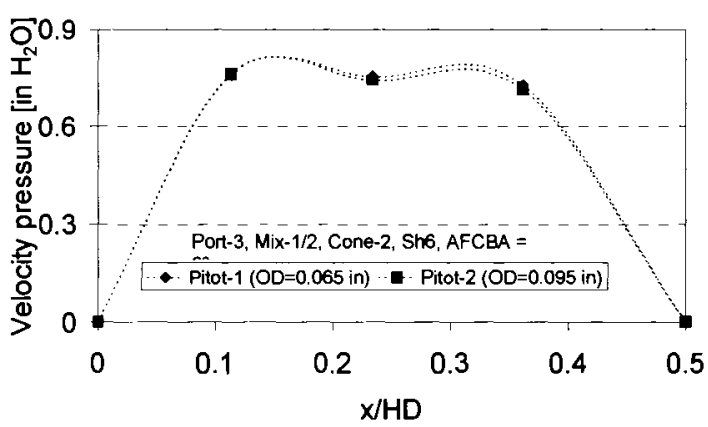

Figure F.9: Effect of pitot-static tube size on the annular region velocity profile (Sh6, Port-2)

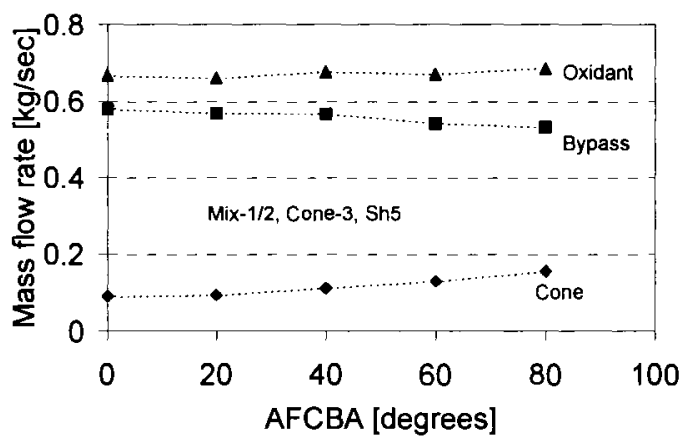

Figure F.11: Effect of AFCBA on the DB mass flow rate split (Mix-1/2, Cone-3 and Sh5) 


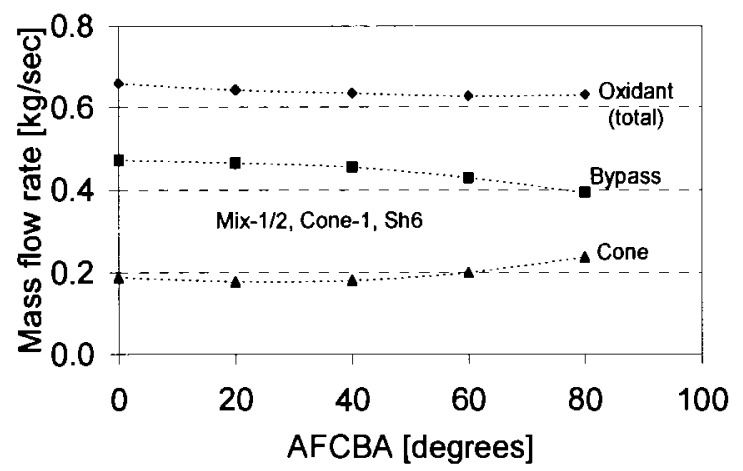

Figure F.12: Effect of AFCBA on mass flow rate split (Mix-1/2, Cone-1 and Sh6)

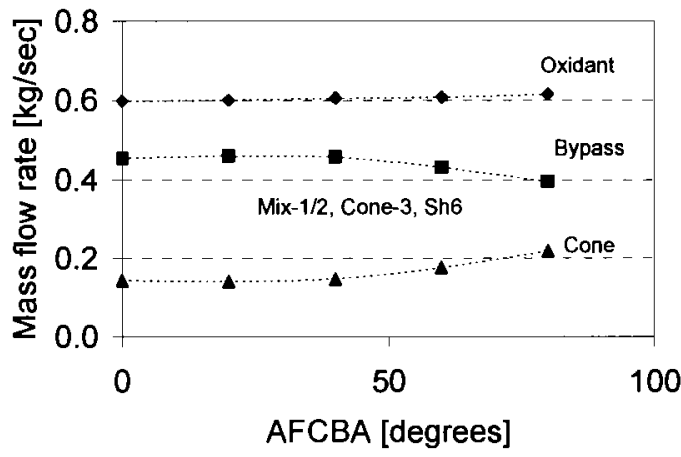

Figure F.14: Effect of AFCBA on mass flow rate split (Mix-1/2, Cone-3 and Sh6)

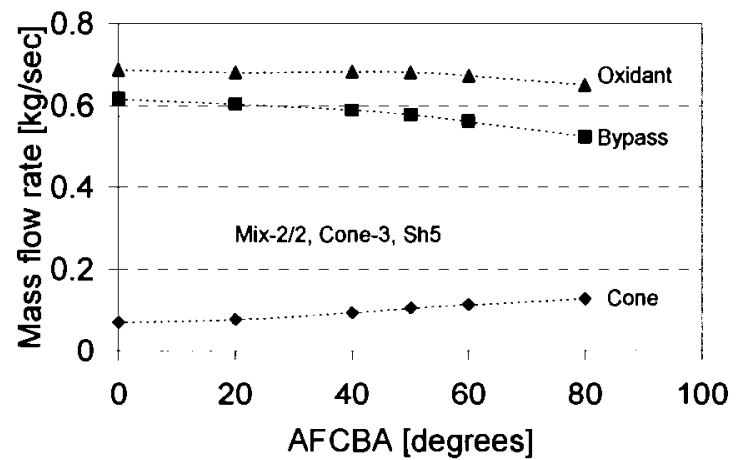

Figure F.16: Effect of AFCBA on mass flow rate split (Mix-2/2, Cone-3 and Sh5)

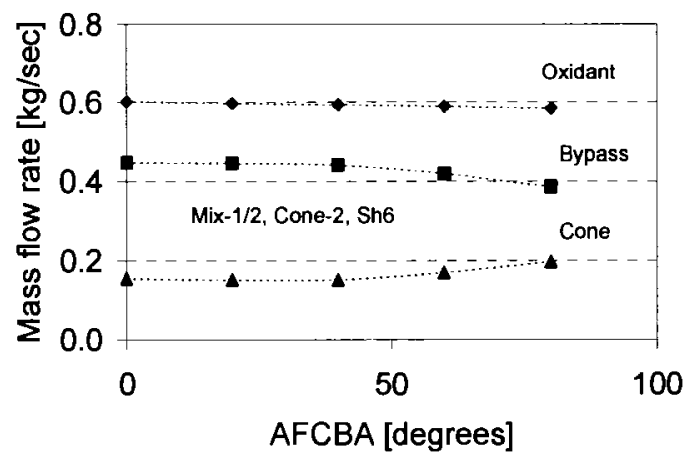

Figure F.13: Effect of AFCBA on mass flow rate split (Mix-1/2, Cone-2 and Sh6)

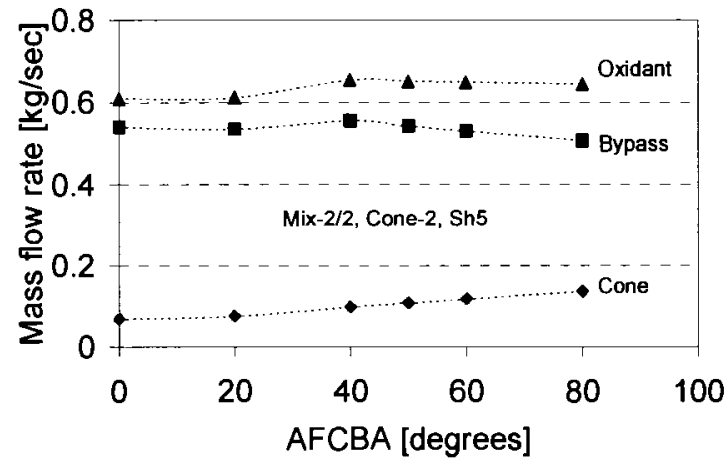

Figure F.15: Effect of AFCBA on mass flow rate split (Mix-2/2, Cone-2 and Sh5)

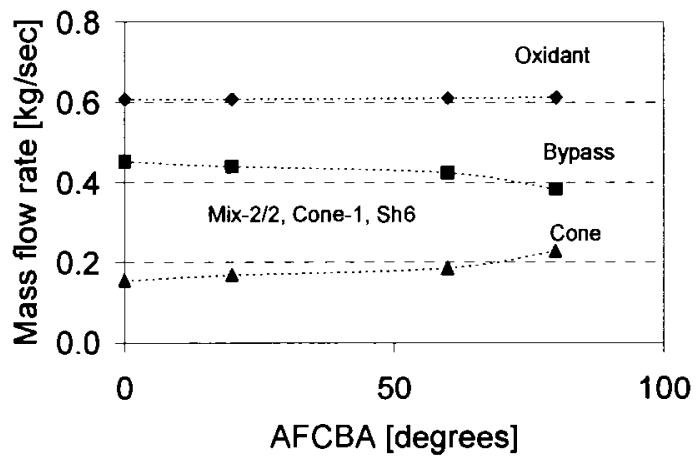

Figure F.17: Effect of AFCBA on mass flow rate split (Mix-2/2, Cone-1 and Sh6) 


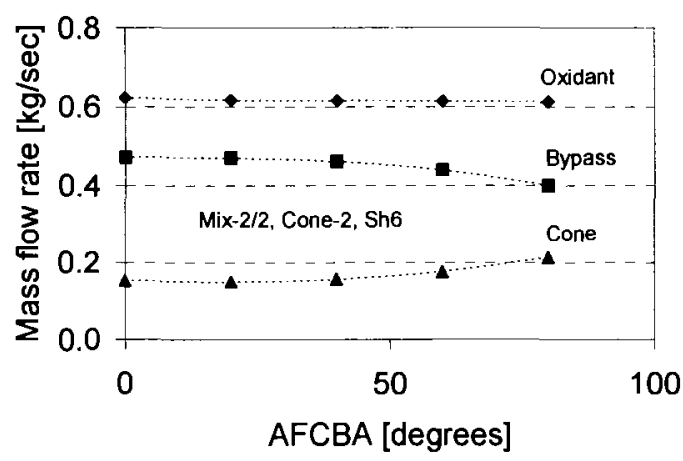

Figure F.18: Effect of AFCBA on mass flow rate split (Mix-2/2, Cone-2 and Sh5)

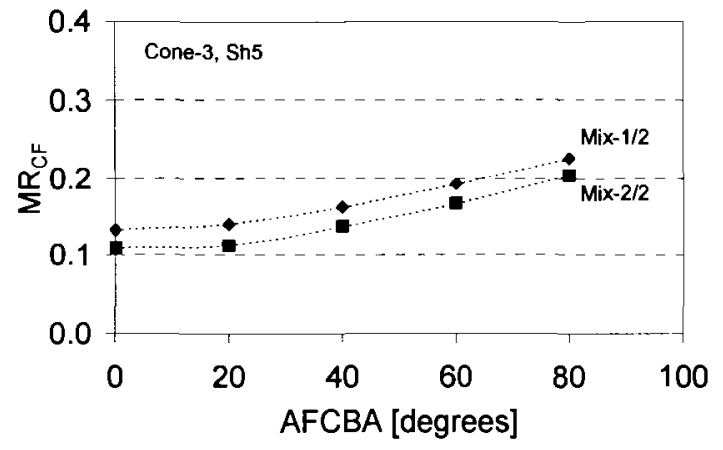

Figure F.20: Effect of mixer design on mass flow ratio (Cone-3 and Sh5)

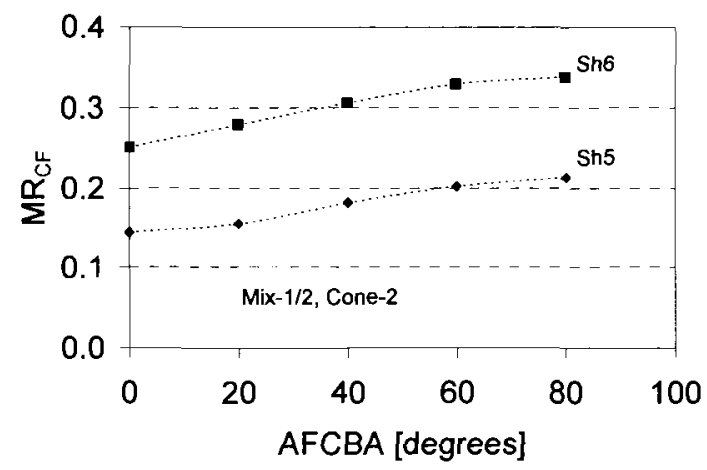

Figure F.22: Effect of $B R$ on mass flow ratio (Mix-1/2, Cone-2)

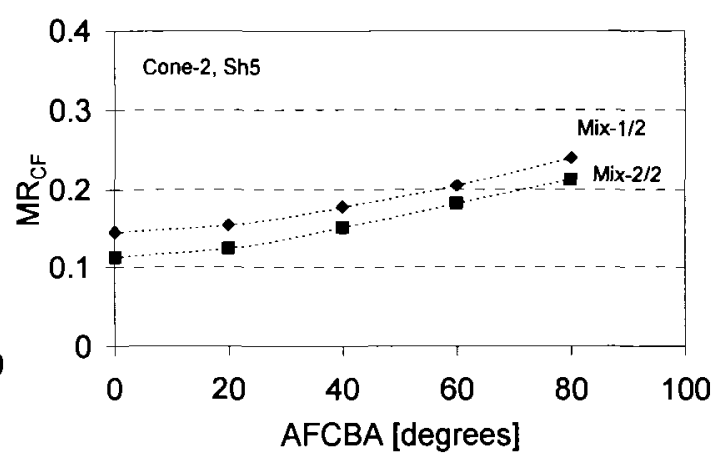

Figure F.19: Effect of mixer design on mass flow ratio (Cone-2 and Sh5)

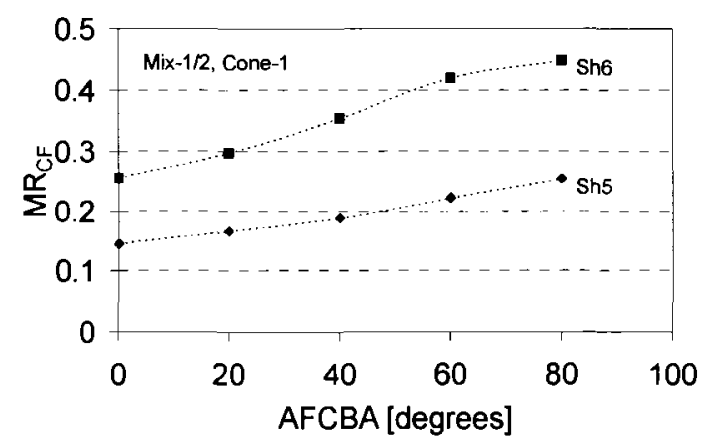

Figure F.21: Effect of BR on mass flow ratio (Mix-1/2, Cone-1)

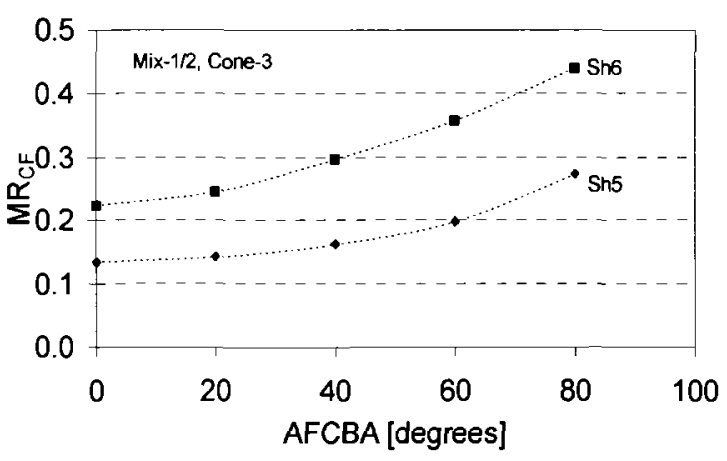

Figure F.23: Effect of BR on mass flow ratio (Mix-1/2, Cone-3) 


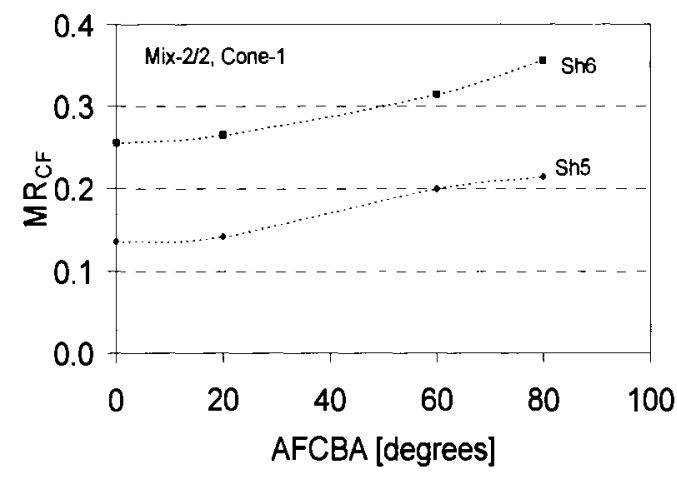

Figure F.24: Effect of BR on mass flow ratio (Mix-2/2 and Cone-1)

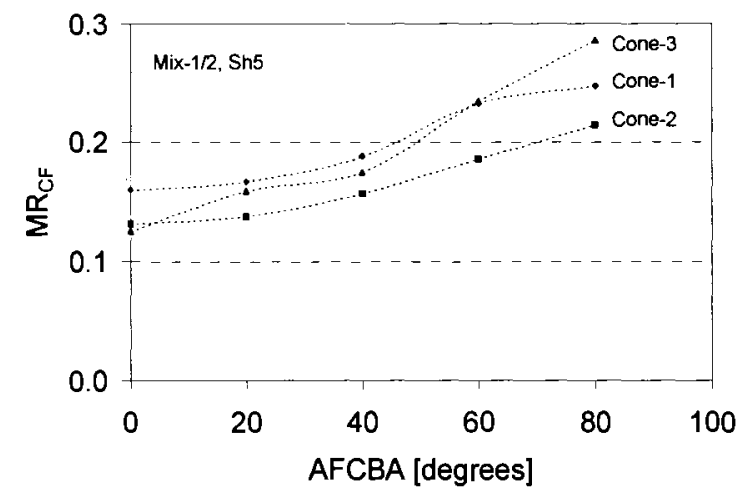

Figure F.25: Cone-3 behaviour, effect of different cones on mass ratio (Mix-1/2 and Sh5)

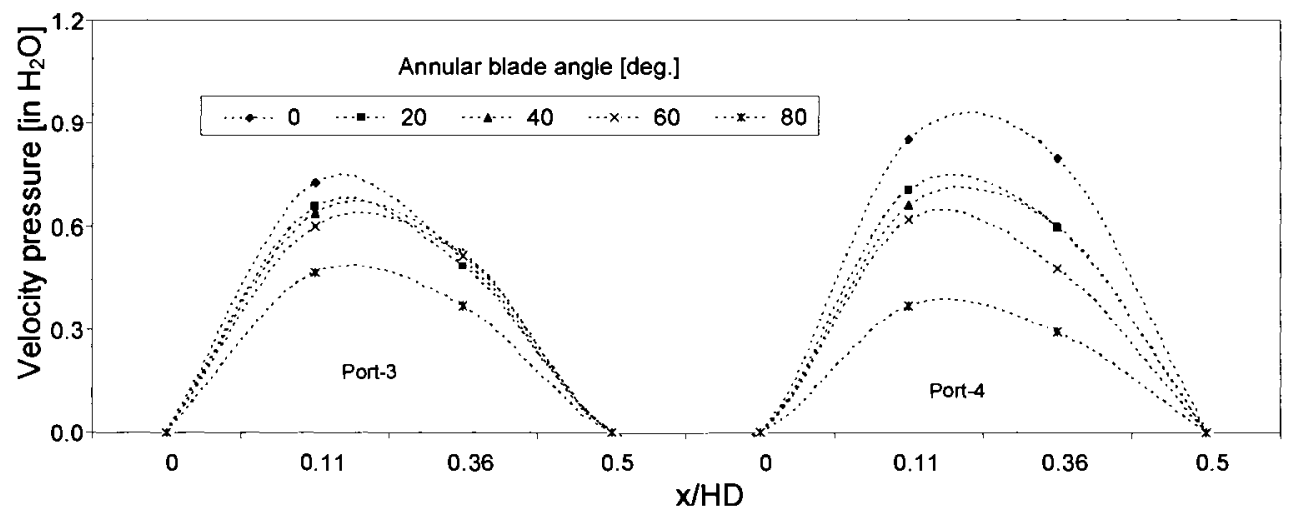

Figure F.26: Effect of the AFCBA on annular region velocity profiles (Mix-2, Cone-2 and Sh6)

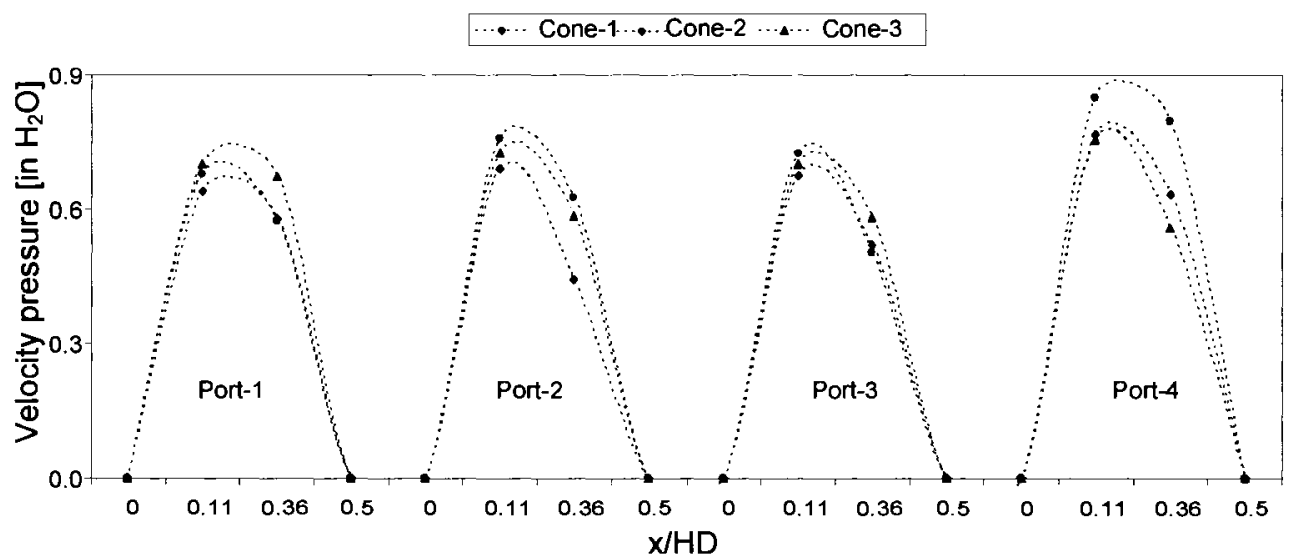

Figure F.27: Effect of conical burner pressure drop on the annular velocity profile $($ Mix -2 and Sh6 at AFCBA $=0$ ) 


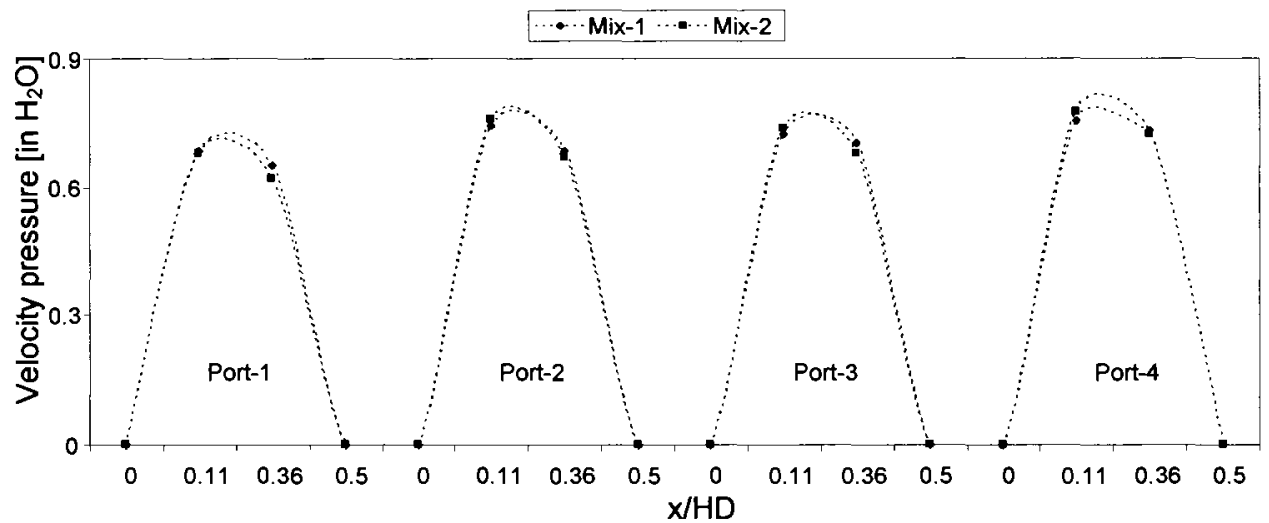

Figure F.28: Effect of conical burner pressure drop on the annular velocity profile (Mix-2 and Sh6 at AFCBA $=0$ )

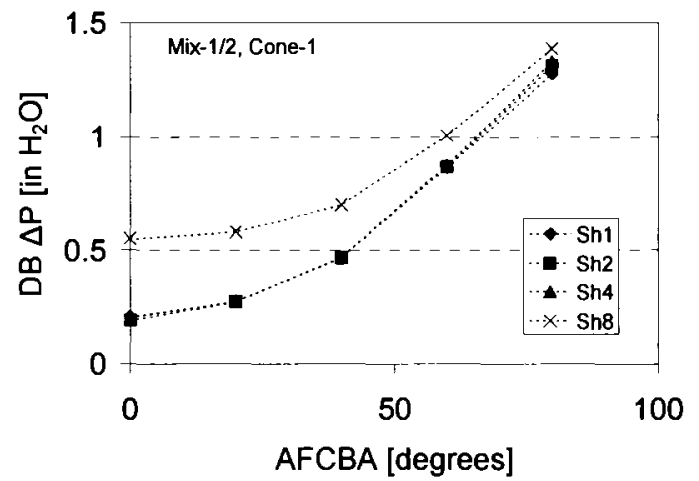

Figure F.29: Effect of $B R$ and $L_{\text {eff }} / D_{\text {shield }}$ on DB $\Delta \mathbf{P}(\mathbf{M i x}-1 / 2$ and Cone-1)

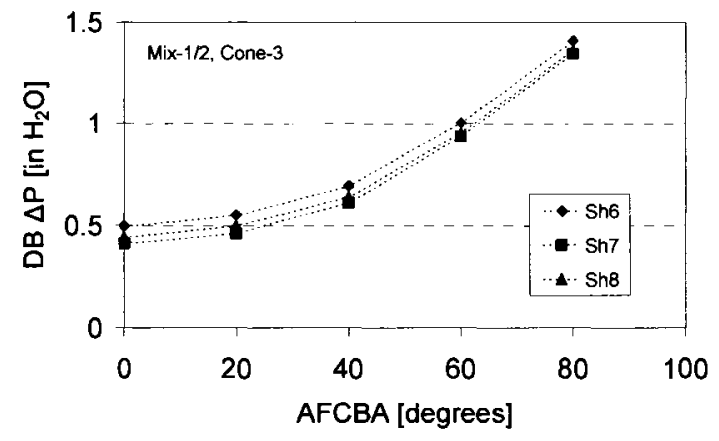

Figure F.31: Effect of $L_{\text {eff }} / D_{\text {shield }}$ on DB $\Delta \mathrm{P}(\mathrm{Mix}-1 / 2$ and Cone-3)

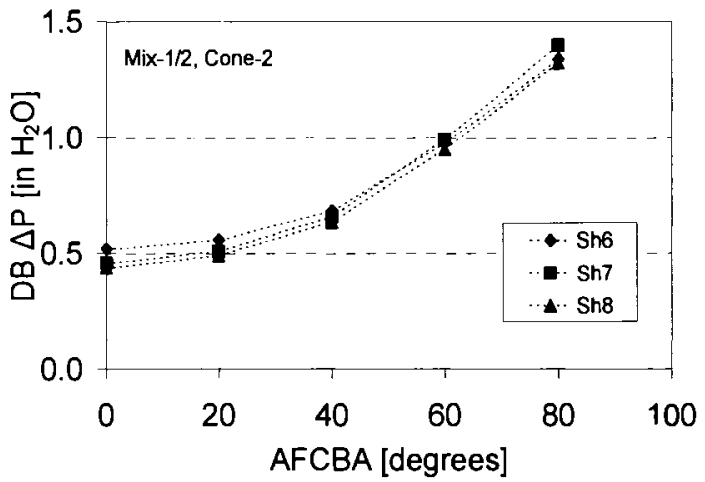

Figure F.30: Effect of $L_{e f f} / D_{\text {shield }}$ on DB $\Delta \mathrm{P}(\mathrm{Mix}-1 / 2$ and Cone-2)

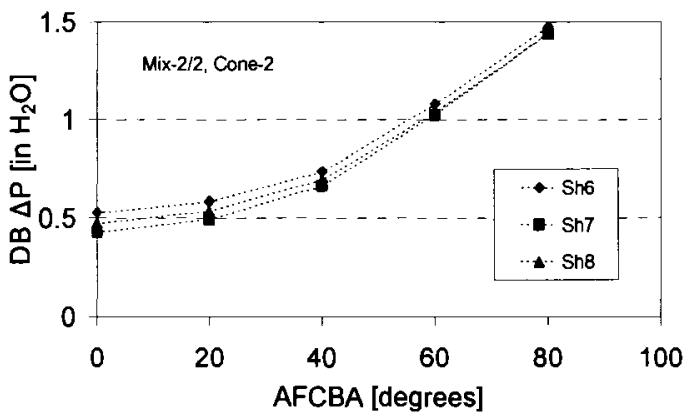

Figure F.32: Effect of $B R$ and $L_{e f f} / D_{\text {shield }}$ on DB $\Delta \mathbf{P}$ (Mix-2/2 and Cone-2) 


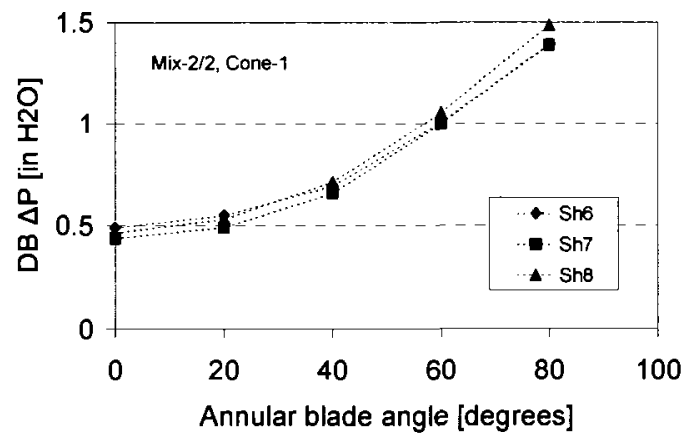

Figure F.33: Effect of $B R$ and $L_{\text {eff }} / D_{\text {shield }}$ on DB $\Delta \mathbf{P}(\mathbf{M i x}-2 / 2$ and Cone-1)

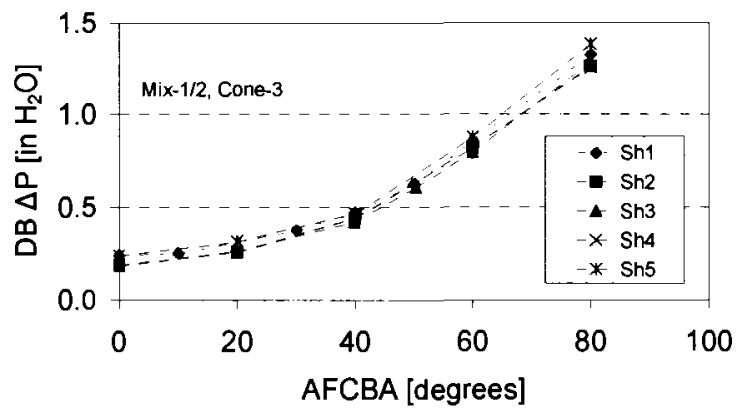

Figure F.35: Effect of $L_{\text {eff }} / D_{\text {shield }}$ on DB $\Delta \mathrm{P}(\mathrm{Mix}-1 / 2$, Cone-3)

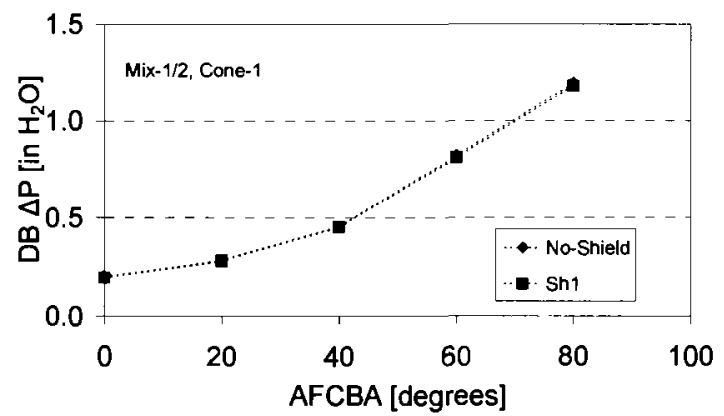

Figure F.37: Effect of using shield on DB $\Delta \mathrm{P}(\mathrm{Mix}-1 / 2$ and Cone-1)

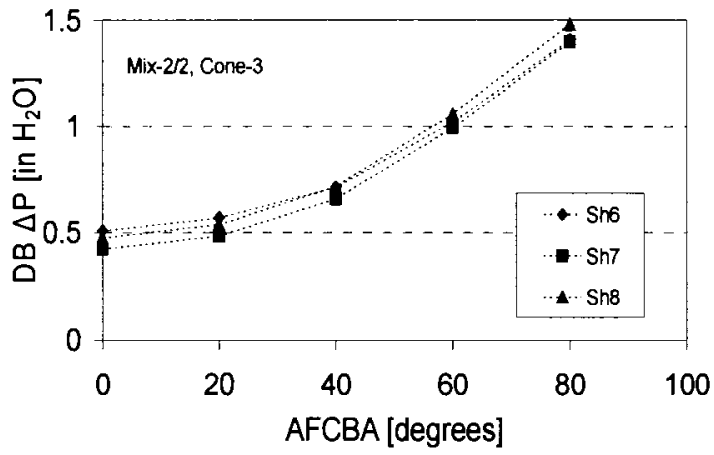

Figure F.34; Effect of $B R$ and $L_{\text {eff }} / D_{\text {shield }}$ on DB $\Delta \mathbf{P}(\mathbf{M i x}-2 / 2$, Cone3)

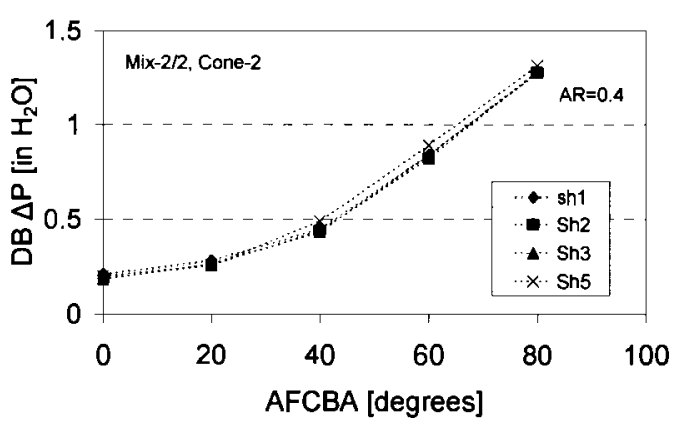

Figure F.36: Effect of $L_{e f f} / D_{\text {shield }}$ on DB $\Delta \mathrm{P}(\mathrm{Mix}-2 / 2$ and Cone-2)

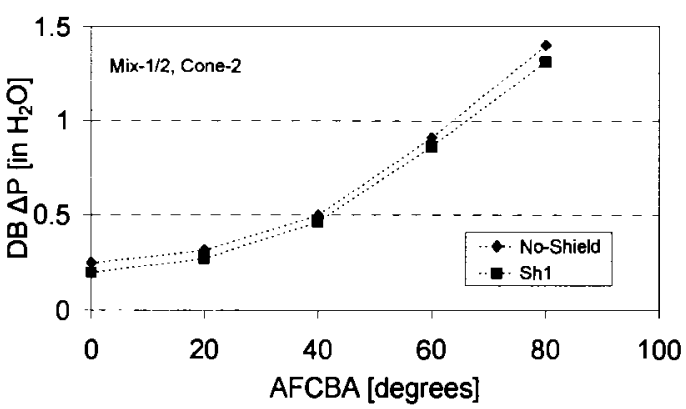

Figure F.38: Effect of using shield on DB $\Delta \mathrm{P}(\mathrm{Mix}-1 / 2$ and Cone-2) 


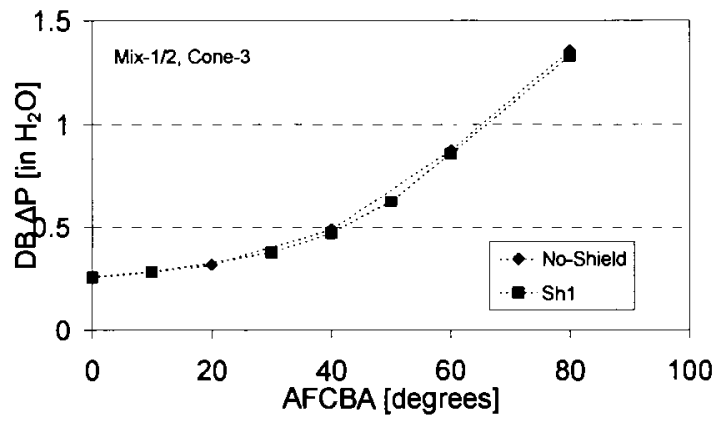

Figure F.39: Effect of using shield on DB $\Delta P($ Mix-1/2 and Cone-3)

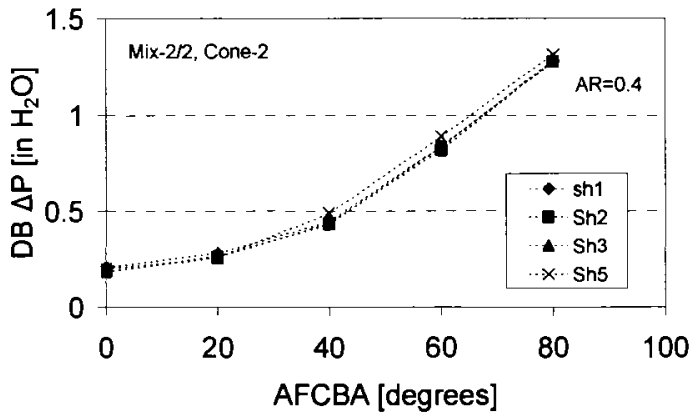

Figure F.40: Effect of $L_{\text {eff }} / D_{\text {shield }}$ on DB $\triangle \mathrm{P}(\mathrm{Mix}-2 / 2$ and Cone-2

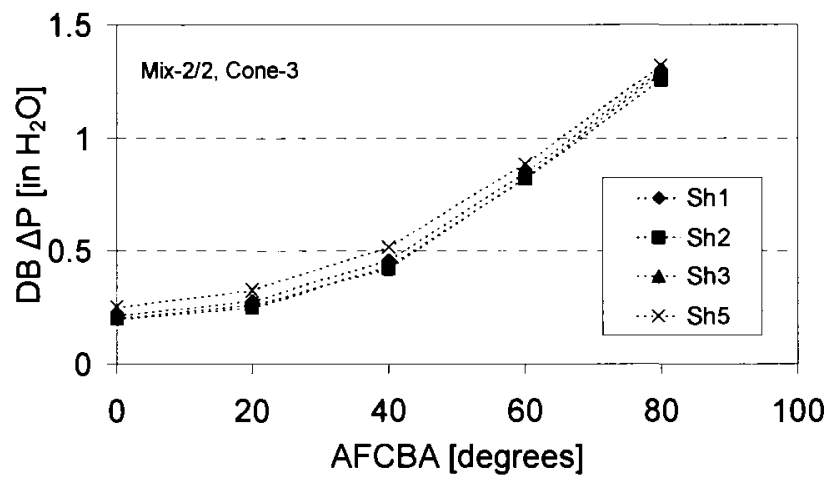

Figure F.41: Effect of $L_{e f f} / D_{\text {shield }}$ on DB $\Delta \mathrm{P}($ Mix-2/2, Cone-3)

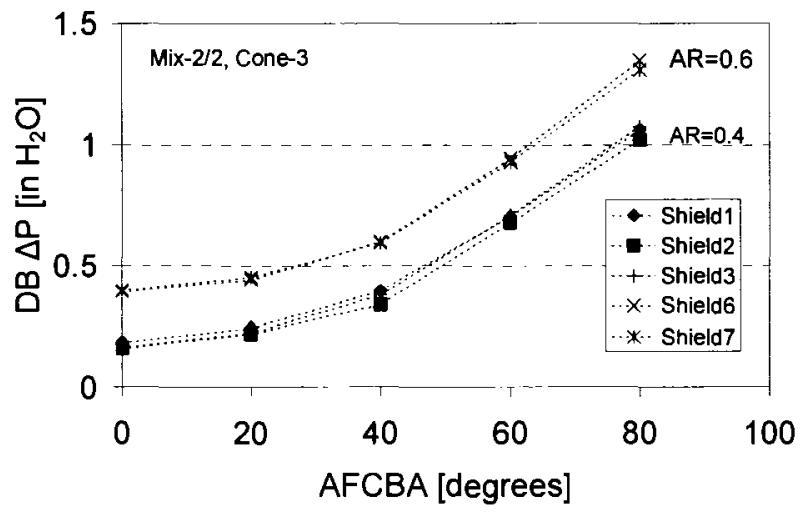

Figure F.42: Effect of BR and $L_{e f f} / D_{\text {shield }}$ on DB $\Delta \mathbf{P}(\mathbf{M i x}-2 / 2$ and Cone-3) 


\section{APPENDIX G: Combustion tests}

\section{G.1 Introduction}

In this appendix two main topics will be covered, first the combustion preliminary results in which the pre-tests conducted prior to the main combustion tests. Secondly, the main combustion tests results which were used in the main conclusion of Chapter 8 and not presented in the main text are also presented in graphical form (plots) in this appendix.

\section{G.2 Combustion preliminary tests}

The first phase of the combustion tests was the preliminary testing or the duct burner shakedown tests. These tests were performed for a selected geometrical setting prior to the main combustion tests to verify the functionality of the different parts of the burner management system (BMS) when integrated with the duct burner. These tests also worked as verifications to the data acquisition system used to have a reasonable level of confidence in the data collected during the main combustion tests. These pre-tests were essential to define the followings; the test procedure, flame scanner location, spark plug insertion distance, fuel pressure limitations, appropriate concentration sampling period and combustion analyzer calibration procedure. Some of the preliminary test measurement results will be presented for selected geometrical parameters in this section.

Figure G.1 and Figure G.2 show examples of the starting characteristics of the duct burner system. Both figures presents the test procedure where the duct burner ignited at a rich mixture then the fuel flow rate adjusted to certain level at which the flame stabilized over the mesh burner. By monitoring the exhaust temperature, the combustion zone temperature, the flame and the analyzer screen until the readings stabilized, the time to steaty state was established. At that time the recording of the measurement started. The combustion analyzer response time was about 45 seconds 
to reach its steady state. A period of 2 minutes was decided to be the waiting time to reach the steady state after the adjusting of the fuel flow rate. Then the sampling period started ( 5 to 8 minutes). The same steps are repeated each time (reduce the fuel flow rate, wait 2 min or more, start the sampling) until the blow-off limit is reached. Figure G.2 shows the practises to find the blow-off limit. At this point, the annular flow control blades were changed to the next setting (i.e., 10 degrees).

To ensure the repeatability of the data, several runs were repeated at different period of time. As an example, Figure G.3 and Figure G.4 show the repeated trend for the measured NOx and CO emissions. The experimental parameters for those runs were kept the same.

During the LSI phase (Chapter 5) of this investigation, different fuel caps were tested to study the effect of their different design on the mixing process. Three were selected for the combustion tests; Cap-2, Cap-3 and Cap-4. The three selected caps have similar design in which the fuel is injected at $90^{\circ}$ angle through the mainstream. The only difference between those three caps was the size of the fuel holes. And it was expected that, the combustion tests results of using different burner parameters with the three caps will in general have similar behaviour or trend. The difference only expected to be in the stability limits (operating ranges) and the emissions. For any certain tested case, with Cap-3, the expected results will be somewhere in between Cap-2 and Cap-4 results for the same burner parameters. Therefore, it was decided to use the caps that has the smaller and the larger hole diameters (Cap-2 and Cap-4), for the main combustion tests. The attempt was to scan and cover all the possible stable operating ranges the duct burner can achieve during this evaluation. A number of combustion tests were performed to check the performance of the three caps.

Figure G. 5 shows the experimental test results of NOx emissions as a function of firing rate and fuel cap type. The results were for burner configuration; Mix-2/2, Cone-2 and Sh3 at $\mathrm{AFCBA}=20^{\circ}$. The duct burner inlet temperature for this test was $227^{\circ} \mathrm{C}$. As expected, it is clearly can be observed that the lower operating point for 
this case was covered by Cap- 2 and the highest operating point was reached when Cap-4 was used.

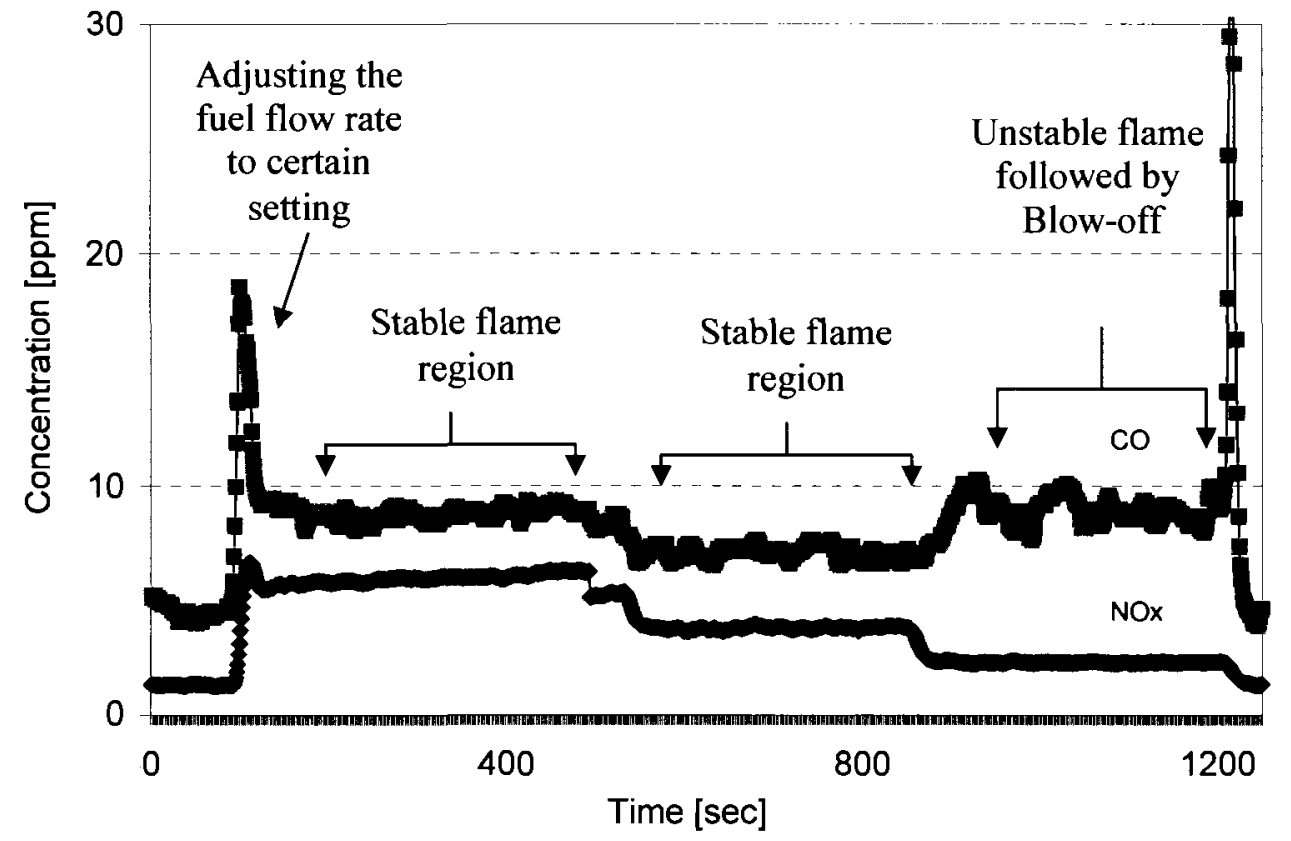

Figure G.1: Combustion preliminary tests emissions results (microturbine + DB)

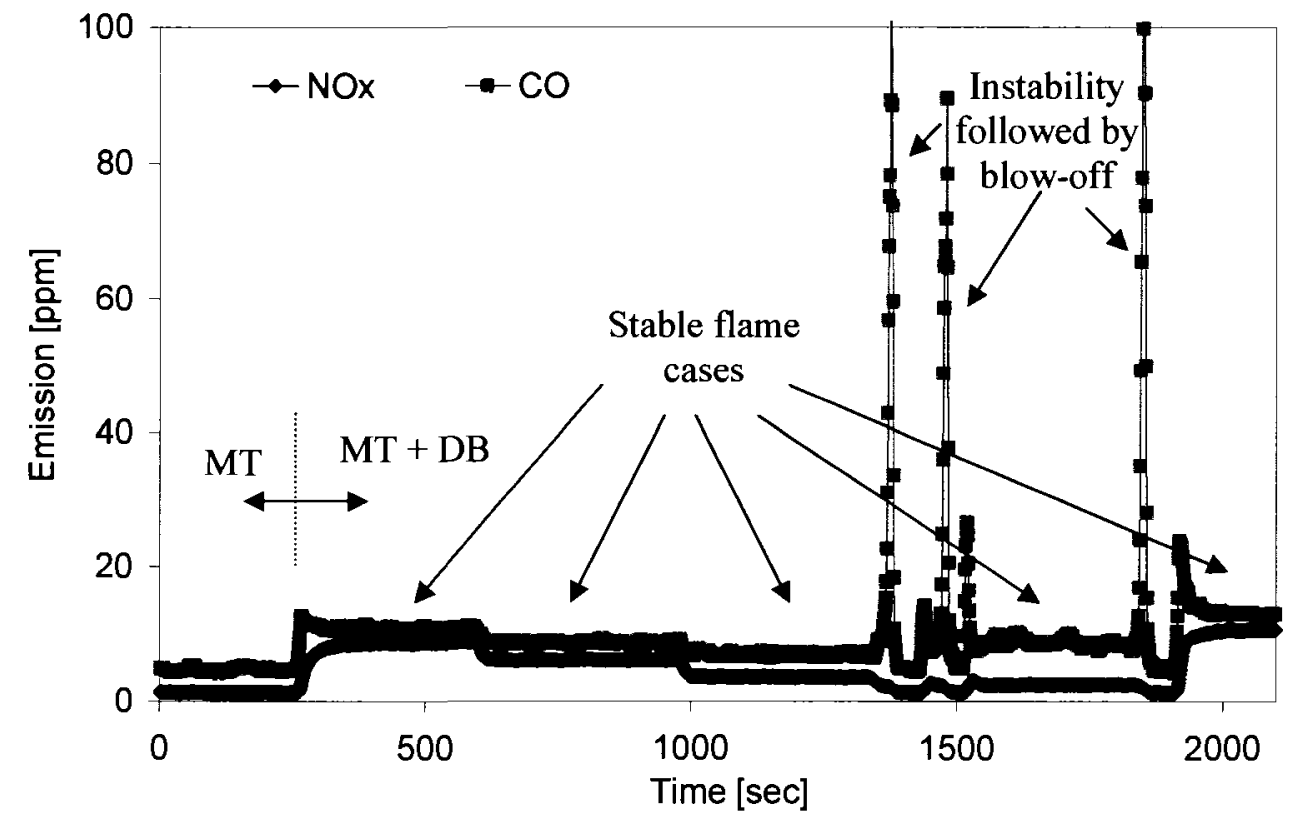

Figure G.2: Combustion preliminary tests emissions results (Mix-1/2, Cone-3, Cap-4 and Sh4 at $\mathrm{AFCBA}=0^{\circ}$ ) 
As conclusion from the above mentioned combustion preliminary tests results it was decided to use Cap-2 and Cap-4 during the main combustion tests in which the stable operating range of the duct burner, pollutant emissions (NOx and $\mathrm{CO}$ ) and pressure drop measurements were performed.

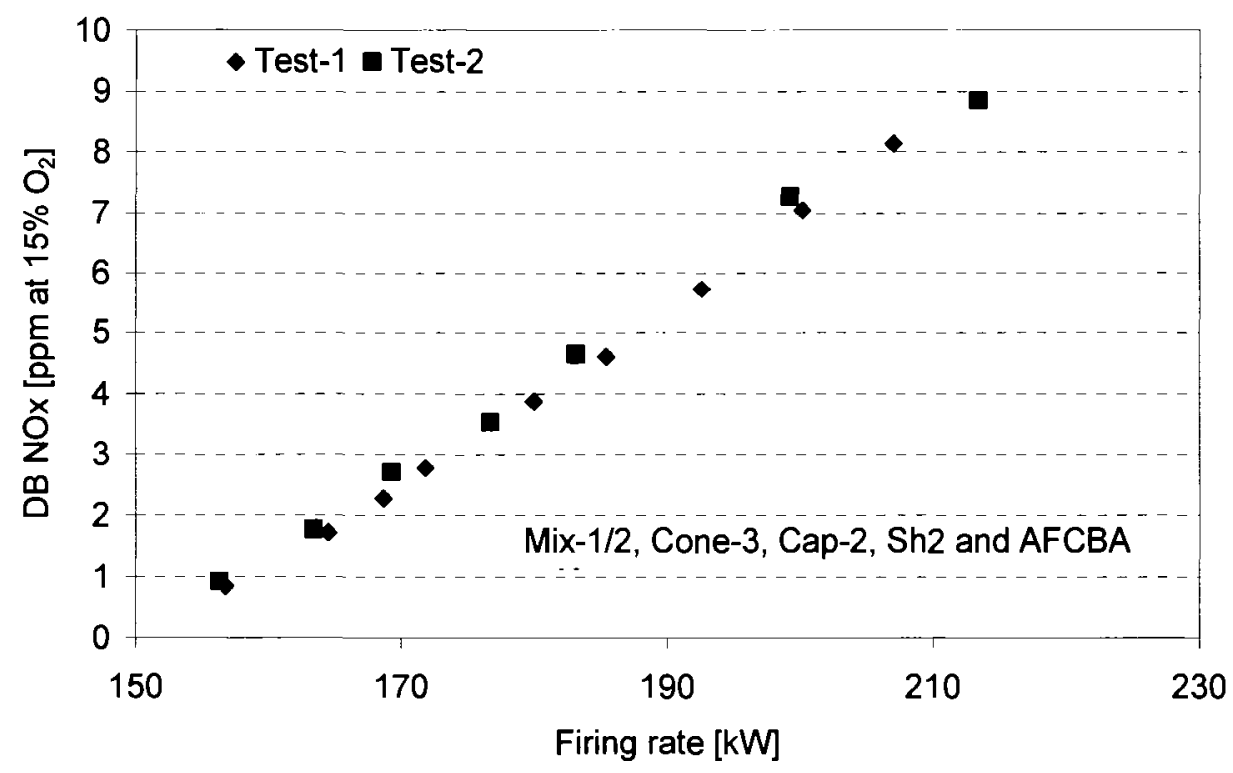

Figure G.3: Combustion preliminary tests NOx emissions results (repeatability test)

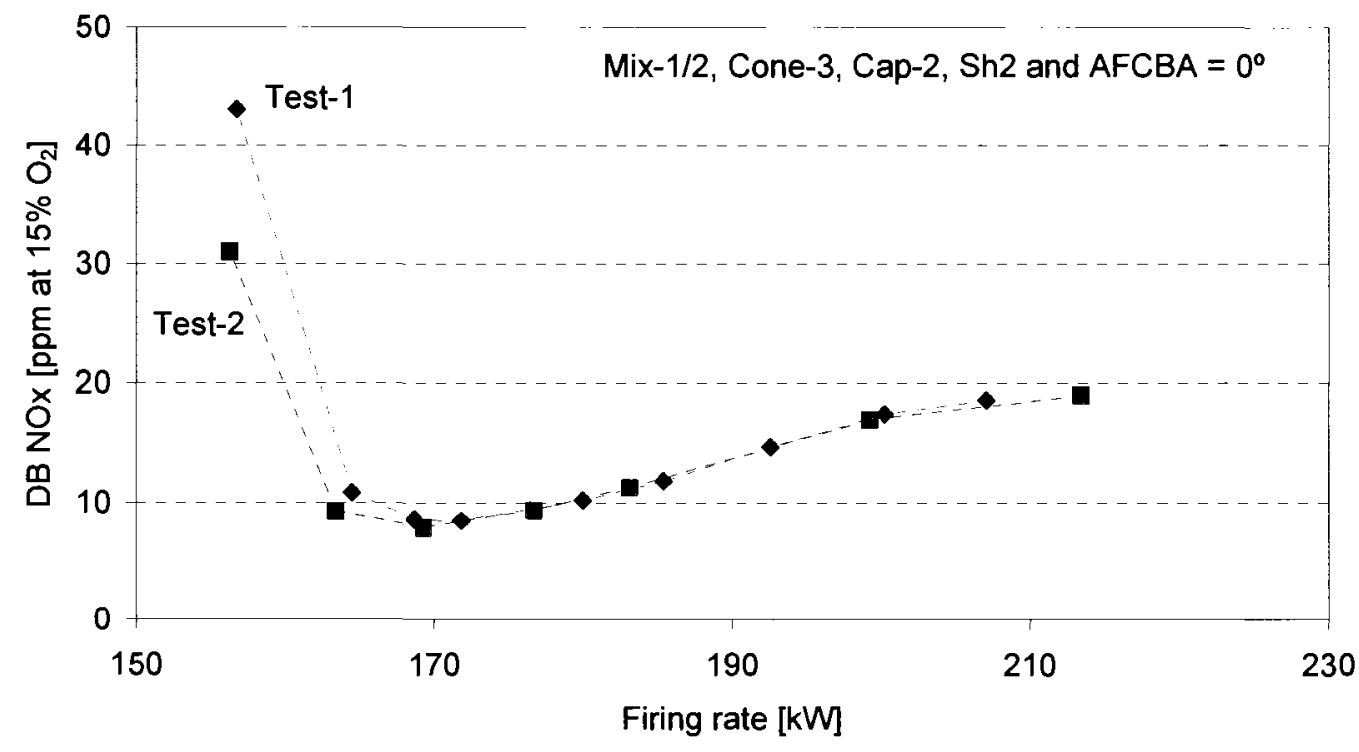

Figure G.4: Combustion preliminary tests $\mathrm{CO}$ emissions results (repeatability test) 


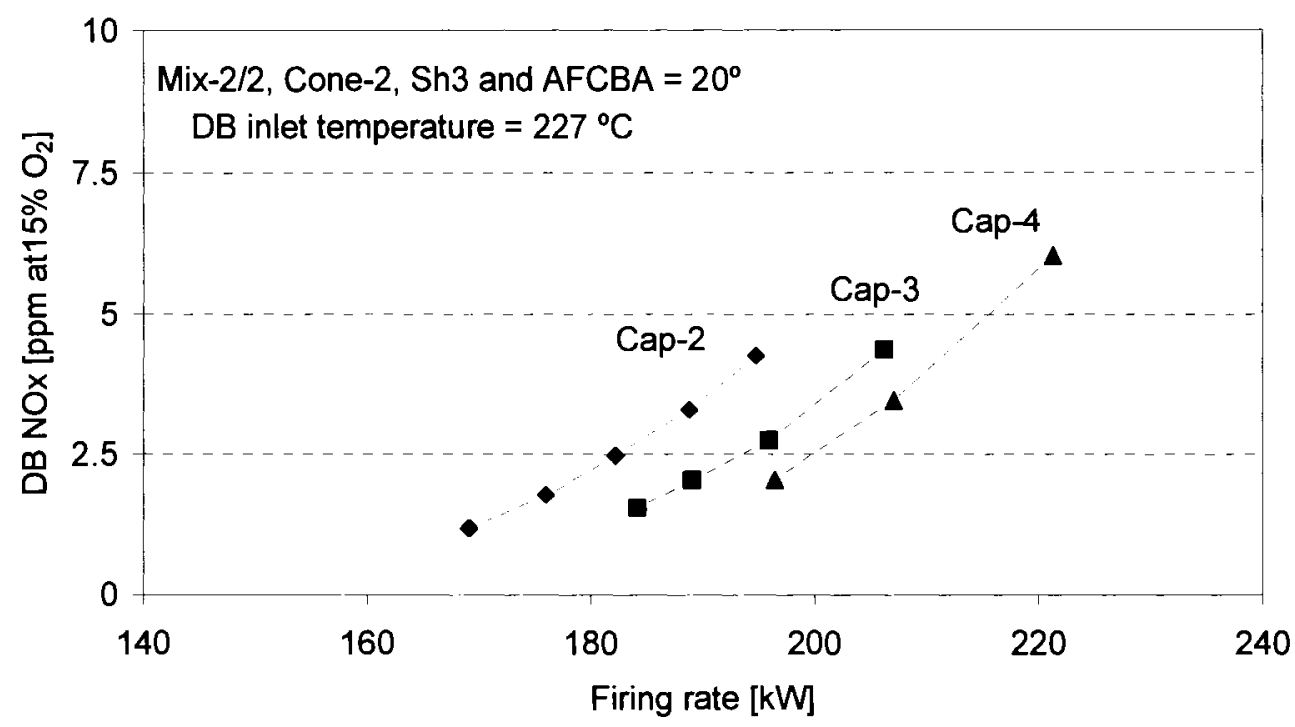

Figure G.5: Combustion preliminary tests NOx emissions results (effect of fuel caps)

Another important test was performed at the time of preliminary testing was to check the accuracy of the combustion analyzer results. In this practice, a comparison wasa made between the different mass flows calculated using the pitotstatic tube results, presented in Chapter 6 , and those calculated from the combustion gas analysis. See Appendix $\mathrm{H}$ for more details.

\section{G.3 Additional combustion tests results}

The results presented in this section covers all the combustion tests results of Cap-3 when tested with both mixers Mix-1/2 and Mix-2/2 and with other duct burner fixed parameters. In addition, results of Cap-2 and Cap-4 which were not presented in Chapter 8 will be presented in this Appendix. The presentation of the results will be in the following order:

- Mix-1/2 and Cap-3 combinations results

- Mix-2/2 and Cap-3 combinations results

- Mix-1/2 with Cap-4, Mix-2/2 with Cap-2, and Mix-2/2 with Cap4 combinations remaining results. 


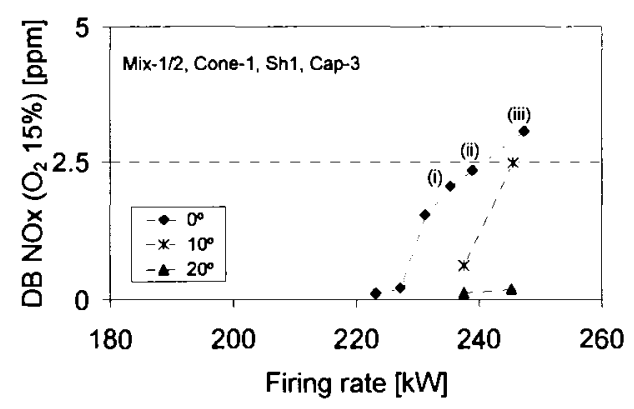

(a) DB NOx emissions

(c) DB pressure drop

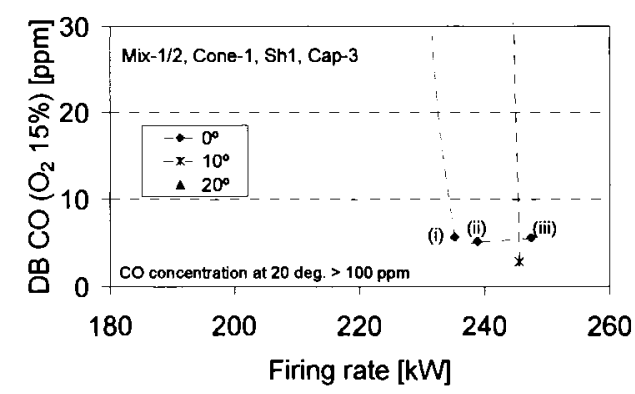

(b) DB CO emissions

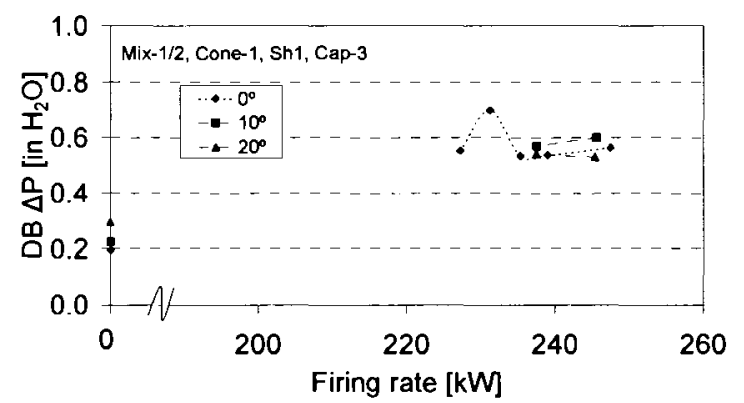

Figure G.6: Effect of firing rate and AFCBA on duct burner performance (Mix-1/2, Cap-3, Cone-1 and Sh1)

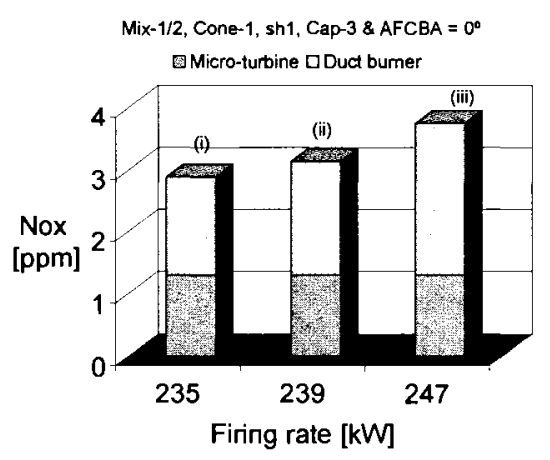

(a) NOx emissions

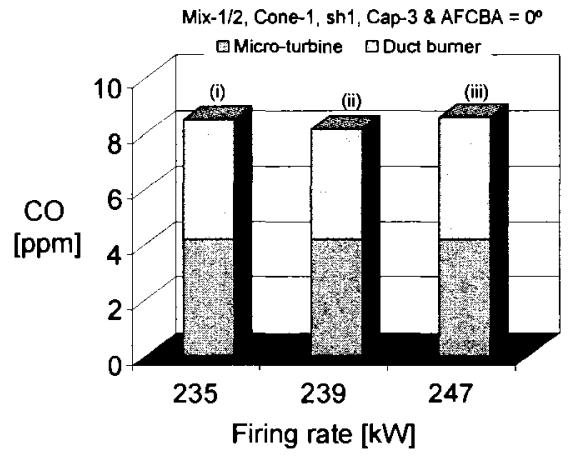

(b) CO emissions

Figure G.7: Effect of Firing rate on duct burner performance, Component contributions (Mix-1/2, Cap-3, Cone-1 and Sh1 at AFCBA $=0^{\circ}$ 


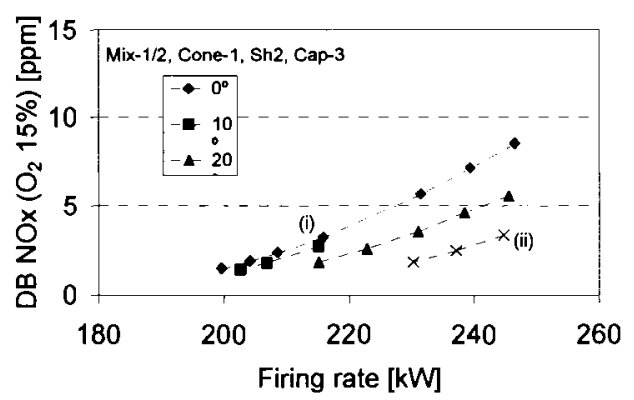

(a) DB NOx emissions

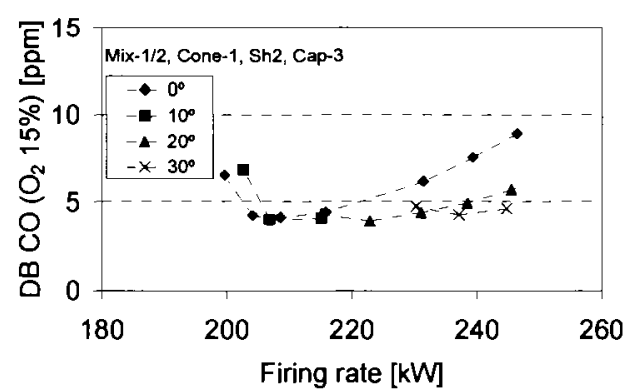

(b) DB CO emissions

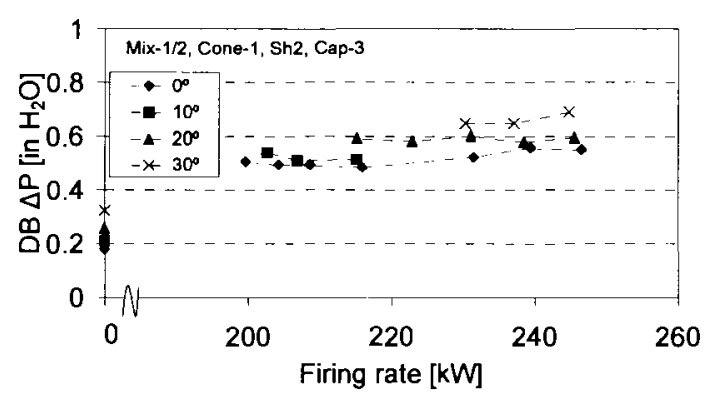

(c) DB pressure drop

Figure G.8: Effect of firing rate and AFCBA on duct burner performance (Mix-1/2, Cap-3, Cone-1 and Sh2)

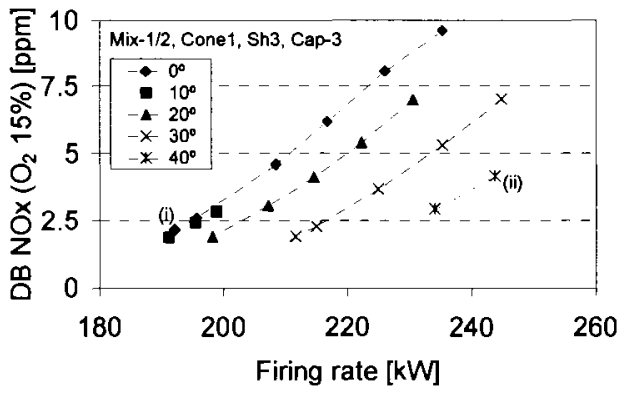

(a) DB NOx emissions

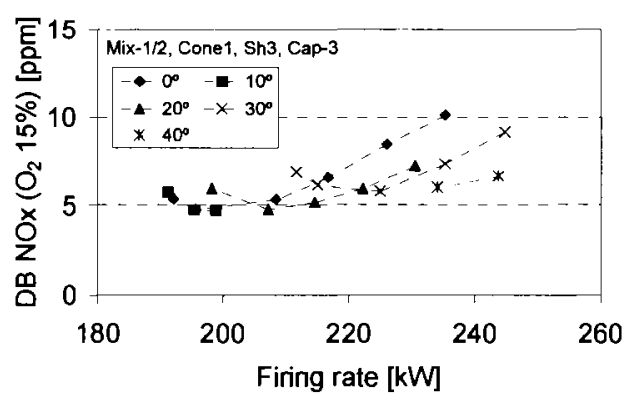

(b) DB CO emissions

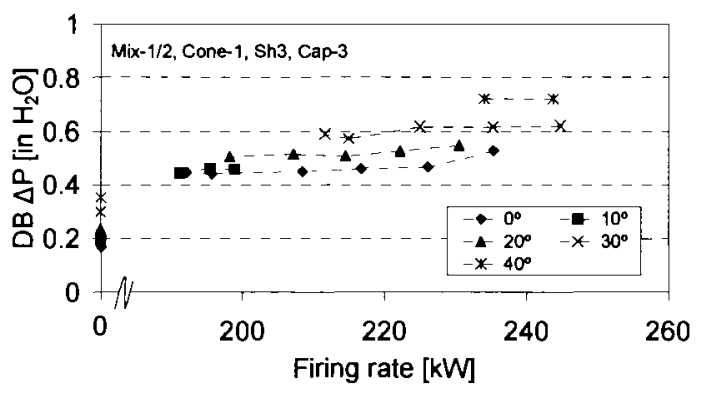

(c) DB pressure drop

Figure G.9: Effect of firing rate and AFCBA on duct burner performance (Mix-1/2, Cap-3, Cone-1 and Sh3) 


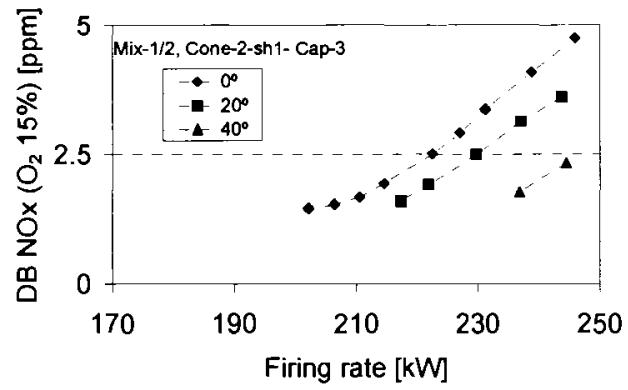

(a) DB NOx emissions

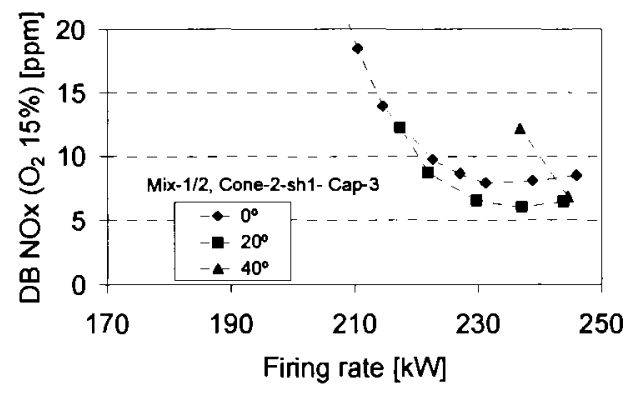

(b) DB CO emissions

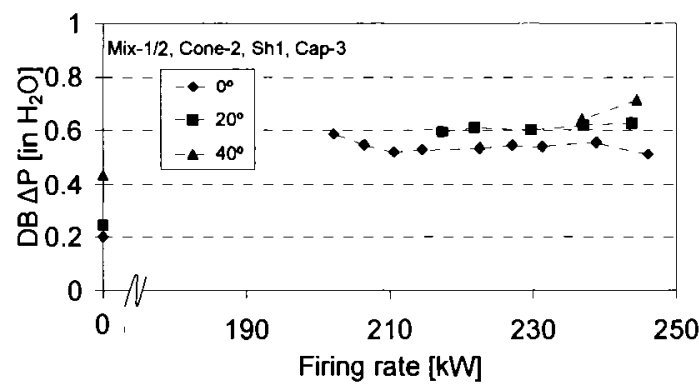

(c) DB pressure drop

Figure G.10: Effect of firing rate and AFCBA on duct burner performance (Mix-1/2, Cap-3, Cone-2 and Sh1

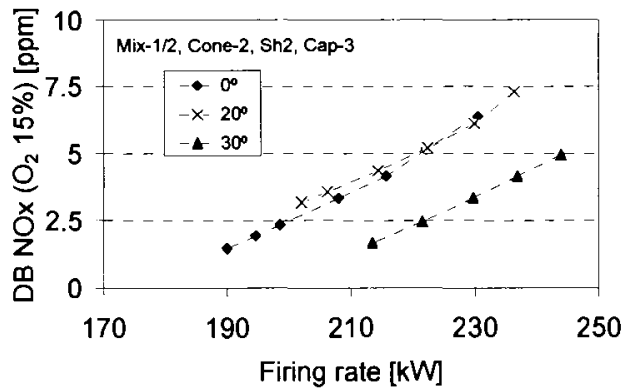

(a) DB NOx emissions

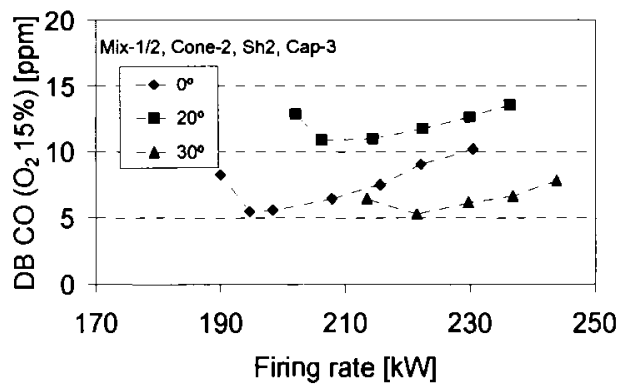

(b) DB CO emissions

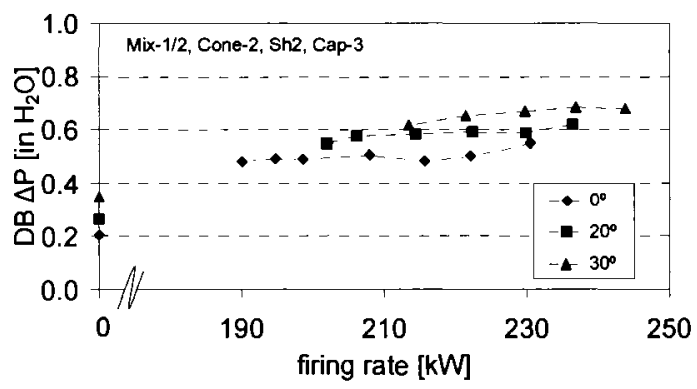

(c) DB pressure drop

Figure G.11: Effect of firing rate and AFCBA on duct burner performance (Mix-1/2, Cap-3, Cone-2 and Sh2) 


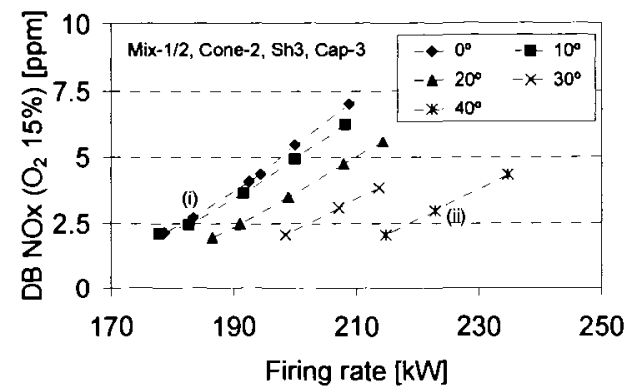

(a) DB NOx emissions

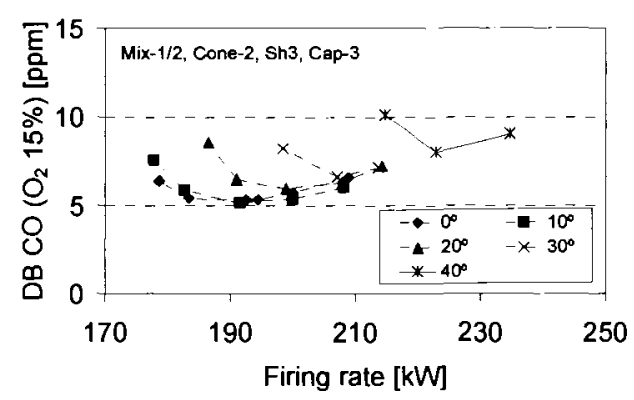

(b) DB CO emissions

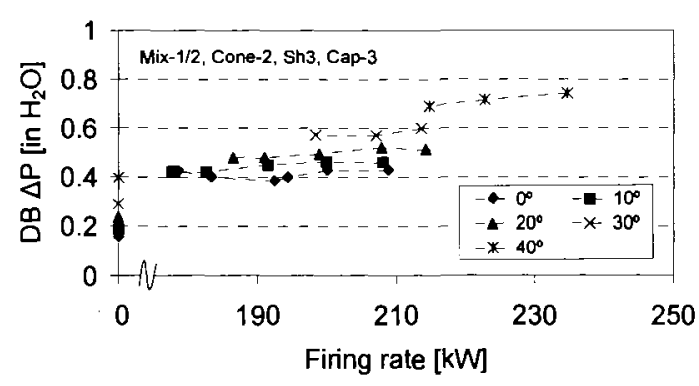

(c) DB pressure drop

Figure G.12: Effect of firing rate and AFCBA on duct burner performance (Mix-1/2, Cap-3, Cone-2 and Sh3)

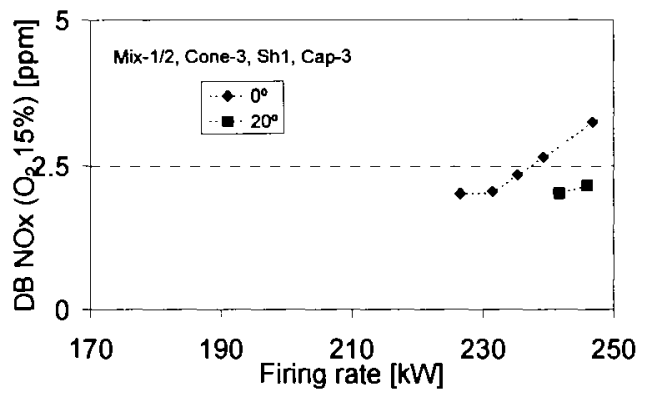

(a) DB NOx emissions

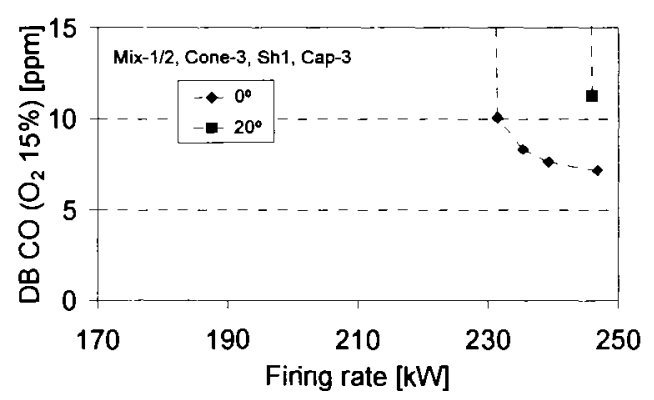

(b) DB CO emissions

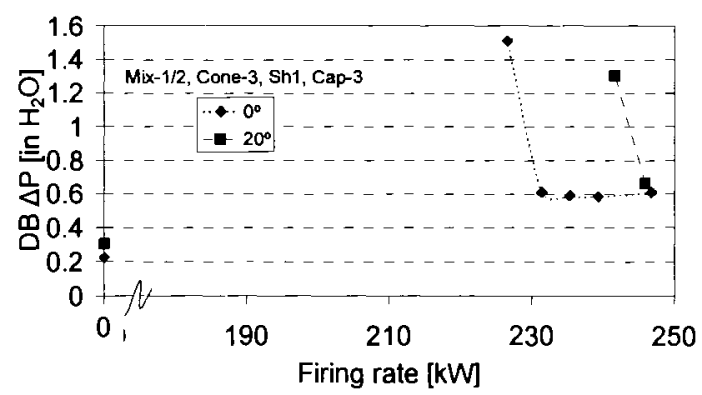

(c) DB pressure drop

Figure G.13: Effect of firing rate and AFCBA on duct burner performance (Mix-1/2, Cap-3, Cone-3 and Sh1) 


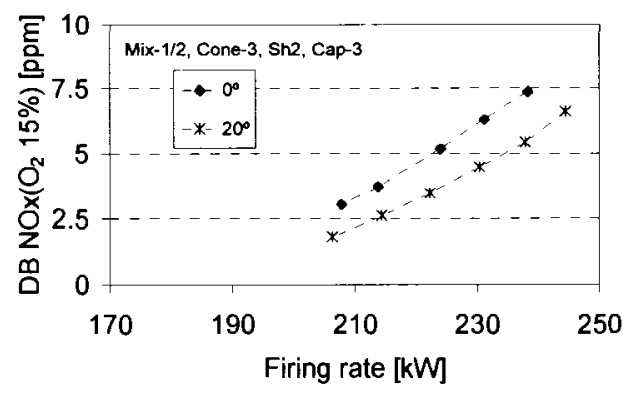

(a) DB NOx emissions

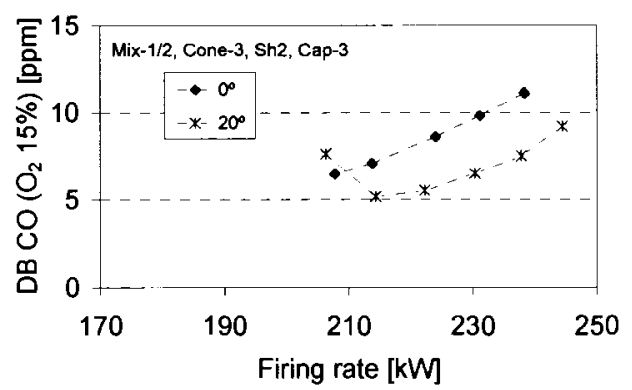

(b) DB CO emissions

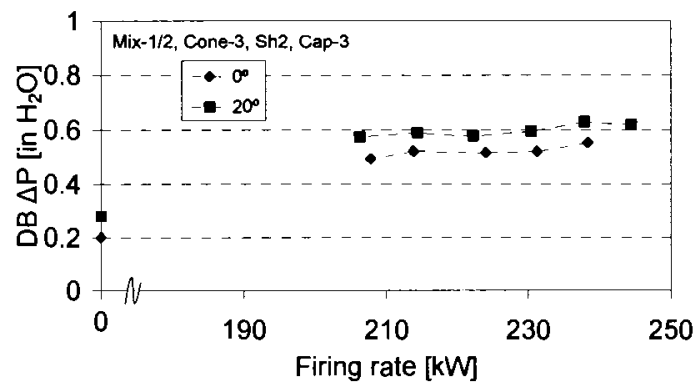

(c) DB pressure drop

Figure G.14: Effect of firing rate and AFCBA on duct burner performance (Mix-1/2, Cap-3, Cone-3 and Sh2)

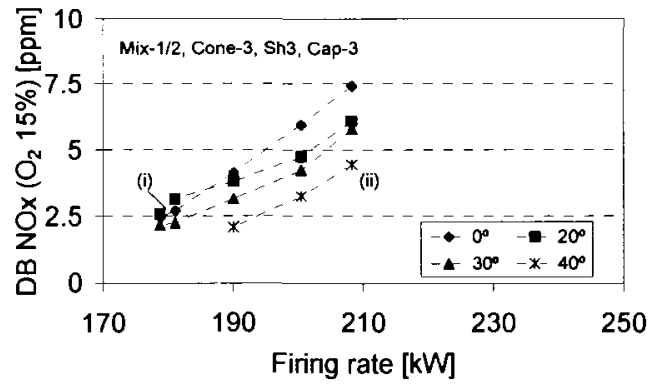

(a) DB NOx emissions

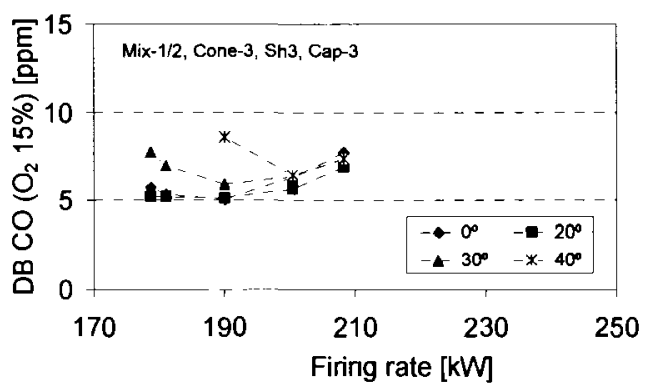

(b) DB CO emissions

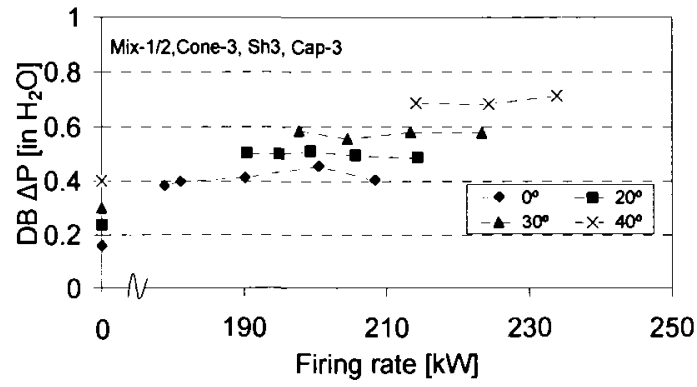

(c) DB pressure drop

Figure G.15: Effect of firing rate and AFCBA on duct burner performance (Mix-1/2, Cap-3, Cone-3 and Sh3) 


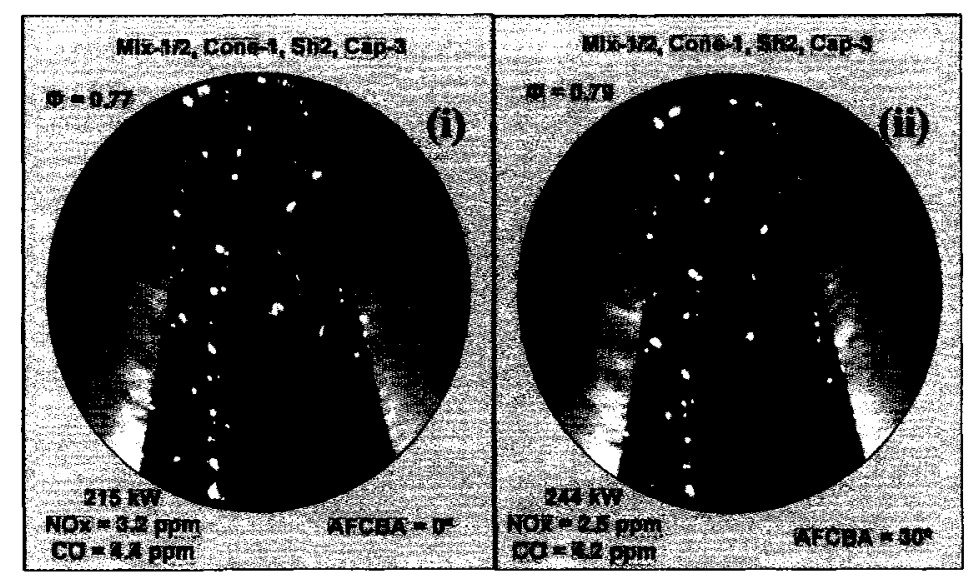

Figure G.16: Flame images taken for points (i) and (ii) in Figure G.8 (a)

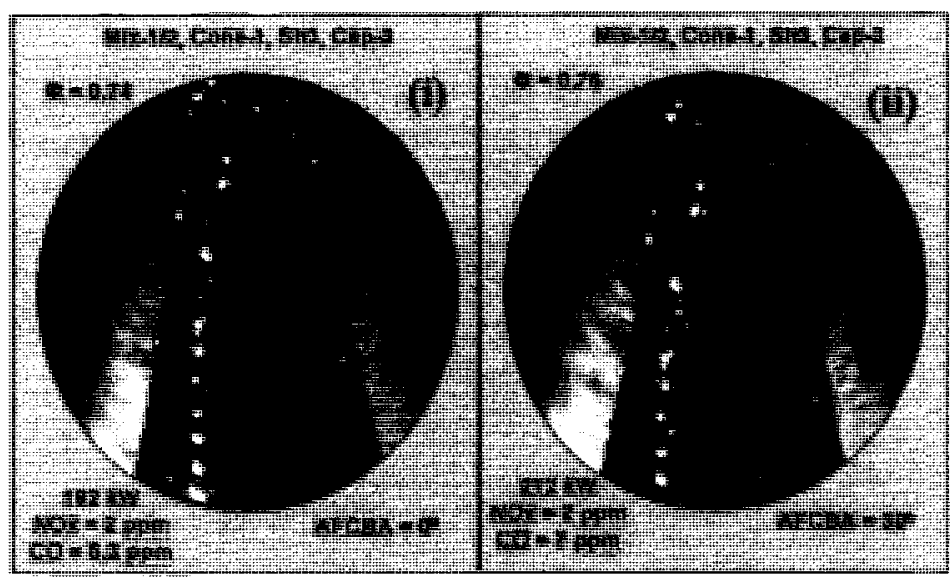

Figure G.17: Flame images taken for points (ii) and (v) in Figure G.9 (a)

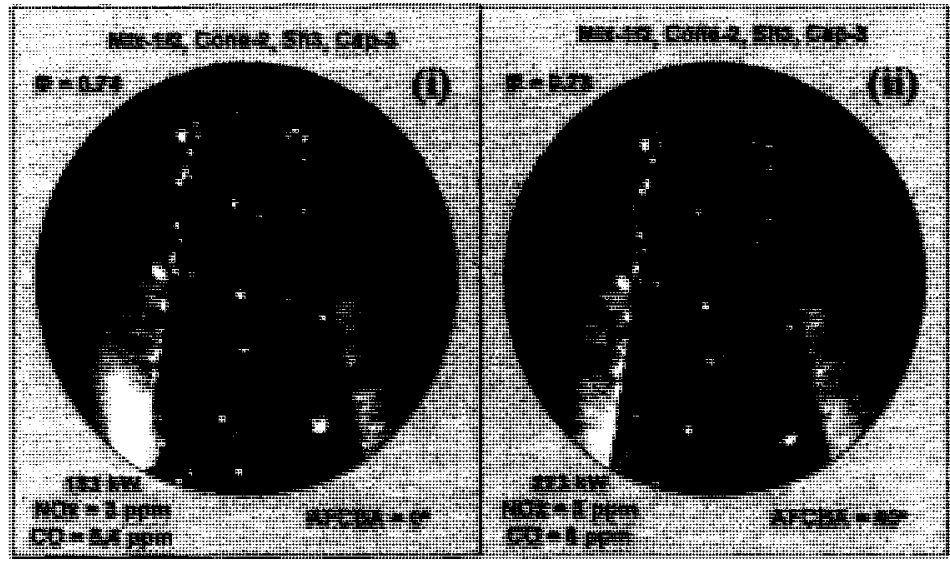

Figure G.18: Flame images taken for points (ii) and (v) in Figure G.12 (a) 


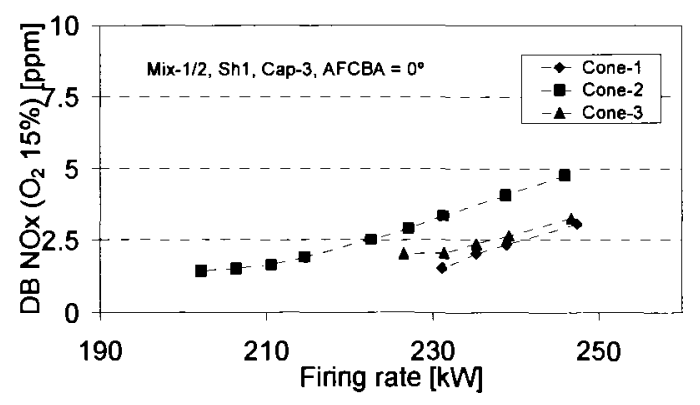

(a) Shl

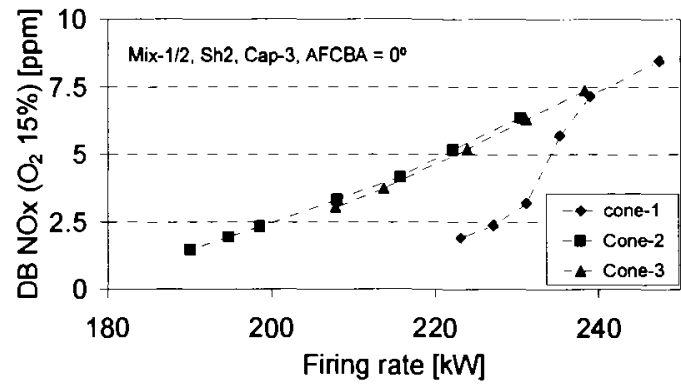

(b) $\mathrm{Sh} 2$

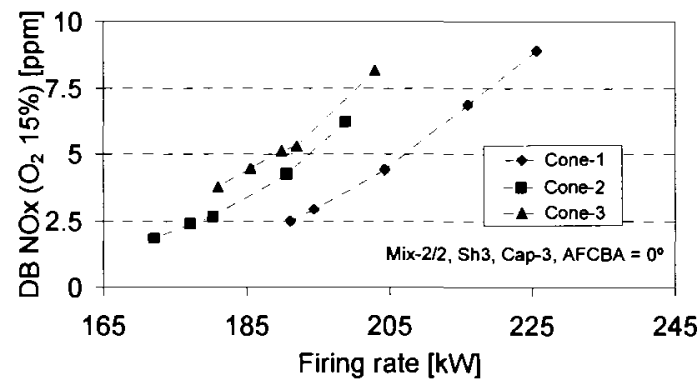

(c) $\operatorname{Sh} 3$

Figure G.19: Effect of firing rate and conical burner pressure drop on duct burner NOx emissions (Mix-1/2, Cap-3 with Cone-1, Cone-2 and Cone- 3 at AFCBA $=0^{\circ}$ )

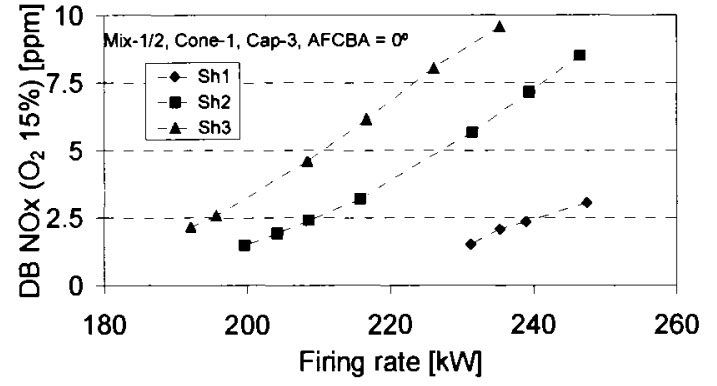

(a) Cone-1

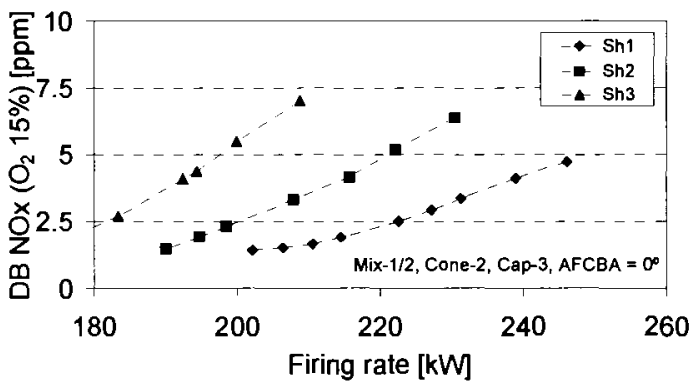

(b) Cone-2

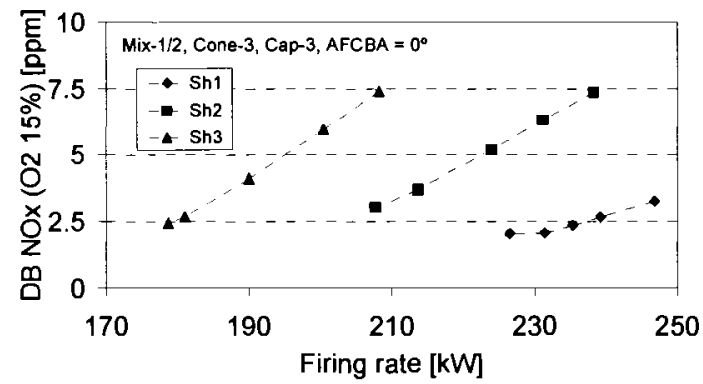

(c) Cone-3

Figure G.20: Effect of firing rate and $\left(L_{\text {eff }} / D_{\text {shiel }}\right)$ on duct burner NOx emissions (Mix-1/2, Cap-3 with Sh1, Sh2 and Sh3 at AFCBA $=0^{\circ}$ ) 


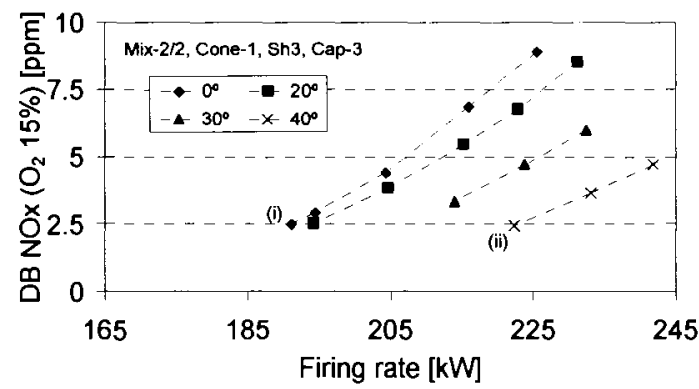

(a) DB NOx emissions

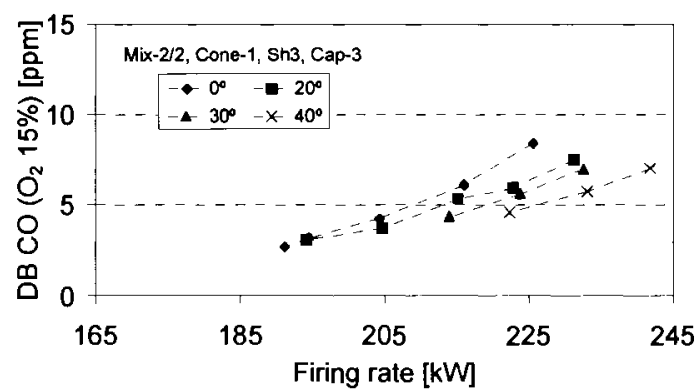

(b) DB CO emissions

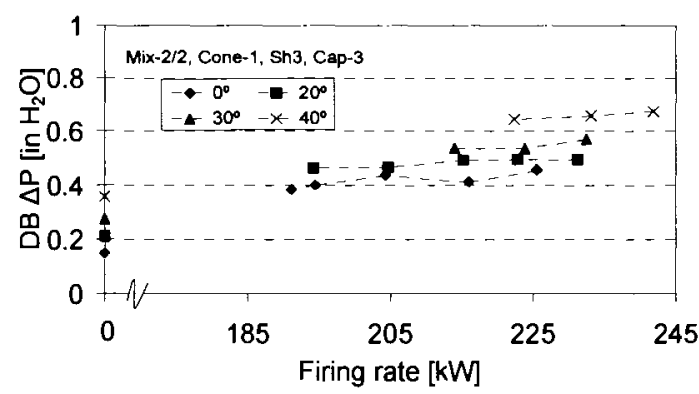

(c) DB pressure drop

Figure G.21: Effect of firing rate and AFCBA on duct burner performance (Mix-2/2, Cap-3, Cone-1 and Sh3)

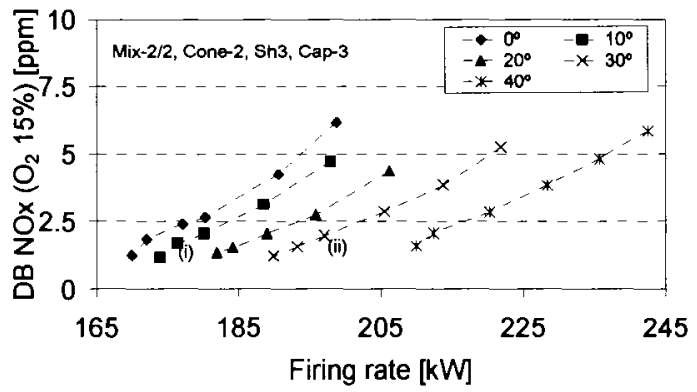

(a) DB NOx emissions

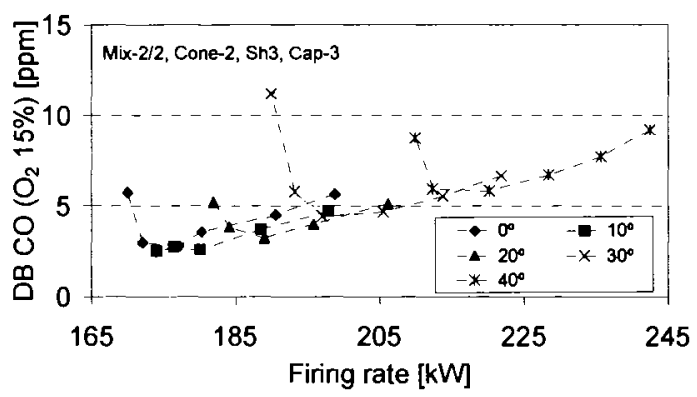

(b) DB CO emissions

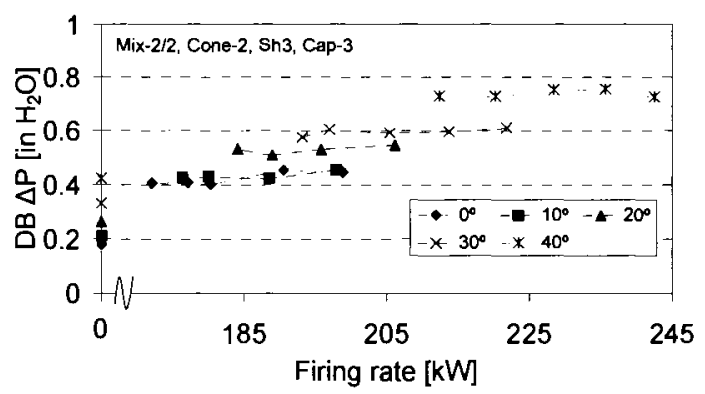

(b) DB pressure drop

Figure G.22: Effect of firing rate and AFCBA on duct burner performance (Mix-2/2, Cap-3, Cone-2 and Sh3) 


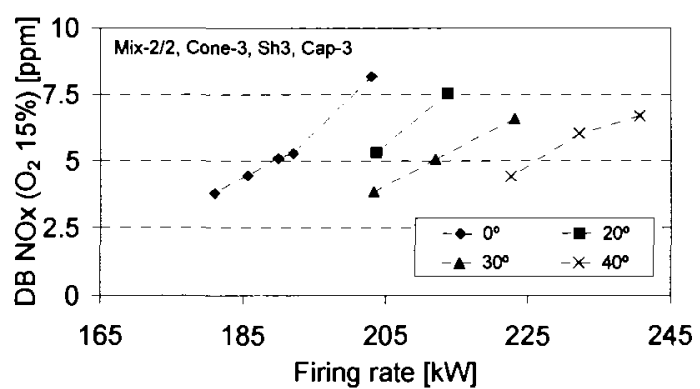

(a) DB NOx emissions

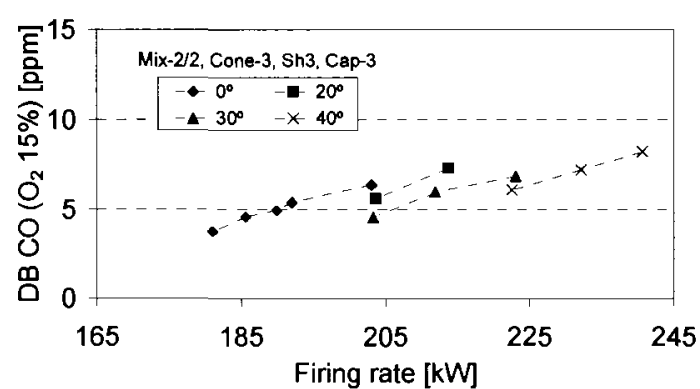

(b) DB CO emissions

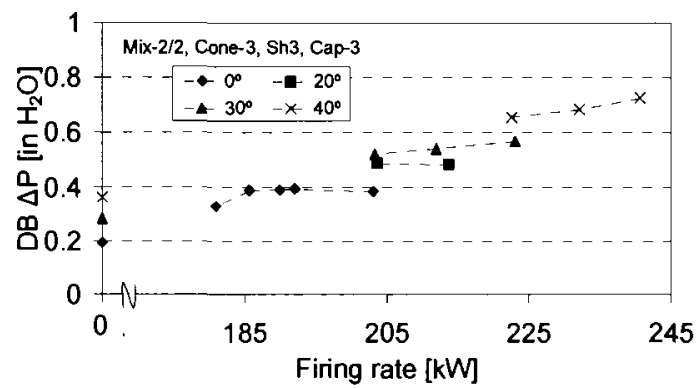

(c) DB pressure drop

Figure G.23: Effect of firing rate and AFCBA on duct burner performance (Mix-2/2, Cap-3, Cone-1 and Sh3)

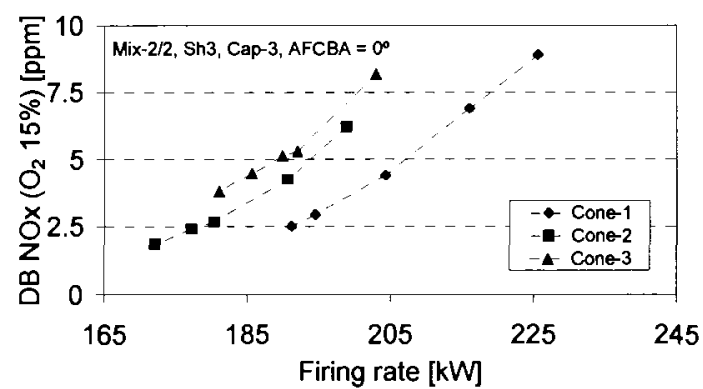

(a) DB NOx emissions

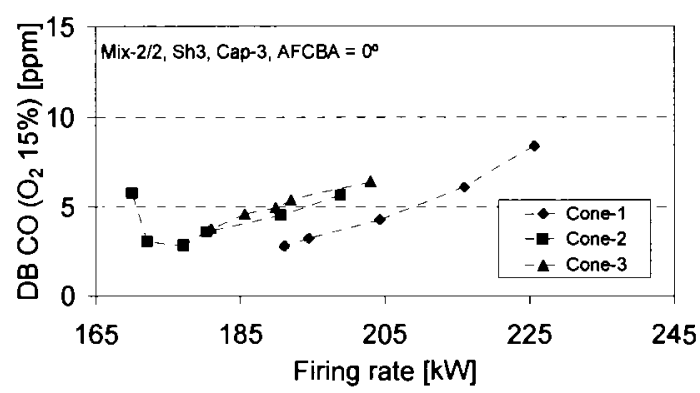

(b) DB CO emissions

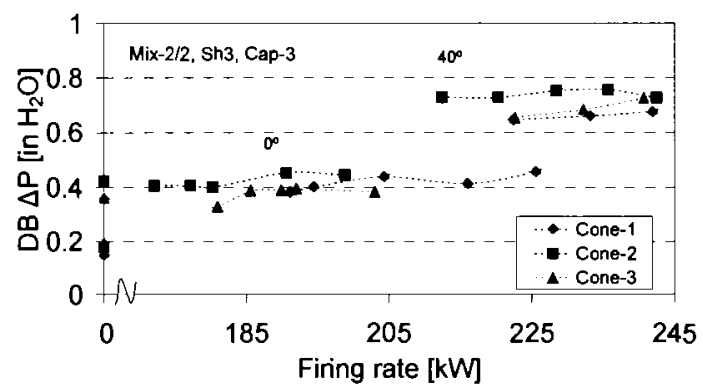

(c) DB pressure drop

Figure G.24: Effect of firing rate and conical burner pressure drop on duct burner performance (Mix-2/2, Cap-3, Sh3 with Cone-1, Cone-2 and Cone-3) 


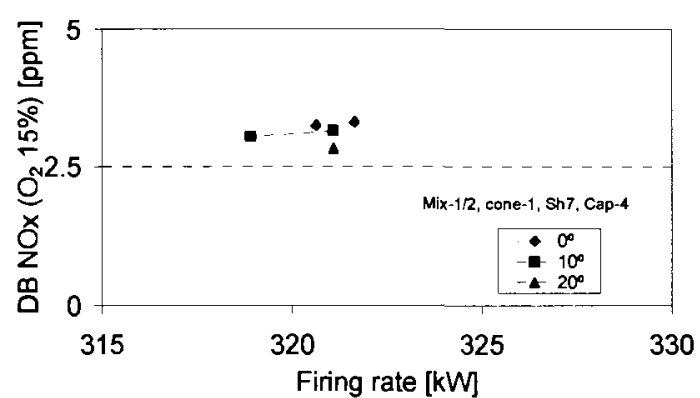

(a) DB NOx emissions

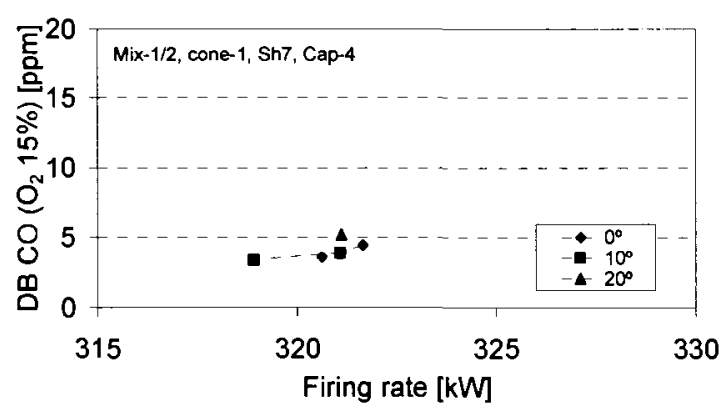

(b) DB CO emissions

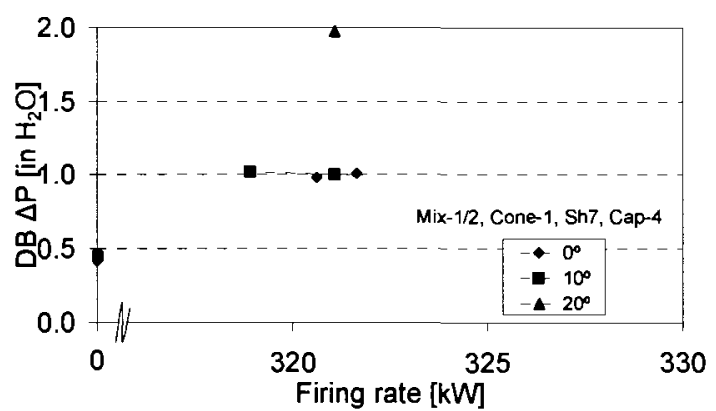

(c) $\mathrm{DB}$ pressure drop

Figure G.25: Effect of firing rate and AFCBA on duct burner performance (Mix-1/2, Cap-4, Cone-1 and Sh7)

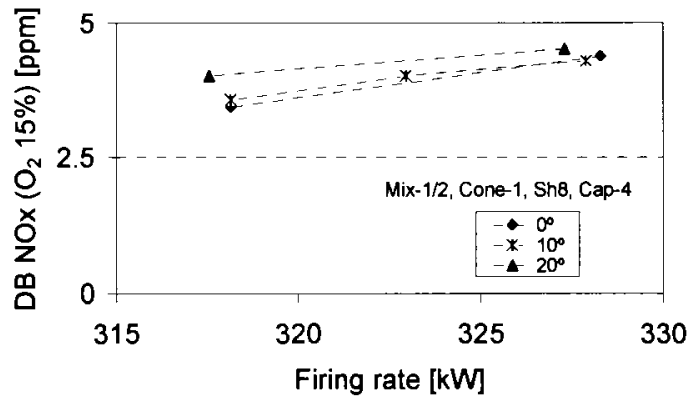

(a) DB NOx emissions

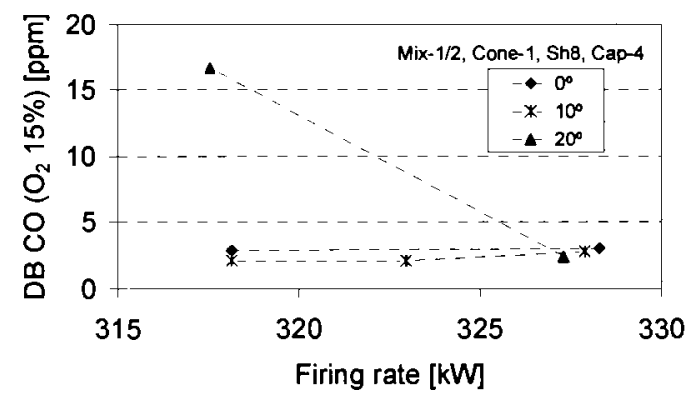

(b) DB CO emissions

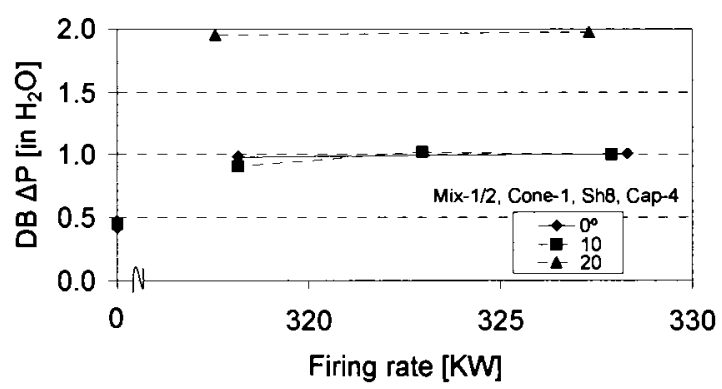

(c) DB pressure drop

Figure G.26: Effect of firing rate and AFCBA on duct burner performance (Mix-1/2, Cap-4, Cone-1 and Sh8) 


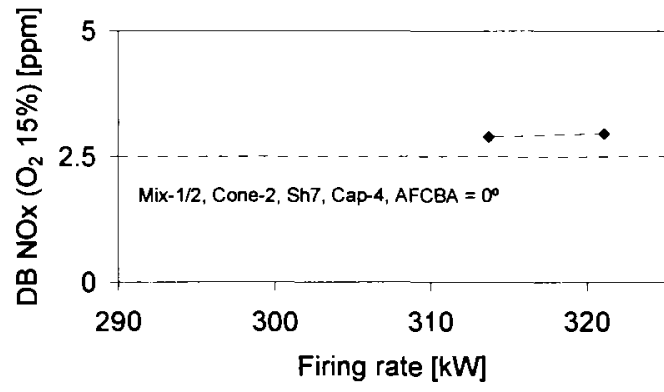

(a) DB NOx emissions

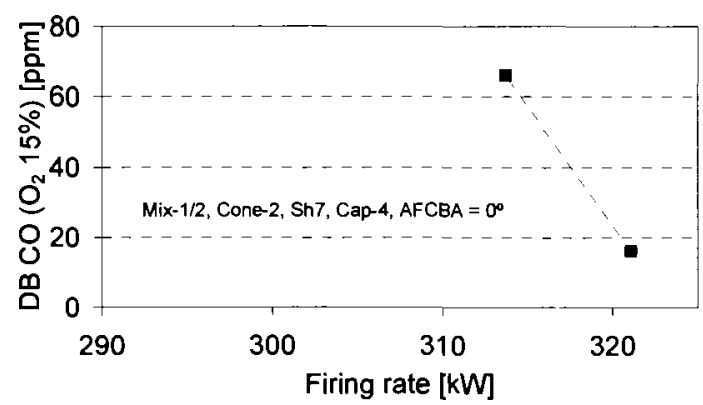

(b) DB CO emissions

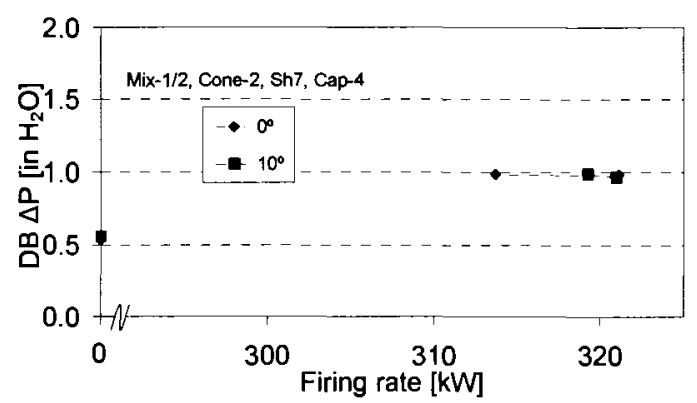

(c) DB pressure drop

Figure G.27: Effect of firing rate and AFCBA on duct burner performance (Mix-1/2, Cap-4, Cone-2 and Sh7)

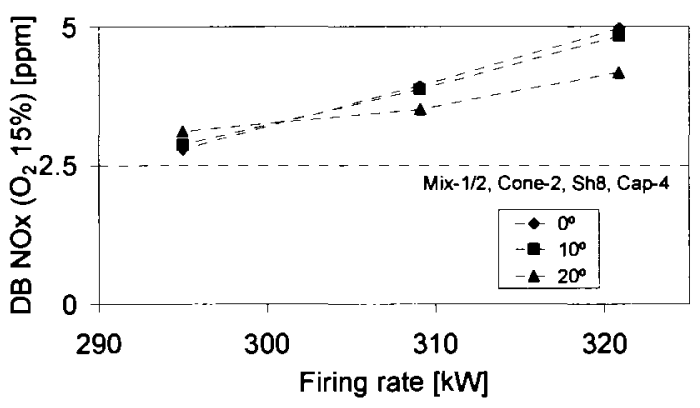

(a) DB NOx emissions

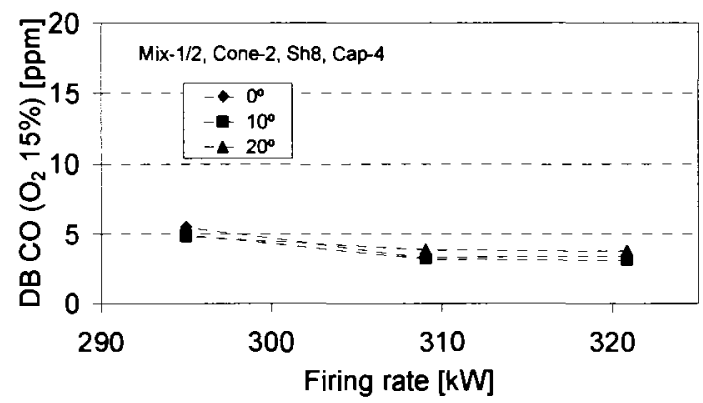

(b) DB CO emissions

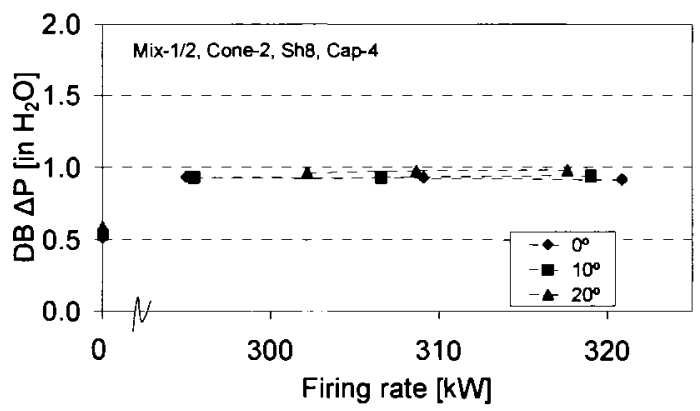

(c) DB pressure drop

Figure G.28: Effect of firing rate and AFCBA on duct burner performance (Mix-1/2, Cap-4, Cone-2 and Sh8) 


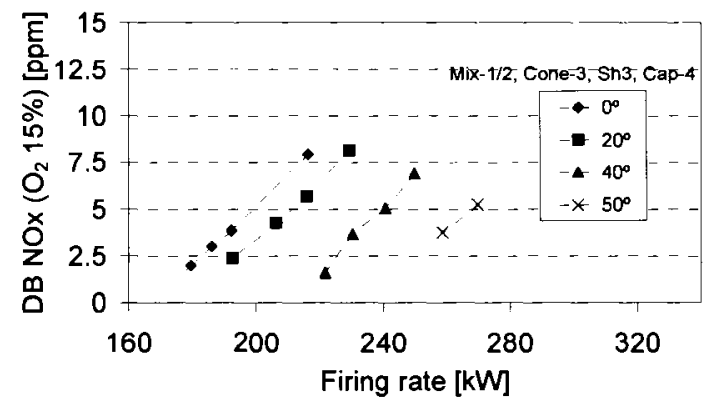

a) DB NOx emissions

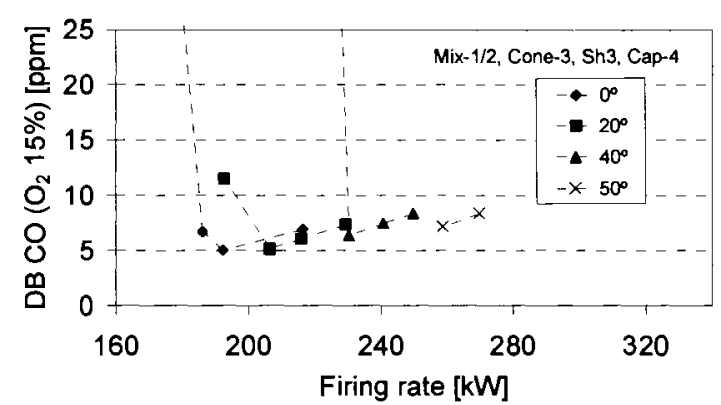

(b) DB CO emissions

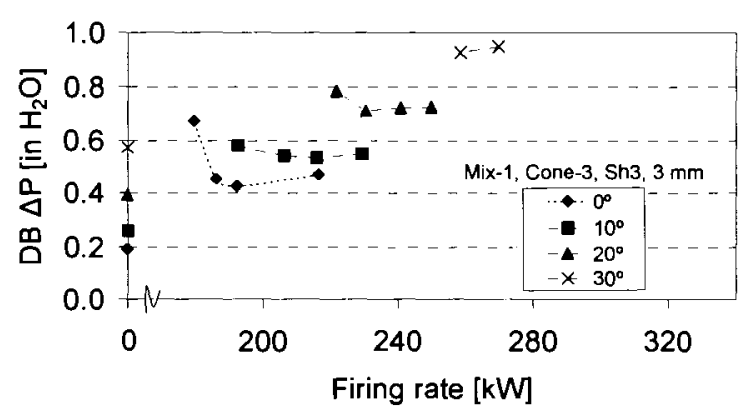

(c) DB pressure drop

Figure G.29: Effect of firing rate and AFCBA on duct burner performance (Mix-1/2, Cap-4, Cone-3 and Sh3)

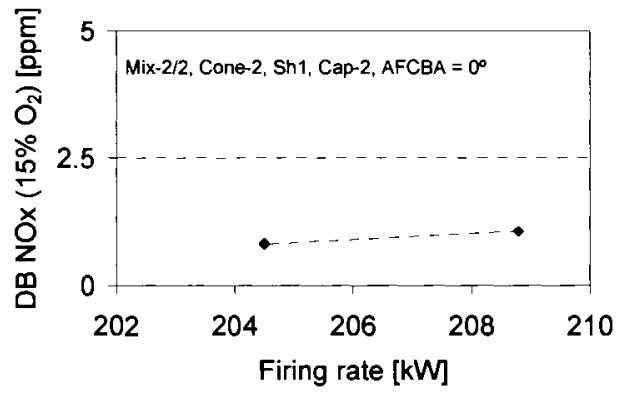

a) DB NOx emissions

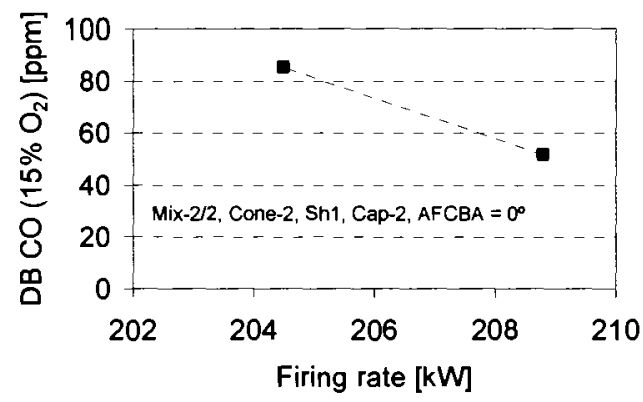

(b) DB CO emissions

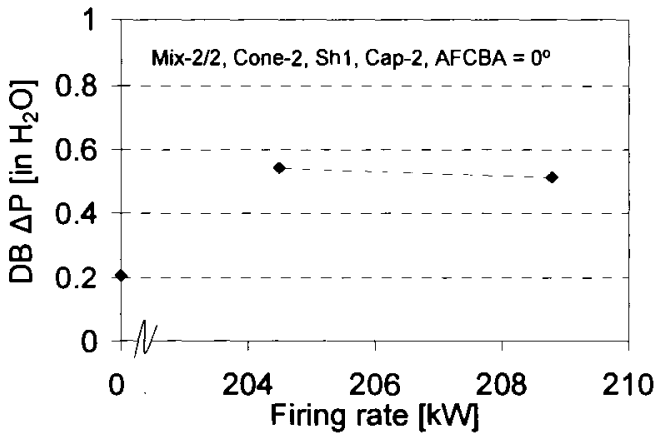

(c) DB pressure drop

Figure G.30: Effect of firing rate and AFCBA on duct burner performance (Mix-2/2, Cap-2, Cone-2 and Sh1) 


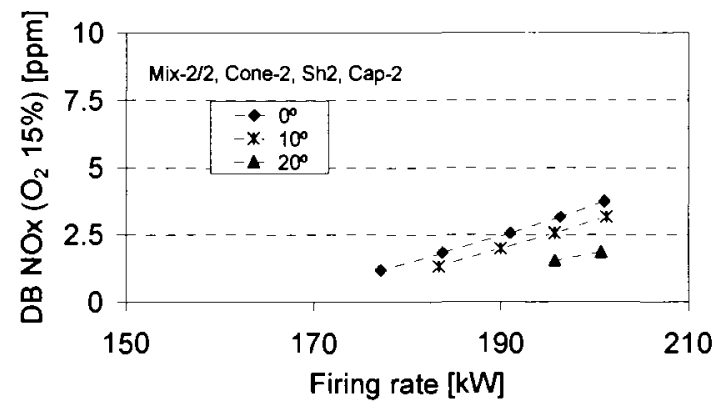

(a) DB NOx emissions

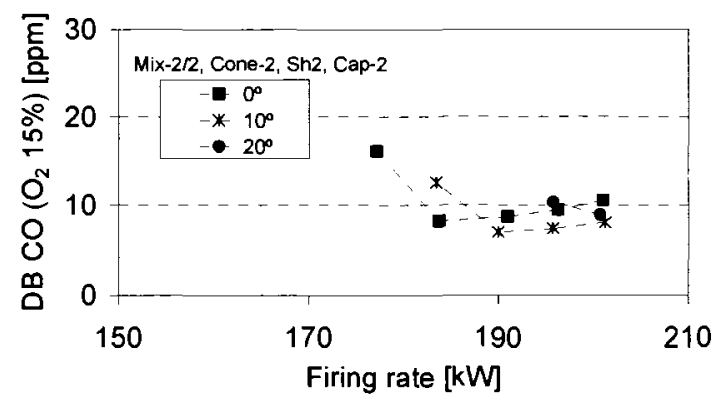

(b) DB CO emissions

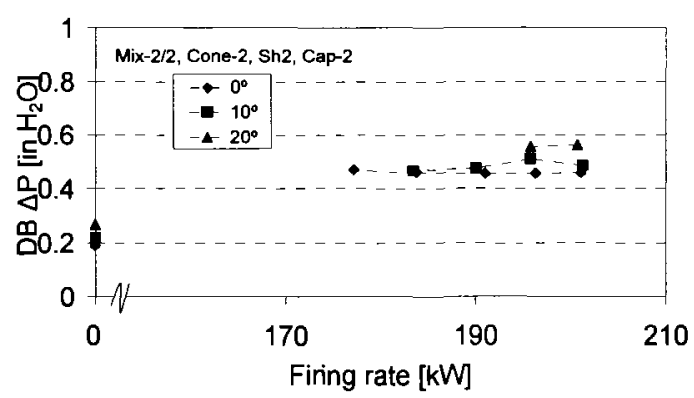

(c) DB pressure drop

Figure G.31: Effect of firing rate and AFCBA on duct burner performance (Mix-2/2, Cap-2, Cone-2 and Sh2)

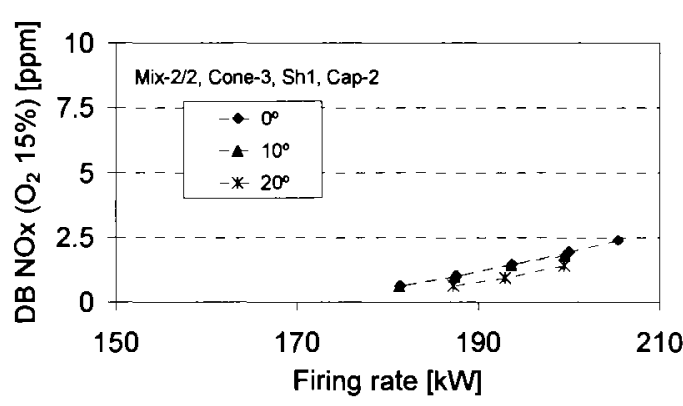

(a) DB NOx emissions

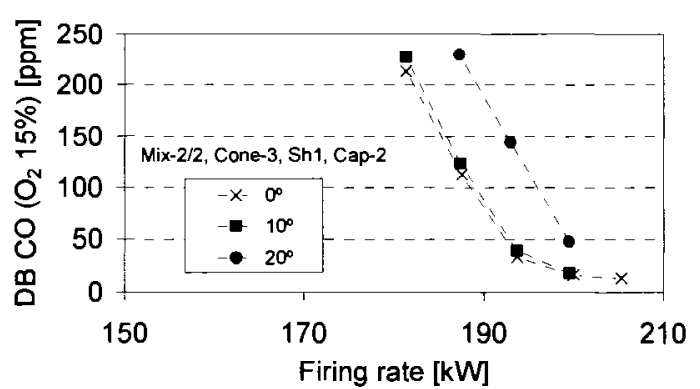

(b) DB CO emissions

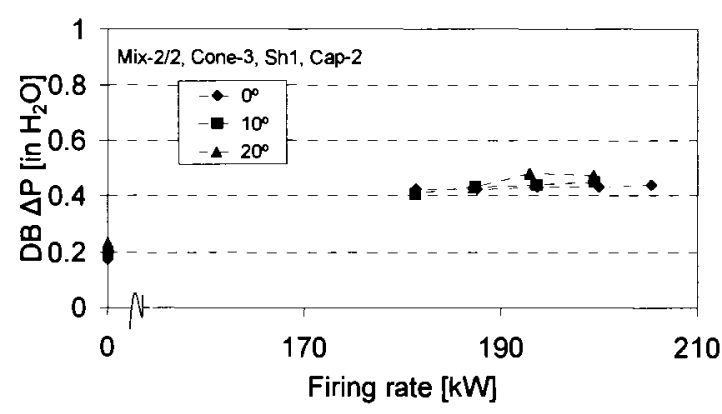

(c) DB pressure drop

Figure G.32: Effect of firing rate and AFCBA on duct burner performance (Mix-2/2, Cap-2, Cone-3 and Sh1) 


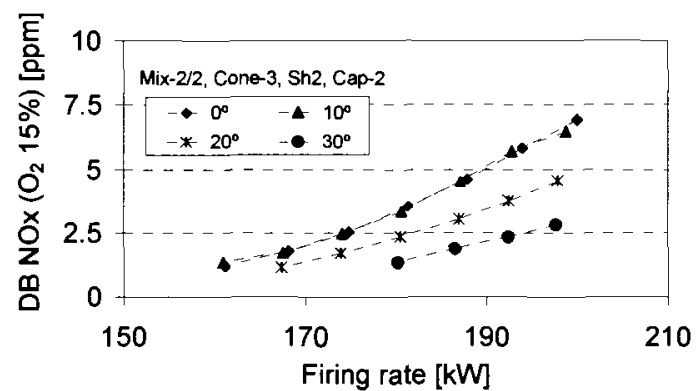

(a) DB NOx emissions

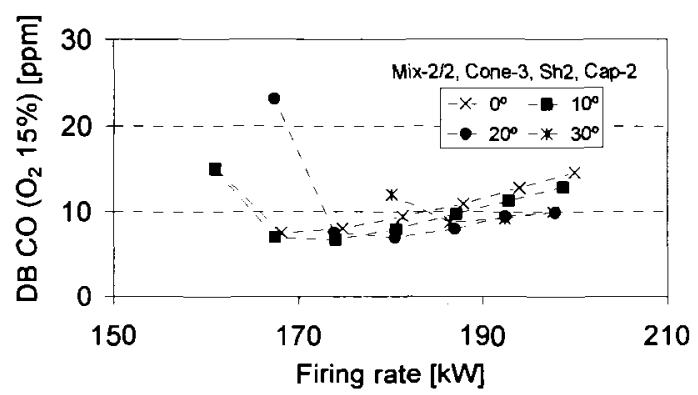

(b) DB CO emissions

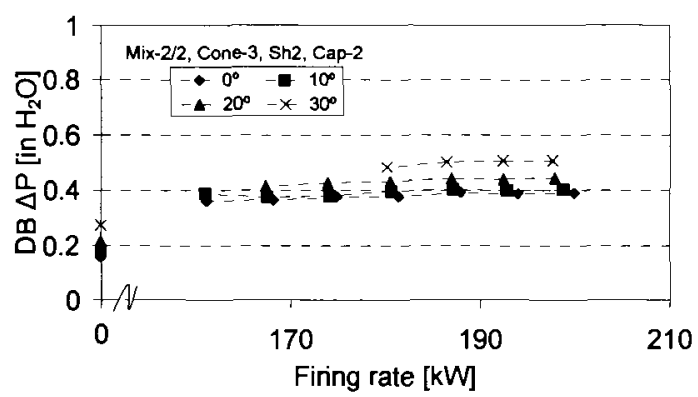

(c) DB pressure drop

Figure G.33: Effect of firing rate and AFCBA on duct burner performance (Mix-2/2, Cap-2, Cone-3 and Sh2)

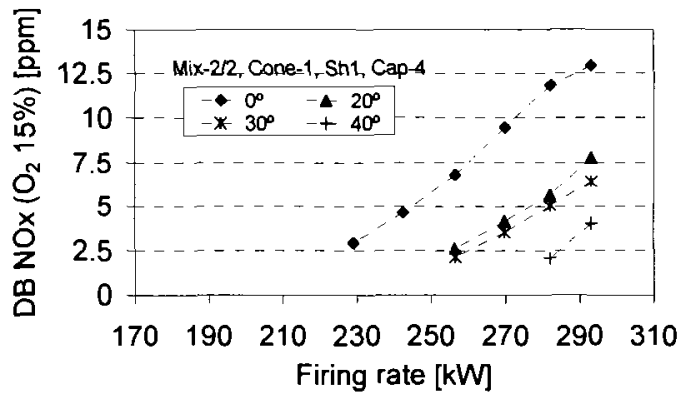

(a) DB NOx emissions

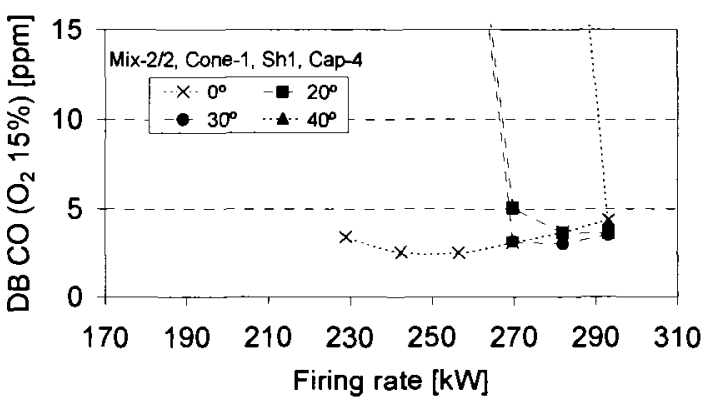

(b) DB CO emissions

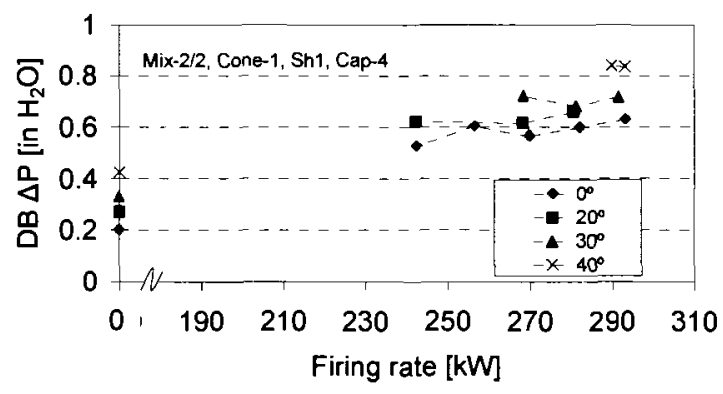

(c) DB pressure drop

Figure G. 34: Effect of firing rate and AFCBA on duct burner performance (Mix-2/2, Cap-4, Cone-1 and Sh1 


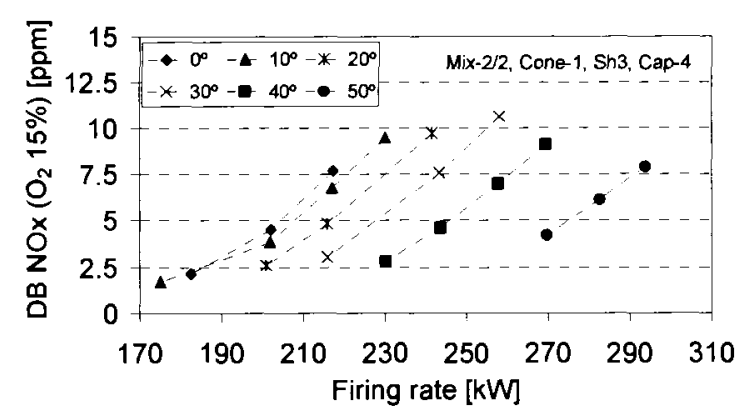

(a) DB NOx emissions

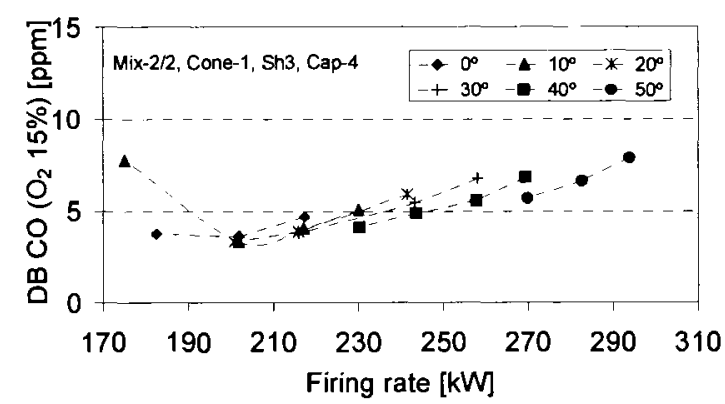

(b) DB CO emissions

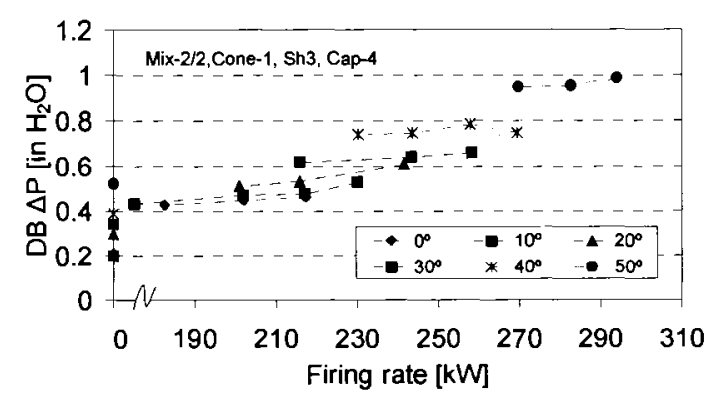

(c) DB pressure drop

Figure G.35: Effect of firing rate and AFCBA on duct burner performance (Mix-2/2, Cap-4, Cone-1 and Sh3)

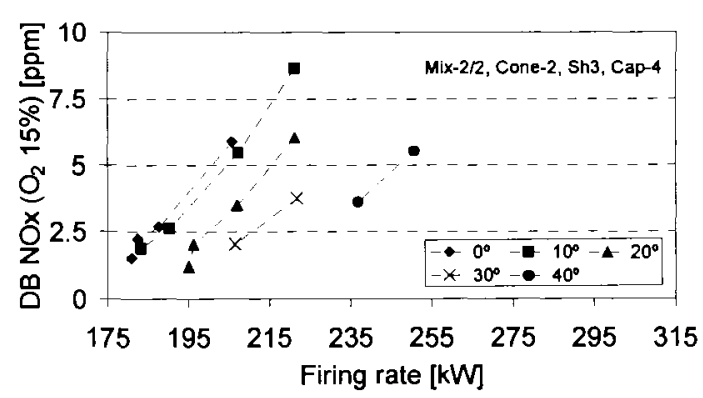

(a) DB NOx emissions

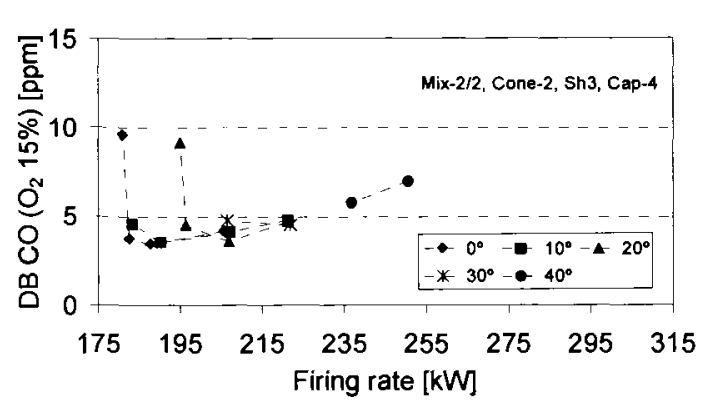

(b) DB CO emissions

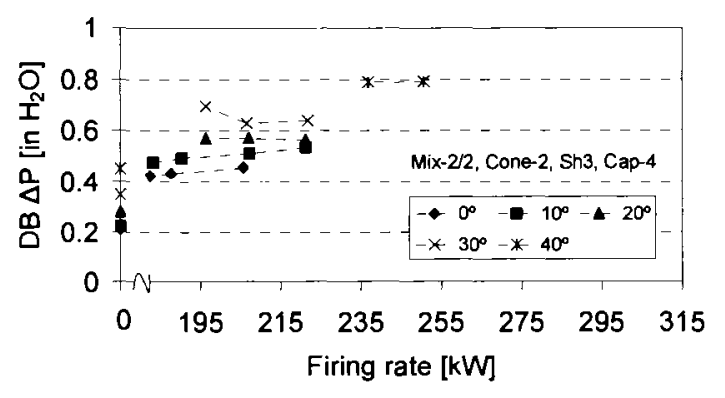

(c) DB pressure drop

Figure G.36: Effect of firing rate and AFCBA on duct burner performance (Mix-2/2, Cap-4, Cone-2 and Sh3) 


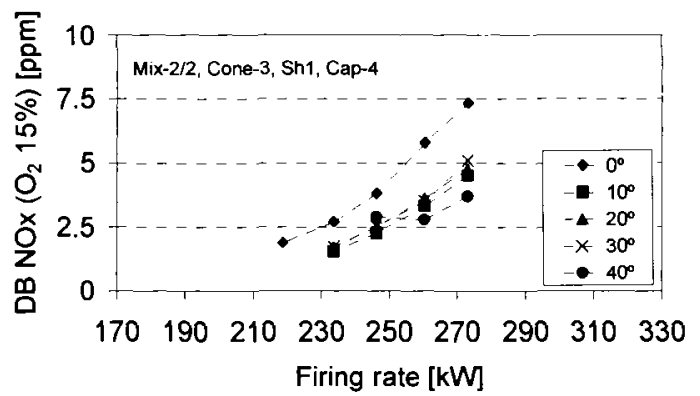

(a) DB NOx emissions

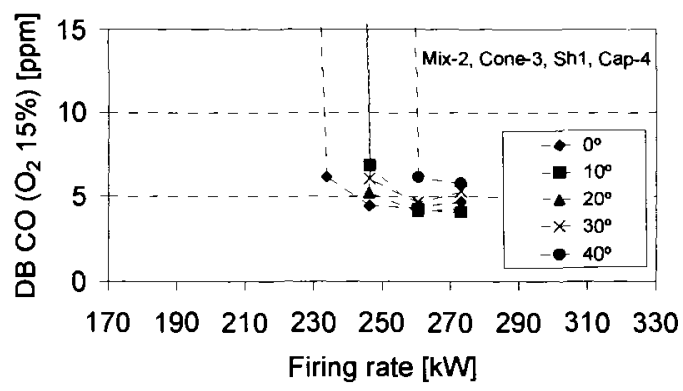

(b) DB CO emissions

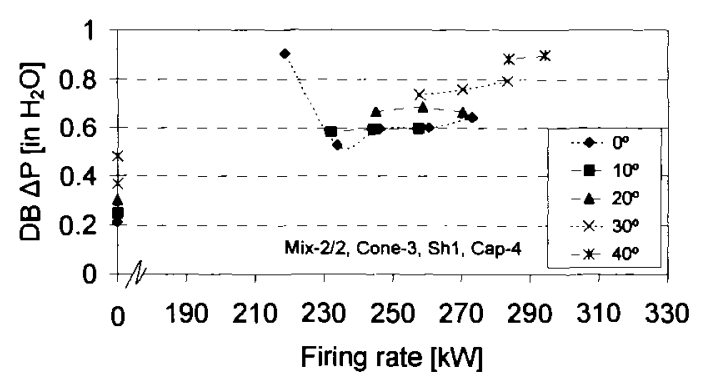

(c) DB pressure drop

Figure G.37: Effect of firing rate and AFCBA on duct burner performance (Mix-2/2, Cap-4, Cone-3 and Sh1)

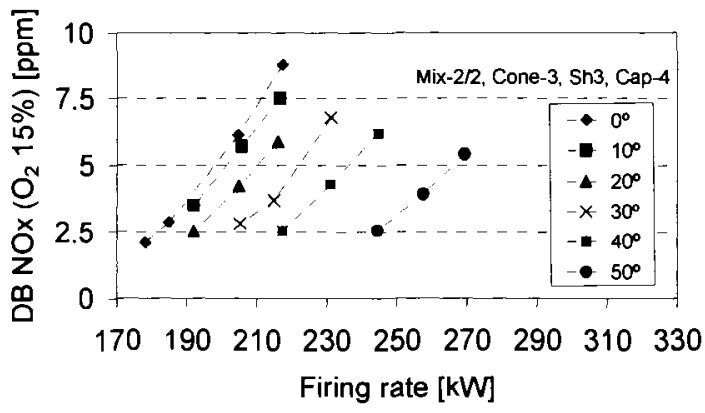

(a) DB NOx emissions

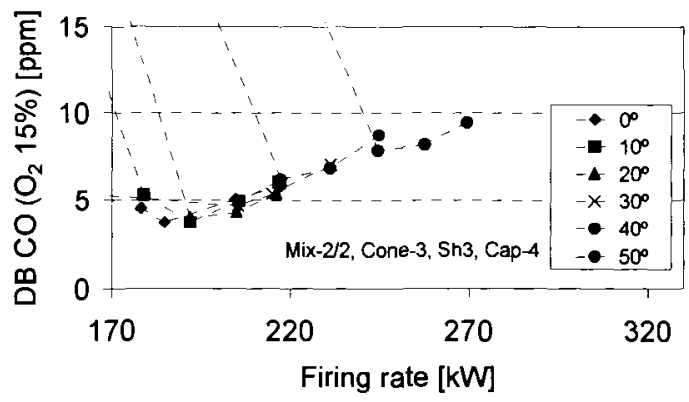

(b) DB CO emissions

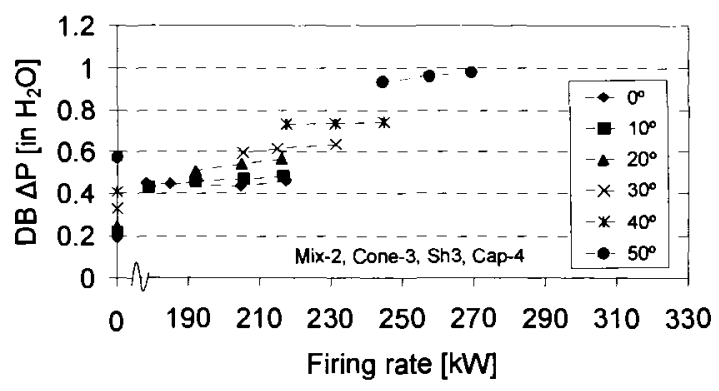

(c) DB pressure drop

Figure G.38: Effect of firing rate and AFCBA on duct burner performance (Mix-2/2, Cap-4, Cone-3 and Sh3) 


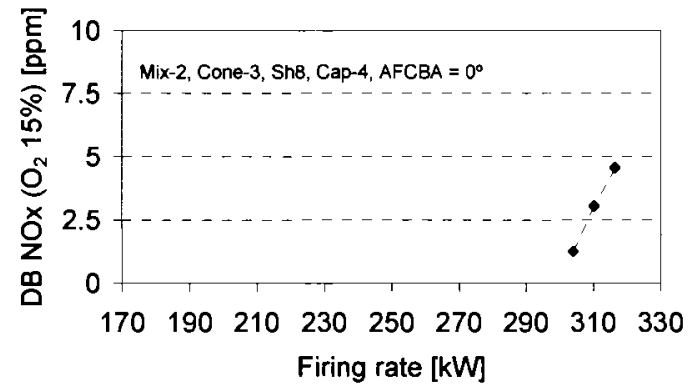

(a) DB NOx emissions

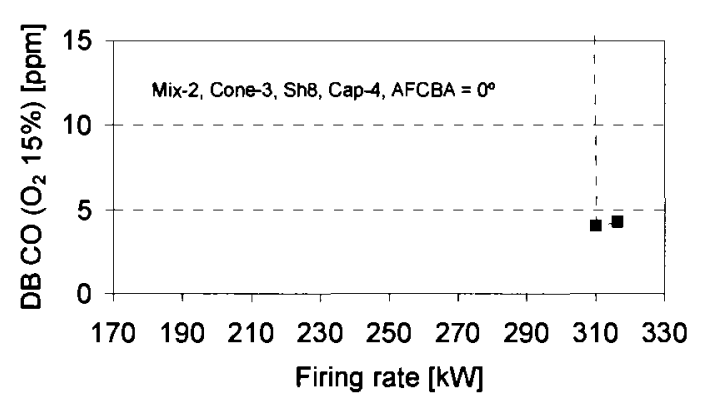

(b) DB CO emissions

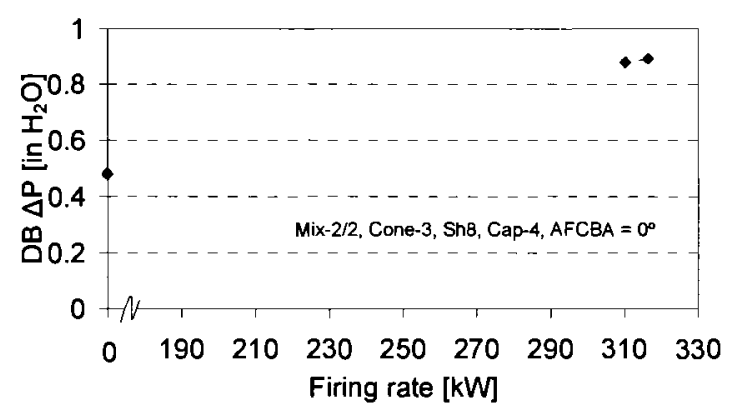

(c) DB pressure drop

Figure G.39: Effect of firing rate and AFCBA on duct burner performance (Mix-2/2, Cap-4, Cone-3 and Sh8)

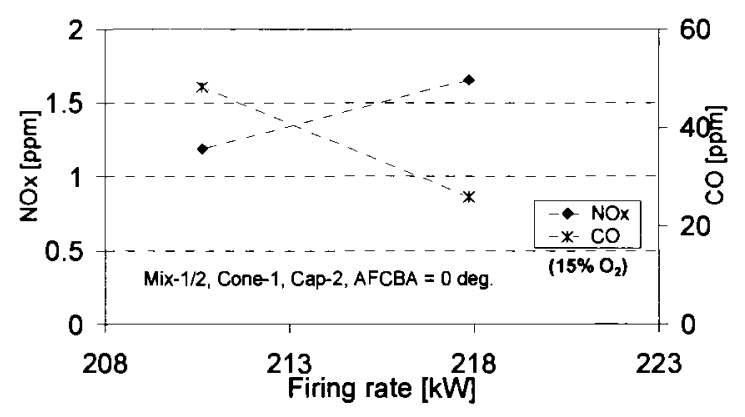

(a) DB NOx and CO emissions

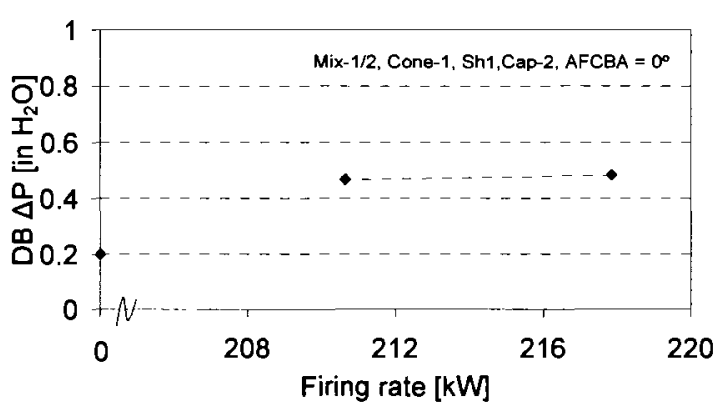

(b) DB pressure drop
Figure G.40: Effect of firing rate and AFCBA on duct burner performance (Mix-1/2, Cap-2, Cone-1 and Sh1) 


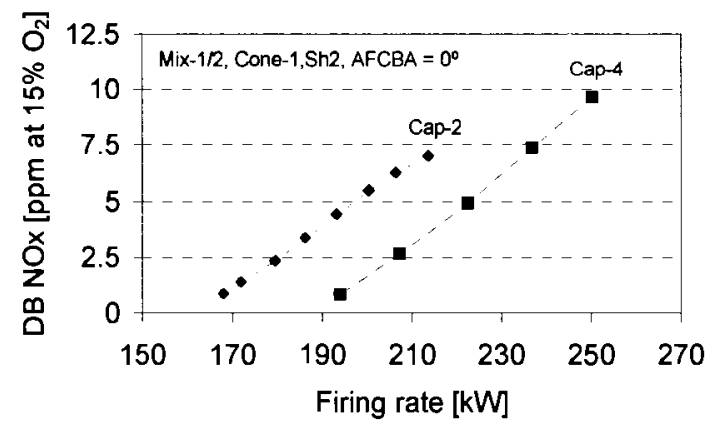

(a) NOx emissions

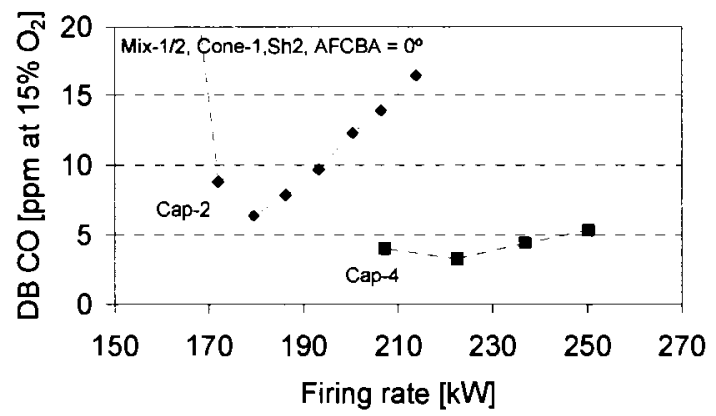

(b) $\mathrm{CO}$ emissions

Figure G.41: Effect of firing rate and fuel caps on duct burner performance, for burner configuration; (Mix-1/2, Cone-1 and Sh2 at AFCBA $=0^{\circ}$ )

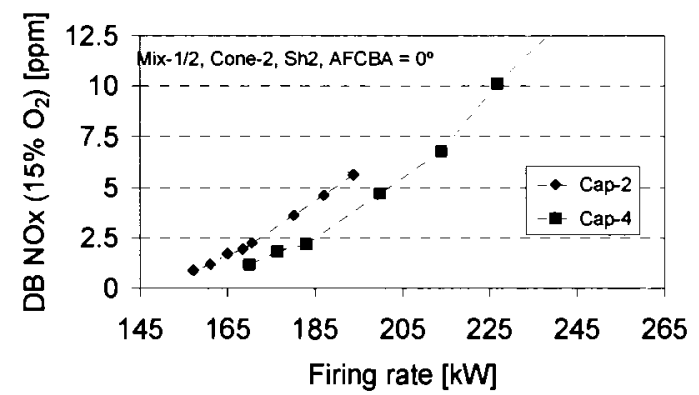

(a) NOx emissions

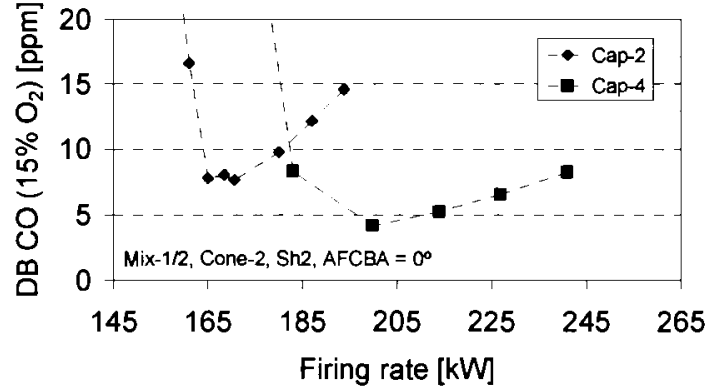

(b) $\mathrm{CO}$ emissions

Figure G.42: Effect of firing rate and fuel caps on duct burner performance, for burner configuration; (Mix-1/2, Cone-2 and Sh2 at AFCBA $=0^{\circ}$ )

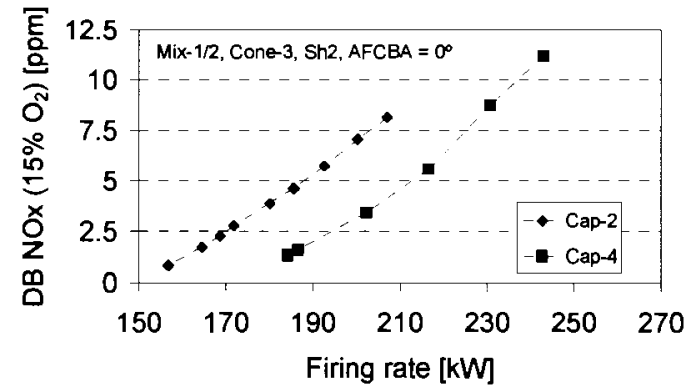

(a) NOx emissions

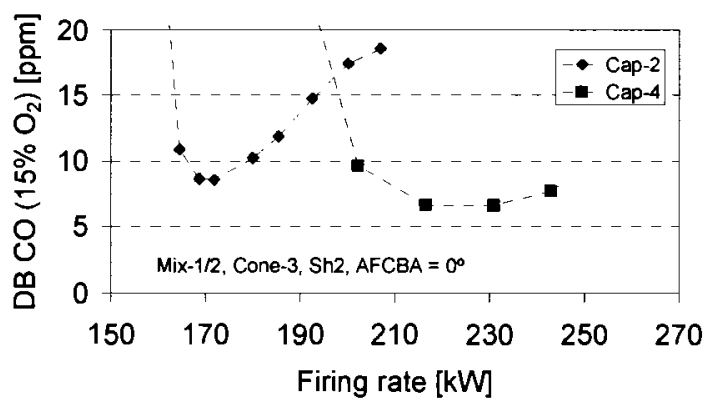

(b) $\mathrm{CO}$ emissions

Figure G.43: Effect of firing rate and fuel caps on duct burner performance, for burner configuration; (Mix-1/2, Cone-3 and Sh2 at AFCBA $=0^{\circ}$ ) 


\section{APPENDIX H: Combustion calculation using exhaust gas analysis}

\section{H.1 Chemical reaction in the duct burner system}

In this appendix, a procedure to calculate the total oxidant mass flow rate, the cone flow rate (amount of oxidant flow through the cone in the combustion zone), actual and stoichiometric oxidant-to-fuel ratio, equivalence ratio and percent of excess air are presented. The main combustion equations used in Chapter 4 will be repeated herein for the reason of continuity. The final derived equations were used to calculate the equivalence ratio, oxidant (total) mass flow rate and the cone mass flow rate from the gas analysis data collected during the combustion tests.

As mentioned in Chapter 4, Section 4.4.1, the oxidizer used in this work was the microturbine exhaust gases. Referring to Figure 4.2, as the oxidant mass flow $\dot{m}_{\text {oxid }}$ enters the duct burner, it splits between the annular passage $\left(\dot{m}_{B y p a s s}\right)$ and the premixer $\left(\dot{m}_{\text {Cone }}\right)$. Inside the premixer the fuel is introduced $\left(\dot{m}_{\text {fuel }}\right)$ and mixes with ( $\dot{m}_{\text {Cone }}$ ). The mixture is ignited and the combustion occurred above the cone surface and inside the cone shield. The combustion products then diluted with the bypassed flow and leaves via the duct burner exhaust section.

The microturbine exhaust composition was analyzed at each test condition during the combustion tests. The concentration of $\mathrm{NOx}, \mathrm{CO}_{2}, \mathrm{CO}, \mathrm{O}_{2}$ and $\mathrm{SO}_{2}$ was measured. The components $\mathrm{NOx}, \mathrm{SO} 2$ and $\mathrm{CO}$ are of no relevance to the combustion heat release because they present in a very small quantities so for convenience, they were combined together and presented as $\mathrm{CO}$ in the calculation.

Therefore the simplified micro-turbine exhausts gas composition (oxidant) used in the present work was: 


$$
\text { Oxidant }=\left(x 1 \mathrm{O}_{2}+x 2 \mathrm{CO}_{2}+x 3 \mathrm{CO}+x 4 \mathrm{H}_{2} \mathrm{O}+x 5 \mathrm{~N}_{2}\right)
$$

The fuel flow rate was measured continuously during the conducted combustion tests. For the hydrocarbon fuel $\mathrm{CH}_{4}$, in the absence of chilled products of dissociation, the stoichiometric combustion equation on a molar basis can be written as: $a \mathrm{CH}_{4}+m_{\text {stoich }}\left(x 1 \mathrm{O}_{2}+x 2 \mathrm{CO}_{2}+x 3 \mathrm{CO}+x 4 \mathrm{H}_{2} \mathrm{O}+x 5 \mathrm{~N}_{2}\right)=b 1 \mathrm{CO}_{2}+c \mathrm{H}_{2} \mathrm{O}+d 1 \mathrm{~N}_{2}$

The mole balance method is used to solve Equation (H.2), and it gives the following:

Carbon balance (C):

$$
a+m_{\text {stoich }}(x 2+x 3)=b 1
$$

Hydrogen balance $\left(\mathrm{H}_{2}\right)$ :

$$
2 a+m_{\text {stoich }}(x 4)=c
$$

Oxygen balance $\left(\mathrm{O}_{2}\right)$ :

$$
m_{\text {stoich }}\left(x 1+x 2+\frac{x 3}{2}+\frac{x 4}{2}\right)=b+\frac{c}{2}
$$

Nitrogen balance $\left(\mathrm{N}_{2}\right)$ :

$$
m_{\text {stoich }}(x 5)=d 1
$$

Solving for the stoichiometric moles of oxidant used $\left(m_{\text {stoich }}\right)$

$$
m_{\text {stoich }}=\frac{2 a}{\left(x 1-\frac{x 3}{2}\right)}
$$

The oxidant-fuel ratio for a stoichiometric process can be defined as:

$$
(\text { Oxidant } / \text { Fuel })_{\text {stoich }}=\left(\frac{\dot{m}_{\text {oxid }}}{\dot{m}_{\text {fuel }}}\right)_{\text {stoich }}=\left(\frac{m_{\text {stoich }}}{a}\right) \frac{M W_{\text {oxid }}}{M W_{\text {fuel }}}
$$

Substituting Equation (H.7) into Equation (H.8) yields:

Therefore,

$$
\frac{m_{\text {staich }}}{a}=\frac{2 a}{a\left(x 1-\frac{x 3}{2}\right)}=\frac{4}{2 x 1-x 3}
$$




$$
(\text { Oxidant } / \text { Fuel })_{\text {stoich }}=\left(\frac{4}{2 x 1-x 3}\right) \frac{M W_{o x i d}}{M W_{C H 4}}
$$

For a non stoichiometric mixture, the general combustion equation on a molar basis is:

$a 1 \mathrm{CH}_{4}+m_{a c t}\left(x 1 \mathrm{O}_{2}+x 2 \mathrm{CO}_{2}+x 3 \mathrm{CO}+x 4 \mathrm{H}_{2} \mathrm{O}+x 5 \mathrm{~N}_{2}\right)=b 2 \mathrm{CO}_{2}+c 1 \mathrm{H}_{2} \mathrm{O}+d 2 \mathrm{~N}_{2}+e \mathrm{CO}+f \mathrm{O}_{2}$

The mole balance method was used to solve Equation (H.11) for the values of $m_{a c t}$ and the actual oxidant-fuel ratio.

Carbon balance (C):

$$
a 1+m_{a c t}(x 2+x 3)=b 2+e
$$

Hydrogen balance $\left(\mathrm{H}_{2}\right)$ :

$$
2 a 1+m_{a c t}(x 4)=c 1
$$

Oxygen balance $\left(\mathrm{O}_{2}\right)$ :

$$
m_{a c t}\left(x 1+x 2+\frac{x 3}{2}+\frac{x 4}{2}\right)=b 2+\frac{c 1}{2}+\frac{e}{2}+f
$$

Nitrogen balance $\left(\mathrm{N}_{2}\right)$ :

Therefore the results will be:

$$
m_{a c t}(x 5)=d 2
$$

$$
\begin{aligned}
& m_{a c t}=\frac{\left(2 a 1+f-\frac{e}{2}\right)}{\left(x 1-\frac{x 3}{2}\right)} \\
& \frac{m_{a c t}}{a 1}=\frac{\left(2 a 1+f-\frac{e}{2}\right)}{a 1\left(x 1-\frac{x 3}{2}\right)}
\end{aligned}
$$

And the actual oxidant-fuel ratio at the combustion region (over the cone) is

$$
(\text { Oxidant } / \text { Fuel })_{a c t}=\left(\frac{\dot{m}_{\text {oxid }}}{\dot{m}_{\text {fuel }}}\right)_{a c t}=\left(\frac{m_{\text {act }}}{a 1}\right) \frac{M W_{\text {oxid }}}{M W_{\text {fuel }}}
$$


Therefore,

$$
(\text { Oxidant } / \text { Fuel })_{a c t}=\frac{(4 a 1-e+2 f)}{a 1(2 x 1-x 3)} \frac{M W_{o x i d}}{M W_{C H_{4}}}
$$

\section{H.2 Mass flow rate calculations from the exhaust gas analysis}

From Equation (H.8) the theoretical mass flow rate can be defined by:

$$
\left(\dot{m}_{\text {oxid }}\right)_{\text {stoich }}=(\text { Oxidant } / \text { Fuel })_{\text {stoich }} \times\left(\dot{m}_{\text {fuel }}\right)_{\text {stoich }}
$$

And using Equation (H.10) we get:

$$
\left(\dot{m}_{\text {oxid }}\right)_{\text {stoich }}=\left(\frac{4}{2 x 1-x 3}\right) \times \frac{M W_{\text {oxid }}}{M W_{C H 4}} \times\left(\dot{m}_{\text {fuel }}\right)_{\text {stoich }}
$$

From Equation (H.19) the actual mass flow rate $\left(\dot{m}_{\text {Cone }}\right)$ can be defined by:

$$
\left(\dot{m}_{\text {oxid }}\right)_{a c t}=\left[\frac{4 a 1-e+2 f}{a 1(2 x 1-x 3)}\right] \times \frac{M W_{\text {oxid }}}{M W_{C H_{4}}} \times\left(\dot{m}_{\text {fuel }}\right)_{a c t}
$$

By measuring the fuel flow rate and the exhaust gas concentrations for both the microturbine and the duct burner, $\left(\dot{m}_{\text {oxid }}\right)_{a c t}$ which is equal to $\dot{m}_{\text {Cone }}$ can be calculated using Equation (H.23)

To find the total mass flow rate $\dot{m}_{\text {oxid }}$ entering the duct burner, the value of $m_{\text {act }}$ (moles of oxidant) in Equation (H.16) must set to unity. Then, the amount of fuel needed to burn the amount of oxidant entering the duct burner and produces the measured amount of products can be calculated as:

$$
\begin{gathered}
\left(\dot{m}_{\text {oxid }}\right)_{\text {stoich }}=(\text { Oxidant } / \text { Fuel })_{\text {stoich }} \times\left(\dot{m}_{\text {fuel }}\right)_{\text {stoich }} \\
a 1=\left(\frac{2 x 1-x 3+e-2 f}{4}\right)
\end{gathered}
$$


Then, the actual oxidant-fuel ratio (from Equation (H.18)) becomes:

$$
(\text { Oxidant } / \text { Fuel })_{a c t}=\left(\frac{\dot{m}_{\text {oxid }}}{\dot{m}_{\text {fuel }}}\right)_{a c t}=\left(\frac{1}{a 1}\right) \frac{M W_{\text {oxid }}}{M W_{\text {fuel }}}
$$

Then

$$
\left(\dot{m}_{\text {oxid }}\right)_{a c t}=(\text { Oxidant } / \text { Fuel })_{\text {act }} \times\left(\dot{m}_{\text {fuel }}\right)_{\text {act }}
$$

And therefore $\left(\dot{m}_{\text {oxid }}\right)_{\text {act }}=\left[\frac{4}{(2 x 1-x 3+e-2 f)}\right] \times \frac{M W_{\text {oxid }}}{M W_{\text {fuel }}} \times\left(\dot{m}_{\text {fuel }}\right)_{a c t}$

By measuring the fuel flow rate and the exhaust gas concentrations for both the

micro-turbine and the duct burner, $\dot{m}_{\text {oxid }}$ (actual, total, oxidant mass flow rate) can be calculated using Equation (H.27).

\section{H.3 Equivalence Ratio}

The parameter that commonly used to present quantitatively whether a fueloxidizer mixture is lean, rich, or stoichiometric is the equivalence ratio $(\phi)$, and it is defined in Chapter 4, Eq. 4.6.

$$
\phi=\frac{(\text { Oxidant } / \text { Fuel })_{\text {stoich }}}{(\text { Oxidant } / \text { Fuel })_{a c t}}
$$

\section{H.3.1 Local (cone) equivalence ratio}

Substituting Equation (H.10) and Equation (H.19) into Equation (H.28) and manipulating yields:

$$
\phi_{\text {Cone }}=\frac{2 a 1}{\left(2 a 1+f-\frac{e}{2}\right)}
$$

Equation (H.29) applied for $0<\phi \leq 1.0$ 


\section{H.3.2 Overall equivalence ratio}

Using equations (H.10), (H.25) with (H.28) the overall equivalence ratio can be calculated as:

$$
\phi_{\text {overall }}=\left(\frac{2 x 1-x 3+e-2 f}{2 x 1-x 3}\right)
$$

Equation (H.30) applied for $0<\phi \leq 1.0$

\section{H.4 Excess oxidant}

The excess air level at which a combustion process operates is defined as the ratio of the difference between the oxidant supplied and theoretical oxidant to the theoretical oxidant

$$
E_{\text {oxid }}(\%)=\left(\frac{\left(\dot{m}_{\text {oxid }}\right)_{\text {act }}-\left(\dot{m}_{\text {oxid }}\right)_{\text {stoich }}}{\left(\dot{m}_{\text {oxid }}\right)_{\text {stoich }}}\right) \times 100
$$

As a fucntion of equivalence ratio the $E_{\text {oxid }}(\%)$ can be defined as:

$$
E_{\text {oxid }}(\%)=\left(\frac{1-\phi}{\phi}\right) \times 100
$$

Substituting Equation (H.29) into Equation (H.32) yields:

$$
\left(E_{\text {oxid }}(\%)\right)_{\text {local }}=\left(\frac{f-\frac{e}{2}}{2 a 1}\right) \times 100
$$

And substituting Equation (H.30) into Equation (H.32) yields:

$$
\left(E_{\text {oxid }}(\%)\right)_{\text {overal }}=\left(\frac{f-\frac{e}{2}}{x 1-\frac{x 3}{2}+\frac{e}{2}-f}\right) \times 100
$$




\section{H.5 Comparisons between the mass flow results}

The oxidant (total) and the cone mass flow rates respectively were calculated from the gas composition using Equations (H.22) and (H.27). The mass flow calculations were conducted for all of the tested configurations. The results of these calculations were compared to the corresponding values calculated from the measurement conducted in Chapter 6. Both results show a good agreement for almost the tested cases where the shields Sh2, Sh3 and Sh4 to accuracies better than $5 \%$ for the oxidant (total) mass flow rate and about $8 \%$ for the cone flow rate. For the short shields, Sh1 and Sh7 the total mass flow rate shows almost similar results but the difference increases to more than $10 \%$ for the cone mass flow rate and that is due to the different in the pressure drop those shields have comparing with the measurement shields used in Chapter 6.

Figures H.1 and H.2 respectively show the comparison between the two calculated mass flow rate results for the duct burner geometries (Mix-1/2, Cone-3, ap4 , Sh3 at $\left.\mathrm{AFCBA}=40^{\circ}\right)$ and $\left(\mathrm{Mix}-1 / 2\right.$, Cone-1, Sh4, Cap-4 at AFCBA $\left.=0^{\circ}\right)$. One case shows the calculated results using the pitot-static tube measurements and the other using the above mentioned equations. In Figure H.1, the difference between the total mass flow rate results was around $2 \%$ and $8 \%$ for the cone mass flow rates. In Figure H.2, the results showed a good agreement between the two results to accuracy of $4 \%$ for both calculated masses. 


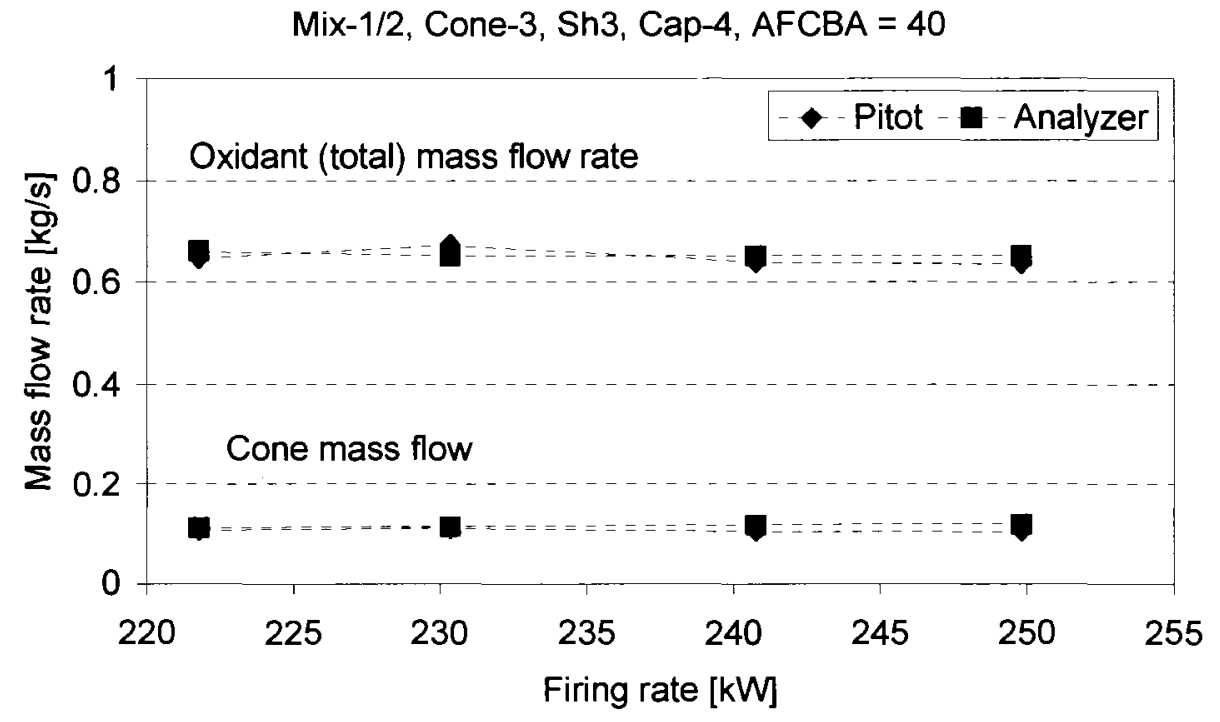

Figure H.1: Comparisons between the mass flow rate results for the burner geometry $\left(\mathrm{Mix}-1 / 2\right.$, Cone-3, ap-4, Sh3 at AFCBA $\left.=40^{\circ}\right)$

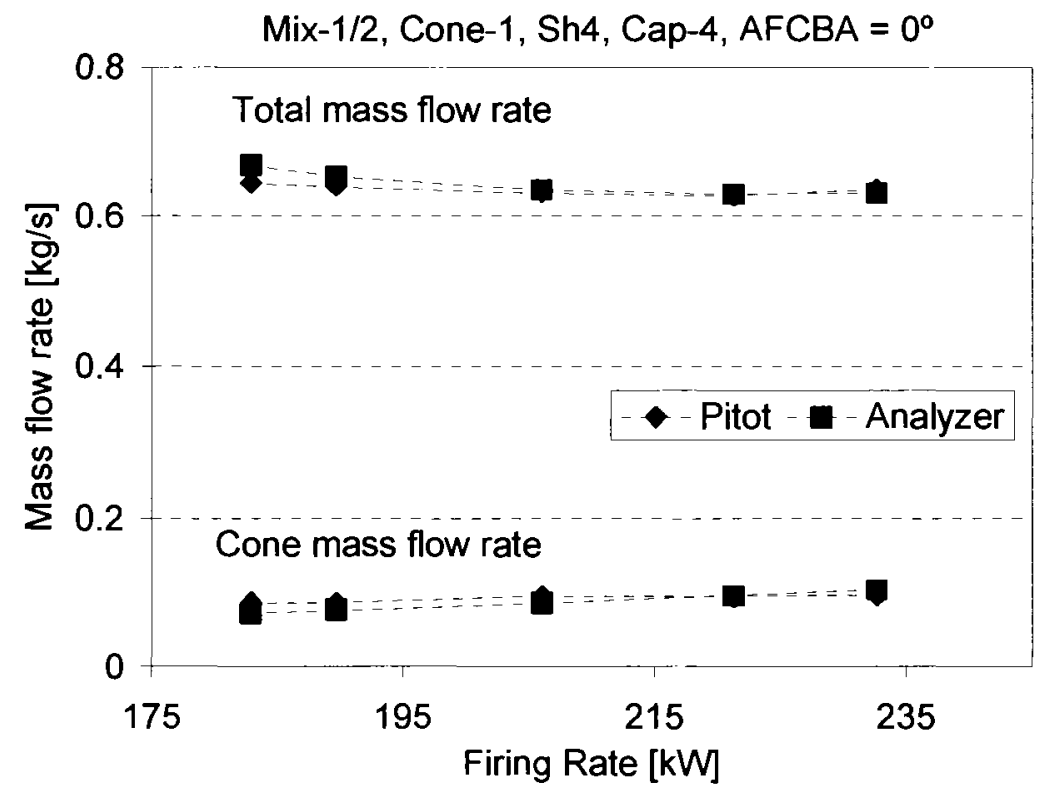

Figure H.2: Comparisons between the mass flow rate results for the burner geometry (Mix-1/2, Cone-1, Sh4, Cap-4 at AFCBA $=0^{\circ}$ ) 


\section{APPENDIX I: Publications}

This Appendix contains a list of presentations and the publications that were prepared during the course of this investigation. All the work presented is based on the work done for this investigation.

1- Ramadan, O. B., Gauthier, J. E. D., Hughes P. M., and Brandon, R., (2005), "Experimental Investigation and Evaluation of Low NOx Natural Gas-Fired Mesh Duct Burner" (Poster presentation) at the $16^{\text {th }}$ Symposium on Industrial Application of Gas Turbines. October, Banff, Alberta, Canada.

2- Brandon, R., Holiday, B., and Ramadan, O. B., (2006), "Inlet Air Supercharging and Low NOx Burner", Presented at the $6^{\text {th }}$ Annual Microturbine Applications Workshop, January 17-19, 2006, San Francisco, CA, USA.

3- Ramadan, O. B., Gauthier, J. E. D., Hughes P. M., and Brandon, R., (2007), "Experimental Investigation and Evaluation of Low NOx Natural Gas-Fired Mesh Duct Burner" ASME Turbo Expo 2007, GT2007-28350, May 14-17 Montreal, Canada.

4- Ramadan, O. B., Gauthier, J. E. D., Hughes P. M., and Brandon, R., (2007), "Design Process and Instrumentation of a Low NOx Wire-Mesh Duct Burner" CANCAM-2007, 3-7 June, Toronto, Ontario, Canada

5- Ramadan, O. B., Gauthier, J. E. D., Hughes P. M., and Brandon, R., (2007), "Testing of a Low NOx Wire-Mesh Duct Burner for Micro-Cogeneration Unit" CANCAM-2007, 3-7 June, Toronto, Ontario, Canada

6- Ramadan, O. B., Gauthier, J. E. D., Hughes P. M., and Brandon, R., (2008), "Design Process of a Novel Microturbine low NOx Conical Wire-Mesh, Duct Burner" GT2007-50948, to be presented at ASME Turbo Expo, June 9-13, 2008, Berlin, Germany. 
APPENDIX J: Engineering drawings 
รి

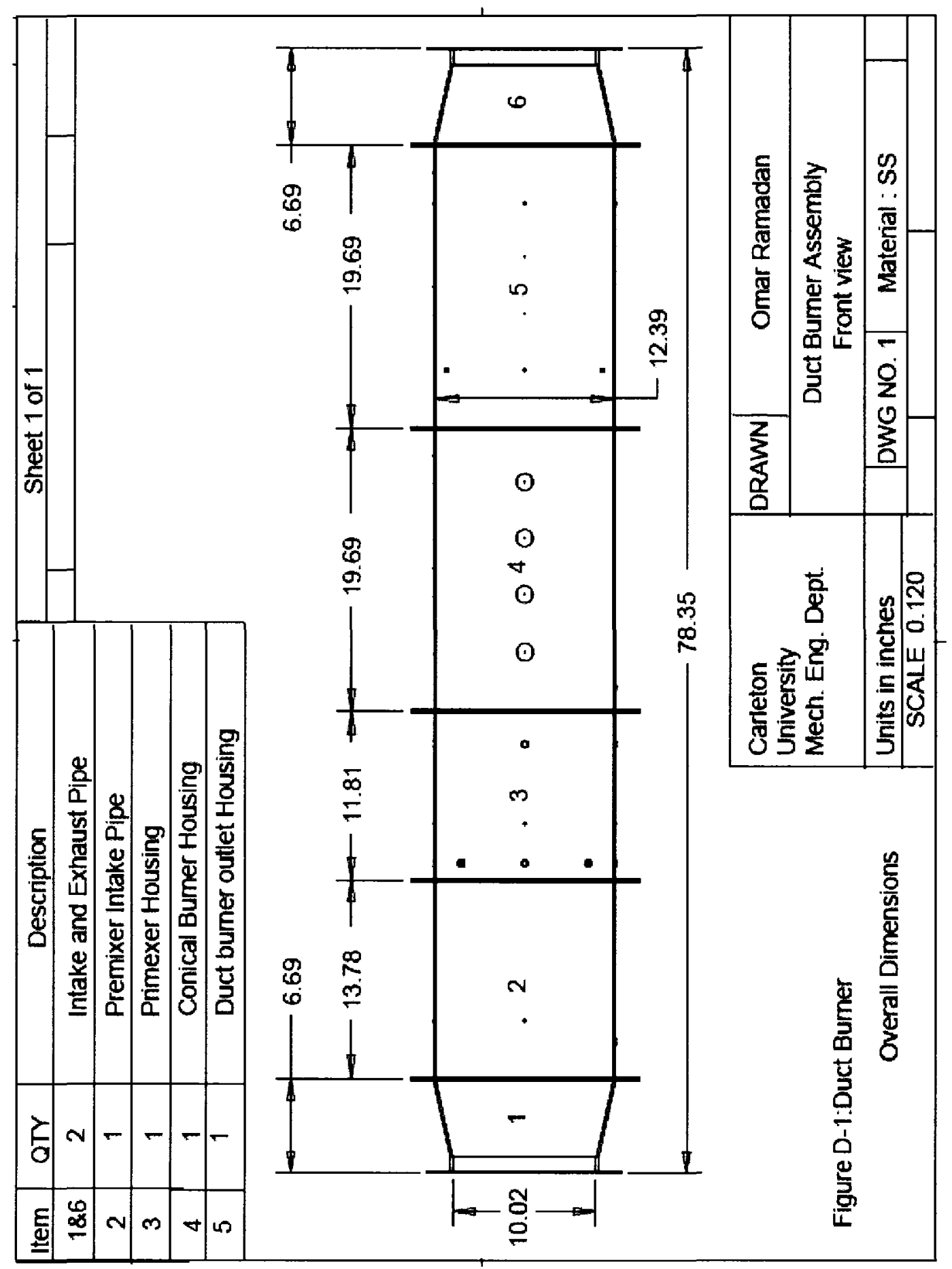




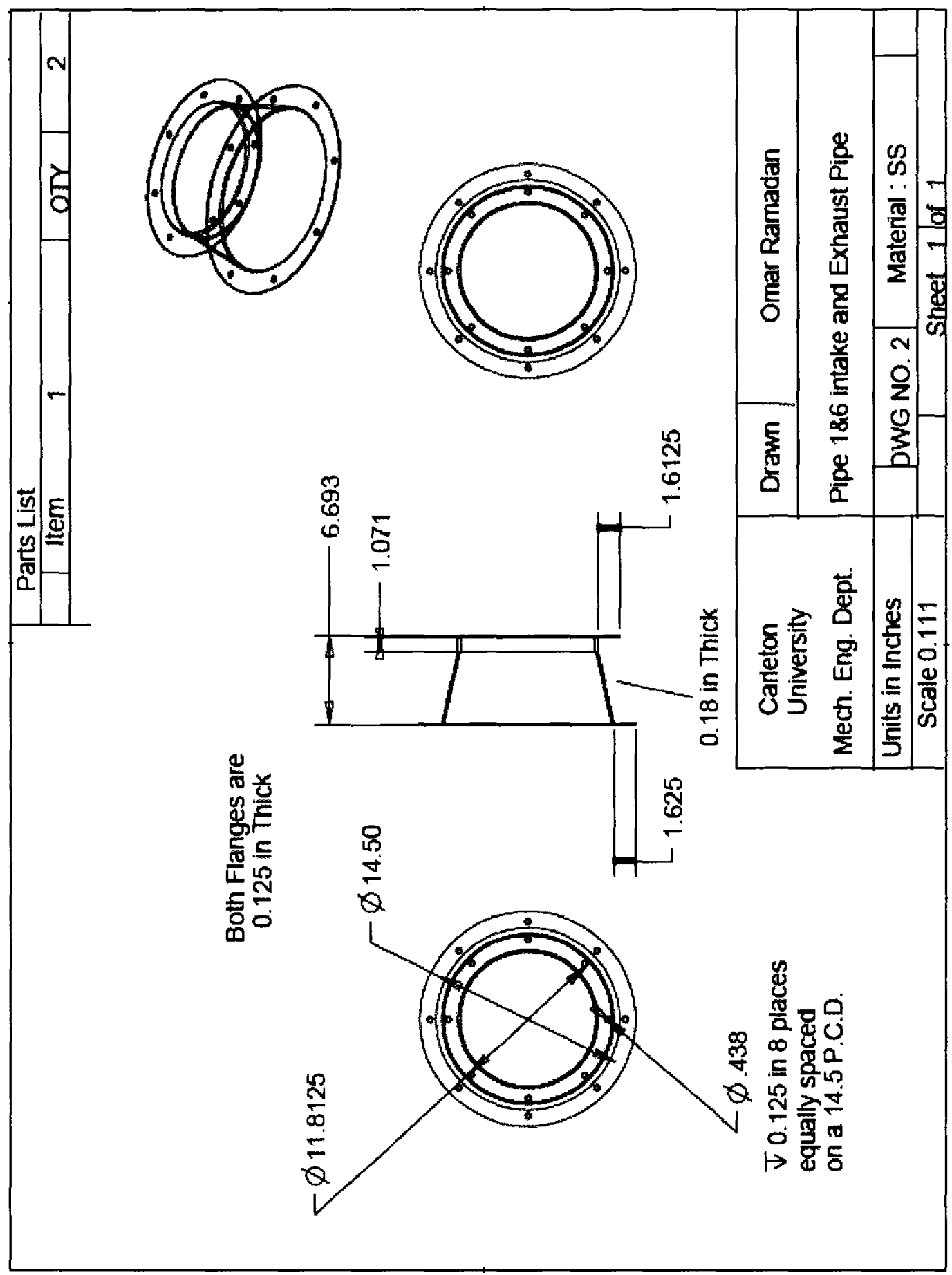


ชิ

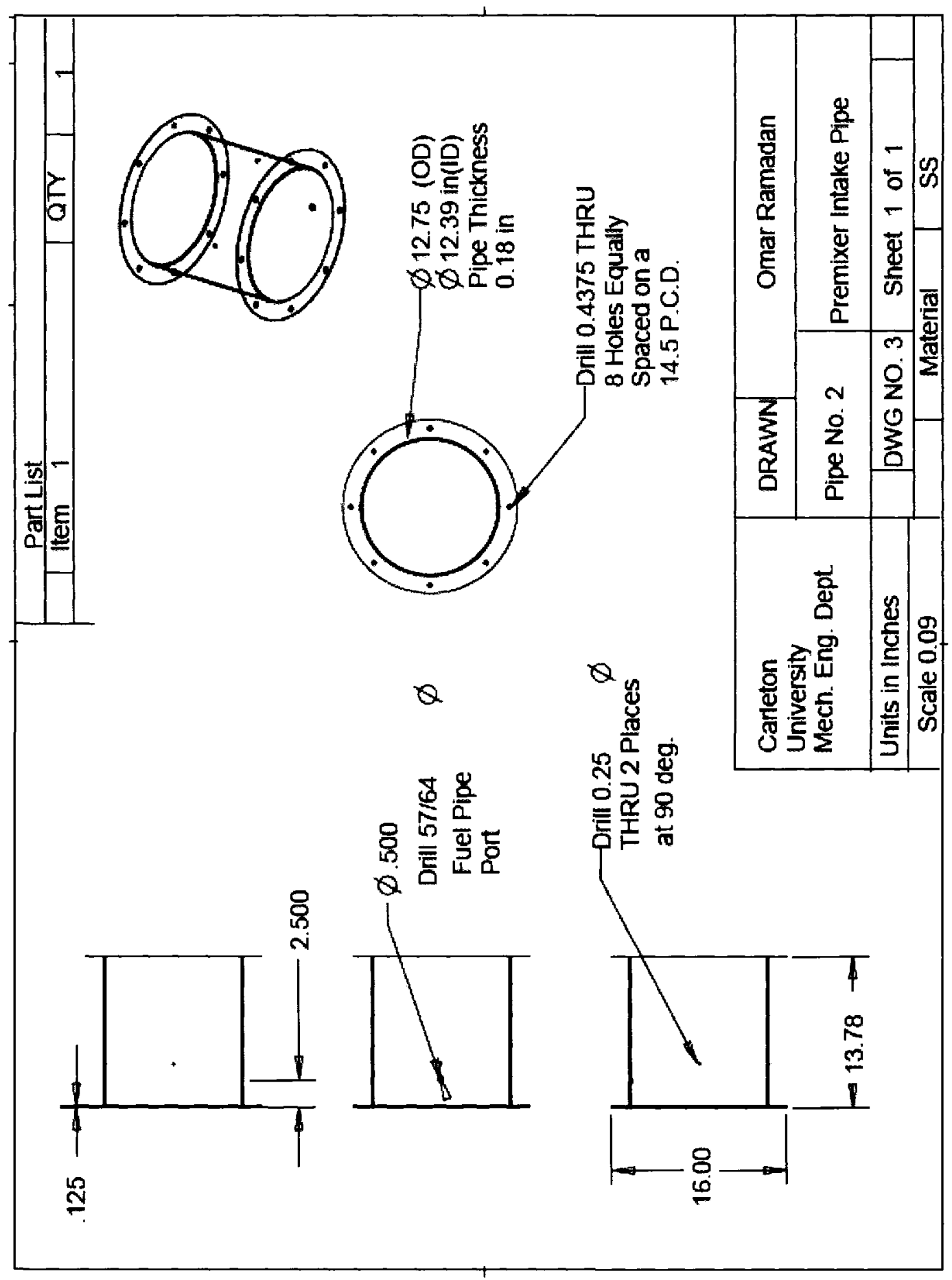


s

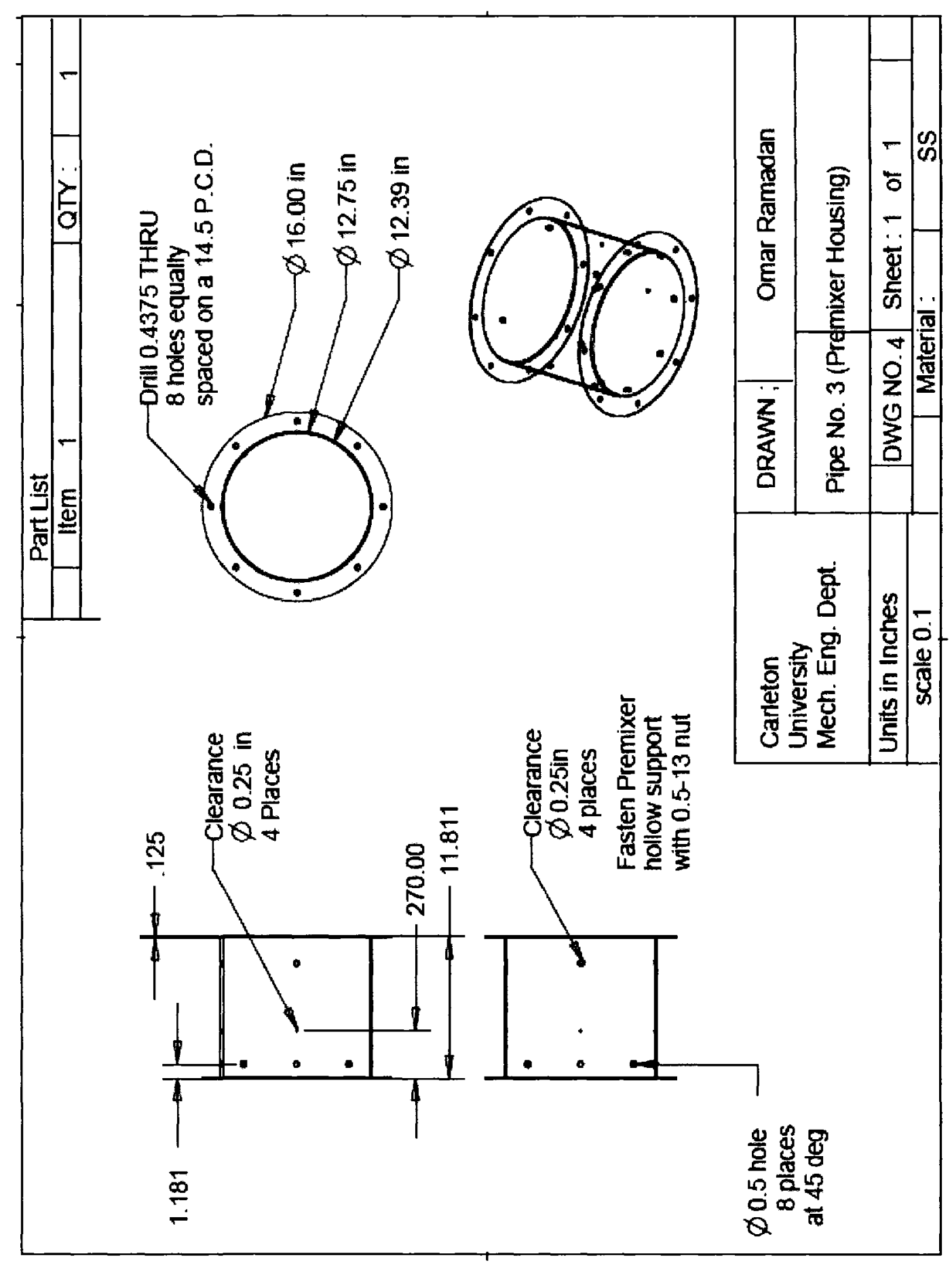


尔

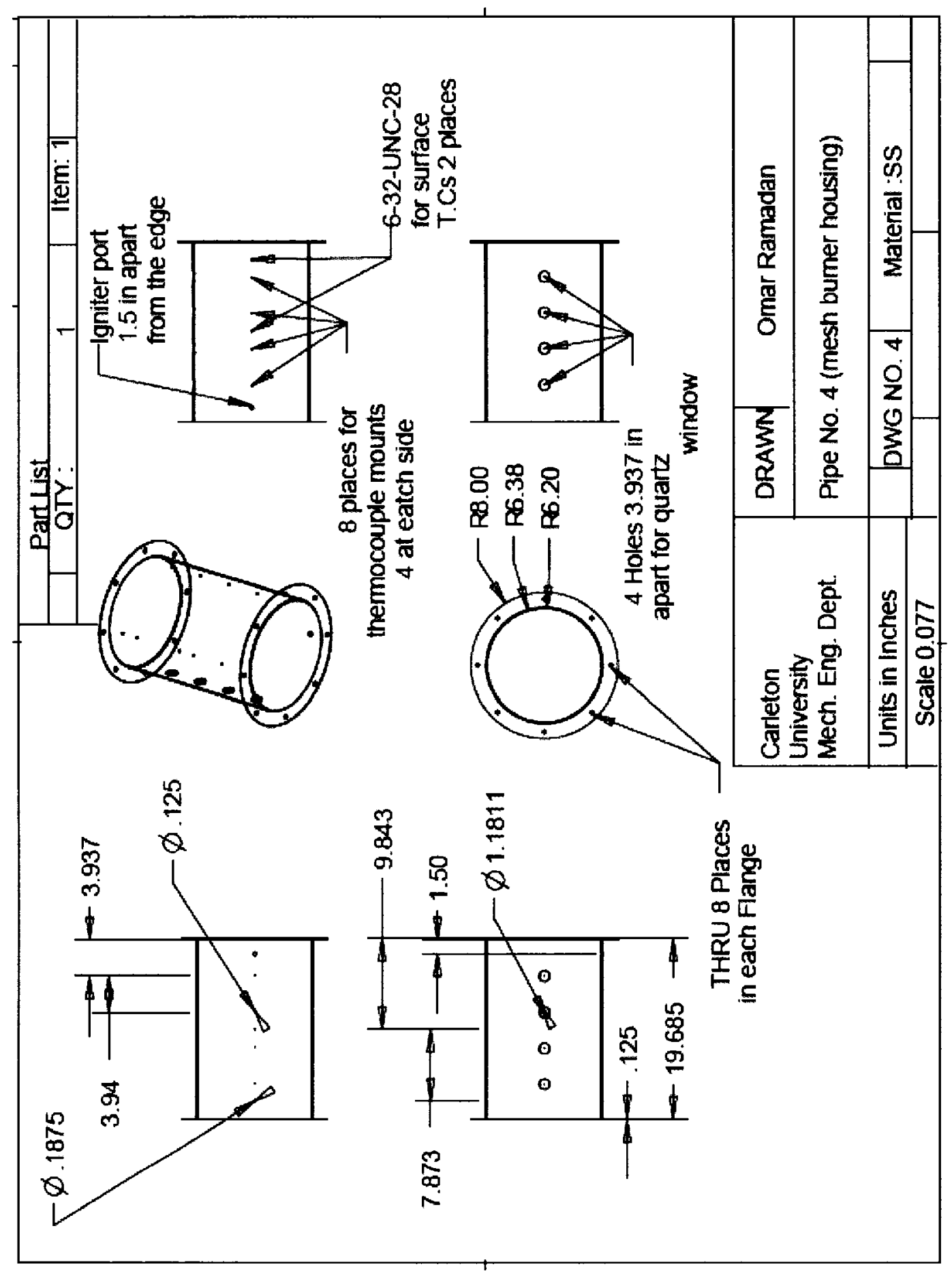


荌

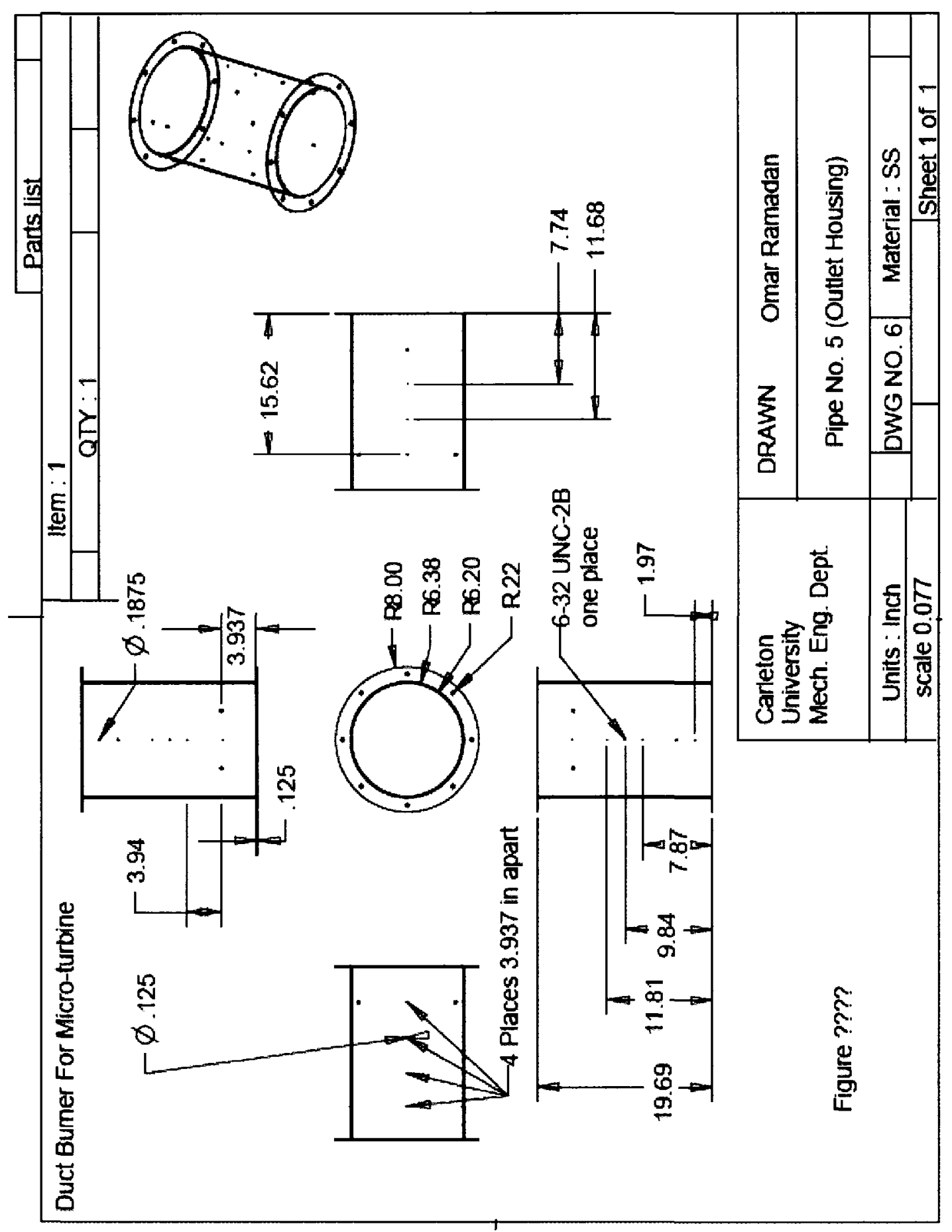


\&

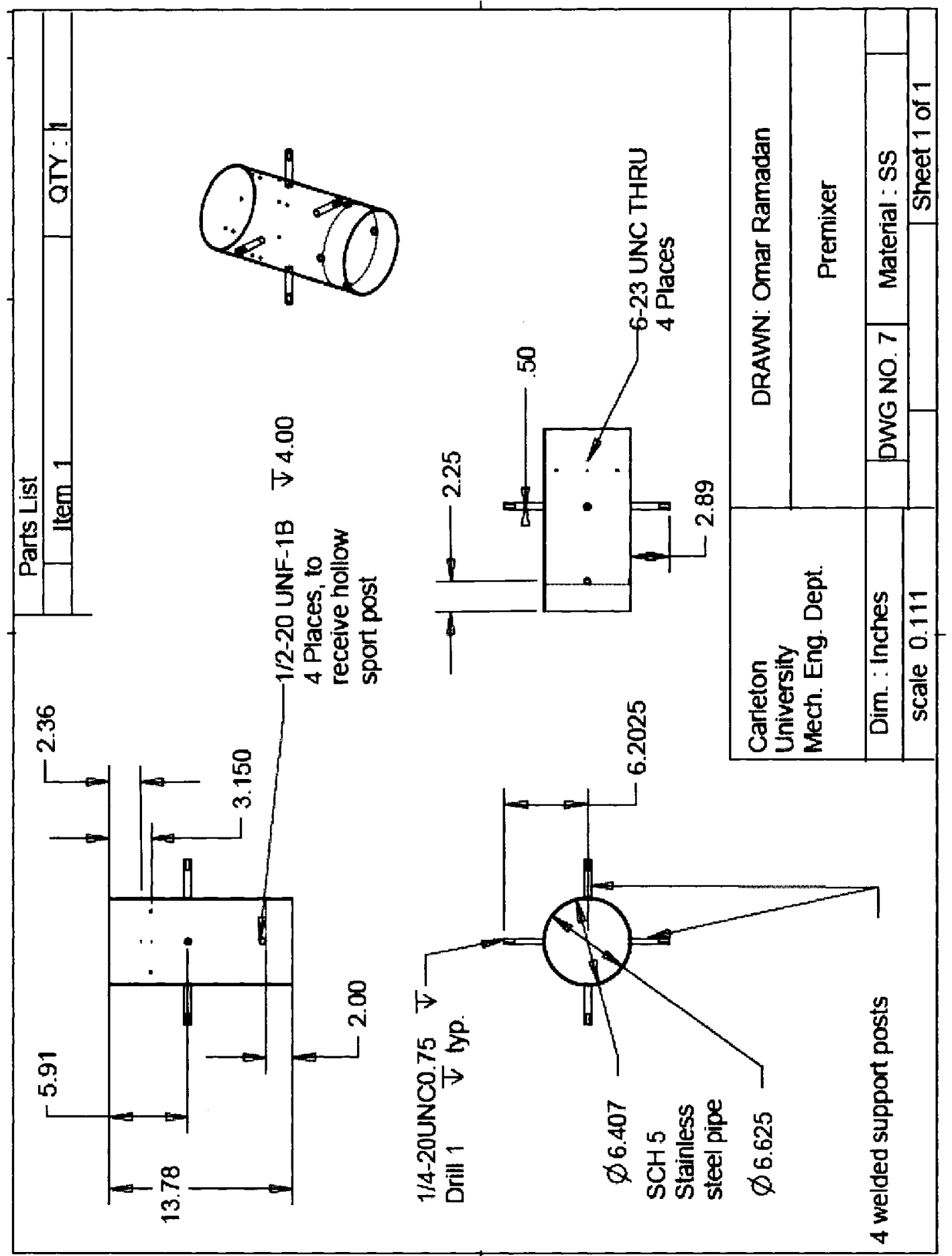


ర్ర

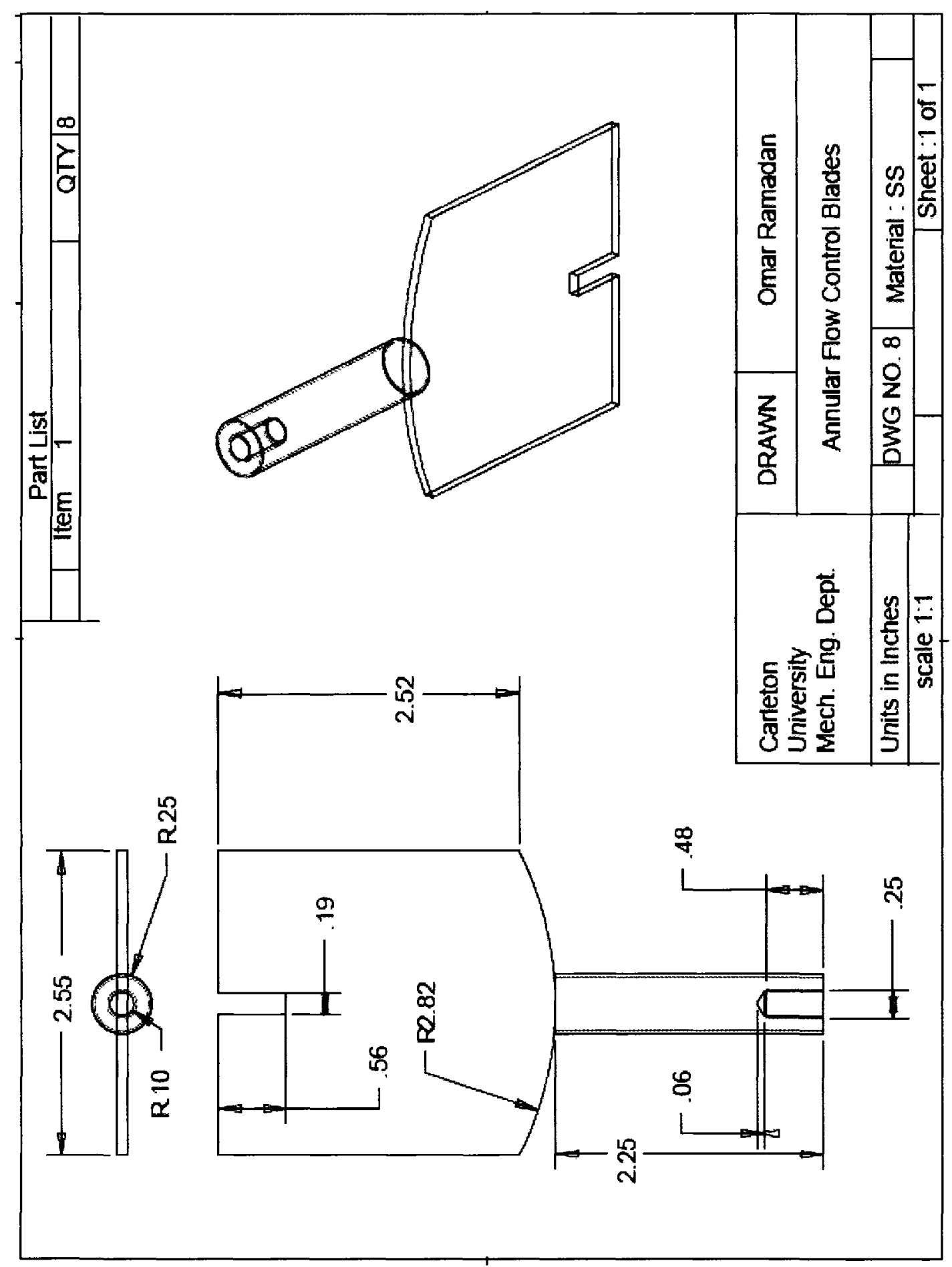


永

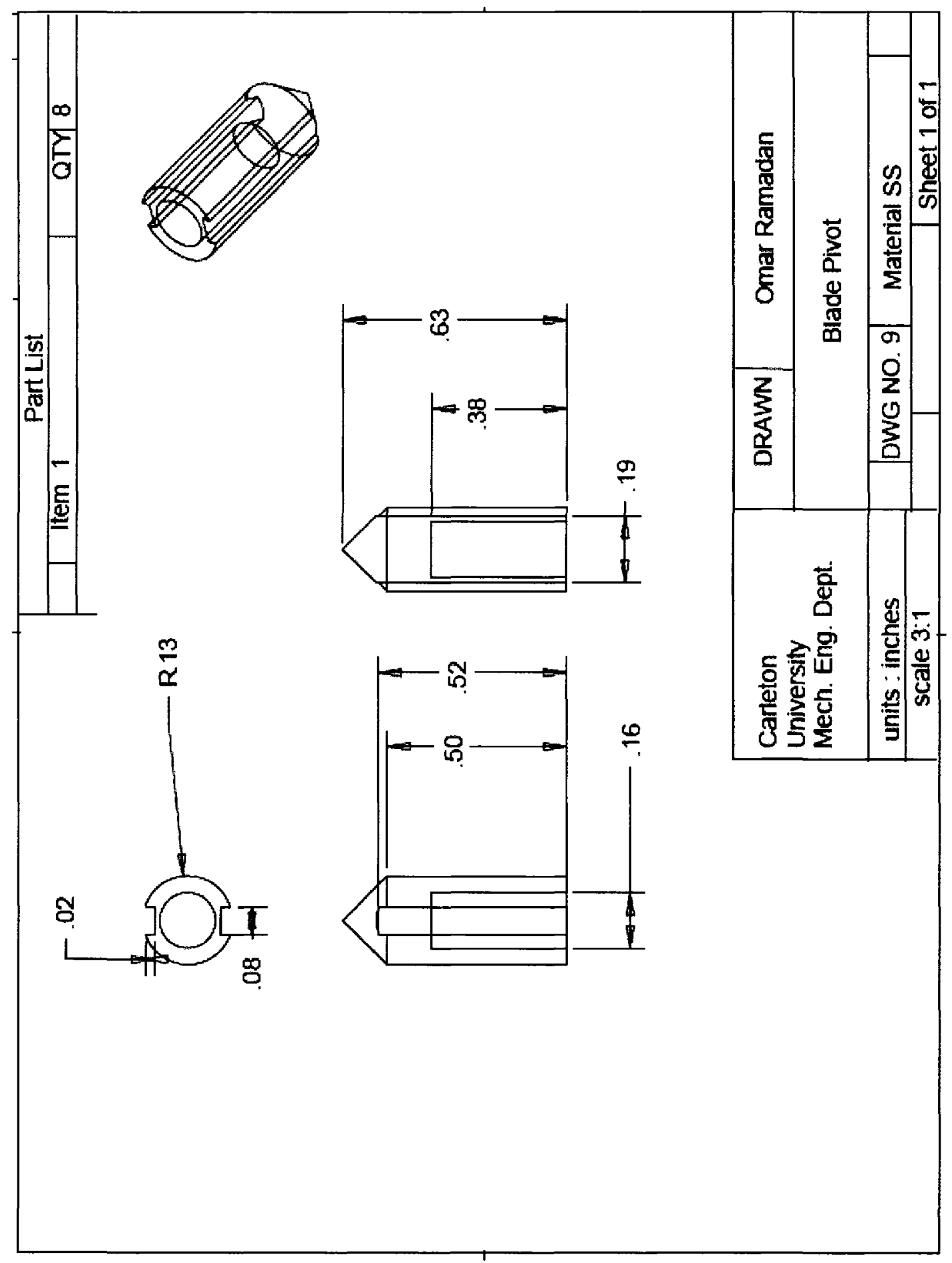


字

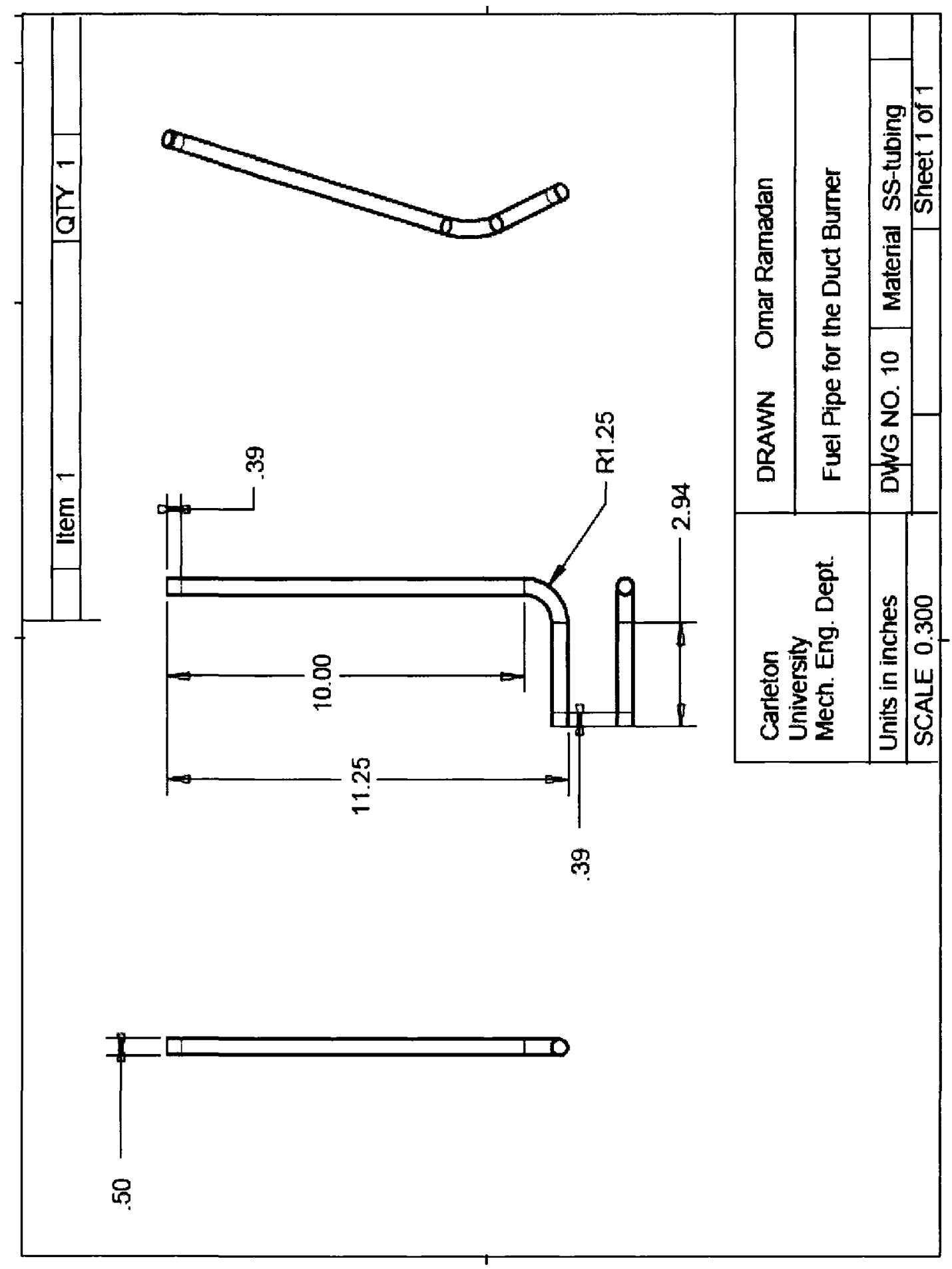


$\frac{8}{7}$

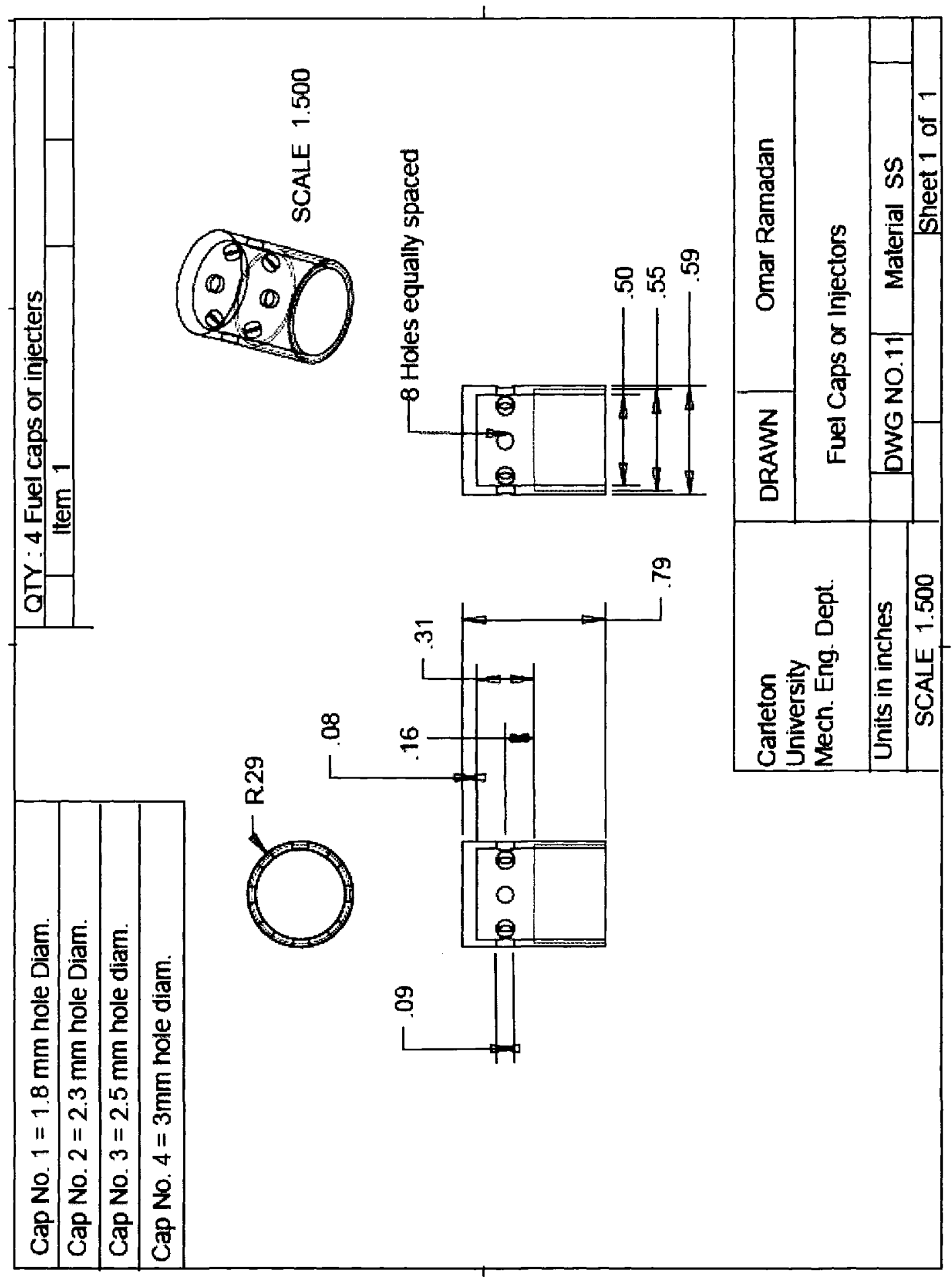


$F$

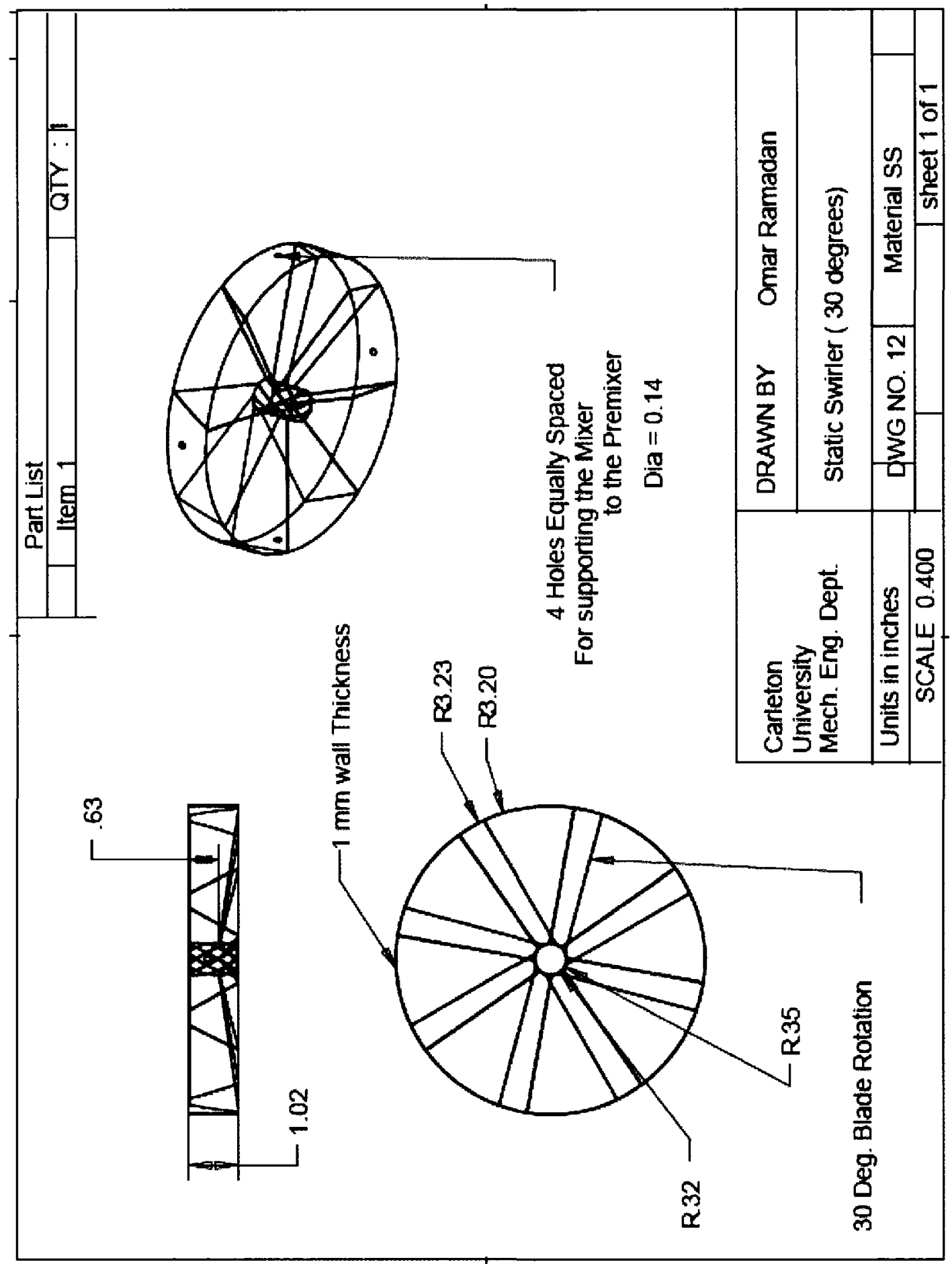


$\frac{1}{8}$

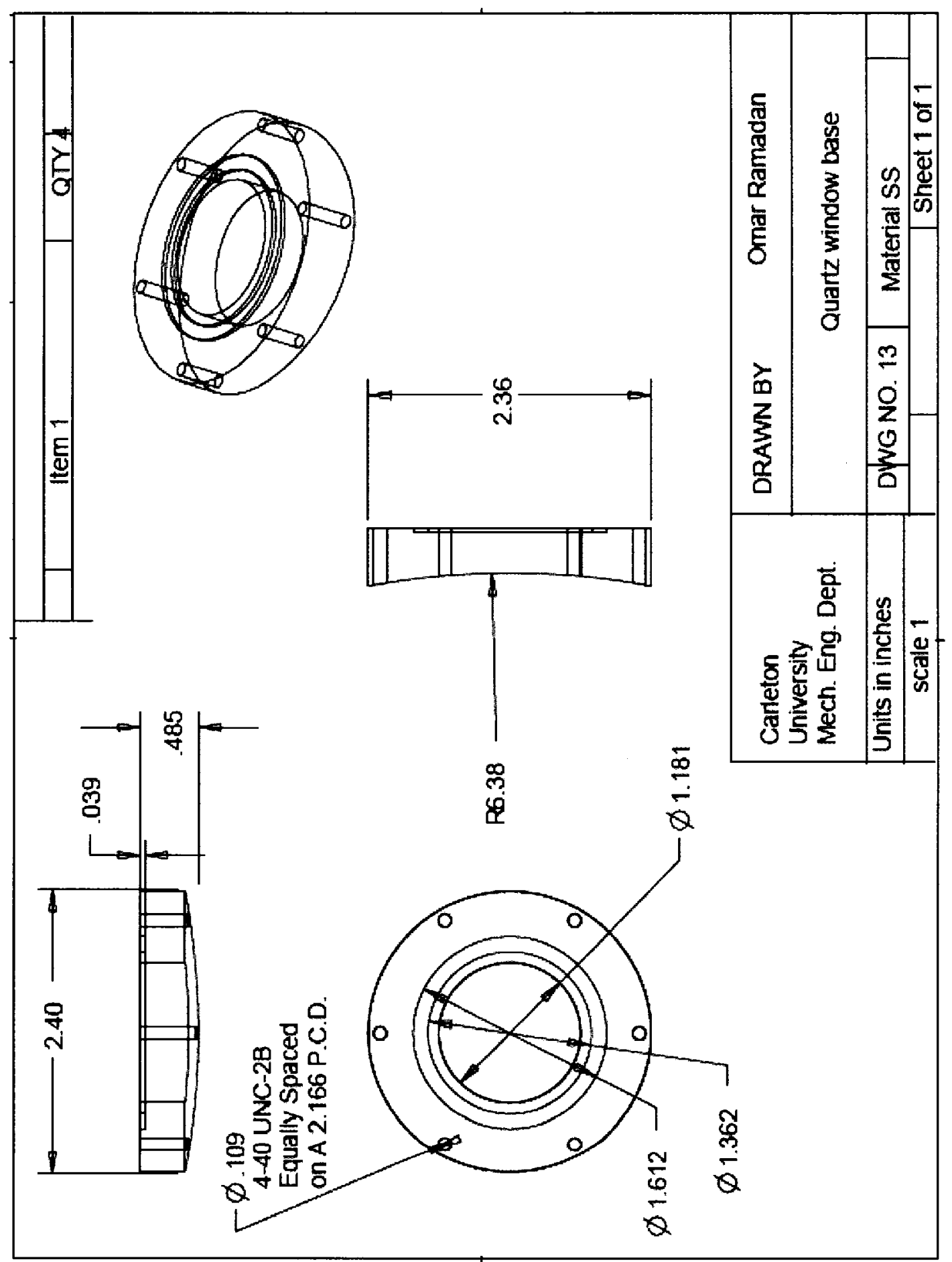


$\stackrel{m}{*}$

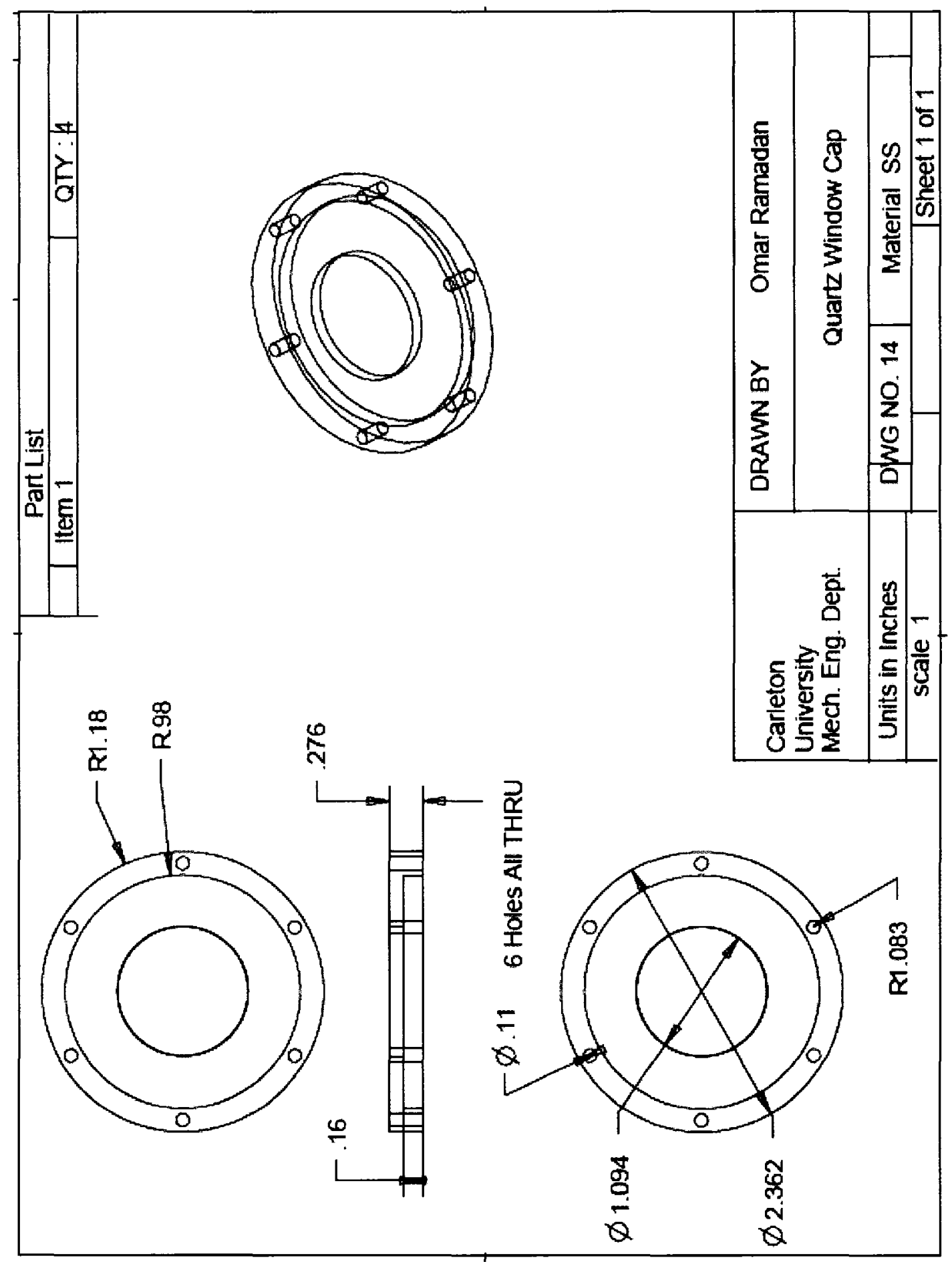


过

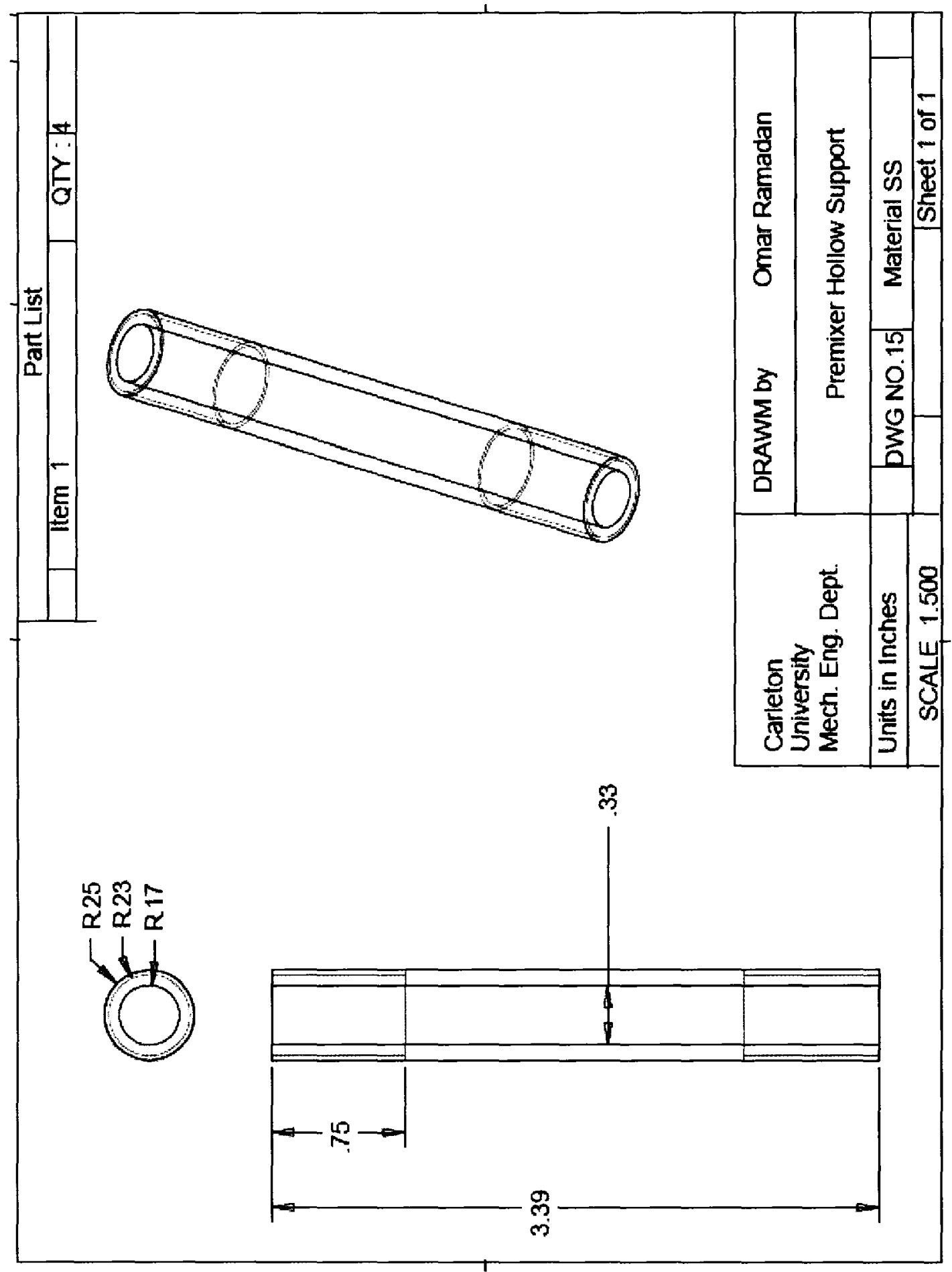


$\frac{n}{8}$

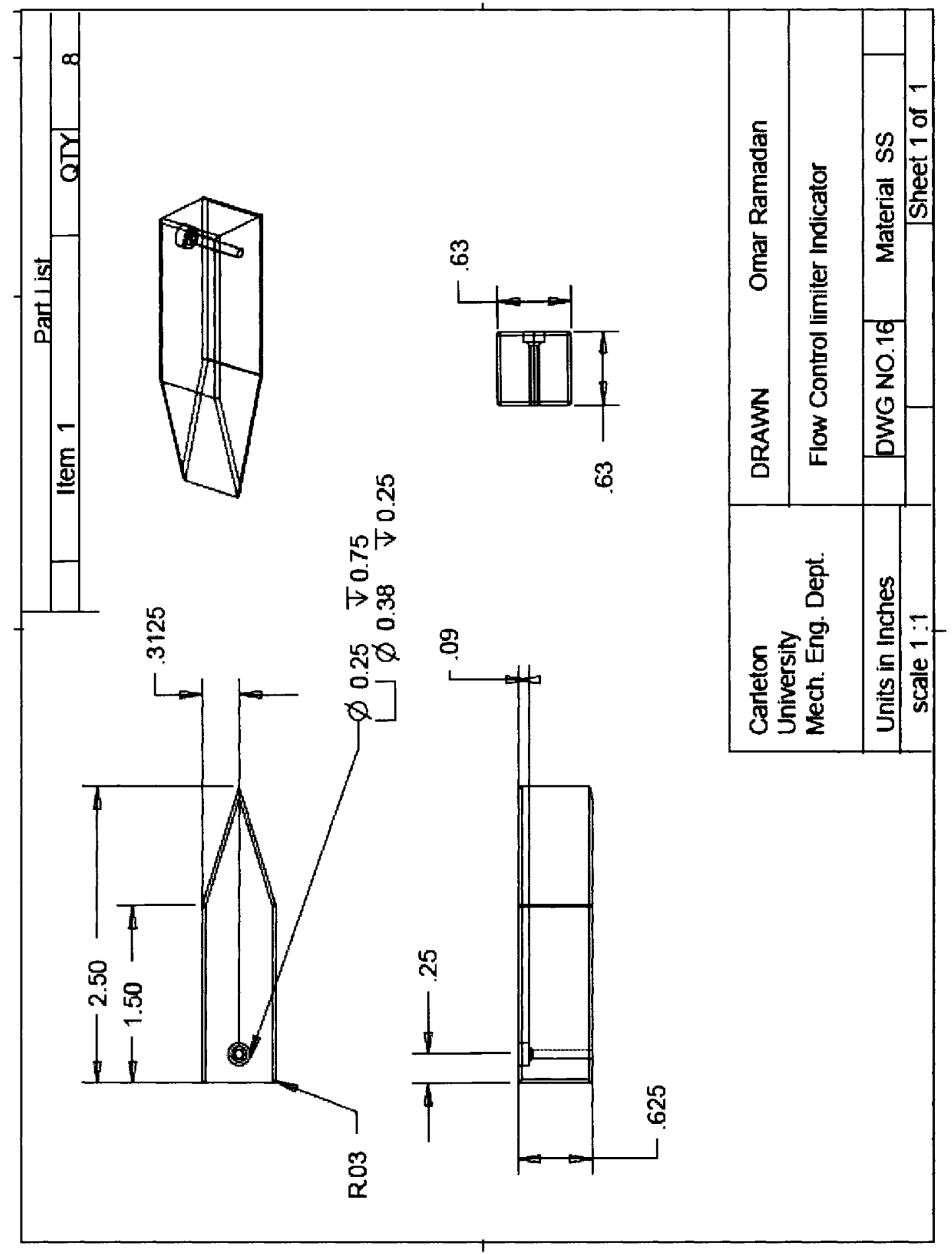

